

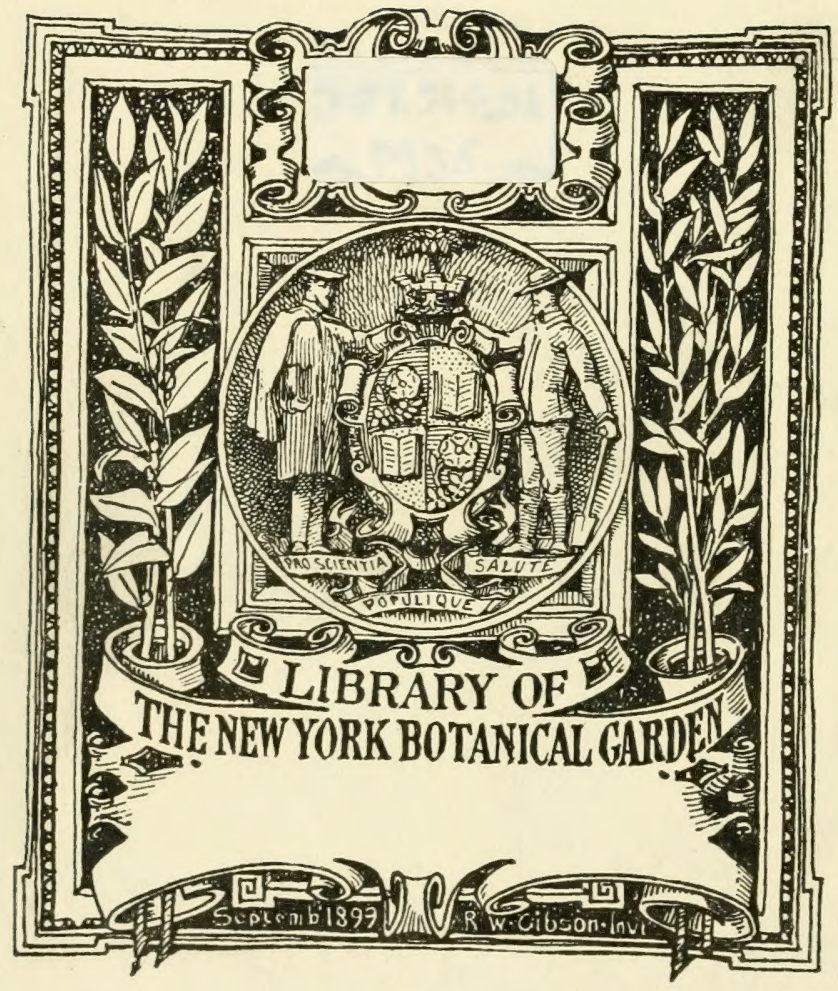





\section{A N N A L E S}

DE

\section{L'INSTITUT' COLONIAL DE MARSEILLE}

publiées sous la direction do

M. Le PROFESSEUR ÉdOUARD HECKEL

Publication subventionnée par le Conseil général des Bouches-du-Rhône

Quatrième année. Troisième volume (1896).

Flore phanérogamique des Antilles françaises (Guadeloupe et

Martinique), par le R.P. DUSS, professeur au Collège de la Basse-Terre.

(Avec annotations du professeur Dr Édouard Heckel sur l'emploi de ces plantes.)

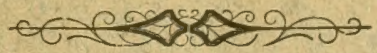

MACON

PROTAT FRÈRES, IMPRIMEURS 



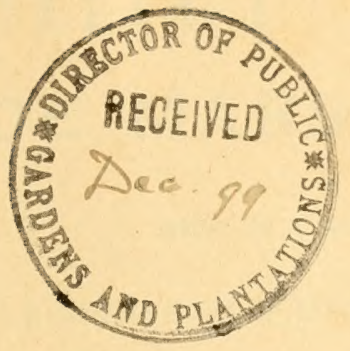

A N N A LES

DE

L'INSTITUT COLONIAL DE MARSEILLE

(Année 1896) 



\title{
A NNALES
}

DE

\section{L'INSTITUT COLONIAL DE MARSEILLE}

publices sous la direetion de

\author{
M. Le professeur EDouArd HECKEL
}

Publication subventionnée par le Conseil général des Bouches-du-Rhône.

Quatrième année. Troisième volume (1896).

Flore phanérogamique des Antilles françaises (Guadeloupe et Martinique), par le R. P. DUSS, professeur au Collège de la Basse-Terre. (Avec annotations du professeur Dr Édouard НескеL sur l'emploi de ces plantes.)

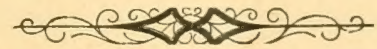

$$
\mathrm{MACON}
$$

PROTAT FRERES, IMPRIMEURS 
N562

annee 3 
Filicetum americanum, seu Filicum, Polypodiorum, Adiantorum, etc., in America nascentium Icones, avec 222 tables.

Plantarum Americanarum fasciculus primus - decimus continens plantas quas olim Car. Plumierus detexit eruitque atque in insulis Antillis ipse depinxit. Has primum .. xneis tabulis illustravit Joh. Burmannus, avec 262 tables.

3. Patrick Browne (1720-1790), The civil and natural History of Jamaica, in three parts, un vol. avec 50 tables, 1756.

1. Christen Friis Rottboell (1727-1797), Descriptionum ef iconum rariores et pro maxima parte novas plantas illustrantium liber primus, avec 21 tables contenant des figures de Graminées et de Cypéracées.

¿. Vahl (1749-1804), Eclogx Americanx..., en 3 fascicules avec 40 tables coloriées.

6. Nic.-Jos, de Jacquin (1727-1817), Selectarum stirpium Americanarum historia.... avec 183 tables.

7. Fusée-Aublet (1720-1778), Histoire des plantes de la Ciuyane francaise, en 4 vol. avec 392 tables.

8. Olavus Swartz (1760-1818), Tova genera et species plantarum, seu prodromus descriptionum vegetabilium. . , quæ sub itinere in Indiam occidentalem annis 1783-1787 digessit.

Observationes botanicre, quibus plantæ Indix occidentalis ... avec 11 tables, 1791.

Flora Indixeccidentalis aucla el illustrata, sivedescriptionesplantarum in prodromo recensitarum, 3 vol. avec 29 tables, 1797-1806.

9. Karl Bernh. de Trinius, species graminum iconibus et descriptionibus illustravit, en 3 vol. avec 360 tables, publiés de 1828 à 1836 .

10. F.-R. de Tussac, Flora Antillarum, sive historia generalis hotanica.... avec 138 tables, publié de 1808 à 1827.

11. Michel-Ĺtienne Descourtilz, Flore médicale des Antilles, ('n 8 vol. avec 600 tables, publiée de 1821 à 1829.

12. James Macfadyen. The flora of Jamaicia, I vol., des Renonculacées aux Légumineuses, 1837.

13. William Roscoë, Monandrian plants of the order Sortumates, avec 112 tables, 1828.

14. Intonio Josi Cavanilles, Monarlelphice classis dissertationes decem, arec 296 tables $(178.5-1790)$. 
15. A. Richard, Flore de Cuba (1838-183̈2), arec tables.

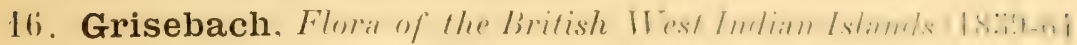

17. Ant.-Laurent-Apol. Fée, les dix mémoires sur los Fougreres (1844-1868).

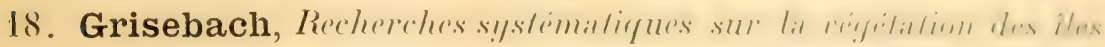
Caraïbes, surtout de la Guadeloupe, Gottingen, 18:57, pelil

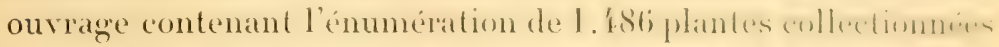
par le 1)' Duchassaing à la Guadeloupe of it l'anamia, alle. les noms de celles qui, par Swartz, Jacquin, West, Wikstroem. de Schlechtendal, ont été indiquées comme appartenant al la flore de Saint-Thomas, de Saint-Christophe, de Sant-linstirche. de Saint-Martin et de Saint-Barthélemy.

Dans l'ensemble de ces ouvrages, on trouve à peu près la moitié des plantes des deux îles représentées par des figures: colles de la basse région y oceupent une plus large place que celles des pramels bois et de la région supérieure. Il élait, en elfel, beaucoup plus litcile de collectionner et de dessiner, avec leurs fleurs et leurs fruits, des végétaux qu'on pouvait avoir sous la main. Pour ceux des régions élevées, il en était tout autrement. Ce n'est pas dans deux ou trois herborisations quon peut se procuree leurs fleurs of leurs fruits. Lia région des grands bois doit ètre visitée tous hes mois: cist liunique moven de se mettre en possession de spécimens complets. I.es vin: geurs qui se sont occupés de botanique n’ont visité nos iles, pour ainsi dire, qu'en passant ef plutiot pour y admirer le's heatus sites que pour y récolter utilement: ils nont pas pénétré sérieusement dans len

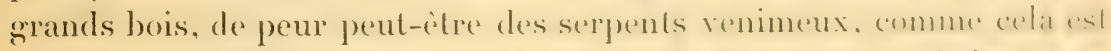
arrivé pour la Martinique, où l'abondances du frignonocephathe ent un obstacle sérieux aux herborisations.

Le manque de figures se fait surtout sentir pour les (Jrchidées ter-

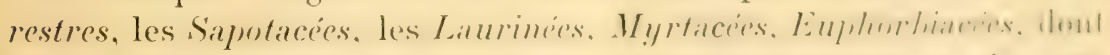

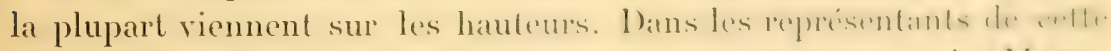

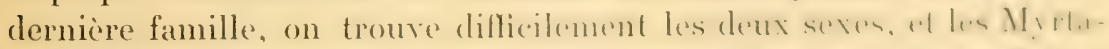

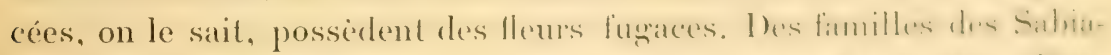
cées et Dilléniacées, il n'est fait mention par ancom explopatmur. I'mur

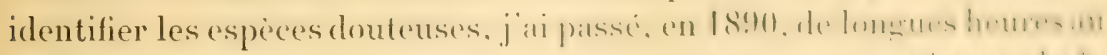

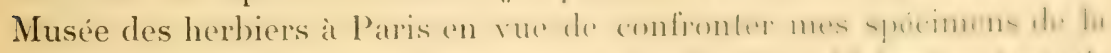

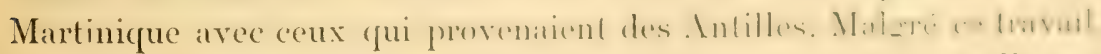
n'ayant pu trouver les noms d'un certain nombre d'entre elles. at 
arrete par les nouvelles especes. jai envoré mon herbier entier au Musée de berlin. La plupart y a été revue. vérifiée et rectifiée par les savants docteurs Ig. Trban, sous-directeur du Musée et Jardin hotanique. ot Kirug. arec la collaboration de plusieurs spécialistes, comme MM. Cogniaux. Pierre. Boecleder. Mez, Heckel. etc. Pour les plantes de la Guadeloupe, j’ai eu recours au même moyen.

\section{GÉOGRAPHIE BOTANIQUE DES DEUX ILES}

Les Intilles francaises, la Guadeloupe avee ses dépendances da Martinique. alppartiennent a cette chaine de soixante iles formant l'archipel américain qui s'étend, en courbe, de l'entrée du golfe du Mexique jusquau golfe de Maracaybo. Elles font partie du groupe des Petites Antilles ou Iles du Vent, et sont comprises entre $14^{\circ} 20$ et $160^{\circ} 40$ de latitude nord, entre 6.3" 10 et 6\%" 80 de longitude onest. La

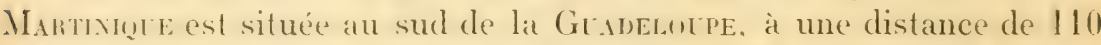
kilometres. et est séparée de sa suer par l'ile anglaise de la Dumxug e.

\section{LA GUADELOLPE ET ILES VOISINES}

Ia Guadecorpe, d'une circonférence de 44 kilom., est divisée en deux parties trés distinctes par un bras de mer très étroit. appelé Riviere-Salée. I a partie occidentale a reçu le nom de Gradecocpe: phophevist mitr: ou de B.sse-Tente. lautre est désignée sous le nom de Graxde-Terre.

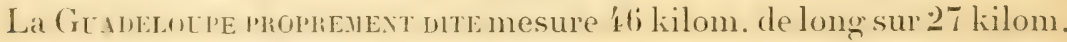
de large: elle a la forme d'une ellipse irréguliere. Elle est entièrement volcanique. Son sol est formé de basaltes, de trachyctes, de porphyres et de laves compactes, cornéennes et porphyritiques. enfin. de tuf volcanique. Les tlanes et les plaines sont recouverts de terres d'alluvion angileuses. tantót rougres, tantòt james, surtout dans les parties moins élevées, situées au nord.

Lne chaine de montagnes, it Jaquelle sadossent, à droite et a gauche. de nombreuses ramitications et des contreforts puissants, lat partage en deux versants inénaux du sud-est au nord-est. Son massif est formé d'un grand volean encore en activite. la sonfrière, silué dans le Sud, d'une altilude de I. is metres point culminant de’s Antilles françaises et de trois volcans eteints: les Denr-.Mamelles, presque au centre de cette chaine, 733 met. d'altitude: la Cirosse-Montayne. 730 met., dans 
le Nord, et enfin le Honëlmont, 12' mètres. Ce dernier, avec les

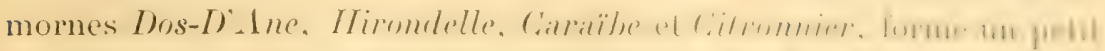

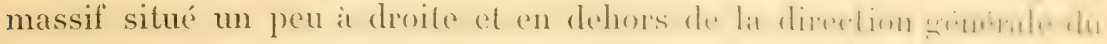
sud au nord et se rattache ì la Soufrière par le col de Gourberre.

La Soufrière, avec le Nez-Cassé, la Grande-Décomverte, 1hbli mit..

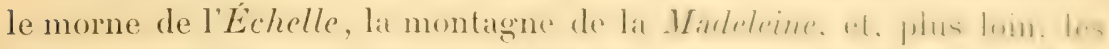

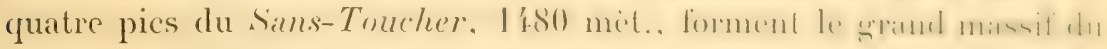
Sud-Fst de löle et en oceupent envirom la demi-sugnelicin. I prafir du Sans-Toncher, les montagnes sabaissent maldurllement, mais forment encore quelques mornes importants, comme colui du timl /,

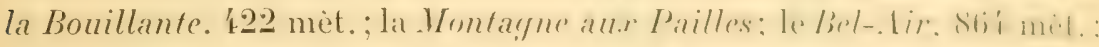
la Montagne Beaugendre, 6ł"̈ mèt.; la Montagne Saint-Jean, qui sépare les deux bras de la Grande-Rivière à Goyave; la Conronne.

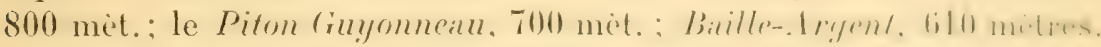

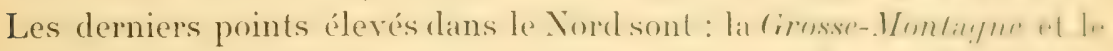
Piton de Sainte-kose, qui vont terminer l’ile, ('n linmant timbit un littoral plat et sablonneux, tantit des promontoires peu comsidirables; la pointe la plus avancée prend le nom do l'ointe-. llégre.

Les deux versants de cette chatune, sillonnes de vallexs, arrosio par 70 rivières, couverts de forêts vierges, connus seulement par les chasseurs intrépides et, dans certains endroits. par de hardis antrebandiers de tafia, le botaniste doit les pareourir, les somder. les soruter, pour découvril les richesses végétales que la Providence y i entassées.

Le versant occidental diflere beancoup) du rersint oriental. Colui-li est moins large, plus proche des sommets: ses momes sont plus il.vés. tantot trés roides. tantot abrupts: le littoral maritime y eit mu rocheux et abrupt, ou bas et marecageux: les rivions qui sidehappent des hauteurs forment des sauts et des cascaules, rouldent dims ders lits

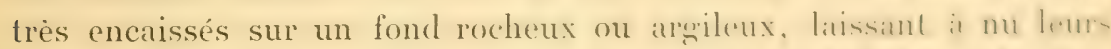

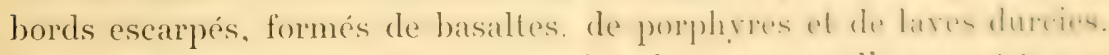
En temps ordinaire, un grand nombre de ces cours d'eatu sont it sec;

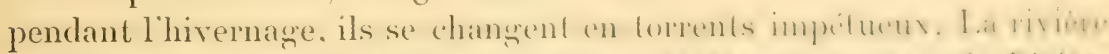

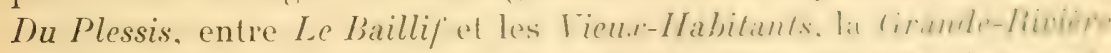

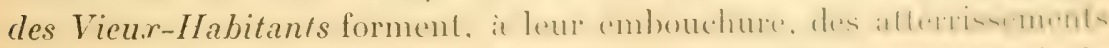
marécageux et malsains, mais riches en végrétalion: la rivière de lir

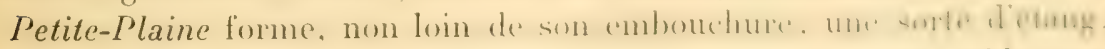
Le bas de toute la côte occidentale est généralement sec, aride, tries pierreux; on y trouve des plantes particulières. 
En traversant l'extrémité Nord, depuis I)eshaies juscu à Sainte-Rose. on rencontre une série de petites rivières de peu d'importance, a lexception de lat riviere Madame, et on arrive sur le versant oriental. Ici. la nature dhange complitement d'aspect. Les mornes descendent en pente douce: les cours d'eau, beaucoup plus considerables et moins fouguenx dans le haut, coulent paisibles dans le bas. En déposant des sables argileux, des laves pulvérulentes, des débris basaltiques. des détritus mélangés ì l'humus des grands bois, ils ont formé peu ì peu ces vastes platines alluvionnatres, marécageuses, ces forêts de palétuviers qui s'étendent sur toute la côte, depuis Sainte-Rose jusqu'au delit de Siante-Marie. Le plus important de ces cours d'eau est la Grande-Rivière à Goyare. Elle prend sa source au Sans-Toucher. marche, dans la plus grande partie de son parcours, du sud au nord, formant la seule vallée longitudinale de l'ỉle; elle reçoit sur sa gauche le Bras-l)avid, le Bras-Saint-Jean, séparé de la (irande-Riviere par la montagne de Saint-Jean. le Bris-de-Sable, près de la Rivière-Chaude. et enfin la Petite-Rivière. A environ 6 kilom. de son embouchure, elle tourne brusquement vers l'est pour se jeter à la mer à travers une foret de mangliers ou paleturiers. Cette riviere, dont le bassin seul oceupe plus du quart de la superficie de la Guadeloupe proprement dite, a trois embouchures et forme un delta dont les alluvions ausmentent tous les ans de 10 i l: jo mitres. Ces paléturiers, dont le principal coté utile est d'abriter les cultures de l'intérieur contre l'air salin de Ja mer, sont un milieu de pullulation microbienne, de multiplication pour les moustiques et les maringouins, qui en rend l'exploration dangereuse; leur végútation est très uniforme, tandis que celle des plaines et des partiess boisées situées en arrière offre à l'herborisateur une riche récolte.

Le reste de la côte, depuis la rivière de la Capesterre jusqu'à la Basse-Terre, est sec, mais continue à ètre arrosé par d'importantes rivieres. Sur le versant oriental, et press du bourg de Baie-Mahault, on rencontre un grand stang, la Digue, entouré de collines et de ravines boiseres, fertiles en toutes sortes de plantes. Sur le plateau boisé de Longmont ì la Capesterre se trouvent deux grands étangs encaissés : le Cirand-Fiang, it 391 met. d'altitude, de forme semilunaire. mesurant pres d'une liese de circonférence, et l'étang Zombi, de forme ovale et d'un tiers environ plus petit. Ces lacs ont des deversoirs souterrains of doment nassance it deux rivieres: le premier it celle de Saint-sianeur et l'autre it celle des Bananiers. C'est 
sur leurs bords et dans les bois environnants quion frotive les plux belles et les plus luxuriantes fougères.

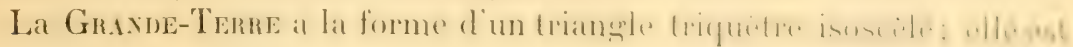
plus petite que la Guadeloups phopmumt mite. Son origine est due aussi à des foyers volcaniques sous-marins, comme le prouvent les

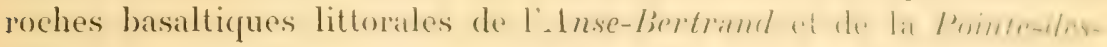
Châteaux, mais les éjections sont peu élevées et ont été couvertes

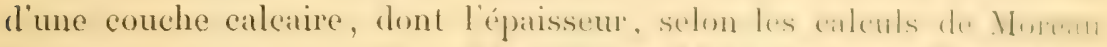

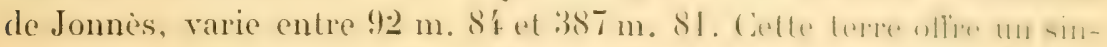

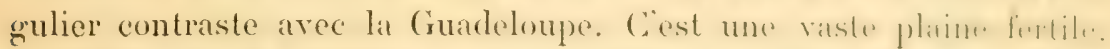

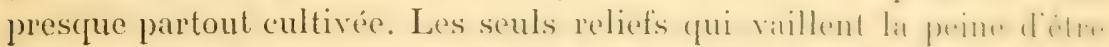

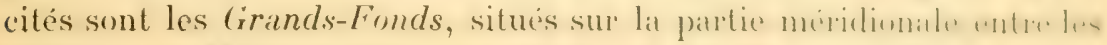

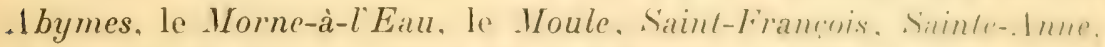
le Cozier et la Pointe-à-Pitre. Ils sont formés de petils mamelons cal-

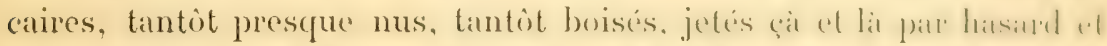

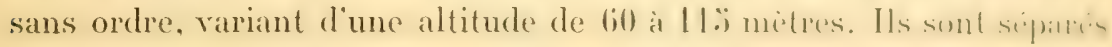
les uns des autres, soit par des coulées recouvertes d'une couche

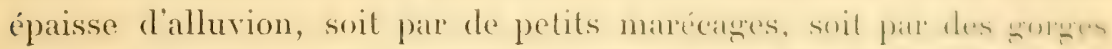

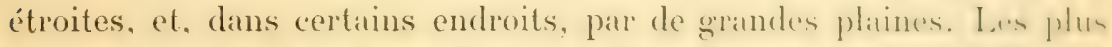

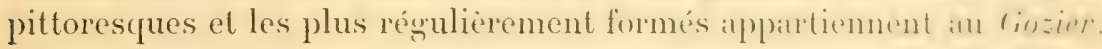
La végétation de ces mornes est en général asse\% pauver ut unilurmu: les poiriers, les mappous, les campeches. le's bris-rinelles. Ires lerisrouges, les Euyenia coriacea et arillaris y dominent. I e pretit platean.

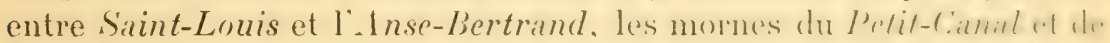
ses environs sont cependant tris interessants alu point de ve hutitnique, et l'herborisateur y fait une ample provision.

Mais si l'intérieur de la Grande-T'erre olfre moins de ressourees au collectionneur, les bords de la mer, par contre, sont plus riches en toutes sortes de plantes; ils sont bien plus piltorespues, an print de rum

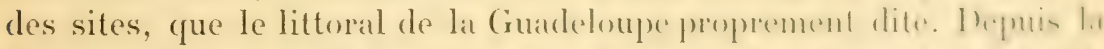

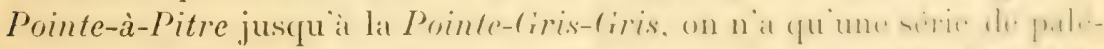

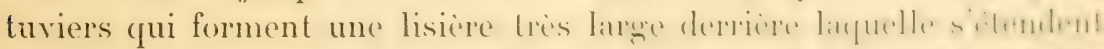

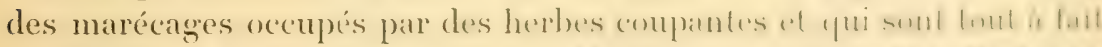

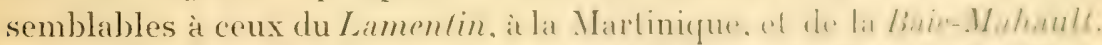

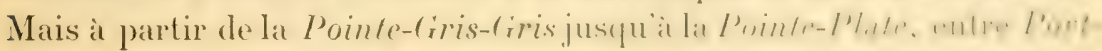

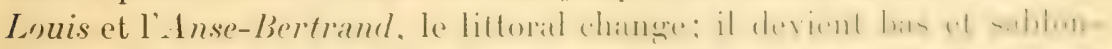

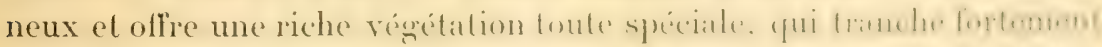

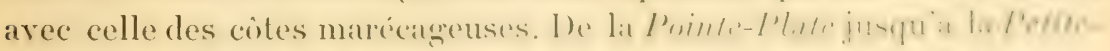
Vigie, et de là jusqu’à la Grande-Vigie, point teminal de la Ciramde- 
Terre, et sur la côte nord-est jusqu'au Mont-Gozier, on ne roit que des fataises nues of wrises contre lespuelles une mer toujour's furieuse vient se heurter. Après le Mont-Gozier, la côte s'abaisse pour former une plage d'abord rocheuse, ensuite sablonneuse, et se prolonge jusqu'aux rochers de la Conronne. De lì, à la Pointe-des-Châteaux, le littoral. extremement intéressant par ailleurs, ne présente que des roches à pic ou des amas de pierres sans végétation. Il n’en est plus de meme de la cote méridionale depuis la Peninte-des-tideatear jusqu it la Pointe-ì-Pitre : celle-ci est généralement basse, parfois marécagreuse. Elle se releve au Pefit-Hatre pour former une serie de faliases boisies el des marecares peu étendus. Ces falaises, surtout celles du Gozier, abritent une végétation particulière et riche en espèces.

Lat faible dévation de ses mornes et l'absence de forcts ne permettent pas a la liramle-Terre d'aroir de puissints cours d'eanu. Les quelques rivières qui y existent méritent à peine ce nom et sont ì sec pendant une srande partie de l'année. Les pluies y sont moins fréquentes qu it la Guadeloupe proprement dite: aussi la sécheresse se fait-elle souvent cruellement sentir. La végétation se ressent nécessairement de cet ítat de choses et revet. surtout pour les plantes herbacées, un cachet anormal. Dans les grandes et profondes mares, qu'on a creusées autour des hathitations ef dans les satranes, on trouve des plantes flottantes tres helles, qui protigent leau contre liardeur du soleil et la conservent limpide. Il en est de mème de quelques grands étanges. nourris par des sourees. comme celui du Cinconyer. près de l'usine de Duchassaing au Moule.

Les nombremx ilots du Ciraml et du Petit-Cul-de-Sac, ceux de SainteRose, ne recèlent aucune végétation sortant de l'ordinaire.

La Désirade, île étroite, longue de 22 kilom., au nord-est de la firande-Terre. un peu en dehors de la courbe formée par les PetitesAntilles. est traversere l'une extrémite à lautre par un platean assez dere. dont le point alminant. le Morne-Frégate. a 280 metres dialtitude. Sa cote orientale est taillee a pic: l'oecidentale s'abaisse presque partout in pente plus ou moins douce. Lïle entiere est de formation volcanique, comme la Grande-Terre, et recouverte d'une profonde couche calcaire, qui fournit une excellente chaux. Cette couche est plus épatisse du crite occidental of se montre parfois at nu, ce qui fait que de loin l'ile rexsemble à un immense rocher couvert d'un peu de vergetation. Ia partie plate ot quelcpues endroits du plateau. comme celui des Latimiers. contiennent une terre fertile. recouverte de sables 


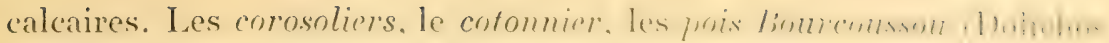
Lablab), les patates, le maís et le manioc y réussissenl bien. Ite luisseau de la ravine Cybèle, entre le bourg de lat Crand'Anse ot la Léproseric, la rivière de la Léproserie et celle de la Pointe-du-Vurl sont à peu près les seuls cours d'eau qui y existent; encore sont-ils presque toujours à see. La constitution géologrique ne permet aux arbres de devenir grands que dans les falaises el sur la plage ocei-

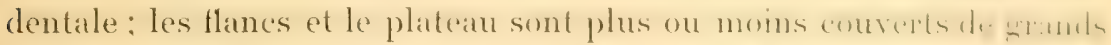

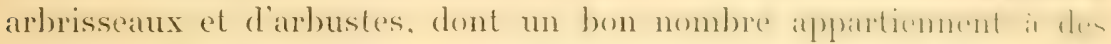
especes toutes particulieres quion ne rencontre nulle patr aillents. 1.i

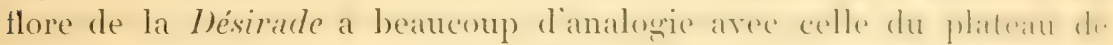

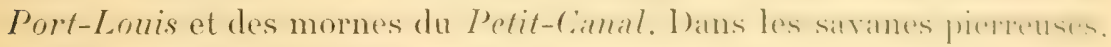
sèches et arides de la Léproserie, exposées au grand vent de la mer,

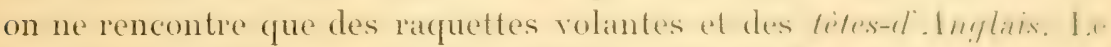
garac. quion dit aroir été commun autrefois, nest plus repreanli: que par trois ou quatre pieds.

L'île de Marme-Galaxte, au sud de la Guadelozpe, est de formation

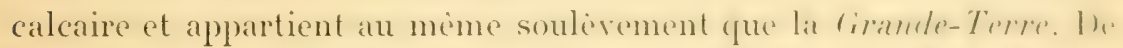

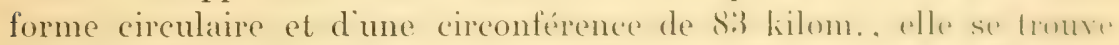
traversée du nord au sud par une petite chane de mornes. qui forment deux petits plateaux. Le premiere d'une altitude de lou melrese val

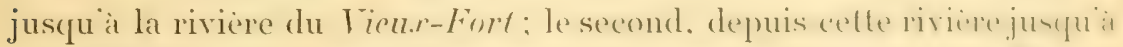
celle de Saint-Louis, présente comme point culminant le MorncConstant, qui ne dépasse pas 205 mètres. La côte de l'Est ou la Côte-du-Vent est formée de falaises à pic : le littoral du Nord. entre la Pointe-de-Ballet et la Pointe-rlu-. Tord, ast courert de pallituviers et de grands arbres. les memes quion rencontro dims lex mamicages du Lamentin; le reste de la côte est généralement bas et

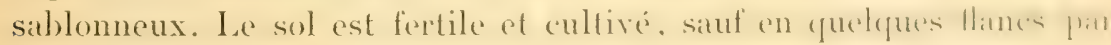
trop pierreux et trop abrupts. La plaine boisée et sablonneuse de Folle-Anse, entre Saint-Louis et le Grand-Bourg, est extrèmement

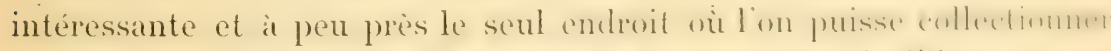

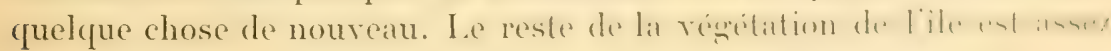
exactement celle des mornes calcaires des Grands-Fonds.

Le groupe des SAntes, composé de huit îlots, d'une élendue lries

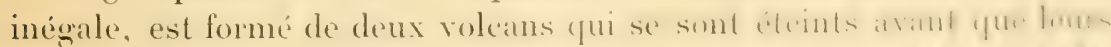

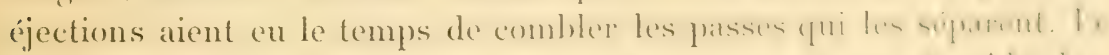

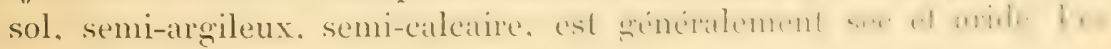


deux principaux ilots. lis Terre-de-Hant et la Terre-de-Bas. ont une végétation un peu dilférente. - I ia premiere et la plus grande est dominée par le morne du Chamean 316 met. de haut), très abrupt du coté de la mer. Il est maigrement boisé par des arbrisseaux et de petits arbustes; dans le Nord. cest-it-dire au Marigot et à la Cirande-Inse. le littoral est plat et marécageux. Par ailleurs, on reneontre beaucoup de mancenilliers. de poirier's et quelques mappous. - La Terre-de-Bas est plus boisce et nourrit de grands arbres: la partie plate est peu considérable et a le mème sol que la Terre-de-Haut; lat partie morneuse est couverte de pierres basaltiques; on y trouve en masse plusieurs espeeces d'épiniers, des Mammea humilis. le petit bois rert (Tochefortia cuneata). En général. la flore des ilots des Saintes se rattache beaucoup a celle des coteaux sees du Vieux-Fort a MarieGalante.

\section{LA MARTINIQUE}

La Mintiveges, un peu plus étendue que la Guadeloupe proprement dite, est entierement roleanique comme celle-ci. Elle a la forme d'un parallélogramme irrégulier, avec des échancrures trés profondes, et peut être considérée comme composée de deux massifs, qui diffierent. au point de rue régétal naturel, presque autant que la Guadeloupe diffère de la Grande-Terre.

Le plus élevé des massifs oceupe le Nord, l’autre le Sud de l’île. Celuilì est formé de deux voleans éteints : la Montagne-Pelée (1.3.30 mèt. d'altitude), ilont l'aire embrasse treize mornes, et les Pitons-du-Carbet (1.207 met.), avec trente-un mornes principaux. Ils sont reliés par le plateau du Morne-Rouge. les montagnes qui entourent le champFlore, les montagnes de la Grand'Inse, du Lorrain et les mornes des Deur-lihoux. Ces deux massifs forment ensemble deux versants bien distincts à l'occident et à l'orient.

I.e massif du Sud, de formation beaucoup plus ancienne, est constitué par quatre volcans éteints : celui de la Plaine. renfermant le plateau de ce nom el six mornes principaux, celui des Roches-Ciarrées, aucpuel s'adossent quatre mornes, celui du Tauclin (.000 mèt.), qui est isolé, et enfin celui du Marin.

I ees deux massifs se touchent par l’intermédiaire des collines et plaines qui sétendent entre la baie du Lamentin et la baie du (ialion. Le massif du Nord est le plus important el donne naissance à cinquante rivieres, sur soixante-quinze que l'on compte dans l'île. Ses quarante-quatre mornes, avec leurs ramifications, ses nombreuses vallées, ses profondes ravines 
sont couverts de grands bois et représentent tielitement lit parkie non-

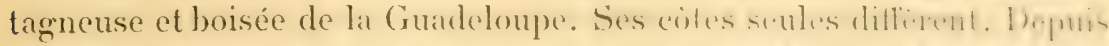

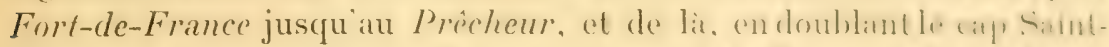
Martin et en suivant le bord oriental, jusqu a ha trinite. le litteral presente tour à tour des plages sabblonneuses et plates. des fatidises a pir et des pentes abruptes, il est toujour's sece nulle part marceigens. it présente peu de découpures. Lees cours dean ne forment pas d'allarrissements.

Le sud de la Martinique, malgré ses reliefs. constitue la partic busse de lî̀le. Les cours d'eau y sont moins considérables ot monins longs, i lexception de la rivièe la Lézarde, la plus grande du pays et qui prend sa source dans le massif des Pitons-du-Ciarlet. Ses cotes sont généralement plates et marécagneuses. Les ciny rivieres qui débouchent dans la raste baie de Fort-de-France y ont formé. par l'apport des détritus, des atterrissements considérables qui contoure ume bande, tantot très large, tantot moins large, de paléturiors. Cethe region est sillonnée par de nombreux canaux, dont deux seulement sont navigables. La flore y est la mème que celle de tous les mangliers des Antilles. Les marécages des Anses-d'. Irlet sont peu dendus, mais nourrissent un grand nombre de Cypéracées particulieres: les alterrissements du canal de la Riviere-Pilote sont assez importants det produisent des Cilumacées rares; sur le coté gauche de la baie du Marin. on rencontre beaucoup de roseaux: dans les palétuvier's du Franerens. du Robert et de la baie de (ialion, le botaniste peut récoltor quelgues.

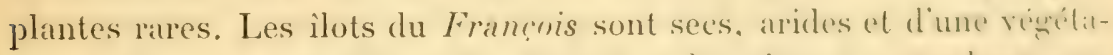
tion paurre; ceux de la baie du linbert ne fournissent, ('ntre beanculp d'autres plantes très ordinaires, que des mancenillier's, de's pririers ot des savonnettiers.

L'extrémitésud de la Martinique est formée par une prescyu'ile reconu-

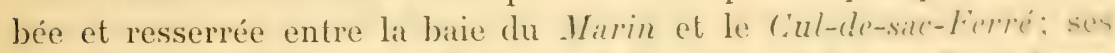
reliefs sont constitués par des mamelons calcaires brisés. I.tur forme

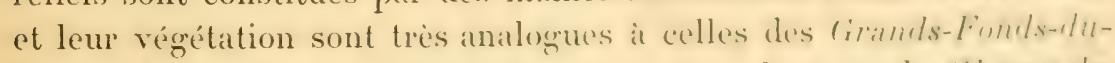
Gosier. Les salines et la plaine connue sous le nom de ClampintePétrification, faisant suite aux mornes, sont prestgue dipoursues de végétation.

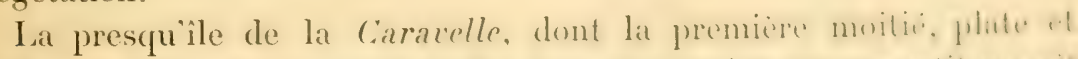

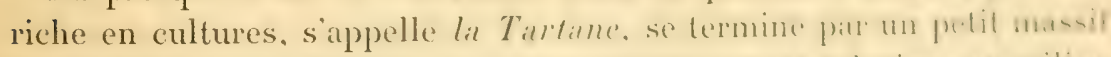
assez élevé, formé d'amas de pierres batsaltiques ct calcatro an milien

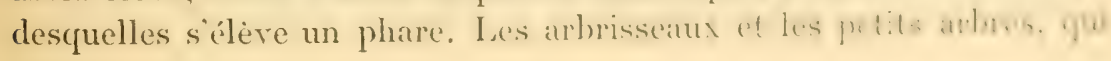


poussent entre ces pierres. forment une végétation riche en especes et marpuese diun cathet toul spécial: clle ressemble beancoup a celle de la Désirade.

Gutre les nombreuses mares quion a été obligé de creuser. surtout dans le sud de lible. et dans lescuelles végetent prescpue toujours des plantes tres interessintes et sourent tres rares. il y a ì la Martinicpue deux lates : colui du cratere steint de la Montayme-Pelée de lö0 mètres de circonférence). et le lac Larcher (étang), au pied des Pitons-duCarbet. En fait de végétation, ils ne recèlent rien de particulier.

Birn que le sol de la Martinique soit en général composé de laves argileuses et spathicpues, de ponces seoriacées et argilo-ferrugineuses, de tuf volcanique siliceux, de divers calcaires, de basaltes, de minerais ferrugineux. on voil cependant que la région de la Montarfne-Pelée, le's flanes ot le's plaines arables qui en dépendent, contiennent une terre essentiellement ponceuse. légère et par consé(quent très perméable. tandis que les quartiers de la Trinité, du Lamentin, du SaintEsprit et du Robert sont reveitus de terres argilo-ferrugineuses, grasses et fortes.

\section{CLIMAT, HUMIDITÉ}

Le plus on moins de régétation et le cachet particulier de la flore de chapue région dépendent d'une multitude de causes, dont les principales sont : la constitution des terres, la direction et la variation des vents. la configuration des accidents telluriques. les conditions climateripues. lialtitude. la situation particuliere des montagnes et la projection de leurs ombres, le voisinage des autres iles, la forme particuliere des mornes. les rariations de température, etc. De quelque point de vue que lon comsidere nos deux îles, elles ont eté tres faroriscies par la Providence et nont rien a envier aux pars les plus riches du monde.

Elles sont placées sous les tropiques, c'est-ì-dire dans une zone chaurle qui, dams nos iles, varie entre $30^{\circ}$ et $32^{\circ} \mathrm{c}$. au maximum, entre 2010 el 2.20" au minimum. P'ar leur constitution géologicpue et minéralosique. elles ont lous les élements d'un sol fertile et varié: par leur contiguralion, qui prósente des montagnes élevées, des plaines et des platerax seecs ou humides, des vallées profondes, étroites ou larges, des 
pentes abruptes ou douces; par la forme conique des mornes, qui augmente l'action sur les nuées électriques, elles ont été admilable-

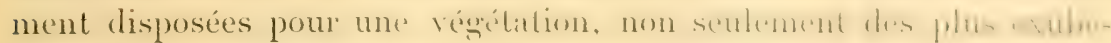
rantes, mais encore des plus variées. De plus, leur's productions

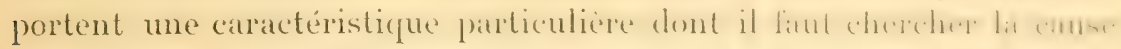

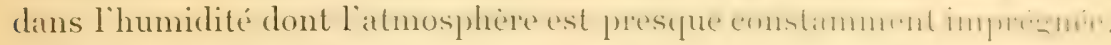
En raison de leur situation au milieu de l'océan, dont l'évaproration.

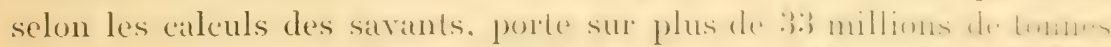

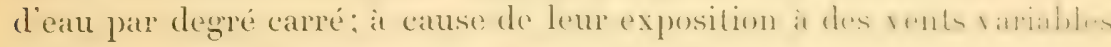
qui poussent les rapeurs et les brumes de la mer vers les montagnes. où elles se condensent en meme temp)s que les vilpurs qui se diwant des rivières, lacs, mares et marécages, il n'est pas étomant (pue ces

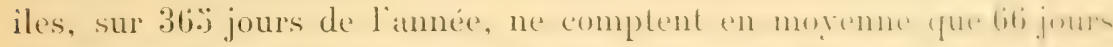

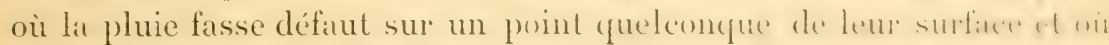

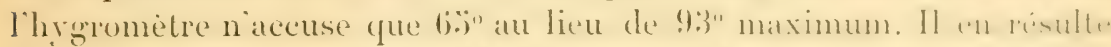
quà la Guadeloupe et a la Martinique il fait deux fois al demi phus humide qu'en France.

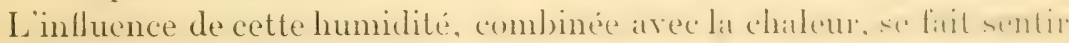

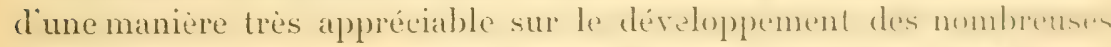

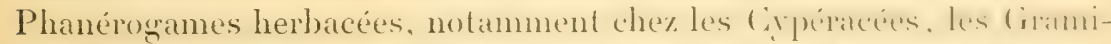

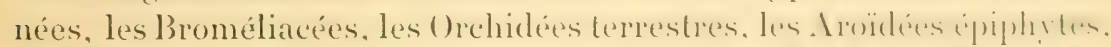

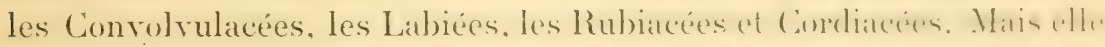

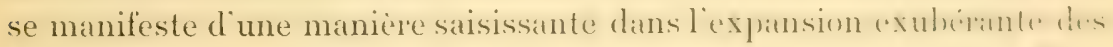
Cryptogmes: et, parmi celles-ci, olle impessionne sumbul lex lin-

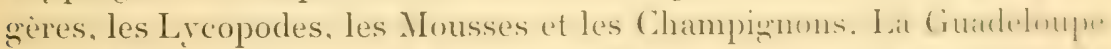

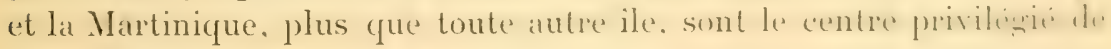
formation des Fougères et des Lycopodes.

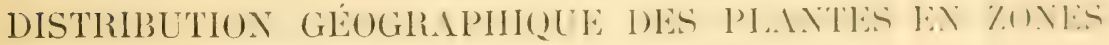

En parcourant les bords de mer, les flanes des montignes et les

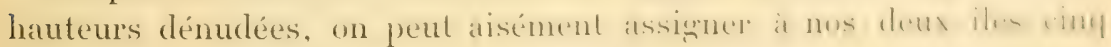
régions végétales offrant chacune une flore distincte:

\section{Région maritime.}

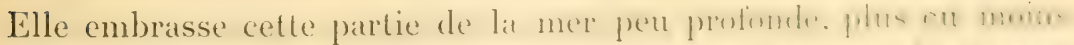

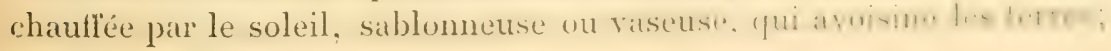


elle contient en abondance, outre les nombreuses Algues, deux Phanérogames stolonifires. complitement immergées et formant un gazon maritime souvent tries épais. Ce sont : Ruppia maritima et Thalassia testudinum, de la famille des Naïadées.

\section{Basse région ou région champêtre.}

Elle commence au niveau de la mer, s'élève jusqu aux grands bois a une altitude movenne de 300 mètres et constitue, a l'exception des environs du Ciamp-tacolb et du Matouba, ou l'homme est allé s'établir plus haut, la zone habitée et cultivée. Elle renferme à elle seule les quatre cinquiemes des espeeces régétales. Lin tenant compte de la variété du sol qui les produit, on peut y distinguer huit sortes de flores spéciales :

\section{Io Flore du hord de mer sec.}

Elle embrasse toute la bande littorale, tantót sablonneuse et plate, tantôt rocheuse et madréporique, arrosée ou inondée par l'eau de mer et exposée directement à l'influence de l'air salin. Ses végétaux se caractérisent par leurs feuilles épaisses ou coriaces et sourent succulentes, par une coloration grise ou peu vive. Les principales espèces sont :

Tournefortia gnaphaludes, Strumpfia marilima, Fimbristylis spathacea, Philoxerus rermiculatus, Suriana maritima, Lithophila muscosa, Borrichia arborescens. - Ces espèces, le plus souvent enracinées dans les pierres et roches madréporiques, où elles reçoivent l'eau de mer, lleurissent toute l'année.

Sesucium purfulacastrum, Screvola Plumieri, Heliotropium curassavicum, Sporobolns virginica et littoralis, Tephrosia cinerea, Thespesia populnea. Pectis humifusa el carthusiana. Hecastophyllum Brounei, Linca rosea. Guilandina Bonducella, Bontia daphnoides, Cakile arqualis, Euphorbia buxifolia, Ipomea pes-caprax, Trianthemum monogynum, Melanthera

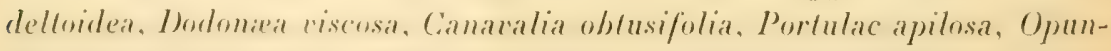
tia Tuna el spinosissima. Tribulus cistrides el maximus, Cyperus brunneus, riscosus, olc. - C Ces esperes croissent sur le littoral maritime sablonneux accidentellement arrosé par l'eau de mer; quelques-umes se rencontrent aussi un peu à l'intérieur.

Morisonia americana, Myriosma buxifolium, Elexodendron dixecum, Einpatwrinm integrifulium. Capparis Breynat et jamaicensis, Mitreola petiolata, Cigmnoyramme lartareat, Ciellis aculeata, Ximenia americana, 
Melocactus communis, Solanum igneum el racemosum, Jacquinia armillan. . Drypetes alba, Rheedia lateriflora, Cordia alba, Parkinsonia aculealia, Eugenia axillaris, etc. - Ces espèces poussent le plus souvent dins les falaises abruptes du bord de mer.

Egletes domingensis, Erigeron jamaicensis, Evolvulus nummularius. Ces espèces forment gazon, soit press du bord de mer. soit un pren it l'intérieur.

$2^{\circ}$ Flore des palétuviers ou mangliers.

Les végétaux propres à cette station sont, le plus souvent, des arbres et des arbrisseaux. Ils ont toujours leurs racines plongénes dins l'eau salée ou demi-salée, ou sont souvent inondés par l'eau de mere. Voici les principaux :

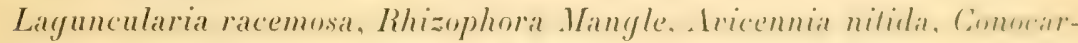
pus erectus, Pavonia racemosa, Brachypteris borealis, Echiles biflora.

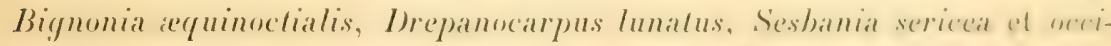

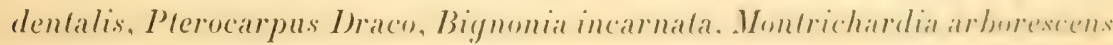
et aculeata, Cihrysodium inlyare. - Les sept dernieres especes se rencontrent aussi dans les marécares d'eau douce asoisinant les palkiluviers.

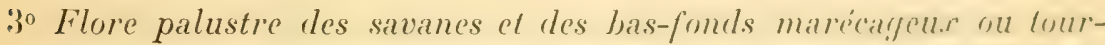
beux, souvent boisés ou it demi boisés, des condroits arpuatirues et des fosses remplies d'eau.

Elle se compose en majeure partie de hautes herbes. connues sons le nom d'herbes couprantes. qui oceupent de frrandes étendurs anx Abymes, au Morne-it-l'Eau, au Lamentin, a Bate-Mahault, de moindres étendues a Port-Lonis, au Petit-Cianal, at Marie-fialante entre te buis

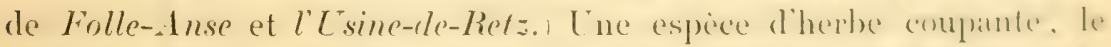
Cladium accidentale. si commune a la (iuadeloupe, nexiste pats at lat Martinique. Les principales plantes qui la forment sont:

Rynchospora aurea, Cladium occidentale, Sclevia microcarpa, Fuirena umbellata, Anona palustris, Pluchea purpurascens, Terhesina alalat. Sparganophorus Vaillanti, Spilanthes uliginosa, Eschynomene sensilicia. Caperonia palustris, Ammannia latifolia et humilis, Neptunia plena de

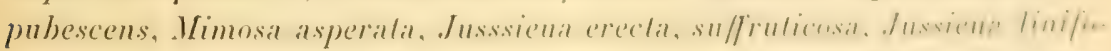

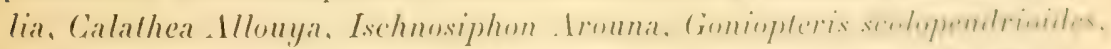

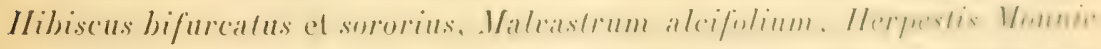
ria, Conobea aquatica, Ilysanthes gratioloides, Ipomea marlinicensis.

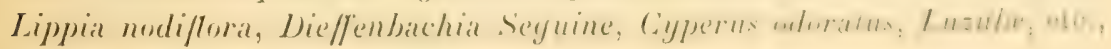


Aspidium unitum, Pleris grandifolia, etc., Polygonum acre, glabrum et acuminatum.

'. Flore cles étangs, mares, canaux, etc.

Elle est constitué par des plantes qui vivent essentiellement dans l'eau. Ce sont :

Nymphea ampla el Rudgeana, Limnanthemun Ilumboldtianum, NepInnia natans, Pistra stratiotes, Pontederia crassipes, Paspalum distichum, Scirpus mutatus el plantagineus, Limnobium stoloniferum, Lemna minor, Ipumea palustris. Echinedorus cordifolius, Potamengeton fluitans et plantatgineus, Panicum amplexicaule.

:i Flore des mormes et pentes rocaillenx. secs. Joisés ou plus ou moins boisés, souvent couverts de pierres basaltiques, soit une partie du massif de Iloü̈lmont of de la Grosse-Montagne-de-l)eshaies sauf les sommets, qui participent à la frore des grands bois), le morne Gommier de la Pointe-Noire, le Gros-Morne de Deshaies, etc. (Guadeloupe); les mornes des Roches-Carrées, la Plaine, le Gommier-du-Marin. les hauteurs molenses de la Riviere-Pilote. les hanteur's pierreuses de la Grande-Rivière (Martinique).

Eile contient beaucoup d'arbrisseaux et de petits arbres a bois dur. peu de Cryptogames et de Glumacées. Les plus belles ()rchiclees, par contre. sont lapanage de celte station. Les végétaux qui y dominent sont :

Excxcaria caribxa, Myginda latifolia, Pithecolobium micradenium, Pithecolobium filicifolium, Schnella splendens, Desmanthus virgatus,

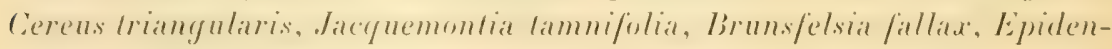
drum ciliatum, Oncidium altissimum, Brassavola cucullata el nodosa,

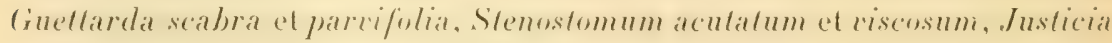
eustachiana et carthagincensis, Erythroxylum oxatum, Talinum quadran-

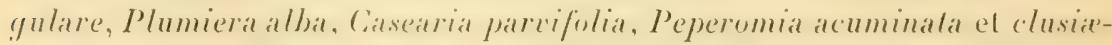
fulia, Olyra pauciftura, Pharus latifulius et glaber. Cheilanthes radiala et elongata, Hemionitis palmata, ete.

(i) Flore des endroits calcaires, suit les Cirands-Fonds, lat Désirade. Marie-Galante, le platean de Port-Louis, les mornes du Petit-Canal Gillatelonje), les mornes de Sainte-Anne el le massif de la Caravelle (Martinique).

Elle contient beaucoup d'arbrisseaux, de grands arbustes et de petits arbres. un assez grand nombre de plantes herbacees et trés peu de Fougères. Les végétaux propres à ces endroits sont : 


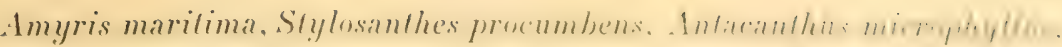
Eugenia pallens et ligustrina, Borrera verticillata, Morinda cilrifolia,

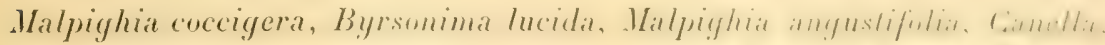

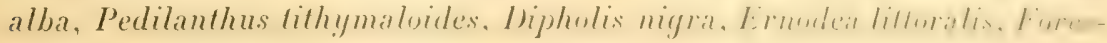
tiera rhamnifolia, Eupatorium canescens, Baccharis divica, Galactia angustifolia, Condalia ferrea, Bumelia cuneatar, Acrodiclidium walicifulium.

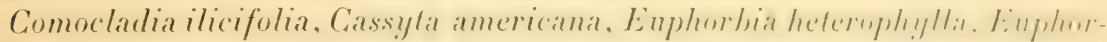
bia Berteroana, Phyllanthus falcatus, Aneimia adiantifolia, Aneimia

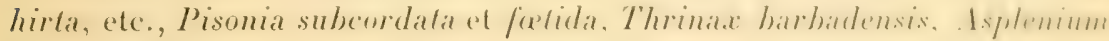
dentatum.

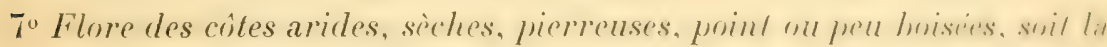

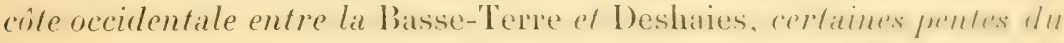

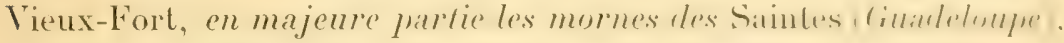
la côte entre le Carbet et Case-Navire, celle du Dianant et de SainteLuce, la grande pente du Gros-Morne, du Diamant, etc. (Marlinique).

Pendant la saison sèche, ces còtes paraissent comme hrultexs part L.

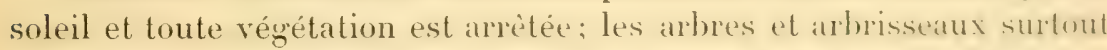
perdent leurs feuilles. Les plantes qu on y tromer sont pen mombremsers. mais portent un cachet tout particulier. Ce sont:

Corchoruss siliquosus, Maldastrum spicatum et fricuspulatum, Shida mrens. hamulosa et jamaicensis, Abutilon crispum, Bastardia viscosal, Ihatia muricata, Tobinia trifoliata, Cracca caribea, Chetocalyx vincentinus,

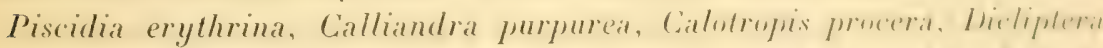

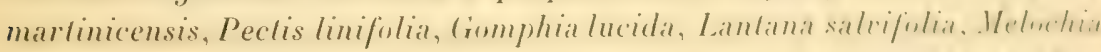

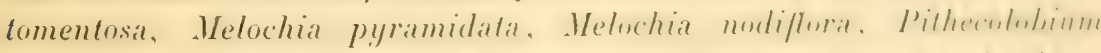
unguis cati, Polyboea corensis, Meliotrupium frulescens. C'assia pulyatena. Evolvulus sericens, Cereus Curtisii, Anona syuamosa, Borreril spinosa. Panicum diffusum, Bontelona litigiosa, ete.

go Flore des terres quelconquess nom comprises dians les sept stations précitées.

Elle est de beaucoup la plus riche en genres et en espéces: elle

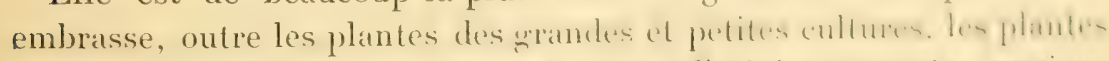

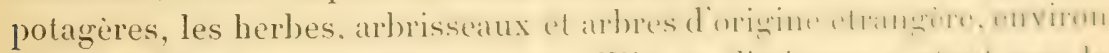

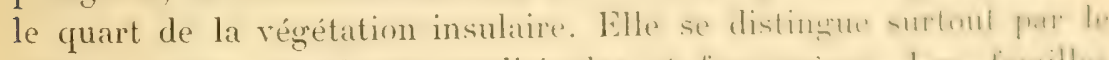
grand nombre de plantes médicinates et fommatgiran. 1... familles

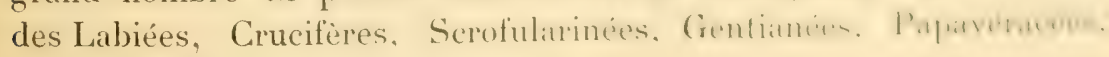


Asclépiadées. Apocrnées, Polyzatées. Nyctaginées. Plombaginées. Hippocratéacées. Terbénacées, Crassulacées, Ampélidées, Bixinées. Liliacées et Iridées nont leurs représentants que dans ce terrain; les Malracées, Solanées, Acanthacées, Borraginées, Bignoniacées, Gesnériacées, Dioscorées. Composées, Rubiacées et Légrumineuses herbacées, les Graminées. Cryéracies et les Fougères en fournissent la majeure partie. Ne citons que quelques grands arbres :

Genipa americana, Hymenxa Courbaril, Mammea americana, Tecoma pentaphylla. Mura crepilins. Erindendron anfractuosum, Cordia Gerascanthus, Cordia Collococca, Cedrela odorata, Crescentia Cujete, Melicocca bijuga, Persea gratissima, Melia sempervirens, Ficus crassinervia et pallida, Sapota Achras, Sideroxylon mastichodendron, etc.

\section{Région des grands bois ou région moyenne.}

Elle commence at une altitude de :300 metres et enbrasse tous les bois a haute futaie jusqu ì une élévation variant entre 800 et 1000 metres. Sur le rersint oriental (les bois de Sainte-Rose, de Sofaya, de la Ravine-Chande et quelques vallées des Pituns-du-Carhet. a la Martiniquej, les fortets descendent au-dessous de $\$ 00$ metres et participent de la tlore de la rézgion inférieure. C'est la zone des forèts vierges, celle ou la régétation cilale un luxe et une beauté qui étonnent l'homme le plus inditlérent. Une couche toujours humide et épaisse d'humus donne aux arbres une ampleur et une hauteur majestueuses. Les Cryptogames protégées par lombre contre l'ardeur du soleil, les plantes épiphytes de toutes sortes poussent avec une vigueur extraordinaire, couvrent les branches et les trones des arbres vivants et envahissent lès vieilles souches at les bois tombés de vétusté. C"est là qu il faut chercher la plupart des arbres qui fournissent du bois de construction, des essences et du tanin. Nous ne mentionnerons que les plus importants:

Magnoliat Plumieri. Shanea Massoni el caribiea. Mernandia sonora, Byrstmima spicala et latrigata. Bunchusia glandulifera, Guarea Perrotelii et Suarlaii, Acrolicilidium sericeum. IIirtella Iriandra. Oxandra laurifolia, Amanna caribiea, Meliosma Merhertii et Pardoni. Styrax glaber. Turpinia wcidentitlis, Dussia martinicensis, Richeria grandis, Nectandra patens, coriacea, Ocotea membrenacea, Prunus occidentalis et sphærocarpa, Guatteria Ouregou, Cicca antillana.

Cäest la cuion récolte les belles Arödées à larges feuilles. les Orchi- 
dées terrestres, et, en fait de Fougères, les Danxa, la plupart des

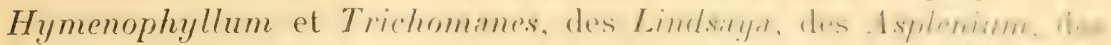

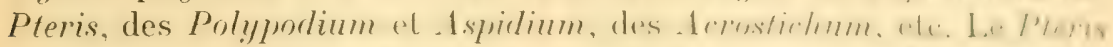
incisa se trouve toujours dans le voisinage des smurees sullureur.

\section{Région de transition.}

A mesure qu'on s'éleve dans les grands bois. on voit que la taill..

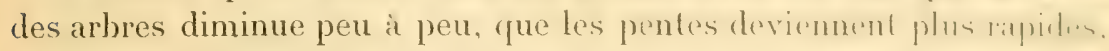

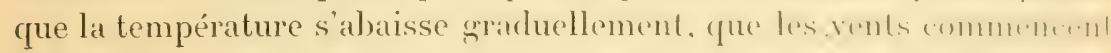
à se faire sentir, que la terre végétale est moins sèche, lavéc ou entrainée qu'elle est par les pluies, que les plantes iplphrytes smit moins nombreuses et moins exubérantes. On arrive alor's dans ce qu'on peut appeler la région de transition ou regrion des lunis at pretil. futaie. Sa limite inférieure se confond avee les erands hois: la suphrrieure est bien tracée et se termine lid ou les Sphaignes commentont it se montrer. Bien que la régétation en cénéral suit celle des luis inliarieurs, on est cependant frappé de la présence de certaines espèces d'arbrisseaux el d'herbes que l'on trouve partout et toujours it cothe altitude. Les principales sont:

Myrsine floribunda, Myrica microcarpa, Charianthus nodosus $(2)$ varié-

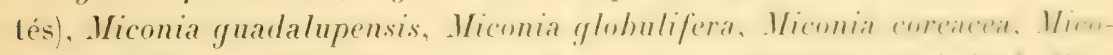
ma marlinicensis, Ilex montana, Freziera amplexifulia. Secialuphyllum umbraculiferum, Peperomia Balbisii, Chusia venosa, Verhesina helianthoides, Myrcia deflexa et Dussii. Eugenia Mnssii, Eugenia lierteri. Luyp-

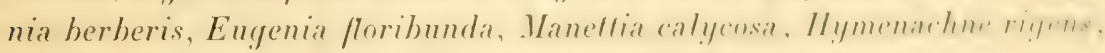
Rynchospora polyphylla, Wachirinm restivides, Viphopheris sermlita. Acrostichum Feei et Plumieri.

\section{Région supérieure.}

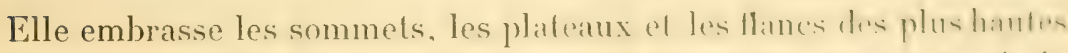
montagnes, soit le cône et le plateau de la sonfriere. une partic d. l.

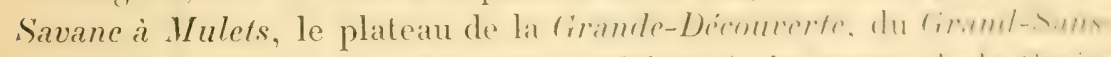

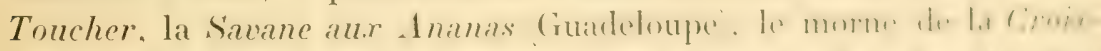

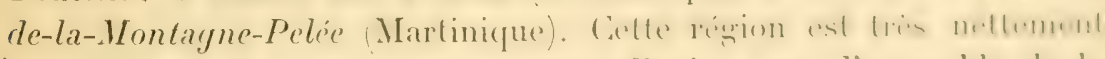
tranchée et offre un contraste extraordinaire avee l'ensemble de lir végétation précédente. Les grands arbres et les lianes variées sonl

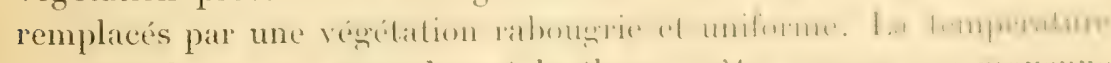
$\mathrm{y}$ descend souvent assez bas et le thermomitre accuse une moyennc 
de $12^{\circ}$ it $14^{\circ}$. A la Soufriere, pendant la saison fraiche et sereine, de janvier juspu en avril, on trouve souvent les feuilles chargees de givre et de glaçons. Le sol est enveloppé d'une toison épaisse de Sphaignes. de Lycopodes et de Fougreres. In fond de cette couche, toujours imprérnéce d'eau ef sous laquelle leurs racines trouvent une protection contre la violence du vent et de la pluie et aussi contre l'ardeur du soleil. surgissent un petit nombre de Phanérogames d'une grande heaute. remarquables par la vivacité de leurs couleurs, qui tranchent fortement avec la coloration terne du reste de la végétation. Toutes les plantes de eette région aérée, battues par des pluies presque quotidiennes et tourmentées sans cesse par une brise froide et riolente, sont pourvues de feuilles rigides.

Un certain nombre de plantes, herbacées ou frutescentes, se rencontrent dans la zone inférieure tout aussi bien que dans la moyenne et même dans la supérieure. De cette catégorie sont surtout:

Palicourea crocea, Arthrostemma glomeratum, Erythroxylon squamatum, Panicum Sloanei, Hydrocotyle asiatica, Mimosa pudica, Sautagesia erecta, Dieffenbachia Seguine, Distreptus spicatus, Philodendrum giganteum, Peperomia pellucida. Eryngium foetidum, Chrysobolanus Icaco, Loranthus: americanus, Wedelia carnosa, Bambusa arundinacea, etc.

La flore indigène des Antilles se rattache évidemment a la flore du continent américain et en particulier à celle de ces parties du Mexique. du Honduras, de Panama. du Vénézuela, des Guranes et du Brésil équatorial formant le versant occidental. Un grand nombre des mèmes especes. qu'il faut principalement ranger dans les Fougèes, les Orchidées, les Glumacées. les Palétuviers, les Légumineuses herbacées et frutescentes et dans beaucoup de grands arbres forestiers appartenant a diverses familles, en sont une preuve. Elle tient a celle des ÉtatsInis, surtout par les framines et Cypéracées. Le Pérou, l'Uruguay, le Paraguay, la Colombie et l'Équateur n'y sont représentés que dins une faible proportion.

Beaucoup de vigritanx utiles et qui, pour la plupart, sont maintenant naturalisés, ont téti introduits dans le passé par les colons, les travailleurs africains et indiens; d'autres ont été répandus par les soins des Chambres d'agriculture par les Jardins botaniques de la Trinidad. de la Jamäique, de Cuba, de la Martinique et de la Guadeloupe; d'autres encore ont ité implantés par des hommes intelligents, désintéressés et soucieux du bien-itre et de la prospérité de leurs pays. 
Nous indicquerons, dans une liste particulime, les nom, al a planim utiles et ornementales dont l'île s'est enrichie.

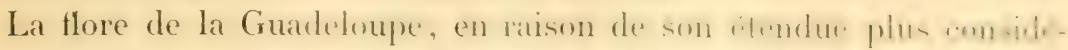

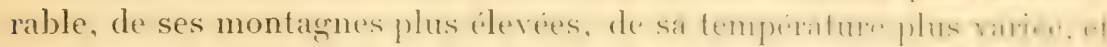

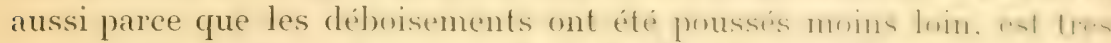

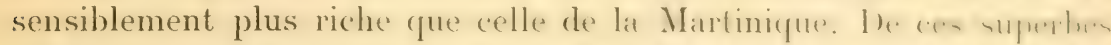
arbres, comme le paléturier jaune. le paléturier intis ou carapale der bois, du bois bandé, du bois graine-violette. du bois de lan, du buinnégresse (Diospyros ebenaster), de plusieurs grands liurles's, yui lonfournissent des bois de charpente, d'un assez frand nombre de Fongères et d'Orchidées terrestres. communes dims less hatulents, on nu. trouve pas trace dans l'île sœur.

\section{FLORAISON}

Le propre de la végétation tropicale est de produire loujours at

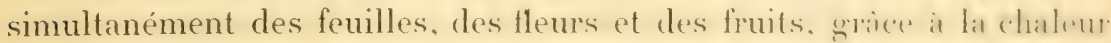
qui entretient une activité végétale incessante. Il dn résulte que. (quel que soit le jour de l'année oì il herborise, le bolaniste mouve foujours une récolte à faire, avec plus ou moins d'abondance, dans quelque lieu qu'il se dirige. Lne secheresse prolongine seule pent mettre obstacle à cet ordre de choses.

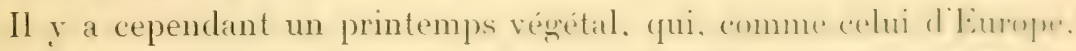
commence généralement en mars et finit en juin. ("xist la satisnn pendant laquelle presque tous les arbrisseaux et la plupart des gramel arbres se parent de fleurs. Apris l'hivernage, ou tempes des framenes pluies (qui officiellement dure du $1: 3$ juillet an 1.3 actolsed, il ? a seconde montée de sève. celle de september an d'ondohre jusplian

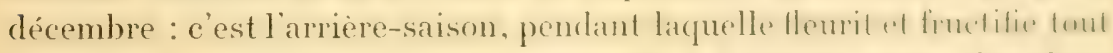
ce qui, dans la première saison, est resté à l'étal de repos. Ces deux règles souffrent de nombreuses exceptinns. I ees lauriers. te carapate de-s grands bois et quelques Meilastomateres choisissent pour the urir thum wn

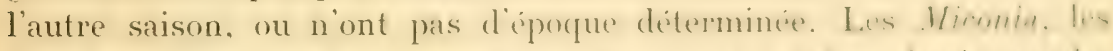

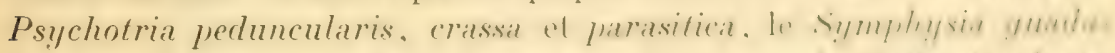

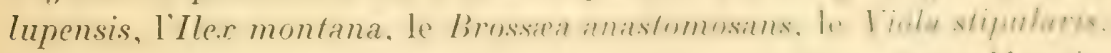
les Freziera et Ternstromia; les palétuviers : Rhizophora .Manyle.

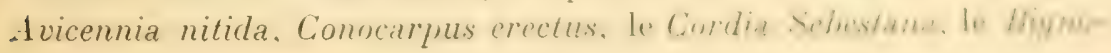


nia stans, le papayer ef le cocolier. les Malvacées suffrutescentes et quelques frutescentes, comme les Maluastrum et les Sirla. plusieurs Hibiscus. la trix grande majorite des plantes herbacées fleurissent toute lannée. Landis qüil est extremement rare de trouver les fleurs du bambou et de certaines Myrtacées des hauteurs éventées.

Les Thrinax, le gayac, les cerisiers du pays produisent deux ou trois fois par an: la sibanea caribrea. les Meliosma Herbertii et Pardoni " bois de sept ans " it lat Martinique), les vieux pieds de courbaril ne fleurissent que tous les trois ou quatre ans.

\section{NOMS VULGAIRES OU VERNACULAIRES}

La plupart des plantes de la région habitée et beaucoup de celles des grands bois portent des noms vulgaires, qui leur ont été imposés par les planteurs, les médicastres, les panseurs, les quimboiseurs (sorciers), les coupeurs de bois et les chasseurs. Les mieux connus sont les végétaux qui servent pour la médecine domestique, pour l'alimentation des animaux, pour la charpente, la menuiserie, la tabletterie, etc.

Rien de plus incertain que ces noms vulgaires : ils changent d'une localité a une autre, à plus forte raison d'une ile à l'autre. Ainsi le ITerlelia carmosa sappelle a Gourberre " patte-de-canard ", a cause de la ressemblance de sa feuille trilobée avec la patte de ce palmipide: au Camp-Jacob. il recoit le nom de "fleur-soleil ". it cause de ses capitules à fleurs radiées; aux Trois-Rivières, la mème herbe est nommée "herbe-à-lapin ", parce que cette bête en est friande. Ce qui à la Martinique est un bois " crécré ") est connu à la Guadeloupe sous le nom de " bois-côtelette ", et le "bois-cotelette " des Martiniquais devient le "bois carré " des Guadeloupéens.

Lne quarantaine de plantes cependant portent, non seulement dans les diffórents quartier's de notre île. mais encore a la Martinique. les mème's démominations pour désigner les mèmes espèces. Soit les noms de: puirier. (ampeche. fromager. sablier. galba, cachiman blanc et rouge, corosol. pomme-cannelle, gavac, grovatier, prume Monbin, prune d'Fspatene, pomme Cuthere. sapotillier, abricotier, suran ou surian, mancenillier, calebassier. Lennetier, pomne dacajou. Jois blanc. 


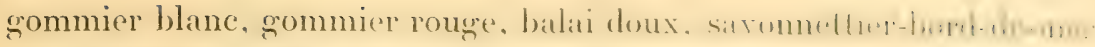

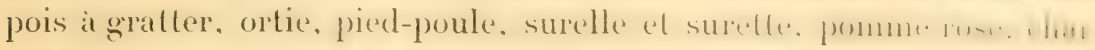
don béni, patate-bord-de-mer, raisinier-bord-de-mer.

On désigne, sous le nom collectif de "collants ) ou " cousins ", des

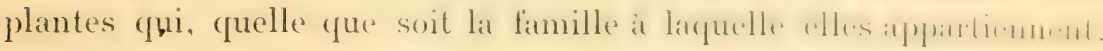
produisent des fruits gluants ou pourvus soit de piquants soit de poils par lesquels ils sattachent and olyjels qui les lomelont (14 espèces). On désigne de même sous les noms :

De "gratte-jambes ", de " crocs-chiens ", des arbrisseaux à branches pendantes, pourvues de piquants (こٌ espèces);

D' "épiniers " ou d'" épineux ", des arbrisseaux ou arl)res droits. munis de piquants forts ( 7 espèces);

De " caca-ravet ", des arbrisseaux ou petits arbres à fruits tres petits (3 espèces);

De "citronniers " ou de " bois-citron », des arbres à fruits ronds de la grosseur d'une graine de poivre ( 4 espèces);

De " merisiers ", des arbres et des arbrisseaux à fruits pulpeux. du volume d'un pois ou d'une petite cerise ( 1 ¿̈ espèces);

De "bois-café ", de "café bâtard ", "café-montagne ", " café-marron ", des arbres et des arbrisstaux qui portent des fruits ay ant lia forme et le volume d'une cerise de café cultivé (10 espèces);

De " bois d'olive ", des arbres ou des arbrisseaux à fruits peu pulpeux, de la forme et de la grosseur d'une olive de firance it esprex :

De " bois-pistolet ), des arbres dont les fruits capsulatires somrrent avec fracas ( 4 espèces);

De "mauricipres » ou " mauricifs" (" bois-tan " a la Martinique). des arbres dont l'écorce sert pour le tannage (3 espèces);

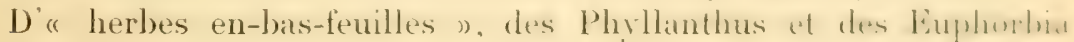

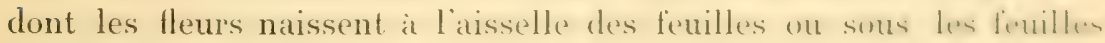
(9 espèces);

De "bois-côtelette », «bois-côte », “ bois carrés », des arbres et dess arbrisseaux dont les branches ont quatre angles on donl lan lowm ont des côtes ou des anfractuosités ( 11 espèces);

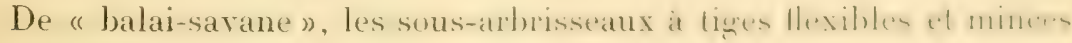
dont on fabrique des balais grossiers ( 1 ö espèces), ete.

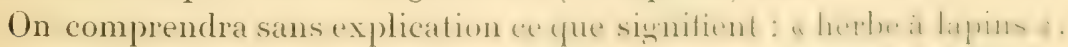
" herbe à vaches ", "oreille-mouton ", "langue à boul" ", " hois ì agouti », " liane à serpent ), " liane rude ), " liane douce ), "patate marron ", " igname marron ", " herbe a pisser ", " herbe it tisane . 
"herbe aux soreiers ", "oseille-bois ", " herbe a miel ", "cachimanbâtons ", " piment-vache ", " bois-cabrit ", " guérit-tout ", ete.

\section{DIFFICULTÉS D'HERBORISATION}

Dans les pays tropicaux, pour herboriser sirieusement, il ne suffit pas de se munir d'un couteatu. d'un instrument à fouiller ot d'une boite de Dillenius: il faut avoir a sa disposition une presse portative dans laquelle on met, sitot après les avoir cueillies, les plantes à fleurs caducques, tendres et délicates. En outre, on doit être accompagné d'un gruide solide, armé d'un coutelas ou d'un sabre, instrument indispensable pour ouvrir des chemins, et d'une hache, pour abattre les ardores éleves et a tronc lisse sur lesquels il est impossible de grimper pour se procurer les fleurs ou les fruits. Ici, je demande pardon a qui de droit, si, sans permission préalable. jai dû faire coucher par terre une quarantaine d’arlores disséminés dans les forêts les plus denses. pour arriver a une récolte complète. Il le fallait : c'est mon excuse.

Ramasser les plantes n'est pas le côté le plus pénible : les presser et les conserver ensuite. Thumidité étant toujours très grande, est chose bien autrement difficile. On comprendra aisément combien de soins et de patience nécessitent la dessiccation et l'empoisonnement de toutes ces herbes grasses et succulentes, de ces fruits pulpeux, qui deviennent si facilement la proie des vers.

En terminint, je suis heureux d'avoir une occasion d'exprimer ici. publiquement, arec mes hommages respectueux, mes plus chauds remerciements à MM. les Curés de la Guadeloupe, de la Grande-Terre et de la Martinique, pour la hienveillante et généreuse hospitalité que tous, sans exception, dans un esprit admirable de fraternité, mont accordée, et sans lacpuelle, vu mes faibles ressources, il m'eût été impossible d'accomplir le travitil d'herborisation que je m'étais proposé. Je remercie également M. le professeur Ileckel des soins spéciaux (quil a bien voulu domer a mon ceuve pour en augmenter la perfection et pour la mise au point des descriptions. En ce qui touche aux notes. relatives ì l'emploi des plantes. qu il a ajoutées ì mon texte. en l'éclaircissant, enfin pour la sollicitude particulière dont il a entouré la composition materielle de ce travail et la correction des épreuves, je ne saurais troplui témoigner ma gratitude. 


\section{PLANTES}

\section{DE LA GUADELOUPE ET DE LA MARTINIQUE}

\section{DICOTYLÉDONES}

PREML̇RE FAMLE. - RENONCUTACBRS.

Clematis L. (du grec "lilema ", sarment, parce que les liges de beaucoup d'espèces sont grimpantes.

C. dioica L. Clématite à fleurs dioïques. Vulgo : Liane à crabes. Sl., Hist. of Jam., t. 128, f. 2; Rich., Cuba, t. 1. C. americana Mill. C. dominica Lam. - Arbrisseau-liane, grimpant, volubile, haut de 3-5 mèt. Feuilles pétiolées.

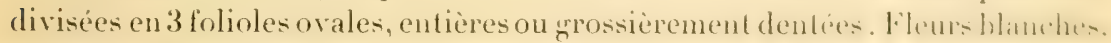
odorantes, en grappes larges, teminales. - Tres rare. I. Jony du canal Mnnléran dans l'intérieur des bois. - Fl. de sept. en nov. [Yo 3254.

Martixiede. Vulgo : Vigne sauvage, liane serpent. - Assez abondant dans les haies du Morne-Ronge et dans les broussailles du Champllom hatrit. Gérard). [No 1761.]

DEUXIÈME FAMLLE. - DIII.ENIACLES.

Pinzona Mart. et Zucc. (dédié à l'Espagnol Vincent Nuncz Pinzon, qui en 1500 découvrit le Brésil.

P. calineoides Eichl. Pinzona à leuilles de Calinea (plante de la Guyane). Vulgo : Liane à eau. - Liane arborescente montant sur les arbores les plus élevés. Feuilles coriaces, elliptiques, mesurant 10-20 $<5$-10 (m) ; i nervures très saillantes en dessous, les jeunes grossièrement dentées-crénelées vers le

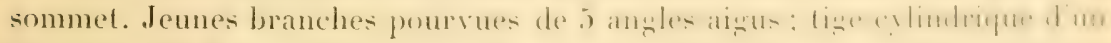
dian. de 6-12 cm. Fleurs blanches, petiles, disposées en pelites mapper axillaires. Fl. en sept. et oct. - Assezabondant dans les grands bois de Solatrat el de la Ravine-Chaude (Iamentin). - Celle liane contient une can tris lim-

Di:s. - Pluntes Gundeloupe et Martinique. 
pide, sans saveur sensible, rafraichissante: pour en avoir une certaine quantiti, il suffit de couper le tronc dans un endroil queleonque. et, pour empècher l'eau de monter dans la partie supérieure de la tigge, d'en détacher lestement un morceau: avec untronenon de I mèt. de long, nn peut remplir un verre à boire. - Alt. $180-300$ mèt. [No 3242.]

Elle n'existe pas à la Martinique.

I. Dillenia speciosa Thunb., arbre superbe par son port ef son leuillage, originaire de la crite de Malabas, a été introduit a la Martinique en 1869 par l'horticulteur I. Hahn. Il est cultive au Jardin botanique el dans plusieurs autres localités de l'île: Carbet, Fort-de-France, etc.

\section{TROISİ̀E FAMLLE. - MAGNOLIACÉES.}

Talauma Juss. (nom qu'on lui donne en Amérique.)

T. Plumieri. I)C. Talauma de Plumier. Yulgen : Maniolia Magnolia bois pin. Desc. Fl. méd. des Ant., vol. Il, 1. 163, p. 140. Magnglia Plumieri Sw. - Arbre majestueux, haut de 25-35 mèt., à tronc jusqu'à $1^{\mathrm{m}} 50$ de diam., à bois dur et noir en dedans, mou et blanc en dehors. Feuilles larges, coriaces, ovales-oblongues, rudes. Fleurs grandes, tris blanches, dine odeur forte et exquise. Fruit strobiliforme. - Fl. habituellement d'avril en juin et aussi de sept. en nor. - Issez abondant dans tous les wrands bnis de la Guadeloupe. [No 2995.]

Mantriger. Vulgn : Bnis pin. - l)ans lous les grands bois de l'ile, jusqu a une altitude de $750 \mathrm{mèt.} \mathrm{[No3.]}$

Le Magnolia yrandiftura S., M. a wrandes fleurs, petit arbre, orignaire de l'Amérique continentale, est cultive daus plusieurs jardins de lîle, où il lleurit tous les ans : ex., à Gourbeyre. - A la Martinique, il existe au Jardin des plantes et dans beaucoup d'autres localités de l'île.

I. Illicium anisalum L., vulgo : l'Anis étoile, arbrisseau originaire du Japon et de la Chine, se rencontre au Jardin botanique de Saint-Pierre, d'où il

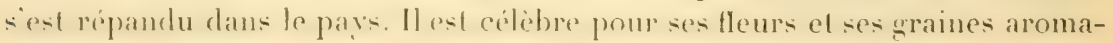
liques el diurétiques. [Nं 1773.

\section{QUATMEME FAMLLE - ANONACLES.}

Anona L. (du mot malais " manoa " ou " minona ".)

A. muricata L. Anone à fruits hérissés, Vulgo : Corosolier. Desc., vol. II, 1. 81, p. 56; 'luss., Fl., II, t. 21. - Petit arbre, dont les plus grands repré- 


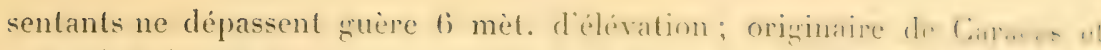

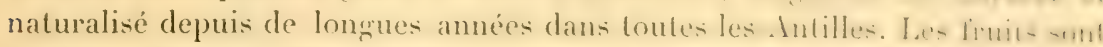

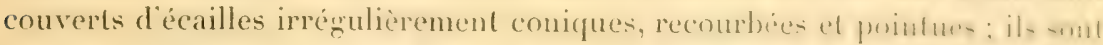
très rafraichissants et se servent à table, surtout le malin; on en manere

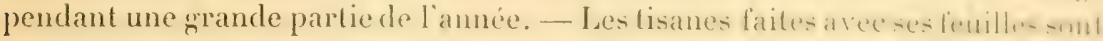
d'un emploi général : elles sont calmantes el lavorisent la dige-fion. I)... courtilz place cet arbre à juste litre dans les stomachiqute astringuhlOn se sert des feuilles macérés dans l'eau tiede, pour lirollep lus parti.-

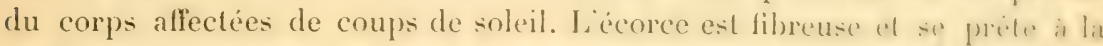

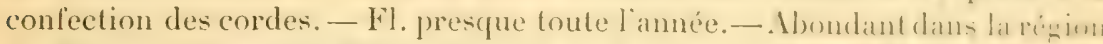
du littoral, Désirade, Marie-(ralante et dans toute lile de la Ciuadeloupe. $\left[\mathrm{N}^{\circ} 3056 \mathrm{~b}.\right]$

Martinique. Vulgo: Corosolier. - Abondant dans toute l'ille. Alt. $0-350$ mèt. [No 1767.$]$

A. palustris. L. Anone des marais. Vulgen : Cachiman eochon, bois flot. Petit arbre touffu dépassant rarement 5 mèt. en hatuleur, i ceorce more. Feuilles elliptiques ou oblongues, pointues au sommet, resiemblanl a-co bien à celles du corosolier. I.e fruit, qui tient le milieu, pour la lorme et les: dimensions, entre la pomme-camnelle ef le cachiman ordinaire, ne se many.. pas ; les crabes en sont friands. - Avee ses racines spongienses, on lableripue quelquefois des bouchons. Aree les leuilles, cuites dams l'eau bouillanle. luhabitants préparent une tisane pour les chevaux atteints de llusion de pui-

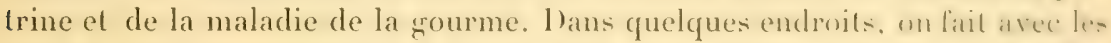
feuilles une tisane contre la diarrhée, à cause du principe astringent ful elles contiennent. Les fruits mùrservent aux pécheurs comme appat. - lil. halpituellement de juillet en janv. et aussi de nov. en mai. - Abondant dans la

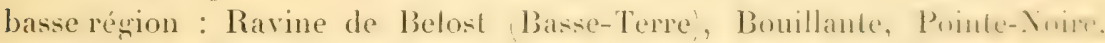
Lamentin, Moule (le long du canal). Alt. 0-140 mèt. [No 3056 .]

Martinque. Vulgo : Mamain ou mamin. - Lamentin (habilation Lareinty), Sainte-Luce, Marin. [No 1764.$]$

A. squamosa L. Anone écailleuse. Vulgo : Pomme-cannelle. Sl., Hist. ol Jam., t. 227; T'uss., Fl., III, t. 4; Desc. Fl. méd. des Ant., vol. II, 1. Si3, p. 65. - Petit arbre souvent tortueux, ne dépassant guère 1 mèl. d'élévar

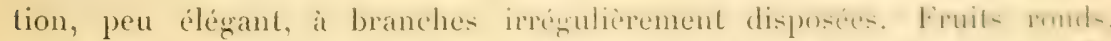

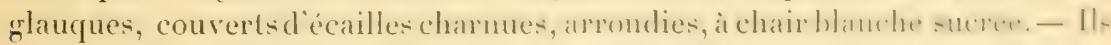

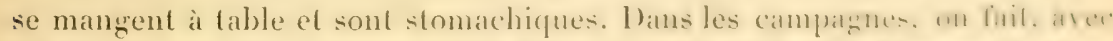

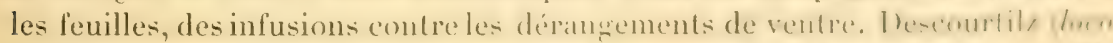

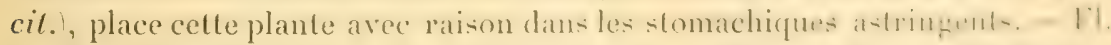
habituellement d'avril en juillet: les fruits mûrissent de sept. en l'ér. -

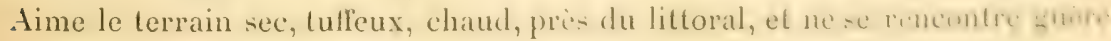
au delà de 140 mèt. d'altitude. [No 305.1.] 
Mantinique. Vulgo : Pomme-cannelle. - Abondant sur tout le littoral. $\mathrm{N}^{\circ} 1766$.

A. mucosa Jacq. Anone muqueux. Vulgo : Cachiman crême. Tuss., Fl., I, 1. 28. - Petit arbre de 4-5 met, de haut. Fruil grand, presque rond, couvert d'écailles larges, charnues, arrondies: chair blanche, sucrée, d'un bon goùt: il se mange à table. - Fl. en avril, mai ; les fruits mûrissent d'août en déc. Assez abondant dans les parties basses el sèches de Case-Pilote, du Carbet et surtout du Prêcheur. Alt. 0-150 mèl. - Nous n'avons pas trouvé cette espèce à la Guadeloupe. [Xo 1763.

A. reticulata L. Anone réticulée. Vulgo : Cachiman cœur de bout'. Aublet, Hist. de la Guyane, p. 618 ; Sl., Hist. of. Jam., t. 226 ; Dese., vol. II, p. 61, 1. 82 ; Tuss., Fl., I, 1. 29. - Petit arbre, haut de 5-7 mèt. Fruits ronds, affectant plus ou moins la forme d'un cueur de bueuf, à surface aréolée, dépourvue d'écailles. - Ils se mangent à table et sont stomachiques. Descourtilz les range dans les stomachiques astringents. Cueillis avant maturité et séchés, on les emploie avec succès contre les diarrhées rebelles. Fl. habituellement en juin-juillet. Les fleurs exhalent, surtout le soir et pendant la nuit, un parfum pénétrant et agréable. Les fruits mûrissent d’août en février. - On rencontre plusieurs variétés, dont les principales sont: cachiman blanc, cachiman rouge et vert. Mèmes localités que la pommecannelle, mais moins abondant. Alt. 0-150 mèt. [ $\Gamma^{\circ} 3055$. ]

Martinique. Vulgo : Cachiman. - Saint-Pierre, Prêcheurs, Case-Pilote, elc. $\left[N^{\circ} 17\right.$.

Rollinia R. Br. dédié i Charles Rollin, né a Paris en 166il, prolesseur de rhétorique et naturaliste: aida Tournefort daus son ourrage : Institutiones rei herbarix 1770.1

R. Sieberi Dun. Rollinia de Sieber botaniste et médecin de Prague, qui a vovagé en Amérique et dans les Antillesi. Vulgo: Cachiman montagne. Petit arbre, haut de ti-8 met. Fruits arrondis, habituellement plus volumineux qu'une grosse pomme-cannelle, couverts d'écailles fortes, larges, droites ou presque droites, arrondies at l'extrémité; chair presque blanche, fondante dans la bouche, légèrement visqueuse, d'une saveur sucrée, agréable. - Fl. habituellement d'arril en juin. - Peu abondant. Cá̀ et lì quelques pieds au Camp-Jacob et à l'habitation Montéran. [No 3059.]

Mantingue. V'ulgo : Cachiman morveux, - Hauteurs du Prêcheur el du Fond Canonville. No 1045.

Guatteria R. Br. (dédié à J.-B. Guatteri, professeur de botanique à Parme.

G. Ouregou Dun. Vulgo: Corosol montagne, petit cachiman des bois.-- 


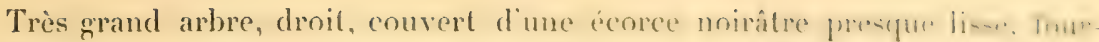
nissant d'excellentes fibres, dont les bùcherons de Pigreon et de La Bonillante font des cordes très solides. Fleurs verdâtres, parfumées, solitaires it

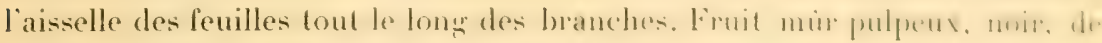
la grosseur et de la forme d'une olive; les oiseaux en sont extrêmement friands. Le bois est léger et sert à laire des canots et des mâts. - Fl. de mars en mai; les fruits mûrissent de juillet en août. - Assez abondant dans les

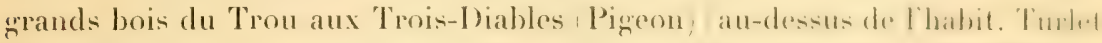
et Lafaye), bord du Galion du côté du Bassin-Bleu, ete. Alt. 500-800 mèt. No 3057 .

Mantixique. Vulgo : Bois de l'Anglais, mahot anglais. - Chà et là dans les bois de la Fontaine Absalon et du camp de l'Alma. Alt. (50-680 mèt. [No $176 \%$.

Oxandra Rich. (du gree " oxus" pointu el "aner " homme, pour faire allusion au prolongement, en haut et en bas des anthères, du connectil en un appendice linguiforme.)

0. laurifolia Rich. Oxandre à Peuilles de laurier. Vulgo: Bois de lan. Lich.. Cuba, 1. 8. - Grand arbre droit, a ecoree noire. Fenilles coriaces, olliptiques. luisantes. Fleurs petites, axillaires el caulinaires, tris nombrenses, disposite le long des branches; boutons verdâtres, exhalant une mauvaise odeur: fleurs très blanches, répandant un parlum délicieux. (Cet arbere ne dome par de fruits; au moins, nous n'avons jamais pu en trouver. - Fl, de juin en août. - Assez rare. Bord de la rivière Noire, chemin de la Cascade de Yauchelet. $\left[\mathrm{N}^{\circ} 3088\right.$.

Ne se rencontre pas à la Martinique.

Cananga Rumph. (nom qu'on donne à cette plante ì la ('uyane.)

C. odorata J. Hook. Vulgo: Cananga, poivre de Guinée, poivre de nègre,

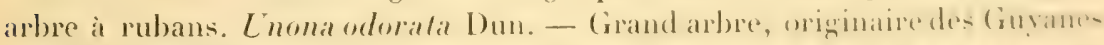
et des Indes orientales, introduit au Jardin botanique, dou il se- répamdu

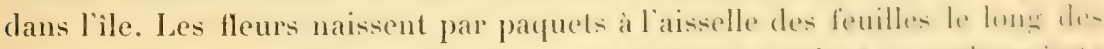

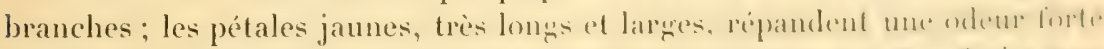
et agréable; on les ramasse souvent pour l'usage domestique. Ix fruits sunt des baies noires, d'un groût âcre et piquant, semblable à un mélange de

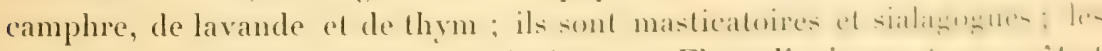
pauvres s'en servent en guise d'épices. - Fl. ordinairement en aout ef septembre. - Saint-Pierre, Fort-de-France, Parnasse, Sainte-Marie, che. Alt. 0-350 mèt. [No 1762.]

L'Arlabotrys odoralissima R. Bro, arbrisseau samenteux, orifinate cle l'ar-

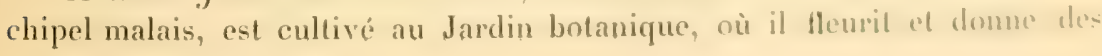


fruits presque toute l'année. Les fleurs et les fruits sont très aromatiques. $\left[N^{\circ} 1768.\right]$

\section{CINQUiÈME FAMLLE. - MYYRISTICÉES.}

Myristica L. (du grec « muristicos », parfumé, odorant.)

M. fragrans Iloutt. Vulgo: Muscadier. Desc., vol. 8, t. 561. M. moschala 'Thunb. - Petil arbre à fleurs dioïques, d'environ 5-8 mèt. de haut, d'un très beau port, originaire des îles Moluques, cultivé depuis de longues anmés dans les Antilles.- Cet arbre est presque continuellement en fleurset en liruits ol 11 '́pprouve qu'une effeuillaison presque insensible.- En incisant l'écorce, en coupant une branche ou en détachant une feuille, il en sort un suc visqueux et assez abondant, diun rouge pâle, qui teint le linge d'une manière asses. durable. Ie bois est poreux, filandreux, d'une grande lécèreté et sans odeur. J.e muscadier commence à porter à l’age de 7 a 8 ans, les graines zerment au bout de 25 à 35 jours. - On peut manger un champignnn noiratre, appelé Bolefus moschali, qui vient sur le brou entasse. Les fruits sont aphrodisiaques. Dans les campagnes où l'on trouve des muscadier's, on administre, à ceux qui ont de fortes coliques, un mélange de vin chaud, de muscade el d'écorce de camnelle râpées; une pâte préparée avec du suil, du laudanum el de la muscade rìpée, mise dans un linge et appliquée contre le front, fait passer en peu de temps les maux de tête; enfin, le vin chaud, avec de la muscade râpée, semploie souvent contre les refroidissements, les forts rhumes el les bronchites. - Cultivé cè et la sur les propriétés. Gourbeyre, Trois-Rivières, etc. [No 3656 .

M.ntivece. V́ulgo : Muscadier. - Plus abondant quà la Guadeloupe, [No 2012.]

M. fatua Sw. Muscadier fou. M. surinamensis Rol. - Assez grand arbre, it feuilles linéaires-oblongues; se rencontre gà et li sur les habitations, mais on ne possède que des pieds à lleurs mâles. - Fleurit en juillet et août. Mazet lindique comme existant à la Guadeloupe; nous ne l'avous jamais trouvé. $\left[\mathrm{N}^{0} 1053.\right]$

M. sebifera Sw. Vulgo : Muscadier porte-suif. - Est cultivé au Jardin botanique de Saint-Pierre.

\section{SIXIÈME FAMILLE. - MONIMIÉES.}

Citrosma R. P. (du grec "kitron ", citron, el "osmè ", odeur, à cause de l'odeur forte qu'exhalent toute les parties de la plante.)

C. glabrescens Prl. Vulgo: Bois citronnier, consoude grand bois. - 


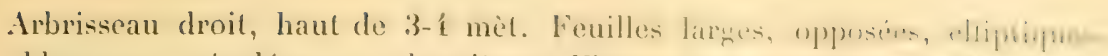

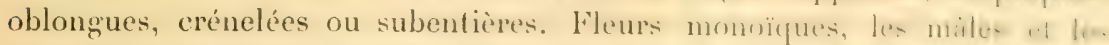

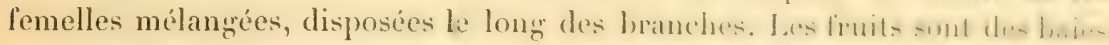
rouges contenant 5-6 semences dures. Toutes les parties de celle plante exhalent une odeur forte qui rappelle plus ou moins celle du citron. - Assez. abondant : Calebasse, Deux-Choux, Camp de l'Alma. Alt. 480-650) mít. [No 1726. ] - Je ne l'ai pas rencontré à la Guadeloupe.

SEPTİ̀E FAMLLE. - MENISPERMIEES.

Cocculus DC. (de " coccus " ou "kokkos ", baie, parer que les fruil- smul des baies noires.)

C. domingensis Engr. Pachygone Miers. Vulgo : Liane hambuchu britard.

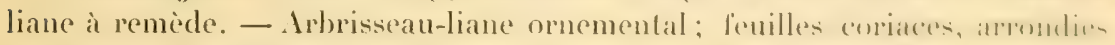
au sommet, oblongues ou elliptiques lancéolées, fres vertes. Brand bes allongées, flexibles. pendantes. Fleur's monoüques en prappes pendantes, allongrix.m. Fruit drupacé, obovale, noir, de la grosseur d'une petite olive.--Assez raro : Morne Gobelin (Gourbeyre). - Fleurit en janvier et f'évrier, ğr mûres en mai et juin. Alt. 100-550 mèt. [No3 132.$]$

Mantineue. Vulgo: Liane perruche,-- Rare : Fonds Saint-Denis près de l'endroit nommé Porte de l'Enfer, Camp de l'Alma. [No 1487.

Le Cocculus laurifolius. DC, arbrisseau d'omement, originaire du lepanl, est cultivé au Jardin bot. de Saint-Pierre, d'où il s'est répandu dans les jardins du pays. [ $\left[\mathrm{N}^{\circ} 1788\right.$.

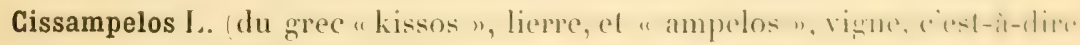
liane-grimpant à la manière du lierre.)

C. Pareira L. Vulgo : Liane amère, liane corde, liane quinze jours. I)ese, vol. 3, t. 201. - Liane ornementale à cause de son leuillage. Racines volumineuses; tiges minces, flexibles, tombantes. Fenilles condiformes arromblir.

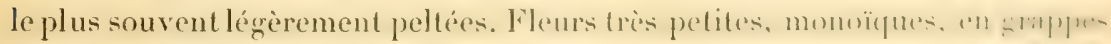

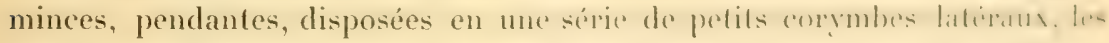
femelles supportées par une bractée, grande, en forme de cuiller. Fruits

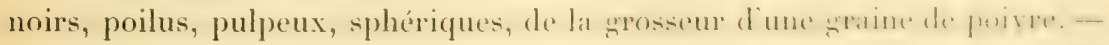
Les feuilles et les racines ont une saveur faiblement amire. 1)esc., p. 2:3:3, met cette espèce dans les alexitères internes; il vante la racine comme très efficace contre les néphrites calculeuses et les maladies des voies urinaires, l'engorgement des bronches et des poumous par des matières visqueuses, ol enfin contre les morsures du serpent. Dans le pays, on we se sert que rarement de cette plante dans la médecinedomestique. - Vil. de nov. on avil.- 
Momelant dans les haies ef les brouscailles de la basse el movenne région :

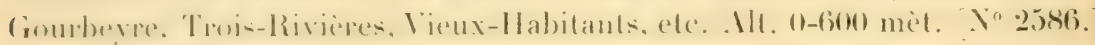

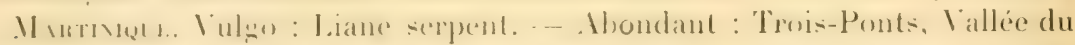

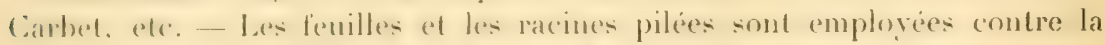
musure du serpent : arece les feuilles el les fruits, on enive les poissons. ¡̃ 1038.j - Variété macrocarpa [No 1040]. Variété Caapéba [No 1011].

\section{HCITIÈE FAMLL. - NTMPIIEACÉES}

Nymphæa J. du zree " numplue ". nimphe, habitante des raux.)

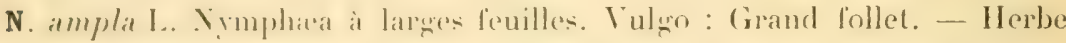
aquatique, vivace, it grandes feuilles larwes. rondes, sinuese-dentées flottant a la surface des mares deau doncer. Les fleurs durent 3 ou f jours, se ferment pendant la muil, se rouvent dans la journes: avant de se faner, elles changent leur couldur blanche oblatante en une belle couleur de feu. - Fl. de mai en nor. - Pelit Canal. Moule mare du Cocotier el dans beaucoup de mares de la Grande-Terre. [Yo 3657.]

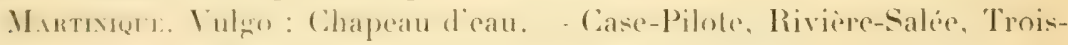
Ilets (mare de la Plaine). [No 1771.

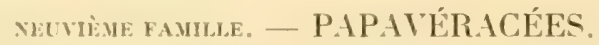

Argémone 1.. (du wree "arenemon ", tache blanche dans liexil, affection de

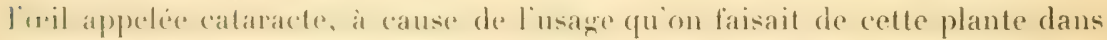
le traitement de celte maladie.)

A. mericatna I. lulgo : Chardon, zerbe chardon, zerbe dragon, lese.,

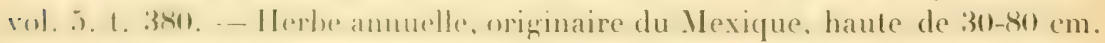

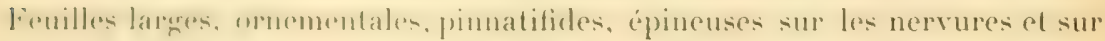

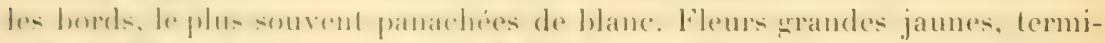

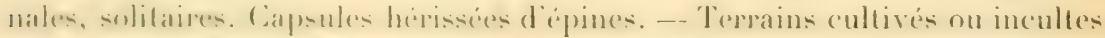

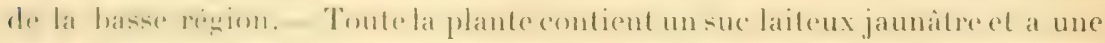

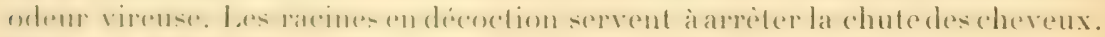

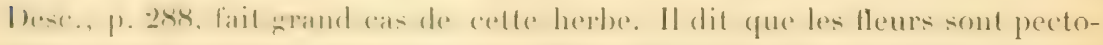

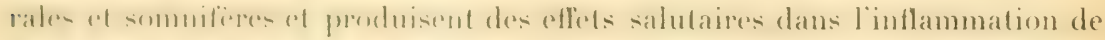
la

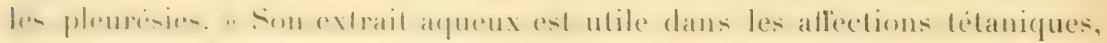

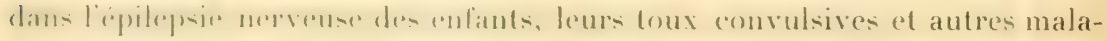

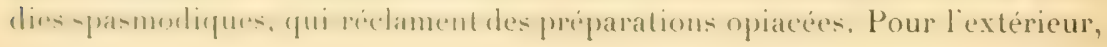


jajoutais des feuilles et fleurs d'aryémone aux injections anndines, propres ¿ calmer les douleurs brùlantes et aiguës des puslules vénériemnes. I.es eraines.enntinue-t-il.sont puratives et ont, parmi les habitations des colonies. la réputation d'etre utiles dans les diarhées et les dyenteries. Jes feuilles. contusées et appliquées extérieurement, apaisent les douleurscéphalalgriques et celles des opthalmies. Comme l'arémóme provoquela sueur et le summeil. on en associe les fleurs aux diaphorétiques el le sirop aux potions calmantes. Le vin de Madère dans lequel on a laissé en macération l'argémone disipe les taies de la cornée el les verrues. "Fleurit de janx. en avril.-Basse-Terre (cimetière des paures, Vieux-Ilabitants, Pigenn. Alt. 0-120 mèt. Xo 2zít.

Martivigle. Vulgo: Chardon marbré, herbe dragon.-Abondant : Carbel, Saint-Pierre, Prêcheur, etc. Dans le sol sablonneux. $\left[\mathrm{N}^{\circ} 1776.\right]$

Bocconia L. Idédié par Limné à Boconi, botaniste sicilien de linordere dés Cisterciens, aut ur d'ourrages botaniques, mort en 1704.

B. frutescens. L. Bocenie en arbre. Sl., Hist. of Jam., t. 125; Desc., vol. I, t. 54.- Suffrutescent, souvent presque arborescent, pourant atteindre jusquà 4 mèt. d’élération. Ies jeunes tiges meurent tous les ans, el la tige principale, en produisant des rejetons, peut durer 5-7 ans. (frnemental, à cause de ses feuilles glauques-blanchâtres, larges, ressemblant asse\% bien, quant à la forme, à celles de l'arbre à pain. Fleurs petites, en panicule ample, terminales. - Peu abondant: çà et là dans les savanes humides et les ravines abruptes de la moyenne région; Camp-Jacob, Gourbeyre, environs de Dolé, etc. - Desc., p. 235, range cette plante dans les vermifuges. Dans le pays, efle est trop rare pour que la médecine domestique puisse en profiter. Alt. $200-700 \mathrm{~m}$. Nus 2439 a et $2439 \mathrm{~b}$.

Mintiviét. - Également peu abondant : Fontaine-Chaude, hauteur du Prêcheur. $\left[N^{\circ} 1775\right.$ a et $b$.

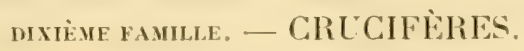

Lepidium L. du grec " lepis ", écaille, allusion à la forme des silicules.

L. virginicum L. Ieppidium de la Vireginie. Vulyo: Cresson de savane. cresson sauvage. Lepidium Iberis. Desc., vol. 1, t. 41. - Herbe annuelle droite, haute de $20-70 \mathrm{~cm}$. Feuilles lancéolées serretés. Fleurs blanches, en racèmes allongés. I ees jemes feuilles se mangent cuites et plus souvent crues en salade. Desc., p. 113, place cette herbe dans les stomachiques antiscorbutiques, presque an mime titre que le cresson. - . Mnndant dans les endroits un peu humides, cultives ou abandonnes. Basse-Terre. $\mathrm{N} \times 2298$. 
Martinique. Vulgo: Cresson de savane. - Se mange souvent en salade. - Saint-Pierre, 'Trois-Ilets, etc. [No 1787.

Senebiera Poir. (dédié au physiologiste Sénébier, de Genève.)

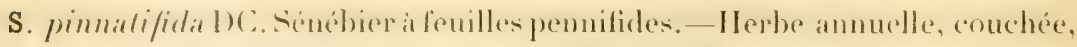
longue de 1.5-f0 cm. Branches llexibles, feuilles profondément incisées pemniséquées). Fleurs vertes, pelites, en racèmes courts, opposés aux branches. Cette plante émet une forte odeur vireuse el désagréable; elle passe pour être vénéneuse. - Dans les champs cultivés et les jardins, où il vit en société el forme parfois un véritable gazon. Saint-Pierre habit. Plaisance, Lamentin. [No 1786.] - Nous ne l'avons pas trouvé à la Guadeloupe.

Cakile 'Toumef. (nom arabe, dont Sérapion s'est servi le premier pour dénommer la plante en question; on prétend qưil vient du grec a kalè is ou "kelè ", enllement, faisant allusion à la nature des racines.)

C. aequalis L'Hérit. Vulgo: Chou bord de mer. Dese., vol. I, 1. 4.3. G. marilima Rich. C. cubensis Kith. Bunias cakile Desc. - Annuel ou bisannuel, plus ou moins droit ou tortueux, haut de $30-80 \mathrm{~cm}$. Feuilles charnues, lancéolées. Fleurs blanches en grappes allongées. - I la Désirade, on mange les feuilles en gruise de salade : elles ont assez exactement le zoout du chou de France. Desc, p. 199, met cette herbe dans les stomachiques antiscorbutiques. - Vit en société sur les plages sablonneuses de la Désirade, du Moule, de Saint-François, de Sainte-Anne, de Marie-Galante, etc. Fl. à toutes les époques de l'année.

Ne se rencontre nullement à la Martinique. [No 3659.$]$

Sinapis L. (du grec " sinapi », sénevé, moutarde.)

S. juncea L. Vulgo: Moutarde: Desc, vol. 6, 1. 430. Sinapis nigra l)esc. - Annuel, droit, haut de 40-90 cm. Feuilles inférieures en forme de lyre, dentelés, les supéricures elliptiques, petites. Fleurs jaunes en grappes allongées. - Fl. surtout pendant la saison des pluies. - Dans les champs et autour des maisons. Au Camp Jacob et à Gourbeyre, on le cultive quelquefois et on vend les graines aux pharmaciens. Alt. 0-800 mèt. [No 2299.]

Martinique. Vulgo : Moutarde sauvage. - Dans les champs : Trois-llels, Trinité. [No 1785.$]$

1.e Nasturtium o/ficinale R. Br., vulgo: Cresson de fontaine, eresson de France, est cultivé dans le pays pour les besoins de la cuisine.- A la Martinique, entre le camp de l'Alma et les Deux-Choux, on traverse des savanes aquatiques où le cresson pousse à foison et sur une grande étendue; on troure atusi sur les bords de la Capote (Champlore beaucoup de petits endroits courerts de cresson. - Il nefleurit jamais. 
ONZIL̀ve FAMILI. - CAPPARIDFES.

Cleome L. (mot employé par Octavius Horalius, médecin romain du

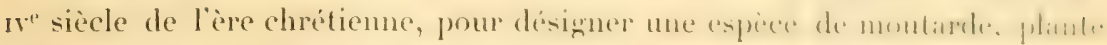
qu'on ne commaît pas exactement, mais dont linnć a pris le nom pour dénommer le genre voisin "Cleome ».)

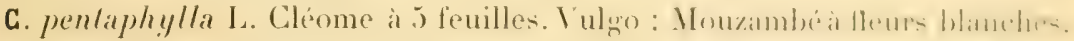
Desc., vol. 7, t 509. Gynandropsis DC. - Herbe annuelle, droile, haute de $50 \mathrm{~cm} .1^{\text {m }}, 50$ selon les terres. Tige souvent ligneuse à la base. Fenilles

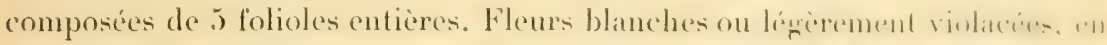
„rappes allongées, terminales. Siliques portés sur de long püfomentependantes. - Fleurit presque toute l'amée. - Toule la plantreshale une uhrur.

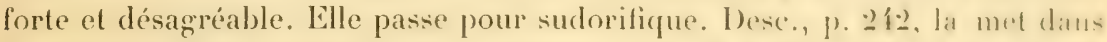
la catégorie des plantes épipastiques vésicantes. I la basso-Torre, m man-in.

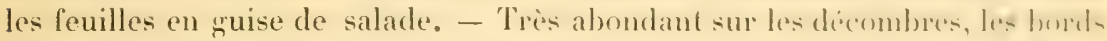
des rivières et endroits abandonnés de la région du littoral. Basse-'lerre. [No 2275.]

Martixieue. - Vulgo s Caya blanc, akaya blanc. - Abondant partout. $\left[\mathrm{N}^{\circ} 570\right.$ bis. $]$

C. speciosa Kth. Mouzambé ì fleurs roses. - Herbe annuclle, très orne-

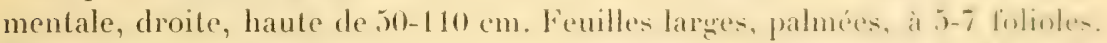
Fleurs roses, en grappes pramides, terminales. - Nalumalise an Murne a l'Eau, à Sainte-Anne, etc., où on la cultive souvent dans les jardins. Fl. d'août en mars. [No 2863.$]$

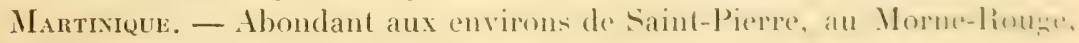
où il s'est naturalisé. [N $\mathrm{N}^{\circ} 570$.

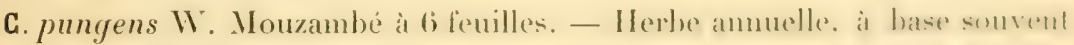
ligneuse, droite, haute de 50-150 cm. Feuilles palmées, ì 5-7 lonlioles, le plus souvent poilues, pourves, à la base du péliole, de pulits piquanta. Fleurs blanches, rarement rosées, en racemes tris allongris, forminams. Très abondant sur les décombres, dans lese endroits abaudommén de lat bian

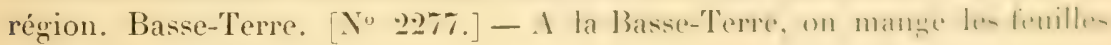
cuites en guise de salade.

Martinique. Vulgo : Caya bord de rivière, - Abondant. Saint-Pierre (rivière de la Roxelane), Marin, Lamentin, elc. [N०570 b.]

C. aculeata L. Cléomace épineux. Vulgo : Mouzambé zípineux. - Anmuel, plus ou moins droit, parfois diffus, à branches éfalées horizonlalement.

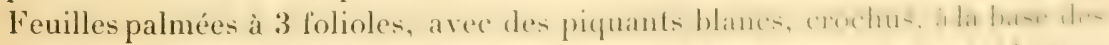

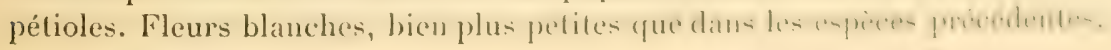


en grappes courtes, lâches. - Rares. Quelques pieds aux environs du presbytère du Baillif. $\left.\mathrm{N}^{0} \cdot 2276.\right]$

Mantrigete. Vulgo: Caya à épines. - Assez abondant sur les décombres et dans les endroits cultivés abandonnés. Saint-Pierre (College), Carbet. Prècheur. $\mathrm{N}^{\circ} 1895$.

C. viscosa L. Cléome visqueux. l'ulgo : Mouzambé a fleurs jaunes. Polanisia DC. - Annuel; droit, haut de 40 ì $80 \mathrm{~cm}$., originaire de l'Asie méridionale, naturalisé depuis de longues années. Fenilles palmées à 5 folioles. Fleurs jaunes en racèmes terminaux. T'ige chargée de poils visqueux. Toutes les parties de la plante sont enduites d'un suc visqueux répandant une forte et désagréable odeur. - Les feuilles sont vésicantes; appliquées contre la peau, elles y déterminent une inflammation. - On sen sert souvent dans la médecine domestique. - Commur dans les endroits abandomnés, sur les décombres, etc. Alt. 0-300 mèt. Basse-Terre. [No 2272.]

Martinique. Vulgo : Caya jaune. - Très abondant dans la basse région de l’ìle. Saint-Pierre. $\boldsymbol{X}^{\circ} 16: 8$.

Moringa Tuss. (de "mu'ringa ", mol dont on se sert pour désigner cet arbre à Malabar, ou formé du tamoul " morunghi».)

M. pterigosperma Gaert. Moringa à graines ailées. Vulgo, à la BasseTerre : Maloko. Tuss., vol. 4, t. 16; Dese., vol. I, t. 27. - Petit arbre de 7-14 mèt. de haut, originaire de l'Asie tropicale, introduit dans les Antilles par les travailleurs indiens et naturalise depuis longtemps. Fenilles 3 fois composées, penniséquées, larges. Fleurs d'un hlane pâle, en grappes terminales, réunies par plusicurs. Siliques longues, pendantes, a 3 coites, déhiscentes; graines garnies de 3 ailes minces. - Les Indiens mangent les jeunes feuilles et les fruits rôtis. L'huile qu'on retire des graines est très fine et ne rancit jamais; elle sert surtout aux horlogers; les parfumeurs la recherchent pour composer leurs essences. La racine et l'écorce ont un goût très prononcé de raifort et exercent sur la peau une action vésicante. Desc., p. 131, le met dans les végétaux stomachiques antiscorbutiques. - Abondant it la Basse-Terre, Pointe-Xoire, Vieux-Habitants, Moule. No 2274.

Martmele. Vulgo: Moringa. - Plus rare qu'à la Guadeloupe : Fond Canonville, Prêcheur, Carbet. [No 1807.

Crataeva L. du nom de Crateras, herboriste du temps du roi Mithridate, it qui il a dédié un ouvrage avec figures sur les pl. médicinales.

C. Tapia L. : ainsi nommé en Amérique. Vulggo: Grand Cosmaya. - Petit arbre droit, mesurant f-5 mèt. de haut. Feuilles trifoliées, ì folioles ovales, acuminées. Fruit rond de la grosseur d'une petite orange Endroits rocailleux, secs, chauds, près des bords de la mer. Rare. Case- 
Pilote. Alt. 0-50 mèt. [No 1823.] - Nous ne l'avons pas trouvé it la Guirleloupe.

Capparis L (du mol arabe "kabar ".

C. Jamaicensis Jacq. Caprier de la Jamaïque. Vulgo : Bois noir. C. intermedia H. B. Kith. Br. Jam., t. 17, 1. 2. - Grand arbre à fronde extrèmement

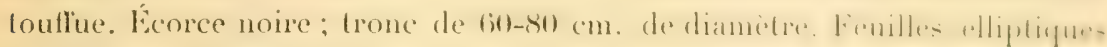
ou ellipliques-lancéolées, luisantes, d'un vert très foncé en dessus, aruenté en dessous. Fleurs très parfumées, d'un rose bleuâtre en s'ouvrant, devenant peu à peu rose tendre et finissant par être blanches. Siliques longues de 10-20 cm, pendantes, toruleuses. Dans les jeunes pieds, les feuilles sont longues, presque linéaires. - Le bois est excellent; il est recherché pour la construction. - Terrain calcaire, pierreux, sec. Désirade, Marie-Galante, Grands Fonds de Sainte-Anne. - Fl. d'août en nov. Fruits mûrs en avrilmai. $\left[N^{\circ} 2864\right.$. $]$

Mantrique. Vulgo: Bois noir.- Assez abondant sur les mornes calcaires el secs de Sainte-Anne. $\Upsilon^{\circ} 66$.

C. Breynia L. Caprier de Breyn. G. amyydalina Lam. Vulgo : Bois de mèche, bois puant. Br., Jam., t. 27, 1. 2. - Arbrisseau, rarement petit arbre, peu branchu. Feuilles d'un vert très terne en destus, squamense-blanchatreen dessous. Fleurs blanches en s'ouvrant, devenant roses avant de se llétrir, en cymes terminales. Fleur's et branches couvertes de petites écailles très nombreuses d'un blane roussitre. Siliques longues de (1)-1.) (mo. toruleuses et ruguleuses. - Très abondant sur les coteaux secs et rocailleux entre le Baillif et les Vieux-Habitants: Sainte-1me, Moule, Desirale, Marie-(ialante. - Fleurit de mars en juin. [Ỹo 2279.]

Martinique. Vulgo : Cosmaya bord de mer, bois puant. - Abondant sur le bord de la mer ou un peu dans lintérieur des terres: Prichenr. Case-Pilute. presquîle de la Caravelle. [No 1052.]

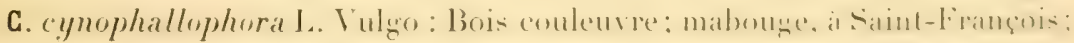
bois mabouge, à Marie-Galante. Desc., vol. 5, 1. 355, p. 193; Jacq., Sel., Amer. stirp. hist., f. 98. - Arbrissean sarmenteux, extrêmement variable quant à la taille et à la forme des feuilles. Feuilles coriaces, très vertes, lantot elliptiques, tantit oblongrues, tantit whovales, whancries on un an sommet. Écorce noire. Fleurs grandes, blanches, s'ourrant vers le soir ef pendant la nuit, très parfumées, surtout au moment de l'éclosion. Siliques pendantes, pulpeuses à endocarpe d'un rougre loncé qui tranche fortement sur les graines entourées d'une pulpe blanche, très variables quant it la lon-

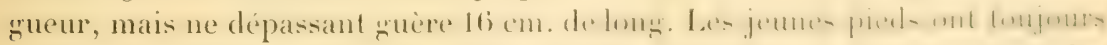
des feuilles très étroites et parfois presque linéaires. - Abondant dans les falaises et endroits abrupts du littoral de toute l'ile. - Descourtilz place celte plante dans la catégorie des antispasmodiques aromil liques. Dans 
le pays elle ne sert pas dans la médecine domestique. Les graines passent pour ètre un poison ; cependant les merles et les grives en sont friands. $X^{\circ} 2271.7$

M.nmtixique. Yulgo : Pois mabouïa, bois mabouïa (" mabouïa » veut dire lézard). - Abondant sur tout le littoral de l'île. Alt. 0-120 mèt. [Yus 626, 1897 , avec quatre variétés.]

C. frondosa Jacq., Capparis toutfu Jacq., Sel. Amer. stirp. hist., f. 199. - Arbrisseau droit, habituellement à tige unique, haut de $2-3$ met. Feuilles larges, tres coriaces et rudes, oblongues ou elliptiques, ramassécs en faux verticilles. Fleurs en cymes terminales, d'un blanc terne. Silique verte, courte, 3-5 cm. de long. - Peu abondant. Terrain sec, pierreux, du littoral ou près du littoral. . 1tt. 0-200 mèt. Basse-Terre rivière Sence।.-Fl. de janv. en mars. $\left[\mathrm{N}^{\circ} 2278\right.$. $]$

M.nrtiniqe Vulgo: Mabouïa. - Case-Pilole, près de la mer. Sainte-Anne. $\left[N^{\circ} 631\right.$ a et $b$.

Morisonia I. dédié par Linné à Morison, Écossais, professeur de botanique à Oxford, auteur de plusieurs ouvrages.)

M. americana L. V'ulgo : Sapotte batard, sapotte diable, sapotillier falaise. Desc., vol. 7, t. 552, p. 336. - Arbrisseau ou petit arbre tortueux, haut de 2-4 met. Ecorce grise: leuilles oblongues-elliptiques, luisantes en dessus. Jeunes branches, pédoncules, lleurs et calices couverts de petites écailles blanchâtres. Fleurs d'un blanc légèrement jaunàtre, nombreuses, caulinaires et axillaires. Fruit gnlobuleux de la forme et de la grosseur d'une petite orange. - Rare. Cà et là dans les endroits secs, rocailleux, chauds, près de la mer. - Descourtilz met cette plante dans la section des végétaux émollients. Dans le pays on ne s'en sert pas. Les Saintes (Terre de Haut), Marie-Galante (Capesterre). Alt, 0-120 mèt. [No 2273.]

Martinque. Vulgo : Mabouïa falaise. - Bord de la mer, entre Fort-deFrance et Case-Pilote. Peu abondant. [X゚०620.]

De cette famille on cultive au Jardin botanique de Saint-Pierre le Steriphoma aurantiacal Spreng.. arbrisseau nriginaire de l'Amérique tropicale, ì fleurs de couleur d'orange, grandes et brillantes, d'une rare beauté.

DOUZTĖME FAMLLE. - BIXINÉES.

Bixa L. (du nom brésilien " biché ».)

B. Orellana L. Vulgo : Roucouyer, rocouyer, roucou; originaire des bords de l'Orellana, plus comm snus le nom de lleuve des Amazones. Tuss., vol. II, 1. 90; Desc., vol. I, I. 4, p. 25 ; Sl., Hist. of Jam. L. 181, I. 1.-Petit 
arbre droit, à branches élalées, dont le plus grand représenlant ne dépasse gruère J mèt. Élait autrefois cultivé en grand à la Guadeloupe el il la Marti nique; aujourd'hui on n'en plante plus : on se contente d'entretenir les anciennes plantations. On rencontre 2 variétés : l'une a fleurs blanches, plus rare, l'autre à lleurs roses. Il existe une espece à capsule sans picpants. Descourtilz lui assigne une place dans les stomachiques ammatiques. W.es

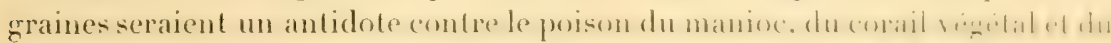

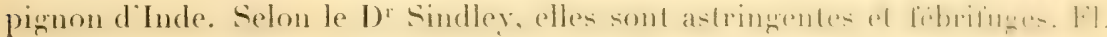
habiluellement en avril, mai. - Gourbeyre, Trois-Rivières, Camp-Jacols, elc. [No 2223.

Mantixique. - Ajoupa-Bouillon, Morne-Rouge, ele. [X'1189.]

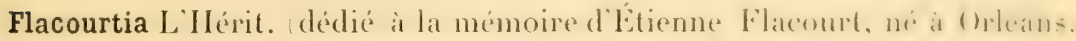
directeur de la Compagnie l'rançaise de l'()rient el auteur de l’hi-horm d. la grande île de Madagascar 1607-1660.)

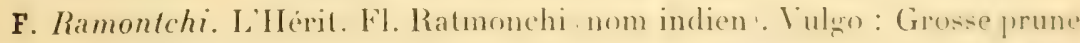
café. - Petit arbre, haut de 1-5 mèt. le plus souvent forturux i branches pendantes, flexibles, garni de piquants sur le trone. Fleursmomö̈ques el diögues, vertes, axillaires. Feuilles obovales-elliptiques, faiblement crometes. Fl. en mai-juin; fr. mûrs en anût et sept. Fruit baceien, whlobulemx, de conteme lirm

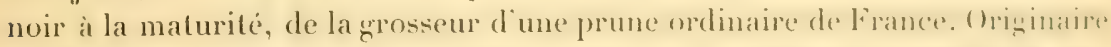
de Madagascar, introduit et cultive à cause de l'excellence de ses livils. qui sont recherchés comme fruits de dessert. - Rare. Basse-Terre (habil. Lispérance). [No 36.58 .

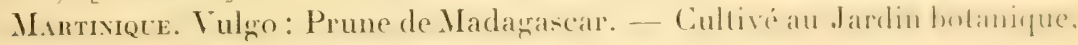
d'où il s'est répandu dans le pays. $\left[N^{\circ} 69,1190,70.\right]$

F. cataphracla Roxb. Flacourtia épineux. Vulgro: Prune cal'é. - Pelit arbre droit, haut de 5̆-10 mèt., le plus souvent garni d'épines sur le tronc el

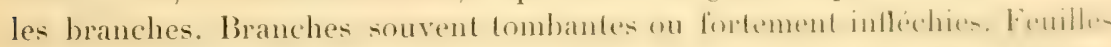
ovales, elliptiques, finement serretées, pointues au sommet, plus longrues.

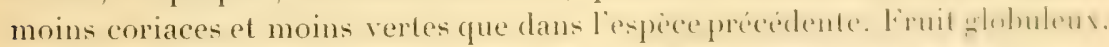
également recherché comme lruit de table. Flents monoüques applatai-ant en juin et juillet. - Originaire des Indes orientales, naturalise ef cullivé en assez grande abondance. Basse-Terre, Gourberre, Trois-livieres, ele. $[102224$.

Avant de les manger, on froisse entre les doigls ces deux sortes de prunes, ce qui fait disparaitre leur saveur âcre et astringente.

Mantivique. Vulgo: Prune de Chine. Naturalisé el cultive. Saint-Pierre (Collège, Trois-Ponts, Carbet, etc. [No 1186.

Myroxylon J. et G. Forst. (dn gree " muron ", batume, el "xulon ", bois, à cause de l'odeur balsamique du bois.? 
M. martinicense Kr. et Lrb. Additamenta ad cognitionem flore. Indice occident. auctore J. Lrban, particula 1, p. 15. - Vulgo : Bois capitaine. - Petit arbre ressemblant au Fl. cataphracta, haut de 5-9 met.. garni, sur le tronc et les branches, de nombrenx piquants noirs, droits, très aigus. Feuilles luisantes, longues de 6-9) cm., serretées-crénelées. Fleurs diö̈ques, axillaires, très nombreuses. Fł. en mai-juin. Fruits mûrs d'un jaune de citmon, shobuleux ou légèrement orales, de la grosseur d'une graine de poivre. - Le bois sert à faire des planches et des poteaux. - Assez abondant dans les bois de la Calebasse, des Fonds Saint-Denis et du Camp de l'Alma. Alt. 450-700 mèt. [ [No 1187.] - Yous n'avons pas trouvé cette espèce à la Guadeloupe.

M. buxifolium Kír. et Urb. (loco citato ex Additament. fl. I. occid., p. 16. Vulgo: Attrape-sot. - Petit arbre très élégrant, de $\mathbf{f}-7$ mèt. de hauteur, à trone el branches garnis de piquants simples ou branchus. Feuilles luisantes, coriaces, longues de 3-5 cm. Fleurs diö̈ques, axillaires. - Assez abondant dans les bois de Folle-Anse à Saint-Louis Marie-(xalante et sous les rochers calcaires du bord de mer du Gozier. - N'existe pas à la Martinique. - Alt. 0-80 mèt. [No 3616 .

Trilix L.. du mot latin " trilix ", tresse croisée de trois fils, faisant allusion à la disposition des trois sépales et des trois pétales de la fleur.)

T. crucis. Gr. Proolita crucis L. - Petit arbre ou arbrisseau, haut de 3-4 mèt., à branches pendantes, à écorce grise. Feuilles triplinerviées, finement serretées, ovales-elliptiques, acuminées au sommet, mesurant $3-4,5 \times\{-10 \mathrm{~cm}$. Fleurs petites, en crmes terminales. Fruit de la grosseur d'un pois garni de poils persistants. Fl. en juin et juillet. - Très rare. Çà et la dans les hauteurs des Trois-llets plaine . Y Y 1191.] - Yous ne l'a vons pas trouvé à la Guadeloupe.

Casearia Jacq. dédié à Jean Cascarius, prètre hollandais, missionnaire en Cochinchine, qui s'est occupé de botanique el a écrit les premiers volumes du " Iortus malabaricus " 1678.

G. parrifola Wild. Casearia i petites leuilles. Vulgo: Coco ravet. Lamarek, Illust., t. 355, f. 2. - Petit arbre, rarement abrisseau, d'une élévation de 3-6 mel, a branches couvertes de petites lentilles blanches tres nombreuses. Feuilles lancénlées, serretées, luisantes, nlabres, qui disparaissent presque toujours à l'époque de la floraison. Fleurs d'un blane terne, axillaires et latérales, disposées en cymes contractees tout le long des branches, exhalant une odeur de miel tries prononcies qui attire une quantite de mouches a miel et de papillons. Fruits de la forme et presque de la grosseur d'une prunecafé, d'abord blanc, ensuite jaune, s'ourrant en 3 valves pulpeuses; pulpe jaune, extrêmement sucrée, d'une saveur agréable. Les oiseaux en sont très lriands. Cet arbre ressemble beaucoup au Fl, calafracta ou it la prune-café. 
Fl. d'avril en mai. - Assez abondant dans les bois sees de la batioc of de la moyenne région. Ravine de Belost, Morne-ît Tache (Basise-Term Camp-Jacob, Ravine du pont du Galion (Basse-Terre). Alt. 2(1)-150 met. $\left[\mathrm{N}^{\text {os }} 2225,2865\right.$.

Martinique. Vulgo : Jaune d'ueul. - Assez abondant dans les bois inlé-

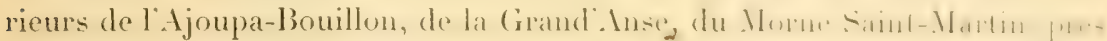
de Saint-Pierre). [Nos $1188 a, b, c$.

Samyda Lam. (du gree "semuda ", bouleau, parce que les feuilles des Samydas ont quelque ressemblance avec celles du bouleau.

S. servulata, L. Samyda à feuilles dentées en scie. Plum., éd. Burm., L. 1.46, f. 2. - Petit arbre, haut de 2-3 mèt., ì branches nombreuses, inclinées.

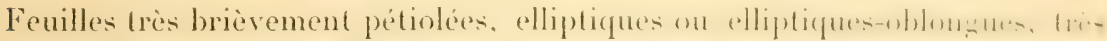
régulièrement serretées, veloutées en dessous. Fleurs axillaires, très blanches: et très parfumées. Fruits de la grosseur d'une prune, s'ourrant en quatre valves, pulpeux; semences entourées d'une arille. - Introduit de SaintMartin et cultivé dans plusieurs jardins comme plante d'ornement. - Fl. de sept. en nov. - Basse-Terre. [No 3258.

Mantivique. - Cultivé au Jardin botanique, d'où il s'est répandu dans le pays.

De cette famille, on cultive au Jardin bolanique de Saint-Pierre une plante intéressante : Inkoba spinosa Forst. de lafriene lropicale. intruduil par Ch. Thierry en 1886.

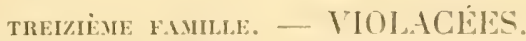

Ionidium Vent. (du grec " ionidion ", diminutif de "ior ", violelle, parce que ce genre est voisin du Viola.

I. strictum W., I. linearifolium Vent., Innide droil. T'ulgo : Petil ipéca, de herbe à Trément. - Herbe annuelle, at base souvent sultrulescente, haute 5-40 cm., droite, très rarement couchée, branchue. Fenilles inlérieure: opposées, les supérieures alternes, lancéolées-linaires. Fleur's blanches lachetées de violet, axillaires, portées sur des pédoncules aussi longs que les: feuilles; pédoncules articulés au-dessous de la heur. - l'l. surtout pendant l'hivernage. - Abondant dans les terres calcaires cultivécs ou incultes. Moule, Morne-à-l'Eau, Désirade (les Lataniers), où il forme gazon en certains: endroits. - Les chères broutent cette herhe avec plaisir; la maine prise en infusion est purgative; on s'en sert souvent. [X' 2959.

N'est pas à la Martinique.

Düss, - Plantes Guadeloupe et Marlinique. 
Viola L. (du grece "ion », qui signifie violette : les Latins ont ajouté un $v$.

V. stipularis Sw. Violette à grandes stipules. Vulgo : Violelte montagne. - Herbe à tigre vivace, rampante, radicante; stipules grandes, dressées,

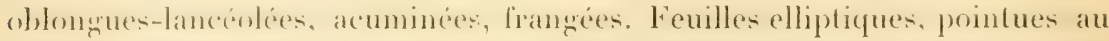
sommet. Fleurs violetles ou plus rarement blanches, portées sur de longs pédoncules axillaires. - Mbondant dans la région supériene des hautesmonLagnes. Soufrière, Savane-aux-Ananas, Grande-Découverte, elc. - Fl. en tout temps. [No 2425.]

Mantivique. Vulgo : Violette montagne. - Abondant à la montagne Pelée et aux pitons du Carbet. [No 1778.$]$

\section{QUATORZIÈME FAMLLE. - POL YGALÉES.}

Polygala L. (du greec "polu », beaucoup, et "gala ", lait : c'est-à-dire plantes domnant beaucoup de lait aux vaches.)

P. paniculata L., Polygale en grappes. Vulgo : Herbe à lait. Sw., Observationes, t. (6, 1. 2. - Herbe très ornementale, annuelle, droite, haute de 15 flom. : tige grole, branches nombreuses, greles, fastigiés. Fenilles linéares rappelant celles du lin. Fleurs blanches ou violacées, en racèmes terminaux, allongés. Fruit capsulaire, elliptique, légèrement échancré au sommet. Fl. toujours, plus ou moins. - Abondant dans les régions moyenne et inlirasupérieure. Camp-Jacob, Matouba, Trois-kivières, elc. [No 2420.]

Mantrique. Vulgo : Estré fragile. - Abondant au Morne-Rouge, à la Calebasse, au Gros-Morne, etc. Alt. 200-900 mèt. - La racine, qui a une forte odem sni generis, joue un grand rôle dans la labrication des quimbois (philtres de sorcier). [No $\mathbf{4} 6$.

P. angustifolia Kith., Polygale à petites feuilles. - Herbe à base suffrutescente, souvent virace, droite ou penchée, peu branchue, haute de 30-60 cm. Tigre finement veloutée. Feuilles elliptiques-lancéolées, très brièvement pétiolées. Fleurs à sépales pourpres, à pétales d'un blanc jaunâtre, en racèmes terminaux. Fruit capsulaire, obovale, émarginé au sommet, contenant ? semences soyeuses, cylindriques, surmontées d'une petite caroncule. - lil. presque toute l'année. - Abondant dans les champs des environs de Sainte-Rose el aux environs de l'usine La Retraite (BaieMahauli). No2981.

Ne se trouve pas à la Martinique.

Securidaca J. du latin "sectris ", hache : allusion a laile membraneuse du fruit, qui ressemble assez exactement i ume hache.) 
S. scandens Lam., Securidaca grimpant. Vulgo : Liane-Pâques. S. Lamarkii Gr., Lam. Illust., t. 529, f. 1. - Arbrisseau-liane, très beau, pouvant s'élever sur des arbres très hauts el les courrir entièrement de ses larires

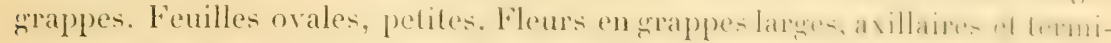
nales, rosées ou d'un violet foncé selon la variété. - l'leurit d'arril en juin. - Abondant dans les hauteurs entre Fort-de-France et la fontaine Didier, ni tous les arbres en sont couverts; Case-Pilote, Trois-llets. [X 1.40.] - Yous ne l'avons pas trouvé à la Guadeloupe.

QUIX/ìne famlle. - EUPHORBIACÉES.

Buxus L. (du gree " puxos », buis.)

B. subcolumnaris Mull. Aro. ; Sw., Fl. Ind. occid,, 1. 7. - Arbrisseau élégant, très droil, haut de $2-4$ mèt. Feuilles très coriaces, elliptiques, pointues au sommet. Fleurs monoïques, en cymes axillaires et latérales, corynbilormes, jaunâtres. Fruit capsulaire à 3 coques sųrmontées chacune d'une petite corne. - Assez abondant dans les bois de la région moyenne. CasePilote (Plateau militaire), Morne-Rouge (bois du Calvaire). - Fl. d'avril en juin. [Y0 578.] - N'existe pas it la Guadeloupe.

Richeria $V$. (dédié à Pierre Richer de Belleval, né en 1553 ì Châlonssur-Marne, professeur d'anatomie et de botanique à Montpellier, mort en 1623.)

R. grandis V., Richeria vigoureux. Vulgo : Bois bandé, bois mandé, bois marbré (à la Ravine-Chaude). Vahl, Églog. Americ., I, p. 30, 1. 1. - Arbre de taille moyenne, rarement de grande taille. Feuilles obovales, larges, coriaces. Branches garnies de grosses cicatrices laissées par les feuilles. Fleurs diö̈ques, vertes : les mâles, en épis interrompus, nombreux, dressís, axillaires et latérales; les femelles, en racèmes courts. Fruit verl, it 3 Ingres, déhiscent de haut en bas, ovoüde ; endocarpe bivalve; semences enveloppées d'une arille (masse pulpeuse). - Fleurit de septembre en novembre; graines mûres en avril et mai. - Excellent bois pour̃ toutes sorles de constructions: mais le plus souvent le trone sert à laire des planches. L'écorce est employe comme antisyphilitique et aphrodisiaque : on la laisse séjourner diuns l'eatu froide, qu'on boit ensuite.' - Abondant dans les grands bois des BainsJaunes, du Matouba, des Trois-livières, de Solaya el de la Ravine-Chaude. $\left[N^{\circ} \cdot 23.77.\right]$

Nexiste pas à la Martinique.

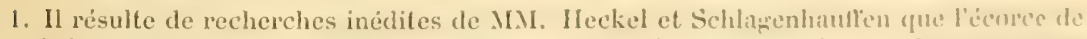
ce végétal ne renferme, en dehors du tanin, ancun principe audquel on puisse rappribter les prétendues proprićtés aphrodisiaques. 
Drypetes V. (du gree " druppa », drupe, parce que les fruits sont des drupes.)

D. glauca Vahl, Drypetes à feuilles glauques. Vulgo : Calé-trand-bois. Arbre de taille moyenne, quelquefois petit arbre, à écorce d'un gris noirâtre, lisse, à branches souvent horizontales. Feuilles très verles, coriaces, elliptiques-oblongues, brusquement rétrécies en pointe au sommet. Fleurs diö̈ques, siluées à l'aisselle des feuilles tout le long des branches, ce qui est un caractère commun à tous les Drypetes: les mâles, fasciculées; les femelles, solitaires. Fruit drupacé, long de 12-15 mm., indéhiscent. - Bois dur, rouge en dedans, recherché pour les constructions dans la terre et dans l'humidité. - Fl. en mai et juin; graines mûres en juillet, août, septembre. - Assez abondant dans les mornes de Houëlmont (Mornes Gobelin et Hirondelle), Camp-Jacob (rivière Noire), Matouba. Alt. 300-700 met. [Yus 3299, 3455.]

Martmeve. Vulgo: Cal'é-grand-bois. Variété macrocarpa hir. el Lrb. Gà et là dans les grands bois de Saint-Martin, au pied de la montagne Pelée. $\left[\mathrm{N}^{\top} \mathrm{3} 3\right.$.

D. Dussii Krr. et Urb. Addit, ad cognit. fl. Ind. occid., part. I, p. 71. Tulgo : Bois-moussara. - Arbre d'environ 6 mèt. d'élévation, plus ou moins tortueux; écorce brune, branches divariquées, souvent horizontales. Feuilles distiques, très coriaces, presque toujours courertes de mousses, obovales-elliptiques. Drupe longue de 25-30 $\mathrm{mm}$, anguleuse-arrondie. Rare. Hauteurs de Case-Pilote; çà et là dans les grands bois des environs du Camp de l'Alma. - Fruits mûrs en septembre et octobre. - Les lleurs mâles nous manquent. [No 34.] - Nous n’avons pas trouvé celte espèce à la Guadeloupe.

D. serrata Kr. et Urb. Addit. ad cognit. /1. Ind. occid., part. I, p. 70. Drypetes glomerala (irish). - Grand arbre d'un port éleunt. Feuilles luisantes, ovales-lancéolées, serretées, très vertes. Fleurs vertes, fasciculées à l'aisselle des feuilles. Drupe longue de 11-1' $\mathrm{mm}$. - Assez abondant à Marie-Galante dans les bois de Folle-Anse, près du bord de la mer. - Fl. en février, mars ; fruits mûrs en mai-juin. [No3628.]

Mantixique. - Très rare. Nous n'en avons trouvé que quelques pieds à lleurs mâles, aux environs de l'habitation Sant-Martin, au pied de la montagne Pelée. [No 50.$]$

Cicca L. (du grec "kiki ", arbre merveilleux, à cause de la ressemblance qui existe entre ces deux arbres el de ce que l'écorce du Cicca est purgative comme les graines de l'arbre merveilleux.)

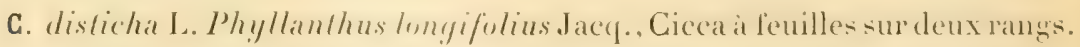
Vulgo: Surette. - Arbre toulfu, haut de 6-10 mèt., originaire des Indes Urientales, introduit et naturalisé depuis de longues amées. Feuilles petites, 
distiques, ovales, pointues, ramassées à l'extrémilé des branches : fronc nu. branches marquées de grosses et nombreuses cicatrices laissées par les feuilles tombées. Fleurs monoïques, mâles et femelles mélangées dans la même grappe; grappes pendantes, vertes, allongées, couvant les branches nues. Fruit drupacé, anguleux, légèrement déprimé, jaunâtre, renfermant autant de semences qu'il y a d'angles. - Fl. de janv. en mars ; fruils murs en juillet-août. - Les fruils sont très acidules, rafraîchissants : on en lait des confitures, qui rappellent celles de l'épine-vinette; les fleurs cxhalent ume odeur agréable et ont une saveur légèrement acide; la racine rend un suc: laiteux d'une saveur âcre. [No 2929.

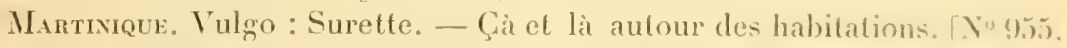

G. Intillana Juss. Vulgo: Bois-savane, bois-diable (au Camp-Jacob). Phyllanthus nobilis Müll. Arg.; Juss., Euph., f. 135, analyt. - Arbre de taille moyenne, très branchu; branches étalées. Feuilles d'un vert tendre, elliptiques-lancéolées. Fleurs dioïques axillaires : les mâles, fasciculées; les femelles, solitaires. Fruit globuleux, légèrement déprimé au sommet. faiblement marqué de 5 angles, un peu plus grand qu'une graine de poivre. Après la déhiscence de l'épicarpe uni au mésocarpe, on voit l'endocarpe, d'un violet pourpre très foncé, enveloppant les ǰ semences, ce qui produit, quand l'arbre est courert de graines mûres, un eflel des plus curieux. - Bois mou et peu propre à la construction. - Se rencontre dans tous les bois de la basse et de la moyenne région, sans être abondant mulle part. Fl. en mai, juin; graines mûres en juillet, août, septembre. - Vieux-Fort, Camp-Jacob (Bagatelle). [Nos 2745, 3237.]

Martnique. Vulgo : Bois-mille-branches, - Bois de l'Ajoupa-Bonillon, vallée du Carbet. No 52.

Amanoa Aubl. (de "Amanua ", nom que donnent les Galibis de la Guyane à cet arbre.)

A. caribiea Kr. et Urb. Vulgo : Palétuvier gris des montagnes, carapate ipar les bùcherons de la Bouillante a cause de la ressemblance de la frime avec celle du ricin, nommé aussi vulgairement carapate. - Grand bel arhre, à trone droit, nu jusçu'à une hauteur de 12-15 mèt. et d'un diamèt. de $80 \mathrm{~cm}$. à $1 \mathrm{~m}$. 20, anfractueux à la base; écorce noirâtre, presque lisse, zarnic de nombreuses aspérités blanchâtres. Feuilles coriaces, elliptiques, fortement veinées. Fleurs monoïques, blanches, en grappes teminales, exhalant une odeur forte et très agréable, qui attire une nuée de monches ì miel. liruil capsulaire, un peu moins grand qu'une pomme de tamarinier des Inders, it :3 coques qui se séparent d'une colonne centrale à 3 ailes; enque biralre. Les fruits mûrs, quand ils sont chauflés par le soleil, éclatent avee bruit: semences 3 , lisses, dépourvues d'arille et de caroncule. - Daus les hauteurs de

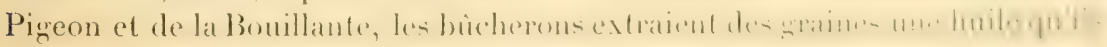


emploient contre les blessures et les plaies. Le bois est recherché pour les construclions : il passe pour être incorruptible dans la terre, il sert aussi pour la menuiserice. - Cet arbe fleurit habituellement en juillet el aout el ausio en janvier et lévier. - Alt. 400-800 mèt. Abondant dans les vastes lorêts entre la Pointe-Noire el la liavine-Chaude, des hauteurs de Pigeon et de la Bonil-

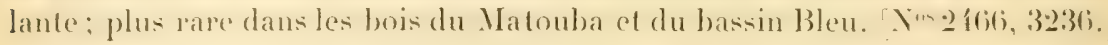

Ne se rencontre nullement ì la Martinique.

Phyllanthus L. (de deux mots grees qui signifient feuille et fleur, c'estit-dire fleurs qui viennent sous les feuilles.)

P. oratus Poir, Phyllanthe à feuilles ovales. Yulgo: En-bas-feuilles grandbois. - Arbrisseau droit, élégant, fortement branchu, haut de 2-i mèt. Feuilles rigides, ovales, pointues par les deux bouts, de $2-4 \mathrm{~cm}$. de long sur 1,5 a $2,5 \mathrm{~cm}$. de large. Fleurs monoïques : les mâles, à l'extrémité; les femelles, dans le bas des branches. Capsules de la grosseur d'une graine de poivre. Peu abondant. Hauteurs du Morne-Rouge (bois du Calvaire), hauteurs de Case-Pilote (Platean militaire). - Nous ne l'avons pas trouvé à la Guadeloupe. [No 53.$]$

P. Conami Sw. Ph. piscatorum Kth. P. brasiliensis Müll. Arg. Vulgo: Bois à enivrer; Aublet, Itist. de la Guyane, 1. 354, p. 927. - Arbrisseau ou petit arbre tresonemental ì cause de son lézer feuillage, droit, trèsbranchu. haut de -2-4 mel. ; branches sourent tortueuses el noneuses. Fenilles distiques-alternes, petites, elliptiques, d'un vert tendre. Fleur's monoïques, très nombreuses, disposées par fascicules tout le long des branches, males et femelles mélangées, portées les unes et les autres sur de longs pédoncules filiformes. Capsule de la grosseur d'une tête d'épingle. - Cà et là autour des maisons. Camp-Jacob, Gourbeyre, etc. $\mathrm{N}^{\circ} 2416$.

Mnrtixique, Vulgo : Enivrage, bois à enivrer. - Assez abondant. - Avec les branches broyées et mises dans un sac, qu'on dépose dans un bassin de pivière, on enivre les poissons. - Saint-Pierre, Morne-Rouge, Ajoupa-Bouillon. [No 2047.$]$

P. mimosoides L., Phyllanthe à feuilles de mimosa. Vulgro : Fougère, bâtard de fougère. - Arbrisseau très élégant, ressemblant ì une petite fougère en arbre. Tige sourent unique, d'un diamèt. de 8-14 cm., marquée de nombreuses cicatrices, haute de 2 - $\mathbf{4}$ mèt. ; branches ramassées à l'extrémité de la tige, ressemblant it des feuilles deux fois componéesennées. Fenilles distiques, obliquement lancéolées-oblongrues, mucronulées, blanchàtres en dessous. Fleurs blanchâtres. Capsule sphérique, légèrement déprimée au sommet et à la base, plus pelite qu'une graine de poivre. - Très abondant dans fous les grands bois humides. Bois des Bains-Jaunes, du bassin Blen, du Matouba, des Trois-Rivières, etc. - Fl. presque toute l'année. - Alt. $400-950$ mèt. [X'०2445.] 
Mantinique. - Très rare. Nous nien avons trouvé que quelques pied. dans les hauteur's boisées de la Grande-Rivière. TY 2015.

P. Niruri L. Phyllanthe Niruri (nom de la plante a Malabar). Vunlun : Enbas-feuilles. - Annuel ou sufrutescent, haut de 15 - $60 \mathrm{~cm}$. Mamules penni-

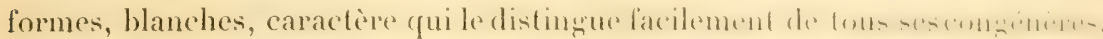

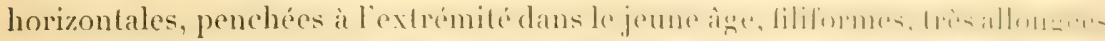

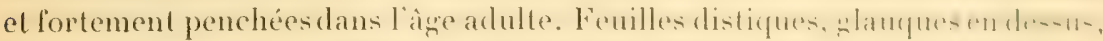

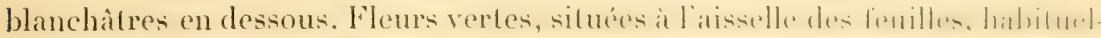

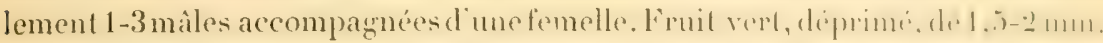

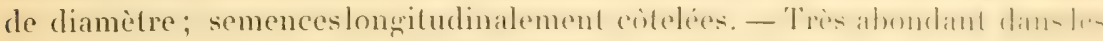
terres cultivées, le long des chemins de la basse el de l'inlina-moyenne rérion. - On se sert souvent, dans les campagnes, de cette herbe contre les lières; on la prend en infusion. - Alt. 0-600 mèt. [Yos 2724, 2417.

Martrigue. Vulgo: En-bas-feuilles blanc. - Abondant daus tout le pays, où l'on en fait usage contre les fièrres.

P. urinaria I. Phyllanthe diurétique. Vulgo: Eu-bas-leuilles rouge. Sulfruteseent, droit ou plus oumoins couché, haut de f(1)-Si) (

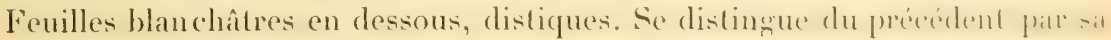

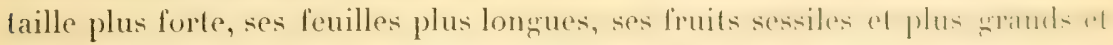
par ses semences transversalement côtelées. - Cette plante s'emploie souvent en infusion contre la rétention d'urine et aussi contre les fières. Moins abondant que le précédent. Aime les endroits humides al omblärer. Basse-Terre, Gourbeyre, Camp-Jacob, etc. Alt. 0-600 mèl. [Y0 .27:202.

Martinique. Vulgo: En-bas-feuilles rouge. - Abondant dans les endroil: ombragés et humides. Saint-Pierre, Carbet, etc. $\left[\mathrm{N}^{\circ} 46.\right]$

P. Carolinensis Walt. Phyllanthe de la Caroline. Vulgo : En-bas-leuilles vert. - Annuel ou sufl'rutescent, cespiteux, haut de j-jo cm. Tignes sans branches dans les jeunes pieds, branches toujours disposées sur le mème plan ou distiques, ce qui lui donne un port particulier qui le distingue, de

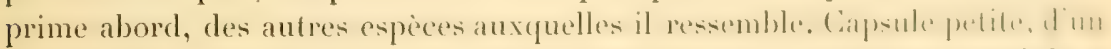
diamètre de $2 \mathrm{~mm}$., semblable à celle du P. Niruri. - S'emploie aussi dans les campagnes contre les fièrres et les rétentions d'urine. - Assez abondan! dans les quartiers cultivés et humides du Camp-Jacob, de Gourbeyre; r'are dans la basse région. $\left[\mathrm{N}^{\circ} 214 \mathrm{H}\right.$. $]$

Mantinique. Yulgo : En-bas-feuilles vert. - Assez abondant. Morne-liouge, Gros-Morne, elc. [No $\mathrm{N}^{\circ}$. $]$

P. lathyroides H. B. Kth., Phyllanthe à feuilles de lathyrus. Vulgro: Linbas-feuilles vert. - Sulfrutescent, droit, haut de $15-60 \mathrm{~cm}$. Fenilles d'un vert très clair en dessus, blanchâtres en dessous, très brièvement pétiolies, ovaleselliptiques, souvent inégrales à la base, longues de $6-10 \mathrm{~mm}$. s.1 $51^{\circ} 5-7 \mathrm{~mm}$. de: large. Ressemble par le port et la taille au P. Niruri; s'en ihoing par ses 
branches plus allongées el plus penchées, par ses capsules et les lobes du calice beaucoup plus grands et ses semences pourvues de lignes longitu-

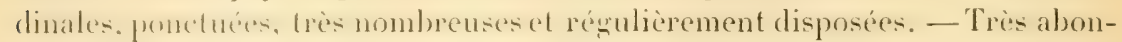
dant dans les sentiers des caféières, cacaoyères, dans les champs de manioc, etc., de la régrion moyenne; plus rare dans la région inférieure. Gourbeyre, Malouba, Camp-Jacob. [No 2921.

Martivece. Vulgo: En-bas-feuilles vert. - Abondant dans les champs cultivés. $\mathrm{No}$. 17 a.

Noтג. - Ces quatre dernières espèces de Phyllanthus sont hygroscopiques; elles ferment leurs fémilles pendant la nuit, el dans la journée quand il pleut. Toutes ont un sue laiteux.

P. spec. Vulgo: En-bas-feuilles rouge. - Suffrutescent ou souvent frutescent, droit, glabre dans toutes ses parties, haut de $15-85 \mathrm{~cm} .$, habituellement nu dans le bas. Tige cylindrique, très verte. Branches gréminées : une grande portant de 2 à 5 ramules, une petile sans ramules; toutes munies, au point de lem insertion, de plusieurs petites stipules pointues. Feuilles distantes, trìs vertes en dessus, pâles en dessous, obovales terminées au sommet en pointe arrondie, pointues à la base; pétiole long de $1 \mathrm{~mm}$., muni de 2 stipules à la base; limbe de la feuille large 'de 6-8 mm. sur 12-14 mm. de long, garni de points translucides à l'état vert. Ramules filiformes, plus ou moins horizontaux, longs de 7-10 cm., garnis de 12-20 feuilles. Fleurs blanches : 1-3 miles aceompagnes de 1-2 lenelles; pédoncules filiformes, celui de la tleur mâle long de $2-3 \mathrm{~mm}$. celui de la femelle long de $4-6 \mathrm{~mm}$. et épaissi au sommet. Capsules très légèrement pubescentes, vertes, déprimées au sommet et a la base, plus larges que longues, $2 \mathrm{~mm}$. de large sur un peu plus de $1 \mathrm{~mm}$. de long. Lobes du calice ovales-lancéolés, de moitié plus courts que la capsule. Semences transversalement ponctuées sur le dos et longitudinalement côtelées sur les deux côtés. - Assez abondant dans les endroits ombragés et surlout sous les manguiers. Gourbeyre, Basse-Terre, Le Baillif, etc. Alt. $0-800$ mèt. [No 3557.

Martingce. Vulgo: En-bas-feuilles vert. - Abondant dans les endroits ombragés. [No 47 b.]

P. spec. - Petit arbrisseau droit, entièrement grlabre, haut de 20 - $15 \mathrm{~cm}$., très

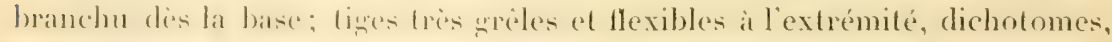
tries verles, cylindrifues; ramules nombreux, filiformes, longrs de 2-3,5 mm., complètement nus dans près de leur moitié inférieure, munis à la base de 2-3 écailles noires en forme de stipules. Feuilles 8-12 à l'extrémité de chacue ramule, vertes en dessus, noires sur les bords, pâles en dessous, neflement obovales, arrondies an sommet, distiques, fres brièrement pétiolées, longues de $5-8 \mathrm{~mm}$. sur $3-5 \mathrm{~mm}$. de large. Fleurs monoïques, axillaires: les mâles, très petites, presque sessiles, au nombre de $1-3$, accom- 
pagnées d'une femelle, mâles et femelles entourées à la base de pelites brac-

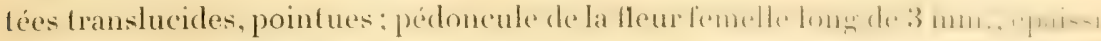
au sommet; lobes du calice de la fleur lemelle obovales-lancénlés, blanc's, translucides et minces sur les bords, épaissis, noirâtres el lérrèrement velus au milieu, moitié plus courts que la capsule mûre. Capsule jaunatre, glabre, plus large que longue, 2-5 $\mathrm{mm}$. de large sur 1-9 $\mathrm{mm}$. de longr semences blanchâtres, très légèrement pubescentes, parcourues, sur le dus

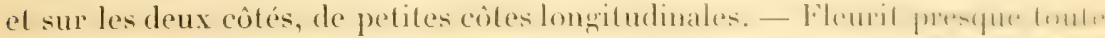

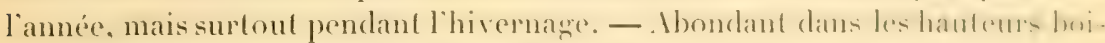
sées, sèches et pierreuses du Vieux-liort, seul endroit oit nous ayons trouvé cette intéressante espèce. Alt. 180-200 mèt. [No 2412.

P. epiphyllanthus L., P. falcatus Sw., Xylophylla falcala Sw. Iulgo: Farine à Zombi, farine chaude, à cause de l'odeur de la lleur qui rappelle lodeur de la farine de manioc, patte-ì-chaux (au Gozier), langue-à-chatle (a) Marie-Cralante). - Irbrisceau tres ornemental, habiluellement droil, haml de 1-2,80 mèt., à tige nue dans le bas el couverte d'une écorce cendrée. Il esst

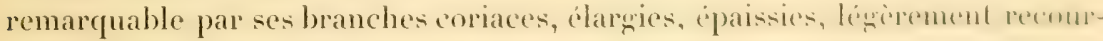
bées en faux, ressemblant à des feuilles. Fleurs monoïques, situées sur le bord de ces phyllodes. - Très abondant dans les endroils pierreux, sees, arides près de la mer. Capesterre (Marie-Galante), Désirade, Gozier (bord de mer), Vieux-Fort, Port-Louis, ete. Alt. 0-150 mèt. [Yo2114.

Mantinique. - Cultivé au Jardin bolanique el daus beaucoup d'autres jardins comme plante d'ornement. [No 2044 .

P. nivosus Hort. Vulgo: La neige. - Arbrisseau superbe, haut de 1-20 mèt., très branchu, droit, à feuilles ovales, obtuses : les inferpiemes, panteheres de blanc, de vert et de rouge; les supéricures et celles des extrémités des branches, plus petites el presque completement blanches, il flours an putilus clochettes très ouvertes, solitaires à l'aisselle des feuilles et portant 5 serrments obeordés. - Originaire des iles de la mere du sud. Introbluil el cullivi dans un très grand nombre de jardins. [No 3532.]

Martinique. - Cultivé dans les jardins. [ $\left.\mathrm{N}^{0} 22.2\right]$

P. roseo-pictus Hort. - Variété plus vigoureuse, à feuilles panachées de blanc, de vert tendre et de vert sombre, obtenue par l'horticulteur anglais Veitch. Elle est également très répandue dans le pays. [No 2467.]

Martivieue. - Abondant dans les jardins. [ No $^{2} 0.46$.

Jatropha L. (selon Linné, du grrec " iatron ", remède, et "phageroin ", manger, parce quion trouve beaucoup d'espèces qui foumissent des remedes. d'autres un excellent aliment.)

I. gossypifolia L. Jatrophe ì leuilles de cotomier. Vulgo : Médecinier bâtard, médecinier rouge (Desc., Fl., II, f. 142; Sl., Hist. of Jam., t. \&1).- 


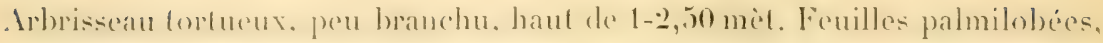
a $3-5$ lobes, les jeunes habituellement noires, luisantes, les adultes rertes.

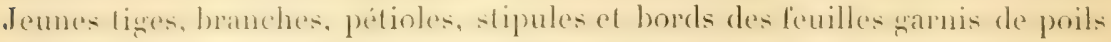
longs, visqueux, branchus, glandulifères. Fleurs en cymes corymbiformes, terminales, couleur rouge de sang. Capsule de la grosseur d'une noisette, a 3 coques dihiserntes. - 1)esenurtilz loen cit., page 30tij range ceste plante dansles purpatives: il dit que la praine eontient un principe itcre, purgatif, el une huile semblable à celle de l'olive; selon lui, une scule graine suffit pour se purger. Dans le pays on ne se sert guère de cette espèce de Jatrophe. Fl. de juin en août. - Endroits secs, rocailleux, calcaires, près du littoral. Abondant. Basse-'Terre, Le Baillif, les Saintes ('Terre de haut et de bas), elc. [N०2928.

Martinigue. Vulgo : Bois-ortolan, graine-ortolan, herbe aux ortolans. Abondant. Case-Navire, Case-Pilote, Prêcheur, etc. [No 2051.

J. multifida I. Médecinier à feuillesfendues. Vulğo: Médecinier d’Espagne, noisetle purgative, corail. - Arbrisseau ormemental, à branches étendues, à ligge nue dans le bas, souvent tortueux, haut de 2-4 mèt. Écorce grisâtre; jeunes tiges marquées de nombreuses cicatrices provenant de la chute des feuilles. Feuilles ramassées aux extrémités des branches, ornementales, lareses, palmifides, composées de 9-11 segments pointus, Inmbants ou fortement penchés, cer qui fait qu elles ressemblent it de petits parasols a moitic ouverts. Fleurs rouge écarlate vif. Capsules à 2-3 coques pulpeuses, tardivement déhiscentes, de la grosseur d'une aveline. - Originaire de l'Amérique, naturalisé et cultivé, moins pour son utilité que comme plante d'ornement. - Toutes les parties de cette plante contiennent un suc aqueux, limpide, âce et amer: les fruits sont pureatifs, mais ne semploient guere dans ce pays. - Fl. d'arril en août. - Basse-Terre (hôpital militaire), Gourbeyre, Moule, Pointe-à-Pitre. [No 2926.]

Martinique. Vulgo : Médecinier épicar. - Se rencontre souvent dans les jardins, les cours, et dans les campagnes autour des maisons. [ [ No $^{\circ} 254$.

J. hastata Jacq., Jatropha pandurifolia Andr. Médecinier à feuilles de violon. (Jacq., Sel. Americ. stirp. hist., p. 256, t. 172, f. 54, une feuille; Jardin des Amat. et manufact, vol. III, t. 32). - Arbrisseau très élégant, haut de - $-\mathbf{t}$ mi.l., remarquahle par ses feuilles en forme de violon et ses lleurs rouge cinabre. - ()rigrinare de Cuba. Cultive el naturalisé. Se rencontre souvent dans les jardins. - Fl. durant toute l'année. - Basse-Terre, CanpJacob, etc. [No 2419.

Mantixique. Vulgo: Médecinier à feuilles de guitare. - Dans beaucoup de jardins. $\left[\mathrm{Y}^{\circ} 205 \%\right.$. $]$

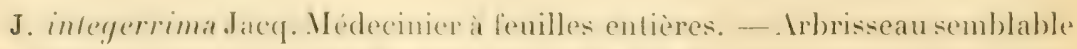
au précédent pour le port al la taille, avee des feuilles a 3 lobes rappelant 
celles du lierre d'Europe. Fileurs en cymes allonereses, leminales, prander. d'un rouge éclatant. - Cultivé çà et là dans les jardins eomme plante d'ornement. En le soumettant it la taille, on en fait de petits arbes qui prennent toutes les formes que l'on vent. Basse-Terre (presbrtere du Carmeli, (rourbeyre, ete. $\left[\mathrm{N}^{\circ} \mathbf{2 1 4 8 .}\right]$

Mantrique. Tulgo : Épicar. - Abondant. Dans benucoup de jamlins dans les campanes. Carbet, Fort-de-France, Prêcheur, Saint-Pierre jurdin de l'Évêché $\}$. No 51 .

J. curcas L., Jatrophe curcas, nom quon hui dome it Malabar. Vulgro:

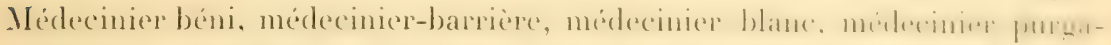
til. Desc., vol. II, t. 141, p. 299. - Arbrisseau ou petil arbre de 3-j) mil.

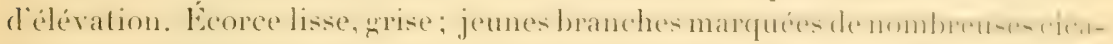
trices. Feuilles larges, anguleuses ou à 3-5 lobes peu marqués. Fleurs rougres

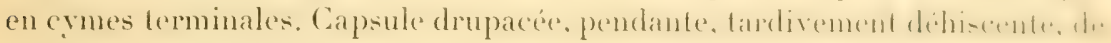
la grosseur et de la forme d'une noix, - Abondant dans toute l'île. - l)escourtilz, loco cit., dit que les racines et certaines parties de cette plante fournissent une teinture violette, que les graines contiennent une huile volatile. pesante et vénéneuse, qu'on prétend que les propriétés éméliques résident dans l'embryon et qu'après l'avoir enlevé on peut manger le fruit san:

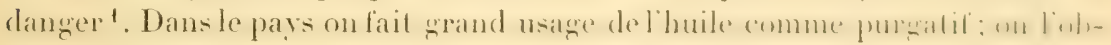
tient facilement par pression; elle sert souvent à frotter les membres affectés

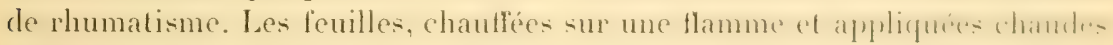
sur la peau, guérissent les névralgies; bouillies daus l'eau salée, clles servent à laver les plaies et les blessures. - Commun dans les champs ot surtout autour des habitations des nègres. On en fait sourent des clotures. - Fl.

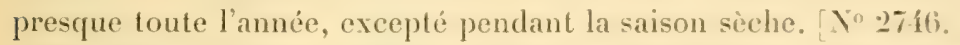

Mantrineve. Vulgo:médecinierbéni, pignon d'Inde. - Abondant. Y Yo $20.5 \%$

J. podagrica Hook, Jatrophe à tige rentlée. Tulga : Corail véurétal. Arbrisseau de $40 \mathrm{~cm}$. a $1 \mathrm{~m}$. Jo de haut, remarquable: par sa lige rentlée dans le bas, surtout quand il est jeune, de manière à simuler une sorte de bullo: par ses feuilles peltées, à 5 lobes, ses fleur's en cymes d'un rougre de comil ol portées sur de longss pédoncules. - Originaire de l'Amérique contrale et de la Grenade. - Ne cesse pas de fleurir. - Cullivé dans les jardins comme plante d'ornement. Basse-T'erre, Pointe-it-Pitre, etc. $[102925$.

Martingue. Vulgo: Corail végétal. - Mondant dansles jardins. X" 20.5.).

1. Cette graine, connue sous le nom de grand pignon d'Inde, yraine de l'onryliere. est très employée aujourdhui pour la fabrication de l'huile de ricin anglarive melangr

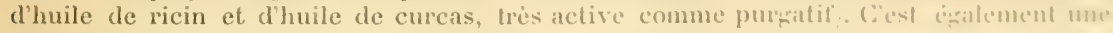
graine grasse industrielle très recherchée par les fabricants de savon. (1) la cullise

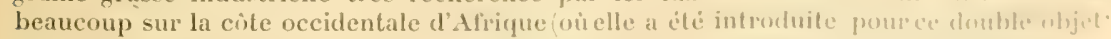

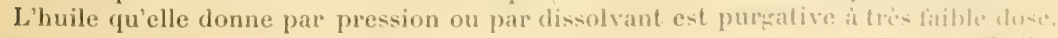


Cnidoscolus P’ohl (du gree "knizein", gratter, piquer, et " scolos ", pieu, piquant, pour faire allusion aux poils rigides et brûlants de cetle espèce.)

C. naprefolins Pohl. C. à feuilles de Napea. Vulgo: Manioc bâtard, manioc brûlant, ricin bâtard, ricin brûlant (Jatropha Desc. ; Juss., Euphorb., fiğ. 36. analys.) - Sulfrutescent, droit, haut de $30-120 \mathrm{~cm}$, remarquable par les poils blancs, rigides, brûlants, qui couvrent toutes ses parties. Feuilles larges, ì 3-5 lobes arrondis. Fleurs d'un blanc très pur. Capsule à 3 coques, à peu près de la même grosseur que le fruit du Jat.gossypifolia. - Il est épispastique, rubéfiant et doit être manipulé avec précaution : les poils, quand ils pénètrent dans la peau, y causent une douleur vive qui dure longtemps; devient grênant pour ceux qui marchent pieds nus.-- Fl. en juin, juillet, août. - Endroits secs et rocailleux. Hauteur de Case-Pilote et des Anses d'Arlet. Alt. 80270 mèt. [No 2047.] - Nous ne l'avons pas trouvé à la Guadeloupe.

Janipha II. B. Kth. nom dommé à cette plante par les indiènènes du brésil, d'où elle est origrinaire.)

J. manihot Kith. Jatropha manihot L. Manihot utilissima Pohl. (Sl., t. 85; Tuss., vol. III, t. 1, 2; Desc., vol. III, t. 176.) Vulgo: Manioc amer. - Arbrisseau plus ou moins tortueux, à tige noueuse, remplie de moelle. Feuilles siluées à l'extrémité des branches, at 3-7 lobes lancénlés. Fleurs peu nombreuses, en cymes racémiformes. Capsule pourvue de 5 ailes longitudinales et souvent ondulées. Les pieds de manioc abandonnés peuvent devenir arborescents et atteindre plus de $5 \mathrm{~m}$. d'élévation. - Fl. habituellement en septembre ef octobre, les fruits qui par ailleurs nont ancume valeur, murissent en novembre et décembre. - On rencontre un grand nombre de variétés, qui diffèrent par la couleur de la tige, par la couleur, la forme et la grosseur de la racine, par le plus ou moins de temps qu'il faut pour leur complet développement, par la richesse el la quantite de farine qu on en retire. Celles qui ont le teint rouge ou violet sont les plus communes et les plus estimées; plus les racines sont nombreuses, moins elles sont grandes; les petites n'excèdent guère $16 \mathrm{~cm}$. de long; quand il ne s'en trouve que 3 ou $\mathbf{1}$, elles peuvent atteindre jusqu’ $\mathbf{1} \mathbf{1 0} \mathrm{cm}$. de long sur un diam. de 6-8 cm. Les plus grosses peuvent peser jusqu'à 30 kilog. Les racines du manioc ne poussent ni verticalement ni horizontalement, mais affectent toujours une position intermédiaire. Il y en a qui mûrissent au bout de 7 mois; mais les meilleures, et celles qui sont le plus en usage, demeurent ordinairement de 15 à 18 mois sous terre, avant d'arriver à parfaite maturité. - Le manioc prend facilement par boutures, et c'est aussi le seul mode de multiplication. - Il se plaît dans les terres fraiches, meubles, bien exposées au soleil et en pente.

Manihot Pohl (du mot brésilien " mandihoca ».)

M. palmata Mul. Manioc a leuilles palmése. Manihol lipi Pohl; Latropha 


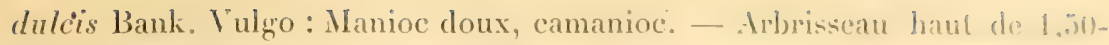
$2 \mathrm{~m}$. Plusieurs botanistes, entre autres Grisb., Fl. of British Il est Indian Islands, considèrent cetle espèce comme une variété du manioc amer, cu disant que daus le manioe doux on trouve aussi des racines vénéneuses; cu eflet, plusicurs propriélaires de la Martinique mont assuré que le manine dégénère au bout de quelque temps el que les racines deviennent vénénenses. Müller, dans le Prodrome de de Candolle, p. 1062, le décril comme unc espèce distincte; il y a bien une petite diflérence : le camanioc est plus drnit. sa lige n'est pas anguleuse, les pétioles sont d’un vert jaunâlre, el jamais bruns ou noirs comme dans le manioc amer; il y a, a la base du pétiole du camanioc, deux stipules ailées, qui, dans le manioe, ne sontreprésentées que par des traces de stipules ou par un appendice ressemblant it un piquant il large base; ses folioles sont plus larges, moins effilées el moins pointues; sa racine cuit plus vile el peut se manger crue; ses fruils sont, en outre, dépourvus d'ailes el légèrement anguleux au sommet. - Le camanioe ne se cultive presque plus actuellement à la Guadeloupe. Environs de la Basse-l'erre, s'à el là aux Trois-lhivières. No 3238.

Mantiveue. Vulgo: Camanioe. - Plus abondant : Mone-liouge, hauleur de la Grand'. Inse, ete. [No $2050 \mathrm{~b}$.

Siphonia Rich. (du gree "siphon ", turau, parce que la fleur est munie d'un petit tuyau, lonğ et étroit.)

S. elastica Pers. Siphonia produisant le caoutchouc. Vulgo : Arbre it caoutchouc. Ilevea guyanensis Aub. (de "héwé ", nom qu'on lui donne ì la Guyane.) - Grand bel arbre à feuilles palmées, contenant' 3-j lolioles entières, lancéolées el souvent arrondies au sommet. - Orizinaire du Brésil et des Guyanes. Est cultivé au Jardin botanique de Saint-Pierre et dans d'autres localités de la Martinique $\left[\Gamma^{\circ} 170\right.$.

Garcia Rohr dédie au médecin du mi de Portugal Gatreiats del Iluedn, yui a écrit sur les racines, 1567 ).

G. nulans Rohr. Garcia a fruits penchés. (Juss., Tent. Einphorf)., p). 11, 1. 13, f. 40). - Petit arbre superbe, très toullu, haut de 3-j mèt lieuilles pétiolées, alternes, obovales, à sommet obtus, luisantes, ì limbe de 10-16 cm. Fleurs blanchâtres, monoïgues, en racèmes, très courtes. Capsule ghlobuleuse, nous-ligneuse, déhiscente, à trois coques, un peu plus petite que le liruil du tamarinier des Indes. Semences globuleuses, d'environ 2 mm. de long. - List cité dans le Prodrome de de Candolle, vol. XV, p. 721, comme ílant indigène à la Guadeloupe. Nous ne l'y avons jamais rencontré.

Martineue. - Y est indiqué aussi, loco cil., comme indigienc, mais nous se l'arons jamais trouré a l'état sauvage; par contre, on roil an dardiu bulanique de Saint-Pierre un assez grand nombre de ces pieds. No 888. 
Aleurites Forst. (du gree " aleurites », farine de blé, faisant allusion à la matière blanche qui courre le dessous des leuilles, les pétioles, etc.)

A. triloba Forst. Aleurites ambinux L., Aleurites a trois lobes. Vulgo: Noir de Bancoul, noix des Moluques, noiselte des Grands-Fonds. Lam., IIl., t. 771. - Arbre de taille movenne, souvent petit arbre, originaire des îles Moluques. Fenilles larges, ovales où les adultes à 3-5 lobes, le lobe du milieu élant toujours plus grand el deltoïde, longuement pétiolées, couvertes d'une pubescence pulvérulente blanche. Fleurs monoïques, blanches, en panicules terminales, longrues de 10-11́ cm. Noix dure, indélniscente, couverte d'un péricarpe drupacé. - Introduit et cultivé cà el là sur les habilations : Le Baillif habitation Sante-sophie Camp-Jacob, su beaucoup dendroits dans les Grands-Fonds. - Les noix fournissent une huile d'assez bon goût, propre aux usiges domestiques pour l'iclairage el pour la fiabrication des chandelles: sèches, elles penvent se manger impunément et ont le goût de la noisette de France; l'huile est laxative. Larbre laisse exsuder une laque tròs belle, qui parait comme une perle ou un bourgeon à l'aisselle des branches ou des feuilles. - Fl. habituellement deux fois par an, de septembre en décembre et de livirier en mai. 「 No 2924 .

Mantrigue, Vulgo: Noix de Bancoul, noix de Saint-Domingue. - Cultivé au Jardin botanique, d'où il s'est répandu dans le pays. - Assez abondant autour de quelques habitations de la plaine (hauteurs des 'Trois-Ilets), où l'on se sert de l'huile de la noix pour les besoins domestiques. [No 692.]

Ricinus L. (à cause de la ressemblance de la graine avec l'insecte appelé ricin ou tique.

R. communis L. Vulgo: Carapate. Desc, Fl., I, 1. 59, et Fl., II, 1. 127. Arborescent, haut de 3-5 mèt.; originaire des Indes Orientales, naturalisé et cultivé dans le pays depuis un temps immémorial. Bien qu'arborescents, les plus forts pieds ne durent guère plus de quatre ans. - Abondant dans la basse région. On rencontre plusieurs variétés, dont les principales sont:

$1^{\circ}$ Variété à lige el branches rouges el couvertes d'une poussière blanche;

20 Variété à tige el branches blanches, également couvertes d'une poussière blanche:

$3^{\circ}$ Variété à grrosses graines el à feuilles très amples;

- Variété à fruits sans picquants.

- La graine est un drastique violent; I'huile, au contraire, est un purgatil asse\% doux, dont on se sert tròs fréquemment. Les paures récoltent souvent

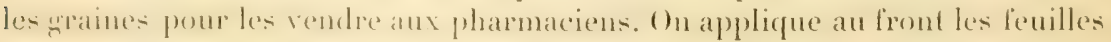
trempées dans du viuaigre, quand on soulfre de maux de tête occasionnés par des insolations; passées sur une flamme ou chaultées au feu, on les mel sur la peau contre les nérralgies el les rhumatismes. - Alt. 0-500 mèt. Basse-'́erre, Camp-Jacol), ete. [ Y 2023. 
Mantrineve. Vulgo : Palma-Christi, ricin abondant. - Ifuile simalement très usitée comme purgatil. $\left[\Upsilon^{\circ} 12.\right]$

Groton L. (du gree "kroton "), pou de chien, tique, parce que les graines de tous les crotons ont la lorme d'une petite tique.

C. balsamifer I., Croton balsamique. Vulgo: Copahu, copahu batard. Arbrisseau droit, n’atteignant guère plus de 3 mèt. d'élévation. Écorce frrise, jeunes branches velues, jaunatres. Feuilles ovales ou ovales-lancéolées en pointe allongée el souvent légèrement recourbée, velues, grises en desisus, blanchâtres en dessous et garuies de poils courts et étoilés; linube muni de deux glandes à la base. Fleurs blanches, en grappes terminales exhalant une odeur de miel. - Le coeur de ce bois est très dur, tout en étant llexible; il sert it faire des manches pour toutes sortes d'outils; avec ce même bois, qu il soit sec ou vert, on fabrique des flambeaux. De toutes les parties de cel arbrisseau, on peut, par incision, faire découler un suc assez épais, jaunatre ou presque brun, balsamique et d'une odeur très suave; on l'emploie pour la gruérison des plaies et des blessures. Dans quelques endroits, on distille la plante avee de l'esprit de vin et on obtient une liqueur appelée eau de Mante el que l'on destine a la toilette. - - Aime le terrain sec, rocailleux près du litloral, où il vit en société. 'Très abondant entre la Basse-Terre et les Vieux-Habitants. it la Pointe-Noire, à la Désirade, à Marie-Galante, aux Saintes, ete. - Fleurit presque toute l'année, mais surtout d'arril en septembre. $\left[\mathbf{Y}^{\circ} 2 \mathbf{2} 66\right.$.

Martixiece. Vulgo: Baume, petit baume. - Sert aux mêmes usages qu'ì la Guadeloupe. - Abondant: Vauclin, Sainte-Anne, Diamant. Alt. 0-250 mèt. [No64.]

C. floculosus Geiss., Croton laineux. Vulgo: Petit baume. - Ressemble beaucoup au précédent pour la taille, la forme des l'euilles, la couleur et les dimensions des tleurs; s'en éloigne par le duvet jaune, court el dense, qui couvre les jeunes branches, par ses feuilles plus épaisses, garnies en dessous d'une couche de duvet plus serré el plus blanc. - Il sert aussi à laire des llambeaux, à cause du suc résineux que contiennent loules ses parties. - Moins abondant que le précédent. Endroits secs, pierreux. - lil. d'arril en juilled. - Diamant, Case-Pilote, Caravelle. ( $\left.Y^{\circ} 63.\right]$ - Nous ne l’avons pas trouvé i la Guadeloupe.

C. Guildingii. Gr. Vulgo: Baume bâtard. - Arbrisseau haul de 1-2 miel.,

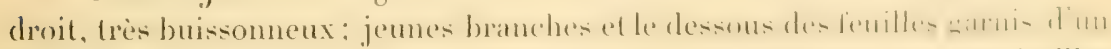
duvet blanc tirant sur le jaune. Dillère des deux précédents par ses leuilles dentées en scie. - Abondant dans les savanes des anses d'Arled el dans les hauteurs de Sainte-Luce. Alt, 80-320 mèt. [No62.] - Vous ne latrons pas trouvé à la Guadeloupe.

G. corylifolius Lam., C. montanus. Croton à feuilles de coudrier. Vulyo : 
Bois-pays; Desc., vol. V, t. 366. Geiss. - Arbrisseau ou petit arbre, haut

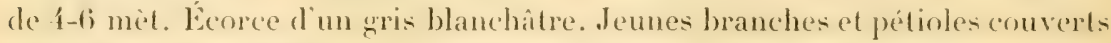
d'un duvel sris. Pétiole long, limbe de la leuille large, ovale, irrésulierement el doublement denté: quelquelois anguleux, parsemé, surtout dans sa jeunesse, d'une multitude de petites taches blanches et rondes. - Se rencontre dans les terrains sees et rocailleux de la basse et de la moyenne région. Peu abondant. Environs de la Basse-Terre (Ravine de la rivière Billaud); Gourbeyre (habitation Bisdary), Vieux-Fort (hauleur). - Fl. de mai en lévrier. - Toutes les parties de cette plante, surtout les leuilles, sont aromaliques. Descourtilz, p. 238 , la place dans la section des antispasmodiques aromatiques el en fait le plus srand éloge. Dans le pays, cet arbrisseau est peu connu, mais, là où il existe, on se sert des feuilles froissées dans les bains tièdes pour les femmes en couches; ces menues feuilles, bouillies et prises en tisane avec une addition d'un peu de rhum, de jus de citron et de sucre, constituent un excellent remède contre les fièvres. Nos $^{\text {2457, } 3419 .}$

Martixiqce. Vulgo: Grand baume. - Assez abondant. Boulevard de Saint-Pierre, 'Trou-Vaillant, hauteurs des Trois-Ilets. Alt. 0-300 mèt. $\left[N^{\circ} 163.\right]$

G. niveus Jacq., Croton à feuilles d'un blane de neige en dessous. Vulgo: Baume blanc. Jacq., Sel. Americ. stipp. hist., 1. 162, f. 2, une leuille. Arbrisseau haut de :-3 mèt., facile at distinguer de tous sescongénères par ses feuilles minces, d'un blane argenté en dessous, et garnies de petites touffes de poils étoilés ressemblant i de petits points blanes. - Endroits secs, rocailleux. Fort-de-lirance (coteau entre le collegre et le fort Dartensonj, Diamant, Trois-Ilets, Vauclin. Vit en société. Alt. 80-200 mèt. [Yo 1990.] - Nous n’avons pas trouvé cette espèce à la Guadeloupe. - Descourtilz, vol. V, p. 238, attribue à ce croton les mêmes vertus qu'au Croton corylifolius.

C. betulinus V., Croton à feuilles de bouleau. - Arbrisseau grêle, plus ou moins droil, à branches nombreuses, noirâtres, haut de $50-80 \mathrm{~cm}$. Feuilles petites, brièvement pétiolées, ovales, grossièrement dentées. Fleurs en grappes très courtes, - Fort rare. Nous n'en avons trouvé qu'un pied dans les terres de l'habitation de Śaint-Martin, près de Saint-Pierre (sept. 1884). $\left[\mathrm{Y}^{\circ} 60.\right]$ - N'est pas à la Guadeloupe.

G. origanifolius Lam., C. it feuilles d'origan. Desc., vol. V'II, t. 471; Sl., 1. 86, f. 3. - - Mrbriseau haut de $80 \mathrm{~cm}$. a $1 \mathrm{~m}$. 20 it branches grèles, a feuilles petites, ovales. - Rare. Nous n'en avons trouvé que quelques pieds dans les hauteurs du Fond-Layette (Case-Pilote). $\left[Y^{\circ}\right.$ 61.] - N'est pas il la Guadeloupe. 


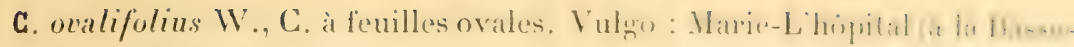

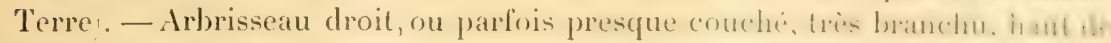

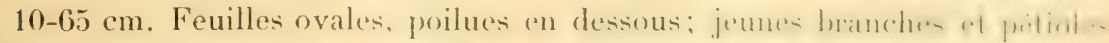

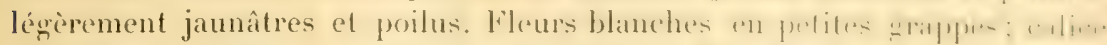

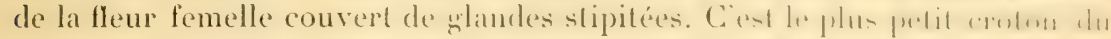
pays. - Abondant dans les environs de la Basse-T'erre (hospice de 'Tillat,

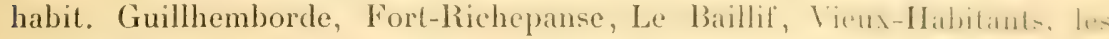
Saintes, Terre de Haut). - Les chevres et les moutons broutont fuldutionles extrémités des branches. I la Basse-Terre, on se serl de col ardri--can pour la confection des bouquets. [No 2458.]

N'existe pas à la Martinique.

C. populifolius Lam., C. à feuilles de peuplier. - Arbrisicau deroit, cildinant. haut de 1-1,50 m. Tige inférieurement ligneuse; jeunes branches el liges herbacées, poilues et remarquables par leurs stipules simples ou division, garnies de glandes stipitées et globuleuses. Feuilles ovales, en cour, pointues au sommet, irrégulièrement dentées en sere. - Pen almondant. (:a et là, dans les endroits secs et pierreux de Saint-Pierre, de Ciase-Piloter de Ducos. Alt. 20-250 mèt. [Nos 58 et 59.j- Nous ne lavous pas frouré a la Guadeloupe.

C. hirtus L'Hérit., C. hérissé. V'ulgo : Ilerbe aux ortolans, ortiersavane. - Herbe annuelle, droite, très branchue, haute de 3.5)-(i0 cm.. entierement garnie de poils raides et droits. Feuilles ovales, arrondies a la base, duthlement crénelées-dentées. Fleurs blanches en grappes courtes, temminales. Fl. toute l'année. - Abondant dans les savanes ef le loner des chemins de Sainte-Rose, du Lamentin, dans les champs de cannes de liale-Mahatult ut du Morne-à-l'Eau. [No 2743.]

Martinique. Vulgo: Ortie-savane. - Fond-Canonville Morme-Cuirlande et Morne-Folie). Alt. 30-100 mèt. [No 612 bis.]

C. lobatus I., C. à feuilles lobées. Vuly̆o: Mouzambi blance all Moule. Gombo française (au Morne-itl'Eau). - Ilerbe annuelle, a hasts quelpueluisuffrutescente, haute de $50 \mathrm{~cm}$. a $1 \mathrm{~m}$. 10, plus ou moins couverte de poils

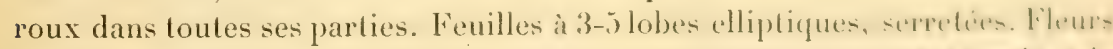

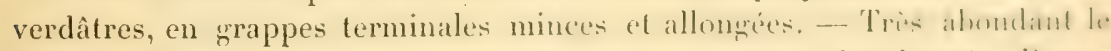
long des chemins, sur les décombers et les endroits abandenmin. liaterTerre, Le Baillif, Moule, etc. Alt. 0-120 mèt. [No 2460.

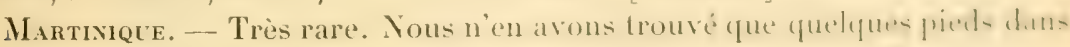
les environs de la batterie Sainte-Marthe (Saint-Pierre). [No 19.

C. astroites Ait., C. à poils étoilés. Vulgo : Baume. - Arbrisseau droit, nu

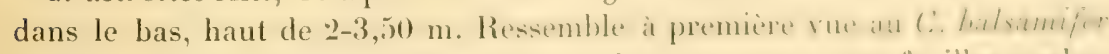
par le port, la couleur des fleur's; mais s'en. écarte par ses lenilles ovales, 
légèrement cordées à la base, par son duvet tomenteux blanc qui couvre le dessous de ses fenilles, mais surtout par la nature de ses fleurs femelles a style profondément 8-tide, par la dimension des lobes du calice, qui sont presque aussi longs que la capsule elle-même. - Vit en société dans les endroits secs, rocailleux, arides. I ésirade environs de la léproserie, GrandsFonds du Gozier, Vieux-Fort. Alt. 18-240 mèt. [Nos 2455 et 2734.]

Ne se trouve pas à la Martinique.

Le Croton Tiglium I.., arbrisseau ou petit arbre, originaire de l'Inde orientale el célèbre par ses vertus purgatives, drastiques et rubéliantes, même vésicantes de la peau. Est cultivé au jardin botanique de Saint-Pierre. [No 1991.] - On cultive à la Guadeloupe et à la Martinique un grand nombre de crotons a feuilles panachées provenant de différents établissements d'horticulture d'Europe et d'Amérique et qui font l'omement des jardins. Ex. : G. variegatus, Andreanus, maximus, longifolius, Jamesoni, tortilis, albicans, complonifolius, etc. La plupart sont d'une culture facile et se propagent par boutures.

Caperonia St. Hil. (dédié à Caperon, dont on n'a que le nom.)

C. castaneifolia St. IIil., C. à feuilles de châtaignier. Vulggo: Ortie grosse, Mâle coq d'Inde (au Moule). Plum., édit. Burm., t. 239, f. 1. - Herbe annuelle, très droite, haute de $50-90 \mathrm{~cm}$. Tiges, branches et pétioles couverts de poils hispides portant à l'extrémité des glandes sphériques. Feuilles ovales-lancéolées, rigides, ressemblant, pour la forme, les nervures et les dentelures, assez exactement à celles du chàtaignier de France, poilues sur les nervures de la face inférieure. Fleur's monoïques, blanches, très petites: fleurs femelles 3-4, unilatérales, situées à la base de petites grappes axillaires et terminales. Capsules garnies de piquants et de poils terminés par des glandes. - Peu abondant. Cà et là dans les endroits liumides et marécageux. GrandsFonds des Abymes, Moule. [No 2737.]

Martingce. Vulgo: Ortie-savane. - Gia et lia dans les champs humides. Lamentin, Ducos. Alt. 8-150 mèt. [No 1989.]

Argyrothamnia P. B. (du gree "arguros ", aryent, et "thamnos ", buisson, a cause de la couleur blanchatre de la tige et du dessous des feuilles.)

A. lanceifulia Mäll. Arrov.; Istaxis glabella Gr. V'ulgo : Bois-d'argent. - Petit arbrisiseau, haut de $8(1)-130 \mathrm{~cm}$., nu dans le bas, très branchu dans le haut, it eorce plus ou moins blanche. Feuilles obovales-lancéolées, dentelées cuscie. Bractées argentées et duvetées. Fleurs blanches, apparaissant souvent avant les fenilles, disposées en épis courts et axillaires. Capsule glabre, it 3 conques; semences sphériques, noirâtres. - Assez abondant dans les endroits sees et rocailleux pris de la mer. Moule, Sainte-Anne, Gozier. Alt. 0-100 mèt. [No 2459.] 


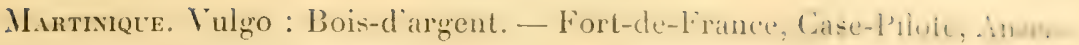
d'Arlet. Alt. 0-50 mèt. [Yo 889 .

Bernardia Müll. Arge. dédié à Bernard de Trans, qui, ch 1\%5\%. a Arril - m

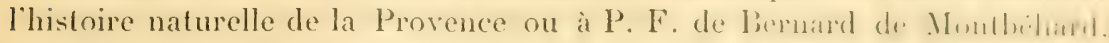
qui a écrit sur la flore du Jura, 1823.)

B. corensis Kl.; Polybara corensis Kil.; Ricinelle de la Birlicune. Hir. Jimm., t. 36, f. 1 ; Jacq., Sel. stirp. amer. hist., p. 254, t. 161); Acalypha Jacq. Arbrisseau haut de $80 \mathrm{~cm}$. a 1 , fo mèt. de haut. droit, mu dans le bas, trí, branchu dans le haut. Feuilles obovales, grossierement serretés. Filursmonoüpur: les mâles, verdàtres, petites, disposées en racèmes spiciformes, intermunum. situés aux aisselles des feuilles; les femelles, en épis tres courts, silmés a lintrémité des branches. Capsule verte, à 3 coques; semences presput pond... blanchâtres. - Endroits sees, rocailleux, près du littoral. Vieux-Forl, Mnule. ravine de Belost (Basse-Terre), Le Baillif, etc., Deshaies. [No 2161.

M.ntixiece. - Abondant. Case-Pilote, Caravelle, Boulevard de sainlPierre, Prêcheur. Alt. 0-100 mèt. [No 83.]

Acalypha I. (de " a " privatif, "kalos ", beau, et "aphé ", contact, c"st-idire plantes qu'il n'est pas agréable de toucher.

A. arvensis Poep. et End., A. des prés. Vulgo : Ortie bâtarde. - Suffrutescent, base de la tige couchée, traçante, d'une élévation de $25-15 \mathrm{~cm}$. Branches, jeunes tiges, fenilles et inflorescences courertes d'une fine pubscence. Feuilles rhomboïdes-ovales, et à pubescence blanche, quand dhe sont jeunes. Fleurs monoïques, vertes, en épis compacls, terminaux : les femelles dans le bas, renfermées dans des bractées uniflores, laimeuses el déchiquetées en $5-7$ lobes allongés; les mâles trés petites il l'uxtrimitio du l'épi. - Cà et là dans les fissures des vieux murs el dans les savanes humides. Camp-Jacob (habit. Michaux), Basse-Terre. Peu répundu ot pu abondant. Alt. 300-600 mèt. [No 2751.]

Mantinique. Vulgo : Ortie bâtarde. - Caà et là dans les champs. TroisPonts, Parnasse, Fort-de-France. [Nº 807.]

A. reptans Sw., A. rampant. Tulgo: Ortie petite, ricin petit. S1., 1. S., I. 3.

A. chamadryfolia Müll. Arer.; A. corcherifolia II. - Vivace par hehals herbacé par le haut, habituellement diffus, parfois droit, haul de l(1)-2) (111. . lri-

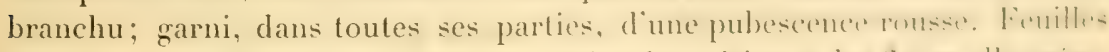

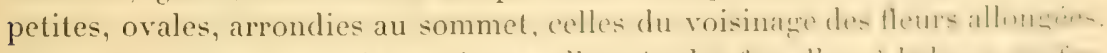

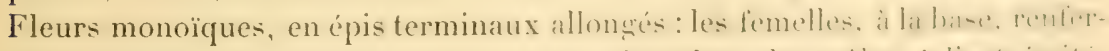
mées dans des bractées arrondies, poilues, dentelés: les miles. il l'ulromiti. - Cà et là dans les savanes sèches, aux pieds et dans les fissures des vieux murs. - Les chèvres et les moutons sont friands de celte herbe. - Vienx- 
Fort, Moule, Désirade, Fort-Richepanse (Basse-Terre). [No 2736.$]$ N'existe pas à la Martinique.

A. indica L., A. de l'Inde. - Annuel ou suffrutescent, haut de $50-90 \mathrm{~cm}$., peu branchu, remarquable par la longueur des pétioles, qui dépassent de beaucoup le limbe. Feuilles rhomboïdes-ovales, serretées. Fleurs en épis très nombreux, situés par 1-2 à l'aisselle des feuilles, presque dès la base de la tige : les femelles renfermées dans des bractées très larges, cuculliformes, alternes, au nombre de 5 - 10 sur chaque épi ; les mâles, très petites, vertes, placées à l'extrémité. - Assez abondant dans quelques faubourgs de la Pointeà-Pitre (environs de l'église de Saint-Jules), Moule. - Fl. toute l'année. $\left[N^{\circ} 27.35\right.$.

Martinique, - Cià et lia dans les environs de Saint-Pierre et dans quelques jardins mal soignés de cette ville. [No 808 .

A. macrophylla. Hort. : Variété à feuilles bordées de blanc. - Arbrisseau ornemental, haut de $2-4,50 \mathrm{~m}$., originaire des îles Fidji, à feuilles larges, dentées. Est cultivé à la Martinique el à la Guadeloupe dans beaucoup de jardins. $\left[\mathrm{N}^{\circ} 3662\right.$.

A. musaica Williams. - Arbrisseau très touffu, encore plus ornemental que le précédent, orininaire des îles de la mer du Sud, à larges feuilles profondément dentées, richement panachées de vert bronzé, de rougre, de cuivre et d'orange. - Extrêmement répandu dans les jardins de la Guadeloupe, où l'on en fait souvent des haies; plus rare à la Grande-Terre. Les deux espèces cidessus fleurissent toute l'année et domnent des graines fécondes. $\mathbf{N}^{\circ} 3363$. $]$ - Elles ont été introduites à la Nartinique, en 1881, par l'horticulteur L. Hahn.

Le Stillingia sebifera Mich.; Stillingflectia Boy. ; Excecaria L. ; Adrien Juss., Tentamen ad Euphorb., p. 49, t. 16. - Arbrisseau ou petit arbre, originaire du Japon et de la Chine, très ornemental, remarquable par ses feuilles d'un vert noir, a limbe plus large que long et brusquement terminé en pointe aiguë. Est cultivé au Jardin botanique de Saint-Pierre et dans d'autres localités de l'île. $\left[\mathrm{N}^{\circ} 1001.\right]$

Tragia L. (dédié à Jérôme Tragusus, maîlre d'école à Zweibrücken, intendant du Jardin ducal, médecin a IIornbach et a Saarbrück; a écrit : Nonveau livre sur les herbes, 1498-1553.)

T. volubilis. Vulģo : ()rtie brûlante, liane brûlante, Sl., t. 82; Plum., édit. Burm., 1. 252, f. 2. - Suffrutescent, volubile, haut de 2-3 mèt., à tiges très minces et flexibles. leuilles largement tronquées à la base, lancéolées-serretées. Fleurs monoïques : les mâles, en épis verts, minces, allongés, très nombreux, axillaires; les femelles, solitaires, portées sur de longs pédoncules 
naissant à l'aisselle des fenilles. Est remarquable far ses pril- lom in | ... lants qui couvrent les jeunes tiges, les feuilles et les capsules. - Assez abondant dans les broussailles de la région du littoral. - Fl. de lévrier

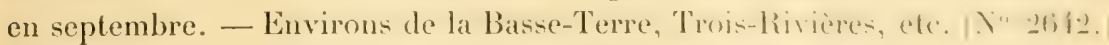

Martinique. Vulgo : Herbe brûlante, liane brûlante. - Saint-Pierre, Lamentin, Trois-Ilets, etc. $\left[\mathrm{N}^{\circ} 28.\right]$

Sapium Jacq. (du mot cellique "sap) ", gras, ghluant, allusion au suc whant de cet arbre. Pline, XVI, 23, se sert du mol "sapium " pour disigner une espèce de pin qui exsude une gomme gluante.)

S. aucuparium Jacq., Sapium des oiseleurs. Vulgo : Bois-de-soie. Desc,, vol. III, t. 154; Jacq., Sel.stirp. Americ. hist., t. 158.- Irbrede taille movemus. Feuilles elliptiques ou elliptiques-lancéolées, entieres on rarement denties: pétioles munis de deux grlandes un peu au-dessous de la base du limbe ; lleurs monoüques, en épis minces, allongés, terminaux : les males ocenpent la pratie supérieure; capsules à 3 coques de la srosseur d'un grain de poirre. - Toules les parties de la plante donnent par incision un suc abondant, loxique et extrêmement corrosif; on le laisse durcir pour en faire de la frlu; om promrail en faire du caoutchouc. Le bois n'a qu'une médiocre valeur et n'est gruère employé pour la construction. - Cà et là dans tous les bois de la basse el de la moyenne région. Alt. 0-1000 mèt. - Fleurit deseptembri en nowembre. [No 2932.]

Martinique. Vulgo : Bois-la-glu, glutier. - Dans tous les bois. [No 29.]

Hippomane L. (du gree " hippos ", cheval, et "mania ", fureur, excitation, et plus directement de " hippomanes n, qui signifie "liquor varina" ", ot yui s'écoule en son temps chezles cavales, et, comme cette matière a quelque ressemblance avec le suc du mancenillier, qui est un poison, on a, par métaphore, donné ce nom à l'arbre même.

H. Mancinella L. Vulgo : Mancenillier de l'espagnol " manzanilla ", diminutif de “manzana ", pomme, parce que les fruits de cel arbre ressemblent à de petites pommes). Sl., t. 195 ; Tuss., Fl., III, t. 5 ; Desc., vol. 11I, 1. 153. Petit arbre ou arbre de taille moyenne, d'un bel aspect. Feuilles vertes, luisantes, elliptiques, serretées ou crénelies, munies dime gimble it hat hat du limbe. Fleurs monoüques, disposees comme celles du wutier. le fiuit est une petite ponme ressemblant, pour la forme et la couleur, à une frumme d'api; elle a une odeur agréable qui vous invite a lat mantrer: la pulpre ("untient un suc blanc, semblable à celui qui réside dans l'écorce el dans les feuilles; le noyau est dur et ligneux. Le suc est abondant, très caustique el

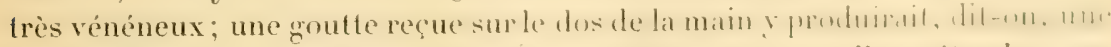
ampoule pleine de sérosité. Il n’est pas vrai, comme on l’a prétendu, que l'ombre et les gouttes de pluie qui tombent de cet arbre soient nuisibles. I mancenillier fournit un bois compact et de très longue durie. d'un hum 
grain, prenant facilement le poli; il est d'un gris cendré, veiné de brun, avec des nuances de jame; on l'emploie pour les boiseries el autres usages domestiques; on en lait particulièrement de beaux meubles, des cassetles, etc.; avec lầce, le cour du bois devient moirâtre. Les ouvriers qui abattent les arbres et en scicut les planches sont obligés de prendre des précautions pour n’ètre pas incommodés par le latex : on environne le pied d'un grand feu pour lui enlever une partie de son suc, et on a soin d'éviter la fumée pendant l'opération; sans cette précaution, on pourrait redouter des enflures occasionnées par les émanations. Les fruits, en forme de pomme d'api, sont très toxiques. L'eau de mer est le remécle le meilleur et aussi le plus usité contre les ampoules et les excoriations causées par le suc de cet arbre; on la fait boire à celui qui en a manéréles fruits, afu d'en empècher l'action nocive. Quand il est durci, ce suc a les mêmes propriétés que le caoutchouc. (Voir au sujet de l'action toxique de ce végétal une étude complite de MII. Heckel el Schlagndenhauffen, Bulletin de la Société de pharmacie des Bouches-duRhône, 1880). - Fl. d'août en novembre, et aussi de février en mars. - Vit en société sur les plages sablonneuses du bord de mer et sur les collines peu élevées de l'intérieur. - Les Saintes, Marie-Galante, Désirade, Moule, etc. $[N \circ 2741$.

Martixique. Vulgo: Mancenillier (par corruption, on dit aussi : maximilier), figuier bord de mer. - Diamant, Sainte-Anne, Caravelle, etc. [No 88.$]$

Hura L. (nom sous lequel cette plante est connue à la Guyane.)

H. crepitans L., H. détonant. Vulgo : Sablier. Desc., vol. II, t. 124; Tuss., Fl., IV, 1. 5. - Très grand arbre, à branches horizontalement étalées et à tronc garni de piquants. Feuilles larges, arrondies à la base ou cordiformes et pourvues de 2 glandes, serretées ou entieres. Fleurs monö̈ques : les mâles, en chatons imbriqués, ovales ; les femelles, solitaires, crrandes, noires, ayant un style simple en forme d'entonnoir, dont le bord renversé contient les stig mates formant 10-12 lobes pendants, arrondis ou subulés. Fruits capsulaires, composés de 10-15 loges s'ouvrant, à la maturité et quand ils sont chaulfés au soleil, élastiquement, tout d'un coup, et avec un bruit semblable à celui d'un coup de pistolet : les graines sont alors jetées dans toutes les directions; semences rondes, biconvexes, blanches en dedans. - Descourtilz, p. 2223, place le Hura dans les purratifs émétiques. Toutes ses parties contiennent un suc laiteux plus ou moins corrosif. Dans le pays, on se sert des feuilles trempées dans l'huile contre les douleurs rhumatismales. I.e bois n'est guère employé pour la construction. Pour empécher les fruits de s'nuvrir, il faut les cueillir avant maturité, les faire bouillir dans l'eau ou dans l'huile; on les vide ensuite et on s'en sert en guise de sablier. - Assez abondant dans la région du littoral de toutes les Antilles. [No 2732.]

Martinique, Vulgo : Sablier. [No 84.] - Dans toute l'île. 


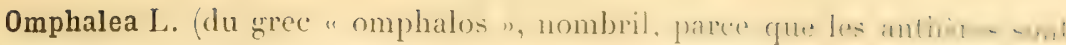
portées sur un disque charnu ayant la forme d'un nombril.)

0. diandra L., O à deux anthères: Vulgo: Liane-papaye. Aubl., IIist. de la Guy., t. 328. - Liane très grande, montant sur les arbres les plus élevés.

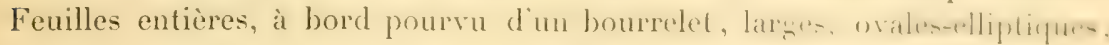
épaisses, coriaces, garnies en dessous d'un duvet court el épais, nervures

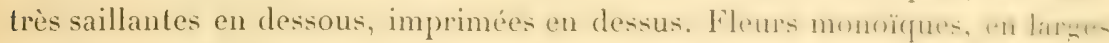
panicules terminales et axillaires : les miles, en peliles cymos acommpandin.

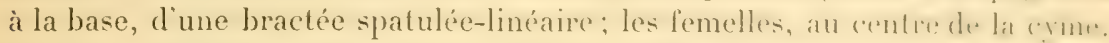
Le fruit est une baie capsulaire, plus volumineuse qu'une grosse orange, jaunitre à la maturité, se partageant en 3 loges, dont chacune conticul nue

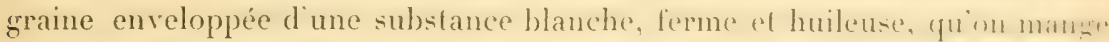

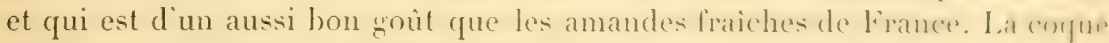
est dure et revêtue à l'intérieur d'un duvet blanc et longr; l'amande est également couverte d'un duvet blanc et long, elle peut se manger, mais il est bon, dit-on, d'enlever la radicule et les cotylédons pour éviter d'être purgé, ce qui arrixerait, parait-il, quand on ne prend pas cette précaution. Cette liane, qui derient arborescente, et dont les branchess, me fois quiclles ont atteint le sommet de larbre, se penchent ef tombent prescyue it lerre, at un trone de $15-20 \mathrm{~cm}$. de diamèt. : il est evlinchique jusqu’à une hauteur de 6-10 mèt. Elle contient un suc abondant, clair et limpide, mais insipide; il tache le linge. - Dans le pays on se sert des feuilles en décoction pour déterger les plaies et les vieux ulcères. Selon Crevaux, c'est avec la coque, mise en petits fragments polis et enfilés à la manière des perles, que les mulìtresses de la Guyane lont leur colliers dis de ouahe. - Fl. con juin el en autit: fruits mûrs en septembre, octobre, novembre et même en janvier. - Bord de mer pres de la rivière Sence prè de la Basse-Terre), liaie-Mahault buis de la Digrue, où elle est abondante), Lamentin. [No 2424.]

Martixique. Vulgo : Ouabé, liane-papaye. - Est devenu très rare à cause des déboisements. Se renenntre eneore ca la dans les buis entre le CiampBalata et Saint-Joseph. [No 57.$]$

Excæcaria L. idu latin " excereare ", aveugler, laisant allusion à l'action du suc de cette plante quand il tombe dans les yeux.)

E. Incida Sw.; Gymnanthes lucida Sw., E. à feuilles luisantes. Vulgo

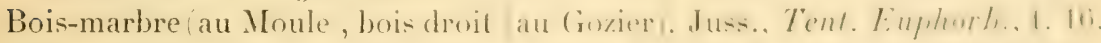
f. 55. - Petit arbre très élégant, très droit, haut de -4-7 mèt. Feuilles rigrides, petites, d'un vert foncé, luisantes, lancéolées ou lancéolécs-elliptiques.

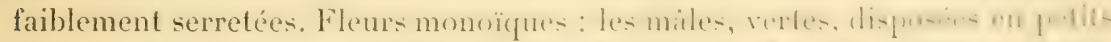

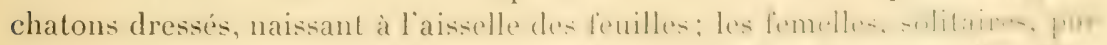

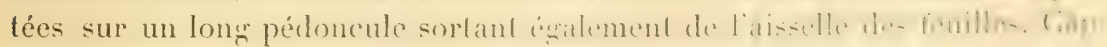
sule à 3 coques, de la grosseur d'un pois. - Endroils boisés des convirons du 
Moule habitation Malettre), où il vit souvent en société; Gozier (sur les rochers du bord de mer). - Fl. de sept. en mars. [Nos 2931, 3640.]

Il n’existe pas à la Martinique.

E. caribsa Gr.; Actinostemon concolor Müll. Aru. variété caribaeum. Excecaria des Caraibes. Vulgo: Bois fricassé, - Arbrisseau élégant haut de 1-2 mèt., à branches étalées, souvent un peu inclinées. Feuilles coriaces, entières, oblongues ou lancéolées-oblongues, pointues aux deux extrémités. Fleurs monoïques : les mâles en chatons axillaires, pourvus, à la base, de 3 bractées cuculliformes; les femelles, solitaires, Innguement pédonculées; capsules ì 3 coques, renfermant chacune une semence ovoüde, noire, luisante. - Très abondant dans les bois rocailleux de Houëlmont, depuis les hauteurs du Vieux-Fort jusquà Gourbeyre; hauteurs des Vieux-Habitants. - Fl. de janvier en avril. [ $\mathrm{N}^{\circ} 2465$. $]$

Martinique. - Plus rare. Endroits rocailleux et boisés des hauteurs de la Grande-Rivière. [No 891.] Alt. 250-400 mèt.

E. speé. - Arbrisseau très élégant, droit, haut de 2-4́ mèt. Feuilles elliptiques, pointues à la base, acuminées au sommet, faiblement dentées en scie, à dents distantes. Fleurs dioïques : les mâles, en chatons très nombreux, souvent très allongés, minces, verts, souvent réunis par 3, naissant à l'aisselle des feuilles; les femelles, solitaires, brièvement pédonculées, axillaires. Trouvé fleuri en septembre : Bois de Sofaya (Sainte-Rose).

Martinique. - Rare. Hauteurs boisées et rocailleuses de la GrandeRivière. Alt. 380 mèt. [No 890 .

L'Excæcaria bicolor IIass., arbrisseau originaire de Java, à feuillesluisantes, d'un vert noir, bleuatre en dessous, est cultivé au Jardin botanique de la Basse-Terre et de Saint-Pierre; on n’a que des pieds femelles. [No 3210.]

Dalechampia L. (dédié à Jacq. Dalechamps, de Bayeux, médecin, botaniste, philologue; a écrit, entre autres choses : Itistoria generalis plantarum, avec des figures, 1513 à 1588 .

D. scandens L., D. grimpant. Vulgo: Ortic rouge, Plum., Descript., t. 101; Jacq., Sel. stirp. Americ hist., 1. 160. - Liane vivace par le bas, volubile-wrimpante, haute de 3-5 mèt., herbacée par le haut, couverte, dans toutes ses parties, de longs poils roussitres et mous. Feuilles larges, à 3 lobes profonds. Fleurs monoïques, axillaires : les mâles, au nombre de 10 réunies en une petite ombelle pédonculée et occupant le centre; les femelles, au nombre de 3 , insérées autour et à la base du pédoncule de l'ombelle : le tout niché dans 2 grandes bractées trifides. Capsule à 3 loges bivalves, renfermant chacume une semence globuleuse. - Rare a la Guadeloupe, assez abondant dans les savanes abandonnées et les brousailles des environs du Moule jsavane Lemercier), Grands-Fonds-de-Sainte-Anne, etc. [No 2463.] 
Martinique. Vulgo : Liane poilue, liane-ortie. - Dans les haics of broussailles : Macouba, Trinité. Alt. 0-300 mèt. [No 2048.]

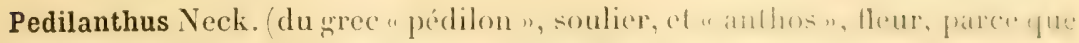
les fleurs ressemblent à un soulier' ou à un pied d'homme.)

P. tithymaloides Poir., Pédilanthe ressemblant an T'ithymale. Vulen : Herder-

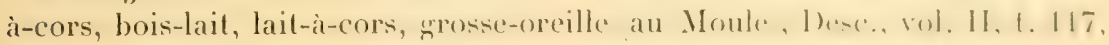
p. 195, et t. 118, p. 199. - Arbrisseau haut de 70 (m.-1 m. 20), it tignelantit sans branches, tantôt très branchue, de l'épaisseur du pelit donght, droite.

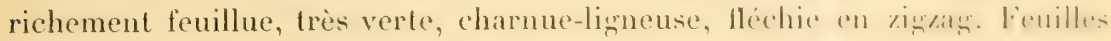
épaisses, placées sur 2 rangrs, ovales-arrondies ou ovales-elliptiques, carénées sur le dos, pubescentes dans leur jeunesse, brievement pítioleses. Firurs inodores, d'un beau rouge, très irrégulières, horizontalement situées, monoïques : les mâles, composées de 18-22 étamines d'iniggale longuenr, in centre desquelles s'élève une fleur femelle unique, longuement pridonculie et dépassant de beaucoup les étamines; ovaire incline, styles 3, longs, surmontés de stigmates. Capsule à 3 coques. - De cel arbrisseau on fait souvent des clôtures, qui, soumises à la taille, deviennent très toullues et très belles. - Toutes les parties de la plante contiennent un suc laiteux, abondant, âcre, caustique, émétique, purgatif, et c'est à juste titre que Descourtilz la place dans la section des plantes émétiques-purgatives. Dans le pays on se sert seulement du suc pour faire disparaitreles cors, les verrues, les callosités, ele. - En transplantant cet arbrissean dans les terres fertiles, on lui fait perdre les formes typiques qu'il avail dans les terratios sees, chauds et pierreux ou il pousse habituellement. Al'ombre, ses ligess allongent, et, de grimpantes et tléchies en ziggagr quelles étaient, deviennemt droites; les feuilles diminuent d'épaisseur et d'ampleur; les fleurs changrnt de couleur, etc., etc. C'est ce qui a donné lieu ì plusieurs varićtion dont beaucoup de botanistes ont fait des esperess distinctes : p. ex. P. pardifulius. Poil., Pédilanthe à feuilles d'orpin; P. any nustifolins Poil., Pedilanthe a fentlles étroites. - Abondant dans les endroits rocailleux, arides, près du littoral. Vieux-Fort, Marie-Galante, Moule, etc. [No 2733.

Martinique. Vulgo : Bois-mamzelle, herbe-à-bordures, herbe-ì-cors. Case-Pilote, Caravelle, Prêcheur, etc. [N०94.]

Euphorbia L. (dédié à Luphorbos, médecin de Juba, mi de Manritanic (Pline, XXV, 38), qui, dit-on, s'est servi le premier de cese enpere-te planter en médecine.)

E. linearis R., Euph. à feuilles linéaires. Vulgo : Bois-lait bord-de-mer. Plum., édit. Burm., t. 251, f. 2. - Arbrisseau ou petil arbre, dont les plus grands ne dépassent guère 4 mèt., très ornemental, droit, nu dans le bas, très branchu, branches dicholomes, ramuscules articulés. Fenilles grisut 
glanques surtout en dessous, oblongues-lancéolées, et souvent tout it fait linéaires. distantes. Fleurs axillaires, subsolitaires : les mâles et les femelles ensemble. Capsule petite: semences spheriques-anguleuses. - Issez abondant sur les rochers et dans les sables du bord de la mer : Désirade. MarieGalante, Vieux-Fort. - Fl. en tout temps. [No 2451.]

Martinique. Vulgo : Bois-lait. - Caravelle, Diamant. Anses-d'Arlet (Pointe-Salomon). [No 957.

E. buxifolia Lam., Euph. à feuilles de buis. Desc., vol. VI, t. 418. Vulgo : Bois-lait petit. - Arbrisseau droit. haut de $15-90 \mathrm{~cm}$. Éconce noire, tige marquée de nombrenses cicatrices; branches courtes, fastigiées. Feuilles petites, ovales, pointues, charnues, entières, grises. Fleurs axillaires, situées à l'extrémiti des branches; capsule petite, glabre; semences presque sphériques. -Dans les sables du bord de mer: Désirade, Moule, Capesterre Guadeloupe, Saint-François. [No 2741 .

Martingue. Vulgo: Bois-lait. - Cararelle, Sainte-Anne (habitation Bertrand) et Champ de pétrification. [ $\mathrm{N}^{\circ} 1986$.

E. thimifolia Burm., Euph. à feuilles de thrm. Vulgo: Petite teigne. - Petite herbe annuclle longue de $8-15$ cm., couchée, diffuse, à branches filiformes, dont lextrémité est souvent dressée. Feuilles très petites, obovales ou ovalesoblongues, plabres, arrondies au sommet, obliquement attachées. Capsules glabres ou poilues aux trois angles, de la grosseur d'un grain de millet; semences transversalement sillonnées et à $\dot{4}$ angles. - Abondant dans toute l'île. - Dans le pays on se sert de cette plante, en tisane avec de l'eau de riz, pour les nourrices, afin de puritier leur sang et de rendre leur lait meilleur: on la prend aussi en infusion contre la dysenterie. [ $\mathrm{N}^{\circ}$ 2739.]

E. prostrata Ait., Euph. couchée. Vulgo: Petiteteignenoire. - Petite herbe couchée rampante. Ressemble beaucoup au précédent; en diffère par ses feuilles plus consistantes ef plus larges, ses capsules ainsi que ses semences plus volumineuses. - Tres abondant dans les chemins peu fréquentés, entre les pavés des rues peu battues, dans les champs de manioc et dans les jardins. - Sert aux mêmes usages que l'Euph. à feuilles de thym. [No 3420 .

Martixique. - Très abondant. Saint-Pierre, Morne-Rouge, etc. [No 1980.] - Les feuilles pilées servent dans le pansement des morsures du serpent.

E. pilulifera I., Euph. hirta L., Euph, pilulifère. Desc., vol. III, t. 227. Vulgo : Mal nommée vraie, zerbe mal nommée, la mal nommée vraie. - Herbe annuelle, pubescente dans toutes ses parties, simple ou branchue, à extrémité penchée, haute de $10-65 \mathrm{~cm}$. Tige rougeâtre. Feuilles semi-ovales, pointues, obliques à la base. Fleurs des deux sexes mélangées, en cymes axillaires et terminales. Capsule poilue, un pen plus grande qu'un grain de millet; semences a f anıles, transversalement ancruleuses. - Fort 


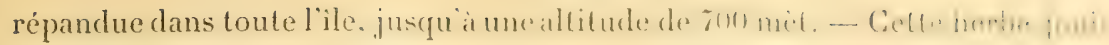
d'une grande réputation dans le pays : on l'emploie surtout en infusion contre les fièvres et contre la rétention de l'urine; elle est préconiséc aujourd'huj officiellement dans la médecine européenne, contre l'asthme spasmodique

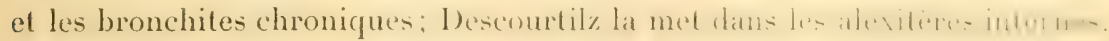
[No 2453 .

Martixique. Vulgo: Mal-nommée. - Est souvent employée contre la morsure des serpents. - Très abondant. [No 1982.

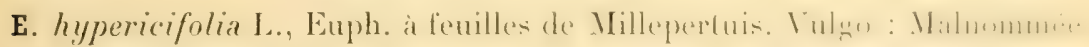
verte, petit-lait ou tilait (à Saint-Anne). - Annuel, à base souvent sulfirutescente, droit, haut de $20-50 \mathrm{~cm}$. Feuilles glabres, oblongues ou lancéolées,

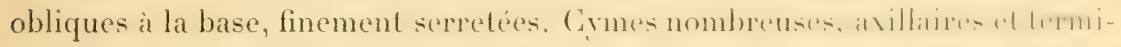
nales. Fleurs mâles blanches. Capsule verte, obtusément anghuleuse, de la grosseur d'un grain de millet. - Extrêmement abondant dans les terres cultivées, le long des routes, jusqu'à une altitude de 900 mèt. [X 2015́1.

Martineue. Vulgo: Mal-nommée verte. - Abondant. No 488.

Dans cette espèce, les semences sont rouges, à 4 angles obtus, ol garnies de petites fossettes transversales peu nombreuses.

E. Preslii Guss., Euph. de Presl. Vulgo: Mahnommée verte. - Ressemble au précédent et a été souvent confondu avec lui, mais, en les voyant pousser dans les champs l'un à côté de l'autre, on décourre d'assez grandes dilférences : dans celui-ci les feuilles sont souvent linéaires et légèrement recour-

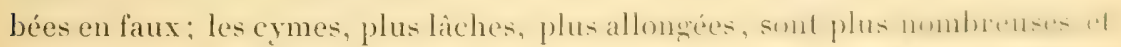

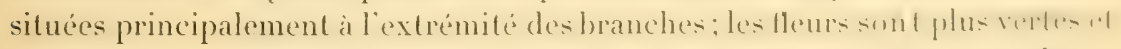
portées sur des pédoncules plus longs; les semences sont plus grandes, d̀

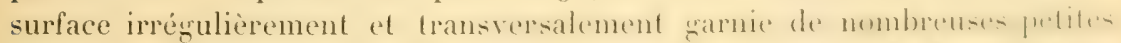
fossettes; les stipules sont triangulaires, tandis que dans E. hypericifullit elles sont lancéolées. - Tout aussi abondant que le précédent, dans les terres cultivées de la basse et de la moyenne récgion, ou il vit en société avec

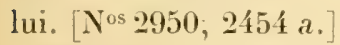

Martinique. Vulgo: Mal-nommée fine. - Abondant. [No 488 a.

E. Berteriana Balb. - Annuel, droit, très branchu, haut de ?(0-35 cm. ;

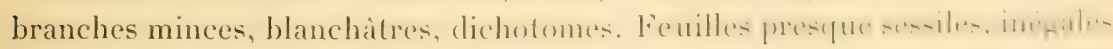
à la base, oblongues-obovales, légèrement dentelées. Fleurs très blanches, ramassées en cymes sessiles, situées à l'extrémité des branches: calpsule poilue de la grosseur d'un grain de millet; semences oblongues, Litragrones, transversalement anguleuses. - Uniquement dans les terres culliveres of incultes du plateau de la Désirade. [No 2738.]

N'existe pas à la Martinique.

E. spec. - Vivace, complètement couché, rampant, lons de 20-j0 cm. 
Racines noires, pivotantes. ridées; tigres rougres, très nombreuses, filiformes, dichotomes, noueuses: les adultes, glabres el cylindriques; les jeunes, faiblement comprimées et poilues, et léxèrement ailées sous les nuruds. Feuilles épaisses, un peu charnues, uninerviées, subentières ou légèrement dentées au sommel, grisess en dessus, glauques en dessous, opposées, inérales à la base, subréniformes ou ovales, arrondies au sommet ou terminées en pointe obtuse; pétiole vigoureux, comprimé, tantôt plus, tantôt moins de $1 \mathrm{~mm}$. de long; limbe de la feuille $3-6 \mathrm{~mm}$. de long sur 1,5-2 $\mathrm{mm}$. de large. Fleurs axillaires, 1-2 a l'aisselle des feuilles des ramuscules situés vers l'extrémité des branches. Capsule verte a 3 sillons profonds, garnie de poils blancs peu nombreux, coques carénées; semences noires sans caroncule, oblongues, tétragones, anguleuses, longues d'un peu plus de $1 \mathrm{~mm}$. - Nous n'avons trouvé cette espèce qu'en petite quantité sur la terre sablonneuse qui couvre les rochers du bord de mer à Vieux-Fort. [No 2740.

N'est pas à la Martinique.

E. geniculata ()rt., Euph. ì articulations en forme de grenou. Vulgo : Malnommée gros. - Annuel, droit, haut de $50-70 \mathrm{~cm}$.; tige grosse, fistuleuse, simple, quelquefois dichotome par en haut. Feuilles larges, elliptiques, entières, assez épaisses. Cymes contractées, presque sessiles, situées à l'extrémité des branches. Capsules glabres, presque aussi grosses qu un grain de poivre. à 3 coques; semences à surlace irrégulièrement tuberculée. - Abondant dans les terres cultivées de la basse et de la moyenne région. - Fl. surtout pendant la saison de l'hivernage. - Basse-Terre La Pintade et champs de cannes de l'habitation Boulogne), Trois-Rivières. [ $\mathrm{N}^{\circ}$ 2452.]

Martnerf. Vulgon: Brinvilliers-batard, grosse malnommée. - Environs de Saint-Pierre, Lamentin, Ducos. $\mathrm{N}^{\circ} 56$.

E. heterophylla L., variété cyathophora Jacq.; Euph. à deux sortes de feuilles. Plum., edit. Burm., t. 251, f.3. - Annuel ou bisannuel, à base ligneuse, très ornemental, droit, haut de $80 \mathrm{~cm}$. a $1 \mathrm{~m}$. 20 au plus. Feuilles ovales, en forme de violon, entières ou grossièrement et obscurément dentées; feuilles florales elliptiques, marquées, dans leur partie inférieure, d'une large tache rouge écarlate. Fleurs rouges en cymes terminales. Capsules à 3 coques, de la grosseur d'un grain de poivre; semences presque rondes, tuberculées. - Route du Morne-i-l'Eau au Moule, Grands-Fonds des Abymes. Est cultivé a la Basse-Terre, dans les jardins et dans les deux cimetieres, comme plante d'ornement. [No 2450 .

Martinique. - Cimetières du Carbet, du Précheur. du Fort (Saint-Pierre), etc.; plus rare à l'état sauvage (hauteurs des Trois-Hets). [ $\left.\mathrm{N}^{\circ} 1985.\right]$

Variéte : graminifolia Englem., a feuilles linéaires, longues de $5-7 \mathrm{~cm}$. sur 2-3 mm. de large. - Hauteurs des Trois-Ilets, rare. [ $\left.\mathrm{N}^{\circ} 1984.\right]$

E. Dussii Kr. et Urb. - Arbrisseau droit, haut de $1 \mathrm{~m}$. 40, droit. Feuilles 


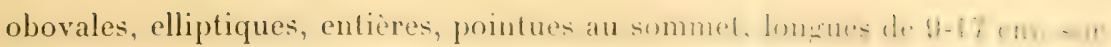
$3-5 \mathrm{~cm}$. de large, très vertes, rapprochées en faux verticilles qui, au nombre de 4-5, sont composés de 5-6 leuilles. Cymes terminales. - Trùs rare.

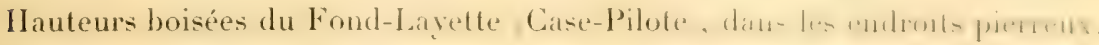
Spécimen imparfait. [No69.]

E. pulcherrima Willd.; Poinsellia pulcherrimal (irah., Luph. lrillant. Vulgo: Petit-flamboyant. - Arbrisseau peu élégant, plus ou moins Lortueux, à branches allongées, tombantes, remarquable par ofe fenille- flurales d'un rouge écarlate très vif. - Originaire des hautes montagnes du Mexique; est cultivé dans toutes les Antilles comme plante d'omement. Il contient un suc laiteux très abondant et extrèmement corresil'. |X"3.3.31.

E. verticillata Poir.; E. petiolaris Sins. Vulgo: Petit mancenillier. -

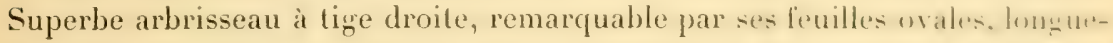
ment pétiolées et verticillées par 3, à limbe noir en desists, it fleurs en cymen paniculées, axillaires. - Originaire de Saint-Thomas el de Porto-Rico. Cultivé au Jardin bolanique de Saint-Pierre el dans beaucoup d'autre- jardins. Il se multiplie très facilement par bouture. [Nº 1987.]

\section{SEIZIÈME FAMILLE. - CARYOPHYLLINÉES}

Stellaria L. (de " stella ", étoile, d'apres la disposition des pritales de la fleur.)

S. media L., Stellaire intermédiaire. - Petite herbe annuelle, à tiges nombreuses, flexibles, tombantes, portant sur toute leur longuene une ligne de poils, alternant à chaque noxud. Feuilles ovales, en forme de cortr. Fileurs

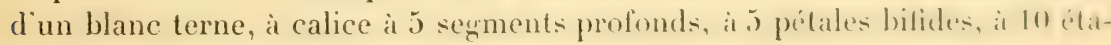
mines. Fruit s'ouvrant en 6 valves. - Introduit de l'Europe et naturalisé dans les jardins du Camp-Jacob, du Matouba, etc. [No 3093.]

Martingue. Vulgo : Mouron. - Très abondant dans les jardins mal soignés du Morne-Rouge, où il forme souvent un verilable gazon. X $3 ! 1$ -

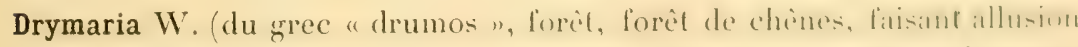
à ces plantes qui rampent au loin, prennent racines aux nouds et forment, pour ainsi dire, de petites forêts.)

D. cordata W., Drymaria à feuilles en caeur. Lam., Ill., 1.51. Vulggo : Mouron blanc. - Herbe tres tendre, conchese, radieante, rampante ind thmm.nt.

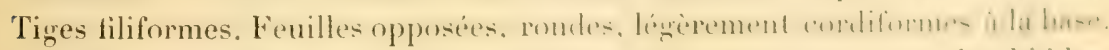
Fleurs petites, d'un blanc terne, étoilées, à 5 sépales, it 5 pétales bilidés.

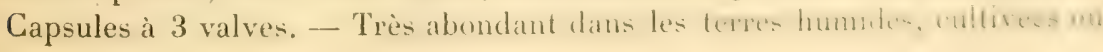


incultes, jusqu'it une altitude de 900 mètres. Basse-Terre, Camp-Jacob, Bains-Jaunes, etc. [No 3092.]

Martinique, Vulgo: Mouron blanc. - Abondant. - A cause de ses vertus sudorifiques, on l'emploic souvent extérieurement et intérieurement dans le pansement de la morsure du serpent. [ $\left.\mathrm{N}^{0} 1779.\right]$

Talinum Ad. (du nom donné à celte plante par les noirs du Sénégal, qui la mangent en salade.)

T. triangulare W. : Porfulaca crassicaulis Jacq., Talin à tige à 3 angles. Pourpier grand-bois, pourpier-bois. - Herbe a tige triangulaire dans le haut et avec des branches également triangulaires, droite, vivace par la base, haute de $60-90 \mathrm{~cm}$. Feuilles molles, légèrement charnues, obovales, entières, rétrécies à la base. Fleurs jaunes, rarement d'un blanc terne, ne s'ouvrant que vers midi, en corymbes terminaux portés sur de longs pédoncules à trois angles. Capsule s'ourrant par déhiscence pyxidaire comme dans le pourpier; graines noires, polies. - Les jeunes tiges et les feuilles peuvent se manger en salade et ont le même groût que les feuilles du pourpier; on la cultive quelquefois dans les jardins. - Assez abondant dans les bois sees et pierreux du Houëlmont. [No 3192].

Martixipe. Vulgo: Grand pourpier, pourpier droit. - Dans les hauteurs pierreuses de Case-Pilote: dans les jardins du Grand-Morne et du Robert. Alt. 150-350 mèt. [No 1781 .

T. patens W.; Portulaca paniculata Jacq.. Talin à grande grappe aux branches étalées. - Vivace par ses racines, herbacé par les tiges qui disparaissent sans laisser de traces, haut de $80 \mathrm{~cm}$. à $1 \mathrm{~m}$. 20. Feuilles ovales, légèrement charnues. Fleurs violet tendre, ne s'ouvrant que vers les 3 ou 4 heures du soir, en large panicule, dont les branches filiformes prennent une direction horizontale. Fruit comme dans le précédent. Les racines de cette espèce sont très volumineuses, $2-3 \mathrm{~cm}$. de diamètre, molles, noires en dehors, blanches en dedans. - Endroits pierreux, chauds: Basse-Terre (Morne-ilVaches), Pointe-Noire, etc. [No 2343].

Martinique. Vulgo: Herbe-salade. - Assez abondant : Trou-Vaillant, Gros-Morne, Saint-Pierre. [No 1782.]

Portulaca L. (de "portula", diminutif de "porta ", porte, pour faire allusion, selon Wittstein, Dictionnairé élymol., p. 723, aux vertus puryatives de ces plantes; selon d'autres, du latin " porto ", je porte, et "lac ", lait, parce que ces plantes sont plus ou moins laiteuses; d'après d'autres, à cause de la déhiscence de ses capsules; selon Gesner, parce que les feuilles ressemblent à de petites portes.)

P. oleracea I., P. cultivé. - Annuel, charnu, habituellement diffus. Tiges dichotomes. Feuilles spatulées, arrondies au sommet: les supérieures, rosu- 
lées autour des fleurs. Fleurs jaunes, sessiles, ne s'ourrant que vers 10 ou 11 heures du matin. On rencontre deux variétés, une ì fleur's plus grandes. l'autre àfleurs plus petites. - Gette herbe se mange souvent crue, en salade. ou cuite, après qu'on a jeté la première eau. - Fl. chant toute l'année. -

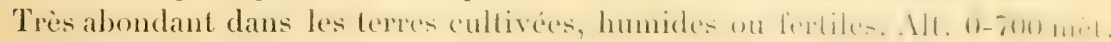
[No 3094.]

Martinique. Vulgo : Pourpier. - Abondant dans toute l'île; se manere également. [No $\mathrm{N}^{\circ}$ 1783. $]$

P. pilosa L., Pourpier garni de toulfes de laine. Vulgo : Quinine, pourpier amer. - Herbe ornementale, annuelle et plus sourent sullirutescente, plus ou moins couchée, souvent rampante, à rameaux nombreux non divisés, droits, longs de $6-20 \mathrm{~cm}$. Fenilles presque cylindriques, pointure, alferm. garnies à la base d'une touffe de laine blanche. Fleurs grandes, pourpreviolet. On la cultive souvent dans les parterres comme plante d'omement: elle perd alors ses caractères typiques. - Elle est amère et jouit dans

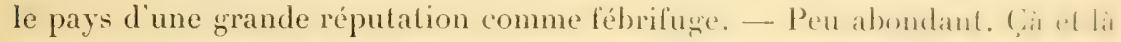
sur le bord pierreux de la mer el quelquefois dans les androils sex's af pierreux, situés un peu dans l'intérieur. Bord de mer entre la Basse-l'erre el le Vieux-Fort, Capesterre (Guadeloupe), Désirade, où il est abondant. [No 2424.]

Martinieue. Vulgo : Pourpier bord-de-mer, pourpier amer. - Diamant (près du bord de mer, Anses d'Arlet), Sainte-Anne. [ $\left.\mathrm{N}^{\circ} 137 \%.\right]$

P. halimoides L., Pourpier ressemblant a l'arroche halimus. Vulü : Pulif. quinine. Sl., t. 129, f.3. - Annuel, haut de 6-11 cm., droit, quand il est jeune, ensuite plus ou moins couché, souvent à branches nombreuses el divisées sur la base. Feuilles très courtes, presque cylindriques, gamies au bas d'une touffe de laine blanche. Fleurs jaunes ou pourpres. - Endroits humides près du bord de mer: Lessintes, Tere-de-Hant sur he drumin du Chameau, Gozier, Marie-Galante, Moule. [No 2978.]

Martinique. Vulgo: Petit pourpier. - Diamant, Anses d'Arlet, Prêcheur. [No 1378.$]$

Sesuvium L. (selon Adanson, synonyme de " sedum ", orpin, plante grasse comme celle-ci.)

S. portulacastrum L., Sésuve à feuilles de pourpier. Vulgo : Pourpier de bord de mer, pourpier-mer (au Moule). Jacq., Sel, stirp. Am. hist., 1. 9.). -

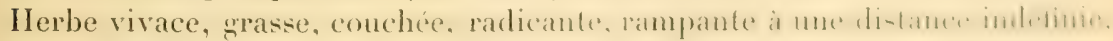
quelquefois à plusieurs mètres, si rien ne trouble sa croissance. 'Tigre cylin.

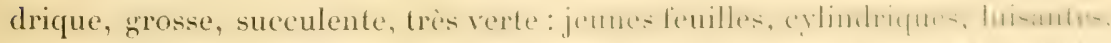

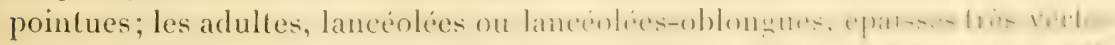

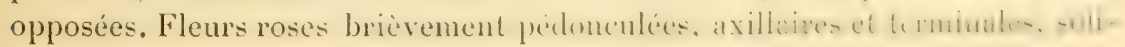


taires. Capsule s'ouvrant par déhiscence pyxidaire. - Uniquement sur les plages sablonneuses du bord de mer, où il vit en société et forme souvent un gazon superbe. - Les fleurs ne s'ourrent que vers onze heures ou midi. - Moule, Désirade, Sainte-Anne, Marie-Galante, etc. [No 3091.$]$

Martinique. Vulgo: Pourpier bord-de-mer. - Très abondant à SainteAnne, Caravelle, Sainte-Luce. $\left[\mathrm{N}^{\circ} 1780.\right]$

Trianthema L. (de deux mots grees qui signifient " trois " et " fleur ", parce qu'on trouve habituellement trois fleurs à l'aisselle des feuilles.)

T. monogynum L. Trianthème à un style. Vulgo: Pourpier courant. Desc., $\mathrm{Fl} ., \mathrm{I}, \mathrm{t} .51$, p. 228. - Vivace par ses racines et le bas de la tige, rampant à une grrande distance sans être radicant. Feuilles opposées : la paire, d'inégale grandeur, arrondies au sommet, obovales, pétiolées, pétioles sélargissant pour devenir engainants. Fleurs petites, violacées, groupées par 2-3 à l'aisselle des feuilles; styles 0-2. Capsules à déhiscence pyxidaire. - Le plus souvent sur le bord de mer et dans les endroits humides dans l'intérieur des terres. Alt. 0-80 mèt. - Avec les feuilles et les jeunes tiges on prépare une bonne salade. Descourtilz (loco cit.) prone cette herbe comme vermifuge. Dans le pays on ne s'en sert pas. - Environs de la Basse-Terre, Capesterre (Guadeloupe), Marie-Galante. [No 2423.

Mantinique. Vulgo : Pourpier courant. - Grand'Anse, bord de mer et dans les jardins el champs de l'intérieur, Basse-Pointe abondant sur les pierres aux environs des magasins du bord de mer). - ( ) la mange en salade à la Grand'Anse. [No 1227.$]$

\section{DiX-SEPTIÈME FAMLLE. - PHYTOLACCÉES.}

Suriana L. dédié par Linné à Jos. Donat Surian, médecin et pharmacien de Marseille, compagnon de Plumier en 1689, auteur d'un traité sur les drogues.)

S. maritima L., Suriane du bord de mer. Vulgo : Oseille bord de mer, romarin noir (au Moule). Sl., t. 162, f. 4; Lam., Ill., t. 389. - Arbrisseau très élégant et ornemental, à feuillage grisâtre, haut de $40 \mathrm{~cm}$., 4 mèt. et davantage, à branches tres nombreuses, fastigiées, granies de poils gris et extrèmement feuillues. Féuilles spatulées-lancéolées se rétrécissant vers la base, sessiles. Fleurs d'un jaune vif, grandes, nombreuses, en grappes courtes, terminales. Fruils sees, composés de jo 6 semences juxtaposées, velues, noires, entourées des sépales persistants. - Abondant sur les plages sablonneuses sieches et dans les pierres madréporiques du bord de mer. Fl. pendant toute l'année. - Désirade, Marie-Galante, Moule, etc. [No 2482.] 
Martixede. Vulgo: Romarin noil. - Peu abondant. Roches madréporiques du bord de mer, du Macouba (V auclin). [No 2061.

Phytolacca L. (du gree "phuton ", plante, el du latin "lacca ", laque, paree que ces plantes peuvent fournix une belle couleur rouge.)

P. icosandra L., Phytolaque ì 20 élamines. Vulgo: Raisin d'. Imérique, épinard doux. - Herbe annuelle, haute de $70 \mathrm{~cm}$ à 1 m. 50. Tige grosse, sucenlente, striée, simple, peu branchue; branches horizontales ou penchés. Feuilles larges, d'un vert très clair, ainsi que la tige, ovales nu ovales-lancéolées, terminées en pointe elfilée. Fleurs d’un blane terne, pédonculées en grappes très allongées, axillaires et terminales, le plus souvent pendantes, longues quelquefois de $25 \mathrm{~cm}$. Fruil baccien, rouge, contenant $10-12$ semences. -On peut manger les feuilles et les jeunes tiges en gruise d'épinard; le sue de la racine et des baies non mûres est purgatif; le suc des baies produil une belle couleur rouge qui, malheureusement, passe trop vite, - Fl. doetobre en mai. - Peu abondant. Cà̀ el là dans les clairières des forếls humides: Matouba, Trois-Rivières (Trou-aux-Chiens). [No 2400.

Martineue. Vulgo : Epinard de Cayenne. - Plus abondant qu'à la Guadeloupe, Champflore, Camp-Balata, Chemin-de-la-'Trace. [Yo 2062.

Microtea Sw. (du grec "mikrotes ", exiguïté, petitesse, ̀̀ cause de la petilesse de ses organes floraux.)

M. debilis. Sw, M. à tiges l'aibles. Vulgo : Ierbe au long case. Iam., Ill., t. 182; Sw., Fl., t. 10, analys. - Herbe amnelle ou bisamuelle, complètement couchée, rampante, souvent radicante ì la base. Tiges nombreuses, flexibles, linéaires. Feuilles d'un rert très clair, petites, ovales, rétrécies en un court pétiole. Fleurs d'un blane mat, très petites, en petiles srappes spiciformes simples ou bifurquées, allongées, portant souvent d'autres petites branches accessoires. Fruit sec, ovale, ruguleux, de la grosseur diune tète d'épingle. - Abondant dans les champs en friches, autour des maisons de

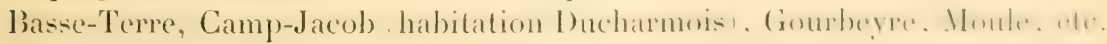
$[\mathrm{N} \circ 2401$.

Martixique. Vulgo : Marie-périne. - Jouil d'une grande répulation commo plante médicinale: on emploie le suc contre les maladies d'yeux el aussi en

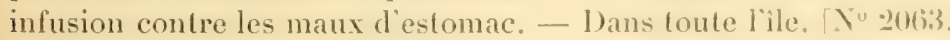

Rivinia L. (dédié par Limné à Augustin Quirinus Rivin, de Leciprign, holaniste et auteur d'importants ourrages de botanique.)

R. laevis L., R. humilis L.; Lam. Ill., t. S1, I. 2; Rivinia il tenilles listes. Vulgo: Herbe blanche, liane blanche. - Arbisseau ornemental, haul de $30 \mathrm{~cm} ., 1 \mathrm{~m} .20$, droit, rarement un peu samenteux, it branches herbacés.

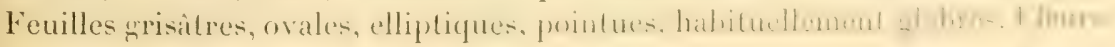

Düss. - Plantes Guadeloupe et Lartinique. 
petites, d'un blanc terne, rarement rosées, en petites grappes terminales; baies grobuleuses, d'un beau rouge vif', plus petites qu'une graine de poivre. - Abondant dans les broussailles de la basse et infra-moyenne région. Fl. en tout temps. - Basse-Terre, Grande route de la Basse-Terre à Gourbeyre. [No 2398 a.] - On rencontre une variété à f'euilles couvertes de duvet. [No $2398 \mathrm{~b}$.

Martingle. Vulgo : Ierbe de Saint-Domingue, herbe Grand-Jean. Abondant: Case-Pilote, Saint-Pierre, Marin. Alt. 0-350 mèt. [No 2064.]

R. oclandra L., Rivinia à 8 étamines. Vulgo: Murette, liane-barrique, boisà-terre (au Moule). - Arbrisseau-liane s'élevant sur les arbres les plus grands et jetant de tous côtés des rameaux qui pendent ensuite, se courrent de fleurs et ofrent un beau spectacle. Tige noire, de la grosseur d'un bras d'homme, couverte d'aspérités el de lenticelles blanchâtres. Feuilles ellipliques-lancéolées, pointues au sommet, luisantes. Fleurs d'un blane légèrement jaunâtre, odorantes, altirant des nuées d'insectes, en panicules lâches, larges, très nombreuses; baie très noire à la maturité, ovale-globuleuse, de la grosseur d'une graine de poivre. - Fl. de février en mars. - Dans le pays on prend les tiges, on enlève l'écorce, on les fend en feuillets minces qu'on unit avec un couteau et on s'en sert pour empailler les dames-jeannes. - Abondant dans la basserégrion. - Aime les endroits sees et rocailleux: Basse-Terre, Le Baillif, ete. Alt. 0-100 mèt. [ No 2399.

Martinique. Vulgo: Laine a barriques. - Abondant près de la mer. FondCoré, Prêcheur, Boulevard de Saint-Pierre, etc. Alt. 0-110 mèt. [Nu 1226.]

Petiveria L. (dédié par Linné à Jacques Pétiver, phamacien de Londres, collectionneur passionné d'objets d'histoire naturelle, qu'il a déerits el dessinés en mars 1718.

P. alliacea L., Péliver à odeur d’ail. Vulgo : Danday, derant-nègre. Dese., vol. V, t. 374, p. 265. - Est connu dans les pharmacies sous le nom de racine de Pipi. - Virace par ses racines el le bas de la tige, herbacé par le haut, droit, haut de $50-95 \mathrm{~cm}$. Racines fortes, pivotantes, blanches en dedans, grises en dehors, fibreuses, pénétrant profondément dans la terre. Feuilles elliptiques ou oblongues, pointues au sommet el à la base. Fleurs d'un blanc pâle, en grappes allongées, terminales, infléchies. Fruil see, de la forme d'une graine d'aroine, mais plus petit, légèrement velu. - Toutes les parties de la plante, surtout la racine, exhalent une odeur forte el pénétrante, peu agréable, qui rappelle celle de l'ail : on s'en sert pour écarter les insectes qui attaquent les habits et les étolles de laine. Les feuilles, les tiges et les racines sont diuréliques: on les emploie contre la pierre el autres maladies de la vessie; la plante tout entière contient du soufre, et comme telle elle guérit la gale; elle est en outre vésicante, antispasmodique et vermifuge. Descourtilz, loco cit., la met dins la calténorie des antispasmodiques fétides. - Abondant dans les 
endroits ombragés, le long des routes el dans les terres incultes de la basse-

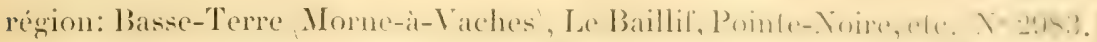

Martixieue. Vulgo : Arrada, herbe-aux-poules de Guinéc. - Abondant.

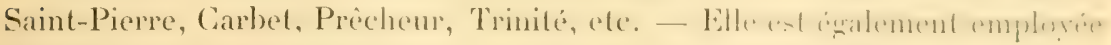
comme diurétique et sudorifique. - Alt. 0-150 mèt. [No 2065.]

\section{DIX-huttì̀me Fanhle. - CHÉNOPODÉES.}

Chenopodium L. (formé du grree " chen ", oie, el "podion ", pied, it cause? ders feuilles palmées de quelques espèces.)

C. ambrosioides L., Ch., qui ressemble à l'ambroisie. Vulgo: Herbe-à-vers, semen-contra, thé du Mexique, Dese., vol. I, L.57, p. 245.-Vivace par la base, herbacé par en haut, droil, haut de $50-95 \mathrm{~cm}$. Branches lastigiées. Fentles lancéolées-oblongues, ou elliptiques-oblongues, les infórientes simuine-dentées. Fleurs vertes, en épis axillaires el leminaux, nombreux, oceupant plus de la moitié de la lige el formant dans leur ensemble une panicule allongée. feuillue, fastigiée. - Toutes les parties de cette plante exhalent une odeur liople qui noest pas désagréable; sa saveure est aromatique ef apploche de colle du cumin; elle exude sur toute sa surface un suc balsamique, gluant et résineux, qui écarte tous les insectes : on 's'en sert comme sudorifique el vermiluge. Descourtilz la place aussi dans les remiluges. Se plante autour des matisons: pour qu'on l'ait facilement sous la main. - Abondant dans toute l'île: Basse-Terre, Gourbeyre, etc. [No 3089.]

Martixique. Vulgo : Herbe-ì-vers, semen-contra, sert aux mêmes usages qu'ì la Guadeloupe. - Abondant. [No 2059.]

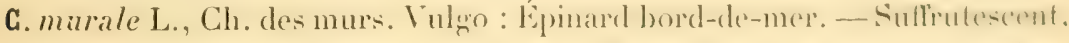
droit ou plus ou moins couche, haut de $10-70 \mathrm{~cm}$. Racine vigoureuse, pivertante. Feuilles deltoüdes, sinuées-dentées, tronquées ì la base, pointues au sommet, glauques en dessous. Fleurs vertes, en petites grappes interrmplues. laxillaires el terminales. - ()riginaire de l'Europe. Peu répandu, Mnule-ur les décombres du bord de mer). [Nos 3090 et 3509.$]$

N'existe pas à la Martinique.

Boussingaultia II. B. idédié à Bousingaull, célibere naluraliste el agroneme français.)

B. leptostachya Moq., B. à épis minces. Vulgo: Guérit-tout - Lianc très

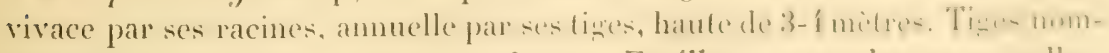
breuses, très minces, flexibles, tombantes. Feuilles un peu charmues, molles,

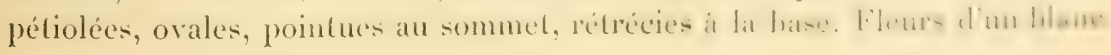


terne, en racèmes très nombreux, sourent très allongés, pédonculés, naissant par 1-3 is l’aisselle des fenilles tout le long des tiges très encherêtrées. Après la floraison, les tiges disparaissent. Nous n'avons jamais trouvé des graines fécondes sur celle plante. Rhizomes cylindriques d'un diam, de 15$25 \mathrm{~mm}$., brun-noir et en dehors, blanes, mous en dedans, situés horizontalement dans la terre el à peu de profondeur. - Les feuilles el les jeunes tiges sont trés émollientes : on les emploie fréquemment surtout dans les bains lièdes. - Fl. de mars en mai, quelquefois en octobre et novembre - Assez abondant dans la basse récyion de lîle: Basse-Terre, Capesterre (Guadeloupe /, Moule,etc. [No 3088 .

Martinique. - Vulgo : Guérit-tout. - Abondant dans les haies et les broussailles du bord de mer et un peu dans l'intérieur. Alt. 0-80 mèt. - Arec les feuilles on fait sourent des cataplasmes émollients, - Carbet, CasePilote, Prêcheur, Saint-Pierre (dans les cours et les jardins). [Y' 87.

Batis L. (du grec "batos ", terme par lequel les Grecs désignaient plusieurs espèces de ronces dont les fruits sont ramassés, allusion aux fruits syncarpés, propres à l'espèce suivante.)

B. maritima L., Batis du bord de mer. Vulgo : Herbe-à-crabes. Desc., vol. VII, t. 496 ; Jacq., Sel. stirp. Americ. hist., t. 40, f. 4.—Vivace, à racines fortes, radicantes, tige ì base ligneuse, herbacée par les extrémites, d’abord droite, ensuite infléchie, sourent presque conchee, haut de $70 \mathrm{~cm}$. it $1 \mathrm{~m}$. 60 . Feuilles succulentes, oblongues, linéaires, planes en dessus, convexes en dessous. Fleurs diö̈ques, en petits chatons très rapprochés placés tout le long des branches. - Vit à la Martinique en société dans les endroits inondés par l'eau de mer où il forme quelquefois des fourrés presque impénétrables. Trois-Ilets (en bas du bourg à côté de la route allant à la livière-Salée. - Abondant. Sainte-Anne habitation les Anghlais près de la mer). [No 2060.] - Nous ne l'avons pas trouvé à la Guadeloupe.

DIX-NeUVì̀e FAMILLE. - AMARANTACÉES.

Celosia L. (du gree "kêleos .), desséché, brûlé, parce que les fleurs ont l'air d'être desséchées.)

C. argentea L., Célosie argentée. Vulgo : Grande immortelle, grande Margarite. - Annuel, très droit, haut de $60 \mathrm{~cm} .-1 \mathrm{~m}$. 80, selon les terres; à ligne subligneuse a la base, striée, blanchâtre. Feuilles glabres, habituellement lancéolées, pointues au sommet, rétrécies à la base. lileurs en épi compacte, oblong pointu au sommet, blanc argenté ou rosé. 1)ans les pieds zras on trouve souvent plusieurs épis. - Cultivé dans les parterres comme plante d'ornement et dans presque tous les cimetières de lỉle, où elle se multiplie ì 


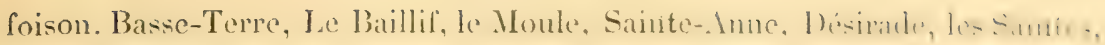
etc. $\left[\mathrm{N}^{\circ} 2805.\right]$

M.ntriere. Vulgo : Amarantine, immortelle błanche, immorledle rentz... - Dans les parteres et sur les cimelieres. Saint-Pierre, Cimbet, Marin, we. [No 1055.]

C. nitida Vahl., paniculata W'. S1., L. 91, f. 1.; C. Célosie brillante.Arbrisseau haut de $40 \mathrm{~cm},-3 \mathrm{~m}$. et davantage. Quand il se trouve isolé, il

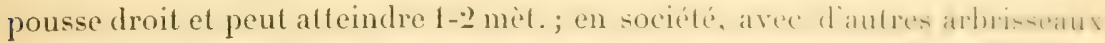

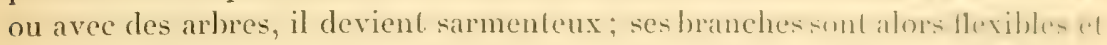

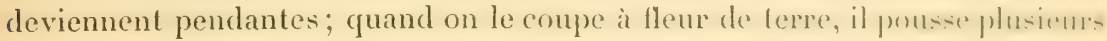
branches; ses racines premnent un grand developpement, el il communter it tleurir à une hauteur de $30 \mathrm{~cm}$. Feuilles peliles, alternes, ovales, acumines, rótrécies à la base. Fleurs entourées de bractées noiratres, husantes, dispusées en épis courts, nombreux, axillaires et terminaux. - Peu répandu. Abondant dans les endroits sablonneux al boises du bord de mer entre PortLouis et l'Anse-Bertrand. [No 3308.$]$

Martivique. - Très rare. Je n'en ai trouvé que quelques pieds sur le bord de mer de la Pointe-Salomon. [No 1043.]

Chamissoa Kith. (dedié par Kunth ì L. Charles Mlabert de Clamisso, ne a Boncourt en Champagne; fit, en 1815-1817, avec Kiotzbue, un royage autour du monde, mort à Berlin, 1781-1838.)

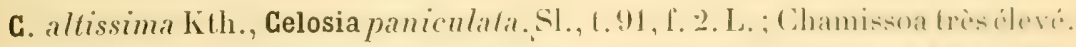

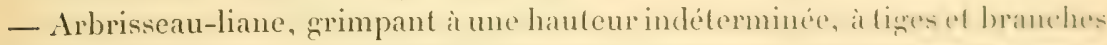
striées, anguleuses, a branches herbacées, pendanfes. Fenilles males, puintues: lessupérieures, ovales-lancéolées. Fleurs jaunatre-doré, en épismombrems. axillaires et terminaux, formant ensemble une larece panicule feuillue. - Trì rare. De celle espece je nai trouvé que deux pieds sur les terene de l'hahilittion Litté au Parnasse. - Fl. en juin, juillet, août. [No91.]. - N’existe pas à la Guadeloupe.

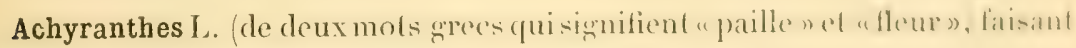
allusion à la couleur de paille des enveloppes florales.)

A. aspera D.; Achyranthe rude. Tulgo: Queue-de-rat, collant, gendarme

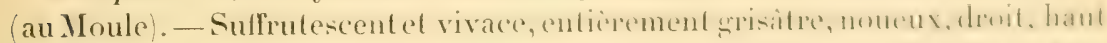

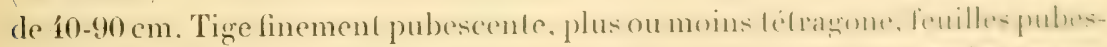

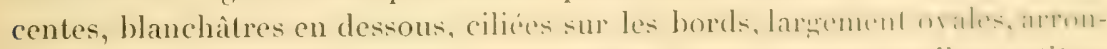
dies au sommet, rétrécies en coin à la base. Fleurs presque sessiles, pelites,

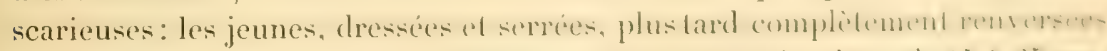

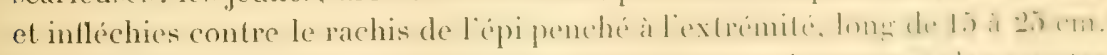

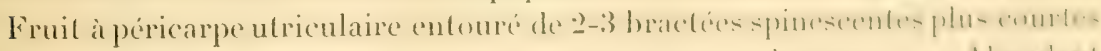

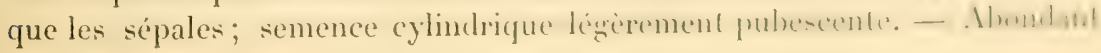


jusqu'à une altitude de 400 mèt. : Basse-Terre, Le Baillif, Deshaies, etc, Aime ces endroits. [No 2803.]

Mrantraque, Yulgo: Queue-de-ral. - Très abondant aux environs de Fortde-Frnnce College, Fort-1)artenson, Carénage, etc.). Moins abondant it Saint-Pierre, [No 2056.]

A. argentea Lam,; Achyranthe argenté. Vulı̧o: Grand-queue-de-rat. Grandcollant, - Annuel, à base suffrutescente, haut de $90 \mathrm{~cm}$, à $1 \mathrm{~m}$. 40 . Tige remplic de moelle, noueuse et renflée aux entrenoxuds, cylindrique dans le bas, obtusément quadrangulaire dans le haut. Feuilles golabres ou très légèremenl pubescentes, larges, ovales, rétrécies à la base, d'un vert très clair: les jeunes, lortement pubescentes et argentées en dessous. Fleurs comme dans le précédent, mais ì calice et à bractées plus allongés, plus luisants, disposées en épis axillaires et terminaux dont le plus long mesure jusqu à $35 \mathrm{~cm}$. Rare. Cà el lì dans les broussailles des environs de la Basse-Terre (Morne-ilVaches, forl Richepanse). - Gelle espèce, que Grisebach, Flora of W. Jrilish $I s ., p .62$, considère comme une variété du précédent, en est tout ì fait différente par sa rareté, sa taille, la couleur, l'enflure des noeuds, la forme des feuilles, la longueur des épis. [No 2804.]

Cyathula BI. (du gree " kuathos ", en latin " cyathus ", gobelel, parce que les étamines adhérentes à la base forment une sorte de gobelet.)

C. prostrata Bl.; Cyathule couchée. - Herbe amuelle, droite par le haut, couchée à la base, haute de $40-60 \mathrm{~cm}$., le bas de la tige eylindrique, te haut sillonné, à angles et légèrement pubescente. Fenilles opposées, ovales, pointues, rétrécies à la base en un pétiole court. Fleurs vertes, très petites, en épi interrompu longuement pédonculé, penché au sommet. - Extrèmement rare. Je n'en ai trouvé que quelques pieds dans un endroit très ombragé du Fort-Saint-Pierre. [N 797.] — Je ne l'ai pas rencontré à la Guadeloupe.

Gomphrena I. (du mol changée "Gromphaena s de Pline, XXVI, 23, pour désigner l'amarante à trois couleurs, espèce voisine de notre plante.)

G. globosa L., Gomphraena ì tète ronde. Vulğo : Marguerite, immortelle. Desc, vol. V, 1. 3:0, p. 60. - Herbe annuelle, grise ou blanchâtre, d'abord droite, ensuite penchée el presque diffuse, à branches étalées, haute de 1.5$50 \mathrm{~cm}$. Tiges nombreuses, glabres, nouenses, tricholomes. Feuilles opposées, elliptiques ou obovales, quelquefois lancéolées, pubescentes, ciliées sur les bords, mucroncess au sommet : les jeunes, fortement pubescentes el aryentées en dessous. Fleurs à 5 sépales colorés, persistants, entourés de 3 bractées, ramassées en capilules, prandes, blanches ou blenes; élamines 5 , il filets rémis; styles, stigmates; 2 capitules portés sur de longrs pédoncules et entourés à la base de 2 braclées foliacées, vertes, apprimées, opposíes; pédoncules longs de $15-20 \mathrm{~cm}$. Fruit a péricarpe utriculaire, entouré de laine blanche. - In 
se sert de cette plante pour faire des lisanes rafraîchissantes; Descourlil loco cil., la met dans les rafraîchissantes aqueuses. - Orighinaire des Incles orientales, cultivée dans les parterres, sur les tombeamx domestiques ot hes cimetières publics, où elle se reproduit facilement : Basse-T'erre, VieuxFort, etc. $\left[\mathrm{N}^{\circ} \mathbf{2}\right.$. 88 .

Martixique. Vulgo : Marguerite blanche, margnerite blene. - Dans les parterres et sur les cimeticres : Saint-Pierre, Carbel, ele. [1, 20,5)

Iresine L. (du gree " eiresioné», branche d'olivier entourée de laine, quion portait solennellement dans les processions, ici pour l'aire allusion au duvet laineux qui entoure les enveloppes de la fleur femelle.)

I. celosioides Moq., Irésine à l'euilles de Célosie. Vulgo : Kerbe-colon. Sl., t. 90, f. 3. - Tantôt amnuel, tantôt vivace par la base, droit quand il se trouve seul, sarmenteux quand il vit en socićté avec des arbrisseaux nu des arbres, à tige et branches grêles, très fragiles, haut de $60 \mathrm{~cm}$, à $1 \mathrm{~m}$. 80 . Fleur's diö̈ques ou polygames, blanchâtres, petites, à jo sépales dans la

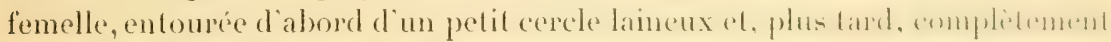
enveloppée de laine blanche; étamines 5. Épis très courts el très mombreux, axillaires et terminaux, formant ensemble une large panicule non leuillue. - Assez abondant dans les haies el les broussailles de la basse el inlinmoyenne région. - Les gens du pays emploient cette plante dans la médecine domestique. On se sert des jeunes tiges et des leuilles pilées en gruise de sinapismes; on les met également dans les bains quion domne aux hydropiques. - Basse-Terre (Morne-ì-Vaches), Moule, Gozier, etc. All. (0-300 mèl. $\left[N^{\circ} 2802,\right]$ - Fl. de mai en septembre.

Martinique. Vulgo : Zerbe-Jeai (a Case-Pilote). - Abondant dans les haies et les broussailles: Trou-Vaillant, Case-Pilote, Morne (Morne-Cinmmicr), etc. [No 1056 .

I. elatior Rich.; Irésine plus élevé. Vulgo : Zerbe-colon. - Annuel el sonvent vivace par le bas, droit, ì lige unique, grèle, très fragile, souvent sarmenteuse, haut de $75 \mathrm{~cm} .-1 \mathrm{~m}$. 70. Feuilles lancéolées, effilées en pointe,

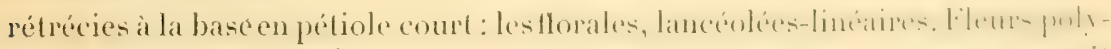
games, blanchâtres dans la femelle, les sépales d'abord entourés par un petil cercle laineux et ensuite enveloppés de laine blanche, disposées en épis très courts, très nombreux, dont l'ensemble forme une large panicule leuillus, pyramidale. - Assez abondant dans les teres incultes, pierreuses et calcaires de la basse région. Environs de la Basse-Terre, bords de l'embouchure

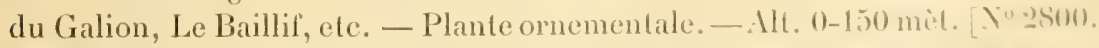

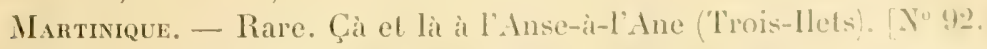

I. Herbotii Hook. - Plante très ornementale, herbacéx, haule de l-2-2 mi.l.. remarquable par ses leuilles panachées, arrondies. - Est sourent cullivic dins les jardins. - [Guadeloupe : $\mathrm{X}^{\circ} 2801$; Martinique : X" 1011. 
Mogiphanes Mart. (du gree " mogis », à peine, et " phainein », paraîlre, pour faire allusion à la forme exceptionnelle du receptacle de la fleur : braclées séparées des sépales par un entrenocud.)

M. Jacquini Schrad.; Mogiphanes de Jacquin. Vulgo : Bouton blanc. Frutescent par la base, herbacé par le haut, d'une élération de $90 \mathrm{~cm} .-$ $1 \mathrm{~m}$. 90. 'lige cylindrique dans le bas, renflée aux entrencuds, pubescente, verte, régulièrement trichotome, le plus souvent droite, grabre. Feuilles glabres, orales-elliptiques, cunéiformes à la base. Fleurs d'un blanc terne et nacré; à 5 sépales séparés des bractées par un petit entrencud; à 5 étamines soudées en un tube campanulé, disposées en capitules globuleux, portés sur de longs pédoncules pubescents. - Peu répandu. Assez abondant à CasePilote (environs du bourg), plus abondant dans les savanes des hauteurs du Fond-Layette, où il forme quelquelois des fourrés épais. Alt. 10-280 mèt. Io 791 .

Philoxerus 12. Br. (du gree "philein ", aimer, et " xeros ", sec, allusion aux enchroits oì pousse la plante.)

$\mathrm{P}$. vermicularis $\mathrm{R}$. Br. Iresine vermiculata Moq.; Philoxerus, qui rampe comme le ver. Vulgo : Amarante bord-de-mer. - Herbe vivace, radicante, couchée, rampante, d'une longueur indéfinie. Tige verte, cylindrique, succulente, légèrement renflée aux nouds, trichotome. Feuilles presque linéaires, épaisses, concaves sur le dos ou (selon les endroits) oblancéoléeslinéaires, se rétrécissant vers la base. Fleurs d’un blanc terne, nacré, à 5 sépales, dont les 2 intérieurs sont plus étroits, tous supportés par une petite toufle de laine; style bipartite; capitules globuleux d'abord, ensuite allongés et ovoüdes, quelquefois réunis par 2- $\mathfrak{t}$. - Très commun sur les plages sablonneuses du bord de mer ou sur le bord des mares et flaques d'eau de l'intérieur: Désirade, Moule, Sainte-Anne, les Saintes (Terre-de-Haut), Marie-Galante. $\mathrm{N} \times 2798$.

Martixique, Vulgo : Amarante bord-de-mer. - Abondant : Rivière-Pilote, Sainte-Anne, 'Trinité, Caravelle, etc. [No 2058.]

Lithophila Sw. (du grec " lithos ", pierre, et " philein ", aimer, parce que ces plantes poussent sur les pierres.

L. muscoides Sw., variété longifolia. Lithophile moussu à longues feuilles. - Petite herbe vivace, grisâtre, complètement couchée, longue de $5-15 \mathrm{~cm}$. Racine pivolante, souvent très longue, forte, blanche. Tiges nombreuses, filiformes, glabres, trichotomes. Feuilles très variables, quant à la longueur, linéaires-oblancéolées, obtuses-pointues au sommet, se rétrécissant ver's la base et portant une petite toufle de laine. Feuilles inférieures rosulées. Fleurs d'un blane terne, à 3 sépales, dont les 2 intérieurs sont plus étroits, tous les 5 supportés par de petites touffes de laine blanche à 2 élamines; capitules 
petits, ovoüdes, pédonculés. - Assez abondant sur les rochers arides, nus et souvent arrosés par l'eau de mer: Désirade (les Galets), Saint-François, Marie-Galante, etc. 「No 2799.

Alternanthera Forsk. (du latin " alternus ", alterne, et " anthera ", fleur, parce que, dans beaucoup d'espèces, les étamines fertiles alternent avec les étamines dépourvues d'anthères ou avec les dents de la cupule.)

A. sessilis R. Br., Alternanthera it fleurs sessiles. - Herbe annuelle, branchue, couchée, radicante el rampant à une distance indéfinie. Jeunes tiges habituellement munies de 2 lignes de poils. Feuilles glabres, tantôt nettement obovales, tantot oloovales-lancénlées, obtusément pointues au sommet, se rétrécissant à la base en un court pétiole. Fleurs à 3 étamines fertiles, les 2 autres dépourvues d'anthères; a 5 sépales; en capitules d'un blanc terne, petits, sessiles à l'aisselle des feuilles. - Herbe fourragère. - Dans les savanes herbeuses, humides, le long des routes. Basse-Terre, Gourbeyre, Trois-Rivières. Alt. 10-700 mèt. [ $\left.\mathrm{N}^{\circ} 2795.\right]$

Martixique. Vulgo : Magloire. - Dans les savanes herbeuses et dans les endroits cultivés. [ $\mathrm{N}^{\circ} 88$. $]$

A. paronychioides St. Hil., Alternanthera, qui ressemble au Paronychia.Vivace, complètement couché, radicant, rampant à une distance indéfinie, formant de longues trainées blanches sur la terre. Tiges laineuses anx entrenouds, le plus souvent légèrement poilues. Feuilles réunies par 2-4 aux entrencuds, et jamais de mème dimension, oblancénlées-efliptiques nu obovales-elliptiques, ou simplement obovales, se rétrécissant tantôt brusquement, tantôt lentement, en un pétiole plus on moins long. Fleursen capitules réunis par 2-5, d'un blanc nacré intense. - Peu abondant. Habiluellement sur les bords des mares d'eau douce près de la mer ou dans les endroits marécageux, où il forme quelquefois un vrai gazon : Saint-François, Gozier, Capesterre (Guadeloupe). [ [No 2794.]

Martineve. Vulgo : Magloire blane. - Rivière-Salée, Ducos, Anses dirlets. [Nos 2147 et 800 .]

On cultive généralement en bordures, dans les parterres el jardins, une variété de Alt. paronychioides à feuilles crispées, panachées de vert, de rouge et de bronze, originaire du Brésil [Guadeloupe: Xo.2797; Martinique : $\mathrm{N}^{\circ}$ 798], avec une variété dégénérée, plus forte, à feuilles sans panachures [Guadeloupe : No 2797 ; Martinique : No 799.]

A. achyrantha R. Br.. Altemanthera it feuilles d'Achranthes. Dill., Eleth., I, t. 7, f. 7. - Annuel ou vivace, rampant, radicant, d'une longueur indéfinie. Tige lénerement comprimée, munie de poils blanchateres, tubercules it la base: sur les jeunes feuilles, poils blanes, plus lonews. Fenilles obovales ou ovales, glabres, munies de points très nombreux. Fleurs en capitules blancs, whohn- 
leux: sépales 5, laineux sur le dos, rignides, à 3 nerrures dont la principale, carence au sommet du sépale, se termine an une pointe rigride. el dont les 2 latérates se joignent il la principale presque an milieu du limbe. calice entibrement entoure de poils laineux. - Abondant dans les saranes herbeuses ef entre les paves de certaines rues de la Basse-Terre: Vieux-Habitants. Le Baillif, Trois-Rivières. $\left[N^{\circ} 2796\right.$.

Mantingers. - Hondant entre les pavés des rues de la Consolation; dans les jardins mal tenus, etc. $\left[\mathrm{N}^{\circ} 2148\right.$.

Amblogyne Ral. du uree " amblus", obtus, el "gूuné ", fenme, allusion à la nature de l'ovaire.)

A. polygonoides Ral., Amblogyue ressemblant au Polygonum. Yulge : Petit épinard. S1. 1. 92. f. 2. - Herbe vivace par la base, très branchue, d'abord droite, ensuite diffuse, haute de 15 i $25 \mathrm{~cm}$. Tige striée, branches horizontales ou tombantes. Feuilles pelites, ressemblant ì celles de l'épinard du pays. Fleurs monoïques: lesmâles, à 3 élamines et à 3 sépales: lesfemelles, à calice 5 -fide et ì lube campanulé, entourées à la base de j-6 bractées aignës, disposies en petites grlomérules tout le long des branches à l'aisselle des feuilles: ovaire à une seule semence, noire, polie, biconrexe, très petite. - Peu répandue. Désirade, en assez grande abondance aux environs du bourer et surtout dans la petite savane du Presbytère. [No 2793.

N'est pas à la Martinique.

Amarantus I. I du gree "amaraino ", je ne thétris pas, pare que la plupart conservent leurs couleurs brillantes après la mort.)

A. spinosus L., Amarante épineuse. Vulgo: Zépinard-piquant, épinard rouge, zépinard-cochon. Dese, vol. 1, t. 114, p. 41 figure trè mauraisei. Annuel ou suffrutescent, droit, à tète penchée, haut de $50-90 \mathrm{~cm}$. Tigne grosse, succulente, striée, snuvent rouge vers le sommet. Feuilles rhomboïdales ou rhomboïdales-lancéolées, longuement pétiolées. Fleurs vertes, polyzames ou monö̈ques, à 3-5 sépales, à 2-3 styles : les mâles, habituellement en panicule terminale, formée d'épis axillaires et terminaux; les femelles sont plus basses, axillaires, ramassées en capitules, à la base desquels se trouvent 2 piquants longs, droits ou en lorme d'alene; quelquelois ils font défaut. - Plante utile, dont les cheraux et les moutons sont friands. Les jeunes rameanx et les feuilles se mangent cuites ou en guise de salade. Toute la plante est douée des vertus rafraichissantes. Descourtilz, loco cil., la place dans les rafraichissantes aqueuses. Il dit quelle agit sur les voies urinaires ef favorise la sécrétion de l'urine par le nitrate de potasse qu'elle contient. - Asse\% abondant dans les environs de la Basse-Terre Mome-íVaches, Le Baillif, ete. - lime les endroits fertiles et graveleux. No 2791.

Martixeres. Vulgo : Zépinard-cabrit, - Peo répandu, Bord de mer du 


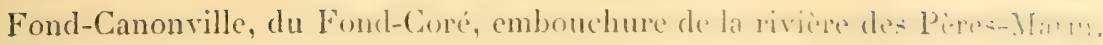
$\left[\mathrm{N}^{\circ} 795.\right]$

A. tristis L., Amarante à tête penchée. Vulğo : Zépinard du pays. -

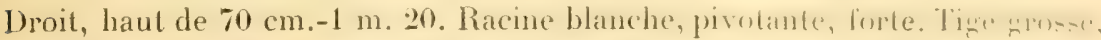
succulente; feuilles rhomboüdales-ovales, longuemenl pilioles, at mmmel légèrement arondi. Fleurs polygames, en épis axillairect terminaus. limmant

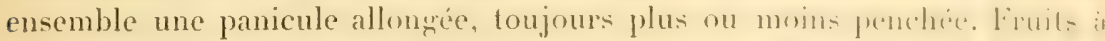
déhiscence pyxidaire comme dans les pourpiers. - Trisabondant dinn le:

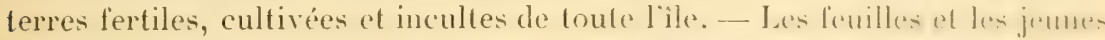
tiges se mangent en salade ou cuites; la plante entiere jouil des mimes purpriétés médicinales que la précédente. - Basse-Terre. Ill. 11-6(m) mid. [No 2792.]

Martmeqe. Vulgo : Képinard de France, zépinard du pays. - Mumdanl dans toute lî̀le. - On se sert des racines pilées el mises dans l'eau livele on lavement contre la constipation. [ $\mathrm{N}^{\circ} 796$.

On cultive dans les parterres différentes variétés de l'Amarantus candirlus: L., très ornementales, qui poussent avec une grande facilité.

\section{vixgtiÈme FAMLLE. - NYCTAGINEES.}

Mirabilis L. (du mot latin " mirabilis ", admirable, paree que les lleurs sont très belles et exhalent une odeur agréable.)

M. Jalapa L. confondue longtemps avec la plante que dome le vrai jalap); M. dichotoma L. Desc., vol. II, 1. 139, p. 192. Vulyo: Belle-de-nuil. - Vivace par les racines, à tiges fermes, à nocuds renflés aux aissulles des feuilles, blanches ou rouges, régulierement dicholomes-étalés, hatules de 40-90 cm. Feuilles opposées, entières, ondulées, ovales, vertess des deux côtés, légèrement glutineuses, ciliées sur les bords: les florales, plus petites que les caulinaires. Fleurs grandes, en entomoir, en cymes ombelliformes, terminales, blanches ou violetles, ou jannes, ou panachées, mulutrées par un involucre persistant, a 5 lobes, 6-7 fois plus court que la corolle. Fruit noir, ruguleux, rond, à périsperme blanc, farinemx, copienx. La racine est pivotante, tubériforme, volumineuse, blanche en dedans t'l couverte en dehors d'une écorce noire et mince. - De sa nature, celte racine est purgative-drastique, et cest aussi dans celte catimoric que l)ucourtilz, loco cit., la place : il dit entre autres choses que, prise a fircid et en

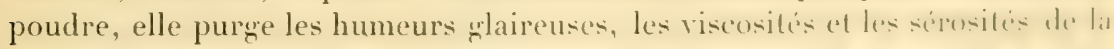
tête, de la poitrine et des articulations, et la recommande contre la soulle.

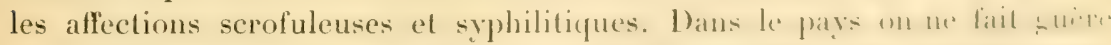

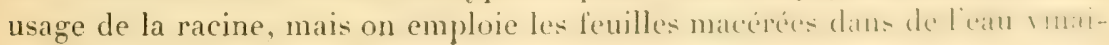


grée en cataplasmes contre les luxations et les foulures. - Assez abondant dans la basse rérion. - Fl, presque toute l'année, mais surtout dans les mois de juillet et novembre. - Basse-Terre, Moule, Trois-Rivières. etc. [No.2887.

MLrtixique. Vulgo : Belle-de-nuit. - Abondant. Saint-Pierre, Fort-deFrance. $\left[\mathrm{N}^{\circ} 2102.\right]$

Boerhaavia I. (dédié par Linné au Hollandais Hermann Boerhaave, né en 1668, à Leyde, médecin, chimiste et botaniste célèbre, ami et admirateur de Limné. De ses nombreux écrits deux seulement ont trait à la botanique : Index plantarum horli Lugduno-Batavi et Vaillanti botanicon Partsiense.)

B. erecta L., B., droit. Vulgo : Patagon (parce que les feuilles sont argentées en dessous et rondes comme le patazon, pièce daryent espagnole, valant environ 1 franc). - Herbe annuelle ou suffrutescente, plus ou moins droite, à racine pirotante, forte, à tige simple, délicate, légèrement tétragone, ne dépassant guère $80 \mathrm{~cm}$. d'élévation. Feuilles petites, ovales ou ovalesoblongues, pointues, ondulées, d'un blanc argentin en dessous. Fleurs très petites, pourpre pale, en ombelles terminales et axillaires, formant ensemble une panicule allongée. Fruil sec, visqueux, obconique, entièrement renfermé dans le calice, qui est devenu dur et s'est fermé au sommet, pourvu de 5 côtes saillantes. - Abondant dans les terres sablonneuses, cultivées ou abandonnées, dans les fossés, le long des routes du littoral. - Dans le pays on se sert de celte herbe comme diurétique el sudorifique. - Basse-Terre, Le Baillif, Sainte-Amer, Moule (tres abondant dans les terres calcaires), Désirade, Marie-Galante, etc. [No 2172.]

N'existe pas ì la Martinique.

B. paniculata Rich., B. diffusa Sw.; B. à fleurs en panicules. Vulgo : Valériane, patagon. - Vivace par ses racines à liges nombreuses, d'abord couchées, ensuite plus ou moins ascendantes, noueuses aux aisselles des feuilles, hautes de $60 \mathrm{~cm} .-1 \mathrm{~m}$. 50. Racine pivotante, allongée, profondément et rerticalement enterée, grise. Feuilles opposées, ovées, arrondies an sommet, souvent ciliés sur les bords, blanchatres, argentées en dessons. Fleurs pourpres, en petites crmes ombelliformes, portées sur des pédoncules grềles. axillaires ef terminales, constifuant ensemble une large panicule, it branches latéralement etalées. Fruil arrondi an sommet, à so coles pourves de glandes visqueuses. - Abondant dans les terres cultivées et meubles sablonneuses, sur les vieux murs, sur les décombres du littoral de toute lîle. [No 2173 .

Mantintele. Vulgo : Patagon blanc. - Abondant dans toute l'île. [ $\left.\mathbf{N}^{0} 2100.\right]$

B. hirsuta W., B. poilu. Vulgo : Patagon rouge. - Ressemble exactement au précédent quant au port, la forme et l'ampleur des feuilles; s'en écarte par ses tiges, ses branches et ses pétioles velus, rouges ou rougeâtres, ses furulles plus ou moins simues, moins blanches en dessous et légèrement pubescentes, ses flenrs rouge de sanğ. - Mème habitat que B. paniculata. - 
Les deux espèces jouissent dans le pays d'une haute réputation comme plantes médicinales; les leuilles el les racines sont stimulantes, fonicpues, vermifuges et surtout sudorifiques; la racine prise en poudre est en outre antispasmodique; les leuilles peurent se manger cuites en žnuse d'aphinards. [No 2174 .

Martineue. Vulgo: Palagon rouge. - Abondant. - On se sert de la racine contre les piqûres du trigonocéphale. $\left[\mathrm{N}^{\circ} 2099\right.$.

Pisonia L. (dédic par Plumier au Ifollandais Guillaume Pison, médecin el naturaliste de Leyde; fit en 1637 avec Maregraaf un royage au Brésil, mort en 1648 ; a écrit, avec ce dernier : Itistoria naturatis Brasilix.)

P. aculeati L., Pisonia à piquants. Vulgo : Croc-chien. Lam., Ill., t. 861; Sl., t. 167, f. 3, 4; Plum., éd. Burm., 1. 127. - Arbrisseau sarmenteux, pouvant s'élever à une grande hauteur, à lige de l'épaisseur d'un bras, à écorce brun noir, à rameaux pendants décussés-opposés, insérés à angle droit. Feuilles pétiolées, ovales, légèrement charnues, rétrécies à la base; pétiole muni, it la base, de 1-2 piquants, le plus souvent recourbés, aigus, perpendiculaires ì la branche. Fleurs très petites, polygames ou dioïques, vert jaunâtres ou noirûtres, en cymes compactes, ombelliformes, axillaires el terminales, pédonculées; calice petit, à 5 dents; étamines 8 . Fruit obovoïde, enveloppé du calice durci, à 5 côtes saillantes, garnies, dans touteleur longueur, de glandes globuleuses stipitées. - Les fruits, à cause de leurs glandes visqueuses, s'attachent à tout ce qui les touche. - Abondant le long des rivières, dans les halliers el endroils abandonnés de la basse région. - On en fait souvent des haies impénétrables. - Basse-Terre, Le Baillif, Deshaies, Pigenn, Trois-Rivières. Alt. 0-250 mètres; rare, au delà de cette altitude. $\left.\Gamma^{\circ}{ }^{\circ} 2171.\right]$

Martnique. Vulgo : Croc-à-chiens. - Abondant dans les endroits secs el chauds : Saint-Pierre, Prêcheur, Case-Pilote, Lamentin, etc. [ Iº $\left.^{\circ} 101.\right]$

P. subcordata L., Pisonia à feuilles presque en cour. V'uigo : Mapou gris. - Arbre de taille moyenne ou petit arbre, à trone vigoureux, peu élevé, de 40-80 cm. de diamèt., nu jusqu'à une hauteur de $2-3^{\mathrm{m}} 50$ seulement, ¿̀ branches horizontales, il fronde arrondie. lenilles coriaces, très vertes ull très glabres, en cocur, à sinus très ouvert. Fleurs diö̈ques, en cymes très arrondies, pédonculées, pédicelles courts; calice de la fleur màle, infundibiliforme, ¿t 5 lobes cour's; celui de la femelle, cylindrique-linéaire. Fruit sec, longr de $1 \mathrm{~cm} .$, cylindrique, aminci vers la base, muni, dans le dernier tiers supérieur, de 5 rangées de glandes stipilées. - A l'époque de la floraison, l'arbre perd complètenent ses feuilles, qui ntapparaissent quaprè lat chule des lleurs. Fl. en arril ou mai. - Le bois est noir et n'a aucune importance. - Asse\% abondant dans les terres seches de Port-Louis, de l'Anse-Bertrand, du Guricu. de presque tous les Grands-Fonds, de Marie-Galante, etc. [N०2172.] 
Il ne se trouve pas à la Martinique.

P. obtusata Sw., Pisonia à feuilles obtuses. Vulgo: Mapou blanc, mapou rouge. - Arbre de taille moyenne, à rameaux plus ou moins pendants, à fronde élancée, à écorce fendillée. Fenilles très vertes, flaccides, ovales, obtuses au sommet, rétrécies à la base, à nervures peu sensibles; pétiole court. Fleur's dioïques, terminales : les mâles, en cymes trichotomes et lonquenent pédonculée; fes femelles, en crmes plus ou moins allongées; calice de la fleur femelle charnu, mou, devenant plus tard pulpeux et formant une seule masse avec le fruit. Fruit oblong, d'abord très rouge, ensuite noir, traverse par 10 petits sillons longitudinaux sans ylandes. - Le bois est assez tendre et ne peut servir tout au plus que pour les constructions à l'intérieur. - Abondant dans les endroits boisés et secs, et dans les savanes du littoral du Vieux-Fort, des Tmis-Rivieres, de la Capesterre (Guadeloupe'. - 11. en avril ou mars. $\left.\Upsilon^{\circ} 2170.\right]$

Mantnique. Yulgo: Mapou. - Abondant au Prêcheur, au Fond-Coré, au Carbet, à Ducos, etc. $\mathrm{N}^{\mathrm{o}} 128$.

P suborbiculata IIems., Pisonia à feuilles presque rondes. Vulyo: Petitmapou. - Arbriseau élégant, peu branchu, nu dans le bas, haut de 2-2"' 50, à écorce grise et lisse. Feuilles petites, rondes ou légèrement obovales, whauques, tres brierement petiolees. Fleurs verditres, diöques, en crmes courles, liches, pédonculées, terminales. Fruit mou, pulpeux, evlindrique, rouge glauqque à la maturité. - Peu répandu. Je ne l'ai pas trouvé à la Guadeloupe.

Il n'existe à la Martinique que sur la crête du morne rocheux, près du bourg de la Rivière-Pilote. [No 1467.]

Les Bugainvillea spectabilis. W ild et fastuosa Hening. tgenre dédié a l amiral Bougainville, qui, en 1766-fig, a entrepris un royage autour du monde et qui a puistamment aide Commeron dans ses travaux scientifiques, lianes, originaires du lbésil. tres fortes, sarmenteuses, épinenses, il branches pendantes, it fleurs pourpre foncé ou pourpre clair, d'une abondance et d'une beauté éblouissantes; sont assez abondamment cultivées dans les deux îles.

viNgT-UYIME FAMLLE, - MALVACÉES.

Malvastrum .1. (ir. "de "malva ", mauve, et "astrum ", chtoile, allusion a la forme de la fleur.)

M. spicalum Gr., Malva polystachya Cav.; Malvastre ì fleur's en épis. Vulgo : Mauve d'Amérique. Diss., t. 20, f. 4; t. 138, f. 3. - Sullirutescent, droit, haut de $50-90 \mathrm{~cm}$., couvert, dans toutes ses parties, d'un duret gris; à 
racine forte et pirotante. Feuilles deltoüdes ou ovales, presque tronquées it la base, pointues au sommel, crénelées-dentées. Fleurs jaunes, petites, en épis nombreux, axillaires et terminaux : ces derniers toujours plus longs; calice à 5 lobes poilus, ovales, pointus, entouré de 3 feuilles involucrales aussi longues que les lobes du calice. Fruit à autant de loges ou de carpides juxtaposés qu'il y a de pistils, le plus sourent 11-15. - Peu répandu. - Fl. de février en juin. - Endroits secs, graveleux, près de la mer. Les Saintes (Terre-de-Haut, chemin du chameau), Pigeon et Bouillante. $\left[\mathrm{N}^{\circ} 3211\right.$.

Martixique. Vulgo: Mauve-savane. - Route du Marin au Vauclin. $\left[N^{\circ} 858\right.$.

M. tricuspidalum. 1.. Gr., Malva americana L. el M. coromandeliana Sw.; Cav. Diss., 1. 22, I. 2 ; M. à carpides à 3 piquants. Vulgo: Pain-doux, balaideux-heures. - Suffrutescent ou frutescent, le plus souvent droil, branchu, haut de 30-80 cm., à lige, branches, pétioles, inflorescence, et le dessous des feuilles couverts de longs poils gris et couchés. Feuilles vert clair, rhomboïdes-lancéolées, dentées en scie. Fleurs jaunes, larges, réunies par 3-5 ou solitaires, axillaires ou terminales. Feuilles involucrales 3 , linéaires; lobes du calice ovales, terminés en une longue pointe; pétales obcordés; carpides 10 , semences armées de 3 piquants, dont 2 placés au coin du sommet et le $3^{e}$ près de la base. - Extrêmement abondant dans toutes sortes de terrain de la basse et de la movenne région de l'île. $\Gamma^{\circ} 2333$.

Inntrique. Vulgo: Balai-savane. - Très commun dans toute l'île. On en fait souvent de gros balais, bons pour nettoyer les cours, les écuries, etc. $\Gamma$ ' 859 .

Noта. - Ces deux espèces ont l'écorce très fibreuse, dont on pourrait tirer profit.

Sida L. (du gree "sidé ", employé par T'héophraste, IV, 11, pour dénommer le Nymphaea alba L. C'est par erreur que Linné a adopté ce nom.)

S. carpinifolia L., Sida acula Burm., S. stipulata Car.; Sida à feuilles de charme. Vulgo : Balai-onze-heures, balai-midi. Cav. Diss., 1. 2, f. 3; 1. 3, f. 10, 11; t. 134, f. 1. - Sulfrutescent, haut de $40-90 \mathrm{~cm}$., droit, glabre dans le bas, légèrement velu dans le haut, ainsi que sur les rameaux. Feuilles elliptiques-lancéolées, dentées au-dessus de la base, nunies, à la base du pétiole, de deux stipules lancénlées, anssi longues on plus courtes que les pédoncules.

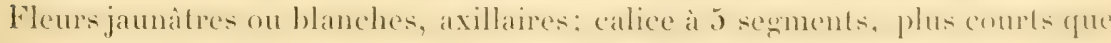
la corolle. Fruit à 10 carpides; semences grarnies de 2 piquants droits, dont chacun est muni, à la base, d'un petit piquant court et obtus. Ressemble au précédent par le port et les feuilles. - Très répandu dans la basse et l'inliramoyenne région de l’ìle. Basse-Terre, ele. [Xo 2338.

Martivique. Vulgo: Balai-onze-heures, balai-savane. - Environs de Saint-Pierre, Carbet, Morne-Rouge, etc. [N०860.] 
S. glomerata Cav., S. à fleurs aggglomérées. Vulgo: Balai-savane. - Suflrutescent el frutescent, haut de $70-90 \mathrm{~cm}$., à tige nue dans le bas, très branchue dans le haut, à branches très rapprochées, penchées à l'extrémilé el légèrement pubescentes. Feuilles petites, brièvement pétiolées, glabres, d'un rert très clair, finement dentelées: base du pétiole munie de 2 stipules larges, obliquement lancéolées, très accuminées, nerrées. Fleurs petites, jaunes ou blanches, sessiles, solitaires dans le bas des branches, agrolomérées et terminales dans le haut: bractées 3-4, lancéolées, linéaires, obliques; calice à 5 sépales; lobes de la corolle largement ovales, brusquement rétrécis en pointe fine. Fruit à 5 carpides grlabres, réticulés, munis de 2 pointes. - Peu répandu. Vit en société dans quelques savanes des hauteurs du fond Canonville, près de Saint-Pierre. [Xo 861.] - Nous ne lavons pas trouvé à la Guadeloupe.

S. ciliaris L. Sida cilié. Vulğo à la Désirade) : Balai-trois-heures, - Suffrutescent, haut de $5-30 \mathrm{~cm}$., tantôt très droit, tantôt diffus, très branchu, dès la base: it lige et branches presque nues jusquau sommet. Feuilles d'un rert jaunâtre, très pelites, oblongues, presque aussi longues que les pétioles, finement serretées au-dessus du milieu du limbe. Fleurs jaunes, axillaires, sessiles, solitaires ou réunies par deux. Feuilles involucrales 4-5̃, oblancéolées-linéaires, fortement ciliées, arec des organes accessoires, filiformes, ciliés; calice i 5 segments étroits, aussi longrs que les pélales; pétales jaunes, tachetés de noir ou de brun en dedans à la base: carpides 5, uberculeux, armés de 2 pointes très courtes et rigides. S1., t. 13\%, 1. 2; Car. 1)iss., t. 3, f.9. Ciest la plus petite espèce de Sida dans les Antilles. - Peu répandu. Désirade (route du Bourer à la Léproserie), où il forme gazon en quelques endroits. [ $\Upsilon^{\circ} 2770.1$

Martixieue. Vulgo: Petit-balai. - Peu abondant et peu répandu : SainteAnne (habitation les Anglais), dans un terrain pierreux et calcaire. [ $\mathrm{T}^{\circ} 86 \%$.]

S. jamaicencis L., Sida de la Jamaïque. I'ulgo : Balai-onze-heures. Car. Diss., t. 2, f. 5. - Sulfrutescent, plus ou moins droit ou diflus, haut de $70-95 \mathrm{~cm}$., à tiges grêles, nombreuses, couvert dans toutes ses parties d’un duvet soyeux et blanchâtre. Feuilles ovales, dentelées au-dessus de la base, obtuses au sommet. Fleurshlanchesaxillaires. presquesessilesou brièrement pédonculées. solitaires ou réunies par 2-4; stipules filiformes; calice à 5 lobes largement ovales et brusquement rétrécis en pointe molle; carpides 5 ; semences finement duvetées à la base et munies au sommet de 2 petites cornes droites. Fl. en arril et mai el en octobre ef novembre? - Les Saintes (Terre-deHaut, sur le chemin du Chamean), bord de la rivière des Pères. [No 3363.]

Ne se trouve pas à la Martinique.

S. spinosa L., variété angustifolia Lam.; Sida épineux. Iulgo : balaionze-heures. Cav. Diss., t. 1, f. 9; 1. 2, f. 2. - Vivace, haut de $80-85 \mathrm{~cm}$, droit, généralement peu branchu, à tige grêle, glabre. Feuilles petites, oblongues-lancélées, souvent lancéolées-linaires, dentelés andersus de leur 


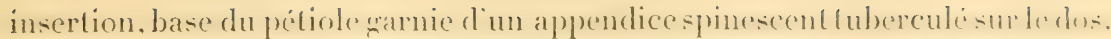
Fleurs jaune pâle, axillaires, solitaires ou réunies par 2-3; pédoncule de la

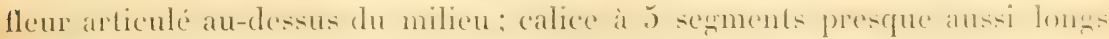
que les pétales. Fruit it 5 -8 carpides; semences légèrement tuberculées, glabres, armées de deux pointes allongées, filiformes, noires. - Abondant dans la région moyenne. Camp-Jacob, Matouba, hauteurs du Baillif, Désirade, etc. $\left[\mathrm{N}^{\circ} 3 \mathrm{H} 98\right.$.

Mantrigue. Íulgo: Balai-sarane. - Gros-Norne, Case-Pilote. [No S69.]

S. rhombifolia L.; Sida à feuilles en losange. V'ulgo: Balai-onze-heures. Cav. Diss., t. 3, f. 4, 8, 12; t. 131, f. 2. - Frutescent, droil, ne dépassant guère $90 \mathrm{~cm}$. d'élévation. Feuilles en losanges plus on moins réguliers, blanchâtres en dessous, dentelées au-dessus de la base, légèrement arrondies au

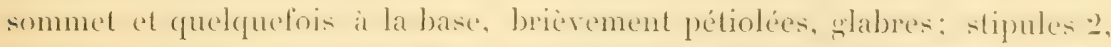

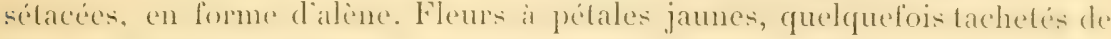
noir ¿̀ la base; à l'intérieur, le plus souvent solitaires, portées sur des pédoncules articulés atu-dessus du milieu el plus longs que dans toutes les espèces précédentes; lobes du calice ovales-ronds, brièvement pointus au sommel, plus courts que dans les autres espèces. Fruit à 8-12 carpides armés de 2 becs linéaires d'inégale longueur, veloutés à la base. - Abondant dans la moveme région: plus rare du cotédu littoral: Matouba, Vieux-Mabilant. Deshaies, ete. $\left[N^{\circ} 2339\right.$.

Martinique. Vulgo : Balai-dix-heures. - Abondant. Morne-Rouge, Calebasse, Parnasse, Gros-Morne. [No 864 .

S. rhombifolia L., variété minor. Vulgo : Balai-dix-heures. — Diffère de lespèce-trpe par ses feuilles constamment plus petites ses pédoncules plus courts et les lobes deltoïdes du calice. - Se rencontre dans le terrains secs et rocailleux. Vieux-Fort, Trois-Rivières. $\mathrm{N}^{\mathrm{o}} 2340$.

Mantixique. Vulgo : Balai-dix-heures. - Caravelle, Gros-Morne, Prêcheur, Marin (Morne-Gommier). No 863.

S. urens L., S. verticillata Cav.; Sida à poils, brûlants, Vulgo : Ortie-long. Car. Diss., t. 2, f. 1; t. 1, f. 12. - Suffrutescent, d'abord droit, ensuite sarmentenx. entierement courert de poils plus ou moins urticants, mais dent la piquure n'incommode pas, à branches grêles très cassantes. Feuilles neltement cordiformes, pointues, dentées en scie, dès la base, longuement pétiolées. Fleurs axillaires el terminales, brierement pédoneulées réunies par 2-s): pétales jaunes, habituellement munis d'une tache rouge, à la base, tube du calice à 5 angles saillants, lobes deltö̈les, poilus, dipatsant le fruit. Iinit à 5 carpides ruguleux, munis de 1-2 becs. - Peu abondant. Củ et lì dans les lisieres el les broussailles du lithoral. Buvirons de la baste-Tere. I. Baillit. Capesterre (Guadeloupe), Maric-Galante, etc. [No 2336.] 
Martingue. Vulgo: Ortie razier. - Peu abondant. Vauclin, Sainte-Anne. $\left[\mathrm{N}^{\circ} 866,867\right.$.

S. nlmifolia Cav., S. truncata L'Hérit.; Sida à feuilles d'orme. Vulgo : Balai-cinc-heures. Car. Diss., t. 2, f. 4. - Suffrutescent ou frutescent, droit ou sarmenteux, haut de $80 \mathrm{~cm} .-1 \mathrm{~m}$. 50. Tiges et pétioles munis de poils simples. Feuilles larses. cordifornes. terminées en pointe elfilée, finement duvelés et blanchitres en desons. crénelées-serretéc. Fleurs d'un jaune terne, axillaires el terminales. solitaires ou réunies par deux, dont une portée sur un pédoncule plus long: prédoneules longst, articulés au-dessus du milieu; tube du calice à 5 angles, lobes deltoïdes plus courts que la fleur. Fruit à 5 carpides surmontés de 2 arêtes courtes. - Assez rare. Dans les haies et savanes Jonusaillenses de la basse région : Le Baillif, Vieux-l'ort, Moule, Grands-Fonds du Gozier et du Morne-ì-l'Eau. [No 2337.

Ne se rencontre pas à la Martinique.

S. arguta Sw.; Sida à feuilles effilées. Vulgo : Balai-deux-heures. - Suffrutercent et plus sourent frutescent, glabre, at tige dabord droite, ensuite plus on moins sarmenteuse, tres wrele, verte, létiement pubescente dans le haut. Fenilles très vertes, cordiformes, eflilées en longue pointe aizuë. irrésulièrenent el doublement crénelées-serrelées: stipules courles, sétiformes. Fleurs axillaires el terminales, solitaires ou réunies par trois, portés sur des pédoncules issus directement de l'aisselle des feuilles, ou de l'aisselle de bractés courtes el minces: pédoncules courts, articulés au-dessus du milieu, durelés: calice tres wabre, lube a is angles, lobes deltoödes, plus courts que les pétales jaunes. - Peu abondant. Caà et là dans les broussailles, sur les côtes seches du Baillif, des Vieux-IIabitantset de la Pointe-Noire. N" 2335.J

Martinique: - Assez rare. Boulevard de Saint-Pierre, Marin (MorneGommier), Case-Pilote. $\mathrm{N}^{\mathrm{o}} 868$.

Ce Sida, que (rrisebach Flura of the British West Indian Islands, page 75) admet comme synonyme du précédent, forme une espèce nettement distincte par son port, sa couleur, la forme et la longueur des branches, la forme des feuilles et surtout par l'absence de poils.

S. pyramidala Cav., Sida dumosa Sw.; Sida a fleurs en grappes pramidales. Cav. Diss., t. 1, f. 12; t. 194, f. 1. - Arbrisseau ornemental, haut de $1 \mathrm{~m} .50$ a $2 \mathrm{~m} .50$, droil, nu dans le bas et glabre, branchu par le haut et finement pubescent. Fenilles laryes, à pétiole presque aussi long que le limbe, penchées dans la journée, cordiformes ou souvent presque tronquées à la hase pubescentes en desions, quelquefols presque J-lobées dentelés en scie, brusquement pointues au sommet. Fleurs en panicules avec des branches primaires en grappes, les secondaires en petites cymes: tube du calice eylindrique, lobes du calice deltörles, pubescents: petales jaune-brun, munis a la base, a linterieur, de taches noir-brun; carpides 5, surmontes de 2 bees 
courts. - Peu répandu. Environs de Saint-Pierre (Trou-Vaillant, TroisPonts $).\left[N^{\circ} 856.\right]$ - Ne se trouve pas à la Guadeloupe.

S. cordifolia L., Sida à feuilles en coeur. Vulgo : Balai-poilu. Cav. Diss., 1. 3, 1. 2, 3,6, 7; s1., 1. 136, 1. 2; 1)ill., Ellham., 1. 171.

S. multiflora Cav., S. hamulosa Salzm. - Sullirutescent et quelquelois frutescent, droil, couvert en entier d'un duvetétoilé, serré, fin, blanchitre. Tigne strice. Feuilles cordiformesou subcordiformes, arrondies au sommed, rrossierement dentés en scie, longzuement pétiolées. Fleurs axillaires ef terminales, solitaires ou ramassées en ontomérules; corolle jaune, plus longrue que le calice; tube du calice a 10 angles avec des lobes deltö̈des. - Fruit à 10-12 carpides ruguleux, tronques et poilus au sommet, surmontés de 2 arétes droites. Facile à distinguer de tous ses congénères par son duvet et son calice a 10 angles. - Vit en société sur les coteaux secs, arides, chauds et graveleux. Environs des cimetieres de la Basse-Terre, Pointe-Noire, Deshaies, Désirade, Marie-Galante. [ Yo 2335.

M.ntriget, Vulgo : Balai-savane poilu. - Abondant entre Saint-Pierre et le Carbet, Prècheur, Marin Morne-Gommier. - Fl. surtout pendant l'hivernage. 「Nos 870 a el $\mathrm{b}$.

Abutilon T. (du grec " a » privatif, ne pas, "bous », bouf, " tilos ", diarrhée, parce que ces plantes sont un remède contre la diarhée des bètes à cornes.)

A. indicum G. Don.; Abutilon de l'Inde. Vulgo : Guimauve. Cav. Diss., t. 7, f. 2, 5, 6, $10 ;$ t. 128, f. $12 ;$ t. 129, f. 1. - Frutescent ou suffrutescent, tris droit, haut de $\mathbf{1 0 - 9 5} \mathrm{cm}$, tres branchu, courert, dans toutes ses parties, d'une pubescence courte, fine, zrise. Feuilles larges, cordiformes, tròs irrézulièrement et grossièrement dentées, souvent plus ou moins trilobeses, pointues au sommet: petioles plus longs que les limbes des leuilles. Fleurs axillaires, solitaires, naissant sur la tige et les rameaux, portées sur des pédoncules longrs et articulés un peu au-dessous de la theur; corolle jaune: calice à j lobes ovales, pointus, deux lois plus courts que les pétales. Firuit volumineux, composé de 18-20 carpides, munis d'une pointe recourber au sommet, verruqueux, ylabres, contenant habituellement 3 semences noires. - Fl. de février en mai. - Peu' répandu. Dans les savanes des environs du Grand-Bours, de Marie-Galante. [No 36 42.]

Mintinique. Vulgo : Mauve. - Rare. Cà el là autour des maisons des environs du Marin. ( No 818.)

A, hirtum G. Don.; Ab. hérissé de poils. Vulgo : Grosse mauve. - Suffrulescent et frutescent, haut de to (cm.-1 m. 50, très branchu, droit, les pétioles et le haut de la tige couverts de poils droits, plus ou moins rigides. Fondille aussi larges que longues, amples, cordiformes, presque rondes et fris 
brusquement lerminées en unc pointe obluse, subentieres on irrésulièrement dentées, parfois à 3 lobes peu prononcés, plus ou moins visqueuses, finement duvetées et blanchâtres en dessous, presque glabres en dessus. Fleurs larges, d'un jaune d'orange; pétales munis d'une large tache noire à la base: ¿̀ l'intérieur, axillaires, naissant soit directement à l'aisselle des feuilles de la ligne principale soit a l'aisselle des feuilles des rameaux, longruement pédonculeses lobes ducalice, grands, deltoïdes, dépassant le fruit arant sa maturité, cnsuite plus courts que lui ; pédoncule articulé un peu au-dessous de la fleur. Fruit composé de 25 -30 carpides veloutés, munis d'une pointe courte et veloutée; semences brunes légèrement duvetées, armées d'une pointe courte et rigide. - Cette espèce diffère de la précédente, surtout: par ses leuilles presques rondes et visqueuses, à l'état vert et exhalant une mauvaise odeur'; par sa couleur vert-jaunâtre; par l'ampleur des fleurs et des fruits ; par ses longs poils. Les fleurs s'ourrent habituellement dans la soirée, vers les 3 ou 4 heures. - Peu répandu. Desirade (dans les savanes el autour des maisons du Bourg); çà et là autour des habitations des environs de la BasseTerre (habitation l'Lispérance). [Nos $2789,3369$.

Martinique. Vulgo : Mauve-savane. - Rare. Marin, Vauclin (sur les décombres et autour des maisons). [ $\mathrm{N}^{\circ} 8 \mathrm{H}$. $]$

A. mollissimum G. Don., Sida mollissima Cav.; Ab. à feuilles très molles. Vulgo: Mauve. - Suffrutescent et frutescent, droit, peu branchu, haut de 1-2 mèt., à feuilles larges, en cœur à la base, eflilées en pointe aiguë au snmmet, à lige, pétioles et pédoncules couverts de longrs poils. Fleurs grandes, légèrement jaunâtres. Fruit comme dans le précédent. - Cultivé au Jardin botanique de Saint-Pierre, d'où il s'est répandu dans les environs. [N" 847 .

A. crispum G. Don.; Ab. crispé. Cav. Diss., t. 7, f. 2; t. 135, f. 2. Dill., Eltham., t. 5; Plum., t. 25. - Frutescent, sarmenteux, à tige et branches wrèles, tres flexibles, léxierement pubescentes. Fenilles petites, en cour à la base, pointues au sommet, duvetées et grises en dessous, crénelées. Fleurs axillaires, solitaires, portées sur des pédoncules filiformes el articulés, audessus du milieu el presque aussi long̈s que le limbe de la feuille; pétales blanc-jaunâtre, plus longs que le calice; lobes du calice, ovales, pointus. Fruit gonflé, vésiculaire, blanc jaunâtre, contenant 10-12 carpides, dont chacun renferme habituellement 3 semences polies et brunes. - Peu abondant. Cà et là dans les endroils secs, rocailleux et chauds de la basse région. Environs des cimetières de la Basse-Terre, Le Baillil, Deshates Gros-Morne?. $\left[N^{\circ} 02342.\right]$

Martingue, - Assez rare. Boulevard de Saint-Pierre, Prêcheur, SainteAnne. $\left[N^{\circ} 852.\right]$

A. striatum Dicks.; Ab. à lleurs striées. - Arbrisseau élégant et très ornemental, haut de $2-3$ mèt. l'euilles glabres, irrégulierement dentées, en 
coeur a la base, à 3 lobes pointus. Fleurs grandes, solitaires, renversées, axillaires, portées sur de longs'sédoncules pendants; pétales veinés, diun jaune orange; calice à 5 lobes prolonds, deltoïdes. - Ne produil pas do fruits. - Originaire du Brésil ; cultivé au Jardin botanique de Saint-Pierre dans un grand nombre de jardins de la Martinique. [ $\mathrm{N}^{0} 2020$.

A. auritum Wall.; Ab. à stipules en forme d'oreille. - Arbrisseau haut de $2-3^{\mathrm{m}} 50$, très ornemental, très branchu, à branches d'abord fastigriées, ensuite infléchies, couvert en son entier d'une pubescence fine et grisâtre, ì lexception du dessus des l'enilles. Fenilles lareges, plus nu moins pendantes. fris longuement pétiolées, cordiformes arec un sinus trisonvert, dentelexs, brusquement pointues au sommet. Fleurs en une ample panicule prramiclale et allongée, dont les branches sont garnies, à la base, d'une large bractée cordiforme, laineuse, appliquée contre la tige principale et disparaissant avec la chute des tleurs; pétales veinés, d'un jaune brun foncé; calice à 5 lobes deltoïdes, beaucoup plus courts que les pétales. Fruit i t: carpides, contenant chacun 3 semences pubescentes. - Je ne saurais dire si cette espèce est indigène nu non : elle existe en abondance dans plusieurs vieux jardins abandonnés de la Basse-Terre. - Fl. de décembre en mars. [No 2321.]

Mantrique. - Introduit au Jardin botanique, d'où il s'est répandu dans le pays et se reproduit spontanément. Trois-Ponts, Carbet, Prêcheur, $\left[N^{\circ} 851.\right]$

Bastardia Kith. (dédié par liunth au botaniste français 'T. Bastarl, qui, entre autres choses, a écril : Essai sur la flore du département de Maine-elLoire, 1809.)

B. viscosa Kth.; Bastardia visqueux. Vulgo : Balai-grand (à la PointeNoire). Cav. Diss., t. 196, f. 1; SI., t. 139, f.4.- Suffrutescent et plus souvent frutescent, haut de $50 \mathrm{~cm} .-1 \mathrm{~m}$. 50, droit, à branches et lige grêles, allongées, finement pubescent dans le haut de la tige et dans toutes les autres parties. Feuilles petites, en cour, pointues, dentelées. Flours petites, jaunes, axillaires, sur des pédoncules presque aussi longs que les pétioles. Fruil petit, à carpides uniovulés, à déhisence loculicide; calice à jobles ovales, à pointe arrondie; semences noires et petites. - Fl. a toutes les saisons de l'année, mais surtout de février en mai. - Peu répandu. Pointe-Noire, dans les terrains rocailleux du bord de mer et des environs du bourer. $\left[\mathrm{N}^{\circ} 3412.\right]$

Ne se trouve pas à la Martinique.

Malachra I. (tiré du sree "malaké ", qui désigne une espèce le maure.)

M. capitata L.; Malachra à fleurs en têtes. Vulgo : Gombo-savane. - Sulfrutescent, très branchu dès la base, haut de $80 \mathrm{~cm},-1 \mathrm{~m}$. -40 , à branches, jeune tige, pétioles, pédoncules revêtus d'un duvet gris, court, soyeux. 
Fenilles palminerviés, dentés : les adultes, at 3 lobes peu prolonds: les jeunes, en forme de violon; stipules 2, séteuses, molles, en forme d'alène. Fleurs en glomérules axillaires, portées sur des pédoncules lantút longs. tantôt courts, renfermant 3-5 fleurs sessiles, entourées de 3 bractées réniformes, cordées à la base et brusquement terminées en pointe, panachées de vert et de blanc, plus larges que longues et hérissées de poils: corolle jaune, plus rarement blanche: alice couvert de poils rigides. dressés: lobes effilés. Fruit à 5 carpides, glabres. - Peu répandu. Noule quelques pieds sur les décombres près du eimetière).

Mantivique. Vulgo : Combo bâtard. - Peu abondant. Trois-llets dans les savanes aroisinant l'Anse-ì-l'Ane) et aux Anses-d'Arlet. [X', 854.

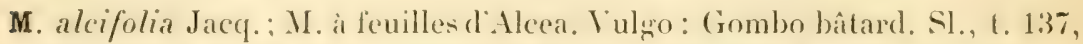
1. 1; Cav. Diss., t. 33, 1. 2. - Haut de $60 \mathrm{~cm}$. a $1 \mathrm{~m}$. 80 . Ammuel ou sulfrutescent, a tige striér, grosse. Feuilles palninerviées : les adultes, à jo lobes ; les jeunes, à 3, hérisses ou ghlabres. Fleurs axillaires disseminées fout le long de la tige ef des branches, sessiles ou brièvement pédonculies. ramassés en grlomérules entourées de bractées laryes, panachées; corolle blanche ou jaume: tube ef lobes du calice hispides. - Abondant dans les endroits humides et dans les fossés, le lnnger des routes. Vieux-IJabilants, la Bouillante, Pigreon. Fl. de juillet en janvier. - Dans le pays, on se sert des fleurs, soit sèches soit fraîches, en infusion contre la toux et les rhumes. [ $\mathrm{Y}^{\circ} 2330$.]

Mantixique. Vulgo : Gombo bâtard, gombo-savane. - Assez abondant. Caravelle, Trinité, Rivière-Salée, Anses d'Arlet. [No 853.]

M. fasciata Jacq. ; M. à fleurs fasciculées. Vulgo : Gombo bâtard. Annuel ou suffrutescent, haut de $90 \mathrm{~cm} .-1 \mathrm{~m}$. 30, loranchu, droit ou penché, ¿ tige épaisse, pouvant atteindre $2 \mathrm{~cm}$. de diametre; facile à distingruer de ses congénères par des poils roux ou blanchâtres, luisants, rigides, droits, presque piquants, qui couvent tous ses organes. Feuilles dentées : les adultes, à 5 lobes peu marqués: les moins adultes, à 3 lobes pointus: les jeunes, ovales ou lancéolées: stipules filiformes, hispides, longrs. Fleurs fasciculées par 2-4, sessiles, axillaires, entourées de bractées beaucoup plus petites que dans les espèces précédentes, très hispides et accompannées de bractées aceessoires, filiformes et hispides; corolle jaune ou blanche. Fruit de 4-5 carpides trigones et tuberculés. - Ies feuilles sont emplovées en cataplasmes émollients, et les fleurs en infusion contre les rhumes et la toux. - Abondant dans les endroits humides el aquatiques de la basse région. Environs de la Basse-Terre, Vieux-Fort, Capesterre, Pigeon. No 3368.$]$

Martingee. Vulgo : Crande-guimaure. - Abondant. Saint-Pierre, Trinité, Caravelle, Matouba. [N॰855.]

Urena L. (du nom Malabar, " urena ».)

U. Lobata L., variété americana L. fils; Crena à feuilles lobées. Vulgo : 
Grand-cousin, cousin-rouge. Car. Diss., I, 185, f. 1 ; Desc., vol. IV, l. 271, p. 179; Cav. Diss., t. 183, f. 2; l. 184, l. 1. - Frutescent, ornemental par

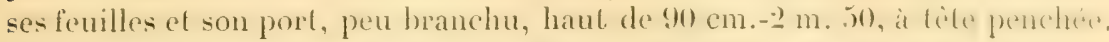

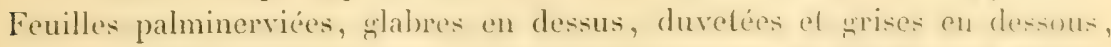

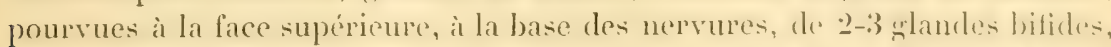
cordées a la base, trilobées, à lobes delon̈des, celui du milieu plus srand

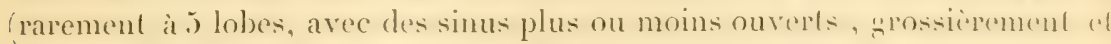
très irrégulièrement dentées-sinuées : les supérieures ot les jeunes, ovales ol sinuées seulement. Fleurs pourpres, axillaires, presque sessiles el terminales; lobes du calice alternant avec les ă seyments lancéolés, hispides ol striés de linvolucre. Fruit à y carpides indéhiseents, durs, sects, ghobulenx, hérissús entièrement de piquants rigides, droits, roux et terminés en hameçon it double crochet, ce qui fait qu'il s'attache à tout ce qui le touche. - Les feuilles ont toutes les vertus des plantes émollientes, adoucissantes el rafraîchissantes : on s'en sert souvent en cataplasme et pour les bains tièdes. Descourtilz, loco cil., vante beaucoup l'infusion des fleurs édulcorées, ou le sirop quion en lait contre les différentes maladies aiguës of inflammatoires; il la recommande en grargarisme contre l'angine, les aphlhes ou excoriations des gencives; en hoisson, contre les gastrites, les mupoisonnement. par des matières âcres et corrosives, contre le flux du ventre, la dysenterie et au début du calarrhe pulmonaire: en lotion, contre les exanthèmes aigus, les maladies éruptives, lès éryipèles, les plenrésies, l'hépatite. Il ajoute quelle procure un frand soulagement dans les néphrites inllammatoires ou calculeuses, dans les deux premières périodes du catarrhe vésical, dans la blennorrhagie et autres maladies des voies urinaires, etc. - Abondant dans les savanes et endroits incultes de la région du littoral ot de la régrion infra-moyenne. Basse-Terre Morne-it-Vaches, Montéran, Ducharmois, Vieux-Fort, Capesterre, etc. - FI. de novembre en mars. - Alt. $0-600 \mathrm{~m}$. [No 2331.$]$

Martinique. Vulgo : Grand-mahot-cousin. - Répandu dans toute l'łle. Saint-Pierre Boulevard;, Carbet, Case-Pilote, Marin, Trinité, ete. - (In en fait usage dans la médecine domestique. [No 2010.]

U. sinuata L., U. Swartzii Macf.; Urena à feuilles sinuées. Vulgo : Cousinpetil. Cav. Diss., L. 185, f. 2. - Diflère neltement du précedent : par la lorme

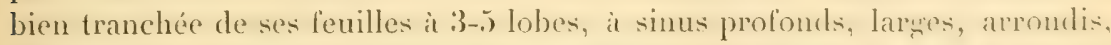
dépassant le milieu du limbe, el rappelant la feuille de la vigne; par lefleurs, habituellement plus srandes, et sa taille moins ćlevée. - Tris ormemental. Jouit en tout des mèmes propriétés médicinales que son continère el śmploie fréquemment dans le pays. - Mimes localitió, maís pluabondant, surtout dans la basse région : Basse-Terre Morne-it- laches, La" Baillif, Trois-Rivières, Deshaies, etc. [No 2332.]

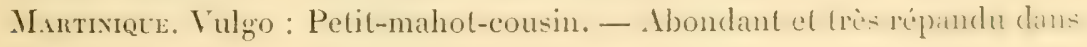


les parties inférieures de l'île et sur le bord de mer. Saint-Pierre, Marin, Prêcheur, etc. INo 2041.]

Pavonia Car. dedié par Caranilles a l'Espagnol Jean Paron, qui, aree son compatrinte Ilip. liuiz et le Fançais I)mbey, a lail jusqu it quatre-ringthuit voyages importants à travers le Chili, le Pérou et les pays voisins; il a écrit avec Ruiz : Flora peruviana et chilensis.)

P. spinifex Cav.; Paronia à fruits armés de piquants. Vulgo: Mahot jaune, coquelicot (au Moule). Car., t. 43, f. 2, 3. - Arbrisseau omemental, haut de 1-2 m. 80, nu dans le bas, médiocrement branchu, glabre. Feuilles litiblement cordées, pointues au sommet, wrossierement dentées. wlabres on paremées de rares poils étoilés : les jemes, ovales. Fleurs yrandes, solitaires, axillaires, longuement prefonculese; calice entouré de s folioles involucrales poilues, plus longues que les lobes lancéolés du calice et beaucoup plus courtes que la corolle jaune et large; étamines 10 . Fruit à 5 carpides secs, trigones, glabres, rugueux, armes de 3 aretes pointues, solides, héristes de petits piquants renversés; 2 de ses arêtes, latérales au sommet des bords; la 3e, au milieu du carpide. - Les fleurs sont très émollientes : on les recherche pour en faire des tisanes contre les inflammations de la gorge el des cataplasmes contre les clous, furoncles et abcès. - Assez abondant dans les environs de la Base-Terre ravine de la rivière Billaud, habitation l'Eeperance et habitation Nadal), Moule (le long du Canal), Morne-ì-l'Eau. Alt. $50-200$ mèt. [Y० 2328 .

Martinique. Vulgo : Mahot jaune. - Assez répandu, sans être abondant. Trois-Ponts, Parnase, Marin Morne-Gommier, Case-Pilote, ete. N"843.

P. racemosa Sw., P. spicata Cav.; Paronia à fleurs en grappes. Vulgo : Mahot-mare, sunabao (au Mloule). Sl., t. 139, f. 2; Cav. Diss., t. 146, f. 1; Desc., vol. VII, t. 525, p. 309. - Arbrisseau droit, haut de 1-3 mèt., à tige simple, completement nue dans le bas. peu feuillu par le haut, a racines fortes et traçantes. Feuilles entières, à peine dentées, en cour à la base, pointues au sommet, larges. Fleurs en grappes simples, terminales, allongrées, it branches inlérieures longuement pédoneulées. Feuilles involucrales 6-8, oblongues-lancéolées plus courtes que les lobes ovales et larges du calice; corolle jaune-orange pâle, peu ouverte; colonne staminifère renfermée. Fruit à carpides carénés, marginés, glabres, munis de deux petits becs, terminant la marge. - Vit souvent en société avec les mangliers, dans les marécages d'eau salée. - Descourtilz met cel arbrisseau dans les plantes émollientes. Dans le pays on se sert quelquefois des feuilles en calaplasmes. - Pointe-d-Pitre, Moule, Baie-Mahault, Lamentin. Yo 2786.

Martixique. Vulgo : Mahol-mangle, gombo-mangle. - Abondant dans les marécages de la Rivière-Salée, de Ducos, du Robert. [No 841.] 
Nota. - Tous les genres de Malvacées cilés jusqu ici ont une écorce très fibreuse, que les habitants utilisent en beaucoup d'endroits.

P. rosea Schlech., P. nemoralis St. Hil. - Arbrisseau haut de $50-90 \mathrm{~cm}$., it fleurs roses, à feuilles coriacées, dentées, ovales. - Est cultivé au Jardin botanique de Saint-Pierre, où il se propage spontanément. [Xo 84.2.

Abelmoschus L. (de l'arabe "halb ", graine, " el-mosk", musc, parce que les graines sont musquées.

A. esculentus $\mathrm{W}$.; Ab. cultivé. Vulgo: Gombo. Car. Diss., 1. 61, f. 2. Tuss, Fl., I, t. 10; Desc, vol. IV, t. 267, p. 165. Hibiscus L. - Annuel, droit, ne dépassant gutre me met délevation. Tige épaisse, forte, poilue dans le haut. Feuilles larges, a 5 lobes irrégulèrement dentées; corolle larye, jaune, munie d'une tache large, noire au fond, à l'intérieur; calice spathacé, enveloppant, en partie, la base de la corolle, entouré de 9-12 folioles involucrales lancéolée-linéaires, caduques, ciliés. Fruit tantit allongé, ohlonglancéolé, tantôt court et ovale, selon la variété, s'ouvrant par déhiscence loculicide en 5 logres multiovulées. - A élé porté des Indes Orientales en Exypte ef est maintenant cultive comme plante alimentaire dans le monde entier. - Fl. habituellement de juin en septembre. - Les fruits encore jeunes et tendres sont très appréciés pour la table : on les mange cuils, assaisonnés avec de l'huile et du vinaigre. La décoction des graines est employée comme diurétique : on se sert des feuilles et des graines en lisane ou en lavement contre la dysenterie; les grames entrent dans la composition du nafé d'Arabie. [No 2785.

Martinique. Vulgo: Gombo - Dans toute l'île. [No 2021.]

A. moschatus Mich.; A. musqué. Vulgo : Gombo musqué. Car. Diss., t. 62, f. 2; Dese, vol. V, t. 361. Hibiscus L. - Annuel, droit, de hauteur variable, mais ne dépassant pas $1 \mathrm{~m}$. d'élévation, à tige, feuilles, pétioles et pédoncules hispides. Feuilles larges, srosiciement et irrégulièrement dentexs en scie : les jeunes, hastées avec des lobes accessoires; les adultes, à 5 lobes deltoïdes, dont celui du milieu plus grand. Fleurs comme dans le précedent, mais plus grandes ou plus ouvertes. Fruil hispide, ovoüde-pyramidal, ì 5 loges souvrant par déhiscence loculicide. - Originaire de l'Égypte et de l'Arabie, naturalisé et cultivé dans toutes les Antilles; se rencontre asse\% souvent à l'état sauvage. - Descourtilz range cette plante dans la classe des antispasmodiques aromatiques et en vante ses propriétés médicinales. Dans le pays elle n'est pas employée, souvent. - Ravine-Clatude, SainteRose, Baie-M[ahault. [N०2781.]

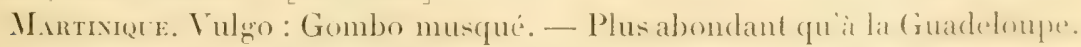
- beaucoup de petits propriétaires le cultivent pour vender les graines ans pharmaciens, - Hauteurs du Lamentin, Ducos, Gros-Morne, etc. [No 121.] 
Hibiscus I. (du grec " biscos », Diosc., III, 163; Plin., XIX, 27; XX, 14, qui est l'Althaea officinalis, composé de "ibis ", oiseau sacré des anciens

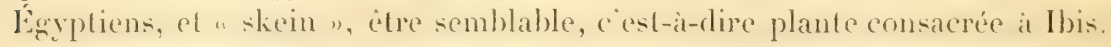

H. sororius I. ; Hibiscus à fleurs jumelles. Vulgo : Liane de framboisin. Arbrisseau haut de $1 \mathrm{~m} .80$ à 2 mèt., droit ou plus ou moins infléchi, ¿̀ racines longues, traçantes, glabre et à tige nue dans le bas, peu feuillu; le haut de la tige, pétioles, pédoneules et le dessous des lenilles converts d'un duvet roussâtre et rude. Feuilles larges, en cocur, crénelées-dentées, arrondies au sommet, longuement pétiolées. Fleurs grandes, à corolle rose, axillaires. portées sur de longes pédoncules arliculés presque au milieu, le plus souvent réunies par 2 ; calice ventru, à 5 lobes ovales et larges, deux fois plus courts que la corolle; folioles involucrales $7-8$, deux fois plus courtes que le calice, élaryies ausommet en un limbe réniforme, caractere qui le distingue facilement de ses congénères. Fruil capsulaire, poilu, ovoüde-ghlobuleux, renfermé dans les lobes du calice, à 5 loges multiovulées et it déhiscence loculicide; semences brunes, légèrement muriquées. Les fleurs souvent de bonne heure le matin el se ferment vers 2 ou 3 heures du soir. - Peu répandu; assez. abondant dans les herbes de l'étang du Cocover, près de l'usine de Inchassaing (Moule). [No3495.]

N'existe pas à la Martinique.

H. bifurcatus Car.: II bifurqué. Vulgo: (inmbo-de-nuil. Cav. I)iss., t. j)1, f. 1. - Vivace, samenteux, très ornemental, haut de 2-4 mèt, à tige et pétioles munis de pelits piquants nombreux recourbés. Feuilles longruement pétiolées. en coxur, à 3-5 lobes profonds, elliptiques, irrégrulierement dentés. Fleurs tres zrandes, d'abord rose pourpre, ensuite rose tendre, axillaires ed solitaires; pédoncules muriqués, poilus, assez courts, rigides, articulés au milieu; calice a jobes orales, acumines, slanduliferes, hispides, f it fo fois plus courts que la corolle ; folioles involuerales distinctes, au nombre de 10 12 bifurquées au sommet, tantôt un peu plus courtes, tantôt un peu plus longues que les lobes du calice. Capsule ovoüde, poilue, aussi longrue que le calice; semences glabres, muriquées. - Fl. de mai en janvier. - Assez abondant dans les endroits marécageux situés entre le boures de la Baie-Mahault et lihabitation Ja Jaille; cat el la le longr de la rivière de la Capesterre Guadeloupe). [N०2780].

Martixique. Vulgo: Gombo-rivière. - Assez rare. Rivière-Salée le long du canal, près du bourg; çà et là dans les endroits marécagreux entre la Rivière-Salée et les Trois-llets. Dans ces endroits on le cultive quelquefois dans les jardins à cause de la beauté de ses fleurs. [No 814.$]$

H. tulipiflorus Hook.; Hib. à lleurs de tulipe. Vulgo : Gombo-grandsbois. - Arbre souvent d'assez grande taille, peu élégrant, habituellement peu branchu, nu dans le bas, à écorce grise, à branches divariquées, souvent 
horizontales, cassantes, ì jeunes branches remplies de moelle blanche; extrémités des branches, pédoncules, pétioles et le desenus des fenilles converts d'une sorte de pubescence rude, apprimée, rousse el blanchâtre. Feuilles tris larges, plus larges que longues, arrondies, tries irréguliomentut et grossièrement dentées, ramassées à l'extrémité des branches: pétiole presque aussi long que le limbe de la feuille. Fleurs grandes, solitaires, axillaires, habituellement penchées, portées sur de trís longes pédoncules: corolle laineuse, dabord blanc pâle, ensuite léxerement jaunatre; calice it 5 lobes ovales, pointus, parcourus par 3 nerrures, deux fois plus courts que la corolle; involuere de J-fi lolioles, à peu pris deux fois plus contertes que le calice. Fruit grand, velu, aréolé, presque aussi large que longr, it 5 ailes, à loges pluriorulées, déhiscentes; semences biconvexes, enveloppées de laine rousse. Les fleurs sont extrêmement émollientes. - Assez abondant dans les bois supérieurs des Bains-Jannes, du Bassin-Blen el du IIaut-Matoubá. [No 2323.]

N'existe pas à la Martinique, mais nous l'avons vu ì la Dominique el à Sainte-Lucie.

H. mutabilis I.; IIib, changeant de couleur. Vulgo : Caractiere-des-dame-, caractère-des-hommes. Desc, vol. IV, t. 270, p. 172. - Arbrisseau droit, haut de 2-5 met., originaire des Indes Orientales; introduit el cultive ça et lit comme plante d'ornement. Feuilles plus ou moins cordiformes, it jlobes pointus et très inégalement dentés, longuement pétiolées, grises en dessous. Fleur's très yrandes, solitaires, ou en corymbe terminal, remarcuables par leur changement de couleur. Le matin, en s'ouvrant, elles sont blanches; vers midi, elles deviennent roses, et le soir, avant de se fletrir, elles prennent une teinte pourpre. Du reste, tous les Hibiscus du pays changent plus ou moins de couleur. - Descourtilz place cet arbrisseau dans les béchiques adoucissants, et recommande les tisanes faites avec ses feuilles contre la toux. Dans les endroits où cette plante existe, on se sert des feuilles et des fletrir: qu'on fait bouillir avee des feuilles de lherbe-it-charpentier et de la verreine queue-de-rat pour préparer des cataplasmes émollients. - Rare. Dans quelques jardins d'amateurs de plantes. Capesterre (Guadeloupe, TroisRivière. - Fl, en lout temps. [No3496.]

Mantinique. Vulgo: Caractère-des-dames. - Au Jardin bolanique et dans: beaucoup d'autres localités. Saint-Pierre, Camp-Balata. [Yo 2086.

H. rosa-sinensis L.; Hib, rose de Chine. Vulgo : Rose de Cayenne. Car. Diss., t. 67, f. 2. - Arbrisseau ornemental, droit, à branches allongées, devenant presque sarmenteuses, originaire des Indes ()rientales. Fentlles ovales, grossièrement dentées; remarquable par ses grande- theurs rontere devenant plus ou moins pourpres avant de se fletrir. - Abondant. - (1n en fait souvent des haies, qui, sons linfluence de la taille, deviemment fint 
belles et solides. on cultive dans les jardins plusieurs belles varietés a fleurs blanches, à fleurs jaunes doubles, etc. - Les feuilles et les fleur's sont mucilayineuses el émollientes. - Batse-Terre, Camp-Jacob, Gourberre, Pointe-àPitre, ele. X"2:32.5.

Mantrigue. Vulgo: Rose de Cayenne. - Abondant, avec les variétés cidessus indiquées. [No 2089 .

H. phœniceus Jacq. ; Hib. it lleurs rouges. Car. Diss., 1. 67, f. 3; Desc., vol. YI, l. 382. - Arbrisseau très ornemental, haut de 1 50-3 mèt., à branches allomgeres, minces, hexibles et penchées, à fenilles petites, deltö̈des,

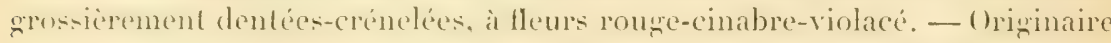
de lat Jamaïque el de Saint-1)omingue. Cultivé dans beaucoup de jardins, où il fleurit abondamment à toutes les saisons de l'année. Basse-Terre, CampJacob, Pointe-à-Pitre, Moule. [No 3209.

Martivique. - Jardins de Saint-Pierre, du Prêcheur, du Fond-Coré, etc. $\left[\mathrm{N}^{\circ} 2088\right.$.

H. surratensis L.; Hib. de Surrate. - Annuel, d'abord droit, ensuite penché, haut de $70 \mathrm{~cm} .-1 \mathrm{~m}$. 40 ; remarquable: par ses feuilles ressemblant à celles du chanve; par sa tige, ses pétioles et ses pédoneules armés de petits piquants recourbés; par ses laryes fleurs d'un noir pourpre-violacé très riche, à calice à 5 segments ovales-lancéolés, très effilés, ligneux, munis de piquants sur les bords et sur la nervure du milieu; par ses 6-9 folioles involucrales distinctes, linéaires-lancéolées, poilues et longuement bifurquées au sommet; par son fruit ovoüde, hérissé de poils, renfermé par les semments du calice. - (hriginaire de l'Ilindoustan anglais, naturalisé au Camp-Jacob): se cultive aussi au Jardin botanique et dans beancoup d'autres jardins. - Fl. d'octobre en février. [Nos 2326,2781 .]

Martinique, - Introduit et cultivé au Jardin botanique, d'oủ il s'est répandu dans les environs et pousse spontanément. [Nº 849.]

H. Boryanus Desc.; Hib. de Bory. - Arbrisseau glabre, touffu, haut de 2-4 mèt.; à branches divariquées; ì feuilles coriaces, ovales, grossièrement dentées au-dlessus de la base ; à fleurs larges, rouges, à calice à 5 lobes profonds, deltödes. moitié plus courts que la corolle; a fruit ì ĺloges, renfermé par les lobes du calice; à semences brunes, velues. - Cultivé dans un grand nombre de jardins comme plante d'ornement. Camp-Jacob, Basse-Terre. Gourbeyre, Pointe-à-Pitre. [No 2327.]

Martineve. - Cultivé au Jardin botanique et dans les jardins de la ville de Saint-Pierre, de Fort-de-France, du Prêcheur, ete. [No 2083.]

H. lavateroides Monc.; Hib. ressemblant au Lavatera. - Arbrisseau ornemental, haut de 1-2 m. 50. Écorce grise, branches flexibles, plus ou moins pendintes; jeunes tiges, branches, pédoncules, pétioles, calices avec calicules, 
et le dessous des feuilles couvert d'un duvet fin et gris. Feuilles presque glabres en dessus, d'un vert très clair, cordiformes, à 3-5 lobes peu marqués

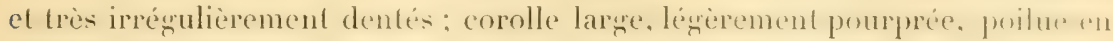
dehors; pétales striés; calice un peu plus court que la corolle; a 5 lobes profonds, deltö̈des; feuilles imvolucrales 8 , obovales, deux fois plus courtes que le calice; pédoncules articulés au-dessus du milieu. Fruit renfermé dans les lobes du calice, à 5 loges; semences petites, entourées de coton gris. Cultivé dans les jardins: Basse-Terre, Pointe-ì-Pitre, ete. [No 2324 .

Martinique. - Cultivé au Jardin botanique, d'où il s'est répandu dans le pays et s'est naturalisé. Saint-Pierre, Morne-Rouge, Fort-de-France, etc. $\left[N^{\circ} 166.\right]$

H. cannabinus L.; Hib. tenant de la nature du chanvre. Vulgo : Groseille, Gombo-chanrre. - Annuel, très ornemental, haut de $80 \mathrm{~cm} .-1 \mathrm{~m}$. 40, très droit, à tige grosse, remplie de moelle. Feuilles ressemblant ì celles du chanrre, dentées en scie, à dents placées à distance et aiguës, à 3-7 segments dont 3-5 très profonds, les 2 latéraux plus courts; pétiole long, souvent deux fois plus long que le limbe de la feuille. Fleurs axillaires et terminales. grandes, à pétales jaunes parcourus de veines noires allant en zigzag; calice gris, jotb fois plus court que la corolle, muni de plandes surmontées diun pril rigide, à 5 lobes lerminés par une pronte effilese, rigide et hispide : lonlioles invonlucrales linéaires, aussi longues que le tube du calice. - Cultivé çà et là autour des habitations, à cause de ses fibres, qui sont très tenaces, et de ses l'ruits, arec lesquels, après qu'on en a retiré les 'graines, on lait des confiLures el du vin, connu sous le nom de vin de groseille. - Capesterre Guadeloupe), Trois-Rivières, Grands-Fonds du Moule, etc. [No 783.

Martixieve. Vulgo : Groseille. - Autour des habitations. Gros-Morne, Grand'Anse, Trinité. [No 2085.] (Spécimen imparfait.)

H. sabdarifa L. (nom de la plante en langue turque); Vulgo : Oseille de Guinée. Desc., vol. I, t. 31. - Annuel, à tige suffrutescente, haute de $90 \mathrm{~cm}$.2 met., branchue dans le haut, entierement wabre. Feuilles larges, noiratres, dentées en scie au-dessus de la base : les adultes, à 3 lobes elliptiques, pointus, celui du milieu beaucoup plus grand ; les jeunes, elliptiques, pointues: pétioles noirs, at la base du limbe. Fleurs axillatres: corolle srande, jatune, rn clochette, veinée de lignes noires allant en zigzag; calice d'un liers plus court que la corolle, à 5 lobes très allongés, lancéolés, veinés de noir: calicule ¿ 8-10 folioles lancéolées-linéaires, plus courtes que le calice. Fruit grand, à 5 loges, à déhiscence ioculicide, renfermé par les lobes du calice; semences brunes, pubescentes. - Après la chute de la corolle, les enveloppes florales

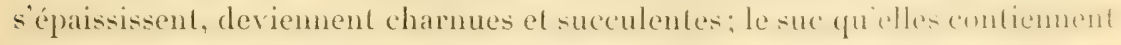
est acide, très agréable et rafraichissint: on en prepare des conditures expuimeel un vin délicieux qu on appelle vin dosesille. - Plus abondant que le pré 
cédent. Basse-Terre, Gourbevre, Lamentin, Capesterre habitation Longmont), etc. No 2782 .

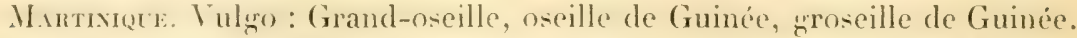
- Assez répandu dans l'ïle. Pricheur, Carbet, Gros-1Ioine. No 2084. Plante introduite de la crite necidentale d't trique, par la culture, dans les deux îles.

H. Cooperi Hort. - Arbrisseau touffu, haut de 2-4 mèt., originaire de la Souvelle-Hollande; introduit par M. Bélanger au Jardin bolanique de SaintPierre en 1880; remarquable : par ses larges fleurs a pétales roses, arec une tache rouge eramoisi au fond: par ses feuilles, panachées de blane, de vert foncé et de vert tendre. - S'est répandu à la Martinique dans tous les jardins ' $x^{2 n} 35$, de même qu à la Cruadeloupe, Basse-Terre, Camp-Jacob, Pointe. ì-Pitre, etc. No 3676 .

H. vitifolius L.; Hib. à feuilles de vigne. - Petit arbrisseau à branches flexibles, penchées, à fleurs jaunes, grandes, avec des taches noires au fond. [No 818.]. - Originaire des Indes Orientales.

H. Lampas Car. - Originaire des iles Philippines. $\mathrm{X}^{7}$ 2087.] - Liespèce précédente ef colle-ci sont cultivées au Jardin botanique de Saint-Pierre, ou elles poussent spontanément.

H. schizopetalus Hort. - Espèce très remarquable paṛ ses fleur's pendantes suspendues à un long pédoncule, à pétales pennilobés ou pennifides. - A été introduit, il y a quelques années, par M. Hip. Clayssen, maire de Gourberre, grand amateur de plantes; il s'est répandu promptement el lait l'ornement des jardins. Basse-Terre, Camp-Jacob, Pointe-à-Pitre, ele. [No 3687 .

Gossypium I. du latin " wossum ", enflure, groitre, allusion i la capsule bourrée de colon; la racine du mot vient probablement de l'arabe " goz ", substance soyeuse.

G. arborescens L.; G. arborescent. Vulgo : Cotonnier. - Arbrisseau plus ou moins tortueux, ne dépassant guère $\mathbf{1}$ mèt. en hauteur. - Se cultive en

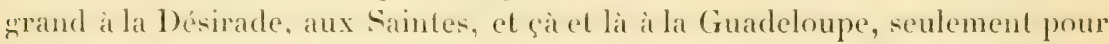
les besoins domestiques. - Fl. de novembre en mars. - On rencontre plusieurs variétés, dont les principales sont : le tros coton, le colon fin et le coton soie; botaniquement parlant, ils ne diffèrent pas assez pour en faire des espèces distinctes $\left[\mathrm{N}^{\circ} 3267\right]$, gros coton, et [ $\left.\mathrm{N}^{\circ} 3364\right]$. coton fin.

Mantisiqce. Vulgo : Colon ordinaire, coton Pierre, petit coton. - Ses racines ripées entrent dans les remedes contre la morsure du serpent; prises en tisane, elles sont employées contre l'oppression, et les feuilles en décoction contre la diarrhée; dans quelques endroits on donne les graines en décoction aux nourrices dont le lait taril : on se sert du coton pour l'appliquer contre les brûlures. 
Paritium St. Hil. (de "parila ", nom malabar de la plante.)

P. tillaceum Ad. Juss. Hibiscus arhoreus Desc.; P. Lenant de la nature du tilleul. Vulgo : Mahot-yombo au Camp-Jacoby, bois-llot ailleurs. Cars. Diss., t. 155, f. 1; Sl, 1. 134, 1. 2; Desc., vol. II, t. 148, p. 327. - Arbrisseau ou petit arbre, droil ou tortueux, haut de 3-5 mèt., à écorce grise-blanchâtre, très fibreuse, ì jeunes branches et tige couvertes d'un duvet fin et blanc. Feuilles larges, aussi larges et souvent plus larges que longues, coriaces, entières, presque rondes, en caur it la base, brusquement terminées en pointe, garnies en dessous d'un duvel fin aronté, avec des nervires très saillantes; stipules -2, grandes, caduques, lancéolées, tronquées it la base, arrondies au sommel, couvertes d'un duvet farineux. Fleurs axillaires et terminales, brièvement pédonculées; corolle jaune, grande, passant au pourpre pâle avant de se faner; calice deux fois plus court que la corolle, blanchitre, it 5 segments allongés, deltoïles. carénés au milieu, pointus; in volucre is 10 dent pointues, blanchat res, plus court que lecalice. Fruitowödearrondi, pubescent, quinqueloculaire à déhiscence loculicide; style épaissi au sommel; stigmates 5, élargis ; semences glabres. - Lécorce de cel;arbusle se détache très facilement : on en fait des cordes solides. - Descourtilz met cette plante dans les purgatives hépatiques et dit que les fleurs sont émollientes et purgatives, que l'infusion faite avec la racine et les lenilles a des vertus sudorifiques, apaise la douleur des ophtalmies violentes offrant dessimptomes inllammatoires, ele. 1 la Guadeloupe, dans les endroits où cette plante existe, on se sert de l'eau tiède, dans laquelle on a macéré des fleurs, contre les maladies d'yeux. - Fl. presque toute l'année, mais surtout de novembre en mars. - Peu répandu. Gourbeyre (Val Canard); Houëlmont (batterie), Camp-Jacob (rivière Noire.) [No 2329.]

M.nтsiers. Vulgo: Mahol-frane, bois-de-liege. - Les pécheurs seservent de son bois blanc, léger et poreux, pour faire flotter leurs seines. - Assez abondant: Parnasse (habitation Litter, Duens, Lamentin, Marin MorneGommier), Sainte-Luce, etc. [Nos 2022, 2023.]

Thespesia Corr. du gree " thesbesios ", divin, parce qui on plante cet arbre dans les Indes Orientales autour des temples.)

T. populnea Corr.; T. qui tient de la nature du peuplier. Vulgo : Catalpa. Cav. Diss., 1. 50, f. 1. - Petit arbre, très touffu, à fronde arrondie, haut de f-fi mit. Feuilles très vertes, luisantes, fermes, presque coriaces, en corur it la base, deltö̈des et pointues. Fleur's axillaires, jannes, munes d'une lache noire au fond, ressemblant à celles du (sombo, mais plus petiles: calice tronqué ou aree 5 petites dents, cupuliforme, entouré de 3 folioles insolucrales disparaissant de bonme hemre. Fruil globuleux, vert, a pen pres de la forme et de la grosseur d'une néfle de France, a s loges indehiscentes, multiovenlées; péricarpe de la consistance du cuir: semences trigones, obovales, 
striées, poilues et anguleuses à la base. - Le bois est dur et sert pour la menuiserie et les travaux de Lour; l'eau dans laquelle on a macéré des feuilles est employée en lavement contre les hémorrhoüdes. - Très répandu. Abondant sur les plages sablonneuse- du bord de mer : Désirade, Marie-Galante. les Saintes, Sainte-Anne, Sénégambie, Indes Orientales, etc. $\mathrm{X}^{\circ} 2779$.

Mantriece. Vulgo : Caltappa. - Abondant. Trinité, Caravelle, SainteAnne, Tauclin. $\mathrm{N}^{\circ} 2024$.

De cette famille on cultive au Jardin botanique de Saint-Pierre et dans d'autres jardins le Goethea stricliflora Nees. el Mart. - Petit arbrisseau droit, haut de $80 \mathrm{~cm} .-1 \mathrm{~m} .20$, originaire du Brésil; remarquable par ses fleurs caulinaires garnissant toute la longueur de la tige.

vixgt-dectiline fanlele. - BOMBACÉES.

Pachira (nom qu'on lui donne à la Guyane).

P. aqualica Aubl., Garolinea princeps I. Lils, P. grandiftora Tuss.. Fl., IV' 1. 3 et 4; P. aquatique. Vulgo : Cacao sauvage. - Grand bel arbre, à branches cassantes. Feuilles larges, glabres, palmées, composées de 5-7 folioles obovales-oblongues, presque sessiles, glauques en dessous. Fleurs axillaires, à corolle longue de $25-30 \mathrm{~cm}$., à 5 pétales d'un rouge de f'eu, duvetés, en forme de lanières; élamines rouge foncé, très nombreuses, d'abord monadelphes sur une longueur de $5-6 \mathrm{~cm}$., se divisant ensuite en 12-16 faisceaux monadelphes, qui à leur tour se subdivisent en faisceaux plus petits; calice tronqué, cupuliforme, couvert d'un duret roux noir. Fruit capsulaire, de la forme et de la grosseur de celui du cacao, saufles sillons, noir, dureté, à 5 loges multiorulies. sourrant par déhiscence loculicide; semences ovoüdes, anguleuses, brunes en dehors, blanches en dedans : elles se mangent crues ou cuites sous le nom de châtaignes. - Fl. en lévrier et mars; fruits mûrs en juillet-août. - Çà et là dans la région inférieure et moyenne : Bagatelle, Basse-Terre (cour du Gouvernement), Camp-Jacob, etc. [N³068.

Martixiqle. Vulgo : Châtaignier. - Introduit de Cayeme, cultivé au Jardin holanique, d'où il s'est répandu dans le pays. [No 2043.]

Eriodendron Desc. (formé de deux mots grecs, qui signifient "laine " et "arbre ", allusion à la soie qui enveloppe les graines.)

E. an/ratchosum Desc.. Bombax Ceibal L..: Fridendre anfractuenx. Vulgo : Fromager. Car. Diss., 1. 151; Desc., vol. IV, 1. 247, p. 64. - Arbre gigantesque, le plus grand des Antilles a trone armé de piquants. surtont quand il est jeune, sourent ventru, a branches horizontalement et irregulierement 
disposées. Feuilles palmées, ì $5-7$ lolioles lancéolées ou oblongues-lancéolées. brièvement pétiolées, entières. Fleurs axillaires, fasciculées, ramassées it l'extrémité des branches, très nombreuses, pédonculées, corolle à 5 pétales cohérents à la base, couverts d'un duvet luisant, argenté en dehors; calice près de deux fois plus courts que la corolle, muni de 5 dents arrondies; élamines 5, subulées exsertes, unies à la base, portant chacune 2-3 anthères uniloculaires, formant ensemble un petil globule anfractueux; style élargi an sommet; stigmate capité. Fruit de la forme d'un petit concombre, rétréci ì la base, à 5 loges multiorulées à déhiscence loculicide; semences nombreuses, ovoïdes, pointues, de la grosseur d'un pois, enveloppées d'un duvel long, brun, cotonneux. - Fl. en janvier et lévrier; fruits mûr's en avril, mai. - Perd les feuilles tous les ans à l'époque de la floraison. - Le bois est mou et ne peut servir pour la construction. Les paurres utilisent quelquefois le coton pour faire des matelas, oreillers, ete. Les fleurs sieches exhalent une très agréable odeur: vertes ou sèches, elles ont toutes les propriétés émollientes des Malvacées. Selon Descourtil\%, qui range cet arbre dans la catégorie des plantes diurétiques, adoucissantes, la racine est apéritive el s'emploie avec succès dans les cas d'ascite ou d'hydropisie du ventre et d'anasarque ou d'hydropisie qui envahit les chairs; l'écorce de la racine serail romitive et son sue, joint à la pulpe de tamarin, provoquerait l'émission des urines et des déjections alvines. Je n'ai pas entendu dire qu'on se serve souvent de celte plante dans le pays. - Assez abondant dans les bois de la moyenne et surtout de la basse régrion : Basse-Terre, Le Baillif, Moule, Morne-à-l'Eau, etc. [ $\mathrm{N}^{\circ} 2322$.

Martinete. Vulgo : Fromager. - Basse el moyemne région : Carbel, Prêcheur, etc. [ [ $\mathrm{X}^{\circ}$ 2029.]

Ochroma Sw. (du gree " ochroma ", pâleur, à cause de la couleur pâle de ses tleurs.)

0. Lagopus Sw.; O. à fruits en palte de lièvre. Vulgo : Pripri, fromagermapou, bois-flot. Cav. Diss., t. 153. - Le plus souvent, arbre de taille moyenne, à branches horizontales el souvent inclinées, très cassantes. Feuilles très larges, un peu plus larges que longues, palminerviées, en cceur à la base, très grossièrement dentées, à 3 lobes peu marqués ou à 3 angles, couvertes en dessous d'un duvet roux, glabres en dessus. Fleurs de 13-14 cm. de long, terninales; corolle jaune pâle, à 5 pétales obovales, pubescents en dehors, ópais et charnus; calice à 5 lobes imbriqués, pubescents, dont deux plus courts ef pointus, avec la pointe réfléchie, et trois autres plus grands, arrondis; étamines en colonne tubuleuse ; anthères nombreuses, linéaires, plissées en zignzag, adnées à 3 masses charnues, contournées en tire-J ouchon el terminées par 5-6 segments; stigmates 5, exserts, linéaires, lordus en spirale en un corps cylindrique pointu; pédoncule longr portant 2-3 bractées caduques. Fruil

Dūss. - Plantes Guadeloupe et Martinique. 
capsulaire long de $20-25 \mathrm{~cm}$., pourvu de 5 sillons longitudinaux, profonds, à 5 valves multiovulées s'ouvrant par déhiscence loculicide; graines très nombreuses, arrondies, brunes, entourées d'un coton lin, roux pâle. - Fl. en mars et mai; fruits mûrs en juin et juillet. - L'écorce est très fibreuse el on en fait des liens très solides. Le bois, à cause de sa légèreté et sa porosité, est impropre à la construction; les pècheurs coupent les branches en morceaux et s'en servent pour faire flotter les filets et les seines; le bois, sec et tendre, sert encore a aiguiser les couteaux el les rasoirs. - Peu abondant. Cà et là dans les ravines, les savanes et les bois de la basse et de la moyenne récrion. Camp-Jacob (rivière aux Écrevisses), Le Baillif (habitation Sainte-Sophie), Deshaies, etc. [No 3634 .]

Martisigte. Tulgo : palte-de-lièrre, bois-flot, bois-rasoir, bois-de-liègre. Sert aux mêmes usages qu'à la Guadeloupe. Peu abondant. - Ajoupa-Bouillon, Fonds-Saint-Denis, hauteur de la Basse-Pointe. $\Gamma^{\circ} 2030$.

Myrodia L. (du gree "muron ", baume, à cause de l'odeur agréable qu'exhalent les fleurs et les graines.

M. turbinata L.; M. à calice turbiné. Vulgoo: Bois-lélé. Sw., Fl., t. 22, analys. - Petit arbre droil, à branches divariquées, irrégulièrement disposées, souvent pendantes, à écorce grise. Feuilles coriaces, elliptiques, entières, ressemblant à celles du cacaoyer, mais de moindre dimension. Fleurs pelites, axillaires et caulinaires, solitaires, fixées tout le long des branches, exhalant un parfum des plus exquis et qui persiste dans la plante sèche; corolle à pétales spatulés, d'abord blanes, ensuite jaunâtres, pubescents en dehors; calice d'abord ovoïde, ensuite turbiné, se déchirant irrégulièrement en $\{-6$ lobes, colonne staminale longuement exserte, élargie au sommet en 5 dents, portant 15 anthères sessiles et biloculaires; stigmate 1, capité. Fruit rond comprimé par le haut, indéhiscent, à 1-2 graines, à péricarpe ligneux. - Fl. de septembre en janvier. - Assez abondant dans les grands bois humides de la fontaine Absalon. [No 588.] - Nous ne l'avons pas trouvé à la Guadeloupe.

De celte famille, on rencontre çà et là l'Adansonia digitala L., originaire d'Afrique. Vulgo : Baobab, pain de singe'. Basse-Terre, enceinte du VieuxGouvernement, et à la Martinique au Jardin botanique, aux 'Trois-llets (habitation Anse-à-l'. Ane, au Robert, etc. [No 1500.

1. Pour les multiples applications des diverses parties de ce régétal à l'alimentation, à la médecine el à la fabrication de textiles, voir : $l^{\circ}$ L'étude de MII. Heckel et Schlagdenhaullen sur cette espèce joumal Les nouveaux remèdes, 1886). 20 Le travail (le M. Gerber sur le genre Ldansonia, dans Annales del Instilut colonial de Marseille, 1896. - La pulpe qui entoure les graines, les feuilles et l'écorce sont des émollients et des rafraîchissants. (E. II.) 


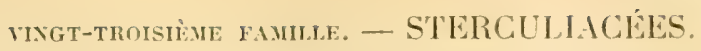

Sterculia L. (de "Sterculus », le dieu des latrines et inventeur des encrrais ; de "stercus \#, excrément, allusion à la mauvaise odeur des fleurs ou des fruits daus quelques espèces.)

S. caribia R. Br, et Benn.; Sterculier des Caraïbes. Vulğo: Bois-mapou, baril, mahot-cochon, bois châtaignier-grande-feuille. Ivira Sw. (partim). - Le plus souvent arbre de taille moyenne, droil, à tronc nu jusqu'à une wrande hauteur, généralement peu branchu. Feuilles ramassies à l'extrémiti des branches, blanchâtres en dessous, longuement pétiolées : les jeunes, ovales-oblongues ou elliptiques, entières; les moins jeunes, à 3 lobes peu marqués; les adultes, a j lobes aigus; petioles cylindriques élarpis et aplatis au sommet et à la base. Fleurs polygrames, apétales, en grappes terminales, solitaires ou réunies par plusieurs; calice rotacé-campanulé, à 5 segments profonds, ovales-lancéolés, de couleur de sout're, portant ì l'intérieur des nectaires: lube staminal terminc par 10 antheres it loures paralleles, ovaires s. distincts, multiovulés, insérés au sommet du carpophore; stigmate capité. recourbé, simple. Fruits brièvement stipités, situés horizontalenent, secs, normalement au nombre de 5 (souvent 1-4 par avortement), semi-elliptiques, biconvexes, couverts d'une pubescence légère, blanchâtre ou f'errugineuse, qui disparaîl de bonne heure, longrs de $7 \mathrm{~cm}$. sur $4 \mathrm{~cm}$. de large, s'ourrant en follicule en une valve ligneuse, dont l'intérieur est entièrement garni d'une couche serrée de poils droits rouge fonce, rigides, légèrement brulants, qui disparaissent sous l'action de la pluie ef du rent; pidoncule commun fort et gros, de longucur variable; sraine habiluellement f-j, léperement obovales. de la forme et de la grosseur d'une olive de France, à tête mince, coriace, très noir, poli, à albumen blanchître, charnu, à cotylédons loliacés, ì embryon droil, a radicule opposéce au hile. On rencontre indifréremment des pieds à feuilles entières et à feuilles it 3-j lobes. - Fl. habituellement deux fois par an, en octobre et novembre, en avril et mai. - Les graines sont bounes à manger et ont le goûl de la noisetle. Le bois est blanc et tendre el se fend très facilement; il sert surtout à faire des fonds et des couvercles de boucauts. - Assez abondant dans les bois des Bains-Jaunes, du Matouba, des Trois-Rivières, de la Ravinc-Chaude, etc. All. 150-1000 mèt. [No 2:345.]

Martinique. Vulgo: Mahot-cochon. - Assez abondant dans les bois de la Calebasse, de l'Ajoupa-Bouillon, des Fonds-Saint-1)enis, de la fontane Absalon et du Camp de l'Alma. - Sert aux mêmes usages qu’ì la Guadeloupe. [ $\mathrm{N}^{\circ}$ 2018.]

Le Sterculia coccinea Roxb., assez grand arbre à fleurs mâles en chatons

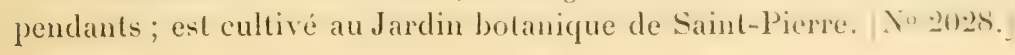


Le Cola acuminata R. Br. et Bemn, arbre originaire de l'Afrique tropicale: est cultivé à la Guadeloupe chez plusieurs propriétaires [ $\mathrm{N}^{\circ} 3680$ ], el à la Martinique au Jardin botanique, comme dans beaucoup d'autres endroits, où il fleurit el rapporte des fruits' 1 - Fl. en mai-juin. [N' 2019 .

L'Heritiera liltoralis Ait. Vulgo : Nirobolan bâtard, grand bel arbre de l'Asie tropicale, it lleurs en grappes terminales; se cultive au Jardin botanique de Saint-Pierre: il fleurit en août et septembre. $\Upsilon^{\circ} 2025$.

mixt-geatrìme mande, - BUETTXÉRIACÉE.

Guazuma L. (nom d'origine mexicaine.)

G. Lomentosa I am., Theobroma Guazuma L.; G. à feuilles duvetées. Vulgo: Hêtre gris. Car., Icones, III, t. 299. - Petit arbre ou arbre de taille moveme. fortement branchu. Feuilles distiques, oblongues-lancéolées, plus ou moins en ceur à la base, acuminées, finement dentelées, couvertes d'un duvet blanchâtre en dessous. Fleurs vert jaunâtre, en cymes axillaires, nombreuses: corolle à 5 pétales en forme de cuiller et terminés par un appendice linéaire-bifide; calice à 3 sépales tomenteux, rétléchis dans la fleur ouverte; étamines monadelphes; styles 5, contigus. Le fruit est une sorte de noix subdrupacée, tuberculée, globuleuse, pourpre noir, à 5 loges multiovulées, longue de 10-12 mm. sur 7-8 mm. de diam., loges tardivement déhiscentes. - Fl. de février en avril, et aussi en juin et juillet. - L'écorce fournit des fibres très tenaces : on en fait des cordes très solides; le bois sert pour la construction. - Cà et là dans la basse et la moyenne région. Camp-Jacob (rivière aux Écrevisses, Bas-Matouba, hauteur du Baillif, etc. [No 3603.]

Martixique. Vulgo : Bois de l'orme blane, mahot-baba. - Assez abondant dans la basse et la moyenne région. Route de Saint-Pierre au MorneRouge, Parnasse, Trois-Ilets, Basse-Pointe. [No 1.$]$

G. ulmifolia Lam.; G. à feuilles d'orme. Vulğo : Hêtre, bois de hêtre, bois de hêtre vert, mahot-baba. T'uss., Fl., IV, t. 24; Desc., vol. II, L. 85, p. 76. - De même taille que le précédent et ressemblant assez bien ì l'orme de France. Feuilles oblongues-lancéolées, obliques à la base, glabres des deux côtés, à l'exception des jeunes qui sont toujours plus ou moins duvetées

1. Ce précieux régétal et les espèces congénères utilisables ont été longuement étudiés par M. Heckel dans un mémoire intitulé Les Kolas africains inséré dans les Annales de l'Institut colonial, 1893. L'espèce a été introduite et préconisée à la Guadeloupe comme dans toutes nos colonies françaises par le professeur Heckel : on sait, par l'usauge quotidien qui s'en fait dans l'Europe entière à cette heure, que la graine de kiola est un des médicaments les plus reconstituants de l'oryanisme humain par les principes actifs qu'il renferme (kolanine, caféine, théobromine). (E. II.) 
en dessous. Branches grises : les jeunes, légèrement duvetées. Fleurs comme dans le précédent. Fruit ghlobuleux, légèrement comprimé au sommel. - Fl. en mai el juin; fruits mûrs en janvier et février. - Le bois est employé pour les constructions à l'intérieur. L'écorce est très fibreuse : on l'utilise dans les campagnes; dans la médecine domestique, celte même écorce jouit d'une grande réputation: on en fait une décoction à laquelle on ajoute du sirop ou du sucre et on en prend un petit verre-avant chaque repas pour exciter l'appétit et fortifier les estomacs faibles ou délabrés. Descourtilz, qui met le bois de l'orme dans les stomachiques astringents, dit que l'écorce du tronc et de la racine contient beaucoup d'acide gallique, qu'elle a une saveur amère, que les fruits donnent un suc stiptique, inodore et mucilagineux, et que la décoction de ses fruits est prise dans les affections dartreuses et syphilitiques dela peau, etc. - Dans la basse et la moyenne région : Camp-Jacob, Deshaies, embouchure de la rivière des Pères, ete. [No 2668.

Martingece. Vulgo : Bois de l'orme, orme du pays. - Assez abondant. On emploie dans les campagnes la décoction de la racine contre la gourme des chevaux. - Champtlore, Fort-de-France (La Dillon), Fontaine-Didier, Parnasse. $\Gamma^{\circ} 1370$.

Theobroma L. (formé de deux mots grees, qui signifient " nourriture des dievix".

T. Cacao (cacao, mol mexicain). Vulgo : Cacao ou cacaoyer. Sl., t. 160 ; Tuss., Fl., I, t. 13; Desc., vol. IV, t. 266, p. 147. - Petit arbre toulfu, rameux, à branches étalées, à écorce grise, originaire du Mexique; introduit par les Français dans les Antilles vers le milieu du xrri siècle. Feuilles

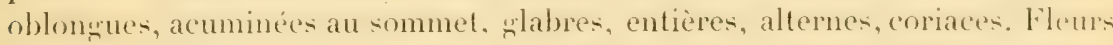
solitaires ou fasciculées, caulinaires, situées sur le tronc et les branches,

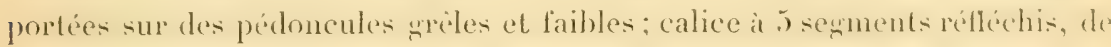
couleur rose ou blanche; pétales 5, blancs, à limbe en forme de cuiller, portant, inséré au milieu ou quelquelois à l'extrémité de ce limbe, un appendice spatulé, verdâtre; tube staminal court, portant 10 étamines, dont 5 stériles. sessiles, plus longues que l'ovaire, noir pourpré, dressées, effilées, très

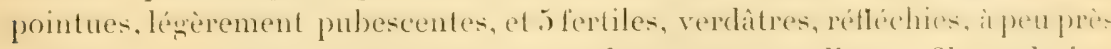
une fois plus courtes que les stériles et alternant avec elles, ì filet aplati el portant 2 anthères biloculaires. Fruit baccien, ovoïde, marqué de 10 sillons longitudinaux, long de 12-16 cm. sur 6-8 cm. de diam., jaune en dehors, on rouge, selon la variété, ì 5 loges indéhiscentes, contenant chacune 8-10 graines, orientées dans le sens de la largeur du fruit, nichées dans une pulpe blanche, quelquefois un peu jaunâtre, acide et très rafraîchissante. Les graines ressemblent assez, quant à la forme et la grosseur, it la fève des marais; péricarpe du fruit dur, coriace, épais. - Le cacao constitue une des 
principales den rées secondaires d'exportation. - Le cacanyer heurit presque toute l'année, mais on ne fail généralement que deux récoltes, la grande et la petite; la première a lieu d'octobre en janvier. - On extrait du cacao un corps gras, solide, appelé beurre de cacao. On torréfie les graines de la même manière que le café : on les concasse, on enlève les pellicules et on les fait bouillir; le beurre qui surnage est recueilli dans des vases : on le laisse ensuite refroidir. Ce beurre est souvent employé dans le pays contre les brûlures, en lavements contre les hémorrhoïdes, en frictions contre les enflures et les douleurs rhumatismales. Descourtilz, après avoir parlé des vertus béchiques adoucissantes du cacaoyer, dit que le chocolat est sans contredit le meilleur des stomachiques, qu'il produit même des miracles, quand il est bien préparé.

On rencontre principalement trois variétés qui diffèrent entre elles par le plus ou moins de régularité des sillons, par la forme, la grosseur et par la couleur extéricure des fruits. [No 2900.

Martineve. Vulgo : Cacaoyer ; cultivé dans toule l'île. [No 2309.]

Herrania alliffora Goudot. Yulgo : Cacan du Pérou; est cultivé au Jardin botanique, où il fleurit tous les ans, mais ne rapporte pas de fruits.

Melochia L. (du mol arabe "melochich ".

M. Iomentosa L.; M. duveté. Vulgo : Bois-champignon. Cav. Diss., t. 172, f. 2 ; Sl., t. 138, f. 2 et 3 . - Arbrisseau élégant, droit, à feuillage gris, haut de $1 \mathrm{~m} .50-2 \mathrm{~m}$. 50. Écorce noire, fibreuse, jeunes branches duvetées, grises. Feuilles plissées-reinées, plus ou moins en cour à la base, ou tronquées, irrégulièrement crénelées, à pointe arrondic au sommet, couvertes en dessous d'un duvet soyeux plus ou moins blane, grises en dessus. Fleurs en cymes terminales; calice couvert d'un duvet gris, à 5 lobes profonds, lancéolés, plus courts que la corolle ; corolle violet pâle, à 5 pétales obovales ; étamines cohérentes à la base; style 5 . Capsule duvetée, ventrue à la base, à 5 loges, à déhiscence loculicide, de forme trapézoïde-pyramidale, à 5 angles, lerminée en pointe. - Vit isolé ou en société sur les coteaux secs, arides et pierreux près de la mer. Le Baillif, Deshaies, Vieux-Habitants, MarieGalante. - Fl. de mars en juin. - Alt. 40-150 mèt. [No 2901.]

Martineve. Vulgo : Bois champignon, - Abondant sur les coleaux secs et pierreux, entre le Carbet et Case-Pilote, Caravelle. [No 1300.]

M. pyramidata L.; M. ì fruit pyramidal. Vulgo : Maure. Car. Diss., 1. 171, f. 1; S1., t. 139, f. 1. - Sullirutescent, haut de $40 \mathrm{~cm} .-1 \mathrm{~m}$. 30, à tige grềle, souvent presque sarmenteuse, à branches inclinées. Feuilles pétiolées, ylabres, oblongues-lancéolées, crénelées-serretés. Fleurs fasciculées, opposées aux feuilles, à pédoncules presque aussi longs que le pétiole, à corolle pourpre, plus rarement blanche; lobes du calice lancéolés, acuminés, un peu 
plus courts que la corolle. Fruit pyramidal, légèrement gonflé, ì ว̆ angles cuspiclés à l'extérieur, près de la base. - Abondant dans les terres cultivées et le long des routes de la basse région. Environs de la Basse-Terre, Pigreon, Vieux-Habitants, Lamentin. [No 2671.$]$

Ye se trouve pas it la Martinique.

M. nodiflora Sw.; M. à lleurs agghlomérées aux aisselles. Vulgo : Maure. Sl. 1. 13.), 1. 2. - Sulfrutescent, haut de $80 \mathrm{~cm} .-1 \mathrm{~m}$. 60, droil, glabre, très vert. Feuilles ovales, pointues au sommet, dentées en scie. Fleurs aggrlomérées aux aisselles des feuilles : les unes, sessiles; les autres, brièvement pédonculées, entourées à la base par plusieurs petites bractées vertes el pointues; corolle lilas, ou blanche rayée de lilas, à 5 pétales spatulés, presque aussi longs queles étamines el le pistil. Capsule pubescente, deux ou trois tois aussi grande qu'une tète d'épingle; semences très petites. - Peu abondant. Cà el lì dans les haies el les broussailles de la basse région : Basse-Terre (Morneà-Vaches), Vieux-Fort, Le Baillif. Alt. 0-210 mèt. [Y 2670 .

Mantixique. Vulgo: Mauve, - Egalement rare. Marin (environs de la ville), Saint-Pierre (Boulevard). - Fl. pendant l'hivernage. [No 1361.]

Waltheria I. déclic a Auguste-trangois Wallher, profensene a Leiprign, qui, en 1735 , a publié une description délaillée des plantes de son jardin.)

W. americana L.; W. de l'Amérique. Vulgo : Guimauve. Cav. Diss., t. 170, 171. - Suffrutescent, très droit, haut de $50-90 \mathrm{~cm}$, ; facile à reconnaître au duvel épais et gris qui couvre toutes ses parties. Feuilles ovalesoblongues ou oblongues-lancéolées, plissées, crénelées ou dentées. Fleurs petites, en gomérules larges, axillaires, tantit presque sessiles, tantit longurement pédonculées; pétales 5, jaunes; calice 5-fide, entouré d'un involucre latéral ; colonne staminale entière; style simple. Fruil à péricarpe bivalve.Vit solitaire ou en société sur les coteaux secs, pierreux, près de la mer : entre la Basse-Terre et Deshaies, Moule, Désirade, Marie-Galante. \Yo 266.

Martixique. Vulgo: Mauve-gris. — Carbel (quartier Monsieur), Caravelle Fond-Canonville, ete. $\left[\mathrm{N}^{\circ} 1362\right.$. $]$

W. glabra Poir.; IV. à leuilles glabres. Vulgo : Nahot-noir. - Sulfrutescent ou frutescent, souvent penché au sommet, glabre sur toutes ses parties, haut de $60 \mathrm{~cm} .-1 \mathrm{~m} .60$, à écorce noirâtre, très fibreuse. Feuilles et glomérules comme dans le précédent; colonne staminale divisée en 5 filaments, it partir du milieu. - Plante particulière à la Guadeloupe, à Marie-Galante et aux Saintes. Très abondant : environs de la Basse-Terre (La Pintade), plaine sablonneuse entre Saint-Louis et le bois de Folle-Anse (Marie-Galante), ete. - On en fait de gros balais pour les cours et les écuries. [No 2269.]

De cette famille, on cultive au Jardin botanique de Saint-Pierre le Commersonia echinata liorst., petit arbre à grandes feuilles duvetées en 
dessous, à fleurs en larges eymes axillaires, à fruits globuleux, hérissés et couverts de poils. $\left[\mathrm{N}^{\circ} 2023\right.$.

Abroma fastuosa Gaerl., arbrisseau des Indes Orientales, à feuilles larges orbiculaires, à lleurs en cymes terminales. [No2137.] A. angusla $\mathrm{L}_{\text {. }}$, it feuilles larges, trilobées, à fleurs axillaires, également originaire des Indes Orientales. X" 20136. Astrapæa Willichii Lind., petit arbre des Indes trientales, remarcuable par ses larges feuilles duvetées, à lleurs aggolomérées en capilules tris grands, suspendus it de tris longer pedoncules. Kleinhovia huspilit L. Cav. Diss., 1. 146, petit arbre, originaire de l'Asie tropicale, à lleurs en larges grappes terminales. Stadmannia australis (i. 1)on., petit arbe it feuilles larges, trilobées, duretées en dessous. Dombeya mollis Cav., à feuilles laineuses, trilobées, à fleurs en longues cymes axillaires.

VINGT-CIXQUỉie YAMLLE, - THALACÉES.

Triumfetta L. (dédié par Linné à Giov. Bapt. 'Triumfetti, mort en 1707; a écrit sur la vie des plantes; son frère, Lolius, élait prof'esseur de botanique ì Rome.)

T. Lappula I. (diminutif de "Lappa ", bardane, à cause des piquants crochus qui courrent le fruit et qui ressemblent aux piquants de l'involucre de la bardane.) Vulgo : Tête-ì-nègre. Desc., vol. II, t. 101, p. 135; Plum., édit Burm., t. 225. - Suffrutescent et frutescent, haut de $90 \mathrm{~cm}$.$1 \mathrm{~m}$. 90, droit, penché aux extrémités, à branches étalées, plus ou moins horizontalement, pubescentes. Feuilles finement duvetées, surtout en dessous, de forme variable: les adultes, à 5 lobes avee des sinus profonds et arrondis; les moins adultes, ì 3 lobes; les jeunes et les florales lancéolées, parfois linéaires, irrégulièrement dentées en scie, dents inférieures du limbe glanduleuses; pétiole pubescent. Fileurs en petites cymes arrondies composant de longs épis interrompus, qui forment ensemble une longue panicule entremêlée de feuilles; calice à 5 sépales; étamines 10 ; pétales nuls, ce qui distingue facilement cette espèce de la suivante à qui elle ressemble beaucoup. Le fruit est un akène globuleux garni entièrement de soies courtes et crochues, ce qui fait qu'il s'attache à tout ce qui le touche. - Écorce très fibreuse dont on peut faire des cordes très tenaces. Descourtilz range cette plante parmi les stomachiques astringentes. Dans le pays, on se sert de la racine mucilagineuse, après qu'on l'a laissée séjourner pendant plusicurs heures dans l'eau froide, en potion rafraichissante, pour préparer l'estomac à subir une purration; la' décoction de la racine est également employée contre la dysenterie. - Fl. vers la fin de l'hivernage el après cette 
saison; les theurs ne s'ourrent habituellement que dans l'après-midi et se ferment lard dans le soirée. - Vit en société dans les broussailles et endroits abandonnés ou incultes de la basse el de l'infra-moyenne région : Basse-T'erre, Le Baillif, Vieux-Habilants, Trois-Rivières, Lamentin, etc. [Y 1371.

M.rrtrique : Vulgo : Mahot-cousin, grand-cousin, hérisson-blane, cousin-blanc, - Abondant: Saint-Pierre, Prêcheur, Marin, Trinité, etc, $[$ No 1363.$]$

T. semitriloba L., T. heterophylla Sam., T. havanensis Kith.; T. it Lrois lobes. Vulgo : Cousin-pelit, tête-à-nègre. Desc., vol. II, t. 102, p. 137. Ressemble beaucoup au précédent par la taille et le port, avec lequel on le confond a première vue; il en diffère par la tige plus noire, ses fevilles moins duretées, ses lobes souvent peu marqués, ou s'ils sont nettement marqués, arec un sinus moins profond, mais surtout par ses 5 pétales, jaune foncé, vif et luisant, el ses étamines au nombre de 15. Mèmes localités que le précédent, mais plus abondant. Écorce également fibreuse el très tenace. - Avec ses racines, on prépare souvent des tisanes rafraîchissantes el antidysentériques. - Environs de la Basse-Terre, embouchure du Galion Sainte-Rose, Morne-ì-l'Eau, etc. [No 2902.]

Martixique. Vulgo : Petit-mahot-cousin, mahol-cousin-rouge. - Abondant: Saint-Pierre (Boulevard), Prêcheur, Carbet, Case-Pilote, Trinité, etc. No 1364 .

T. grandiflora Vahl.; T. ì grandes lleurs. Vulgo : Grand-cousin-bois. Frutescent, extrémités des tiges et des branches frutescentes, haut de $1 \mathrm{~m} .50-2 \mathrm{~m} .80$, droit, rarement ì branches pendantes ou sarmenteuses, pubescent dans le haut, écorce noire, très fibreuse. Feuilles larges, largement ovales, pointues au sommet, inégalement dentées en scie. Fleurs en cymes distancées, pédonculées, formant ensemble une sorte de panicule 'dichotome, à branches très écartées et divariquées; calice à 5 sépales lancéolés-linéaires, terminés par deux pointes, dont une courte, émoussée, ef lautre longue et infléchie; pétales grands, d'un jaune rert et luisant, obovales; étamines 20 ; stigmate à 5 branches. Fruit globuleux noir, à piquants crochus, longs, glabres. - Rare. Caì el lit dans les broussailles d'endroits humides de la moyenne région. Hoü̈lmont, Camp-Jacob (rivière aux Écrevisses), Malouba. - Fl. vers la fin et après l'hivernage. $\mathbf{N}^{\circ} 2318$.

Ne se rencontre pas à la Martinique.

Corchorus L. (du gree " liorchoros ", dérivé de "kore ", netloyer, purger. parce que ces plantes ont des vertus purgatives. Ce nom, employé par Théophraste, correspond à notre Anagallis arvensis L.)

C. siliquosus L.; C. ì siliques nombreuses. Vulgo : Petit-balai. S1., 1. 91, f. 1. - Suffrutescent, haut de $50 \mathrm{~cm}$. à $1 \mathrm{~m}$. 30, à branches et liges noires, 
souvent munies d'une ligne pubescente. Feuilles pelites, glabres, pointues, serretées. Fleurs petites, axillaires, solitaires ou rémies par 22-3; calice à 4-5 sépales lineaires; pétales $\mathbf{1}-5$, jaunes, obovales ou spatules ; itamines en nombre indéterminé; siliques longues de $5-7 \mathrm{~cm}$, linéaires, droites, comprimées, à loges multiovulées, s'ouvrant par déhiscence loculicide en 2 valves, munie chacune de deux petites cornes recourbées; semences petites, brunes, tronquées au sommet et à la base, contiguës les unes aux autres. Les fleurs ne

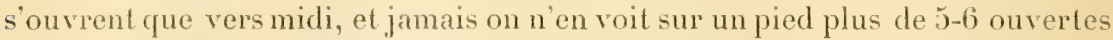
en même temps. - Vit en société dans les savanes sèches, arides et pierreuses près de la mer. Environs de la Basse-Terre (habitation l'Espérance, Guilhembarde), etc., Le Baillif, Deshaies, Vieux-Habitants, Moule, Désirade, Marie-Galante, etc. [No 2316.]

Mantmique. Vulgo : Zerbe-savane, balai. - Abondant dans les savanes sèches et pierreuses. Carbet, Prêcheur, Case-Pilote, Caravelle. [ $\mathbf{X}^{\circ} 1365$.

C. hirtus Pl., G. torlipes, St. Hil.; C. velu. Vulgo : Petit-balai. Plum., édit. Burm., 1. 103, f. 2. - Annuel, droit, haut de $40-70 \mathrm{~cm}$., sans branches ou peu branchu, à jeune tige garnie de poils fins, roux. Feuilles presque glabres, ovales, crénelées-dentées. Fleurs axillaires, réunies par 1-3 ì l'aisselle des feuilles; pétioles poilus; sépales poilus; pétales jaunes, spatulés; étamines nombreuses, en nombre indéterminé; silique longue de 2,5-3,5 cm., pointue au sommet, à deux loges déhiscentes. - Herbe de peu d'utilité. Rare. Cà et là dans les savanes herbeuses et dans les fosses, le long des chemins : Vieux-Fort. No 2903.

Martixive. Vulgo : Pelit-balai-poileux, - Endroils aquatiques el humides : Ducos, Trois-llets. [No $136 \%$.]

Heliocarpus L. (nom formé de deux mots grees qui signifient "soleil " et "fruit ", à cause des soies qui garnissent les bords du fruit, simulant un pelit soleil.)

H. americanus L. - Assez grand arbre, très toulfu, originaire de l'Amérique tropicale, cultivé au Jardin botanique de Saint-Pierre, d'où il s'est répandu dans les environs et se propage spontanément. Feuilles larges, orales, presque trilobées, jeunes branches duvetées. Fleurs blanchâtres, en grappes terminales, compactes. Fruit petit, elliptique, comprimé, à bords entourés de poils ciliés. - Trois-Ponts, Carbet, Prêcheur. [N० 1367.]

Sloanea L. (dédié à Sir H. Sloane, né en Irlande en 1660, mort en 1752, médecin du roi Georges II ; a voyagé à Madère, à la Barbade, à Saint-Christophe et à la Jamaïque; a publié, entre autres choses : Catalogus plantarum quax in insulâ Jamaïca sponte proveniunt et la Flore et la faune des îles ci-dessus dénommées.)

S. caribiea Kr. el Urb.; S, des Caraibes. Vulgo : Acoma-boucan. - 
Arbre gigantesque, le plus gros après le fromager, a trone nu à une grande hauteur, à base anfractueuse, à écorce grise ou noirâtre, à branches étalées. Feuilles coriaces, légèrement luisantes, elliptiques-ovales, i pointe arrondie au sommet. Fleurs petites, en cymes ombelliformes, trichotomes, formant ensemble des panicules terminales ou axilläres, portées sur de longs pédoncules gris et finement duvetés; calice à flobes, gris, duvetés des deux côtés. ovales, valvaires, réfléchis; pétales nuls; étamines nombreuses, cn nombre indéterminé, à anthères très allongées, presque deux lois plus longues que le lilet, un peu plus courtes que les sépales. Capsule de la grosseur d'une grosse noisette, couverte d'un duvet roux gris ou ferrugineux, globuleuxovoïde, marquée d'un ombilic au sommet, s'ourrant en 4 valves ligneuses, épaisses; semence unique, enveloppée dans sa moilié inférieure d'un arille d'un beau rouge foncé. - Cet arbre ne lleurit que tous les trois ou quatre ans, de mars en mai; les fruits restent longtemps sur pied : les grrands oiseaux en sont friands. - Le bois n'est guère employé pour la construction. - Assez abondant dans les yrands bois des Bains-Jaunes, au Malouba, au basin IBleu, des Trois-Rivières, de la Bouillante el de Pigeon. [Nos 2318, 348j.]

N'existe pas à la Martinique.

S. Massoni Sw ; S. de Masson. Vulgo: Châtaignier-grande-feuille. - Grand arbre à écorce noirâtre, rude, à jeunes branches convertes d'un duvet ferrugineux et fin. Feuilles larges, très coriaces, ovales, arrondies au sommet et à la base, pétiolées, duvetées en dessous et à nerrures très saillantes; pétioles duvetés; stipules linéaires. Fleurs en une sorte de petites panicules axillaires, situées pres de l'extrémité desbranches; calice de (i-10 sépales oblongs, lancéolés, acuminés; étamines pubescentes, nombreuses, un peu plus courtes que les lobes du calice; filets linéaires, aussi longs que les anthères; style exserte, 5-fide. Capsule grande, globuleuse, entièrement garnie de longs

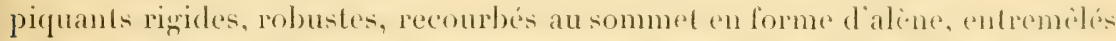
de piquants plus petits, plus minees et plus cour's ; péricarpe ligneux, d'une épaisseur de 10-12 mm., très dur, s'ouvrant en 4 valves par déhiscence loculicide; endocarpe d'un rouge foncé et brillant. - Abondant dans tous les grands bois. - Fl. en mai et juin. - Le bois vert est assez tendre; sec, il devient très dur : on l'emploie de préférence pour les constructions à l'intérieur, ne résistant pas longtemps à l'humidité; le trone, qui peut mesurer 1 mèt. de diamèt., lournil de belles planches. - Bois des Bains-Jaunes, du Matouba, de la Bouillante, ete. [No 3268 .

Martineue. Vulgo: Châtaignier-grande-feuille. - Abondant dans le bois des Fonds-Saint-Denis, de la fontaine Didier, de la fontaine Absalon, du camp de l'Alma, etc. [No 2109.

S. sinemariensis Aubl.; S. de Sinémarie. Vulgo : Châtaignier-petite-feville Aubl., Hist. de la Guy., t. 212. - Grand arbre à écorce rude, jeunes branches 
pétiolées, nerrures couvertes d'une pubescence fine, très courte el grise. Feuilles très coriaces, plus petites que dans le précédent, ovales, à base tantôt arrondie, tantôt cordiforme, tantôt tronquée, à sommet arrondi ou muni d'une pointe obtuse; pétiole épaissi aux deux extrémités, plus court que le limbe de la feuille; stipules petites, tombant de bonine heure. Fleurs en corrmbes axillaires ausi longs que les pétioles. Capsule ligneuse, dure, pelite. ovoïde, hérissée de poils ciliés, peu rigides et roux, longs de $4-7 \mathrm{~mm}$, it 4 loges s'ourrant en autant de valves par déhiscence loculicide; semences 1-2 (les 2 ou 3 autres avortant) enveloppées d'un arille pulpeux. - Fournit un des meilleurs bois de construction. - Fl. en juin, juillet, août. - Mêmes localités que le précédent. $N^{\circ} 2317$.

Mantrique. Vulgo: Châtaignier, châtaignier-petite-feuille. - Assez abondant dans tous les grands bois, mais surtout dans les bois des Fonds-SaintDenis. $[\mathrm{X} \div 1367$.

S. (spec.) Vulgro : Châtaignier-coco, petit-coco, châtaignier-petit-coco. Grand bel arbre, à fronde pyramidale, à jeunes branches grises et duvetées. Feuilles coriaces, ovales ou légèrement obovales, terminées en pointe courte et obtuse; pétioles courts, finement duretés, canaliculés. Fleurs en cymes axillaires. Capsule ovoïde, ì $\mathfrak{t}$ loges déhiscentes, dont une seule porte une semence (les autres avortant) de la grosseur d'une noix de France; ralves hérissées de soies courtes, droites ou courbées en alìne : les plus fortes, tuberculées à la base; péricarpe ligneux, très dur; endocarpe rougre et luisant du côté extérieur. - Fournit un bois de construction très recherché. - Assez rare. Cá et là dans les bois de la fontaine Absalon el du Champflore (bord de la rivière Claire). $\left[\mathrm{N}^{\circ}\right.$ 1363.] (Spécimen sans lleurs). - Nous ne l'arons pas trouvé à la Guadeloupe.

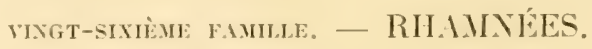

Condalia Car. dédie à l'Espannol Int. Condal, médecin et compasnon de Löflling dans ses royages.

G. ferrea (ir., Zizyphus emarginatus sw.. Ceanothus ferreus D)e.c.; C. it bois dur comme le fer. Vulgo: Petit bois-de-fer, bois de fer frane. - Arbrisseau ou petit arbre élécrant, ne dépassant guère 'f mèt. d'élération. Feuilles assez petites, luisantes, coriaces, minces, émaryinées au sommet, entières. Fleurs axillaires en cymes ombelliformes, aussi longues que les pétioles, portées sur des pédoncules courts ; pétales nuls; calice cupuliforme à 5 dents très courtes. Fruit drupacé, globuleux, noir, uniloculaire, de la grosseur d'une graine de poivre. - Fl. en avril, mai. - Peu abondant. Endroits secs, pierreux, chauds. Moule (dans les monceaux de pierres, le long du canal), 
hanteurs du Vieux-Fort, Gozier (bord de mer). - Le bois est trùs dur, mais flexible, et sert à laire des manches de toutes sortes d'outils. [Yo 3256.

Mantmeqe. Vulgo: Bois-de-fer, petite feuille. - Assez abondant sur les collines calcaires de Sainte-Anne, Caravelle (environs du Phare, dans les endroits couverts de pierres). [Xं 182.

Golubrina Rich. (du latin " coluber ", serpent, allusion it la disposition

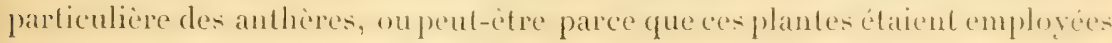
contre la morsure des serpents.

G reclinata Brongn., Rhamnus elliplicus Sw.; C. à branches inclinées. Vulgo : Bois-mabi. - Arbrisseau ou petit arbre, n’excédant guère 1-5̆ mèt. d'élévation, à tige droite, à branches allongées, fortement inclinées. Feuilles elliptiques-lancéolées entieres, portant quelquefois de petites wandes sur he bord, au-dessus de la base. Fleurs en cymes ombelliformes axillaires, vertes; calice adné à l'ovaire, à 5 lobes deltö̈des, et carénés au milieu, à l'intérieur; pétales 5 , spatulés, horizontalement étalés, alternant avec les lobes du calice: style trifide; étamines 5, insérées à la base des pétales et opposées à eux et les dépassant. Fruit globuleux, niché à un tiers près dans le tube persistant du calice, un peu plus grand qu'une graine de poirre, se divisant tardivement en 3 coques monospermes, qui s'ourrent du côté intérieur en 2 valves; semences à enveloppe (testa) coriace, très noire, polie, luisante. Avec le bois on fabrique une boisson acidulée, rafraîchissante et agréable, connue sous le nom de Mabie. - Fl. de juillet en octobre. - Introduit de Saint-Martin, cultive au Jardin botanique et it l'hripital Militaire de la BarseTerre. $\mathrm{N}^{\prime \prime 2}-2.39$.

Martixique. Vulgo : Bois-Mabi. - Rare. Cà et là quelques pieds dans les hanteurs du Dianant terres de l'habitation kikandon et de Sainte-Lucie. No 641.$]$

G. astatica Brongn., Geanothus L.; C. de l'Asie. - Arbrisseau ou petit arbre ì branches très allongées, plus ou moins sarmenteuses; à feuilles très luisantes, ovales, dentées; ì fleurs en cymes axillaires; à graines et fruits comme dans le précédent. - Est cultivé au Jardin botanique de Saint-Piorre. d'où il s'est répandu dans les environs et pousse spontanément. Probablement introduit de la Jamaïque, ou il est indigène. Cav., Icones, t. 1 tí. X"s.

Gouania L. (dédié par Linné it Ant. Gouan, né en 1733, professeur de botanique à Montpellier, défenseur de Linné, auteur de plusieurs Flores de Montpellier el d'autres ourrages de botanique, mort en 182.2.

G. domingensis I.; Gouania de Saint-Domingue. Vulgo : Liane-saron. Jacq., Sel. Am. stirp. hist., f. 117. - Liane vivace, ornementale, d'une hauteur indéterminée, a branches très allongées, flexibles, pendanter, sonvent 
munies de rrilles. Feuilles luisantes, alternes, palminerviées, elliptiquescrénelées, crénelures distancées el souvent terminées par une glande. Fileurs en petites cymes formant des grappes terminales el axillaires, pédonculées, allongées, odorantes, siluées à l'extrémité des branches et simulant une large panicule feuillue; tube du calice adné à l'ovaire; pétales spatulés à 5 lobes et opposés aux lobes du calice: style trifide. Capsule à 3 ailes arrondies au sommel el a la base, el se séparant en deux cloisons à la maturité du fruit; semences 3, noires, polies, convexes sur: le dos, à deux faces du côté intéricur. - Fl. de novembre en mars et aussi d'avril en juin. - Assez abondant. Bord de mer, entre la Basse-Terre el la rivière des Pères, halliers près de l'embouchure du Galion, Houëhmont. Alt. 0-250 mèt. [No 2979.]

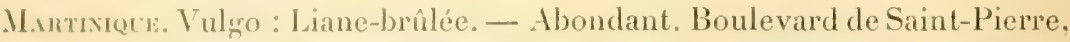
'Trois-Ponts, Parnasse, Carbet, Prêcheur, Marin au pied du morne Gommier. $\mathrm{X} \cup(j \mathrm{j})$.

Zizyphus T. (du mol arabe "zizul").

Z. Jujuba Sam, ; J. Jujube. Vulgo : Surette. - Petit arbre pouvant devenir, selon les endroils, arbre de taille moyeme, souvent tortueux, à écorce blanchâtre. Branches llexibles, lléchies en zigzag, infléchies et souvent presque pendantes, épineuses: les jeunes, finement duvetées; épines 1-2, à l'aisselle des feuilles, semblables aux griffes de chat, noires et luisantes a l'extrémité. Feuilles elliptiques, finement dentelées au-dessous de la base, à 3 nervures principales, couvertes en dessous d'un duvet serré fin et blanc, d'un vert tendre en dessus; péliole court, duvelé. Fleur's verdâtres, en cymes axillaires tout le long des branches; tube du calice adné, à 5 lobes libres, deltoïdes rolacés; pétales 5, petits, spalulés, tronqués au sommet, creusés en goutlière, alternant arec les lobes du calice, penchés en dehors; étamines 5, adhérentes, par la base, aux pélales el opposées à eux; filets vigoureux, comprimés; anthères introrses, à 2 logres; style le plus souvent trifide, plus rarement bifide; ovare niché dans un disque angruleux sur les bords et adné. Fruil de la grosseur d'une olive, ou un peu plus gros, ovoüde, globuleux, a 2 loges contenant chacune une graine, pulpeux, pulpe jaune verdâtre en dehors, presque blanche en dedans; noyau volumineux, dur, bosselé, épineux; semences jauntras, ovales-arrondies, aplaties. - Les fleurs exhalent une odeur lorte el matraise, qui derient très incommode pour certaines persomnes; la pulpe est acide el très rafraîchissante : on en prépare des confitures el des gelées exquises. I.e bois est dur et sert pour la construetion. - Fi. de juin en octobre. - Très probablement introduit. Abondant dans les environs de la Basse-Terre; assez abondant au Baillif el au Moule, çà et lit aux 'Trois-Rivic̀res, au Gozier, au Morne-it-l'Eau; assez abondant it MarieGialante. $\left[\mathrm{X}^{\circ} 20238\right.$.

Mantrace. Vulgo : Jujubier. - Était cultivé autrelois au Jardin bola-

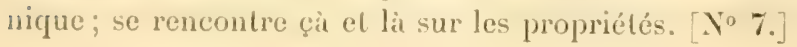


vingt-SEPTİ̀M: RMLLE. - AMPÉLIDÉES.

Cissus L. (du grec " kissos ", lierre, parce que ces plantes sont volubles et grimpent comme le lierre.)

G. sicyoides L., G. ovata Lam., G. smilacina Kith.; Cissus ressemblant au Sicyos, qui est une Cucurbilacée. Vulgo : Liane-molle, liane-it-eau, lianedes-chasseurs, liane-brûlante, liane-douce. - Sl., I. 14́4, l. 1; Desc., vol. V. 1. 309 el 311 ; vol. VII, t. 481. - Vivace, grimpant, pourvu de vrilles, s'élevant sur des arbres de grande altitude. Tige cylindrique, nue, verte ou rougre, fendillée. Branches llexibles, pendantes. Fenilles simples, cordés-oburater. charnues, luisantes, dentées en scie, surtout vers le sommet, dents très aiguës, inclinées vers le limbe. Fleurs jaune verdâtre, en ombelles composées, axillaires, nombreuses; calice à 5 dents courtes; pétales 1 , adhérents au sommet, disque à 5 lobes. Fruit globuleux, noir, pulpeux, environ deux fois plus gros qu'une graine de poivre, contenant une seule semence. - Les fruits ne se mangent pas, mais les oiseaux en sont friands; avec les tiges, quand elles sont débarrassées des parties corticales, on fail des liens asse\% solides. Ces mêmes tiges, surtout quand elles sont jeunes, contiennent de l'eau, et Descourtilz, qui met cette liane dans les rafraîchissants aqueux, dit, p. 24, qu'on dome l'eau pour apaiser la soil des fiérreux : ils s'en trouvent soulagés. Dans le pays on ne s'en sert pas. - Fl. de juin en septembre. - Très abondant dans les parties inférieures et basses de la Guadeloupe et de la Grande-Terre. [No 2958.]

Mantixique. Vulgo : Liane-douce, liane-corde. - Très abondant dans toute l'île: Carbet, Saint-Pierre, Prêcheur, Trinité, etc. [X'1812.]

On rencontre dans les jardins de la Guadeloupe et de la Martinique le Cissus discolor Bl., originaire de Java, une des plus belles lianes, très remarquable par ses f́euilles panachées.

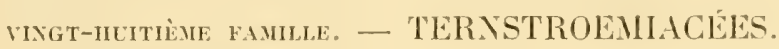

Ternstroemia L. (dédié au Suédois C. T'ernstroem, naturaliste, mort en 1745 , pendant son voyage d'exploration en Chine.)

T. obovalis Rich.; T. à feuilles obovales. Vulgo : Bois-vert, cacao-montagne. Rich., Fl. de Cuba, t. 25. - Grand arbre, se laisant remarquer de loin par la verdure foncée de ses feuilles. Feuilles entières, petites, obovales ou spatulées, arrondies au sommet, rétrécies à la base, coriaces, souvent roulées sur les bords. Fleurs d'un blanc mal, solitaires, situées à l'aisselle des 
feuilles, vers l'extrémité des branches pédonculées; pédoncule près de la moitié aussi long que le limbe de la leuille; sépales 7 , disposés sur 3 rangs, 2 extérieurs, très pelits el opposés, 22 au milieu el 3 à l'intérieur; les jo derniers arrondis au sommet; péláles j, cohérents à la base el porlant les étamines: ćlamines nombreuses, en nombre indéterminé, à filels courts, it anthères jaunes, linéaires, dressés; style filiforme, stigmate simple, capité. Fruit sec, indéhiscent, ovale, environ deux fois plus grand qu'une noisette, surmonté du style persistant. 2-5) loges, ne renfermant i la maturité que ¿-f traines, - Fl. d’aril en juin. - Le bois est recherché pour les construelions à l'intérieur. - Peu abondant. Çà el là dans les grands bois des TroisRivieres, du Matouba: très rare dans les bois des Bains-Jaunes. - Dans la haute région, comme a la Sarane a Nulets et i la Sarane aux Ananas, cet arbre reste à l'élat d'arbrisseau rabourri. - Alt. $450-1100$ mèt. [No 2987.$]$

M.nтmiget, Vulgzo: Bois vert, bois-l'épreuve. - Plus abondant qu'à la Guadeloupe. Bois des Fonds-Saint-1)enis ravine de la rivière Colas), de Case-Pilote et de la fontaine Absalon. Alt. 380-901 mèl. [No638.

T. elliptical Rich.; T. à feuilles elliptiques. - Petit arbre peu branchu, à branches horizontalement étalées, à écorce grise. Feuilles ramassées à l'extrémité des branches, elliptiques ou spatulées, entières, rétrécies à la base, souvent échancrées au sommet, plus petiles que dans le précédent et beaucoup moins rertes. Fleurs blanches, plus grandes que dans l'espèce précédente, axillaires, solitaires, portées sur des pédoncules comprimés, pendants plus longrs que la moitié du limbe de la feuille; sépales disposés comme dans le précédent, mais brusquement terminés en pointe; pétales soudés, dans leur moitié inférieure, en un lube ventru, à 5 lobes deltoïdes. Fruit largement ovale, sec, surmonté d'une pointe courte et robuste, qui est un reste du style persistant, de la grosseur d'une noisette; semences oboroüdes-blanchâtres.Peu répandu. Cà el là dans les mornes sees et pierreux du Vieux-Fort, assez abondant dans les sables du bord de mer, du bois de Folle-Anse, à MarieGalante. - Fl. de mars en septembre. [Nos 2352, 3651.]

M.ntrieul - Peu abondant el peu répandu : Case-Pilote (dans un endroil sec el pierreux du Plateau-Militaire). [ $\mathrm{X}^{\circ} 1825$.

Freziera Sw. (dédié à Amédée Frezier, ingénieur, né à Chambéry, mort en 1773 ; a entrepris, par ordre du Gouvernement, un voyage scientifique au Pérou el au Chili.)

F. cordala Tul.; F' à lleurs en cour. Vulgo : Bois-d'épice, goyavier-montagne. - Arbrisseau haut de 1-2 m. 50, à branches inférieures couchées : les supérieures, très étalées el souvent pendantes; jeunes branches et jeunes l'euilles couvertes d'un duvel roux et couché. Feuilles larges, très rapprochées, coriaces, sessiles, en curur à la base, à lobes amplexicaules, dentées en scic, ovales-elliptiques, ressemblant assez ì celles du goyavier ordinaire; 
nervure principale très forte, nervures secondaires très rapprochées, nombreuses, saillantes en dessous, imprimées en dessus. Fleurs axillaires, réunies par 3 en une glomérule très brièvement pédonculée; sépales duvetés, pétales? (spécimen imparfait). — Fruit noir, ovale surmonté du style persistant. - Abondant à la Montagne-Pelée, surtout aux environs du lac. —Fl. a toutes les saisons de l'année. - Alt. 900-1000 mèt. \No 576.7 Ne se trouve pas à la Guadeloupe.

F. undulata Sw. Ternstroemia salicifolia D. C.; I', is feuilles ondulées. Vulgo: Graine bleue des hauts. - Petit arbre, droit, élégant, rarement arbre de taille moyenne, à branches tantôt plus ou moins horizontalement chateces. tantôt fastigiées, it jeunes branches el feuilles couvertes d'un durel sorreux. brillant el roux. Feuilles lancéolées-elliptiques, vert jaunitre, surtnut en dessous, terminées en pointe, rétrécies à la base, dentées en scie. Fleurs polygames, axillaires, réunies par -2-5, a prédoncules presque aussi loners que les pétioles, blanches; sépales 5 , arrondis, ciliés, les 2 extérieurs une fois plus courts que les 3 intérieurs qui, eux-mêmes, sont trois fois plus courts que les 5 pétales; stigmates 3, distincts. Fruit a 3-5 logres multiovulées, noir. ovoïle, muni du style persistant. - Abondant dans les bois du Matouba, du morne Matelyane et dans la région supérieure du morne de la Madeleine (Trois-Rivières). - Le bois sert pour les constructions à l'intérieur. - Fl. habituellement d'octobre en décembre et de mars en juillet. [ $\mathrm{N}^{\circ} 2988$.

Martinique. Vulgo : Bois anonli. - Abondant dans les bois de la Calebasse et du Champflore. [No 644 .

F. elegans Tul., Gleyera theoides Planch., C. elegans Chois.; F. élénant. Vulgo : Bois-de-savane. - Petit arbre ou arbrisseau très élégant par son port et son feuillage d'un vert jaunâtre doré, à écorce noire, à branches étalées ou fastigiées. Ressemble beaucoup an précédent; en diffère par sa taille plus faible, ses feuilles plus petites el it dents plus aignë́s, ses fleurs de moindre dimension, réunies le plus souvent par deux, ses fruits plus petits at plus allongés. - Plus rare que le précédent et confiné dans la région supé rieure des montagnes: Savane a Mulets el Savane aux Ananas, etc. No 3 \{:26i.

Martinique. Vulgo : Bois-montagne, bois-anoli. - Abondant aux DeuxChoux et dans les bois des Pitons-du-Carbet. [No 64 a a.]

VINGT-NeUViène FAMLLE. - OCHNACÉLS.

Gomphia Schreb. (du gree." gomphos ", clou, allusion it la forme des pétales.)

G. nitida Sw.; Gomphia à feuilles luisantes. Vulgo : Bois-baguette (it Diss. - Plantes Guadeloupe et Martinique. 
Pigeon). - Tantôt arbrisseau buissonneux, élégant, tantôt petit arbre à branches disarquese, haut de i-jo met. et perdant complitement les feuilles à l'époque de la floraison, à bois dur mais flexible, à écorce gríse, polie. Feuilles petites, coriaces, luisantes, ovales-elliptiques ou nettement elliptiques, crénelées-dentées ou finement dentelées, à dents très pointues, piquantes et infléchies vers le limbe; nervures fines, irrégulières, peu saillantes. Fleurs d'un jaune vif, en panicules axillaires et terminales, courtes, très nombreuses, pédonculées; pédicelles linéaires, noirs, articulés au-dessus de la base; boutons floraux nettement ovales, environ deux fois plus longrs que les pédicelles; sépales 5 , bruns, réfléchis dans les fleurs ouvertes, ovales, les 2 extérieurs plus étroits ; pétales 5 , hypogynes, onguiculés, un peu plus longrs que les sépales et alternant avec eux; étamines 10 , hypogynes; filets courts; anthères dressées, introrses, oblongues, jaunes, biloculaires, sourrant par 2 pores; style central simple, droit, plus long que les étamines; ovaire à 5 loges profondes uniorulées; inséré sur un carpophore, lequel, grandissant, fait que les loges se séparent pour former 5 fruits distincts. Fruits 1-5, drupacés, ovoïdes noirs, poils insérés obliquement dans le tiers supérieur du carpophore obconique charnu, long de $5-6 \mathrm{~mm}$. sur 6-7 mm. de large, persistant longtemps après la chute des fruits. - Fl. en arril et mai. - Assez abondant dans les terres basses, sèches et pierreuses de Pigeon et de la Bouillante. $\left[N^{\circ} 2307.\right]$

Martinique. Vulgo : Bois-café. - Gà et là dans les terres sèches et pierreuses et dans les falaises de la presqu'île des Trois-Ilets. [No $\mathbf{N}^{\circ}$.

G. longifolia Desc., Gomphia ì longues feuilles. Vulgo : Café-bois au Camp-Jacob, langue-à-bouf à Gourbeyre. - Petit arbre ou grand arbuste peu élégant, haut de 3-4 mèt., à branches peu nombreuses, très divariquées, horizontales on inclinées. Feuilles longues de $15-2.2 \mathrm{~cm}$. sur $5-8 \mathrm{~cm}$. de large, coriaces, polies, entières, elliptiques, légèrement cordées à la base, à côte forte et très saillante en dessous. Fleurs d'un jaune d'or vif, plus larges que dans le précédent, disposies en panicules très lâches et pendantes; pétales ausil longt que les sipales: étamines, pistil comme dans le précédent. Fruits 1-5, insérés sur un carpophore obovale, très noirs, polis, de la grosseur d'une petite olive. - Fl. presque toute l'année, mais surtout de septembre en février. - Assez abondant dans le bois de Matouba, des Bains-Jaunes, de la Pointe-Noire; assez rare à Gourbeyre (Mornes-Goblin et Hirondelle). [No 3243.

Ne se trouve pas à la Marlinique.

Thexrìme Fande. - GUTTIFliRE.

Glusia L. (dédié par Limné à Ch. de l'Écluse, en latin "Clusius ", né à

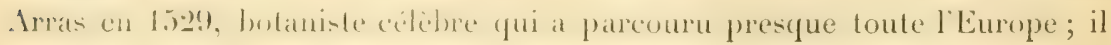


fut, de 1575-1583, directeur du Jardin botanique de Viemne et, en 1593, professeur de botanique à l'université de Leyde, où il mourul.

G. rosea L.; Clusia à tleurs roses. Vulgo: Figuier-maudit, figuier-mauditmarron. Tussac, $F l$., IV, I. 15; Desc., vol. VII, t. 485, p. 145. - Grand arbuste ou petit arbre parasite, à branches allongées, droiles, à rameaux tantòt fastigiés, tautôt horizontaux; pousse quelquelois sur les rocher's, mais le plus sourent sur les arbres qu il entrelace de ses racines, les étreint peu it peu et finit par prendre leur place. L'écorce est lisse et noire. Dans les hautes montagnes, ils vivent à terre et souvent en société. J'ai vu, au morne Diablotin de la Dominique, une grande forêt uniquement composée de ces arbres. Dans ce cas, leurs racines adventives sont courtes et très fortes; suls poussent dans le haut des autres arbres, les racines adventives deviennent alors très longues, pendent verticalement et se ramifient. - Toutes les parties de la plante, surtout les fruits, contiennent une sorte de gommerésine, très gluante, janne et légèrement aromatique. Les fruits sont, paraitil, un poison pour les animaux qui en mangent accidentellement; cependant les oiseaux sont friands de ses graines et s'en trouvent bien. Descourtilz range ce végétal dans la catégorie des détersives et lui attribue toutes sortes de vertus; dans nos îles, on n'en fait absolument aucun usagre dans la médecine domestique. Le bois est léger el ne sert qu'à faire du charbon'. - Fl. habituellement de mai en juillet. - Abondant dans la haute et la moyenne région des grands bois des Bains-Jaunes, du Matelyane, du Matouba, de la Pointe-Noire, de la lBonillante, ete.; plus rare dans la basse régrion (route de Sainte-Rose au Lamentin). Alt. 15-1000 mèt. [No 3168.

Je crois que le Clusia alba, considéré comme une espèce particulière par Jacquin, n'est que le G. rosea à fleurs blanches.

Martixique, Vulgo : Aralie, aralie-z'abricot. - Également abondant dans les grands bois des Fonds-Saint-Denis, de l'Ajoupa-Bouillon, du Champthore, du Parnasse, de la Fontaine-Absalon, etc. Un le rencontre quelquefois sur le bord de mer, dans les endroits éventés : Trois-llets. [No 1829.$]$

C. renosa Jacq.; Clusia à feuilles veinées. Vulgo : Palétuvier-montagne, mangle-montagne, mangle-rouge-montagne, figuier-maudit-montagne. Arbrisseau ou petit arbre tortueux dans le bas, droit par le haul, d'une élevation de 2 à 3 mèt. 50, à écorce noire ou noirâtre. Feuilles largeś, entic̀res, très épaisses et coriaces, opposées, largement obovales, arrondies ou presque tronquées au sommet, rétrécies à la base, ramassées à l'extrémité des branches; pétiole très court, s'élargissant et devenant semi-amplexicaule. Fleurs bien plus petites que dans le précédent, disposées en une sorte de panicule terminale, portant le plus souvent une cymule terminale de 7 -ln

1. Cette espèce et les deux suivantes laissent exsuder du tronc et des étamines une gomme-résine jaunâtre, épaisse, balsamique, amère, qui est réputée purgative. (E. H.) 
ritroms, of plu- has -2 amules latimales plus pelites, portant chacume 3 rayons;

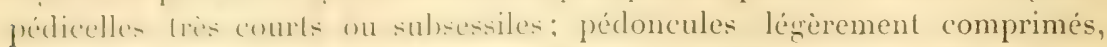

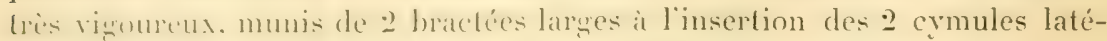
rales; calice à $6-8$ pétales scarieux, fermes : les 2 extérieurs, opposés; les

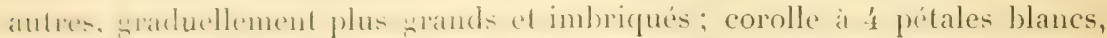
imbriques: étamines nombrenses, en nombre indétermine; stizmates -4-5 prentue sesiles; antheres lineares, james, dresses. Fruil tardivement déhiscent, jaunâtre, de la grosseur d’une petite olive. - Produit assez rarement des fleurs, mais on troure sourent des fruits, qui mûrissent très lentement. - Vit isolément ou en société dans les parties des hautes montagnes frès éventées. - Ses tiges, dans leur moitié inférieure, portent des racines adventives recourbées en are; celles qui sont près de la terre deviennent souvent chevelues, - Savane à Mulets, Grande-Découverte, Sans-Toucher, Savane aux Ananas, elc. Alt. 1000-1200 mèt. [No 2351.]

La Martinique ne possède pas cette plante.

Tovomita Aubl. (du mot "Tovomite ", employé chez les Galibis à la Guyane pour désigner cette plante.)

T. Plumieri (ir. : Tovomite de Plumier. Vulg̈o: Mangle-bois, paléturier grand-bois. Plum., édit. Burm., t. 87, f. 2. - Arbre élégant, au-dessus de lit liille mornne, trés banchu, branches inférieures longues et horizontales, le bas muni, sur une étendue de 1 mèt., de racines adventives nombreuses ardubes, sonfonganl dans la tere, flexibles, de l'épaisseur d'une barnette. lesilles culieres, lareses, fermes, elliptiques on lexirement obovales, mucronées, portant 8-10 nervures principales distancées. Fleurs blanches, polygames, exhalant une forte et agréable odeur, en cymes courtes, corymbilommer. Irminales, composée de 3-7 ravons; pidicelles articulés au-dessus dela base, plus longs que les boutons: calice a f sépales persistants, opposés, (oncaves. bruns : corrolle rosacée de tétales imbriqués, hypogryes, blanes, opposés aux sépales, orales, arrondis; étamines nombreuses, en nombre indefemines libes, linéaires, jaunes, de Inngueur légèrement inégale, insérées sur un réceptacle large et charnu; anthères jaunes, biloculaires, s'ouvant lompiludinalement, alnes au sommet des filets; ovaire libre, sessile, at

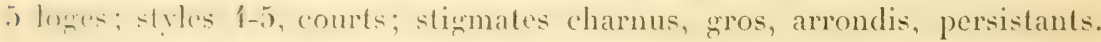
Fruit drupacé, noir, s'ourrant par déhiscence septifrage comme celui du Clusia rosea, plus petit que lui. - Fl. d'avril en juillet. - Toutes les parties du végétal contienment une assez forte dose de gomme-résine; le bois est

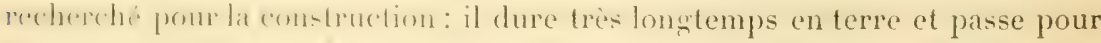
Chre incorruptible. - Assez aboudant dans les bois de l'Ajoupa-Bouillon, du Mone-kouge, etc. Alt. 500-800 mèt. [No 1834.] - Je ne l'ai pas trouvé à la (inadeloupe. 
Moronobea Aubl. (nom de la plante chez les Galibis de la Guyane.)

M. coccinea Aubl., Symphonia ylobulifera L. f.; M. à fleurs écarlates. Vulgo : Palétuvier jaune. - Grand bel arbre, très remarquable par la beauté et la richesse de ses fleurs qui se succèdent pendant deux mois, par son feuillage toujours très vert; trone droit et nu jusqu'à une grande hauteur, d'une álévation de 20-35 mèt.; écorce grisatre ou noiratre, presque lisse, couverte de nombreuses aspérités blanchàtres; branches sourent pendantes; racines adventives peu considérables, naissant près de la base clu tronc sur une étendue de 2-3 mèt. Feuilles de la grosseur et de la forme de celles du muscadier ordinaire, à nervures tris rapprochies, droites, fines, visibles seulement ì la surface inféricure. Fleurs d'un rouge écarlate foncé, très nombreuses, en cymes ombelliformes, axillaires et terminales; pédicelles comprimés, épaissis au sommet el i la base; boutons floraux, gros, ovoüdes; calice a 5 sépales persistants, imbriqués, arrondis : Ies deux extérieurs, plus petits; pétales 5, fortement rélléchis et roulés en dedans dans la fleur ouverte, insérés sur un disque hypogrne et annulaire; étamines 15-20, insírées sur un disque, soudées en un tube conique-ventru; qui se fend par en haut en 5 segments planes et arqués auxquels sont adnées 3-4 anthères linéaires, introrses, paralleles et longitudinalement déhiscentes; style cylindrique, vigoureux; stigmates 5 à segments rotacés, pointus, exsertes; ovaire libre, renfermé dans le tube staminal, it 5 loges contenant chacune 2 ovules dont I avorte souvent. Fruit ovoüde, drupacé, indéhiscent, long de 3-1́ cm.; péricarpe cartilagineux, mince, lisse en dehors el jaune à la maturité du fruit; embryon sans albumen, comme dans les deux espèces suivantes; cotylédons charnus, ne s'ouvrant pas lors de la germination, munis sur toute leur surface de sillons ou de fossettes longitudinales, irrézulièrement disposées; radicule léyèrement courbe, tournée vers le micropyle. - Toutes les parties de la plante contiennent une gromme-résine jaune, épaisse, tris visqueuse '. Le bois est rouge ou jaunâtre à l'intérieur, dur et très apprécié pour la charpente, le charronnage : on en fait aussi de belles planches; les vers ne l'attaquent pas, et il résiste longtemps à l'humidité. - Vit en société dans l'étang du Valcanard (Gourbeyre). Abondant sur les bords du Grand-Étang et de l'Étangr-Zombi (Capestere), où il devient tris grand; dans les marécages de l'îlet La Jaille (Baie-Mahault) et dans les marécages des montagnes (Matouba). Alt. 30-800 mèt. [No 2350.

La Martinique ne possède pas ce bel arbre.

1. Cette substance nommée Résine de Mani ou de Manil s'épaissit à l'air et prend une coloration d'un vert noirâtre qui lui donne quelque ressemblance avec la résine de Caragne (Icica Carayna H. B. K.) Elle est employée pour le calfetage des navires et sert ¿ fabriquer des torches. C'est également au même végétal qu'il faudrait attribuer, selon le $\mathrm{D}^{\mathrm{r}}$ Bancroft, la résine-cochon (Hog-gum des Anglais) qu'on rapporte d Hedwigia balsamifera Swartz. C'est douteux. (E. II. 
Mammea I. (du latin " mamma », mamelle, allusion à la forme du fruit.)

M. americana L.; Vulgo : abricotier du pays. Tuss., Fl., III, t. 7; Desc., vol. 1, t. 2, p. 8. - Arbre majestueux, très élevé; à large frondaison; à funilles mmemulates, wrandes. luisantes: a fleurs blanches, axillaires, odorantes, monoïques ou polygames. Les fruits mûrs se mangent crus, sans apprêts, ou à table, apprêtés avec du sucre ou du vin blanc sucré. La

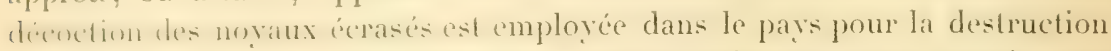
des tiques. I.e bois a une leinte rouse, se lend facilement el peut servir pour la construction'. Descourtilz, loco cit., vante les propriélés stomachiques, astringentes de l'écorce et des fleurs; dans le pays on ne s'en sert que rarement. - Fl. habituellement deux fois par an, - Assez rare dans les bois de la moyenne région, plus abondant autour des habitations de la zone inférieure et basse. Alt. 10-500 mèt. [No3467.]

Martinique. Vulgo: Abricotier. - Assez abondant. [No 1828.]

M. humilis, variété macrophylla Mart.; M. à petite taille. Vulgo : liois-]'menent. a cause de son sue jaune et gluant; Rheedia lateriflora L. Plum., édit. Burm., t. $25 \%$; Desc., vol. I, t. 343, p. 149; Tuss., Fl., III, 1. 32. - Petit arbre, haut de 6-7 mèt., rarement plus élevé, fortement branchu : jeunes branches, comprimées, écorce lisse, noire. Feuilles elliptiquesoblongues nu orales, rigides. luisantes, polies, termineses par une pointe obtuse: nervures fines, non paralleles el légèrement saillantes des deux côtés: pétioles épaissis an point d'insertion, et ridés, noirs. Fleurs très nombreuses. pelites. blanches, fres odorantes, situés tout le long des branches, solitaires cu réunies par fascicules de 2-6j rayons, portées sur des pédoncules épaissis au sommet, 4 ou 5 fois plus longrisque les fleurs ; sépales 2. opposés, arrondis all sommel. pelits, 3 fois plus courts que les pétales et tombant après l'éclosion de la lleur: pétales i, spatulés-arrondis; etamines 12-20, libres, hypos.yers: anthires pelites, arrondies, introrses, obliquement adnées au sommet du filet. Fruit drupacé d’une grande beauté, long de 6-7 cm., ovoïde, à péri-

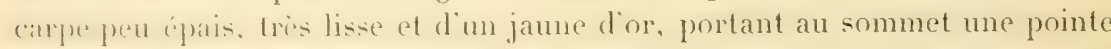
Ironquée et courte; semences le plus souvent 1, rarement 2, plus rarement 3. is surface irrégulierment reusée de petits sillons longitudinaux; cotylédones 2, s'ourrant en deux moitiés égales. - Fl. généralement de mars en avil: frnits murs en juin ef juillet, aout. - Aucun animal ne les mange. De toutes les parties de l'arbre découle une gomme-résine, épaisse, d'une

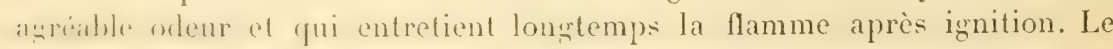
bois est blanc à l'intérieur et s'emploie souvent pour la charpente et la menuiserie. Ie bas du frone émet sourent des racines adrentives droites ou

1. L'écorce donne une gomme-résine appelée Résine de Mami; elle est usitée par les nésres prour faciliter la sortie des épines qui s'introduisent dans leurs pieds. L'écorce est encore employéc aux Antilles en décoction contre les maladies parasitaires et pour le pansement des plaies phagédéniqques. Mlême observation pour l'espèce suivante. (E. H.) 
arquées. - On rencontre deux variétés, une qui pousse dans les falaises et endroits rocailleux du bord de mer ou un peu à l'intérieur, l'autre dans les grands bois humides. Ies saintes bord de mer de la Terre-de-Basj, VieuxFort, Gozier, Désirade bord de mer, IIouëlmont batterie, hauteur de la Bouillante et de Pigeon. Alt. 10-400 mèt. [No 2353.

M.nтाNiqle. Vulyo : Cirnyer, abricol batard, abricot bord-de-mer, abricntmontagne. - Caravelle (près du bord de mer); très abondant dans les bois de la Savane de Saint-Cyr, entre Case-Pilote et la fontaine Absalon. $\left[\mathrm{N}^{\circ}\right.$ 1831.]

Calophyllum L. (formé de deux mots grees qui signifient "belle fecuille n: " calos ", beau, "phullon ", feuille.)

C. Calaba L. (nom caraïbe de la plante). Vulgo : Galba. Jacq., Sel., Americ. stirp. hist., t. 156; Dese., vol. II, t. 74, p. 30. - Grand arbre, droit, souvent plus ou moins tortueux, à tronc jusqu'à 1 mèt. de diamètre. Fournit un des meilleurs bois de construction : il est très résistant, dure longtemps dans la terre et dans l'eau; il est également recherché pour le charromnage et la tabletterie; l'écorce est aromatique!. Selon Descourtilz, loco cit., les fleurs et l'écorce ont des vertus stomachiques et astringentes; dans le pays on ne s'en sert pas souvent. - Fl. ordinairement en juin et juillet. - Basse-Terre sur les terres du Jardin botanique), Camp-Jacob (habitation Rollin), Pointe-Noire (le long de la Rivière de la Petite-Plaine), etc. $\left[\mathrm{N}^{\circ}\right.$ 2349.]

Martinique. Vulgo : Galba. Plus abondant qu'à la Guadeloupe: on la plante en lisières à la place du Pois doux, pour abriter les plantations. $\left[\mathrm{N}^{\circ} 1833.\right]$

Trexte-unièe famile. 一 CANELLACÉES.

Canella P. Br. (de l'espagnol " canela », qui, lui-même, dérive du latin "canalis ", rigole, tuyau, parce que l'écorce se vend enroulée en cylindre.)

G. alba Murr., Winterana canella L., G. laurifolia Lodd.; Canelle banche. Vulgo : Bois-canelle. Fl., t. 191, f. 2); Desc.. vol. VII, 568. p. 22.9): Br. Jam., t. 27, f. 3. - Grand arbuste ou petit arbre à écorce grise, à branches très nombreuses, droites, inclinécs, très feuillues. Feuilles toujours vertes, très rapprochées, parsemées de glandestranslucides, entièress, spatu-

1. De cette écorce découle naturellement ou après incision une oléorésine qui, après dessication, forme le haume vert de l'Amérique, ou baume Jarie, ou baume vert des Antilles, substance très parfumée, douée d'une agréable odeur de mélilot. Ce produit est employé avec succès, aux Antilles, comme vulnéraire dans le pansement des plaies de mauvaise nature. Les graines renferment une huile résineuse verte. (E. II.) 
lées, brièvement pétiolées. Fleurs très odorantes, en corymbes bien fournis, lerminaux; calice à 5 sépales persistants, imbriqués, courts, arrondis et concaves au sommet; pétales 5, imbriqués, charnus; élamines 10-20 hypogynes, soudées en un tube élargi à la base et tronqué au sommet, plus courtes (que les pétales; anthères 10, adnées, jaunes, parallèles, contiguës, ì deux loges sourrant longitudinalement; pistil renfermé dans le tube stamiminal; style cylindrique, court, ferme; sligmate persistant, à 3 lobes à peine distincts; ovaire à 2 loges. Fruit globuleux, un peu plus grand qu'une Æraine lrâche de poivre, remplie d'une matière visqueuse, brune et très. aromatique, dans laquelle se trourent superposées 1-3 semences, noires, luisantes à testa crustacé. - Toutes les parties de cette plante sont aromaliques, antiscorbutiques, mais c'est surtout dans l'écorce que résident les propriétés toniques et stimulantes qui lui ont valu une si grande réputation. Elle les doit à une huile essentielle, à saveur chaude, brûlante et d'une âcreté très prononcée!. Au lieu et place de la canelle blanche, dans le commerce et en pharmacie, on utilise, sous le nom d'écorce de Winter, une écorce sarmenteuse qui provient d'un arbre de la famille des Magnoliacées, la Drymis II interi Furst, oringare du délroit de Magellan, mais on emploie

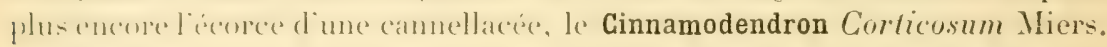
- Mbondant sur le plateau calcaire de la Désirade; moins abondant sur le plateatu entre Port-Lonis et l' Anse-Bertrand; assez rare à Marie-Galante; tres rare aux Saintes (Terre de Haut). - Fl. de juin en septembre; fruits mûrs en avril, mai, juin. $\left[\mathrm{N}^{\circ} 2869\right.$.

Mantivique. Vulgo : Canelle-bois. - Très rare. Je n'en ai trouvé que 'quelques pieds sur un morne pierreux des hauteurs du Fond-Layette CasePilote). [ $\mathrm{N}$ \% 1501.$]$

TRENTE-DEUXì̀e FAMLLE. - MARCGRAAVIACEES ? .

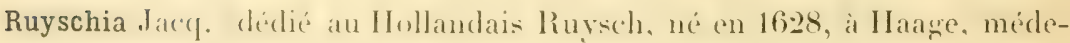
cin et prof'esseur d'anatomie à Amsterdam, mort en 1717; son fils Henri étail également médecin et botaniste, mort en 1731 .

R. clusirfolia Jacq., Ruyschia à feuilles de Clusia. Vulgo : José, boisJosé. - Arbrisseau voluble-grimpant, s'élevant très haut sur les arbres, ̀̀

1. Celte écorce renferme en dehor's de l'huile essentielle $(10 / 0)$, de la résine, un principe amer, de lit mannile, du mucilage et de l'amidon. Cette huile essentielle renferme quatre huiles differentes dont une est identique avec l'acide eugénique. Elle a une odeur qui rappelle celles de la menthe et du cajeput. (E. H.)

2. Celte petite famille est aujourd'hui considére avec raison comme formant une simple section des Ternstrœmiacées. (E. H.) 
branches très nombreuses et très enchevêtrées, à écorce noire. - Feuilles entieres, alternes, obovales, articulées à la base el laisisant après la chute de larges cicatrices, coriaces-charunes, brievement péliolese a nerrures imperceptibles, à cote large, aplatie. Fleurs en mrappes terminales, spiciformes. souvent très allongées, toujours dressées; pédicelles courts, un peu plus longs que les fleurs; d'abord réfléchis vers l'axe de la grappe, ensuite horizontaux; calice it 7 stepales arrondis el imbriqués, les 2e extérieurs plu. courls. Au sommet de chacque pédicelle pend, inséré it angle droit, une bractée charnue, persistante, ou un ascidium en forme de cuiller, très concave, qui se termine par une pointe tournée de bas en haut; pétales 5 , fortement réfléchis; étamines 5, ì anthères basifixes, allongées, introrses, quadriloculaires, à déhiscence loneritudinale; pistits concrescents. formant une petite colonne; stigmates étalés, sessiles; ovaire libre a J loges imparfailement séparées par des cloisons et renfermant 3-6 ovules. Fruit globuleux, de la grosseur d'un pois, à péricarpe charnu-coriace, s'ouvrant de bas en haut par déhiscence loculicide : graines petites, noires, anguleuses. - Assez abondant dans les bois inférieurs et moyens des Bains-Jaunes, du Matouba; plus rare

Gourbeyre (morne Goblin). - Les fruits frais se mangent et ont le groût de la fraise. - Fl. d'octobre en janvier. [No 2302.]

Martingue. Vulgo : Aralie petite-feuille. - Cà et là dans les bois des Fond-Saint-Denis, des hauteurs de l'habitation Pecoul, etc. $X^{\circ} 1827$.

Marcgraavia L. (dédié par Linné au Hollandais Georges Marcgraal, né en 1610, à Sebstadt; a voyagé dans l'intérèt de la botanique : au Brésil, de 1636-1643; à la Guyane, en 1641; en Chine, où il est mort; a écrit avec Pison : Historia naturalis Brasilix.)

M. spiciflora Rich.; M. à fleurs en épis. Vulgoo: José-vrai. - Arbrisseau droit ou tortueux, haut de 1-3 mètres, à tige souvent noueuse et toujours nue dans le bas. Feuilles comme dans le précédent. Fleurs en grappes corymbiformes, longues, de $8-10 \mathrm{~cm}$, axe de la grappe plus gros que la tige;-pédicelles fortement épaissis au sommet, longs de 3-3, $5 \mathrm{~cm}$., subeylindriques; calice a 6 sépales imbriqués, les 3 extérieurs plus petits ; ascidium en forme de cuiller naissant au-dessous du milieu des pédicelles; corolle en forme de cape, conique avant louverture, it f-5 pétales, rétléchis dans la fleur épanouie; etamines habituellement 20, uniseriées, légèrement concrescentes à la base et insérées sur un disque étroit entourant l'ovaire ; anthères biloculaires, blanches, introrses, s'ouvrant longitudinalement, articulées avec le filet au-dessus de la base ; stigmate sessile; oraire longitudina-

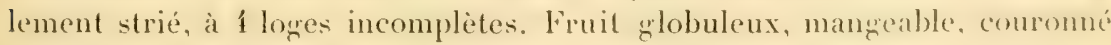
par le style persistant. Lardivement et irrégulièrement déliscent de bas en haut, légèrement ruguleux, à péricarpe résistant; graines nombreuses, petites, noires, luisantes, polies, tantôt obovales, tantôt arquées, tantôt 
plus ou moins réniformes. - Vit isolément ou en société dans les sphaignes, sur les montagnes les plus élevées : Savane aux Ananas, Savane à Mulets. plateau et cône de la Soufrière, elc. - Fl. d'octobre en février. - Alt. $1200-1470$ mèt. [No 2303.

Il n'existe pas à la Martinique.

M. umbellata L., M. coriacea V.; M. à fleurs en ombelles. Vulgo : Boiscouilles. Br. Jam., t. 25; Tuss., Fl., IV, t. 13 ; Desc., vol. IV, t. 239,

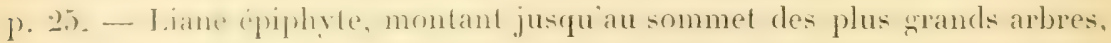
tries remarqualhe par les changements que subissent les feuilles el les tiges. Dans le premier âge, les tiges sont filiformes, rampantes, très radicantes et fortement altachées aux pierres, souches et trones sur lesquels elles poussent; les feuilles, longues de $3-15 \mathrm{~mm}$., sont pétiolées ou sessiles, presque linéaires d'ảbord, ensuite elliptiques et sans nervures. Dans le second âge, les liges deviennent striées, comprimées, tétragones et se couvrent souvent de petites écailles; les feuilles ont une longueur de 30-40 mm. sur une largeur de 20-30 $\mathrm{mm}$.; elles sont subsessiles, cordées à la base, ovales, arrondies ou échancrées au sommet, très souvent crénelées et toujours minces et translucides sur les bords: la face supérieure porte frequemment des panachures ou des stries blanchâtres, un des lobes basilaires el quelquefois les deux couvrent la tige, la côte est bien prononcée, mais les nervures sont à peine perceptibles dans les feuilles vertes. I l'àne adulte, les tiges sont plus ou moins cylindriques, quelquefois tout à fait cylindriques, et tout en restant radicantes elles émettent des branches d'abord dressers, ensuite pendantes, florilères; les feuilles sont longues de 8-10 $\mathrm{cm}$., brièvement pétiolées, ovales-elliptiques ou ovales-oblongues, ricrides, it coite, nervures et nervilles bien prononcées, et rappellent assez, bien celles de certains merisiers (Eugenia), ou encore celles du caféier. Dans les endroits ombragés, les feuilles adultes sont moins développées et prennent une forme linéaire-lancéolée, ont une cote rouge et forte, point de nervure el la lace inférieure est couverte d'un duvel court ef ferrugineux. Fleurs verditres, en ombelles pendantes terminales comptant jusqu à 23 rayons Innguement pédicellés, ruguleux et couverts de lentilles allongées ou rondes et blanchàtres; pédicelles extérieurs ébracténlés, les 3-5 du centre changés en bractées longnes, en forme de sac largement nuvert avec des pédicelles soudés à la base, ce sont des rayons extérieurs de l'ombelle; corolle en forme de capuchon, qui ne s'ouvre jamais et tombe d'une seule pièce; étamines nombreuses, droites, insérées sur le calice: anthères recourbées. Fruit de la urosseur d'une cerise, plus large que long, gris-brun ou rouge et ruguleux en dehors, surmonted d'un mamelon strié, reste du stigmate persistant. - . Bondant dans tous les srands bois de la Guadehoupe. . 1tt. 100-950 mèt. [No 2301.]

Mantixique, Vulgo : Bois-pétard. - Dans tous les grands bois. [No 1826.$]$ 1)e cedte familleon cultive at la Basse-Terre et a la Pointe-i-Pitre le Norantea 
guyanensis Aubl. (IIisl. de la truy., t. 2200). grande liane origimaire d. la Guyane, it racines adventives, aériennes, filiformes, très Inngues, at leuilles épaisses, luisantes, à fleurs violettes, tries allongrés. Les pédicelles porient de grandes bractées écarlates en forme de sac, qui produisent le plus bel effet. Elle fleurit régulièrement d'octobre en janvier, mais sans produire de fruits. $\left[\mathrm{N}^{\circ} 3208.\right]$

Martinique, - Jardin botanique; introduit en 188\%. [No 2110.

TRENTE-TROISİ̀e FAMLLE. - HYPÉRICINÉES.

Marila Sw.; (du nom carä̈be de la plante dans les Antilles.)

M. racemosa Sw.; Marila à fleurs en grappes. Vulgo : Bois casse-rose. Petit arbre peu élégant, dépassant rarement 8 mètres d'élévation, à branches allongées, souvent horizontales el inclinées, à écorce zrrise. Fenilles distiques, pétiolées, oblongues-lancéolées, ressemblant a celles du cachiman Anona reticulata L.); à limbe de $14-17 \mathrm{~cm}$. de long sur $3-4 \mathrm{~cm}$. de large, pourvues d'une multitude de points et de lignes diaphanes, à nervures aboutissant it un are marginal. Fleurs blanches, trè odorantes, en grappes simples, axillaires et terminales, plus courtes que les feuilles; pédicelles plus courts que les fleurs; calice persistant, à 5 sépales imbriqués, presque égaux, un peu plus courts que les 5 pétales hypogynes et alternant avec les sépales; étamines nombreuses, en nombre iudéterminé, hypogynes, placées sur plusieurs rangs; sépales et pétales très réfléchis dans les fleurs ouvertes: anthères blanches, dressées et oblongues, s'ourrant longitudinalement, terminées par une glande; ovaire libre, oblong-linéaire, à $3-4$ loges; style très court; stigmate capité, persistant. Fruit capsulaire en forme de silique, longr de $3-4 \mathrm{~cm}$., s'ouvrant en 4 valves, par déhiscence loculicide; semences très petites, nombreuses, imbriquées, comprimées et ciliées. - Fl. de mai en juillet. - Le bois est mou et blanc en dedans et sert tout au plus pour les constructions à l'intérieur. - Assez abondant dans les bois des BainsJaunes, du Matouba, de Pigeon, des Trois-Rivieres, de la Ravine-Chaude. Alt. 190-900 mèt. [No 2435.]

Martrigle. Vulgo : Bois-cachiman, cachiman grand-bois. - Champllore, Calebasse, Fonds-Saint-Denis, fontaine Absalon. [No 1835 a.]

TRENTE-QuatrièMe Famille. - SALiCiNÉES.

De cette famille, on cultive deux espèces introduites: $1^{\circ}$ Salix Ilumboldtiana W. Vulgo : Saule-peuplier, arbre ornemental, ressemblant au 
peuplier d'Italie. - Il ne fleurit pas dans le pays. - Abondant à Monteran, cà ef là ì Gourbeyre, aux Trois-Rivières et au Camp-Jacob. [No 3769.]

Mantinequ. Vulgo : Saule-peuplier. - Fort-de-France (derrière l'hôpital Militaire, et au Collège), ete. [No 495.] 20 Salix babylonica Sw. Vulgo : Saule-pleurur. Lasso-Tore Jardin bolanique, élablissement de Versailles), Pigeon (gendarmerie), Pointe-ì-Pitre, elc. - On ne connaît que les fleurs femelles.

TRFTE-CINQUÈ̀e FAMLLE, - SAUVAGLSIÉES 1.

Sauvagesia Jalcy. (déclić à l'r. Boissier de Saurages (Saurages de la Croix), né en 1706, à Alais, mort en 1767, d'abord professeur de médecine, ensuite profenserur de botanique à la Faculté de médecine de Montpellier, auteur de : Methodus foliolorum, ou classification des plantes d’après la forme de feuilles.)

S. erecta L.; Sauvagésie droite. Vulgo : Thé-de-montagne, herbe de SaintMartin, thé-savane. Br. Jam., t. 12, f. 3; Desc., vol. IV, t. 299, p. 310.Herbe anmelle, d'abord droite, ensuite plus ou moins couchée, à tige flexible, mince, souvent radicante, quelquefois un peu sarmenteuse, haute de 20-70 ('m. Fieuilles elliptiques-lancéolées, petites, serretées, pointues, rétrécies à la base en un court pétiole; stipules ovées-lancéolées, à longues branches sur les bords. Fleurs blanches, à corolle rotacée, portées sur des púdoncules filiformes axillaires; sépales 5, persistants, lancéolés, acuminés et sétifères au sommet, presque aussi longs que les pétales et la capsule; pétales 5, caducs, obovés; étamines sur 2 rangs: les extérieures, nombreuses, stériles; celles du rang intérieur, 5; entre les deux rangs se trouve une série d'écailles blanches, pétaloüdes; style simple, ovaire-uniloculaire à trois loges s'ouvrant par déhiscence marginicide; semences petites, crustacées, attachées a 3 placentas. - Très abondant dans toutes les savanes humides et dans les clairières et sentiers des bois. - Fl. toute l'année et constitue un fourrage assez apprécié. - Dans la médecine domestique, cette herbe jonit d'une srande réputation : on l'emploie fréquemment en inlusion contre la toux, les bronchites, les rhumes. Descourtilz, loco cit., la place à juste titre dans les béchiques aromatiques et la recommande, en outre, at cause de ses propriétés amieres el aromatiques, comme stomachique, cordiale el digestive." - Alt. 40-1100 mèt. [No 2439.]

1. Cette petite famille est aujourd'hui généralement considérée avec raison comme une simple tribu des Violacées. (E. H.

2. Cette plante, qui mériterait une étude plus complète de ses propriétés médicinales, est employée couramment à la Guyane française, où elle est commune, comme diurétique dans les affections des voies urinaires et comme antidiarrhéique. (E. H.) 
Martnreve. Vulgo : Thé-savane. - Abondant el employé dans tout le pays contre la toux et les maux d'estomac. [ $\left.\mathrm{N}^{\circ} 1777.\right]$

\section{TREXTE-SIXIÈMe FAMLLe. - ÉRYTHROXYLÉES.}

Erythroxylon L. (de deux mots grees, qui signifient "bois ") et "rouge ".)

E. obtusum Desc., E. areolatum Poep.; E. à feuilles obtuses. Vulgo : Bois-marbré bâtard, bois-vinette petite-feuillle. - Arbrisseau toulfu on grrand arbuste, rarement petit arbre, droit, à branches fastigiees, ou horizonLales ou inclinées, à écorce grise et couverte, dans les jeunes branches, d'une multitude de lentilles blanches. Feuilles petites, ovales ou légèrement obovales, membraneuses, très entières, lisses, glauques, blanchâtres en dessous, vert pâle el luisantes en dessus, brièvement pétiolées, à nervures peu prononcées : les jeunes, traversées par deux veines latérales arquées et formant un aréa lancéolé. Fleurs blanches à odeur de miel, attirant une masse d'insectes ailés et de petits oiseaux, disposées par fascicules axillaires et caulinaires sur de petites protubérances; pédicelles filiformes, plus longs que les pétales; stipules alternes, nombreuses, triangulaires, subulées, élargies à la base, insérées à la base des feuilles et des pédicelles; calice monosépale persistant, à cinq divisions profondes; corolle à 5 pétales onguiculés, doublés à l'intérieur de deux écailles adhérant aux onglets ; étamines 10, monadelphes ; ovaire de 1-3 loges; styles 3, libres. Fruit drupacé, rouge, ellipsoïde, pourvu de 3-5 sillons, peu profonds, longitudinaux; semence 1. - Cet arbuste perd habituellement les feuilles à l'époque de la floraison. - Assez abondant ì Vieux-Fort (au pied de Houëlmont), Gourbeyre (habitation Bisdary), où il se plait dans le terrain sec, pierreux. - Le bois est dur et fibreux : on en fait des manches d'outils. - Fl. régulièrement d'avril en juin. - Alt. 15-300 mèt. [ $\mathrm{N}^{\circ} 2404$ b.]

Martinique. Vulgo : Brésillet. - Endroit secs et pierreux : Prêcheur Carbet, Case-Pilote, Marin (morne Gommier). [No 661 a.]

E. ovatum Cav., E. havanense Jacq.; E. à feuilles ovales. Vulgo : Boisvinette. Cav. Diss., VIII, t. 535. - Ressemble beaucoup au précédent et n’en diffère que par ses feuilles plus arrondies au sommet qui, au lieu d'être yrlauques en dessous, sont d'un vert pâle des deux còtés, et par ses pédicelles plus longs. On rencontre du reste entre l'E. obtusum et oratum de nombreuses variétés qui permettent de croire qu'il existe des hybrides entre ces espèces. - Abondant dans les mornes calcaires des Grands-Fonds, de Marie-Galante, de la Désirade, etc. - Fl. en mars et mai. - Alt. 0-200 mèt. [Nos 2404, 3399.] 
Ifartingue. Vulgo : Cerisier bâtard. - Abondant à la Caravelle et sur les mornes de Sainte-Anne. No 661 .

E. squamalum Tahl.; L. squanneux. Vulgo : Girofma ipour les bûcherons de Houëlmont), grande-vinette, bois rouge à grives. - Grand arbuste ou pertit arlore, facile a distinguer des deux précédents : par son port, ses feuilles d'un vert foncé, surtout en dessus, beaucoup plus larges, rigides, très ourertes alliptiques terminés brusquement en une pointe obtuse, munies sonvent de denx glandes a lá base, du còté supérieur; par ses stipules plus larges el moins rapprochées, qui garnissent les jeunes branches; par ses pédoncules quadrangulaires, sépaisissant graduellement jusquau sommet: enfin par ses fruits beaucoup plus volumineux, longs de 6-13 mm., d'un rouge tres foncé. - Peu abondant. Dans les bois de la movenne et de la base région, aux endroits abrités contre les vents, il ne perd pas ses feuilles lors de la lloraison: Bains-Jaunes, Matouba, Trois-Rivieres, ete. Alt. 160-1000 mèt. [N०2402.]

Martinique. Vulgo: Bois-piquette, bois à graines rouges. - Assez abondant dans les hauteurs de Case-Pilote, dans les bois du Morne-Rouge et dans les bois de la Régale. [N¹813.]

Erythroxylon Coca L. Cav. Diss., VIII, t. 229. Vulgo : Le coca. - Origrinaire du Pérou et du Brésil ; a été introduit à la Guadeloupe où l'on cultive

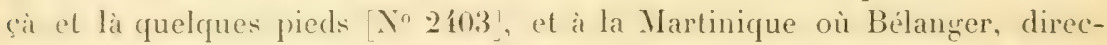
leur du Jardin botanique, a lait en 1869 des essais d'acclimatation. Les cultures ont parfaitement réussi, mais ont été abandonnées. On sait qu'on extrait des fenilles un alcaloüde : la cocainne, qui est un puissant anesthésique local et passager'. [No 1812 .

\section{TRENTE-SEITIÈME: FAMILIE。 - MALPIGHIACÉES.}

Byrsonima lich. (tu gree " burseucin ", tanner, parce que les écorces de toutes les espèces contiennent beaucoup de tanin.)

B. lacrigitla Rich.; Bypsonima a feuilles lisses. Vulgo : Abricotier hàtard. - Très grand arbre, haut de 20-30 mèt., à tronc droit, nu, anfractueux à la base, at frondaism tries ample. Feuilles larges, coriaces, ovales-elliptiques, (b)tnément printues an sommet. Fleurs jaunes en racèmes terminaux; calice muni de 10 mtandes: pétales 5. ondulés sur les bords, styles 3. - Fl. en avril el mai fruits murs en juin et juillet. - Dans les grands bois humides du

1. D'après quelques recherches personnelles actuellement en cours d'exécution, tout fail supposer que le même principe actif existe, en plus ou moins grande abondance, dans les espèces propres aux Antilles; c'est à voir de plus près. (E. H.) 
Gommier, du Matouba, du Bassin-Bleu, des Trois-Rivières, de la liavineChaude, etc. - Cette espèce se distingue de toutes ses congénères par l'ampleur des feuilles et des fruits, - Alt. 250-900 mèt. [N03675.]

Ne se trouve pas à la Martinique.

B. martinicensis $\mathrm{Kr}$. et Urb., nova species. Vulgo : Bois-tan-montagne. - Arbre de taille moyenne, droit, ì feuilles coriaces, elliptiques ou elliptiques-ovales, arrondies ou légèrement échancrées au sommet. - Fl. en août et septembre. - Dans les grands bois du Lorrain, de la Calebasse et de la Iontarne-Pelée. Alt. 600-860 mèt. $\mathrm{X}^{\circ}$ 593.] - Je nai pas trouvé cette espèce à la Guadeloupe.

B. trinitensis Juss.; Byrsonima de la Trinidad. Vulgo : Mauricif ou mauressif. - Assez grand arbre, droit, à feuilles ovales ou elliptiques, obtusément pointues au sommet, plus petites que les deux espèces précédentes. - Fl. en avril, mai. - Bois inférieurs des Bains-Jaunes et du Gommier. Alt. 450-700 mèt. [N०3212.]

Ne se rencontre pas à la Martinique.

B. spicata Rich.; Byrsonimat à fleurs en épis. Vulgo : Mauricif, bois-tan. Cav. Diss., VIII, t. 237; Dese., vol. II, t. 91, p. 97. - Arbre de taille moyenne, rarement de grande taille; se distingrue facilement de ses congénères par ses feuilles lancéolées, luisantes, pointues aux deux extrémités, et par ses fruits jaunes. - Assez abondant dans tous les grands bois du Commier, des Bains-Jaunes, du Matouba, des Trois-Rivières, de la PointeNoire, etc. - Fl. en avril, mai. - Descourtilz, loco cit., classe cet arbre dans les stomachiques astringents et recommande la décoction des fruits en gargarisme et en lavement contre l'angine, et le rob des fruits contre la dysenterie, dont on veut modérer le cours : on le délaye dans une décoction de l'écorce, lorsque la maladie touche à son terme; les baies, prises à une certaine dose, deviennent laxatives. Dans le pays on se sert souvent de la décoction de l'écorce et des graines contre les cours de ventre. - Fl. en avril et mai. - Alt. 200-900 mèt. [No 2416.]

Martinique. Vulgo : Bois-tan. - Assez commun dans tous les bois. [N"1475.

Nота. - Tous les Byrsonima précités ont des fleurs jaunes très belles, en grappes courtes, teminales, un calice muni de 10 ghlandes longiludinales, symétriquement disposées, une corolle à jótales onguiculés, 10 étamines avec des anthères adnées et des fruits ovales de la grosseur d'une petite cerise, munis au sommet d'une pointe, reste du style; tous contiennent beaucoup de tanin : les tanneurs de la Basse-Terre se servent surtout de l'écorce du B. spicata, en raison de l'abondance de ce végétal; tous fourniscent un excellent bois pour la construction; les oiseaux sont avides de leurs fruits.

B. lucida Rich.; Byrsonima à feuilles luisantes. Vulgo : (Olivier. - Grand 
arbuste nu pelit arbere. sourent lortueux, a branches tantit fastigriées, tantot divariqués. Lantot inclinées. al lige nue dans le bas, à écorec grise. Feuilles ramassies anx cxtrémités des branches. spatulées, petites, légèrement roulées sur les bords. Fleurs pourprées, disposées en grappes courtes, termimales: damines vinlettes. Fruit drupacé. ovale, pointu. de la crrosseur diune petite olive. - Vit solitaire ou en société dans les terres calcaires de la 1) cirate. sur le plateau entre Port-Louis et l'Anse-Bertrand, du Morne-dl'Eau, de Marie-Galante, etc. - Fl. presque toute l'année. [No 2891.

N'existe pas à la Martinique.

Bunchosia Rich. du mot "bunchos ", nom quion domnait autrelois au calé.)

B. ylandulifera Desc. ; Bunchosie à feuilles cylanduleuses. Vulgno : Prunecafé, bois-café-bois. - Arbre de taille moyenne, droit, haut de 15-18 mèt., ressemblanl au Byrsonima spicata. Feuilles larges, variables, membraneuses, elliptiques ou ovales-elliptiques. brièvement pétiolées, opposées, munies près de la base, de chaque côté de la côte principale, de 1-2 taches brun-jaunatre, larges, arrondies ou allongres. Fleurs jaunes, en wrappes spiciformes. axillaires, allongées, pédonculées, opposées, plus courtes que les feuilles. naissant it laisselle des feuilles situées sur les branches de la derniere poussée; calice à 10 glandes larges ; styles 3 . Fruit drupacé, très jaune en dehors. ¿ pulpe molle. brune. fris douce et agréable au zoût: semences le plus souvent au nombre de deux. - Le rob du fruit est très astringent. Le bois sert pour la construction. - Fl. en avril et mai. - Assez abondant au Gommier (bord du Galion), dans les bois des Bains-Jaunes, du Matouba. Alt. 400-800 mèt. [Nos 2411, 3213.

Martixique. Vulgo: Café-bois, café-moka. - Assez rare. Hauteurs boisées du Robert, des Roches-Carrées et de la Régale. [No 486 .

L. B. glandulosa Rich.; Vulgo: Prune-café. Cav. Diss., VII, t. 239, originaire de la I ominique, petit arbre très branchu el à larges feuilles; est cultivé. i cause de sesfruits, sur quelques habitations: Habitation Longmont Capesterre, Guadeloupe), et ì la Martinique, au Jardin botanique, enfin sur quelques habitations de la Rivière-Salée.

Malpighia L.; idédié par Limné au célèbre Italien Marcelle Malpighhi, né en 16:2s, a Crevalcoure, pres de Bologne: depuis 16.56, professeur de médecine ¿ Bolnenne, médecin du pape Innocent XII, mort à Rome, en 1693; a écrit entre autre choses : Anatomia plantarum.

M. glabra L.; Cav. Diss., VIII, 1, 234. Malpighie à feuilles glabres. Vulgro: Cericier dupays. - Irbrisseau tantit tres touffu, tantút petit arbre plus ou moins fortueux, fortement branchu. Feuilles petites, ovales, habituellement prointues, brierement pétinlés. Fleurs pourperes, plus rarement blanches. 
solitaires ou réunies en ombelles, axillaires, nombreuses; pédicelles filiformes, articulés au milieu; calice it 6-10 mandes; slyles 3. Fruit subulobuleux, a 3-4 cotes faiblement accusées. - Fl. habiluellement deux on trois tois dans l'année. - Endroils secs, rocailleux, près de la mer : Vieux-Fort, sà et là dans les terres calcaires de la Désirade et de Marie-Galante. Alt. 10-120 mèt. [No 2890.]

Mantineue. Vulgo : Cerisier du pays. - Assez abondant à la Caravelle, dans les endroits calcaires des environs du Phare. - Les fruits sont aqueux et très rafraîchissants. [N $\left.{ }^{\circ} 1479.\right]$

Le M. punicifolia L., Plum., édit. Burm., t. 166, 1.2. M. biflora Poir., Cav. Diss., VIII, t. 234, 1'. 2; 'Tuss., Fl., III, 1. 2\%. Vulgo: Cerise carrée, cerisier à côte; n'est, à mon avis, que le M. glabra cultivé.

M. urens. J., Plum., édit. Bum, 1. 167. 1. 1; Cav. 1)iss.. VIII, 1. 235; Desc., vol. VIII, t. 569, p. 234. Malpighie à feuilles brûlantes. Vulgo : Cerisier-grosse-côte. - Petit arbre, souvent tortueux, à branches très divariquées, presque toujours horizontales, à jeunes branches couvertes de lenticelles nombrenses, blanchatres, à écorce fendillée. Feuilles variables, nettement elliptiques ou elliptiques-oblongues, obtuses ou pointues an sommet, glabres en dessus, munies en dessous de poils longs, couchés, luisants, brulank et hicuspides. Fleurs pourpres ou légèrement pourprés on blanches, en ombelles de 3-6 rayons, tantôt subsessiles, tantôt pédonculés; calice

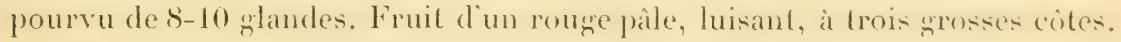
- Descourtilz classe les fruits de ce végrétal au nombre des rafraichissants aqueux et les recommande dans les fièvres inflammatoires et bilieuses: on en fait grand usage dans le pays. Le bois est dur : on en lait des poleaux solides et même de petits meubles. - Rare à l'état sauvage; se cultive souvent autour des habitations : Gourbeyre, Camp-Jacob, Trois-Rivières, Lamentin. [No3719.

Martineue. Vulgo: Cerisier-capitaine, grosse cerise. - Au Jardin bolanique el çà et là dans les campagnes : Lamentin, Ducos, elc. [No 478.

M. urens L., variété lanceolata Gr., Malpighie à feuilles lancéolées. Vulgo (aux Saintes) : Cerise-ruban-couleuvre. - Arbrisseau ou pelit arbre, très élégant, droit, très touffu, à feuilles petites, lancéolées, garnies en dessous de nombreux poils couchés, brûlants; se trouve çà el là aux Saintes (Terre-de-Haut et Terre-de-Bas. - Fl. en avril, mai; les fruits, moins cros que dans le M. urens, sont excellents et très rafraîchissants. TNo 2888.

Cetle variété n'existe pas à la Martinique.

M. angustifolia I., Malpighie à feuilles élroites. Vulgo : Bois-royal. Cav. Diss., VIII, t. 536, 1. 1. - Arbrisseau des plus élégants, très Inullu dès la base, haut de 2-3 mètres, à branches flexibles, souvent inclinées el mème 
tombantes. Feuilles linéaires-lancéolées, luisantes en dessus, couvertes en dessous de nombreux poils couchés, très brûlants et bicuspidés. Fleur's blanches ou pourpres, solitaires ou en petits corymbes, axillaires, peu nombreux. Fruit pulpeux, ovoïde, pelit, muni de 9 petits sillons et de 3 côtes. On peut les mangrer. - Abondant sur le plateau et sur la côte de la Désirade; assez rare a Marie-Galante; rare aux Saintes (Terre-de-Haut, route du Bourg-au-Chameau). - Fl. de septembre en janvier. [No 2889.

De cette belle espece on ne trouve pas frace à la Martinique.

M. coccigera 1., Car. Diss., III, 1. 235, f. 2. Malpighie à fruits durs. Yulgo: Bois-petit-houx. - Arbrisseau très ornemental, couché, rampant, ou parfois ascendant, ¿ branches minces, allongées, flexibles, enchevêtrées. Feuilles trìs petites, rigides, trìs luisantes, ovales-arrondies : les jeumes, entières; les adultes, sinuées-dentées, à 1-6 dents terminées par un mucro aigu, rappelant celles du houx de france (un certain nombre de feuilles sont presque tronquées au sommet et (ricuspidées). Fleurs solitaires, axillaires, portées sur des pédoncules longs, filiformes. Fruit petit, globuleux, presque sec, à 3 sillons, qui deviennent plus profonds vers la base. - Peu répandu et peu abondant. Je n'ai trouré celte magnifique espèce que sur les rochers, pròs du bourg de la Rivière-Pilote. [N 1477.$]$ - Je ne l'ai pas vue à la Guadeloupe.

Brachypteris Juss. (du grec « brachus », court, el " pterux », aile, parce que, dans les espèces-types, les leuilles sont pourvues, à la base du limbe, de deux petites stipules.)

B. borealis Juss., Cav. Diss., VIII, t. 237, 1'. 1. Brachyptère boréale. Vulgo : Liane bord-de-mer, aile ravet-bord-de-mer. - Petite liane vivace, haute de 0,80-2 mètres, d'abord droite, ensuite voluble, branchue, à branches

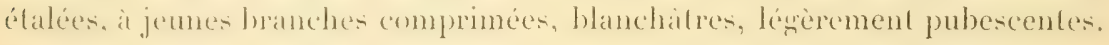
Feuilles opposées, ovales, arrondies à la base et garnies de 2 glandes ; à pélioles courls, munis au sommet de 2 glandes arrondies. Fleurs jaune vif,

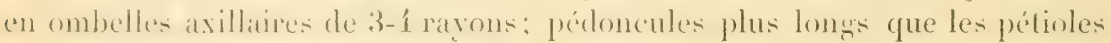

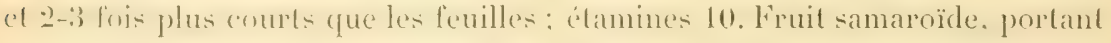
une aile latérale, courte el arrondie au sommet. - Endroits marécageux du bored de mer el endroils imondés par la mer. Pointe-i-Pilre roule du Gozier). [No 2893.$]$

M.ntricue. Vulgo : Mibi bord-de-mer. - Très abondant dans les marécages d'eau salée du Robert, du Francois (le long du canal) et de la l'artane. [No 14.1.]

Stigmatophyllum dus. dusper "sligma "stignate, el "phullon ", fenille, parce que les :3 stigmales se terminent chacun par un appendice foliacé.)

S. convolvulifolium Juss., Cav. Diss., IX, L. 256. Stigmatophylle à feuilles 
de liseron. Vulgo: Mibi, liane-mibi, - Liane ornementale, vivace, d branches trichotomes, très allongées, très flexibles et pendantes, haute de 3-5 mètres. Feuilles larges, opposées, ovales, pointues, glabres, ondulées et glanduleuses sur les bords, légèrement cordées à la base; pétiole court, biglanduleux au sommet. Fleurs larges, d'un jaune citron, en corymbes ramassés, ombelliformes de 5-12 rayons, axillaires el terminaux, portés sur un long pédoncule; pédicelles articulés au milieu; pétales frangés; étamines 6 , dont 4 stériles, plus courtes que les 2 fertiles. Fruit samaroïde, ì une aile large, membraneuse, oblongue, arrondie et mince au sommet, munie, sur le dos, de deux appendices obtus. - Assez abondant le long des rivières de la basse région. - Fl. en septembre, octobre et novembre. - SainteMarie, Marigot, Carbet, Case-Pilote. Nl. 10-250 mèt. [Yo 1572.] - Je ne l'ai pas vu à la Guadeloupe.

S. puberum Juss.; Stigmatophylle velu. Vulgo : Liane aile-ì-ravets. Ressemble au précédent par le port, l'inflorescence et la couleur des fleurs et la forme du fruit; il en diffère par ses feuilles plus petites, plus pointues, luisantes, lisses, mais surtout par le duvet blanc argenté qui en revêt toute la face inférieure comme il revêt les pédoncules et les pédicelles, les branches et les jeunes tiges. - Abondant dans les halliers, le long des rivières et dans les endroits abrités contre le vent. Basse-Terre (rivière aux Herbes), Gourbeyre (rivière Sence), Moule, Capesterre (Guadeloupe). [No 2414.]

Martinieue. - Vulgo: Mibi, liane-à-corde. - On se sert des liges pour faire des liens. - Saint-Pierre (Trois-Ponts), Carbet, Grande-Rivière, 'Trinité, Marigot. [No 1473.]

S. emarginatum. Juss., Banisteria splendens Macf.; Cav. Diss., IV, t. 249. Stignatophylle à leuilles échancrées. Vulgo: Liane noire, liane aile-à-ravets. - Liane vivace, pouvant grimper à $4-6$ mètres de haut, souvent rampante par défaut de support et alors diune dévation de quelques pieds. Feuilles variables,

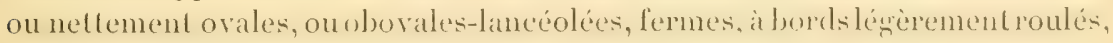
largement ou peu échancrées au sommel ou terminées par une pointe obtuse, luisantes en dessus, couvertes en dessous d'un duvet fin, blanchâtre et épais; pétiole court, duveté, blanc et muni au sommet de deux glandes noires el sessiles. Fleurs grandes, jaune vil, en panicules terminales, dichotomes, composées de corymbes ombelliformes ou en onbelles simples et axillaires;

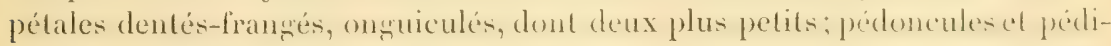
celles duvetés, blanchâtres. Fruits réunis par 2, à aile glabre, membraneuse, pourve de petils sillons el portant sur lo dos deux petils appendicen membraneux. - Abondant dans les terres sèches, calcaires et arides du littoral: Vieux-Fort, Le Baillif, Vieux-IIabitants, Gozier, Marie-Galante, Désirade, etc. - Fl. principalement d'avril en juillet. [No 2313.]

Mantivique. Vulgo : Petit-mibi, mibi-falaise. - Sainte-Luce, Diamant, Sainte-Anne, Caravelle (environs du Phare). [No 437.$]$ 


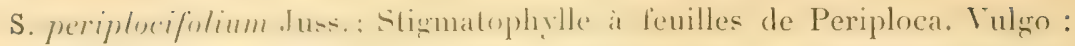
Petit-mibi. Sl., t. 162, f. 2. - Petite liane vivace, souvent rampante, à

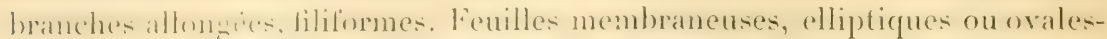
lancéolées, toujours glabres des deux côtés, échancrées au sommet el munies d'une pelite pointe. Fleurs jaunes, en corymbes ombelliformes; pédicelles filiformes bibractéolés au milieu, caractère qui distingue facilement cette espèce de la précédente. Dans les deux dernières espèces, l'appendice du stigmate est lronqué et petil. - Peu abondant. Endroits rocailleux el secs de Sainte-Luce. Alt. 0-150 mèt. [Nos 438, 439.] - Je ne l'ai pas trouvé à la Guadeloupe.

Heteropteris kith. Glu wree "heterns", différent, et "pterux ", aile, allusion à la forme particulière des ailes du fruit.)

H. purpurea Kith., Cav. Diss., IX, t. 2t6, f'. 2; Hétéroptère à lleur's pourprées. Vulgo : Aile-à-xavets, liane-à-ravets, liane-caraïbe. - Liane ornementale, très llorifùre, à branches très enchevêtrées, longues, très flexibles, minces, pendantes, haute de $2-5$ mèt., à vieilles tiges d'un diamètre de 7$10 \mathrm{~mm}$., très fendillées et subéreuses. Feuilles petites, ovales ou elliptiques, membraneuses, flauques en dessous. Fleurs pourpres, petites, en panicules ferminales as asllatres. composées d'ombelles: pédicelles articulés anteressous du milieu, bibractéolés à la base et aux articulations; glandes du calice pourpres: chamines foutes fertiles. Fruit petit, prolongé latéralement en une aile membraneuse arrondie au sommet. - Fl. d'arril en juillet. - Abondant dans les halliers de terres sèches et rocailleuses du littoral : environs de la Basse-Terre, Le Baillif, Vieux-Fort, Deshaies, Désirade, Marie-Galante, etc. Alt. 10-200 mèt. [No 2412 .]

Martingue. Vulğo : Aile-à-ravets. - Abondant : Carbet, Prêcheur, CasePilote, Marin, Caravelle, ete. $\mathrm{N}^{0} 1470$.

H. platyptera D. C.; Hétéroptère à ailes plates. Vulgo : Liane-ì-ravets. - Liane vigoureuse, très ornementale, peu élevée el peu sarmenteuse, à branches d'abord droites, ensuite inclinées, à écorce roussâtre couverte de nombreuses lenticelles globuleuses. Feuilles très coriaces, larges, opposées, oblongues ou elliptiques-oblongues, très glabres, luisantes en dessus, roussâtres en dessous. Fleurs d'un jaune vif, en panicules larges, terminales tricholomes, avee des grappes simples, situées aux extrémités des branches; pédoncules principaux et pédicelles primaires longrs, rigrides, droits; pédicelles tertiaures courts, gros, articulés el souvent bibractéolés au milieu, lous couverts d'un duvet court et ferrugineux. Fruits larges, réunis par 2-3, à aile large, lantôt droite, tantôt recourbée, Iongue de 25-30 mm. sur 8-10 mm. de laregre. - Abondant le longr des rivières et dans les coulées aérées des parlies inférieures de la Pointe-Noire (rivière de la Petite-Plaine), 
de Pigeon (rivières Lostau et Bourceau), etc. - Fl, en avril et mai. - Alt. 0-300 mèt. 「No 3377 .

Martinique. Vulgo: Liane-caco (à cause de la ressemblance de ses feuilles avec celle du cacoyer). - Le long des rivières de la Gapote, de la Grand' Anse, ravine de Ducos, elc. [No 169.]

Tetrapteris Cav. (du grec " tetra ", quatre, el " plerux ", aile, parce que le fruit a quatre ailes.

T. inaequalis Cav., Diss., IX, t. 260 ; Tétraptère inégale (fruit à quatre ailes de longueur inégale). Vulgo : Aile à ravets. - Forte liane, d'abord droite, ensuite sarmenteuse, à branches fortement inclinées, à jeunes branches et jeunes feuilles couvertes d'un duvet blane et farineux, qui disparait lacilement. Feuilles ovales ou elliptiques, pointues: les jeunes, molles: les adultes, coriaces. Fleurs d'un jaune vif, en panicules trichotomes, composées d'ombelles de 3-4 rayons; pédicelles articulés et bibractéolés au milieu; calice à 8 glandes; étamines toutes fertiles; styles 3 . Fruit à $\mathbf{f}$ ailes dont:- supérieures, divergentes et plus grandes, et 2 inférieures, paralleles, beaucoup plus étroites et plus courtes. - Peu abondant : bord de la rivière du Céron (Prêcheur), hauteurs pierreuses de la Grande-Rivière. Alt. 20200 mèt. [ $\mathrm{N}^{\circ}$ 1469.] - Je n’ai pas trouvé cette espèce à la Guadeloupe.

De cette lamille on cultive dans tous les jardins le Galphimia ylanca Car. G. elegans. Bartl., arbrisseau originaire de l'Amériñue tropicale, droit. d'un très beau port, haut de 1-3 mèt., à fleurs jaunes en panicules pyramidales, courtes. Guadeloupe [ $\left.\mathbf{N}^{\circ} 2415.\right]$ - Martinique [ $\left.\mathbf{N}^{\circ} 1471.\right]$

\section{TREXTh-HCitiL̀m FAMLLE. - SAPINDACÉES.}

Cardiospermum L. (du grec "kardion ", cœur, et "sperma ", semence, parce que les graines portent une tache noire affectant la forme d'un cour.)

G. Halicacabum L.;-Cardiosperme it fruit de coqueret (nom spécifique tiré du gree " hali ", sel, et "kakabon ", tonneau, parce que les Grecs comparaient le fruit, qui a la forme d'une vessie, à un tonnelet dans lequel ils conservaient le sel). Vulgo : Persil bâtard, Desc., vol. IV, t. 241, p.40.Liane herbacée, annuelle on suffrutescente, grimpante, très ornementale, it cause de son feuillage; it liges minces, pubescentes, très llexibles: a jennes liges à 4 angles. Feuilles biternées. incisées et grossièrement dentées. Fleurs blanches, petites, en corymbes axillaires, longuement pédonculés: pédnncules filiformes, munis au sommet de 1-3 petites vrilles filiformes: sipales 4 , les 2 inférieurs plus larges: pétales f, inégraux, portant de petites céailles separées des étamines par un petit disque; étamines 8: styles 3. Fruit vesiculaire, dont la forme rappelle un bonnet de prètre, plus larese que long, 
Lardivement dihisent. pubescent: =emences 3, blenes, spheriques, portant it la base une largre lache noire en forme de cour. - Abondant dans les savanes el les halliers de la région du liltoral. - Descourtilz range cette herbe dans les diurétiques excitants et dit que la décoction de la racine est spécialement recommandée dans les affections de la vessie el des voies urinaires. Dans le pays, on se sert fréquemment des feuilles et des liges dans les bains tièdes el en cataplasmes émollients contre les abcès, les phlegmons et les furoncles; l'eau dans laquelle on a laissé séjourner les feuilles pendant quelque temps constitue un des meilleurs rafraichissants. - Fl. pendant lhiveruage. - Environs de la Basse-Terre, Gourbeyre, Trois-Rivieres, PetitBourg, Capesterre, etc. Alt. 0-380 mèt. [No 2521.]

Mantisioue. Vulgo : Bonnet carré. - Abondant : Saint-Pierre, Parnasse, Carbet, Marin, etc. [No 39.

La variété F. microcarpum BI. se distingue du précédent par ses fruits

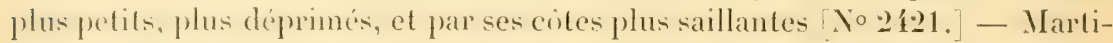
nique $[$ Yos 38 el 38 a. $]$

Urvillea Kith déche par Kunth au navigateur français J. Dumont d'Lrville, né à Condé-sur-Noireau; il a entrepris, de 1826-29, un voyage de découvertes en fustralie; a écrit une énumération des plantes des îles Falkland el Enumeratio plantarum, quas in insulis Archipel. et littoribus PontiEnxini collegit.)

U. ulmacea Kith; Urvillée à fruits d'orme. Vulgo : Liane-persil, lianesavon.- Vivace, grimpant, à liges minces, flexibles, striées et à $\mathbf{4}$-6 angles saillants. Feuilles ternées, d'un vert très pâle, à folioles ovales, acuminées, srossiement el irrigntierement dentées, arrondies au sommet ou terminées en pointe; pétioles secondaires très légèrement ailés; vrilles de deux sortes : les unes longues, axillaires, sortant des aisselles des feuilles; les autres toujours par 2, contes, naissant at sommel des pédoncules. Fleurs blanches, en grappes : les unes axillaires, les autres portant des vrilles pédonculaires; sépales 5; pétales 4, munis d'écailles; étamines 8. Fruit samaroïde, vésicu-

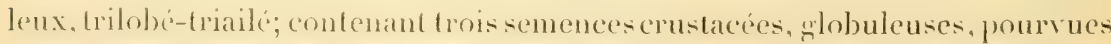
d'une arille blanc. - Rare : route des Trois-Ilets aux Anses-d'Arlet. [Xos $10,1482$.$] - Je ne l'ai pas trouvé à la Guadeloupe.$

Paullinia L. (dédié par Limné à Simon Paulli, né en 1603, à Rostok; en 1632, prolesseur de médecine, et, en 1639, professeur d'anatomie, de chirurgie el de botanique à Copenhague, mort en 1680; a écril: QuadripartiInm bolanicum de simplicium medicamentorum facullatibus, et la Flore danoise. [Fern. Paullini a écrib, en 1664, de Abusu Tabaci et Herbe There; Christ. Franc. Paullini, en 1688, sur le Salvia, en 1700, sur le Jalap, en 1701, sur la Muscade. 
P. Vespertilio Sw.; Paullinie à pattes de chaure-souris. Vulgo : Lianepersil. - Puissante liane, haute de 10-15 mèt., à tiges adultes cylindriques, ruguleuses, noiritres, à jeunes ligeses prodondément sillonneses ou seulement striées, à branches pendantes. Feuilles imparipennées, Innguement prétiolies, ¿ 5 folioles ovales-oblongues, très grossièrement dentées vers le sommel : la paire inférieure est très éloignée de la supérieure, qui se trouve au même niveau que la foliole terminale. Fleurs très petites, jaune pâle, en grappes axillaires allongées, portées sur de très longses pédoncules qui sont pourvis. al la base, dedeux stipules ovales-lancénlées, munies ausommet de deux grande: vrilles comprimées; sépales 5 ; pétales 4 , pourvus de petites écailles; étaminess; disque formé de quatre glandes. Fruil large, profiforme, s'ourrant par déhiscence septicide, pourvu au sommet de trois ailes membraneuses el oblongues, plus courtes que le lruit et situées horizontalement; semence 1, brune, à moitié plongré dans un arille blanc, ondulé sur le bord, spongieux à l'état frais. - Avec les tiges, on fabrique des bâtons à la fois très flexibles et très solides. - Fl. en février et mars; fruits mûrs en octobre et novembre. - Assez abondant dans les bois inférieurs des Bains-Jaunes (canal Dupuy, rivière Roche, etc.). [ $\mathrm{N}^{\circ} 3599$.

Martixique. Vulgo : Liane-persil. - Parnasse, Fonds-Saint-Denis, GrandeRivière. [Nos 1.483, 1.183 b.] P. microsepali Radlk, in Monogr. l'aullinile, $1895-96$, p. 253.

P. Cururu L. part. ', Plum., édit. Burm., t. 111, fig. 2; Paullinie Cururu (mot caraïbe). Vulgo : Liane à scie, liane-mangle, persil noir. - Vivace, grimpant, haut de 22-fi met., à branches flexibles, pendantes, a jeunes branches quadrangulaires-sillonnées, à angles saillants. Feuilles divitées-trifoliées, à folioles très brièvement pétiolées, ovales-elliptiques, acuminées, prosièrement et irrégulièrement dentées vers le sommet: la terminale plus grande; pétiole commun ailé. Fleurs blanches, en grappes courtes, axillaires; stipules courtes, lancéolées: vrilles opposées aux feuilles ou caulinaires. Fruit pyriforme, trigone, surmonté de trois styles persistants, s'ourrant par déhiscence septicide; semences 1-3, noires, luisantes, nichées dans un arille épais el blanc. - Dans l'opinion des habitants, les graines passent pour être un poison ${ }^{2}$. Avec les tiges, on fait également des bâtons solides el flexibles. Abondant dans les endroits marécageux du bord de mer : Lamentin, TroisIlets, Ducos; plus rare à l'intérieur : boulevard de Saint-Pierre, Prêcheur. $\left[\mathrm{N}^{\circ} 1485.\right]$ - Elle ne se trouve pas ì la Guadeloupe.

\section{P. pinnata L., Plum., Descript., L. 91 ; Paullinie à feuilles pennées. Vulgo :}

1. Partim Serjania nodosa Radlk. - Madlk., Monogr. Serjania, 1875, p. 341; Monoyfr. Paull., 1895-96, p. 1:4, obs. no 3 , p. 128, 133).

2. Cette espéce donne un suc qui serait employé par les sauvages de la Guyane, où cette plante existe, pour empoisonner leurs fieches. Il entrerait dans la préparation du curare. (E. H.) 
Liane-persil. - Virace, haut de 2-5 mèt., à jeunes tiges sillonnées-striées.

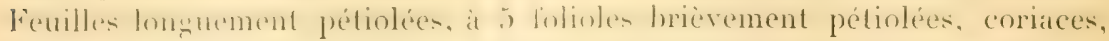
luisantes, ovales-elliptiques, acuminées, irrégulièrement et grossièrement

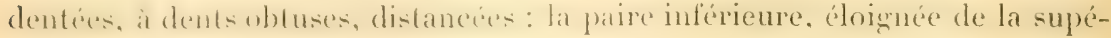
ricure, est au niveau de la foliole torminale; le pétiole principal est ailé

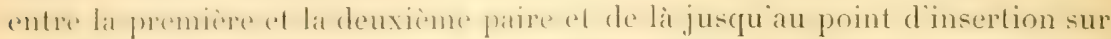

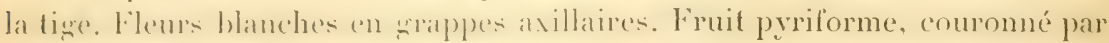
les restes du style. Cette espèce se distingue de la précédente surtout par la forme de ses feuilles et de ses folioles. - Issez rare. Cà et là dans les halliers de la région inférieure : Lamentin, Rivière-Salée, Parnasse. [No 1484.] - Je ne l'ai pas trouvé à la Guadeloupe.

P. Plumerii Tr. et Pl. - Voir à la fin de l'ouvrage, aux Addenda, la description omise par l'auteur. (Radlk., Monog. Paulliniae, 1895-96, p. 309.

Cupania L. (dédié par Limné à Franç. Cupani, né en 165\%, à Myrti en Sicile; étudia la médecine, entra, en 1681, dans l'ordre de Saint-François; devint diredeur du Iardin botanique du comte della Catholica et professeur de théologie ì Palerme, mort en 1700; a écrit : Hortus Catholicus; Catalogus plantarum sicularum; a travaillé pendant vingt et un ans à l'histoire naturelle de la sicile et a laissé un ouvrage de 700 planches dont 191 furent imprimées.

C. americana L., Desc,, vol. II, t. 89, p. 89; Plum., édit. Burm., t. 110. Vulgo: Yeux-crabes. - Arbre de taille moyenne, à branches très étalées, horizontales, à écorce roussâtre, unie. Feuilles paripennées à 4-5 paires de folioles alternes, obovales-oblancéolées, régulièrement dentées en scie, à dents inférieures distantes: celles du sommet du limbe, arrondies, rapprochées; côtes, nervures el nervilles de la face inférieure couvertes d'un duvet roux. Fleur's petites, blanchâtres, en panicules larges, terminales; jeunes branches. pédoneutes, pédicelles et calices couverts d'un duvet très roux et fin: sepales .5, imbricques: pretales 5) : ctamines 8 , inserées sur un disque complet. Fruit large, déprimé au sommet, duveté de roux à trois coques sousligneuses, s'ourrant par déhiscence loculicide, contenant chacune une semence globuleuse, brune, lisse, luisante, enchâssée d'un arille rouge et irrégulièrement frangé. - Descourtilz place cette plante dans les stomachiques astringents it cause du tanin que contiennent les feuilles et les fruits: il ajoute que les feuilles prises en infusion s'administrent dans le catarrhe vésical et toutes les fois qu'il s'agit d'exciter la membrane muqueuse des voies urinaires el des autres membres frappés d'atonie. - Fl. en avril, mai. - Le bois est dur el blanc en dedans. - Très rare. De cette espèce, je n'ai trouvé qu'un pied sur le plateau des Trois-llets. [No 1486.] - Il ne se trouve pas il la Guadeloupe.

C. Iripuetra 1. Rich. : Cupanie à fruit triquitre. Vulgo : Bois-châtaignier, 
caconnier rouge. - Arbre de taille moyenne, à écorce rousse, à branches très étendues. - Ressemble au précédent par la tiille et le port; il en diffépe par ses feuilles adultes grlabres, moins dentées, les pédoncules et pédicellebeaucoup moins duvetés, mais surtout par son fruit à angles aigus. - Fl, en décembre et janvier; fruits mûrs en mai, juin, juillet. - Peu abondant : çà et là dans les bois sees de la ravine Blondeau (Trois-Riviores'sur le bord de la rivière de la Petite-Plaine (Pointe-Noire) et de la rivière Noire, près du Saut-de-Constantin. [Nos $3376,3561$.

Il n'existe pas à la Martinique.

Sapindus L. (du latin " sapo ", savon, et "indus ", indien, parce que les graines servent de savon dans l'Inde.)

S. saponaria L., Desc., vol. IV, t. 261, p. 121 ; Sapindus saponaire. Vulgo : Savonnette, savonnier, bois mousseux. - Grand bel arbre, à trone très droit, cylindrique, à frondaison allongée, à branches peu étendues, lantit fastigiées, tantôt étalées, à écorce grise, mince, sèche et lisse : celle des jeunes branches couverte de lenticelles blanchâtres. Feuilles paripemnéen it 4-5 paires de folioles oblongues-lancéolées, coriaces, inégales à la base; pétiole principal étroitement ailé. Fleurs blanchâtres, petites, disposées en panicules larges réunies en groupe, snit à l'extrémité des branches, snit à l'aisselle des dernières feuilles; pédoncules el pédicelles couverts d'un duvel roux pâle, très court; sépales et pétales 5 ; étamines 10 , insérées sur un disque complet; styles 3. Fruit drupacé, sphérique, noir en dehors, de la grosseur d'une cerise, muni à la base, à côté du pédicelle, d'une large grlande traversée d'un sillon profond; semence 1, par avortement des 2-3 autres ovules, complètement sphérique, noire, lisse, dure. - On se sert des graines pour fabriquer des chapelets et des bracelets; la pulpe des fruits, mise dans l'eau, donne une écume blanche très abondante dont on se sert pour laver le linge en guise de savon; les feuilles, macérées, produisent également une écume savonneuse'; le bois est dur, grisâtre en dedans, pesant : il sert à faire des rouleaux de moulins, des moyeux, ete. - Descourtilz met ce végétal au nombre des diurétiques sédatifs; il dit que le sue visqueux des fruits, qui renferme du tanin, est administré à l'intérieur et en injections vagrinales contre les hémorrhagies utérines; il ajoute que la décoction de l'écoree de la tige est bonne, en injection, dans la leucorrhée vaginale et l'uréthrite; en lotions, contre les vieux ulcères. - Malheureusement, cet arbre est devenu rare : çà et là autour des habitations et le long des rivières de la basse région. - Fl. en janvier et février; graines mûres en juin et juillet. -

1. Toutes les parties de ce végétal (fruit, fenilles), qui rendent l'eau mousseuse, renferment de la saponine comme le bois de Panama. On utilise les mèmes proprićtés dans les fruits et feuilles du S. arborescens Aubl. à la Guyane et du S. rigida Vah! aux Mascaraignes, L'écorce de ces végétaux est réputée fébrifuge. (E. II.) 
Rivière de la Pelile-Plaine (Pointe-Noire), environs des Abymes et du Moule. All. 0-30(1) mèt. [No 35.90 .

Mantraqu. Vulgo: Savomellier. - Plus abondant qu’à la Guadeloupe Saint-Pierre (cours de lhospice), Fort-de-lrance, Lamentin. [No 614.

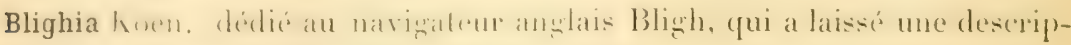
lion d'un voyage dans les mers du Sud, 1792.

B. sapuila Koen., Akeesia africana 'Tuss., Tuss., Fl., I, t. 3 ; Desc. vol. VIII, t. 560; Blighic savoureuse. Vulgo: Ris-de-reau. - Petit arbre à feuilles pennées, à :3-1 paires de folioles opposées, à fleurs blanches, pubescentes, en grappes axillaires, à fruits grands, rouges en dehors, obovalesoblongrs, à trois grosses côles, s'ourrant par déhiscence loculicide, contenant 1-2 graines noires, polies, entourées dans les deux tiers de leur longueur par un arille blane, charnu, ressemblant à des ris de veau. - Cet arille se mange dans les fricassées de poulet ou autrement. L'arbre est originaire de la Guinée (Irique tropicale), d'où il fut apporté par un vaisseau négrier ì la Jamaïque. Il est maintenant répandu dans toutes les Antilles. - Le bois est d'une consistance solide et sert pour la menuiserie. Les fleurs, odorantes, permetlraient de préparer une eau distillée aromatique. - Se cultive çà el là autour des habitations : Saint-Pierre (Fond-Coré), Basse-Pointe, Fort-deFrance, etc. [No 1810.] - On dit qu’il existe aussi à la Guadeloupe.

L. Lepisanthes telraphylla Radli., artore de petite taille, oricrinaire de Harchipel inclien, est cultive an Jardin botanique de Saint-Pierre, ou il flenrit tous les ans, mais ne donne pas de fruits. [No 1837.

Schmidelia Sw. dódic il Casimir Christ. Schmidel, né a Baireuth en 171s: devint, en 1742, professeur dans sa ville nalale, et, en 1743, à Erlangen; en 1763, médecin du Maregraf d'Ausbach; s'occupa beaucoup d'histoire naturelle, surtunt de Jutanique; il a laissé, sutre autres choses : Icones planlarum et analysis parlium.)

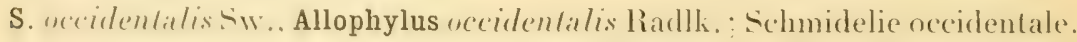
Vulgo: Café jaune, pelit-café. - Arbuste ou petit arbre, à branches étalées,

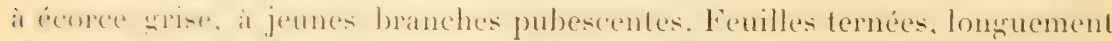
péliolées, ¿̀ folioles elliptiques, sinuées-dentées, à dents courtes, aiguës, infléchies vers le limbe, grlabres en dessus, duvetées et grisâtres en dessous.

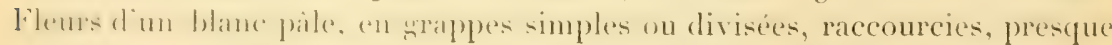
aussi longues que le péliole principal; sépales 5, ciliés; pélales 4, ciliés; étamines 8, de longueur inégale, entourées, à la base, d'un disque glanduleux. Fruit sphérique, un peu plus grand quime graine de poivre, jaune en dehors, contenant une semence globuleuse. - Cet arbrisseau perd sourent les feuilles en temps de floraison. - Fl. en mai, juin et juillet. - Peu abondant. Cáa et là dans les bois et les falaises de la basse région : rivière Noire 
pres du Saut-de-Constantin, IIonëmont batlerie. Tienx-llabilants. Mlt. 150-380 mèt. [ $\mathrm{X}^{\circ} 2908$.]

Martinique. Vulgo: Bois-négresse. - Assez abondant au plateau des Trois-Hets, à la montagne du Vauclin et dans les hauleur's de Case-Pilote. [No 581.$]$

Melicocca L. (du gree " meli », miel, et " hokkos », baie, fruit, allusion à la saveur du fruit.)

M. bijuga L., Jacq., Sel. Am. stirp. hist., t. 172. Melicocca à feuilles bijuguées. Vulgo : Kenettier ou kénepier. - Grand arbre, à tronc droit, anfractueux à la base, à frondaison large, arrondie, à écorce grise ou noirâtre, peu fendillée. Fenilles paripennés, a deux paires de folioles opposés. wlabres, entieres, elliptiques. Fleurs blanchatres, exhalant une odeur forte, plus ou moins agréable, souvent dioïques, plus rarement monoïques, rarement polygames, en panicules terminales, avec des grappes simples, axillaires, situées dans les aisselles des l'euilles de l'extrémité dés branches : les panicules des fleurs femelles beaucoup plus courtes que celles des mâles: calice à 4 segments profonds; pétales 4 ; étamines 8 , insérées sur un petil disque complet, noir: styles ?2; stigmates 4 , hilobes, fris courts: ovaire placé dans le disque, entouré, à la base, d'écailles ciliées-frangées. Fruit globuleux-ovoüde, à péricarpe subcharnu, mince, vert en dehors, blanc en dedans; sraines volumineuses, entierement enveloppées d'un arille geilatineux d'une saveur légèrement acidulée, astringente et très agréable. - L'amande, cuite ou rôtie, peut être mangée comme la châtaigne; le bois est dur et se prête à la construction. - Fl. en avril, mai; fruits mûrs en juin, juillet, août. Alt. 0-350 mèt. Dans toute la Guadeloupe el la Grande-'Terre. [No 3718.

Mantmique. Vulgo : Kénettier. - Dans tout le pays. [Yo 1809.

Dodonæa L. (dédié à Rembert Dodoens fen latin Dodnuteus. né en 1518 à Mechelen, en Belgique; fut médecin de l'empereur Maximilien II et de

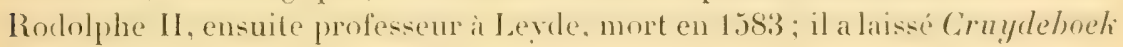
avec figures, ourrage corrigé de : ITistoria slirpium.)

D. viscosa L., Sl., 1. 162, f. 3; Dodonée visqueuse. Vulgo : Mangle-oseille. - Arbuste buissonneux, élégant, très droit, rarement petit arbre, à branches listigieses, a leuilles, fruits, pédoneules el jeunes branches visqueux. Feuilles nbovales-lancéoless, olslancéolées. Fleurs verdatres, en corrmbes panicules : les terminaux, plus larges; les axillaires, plus courts; calice à 4 sépales; pétales nuls; itamines 10, insérées sur un disque hypongrne. Fruil samaroïde. i 3 ailes énales, arrondies, membraneuses, formant au sommel, i leur point de jonction, trois sinus profonds, à 3 logeses, sourrant par débiserence seputicide,

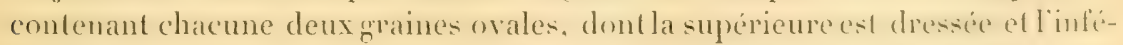
vieure pendante. - Isie\% abondant sur le plateau calcaire de la bisirite, 
dans les sables du bord de mer, de Folle-Anse (Marie-Galante). - Fl. en arril, mai, juin, sonvent aussi en septembre et octobre. [Nos 2904, 3627.]

Mantmeul: Vulgo : Olivier bord-de-mer. - Fond Canonville (rare); abondant au bord de mer des Anses-d'Arlet (surtout à la Grand'Anse) et du 1)iamant. ГXo 3tis.

LEuphoria Litchi Commers., Nephelium Litchi L. Iulgo : Litchi ou Letchi; a élé introduit à la Guadeloupe, il y a une quarantaine d'années : le premier pied a été planté au Petil-Bourg, d'où il s'est répandu dans le pays. Pour le faire produire plus vite on le propage par marcottes. - Fl. habituellement en janvier ou février. [No 2909.

Martaique - Le premier Letchi a été planté en 1826 dans le jardin du Gouvernement de Fort-de-France; selon le rapport de M. Bélanger, direcreur du Jardin botanique de Saint-Pierre, il a fleuri une fois et a produit des fruits. Les pieds qui existent actuellement dans le pays proviennent de deux crrands pieds, qui ont été pris à la Guadeloupe et plantés dans le jardin de II. Eme-t luchamp. ex-notaire, sur lhabitation Baranville, aux Trois-Ponts. $\left[\begin{array}{ll}1 & 1811 .]\end{array}\right.$

Trexte-Xeutìie Fumle. - STAPHYLÉACÉES.

Turpinia Vent. dedic par Ventenat an Français P. J. Fir. Turpin, botaniste et peintre de plantes, mort en 1840; il a écrit : Essai d'une iconographie des plantes, 1820, et avec A. Poiteau : Flores parisienses, 1808.)

T. occidentalis Don., Sl., t. 220. Staphylea Sw.; Turpinia occidental. Tulgo: Bois-pilori. - Assez grand arbre, à branches souvent très étalées, à jemues branches cas-rantes, verruqueuses, tachetées de lenticelles liqneuses,

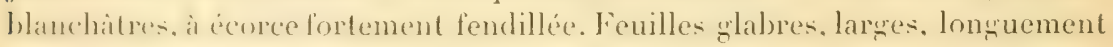
prélinkes. imparipennées, à 7-11 folioles ovales-lancéolées, acuminées, serrelés, a denls alinuës. blanches, droites ou inflechies vers le limbe. Fleurs diun blanc mat, en panicules terminales, trichotomes, très lâches, plus ou moins

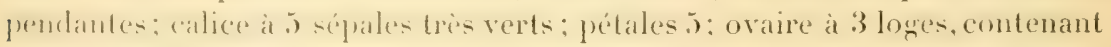
chacune 1-3 ovules; styles 3, distincts; étamines 5 , insérées sur un disque hyprove. Iruil baceien, trimametome-trigone au sommet, chaque mamelon portant une pointe, reste du pistil; graines 1-3, osseuses, d'un gris blanchâtre, tris lisses, luisantes. Fl. en avril, mai; graines mûres en juin, juillet, août. - Abondant dans les bois des Bains-Jaunes, du Matouba, des Vieux-Habitants: plus rare dans les bois de la Pointe-Noire. Alt. 450-1000 mèt. [No:3136.

Mantinqu: Vulgo : Bois-rignot. - Rare : ça et là dans les bois de l'habilatirn Saint-Mantin, su le Hanc occidental de la Montagne-Pelée. No 1821.] 
QUARIXTIME FAMLLE. - SABIACEES.

Meliosma Urb. (du grec " méli "), miel, et "osmé ", odeur, parce que les lleurs exhalent une odeur de miel.)

M. Pardoni Kir. el Urb., nova species; Meliosma de Pardon Gouverneur de la Guadeloupe, 9 juillet 1891-8 juin 1895). Vulgo : Graines vertes. Grand arbre, haut de $18-25$ mèt., très branchu, à tronc droit, anfractueux à la base, à écorce noiritre et fortement fendillée, a branches superioures lastigriées : les inférieures, étalées. Feuilles très coriaces, rudes, épaisses, obovales ou obovales-elliptiques, arrondies au sommet ou terminées en une pointe tris courte el obtuse, rétrécies en coin à la base, habituellement roulées sur les bords, très vertes en dessus, d'un vert ferrugineux en dessous el entièrement couvertes de squamules minces; côtes principales et secondaires, fortes, saillantes en dessous, imprimeses en dessus, cotes secondaires arquées, reliées par des arcades, près du bord du limbe; limbe long de $8-12 \mathrm{~cm}$. sur $3-5 \mathrm{~cm}$. de large; feuilles des branches de la panicule (prophylla) 2-5 plus courtes; pétioles courts, a base élaruie, épaissie, ruguleuse. grise el transversalement fendillée: partie supérieure de laxe de la panicule, et surtout les pédicelles, couverts d'un duvet ferrugineux. Fleurs petiles. sessiles, d'un blanc très pur, à odeur de miel, en panicules pyramidales. Inngues de $11-13 \mathrm{~cm}$., soit terminales, soil situées à l'extrémité des branches: calice à sépales persistants, imbriqués : les 3 extérieurs, plus zrands ; étamines 5, dont 2 seules fertiles, insérées sur un disque hyposyne; anthères biloculaires, grlobuleuses, ì lorges opposées el longiturlinalement déhiscentes; style 1, simple, ovaire sessile, à 3 loges, contenant chacun 2 orules. Fruit drupacé, peu pulpeux, obové, de la grosseur d'un grain de muscal, muni, ¿̀ la base, diune petite próminence latérale; endocarpe osseux, très dur, irrónulièrement sillonné-bosselé ou raboteux. Avant d'être mûr, son épicarpe est luisant, très lisse, presque translucide, très légèrement ponctué, vertglauque clair, de sorte que la panicule entière ressemble, à s'y méprendre, d une grappe de raisins non mûrs a l'état de maturité, l'épicarpe devient nor et porte des taches grises et irrégulières; la pulpe disparaît; semence 1 , oléagineuse. - Fl. en mai et juin; les fruits mûrs restent plus d'un au sur l'arbre. La plante fleurit avec une grande abondance pendant deux ou trois saisons : elle se repose ensuite pour refleurir quatre ou cinq ans après. Le bois est dur et rouge, variant jusqu'au brun; il passe pour être inattaquable par les poux de bois el incorruptible: on l'emploie aree avantape pour les constructions dans l'eau et dans la terre; on en fait aussi de belles planches 
pour les boiseries. - Assez abondant dans les bois inférieurs des Bains-

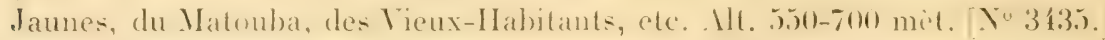

Il n'existe pas ì la Martinique.

M. Ilerbertii Rolfe: Meliosma de Herbert. Vulgo : Graines-violetles, boisviolet. - Le plus souvent grand arbre, à branches nombreuses : les inférieures, étalées; les supérieures, fastigiées, à jeunes branches très anguleuses, couvertes de verrues grises ou rouges et de cicatrices laissées par les leuilles. Fenilles obovales-elliptiques. pointues au sommet. rétréces en coin a la base, longues de $10-15 \mathrm{~cm}$. sur $3-5 \mathrm{~cm}$. de large : consistance, couleur et neprures des feuilles, pétiole, pubescence des pédoncules et des pédicelles, forme, couleur et parfum des fleur's, à quelques petits détails près comme dans le précédent. Panicule allongée, dépassant de beaucoup les feuilles, longue de $18-22 \mathrm{~cm}$. à la base, d'une largen de $5-6 \mathrm{~cm} .$, portée sur un pédoncule beaucoup plus long que dans le M. Pardoni. Fruit non mûr violet foncé, ensuite violet noir, d’abord pulpeux, ensuite sec, long de $22 \mathrm{~cm}$., obové, muni,

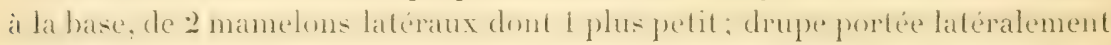
sur un pédoncule prenant naissance au petit mamelon. I mesure que les fruits mûrissent, la panicule s'allongre et devient peu à peu pendante. - Le bois est dur, noirâtre en dedans arec des reflets jaunes; il est élastique, résistant et peut servir pour la menuiserie aussi bien que pour les constructions dans la terre et dans l'eau. Les graines restent également plus d'un an sur larbre qui tleurit avec une grande abondance pendant le mois d'arril ou de mai et cesse ensuite durant plusieurs années. - Assez abondant dans les bois inférieur's des Bains-Jaunes, du Matouba, dans les bois du Gommier, des Trois-Rivières. Alt. 100-750 mèt. [No 2442.

Mantixique. Vulgo: Bois-de-sept-ans (parce qu'on croil qu'il ne fleurit que tous les sept ans). - Bois des Fonds-Saint-Denis, du Lorrain, du Campde-l'Alma. [No53.

QUARANTe-Uxième FAMLLE, - MÉLIACEES.

Melia L. (du šrec " mélia ), frêne, allusion ì la forme des feuilles : le mot dérive de " méli », miel, parce que plusieurs espèces de frêne contiennent un suc doux.)

M. sempervirens Sw., M. azedarach L.; Melia toujours vert. Vulgo : Lilas du pays. - Arbrisseau ou petit arbre, ne dépassant que rarement 5 mèt.

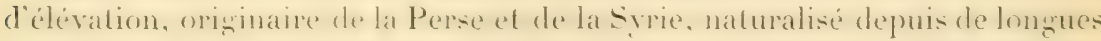
années dans toules les Antilles, très élégant par son port, son feuillage et ses branches lastigices : quand il est jeune. toujours tris ornemsental par ses 
fleurs; peu gracieux, quand il est âgé, à cause de ses branches horizontales

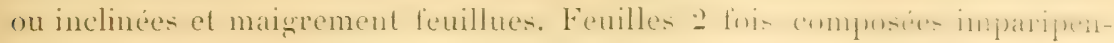
nées, à 3-11 folioles dentées, ovales-elliptiques. Fleur's it odeur de lilas en cymes paniculées, larges, soit terminales, soit accompagnées d'autres panicules situées aux extrémités des branches; calice monosépale a 5 dents profondes; corolle polypétale à 5 pétales violets ou violacés, ou panachés de blanc et de violet, alternant arec les lobes du calice; étamines soudées en tube, 20-30, violet foncé, élargies au sommet; anthères 10, sessiles au sommet du tube. Fruit drupacé, globuleux ou globuleux-ovor̈le, jaune en dehors; à la maturité, de la grosseur d'une petite noisette; grappes dressées quand elles fleurissent, pendantes quand elles sont chargées de graines. Fl. habituellement deux fois par an. - Le bois est blanc, mou, très cassant et ne peut servir que pour le chauffage; l'écorce et la racine sont vermifuges; la pulpe est, dit-on, un poison pour l'homme; elle est mortelle pour les chiens; avec les noyaux on fabrique des chapelets'. - Cà et là dans la région inférieure, se cultive souvent dans les jardins et les cours. Alt. 0 -350 mèt. [Yo 2310 .]

Martiniece. Vulgo : Lilas du pays. - Assez abondant dans toute l'île. [N०1488.]

Trichilia Sw. du gree " tricha ", par trois, friplement, pare que dans les espèces-types les feuilles sont composées de 3 folioles, ont un ovaire à 3 ovules el un fruil à 3 valves.)

T. simplicifulia Spreng., T. dicersifolia Tus... Trichilie it feuilles simples. Vulgo : Bois-de-fer bâtard. - Petit arbre ne dépassant guère s mèt. d'élévation, très branchu, à écorce grise, unie. Feuilles très variables, tantôt simples, tantôt imparipennées à 3-5 folioles ovales-elliptiques, entières, coriaces. plus ou moins luisanter en dessur ; foliole terminale toujours beancoup plus ample que les 2 ou 4 autres qui vont en décroissant. Fleurs petites, banches, exhalant une odeur excuise el lonte en panicules contes. axillaires; calice à $\mathbf{1}-5$ dents courtes, aiguës; pétales 5 ovales-oblongs; étamines soudées en un tube court; oraire à 3 loges. Fruit gris, de la grosseur d'une petite noisette, s'ourranten 3 valves par déhiscence loculicide; graines 1-3, brunes, lisses, luisantes, entourées, ¿a la base et d'an côté, d'un arille blanc qui derient noir en se desséchant. - Fl. en avril, mai, juin. - Le bois est dur, excellent pour la construction el aussi pour la menuiserie. - Assez. abondant dans presque tous les bois humides ou secs du pays. Bains-Jaunes, Matouba, Pointe-Noire, etc. Alt. 300-900 mèt. [Nos 2312, 3217.]

1. L'écorce de ce vérétal est nausćeuse et amẻre. Les feuilles sont réputées astringentes et stomachiques; dans l'Inde on les applique en cataplasme sur les ulcères. Les liruits sont vénéneux à haute dose, les semences fournissent environ is \% d'une luuile fixe. odorante, qui pourrait ètre utilisće dans l'industrie du savon. (E. H. 
Mantrigue. - Bois-de-l'Anglais, mahot-anglais. - Calebasse, CampBalata, fontaines Didier el Absalon, ete. [Nº 165.$]$

Guarea L. (nom qu'on donne ì cette plante à Cuba.)

G. ramiflora Vent., Guarea humilis Bertero; Guarea à fleurs situées sur les branches. Vulgo : Néllier-des-bois, tamarin-des-bois, bois-pistolet. Arbre de petite taille, ì branches irrégnulièrement disposées, le plus souvent étalées. Feuilles paripennées ì 1-3 paires de folioles très vertes, glabres, elliptiques, membraneuses, larges, pointues au sommet. Fleurs blanches exhalant une forte et très agréable odeur, en grappes simples, rarement composées, striées à l'extrémité des branches; pétales 4, ovales, arrondies au sommel; étamines soudées en un tube conique, très évasé à la base; anthères sessiles, insérées près du bord inférieur du tube; pistil aussi longr que le tube; style filiforme; stigmate capité; ovaire entouré vers la base d'un anneau, à $f$ loges biovulées. Fruit brun, ruguleux, tacheté de pointes grises, de la grosseur d'une nèfle de France, s'ouvrant en 4 valves par déhiscence loculicide; semences 4, d'un magnifique rouge vermillon et luisant sur le dos, blanches sur tout le côté hilaire. - Assez abondant dans les bois de Gourbeyre (morne Goblin), des hauteurs du Baillif, du Gommier, du Matouba, des Vieux-Habitants, ete. - Le bois est dur et recherché pour la construction. - Alt. 400-900 mèt. [No 3301 .

Martinique. Vulgo : Bois-pistolet. - Dans presque tous les bois du pays, mais surtout dans les bois de la Sibérie (Prècheur). [No 591.

G. Perolletii A. Juss., G. trichilioides Gr.; Guarea de Peroltel (botaniste français). Vulgo : Bois-pistolet. - Arbre de taille moyenne ou plus petit. Feuilles paripennées, à 2-5 paires de folioles oblongues ou elliptiquesoblongnes, très glabres, coriaces, très vertes et luisantes en dessus. Fleurs en grappes allongées, spiciformes simples ou plus rarement composées à la base; calice pubescent, à $\mathbf{f}$ dents arrondies; pétales 4 , pubescents en dehors; ovaire pubesecent; pédoncule principal vigoureux, ruguleux, fendillé et couvert de lentilles blanches et allongées. Fruit pyriforme, plus petit que dans le précédent, pourvu de côtes et de bosselures irrégulières; déhiscence et semences comme dans G. ramiftori. - Fl. en avril, mai, ou en décembre el janvier. - Dans les bois des Bains-Jaunes, dans les falaises des rivières Rouge et Noire, dans les bois du Matouba et de Gourbeyre, etc. - Le bois est dur el s'emploie avantageusement pour la construction. - Alt. 350900 mèt. [No 2314 .

Martinipuz. Vulgo: Bois-caco, - Dans les bois de l'Alma, de la Calebasse, de l'Ajoupa-Bouillon et du Lorrain. YNo 1499.

G. Kunthianum A. Juss, variété IIahnianum Kr. et Urb. Vulgo: Goyavier-bois, bois-de-rose, bois-pistolet. - Arbre de petite taille, a branches 
très élendues, horizontales ou inclinées. Feuilles lareces, paripennées, it:-3 paires de folioles elliptiques, tres vertes el luisantes. Fleurs blanches, tris odorantes, en panicules terminales ou situées aux extrémités des branches: calice à $f$ dents très courtes el arrondies; pétales $\{$; anthères sessiles, insérées au sommet du bord intérieur du tube staminal; slignate exsert. Fruil de la grosseur d'un ceul de poule, obové, gris brun en dehors, uni, déhiscent. s'ouvrant en valves ligneuses el épaisses; semences 5 ou 8 et alors superposées, rouge vermillon sur le dos avec une tache blanche au milieu. Cette espèce se distingue facilement des autres par l'ampleur des feuilles et dı fruit. - Fl. en avril, mai; fruit mûr en juin, juillet et août. - Rare. Alt. $400-800$ mètres. Cì et lì dans les bois de la Calebasse el de la fontaine . Mbsilon. [No 1489.$]$ - Je ne l'ai pas trouvé à la Guadeloupe.

Cedrela L. (du mot latin " cedrus ».)

C. odorata L.; SI., t. 220, f. 2; Br. Jam., t. 10, f. 1; Desc., vol. VI, t. 411, p. 120 ; Cédrèla odorant. Vulgo : Acajou amer, acajou du pays, acajou ì meubles, acajou senti. - Grand arbre à tronc droit, à écorce fendillée et à base anfractueuse, quand il est vieux. Feuilles imparipennées à $10-16$ folioles entières, ovales-elliptiques ou elliptiques, pointues, inézrales à la base ou obliques; pétiole court, pubescent. Fleurs petites, blanchâtres ou légèrement jaunâtres, émeltant une odeur forte et peu açréable, en panicules longues, terminales et pendantes; calice à .j lobes; pétales $\mathbf{4}$, hypogynes, oblongr. pourvus d'une nervure médiane qui, à l゙intérieur, forme un petit pli; tube staminal combiné avec le gynophore; étamines 10, dont 5 stériles; nvaire it 5 loges, contenant chacune 8-12 ovules. Fruit capsulaire s'ouvrant de haut en bas en 5 valves, par déhiscence septifrage; traines imbriquées, pourvues d'une aile membraneuse et mince. - Abondant dans les mornes el les falaise. et autour des habitations de la région inférieure. - Son bois est assez dur, sans aubier, rougeâtre avec de belles nuances; exhale, surtout quand il esil sec, une acréable odeur : il se laisse facilement travailler et, a cause de son amertume, il ne se laisse jamais attaquer par les insectes. C'est pour ces raisons qu'il est employé si fréquemment pour la fabrication des meubles. des cercueils, des cassetles, des rayons de bibliothèque, des boîles it cinares, etc. Dans le pays, on emploie l'écorce réduite en poudre pour sécher les plaies, et les leuilles, dont l'odeur est désagréable, pour chasser les puces 1. - Fl. en mai et juin; fruits mûrs en juillet et août. - Alı. 0-350 mèt. $[\mathrm{N} \cdot 2315$.

1. L'extrait du bois est fébrifuge : ce bois laisse exsuder une résine aromatique. L'infusion des feuilles et des fleurs est considérée comme antispasmodique à la Gryane, et employée en injection dans les maux d'oreilles. L'écorce est très astringente, amère, el constitue un bon tonique et fébrifuge. Le fruit serait anthelminthique. I'huile des sraines est recommandéc pour la cicatrisation des brûlures et blessures. Il serait intéressant d'étudier la résine aromatique de ce bois. (E. II. 
M.mprieus, Vulgo : Acajou, - Assez abondant. [No 1498.]

De cette lamille on cultive dans les deux îles trois espèces d'arbres, introduits el d'une grande importance :

$1^{\circ}$ Le Kaya senegalensis.A. Juss,, Swietenia senegalensis Desr. Vulgo: Mahogani du Sénégal. - Très grand arbre, à large fronde, à branches très étendues, à feuilles paripennées de $2-4$ folioles, à fruit de la forme el de la grrosseur d'une poire, s'ouvrant en 5 valves, de haut en bas, par déhiscence septifrage. Introduit du Sénégal, où il est indigène. - Fl. en juin et juillet, el rapporte des fruits en novembre, décembre et janvier. - Basse-T'erre hopitil Militaire, habitation Saint-Aude-(rall), Vieux-Habitants habitation Rollin]. [No 3215.

Mantixique. Vulgo : Acajou du Sénégal. - Rareł. Prêcheur (habitation le Céron) et Jardin botanique de Saint-Pierre. [No 507.]

20 Le Swietenia Mahayoni L., Tuss., Fl., IV, 1. 23; Desc., vol. I, 1. 99, et vol. VI, t. 116. Vulgo: Acajou de Saint-Dominique. - Très grand arbre ì feuilles paripennées, à $6-10$ paires de folioles petites et inégales à la base, à lleurs hlunches en petites panicules corymbiformes, situées à l'extrémité des feuilles, it fruit large, pyriforme, s'ouvrant de bas en haut en 5 valves ligneuses. - Fl. en mai; fruits mûrs en septembre et octobre. - BasseTerre (Jardin botanique) et ẹa et là autour des habitations.. [No 3214.$]$

Martixique, Vulgo : Acajou de Saint-Dominique. - Jardin botanique de Saint-Pierre et sur plusieurs propriétés de l'île. [No 1497.$]$

Ces deux espèces fournissent un bois précieux (bois d'acajou) pour la menuiserie, les boiseries, etc., et devraient être plantées en grand².

$3^{\circ}$ Le Garapa guyanensis Aubl.; Carapa de la Guyane (nom donné par les Tamanacos, peuple de l'Amérique du Sud, et qui signifie " huile, graisse ", parce que les graines sont très oléagnineuses). Vulgo : Carapate. Desc., vol. VI, t. 466. - Grand bel arbre, à branches supérieures, fastigiées, les inférieures, horizontales; it feuilles larges, pennées; ì tleurs en panicules larges, racémiformes: les unes, terminales; les autrés, siluées à l'extrémité des branches; it fruits larges, ressemblant, pour la forme et la grosseur, à un petit cacao, s'ourrant par déhiscence septifrage en $4-5$ valves charnues; à semences larges, anguleuses, oléatrineuses el mangeables. - Rare. Basse-Terre habi-

1. Ce vémétal précieux donne l'écorce de cail-cédrat des oflicines, qui, d'après Cavenlou (18:9), renferme un principe amer particulier, le cail-cédrin, une matière grasse et des maticres colorantes. Cette écorce, désignée quelquefois sous le nom de quinquina du Sénéffal, est simplement donce d'une action tonique (caïl-cédrine), qu'on peut utiliser contre les fières légères. (Li. II.)

2. En outre, la décoction de l'écorce est employée à la Guyane pour panser les blessures par armes à feu : celle écorce, amère, astringente, antiseptique (par son essence) ct fébrifuge, aurait à être étudiće arec soin. Son fruit (capsule ovoüde) donne, par ses graines, une luuile dite de carapa, à la Guyane, qui mériterait aussi d’ètre étudiée. (E. H.) 
Lation La Jacinthe), el dans le payssur quelques propriétés. - Fl. en norembre el décembre. $\left[\mathrm{N}^{\circ} 3216 .\right]^{\prime}$

Martinique. Vulgo : Carapate, bois rouge. - Au Jardin bolanique, d'où il s'est répandu dans le pays; on le trouve naturalisé an Morne-Jubin, dans les hauteurs de l'habitation Pécoul. [No 1496.$]$

\section{Quarante-deuxì̀me famlle. - AURANTIACÉles.}

Les représentants de cette limille, qui constituent un groupe de petits arbres ou arbrisseaux très importants, sont tous exotiques, mais naturalisés depuis longtemps; ce sont :

Citrus L. (du grec " kitron, kitria, kitrion, kitros ", qu'on croil être un mot africain.)

C. medica L. Vulgo : Citronnier. Desc,, vol. V, t. 339, p. 131. - Originaire de la Médie. On rencontre un nrand nombre de variétés, soit cultivées soit à l'état sauvage; entre autres : le limonier à peau très ruguleuse et épaisse, le citronnier de Valence, le limetlier, le citronnier doux, le citronnier. sans piquants, etc. - Dans quelques endroits, surtout à la Martinique, on fait avec le citronnier des haies vives, impénétrables qui, soumises à la taille, deviennent très belles; les graines pilées sont employées comme vermiluges; le jus du fruit est fébrifuge, stomachique, antiscorbutique el surlout sudorifique; les charbonniers, les coupeurs de bois et de chou palmiste, les bracomniers de la Martinique se munissent habituellement de quelques citrons, pour que, dans le cas où ils seraient piqués par un serpent, ils puissent boire le jus et s'en frotter l'endroit piqué, pour neutraliser le venin. Le bois est compact, solide et a de belles nuances : il est employé avantageusement dans la menuiserie et pour les ouvrages de tour. - L'arbre pousse jusqu'i une altitude de 700 mèt. [No 3758 . $]$

Martinique. [ $\left.\mathrm{N}^{\circ} 600.\right]$

G. Aurantium L. Vulgo : Oranger, orange douce. Tuss., Fl., III, I. 14; Desc., vol. V, t. 338, p. 127. - Petit arbre, plus grand que le citronnier, selon toutes les probabilités originaire des contrées méridionales de la Chine el des îles de l'archipel indien; introduit par les Portugais anx Cimaries, it Madère, d'ou il fut propagé dans tous les pays que baignent les eaux de la Méditerranée. On cultive plusieurs variétés, surtout la lime, la bigarade.

1. L'huile des graines de carapa est amc̀re, mais pourrait servir a l'industrie des savons: l'écorce, riche en tanin, est employée comme tonique et fébrifuge, propriétís qu'elle doit à la présence d'un alcaloüde (Caventeu, 1859). (E. H.) 
Vulgo : Orange amère ou orange-sure, et qui possède par excellence des vertus föbrifuges et sudoritiques. - Dans le pars on se sert des feuilles en infusion theiforme contre les dérangements du ventre el auss comme antispatmodique. I.e hois est utilise au mème titre que celui du citromier. Alt. 0-700 mèt. [No 2354 .

\section{Martixigle. [Nं 1817 .}

C. sinensis Riss.; Orange de Chine. Vulgo : Mandarine, orange-macaque. - Pelit arbre, originaire des parties chaudes de la Chine. (On cultive deux variétés : la grosse et la petite. (Les spécimens manquent.)

C. decumana L. (du latin " decumanus ", grand, immense); Tuss., Fl., III, 1. 17, 18; Dese, vol. III, t. 220. Vulgo : Chaddok, fruit délendu, lruit du Paradis. Originaire de la Chine et porté en Europe par le capitaine écossais Chaddok. - Petit arbre de la taille de l'oranger. [No 3766.]

Martinique, [No 1939.]

C. myrtifolia Riss. et Pav.; Oranger à feuilles de myrte. Desc., vol. III, 1. 219, p. 308. - Arbrisseau haut de 1-2m 50, originaire de la Chine, très dénant: it feuilles très petites el très rapprochées: à fruits sphériques, de la frrosecur llune mandarine. - Cà et lat dans les jardins de quelques habilalions: Gourbeyre (aux Palmistes). [No 3767.]

MLrtinique. - Grand'Anse (habitation Diobine). [No 1941.]

Triphacia trifuliata D. C., Limonia trifoliata L. Vulgo : Citronnelle. -Arbristenu élégant on petit arbre, haut de $2-3$ met., introduit et originaire des Indes Urientales; a feuilles trifoliées ; à tiges et branches sans piquants: it fruits pulpeux, noirs, mangeables. Cultivé dans beaucoup de jardins: se rencontre quelquefois à l'état sauvage. - On en fait des haies vives très belles et tres solides: la pulpe, mélée aree de la suie, fournit un beau vernis pour les souliers '. - Basse-Terre, Gozier, Lamentin, etc. [No 3765.$]$

Martinique. [No 1941.]

Murraya exofica L. Vulgno: Buis de Chine dédié au Suédois Jean . Indré Murray, medecin et directeur du Jardin botanique de Gottingue. 17亿0-17911.

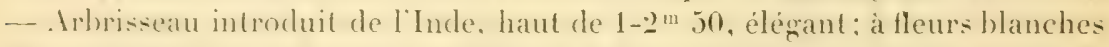
tres ndorantes, en crmes terminales: se cultive dans beaucoup de jardins?. [No 3768.

M.artiniqe. $\left[\mathrm{N}^{\circ} 1940\right.$.

1. Le bois de ce petit arbuste est à grain très fin et usité pour l'ébénisterie à La Réunion oủ il a été introduit également. (E. H.)

2. Ce vérétal donne un bon bois, que son grain clur et serré rend susceptible d'un beau poli et qui peut être employé pour le tour et l'ébénisterie. Toutes ses parties sont considérées comme astringentes et stimulantes (huile essentielle). L'écorce est insipide mais Inuleuse: les feuilles ont une saveur âcre; les fleurs donnent, à la distillation, une essence pariuméc les pétales renferment un glucoside : la Murrayine. (E. H.) 
Le Cookia punctata Retz. idédié au célèbre navigateur anglais ('inok, 17:2:)1779). Cookia à fruits tachetés de points bruns. - Pelil arbre, oricrinaire de la Chine et des Moluques; à fleurs blanchâtres, en panicules lareses, terminales; à fruits pulpeux, ovoüdes, de la grosseur d'un exuf de pigeon, d'um saveur très sucrée el agréable; se cultive au Jardin bolanique de saint-Piere et chez quelques amateurs de plantes utiles. [No 1942.] - Il ne se trouve pas à la Guadeloupe.

QuARANTE-TRoisième FAmille. - GERANIAClís.

De cette lamille on cultive très fréquemment dans les jardins le Pelargonium zonale I., Cav. Diss., 98, et plus rarement le Geranium odoralissimum I.., Cav. Diss., 103; tous deux introduits de l'Europe.

QUARANTE-QUATRİ̀Ee FAMILLE. - BALSAMINÉES.

Le Basalminum hortense Desp., introduit de l'Europe, sest naturalisé et pousse à foison autour des cases et sur les bords des chemins des calcérires, aux 'Trois-Rivières; les fleurs sont simples.

QUARANTE-CINQUì̀me FAMILLE. - OXALIDÉES.

Oxalis L. (du gree " oxalis ", composé de " oxus ", pénétrant, aigu, acide, et "hallis ", eau salée, parce que les feuilles et les fruits sont acides et conlienneñt de l'acide oxalique.)

0. Martiana Zuc.; Oxalis de Martian. Vulgo: Herbe de Vauchelel qui l'a introduit à la Guadeloupe). - Herbe vivace par ses tubereules agrénés. haute de 20-10 cm. Feuilles radicales, digitéestrifoliées, a folioles larentes. sessiles, obcordées, plus larges que longues, élroitement échancrées an sommet; pétiole très long, plus ou moins violacé dans le haut, fililorme, le plus souvent poilu; hampe plus longue que les feuilles, dressée. Fleurs lilas, t'u cymes ombelliformes, souvent penchées; sépales 5, unis à la hase, velus: pétales 5, striés à partir du milieu du limbe el jaunatre rors la bases citatmines 10, dont 5 plus courtes, alternant avec des longues; anthiores jaunes:

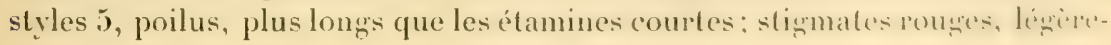




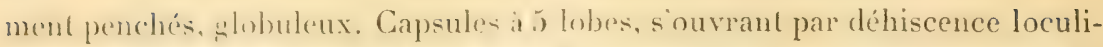
cide: semences petites, enveloppées d'un testa charnu, qui se sépare du texument. I ex feuilles sont acides el peuvent remplacer l'oseille de France.-Tries abondant lo long des router, dans les endroits humides of fertiles, ou il forme parfois m vérilable gazon; il se propage avec une grande facilite, it

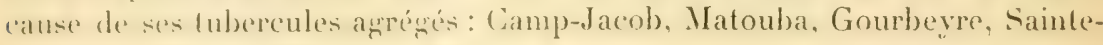
Rose, etc. Alt. 30-800 mèt. [No 2355.

Mantiveue. Vulgo: Petite-oseille. - Saint-Pierre, Camp-Balata, Parnasse. Abondant. [No 1818.]

0. corniculala I... variété microphylla Poir.: Oxalis corniculé. Vulgo : Petite-nseille-savane. - Pelite herbe annuelle, rampant à une distance indélinie : a lines filiformes, pubescentesoug glabres; a racines pivolantes, blanches. Finilles digitéestrilioliés, sessiles, obcordées; pétioles filiformes, longrs, pourvus, a la base, de 2 stipules liliformes. Fleurs jaunes, en cymes de 1-3 rayons. Capsule oblancéolée, terminéc par un petit bee, reste du pistil. Abondant dans les terres cultivées, le long des routes, sur les murs, etc. Alt. ()-8100 mit. Basse-Terre, Camp-Jacob, Gourbeyre, Moule, etc. [No 2354.] Martineue. Vulgo : Petite-oseille.-Abondant. [No 1817.]

0. Barrelieri Jacq.; ()xalis de Barrelier. Vulgo : Oseille-sarane, oseillemaronne. - Herbe amnuelle ou suffrutescente, haute de $40-65 \mathrm{~cm}$, très branchue of fruillue, quand elle est jeme, el qu elle pousse dans un terrain fertile; nue dans le bas, quand elle est adulte. Feuilles pennées-trifoliées, a folioles ovales ou ovées-oblongues, la troisième plus grande, distante des deux autres; pitiole filiforme, long, pubescent. Fleurs violet pâle et jaune au fond, à lintérieur, en cýmes ombelliformes, portées sur des pédoncules longs, filiformes, rémuis par za à l'aisselle des feuilles de l'extrémité des branches. Capsule ovale-oblongue. - Pendant la nuit et quand il pleut, les folioles sont pendantes. - Herbe fourragère. - Abondant dans toutes sortes de terrains humides, mais surtout dans les champs en friches: Basse-Terre, Gourbeyre, Sainte-Rose, Gozier, elc. Alt. 0-610 mèt. [No 2357.]

Mantriget Vulugo: ()seille bâtard. - Abondant dans toute l'île. [ $\mathrm{N}^{\circ} 1$ 191.]

0. sepium St. Hil.; Oxalis des haies. Desc., vol. I, t. 32, p. 153. Vulgo : Oseille-maronne-des-bois. - Sous-arbrisseau, haut de $40 \mathrm{~cm} .-1$ mèt., très branchu, mais peu fenillu, fortueux ou plus ou moins couché. Feuilles très ghabres, molles, d'un vert intense, pennées-trifoliées ou simples; celles des branches adultes, beancoup plus lareses. Fleurs larges, d'un jaune d'or vif, unilorme, "n crmes terminales, portées sur des pédoncules bifides, longs, munis, priss de la hase, de 2 slipules placces a des hauteurs différentes. l) (xisourtil\% classe celle plante dans les stomachiques antiscorbutiques; dans le pays, on n'en fail aucun usagoe. - Peu abondant. Cà et là dans 
les environs du Camp-Jacob; se cultive souvent dans les jardins à cause de ses fleurs. - Fl. d'avril en juillet. [No 2358 .

Il n'existe pas à la Martinique.

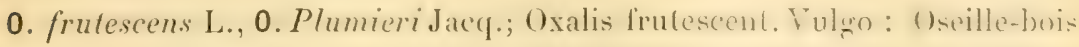
jaune. - Arbrisseau haut de $80 \mathrm{~cm} .-^{\mathrm{m}} 40$, tortueux; à tige noueuse el nue dans le bas, branchue dans le haut. Feuilles pemnicstrifoliées, at foliole: molles, ovales, arrondies ou émaryinées au sommet. l'lenl's jaunes. nombreuses, en cymes terminales, contenant 3-6 rayons, - Fl. presque toute lannée. - Endroits secs, pierreux. Se cultive quelquelois dans les jardin: en guise de bordures, qui, soumises à la taille, produisent un heel effed. Hanteurs pierreuses des Vieux-Habitants, Basse-Terre Jardin botinique. [No 2356.]

Martmique. Vulgo: Oseille jaune. - Hauteurs du Fond-Layelte (CasePilote), Caravelle (Trinité). [Nº 1819.

Li Averrhoa Bilimbi L.: Desce. vol. V, t. 333, p. 110 idédié au médecin arabe Averhoës, 11\{9-1217-Bilimbi nom malabari. Vulgo: Bilimbi, cornichon. - Petit arbre, originaire et introduit des Indes Orientales, it trone très noneux; est cultivé dans plusieurs endroits. - Les fleur's paraissent sur le tronc et sur les branches; ses fruits, hacciens, crlindriques-oblongrs. contiennent un suc très acide, qui renferme du bioxalate de potasse : on les emploie, pour cette raison, dans la lessive et surtout pour l'enlevement des taches d'encre; confits avec du sucre et préparés avec du vinaigre et du sel. ils peuvent servir de condiment. Iescourtily place l'arbre dans les rafiachichsints acides; il dit qu'on compose avec les fruits un sirop très estime dans les maladies inflammatoires et particulièrement daus les hépatites aignës: on emploie aussi la décoction avec du riz non pelé comme un remède excellent dans la meme maladie et toutes les fois quil sayit de temperer la livere et de modérer les diarrhées el les coliques bilieuses. - Fl. pendant toute l'année. - Basse-Terre hòpital Militaire), Gourbeyre, Petit-Bourw, ete. $\Upsilon^{\circ}$ 3473.7

Martivere. Vulgo : Cornichon, - Saint-Pierre Collecre el Jardin botanique), Trinité (habitation Saint-Joseph, Marin (usine e, ele. Y"18:20.

L'Averrhoa Carambola L.; Desc., vol. V, L. 335, p. 116. Vulgo : Carambolier, est cultiré aussi sur quelques habitations, notamment autour de l'usine du Marin et sur l'habitation Saint-Joseph Trinite. - Je fruit al les mèmes propriétés que celui de l'espèce précédente.

\section{QUARANTe-sixtìne FAMLLE. - ZYGOPHYLLÉES.}

Tribulus L. (du grec " treis », trois, et "bolos ", trail, tlèche, parce que les fruits sont munis de trois ou quatre pointes aiguës.) 
T. cistoides I., Desc., vol. IV, t. 250, p. 77; Tribule ressemblant au Ciste. Vulgo : Herse, pourpier bord-de-mer. - Herbe vivace, couchée; à racines forles, longues et grises; à tiges noueuses, relevées aux extrémités. firuilles opposies, paripennés, à s folioles petites, opposées, oblongues. mucronées au sommet, blanchâtres en dessus, couvertes en dessous d'un duret arwente et fin: stipules 2. juxta-axillaires. Fleurs larges, jaune vif, trie belles portées sur des pidoncules solitaires, axillaires, presque aussi longe que les feuilles: sépales jo lancéolés-acuminés, une fois plus courts que les jótales : étamines 10; pistil srmearpé. Fruit crustacé. tuberculé, se séparant en f́, rarement en jo coques indéhiscentes, dont chacune est armée de 2 piquants droits, rigides, divergents la disposition des coques avec leurs piquants est telle que le fruit ressemble assez bien à une croix militaire). - Desenurtilz classe cette herbe dans la section des diurétiques excitants et dit entre autres choses qu'elle contient beaucoup de mucilage et un "xtrait aromalique. A Marie-Galante, on se sert des feuilles en cataplasme contre les contusions et de la racine en décoction comme apérilive. - Peu répandu. Abondant dans les sables du bord de mer, entre la Capesterre et l'usine (Marie-Galante). - Fl. presque toute l'année. $\mathrm{N}^{\circ} 3645$.

Martinique. Vulgo: Herbe-soleil, pourpier. - Sainte-Anne (habitation Bertrand). $\left[N^{\circ} 1815.\right]$

T. maximus L., Sl., t. 132, f. 2; Plum., édit. Burm., t. 254, f. 1; Br. Jam., 1. 21, I. 3; Grande Tribule. Vulgo: Cresson-courant, pourpier bâtard. - Herbe annuelle ou suffrutescente et souvent frutescente, rampante, s'étendant quelquefois à plus de 4 mètres; à racines longues, pivotanteslibreuses, blanchâtres, épaisses. Feuilles paripennées, le plus sourent it 3 paires de folioles, d'abord rertes, ensuite blanchâtres en dessus, d'un blanc argenté en dessous, obliquement insérées, d'abord ovales, ensuite lancéolées-linéaires. Fleurs tantôt jaunes, tantòt blane jaunâtre, beaucoup plus petites que dans le précédent; calice persistant, pédoncules presque aussi longs que les féuilles. Fruit composé de A-fi coques juxtaposées, transversalement tuberculées sur le dos et se séparant tardivement de l'axe central. - Très abondant dans les terres sèches et sablonneuses, près de la mer. Basse-Terre, Le Baillif, Vieux-llabitants, Pigeon, Sainte-Amne, Gozier. [No2427.]

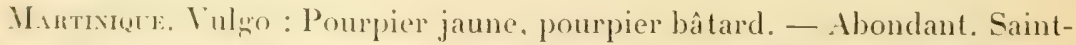
Piere boulevard, Case-Navire cimetiere), Case-Pilote, Trois-Ilets, ete. NNo 1816 .

Guajacum I.. (du mot caraibe " guajak ".)

G. officinale I., SI., 1. 222, t. 3-6; Tuss., Fl., IV, t. 35; Desc., vol. VII, 1. 463; Gä̈ac officinal. Vulgo: Gä̈ac. - Arbre de grande taille, quand il 
est vieux; à branches le plus souvent étalées : les inlérieures, presque toujours horizontales et penchées aux extrémités; à écorce dure, couverte de croûtes brunes ou légèrement jaunâtres, qui se détachent par plaques.

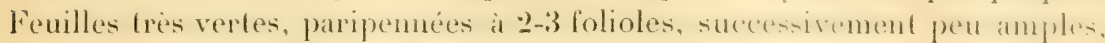
obovales ou ovales, arrondies au sommet, inégales it la base. Fleurs très nombreuses, bleues à l'anthèse, devenant plus tard bleuâtres ou blanchâtres, en ombelles terminales, composées de 5-12 rayons pédonculés: sépales 5. pubescents, ovales, trois fois plus courts que les pétales; patales 5. spatulés; étamines 10, bleues, d’inégate longueur; style pointu; slignate simple; ovaire stipité. Fruit à loges uniovulées, jaunâtre en dehors, obovéarrondi, largement rétus au sommet, et muni, au milieu, d'une pointe, s'ouvrant par déhiscence septicide; graines ovales, bianguleuses, complitement entourées d'une matière rouge écarlate, dont la couleur s'effice facilement; embryon orthotrope. - Le cueur du bois est noir, extrimement dur et pesint, d'où son emploi rare en ébénisterie, malgré son beau poli; il es con culre sints odeur, mais la rêpure en est légèerement aromatique el lait éternuer; lécorce est dépurative et s'emploie contre les maladies de pean, mais surtout contre la syphilis. Descourtilz range la plante dans la classe des sudorificques et dit, entre autres choses : que la racine, l'écorce et la résine sont stimulantes et toniques '; que les feuilles sont puryatives, el que l'huile qu'on obtient des fruits sert avec succès pour combattre la carie des os. Malheureusement, it la Guadeloupe ce bel arbre n'existe plus à létat saurage el est devenu une plante presque inconnue. Si on le cultive encore dans quelques rares endroits, c'est plutôt pour la richesse et la beauté de ses fleurs que pour son bois et ses vertus médicinales. A la Désirade, où il abondait autrefois, on l'a presque complètement détruit : on se servait de son bois pour chaulfer les fours à chaux; en août 1892, je n'ai pu en découvrir que quatre pieds mal venus, dont deux, plantés près du bord de mer et couverts de pucerons, paraissaient disposés à faire le sacrifice de leur vie. - L'arbre pousse très lentement; a l'átat de culture, il fleurit habituellement deux lois dans l'année; les graines germent en deux jours mais perdent leur faculté germinative en quatre ou cinq semaines. - Basse-Terre (habitation Saint-AudeGall). [ $\mathrm{N}^{0} 2956$.

Martixque. Vulgo: Gaïac. - Plus abondant, quoiqu'il ne se rencontre

1. Le bois de Gayac possède une odeur aromatique et une saveur légèrement àcre, qu'il doit à la résine qu'il renferme. Celle-ci est employée comme diaphorétique et antisyphilitique, antigontteuse, etc. Elle est douée d'une saveur aromatique qui rappelle celle du benjoin et s'augmente par le frottement ou la chaleu': sa saveur d'abord peu sensible devient ensuite très âcre. Elle est dure, mais cassante, et la cassure est brillante ef vitreuse; ses fragments, considérés sur les parties minces, sont transparents et d'un brun verdâtre; sa poudre d'abord grise verdit peu d̀ peu it l'air. D'après Lucker (1892), cette résine est formée de trois acides : gal̆acinique, galaconique et résino-gä̆acique. Le bois de gayac en râpure est employé sous forme de décoction nu d'extrait, c'est un des quatre bois sudorifiques: sa teinture alcoolique forme un bon dentifrice. (1) II. 
plus a l'étal sanvigre. Saint-Pierre Coullige. Jardin bolanique et Trois-Pontsi. Fort-de-France, Prêcheur, Lamentin, etc. [Nº 1814.]

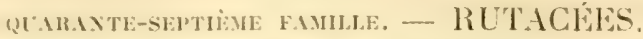

Pilocarpus Vahl (du gree "pilos », chapeau, et " carpos », fruit, parce que les fruits à 1 coques premnent, après la déhiscence, la forme d'une coille ou d'une mitrej.

P. racemosus V. Plum., éd. Burm., t. 127; Vahl, Eglogre, 1. 10; Pilocarpe à fleurs en grappes. Vulgo. Flambeau-caraïbe. - Arbrisseau souvent buissomneux el touffu, droit, haut de $3-3^{\text {m }} 50$. Feuilles larges, elliptiques, arrondies ou échancries au sommet, garnies de très nombreuses cryptes translucides, comme les feuilles du cilronnier. Fleurs en grappes simples, tris allongées, terminales, le plus souvent penchées, pédonculées; pédicelles longs. insérés à angle droil; calice à 5 lobes; pétales 5, jaune safran; étamines 5, étalées. inséresesur un large disque; ovaire a 5 lobes. Fruits -2-1, folliculaires, a endocarpe bivalve; semences ovales, noires, luisantes, petiles, terminées en un bee court et légèrement recourbé. - A la maturité du fruit, le péricarpe se détache de l"endocarpe el reste Inngtemps attaché al la grappe, tandis que celui-ci disparait de bonne heure. Toutes les parties de la plante exhalent une odeur forte, pénétrante, plus ou moins désagréable 1 ; avec les tiges on lait des flambeatix qui brûlent comme une chandelle. - Fl. de novembre en janvier et très souvent de juin en septembre. - Rare. Cà et là dans les endroits secs et rocailleux des hauteurs du Vieux-Fort. [Yo 2240.

Martingue. Vulgo : Flambeau noir. - Endroits secs el pierreux, hauteurs boisces des Trois-llets, morne Gommier (Marin), hauteurs de Sainte-Luce. [No 1193.$]$

Tobinia Desv. (nom américain de la plante.)

T. punctata Gr.; Tobinia à feuilles pointillées. Vulgo : Lépineux rouge, bois-flambeau, bois d'Inde marron au Moule. - Irbrisseau buissonneux ou petit arbre; à écorce lisse, noirâtre. Feuilles paripennées à 5-6 paires de folioles, tries luisantes, coriaces, elliptiques ou lancéolées-elliptiques, très finement crónelées, munics i la lace inférieure, entre les nervures, d'un grand nombre de petits points noirâtres. Fleurs très petites, diö̈ques. en cymes

1. Ce végétal contient assurément une huile essentielle qui est peut-être voisine de celle du jaborandi (Pilocarpus pinnatifolius L.); il serait intéressant de rechercher si. comme il laut le prévoir, elle renferme aussi l'alcaloïde pilocarpine, dont les propriétés sialagogues et sudorifiques sont si souvent et heureusement utilisées par les médecins. 


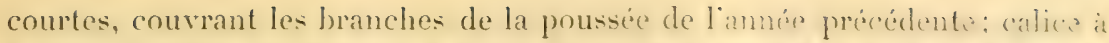
2 lobes; pétales et étamines 3. Fruit folliculaire, trnis fois plus petit qu um. grraine de poirre, ovale, comprimé, muni d'une pointe au sommet, contcuant une graine globuleuse, crustacée, très noire el frós luisante. - I es fenille: de cet arbrisseau sont tris variables : les pieds adultes n e'n portent (fu it $1-2$

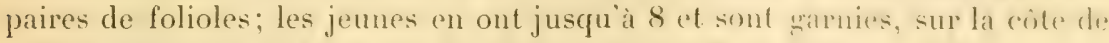
la face inférieure el à la base du pétiole, d’aiguilons luisants, frés prointus: les tiges sont émalement munies de ces aiguillons tres mombreux, forts, cylindriques et insérés à angrle droit. Avee les tiges on fait des flanbeaux, qui brûlent avec une grrande facilité à cause de l'huile essentielle qui y résirle. Fl. d'avril en juin. - Abondant dans les terres sablonneuses du bord de mer et sur les mornes peu élevés, calcaires ou pierreux : Marie-Galante (Folle-Anse), les Saintes Morne-du-Chameau, l)eshaies ( imos-Morne. D) -irade, etc. [Nos 2974, 2995, 3629.]

Martmeue. Vulgo : Bois-flambeau noir. - Abondant dans les bois sees de la Plaine des Trois-llets, du morne Gommier Marin et des mornes calcaires de Sainte-Anne. [No 494.]

Fagara L. Ie médecin arabe Avicenne domne ce nom à une plante aromatique quion ne connaît pas; Linné se sert du mème mot pour dénommer une autre plante aromatique.)

F. microphylla Desf., F. pterota L. (partim). Br. Jam., t. 5, f. 1; Fagara ì petites feuilles. Vulgo : Bois-it-piano, bois-chandelle, bois-lépineux blanc. Grand buisson ou petit arbre tortueux, tres ornemental, surtout quand il $\$$ t jeune, à cause de son léger et joli feuillage; a branches très nombreuses, souvent étalées et inclinées, pourvu, sur la tige et à la base des feuilles, d'aiguillons droils, trics aigus. Feuilles petites, imparipennés, a 3 folioles coriaces, ovales ou spatulées, sessiles, souvent échancrées au sommet pétiole ailé. Fleurs diö̈ques, très nombreuses et très petiles, disposées en petites cymes axillaires et sessiles. Fruit folliculaire, souvrant en 2 valves ; graines globuleuses, très noires et très luisantes. - Toute la plante exhale une odeur aromatique et forte'; le bois est très dur et incorruptible : il sert pour les constructions sous terre; on en fait des traverses, des poteaux, efe. - l)ins les terres sèches, arides et pierreuses: Je Baillif, Tieux-Habitants, Désirade, Moule, les Saintes, Marie-Galante, Gozier. Alt. 0-200 metres. |X" 2076.

Martiniple. Vulgo : Bois-llambeau. - Case-Pilole, Caravelle, RivierePilote (bord de mer). [No 1192.

1. L'écorce et les fruits de cette plante ont une saveur brûlante et poivrée qui en justifle l'emploi à titre d'épices : l'écorce passe pour être sudorifique, el sous forme de cataplasme agissant sans doute par son action antiseptique due à l'essence aromatique qui $\mathrm{y}$ est contenue, serait un bon remède contre le pian. (E. II.) 
Zanthoxylon I., (du grec " xanthos ", jaune, et "xulon ", bois, allusion à la couleur du bois.

Z. aromaticum IV. Vulgo : Lépineux blanc. - Le plus souvent arbre de taille moyenne; à tronc et branches munis de piquants; à branches étalées, souvent horizontales; à écorce noirâtre, très ruguleuse ef fendillée. Fenilles imparipenues, a $6-7$ paires de folioles elliptiques, glabres, coriaces et luisantes, à crénelures larges et tronquées au sommet. couvertes de points translucides. munies de glandes au fond des crénelures, ì la face intérieure. Fleurs polyzames, en panicules courtes, ramassées el pramidales: predoncules et pédicelles rudes et veruqueux: sépales à -1-J lobes arrondis; pétales 5 ; ovaire le plus souvent 5 , inséré sur un carpophore. Fruits folliculaires, solitaires ou rémis par 2--5 sur le carpophore: graines whbuleuses-comprimeses, tres noires et tres luisantes, restant longtemps attachées aux valves. - Toutes les parties de l'arbre répandent une odeur aromatique of tris pénétrante. A la Grande-Terre on prépare avec les feuilles une tisane astringente et tonique. Laubier est blanc et tendre, mais at lintérieur le bois est rouge el dur; a cause de son odeur, les poux de bois termites ne liattaquent jamais : il est employé pour les constructions dans l'eau et dans la tere; il sert ausi dans l'éhénisterie. - Cò et là dans les plaines du IamenLin; plus abondant au Moule et dans les Grands-konds du Gozier. - Fl. en mai et juin. - Alt. 10-280 mèt. [No 3437.

Mantixique. Vulgo : Lépiné blanc. - Parnasse, hauteur du Prêcheur, Ajoupa-Bouillon, Marin (morne Gommier.) [ $\left.N^{\circ} 1195.\right]$

Z. microcarpum Gr.; Zanthoxylon a petits fruits. Vulgo : Lépineux rouge. - Petit arbe, tris droit, ornemental, habituellement sans piquants. Feuilles imparipennés, a 5-7 paires de folioles petites, crénelées-serretées, subsessiles, lancéolées ou lancéolées-obovales, munies de points translucides. Fleurs en panicules terminales, pyramidales. Follicules solitaires, petits, sessiles, it péricarpe verruqueux; semences globuleuses, tres noires ef très luisantes. (In rencontresouvent une variété, dont le pétiole commun ainsi que les nervures principales des folioles sont garnis, a la face inférieure, de piquants droits ou recourbés. - Toute la plante exhale une odeur forte et peu agréable; le bois nest pas dur et ne peut servir que pour les constructions i l"intérieur. - Abondant dans les terres sèches et pierreuses de Bouillante, de Deshaies, des hauteurs du Vieux-Fort, des Grands-Fonds du Moule et du Gozier. - Fl. en mai et juin. - Alt. 20-300 mèt. [N³436.

Martixique. Vulgo : Bois-lépiné rouge, bois-noyer. - Plaines de 'TroisIlets, hauteur du Diamant, montagne du Vauclin, etc. [No 1183.$]$

Z. flavum Vahl; Zanthoxylon jaune. Vulgo : Noyer, bois-noyer. - Petit arbre élégant, rarement arbre de taille moyenne, dépourvu de piquants.

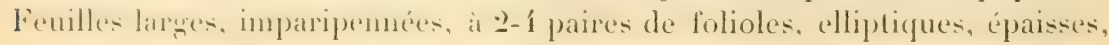


grossierement crénelés, pourves de nombreux points translucides. Flen: en panicules terminales. Cette espèce se distingue facilement de toules ses conénères par ses folioles larges, netlement elliptirgues el ses folliculas pluvolumineux. - Rare. Cà et là dans les terres sablonneuses ou rocailleuses voisines de la mer: Sainte-Anne, Marie-Galante (bois de Folle-Anse). [No 3631.$]$

Il n'existe pas à la Martinique.

Z. martinicense L. Vulgo : Lépineux jaune. - Petit arbre à branches fastigiées ou élalées, aj jeunes branches couvertes de lenticelles blanches, lom riludinales. Feuilles unifoliés, elliptiques, entières, courertes de points transparents; pétiole articulé, près du sommet. Fleurs diö́cques, en petites panicules terminales; calice très petit, se réduisant à quelques iecailles moires; pétales 4-5, blanc jaunâtre; ovaire inséré sur un gynophore, en forme de disque. Fruit folliculaire; semences comme dans les précédentes espèces. Abondant dans les falaises, dans les haies, aux lieux secs et pierreux. - La plante répand une odeur très prononcée, aromatique, mais peu aqréable. I. bois, à aubier jaune et à cour rouge et dur, sert pour les constructions dans la terre; avec les branches on fabrique généralement des manches de loutes sortes d'outils, des charrues, des broueltes, etc. - Fl. en mai ou juin. -1lt. 20-400 mèt. Ies Saintes (Morne-du-Chameau), Désirade, Marie-Galante, Grands-Fonds du Gozier, etc. [No 2972.]

Mantixique. Vulgo : Lépiné jaune. - Abondant dans les terres sèches, le long des rivieres et dans les mornes inférieurs boisés: Trois-Ilets, morne Gommier Marin), Sainte-Anne, Fort-de-France (route de la fontaine Didier at Camp-Balata, etc. $\left[N^{\circ} 1196.\right]$

Quassia I. (du nom de "Quassi ", nègre, esclave de Surinam, qui, avec: celte plante, guérissait les mauvaises fièvres.)

Q. amara L., Desc., vol. I, t. 5; Quassia amère. Vulgo : Quinine de Cayenne. - Arbrisseau ornemental, quand il est jeune, ou tres petil arbre, originaire des Guyanes, à branches nombreuses, fastigiées ou divariquées. Feuilles imparipemnés, à jolioles elliptiques-oblongrues, pointues, entieres, subsessiles ou à pétioles courts et noirs: la paire inférieure, très distante des 3 folioles terminales qui partent du mème point; pétiole commun aile. Fleurs en grappes allongées, lantôt solitaires ou réunies en groupess. lerminales, ou plus rarement en panicules laches; calice petit, a i) dents profondes, corolle grande, écarlate, à j) pétalestordus, ne siourrant que tris peu; ovaire inséré sur un carpophore charmu obconique, rouge écarlate luisant. Fruits 1-j, ovoüles-bianguleux, laissant, après la chute, autant de rreux jaume vert sur le carpophore devenu plus longr que large. - Cet arbrisseau comstilue une plante médicinale précieuse. L'écorce et le bois sont très amers. toniques et fébrifuges. Dans le pays on coupe les branches par petits mor- 
ecaux, quion latise infuser dans l'eau froide, dont on prend un verre le matin el a midi. on lien on prépare, aree les fruits également tris amers, une sorte de vin, qu'on donne à boire avant le principal repas, comme on ferait pour le vin de quinquina ${ }^{1}$. - Se cultive souvent dans les jardins et autour des habitations: Basse-Terre, Vieux-Ilabitants habilation Rollin, Gourbeyre. - Fl. en mai.

Mantrique. Vulgo : Quinquina Cayenne. - Plus abondant quà la Guadeloupe. [ $\left.\mathrm{N}^{\circ} 1197.\right]$

Simaruba Aubl. (nom indigrène de la plante de la (iuyane française.)

S. amara Aubl., Hist. de la Guy., t. 332. S. officinalis D. C.; Simarube amer. Vulgo: Acajou blanc. - Arbre de taille moyenne, à tronc droit et nu, sur une étendue de (i-9) mèt., à écorce grrise, blanchâtre, lisse. Feuilles paripennées, à 5-7 paires de folioles alternes, entieres, oblongues ou oblongues-lancéoléesé, épaisses, coriaces, teminées en me pointe arrondie, d’un rouge ferrugineux en dessous, d'un vert foncé en dessus. Fleurs diö̈ques, en petites cymes formant ensemble une large panicule terminale; calice à 5 dents peu prolondes; petales 5, hypogrynes, élalés; ćtamines 10, insérées sur une écaille arrondie; slyle j-lide. Fruit drupacé, bianguleux, ovoüde. - Le bois est assez dur, résistant el élastique; a l’intérieur, il a une teinte jaune clair. L'écorce de la racine est amère, lonique el fébrifuge; elle est employée en décoction pour combattro lanémie, la dyspepsic, les fières intermittentes et la dysenterie chronique; à haute dose, elle devient purgative et vomitive ${ }^{2}$. - Assez abondant dans les bois inférieurs des Bains-Jannes, du Matouba, des VicuxHabitants, de Pigeon, des Trois-Rivières. - Fl. en mai, juin, juillet. - Alt. 250-700 mèt. [No 2973.

Martixique. Vulgo: Bois blanc. - Abondant. Savanes du Morne-Rouge, du Champtlore, bois de l': ljoupa-Bonillon, fontaine Didier, ete. [No 1198.$]$

Picramnia Sir. (du gree "picros ", amer, el "thamnos ", buisson, allusion à l'amertume des f'euilles et des fruits.)

P. pentandra Sw., P. micrantha Tul.; Picramnia à 5 étamines. Vulgo : Graines dorées, bois-montagne, bois-poisson. - Arbrisseau ou très pelit

1. Ce végétal fournit, en Europe, le hois de Surinam des pharmacies, qui doit ses propriétés amères et toniques à un principe amer nommé quassine, que Oliveri et Denaro (188:) considèrent comme un éther diméthilique de l'acide quassique. Massute (1890) a ajouté à la connaissance de cette quassine l'existence dans le bois de Surinam de trois autres corps cristallisés et amers, dont deux, bien étudiés, représenteraient des homolognes supérieurs de la quassine. Ce dernier principe actif n'est pas azoté. (E. H.)

2. L'écorce de lit racine de simarouba, qui est officinale, renferme de la quassine, une maticre résineuse, une huile volatile, dont l'odeur rappelle celle du benjoin, des acides gallique et malique. C'est un tonique amer qu'on trouve dans une foule de préparations complexes et notamment dans la formule de tous les élixirs anticholériques; elle est caractérisée par son amertume intense et son défaut d'odeur et enfin uné structure spéciale. Elle est supérieure au quassia amara comme tonique et fébrifuge. (E. II.) 
arbre, ornemental, à branches pendantes. Feuilles imparipennées à כ̆-9

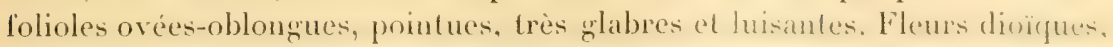
très petites, ramassées en petites glomérules, assises sur des hranches spiciformes qui constituent ensemble des panicules pendantes, terminales of avillaires, allongées, plus rarement des grappes simples; (allice at jolents; pritales

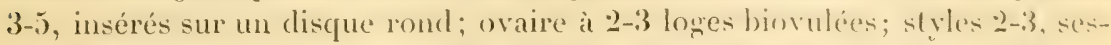
siles. Fruit jaune pâle en dehors, drupacé, lisse et luisant, à moitié aussi gros qu'une olive, contenant une seule graine. - Le bois est très amer. La racine et le bois jouissent dans le pays d'une grande réputation : on les emploie en infusion contre les affections lépreuses et contre la syphilis. FI. en avril et mai. - Se rencontre un peu dans tous les bois, sans être abondant nulle part: Houëlmont, Vieux-Habituts, Grands-Fonds du Morne-isl'Eau. Alt. 60-400 mèt. [No 3257.]

Martinique. Vulgo : Bois-moudongue, bois-madame. - Plus abondant quà la Guadeloupe : il śemploie pour les mêmes usages. Morne-Roure (Calvaire), Parnasse, Lamentin (Roches-Carrées), etc. [Nº 200.

Picræna Lind. (du z̧rec " picraino ", rendre amer, allusion à l'amertume du bois et de l'écorce.)

P. excelsa Lind., Simaruba excelsa D. C. ; Vulgo : Bois-noyer, graines vertes. - Arbre d'assez grande taille, élancé, à écorce grise, peu fendillée. Feuilles imparipennées, à 9-11 folioles oblongues ou oblongues-lancéolées, terminées par une pointe obluse, entières, coriaces. lileurs polygames, en cymes larges. corymbiformes, terminales, beaucoup plus courtes que les fenilles; calice it 5 dents; pétales 5 , oblongs, jaune pâle; étamines 5, insérées sur un disque; nvaires 3 , distincts; style fendu en 3 branches. Fruil drupacé, sphérique, bleu foncé et grlauque à la maturité. - Le bois, de couleur blanchâtre, nuancé de jaune verdâtre en certains points, sert pour les constructions ì l'intérieur. Je bois et l'écorce sont amer's : on les emploie en infusion contre les fièvres'. - Peu abondant: Bois de Gourbeyre (Morne-Goblin), CampJacob (bords des rivières Noire et Rouge). Alt. 400-700 mèt. [X"36330.

Mantiviqer. Vulgo: Bois amer. - Hauleur des Trois-Ilets, montanne du Vauclin, Sainte-Anne, etc. $\left[\mathrm{N}^{\circ} 1192.\right]$

1. On emploie surtout le bois dans la pharmacie européenne, qui en fait grand usage sous le nom de quassia de la Jamä̈que, presque à l'exclusion entiere du quassia de Surinam (Quassia amara L.). Massute (1890) a retiré de ce quassia de la Jamaïque comme principes actifs, deux corps cristallisés qu'il appelle picrasmines; l'un fond à $20 i^{\circ}$ et l'autre à 209-2120. Le premier, traité par l'acide chlochydrique, donne de l'acide picrasmique qui n'est pas identique à l'acide quassique d'Oliveri et Donaro voil note à Ia fin de Qnassia amara). Il résulte de ces travaux que la matière amère des deux bois de quassia (de Surinam et de la Jamaïque) est constituće par une série de corps homologues, mais dilférents dans les deux espèces. C'est avec le bois de ce l'icraena excelsal qu'on fait les gobelets tournés dans lesquels on laisse séjourner de l'eau, qui y acquiert trés rapidement une grande amertume. Les copeaux provenant de la fabrication de ces gobelets sont aussi vendus en pharmacie. (E. H.) 


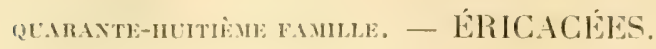

Brossæa 1). C. idédié à Crui de la Brosse, médecin de Louis XIII, fondateur du Jardin botanique roval de Paris: a publié, outre la description de ce jardin, un traité sur la nature, l'utilité el les vertus des plantes.)

B. anastomosans (x., Epigæa cordifolia Sw., Gaultheria buxifolia IV: : Brossea à nervures l'oliaires anastomosées. Vulgo: Myrtille. - Très petit arbrisseau, ornemental, plus ou moins radicant, haut de $30-60 \mathrm{~cm}$., à écorce noire ou zrise. Feuilles pelites, ovés, légèrement cordées, cartilagineuses. finement serretées; à dents aiguës, très brièvement pétiolées; à limbe ne dépassant jamais $8 \mathrm{~mm}$. de Inng sur $3 \mathrm{~mm}$. de large; à nervures principales el secondaires souvent parsemées de poils courts et rigides. Fleurs en petiles evmes terminales; calice persistant, couleur lie de vin; a 5 dents profondes. deltö̈des, arefuées; corolle rouge carmin vif, en clochettes conoüdes, fortement élargries à la base, terminées par 5 dents; étamines 10, incluses, à anthères pourves, au sommel, de 2 petites arètes; pédoncules el pédicelles yarnis de plusieurs bractées rouges, écailleuses et pointues. Fruit globuleux, à moitié niché dans le calice, pulpeux, mangeable, tardivement loculicide, contenant un grand nombre de très petites graines brunes. - Abondant dans les sphagnums de la Soufrière; plus rare à la Grande-Découverte. - Fl. presque toute l'année, mais surtout en décembre, janvier, février et ¡mars. - Alt. 1100-1480 mèt. [No 2255.

Martinique. Vulgo: Myrtille. - Peu abondant : sommet de la MontagnePelée (Morne-de-la-Croix) el dans la coulée du Prêcheur, qui aroisine le lac. $\left[\mathrm{N}^{\circ} 1358\right.$.

Symphysia Prl. (du greec "symphysis ", union, connexion, parce que le calice adné à l'ovaire forme une seule masse avec lui.)

\section{S. yuadalupensis Kl., S. martinicensis 1)eless., Hornemannia marlinicensis} Hook fils. Vulgo : José. - Arbrisseau ornemental par son feuillage tortueux ou plus ou moins sarmenteux, quand il peut trouver un appui, à branches nombreuses, toujours fortement inclines, haut de 2-3 met. Feuilles vert clair, carlilagrineuses, elliptiques ou elliptiques-lancéolées, atténuées à la base, pointues au sommel, crénelées ou subentières, à nervures invisibles en dessus, bien dessinées en dessous, 2-33 paires de nervures secondaires partant de la crite principale el formant un area dans la partie supérieure du limbe. Fleurs en cormbes, le plus souvent terminaux, renfermant 15-25 rayons Innguement pédicellés; calice campanulé, adné a l'ovaire, a fi-8 dents, largement arrondies et souvent munies d'une petite pointe; corolle campanulée. charnue, à 6-8 dents; étamines 15 , distinctes, incluses, insérées en cercle à 
la base du tube, un peu au-dessus de l'ovaire; anthères larges, ovalesoblongues, dressés, laissant échapper le pollen par un petil pertuis summint l'anthère; filets élargis à la base et s'alténuant vers le sommet; ovaire à 6 loges, dont les cloisons se détruisent plus ou moins. Firuit pulpeux, tronqué au sommel, dépassé par le bord du calice et muni, au milieu de la parlie plate du sommet, d'un petit enfoncement, trace du style; semences scobiformes. très nombreuses, situées dans la partie inférieure du fruit, la partie supérieure étant remplie par une matière dure. - Les l'ruits mûrs sont noirs el peuvent se manger; leur saveur rappelle celle des myrtilles de France. - Cá et là dans les clairières des grands bois, très abondant ì la Soufrière, î la Grande-Découverte, à la Savane aux Ananas, où les pieds sont petits el rabougris. Alt. 500-1480 mèt. $\mathrm{N}^{\circ} 2243$.

Martineve. Vulgo : Myrtille du pays. - Calebasse, Monlagne-Pelée, Pitons du Carbet, etc. [ Yo 1359.

QUARANTE-NeCTì̀e FuMLLE. - CYRILLLÉES.

Gyrilla L. (dédié à l'Italien Dominico Cyrillo, professeur de médecine à Naples; a écrit : Collectio plantarum rariorum regni Neapolensis, 1788; Tabulix botanice, 1790.)

G. Antillana Mich.; Cyrille des Antilles. Yulgo : Bois-couché, olivier-demontagne. - Arbrisseau droil, touffu, très ornemental, par l'ensemble de son port, de son fenillage et de ses fleurs, toujours très vert, haut de $80 \mathrm{~cm}$. sur le cône et le plateau de la Soufrière, de la Grande-Découverte, petit arbre aux sources du Galion et au Matouba, où il vit en société, arbre vigantesque dans les bois de Sofaya (Sainte-Rose), à l'endroit nommé "le bois-couclié \#. Feuilles vert clair, rigides, très rapprochées el confinces anx extrémités des branches, lancéolées-oblongues, léuèrement échancrées au sommet, tinement réticulée. surtout en dessous. Fleurs petites, blanches, en racèmes serrés, allongés, nombreux, axillaires, situés aux extrémités des branches, plus lomers que les feuilles; pédicelles courts, aussi longs que les pétales; calice très petit, à 5 divisions; pétales 5 , pointus; étamines 5 ; anthères s'ouvrant par une fente latérale; style court; stigmate bifide; ovaire ovale, inséré sur un petit torus, à 2 loges. Fruil capsulaire s'ouvrant en 2 valves; semence 1. - Fil. en mai, juin, juillet. - Alt. 280-1480 mèt. [No 2316 .

Cel arbre si commun à la Guadeloupe ne se trouve pas à la Martinique.

\section{CINQUANTİMe FAMLLE. - CÉLASTRINÉLS.}

Maytenus Juss. (du nom chilien " mayten ».)

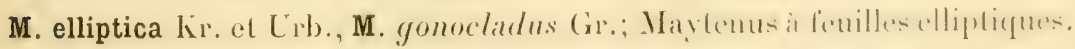
Dïss. - Plantes Guadeloupe et Martinique. 
Vulgo: Bois-citron. - Petit arbre, très droit, haut de 3-4 mèt., à écorce zrrise, à jeuncs branches tétragones et à écorce brune. Feuilles elliptiques ou

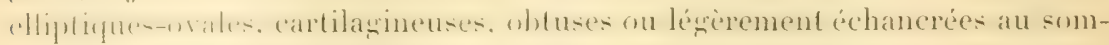
met, luisantes en dessus, rrises en dessous, délicatement veinées. Fleurs très petites, axillaires, solitaires ou en cymes très courtes, situées à laisselle des l'euilles: calice cupuliforme, a 5 dents; pétales 5 ; étamines 5 , insérées sur le fond d'un disque rond; pistil syncarpé; ovaire plongé dans le disque. Fruit i) 2 loges uniovulées; stvle court ; sligmate bilobé; semences 1-2, orbiculares, fortement comprimées-aplaties, dures, d'un brun noir, luisantes, polies. prescue complètement entourées d'un arille légèrement violacé. - Fl. en avril ou mai: fruils mûrs en juillet. - Assez abondant dans les endroits calcaires ou pierreux et sees: Tieux-Fort, Maric-Galante (Folle-Anse), Gozier. Alt. $0-300$ mèt. No 2176.

Mantrige. Tulgo : Bois-citron, bois-Guillaume. - Hauteurs de CasePilote (Fond-Jayette), Diamant (habitation Kikandon), morne Gommier (Mariil). No 809.

M. guyanensis Gr.; Tulgo: Café-bois, bois-café.-Petit arbre, Lantôt droit ef à branches tout à fait horizontales, tantôt tortueux, ì branches inclinées et allongées. Feuilles trois fois plus larges que dans le précédent, vertes des deux côtés, luisantes, brièrement pétiolées, elliptiques, terminées en pointe, ¿ côte saillante en dessous. Fleurs jaune verdâtre, très petites, en cymes très courtes, insérées a l'aisselle des feuilles. Fruit ovoïde, un peu plus grand qư une cerise de café, s'ourrant en 2 valves, transversalement sillonnées en dedans; semences 2, ovoüdes-aplaties, entièrement couvertes sur le dos et sur plus de la moitié du côté rentral d'un arille rosé.-Fl. en avril, septembre. Peu abondant. (uì et là dans les bois inférieurs des Bains-Jaunes; moins rare dans les bois marécageux du bord de mer, entre le Vieux-Bourg et le canal des Rotours. Alt. 0-650 mèt. Yos 3101 et 3673 .

Mantrance. Vulgo : Café-bois. - Bois inférieurs de la Montagne-Pelée (rare), Trois-llets (I a Plaine). [No 2133.]

Elæodendron Jaç. (du grec " elaion ", huile, et " dendron ", arbre, parce que les fruits ressemblent à une olive et que plusieurs espèces contiennent de lihuile.

E. xylocarpum D. C.; Eléodendre à fruits ligneux. Vulgo: Prune bord-demer. - Petil arbre peu élégant, presque toujours plus ou moins torlueux, à écorce noire, rude, transversalement fendillée, à branches très étalées, souvent fortement inclinées. Feuilles cartilagineuses, elliptiques-obovales, atténuées ¿ la base en un court péliole, crénelées, à crénelures grosses, dislancées, peu profondes. Fleurs polynames, en cymes terminales; calice à $\mathbf{1}-\mathbf{J}$ divi_ sions profondes; pétales 5 ; étamines 5 , insérées sur le bord d un disque rond:

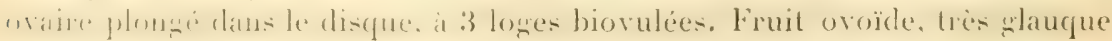


et légèrement pubescent avant la maturité, tantôt grand comme une noix di France, tantot comme une olive; it épicarpe et mésocarpe secs; it endocarpe osseux el épais; semences 1-3, oléagineuses.- Peu abondant. (Yà et lí entre les pierres des falaises du bord de mer. - Fl. en mai et juin; fruits mûrs en septembre, octobre et novembre. - Les fruits restent longtemps allachés au pied. - Gozier. [No 3680.

Mantisege, Vulgo: Prune bord-de-mer. - Assez abondanl entre les pierres des environs du phare de la Caravelle. $\left[Y^{\circ} 587\right.$.

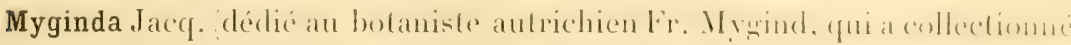
les plantes de la Barbade pour l'herbier de Jacquin.

M. Rhacoma Sw. (de "Rha ", vieux nom de la Wolga, d'où l'on tirait cette plante. Le Rachoma de Pline, XXYII, 105, est le Rheum rhaponticum, plante tres diflérente de celle dont il est question ici. Rhacoma uragrya Rich. Br. Jam., 1. 17, 1. 1; Desc., vol. IV, 1. 25, p. 81. - Grand arbuste ou arbrisseau, élégant, très touflu, ì branches divariquées ou lastigiées. Feuilles petites, membraneuses, obovées ou ovales, parfois nettement elliptiques, crénelées-serretées, à pétiole court. Fleurs très petites, en cỹmes axillaires, courtes; pédoncules filiformes, plus courts que les leuilles et bifurquées au sommet; calice persistant, à $\mathbf{f}$ divisions profondes; pétales 4; étamines 4 , insérées sur le bord d'un disque; ovaire niché dans le disque, à f́loges uniovulées. Fruit drupacé, rouge, très dur, plus petit qu'une graine de poivre. Descourtilz elasse cette plante dans les diuréliques excitants et recommande la racine dans les néphrites calculeuses; il ajoute que les colons des Antilles s'en servent pour cicatriser les abcès des reins et de la vessie, et quils absorbent dans ce cas la poudre de la racine dans du lait. Dans les endroits de la Guadeloupe et de la Martinique où cet arbuste existe, on se sert quelquefois des racines en décoction comme diurélique. - Aime les endroits secs el calcaires. - Abondant à la Désirade (côte occidentale), à Marie-Galante (Capesterre), aux mornes calcaires, entre Port-Louis et l'Anse-Bertrand. [N० 2870 . ]

Nota. - La figrure de Descourtilz représente mal le fruil; dans mes spécimens, provenant de la Désirade et de Marie-Galante, on trouve, en dehors des cymes axillaires, des panicules terminales assez allongées et formées de petites eymes.

Mantriece. Vulgo : Petil merisier. - Assez abondant an Vanclin (Macouba) el sur les mornes calcaires de Sainte-Anne. [Xo 569.

M. pallens Sw.; Myginda à feuilles vert pâle. Vulwo : Pelit merisier. Petit arbre droit, à branches divariquées souvent inclinées: les jeunes, létragones; les adultes, eylindriques, it écorce lisse ot grisitre. lienilles petites, membraneuses, obovales ou obovales-oblongues, th pointe obluse on échancrée, subentières ou faiblement crénelées. Fleurs très petites, en crmes 
axillaires, portécs par 2 pédoncules filiformes opposés et bifurqués au sommet, plus courts que les feuilles; drupe rouge, obovale, couronnée du stigmate persistant. - Rare. Cà et là dans les endroits sees et pierreux de Houëlmont. - Fl. en tout temps. - Alt. 190-300 mèt. [No 2177.]

Je ne l'ai pas trouvé à la Martinique.

M. Latifolia Sw.; Myginda à larges feuilles. Yulgo: Petit merisier. Arbuste on petit arbre élégant, très droit et très touffu, à jeunes branches létragones. Fenilles très rigides, elliptiques, ou obovales ou spatulées, subenlières ou grossièrement crénelées vers le'sommet, et souvent profondément échancrées. Fleurs très nombreuses, blanches, odorantes, en cymes dichotomes ou trichotomes, courtes, fasciculées, formant ensemble un corymbe terminal ou axillaire, Le fruit manque. - Fl, en août el septembre, - Assez rare. Cà el lì sur le plateau calcaire de la Désirade. [No 2871.]

Il n'existe pas à la Martinique.

Schaefferia Jacq. (dédié au pasteur protestant allemand, Jac. Christ. Schaefler, né ì (Querfurt (Saxe), en 1718, grand prédicateur et chel de consistoire, auteur de différents ourrages de botanique.)

S. frutescens Jacq., Sl., t. 209; Sw., Fl., t. 7, analyt.; Schaefferia frutescent. Vulgo : Merisier. - Arbrisseau buissonnant, élégant, haut de 1-2 mèt., à branches minces, flexibles : les jeunes, bianguleuses-comprimées et finement striées. Feuilles alternes, vert pâle en dessous, glabres, rigides, elliptiques, pointues au sommet, rétrécies à la base en un court pétiole. Fileurs diö́ques, axillaires, diversement gronpées : les mâles, presque sessiles, en petites glomérules axillaires; les femelles, en cymes sur un pédoncule تrénéralement long el portant 4-fi ravons; pédicelles petits, filiformes, épaissis au sommet, aussi longs que les fleurs femelles; calice petit, persistant, it 4 divisions arrondies; pétales f́, écarlates; étamines f́, hypogynes; ovaire it 2 loges uniovulées. Fruit pulpeux, ovoïde-comprimé, surmonté du style et du stigmate persistants, traversé au milieu, sur les deux côtés, par un sillon; semences 2. - Fl. en juin et juillet, en septembre et octobre. - Dans les terrains secs et pierreux : Moule (le long du canal), momes calcaires de PortLouis et aussi dans les sables du bord de mer. [No 2872.]

Martinique, Vulgo : Petit merisier. - Hauteurs du Carbel (le long du canal), mornes calcaires de Sainte-Anne. [No 590.

CINQCANTE-UNìne FAMhLL, - ILICINÉES.

Ilex I. (du celtique " ec » ou " ac ", pointe, parce que les feuilles des. espèces-types portent des piquants.) 
I. montana Gr., variété orientalis Loes. Houx des montagnes. Vulgo: Graines vertes, pruneau. - Petil arbrisseau, très élégant à cause de son port et son feuillage toujours très vert, à branches fastigiées, ou petit arbre it branches étalées, à écorce d'un brun foncé, verruqueuse et peu fendilléc. Feuilles simples, elliptiques ou ovales-lancéolées, acuminées au sommet, atténuées à la base, dentées en scie, à dents aiguës, infléchies ver's le limbe, veines saillantes en dessous; pétiole court, noir. Fleurs complètes, petites, en corymbes de 8-20 rayons, plus longos que les pétioles; calice monopétale 4-6-partite; corolle blanche, rotacée, ì 6 pétales concrescents près de la base; étamines 6 , insérées à la base de la corolle et alternant avec les segments du calice; filet filiforme; anthères introrses, sourrant fongiludinalement; ovaire sessile, à $\mathbf{f}$ loges; stigmates 4 , sessiles, distincts, noirs et très visqueux. Fruit brun, baccien, globuleux, de la grosseur d'une graine de poirre, surmonté du style persistant; semences 2-t, triquètres, légèrement camnelées. - Assez abondant dans la région supérieure des haules montagnes: cône et plateau de la Soulrière, où il est rabougri, sources du Galion, GrandeDécouverte, Savane aux Ananas. - Fl. presque toute l'année. - Alt. 9501480 mèt. [Nos 2558,3435 .

Martinique. Vulgo : Petil citromnier. - Abondant à la Montagne-Pelée, au-clessus de la petite savane et aux Pitons-du-Carbet. [No 616.$]$

I. sideroxyloides Gr. ; Houx ressemblant au Sideroxylon. Vulgo : Bors-citron, citronnier blanc. - Petit arbre ou arbe de taille moyenne, at branches inférieures divariquées : les supérieures, fastigiées, à écorce blanchâtre, peu léndillée. Feuilles variables, elliptiques ou obovales, rétrécies it la base, obtusément pointues ou échancrées au sommet, d'une consistance de parchemin, luisantes et vertes en dessus, grises en dessous; pétiole court, cannelé. Fleurs très nombreuses, en petites cymes ombelliformes axillaires de 3-13 rayons, aussi longs ou une fois plus longs que les pétioles; corolle blanche, rotacée, plus large que dans le précédent. Fruit globuleux, comprimé au sommet, plus grand qu'une graine de poivre. - Cet arbre fournit un bois recherché pour la charpente, la menuiserie et le charronnage. - Fl. de janvier en mars; fruits mûrs en mai et juin : les oiseaux en sont friands. - Abondant dans tous les grands bois des Bains-Jaunes, du Matouba, des Vieux-IJabitants of du massil de Houëlmont. Alt. 200-900 mèt. [No 2309.

Mantinique. - Variété typica Loes., lorma vulgaris Loes. Vulgo : Bois gris. - Abondant dans les bois inférieurs de la Montagne-Pelée bois de (ialldiale, des Fonds-Saint-Denis, des hauteurs de la Grand'Anse, et ì l'état de buisson dans les terres calcaires de la Caravelle et des mornes de Sainte-Anne. Alt. 50-600 mèt. [Nos 654, 1246.

I. nitida Max.; Houx à feuilles luisantes. Vulgo : Citromier, graines vertes, pruneau noir. - Arbre de taille moyenne, droit, ì écorce grisâtre, converte e rugosités, à branches munies de verrueset de lenticelles, a jeunes rameaux 
noirs ou bruns, lisses, légèrement striés. Feuilles membraneuses, vert noir en dessus, larges, elliptiques ou elliptiques-oblongues, grossièrement crénelées au-dessus de la base, roulées sur les bords, obtusément pointues au sommet. Fleurs petites, nombreuses, en corymbes axillaires. Fruit comme dans le précédent, mais à épicarpe noir et luisant; semences f́, triquètres, netlement cannclées. Se distingue facilement de ses congénères par ses feuilles plus largenes et crénelées, ses fleurs plus petites el plus ou moins verdâtres. - Abondant dans les mêmes habilats que le précédent. - Fl. en mars el avril. - Alt. 100-700 mèt. [No 2867.

Mantrigce. Vulyo: Bois-petit-Jean. - Parnasse, Fonds-Saint-Denis, fontaines Didier el Absalon, etc. [No 656 .

I. dioica Gr.; Houx à lleurs diö̈ques, Vulgo : Citromier-montagne. - Petit arbre tortueux, à écorce vep̧ruqueuse, ì jeunes branches comprimées et striées. Fenilles larges, cartilagineuses, elliptiques ou ovales, subentières ou à peine crénelées au-dessus de la base, terminées en pointe obtuse, arrondies à la base, côte très saillante en dessous, imprimées en dessus; pétiole court, large, cannelé. Fleurs nombreuses, en corymbes ombelliformes ou en simples ombelles naissant d'une tubérosité, a 5 - 14 rayons aussi longs que les pétioles; corolle rotacée. Fruit globuleux, à peu près deux fois plus petit qu une graine de poivre, surmonté d'une pointe courte, reste du style persistant. C'est de tous les Ilex de nos colonies l'espèce dont les fruits sont les plus petits. Asse\% rare. Cià et là dans les Pitons-du-Carbet. Alt. 780-850 mèt. [X'os 237, 655.] - I1 n'existe pas à la Guadeloupe.

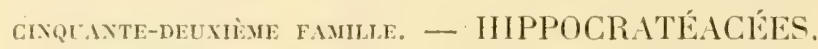

Hippocratea L. dédie au célebre médecin sree Hippocrate, né à l'ile de Cos, en 470 ou 460 avant J.-C. ; mort it Larisse, en 372 ou 351.)

H. ovala Iam.; Hippocratea it feuilles ovées. Vulgo: Liane-z'amande, boisz'amande, liane rouge. Lam., IIl., t. 28, 1. 2; Desc., vol. IV, t. 290, p. 265. - Arbrisseau sarmenteux, pourant s'élever très haut, quand il trouve un appui, à branches très nombreuses, décussées, insérées à angle droil, tordues el enchevêtrées, pendantes dans les vieux pieds : les supérieures et les terminales, changées en vrille; écorce noirâtre ou grrise, presque lisse. Feuilles opposées, elliptiques ou oblongues, ou ovées, terminées en pointe obtuse, tantôt netlement crénelées, tantòt faiblement dentelées au-dessus de la base: pétioles courts, articulés tout près de la base. Fleurs très petites, en panicules trichotomes, terminales et axillaires, composées de eymes dichotomes et bibractéolées à la base; pédoncules tétragones; pédicelles et pédicellules 
légèrement duvetés; calice J̆-fide; pétales 5, obovés, vert jaunâtre; étamines 3. insérées sur le côté d'un disque large, annulaire; ovaires 3; styles 3, cohérents ì la base. Fruils uniloculaires, réunis par 3 sur un carpophore allenant au disque lignifié, larges, très comprimés, elliptiques ou légrèrement orales, ou oborales (dans mes spécimens), longs de 5 cm. sur ㄹ-3 cm. de large, s'ourrant des deux côtés, en deux valves nariculaires; péricarpe membraneux, gris, lisse, finement et longitudinalement strié; semences (i, pendantes, comprimées, prolongées inférieurement en une large aile membraneuse. - Fl. presque toute l'année, mais surtont d'anût en novembre. - Lamentin (bord du canal et dans les broussailles qui aroisinent les marais . Baie-Mahault. [Nos 2996, 3400.]

Martinique. Vulgo : Liane-crabe. - Rare : Ravine-de-Ducos, ravines du Parnasse (près de l'habitation Littée). [ $\mathrm{N}^{\circ}$ 181.]

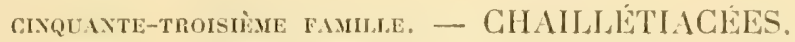

Tapura Mart. (nom de la plante à la Guyane.)

T. guyanensis Aubl. Vulgo : Bois-côtelette noir, bois-côte noir. Aubl., Hist. de la Guyane, t, 48. - Arbre de taille moyenne, plus rarement grand arbre, à trone droil, pourvu de 3-5̆ côtes, qui, peu saillantes dans le haut, deviement de plus en plus fortes dans le bas et finissent par former une base très anfractueuse; à écorce grise, peu épaisse, fendillée; à branches souvenl horizontales, très étalées; a rameaux toujours inclinés. Feuilles cartilagineuses, glabres, luisantes, très vertes en dessus, pâles en dessous, légèrement obovales, arrondies à la base, brièvement pointues au sommet, entières, alternes, ì côte et à nervures très saillantes en dessous, peu visibles à la face supérieure; pétiole court, gris, épaissi, ruğuleux, souvent cannelé. lileur's en

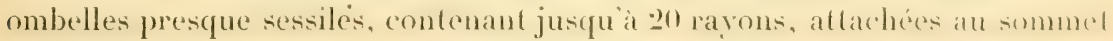
du pétiole ou quelquefois à la base du limbe; calice monosépale, à 5 lobes pubescents, ovales, dont 3 extérieurs el plus grands, el 2 intérieurs, el placés plus haut; corolle à 5 pétales, longrs de $1-2,3 \mathrm{~mm}$., blancs, insérés au fond du calice; étamines 8-11, blanches, exsertes, d'inégale longueur, tantôt libres, tantôt légèrement cohérentes et laineuses, simulant un tube dont le sommet est rempli d'une matière laineuse et blanche; anthères longues de $1 \mathrm{~mm}$., presque aussi larges, dorsifixes, introrses; pistil trilobé, cylindrique, aminci vers le sommet; ovaire sessile, velouté, ovale, triloculaire. Fruit drupacé, long de $18-22 \mathrm{~mm}$. sur 12-45 mm. de diamètre, oboroüde, ¿ो

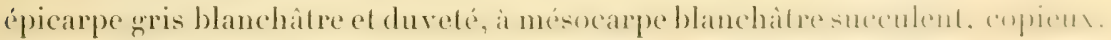
d'une saveur très sucrée et fort agréable; semences ovoödes-allongées. 
blanches. Les rats, les oiseaux et les chauves-souris font aux fruits une guerre acharnée. - Le bois est blanchàtre, dur et sert pour la construction. - Assez rare dans les bois des bains-Jaunes, du Matouba et de Gourbeyre; assez abondant dans les forêts des environs du Grand-Étang, de l'ÉtangrZombi (Capesterre) et des Trois-Rivières. - Fl. en avril et mai, el aussi en septembre et octobre. - Alt. 300-800 mèt. [Nos 3462, 3622.]

Mantriqua. Vulgo : Bois-côte. - Abondant dans les bois du Morne-Rouge, de l'Ajoupa-Bouillon, des lionds-Saint-Denis, du Lorrain et du Camp de l'Alma. No 183.

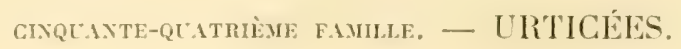

Celtis (Pline désigne par ce mot une espèce de Lotus, clu grec " kellein ", pousser, "keltis ", cravache, parce que les branches flexibles peuvent servir de cravache.

C. aculeata Sw., Rhamnus iguaneus L.; Celtis à piquants. Vulgo : Crocchien, gratte-jambes. Desc., vol. VII, t. 492? - Arbrisseau sarmenteux, à lranches allongeres, distiques. tlexibles et inujours pendantes ou fortement inclinies, pourves de piquants slipulaires, solitaires et recourbés : les vieux pieds, à écorce rude; les jeunes branches, à écorce couverte de tubérosités lenticulaires el blanches. Foulles obovales-oblongues. brievement pétiolées, ¿ 3 nervures partant de la base du limbe, à pointe obtuse au sommet, subcordées à la base, membraneuses, légèrement gaufrées, alternes-distiques. lileurs polygames, très petites, verdâtres, en cymes axillaires, portées sur des pédoncules articulés au sommet et aussi long's que les pétioles; calice j-partite: ste bifide, a branches recourbes. Fruit globuleux, drupacé, un peu plus volumineux qu'une graine de poivre, à endocarpe dur, renfermant 1 semence. - Fl, en mai et juin. - Endroits secs, sablonneux ou pierreux du littoral ou dans les sables du bord de mer: Basse-Terre (La Pintade), rivière Sence, Deshaies, Pointe-Noire. [No 2849.]

Martingue. Vulgo: Croc-à-chiens. - Carbet (bord de mer du Quartier-

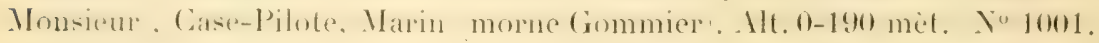

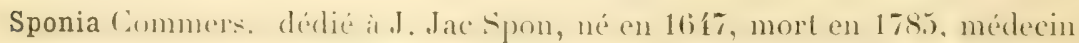
¿ Lyon; a publié, en 1775 , les résultats de ses royages en Italie, en Dalmatie, en Grèce et en (rient.)

S. micrantha Decs.; Sponia à petites fleurs. Vulgo: Bois-de-l'Orme, petitorme, orme petite-feuille. - Petit arbre très droit, élégant à cause de son port et de son leuillage, haut de 6-7 mèt., rarement plus élevé, à écorce 


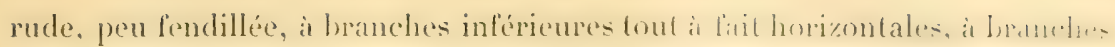

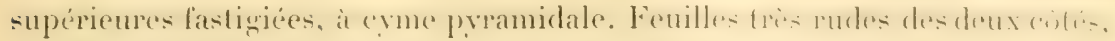
membrancuses, gaufrées entre les nervures, triplinerviécs; à nervures el nervilles rougeâtres en dessous, ovales-lancéolées, acuminées, finement dentelées en seie, légèrement cordées à la base; a lobes inégaux. Fleurs polygames, très petites, en cymes axillaires, très nombreuses, courtes, géminées ou trichotomes, tantôt plus courtes, tantôt plus longues que les pétioles; pédoncules et pédicelles sourent bibractéolés au sommel; calice j-partite; anthères exsertes. Fruit drupacé, très petit, surmonté du style persistant. Peu abondant. Cà et là dans toutes sortes de terrains de la région inférieure. - Le bois est blanchâtre et sert à faire des lattes, des poteaux, ctc. - SainteRose (environs du bourg), Camp-Jacob(dans le bas de la rivière Toire, elc.). Alt. 30-100 mèt. [Yos 2858, 3639.]

Martivique. Vulgo: Bois-de-l'Orme. - Assez abondant au Champflore el dans les bois de l'Ajoupa-Bouillon, ete. [ $\mathrm{N}^{\circ} \mathbf{1} 400$.

S. Lamarkiana Decs.; Sponia de Lamark. Vulgo : Orme petite-leuille, caca-ravet. Plum., édit. Burm., t. 206, f. 2. - Arbrisseau ou petil arbre très élégant, à écorce grrisâtre, très rude, à branches inférieures horizontales, à rameaux distiques, i jeunes rameaux duvetés. Feuilles petites, ovales-lancionlées, pointues aux deux extrémités, brièvement pétiolées, extrêmement rudes sur les deux faces, finement dentelées en scie, inégales à la base, roulées sur les bords, d'un vert grrisâtre, à côte et à nervures imprimées en dessus et couleur de rouille. Lrès saillantes et duvetées en dessous. Fleur's el fruits comme dans le précédent, ducpuel il se distingue lacilement par la petitesse et la rudesse de ses feuilles, par ses cymes subsessiles et plus longues que les pétioles. - Fl. en septembre et octobre. - Cà et là dans les mornes secs et dans les falaises: Rivière-Noire, Deshaies, Pointe-Noire, Alt. 150300 mèt. [No 3572 .

Martixique. Vulgo : Caca-ravet. - Assez abondant dans les mornes secs des hauteurs du Precheur habitation de Messimy, morne Commier I Marin . [No 1398.$]$

Ficus I. (du gree "sukon », figue, que les Latins ont changé en " licus ».)

F. laurifolia Lam., F. martinicensis W., F. virens tit.; Figuier à feuilles de laurier. Vulgo: figuier à agouti. Sl., 1. 223. - Arbre souvent énorme, à tronc de $1^{\text {m }} 60$ de diamètre, très anfractueux à la base, à cyme très étendue, ¿̀ branches divariquées ou horizontales, très divisées, à écorce rougentre, généralement très peu fendillée. Feuilles larges, membraneuses, plus ou

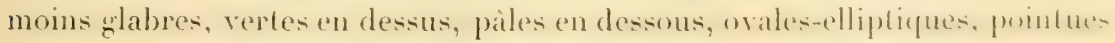
au sommet, arrondies à la base, ì côte large el aplatie, à 12-15 paires de

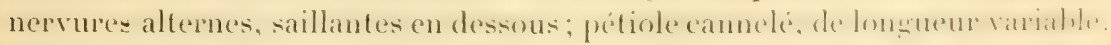

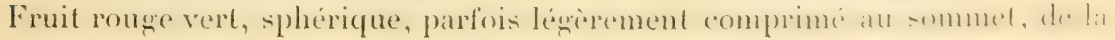


forme ef de la grosseur de celui du tamarin des Indes, le plus souvent tacheté de brun ou de jaune, d'un diamètre de $25-30 \mathrm{~mm}$., porté par un pédoncule long de 1f-18 mm. - Les agoutis sont particulièrement friands de ce fruit. Le bois est mou, il pourrit facilement el ne s'emploie pas pour la construclion. - Cai et là dans les falaises et sur les bords de rivières des bois inférieur's: Bains-daunes, rivière Rouge, T'rois-lkivières. Alt. $50-600$ mèt. X" 2191 .

Mantmone: Vulgo : Figuier maudit. - Plus abondant qu'à la Guadeloupe; se reneorstre dans tous les grands bois inférieurs. [Yo 1412.]

F. crassinervia Desf.; Figuier à fortes nerrures. Vulgo : Figuier grandefeuille. - Arbre de taille moyenne, plus rarement très grand arbre, presque toujours muni de racines adventives, ì tronc droit, à branches peu divisées, tonjours horizontales ou inclinées, à écorce grise, épaisse, fendillée dans les vieux pieds. Feuilles larges, eartilagineuses, ramassées à l'extrémité des rameaux courts, vert pâle en dessus, grisâtre en dessous, orales, arrondies ì la base et au sommet: les jeunes, souvent obovales et atténuées en coin, ì la base; à nervures larges, carénées et très saillantes à la face inférieure; pétiole long, cannelé, comprimé, élargi à la base et laissant de grrandes cicatrices blanches. Fruit globuleux, subsessile, de $8-10 \mathrm{~mm}$. de diamètre, légèrement plus long que large, velouté, marqué de taches rondes, vertes ou brunes. Feuilles involucrales 2, persistantes, larges, arrondies, opposées, fortement appliquées contre le fruit, finement duretées et noires, ce qui tranche fortement avec la couleur grise du péricarpe, ouverture du sommet annulaire, formée de 2-3 écailles. - Fruits mûrs en avril et mai. - Assez abondant dans les mornes, les falaises boisées et les savanes de la région du littoral: Basse-Terre (rivière des Pères), Houëlmont, Vieux-Fort, Capesterre Guadeloupe), etc. Alt. 10-350 mèt. [N²196.]

Martixquer, Vulgo : Figuier blane. - Cà et là dans la basse région : Vauclin (route du Marin), Trois-Ilets, Sainte-Luce, etc. [No 1411.

F. lentiginosa V.; Figuier à formations lenticulaires. Vulgo : Figuier blanc. - Arbrisseau souvent gigantesque, produisant sur le trone et les branches une masse de racines adventives de l'épaisseur d'un crayon, courant quelquefois au loin sur la terre, devenant alors beaucoup plus grosses et se courrant de nombreux corps lenticulaires blancs; a branches très étendues, divariquées, horizontales, ì écorce grise ou blanchâtre, grercée; ì trone formant, it la base, des anlractuosités énormes. Feuilles membraneuses, beaucoup plus petites que dans le précédent, membraneuses, lisses, vert tendre, longuement pétiolées, faiblement cordées ou plus rarement arrondies ¿t la base, terminées en pointe obtuse au sommet. Fruit mûr, blanchâtre, souvent tacheté de rouge, de brun ou de vert, globuleux, glabre, deux fois plus gros qu'une graine de poivre, muni, à l'ouverture, d'une petite proémi- 
nence rouge, mammiforme. lieuilles involucrales petites, bilibées. - Asse\% abondant dans les mornes inféricurs: Abymes (morne du Calvaire), Gozier (bord de mer), dans les falaises de la rivière Noire et de la rivière des Pères, etc. Alt. 10-500 mèt. [No $217 \%$.

Mantrieve. Vulgo : Aralie-cerise. - Parnasse, Prècheur, Case-Pilote, Lamentin, Ducos, Trinité, ete. $\left[\Upsilon^{\circ} 1-407\right.$.

F. pertusa L..; Figuier à feuilles percées. Vulgo : Multipliant, figuicr petite-feuille. - Petit arbre, haut de 7-10 mèt., ornemental, toujours très vert; à branches très nombreuses, fastigiées et extrêmement feuillues; rameaux tétragones; it écorce lisse et grise. Feuilles petites, coriaces, obovales-lancéolées ou légèrement oblongues, arrondies au sommel, obtuses ì la base, finement veinées; pétiole court, renflé. Fruits très nombreux, glabres, globuleux, souvent tachetés de brun, solitaires ou géminés, de la grrosseur d'une graine de poivre, fermés au sommet par une proéminence mammiforme. Feuilles involucrales, petites, bilobeses: pedicelles crlindriques. un peu plus courts que le fruit, - Fruits mûrs en mai et juin. - Les petits oiseaux les mangent avec avidité. - Abondant dans les savanes et les bois inférieur's des Bains-Jaunes, du Matouba, du Gommier, des Vieux-Habitants, ete. Alt. 400-800 mèt. To 2195.

Martingue. Vulgo : Aralie petite-cerise. - Abondant au Champtlore (bords de la Capote), dans les bois de la Grand'Anse, du Lorrain, de la Calebasse, des Fonds-Saint-Denis, du Camp de l'. Alma, ete. [Xo 1408.

Le Ficus carica L. Vulgo: Finguier de France, est cultivé dans beaucoup de jardins; le Ficus elastica $L_{\text {. }}$, très grand arbre, à racines adventives, originaire des Indes Orientales, se rencontre dans plusieurs endroits, entre autres ì la Basse-Terre (cour de la prison) [ $\left.\mathbf{N}^{\circ} 3271\right]$, el it la Martinique (Saint-Pierre, Prêcheur). $\mathrm{N}^{*}$ 1-413.

Le Ficus metallica Hort, avec ses feuilles à reflets métalliques, a été introduit, en 1879, it la Martinique par l'horticulteur Louis Hahn et est cultivé chez plusieurs amateurs de plantes. [No 1414.

Artocarpus L. (du gree "artos", pain, et "karpos ", firuit, parce que le fruit de cet arbre forme la principale nourriture des habitants des îles de l'Océanie.

A. incisa L. : $\alpha$, variété non seminifera; Artocarpe à feuilles incisćes. Vulgo: Arbre à pain, fruit à pain. Desc., vol. VIII, t. 539, p. 28. - Arbre de deuxième grandeur, d'un beau port, à fronde ample, à branches étendues : les inférieures, horizontales, à écorce grrise, grercée el crevassée. Feuilles en touffes, à l'extrémité des rameaux, très larges et très vertes, luisantes, glabres, pinnalifides, it 8-11 lobes oblongrs, pointues, plus ou moins profondes et disposées avec plus ou moins de régularité, à côte carénée, extrêmement forte et saillante en dessoss; pétiole cylindrique-comprimé, vigon- 
reux : jeunes féuilles, renfermées dans deux bractées spalhiformes-naviculaires, jaunes, opposées, imbriquées sur les bords. Fleurs monoüques, incluses sur les branches finctilères, dans la mème double bractée, soit les mâles, soit les lemelles séparément, soil les deux réunies : les mâles, sessiles, très nombrenses et très rapprochées, couvrant entièrement un réceptacle d'abord droil, ensuite pendant, spongieux, mollet, arrondi au sommet, cylindrique-comprimé, longr de 15-2-2 cm. sur $3 \mathrm{~cm} .-3,50$ de large, pédonculé; clles sont composées de deux sépales blanchâtres, soudés it la base, obtus, concaves, el d'une élamine à filet très court, à anthères oblongues, ne dépassant pas les lobes des sépales. Habituellement les sépales forment un tube complet, fermé au sommet et contenant l'étamine stérile; les femelles, insérées sur un réceptacle globuleux ou oblong, mesurant $\mathbf{t}-6 \mathrm{~cm}$. de long, et se composant: J'un calice allongé, prismatique, hexagone; d'un ovaire uniovulé, enfoncé dans une substance spongieuse, presque charnue et blanche; d'un style à 3 divisions filiformes, surmontées de deux stirmates. Dans cette variété les ovules ne sont jamais fécondés parce que les anthères sont toujours stériles. Les jeunes chatons sont portés sur des pédoncules pourvus de poils roux, longs et droits, et disparaissent quelque temps après leur sortie de la spathe. Le fruit est sphérique, de la grosseur d'un melon vert, jaunâtre en dehors et marqué d’aréoles irrégulières à $\mathbf{f}$ ou jangles. - Quand il est parfaitement mûx, sa pulpe est succulente, fondante, très laxative, d'une saveur doucêtre. Pour l'usage domestique, on le cueille un peu avant sa maturité; sa chair est alors ferme, blanche, et constitue un aliment sain ef facile à digérer. Sa préparation consiste à l'éplucher et à le couper par tranches, qu'on fait rôtir ou bouillir; sa saveur approche de celle du pain de froment. Les chatous mâles se mangent confits; secs, ils peuvent tenir lieu d'amadou. Cette espèce ne produisant pas de graines, on multiplie les pieds par les drageons qui poussent aux racines. Toutes les parties de l'arbre et le fruit, avant qu'il ne soit mûr, contieunent un suc laiteux, très visqueux, qui, en se durcissant, donne du caoutchouc'. - Fl. presque toute l'année, mais surtout de mars en aout. - Originaire de Java, des Moluques, etc. Introduit à la Guadeloupe et à la Martinique, en 1793, par les Anglais, qui les ont apportés de Saint-Domingue. - Très abondant dans tout le pays. $\mathrm{N}^{\circ} 3771$. Mantrareus. Vulgo: Arbre à pain, fruil à pain. - Abondant. $\mathbf{N}^{\circ} 1101$.

F, variété seminifera. Vulgo: Châtaignier, châtaigne. - Cet arbre est plus élancé mais moins grand que le précédent, ses branches inférieures sont plus inclinées, ses rameaux creux et remplis de moelle blanche portent, à l'extérieur, des cicatrices anuulaires laissées par les feuilles. Celles-ci ont la forme

1. Ce caoutchouc, comme celui de l'espèce suivante, serait à étudier de près aussi bien du reste que celui qui provient des divers Ficus précédemment énumérés. Il y a là peut-être un intérét industriel. (1:. H. 
et les dimensions dü précédent, mais la côte, les nerrures, les pétioles et souvent les bords du limbe sont converts de poils. Chaton femelle ovalearrondi, presque globuleux, Inng de $8-12 \mathrm{~cm}$., moins long que le pédoneule el hérissé, de toutes parts, de pointes molles, très nombreuses, longrues de 4-5 $\mathrm{mm}$; ; ovaire à style distinct, mais caché. Fruit plus ou moins grobuleux, de la grosseur d'une lète d'enfant, souvent diftorme, selon les variétés, verdâtre, raboteux en dehor's, avec des aréoles pentagones ou hexagones; il contient, sous une peau épaisse, une pulpe d'abord blanche, un peu fibreuse et comme larinense; en mùissant, elle derient jaunatre, snceulente, d'une consistance grélatineuse. Dans cette pulpe sont nichées 60-80 graines ovales-oblongues, presque aussi grosses qu'une châtaigne de France el couvertes de plusieurs membranes brunes el fines. - On les mange cuites dans l'eau avec du sel. Les cotylédons sont très inégaux et dépourvus d’albumen; la radicule est supère et relativement courte. Les graines germent très vite el perdent en peu de temps leur faculté germinative. - Gà et lì autour des habilations dans les deux colonies.

A. integrifolia L.; Arlocarpe à leuilles entières. Vulgo : Jaquier. Tuss., Fl., II, t. 4. - Grand arbre à cime majestueuse, d'un port élégant; à écorce épaisse, pleine d'un suc laiteux; ì rameaux nombreux, cylindriques, très feuillus et remplis de moelle. Feuilles alternes, pétiolées, ovales-cunéitormes, coriaces, luisantes, surtout en dessus : les adultes, entières; les jeunes, sourent it 3-5 lobes, à sinus très profonds; bractées renfermant les bourgeons terminaux, courtes, glabres, lisses, brunes en dehors, blanches en dedans, ovales-arrondies, tronquées à la base. Fleurs en chatons mâles el femelles, renfermés séparément dans les mêmes bractées, qui abritent les feuilles avant l'éclosion: les mâles, courts, cylindriques, grêles, pédonculés, silués sur les petits rameaux et à l'aisselle des feuilles supérieures, réunis par 2-4 el d'un t̂ge toujours différent; les femelles, plus on moins globuleuses, situées sur le trone et les grosses branches. Fruit extrèmement gros, long de $50-70 \mathrm{~cm}$. sur 25-10 de large, souvent difforme, en grénéral ovale-oblong, it surface hérissée de pointes courtes, siluées au milieu d'une petite aréole pentagone ou hexagone. - Arant la maturité, la pulpe est blanche et ferme, et devient ensuite jaunâtre; elle a une saveur acidulée et agréable, malghré l'odeur puante qui elle exhale : on lui attribue des rertus rafraichissantes. Dans cette pulpe sont placées côte à côte une masse de graines oblongues comprimées, plus ou moins pentagones, de la grosseur d'une châtaigne; elles se mangent crues ou cuiles dans l'eau avec du sel, ou rôties. L'arbre pousse lentement. Le bois est dur et peut servir pour la construction et la menuiserie. Uriginaire des Indes Orientales el desîles du Pacilicque. - Rare: Basse-'Terre (habitation Saint-Aude-Gall), morne Ilouëlmont (aux environs de la balterie). Sainte-Rose, etc. [No 2859.]

Mantrique. Vulgo: Jaquier. - Plus abondant qu’à la Guadeloupe: 
Jardin botanique de Saint-Pierre, Champflore (habitation Gérard), BassePointe, Grind'Anse, ete. T'n 1399.

LiArtocarpus Liecucha Roxb., arb)e il larges feuilles, rudes, elliptiquesarrondics; est cultivé au Jardin botanique de Saint-Pierre. YTo 1402.

Gecropia L. (du gree "kekragein ", crier", parce que les pétioles el le tronc sont creux comme les instruments de musique à vent.)

C. obtusa Tréc., Cecropia à leuilles obtuses. Tulgo: Bois-trompette. Sl., 1. 88, 1. 2, el 1. 89; Dese, vol. 1, t. 75, p. 34. - Arbre ornemental, dont les plus grands ne dépassent pas 1 í mètres d'élévation, à trone droit, nu, rude. mais jamais unercé ni crevassé, à branches nulles ou peu nombreuses, nues et toujours confinées dans les parties supérieures. Feuilles ramassées en toulfes ¿ l'extrémité des branches : les jeunes, renfermées dans une bractée commune, naviculaire, tenant lieu de spathe, pointue au sommet, longrue de 14-16 cm. sur 3-1 cm. de large, membraneuse, couverte, en dehor's, de poils gris, laineux, brune et glabre en dedans; f'euilles adultes, longues de 35$45 \mathrm{~cm}$. sur autant ou presque autant de large, blanches, tomenteuses en dessous, peltinerviées, palmilobées à 7-9 lobes arrondis, à sinus plus ou moins profonds, it côtes très saillantes en dessous et ì nervures primaires rouges; pétiole longr de $15-24 \mathrm{~cm}$., creux, blane, tomenteux et semi-amplexicaule à la base, laissant sur les branches de largres cicatrices en forme d'écusson. Fleurs diö́ques, sessiles, sur des réceptacles charnus et disposés en ombelles axillaires, renfermés dans une bractée obovale, pointue au sommel, membraneuse, tomenteuse, blanchâtre, longue de $6-8 \mathrm{~cm}$. sur $3-3,5 \mathrm{~cm}$. de large, et qui est elle-même contenue dans la grande bractée commune qui abrite les jeunes feuilles; ombelle des réceptacles mâles de 8-16 rayons, brièvement pédonculés, cylindriques, wrèles, longrs de $3-5 \mathrm{~cm}$. , portant des lleurs composées d'un calice tubulaire, anguleux, aminei vers la base, et de deux étamines à filets courts; réceptacles des ombelles femelles sessiles au nombre de 2-4, plus longs ou aussi longs, ou plus courts, mais toujours beaucoup plus gros et plus charnus que les réceptacles mâles, portant des fleurs à un ovaire libre, uniloculaire, uniovinté, surmonté d'un stigmate à plusicurs branches courtes. Les fruits sont des akines ovoïdes, allongés, enveloppés par le calice devenu pulpeux, de la grosseur d'une graine de poivre. Chaque grosse bractée laisse, après sa chute, sur le jeune rameau une ligne circulaire en relief, couverte de poils couchés, roux el caducs. Les jeunes liges et les branches sont creuses de distance en distance, et transversalement cloisonnées à l'instar des bambous; à l'extrémité des branches, les cloisons sont très rapprochées el les creux sont à demi remplis d'une moelle. Dans les vieux trones, les cloisons disparaissent, le bois devient massif, et lécorce se courre de petites tubérosités lenticulaires el blanches. - Le bois est poreux, blanc, tendre, rude au toucher; il se 
fend facilement : on en fail du charbon. Toutes les parties de la plante sont le siège d'un latex îcre, très amer, contenant un principe corrosif el astringent. Dans le pays, on n'en tire aucun profit. - F'l presque toute l'année. - Abondant dans les bois et les falaises, jusqu à une altitude de 900 . mèt. No 2860 .

Martrique, Vulgo: Bois-canon', - Abondant. [Yo 1.105.

Maclura Nutt. (dédié à W'ill. Maclur, naturaliste des Lítats-Ünis du Nord; mort au Mexique, en 18 fo.

M. xanthoxyloides Endl.; Maclure ressemblant au xanthoxylon. Vulgo : Mûrier du pays. Plum., éd. Burm., t. 201. - Arbre de taille moyenne, ćlégant, très toulfu, avec ou sans piquants; it branches horizontales; it rameaux penchés; à écorce grrise, rude, légèrement grercée. Feuilles grossièrement dentées en scie, ovales-oblongues, pointues au sommet, arrondies it la base

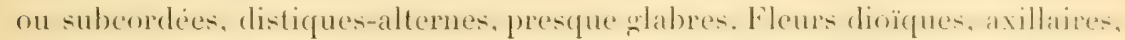
pédonculées : les mâles, en épis cylindriques, composées d'un calice monosépale, it $\mathbf{4}$ segments profonds et imbriqués, à 4 étamines exsertes; les femelles, en capitules globuleux, composées d'un calice it f́ folioles, qui, à la maturité du fruit, deviennent dures et écailleuses, d'un oraire libre, sessile, à style simple, persistant. Akenes 30-40, insérés sur un réceptacle presque charnu, de la grosseur et de la forme d'une framboise. - Les fruits ont une saveur sucrée et très agréable; les enfants en sont très friands. Le bois est solide, d'un jaune brillant; il est apprécié des menuisiers. - Asse\% rare: Troisllets, à l'Anse-í-l'Ane, près du bord de mer, et quelques pieds aux Ansesd'Arlet. Ce bel arbre tend à disparaître. On le rencontre en assez grande abondance le long de la rivière de la ville de la Soufrière el de la ville du Vieux-Fort, à lîle de Sainte-Lucie. Son congénère, le M. tinctoria Don., qui

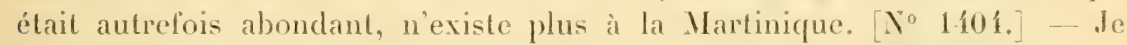
n'ai trouvé ni l'un nil'autre it la Guadeloupe.

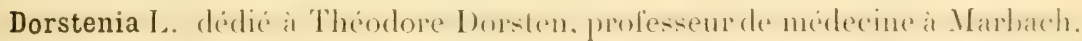
mort en 1539, à Cassel; a écrit Botanicum, qui a paru un an après sa mort.

D. Contrajerva L.; Dorsténie, contre-poison (mot it mot en espagnol : herbe contre). I'ulgo : IIerbe-chapeau. Desc, vol. III, 1. 207, p. 256. Herbe sans tige, vivace par ses rhizomes noueux et tubérilormes, haute de 25-30 cm. Feuilles rosulées, au nombre de 3-6, très longuement pétiolées. cordées-arrondies à la base, palmatipartites ou palmatifides; it segments larges, ovales ou oblongs, habituellement acuminés, grossièrement et très

1. Sous le nom de hois-cinon, on désirne à la Guyane le Cecropia pellatia Is., dont. le suc caustique est enployé couramment contre les verrues et les dartres, dont les feuilles et l'écorce sont un astringent employé contre la blennorwagre. Le C. obtusat pourrait servir aux memes usares aux Antilles. (L. II.) 
irrégulièrement dentés. Fleurs monoïques, insérées en grand nombre dans les alvéoles d'un réceptacle pelté, convexe à la face supérieure, arrondi ou elliptique, ou quadrangulaire ou lacinié, porté sur un pédoncule plus long que les feuilles, dressé, lerme, élargi au sommet : les mâles, sessiles, sans calice (1)escouptil\% se trompe en disant qu'il y a un calice ì 4 divisions obtuses), à 2-4 élamines, ì lilets filiformes, à anthères globuleuses; les femelles, sans calice, avec un ovaire libre, muni d'un style recourbé, latéral, bidenté el d'un stigmate simple; semences oroüdes-arrondies, nichées dans le réceptacle charnu el succulent, surmontées d'une pointe courte et recourbée. - La racine fraîche a une odeur aromatique, une saveur amère, son suc est légrèrement caustique; elle est d'un jaune brun el ressemble à celle du sceau de Salomon. Descourtilz place cette herbe dans les alexitères internes et la recommande comme diaphorétique et cordiale dans certaines fièrres lentes et nerveuses, surtout quand il est nécessaire d'activer la circulation, de stimuler les intestins el l'estomac; il ajoute que le sue de la racine favorise puissamment l'éruption languissante des aflections cutanées et qu il arête, employé en gargarisme, les progrès de l'angine gangreneuse ${ }^{1}$ - - Aime les endroits ombragés. - Abondant au Jardin botanique de Saint-Pierre, où les panseurs se servent des feuilles et des racines contre les piqûres du serpent; assez commun au morne Gommier (Marin). On le rencontre quelquefois dans les jardins comme plante d'ornement. [ $\left.N^{\circ} 1403.\right]$ - Je ne l'ai pas trouvé à la Guadeloupe.

Le Morus nigra L. V'ulgo : Mûrier noir; se rencontre à l'état de culture : on en fait quelquefois des haies; les fruits sont un objet de friandise pour les enfants. - Gourbeyre, Sainte-Rose, Camp-Jacob. 「 \º 2186.

Martixique. Vulgo : Murier noir, bonbon noir. - Saint-Joseph, fontaine Didier. NNo $^{\circ} 503$.

Le Broussonetia papyrifera V'ent, arbre oriminaire de la Chine et du Japon, it leuilles larges, trilobées; se trouve au cimetière du Lamentin, où il y en a plusieur's pieds X"3534, et a la Martinique au Jardin botanique. X" 11 .

Fleurya Gaud. (dédié ì J.-F. Fleury, qui, en 1819, a fail la description des Orchidées des environs de Remnes.

F. iestuans Gaud., Urtica Jacq. ; Fleurya brûlant. Vulgo : Ortie-brûlante. Gaudich., Voyage it hord de "la Bonite", t. 83. - Herbe annuelle, droite, haute de $30-80 \mathrm{~cm}$., it tige épaisse, succulente, lisse, sillonnée-striée, souvent pourvue de poils brûlants et droits. Feuilles larges, ovées, pointues, arrondies à la base, grossièrement et régulièrement dentées en scie, glabres,

1. Cette espèce, conme sa congénère D. hrasiliensis Lamk, est employée au Mexique ou elle existe, contre la morsure des serpents et de tous les animaux venimeux. Sa racine se distingue de celle de D. hrasiliensis par sa forme noueuse tout à fait irrégulière, sa couleur noirâtre ef l'absence d'odeur après dessication. (E. H.) 
pubescentes, souvent munies, à la surface supérieure el à l'extrémilé des dents, de poils terminés par une glande brialante; pétiole long, strić-sillonnes. Fleurs monoïques, en panicules lareses, terminales et axillaires, compresices de cymes scorpioïdes : les mâles, à calice à $4-5$ lobes profonds, égraux, à i étamines blanches, inflechies, se chessant élastiquement; les femelles, it calice à 4 divisions profondes, inégales, à style ovale, court, simple. Mkine oblong, tuberculé. - La plante est sudorifique, et les gens de la campagne préparent, avec les feuilles et les jeunes tiges, une décoction contre les pleurésies et les fluxions de poitrine. - Abondant sur les décombres, dans les lieux incultes et dans les fossés, le longr des routes et au pied des murs, elc.: Basse-Terre, Gourbeyre, Lamentin, etc. Alt. 0-600 mèt. [No 2190.]

Martinique. Vulgo : Ortie-brûlante, z'herbe-brûlante. - Abondant dans toute l'île. [ $\mathrm{N}^{\circ} 1389$.

Urera L. (du latin " urere ", brûler.)

U. caracassana Gaud.; Urera de Caracas. Vulgo: Bois-de-l'rédoche, grandeortie. - Arbrisseau haut de $2-2{ }^{\mathrm{m}} 80$, le plus souvent à une seule tige, grise ou rouge, cassante, remplie, surtout it l'extrémitc, d'une moelle blanche très copieuse. Feuilles très amples, souvent gaufrées, largement ovales, pointues au sommet, arrondies ou très légèrement cordées it la base, lantit très faiblement crénelées-serretées, pubescentes en dessous, sur les nervures et les nervilles, souvent poilues en dessus, les poils naissant sur de petites pustules. Fleurs monoïques dans les pieds que jai rencontrés, en cymes axillaires et caulinaires, dichotomes ou tricholomes, petites, courrant la ligne entière dans ses deux tiers supérieurs. Fleurs comme dans le précédent, mais calice femelle devenant pulpeux et rouge, renfermant complètement les akènes globuleux surmontés des styles formant pinceau. - Peu abondant. Çà et là le long des rivières des grands bois humides et abrités contre le. vents : Camp-Jacob (rivière Noire, près de la Cascade de Vauchelet), bois des Bains-Jaunes, Trois-Rivières (bois du Trou-aux-Chiens). Alt. it(0)-Z(1)1 mèt. [Nos 2195, 2861.]

Martinique. Vulgo : Grande-ortie. - Rare : Fonds-Saint-Denis, Route des Deux-Chous au Gros-Morne, etc. [No 1387.]

Pilea Lindl. (du gree " pilos » ou du latin " pilus ", chapeau, parce qu'un des trois segments du calice de la fleur femelle a la forme d'un petil capuchon.)

P. microphylla Liebm.; Pitea at petites feuilles. Vulgo: Teigne. petite-teigne blanc. Sl., 1. 93, f. 2. - Petile herbe annuelle, difluse, ou plus ou moins droite, haute de 4-15 mm., cespiteuse, à tiges et branches molles, délicates, succulentes, aqueuses el lisses. Feuilles tries petites, halpituellement rímies par 2-4, dont 1-2 plus grandes, obovales ou prescque rondes, somvent mucro- 
nées, entières, uninerviées, couverles en dessous de lignes transversake. Fleurs momoïques en crmes subsessiles, contractées, beaucoup plus courtes que les leuilles: les mâles, avec un calice à 4 segments; les femelles, avec un calice à 3 segments, dont un plus grand et bossu au-dessous de l'exfrimiti, aree un slyle tres eourt, at sligmate multipartite, formant un petil pinceau. Akène scobiforme, enfermé dans le calice devenu charnu. - Très abondant dans toutes les localités de l'île; il se plaît dans les endroits humides, sur les vieux toits pourris, les vieux murs, dans les sentiers peu fréquentés, le long des rigoles, etc. - Il a des vertus sudorifiques et s'emploie frefurmment, dans le pays, ch tisane ou en décoction contre les fières. - Alt. 0-900 mèt. [No 2192.]

Martinique. Vulgo : Pelite-teigne. — Très abondant. [No 1395.]

On cultive dans les jardins et les parterres une variété : le P. trianthemoides Lind., haute de $20-50 \mathrm{~cm}$, à tige grosse, vigoureuse, succulente, à branches flabelliformes; elle sert à faire des bordures très fournies et ornementales. Entre cette variété el l'espèce-type, on rencontre une masse de variétés intermediaires, qui diflerent par la taille, la largene des feuilles et la disposition des cystolithes. [No $345 \%$.]

Martinique, Vulgo: Herbe à bordure. - Abondant dans les jardins. $\left[N^{\circ} 1393.\right]$

P. ciliaris Wedd.; Pilea à feuilles ciliées. Vulgo : Ortie-des-bois. Plum., édit. Burm., t. 120, 1. 2. - Herbe annuelle, souvent suffrutescente, tortueuse, rarement sarmenteuse, haute de $50 \mathrm{~cm} \cdot-^{\mathrm{m}} 20$, à tige glabre, peu branchue, noueuse aux aisselles. Feuilles larges, membraneuses, ovées ou ovales-lancéolées, acuminées au sommet, arrondies ou pointues à la base, entieres, hathiluellement poilues en dessus, ciliées sur les bords, à 3 nervures bien marquées prenant naissance à la base du limbe; pétiole plus court que le limbe de la feuille. Fleurs en cymes unisexuées, axillaires et terminales, plus courtes que les feuilles. - Très abondant dans les clairières et le long des sentiers des bois supérieurs des bains-Jaunes, du Matouba, des TroisRivières. Alt. 500-1100 mèt. [Ỹo 2191.]

Martixigue. Vulgo : Ortie-montagne. - Bois supérieurs des Fonds-SaintDenis, des Deux-Choux, du Camp de l'Alma, des Pitons-du-Carbet, etc. $\left[N^{0} 1386.\right]$

P. elegans Wedd.; Pilea éléz̧ant. Vulgo : Ortie rouge. - Herbacé bisannuel ou trisannuel, rarement droit, à tigre grosse, succulente, rétrécie aux nouds, haute de $30-60 \mathrm{~cm}$. Feuilles épaisses, ovées-oblongues, brièvement acuminées au sommet, pointues à la base, brièvement pétiolées, irrégulièrement dentées en scie, à côte large, aplatie, à nervures latérales dont deux prennent maistance i la hase et les drux ambes au-dessus de la base du limbe, les quatre

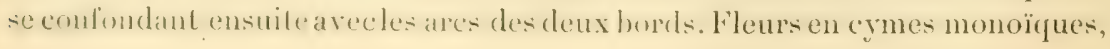




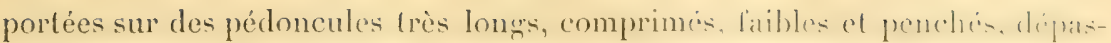
sant de beaucoup les feuilles : les mâles, en cymes contractés; les fimmiles.

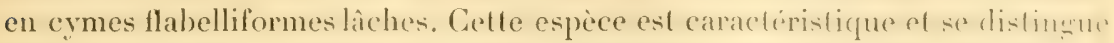
facilement de ses congénères par l'épaisseur de ses fruilles et la di-proilion particulière des nervures principales. - Abondant dans tes bois pierreux. secs ou humides de tout le massif de IIouëlmont, des hauteurs de locshaies. de la Pointe-Noire, etc. Alt. 150-500 mèt. [No 2187.]

Mantrigle. Vulgo: (Mrtie-des-bois. - . bondant: Hauteur des Trois-llets, Roches-Carrées, Rivière-Pilote, etc. $\left[\mathrm{N}^{\circ} 1390.\right]$

P. chamedrys Willd.; Pilea petit-chène. Vulgo: Petite-ortie. - Iterhacé, haut de $15-30 \mathrm{~cm}$, à tige habituellement poilue, plus ou moins conchere, ensuite ascendante. Fenilles membraneuses, ovées, grossièrement dentés pu scie, obtusément pointues au sommet, arrondies a la base, scabres-puberscentes en dessous, a 3 nervures naissant à la base du limbe. Fleur's en crmes's unisexuées, corymbiformes, aussi longues ou plus longues que les feuilles, i pédoncules grêles, souvent penchés, terminaux ou situés à l'aisselle des dernières feuilles. Akène très petit. - Abondant dans les clairières of le lonn des ruisseaux et des rivières des bois de la rénion supérieure: Bains-Jaunes, Matouba, Matélyane, Trois-Rivières, ete. Ilt. 700-1100 mèt. No No18s.

Martinipee. Vulgo : Ortie-bois. - Abondant. Calebasse, Montagne-Pelére. Pitons-du-Carbet, Deux-Choux, etc. [No 508.]

Boehmeria Jacq. (dédié à Georg. Rodolphe Boehmer, né en 17:2:3, a Liewnity, professeur d'analomie el de botanique à Wittenberg; mort en 18033; a écrit, entre autres choses: Flora Lipsix; De plantarum semine, etc.)

B. ramiflora Jacq.; Boehmeria à fleurs caulinaires. Vulgo : Grande-orlie des bois, ortie-bois, ortie-grande. Jacq., Sel. stirp. Am. hist., 1. 157. Arbrisseau ornemental, haut de $1^{\mathrm{m}} 50-2^{\mathrm{m}} 50$, a tige le plus souvent unique. it branches allongées, toujours inclinées, portant des leuilles placées it leur extrémité. Feuilles plus ou moins pendantes, obliquement ovées-oblongues. longuement acuminées ou quelquefois pointues au sommet, distiquesalternes, dentées en scie presque dès la base, glabres ou pubescenter, me plus grande succédant alternativement ì une plus petite, les deux nervures latérales d’inégrale longueur: les jeunes, pustulées; pétiole plus an moins: long, velu ou grabre: stipules allongrées, distinctes. Fleurs monnicques en glomérules nombreuses, sphériques, sessiles, occupant la partie supérienre

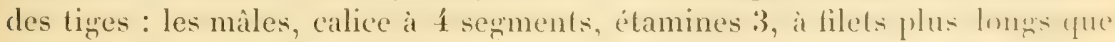
le calice et à anthères arrondies; les femelles, calice tubulaire à $2-\ell$ dents ovales; style simple, persistant, fort long, pubescent d'un criti, waire sup iew. Fruit composé de trois petits carpelles contenant chacun une semenes dressée, oblongue et biconvexe. - Çà et là dans les bois des Bains-Jaunes; abondant sur le bord de la rivière Noire et surtont sur le chemin de la cas- 
cade de Vauchelet: assez rare dans les ravines humides de Houëlmont. Alt. 300-700 mèt. [No 2184.]

M.rimineve. Vulgo : Ortie-bois. - Plus abondant qu’à la Guadeloupe : l'arnaste, Cahobasse, Champtlore, bois inférieurs de la Montagne-Pelée, Fonds-Saint-Denis, chemin de la 'Trace au Gros-Morne, etc. [ $\left.\mathbf{Y}^{\circ} 1391.\right]$

Phenax L. du gree "phénalie ", linsse chevelure, à cause des bractées qui entourent le calice.)

P. vulgaris Wedd.; Phénax commun. Vulgo : Ortie bâtard. - Herbe annuelle, haute de $60 \mathrm{~cm} .-1$ mèt., ressemblant à la pariétaire de France, à lige droite, tres branchue dans le haut, glabre, parsemée de poils hispides. Fenilles ovées-lancénlées acuminées, dentées en scie au-dessus de la base, à 3 nervures principales. Flenrs monö̈ques en petites glomérules sphériques, sessiles, frè nombreuses, entourées de bractées aussi longues que les stipules subuleses : les mâles, avec un calice à 4-5 lobes, infléchies, ciliées el munies d'un pli transversal, à t-J ćtamines; les femelles, sans calice, à ovaire libre, sesile, at stignate filiforme caduc, à akène ové, pointu et légèrement muriqué. - Abondant dans les terres cultivées et incultes, sur les décombres, etc. : Camp-Jacob, Gourbevre, Lamentin, Basse-Terre, Vieux-Habitants, etc. Alt. 30-600 mèt. [No 2862.]

Mantrxique. Vulgo : Orlie-savane. - Abondant dans les terres en friches: Morne-Rouge, Parnasie, Fonds-Saint-Denis, Trois-Hets, ete. [Xn1388.]

1)u Boehmeria nivea IIook., Urtica nivea L., variété utilissima, vulgo : Ramie ou China-grass, dont on avait entrepris, dès 1870 , la culture en grand à la Capesterre, à Baie-Nahault, à la Goyave, etc., et qui a dû être abandoméce, on trouve souvent des pieds en masse, qui se propagent seuls. [N०2193.]

Martasieue. Vulgo : Ramie. - Ajoupa-Bouillon, Saint-Pierre, TroisPonts, Grand'Anse, etc. [No 1396.$]$

CiNQuANte-Cirquièse famlle. - POLYGONÉES.

Polygonum L. (du grec " polu ", beaucoup, et " gonos ", nœud, genou, à cause des nouds enflés des tiges et leur ressemblance avec un genou.)

P. acre Kth.; Renouée, à saveur âcre. Vulgo : Piment-vache. - Herbacé, vivace, à tige couchée, rampante, ensuite ascendante, à nœuds fortement renllin. Fenilles lanciraleses, acumineses, entieres, munies, sur les bords, dre cils courls. fins el tries rapprochés: lace inférieure du limbe pourve de

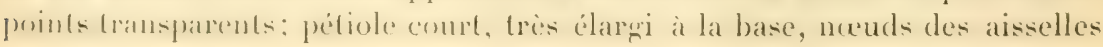


entourés d'une gaine frangée de longs cils poilus, ubulense, membranense, caduque, très brune. Fleurs à pétales, blanches nu plus ou moins posites, wh racèmes allongés, penchés, asser sourent branchus it la base; pédicelles articulés, d'abord très courts, ensuite plus longs; calice כ̌-partite, pourru do petites glandes; étamines 8 ; ovaire simple, uniorule; trles 3. Alione trigone, luisant, lisse. - Herbe très âcre et brûlante, qu'aucun animal ne mange. Dans le pays, on la met dans les nids des poules couvenses prour lus préserver des parasites. - Vit en société dans les endroits aquatiques, lo long de ruisseaux et sur les bords des étangs : Basse-Terre, Gourbeyre, Camp-Jacob, Le Baillif, Pointe-Noire, etc. Alt, 0-700 mèt. [No 2178.

Martivique. Vulgo: Herbe-piment. - Abondant dans les savanes du Lamentin et du Ducos, etc. [No 1209.$]$

P. acuminatum Kth.; Renouée à feuilles terminées en longue pointe. Vulgo: Piment-vache. - Ressemble au précédent; il en diffère : par ses feuilles, plus acuminées et plus larges: par les gaines, plus longues, frangées de cils très longs, strigilleux et fortement appliqués contre la tige: par tes racèmes, dressés, a fleurs plus serrées et plus larges; par le calice dépourvu de points transparents; étamines 6 ; styles ‥ Akène plus large et biconvexe. - Mêmes localités et tout aussi abondant que P. acre. [No 3533.

Martiniqe. Vulgo: Herbe-piment, herbe-piment-vache. - Endroits aquatiques de la Rivière-Salée et du Saint-Esprit. [No 3095.

Coccoloba Jacy. du gree "kokkos ", graine, baie, et "lobos ", lobe, parce que le fruit est trigone et se termine par plusieurs lobes.)

G. uvifera Jacq.; Coccoloba portant des raisins. Iulgo: Raisinier bord-clemer. Sl., t. 220, f. 3-5; Desc., vol. II, t. 77, p. 31. - Arbre de taille moyenne, plus rarement grand arbre, at racines tortueuses, traçantes, chevelues, à tronc tortueux, noueux, à branches le plus souvent horizontales, à écorce grrise ou blanche. se détachant par plaques. Feuilles alternes, cartilagineuses, cordiformes-orbiculaires, le plus souvent plus larges que longues, glabres, polies, d'un vert clair, côte et nervures rouges; pétiole court, rougeàtre, pubescent, inséré sur le dos on près de la base d'une gaine fendue. souvent bilobée, coriace, noirâtre, non appliquée contre la branche et laissant, après la chute, des cicatrices annulaires et brunes. Fleur's d'un blane mat, d'une odeur suave, en grappes terminales, spiciformes, souvent très allongées, dressées, toujours penchées, quand elles sont chargées de liruils: calice 5-partite, devenant charnu et formant une seule masse avec le fruit: étamines 8 ; styles 3 ; pédicelles courts, rougeatres, articulés au-dessus du milieu. Fruit pulpeux, de la grosseur d'un raisin, de couleur prourpre, d'un saveur légèrement aigrelette et agréable; semence ovale-trignone, noire, luisante, polie, renfermant une amande amère et blanche. - Ie bois, au centre duquel se trouve une moelle rouge, est dur et incorruptible: on l'emploie 
pour las constructions sous tere dau-i pour le charmonnage, plus rarement

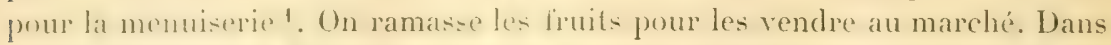
le pays on emplnie le rob des raisins contre la dysenterie, la décoction des racines et de la lige contre la diarrhée. - Fl. en avril, mai; fruits mûrs en juillet, anit. - Sur les vieilles sonches on trouve une espèce de champignon blane, qu'on peut manger. - Abondant dans les sables et sur les rochers du liltoral de lonte lïle, quetquefoì aussi un peu dans lintérieur. [X"2183.

Martixique. Vulgo : Raisin bord-de-mer. - Abondant sur les plages sablonneuses et rocailleuses. [ $\mathrm{N}^{\circ} 1742 \mathrm{a}$.

Sur la plage du l hamant, du Macouba Yauclin et à l'Anse-Raisinier Trinite, on tronve une variété a feuilles plus petites, à fruits blanes, plus ronds et plus petits. [ $\mathrm{N}^{\circ} 1472 \mathrm{~b}$. $]$

C. pubescens L.; Coccoloba à feuilles pubescentes. Vulgo : Raisinier srande-fenille. - Petit arbre (dans nos deux Colonies), droit, habituellement peu branchu ef peu ramifié, à écorce brune, assez fortement crevassée. Feuilles tris amples, mesurant jusqu'a $4.5 \mathrm{~cm}$. de large, toujours plus laryes que longues, orbiculaires, entières, échancrées en cœur à la base, très coriaces, d'un vert très pâte, à côte, nervures et nervilles très saillantes en descous of couleur de rouille; gaine large, chargée de poils roux qui, dans les jeunes branches, deviennent tris longs. Fleurs blanchâtres, petites, porlées sur des pédicelles réunis par ㄹ- 4 , et disposées en grappes simples et allongées. Fruit orö̈de, noirâtre it la maturité, plus gros que dans le précédent. - Le bois est dur, pesant et incorruptible, d'un rouge foncé : on l'emploie avantagensement pour les constructions dans la terre, dans l'eau; dans les endroits argilenx, la partie enfoncée dans la terre devient dure comme la pierre. - Fl. en septembre et octobre, et souvent aussi en mai et juin. A-rez abondant dans les hauteurs pierreuses et sèches du Vieux-Fort, sur le plateau calcaire de la Désirade, sur le bord de mer du Gozier, etc. [N" 2193,33999 .

Martinique. Vulgo : Bois grande-feuille. - Ábondant dans les hauteurs pierreuses de Case-Pilote; plus abondant encore sur le plateau des Troisllets, elc. [No 1793.$]$

C. harhadensis Jacq., G. diversifolia Jacq.; Coccoloba de la Barbade. Vulgo : liois rouge. - Arbre élégant, le plus souvent d'assez grande laille, anfractueux à la base, à rameaux grisâtres et souvent pendants, à ramusculesstriés, ì écoree peu fendillée. Fonilles rigides, très glabres, de forme variable, généralement ovees, terminées en pointe plus ou moins obtuse,

1. Le hois donne par décoction dans l'eau un extrail rouge brun qui constitue un des linos appréciés dans le commerce, oủ il est désigné sous les noms de hino de la Jamaíque ou des Indes Occidentales. Il est probable que les espèces suivantes jouissent des mèmes propriétés. (E. H.) 
arrondies à la base ou cunéiformes, à nervures plus saillantes en dessous

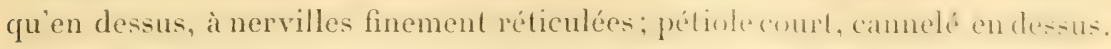
Fleurs blanches, en grappes spéciformes, terminales, plus longues que les feuilles, d'abord droites ensuite plus ou moins penchérs: pédicelles fries courts, aussi longs que les fleurs, articulés au sommed, snlitaires, entourés. a la base, d'une bractée circulaire; gaine petite, membraneuse. Fruit ové, très vert à la maturité, poli, luisant, finement strié, surmonté d'une pointe qu'entourent et dépassent les 5 lobes du calice. - On peut le manger; les oiseaux et les rats en sont avides. Le bois est dur, rouge en dedans et se fend facilement: on le recherche pour la charpente et la construction a l'extérieur. Dans le pays, on emploie l'écorce séchée, réduite en poudre et conservée dans le tafia, comme un excellent remède contre les rhumatismes. - . Dondant dans les bois montueux et sees: Houëlmont, bois de lisisdary, de Gourbeyre (mornes Dos-d'Ane et Goblin), Vieux-IJabitants, Pigeon, ete. Alt. 200-600 mèt. [No 3251.]

Mnntrigte. Vulgo : Bois rouge. - Abondant. Bois-de-la-Rérgale, hauteur du Diamant et des Trois-Ilets, etc. [Nos 37, 248.]

C. Dussii Kir. et Urb). Vulgo : Raisinier marron, raisin marron (au CampJacob), Jaquot brulot (a la Ravine-Chaude. - Forte liane, pourant s'ilever à plus de 15 mèt. de haut, à ligre cylindrique-anguleuse, rugruleuse, noirâtre, d'un diamètre de $6-9 \mathrm{~cm}$., nue dans le bas, a branches flexibles, allong'ées, trìs enchevêtrées, presque toujours pendantes, i jeunes rameaux noirs. Feuilles longues, de 12-17 cm. sur 8-10 cm. de large, très coriaces, ovaleselliptiques, arrondies ou subcordées à la base, obtusément pointues au sommet, à côte, nervures et nervilles imprimées en dessus, carénées, très saillantes et roussâtres en dessous, nervures secondlaires 7-9 paires alternes, reliées sur les bords par des ares; pétioles le plus souvent tordus, souvent contournés, rarement droits, subcylindriques, cannelés en dessus, ruguleux, longs de 12-15 mm., insérés à la base de l'ochréa qui est fenclue jusqui a la base, a $2-3$ lobes inégaux, longs de $3-6 \mathrm{~mm}$. Fleurs blanches, d'une odeur suave, mais forte, en grappes allongées, spiciformes, terminales, souvent plus courtes que les feuilles; pédnncules comprimés, noirs, scalres, munis it la base de 2-5 bractées imbriquées, alternes, conleur de rouille, tubulenses à la base : les inférieures, plus courtes; les supérieures, successivement plus grandes, pointues et fendues; pédicelles réunis par 2-3, noirs, longis de 3, $5 \mathrm{~mm}$., articulés et renflés au sommet, articulés à la base, au niveau d'une protubérance entourée de bractéoles; tube du calice campanulé, it lobers ovales-arrondis; étamines aussi longues que les lobes. Fruil pulpeux, noir foncé ì la maturité, luisant, lonğ de $2010-26 \mathrm{~mm}$, ovoüde, rétréci ver le met que termine une pointe formés par les lobes charums du calice, brusquement rétréci à la base, cylindrique et court; semence ovoïde, à peine trigone, noire et très polie. - Les fruits sont bons à manger; les oiseaux el 
les rats en sont friands. - Fl. en juin et juillet; fruits mûrs en décembre et janvier. - Cà et là dans les bois des Bains-Jaunes, de Gourbeyre (mornes Goblin el lons-d Ane ; plus abondant dans les bois de la Ravine-Chaude et de la Pointe-Noire. Alt. 250-600 mèt. [No 3430.]

Il n'existe pas à la Martinique.

G. ascendens Duss.; Coccoloba ascendant. Vulgo : Raisinier-grand-bois, liane tordue. - Puissante liane, montant à une grande hauteur, quand elle trouve un appui, ou petit arbre ì branches pendantes, allongées, à écorce grise presque lisse. Feuilles longues de $13-16 \mathrm{~cm}$. sur $10-12 \mathrm{~cm}$. de large, ovales ou légèrement obovales, arrondies ou obtusément pointues ou subcordées à la base, arrondies au sommet, à $4-5$ paires de nervures principales, à côle et nervures rouges, saillantes sur les deux faces, mais plus marquées en 'dessous; pétiole camnelé, souvent ruguleux et transversalement gercé; ochrées fendues jusqu'ì la base, acuminées, longues de 15-18 mm., glabres. Fleurs d'un blane mat, en grappes nombreuses, terminales et axillaires, mais droites ou recourbées quand les rameaux avortent; pédoncules entourés, à la base, de plusieurs bractées membraneuses : les inférieures, courtes; les supérieures, successivement plus grandes; rachis strié-sillomé; pédicelles réunis par :2- $\mathbf{f}$, délicats, cylindriques, longs de $3 \mathrm{~mm}$. Fruit rouge vert avant d'étre mùr, bleu foncé à la maturité, pulpeux, mangeable, long de $15-17 \mathrm{~mm}$, de même forme que celui du précédent. - On emploie la décoction ou l'inlusion de la racine comme dépurative dans les maladies vénériennes. Les liges se fendent facilement : les pêcheurs s'en servent pour fabriquer des nasses, des paniers et pour empailler des dames-jeannes, etc. - Fl. en mars et avril, et aussi en octobre et novembre. - Assez abondant dans les bois de la Pointe-Xoire, de la Ravine-Chaude; plus rare à Gourbeyremorne Goblin . Alt. 300-600 mèt. [ Nos 2180, 2189.]

Martingli. Vulgo: Liane Lordue. Bois du Morne-Rouge (Savane Chazot, des Fonds-Saint-Denis, du Camp de l'Alma, de Saint-Joseph, de Ducos (ravine). Alt. 60-700 mèt. [No 36 .]

G. excoriata L., G. nivea Jacq.; Coccoloba sans écorce. Vulgo: Raisincoudre, raisinier-des-coudres, raisin-coudre (probablement parce que les premiers colons exuropéens l'appelaient raisin du coudrier). Jacq., Sel. Am. stirp. hist., p. 215, t. 78; Desc., vol. V, t. 352, p. 178. - Petit arbre haut de 4-7 mèt., lequel a, de sa nature, un tronc simple, mais qui, quand on le coupe, pousse ì la base une masse de rejets, de manière à former un grand ct souvent un émorme buissnn toulfu el très leuillu. Écorce mince, lisse, asse\% semblable is celle du wrovavier, grise; jeunes tiges et branches habituellement couvertes de lenticelles nrbiculaires, on elliptiques ou linéaires. Feuilles insérées un peu au-dessus de la base de l'ochrée, glabres, membraneuses-coriaces, oblongues-overes ou obhngute-obovées, acuminées au sommet, pointues ou 


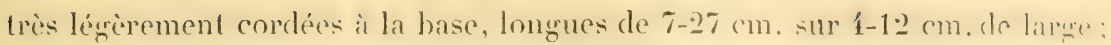
nervures à moitié imprimées en dessus, saillantes en dessous; nervilles sail-

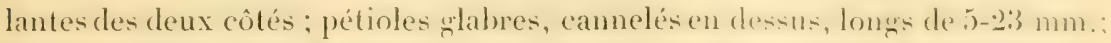
ochrées longues de 1-8 mm., fendues, acuminées au sommel, membraneusen et glabres. Fleurs blanc jaunâtre, très odorantes, glomérulées, en sqrappen eflilées, penchées ou redressées, de la longueur d'une feuille de moyenne grandeur, très brièvement pédicellées ou sessiles, entourées. à la base de petites bractés triangulaires, pointues et noiritres; rachis thabre, linement strie; calice a joserments profonds; ćtamines a filets subulés, aussi longues que les lobes du calice; anthères exsertes. Fruit ovoüde, petit, trigone, lonts de $6 \mathrm{~mm}$, à péricarpe blanc, formé des lobes du calice devenus charnus, cutourant les carpelles jusque vers leur milieu et restant assez visiblement distincts jusqu à la base; semence a 3 sillons. - Les fruits sont tantot sucrés, tantot aigrelets ef très rafraichissants; les enfants en sont particulièrement friands. Le bois est rougeâtre, tendre et léger; il ne peut servir que pour les constructions à l'intérieur. - Assez abondant dans la région sèche et pierreuse du littoral. - Fl. en juin ou juillet; fruits mûrs en juillet et août. - Bord de mer : la Basse-Terre et le Vieux-Fort, Le Baillif, Vieux-IIabilants, Pigeon, Deshaies, etc. $\left[\mathrm{N}^{\circ} 3250.\right]$

Martinique. Vulgo : Raisin-coudre. - Assez abondant sur le littoral et les mornes inférieurs et pierreux de Case-Pilote, du Carbet; plus rare à CaseNavire et au morne Commier (Marin). - On emploie les tisanes faites avec les fruits contre les échauffements; la décoction des fruits séchés el pilés contre la dysenterie. $\left[\mathrm{N}^{\circ} 1744.\right]$

De cette lamille on cultive au Jardin botanique et dans beacoup d'autres jardins le Muehlenbeckia platyclada Lind., petit arbrisseau très ornemental, à branches allongres ayant la forme de feuilles, sur les bords desquelles see trouvent une masse de petiles fleurs blanchàtres. Il est originaire de l'ite de Salomon. [Yं 2091.

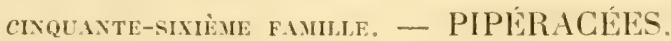

Peperomia R. Br. (du gree " peperi ", poivre, et "homos ", semblable, parce que ces plantes ont des vertus et une saveur semblables à celles du poivrier.)

P. nummularifolia Kth.; Pépéromie à feuilles de nummulaire. Vulgo : Girontlé mot corrompu de giroflé). Plum., édit Burm., 1. 69. -- Petite hertse épiphyte, vivace, rampant en tous sens, radicante, à tiges très nombreuses, sonvent très allongées, filiformes et partout de la mème épaissure, tris puche- 
vètrées. Feuilles petites, rondes, quelquefois légèrement obovées, larges de 5-7 mm., convexes en dessous, concaves en dessus, succulentes, vert clair tendre, palminerviées, à 3 nerrures à peine visibles; pétioles filiformes, plus courts ou aussi longe, ou plus longs que les feuilles. Fleurs en épis pédonculís, en forme de petits chatons cylindriques, solitaires, longs de $18-20 \mathrm{~mm}$., droits nu arqués; étamines 2 , à anthères sessiles; stigmate sessile, très petit. Fruit ovoüde, sessile. - Sur les arbres vivants ou pourris et sur les pierres humides des grands bois du Lorrain, du Camp de R:Ama, de la MontagnePelée, etc. - Celle herbe est aromalique, surtout quand elle est sèche; elle est tris sudorifique: les butcherons, les charbonniers la recueillent el śen servent en décoction ou en tisane contre les lluxions de poitrine, les pleurésies, les bronchites, ete. Alt. $400-900$ mit. $\left[X^{\prime \prime} 269.\right]$ - Elle ne se trouve pas at la Guadeloupe.

P. rolundifolia Kith.; Pépéromie à leuilles rondes. Vulgo: Petit-mouron. - Ressemble beaucoup au précédent; il en diffère par ses feuilles plates, finement ciliées sur les bords et par ses épis plus longs. - Elle est également sudorifique et s'emploie souvent contre les fluxions de poitrine et les bronchites. - Sur les arbres vivants et les souches pourries des grands bois humides des Bains-Jaunes, de Matouba, du Gommier, des Trois-Rivières, etc. $\left[\mathrm{N}^{\circ} 2828\right.$. $]$

Je ne l'ai pas trouvé à la Martinique.

P. exilis Grisb.; Pépéromie à tiges délicates. Vulgo : Petite-gironflée. Épiphyte, rampant, radicant, à tiges capillaires, très délicates. Feuilles rondes, succulentes à l'état vert, membraneuses el comme transparentes à l'état sec, longues de 1-25 mm. Fipis longrs de $1-6 \mathrm{~mm}$. Branches fructilères aussi longues que les épis. - Rare : Bois du Camp de l'Alma, des Pitons-du-Carbet, de la Calebasse, etc. Alt. $5000-900$ mèt. [No 1260.] - Je ne l'ai pas trouvé à la Guadeloupe.

P. emarginella $\mathrm{S}_{\mathrm{w}}$; Pépéromie à feuilles échancrées. - Épiphyte, radicant, rampant, ì liges très nombreuses, filiformes, très enchevètrées. Fenilles obcordées, rétrécies à la base, longues de 1-3 mm., un peu plus longues que larges. Épis solitaires, filiformes, longrs de 10-12 mm., pédonculés. Assez rare. Cà̀ et là sur les arbres et les vieilles souches des grands bois, dans les endroits sombres: (Grand-Etang (Capesterre), Trois-Rivières. Alt. $370-800$ mèt. [No 2829.]

Il n'existe pas à la Martinique.

P. tenella 1)ietr.; Pépéromie délicate. Vulgo: Mouron vivace. - Épiphyle, rampant, radicant, à tignes comprimées, très llexibles, souvent presque filiformes, loujours ascendantes. Feuilles alternes-distiques, confinces aux extrémités des branches, ovales-lancéolées, épaisses, brusquement rétrécies, en pointe obluse an sommet, allénuées it la hase, longues de $5-12 \mathrm{~mm}$. sur 
3-8 mm. de large; à 3 nervures distinctement visibles en dessus, vert pâte nu blanchâtres en dessous. Épis légèrement recourbés, longs de $10-13$ mm., alsiser longuement pédonculés; étamines a filaments distincls; stignates en forme de pinceau. Fruit elliptique, rétréci aux deux extrémités, de la grosscur d'une petite tête d’épingle. - Rare. Vit en société daus les mousses. sur tere arbres vivants ou pourris de la haute région: plateau de la Soufrière, conlée de la Ravine-ì-Déjeuner, au pied de la Grande-Découverte, morne du Matelyane, etc. Alt. 800-1400 mèt. [Nos 3248, 3616.]

P. pellucida Kith.; Pépéromie à feuilles transparentes. Yulğo : Cochlearia. Desc., vol. III, t. 220, p. 340 . - IJerbe aunuelle, tantôt droite, tantôt plus ou moins couchée, à racines blanchâtres, filiformes, traçantes ou non ; ì tig̣es délicates, aqueuses, très glabres, blanchàtres ou rougeâtres, de hauteur variable, mais n’excédant qu'exceptionnellement $50 \mathrm{~cm}$. d'élévation, alternativement et laroxement cannelées entre les noxuds. Feuilles alternes, subcordées-deltö̈rles, obtusément pointues au sonmet, palminerriées; à 5 nervures principales, très vertes en dessus, vert pâle en dessous, succulentes à l'état vert, membraneuses et munies d'une inlinité de points transparents à l'étal sec : les adultes sont larges de $13-15 \mathrm{~mm}$. et presque toujours plus larges que longues; les pétioles sont cannelés, plus courts que les feuilles. Epis axillaires et terminaux, cylindriques, solitaires ou réunis par deux, effilés, légèrement recourbés, brièvement pédonculés, longs: de 3-6 cm.; bractées oblongues, caduques; étamines 2 , à filets distincts, insérées à la base de lovaire; stigmate en forme de pinceau. Fruits placés à distance, ovoüles-arrondis, sessiles, d'abord verts, ensuite jaunâtres, puis noirs, du volume de la tète d'une petite épingle. - Descourtilz classe cette' herbe dans les alexitères internes. On se sert souvent de la décoction des tignes et des feuilles comme un excellent sudorifique et un puissant antiscorbutique; la même décoetion, employée en gargarismes prolongés, calme les maux de dents. - Très abondant dans les terres cultivées, le long des murs et des sentiers, sur les vieux toits el autour des vieux bâtiments de toute l'île. Alt - 0-900 mèt. [No 2571 .

Mantingue. Vulgo: Herbe à courèze ou couresse (parce qu'on croil que la couleurre, nommée coureze ou couresse, fait la guerre au trigonocéphale et qu' elle a recours à celte herbe comme à un contre-poison, lorsqu'elle est piquéc dans la lutte). - Très abondante dans tous les quartiers de l'ỉle, où elle joue un plus grand rôle qu ì la Guadeloupe, à cause de son emploi interne et. externe contre les morsures du serpent. [ $\left.\mathrm{N}^{\circ} 1265.\right]$

P. acuminata I.; Pépéromie à feuilles acuminées. Vulgo : pourpier bâtard. - Vivace, haut de 40-60 cm., terrestre, stolonifère, droit, penché aux extrémités, a une ou plusieurs tiges, grosses, très succulentes, nues dans le bas, peu branchues, rougeàtres ou blanchâtres, fortement renllées aux nuuds: 
partie supéricure des tiges et des rameaux, à 3-4 angles aigus. Feuilles longues de 2.5-3.5 cm. : les inférieures, alternes: les supérieures, opposées, succulentes avant la dessication, elliptiques, acuminées au sommet ou en pointe obtuse. munies sur les deux laces de nombreux points transparents, i. 5 nervures principales, dont les 3 intérieures sont peu prononcées; pétiole larane, court, cannelé en dessus, semi-amplexicaule. Épis solitaires, réunis par 2, plus rarement par 3, toujours d'un âge différent, effilés, longs de 9-10 cm.; pédoncules courts; stigmate petit. Fruit globuleux, sessile, surmonté d'une pointe courte et rigide. - Ahondant dans les endroits pierreux, montueux et secs : Itonëlmont, Gourbeyre (morne Goblin, momes calcaires des Grands-Fonds du Gozier. Alt. 100-430 mèt. [No 2830.]

Mantinelé. Vulgo : Pourpier-bois, pourpier bâtard. - Abondant au plateau des Trois-Ilets, dans les hauteurs pierreuses de Case-Pilote habitation Fond-Layette). [Nos 498, 1262.]

P. glabella Dietr., variété nigropunctata Miq.; Pépéromie à feuilles glabres, rariété a feuilles ponctuées de noir. Vulgo: Mouron. - Fiphyte, rampant, radicant, flexible; it branches libres, très souvent pendantes et loujours divergentes, allongées et munies de points noirs. Feuilles glabres, succulentes, ovées ou orées-lancéolées, acuminées el obtusément pointues au sommet, longues de 2-7 cm. sur 6-40 mm. de large, rétrécies à la base; à 3-5 nepvures principales, habituellement munies des deux côtés de points noirs: pétiole court, étroit, cannelé en dessus. Épis minces, allongés, le plus souvent réunis par deux, d'un âge différent, longs de 6-9 cm., souvent recourbés au sommet; pédoncules longs de 5-7 mm. Fruit sessile, ovoïdeglobuleux, surmonté d'une petite pointe. - Très abondant sur les arbres, les pierres, les souches pourries des grands bois et des savanes humides. Alt. 30-900 mèt. - Celte herbe est sudorifique et s'emploie souvent dans la médecine domestique. $\left[\mathrm{N}^{\circ} 2567\right.$.

Martinique. Vulgo : Mouron grande-feuille. - Très abondant dans les bois, jusqu'à une altitude de 800 mèt. [Nos 500, 501.]

P. hernandifolia I)ietr.; Pépéromie à feuilles de Hernandia. V'ulgo : Mouron grand-bois, siguine noire, petite siguine. - Petite liane, très ornementale, rampante ou le plus souvent grimpante, radicante, à lige peu branchue, succulente, renflée aux nœuds, haute de $1-2^{\mathrm{m}} \cdot 60$. Feuilles petites, alternes, épaisses, ovées, cuspidées au sommet, longues de $8 \mathrm{~cm}$. sur $6 \mathrm{~cm}$. de large; à 7-9 nervures invisibles sur les feuilles vertes et à peine visibles sur les siches: face inlérieure, d'un blane verdatre; face supérieure, vert noir, luisante el comme veloutée. souvent panachée de vert tendre: pétiole prenant naissance dans le dernier tiers inférieur de la feuille, à peu près de la mime longueur que le limbe, cylindrique comprimé. Épis terminaux ou axillaires, longs de $3-4 \mathrm{~cm}$.; pédoncules le plus souvent plus longs que les 
épis. - Assez rare. Cà el là dans les endroits très humides el sombres des grands bois : chemin des Bains-Jaunes a la savane a Mulets, bois de TroisRivières, morne du Matelyane, etc. Alt. 400-1000 mèt. [No 2570.]

Martinique. Vulgo : Gironflé grande-feuille. - Bois élevés de l'AjoupaBouillon, du Matouba, du Lorrain, etc. [No 1264.

P. bracteiflora D. C.; Pépéromie à fleurs entourées de bractées. Tulgo : Mouron. - Epiphyte, rarement terrestre, haut de $20-10 \mathrm{~cm}$., couche, radicant, ensuite ascendant; it liges cylindriques, noires, légèrement renflées anx nouds, a jeunes tiges et branches velues, disposées en zigzag. Feuilles longues de 1-5 cm. sur $5-3 \mathrm{~mm}$. de large, ovées, brièvement acúminées au sommet, subarrondies ou rétréciés a la base, finement et fortement ciliées sur les bords, légèrement pubescentes en dessus, blanchàtres en dessous el convertes d'une infinité de petites écailles, qui, à l'élat vert, les font paraitre comme saupoudrées de petits cristaux luisants', munies (à l'état sec) de points transparents; pétiole court, velu. Épis longrs de 3-5 cm., à fleurs insérées sur de petites protubérances constituées par des bractées verruqueuses. Fruit gilobuleux et verruqueux. - Assez abondant le long des ruisseaux, sur le vieux bois, les arbres vivants, les pierres humides, etc. : Ravine-à-Déjeuner (au pied de la Grande-Découverte), au Matelyane, route des Bains-Jaunes ì la Savane à Mulets, montanne de la Madeleine (Trois-Rivières), ete. Alt. 5001000 mèt. [ $\mathrm{N}^{0} 2567$ a. $]$

Martinique. Vulgo : Gironflé. - Abondant dans les clairières de la Montanne-Pelée, des bois des Fonds-Saint-Denis, du Camp de l'Alma, etc. $\left[N^{\circ} 497.\right]$

P. magnolifolia Dietr.; Pépéromie ì leuilles de Magnolia. Vulgro: Queuede-lézard. - Épiphyte et terrestre, rampant, radicant, ensuite ascendant, à lige sourent unique, charnue, ferme, cylindrique, nue dans le bas, peu leuillue dans le bout, ne dépassant que rarement $40 \mathrm{~cm}$. de haut. Feuilles glabres, épaisses, charnues, longues de 7-10 cm. sur 5-7 cm. de large, obovales, arrondies ou plus rarement échancrées au sommet, à nervures pennées, presque invisibles à l'état vert; pétiole plus ou moins cannelé et amplexicaule. Épis minces, fermes, solitaires ou réunis par -2, terminaux, longrs de 10-16 cm.; anthères blanches. Fruil ovoïde, sessile, plus long que le bee subulé qui le surmonte. - Abondant dans les terres pierreuses, sèches: IIouëlmont, hauteurs du Vieux-Fort, Trois-Rivières (dans les chemins de certaines caféières). Alt. 80-400 mèt. [No 25\%2.]

M.ntnineze. Vulgo: Queue-de-lézard. - Abondant. Hauteur's pierreuses de Case-Pilote et des Trois-Ilets, etc. [No 1267.$]$

P. obtusifolia Dietr., variélé cuneata Miq.; Desc., vol. V, t. 313, p. 37. Plum., Descript., 1. 70. - Pépéromie à feuilles obtuses, varieté cunéiforme. Vulgo: Queue-de-lézard. - Vivace, à tigne couchée, ensuite ascenclante, peu 
branchue, hatute de $30-40 \mathrm{~cm}$. Feuilles longues de $35-45 \mathrm{~cm}$. sur $10-15 \mathrm{~cm}$. de larre, charnues, fermes, obovales, rétrécies en un pétiole court, cannelé en dessus, amplexicaule. Épis très droits, fermes, longs de $11-12 \mathrm{~cm}$. Fruit ovoüde, aussi long que le bee recourbé qui le surmonte. - Descourtilz, qui place celle herbe dans les rafraîchissants aqueux, dit que le suc récent de toute la plante est doué de propriétés rafraîchissantes, tempéremtes et laxatives; il le prescrit dans tous les cas inflammatoires, surtout

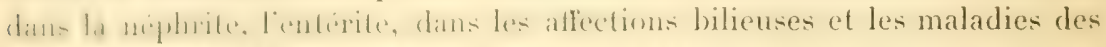

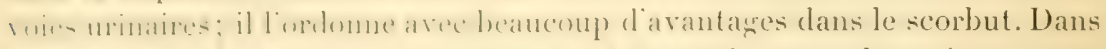

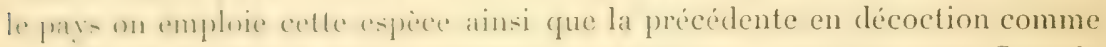
sudorifique contre les relroidissements et les fièvres. - Assez rare. Gà et là sur les pierres el les souches pourries des bois inférieurs des Trois-llets, de

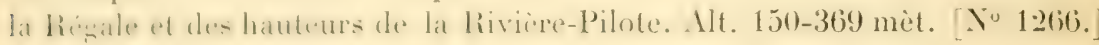
- Je ne l'ai pas trouvé à la Guadeloupe.

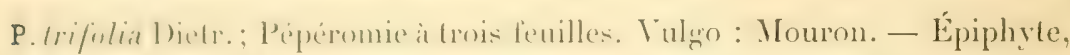

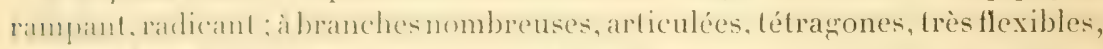
movenl trits allongues rel verticalement pendantes : les jeunes, pubescentes. Fenilles longues de $111-1.5 \mathrm{~mm}$. sur $7-1: 3 \mathrm{~mm}$. de large, le plus souvent verticillées par 3, rarement par 4, ovales, rondâtres ou obovales, arrondies ou linirement ichancres au sommet, succulentes, a 3 nervures bien prononcées; pétiole pubescent; rachis fovéolé. Épis droits ou recourbés, termi-

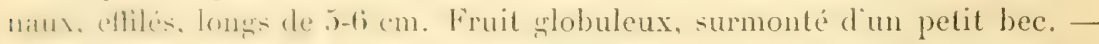
Abondant sur les arbres vivants, les vieilles souches et les trones pourris : Monteran, Campl-Ja(col), riviore Noire, hauteurs des Vicux-Habitants, bois

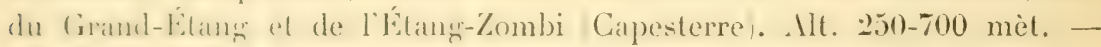
Celle herbe jonil diune srande répulation comme sudorifique : on l'emploie

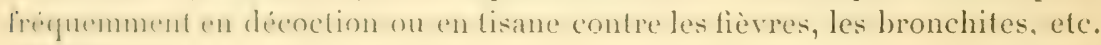
$\left[\mathrm{N}^{\circ} 3617.\right]$

Mantineus, Vulgo: Gironflé, mouron. - Abondant. - On en fait le mêne usage quà̀ la Guadeloupe. - Morne-Rouge, Parnasse, Calebasse, hauteurs humides du Prêcheur, fontaine Didier, etc. [No 1263.$]$

P. Ballisii Dahlsted: Pépéromie de Balbis. Vulgro : Mouron rougre. -

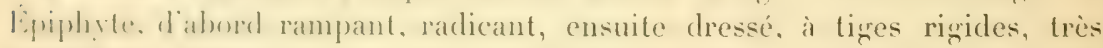
bramblum, fiblatgrnes-cannelés, sonvent dichotomes. inlérieurement nues.

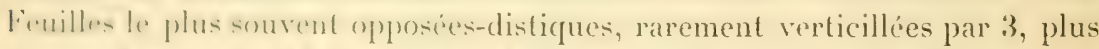

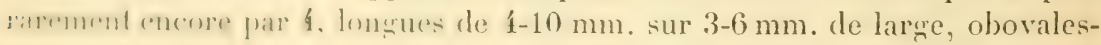
elliptiques, arrondies ou échancrées au sommet, rétrécies à la base en un

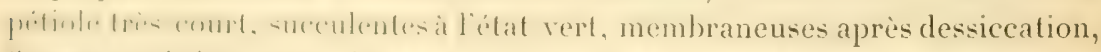

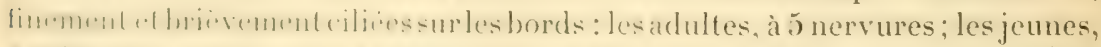

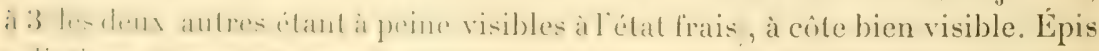

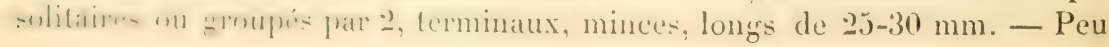


abondant. Çà et là sur les trones pourris, sur les arbres vivants, au milieu des mousses et des petites fongères : Bains-Jaunes, Camp-Jacob, coulée de la Ravine-ì-1)éjeuner au pied de la (irande-Découverté, plateau de la Soufrière. Alt. 700-1480 mèt. [Х̌० 2566.]

Il n'existe pas à la Martinique.

Piper L. (du latin "piper", poirre, venant du gree "peperi ", ou du nom indien " pipla ".)

P. pellatum L.., Pothos peltata Miq.; Poivrier it feuilles peltées. Vulgo: Bois-anisette. Plum., Descript., t. 74; Desc., vol. IV, t. 236, p. 14 (figure mal faite). - Sous-arbrisseau haut de $1-1^{\mathrm{m}} 60$, à racines blanches, chevelues, stolonifères, traçantes. à plusieurs ligges droites, grosses, fortement renflées aux nxeuds. Feuilles peltées, cordées-rondâtres, amples, souvent obtusément pointues au sommet, membraneuses, glabres, blanchàtres en dessous el marquées de points transparents, à 13 nervures principales, la cóte portant en outre $\geq$ nervures latérales; pétiole engainant, prenant naissance au-dessous du milieu du limbe, gris, finement strié, pubescent, un peu plus court que le limbe. Épis disposés en une ombelle axillaire, pédonculée, de 3-10 rayons d'un àge très inégal, lonğs de $7-9 \mathrm{~cm}$, recourbés ou droits; pédoncule longr de :2-3 cm., et les pédicelles de 6-9 mm. ; élamines 2, latérales par rapport à l'ovaire; stigmates 3 , sessiles, recourbés. - Isse\% abondant dans les mornes boisés inférieurs et dans les endroits humides : Saint-Pierre Boulevard/. Parnasse, morne Saint-Martin, etc. Alt. 20-500 mèt. [N०1340.] - Je ne l'ai pas trouvé à la Guadeloupe.

P. smilacifolium H. B. Kth., P. Decumanum W:; Poivrier à feuilles de salsepareille. Vulgo: Queue-de-rat. - Arbrisseau buissonnant ou petit arbre, haut de 3-5 mèt., à tiges cylindriques, renflées aux nexuds, nues dans le bas, médiocrement feuillues dans le haut. Feuilles longues de $15-22 \mathrm{~cm}$., sur $8-12 \mathrm{~cm}$. de larre, glabres, membraneuses, ovées ou ovales-elliptiques, acuminécs au sommet, obliques et arrondies a la base, apposées sur une feuille avortée et bractéiforme, palminerviées, à $5-7$ nervures : face inférieure des limbes pourrue de points transparents; pétiole long de 10-15 mm., cannelé en dessus. épais, à base amplexicaule, laissant, après la chute, de larges cicatrices. Épis axillaires, allongés, plus courts que les feuilles. Fleurs contiguës. - Assez rare. Çà et là dans les mornes inférieurs secs et pierreux : Houëlmont, bord de l'embouchure du Galion, etc. Alt. 5-200 mèt. [No 2834.]

M.ırtingre. Vulgo: Queue-de-rat. - Également peu abondant: Parnasse, lisière des bois du morne Saint-Martin, Morne-Rougre, Marin (morne Gommier). Alt. 200-406 mèt. [No 502.]

P. reticulatum L.; Poivrier à feuilles réticulées. Vulgo : Queue-de-rat

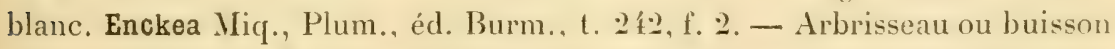
d'une élévation de $2-3$ mèt., droit, à racines traçantes, à tiges cylindriques el 


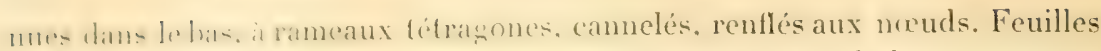

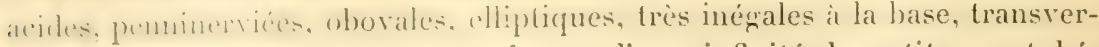
salement réliculées, couvertes en dessus d'une infinité de petites protubé-

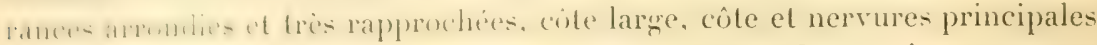
scabres-poilues et rougeâtres, limbes d'une longueur de $12-14 \mathrm{~cm}$. sur une lareur de 5-7 cm. Épis long de 12-14 cm., droits, à fleurs circulairement di-pu-in: Aamines hlandhes. - Asse\% abondant dans les grands bois de la rérion moyeme el parfois dans la région infra-moyenne: Bains-Jaunes, Ialouba, Gommier, Trois-Rivières. Alt. 350-900 mèt. [No 2835.

M.ntrique. Vulgo: Queue-de-lézard, - Morne-liouge, Champflore, Parnasse, Ajoupa-Bouillon. [No 21:17.

P. dilatatum Rchb.; Poivrier à feuilles élargies. Vulgo : Queue-de-rat. Arbrisseau asse\% élevé, droit, glabre dans toutes ses parties; à écorce fine, fum morilre: a rameanx lérerement comprimés, camelés-striés. Feuilles de meme forme que dans le précédent, mais plus petites, pustulées-rugruleuses. lipis avillares. prescue foujours recourbes au sommet. Fleurs situées sur de pelits anneamx tres rapprochés. - Mbondant dans les falaises et le loner de

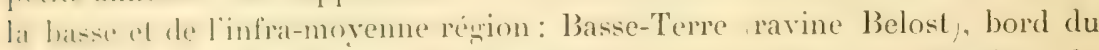
Cialion pris de liembouchure, IIouëhmont, Grands-Fonds du Moule et du Gozier. All. 10-600 mèt. [No 2569.

M.artivique. Vulgo : Queue-de-lézard. - Abondant: Carbet, Parnasse, ("nvirnm d, Samt-Pitre, Case-Pilote Fond-Layette), Marin (morne Gommier). $\left[N^{\circ} 2112.\right]$

P. macrophyllum II. 13. Kith. : Poirrier it grandes feuilles. Vulgo: Queue-derat. Sl., t. 88, f. 1. - Arbrisseau haut de $2-3$ mètres, droit, souvent buissonneux, à branches légèrement inclinées, à jeunes rameaux striés. Feuilles

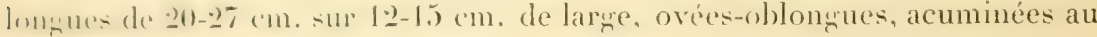
sommet, inégrales à la base, membraneuses, à $4-5$ paires de nervures princi-

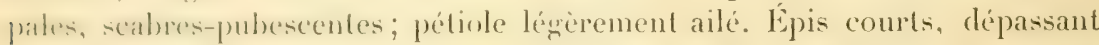
rarement $1 \mathrm{~cm}$. de long, axillaires, toujours horizontaux et opposés aux feuilles, brusquement terminés en une pointe conique, courte et noire;

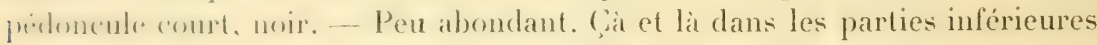
des Bains-Jaunes, du Matouba, du Gommier, etc. Alt. 400-700 mèt. [No 3696.$]$

Il n'existe pas à la Martinique.

P. hirsutum Sw.; Poivrier à feuilles hirsutes. Vulgo: Queue-de-rat. - Arbrisseau laaul de 3-1 mèt., à une ou plusieurs tiges cylindriques,

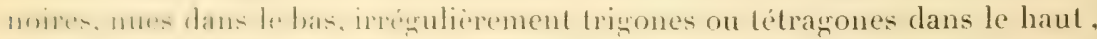

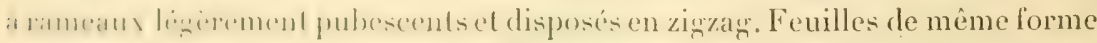
que dans P. dilatalum, mais un peu plus larges, plus acuminées ; à 5 paires de nervures principales, dont la paire supérieure prend naissance à peu près 
au milieu de la nerrure médiane; cúte, nervures el nervilles, surtout des jeune:feuilles, couvertes de poils courts, couchés, blanchâtres : face supérieure ruguuleuse, dépourvue de points transparents; pétiole le plus souvent poilu, toujours plus ou moins pubescent. Epis opposés aux leuilles, droits, drabord dressers, ensuite horizontaux, longs de $10 \mathrm{~cm}$. - Abondant dans les falaises el le long des rivières de la basse région, et sur les lisières des bois de la moyeme zone: Basse-Terre (ravine de Belost), Gourbeyre (Grande-Savane), Camp-Jacob, Gommier, etc. Alt. 70-600 mèt. [N² 2568.]

Mantinique. Vulgo : Queue-de-lézard. - Abondant: Parnasse, MorneRouge, Case-Navire, Carbet, etc. [ $\left[\begin{array}{ll}N^{\circ} & 21 \\ & \end{array}\right.$

P. incurvum Sieb., Artanthe marlinicensis Miq.; Poivrier it épis recourbés. Vulgo: Poivrier bâtard. Queue-de-rat. - Arbrisseau sarmenteux, d'abord rampant, ensuite grimpant, pouvant s'élever jusqu'à 12 mèt. de haut; à tige grosse, noueuse, nue dans le bas, presque cylindrique, très branchue dans le haut; à branches allongées, irrégulièrement tétragonescannelées, tonjours pendantes et disposées en zigzag. Feuilles longues de 8-11 cm., alternes-distiques, très vertes et luisantes en dessus, pâles en dessous, pointues au sommet, palminerviées it f́ paires de nervores latérales, dont les 3 inférieures prennent naissance à la base et la supérieure au-dessus de la base de la côte : les jeunes, ovées, brièvement rétrécies à la base; les adultes, nettement cordées, rondâtres, un peu plus larges que longues; pétiole cannelé en dessus, cylindrique en dessous, trois fois plus court que le limbe. Épis axillaires, recourbés, difformes-toruleux, amincis vers le sommet, souvent réunis par deux, longs de $8-14 \mathrm{~cm}$. Fruit pulpeux; semence arrondie-comprimée, très brièvement stipitée, longue de près de $2 \mathrm{~mm}$. Abondant dans toutes les forêts humides : Bains-Jaunes, Gommier, rivières Noire et Rouge, Natouba, Trois-Rivières, ete. Alt. 500-900 mèt. [No 2565.

Martinique. Vulgo : Poivrier bâtard, Queue-de-lézard. - Abondant: Calebasse, Ajoupa-Bouillon, bois du Lorrain, du Camp de l'Alma, etc. [No 1333.

P. ceanothifolium H. B. Kith., P. medium Jacq.; Poivrier à feuilles de Ceanothus. Vulgo: Malimbé, queue-de-rat. Desc, vol. VI, 1. 427, p. 194. Enckea Sieheri Miq. - Arbuste buissonnant, ou grand arbuste, rarement petit arbre, haut de $4-4^{\mathrm{m}} 50$, droit, à tiges dichotomes, cylindriques, lisses, à écorce noire, à jeunes branches cannelées sur un côté. Feuilles ne dépassant guère $10 \mathrm{~cm}$. de longueur sur $7 \mathrm{~cm}$. de largeur, très glabres, luisantes, papyracées, ovées, légèrement obliques à la base, pointues an sommet, palminerviées, à 2 paires de nervures latérales, prenant naissance à la base de la côte; pétiole court, mince, noir, comprimé. Épis axillaires, solitaires, opposés aux feuilles, longs de $\mathbf{t}-\mathbf{f}$ (m., droits, à pédoncules $2-3$ fois plus courts que l'épi. Fleurs insérées sur de petits anneaux très rapprochés. 
Fruit lexipement pulpeux, orö̈de beancoup plus grand que dans tous ses

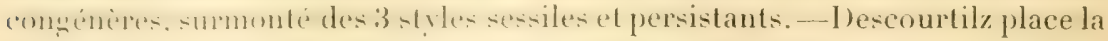
plante dans la catégorie des masticatoires, mais dans le pays on n'en fait aucun usagre, même populaire. - Abondant dans les falaises, le long des rivières el dans les halliers de la basse et de la moyenne région : environs

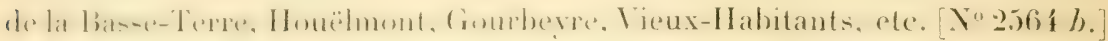

Marminete. Vulgo: Malimbé, queue-de-rat. - Abondant : Trois-Ponts, Carbet, Parnasse, Marin, Trois-Ilets, Gros-Morne, etc. [No 1332.]

P. Inherculatum II. B. Kth.; Poivrier tuberculeux. Vulgo : Queue-de-rat. - Arbrisseau touffu, à une ou plusieurs tiges, haut de 2-3 mèt., renflé aux nouds ; à écorce noire ; à rameaux pubescents, inclinés. Feuilles longues de 8-11 cm. sur 5-8 cm. de large, vert noir en dessus, ovales-oblongues, pointues au sommet, très inégales à la base, pustulées en dessous; pétiole très court, pubescent, amplexicaule. Épis allongés, dressés, presque toujours arqués, opposés aux feuilles, solitaires. - Je ne crois pas que cette belle espèce soit indigène. - Habitation la Jacinthe, près de la Basse-Terre. [No 2831 .

P. xquale Vahl.; Poivrier à feuilles égales à la base. Vulgo : Suriau maladif (aux Vieux-Habitants), queue-de-rat. - Petit arbrisseau haut de $60 \mathrm{~cm}$.1"' so, rarement plus ibeve, le plus souvent it tige unique, droite, grele, dichotome, très fortement renflée aux nouds, nue dans le bas, à rameaux dressés ou légèrement inclinés. Feuilles longues de 10-15 cm. sur $4-7 \mathrm{~cm}$. de large, rarement plus amples, fermes, opaques, membraneuses, brusquement termi-

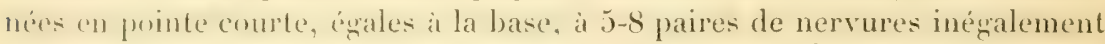
distanter: pétiole camnelé, aussi long que le pédoncule. Épis solitaires, opposés aux feuilles de longucur variable, la plus longue ne dépassant jamais $6 \mathrm{~cm}$., droits. - Abondant dans la région supérieure des grands bois : Matouba, Trois-livieres, environs du Grand-Etang et de l'Étang-Zombi, Bains-Jaunes, etc. Alt. 600-900 mèt. [Nos 2563, 2564.]

Martinique. Vulgo: Queue-de-rat. - Abondant : Fontaines Didier et Absalon, Camp de l'Alma, Champflore, Lorrain. [Nos 1335, 1336.]

P. citrifolium Lam.; Poivrier à feuilles de citronnier (le nom n'est pas juslifié). Vulgo : Queue-de-rat. - Arbrisseau haut de 1-1 ${ }^{\mathrm{m}}$ 60, habituellement loulfu, it liges gribes, rentleces anx meuds, droites. Feuilles longues de 10-1't $\mathrm{cm}$. sur $3 \mathrm{~cm}$. de large, un peu inégales à la base, souvent inégalement divisées par la côte, scabres-ruguleuses, lancéolées, fortement acuminées et à

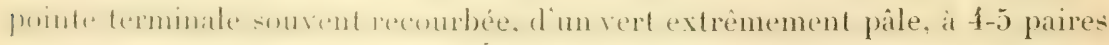
de nervures; pétiole très court. Épis longs de $1-6 \mathrm{~cm}$., droits ou recourbés. - Cor el da dans len particesuperieures des grands bois: Champtlore Piton-

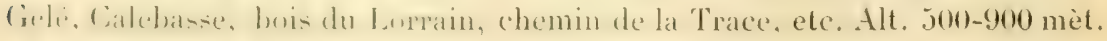
No 1334. - Je ne l'ai pas trouvé à la Guadeloupe. 
P. nigrum L.; Poivrier à fruits noirs. Vulgo : Poivrier, poivrier vrai, poivrier aromatique. Desc., vol. VI, t. 429. - Liane radicante, grimpante; à racines fibreuses, noirâtres; à tiges souples, lisses, dichotomes, renflées aux nœuds, à branches libres, pendantes. Feuilles longues de 10-18 cm. sur $5-8 \mathrm{~cm}$. de large, très vertes en dessus, ovales, acuminées au sommet, souvent inégales à la base, épaisses, opaques, palminerviées, à supérieures latérales partent de la côte au-dessus de sa base; pétiole cannelé,

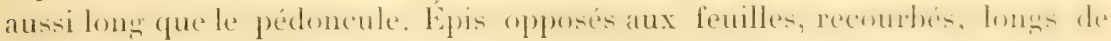
7-9 cm. Fleurs inférieures de l'épi ordinairement stériles. Fruit globuleux, légèrement charnu à l'état frais, d'abord verdâtre, ensuite rouge et noir. Un épi contient 20-30 fruits, qui mûrissent quatre mois après la floraison. Le poivrier ne rapporte qu'au bout de trois ans; la culture en est facile : il suffit de le placer dans une bonne terre et d'arracher avec soin, pendant les trois premières années, les mauvaises herbes qui poussent autour des racines. Pendant les cinq premières années, il produit avec une grande abondance; après ce temps, les récoltes commencent à diminuer et, au bout de douze ans d'existence, il faut le remplacer par un nouveau pied. Le poivre blanc ne constitue pas une espèce à part. On laisse séjourner les fruits du poivrier noir pendint quelque temps dans l'eau de mer; on enleve ensuite, pour n avon que des graines blanches, les pellicules, qui se sont gonflées. - Originaire des îles de la Sonde; cultivé çà et là autour des habitations, pour la consommation locale: Bass-Terre Jardin botanique), (iourberre, CampJacob, Sainte-Rose, Capesterre (habitation Longmont), Lamentin, etc. [No 2832.]

Martinique. Vulgo : Poivrier. Cultivé en différents endroits. [Nº 1338.]

P. Betle L., Ghavica Betle Miq.; Poivrier Bétel. Vulgou : Bétel, poivrier des Indiens. - Arbrisseau grimpant, radicant; a tiges articulées, flexibles. lisses et striées: a feuilles alternes, pétiolées, habituellement plus latrges que celles du poivrier, ovales, acuminées, un peu inégales et obliques à la base, très vertes et luisantes en dessus; à 7 nervures principales alternes, dont les 2 dernières et supérieures prennent naissance an-dessus de la base de la coute. Épis longes de 4-5 cm., portés sur des pédoncules noirs, une fois plus courts que les épis, opposés aux feuilles. - Originaire des îles de la Sonde et des Moluques, cultivé dans quelques endruil: : Basse-Terre, Pointe-i-P'itre jardin du Musée L'Herminier), Matouba (morne Savon), Pointe-Noire, etc. Les Indiens, surtout ceux de Madras ef de lombay, font, averes lesuilles, de la chaux el la noix d'aree, une e-prece de masticatoire dans laquelle la chaux'

1. Les feuilles de bétel doivent leurs propriétés à une huile essentielle, brune, đuton obtient par distillation, dont l'odeur rappelle celle du thé et dont la saveur est brùlante ; les feuilles séches en donnent $1 / 2 \%$. Cette essence de bétel est employée à Java couramment dans les catarrhes de toute nature, dans les inflammations de la gorge, du larynx et des bronches. (E. H.) 
domine. Ce midange raffermit les gencives et conserve les dents longtemps

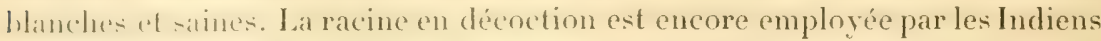
contre les fièrres. [No 2833 .

Marminique. Yulgo: Bétel. - Plus abondant qu'à la Guadeloupe, habitations Pécoul et Perinell (Saint-Pierre), Rivière-Salée, etc. [No 1339.]

\section{SOIXANTE-SEPTIEME FAMLLE。 - CHILORANTHACÉES.}

Hedyosmum (du gree "hedus ", doux, agréable, et "osme ", odeur, parce que ces plantes émettent un parfum fort et agréable.)

H. arborescens Sw:; Hédyosme arborescent. Vulgo : Bois fragile. Petit arbre, haut de 3-6 mèt., résineux; à tronc droit ou tortueux, nu dans l. bas: a branches nombrenses, lastigiées dans le jeune âge, divariquées et horizontales dans l'age adulte, très fragiles, remplies de moelle, renflées aux nouds. Feuilles opposées, penninerviées, longues de 8-10 cm. sur environ $3 \mathrm{~cm}$. de large, elliptiques-lancéolées, obtusément pointues au sommet, pointues et dentées en scie au-dessus de la base, épaisses, plus ou moins succulentes, a colte large, plate, à nervures fines, nombreuses et très rapprochés, pétioles courts comprimés, insérés sur une gaine qui, élargie au sommet, va en se rétrécissant de haut en bas et porte à l'extrémité supérieure. de chacque côté, deux petits bees. Fleurs diö̈ques (dans les spécimens que j’ai trouvés), en chatons opposés : les mâles, à 1 étamine longue de près de $2 \mathrm{~mm}$., ébractéolée, jaune vert, à filet droit, fort, strié, tronqué au sommet, inciré it angle droit, ì anthère subsessile, assise sur le bord de la lête du filet, dirposées en rhatons cylindriques, nombreuses, axillaires-opposées, pédoncules oblus au sommet et alténués a la base, longs de 2. $5-3 \mathrm{~cm}$.; les femelles,

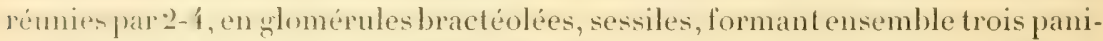
cules fortement interrompues. Une fleur toujours terminale et deux axillaires mennent naissance dans les deux avant-dernières aisselles; stigmate sessile, simple. Fruit drupacé, lénèrement violacé, petit; semence trigone, de près de $2 \mathrm{~mm}$. de long, surmontée d'un tube très court. - Toutes les parties de la plante exhalent une odeur forte et aromatique'. - Fl. en octobre et novembre. - Asse\% abondant dans les clairières des bois et dans les savanes du Matouba, des environs des Bains-Jaunes; plus rare dans les bois des Trois-Rivières. Alt. 600-900 mèt. [No 2960.]

1. II est étonnant que celte plante ne reçoive, aux Antilles, aucun emploi de ses pro priétés aromatiques qu'elle partage, du reste, avec toutes les Chloranthacées. Ce qu'il y a de certain c'est que les jeunes pousses et les feuilles d'H. nutans et de $\mathbf{H}$. arborescens sont employées couramment à la Jamaïque, où ces espèces existent, dans la médecine populaire, comme antispasmodiques et digestives. (E. H.) 
M.rntinele. Vulgo : Bois-de-l'eau. - Plus abondaut qu ì la Guadeloupe: Calebasse, route du Camp de liAma aux Deux-Choux, bois du Lorrain. [No 2105.]

\section{SOIXANTE-IIUITIÈME FAMILLE. - TÉRÉBINTHACÉES.}

Bursera L. (dédié au Danois Joachin Burser, né à Kaminz ver's la fin du $\mathrm{xrr}^{e}$ siècle, élève et ami de Bauhin, médecin à Annaberes, ensuite profésisur à Saroë, dans l'île de Seeland, grand amateur de plantes, mort en 1649.)

B. gummifera L.; Bursère produisant de la gomme. Vulgo: Gommier rouge, gommier-barrière. Sl., t. 199, f. 1, 2; Desc., vol. II, t. 97, p. 117; Jacq., Sel. Am. stirp. hist., 1.65.-- Habituellement arbre de taille moyeme, rarement grand arbre dans nos colonies; à tronc souvent tortueux, gros, anfractueux à la base; à branches le plus souvent étalées, nombreuses; i écorce rouge, lisse, se détachant par lambeaux minces, transparents. Feuilles alternes, imparipennées, à 3-9 paires de folioles ovées-oblongrues, lisses, luisantes, pétiolées. Fleurs blanc pâle, polygames, en panicules terminales et axillaires; calice 5-partite, à segrments fortement repliés après l'éclosion de la fleur; pétales 5, valvaires; étamines 8 , périgynes, à anthères oblongues; ovaire à 3 loges; style trilobé au sommet. Fruit de la grosseur d'une petite noisette, pourpre, trigone, à faces convexes; péricarpe drupacé s'ouvrant en 3 valves; semence 1 , subtrigone, à face dorsale polie, convexe, beaucoup plus grande que les deux faces ventrales (qui sont marquées au milieu d'un aréa ovale) proéminent et pointu. - Larbre perd ses feuilles à l'époque de la floraison ; toutes ses parties laissent suinter, it la moindre incision, un sue blanc aromatique, qui s'épaissit vite et s'emploie en gruise d'encens. Le sue de la racine passe pour un des meilleurs rulnéraires: on en fait un usage fréquent pour guérir les plaies, les blessures, les foulures, les luxations des membres'. Le bois est mou et ne peut servir pour la construction. Les branches les plus grosses prennent très facilement par boutures, et on en fait sourent des clôtures. - Fl. en mai et juin. - Abondant dans les endroits secs et pierrenx de la basse région : environs de la Basse-Terre, Le Baillif, Deshaies, PointeNoire, Pigeon et Bouillante, Gozier, Désirade, Marie-Galante, etc. [N"32\%ti. Martinique. Vulgo : Gommier rouge. - Abondant dans toute l'île. $\left[\mathrm{N}^{\circ} 1945.\right]$

1. La résine de Gommart, qui a pris une si grande place dans l'industrie des vernis en Europe, est fournie par ce végétal : le mème produit d'exsudation est désigné encorc sous les noms de: Elemi des Antilles, Tacamaque jaune terne, Tacamaque de Guatémala, Gommart d'Amérique, Gomme chibou. En Amérique tropicale, le bois et l'écorce de cet arbre sont employés comme diurétiques et diaphorétiques. (E. II.) 
Icica Aub. (du nom de la plante à la Guyane: ce mot veut dire " gomme ».)

I. heptaphylla Aubl.; Icica à sept folioles. Vulgo: Bois d'encens, gommier blanc. Aubl.. IIist. de la Guy., L. 130; Rich., Cuba, t. 37. - Le plus souvent arbre de taille moyenme, rarement de grande taille dans nos deux îles, droil; à branches souvent pendantes; à écorce rougeâtre, rude et gercée. Fenilles imparipennées, à 5-7 folioles, rarement à 3 , dont les plus grandes nexcèdent uère $10 \mathrm{~cm}$. de long, coriaces, elliptiques, acuminées, souvent inécrales à la base. Fleurs hermaphrodites, en panicules corymbiformes, axillaires, situćes à l'extrémité des branches, plus courtes ou plus longues que le pétiole commun; calice court, à $4-5$ dents deltoïdes; pétales 4 , valvaires, orales, pointus, verts en dehors et pubescents sur les bords; étamines 8; anthères oblongues; styles 4-5, lobés à l'extrémité. Fruit long de 10-13 mm. de la grosseur d'une olive, recourbé, ovale, pointu, à péricarpe drupacé, rouge en dehors, souvrant en 3 valves; semences $1-2$, longues de $8 \mathrm{~mm}$, irrégulièrement trigones, à face dorsale beaucoup plus large. — Toutes les parties de la plante émettent un suc blanc et aromatique, qui s'épaissit jurmptement af quiom emploie pour les cérémonies religieuses: il jouit éralement d'une grande réputation comme vulnéraire : on s'en sert aussi pour parfumer les appartements; sa fumée chasse les moustiques et les maringouins'. L'aubier est blanc, le centre est rouge : ce bois est rarement employé pour les constructions. - Fl. en mai et juin, ou en août. - Cà et là dans la plupart des grands bois 'inférieurs: Rivière-Rouge, Gourbeyre mmones (roblin el Ilimondelle, Pointe-Noire, Deshates. Alt. 300-700 mèt. [No 3276.

Mantixique, Vulgo: Bois-gommier, gommier blane, bois d'encens. As-e\% rare (at dit dans les bois du Lorrain, de Sainte-Marie el de la Grand'Anse. $\left[\mathrm{N}^{\circ} 105 \dot{1}\right.$.

Je l'ai vu en abondance à l'île de Sainte-Lucie el à la Dominique.

Dacryodes Vahl. (du grec “ dacruon », larme, et " eidos », forme, qui ressemble ì des larmes, allusion ì la gomme qui découle de l'arbre.)

D. hexandra Gr.; Dacryode à six étamines. Vulgo : Gommier blanc, boiscochon. - Arbre énorme, parfois gigantesque; à tronc très anfractueux à la base, d'un diamètre de $1^{\text {III }} 60$; à écorce rude, très gercée; à branches très lompurs al chabe: it rameaux sourent rerruqueux. Feuilles imparipennées, i) 3-5 folioles de $8-12 \mathrm{~cm}$. de long sur 7-8 cm. de large, souvent en forme de cuiller ou roulćes sur les bords, obovales ou elliptiques-oblongues, très coriaces, arrondies au sommet, rétrécies à la base en un pétiole comprimé-

1. Ce produit dicxsudation constitue la Tacahamaque jaune terreuse de Guibourt, qui est la 'T'acahamaque la plus répanduc dans le commerce de la droguerie européenne. Elle a une odeur résincuse et térébinthacée; sa saveur est amère et ácre; elle se dissout complètement dans l'alcool. (E. II.) 
ailé et transversalement ruğuleux; pétiole commun, tantht très Innğ, tantôt court, comprimé-ailé ou comprimé-légragnone. Fleurs din̈̈ques : les màles, a calice tronqué, adné, à 3 , plus rarement à 4 pétales ovales et arrondis, à 6 étamines subsessiles, à anthères biloculaires; les femelles ont un calice adhérant a l'ovaire et un style simple, panicules males très branchues, pyratmidales, brièrement pédonculées, plus courtes que les panicules femelles, qui sont allongées et de $16 \mathrm{~cm}$. de long. Fruit drupacé, indéhiscent, pourpréglauque à la maturité, de la grosseur d'une olive et souvent plus gros, surmonté d'une petite pointe, reste du style; endocarpe crustacé, blanchatre; semence 1. - Toutes les parties de la plante, surtout l'écorce, contiennent un suc laiteux très aromatique : il sert pour la guérison des blessures ef pour les cérémonies religieuses, Avec le tronc, qu'on creuse et qu'on carbonise extérieurement, on fait des pirogues qui durent très longtemps. - Fl. en juillet; graines mûres en janvier, février, mars. - Cà et là dans tous les grands bois : Bains-Jaunes, Matouba, Trois-hivieres, Pointe-Yoire, etc. Alt. 400-900 mèt. [ $\mathrm{N}^{\circ} 330 \%$ ]

Martinique. Vulgo : Gommier blanc, bois-cochon. - Dans les bois du Morne-Rouge, des Fonds-Saint-Denis, du Camp de l'Alma, du Camp Balata, du Lorrain. [ $\left.\mathrm{N}^{\circ} 1946.\right]$

Nota. - Les graines de tous les gommiers sont recherchées par les oiseaux.

Amyris L. (du grec " alpha ", augmentatif, et " muron " ou " muris ", baume, allusion à l'odeur de la résine que contient la plante.)

A. elemifera Willd., Elaphrium elemiferum Royle; Amyris produisant la résine élémi. Vulgo : Bois-chandelle. - Arbrisseau très élégant, toulfu, très florifere, ou petil arbre à branches plus ou moins ctalées, à rameaux grềles, à écorce grise et ghlabre. Fenilles imparipennées a 3 , moins souvent it so folioles, de grandeur variable, mais n'excédant que rarement $6 \mathrm{~cm}$. de longueur sur'3 cm. de large, largement ovées nu presque triangulaires, médiocrement acuminées au sommet, ou souvent obtusément pointues, fréquemment presque tronquées ¿ la base, coriaces, luisantes en dessus, pälesou blanchâtres, ou de couleur de rouille en dessous; pétiole commun, long de 1-2 cm., rarement plus long; pétioles partiels, longs de $\mathbf{1}-5$ mm. Fleurs blanches, odorantes, en panicules corymbifères, terminales et axillaires, plus courtes que les fenilles; calice petit, quadrifide; pétales 4 , ovales; étamines 8 , hyporynes, plus longues que les pétales; stigmate capité, sessile; ovaire à deux ovules. Fruit drupacé, globuleux, noir à la maturité, de la grosseur d'un pois, f-6 mm. de diamet. Toute la plante contient un suc résineux, aronatique, dont l'odeur rappelle celle de la rue ${ }^{1}$. - Fl. en juin et juillet; graines mûres en septembre et

1. Ce produit porte, pour le distinguer des autres élémis de provenance botanique ou géographique fort diflérente, le nom d'élémi du Mexique, parce que ce végétal croit dans cette contrée (environs d'Oaxaca). Elle a du reste presque complètement disparu du com 
octobre. - Abondant dans les mornes inférieurs, pierreux et secs, et sur le

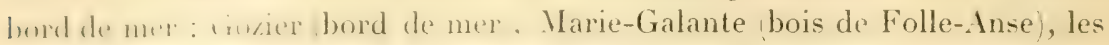

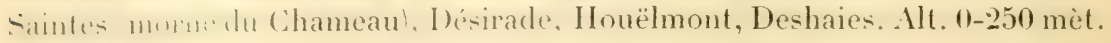
$x+3=\div 1$

Martinieze. Vulgo : Bois-chandelle, bois-chandelle blanc. - Abondant.

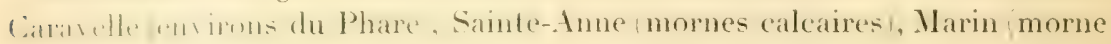
Gommier). [N" 96.]

A. maritima Jacq.; Amyris maritime. Vulgo : Bois-flambeau, bois-chandelle, bois-pini (au Noule). - Ressemble beaucoup au précédent par le port, la taille, linllorescence; il en diffère : par ses folioles, qui sont toujours au nombre de 3 et luisantes en dessous; par ses pétales obovales; par ses anthères fermées, ovées, et par son gynophore nettement accusé. - Même habitat que le précédent. [No 184.] - Je ne l'ai pas trouvé à la Guadeloupe.

Comocladia L. (du gnrec " komé ", chevelure, et "klados ", rameau, allusion aux feuilles qui forment une rosette à l'extrémité des branches.)

C. ilicifolia Sw.; Comoclade à feuilles de houx. Vulgo: Houx du pays. Plum., édit. Burm., t. 118, f. 1. - Arbrisseau très élégant, le plus souvent a plusieurs tiges, hautes de $2-3^{\mathrm{m}} 50$, nues dans le bas et marquées de grosses cicatrices cordiformes, provenant des feuilles tombées; à rameaux courts; ì écorce cendrée, rude et couverte de nombreux tubercules lenticulaires. Feuilles alternes, imparipennées, dont les plus longues nexcèdent guère $20 \mathrm{~cm}$. de longueur; à $5-10$ paires de folioles, opposées, longues de 7-10 mm. sur 5-9 mm. de large, sessiles, largement ovées-deltoïdes, subcordées ou arrondies à la base, luisantes des deux côtés; à 3 nervures formant sur le bord 3 épines rigides, très acérées, ce qui leur donne l'aspect de leuilles de houx: foliole terminale munie de 5 - 7 piquants; pétiole commun zrite. leyerement pubescent. Fleurs polyzames, très petites, en glomérules multillores. placés a distance, formant ensemble une grappe interompue; srappes rarement solitaires, presque toujours réunies par 2-16, naissant au smmet dinne protubirance, termmales ou axillaires : ces dernieres toujours plus courles el échelonnées le longr des tiges; calice tripartite; pétales 3 , hyperaterifume- calice ef pétale d'un bleu rouge foncé; étamines 3 , ovaire à 1 loge uniovulée; stigmates 3 , sessiles. Fruit drupacé, oblong, rouge, à noyau allongé. - Fl. en avril et mai. - Abondant et exclusivement propre au terrain sec et calcaire: Désirade, mornes entre Port-Louis et l'Anse-Bertrand, mornes calcaires du Petit-canal, etc. [No3274.]

II n'existe pas a la Martinique.

merec de la drogueric européenne, au profit des élémis de Manille et des Philippines, fournis par les Canarium. Ellc a une teinte jaune blond, marquée çà et là de taches verdatres. Elle porte ì sa surface des débris de feuilles brunâtres qu'on retrouve dans l'inlérieur des morceaux. Odeur très prononcée, un peu térébinthacée; saveur légèrement aneire. I: II. 
Spondias L. (du grec "spondias ", prune, allusion à la forme des fruits.)

S. Monbin Jacq., Myrobolanus lutea, Macf. Vulgo: Monbin, prune Monbin, prune Myrobolan. Desc., vol. VI, t. 397, p. 61. - Grand arbre élégant, ayant l'aspect du frêne d'Europe, très branchu, à fronde ample, à écorce très épaisse, crevassée, couleur cendrée; tronc et grosses branches très souvent munis d'aiguillons naissant sur des mamelons elliptiques; à raneaux très cassants. Feuilles ramassées à l'extrémité des rameaux, imparipennées, it 5-7 paires de folioles, pétiolées, dont les plus longues n’excèdent guère $9 \mathrm{~cm}$., ovales-lancéolées ou lancéolées, en pointe allongée el obtuse au sommet, inégales à la base, ondulées sur les bords, subentières ou dentées-crénelées au-dessus de la base : les inférieures, plus petites, distantes, alternes-opposées; les supérieures, successivement plus grandes, opposées et rapprochées. Fleurs odorantes, d'un blanc mat, polygames, en panicules tres ouvertes, lâches, à branches secondaires insérées à angle droit, solitaires ou réunies par 2-3, souvent pendantes, aussi longues que les feuilles; calice très petit, 5-fide, à dents aiguës; pétales 4-5, lancéolés, très ouverts, plus longs que les sépales, sur un disque hypogyne ; ovaire à 3-5 loges uniovulées, habituellement bien développées; styles courts, en même nombre que les loges. Fruit drupacé, ovoïde, long de $25-30 \mathrm{~mm}$. sur 18-20 mm. de diamèt., jaune et lisse en dehors, portant, à quelque distance du sommet, trois à cinq petits enfoncements; ce sont des traces laissées par les styles; épicarpe mince; mésocarpe copieux ; endocarpe composé d'une matière spongieuse-filandreuse, épaisse et parcourue par cinq faisceaux longitudinaux. - La pulpe est astringente, plus ou moins acidulée : on en fait d'excellentes gelées el des confitures; par distillation, on en obtient un alcool très apprécié dans le commerce. Descourtilz place la plante dans la catégorie des antiophtahmiques et dit que la décoction des bourgeons, de la racine et de l'écorce du trone est prescrite en tisane contre la diarrhée et la dysenterie, en gargarisme dans les angines, en collyre dans les ophtalmies, et en injection contre la gonorrhée; d'après lui, la fumée très chaude des noyaux calme les douleurs de la goutte. Dans le pays, on se sert de la décoction des feuilles et des bourgeons pour laver les plaies et les ulcères; dans les campagnes, les femmes en couches emploient communément, en bains tièdes, les feuilles froissées, à cause de leurs vertus astringentes. La partie subéreuse de l'écorce prend un très grand développement; elle est compacte et se laisse facilement travailler : on en fabrique des bouchons, des cachets, des couvercles, des tabatières et de petites cassettes. Le bois est mou et tendre et ne peut servir pour la construction; l'arbre pousse très vite et prend très facilement de bouture. - Abondant dans la basse réggion de toute l'île. - Fl. en mai ou juin. Alt. 0-300 mèt. [No 3272.]

Martinique. Vulgo : Prune Monbin. - Abondant. [No 322.]

S. Cytherea Tuss. (du grec "Kuthereia ", surnom de Vénus, qui recevait un eulte particulier à l'ile de Cythère: allusion a la beaute et a la doucem du 
fruit.) Tulgo: Pomme Cythère. Tuss., Fl., III, t. 28; Lam., Illust., t. 384. - Petil arbre on arbre approchant de la taille moyenne, à branches habituellement peu nombreuses, dirariquées, fortes: les inférieures, toujours horizontales ou penchées, à rameaux très cassants et épaissis à l'extrémité, dans la portion qui recoit les feuilles: à écorce verte, lisse, surtout celle des branches. Fenilles à peu près comme dans le précédent, mais à folioles plus étroites, plus vertes, subchamues à l'élat frais, ornées sur les bords d'un liséré crrisatre. large de près de $1 \mathrm{~mm}$., dentées-crénelées au-dessus de la base; à crénclures distancées; à nervures fines, rapprochées. Fleurs blanches, odorantes, en panicules pouvant atteindre jusqu'à $45 \mathrm{~cm}$. de long, lâches, habiluellement pendantes; à axes primaires et secondaires striés-anguleux, très vigoureux. Fruit drupacé, d'une longueur moyenne de $8 \mathrm{~cm}$. sur $4-5 \mathrm{~cm}$. de diamètre, généralement ovoïde ou obovoïde, jaune en dehors; à épicarpe mince; à mésocarpe copieux, entrelacé de fibres, qui naissent sur l'endocarpe herisso de loutes parts de pointes filamentenses; loges du fruit écartées entre elles et de l'axe commun. - Les fruits sont très estimés dans les colonies : on en mange pendant quatre ou einq mois. Le bois est tendre et léser et ne peut servir que pour le chaulfage; les branches et même les gros trones, mis en terre, prennent avec une très grande facilité. Les feuilles servent pour les bains comme celles du S. Monbin. Ce végétal jerd habiluellement ses feuilles a lépoque ou les fleurs commencent at paraitre. - Introduit et cultivé, originaire des îles de la Société; selon d'autres, de l'île de Taîti. - Fl. en mai et juin. - Autour des habitations de toute l'île. Alt. 0-100 mèt. [No 3760 .

Mantineue. Vulgo: Pomme Cythère. - Abondant. C'est dans les quartiers de Ducos et du Lamentin qu'on rencontre les meilleures variétés. [ $\left.N^{\circ} 323.\right]$

S. purpurea L.; Spondias à fleurs pourpres. Vulgo: Prune d'Espagne, prune rouge, Monbin rouge, prune-à-téter. Tuss., Fl., III, t. 28; Desc , t. 336, P. 119 ; Sl., t. 219 , f. 3-5. - Arbre peu élevé; à tronc gros, le plus souvent forlusux: a hranches fris divariqués, fresouvent horizontales ou penchées : jeune tronc et branches, à écorce verte, lisse, souvent couvertes de rugosités lenticulaires; vieux tronc, à écorce grise ou grisâtre et crevassée. Feuilles ramassées aux extrémités des rameaux courts, imparipennées, longues de 1:3-1.5.m., à 8-10 praires defolioles opposées, brievement péliolées, ellipliquesoblongues, arrondies ou pointues, ou souvent mucronées au sommet, subentières ou dentelées, inégales et rétrécies à la base, légèrement roulées sur les bords, d'une longueur moyenne de $3 \mathrm{~cm}$. sur $1-5 \mathrm{~cm}$. de large; pétiole commun comprimé. Fleurs polygames, petites, rouges, portées sur des pédon-

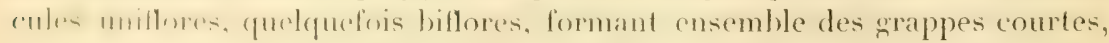
très nombreuses, situées tout le long des branches; calice à 5 lobes arrondis, concaves; pélales 5, obtus el concaves à l'extrémité; stigmates 5; ovaire a 3-5 loges, dont deux ou trois avortent souvent. Fruit pulpeux, pourpre 
noirâtre, lisse, luisant, en général obovoïde, d'une longueur moyenne de

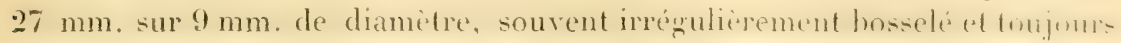

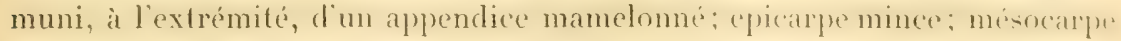
peu pulpeux : endocarpe dur, bosselé - La pulpe est jaune, rafraichis-ante. légèrement acide: on en lait des confitures et des marmelarles très anvéahler. dont le goût rappelle celui du raisin sec. Descourtilz place l'arbre dans les plantes astringentes, et préconise les bourgeons en collyre dans les maladies d'veux; il ajoute que les fruits murs sont antidyenteriques. Dans le pays, on emploie quelquefois les feuilles dans les bains tiedes. Le bois en blane et mou, et la facilité avec laquelle il prend de bouture te fait emploser couramment pour la labrication des haies. Si on plante une branche chargée de fruits non mûrs, ceux-ci continuent à grossir et arrivent à maturité. L'arbre exsude une gomme verdâtre, dont la saveur est à peu près celle de la gomme arabique; les enfantss'amusent à la manger. - Fl. en mai et juin. - Abondant dans la basse région de toute l'île, jusqu'à une altitude de 500 mèt. [No 3278.$]$

Martinique, Vulgo : Prune rouge, prune-pacôme, prune d'Espagne. Abondant dans toute l'île. [No 326 .

La prune nommée vulgairement prune de Chili, prune jaune, assez abondante à la Guadeloupe ef ì la Martinique, it fruit jaune, point ou peu bosselé, it pulpe plus copiense, d'une saveur agréable, astringrente el acide, ue constitue pas une espèce hotanique diflémente, les feuilles et les fleurs étant identiquement les mêmes, et les semences avortant toujours.

Lne nouvelle espiece, le Spondias pleiogyna L, originaire de Queensland (nord de l'Australie), a été introduite à la Martinique par M. Emest Duchamp, de Saint-Pierre, en 1883: elle a fleuri pour la première fois en mai et juin de l'année 1886 , et a produit une masse de fruits; depuis, elle n'a cessé de fleurir et de produire tous les ans.

Mangifera L. (du mot indien " mange ", mangue, el dulatin "fero ", je porte.)

M. indica L.; Vulgo : Manguier. Tuss., Fl., II, t. 15; Desc, vol. I, t. 25, p. 121. - Arbre de très grande taille dans la région inférieure, moins élevé dans la région supérieure, originaire des Indes Orientales et naturalisé dans tous les pays tropicaux; à trone pouvant dépasser $1^{\mathrm{m}} 50$ de diamètre à la base; à fronde majestueuse, touffue; à branches tri- ou quadrichotomes; à écorce épaisse, jaune en dedans, raboteuse, gercée, noirâtre et cendrée en dehors. Feuilles alternes, éparses au sommet des branches, oblongues ou lancéolées, pointues, entières, coriaces, vertes des deux cólés, lisses, glahres. à nervures jaunatres, parallèles; pétioles de longueur varialole, comprimis en dessus, légèrement rentlés el transversalement rugulenx it hat has. Floms polygames, petites, rougeatres, en panicules larges, terminales, pramidales. dont les dernières divisions portent, à la base, une bractéole courte, ovale 
('t printue: 'alice 5-partite: pétale's 5, striés de noir en dedans, réfléchis: clamines 5. prerisnes, 1-2 fortiles. 2-3 steriles, à filets subulés, à anthères prespue rinflomes: ovaire it 1 loges style simple. Fruit drupacé grand, lisse et winiralement jaunatre en dehors. comprimé des deux côtés et un pur arqui ar forme de rein: ì épicarpe plus ou moins épais. se détachant al pe phe ou moins de faciliti: a mesocarpe charnu, le plus souvent jaunâtre. traverele fibers qui partent d'un endocarpe ligneux-cartilagineux, s'ourrant

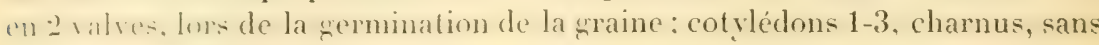
albumen: radicule infère.

Le fruit est succulent, très sain et bienfaisant; il a un léger goût de térébenthime. (m compte une masse de variétés, qui diffèrent par le volume, la couleur, la forme, le plus ou moins de fibres, etc.; il y en a qui n'excèdent pas la grosseur d'un ouf de poule; d'autres qui pèsent jusqu'à deux livres. (1) sesert sourent des especes sans fibres pour la confection des confitures et des marmelades. Sous l'influence de la culture et surtout de la greffe, on a obtenu des espèces qui, par leur volume, la finesse et la délicatesse de leur chair, latisent lnin derriere elles l'espece primitive Ie fruit du manguier greffé s'appelle « mangue ». - Les meilleures espèces sont : la mangue FiffineGibriclle, de Cayenne; la mangue Julie, introduite de Cavenne en 1860 ou 1861 par M. Neyrat, qui planta cette variété sur son habitation, le «Parnasse " : de forme ovale, aplatie, à couleur d'un vert pâle, à chair sans fibres, d'un goût délicieux, ce fruit, à graine mince, avorte presque toujours; la mangue Martin d'un beau jaune, souvent un peu rosé, à pulpe légèrement lérébenthinée, it forme moins aplatie que la mangue Julie; la mangue divine, de forme allongée et peu aplatie, it chair d'un brun clair, sans fibres, assez fortrment térbenthinée; la mangue d'or, assez volumineuse, presque ronde, un peu arquée. à peau épaisse adhérente à la chair, d'une saveur très sucrée; la mancrue Reine-Imélie, à peau très fine ef un peu tachetée, se détachant facilement de la chair; la mangue Crassous, à forme oblongue, d'un vert clair en dehors, à chair peu fibreuse; la mangue Freycinet, à chair rougeâtre et sans fibres, de couleur sourent rosée en dehors; la mangue Rarnaud, oricrimaire de l'archipel indien, petite, ronde, de couleur pâle en dehors, à chair banchitre bien parfumés: la mangue sans-pareille, la plus grande de toutes, de forme oblongue, à chair aqueuse, d'une médiocre valeur; la mangue Cédrot, qui a beaucoup d’aflinité avec la mangue Crassous; la mangue Albert, la mangrue Emmonet, qui se rapprochent des espèces déjà citées. - Le fruit abtenu d'un pied provenant de la graine d'une mangue greffée se nomme " mangotine ". Ites mamuiers greffés sont loin d'atteindre les dimensions du manguicr sauvage. I.e huis est blanchatre; il a à peu près la dureté du peuplier de lirance : on ne l'emploie que pour faire du charbon el comme bois le chaullage. I'ai v'u cependant a la Martinique quelques beaux meubles faits avec le bois du manguier. - Fl. en janvier, février, mars; fruits mûrs en 
juin, juillet. - Descourtilz place l'arbre dans les stomachiques antiscorbutiques; les fleurs et les feuilles prises en infusion sont pectorales. vermifuges, sudorifiques et antiscorbutiques. Dans le pays, on enploie le: noyaux rotis pour arrêter les cours de ventre. Selon le chevalier de Tussic. le manguier aurait été importé à Saint-Domingue, en 178.2, par le capitaine de vaisseau anglais Marshal, qui l'a rapporté de l'île de France avec une quantité d'autres arbres utiles; de Saint-Domingue il ne tarda pas it se répandre dans les autres. Antilles.-Alt, 0-400 mèt.; au delit de cette altitude. le manguier pousse encore très bien, mais fleurit et rapporte difficilement. [No3275.]

\section{Martinique. [No 333.$]$}

Anacardium L. (du gree " ana ", approchant, ressemblant, et " kardion ". cour, parce que les fruits de cet arbre ressemblent, quant à la couleur et is la forme, à un cœur desséché.)

A. occidentale L.; Anacarde d'Occident. Vulgo : Pomme d'acajou, noix d'acajou. Tuss., Fl., III, t. 13; Desc., vol. VII, t. 507, p. 233. - Petit arbre tortueux, peu élégant à l'état sauvage et ne dépassant guère 5 mèt. de haul (arbre élégant et droit, d'une élévation de 10-15 mèt. à l'état de culture. dans les endroits bien abrités et exposés au soleil), à cyme arrondie, it branches très divariquées, souvent horizontales, à écorce grise, peu fendillée. Feuilles naissant par bouquets aux extrémités des rameaux, épaisses. coriaces, obovées ou obovales, arrondies ou échancrées au sommet, it còte saillante en dessous : les jeunes, rouges ou rougeâtres, passant ensuite et bientôt au jaune, selon le terrain dans lequel il pousse; pétiole court, rentlé et ruguleux à la base. Fleurs polygames, en panicules terminales, larges, plus long:ıes que les feuilles, a branches écartées, terminées par des corvmbes arrondis; pédoncule long, comprimé; pédicelles et pédicellules pourvus, a la base, d’une bractéole ovée, acuminée, duretée-glauque; calice caduc i-j partite, à segments duretés en dehors; pétales 5 , longs de $9 \mathrm{~mm}$., deux plus longs que les divisions du calice, linéaires, acuminés, recourbés, d'abord blanchâtres, devenant peu ì peu pourpres; étamines 9-10, périgynes, dont une plus longue et fertile, les autres stériles: style simple, filiforme, léxièrement courbe ou droit, près de deux fois plus long que les étamines: stigmate brun, tronqué-capité. Fruit réniforme, comprimé-biconvexe, longr de 28-3-3n $\mathrm{mm}$. sur $18-25 \mathrm{~mm}$. de large, à péricarpe épais, cartilagineux-ligneux, hrun clair; pédoncule très gros, charnu, plus ou moins pyriforme-obovale, tronqué au sommet, poli et luisant, d'abord vert, puis jaunâtre, ensuite couleur de feu plus ou moins intense.

Le fruit, qui porte le nom de "noix d'acajou ", renferme une anande blanche, très bonne à manger, et dont le goût rappelle la noisette de Francer on la mange crue ou rótie; dans le pays, elle remplace somvent l'amimd. 
donce dans la confection des orgeats, des nougats, etc.; elle contient aussi une huile très agréable, qui vaut celle de l'amande douce. Entre l'épicarpe et l'endocarpe, on troure une matière, huileuse extrêmement caustique et Acre, qui oxyde très promptement le fer, qui sert à marquer le linge en caractìres indélébiles et qui peut aussi détruire les verrues, les cors; c'est grâce a cette matière (ni les insectes ni les rats n'osent l'affronter) que les noix d'acajou se conservent longtemps'. - Le pédoncule, charnu, qui prend le nom de "pomme d'acajou ", renferme, dans une matière spongicuse et fibreuse, un suc aqueux, abondant, astringent, acirle, qui oxyde Lrès vile le fer et l'acier; il a une saveur vineuse et peut en quelque sorte remplacer le vinaigre; par la distillation, on en obtient une excellente eau-devie. Dans nos colonies, le suc entre dans la préparation des punchs, et, avec les pommes dont on a exprimé le jus et enlevé la peau, on fait d'excellentes confitures. - Ia pomme, mangée crue, est indigeste à cause de son acidité.

Du tronc de l'arbre découle une gomme transparente, qui, quoique inféricure à la comme arabique, est propre à faire de la colle 2 . Le bois est blanc et sert pour la menuiserie et la construction. - Fl. en janvier et férrier; fruils mûrs en mai et juin. - Abondant dans les endroits secs, sablomneux et pierreux de la basse région. Alt. 0-280 mèt. [No 3277.]

Martinique. Vulgo: Noix ou pomme d'acajou. - Abondant. [No 334.

Solxante-NeUYì̀e FAMLLE。- AMENTACÉES.

Casuarina Kumph (nom donné par Kumph, ì cause de la ressemblance des ramuscules avec les plumes du casoar.)

G. equiselifolia Forst.; Casuarina à rameaux en crin de cheval. Vulgo : Filao. - Grand arbre, originaire de Madagascar et de l'archipel indien, très ornemental, à écorce cendrée, raboteuse, se détachant par plaques : les jeunes pieds, à Jranches inférieures horizontales; les vieux, à branches inférieures penchées, et à tronc anfractueux à la base. Feuilles petites, verticillées, concrescentes; ramuscules rappelant l'Equisetum, filiformes, nombreux, très rapppochés et ramassés à l'extrémité des branches, longs de 20 -

1. Celte substance caustique renferme de l'acide anacardique, du cardol, du tanin, de l'acide yallique, une gomme résine et une matière colorante. L'acide anacardique est blanc, cristallin, inodore, d'une saveur âcre et brûlante, aromatique; il est insoluble dans l'eau et donne par l'acide sulfurique une couleur rouge de sang; le cardol est un liquide oléagineux, jaune, très altérable, insoluble dans l'eau, soluble dans l'éther; il est vésicant.

(E. H.)

2. Cette gomme, qui se produit seulement sur les pieds âgés, se concrète en masses stalactiformes, est d'une couleur jame et rougeâtre et se dissout incomplètement dans l'eatu. Lille est formée d'arabine et de bassorine. (E. II.) 
$26 \mathrm{~cm}$., composés de 30-35 articulations, striées, à feuilles s'enganant les unc. dans les autres et terminées par autant de dents qu'il y a de stries. Fleur's i

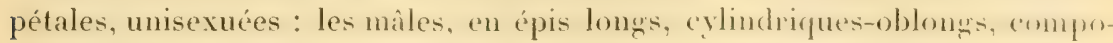
sés d'une multitude de petites articulations, courtes, engainées les unes dans les autres, longues de 1,5 mm., terminées circulairement par six dents velues et pointues; étamine 1, naissant latéralement au fond de la gaine et munie de deux bractese el de deux sépales diaphanes, i filet filiforme, d'abord court, s'allongeant ensuite pendan't la floraison: les femelles, réunies en capitules strobilacés, pédonculés, d'abord phlobuleux, ensuite cylindriquesglobuleux, silués vers l'extrémilé des ramuscules; ovaire sessile au fond de deux bractées latérales, ovales, ligneuses, striées, soudées inférieurement en tube ouvert, au moment de la floraison, fermé après la lécondation, pour s'ouvrir de nouveau après la maturité de la graine; ovaire uniloculaire et uniovulé ; style court; stigmates 2, filiformes et allongés ; semence pelite, longue de $\mathbf{1}-\mathbf{6} \mathrm{mm}$, prolongée en une aile membraneuse, mince et diaphanc. - Le bois est presque aussi dur que le fer, il ébrèche les outils les mieux trempés : l'aubier est blanchâtre, le coeur est d'un rouge loncé et on peut en extraire une couleur rouge. Quand le vent souflle à travers les ramuscules, il produit un bruissement vague, agréable et poétique.-Fl. de juin en en aout. - Pointe-ia-Pitre (cimetière) Basse-Terre (Jardin botanique, CampJacob (habitation Rollin), etc. [No 2999.

Martineue. Vulgo : Filao. - Fort-de-France (port des Transallantiques), morne Rouge, Trinité, etc. [No2092.]

Un cultive chez quelques amateurs de plantes le G. quadrivalois Labill. et c. tenuissima Hort.

Myrica L. (du gree " muriki " (le Tamariscus des anciens) venant de "muron ", baume, suc, parce que cesplantes contiennent habiluellement de la cire odorante.)

M. microcarpa Benth.; Myrica à petits fruits. Vulgo : Caca-rávet. Arbrisseau extrêmement toulfu, haut de 1-2m 50, à branches élalées, formant une cyme aplatie, à tiges et branches nues dans le bas, à écorce grise, à bois dur. Feuilles longues de 4-6 mm. sur 2,5 cm. de large, elliptiques, coriaces, très vertes, brièvement pétiolées, couvertes en dessous de sécrétions globuleuses, grasses, résineuses: les jeunes, tris grossierenent el irrénulierment sinuées-dentées, de manière à simuler des feuilles de chêne: les adultes, subentières ou dentées au-desisus de la base, el sonvent faiblement roulés sur les bords, à còte saillante en dessous et munie d'un duvet conleur de ronill. Inflorescence en petits chatons dioïques, solitaires ou réunis par 2, aux aisselles des feuilles, longs de $f-7 \mathrm{~mm}$., à bractées en forme de coin : les chatons mâles, courts, cylindriques, portant des lleurs di ítamines, units: au milieu, formant une petite colonne filiforme el velue; les chatons 
lemelles, ovoüdes, à bractées caduques, à fleurs avec 1 ovaire à 1 loge uniovulee. Fruit drupacé, rond, trois feis plus petit qu'une graine de poivre.Abondant sin le plateau de la montagne de la Madeleine Trois-Rivières). - Très rare à la Savane aux Ananas. Alt. 1050-1100 mèt. - Fl. en avril, mai. [No 3000 .

Il n'existe pas à la Martinique.

\section{SOIXANTE-DIXIÈME FAMILLE. - LÉGUMINEUSES.}

\section{I. - PAPILIONACÉES.}

Grotalaria 1. (du gree " krotalon ", cliquette, castagnette, allusion au bruit résultant de la secousse des gousses, dans lesquelles les graines se sont détachées.)

C. stipularis Desv., C. sagittata Desv.; Crolalaire à stipules. Vulgo : Herbe lchatcha. Desc., vol. VI, t. 434, p. 227. - Herbe annuelle, plus ou moins velue, haute de $15-65 \mathrm{~cm}$, droite. Feuilles ovales ou lancéolées, ou lancéolées-linéaires, subsessiles, finement mucronées; stipules larges, décurrentes, s'étendant d'un nœud à l'autre, à sommet terminé en un croissant bien prononcé. Inflorescence en zrappes longuement pédonculées, axillaires, opposées aux feuilles. Fleurs peu nombreuses, james; calice à 5 divisions profondes, lancéoléest, aussi longues ou plus lonerues que la corolle; étendard cordé au sommet; carène arquéc. Gousses courtes, d'abord pubescentes, ensuite glabres, oblongues, portées sur des pédicelles courts. - Fl. presque toute l'année. - Dans les savanes herbeuses, humides et sablonneuses de la région inférienre: environs de la Basse-Terre, Gourbeyre, Trois-Rivieres, Baie-Mahault, etc. Alt. 15-400 mèt. [Nos 2664, 3432.]

Martinique. Vulgo: Herbe tchatcha. - Environs de Saint-Pierre (TrouVaillant, morne Saint-Martin, hauteurs de la Rivière-Salée, ete. [No 1113.$]$

C. verruevsa I., C Crotalaire à feuilles verruqueuses. Vulgo : tchatcha, poiszombi. - Annuel, très ornemental, sous-ligneux à la base, droit ou tortueux, Habre. a branches nombreuses, quadrangulaires, étalées et souvent penchées,

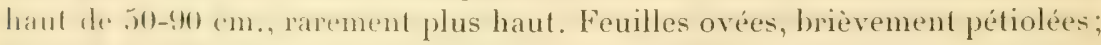
slipules 2, larges, sessiles, arrondies à la base et inégales, pointues au sommel, abliquement appliqués contre la tige. Inflorescence en grappes termi-

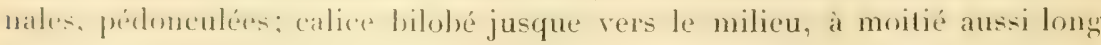
que la corolle : lobe supérieur, ové; l’inférieur, lancéolé; corolle large, violette ou panachée de violet sur fond blanc; pédoncule à $3-4$ ailes, ce qui distingur relle esprec trís facilement de tous ses congénères. Gousses 
oblonghues, brièrement pédicellées, munies, an sommet, diun bee recourbe: - Assez abondant dans les savanes herbeuses et le long des routes de la région inférieure de toute l'île. [ $\mathrm{N}^{\circ} 2643$. $]$

Martinique. Vulgo : Pois-zombi. - Abondant. [No 1142.]

G. retusa L.; Crotalaire à feuilles rétuses. Vulgo : Pois à zombi jaune. Annuel, à base sulfrutescente, haut de $0^{\mathrm{m}} 70-1$ mèt., le plus souvent très branchu, à rameaux striés, grisâtres, pubescents. Feuilles spatulées, très brièvement pétiolées, arrondies ou rétuses au sommet, glabres en dessus, couvertes en dessous d'un très léger duvet soyeux et blanchâtre; stipules subulées. Intlorescence en grappes allongées, terminales; calice bilobé, plus court que la corolle : lobes supérieurs, ovés; les inlérieurs, lancéolés; corolle grande, jaune; étendard souvent strié de noir. Gousses oblongues, très brièvement pédicellées, glabres. - Abondant dans les savanes et le long des routes, jusqu'à une altitude de 700 mèt. [No 3018.$]$

Martinique. Vulgo : Pistache bâtard. - Abondant. [No 1110.$]$

C. incana L.; Crotalaire à feuilles blanchâtres. Vulgo : Pois à zombi. Sl., 1. 179, f. 1. - Ornemental, annuel, droit, haut de $0^{\text {m }}$ 70-1 ${ }^{\mathrm{m}} 20$, sous-ligneux ¿t la base, a jeunes tiges, branchess, pédoncules, pédicelles el gonsises finement duvetés. Feuilles longuement péliolées, à 3 folioles très rapprochées, obovées ou ovales, glabres ou duvetées en dessous; stipules très petites, caduques. Inllorescence en srappes axillaires of terminales: les axillaires, opposées aux feuilles; calice à 5 divisions profondes, ovales-lancéolées; corolle jaune verdâtre, plus longue que le calice; carène fortement barbue sur les bords. Gousses pendantes, oblongues, brievement pédicellées, couvertes de poils courts et roux. - Abondant dans les savanes herbeuses et humides de toute la Guadeloupe; plus rare à la Grande-Terre. All. (1-600 mel. No.2660.

Martinique. Vulgo: Pistache marron. - Abondant dans toute l'île. [N॰1109.]

C. lotifolia L.; Crotalaire à feuilles de lotier. Vulgo : Pistache bâtard, tchatcha.-Sl., t. 176, f. 1, 2. - Suffrutescent, très droit, haut de $0^{\mathrm{m}} 70$ 1 mèt. Fenilles trifoliées, très brièrement pétiolées, elliptiques ou obovaleselliptiques: pútiole commun plus long que les folioles el cannelé au-dessus: stipules tries petites. Fleurs solitaires a l'aisselle des feuilles; calice plus court que la corolle, à cinq divisions profondes et lancéolées; corolle jaunâtre; étendard strié de brum. Gousses petites, pendantes, spatulées-oblongues. grabres ou légèrement pubescentes, ferminées par un bee tries recourbé. Rare : çà et là dans les hatiteurs du Diamant (habitation Kikandon). [No 1107.] - Je ne l'ai pas trouvé à la Guadeloupe.

C. pendula Benth.; Crotalaire à gousses pendantes, Vulgo : Pois sarane. .-Amnuel, haut de $0^{\mathrm{m}} 70-1^{\mathrm{m}} \geq 0$, plus ou moins grimpant, is figes et hranche: très grèles. Feuilles longuement pétiolées, à 3 folioles petites, clliptiques: 
la supérieure, beaucoup plus grande; pétiole commun presque aussi long que les folioles; stipules très petites. Inflorescence en grappes axillaires, allongées, plus longues que les feuilles; calice à 5 divisions deltoïdes-subulées; corolle petite, jaune. Gousses ovoïdes, courtes, pendantes, longues de 11 mm., munies, près du sommet, sur la soudure ventrale, d'une longue arête rigide, fortement repliée sur elle-même; semences $\mathbf{4}-\mathbf{5}$, rondâtres, brunes, lisses. - Peu répandu : hauteurs du Carbel, dans les champs de cannes de l'habitation Crassous. [No 818 b.] - Elle n'existe pas à la Guadeloupe.

I.es G. juncea I. el quinquefolia I... originaires des Indes Orientales, pousient spontanément dans le Jardin botanique de Saint-Pierre. Nou 1111 et 1108 .

Indigofera 1. idu mot indign "indicum " ou couleur indienne, parce que, autrelois, on recevail cette maliere tinctoriale de l'lude, el "fero ", je porte.

I. tinctoria L.; Indigo tinctorial. Vulgo: Indigo vrai. Sl., t. 176, f. 2; Desc., vol. I, t. 17, p. 81. - Sous-arbrisseau, haut de 1-1 m50, légèrement pubescent, droit, grisitre, buissomneux ou it tige simple, it branches nomhreuses, italés et infléchies. Feuilles imparipennées, pétiolées à f-li paires de folinles opposées, ovales ou obovales-oblomstues: stipules subulées. Infloresconce en srappes axillaires, sessiles, minces, allongées, presque aussi longrues que les feuilles: calice à jo divisions triangulaires: corolle petite, pourpre; itamines diadelphes; pédicelles très courts el bractéolés à la base. Gousses subeomprimées-cylindriques, légèrement toruleuses, linéaires, longues de $3-3,4 \mathrm{~cm}$; un peu arquées, munies d'un bourrelet dorsal; semences 10-15. - Fl. de mai à septembre. - Originaire des Indes Orientales; introduit autrefois pour la grande culture. - Abondant dans les endroits secs, sablonneux ou calcaires de la basse région : environs de la lasse-Terre, Le Baillif, les Vieux-Habitants, Vieux-lort, Marie-Galante, la Désirade, etc. [Nos $2649 \mathrm{~b}, 3015$.

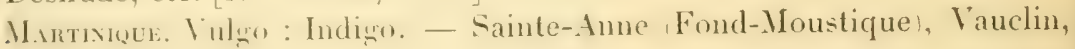
Marin, elc. [No 1058 b.]

I. Anil I. ; Indigo anil (du mot arabe " annil », " nil » ou " nilch », qui veut

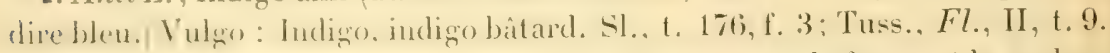
- Vescemble au prérident pour la taille, linflorescence, la forme et la couleur des fleurs; il en dillore par ses feuilles plus prises en dessous et a $3-7$ paires de folloles, matis surtout par ses gonsses plus courtes, très recourbées, non lomlenses, munies diu bunrelet dorsal tres épais, longues de 11-13 mm., ne contenant que 1-6 semences. - Fl. de septembre à février. - Abondant : miginaire des lndes frientales: introduit autrefois pour la grande culture. - Même habitat que le précédent. [Nos 2619, 3414.] 
M.nmtixique. Vulgo: Indigo, - Se renemtre dans la basse région de toute l'île. $\mathrm{N}^{\circ} 1858$.

L'I. disperma L., arbrisseau droit, haut de 1-2 mèt, à gousses ne contenant que deux semences; a été introduit en 1887 à la Martinique, par Ch. Thierry, directeur du Jardin botanique de Saint-Pierre, pour l'exploitation de l'indigo. Il est originaire du Venezuela et fleurit en juin, août, septembre. 'Il paraît réussir très bien dans l'île et donne de beaux résultats. $\left[N^{\circ} 1059\right.$.

Tephrosia Pers. (du gree " tephros ", couleur cendrie, allusion a la couleur de la plante.)

T. cinerea Pers.; Tephrosic à couleur de cendres. Vulgo : Mort aux poissons, herbe à enivrer. - Herbe suffrutescente, plus ou moins couchée, entièrement grise, ì lige grèle, peu branchue, haute de 15-fio cm. Feuilles imparipennées, brièrement pétiolées, at $4-7$ paires de folioles opposées, oblancéolées-linéaires, couvertes en dessous d'un léger duvet argenté, à nervares trìs nombreuses et très fines; stipules subulées, sétiformes, très petites. Inflorescence on grrappes lâches, allongées, terminales et axillaires: les dernières opposces aux feuilles; calice à 5 lobes subulés, inégaux; corolle blanc pâle ou rosée; étendard soyeux, trois fois plus long que le calice; élamines diadelphes. Gousses linéaires, oblongues, arquées, comprimérs, longues de 4-5 cm., contenant 5-10 semences. - A la Désirade, on se sert de cette herbe pour enirrer les poissons. - Peu répandu. Abondant dans les sables du bord de mer et aussi un peu à l'intérieur : Désirade, Saint-François, Marie-Galante. [No 3014.$]$

Il n'existe pas à la Martinique.

Cracca L. (du ğrec "krazein », crier, c’est-à-dire plante recherchée par les animaux criants, sans doute les oiseaux.)

C. caribiea Benth.; Cracea des Caraibes. Vulgo : Pois-zoiseaux. - Sulfrutescent et plus souvent arbrisseau, parfois sarmenteux, haut de 0$)^{\text {"I }} 80$-2 2 mit., à une ou plusieurs tiges greles, peu branchues et nues dans le bas, toujours penchées au sommet. Fenilles imparipemées, brièvement pédonculées, à 5-11 paires de folioles nettement elliptiques, mucronées, convertes en dessous d'un duret argenté el soyeux; stipules longnes, sétiformes, subulées. Inflorescence axillaire en strappes très lìches, pédonculées, paucilloress, it

1. Les Indigofera ne sont pas seulement des plantes industrielles d'une haute valeur. elles se recommandent encore par quelques rertus médicinales qui les font employer dans leur pays d'origine ou de culture. C'est ainsi quen Amérique les ritcinés de l'I. inil sont réputées néphrétiques et lés feuilles passent pour altérantes et purpiltives: lit racine dI. tinctoria est employée communement aux Antilles, dit-on, comme fébrifuge, ct dans l'Inde comme antiépileptique: les feuilles en décoction sont réputés alexitipés ét employées aussi contre les douleurs néphrétiques. (E. II. 
Menus distantes les unes des autres; calice 5-fide, à lobes deux fois plus longs que le lube ; corolle blanche, plus rarement rosée; ailes transversalement ruguh'uses: damines diadelphes. Gousses linéaires, aplaties, droites ou légèrement anquées, longues de 6-7 cm. sur 2-3 mm. de large; semences 15-18, séparées par de fausses cloisons. - Fil. presque toute l'année. - Dans les terres pierreuses, seches et chaudes près de la mer: Pointe-Noire, Deshaies, Pigeon, alc. $x^{\circ} 2(0.5)$.

Manmate. Vulgo: Pelit pois, - Case-Pilote, Diamant, Sainte-Anne (aboudant). No 1061 .

Agati Ad. (du nom de celte plante à Malabar.)

A. Irandiflora Desv, Agali à grandes fleurs. Vulgo : Colibri végétal. Pelil arbre, droit, très ornemental, originaire des Indes Orientales et de

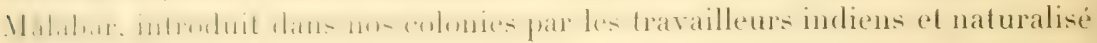
depuis de longues amées, a fronde pyramidale et à branches inférieures horizontales. Feuilles alterues, paripennées, brièvement pétiolées, à $15-22$ paires de folioles, opposées, très brièvement pétiolées, elliptiques ou elliptiquesublongrues, grisitres en dessous. Inflorescence en grappes axillaires, paucillores, pendantes; calice campanulé, environ quatre fois plus court que la corolle, dentelé-ondulé sur les bords; corolle blanche ou rose, très large; ciendard ovale-oblong, plus court que les ailes libres et la carène arquée; élamines diadelphes. Gousses verticalement pendantes, mesurant jusqu'à is cm., droites, stipitées, terminées par un bec long, large et droit, linéaires, comprimées, pourvues d'un bourrelet sur les quatre bords, contenant jusqu'à 2 í semences, séparées les unes des autres par de fausses cloisons. - L'écorce est amere el, suivant le $D^{r}$ Jackson, elle est employée dans l'Inde comme lübrifuge el en infusion contre la variole!. Les Indiens mangent les jeunes fenilles après les avoir apprêtées à leur manière. - Fl. en mai et juin, et aussi en octobre et novembre. - Cultivé dans les jardins, dans les cours et autour des habitations, pour la beauté de ses fleurs. [Yo 3013.$]$

IIntrifurt: Vulgo : Colibri végétal. - On y rencontre souvent la variété i fleurs roses. - Cultivé dans les jardins et autour des habitations. 1. 11657 .

Sesbania Pers. (du mol arabe " seiseban ".)

S. sericeit I). C.; Sesbanie à feuilles soyeuses. Vulgo : Z'aiguille-mare. Sultrutescent el frutescent, haut de $1^{\mathrm{m}} 50-2^{\mathrm{m}} 80$, droit, à branches peu nomIrenses: les inlériemres, toujours horizontales, à jeunes tiges et branches

1. Cut intore liasse exsuder une gromme d'abord rouge puis noirâtre qui est analogue au Limo, ì linguelle clle doil ses propriétés astringentes et qui mériterait d'être étudiée. L.acmer, les fenilles et les ponses sont aussi astringentes; le sue des fleurs et des feuilles serait m remede pepulaire contre le coryza; la racine serait antirhumatismale. (E. H.) 
pubescentes. Feuilles grisâtres, paripennées, ì 10-20 folioles oblonųueslinéaires, snyeuses en dessous, plus rarement glabres, le plus souvent mucronées au sommet. Inflorescence en srappes axillaires, pédonculées, trois ou quatre fois plus courtes que les fenilles; calice a 5 dents subulées; corolle jaune; étendard veiné de noir ou de brun; étamines diadelphes. Gousses d'abord biconvexes, ensuite comprimées, linéaires, pourves de hourrelets sur les côtés, arquées, longues de 12-22 cm., terminées par un onglet court. - Fl. en avril, mai. - Vit solitaire ou plus souvent en société dans les endroits aquatiques et marécageux près de la mer: Lamentin, Sainte-Anne, Moule, Baie-Mahault. [No 3012.]

Martixique. Pois-mare. - Trois-Ilets, Anses-d'Arlets, Fort-de-France, Trinité, Galion, Marigot, etc. [ $\left.\mathrm{N}^{\circ} 1060.\right]$

Aeschynomene L. (du grec "aïschunomaï ", j’ai honte, parce que les feuilles se ferment quand on les touche.)

A. sensitiva Sw. ; Aeschynomène sensitive. Vulgo : Honteuse mâle. Plum., édit. Burm., t. 149, f. 2. - Annuel, ligneux ou sous-ligneux à la base, très droit, entièrement slabre, haut de $0^{\mathrm{m}} 8(t) 1^{\mathrm{m}} 80$, le plus solvent très branchu dans le haut. Feuilles irritables, imparipennces, à 15-202 folioles oblongueslinéaires, uninerviées, sessiles; stipules semi-sagittées, scarieuses. Intlorescence en grappes terminales, liches, courtes, pédonculées, portant 3-6 lleurs; ealice bibractéolé à la base, ì deux levres; corolle jaune ou jaunàtre brun ou blanchàtre, petite; étendard arroudi, entier; carene en forme de nacelle, avec pétales séparés à la base; élamines 10, divisées en deux faisceaux égaux. Gousses lomentacées, longues de 12-14 cm. sur $5 \mathrm{~mm}$. de large, composées de 6-9 articulations carrées, rectilignes, sauf sur le côté dorsal. - Fl. de novembre à février. - Vit en société dans les endroits aquatiques ou marécageux, sur le bord des étangs et des mares : Le Baillif, rivière des Pères, Camp-Jacob, Pointe-Noire, Lamentin, Baie-Mahault, etc. [No 2655.]

Martinique. Vulgo : Honteuse mâle. - Champllore, Trois-Ilets, Ansesd'Arlet, Rivière-Pilote, Le Robert, etc. Alt. 0-500 mèt. [No 1062 .]

A. americana L. Vulgo: Honteuse femelle. Sl., t. 118, 1. 3. - Herbacé, sous-ligneux il la base, annuel, haul de $\mathbf{1 0 - 9 0} \mathrm{cm}$., branchu ou sans branches, ¿̀ tige srèle, délicate, toujours inclinée à l'extrómité, couvert, dans toutes ses parties, de poils roux, droits. Feuilles délicates, pétiolées, irritables, imparipennés, it 15-32 folioles, très petites, oblongues-linéaires, obliques ì la base, trinervées, finement mucronées; stipules ovales, subulées, à deux branches opposées, dont une se dirige de bas en haut, et l'autre de haut en bas. Inflorescence en grappes axillaires ef terminales, pédonculées, très lâches, courtes, à 2-6 fleurs jaune brun ou jaunâtre, veinées de brun; pédoncules et pédicelles filiformes, bractéolés ì la base, à bractéoles ovales. ciliées-dentées; calice bilobé; corolle comme dans le précédent. Gousses lomentacées, stipi- 
tées, longues de $25-30 \mathrm{~mm}$. rectilignes sur le dos, sinuées sur le ventre, composées de 6-7 articulations contractées. - Fl. de mai à juillet. - Celte berbe, quand elle est jeune, fournit un assez bon fourrage. - Très abondant dans les savanes humides, le long des ruisseaux et des étangs de la basse région, où il vit solitaire el plus souvent en société : environs de la BasseTerre, Gourbeyre, Camp-Jacob, Jamentin, Sainte-Rose, elc. Alt, 0-600 mèt. [N 26.15 .

Mantixige. Vulgo : Honteuse femelle. - Abondant : Lamentin, TroisHets, Caravelle, ete. $\left[\mathrm{N}^{\circ} 1065.\right]$

Zornia Gmel. (dédié à l'Allemand Jean Zorn, né en 1737, à Kempten en Bavière, pharmacien et sénateur de cette ville; a écrit sur plusieurs plantes rares et a publié des figures de plantes officinales.)

Z. diphylla Pers.; Zornie à deux feuilles. Vulgo : Zerbe-cabrite. - Petite

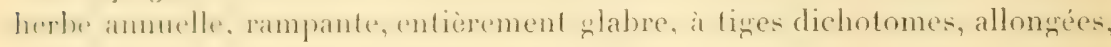
qrêles et flexibles, Jongues de $10-20 \mathrm{~cm}$., souvent relevées aux extrémités.

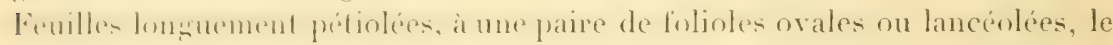
plus souvent pointues au sommet, très brièvement pétiolées; stipules lanciolders subulexs, munies d'un prolongement basilaire. Infloresenee en épis allongrés, terminaux, pédonculés, à rachis filifomes. Fleurs très distantes, alternes, chacune à moitié cachée dans deux bractées elliptiques; calice à deux lèves : la supérieure, émarginée-obtuse; l'inférieure, trifide; corolle

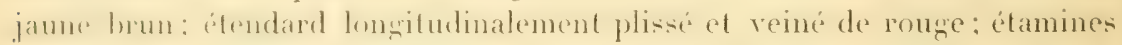

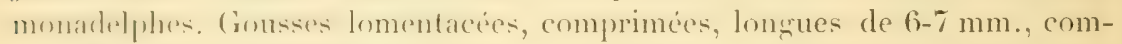
posées de $\mathbf{1 - 6}$ articulations rondes, biconvexes et fortement muriquées. -

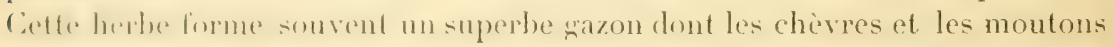
sont très avides: broutée, elle devient vivace; la racine pivotante prend un grand developpement of les liges se multiplient; quand elle pousse dans des "mbluts wi hes hestianx n arrivent pas, la tige reste simple et sallonge indéfiniment. - Abondant dans les savanes sèches ou plus ou moins humides et

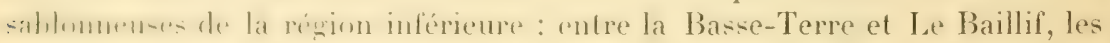
Vieux-Habitants, Vicux-Fort, Pigeon, Pointe-Noire, etc. Alt. 0-500 mèt. $\left[N^{\circ} 2650.\right]$

Mantinece. Vulgo: Zerbe-mouton. - Hauteurs du Diamant, de Case-

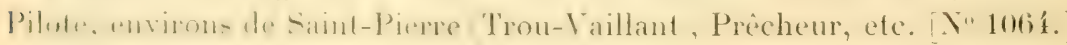

Le Lourea vesperlilionis Desv, herbe annuelle, droile, à feuilles de chanves-souris, originaire des Indes Orientales; s'est naturalisé au Jardin bolanique de Saint-Pierre et dans quelques autres localités de lîle. [Nंก 1065.]

Alysicarpus Neck. (du grec " alusis ", chaîne, et " harpos ", fruit, parce

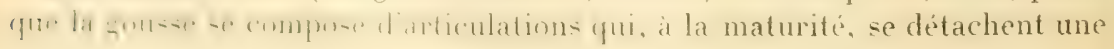
à une.) 
A. vaginalis D. C.; Alysicarpe à stipules engainantes, Vulgo: Zerbesavane. - Annuel ou vivace, selon qu'il est brouté ou non, couché, entièrement wlabre, a branches trè flexibles, souvent tri- allongeses. Fenilles simples, petites, nettement elliptiques ou ovales-liniaires, a pétioles filiformes, environ trois fois plus courts que les feuilles; stipules longues, scarieuses, engainantes it la hase, plus courtes que les pótinkes. Intlorescence en trappes courtes, terminales it 3-8 fleurs; calice tuluntenx, 5-fide, at lobes subules, rigides: corolle jaune pourpre; étamines diadelphes. (inusees lomenttacées, droites, presque cylindriques, in 2-8 articulations, muriqueses et tronquées aux deux extrémités. - Peu abondant; constitue un bon fourrage. Savanes sèches de la région inférieure : environs de la Basse-Terre, Inoule. Gozier, Trois-Rivières, etc. Alt. 20-400 mèt. [No3011.

Desmodium D. C. (du gree " desmos ", lien, allusion aux étamines rémies en un tube dans la plupart des espèces.)

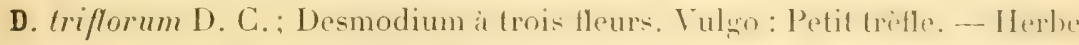
délicate, annuelle, devenant parfois vivace quand elle est brontee, complietement couchée, parfois voluble quand elle trouve un appui, radicante, à tipes et branches nombreuses, tres flexibles, filiformes, a jennes tiges of branches pubescentes. Feuilles digitéestrifoliées, très brièrement pétiolies, sessiles, très petites, obovées ou obcordées, parfois presque roudes ; stipules relativement grandes, acuminées, persistantes. Fleurs peu nombreuses, terminales, réunies par 2-4, opposées aux feuilles; calice brièvement campanulé, à 5 segments rigides et poilus; corolle pourpre foncé, rarement blanchatre ou blanche; étendard obové: ailes adhérentes a la carène of biauriculies it la base. Fruit lomentacé, légèrement arqué, composé de 3-6 articulations presque carrées, légèrement arrondies sur le hord de la suture dortale. Excellent fourrage pour les moutons et les chèves. - Abondant dans certaines saranes sablonneuses, humides ou sieches, git il forme souvent un fort joli gazon : environ de la Basse-Terre (ravine Belost), les Vienx-IIabitanle, Pigeon, Trois-Rivières, etc. Alt. 10-700 mèt. [No 3005.]

Martinique. Vulgo : Corde à violon, petit trèfle. - Fond-Canonville (abondant); Marin, Trois-llets, etc. [ $\left.\mathrm{N}^{\circ} 809.\right]$

D. ascendens D. C.; Desmodium ascendant. Vulgo : Cousin. - Annuel ou virace, à tige rampante, radicante, cylindrique, verte, ascendante: jeune lige et branches, pubescentes. Feuilles pétiolées, pennés-trifolices, a folioles obovées ou ovales-arrondies, frès vertes en desins al burdés d'un liseré rouge, blanchâtres en dessous : la froisieme foliole. distante et plusis grande: stipules 2 , distinctes, petites, ovales-lanciolées, apprimes. Fleure

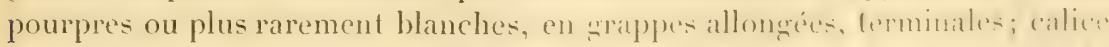
comme dans le précédent; corole petite. Fruit homentace, druil. convert de

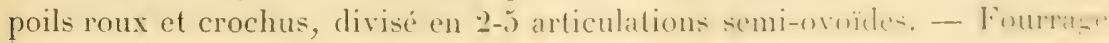


recherehe par lon- les hestianx. - Mondant dans toutes les savanes humides

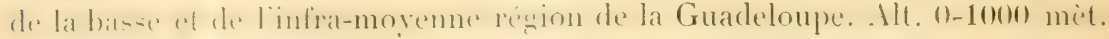
[No 2939.

Mantixique. Vulgo: Cousin, trèfle-savane. - Abondant dans toutes les savanes humides. [No 812 .]

D. incanum D. C.; Desmodium à feuilles blanchâtres. Vulgo : Cousin-. grand'savane. S1., t. 118, f. 1, 2. - Annuel ou vivace, couché, ascendant et souvent dress atux extromitis, a jeunes liges of branches pubesentes. Feuilles

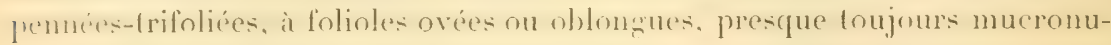
lées : les jeunes souvent ovales-elliptiques; la troisième beaucoup plus framde of distante des deux autres: pétiole commun poilu, pétiolules courts. velus: slipules connés jusquau milien. Fleurs en grappes allongeges, terminales, multillores; conolle pourpre lincé, plus rarement blanche. Fruit lomentacé, subsessile, arqué, couvert de poils crochus, articulations 2-8, à suture ventrale mue ef rectilisne, suture dorsale presentant autant d'entailles qüil y a d'articulations. - Cette herbe constitue un précieux fourrage. - Abondant dans toutes les savanes humides ou sèches de la basse et de la moyenne région de la Guadeloupe; moins abondant à la Grande-Terre et dans les dépendances. Alt. 0-800 mèt. [No300\%.]

Martinique. Vulgo: Trèfle-savane, cousin. - Très abondant. [No 813.]

I. D. latifolinm D). C., orierinaire des Indes ()rientales, droit, haut de 0 ${ }^{m}$ So$I^{m} 20$, à feuilles larges, pubescentes en dessous, à tige grosse, à fleurs violettes on blanchatres, en grappes fres nombreuses axillaires et terminales; 'st naluralisé au Jardin botanique de Saint-Piere' et aux environs de la ville. $\left[\mathrm{N}^{\circ} 811.\right]$

D. axillare D. C.; Desmodium à fleurs axillaires. Vulgo : Cousin-falaise. - Suftrutescent, rampant, radicant, s'étendant à une distance indéfinie, ascondant aux extrémités ef moluble quand il peut trouver un appui, à tignes ol branches nombreuses, filiformes, tres tlexibles, légèrement pubescentes: les jeunes, poilues. Feuilles larges, souvent panachées, très longuement

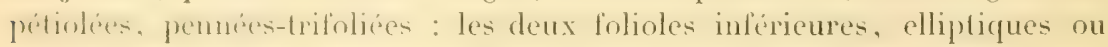
nvales: la lminime, flus wrande, ovale, deltö̈de en dessus de la base: pétiolules courts et poilus ; stipules distinctes, poilues, élargies à la base, termi-

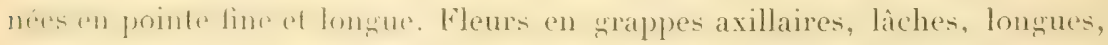
dressées, naissant aux aisselles radicantes; pédoncules très longs, dressés, fermes puhesente: correlle pourpere ou blanche. Fruil lomentacé, composé de deux articulations larges, demi-rondes, couvertes de poils roux et

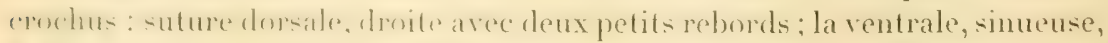
i sinu- profonds: pridicelles filiformes, tanteit anssi longs, tantit un peu plus courts que le fruit. - Constitue un bon fourrage. - Beaucoup moins abon-

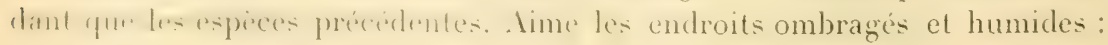


Basse-Terre (ravine de Belost), Gourbeyre, Trois-Rivières, Camp-Jacob, Moule, Gozier, Morne-à-1'Eau, etc. Alt, 10-800 mèt. Y'o 2640.

Martinique. Vulgo : Trèfle courant. - Assez abondant dans les haies, sur les lisières des bois de la basse et de l'infra-moyenne rérgion de l'île : MorneRouge, Parnasse, Carbet, Marin, Trois-llets, etc. [Yo 810.

D. scorpiurus Desv.; Desmodium à lruits en forme de queue de scorpion. Vulgo : Cousin-trèfle. - Suffrutescent, radicant, rampant à une distance indéterminée, à tige anguleuse, à jeune tige et branches fililormes, pubescentes. Feuilles pennées-trifoliées, à folioles elliptiques ou ovales, ou oblongues, blanchâtres en dessous, pétiole commun filiforme, plus long que les folioles; stipules subulées, obliquement insérées à la base. Fleur's en grappes terminales, allongées, liches; comble blanche, petite, strite te vindet. pédicelles capillaires, délicats. Fruit lomentacé, long de 3-5 $\mathrm{cm}$., droit ou arqué, toruleux, légèrement contracté aux cloisons, composé de 2-7 articu-

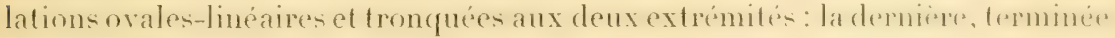
en pointe allongée. - Assez répandu dans la basse région : bords du Galion (près de l'embouchure), dans les savanes, le long des routes et sur les vieux murs. Alt. 0-300 mèt. [No 3008.]

Martinque. Vulgo: Trèfle-savane, petit trèfle. - Dans les savanes el le long des routes : environs de Saint-Pierre, Prêcheur, Basse-Pointe, Jacouba, etc. [No 815.]

D. tortuosum D. C.; Desmodium à fruits torlueux. Vulgo : Cousin. Annuel, très droit, ornemental, à tige unique, très branchue dans le haut,

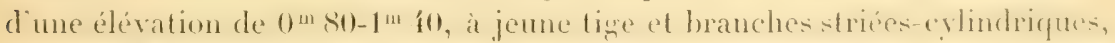
couvertes de poils rigides ef crochus. Fenilles pennesestrifolibus a fonlindes

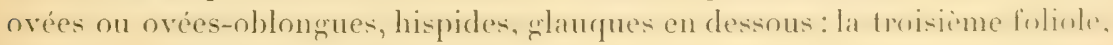
beaucoup plus large; stipules obliquement subulées. Fleurs en grappes allongées, terminales et axillaires : les dernières, situées dans les aisselles des feuilles supérieures; pédoncule long; corolle pourpre violet ou violette, ou

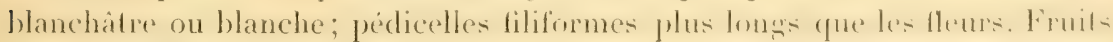
lomentacés, subsessiles, tortueux, couverts de poils rigides el crochus; articulations 2-6, comprimées, très contractées aux jointures, arrondies. - Abondant dans les savanes sablonneuses, le long des routes, sur les décombres, et dans les endroits défrichés de la région inférieure de toute l'île. Alt. f-500 mèt. [No 3007.

Martinique. Vulgo : Cousin. - Abondant dans les environs de SaintPierre, au Carbet, à Case-Pilote, au Marin, etc. [No 814 .

D. spirale D. C.; Desmodium à fruits en spirale. Vulgo: Cousin. - Annuel ou vivace, haut de $50-80 \mathrm{~cm}$., d'abord couché et radicant, ensuite plus ou moins droit, à tiges flaccides, délicates, allongées, anguleuses, glabres. Feuilles pennées-trifoliées, à folioles ovées ou lancéolées, presque toujours 
fanathes de Hane an dessus: fipules setacées, obliquement insérées et légèrement élargies à la base. Fleurs en grappes axillaires courtes ou en

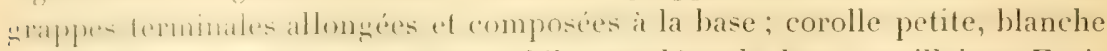

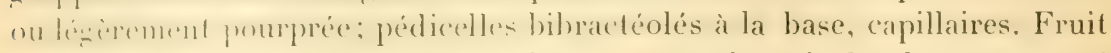
lomentacé, très tortueux et restant dans cet élal jusqu'à la chute, composé

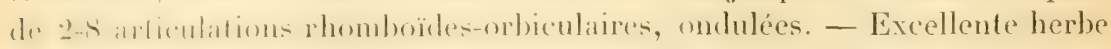
fourraçère - Peu répandu. Assez abondant sur les bords du Galion (près de l'embouchure), Gourbeyre (Grande-Savane, abondant), quelques savanes entre Pigeon et la Pointe-Noire. Alt. 10-300 mèt. [No3010.]

Mntrixeue. Vulgo : Petit trèfle, cousin. - Assez abondant au Vauclin, au pied des murs et dans quelques savanes, où il forme gazon. [No 816.

D. molle D. C.; Desmodium à feuilles molles. Vulgo : Cousin. - Annuel,

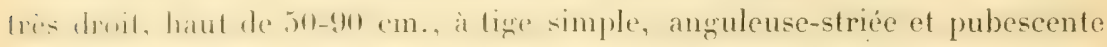
dans le haut. Feuilles pennées-trifoliées, à folioles ovales, pubescentes en

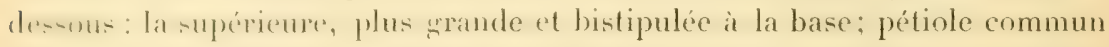
lonę, très comprimé, cannelé-strié; stipules sétacées. Fleurs en grappes effilées, très allongées, simples; corolle pourpre ou blanche; pédicelles réunis par 2-3, filiformes, bibractéolés au sommet. Fruit lomentacé, subsessile, à deux articulations tortueuses, dont l'inférieure avorte et dont l'autre seule se développe, devient large, membraneuse, et est munie d'une entaille sur le bord supérieur. - Très rare. De celte espèce, je n'ai trouvé que trois pieds dans une savane herbeuse, aux environs du bourg de CasePilote (Martinique). [No 817.

I. D. yirans 1). C. ; In:molium à feuilles oscillantes, Vulgo : Télégraphe, oringaire des Indes (trientales, cultivé autrefois an jardin botanique de Saint-Pierre; s'y est naturalisé et aussi dans les environs. [ $\left.\mathrm{N}^{\circ} 1105.\right]$

Stylosantes Sw. (du grec "stulos », pistil, et " anthos ", fleur, allusion au grand développement du style.)

S. premmbens. I. . Silylosanthe penché. Vulgro: Trèfle jaune. - Suffrutescent ou plus souvent vivace, d'abord droit, ensuite plus ou moins couché, très

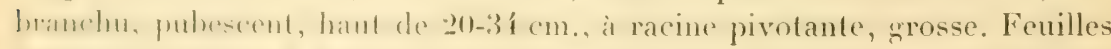
J"mnrestrilolines, it folioles lancénlées-oblongues, mucronées, entièrement pubescentes; remarquables par les nervures, qui sont très saillantes en

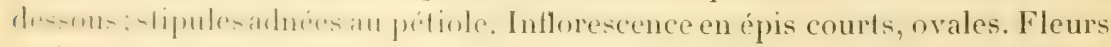
pelites, accompagnées d'un pédicelle accessoire, velu, et entourées de plusieurs J)ractées rigides; calice à tube filiforme, caduc; corolle jaune, striée

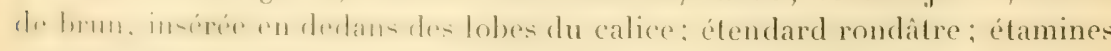
monadelphes; anthères alternativement inégales. Fruit lomentacé, sessile, composé d'une articulation réticulée-côtelée, plate d'un côté, aussi longue que son bec allongé et tourné en crosse. - Jeune, cette hẹbe constitue un bon 
fourrage. - Abondant dans les terres calcaires du Petit-Canal, du Moule. du Gozier, de Saint-François, de la Désirade, de Marie-Galante, elc. $\left[\mathrm{N}^{\circ} 3017.\right]$

Il n'existe pas à la Martinique.

Arachis L. (du grec "arachné ", araignée, à cause de la surface du fruit, qui présente quelque ressemblance-avec une toile d'araignée.)

A. hypogxa L.; Arachicle souterraine. Vulgo : Pistache, pistache-vraie. - Herbe annuelle, longue de $40-60 \mathrm{~cm}$., d'abord plus ou moins droite, ensuite couchée, se relevant aux extrémités; à racine fusiforme, allongée. portant un wrand nombre de radicelles fibrenses, munies de petils luberculearrondis; à tige simple ou ramifiée; à jeunes tiges et branches comprimées,

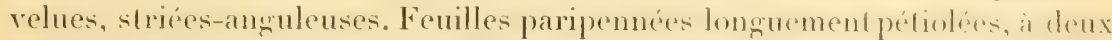
paires de folioles presque sessiles, très vertes, légèrement obovales ou

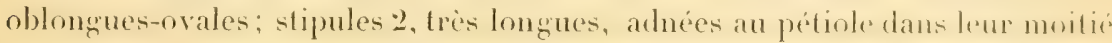
inférieure, longuement acuminées dans la moitié supérienre. Flenrs jaunes. larges, axillaires : celles des aisselles supérieures, habituellement mâles; celles des inférieures, femelles. Après la fécondation, le pédoncule de la fleur femelle s'allonge, portant l'ovaire à son extrémité et s'enfonce peu à peu sous terre pour y laisser mûrir le fruit, qui est lomentacé, composé de 1-2 articulations indéhiscentes. - Originaire de l'Afrique occidentale, de l'Amérique centrale et du Brésil; cultivé et naturalizé dans tontes les Intilles. - La graine, nommée pistache de terre, fournit une huile peu rancissable et très estimée dans le commerce. On la cultive pour la consommation locale et on la mange rôtie aux Antilles '. - Fl. de mai en juillet. [Nos 3004,3581 .

Martinique. Vulgo: Pistache. $\mathrm{N}^{\circ} 1066$.

Chætocalix D. C. (du grec "chaïté "), crinière, crin, et "kalux », calice, à cause des aiguillons allongés qui couvrent le calice.)

C. vincentinus D. C.; Chretocalyx de Saint-Vincent. Vulgo : Corde à violon. - Petite liane délicate, ligneuse à la base, à tige unique, branchue dès la base, haute de $1^{\mathrm{m}} 50-2^{\mathrm{m}} 80$, à tige et branches très flexibles, minces, très enchevêtrées, cylindriques, glabres et noirâtres. Feuilles pétiolées, imparipennés, a 5 folioles elliptiques ou colliptiques-oblongues, mucronites, à pétiolules courts et filiformes. Fleurs jaunes, laryes, axillaires, soit rimnic en fascicules, soit disposées en grappes courtes, simples; à pédoncule et rachis couverts de très petits piquants, élargis à la base et capillaires au sommet; calice J-fide, à lobes inégaux, subulés, partie lubulenéce du calicer

1. Ces graines donnent, par expression ì froid de leurs cotylédons, de 40 à $50 \%$ d'une huile agréable, de saveur douce. Cette huile est constituée par un mélange d'oléine, de palmitine, d'hypogreine et d'arachidine. Elle est surtout employéc en Europe pon la fabrication du savon et des fromages de Hollande. (E. H. 


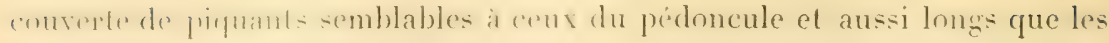
dents les plus longrues du calice; étendard pubescent, arrondi-émarginé; étamines monadelphes. F'ruit lomentacé, arqué, linéaire, glabre, composé de 6-S articulations, longues de $8 \mathrm{~mm}$., comprimées, convexes sur les bords et tronquées aux deux extrémités, finement striées. - Les chèvres et les moutons sont friands des feuilles et des jeunes tiges. - Exclusivement propres aux terrains sees, pierreux el arides: Le Baillif, les Vieux-Habitants, VieuxFort, Pointe-Noire, Désirade, etc. - Fl. pendant la saison des pluies. Alt. $0-150$ mèt. $\mathrm{N}^{\circ} 3003$.

Martineue, Vulgo : Liane-corde, cordon de violon. - Abondant sur la côte, entre le Carbet et Case-Navire, Sainte-Anne, Diamant, etc. [No 1067.$]$

Abrus L. (du gree " ab)ros ", élégant, allusion au tendre et joli feuillage de cette plante.

A. precatorius L.; Abrus propre à prier, Jéquirity. Vulgo : Graines d’église, liane à réglisse, réglisse. Sl., t. 112, f. 4; Dese., vol. IV, t. 275, p. 194. - Sulfrutescent, voluble, haut de 1-3 mèt., branchu; à tiges el branches rrêles, très flexibles et très enchevêtrées; à racines traçantes, chevelues. Findles paripumies, délicates, à 10-12 paires de folioles opposées, arrondies aux deux extrémités ou mucronées au sommet. Fleurs roses ou rosées, en grappes courtes, simples, habituellement situées à l'extrémité de branches sans feuilles; calice tronqué; carène plus longue que les ailes; étamines 9 (celle qui est opposée à l'élendard manquant), réunies en tube court, fendu

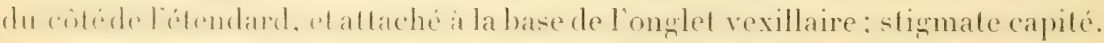

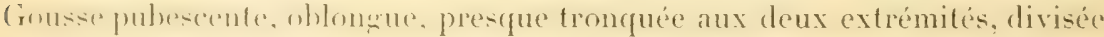
en 2-1 fausses cloisons transversales, contenant chacune une graine ronde ou ovale, rougre écarlate, et munie, à la base, d'une tache noire. - Les semences restent longtemps attachées aux valves fortement tordues, au milieu

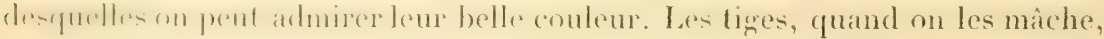
ont le goût de la réglisse d'Europe. - Descourtilz place la plante dans les béchiques adoucissanls; dans le pays, on se sert en effet des feuilles, et surtout des tiges el des racines, en tisane contre la toux, l'oppression, l'irri-

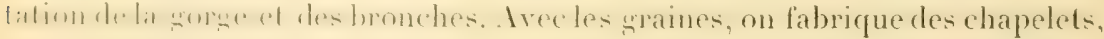
des colliers, des bracelels, etc. 1 - dime les terrains secs, chauds et pierreux

1. L.es racines sont employées dans plusieurs colonies tropicales comme succédané de la réglisse, de lá le nom de liane-réglisse donné à la plante, ou de réglisse d'Amérique. I.es graines de cette espece sont employées avec succès en Europe, sous forme de macération dans l'ean, contre la conjonctivite granuleuse chronique; elles doivent cette action a la présence d'une substance albuminoïde très toxique, l'abrine, qui appartient à la classe des ferments solubles. Cetle substance se présente sous la forme d'une poudre brun jaunatre, soluble dans l'eau; elle peut ètre employée aux lieu et place de la graine de jequirity (1 pour 500.000 d'eau). (E. H. 
de la basse région: Basse-Terre, Le Baillif, Tieux-Fort, Pointe-ioire, Grands-Fonds du Gozier, du Moule, de Sainte-Anne, etc. [No 3413.

Mantinique. Vulgo : Liane-réglisse. - Abondant. No 1068.

Rynchosia Lour. (du grrec "rhunchos », bec, trompe, allusion à la forme particulière de la carène.)

R. minima D. C., R. caribaea Torr. et Gr.; Rynchosie très petite. Vulggo: Pois-z'oiseaux, petit pois. Sl., t. 115, f. 1. - Liane annuelle, haule de $1^{\mathrm{m}} 50-2^{\mathrm{m}} 50$, élégante, très branchue, à tiges et branches anguleuses, très flexibles et grêles, infiniment enchevêtrées. Feuilles velues, à 3 folioles ovées-rhomboïdes, pourvues, à la base, de deux stipules. Fleurs jaunes, trìs réduites, en grappes tris nombreuses, petites, axillaires, longuement prinlonculées; calice 5-partite, à lobes lancéolés-linéaires, inégaux : l'inférieur, environ de moitié aussi long que la corolle: étendard arrondi; ailes et carène veinées de noir; étamines monadelphes. Gousses longues de 12-15 mm. sur $3 \mathrm{~mm}$. do large, comprimées, recourbées à l'extrémité, rétrécies à la base, contenant deux semences noires, réniformes, avec un petit raphé blanc. - Les graines passent pour être toxiques et corrosives. - Fl. pendant l'hivernage. - Abondant dans les halliers de la basse région : environs de la Basse-l'erre, Le Baillif, Moule (commun), Gozier, Lamentin, etc. Alt. 0-150 mèt. [No 2642.]

Martinique : Vulgo: Pois-halliers, pois-sucrier. - Fort-de-France, 'TroisIlets, Lamentin, Ducos, ete. [No 1069.]

R. phaseoloides D. C.; Rynchosie à feuilles de haricot. Vulgo: Pois-hallier. - Liane élevée de 5-10 mèt., suffrutescente, peu branchue; à lige adulte, très comprimée; à jeune tige el branches cylindriques el velues. Feuilles pennées-trifoliées, à folioles ovées ou ovées-rhomboïdes, pointues,

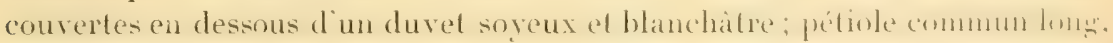

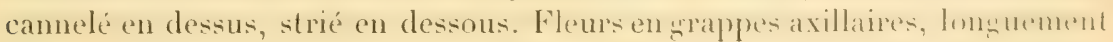
pédonculées, multiflores, longues de $10-17 \mathrm{~cm}$; calice d̀ 5 lobes inégraux : l'inférieur, de moitié plus petit que la corolle; étendard strié de pourpre. Gousses longues de $18 \mathrm{~mm}$. sur $10 \mathrm{~mm}$. de large, garnies d'un duret fin et roux, terminćes par une pointe large et courte, contractées entre les deux

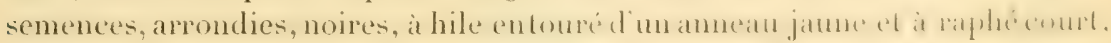
oblong-linéaire.-Fl. en janvier et février. - Rare : cà et là dans les grands

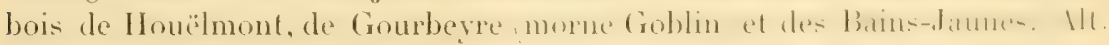
250-700 mèt. [No3022.]

Il n'existe pas à la Martinique.

Cajanus I). C. paraît venir, selon l)mpelit-Thouars. (lu mol malai- ant. jung », qui désigne une légumineuse.)

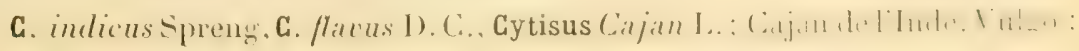


Pois de bois, pois de lisière. 'Tuss., Fl., IV, t. 32; Desc., vol. IV, t. 280, p. 221. - Arbrisseau droil ou souvent tortueux, haut de $1^{\mathrm{m}} 50-2^{\mathrm{m}} 80$, originaire des Indes Orientales, cultivé et naturalisé dans toutes les contrées chaudes de linérique. Fenilles pennés-trifoliées, à folioles lancéolies-oblongues, pointues, duvelées el blanchâtres en dessous. Fleurs vertes en dehors, jannes en dedans et souvent strieses, entrappes axillaires et terminates, simples ou souvent rameuses; calice quadrifide, bilobé : le lobe supérieur, souvent lidente; étendard arrondi, auriculé a la base ; étamines monadelphes. Gousses comprimées, obliquement imprimées à l'endroit des graines, stipitées, pointues au sommet et rétrécies à la base, à valves minces, parcheminées. - Descourtil\% cite la plante comme bichique-adoucissante, et dit : que les bourgeons sont peedoraux et les fleurs báchiques; que les feuilles bouillies el appliquées sur les plaies les guérissent : que la décoction des feuilles déterge les ulceres et apaise le prurit dans les maladies de la peau. Dans nos colonies, on se sert, en effet, de la décoction des feuilles pour laver les plaies: on emploie en outre la farine faite avec les semences comme résolutive; les feuilles bouillies et pilées avec du sel contre les foulures, les entorses et les luxations; les feuilles séchées sur une plaque métallique servent en décoction contre la diarrhée; les feuilles vertes, en tisane contre les dérangements de ventre et les coliques; les fleurs sèches, en infusion contre la toux. On utilise encore les feuilles vertes pour les bains émollients. - Il existe plusieurs variétés de cette espèce. - Les pois de bois constituent un aliment sain et nourrissant; ils sont d'une grande ressource pour l'alimentation publique. - Les pieds adultes fleurissent presque toute l'année : on peut les tailler, mais ils ne vivent gruère au delà de trois ans. - Alt. 0-600 mèt. [No3001.]

Martinieue. Vulgo: Pois d'Angole. [No 1071.$]$

Flemingia lioxl). (dédie a l'Anglais John Fleming, président du Medical board au Bengale, au commencement de ce siècle, grand ami et promoteur dess sciences naturelles, auteur d'un Catalogue des plantes médieinales et des drogues des Indes Orientales.)

F. strobilifera R. Br.; Flemingia strobilifère. Vulgo : Goyavier bâtard fainsi nommé ì cause de la ressemblance de ses feuilles avec celles du Psidium pomifernm (lu pays). - Arbrisseau haut de $0^{\text {m }}$ 80-2 mèt., droit, habiIuellement tries toullu, foujours fortement feuillu, à racines tragantes. Fenilles simples, ghtandulifires an destus, larges, elliptiques, parcheminés, arrondies ì la base. Inllorescence en épis côniformes, axillaires et terminaux : ces derniers sont lons de 12-15 cm.; les axillaires, plus courts. Fleurs blanches, petites, cachées dans de larges bractées réniformes, plissées en deux, scarienses, diun blane pake, distignes-athernes, pubecentes et formant ensemble une inflorescence strobiliforme allongée el ovoïde; calice 5-fide, à lobe inférieur plus long; étendard arrondi, auriculé à la base et infléchi; ailes adhé- 
rentes à la carène. Gousses longues de 10-11 mm., ovoïdes, pubescentes. munies d'un bec à l'extrémité, renfermant deux semences noires et presque rondes. - Les inflorescences restent très longlemps atlacheses a la plante : wn fi.cueille avec les branches pour en faire des bouquets qui se conservent intacts pendant plusieurs années. - Abondant dans les endroits ombragés, comme aussi dans les endroits secs ou aquatiques : environs de la Basse-Terre, Camp-Jacols (lieux inondes et humides), Gourberre, Monteran, Matunlat. - Originaire des Indes Orientales, naturalisé depuis de longues années. Alt. 5-700 mèt. [No 2661.]

Martinique. Vulgo: Herbe Madeleine. - Abondant : lit inférieur de la rivière des Pères, Trois-Ponts, Trois-Ilets fextremement abondant daun lus savanes), Marin, etc. [ $\left.\mathrm{N}^{\circ} 1070.\right]$

Clitoria L. (du gree "klei toris ", clitoris, de "kleio ", je ferme, allusion à la forme de la corolle.)

C. Ternatea L.; Clitorie de Ternate (une des îles des Moluques). Vulgo: Pois-savane. - Liane annuelle ou bisannuelle, à base suffrutescente et frutescente, grimpant à une hauteur indéfinie, quand elle trouve un appui, rampante, quand elle n'en trouve pas. Feuilles très pâles, imparipennées, pétiolées, à 5 folioles distantes, pétiolulées, ovales ou ovées, arrondies au sommet, chacune pourvue de deux petites stipules sétiformes; stipules du pétiole commun subulées, pointues, élargies a la hase. Fleurs solitaires, asillaires, brièvement pédonculées; bractées 2, presque rondes, vemées, blanches, à moitié aussi longues que le calice; calice campanulé, à 5 lobes profonds, lancéolés et acuminés; étendard émarginé, rondâtre au sommet, bleu ou pourpre foncé, rarement blanc, avec une grande tache jaunatre naissant au milieu-et s'étendant jusqu'à la base de l'onglet; ailes et carène 2-3, plus courtes que l'étendard; style bilobé ef barbu an sommet. (romsese liniaines. aplaties, longues de 10-13 cm. sur $1 \mathrm{~cm}$. de large, terminées, du côté du dos,

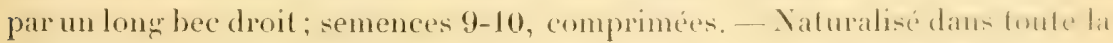
Guadeloupe et surtout à la Grande-Terre. Alt, 0-400 mèt. [No 3232.]

Martinique. Vulgo : Pois-marron, pois sauvage, lentille sauvage. Répandu dans toute l'île. - A cause de la beauté de ses lleurs, on le cultive souvent sur des treillis et des grillages. [N¹073.]

C. glycinoides D. C.; Clitorie ressemblant à la glycine. Vulgo : Poismarron, pois-halliers. - Vivace, voluble, quand il trouve un appui; couché ou ascendant, dans le cas contraire; à racines fortes et pivotantes; it lige

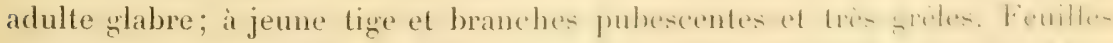

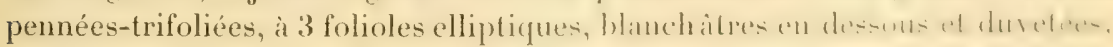
surtout les jeunes; pétiole principal long; pétiolules courts, épaissis, noirâtres, velus; stipules des folioles subulées-lancéolées: celles des feuilles:

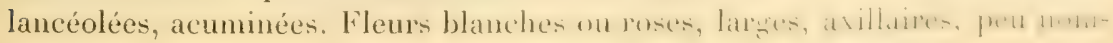


breuses, réunies par 1-3, longuement pédonculées el entourées, à la base, de bractées ovales-elliptiques el striées; calice deux fois plus court que la corolle, campanulé, ì 5 lobes prolonds, lancéolés, acuminés. Gousses stipilées, longues de 3-5 cm., presque tétragones, à valves marquées au milieu d'une côte saillaute; semences rouges, rondes. - Peu abondant. Çà et là dans les halliers ou dans les savanes, ou dans les endroits aquatiques: Lamenlin, Trois-Rivières, Marie-Galante, etc. [No 3233. .

Mantrique, variété ecoslata Urb. Vulgo : Pois-raziers, haricot-marron. Macouba, Basse-Pointe, Carbet. No 1075.

C. arborescens Ait. - Arbrisseau d'abord droit, ensuite voluble, originaire de la Guyane; est cultivé au Jardin botanique de Saint-Pierre (Martinique).

Centrosema Benth. (du gree "kentron ", aiguillon, et " sema ", étendard, ì cause de la pointe que porte l'étendard près de la base.)

G. Plumieri Benth.; Centrosème de Plumier. Vulgo: Pois saurage. Desc., vol. VIII, t. 591, p. 242. - Voluble, haut de 3-4 mèt., suffrutescent ou frutescent et pouvant durer plusieurs années, ì tiges adultes, ì $4-5$ ailes étroites, jeunes tiges et branches tétragones et très flexibles. Feuilles pennées-trifoliées, longuement pétiolées, à folioles largement ovées, amples; bractées ovées, deux fois plus longues que le calice; calice infundibiliforme, à dents très courtes et inégales; corolle blanche, striée de pourpre, pubescente; étendard plus large que long, muni à l'extérieur, près de la base, d'une bosse conique, tournée vers le bas. Grousses longues, de $14-18 \mathrm{~cm}$. sur $1 \mathrm{~cm}$. de large, terminées par un bec arqué; valves 2, traversées, à l'extérieur, par une

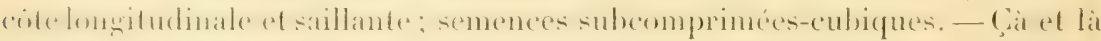
dans les halliers de la basse région : environs de Saint-Pierre (Trois-Ponts, Trou-Vaillant), Macouba, Carbet, etc. Alt. 0-300 mèt. [Nos 821, 822.] - Il ne se trouve pas à la Guadeloupe.

C. pubescens Benth.; Centrosème à fleurs velues. Vulgo : Pois bâtard, pois-hatlier, pois sauvage. - Annuel, voluble, grêle, à branches nombreuses, fililormes, slabres, pendantes : les jeunes, pubescentes. Folioles 3 , ovées ou

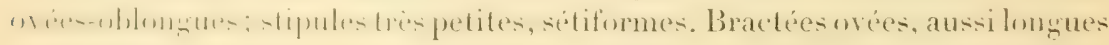
que le calice. Fleurs réunies par 2-4, axillaires, portées sur un pédoncule long: calice infundibiliforme, à dents allongées, plus longues que le tube; corolle ayant même couleur, même forme et même étendard bossu que dans le précédent. Gousses droites, linéaires, comprimées, longues de $10 \mathrm{~cm}$. sur $5 \mathrm{~mm}$. de large, terminées par un long bec droit, à valves rehaussées près du bord, de chaque côté, par une côte longitudinale, saillante, large de près de $1 \mathrm{~mm}$.; semences subcomprimées-cubiques. - Très abondant dans tous les halliers et les haies, qu'il courre souvent entièrement. - FI. de novembre en février. - Alt. 0-500 mèt. [No 3234. 
Mantinique. Vulgo : Pois-raziers, pois-marron. - Très abondant dans toutes les parties de la basse région de l'île. [No 820.]

C. virginianum Benth.; Centrosème de la Virginie. Vulgo : Pois sauvage, petit pois, pois bâtard savane. Desc., vol. VIII, t. 590, p. 339. - Annuel ou bisannuel, at base sulfrutescente ou frutescente, hant de $11^{m} \mathrm{~s}(1)-2$ w 511 , it lige et branches très grèles, llexibles et filiformes, volubles ou rampantes. Folioles 3, ovées, oblongues ou sourent linéaires, toujours thlabres; bractées orier. généralement plus courtes que le calice; calice infundibiliforme, à jobles très inégaux, rélléchis ì l'extrémité, linéaires, plus longs que le tube; conlle pourpre foncé, plus rarement blanche ou lavée de pourpre; étendard large. bossu comme dans la précédente espèce, pubescent en dehors. Gousses

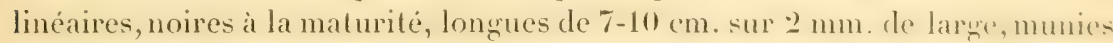
d'un bec long et droil; semences comme dans le précédent, mais plus petiter. Se distingue facilement de ses congénères par la couleur de ses flenrs ol les moindres dimensions de toutes ses parties. - Mondant, surtout daus lat rémion du littoral ou il aime de préférence les endroits secs et pierreux : Le baillif, les Vieux-Habitants, Deshaies, environs de la Basse-Terre, Gourbevre, efc. [No3235.]

Mantinique. Vulgo : Pois-marron savane. - Abondant dans toutes les parties basses de l'île. [No 819.$]$

Teramnus Sw. (du grec " teramos ", tendre, allusion probahle aux poils tendres qui couvrent les tiges, les pédoncules et le calice.)

T. labialis Spreng., T. volubilis Macf. (partim); Teramne à grandes lèvres. Vulgo : Pois-z'oiseau, pois enivrant. - Annuel, voluble, délicat, suffrutescent it la base, it branches très nombreuses, filiformes, extremement flexibles et très fortement enchevêtrées, à jeune lige, branches, pétioles. pédoncules hispides. Feuilles pennées-triloliées; folioles elliptiquess ou meirs. souvent légèrement pubescentes en dessous. Fleurs jaune's, petites, stríes of tachetées de brun, en grappes axillaires, très nombreuses, ellilées, droites. généralement aussi longues que les feuilles; calice campanulé-lubulenx. J-fide, à lobes légèrement inégaux; carène un peu plus courte que les ailes: étendard obové; étamines monadelphes, alternativement slériles et líconders: stigmate capité. Gousses longues de 4 cm. sur 1-3 mm. de large, lineiries. comprimées, arquées, arrondies au sommet et terminées par un bec courl et recourbé, rétrécies à la base, pubescentes, rarement glabres: semences noires, comprimées-cubiques, séparées par des fausses cloisons. - linns les haies et les broussailles de la basse région, de toutes sortes de terrains. Fl. presque toute l'année, mais surtout de mar's at septembre. X" "-26.5.3.

Martinique. Vulgo: Pois-colibri. Dans la région inférieure de toute l'ille. $\mathrm{N}^{\circ} 682$.

Düss. - Plantes Guadeloupe et Martinique. 
Galactia P. Br. (du grec " gala ", lait, allusion au suc laiteux que contiennent la plupart de ces lianes.)

G. longiflora Arn.; Galactic à longues fleurs. Vulgo : Pois rouge bâtard. - Annuel, très ornemental, à base sulfrutescente, voluble, haut de 2-4 mèt.,

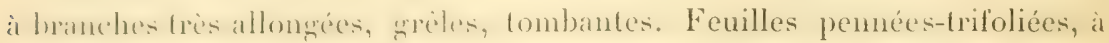

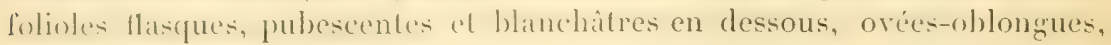
mucronées, presque aussi longues que le pétiole commun. Fleurs larges,

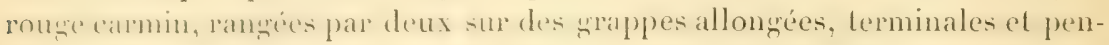
dantes; calice campanulé quadrifide, à lobes lancéolés, longuement acuminés, inégaux : l'inférieur et le supérieur, plus longs que le tube; les denx latéraux plus courts et égaux; étendard glabre, obové-spatulé, deux lois ansi long que le calice : etamines monadelphes. Gousses bivalves, longues de (i-12) cm. sur (i-9) mm. de large, linéaires-oblongues, pubescentes, arrondies au sommet et munies d'une pointe; semences 7-15, séparées les unes des autres par un tissu cellulaire. - Fl. de septembre à février. -Assez abondant dans les haies et les broussailles de la basse région sèche : environs de la Basse-Terre, Le Baillif, les Vieux-Habitants, Pointe-Noire, Capesterre, etc. Alt. 5-300 mèt. [No 2657.]

Martinique. Vulgo : Pois bâtard raziers. - Environs de Saint-Pierre, Carbet, Parnasse, Prêcheur, Trois-Ilets, ete. [No 823.$]$

G. filiformis Benth.; Galactie à branches filiformes. Corde à violon. Voluble, haul de 2-4 mèt., vivace, à branches très nombreuses, filiformes, extrêmement enchevêtrées, à jeunes branches légèrement pubescentes. Fenilles pemées-trifoliées, à folioles caduques, obovées, rigides, échancrées et mucronulées au sommet, roulées sur les bords, très vertes et luisantes en desins. pates en dessous: pétiole commun ausi long que la foliole terminale. Fleurs petites, très blanches, peu nombreuses, réunies par trois sur des grappes axillaires très courtes; calice campanulé, à f́lobes lancéolés, rigides, lógèrement inégaux, glabres, plus longs que le tube, deux fois plus courts que la corolle: étondard arrondi; étamines diadelphes. Gousses aplaties, pubescentes, longues de $5 \mathrm{~cm}$. sur 7-8 mm. de large, recourbées-arrondies au sommet, à suture ventrale terminée par un bec court et élargi à la base; semences brun mir, renfermées dans un lissu cellulaire blanc. - Se rencontre exclusirment dans les endroits calcaires, pierreux, très secs de la région du littoral : Vieur-Fort, Port-Lonis, Désirade. Narie-Galante, ete. No 3023.$]$

Il n'existe pas à la Martinique.

G. angustifolia Kth.; Galactia à feuilles étroites. Vulgo : Pois-savane. - Amnuel, haut de fit--90 com., dabord droil, ensuite voluble, at lige unique,

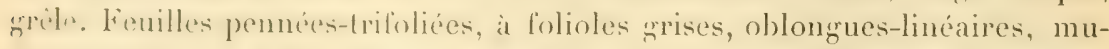
croncips, beaucoup plus longnes que le pétiole commun, finement duvetées, surtout en dessous: les jennes, il duvet argenté. Fleurs roses, pédonculées, 


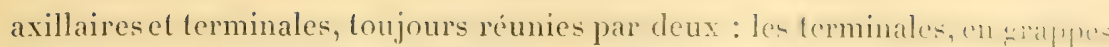
interrompues, allongées; calice à tube campanulé, at i lobes lancroblís, diras fois plus longs que le tube, légèrement inçgaux : le stpérieur, plus lange: étamines diadelphes. Gousses longues de $\mathbf{1}-5 \mathrm{~cm}$. sur $4 \mathbf{4} \mathbf{~ m m}$. de large, pubescentes, légèrement arquées et terminées par un bec court. - Fl. de janvier à septembre: - Peu répandu : Marie-Galante, dans un champ sablonneux des environs du Grand-Bourg. [No 3641 .]

Pachyrhiza Rich. (du grec " pachus ", gros, épais, et " rhiza ", racine, allusion aux grosses racines tubériformes de cette plante.)

P. angulatus Walp., Dolichos bulbosus L.; Pachyrhize it leuilles andzuleuses. Vulgo : Pois-patate. Plum., édit. Burm., t. 222. - Vivace par ses racines, annuel par ses tiges volubles pouvant atteindre le sommet de trie grands arbres. Feuilles longuement pédonculées, pennées-trifoliées, à forlioles larges, deltö̈des-ovées, trinerviées, pubescentes endessous, anghulenses on lris grossierement dentées, à dents mucronces : jeunes lignes, cylindriques, hérissées de poils roux. Fleurs bleu foncé, en grappes terminales, drosies, fres longuement pédonculées; pédoncules gros, cylindriques, revétus de poils ronx : calice bilobé : lèvre supérieure, bidentée; l’inférieure, tripartite; élendard obové, biauriculé à la base; étamines diadelphes; style comprimé, velu; slinmate latéral. Gousses longues de13-14 cm. sur 16-17 mm. de laręe, comprimées, plus larues a l'extrémité qu'à la base, imprimées culre les nranes, terminées par un bec court et légèrement recourbé, revêtues de poils roux et couchés; semences 9-10, comprimées, arrondies. - Fl. en février, mars et mai. - Assez rare : çà et là dans les mornes inférieurs et dans les ravines abruptes : bord de la riviore Noire (pris du Saut-de-Constantin), Gounderve (habitation le Bisdary), Trois-livières (près du Trou-aux-Chiens). d "3tivi.

Martinique. Vulgo: Patate-cochon. - Abondant dans les mornes du Jaldin botanique, hauteurs du Prêcheur, environs du bourg du Macouba. $\left[N^{\circ} 1085\right.$.

La racine est globuleuse, souvent de la grosseur d'une tête d'homme; elle est traversée par de nombreuses fibres of contient un suc aqueux; quand plle est jeune et tendre, elle peut se manger cuite et possède, dit-on, des verlus résolutives.

Vigna Sw. (dédié à l'Italien Dominique Vigna, de Florencer, profir-moll de" botanique à Pise, auteur de : Animadversiones in Theophrasti libros; De historia et causis plantarum, 1628.)

V. Luteola Benth.; Vigna a fleurs jaunders. Vulgo : Pois-mmini - Ramprant ou grimpant, à tiges annuelles, à base sullirutescente. Feuilles pennées-triloliées, à folioles ovées, très glabres, pourvues de stipules; pétiole commun plus long que les feuilles, strié-cannelé, comprimé. Fleur's largés, jaunes, 
axillaires ut treminales, brievement pédicellées, réunies en ombelles de 3-7 rayons: priduncule commun tris long, cylindrique-comprimé, dressé; calice campanulí, quatritide, quatre fois plus court que la corolle, a lobes subulés ansis longs que fe lube: carene subdelteïde, pointue étendard large, arrondiéchancré au sommet, auriculé à la base ; élamines diadelphes; style cartilagrinenx at velu; stigmate latéral. Gousses longues de près de $5 \mathrm{~cm}$., subeylindriques, glabres, jaunâtres, arquées et pourvues, au sommet, d'une pointe très courte el recourbée; semences 5-9, brunes, semi-ovoïdes-globuleuses, avec un hile blanc, - Abondant dans les champs, le long des rivières et des roules de la region inférieure : environs de la Basse-Terre, Capesterre, TroisRivières, Lamentin, Moule, Gozier, Sainte-Anne, etc. [No 2656.

Mantinique. Vulgo : Pois-pigeon. - Très abondant sur le bord de mer et un peu à l'intérieur : Fond-Canonville, Prêcheur, Caravelle, Robert, etc. IX"159.

$1^{\circ} \mathrm{V}$. sinensis Endl. Vulgo : Pois-chique, dont il y a deux variétés : une, haute de 30-10 cm., el une autre, grimpante No 3032. Martinique, vulgo: Pois-choucres [No 676].

$2^{\circ}$ V. sesquipedalis L. Vulgo: Pois-ficelle, pois long [ $\mathrm{N}^{\circ}$ 3466]. Martinique, vulgo: Pois-rigoise, pois-ficelle No 1103]. Sont cultivés comme plantes alimentaires. (1n rencontre aussi, mais plus rarement, le Psophocarpus tetragrmolubus 1). C. Vulgo: Pois carré [X"3761]. Martinique? Y $^{\circ} 677$ ]. Les pois commus sous le nom vulwaire de pois-pizeon, pois-cassé-canari, pois-chicane, pois-de-dame ne sont que des variétés du V. sinensis.

Dolichos L. du gree " dolichos ", long. - Téophraste désigne par ce mot le haricot ordinaire (Dolichos vulgaris L.), in cause de ses longues liges grimpantes. Les Dolichos, qui ressemblent au haricot quant au port, et aussi parce qu'ils ont de longues gousses, ont justifié cette dénomination.)

D. Lablab L.; Dolic Lablad (du mot arabe " lablab ", " liblac " ou "leblab", ce qui tourne autour; selon d'autres, le mot "lablab" signifie " jeu ", parce que les Arabes se servaient des graines pour jouer.) Vulgo : Pois-bourcoussou, pois indien. - Annuel, voluble, à tiges glabres, noires ou binchatres, seton la varieté. Feuilles pennées-trifolices, à folioles vert noiribre, rhomboüdes-ovales, stipulées : les deux latérales à lobe arrondi. Fleurs fitciculés, espactés, en grappes axillaires et terminales, allongées, pédonculies; calice campanulé, quadrifide, à lobe supérieur plus large ; étendard arrondi et muni, extéricurement, de deux callosités médianes, auriculé à la base; carène en forme de faux, et recourbée en pointe courte au sommel; style comprimé, cartilagineux el velu à l'extrémité; stigmate terminal. Cimsisesen forme de cimplerre, comprimées-envexes, muriquées sur les bords, Laminés en printe trés recourbée ou plus ou moins droite et plus ou moins longue; semences subcomprimées, pourvues d'un raphé épais et blanc. 
On rencontre trois variétés principales de cette espèce :

ж. Variété à fleurs bleues, avec des gousses bleues, longues (le bec compris) de $4-5 \mathrm{~cm}$. sur près de $2 \mathrm{~cm}$. de large, à graines noires, ovales. $\left[N^{\circ} 2651 \mathrm{a}\right.$.

3. Variété à fleurs blanches (D. albiflorus D. C., SI., 1. 113), avec des gousses également blanches el de même longueur que dans la prérédentu. $\left[N^{\circ} \cdot 2615 \mathrm{~b}.\right]$

$\gamma$. Variété avec des fleurs blanches et des gousses longues de $12-13 \mathrm{~cm}$. sur 13-14 mm. de large, blanches et rétrécies aux deux extrémités; à semences blanches ou noires. [No $2651 c$. $]$

Il existe un certain nombre de variétés intermédiaires à caractères peu constants. - Les Indiens sont grands amateurs de ce pois et c'est surtout autour de leurs cases quion les trouve cultivés. Naturalisé el abundant : Désirade, Guadeloupe et Grande-Terre. Originaire des Indes (Orientales.

Martinique. Vulgo : Pois-bourcoussou, pois-d'un-sou, pois-contour, poisCoolis, pois indien, pois-en-tout-temps. [Nos $\left.1103, \beta, \gamma_{\cdot}\right]$

Phaseolus L. (du grec " phaseolos ", canot, allusion à la forme des graines.)

P. lunatus L.; Haricol en forme de demi-lune. Desc., vol. VIII, t. 558 , p. 143. - Bisannuel ou triannuel, voluble. Feuilles pennées-trifoliées, ̀̀ folioles vert pâle, ovées, pointues au sommet; pétiole commun plus longr que les feuilles. Fleurs blanc verdatre, petites, en frappes axillaires, courtes on allongées, longruement pédonculées; calice campanulé, ¿̀ quatre dents plus longues que les bractéoles : dent inférieure, triangulaire; la supérieure, tronquée; élendard blanc, arrondi; ailes et carène verdâtres; carène en spirale. Gousses en forme de cimeterre, comprimeses, munies d'un bec a l'extrémité. - Cultivé dans toutes les Antilles comme plante alimentaire. ()n en rencontre principalement trois variétés :

ж. Variété à petites gousses, longues de $3-5 \mathrm{~cm}$. sur 11-12 mm. de large, contenant 3-í graines : c’est la pluscommunément cultivée. Tulgo: Pois-savon

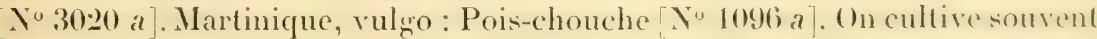

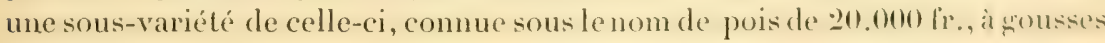
de $3-\mathbf{f} \mathrm{cm}$. de long, à 3 semences, très recherchée à cause de son exquise saveur légèrement sucrée. C’est le Phaseolus saccharatus de Matcladièn. [No.1095.]

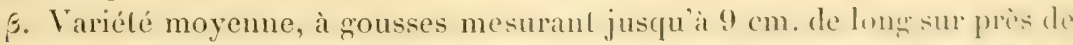

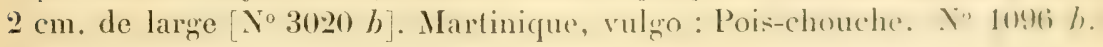

$\gamma$. Variété à gousses atteignant jusqu'à $15 \mathrm{~cm}$. de long. sur $2 \mathrm{~cm} .5$ de large,

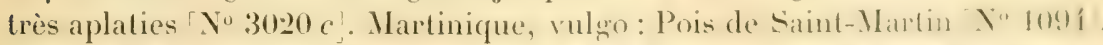
C'est le P. latisiliquus Mact. qui porte a la Guadeloupe he mom de "pois de Sainte-Catherine ". De ces trois variétés typiques, on a obtenu par la culture plusieurs variétés intermédiaires. 
P. vulgaris L., P. nanus L.; Haricot commun. Vulgo : Haricot ordinaire, haricot blanc. Sl., t. 115, f. 2, 3. - On en cultive deux variétés : une qui n'atteint pas plus de $20-40 \mathrm{~cm}$. de haut, à fleurs pourpres ou violettes, on blanches ou violacées, vulgo: Haricot-terre, petit haricot, et une autre qui grimpe, vulgo: Haricot-rame. Originaire de l'Asie et de l'Afrique; cultivé dans toutes les Antilles [No 3583]. Martinique [No 1101].

P.adenanthus Mey., P.rostrata Willd., P.truxillensis Kth., P. surinamensis Miq., P. amonus Macf.; Haricot à fleurs glanduleuses. Vulgo : Corde à violon. - Annuel, voluble, à tige et branches flexibles, enchevêtrées, haut de $0^{\mathrm{m}}$ 80-3 mèt. Feuilles pennées-trifoliées, à stipules ovées, rélléchies; à folioles ovées, pointues, stipellées : les deux latérales, inégales à la base. Fileursblanches nu violacées, en frappes d'abord courtes, s'allongeant ensuite, portées sur des pédoncules habituellement plus courts que les feuilles; calice campanulé, quadrifide, à lobe inférieur lancéolé-linéaire, aussi longr que le tube : les deux latéraux, plus courts et en forme de faucille; le supérieur, tronqué; corolle larege; étendard échancré au sommet et biauriculé it la base, quatre ou cing fois plus long que le calice; carène fortement tordue en spirale; rachis portant, à la base et au sommet, des tubérosités, restes des fleurs non fécondées. Gousses longues de 10-11 cm. sur $1 \mathrm{~cm}$. de lareve, fortement arquées, comprimées-convexes, à suture ventrale terminée par $u n$ bec légèrement recourbé; semences 10-13, brunes, comprimées, à hile ellipticque, blanchatre. - Ornemental et abondant dans les savanes et halliers de la région inférieure, jusqu'à une altitude de 500 mètres. - Fl. de septembre à mars. [No 2647.]

Martixique. Vulgo : Pois-marron. - Abondant, surtout dans les savanes du Lamentin, de la Rivière-Salée et de la Trinité. [Nº 1097.]

P. semierectus L.; Haricot à moitié droit. Vulgo : Pois-poison. - Annuel, haut de $0^{\mathrm{m}} 80-1$ mèt., à tige simple, droite dans le bas, plus ou moins penchere ou plus ou mrins voluble dans le haut: jeune tige et jeunes branches, habitullement soyenses, plus rarement glabres. Fenilles pennées-trifoliées, it lulinles fres verles, orées ou lancéolées. Fleurs caduques, pourpre foncé, an whepes axillaires el terminales, d'abord tres courtes, sallongeant ensuite it mesure que les fleurs s'ouvrent; pédoncules très longs; pédicelles très courts; calice campanulé, à cinq dents ovées-lancéolées, pointues : la supérinue, un plus courleque les quatre autres. (iousses subeylindriques linéaires,

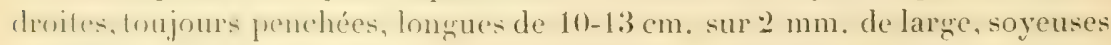
on grabres, munies d'un hre droit, de la mème largeur que la grousse et s'amincissant peu ì peu; semences 15-20. - Commun dans les terres sablonneuses, fertiles, sèches ou humides de la basse région. Alt. 0-300 mèt. [No 2616.]

Munsure. Vulgo : Pois-poison, - Tries abondant au François, dans les 


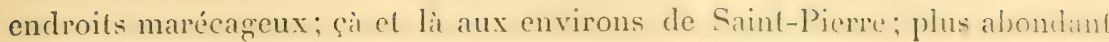
au Carbet, etc. [No 1100.$]$

Ganavalia D. C. (du mot " canavali ", emprunté à la langue indigène des îles du Sud.)

C. obtusifulia D. C., Dolichos rosens Sw.; Canavalie it feuilles obtuses : Vulgo: Pois bord-de-mer. (Dolichos L.); Desc., vol. VIII, t. 559, p. 144. Frutescent el vivace par la base, herbacé el annuel par les hranches, rampant ou grimpant, at tiges grosses, nombreuses et tres branchues; tombantes, quand elles ont pu strimper. Feuilles peméestrifolieses, à folioles coriacre-charnues, obovales, obtuses ou nettement elliptiques. Fleurs pourpre fincer, en wrappes axillaires longuement pédonculies; calice campanulé, bilobe : a livre supérieure, largement bilobée, beaucoup plus courte que le tube; l'inl'́rieure, trifide; étendard arrondi; étamines vexillaires adhérentes il la colonne formée par les autres étamines; carène courbe, obtuse. Gousses pendantes, oblongues, brièvement pédicellées et stipitées, comprimées-convexes !nnguesde $10-13 \mathrm{~cm}$. sur un peu plus de $2 \mathrm{~cm}$, de large, droites ou lémèrement arquées, munies d'un bec court, pourves de deux côtes proéminentes qui courent parallìtement ì la suture dorsale et à peu de distance d'elle; semences 3-7, oroüdescomprimées, brunâtres, polies, transversalement nichées dans un tissu cellulaire blanc. - Sur le bord de mer ou un peu à l'intérieur : entre BasseTerre et Le Baillif, Deshaies, Capesterre, Désirade. [No 2652.]

Martixique. Vulgo : Vonvon, pois-vonvon, pois-cabril, pois-Makendal. Abondant : Carbet, Case-Pilote, Fond-Canonville, Trinité, Robert, etc. $[\mathrm{N} \circ 1076$.

Cette liane couvre parfois des plages entières; la couleur très verte de ses feuilles tranche agréablement avec le sable blanc et repose les yeux; les graines sont, dit-on, toxiques et corrosives; les bestiaux sont friands des feuilles et des rameaux.

C. gladiala D. C. ; Canavalie à fruits en forme de glaive. Vulgno: Ifaricotsabre, pois-goganne. Sl., t. 114, f. 1-3. - Ornemental, voluble, bi-ou triannuel; diffère du précédent: par ses feuilles plus longruement pítiolíce. plus

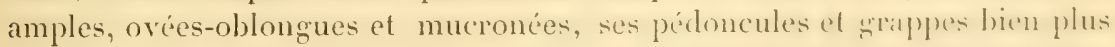

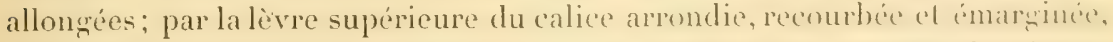
plus longue que le tube campanulé ; par sa corolle d'un ponrpere plus foncé, mais surtout par ses gousses qui peurent atteindre jusqu it $32.2 \mathrm{~cm}$. de long sur environ $3 \mathrm{~cm}$. de large et portent deux ailes ou crêtes étroiles qui courent parallèlement à la suture dorsale et it une distance de f-, mm. ; far ses graines blanches, ovoüdes-oblongues, subemprimés, trio blanches. polies, munies d'un raphé brun, elliptique. - Rare : çà et lì dans les jar-

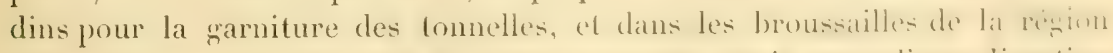
inférieure. - Les senences peuvent se manger, mais sont dine digertion 
difficile. - On en rencontre deux variétés : une à gousses recourbées, ensiformes; l'autre à gousses droites et à graines blanches ou brunes : BasseT'erre (rariété à gousses droites), Le Baillif, Moule. [No3051.]

Martiniqu : Vulgo : Pois-haricol-sabre, pois-Makendal, variété ensiformis D. C. - Saint-Pierre, Fort-de-France, Carbet, le long de la rivière (rare). [Nos $1077 \mathrm{a}, \mathrm{b}$. $]$

\section{Mucuna Ad. (nom brésilien.)}

M. pruriens D. C.; Mucune pruriente. Vulgo: Pois à gratter, pois-gratter. Br. Jam., t. 31, f. f; Desc., vol. I, t. 49, p. 221. (Dolichos L.) - Annuel, voluble, pouvant grimper à 4-6 mèt. de haut, à liges flexibles : les jeunes, toujours poilues. Feuilles pennées-trifoliées, à folioles larges, soyeuses, surtout en dessous : les jeunes, légèrement argentées, foliole terminale rhomboïde; les latérales, obliques-deltoïdes. Fleurs en grappes axillatres, simples, toujours rerticalement pendantes, longruement pédonculées: calice brièvement campanulé; quadrifide, à lobe supérieur largement deltoïde; corolle pourpre foncé; étendard ové, plié en deux, rétréci el auriculé à la base; ailes une fois plus longués que l'étendard; carène cartilagineuse au sommet et terminée par un bec recourbé; anthères monadelphes, alternativement inégales. Gousses longues de $\mathbf{1 - 5} \mathbf{c m}$. sur $1 \mathrm{~cm}$. de large, oblongues-linéaires, affectant la forme d'un $\mathrm{S}$, comprimés-lurgides, entièrement couvertes de poils roux, droits, serrés, brûlants el lragiles; semences brun noir, polies, luisantes, munies d'un raphé épais et blanc, formant un rebord autour du hile.- Quandon touche une gousse mure, les poils pénètrent sous la peau el y produisent une démangeaison trèscuisante (pui cesse, dit-on, de suite par l'applicalion de cendres chaudes. Ies mêmes poils, confits dans le sirop et administrés dans un morceau de figue banane, constiluent un des plus infaillibles remides contre les vers intestinaux : les jeunes gousses, avant de se couvrir de poils, sont comestibles. - Fl. de novembre à mars. - Très abondant dans les broussailles de la régrion inférieure de toute l'ile. $\left[\mathrm{N}^{\circ} 3019\right.$.

Martixique. Vulgo: Pois à gratter. - Abondant. [No 1081.]

M. urens 1). C. ; Mucune brûlant. Vulgo : Zieux-bourrique, żieux à boeufs, wil de bourrigue. (Dolichos J.., Negretia Tuss.) - Grimpant, pouvant monter fris haut ol convir de ses branches des arbres trìs élevés. Feuilles peméesfrifolices, al folioles ulabres en dessus, duvetées, argentées et luisantes en dessous, arrondies ol olblipues it la base, acuminées au sommet. Fleurs jaunes en "raplyes diabord courtes, axillaires, verticalement suspendues à un pédoncule long de $0^{\mathrm{m}}$ 20-3 mèt. ou même davantage, selon la hauteur de l'arbre et la disposilion deses branches; calice campanulé, à quatre dents : dent inlérieure, lanciolée, ausis longuc que le tube: la supérieure, plus courte el delloïde: 
corolle jaune, large, à étendard ové-lancéolé, à moitié aussi long que les ailes; carène cartilagineuse au sommet et recourbée en bec. Gousses longries

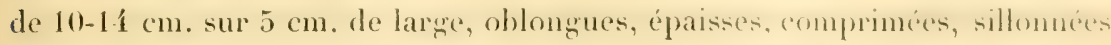
de rides el de crêtes nombreuses, irrégulières, prolondes, transversales, hérissées de poils très roux, rigides, courts, fragiles, piquants, mais nexcitant que de légères démangreaisons, surmontées d'un bee courl, rignide; condecarpe blane nacré, luisant. Graines orbiculaires, biconvexes, presque entiemement entourées par le funicule comprimé, large de $1-3 \mathrm{~mm}$. ef laissant une cannelure entre deux bandelettes brunes. - Fl. en décembre. - Rare : Camp-Jacoh) (pont de Nozières), bord de la rivière Noire, etc. [No 3568.

Martivique. Vulgo: OEil-bourrique. - Moins rare qu'ì la Guadeloupe : collines entre le Vauclin et le Marin. $\Upsilon^{\circ} 1078$. Les graines seraient amires, cependant elles peuvent se manger rôties; elles seraient diurétiques-excitantes. Les feuilles contiennent un suc colorant.

M. altissima D. C.; Mucune très élevé. Vulgo : OEil-bourrique noir, canicroc. Jacq., Sel. stirp. Americ hist., t. 182, f. 84. - Liane très élevée, à tige ligneuse, vivace : jeune tige et branches couvertes de poils rousstitres. Fenilles pennées-trifoliées, à folioles glabres, elliptiques et pointues. Fleurs en grappes courtes, pendant verticalement à l'extrémité d'un pédoncule filiformes, pourant atteindre jusqu’à 5 mèt. de long; calice soyeux, brièvement campanulé, ì quatre dents: les trois supérieures, étroites ou peu dévelopées; l'inférieure, plus longue; étendard ové-oblong, presque aussi long que les ailes : cess deux organes sont pourpre foncé; carène tachetée de vert jaunâtre. La plupart des fleurs avortent et la grappe ne contient jamais plus de 3-4 grousses, de même forme que dans le précédent, mais à crètes foliacées, formant des sillons plus profonds; semences aussi de mème forme, maishabituellement plus petites. Fl, en août et septembre. - Peu abondant: marécages du Lamentin, de Baie-Mahault ; çà et là dans les Grands-Fonds du Moule. [No 3582.]

Martmigue. Vulgo : OEil-hourrique. - Parnasse, hauteurs de la Rémale, hauteurs du Prêcheur, etc. [No 683.]

Erythrina L. (du gree " eruthron ", rouge, allusion à la couleur des fleurs.)

E. Corallodendron L.; Erythrine, arbre à corail. Vulgon: Bois-immortel vrai, Sl., L. 178; Desc., vol. IV, 1. 298, p. 305 ; Flore des Jardiniers, Amateurs et Manufacturiers, vol. II, t. 20. - Arbre le plus souvent de petite taille dans nos colonies, rarement de grande taille, à tronc noucux, souvent tortueux, trone et branches le plus souvent garnis d'épines courtes, noires,

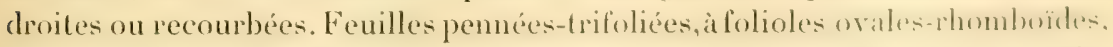
pétiolées : pétiole commun quelquelois armé de piquants: la lolishe terminate. plus grande et distante. Fleurs très belles, rouge corail, disposées par fasci- 


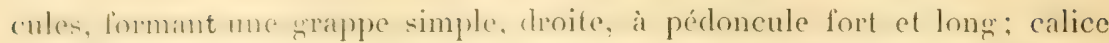
("amplanuke, lompur ou a dents pudimentaires, un peu plus court que les ailes; élendard dressé, linéaire-oblong, obtus au sommet, enriron cinq fois plus longr que les ailes et la carène; étamines monadelphes à la base. Gousses stipitées, longues de 12-14 cm., moniliformes, subcomprimées, glabres, arquées, contenant jusqu'à 12 graines, rouge écarlate, ovoïdes, luisantes, munies habiluellement d'une grande tache noire. - Fl. en mars, avril, mai. - On en fait souvent des bordures qui croissent promptement; le bois est tendre el blanchâtre, mais les vieux trones se pétrifient dans les terres argileuses, d'où le nom de "bois-immortel ». - Les feuilles et l'écorce sont,

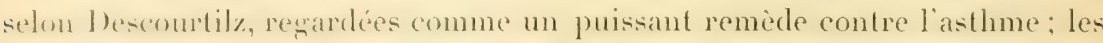
feuilles sont en outre stomachiques; les fleurs sont employées contre les maladies vénériennes. Dans le pays, on ne se sert pas souvent de cette plante dans la médecine domestique'. - Abondant, surtout dans la basse région sèche : environs de la Basse-Terre, Le Baillif, les Vieux-Habitants, PointeNoire, Meshaies, Iamentin. Grands-Fonds-du-Gozier, du Moule, Désirade, Marie-Galante, etc. Alt. 0-450 mèt. [No 3026.$]$

Martinique. Vulgo: Bois-immortel. - Assez abondant : Trou-Vaillant, Parnasse, Prêcheur, Grand'Anse, Diamant, Trois-llets, etc. [No 1082.

E. indici Iam. : Erythrine de l'Inde. Tulgo: Immortel-yrand, holocauste. - Grand arbre, à tronc le plus souvent droit, sans piquants; à branches très élalées : les inférieures, toujours penchées dans les vieux pieds; à écorce noirâtre, fortement crevassée; à rameaux armés de petites épines noires, lermes, fries dargies à la base. Feuilles pennées-trifoliées, à folioles larres, tres vertes, fermes, glauques en dessous, elliptiques-arrondies : les latérales. inégales it la base; stipules des folioles remplacées par des protubérances ylanduliformes. lileurs d’un rouge écarlate trìs vif, d'une grande beauté, en zrrappes terminales, simples, racourcies, à pédicelles très rapprochés ; calice spathiforme, lermé ì la base, supérieurement plissé en deux, aussi lonğ que la carène el terminé par 2-3 pointes linéaires, recourbées ou souvent arortés: itendard longe de 6-7 cm. sur 2 cm.5 de larexe, obovale, obtusément pointu jusquau sommet, très rétréci a la base, veiné et fortement rétléchi, près de un tiers plus long que les ailes et la carène; ailes semi-obovales, arrondies au sommet, de même forme et de même étendue que les pétales libres de la carène; étamines diadelphes : les vexillaires, plus courtes; les autres, soudiess dube dans un peu plus de la moitic de leur lonerueur, alterna-

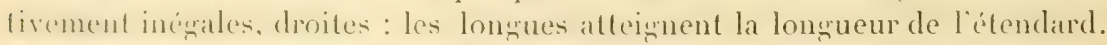

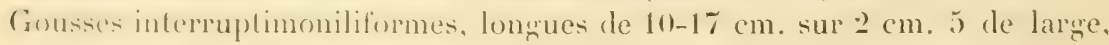

1. Cette écorce renferme (Rochefontaine et Rey) un alcălö̈de, l'érythrine, et un glycoside (lung), la migarrhine, qui en sont les principes actifs. C'est un hypnotique bien établi par les expériences de Rey; bon contre l'asthme, la coqueluche et les névralgies histéricues. (E. II.) 


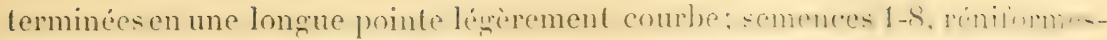
ovoïdes, longues de $2 \mathrm{~cm}$. sur 1-1, $2 \mathrm{~cm}$. de large, brunes, lisses, dures; it

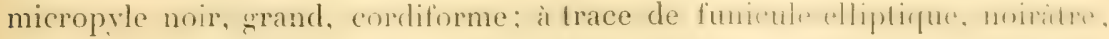
entourée d'un rebord verdâtre. - L'arbre se dépouille de ses feuilles ì l'époque de la floraison. - Fl. en avril oụ mai. - Assez abondant dans la basse région, le long des rivières et dans les falaises : environs de la BasseTerre, Jamentin, Sainte-Rose. Morne-it-l'Lau, Gozier, les Mymes. Y 31-2.).

Martinieve. Vulgo : Bois-immiortel vrai. - Environs de Saint-Pierre, Carbet, Grand'Anse, Ducos, Lamentin, etc. [No 675.

L'E. Amasica Spruce. Vulgo : Immortel jaune, arbre gigantesque, originaire de Caracas, introduit pour servir d'abri aux caféiers et aux cacaoyers ; est assez commun au Camp-Jacob, où il fleurit avec une grande abondance en février ou mai, mais ne rapporte pas de fruit [No 3724 ]; l'E. crisla-galli L., petit arbe at fleurs d'une beauté remarquable, originaire du Venezucla: est cultivé dans plusieurs jardins du Camp-Jacol), ou il theurit en mai el juin Y $\mathrm{Y}$ 376:- et au Jardin bolanique de Saint-Pierre comme dans d'autres localités de l'île. [No 1083.]

Lonchocarpus Kith. (du grec "lonché ", lance, et "karpos ", fruit, c'estì-dire fruit en forme de lancette.)

L. violaceus Kith. : Lonchocarpe a lleurs violettes. Vulgn : Bois-savomette. Dese, vol. VII, t. 522. - Petit arbre, ornemental, rarement de taille moyenne, le plus souvent tortueux, à branches très divariquées, presque toujours inclinées, à écorce grise. Fenille imparipennées, à 3-1́ paires de folioles ovales, chlabres, opposies, blanchâtres en dessous et munies de point: transparents. Fleurs violettes ou plus rarement violacées, très rarement blanches, en wrappes simples, terminales of axillaires : les dernitres. siluées à lextrémité des branches: pédicelles filitormes, sourent géminés: calice campanulé, subtronqué, environ trois fois plus court que la corolle: itendard wlabre: ailes adhérentes a la carène: étamines monadelphes sunderes en un tube dans près des trois quarts de leur longrneur. (ronswes indéhis-

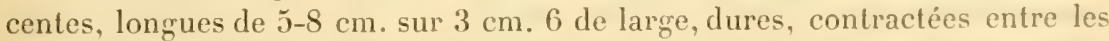
graines, pointues aux deux extrémités, concaves d'un côté et convexes du côté opposé; semences 1-3, très comprimées, beaucoup plus larges que longues, réniformes, brunes. - Fl. en juin, juillet. - Abondant sur les rochers des mornes inférieurs, secs, et dans les falaises du bord de mer. Alt. 0-200 mèt. [No 2663 .

Martinique. Vulgo : Bois-savonnelle. - Abondant : à Case-Pilote, au

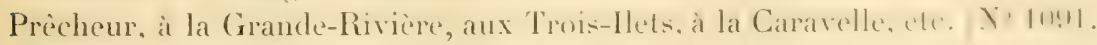

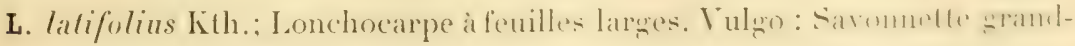
bois. - Arbre de taille moyenne, rarement de grande taille, anfractueux ì

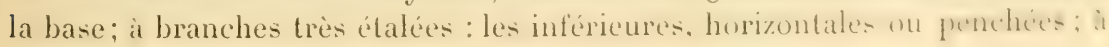




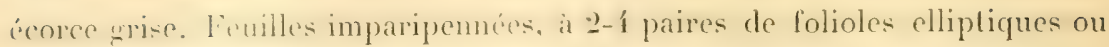
lancéolées-oblongues, pointues, blanchâtres en dessous et revêtues d'un léger duvet. Fleurs petites, blanc verdâtre, en grappes serrées, simples, terminales el axillaires; calice soyeux, tronqué ou à 3-5 dents courtes, dedtrides: chendard soveux. (iousses minces, cartilagineuses, ylabres, subsinuées, oblongues, pointues au sommet et rétrécies à la base, longues de 8-12 cm. sur environ $1 \mathrm{~cm}$. de large, contenant $1-3$ semences semblables à celles du précédent. - Fl. en mai, juin, juillet. - Assez abondant dans les bois inférieurs et le long des rivières de la basse région : Capesterre, IIouëlmont, Gourbeyre (morne Goblin), Deshaies, Pointe-Noire. Alt. 10450 mèt. $\left[\mathrm{N}^{\circ} 2665\right.$. $]$

Martixique. Vulgo: Savonnette grand-bois. - Également assez abondant: bois de Saint-Martin. Fond-Saint-Denis, hauteurs du Précheur et de la BassePointe, etc. $\left[\mathrm{N}^{\circ} 681\right.$.

L. sericeus Kth.; Lonchocarpe soyeux. Vulgo : Savonnette-rivière. Généralement arbre de taille moyenue; a trone droit. lisse on lézrèrement grepé: a branches peu nombreuses, étalées: a rameaux garnis de nombreuses lenticelles blanches. Folioles .)-9. elliptiques-ovales, coriaces, duvetées et grisâtres en dessous. Fleurs violettes en grappes terminales el axillaires; calice soveux, subtronqué: étendard soyeux. Gouses ligneuses, léxèrement sinuées el oblongues, garnies d'un duvet soyeux et gris, longues de 8-1:2 cm. sur $2 \mathrm{~cm}$. de large; semences 1-3. - Fl. en avril, mai, juin. - Çà et là dans les grands fonds marécageux du Gozier, de Sainte-Anne, du Moule, etc. $\left[N^{\circ} 3635\right.$.

Martiviqee. Vulgo : Savonnette-rivière. - Plus abondant qu’à la Guadeloupe : Trois-llets (Anse-à-l'Ane), Vauclin, Lamentin (bord de la rivière Lézard), etc. Alt. 0-150 mèt. $\left\lceil\mathrm{N}^{\circ} 685\right.$.

Piscidia I. udu latin "piscis ", poisson, allusion a l'emploi de la plante, qui sert ì prendre les poissons.)

P. Erythrina L.; Piscidie à fleurs rouges. Vulgo: Bois enivrant, bois à enivrer. Desc., vol. VIII, t. 196, p. 203; Sl., t. 176, f. 4, 5 ; Plum., édit. I3urm. 1. 23:3, f. 2-.-Petit arbre, droit, habituellement très branchu, ou souvent dans les endroits tress secs) grand arbuste, it racines traçantes produisant une masse de rejetons; dans les endroits humides, arbre de taille moyenne. Fenilles imparipennées, à 3-5 paires de folioles d'un vert très pâle, opposion, oblongues on elliptiques, pointues ou obtuses au sommet, membraneuses. Flenurs rose foncri, en panicules larges, allongées: pédicelles articulés presque au milieu; calice turbiné, à cinq dents courtes, deltoüdes; carène en forme de faucille; ailes transversalement striées, plus ou moins lacérées sur les bords, adhérentes à la carène; étamines comme dans les Lonchocarpus. Gousses indéhiscentes, comprimées, brièvement stipitées, membraneuses, 
tronquées it la base, échancrés ou rarement tronqués au sommet, Iron-uxs de 7-10 cm., remarquables par les quatre ailes, larges de $2 \mathrm{~cm}$, qui courent le long de leurs bords ; semences $2-6$, transversalement oblomgues-riniformes, comprimées. - Cette espèce perd ses feuilles à l'époque de la floraison. La plante étant toxique et narcolique', les pècheurs s̀n servon pour enirrer le poisson. Ils coupent les branches, les froissent et les brisent un peu, les lient en fagots, les mettent an fond des hassins ou des rivieres cet les charent de pierres pour les y maintenir. - Fl. en avril ou mai; l'ruits mûrs en juin el juillet. - Assez abondant dans les terres sèches, sablonneuses el pierrenses du littoral, entre la Basse-Terre et Deshaies, Marie-Galante, lessantes Terrede-Haut). Alt. 0-150 mèt. [No 2662.]

Il n'est pas indigène à la Martinique, mais se cullive au Jardin bolanique de Saint-Pierre. [No 120.$]$

Pterocarpus L. (du grec "pteron », aile, et "karpos ", fruil, parce que le fruit est entouré d'une membrane en forme d'aile.)

P. Draco L.; Ptérocarpe sanģ-dragon. Vulgo : Mangle-médaille, palétuvier. - Arbre de taille moyenne, assez souvent très grand arbre; à tronc droit; à fronde large; à branches très étendues : les inférieures, toujours plus ou moins penchées: à écorce noire, très fendillée. Fenilles imparipennées, de 5-9 folioles opposées, réticulées, membraneuses, luisantes, très vertes, oblongues, arondies ou obtusément pointues au sommet, ressemblant, dans leur ensemble, aux feuilles du caf'éier. Fleurs jaunes, en panicules courtes, nombreuses, axillaires, à pédoncules de longrueur rariable, situés à l'extrémité des branches; calice turbiné, a i) dents, pédicelles courts, pubescents: tube staminal ouvert. Fruits indéhiscents, spongieux, ruguleux, angruleuxobcortés, fortement rétrécis a la base, tronqués ou rélus au sommet, loness de f cm. sur autant de largeur; semence 1. - Fl. d'août en octobre. - Vit en société el sur une grande élendue dans les marécarges salés, ou dans les fonds inondés pendant l'hivernaye : Lamentin, les Abymes, Morne-itliau, fonds marécagreux du Gozier, de la Pointe-à-Pitre, de Baie-Mahault, de MarieGalante. [No 3027.$]^{2}$

Il croît à la Dominique, mais n'existe pas à la Martinique.

Drepanocarpus Mey. (du gree " drepanon ", faucille, et "liarpos ", linit, parce que les fruits sont en forme de faucille.)

D. lunatus Mey.; Drépanocarpe en forme de demi-lune. Vulğo : Croc-à-

1. Cette écorce est employée comme hypnotique; elle est douée de proprictés analźćsiques qui la rapprochent des Gelseminm et qu'elle derrait à la picroloxine, alcaloïde reconnu par 13ruel et Tanret. On la donne sous forme d'extrait fluide ( 3 a i gr. par jour) ou de teinture alcoolique (50 gouttes par jour). (L. H.)

2. C'est d cette plante qu'on attribue une sorte de sang-dragon, nommé sang-dragon d'Amérique, qui est d'ailleur's sans emploi jusqu'ici en Europe. 
chiens, croc-chien. Plum., édil. Burm., t. 201, 1. 2. -- Grand arbuste ou petit arbre, plus souvent tortueux que droit; à trone avec ou sans piquants; it branches très divariquées et souvent très penchées; à écorce noire, lisse; a branches et rameaux armés d'aiguillons noirs, courts, forts, droits ou

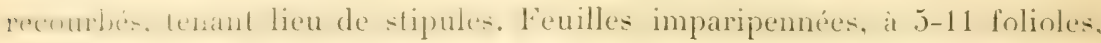
pelites. coriaces, elliptiques, très vertes et très glabres, à nervures très fines

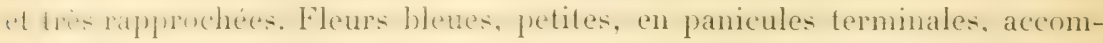
pagnées de panicules axillaires et plus petites; calice campanulé, à cinq dent- larpes a la base: colonne taminale comme dans les Pterocarpus. Fruit stipilé, réticulé-strié, aplati, ligneux indéhiscent : les deux extrémités se palphochant de maniere a former un cercle seulement interrompu par un petit sinus profond; diamètre du fruit $3-4 \mathrm{~cm}$. ; semence 1. - Fl. en avril, mai, juin ; les fruits restent longtemps sur pied. - Vit solitaire ou en société dans les mareages sales el deau douce pres de la mer: Pointe-Yoire dans les marécares d'eau douce, derriere le bourn. Lamentin le long du canal et dans les marécages $)$, Baie-1 Iahault. [Nos 3371, 3458.

Martinique. Vulgo : Croc-chien, mangle, mangle-médaille. Abondant : Lamentin, Ducos, Rivière-Salée, Trois-Ilets, Robert, etc. [N 1092.]

Hecastophyllum P. Br. 'du gree "hecastos », chacun pour soi, et "phyllon ", feuille. (cet-it-dire arbres à feuilles simples, par rapport au Pterocarpus a leuilles composées, à qui ce genre appartenait autrefois.)

H. Browni Pers.; Hécastophylle de Brown. Vulgo : Liane à barriques. Desc., vol. IV, t. 258, p. 108 ; Br. Jam., t. 32, f. 1. - Liane haute de $1^{\text {m }} 50$ A met. dabord droite, ensuite samenteuse, i écorce trise. Feuilles simples. (mbieres. glabres, vert pâle, ovées ou nrés-oblongues. pointues, léterement pubesentes et trises en dessous. Fleurs blanches, en srappes corrmbiformes, trescontes axillaires, tres nombrenses, ausi longues que les pétioles, situés tout le long des branches; calice à cinq dents courtes et inégales; étamines

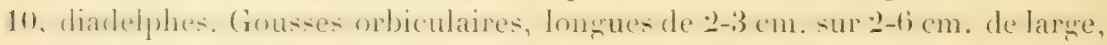
très plates, portées sur des pédicelles aussi longs que le calice; semence 1. - Fl. en août et septembre. - Sur le bord de mer et dans l'intérieur, le longr des canaux, où il vit souvent en société sur une assez grande étendue; plus rare sur le littoral sec : Vieux-Fort, Trois-Rivières, Pointe-Noire, Bonillante, Pineon. Lamentin, Sainte-Anne, Gorier, Pointe-it-Pitre, ete. [No 2658.

Mantinique, Vulgo : Liane-barrique bord-de-mer. - Assez abondant: Cats-Xavire. Fort-de-liance Marignot, Trinité Galion', Caravelle, etc. $\left[N^{\circ} 1099.\right]$

H. monetaria D. C.; Hécastophylle à fruits en forme de monnaie. Vulgo: Liane it barriques. Plum., édit. Burm., t. 246, f. 2 ; Miq. Surin, t. 5. Liane puir-ante, "rimpant ar les arbres les plus élevés; à tige d'un diamètre 
de 10-15 cm.; à branches très enchevêtrées, tombantes. Fevilles imparipennées, à 3-5 folioles alternes, distantes, ovées ou ovales, prointues. con ints,

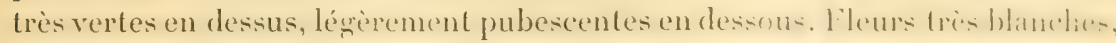
petites, en corymbes beaucoup plus courts que le pétiole commun; calice pubescent; étamines 9, triarlelphes; pédicelles plus longs que le caliere. Fruit: indéhiscents, orbiculaires, coriaces-ligneux, concaves d'un côté et convexe de l'autre, longs de $3 \mathrm{~cm}$. sur presque autant de large; semence 1. - Dans les grands bois inférieurs : Trois-Rivières (Trou-aux-Chiens), Capesterre

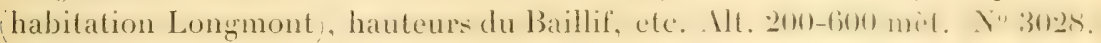

Mantrique. Vulgo : Liane-barrique. - Très abondant dans les bois du Lorrain, de la fontaine Absalon, du Champflore, de la liégale, etc. - Elle forme souvent des fourrés impénétrables. [Yo 1098.

Dans les deux colonies, on se sert des branches fendues longitudinalement pour faire des cereles de barriques.

Andira Lam. (ainsi nommé par Indigènes du Brésil.)

A. inermis H. B. Kth.; Andira sans piquants. Vulgo : Bois-olive, Lam., Ill., t. 600, f. 1.; Desc. vol. I, t. 33, p. 233; Aublet, t. 373. - Bel arbre, d'une taille moyenne, à tronc très droit, parfois muni de quelques rares piquants plus ou moins avortés. Feuilles inprapennées, à $7-18$ lonlioles opposées, elliptiques ou lancéolées-oblongues, luisantes, glabres, pourvers, à la base, d'une spinule stipulaire : pétioles secondaires, noir's. Flang's tres odnrantes, violacées ou purpurines, ou pourpre noir, en panicules terminales, laroses, pyramidales; pédicelles, pédoncules et rachis warnis d'un duvet courl, couleur de rouille; calice campanulé, subtronqué, à cinq dents courtes;

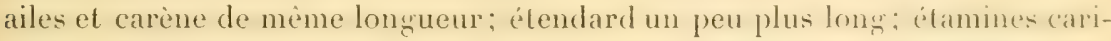
nales libres jusqu' à la base; ovaire longuement stipité, à un orule. Fruil drupacé, ovoïde, d'une longueur moyenne de $3 \mathrm{~cm}$. - L'amande est amère et a un mauvais goût. Le tronc fournit un excellent bois de construction, mais il est plus souvent employé, surtout a la Martinique, pour te charromnage. 1 Fl. en mai, juin, et aussi en décembre, janvier et février. - Peu répandu : Pointe-Noire dans le bas, le long de la rivière de la Petite-Plaine. Pigenn (le long de la rivière Lostau), etc. [No 3231.]

Martinique. Vulgo : Angelin, - A Saint-Pierre et au Carbet, on se sert du bois pour construire les carcasses des grands canots, des chalands. ete. - Plus abondant qu’à la Guadeloupe : hauteurs du Prêcheur, Carbet, Grande-Rivière, etc. [N० 1089.$]$

Dussia Kr. et Urb. (novum genus.)

1. Sous le nom degraine d'angelin, les semences de ce végétal sont employécs au lBrésil comme vermifugres; ces propriétés se retrouvent dans l'ćcorec qui serait cn outre évacuante. C'est cette espéce qui foumit, suivant toute probabilité (avec Andira racemosa Lk peut-être), l'écorce de Geofjrée de la Jamaïque. (L. H.) 
Dussia marlinicensis Kr. et Urb. Vulgo : Caconnier blanc. - Arbre de wrande taille. i fronc dront et nu jusquà une grande hauteur; à branches très ifonduns, divariquées, horiznntales el sourent fortement penchées ; à écorce lisse, très épaisse et grise; à rameaux adultes verruqueux, marqués de latres criatrices. et souvent eouverts de lenticelles; à rameaux foliilères très cpatissis. lenilles ramassées aux extrémités des rameaux: les plus longues mesurant jusyu it 35 cm. de longr. imparipennées, à 7-11 folioles opposées, ou subopposées ou alternes, longues de $9-15 \mathrm{~cm}$. sur $3-6,5 \mathrm{~cm}$. de large, dislantes, subentiores, ovales-elliptiques, brusquement pointues au sommet, sub. cordecs on ampondies, ou presque tronquées à la base: les jeunes, très ronges,

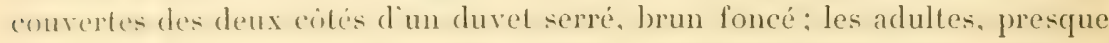
grlabres en dessus, plus ou moins grises en dessous, à nervures courbes, à rite saillante en dessous; côte. nerrures el réliculations garnies en dessous dun duret court, tres roux. Pétioles secondares, longes de 3-4 mm.; pétiole commun carémé en dessous, comprimé en dessus et garni également d'un duvet roux. Inflorescence en grappes laches, plus courtes que les feuilles, simples ou composées, axillaires et terminales : les composées portant à la base 2-5) branches distantes, de longueur variable, mais nexcédant ruère $25 \mathrm{~cm}$. de long; les axillaires, au nombre de 2-7, situées à l'extrémité des rameaux, presquau niveau des zrappes composées; calice très oblique, bossu à la base, du côté de l'étendard, à tube évasé, bilobé; à lèvre supérieure, large, deltoüde, bidentée, apprimée à lève inférieure, plus courte, it:3 dents deltoüdes, non apprimées et tournées vers le bas; base du calice entourée de 1-2 bractéoles apprimées, elliptiques, persistantes, longues de 5mm; corolle de couleur lilas, plus ou moins foncé, rarement presque blanche; clendard long de 2 cm. sur 1,5 cm. de large, veiné de lilas plus foncé, pubescent, cilié sur le bord supérieur, ovale-arrondi, et légèrement échancré au sommet, environ deux fois plus long que le calice, se rétrécissant à la base en un onglet de $4 \mathrm{~mm}$. de long; ailes étroites, ovales-lancéolées, obtuses, libres, larges de 2, 5 mm., un peu plus courtes que l’étendard, biauriculées à la base, atobesinçana, arondis l'und'eux très souvent placé plus haut, onguiculeses, i onglets filiformes-comprimés, longs de $3 \mathrm{~mm}$. et prenant naissance (nutre les denx lobes; étamines 10, dressées, diadelphes : la vexillaire, libre jusqu i la base; les autres, réunies en un tube court et fendu; calices, bractées, bracfioles, pédicelles el pédoncules garnis d'un duvet roux; pédicelles tantôt plus comrt-, fantiol phus lonss que le calice, munis, à la base, diune bractée longue d, $7 \mathrm{~mm}$. brusquement acruminées en une pointe linéaire el tronquée; ovaire couvert d'un duvet blane argenté, sessile ou très brièvement stipité, à 1-1 ovules. Gousses folliculaires, longues de $9-10 \mathrm{~cm}$. sur $2,6 \mathrm{~cm}$. de large, crlindrigues-convexes, allénuées aux deux extrémités, rouge jaunâtre en

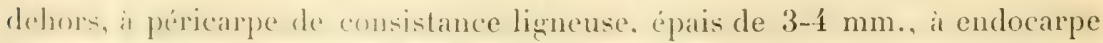
blanc: en dedans; semences 1-4, longitudinalement situées, entierement enve- 
loppées d'un arille ferme, d'un rouge vermillon l'oncé, d'une épaisseur (ì l'état frais) de près de $1 \mathrm{~mm}$., testa d'un rouge écarlate foncé, lisse, l'erme; le volume des semences est très variable : s'il n'y en a qu'une, elle est longue de 4-4,5 cm. sur $2,5 \mathrm{~mm}$. de large, ovoïde-convere, alténuée aux extrémilés: s'il y en a deux, elles sont nettement, obliquement ou non obliquement tronquées et se touchent du côté tronqué; s'il s'en rencontre trois ou quatre, celles du milieu seules sont tronquées et cela aux deux extrémités; hile blane, allongé, situé sur le côté, vers la base de la graine; funicule large, court. $\Lambda$ la maturité, le péricarpe se roule et se ferme ; les semences dès lors sont saillantes en dehors, où elles se trahissent par leur belle couleur. - Les rats sont très friands de ces graines. - Le bois est mou et blane en dedans et ne peut servir pour la construction. - Abondant dans les grands bois de Trois-

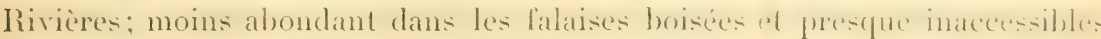
des rivières Rouge et Noire, etc. - Fl. en avril, mai fruits mûrs en août et septembre. Alt. 280-600 mèt. [No 3557 .]

Martintque. Vulgo : Bois-gamelle. - Plus rare qu'à la Guadeloupe. Çà el

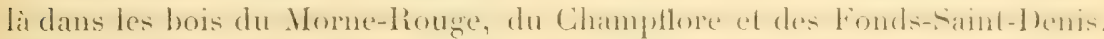
$[N \circ 1072$.

Ormosia Jacks. (du grec "ormos ", collier, chaine, allusion à la forme de la gousse.)

0. dasycarpa Jacks.; Ormosie à fruits poilus. Vulgo : Caconnier rouge. -

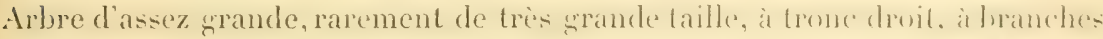

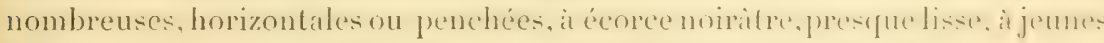
rameaux striés, garnis d'un duvel roux brun foncé. Feuilles imparipennées,

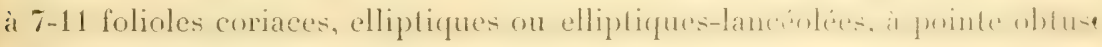
au sommet, à nervures nombreuses, parallèles, saillantes en dessous ainsi que la côte. Fleurs en panicules larges, serrées, très divisées, terminales; calice

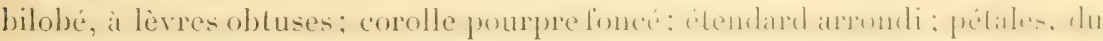
côté de la carène, soudés en un seul organe ; les autres, libres el distincts ; stigrmate latéral. Gousses déhiscentes, insérées sur un pédoncule épaissi el terminé par une sorte de cupule, longues de $7 \mathrm{~cm}$., à valves lerminées par une pointe très forte, très large à la base et obtuse au sommet, rétrécies entre les semences, s'il y en a deux; orbiculaires, convexes et longues seulement de 4-5 cm., s'il ne se rencontre qu'une graine. Gousses, calice, pédicelles, pédoncules et rachis garnis d'un duret tomenteux, brun noir. - Le bois est dur et s'emploie pour la charpente. - Çà et lì dans les bois inféricurs des Bains-Jaunes, de la rivière Noire; très abondant dans les bois de la liavine-

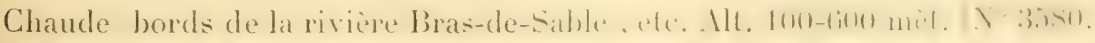

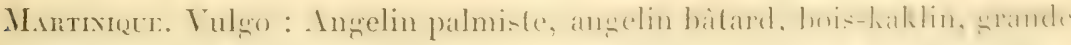
savonnette, caconnier blanc. - Assez abondant dans les bois du Champflore 
lurd de la Capmete, des Fonds-saint-Denis, de l'Ajoupa-Bouillon, de la Grand'Anse, cte. [Nos $686,1010$.

Sophora L. (du mot arabe "Sophera ".)

S. Lomentosa L.; Sophora à feuilles tomenteuses. Sl., t. 178, f. 2; Br. Jam., 1. 34, f. 1; Dese., vol. VII, t. 475, p. 95. - Bel arbrisseau, droit, haut de ? $1-2$ mil. a jerunes branches, pidoncules, pétioles, gousses, et le dessous des lemilles garnis d'un duvet cotomneux-farineux, fin, court. Feuilles alternes, impraripennéc, it 7-13 folioles vert pâle, entières, elliptiques, inégrales ì la base, roulées sur les bords, obtusément pointues au sommet. Fleurs jaunes, en panicules lemminales, allongées, pramidales; calice eampanulé, obliquement subtronqui, a jesu pres deux fois plus court que la corolle; étendard ovoüdeoblong, rétréci à la base; pétales de la carène distincts au sommel; ailes et carène de même longueur que l'étendard; étamines 8, incluses, distinctes, jurqu it la bate. (rousies longues de $8-13 \mathrm{~cm}$., longuement stipitées, nettement moniliformes, indéhiscentes, contenant 2-10 graines brun pâle, ovoüdes; ‘̀ hile bance entouré d'un rebord. - Peu répandu: dans les mornes calcaires et seres des environs du boury de la Capesterre (Marie-Galante). - Fl. de juillet à novembre; fruits mûrs en mars, avril. [ $\mathrm{N}^{\circ} 3643$.

Martinique, Vulgo: Haricot bâtard. - Rare: Rivière-Pilote (bord de mer de l'habitation Lormier-Ducanet), Caravelle. [ $\left.\mathrm{N}^{\circ} 1088.\right]$

I. Deguelia scandens Aublet (Ifisl. de la Giny., vol. II, t. 300; Lamark., IIl., t. 603), liane très belle, à feuilles imparipennées, à folioles très luisanter, a fleurs blanches, on srappes axillaires très nombreuses [ $\mathrm{X}^{0}$ 1087]; le Nissolia quinata Aubl. (Jacq., Sel. Amer. stirp. hist., t. 174, no 48), arbre-liane, it branches volubles, sétendant très loin, pourvues de vrilles, à Heurs en panicules of it fruits en forme de couteau $\left[\mathrm{N}^{\circ} 350\right]$; le Dipterix odomalas Schreb, vulgoo: Fève de Tonka, petit arbre dont les fruits, drupacés, ovoïles, d'une odeur des plus agréables, sont employés pour parfumer le linge $\left.N^{\circ} 610\right]$, constituent autant d'espèces introduites et cultivées au Jardin botanique de Saint-Pierre (Martinique).

\section{DEUxiÈne tRibu. - CAESALPINIÉES.}

Hæmatoxylon I. idu grec " haïma ", sang, et "xulon ", bois, à cause de la couleur rouge de ce bois.)

H. Campechianum L.: II'matoxylon de Campêche. Vulgo : Campêche. 'Tuss., Fl., IV, I. 36; Desc., vol. II, t. 73, p. 25. - Habituellement petit arbre dan- nos colonies, rarement srand arbre, it tronc anfractueux, a écorce grise, 
lisse, à branches le plus souvent munies d'épines. Feuilles paripennées, at :3-1 paires de folioles obovées, rétuses, coriaces, luisantes, glabres. Fleurs jaunes,

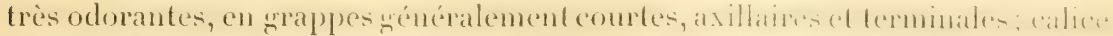
5-partite; pétales 5, presque égaux; étamines 10. Fruil long de 2-1 cm. sur $1 \mathrm{~cm}$. de large, oblong, membraneux, très aplati, rétréci aux deux extrémités, déhiscent, s'ouvrant longritudinalement sur les deux côtés, el formant alor's deux valves naviculaires, très comprimées, dont celle qui porte les graines est une fois plus étroiteque l'autre; semences 1-3, transversalement oblongrues-linéaires, très aplaties, altachées latéralement. - Fl. en avril ou mai. - Son bois est pesant, dur, résistant et élastique; il a une teinte rouge foncé el exhale une agréable odeur; il est excellent pour le chauffage; on peut en faire de beaux meubles, mais son emploi en menuiserie est assez rare. Son incorruptibilité le désigne pour les constructions souterraines; on l'emploie souvent pour faire des poteaux, des traverses de chemin de fer, des ponceaux, etc. Le bois de campêche est aussi un article d'exportation, et comme c'est le coeur qu'on utilise pour l'extraction de la matière colorante, on enlève d'abord l'aubier. En l'année 1849, on a commencé par exporter 2.500 kilog. de ce bois; ce chilfre a augmenté d'année en année, et en 1895 (annuaire colonial)il en a élé

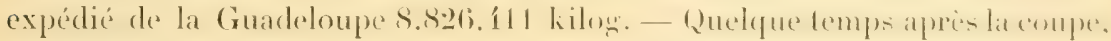
le bois noircit: si, en cet élat, on le met à bouillir dans l'eau, après y avoir ajouté quelques gousses vertes d'acacia odorant (Acacia Frarnesiana) et du jus de citron, on obtient une encre d'un beau noir. Avec le campêche, on fail souvent des haies très fortes et impénétrables, qui, soumises à la taille, deviennent très belles. L'écorce laisse exsuder une espèce de gomme rougreâtre; les feuilles sont aromatiques; le bois est stomachique et astringent ' . Naturalisé dans toutes les Intilles; abondant surtout dans lesendroits calceares de la Grande-Terre. [No3221.]

Martinique. Vulgo: Campêche. [No 1137.

Parkinsonia L. (dédié à l'Anglais John Parkinson, phamateien et directent du Jardin botanique de Hampton-Court, né en 1567, auteur du Theatrum botanicum (1629), et du Paradisus terrestris (1640)).

P. aculeata L.; Parkinsonic à piquants. Vulgo : Bois caca-rat, acacia-savane, arrête-boufs. Desc., vol. I, t. 12, p. 5t. - Petit arbre, très ornemental à cause de son lérer et singulier leuillage, n'ixedant que rarement a mi.l. de. haut, à branches presque toujours penchées et nues, à rameaux épineux, à écorce grise ou rougeâtre, et assez rude. Feuilles ramassées aux extrémités des rameaux, pennées, réunies par 1-3; pétiole commun cylindrique, noi-

1. Le bois de campêche doit ses proprićtés colorantes à un principe cristallisć quii a été isolé par Chevreul sous le nom d'hématine ou hémaloxyline. L'emploi thérapeutique de cette substance est très limitée : on l'a parfois uliliséc comme astringente cl antidiarlućique, ses usages industriels sont au contraire trés répandus. (IE. II. 
râlre, tròs court, long de 3-4 mm., s'étendant ensuite en une lanière étroite, biailée, longue de $15-25 \mathrm{~cm}$. sur une largeur moyenne de $1 \mathrm{~mm}$., et portant $26-60$ folioles très petites, alternes, longues de $2-6 \mathrm{~mm}$. sur environ $1 \mathrm{~mm}$. de large : celles du haut et du bas du pétiole réduites à de simples écailles; épines longues de $3-7 \mathrm{~mm}$., acérées, droites ou courbes. Fleurs jaunes, en crappes simples, axillaires et terminales, pédonculées; calice 5-partite; pélales 5 : les pétales vexillaires plus longs; étamines 10; ovaire sessile.

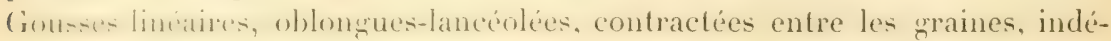
hiscentes, longues de (y-1:3 cm. : semences 1-5. oblongues, obtuses aux extrémités, situées longitudinalement. - Fl. presque toute l'année. - On les plante quelquefois en allées, souvent on en fait des haies. - Çà et là sur le hord de mer ot un peu a lintérieur : I.e Baillif, Deshaies, Sainte-Amne, ele. $\left[N^{\circ} 2624\right.$.

M.nmtinique. Vulgo : Arrête-bocufs. - Case-Pilote, Marin, Vauclin, etc. [No 1138.

Guilandina L. délie au Prussien Melchior Guilandinus (Wieland), qui, en 1559 et 1560 , entreprit un voyage en Orient, ou il fut pris par les pirates. Après sa délivrance, il devint professeur à Padoue, mort en 1590; a laissé des écrits sur la botanique.)

G. glaher Mill. : (ruilandine a leuilles grlabres. Yulgo: Zieux-chat, nil-dechat. - Arbrisseau sarmenteux, entièrement couvert d'épines courtes, très acérées, jaunâtres ou brunes, droites ou courbes, longues de 2-4 mm., à maneaux remplis de molle blanche. Fenilles larges, paripennées a 3-6 paires de pennes, portant i jatres de folioles, brièvement pétiolées, elliptiques ou

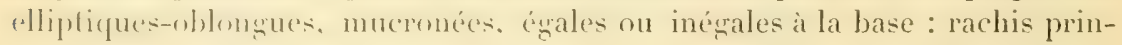
cipal, strié; rachis secondaires, garnis d'un duvet roux; stipules 2, très lareses, profondement ef irrérulierement tri-quadrilobees, arrondies, souvent dentés ed at dents termine's par une spinule droite. Fleurs jaune brun,

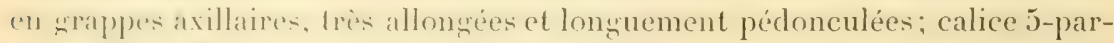

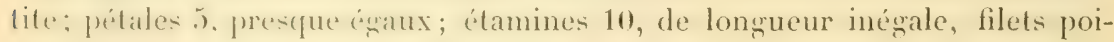
lus dans le bas. Gousses déhiscentes, s'ouvrant en deux valves, ovées-

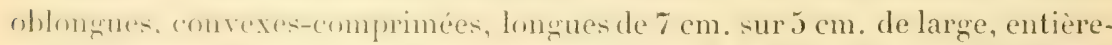
ment hériscres te spinules rigides; semences 1-f, subglobuleuses, grises, osseuses, luisantes, polies, attachées à un funicule droit, court, filiforme;

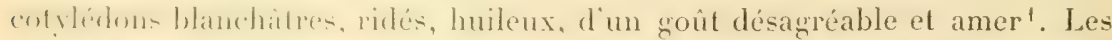
maine -rut loin de remplir les gonses, et y restent longtemps attachées;

1. Il est probable que cette graine et celle de l'espéce suivante jouissent des mêmes proprićtés fébrifuges et du même principe actif (bonducine) que celles des Guilandina

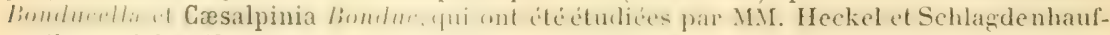
en (journal Les Nouveaux Remèdes, 1886), et oủ ces auteurs ont découvert la bonducine. (E. II.) 


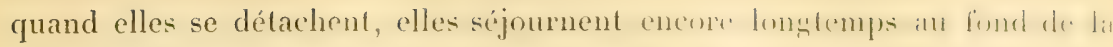
gousse : alors si le vent agite l'arbrisseau, elles roulent dans l'intérieur de ces gousses et produisent un bruil étrange. - Fl. de septembre en janvier. -

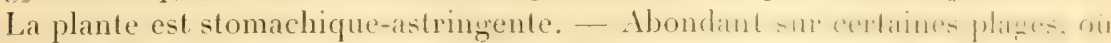
il forme souvent des fourrés impénétrables: bord de mer entre la Basse-

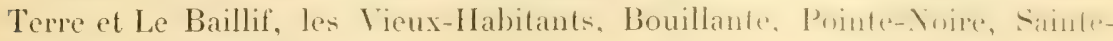
Anne, elc. [No 3046.$]$

Martineue. Vulgo : OEil-de-chat, zieux-chat. - Abondant: Fond-Canonville, Marin, Sainte-Anne, 'Trinité, etc. [N 1136.$]$

G. Grisebachiana Kr. et Lrb., Guilandine de Griseluach. Vuluo : Canique. jaune. - Ressemble au précédent par le port, les feuilles, les llemen al par lit forme des gousses; il en differe par ses folioles plus pelites, plus incinales il la base; par ses gousses moins épineuses el munies, pris de l'extrémité supurieure, d'un bec corné, fort, recourbé, et par ses graines jaunes. - Plus rare que l'autre. Çà et là sur le bord de mer et dans les mornes pierreux avoisinant la mer: Désirade (les Galeds et mornes calcaires au-desius du lisurir. Marie-Galante (Capesterre), Sainte-Anne, etc. [No30 15.$]$

Martixique. Vulgo : Canique jaune. - Trois-llets, Marin, Vauclin. $[N \circ 1136$.

Cæasalpinia L. dédié à l'Italien And. Cersalpini, 1.519-l60)3, né à Irezzi, professeur de médecine et directeur du Jardin botanique de Pise, médecin du pape Clément VII; a publié une classification des plantes, d'après les fleurs et les fruits.)

C. sepiaria Roxb.; Cresalpinie des haies. Vulgo : Arrête-boufs. - Arbrisseau ornemental, sarmenteux ou tortueux, quand il ne trouve pas d'appui, à écorce noirâtre ou grise, a lige, branches ef pétioles garnis de piquants aceris.

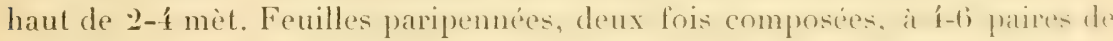
pennes, portant 8-12 paires de lolioles, petites, oblongues, limirement duretées et blanchâtres en dessous, arrondies au sommet, à pétiolules courts; rachis à piquants crochus et plantés à rebours; stipules semi-sagittées. caduques. Fleurs jaunes, larges, en grappes simples, nombrenses, dresines. axillaires et terminales; calice à tube turbiné, vert, persistant, à 5 lobes

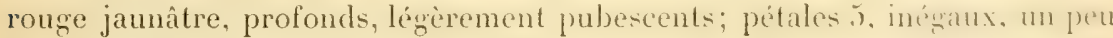

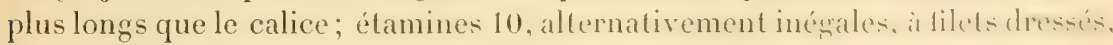
exserts et laineux dans leur tiers inférieur; stigmate épais, concare; pédi-

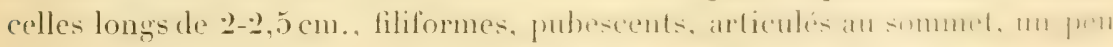
plus cours que la fleur. Gousses déhiscentes, longues de 7 cm. sur environ $2 \mathrm{~cm}$. de large, glabres, convexes, ligneuses, arrondies aux deux cxtrémilés, droites, terminées par un bec dur el droit; semences 6-7, ovoïdes, panachées de jaune pâle sur fond brun. - Fl. de novembre ì février, - Orighinare 
des Indes Orientales; introduit aux Antilles pour la formation de haies. - 1 Naturalisé et abondant dans la basse et l'infra-moyenne région de la Guadeloupe el de la Grande-Terre : environs de la Basse-Terre, Le Baillif, Deshaies, Sainte-Rose, Moule, Sainte-Anne, etc. Alt. 0-600 mèt. [No 2628.]

Mantrinque. Yulgo : Arrête-boul's, - Abondant dans toute l'île. [No 1139.

G. pulcherrima Sw.; Casalpinie la plus belle. Vulgo : Baraguette. Desc., vol. I, 1. 6, p. 27. - Arbrisseau omemental, à cause de son port et de ses fleurs, droil, haut de 2-4 mèt., rarement plus haut, quelquefois plus ou moins tortueux, le plus souvent dépourvu d'épines ou garni de piquants à moitié avortés. Feuilles larges, paripennées, deux fois composées, à 5-9 paires de pennes, portant 5-10 paires de lolioles oblongues ou spatuléesoblongues, arrondies au sommet, finement mucronées. Fleurs larges, en stappes simples. droiles pyamidales, longues souvent de $35 \mathrm{~cm}$., axillaires el terminales : ces dernières, toujours plus longues : les axillaires, situées près des terminales, toutes longuement pédonculées; pédicelles inférieurs

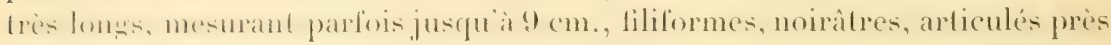
du sommet; calice tubuleux, turbiné, persistant, à 5 lobes profonds, de même couleur que les pétales; corolle large, jaune ou jaune pourpre; pétales 5 , frangés ou lacérés sur les bords, près d'un tiers plus longs que le calice; étamines exsertes, pourpre foncé, filiformes, trois fois plus longues que la corolle. Gousses noires, longues de 11-12 cm. sur 11-13 mm. de large, très aplaties, légèrement obovales, obliquement arrondies au sommet, avec une pointe rigide, droite, terminant la suture dorsale; semences 8-10, ovoïdescomprimées, nichées dans un tissu cellulaire peu abondant. - Fl. de juillet à février. - Dans nos deux colonies, les fleurs sont fréquemment employées conme un des meilleurs et des plus puissants emménagogues. - Assez abondant dans la basse et l'infra-moyenne région de l'île. On en rencontre deux variétés : une à fleurs jaunes, l'autre à fleurs jaune pourpre. [ $\mathrm{N}^{\circ}$ 2623.]

Martingue. Vulgo: Macata jaune, fleur de paon, willet d'Espagne. Abondant. - On en fait souvent des haies. [No 1033.

Poinciania I. (Princlia Neck.) dédic par Yecker à lich. de Poiney, wouverneur général des îles Prançaises sous le Vent (1617-1660), qui a laissé des écrits sur l'histoire naturelle des Antilles.)

P. regia Boj.; Poinciane royale. Vulgo : Flamboyant, grand flamboyant. - Arbre ornemental, de taille moyenne, approchant de la grande taille; à tronc assez, souvent tortueux, très anfractueux; à branches très étalées, horizontales; i rameaux penchés; à racines traçantes, superficielles, très étendues; in fleurs très larges, rouge vermillon, d'un elfet merveilleux; à pétale postérieur, beaucoup plus large et plus long, panaché de vermillon sur fond blanc; en grappes très nombreuses, terminales, racourcies, pédonculées; à gousses déhiscentes, mesurant jusqu'it $50 \mathrm{~cm}$. de long sur $7-8 \mathrm{~cm}$. de large 


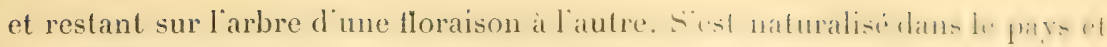
dans toutes les Antilles. - Fl, en mai ou juin, ou juillet, selon la saison. Originaire de Madagascar. [No 2628.$]$

Martinique. Vulgo : Flamboyant. [No 1135.$]$

Le Lebidibia coriaria Schlecht. Vulgo (par corruption! Dividivi : arbere dont les gousses sont très riches en tanin; est cultivé au Jardin bolanique de Saint-Pierre et sur plusieurs habitations de l’ile. Il est orisinaire du Mexirgue. [No 1134.]

Cassia L. (du mot " kassia ", de Dioscoride; de " cassia », de Pline, par lequel il désigne l'écoree du Laurus Cassia de Limné, probablement rapportí par erreur à ces Légumineuses.)

C. fistula L.; Gasse fistuleuse. Vulgo : Canéficier, casse-habitant. 'Tuss., Fl., IV, t. 2; Desc., vol. II, t. 125, p. 231. - Petit arbre, rarement arbre de taille moyenne, à branches inférieures horizontales, d corce ferée dans les vieux pieds. Feuilles paripennées, plus rarement imparipemées, a t-9 paires de folioles, larges, opposées, ovées-oblongues, nettement pointurs an arrondies au sommet, glauques en dessous. Fleurs larges, jaunes, en grappes lâches, simples, d'abord dressées, ensuite verticalement pendantes, longurus de 15-45 cm., pédonculées; calice it 5 sépales inézaux, ovales, subdistincts, caducs; pétales inférieurs plus grands; étamines 10, dont 3 beaucoup plus longues et fortement courbées en avant; anthères grandes, ovéesoblongues, souvrant, a la base, par deux pores. Gousses incléhiserntes, cylindriques, droites, pouvant atteindre jusqu'ì $50 \mathrm{~cm}$, de long sur un dianetre de plus de $2 \mathrm{~cm}$., verticalement pendantes, divisés, à l’intérieur, en cluisons parallèles, transversales, rapprochess: semences cordiformes, aplaties, dures, nichées dans une pulpe noire. - Fl. en avril ou mai. - Originaire de l'Égypte et des Indes Orientales; naturalisé dans toutes les Antilles. - La pulpe est acide el s'emploie fréquemment, dans le pays, comme laxative et purgative. On en prépare aussi des confitures. - Alt. 0-250 mèt. [No 3061 . ]

Martinique. Vulgo : Canéficier, canéfice. [No 1114.]

C. bicapsularis I.; Casse à double capsule. Vulgo : Sou marqué, canélice bâtard. Plum., éd. Burm., t. 76, f. 1. - Arbrisseau sarmenteux, ou petil arbre, droit, haut de 3-f mèt., très rameux, a branches llexibles, allongters, cylindriques, striées, toujours pendantes a l'extrémité, à écorece lisse el prise. Feuilles alternes, paripennées, à 3-1 paires de folioles, shlabres, suluchammen. glauques en dessous, moins glauques en clessus, obovales ou ovales, arrondies ou échancrées au sommet: celles de la paire inférieure, rondâtres; pétiole commun portant, entre toutes les folioles ou seulement entre les folioles de la paire inférieure, une glande noire. Fleurs jaunes, en grappes

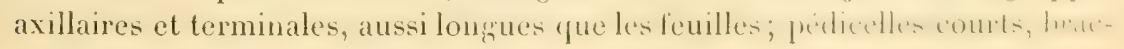


téolés; étamines 10, dont 7 fertiles. Gousses longues de $9-12 \mathrm{~cm}$. sur $1,2 \mathrm{~cm}$. de diamèt., stipitées, subcylindriques, toujours pendantes, déhiscentes le long de la suture, obtuses au sommet, divisées intérieurement en deux par une cloison longitudinale et incomplète; semences très nombreuses, situées transversalement et nichées dans une pulpe brune, légèrement sucrée et comestible. - Hl. de septembre à février. - Assez abondant dans les halliers, les falaises et endroits abandonnés de la région inférieure : environs de la Basse-Terre, Vieux-fort, Le Baillif, les Vieux-Habitants, Deshaies, PointeNoire, Moule, Morne-ill'Lau, Gozier, Désirade, Marie-Galante. [Nos 2624, 311?.

M.ırtingue. Vulgo : Sou marqué, canéfice bâtard, casse-hallier. - Aboudant dans toute l'île, jusqu'ì une élévation de 300 mèt. [No 1115.]

C. emarginata L.; Casse à feuilles échancrées. Vulgo : Casse-savane. Grand arbuste, peu élégant : très touffu, quand il est jeune; à lige et branches nues, haut de 3-4 mèt., à l'âge adulte, à rameaux striés : à jeunes rameaux, noirâtres et pubescents. Feuilles paripennées, à 2-5 paires de lubioles ovales-ublongues, poinlues ou le plus souvent émaryinées au sommet, pulusentes al rousteitres en dessons; pétiole commun sans glandes; stipules courtes, séliformes. Fleurs jaune chrome assez foncé, en grappes corymbiformes, axillaires et terminales, plus courtes que les feuilles; étamines 10 , dont 3 stériles. Gousses longues de 21-28 cm. sur $1 \mathrm{~cm}$. de large el de 1-2 mm. d'épaisseur, noires à la maturité, jaunes avant d'être mûres, toujours verticalement pendantes, droites ou légèrement arquées, fortement et uniformément aplaties, à rebords relevés; semences transversalement situées, obovales, brunes, luisantes. - Fl. en février et mars; perd les feuilles à l'époque de la floraison. - Exclusivement propre au terrain sec, pierreux, calcaire, chaud, près de la mer. Abondant sur la côte entre Le Baillif et Deshaies, MarieGalante, les Saintes (Terre-de-Bas). [No 2620.]

Il n'existe pas à la Martinique.

C. glanca Lam., C. planisiliqua Lam.; Casse à feuilles glauques. Vulgo :

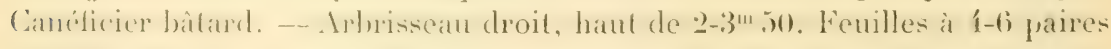
defolioles, lamess ovales-ol)longutes ou ovales, obtusiment pointues, glauques (2n destens; fundes ovoüdes, lareses, entre chaque paire de lolioles; slipules

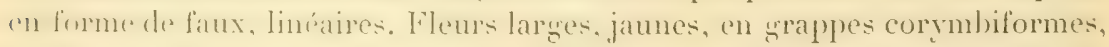
ariltaires of tomninales, longuement péfonculées. Gousses longues de 12$1: \mathrm{cm}$. sur 10-1:3 mm. de large, extrêmement aplaties, sensiblement plus larges au sommet qu'ì la base, lerminées par une longue pointe, transversalement imprimées entre les graines et marquées d'autant de lignes relevées el droites qu'il y a de semences; semences de 20-25, oblongues, très comprimées. - T'rès rare. 'Trouvé une fois dans les hauteurs de Saint-Joseph. [No 1116.$]$ - Je ne l'ai pas vu à la Guadeloupe. 
C. glandulosa L.; Casse glanduleuse. Vulgo : Zinting, gros balai. -

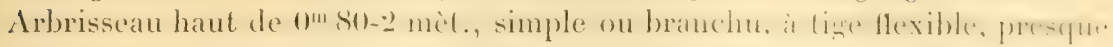
toujours penchée au sommet. Feuilles ovales, à $5-14$ paires de folioles obovales ou oblongues, très minces, finement mucronées au sommel, arrondies à la base, petites, presque sessiles; pétiole commun portanl 1-3 glandes stipitées, arrondies, diversement placées; stipules très pelites, sétiformes ou lancéolées-acuminées, subulées. Fleurs jaunes, le plus souvent disposées par

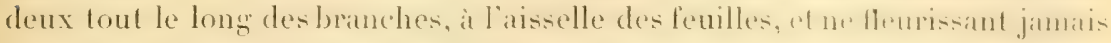
en même temps; pédoncules filiformes, plus courts que les feuilles; calice 5-partite, à lobes lancéolés-acuminés, dont 2 falcilormes; pétales inégraux, plus longs que les lobes du calice. Gousses longues de $3-3 \mathrm{~cm}$. sur $3 \mathrm{~mm}$. de large, obovales, habituellement glabres, terminées en pointe recourbée. - Très abondant dans toutes les savanes, les haies el les broussailles de la base ef de: la moyenne région, où il vit souvent en société sur une grande étendue. Alt. $0-700$ mèt. [No 2627.

Martivique. Vulgo: Diotine, balai-savane. - Abondant dans toute l'île. [No 1117.$]$

C. multijuga Rich.; Casse à multiples paires de folioles. Vulgo : Cané-

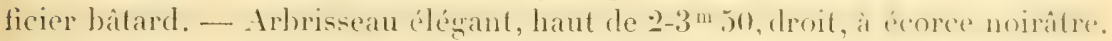

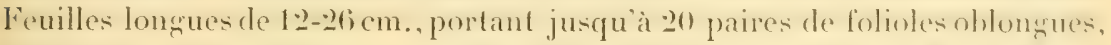
mucronées-obtuses, glauques en dessous; pétiole commun muni d'unc wande cylindrique entre la premiere paire de folioles. Fleurs jaunes, larues en panicules terminales et axillaires: les dernières, situées dans le voisinage des terminales. Gousses longues de $9-13 \mathrm{~cm}$. sur 12-15 mm. de large, oblongueslinéaires, noires, unies, lisses, très aplaties, droites, presque tronquées au sommel, are une pointe courte. émoussé, ondules sur les bords, imprimés transversalement entre les semences aplaties. - Originaire de la Guyane et cultivé autrefois au Jardin botanique, d'où il s'est répanclu dans le pays: environs de Saint-Pierre, Trou-Vaillant, Fort-de-France Marisoti. X"zlls. - Il n’est pas à la Guadeloupe.

C. ligustrina L.; Casse à feuille de Troëne. Vulgo : Sené-zombi. Desc., vol. II, t. 134, p. 273. - Arbrisseau haut de 1-1,50m. ou grand arbuste haut

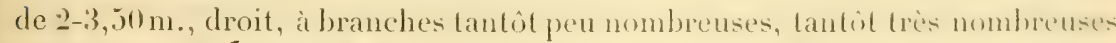
el inclinées. Feuilles a j-8 paires de folioles lancéoleses, acuminérs, habiturl-

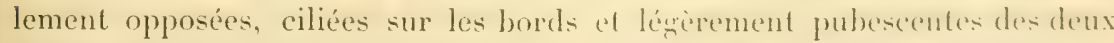
côtés; pétiole commun pourvu d'une glande ovoïde au-dessus de sa base. Fleurs jaune pâle, en corymbes terminaux. Gousses ressemblant extérieurement à celles du C. bicapsularis, longues de 9-10 cm., légèrement arquées, glabres, sessiles, terninées par une pointe obtuse et droite, déhiscentes le

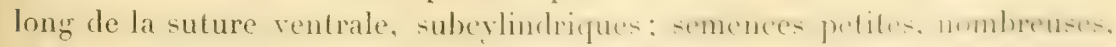
obovoüdes-comprimées, nichées dans une pulpe blanchâtre peu copiense, - 
Assez rare. Cai et là dans les savanes et endroits incultes ou abandonnés : (iourbere, Baire-Mahault (quai de l'embarquement), environs de la BasseTerre (habitation l'Espérance). [ $\mathrm{N}^{\circ}$ 2622.]

Martinique. Vulgo : Canéfice bâtard, casse-savane. - Peu abondant: chvirons de Saint-Pierre Trou-Yaillant), Carbet (habitation Crassous), Lamentin (environs du bourg). [ $\mathrm{N}^{\circ} 1835$.

C. alala L.; Casse à fruits ailés. Vulgo: Dartrier, herbe à dartres. Sl., t. 175, f. 2; Desc., vol. VI, t.445, p. 263. - Sous-arbrisseau, souvent annuel, et bisannuel, haut de $0^{m} 9\left(0-1^{m} 40\right.$, rarement presque arborescent, haut de $3^{\mathrm{m}} 50$, plus ou moins tortueux, branchu, à feuillage vert jaunatre. Feuilles larges, ì 6-14 paires de folioles oblongues, arrondies ou réluses au sommet, subtronquées a la base, subsessiles : celles de la dernière paire, plus petites, disfantes des autres el très rapprochées de la base du pétiole commun, qui est triangulaire el dépourvu de glandes. Fleurs jaune vif, en grappes simples, rarement composées à la base, terminales, très denses, un peu plus courtes que les feuilles, longues de $20-35 \mathrm{~cm}$.; bouton de la fleur à moitié enfermé dans une bractée naviculaire, large, obovale, souvent lacérée sur les bords, tombant arec l'éclosion de la fleur. Gousses tétragones, longues de $12-16 \mathrm{~cm}$., noires, droiles, mueronées au sommet, longiludinalement quadriailées, à ailes larges, crénelées sur les bords; semences nombreuses, brunes, trigones, comprimées, pourvues, des deux côtés, d'un aréa, sćparées par des fausses cloisons. - Fl. en avril, mai. - Toute la plante exhale une odeur forte et désagréable. - Avec les jeunes feuilles et les fleurs, on prépare dans le pays un onguent contre les dartres et les maladies de peau; le suc des feuilles, pilées el délayées clans l'eau, constitue un excellent gargarisme contre les maux de gorge' - - Assez abondant dans les endroits marécageux ou aquatiques ou humides et le long des ruisseaux : Pointe-Noire, Sainte-Rose, Lamentin, environs de la Pointe-à-Pitre. Alt. 0-350 mèt. [No 3224 .]

Martinique, Vulgo: Dartrier, casse puante, casse ailée. - Un peu partout, sans être abondant nulle part : Rivière-Salée, Anses-d'Arlet, Ducos, Robert, etc. $\left[\mathrm{N}^{\circ} 1119\right.$.

C. hirsula L.; Casse hérissée de poils Vulgo: Sou marqué poilu. Annuel, droit, haut de (1m 81)-1"m30, entièrement garni de poils fins, gris, couchés, plus ou moins longs, qui disparaissent sur la tige adulte; à jeunes branches, anguleuses-striées. Feuilles a t-6 paires de folioles, successivement plus grandes, elliptiques on clliptiques-oblongues, acuminées, de consistance molle: pitiole commun sarni d'une gollande cylindrique au-dessus de sa base;

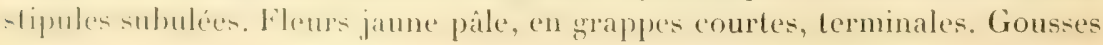

1. La poudre de feuilles de Cassia alata est le remède par excellence contre l'herpès circine, affection si commune dans nos colonies chaudes et en particulier dans celles de l'Extrème Orient. On en saupoudre la partic malade. (E. H.) 
longues de 11-14 cm. sur 4-6 mm. de large (j’ai des spécimens de gousses qui ont $32 \mathrm{~cm}$. de long), marginées, comprimées-convexes, déhiscentes; semences ovoïdes, brunes, séparées par des fausses cloisons. - Peu abondant. Çà et là dans les champs incultes et abandonnés de la région inférieure : environs de la Basse-Terre, Vieux-Fort, Trois-Rivières, etc. Alt. 10-250 mèt. [No 3048 .

Martinique. Vulgo : Herbe puante, herbe puante bâtard. - Un peu partout, sans être abondant nulle part. [Nos 829 et $829 \mathrm{~b}$.]

C. occidentalis L.; Casse des Indes Occidentales. Vulgo : Herbe puante, casse puante, pois puant. Desc., vol. II, t. 135, p. 277. - Annuel ou bis-

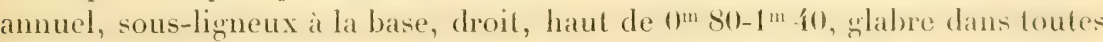
parties, à tige sillonnée, verdâtre. Feuilles imparipennées, à 7-11 folioles ovales-lancéolées ou lancéolées, acuminées; pétiole commun pourvu d'unc glande ovoïde près de la base. Fleurs jaune pâle, en grappes courtes, làches: pédicelles bractéolés. Gousses longues de 10-12 cm. sur 5-7 mm. de large, arquées, comprimées-convexes, déhiscentes, mucronées au sommet, marginées; semences ovoïdes, brunes, dures. - Abondant dans toutes les natures de terrains de la basse et de l'infra-moyenne région de toute l'île. - Les fenilles exhalent une mauvaise odeur; elles sont dépuratives, purgatives et légrèrement sudorifiques; les racines, infusées dans l'eau tiède, sont employées contre les maladies de peau, contre les enflures des jambes; les semences sont fébrifuges et emménagogues '; torrifiées, elles peuvent remplacer le café; elles calment, comme la fève d'Arabie, les crises d'asthme, les oppressions et les maux d'estomac. Alt. 0-500 mèt, [ $\mathrm{N}^{\circ} 3225$.

Mantinique. Vulgo: Café bâtard, herbe puante, pois puant, - On rencontre une variété à feuilles velues. [No 1120.$]$

C. obtusifolia L.; Casse à feuilles obtuses. Vulgo : Séné, sou marqué, sous marqué bâtard. Sl., t. 1:5, f. 5; Dill., Eltham., t. 63, f. 73. - Annuel, droit dans le bas, penché au sommet, sous-ligneux à la base, haut de $0^{\mathrm{m}} 50$ (1) 95, rarement plus. Feuilles a $2-3$ paires de lolioles, subcharnues, wlauques en dessous, nettement obovées, mucronées-arrondies au sommet, souvent munies d'un liséré vert foncé sur les bords, cunéiformes à la base; pétiole conmun garni d'une glande conique, stipitée, entre la paire inférieure el quelquefois entre les deux dernieres paires de folioles; stipules longnes, ciliées,

1. MII. Heckel et Schlagdenhauflen ont publić dans les Archives de médecine navale (1886), sur cette espéce tropicale ubiquiste, un mémoire détaillé démontrant ses proprićtés fébrifuges. L'emploi de cette plante réussit nieux que la quinine dans certains cas spéciaux de fièrre rebelle. - La graine, sous le nom de café nègre, cafia, s'est introduite largement dans la consommation européenne, où elle est très demandée pour être mêlée ou substituée au vrai café; à cet égard, elle pourrait faire l'objet d'une culture très rénunératrice dans nos Antilles françaises. Elle est couramment employéc par les peuplades de la côte occidentale d'Afrique, ì titre de fébrifuge, sous les noms de m' bentamiré ou fedegosa. (E. II.) 
linciares-riblests caduques. Fileurs jaune pile, en grappes corymbilormes, terminales et axillaires, réunies par 2-3. Gousses cartilagineuses, glabres, aryures. limproment mucronces linkiares, comprimées-télragones, longues de 11-16 cm. sur 2-3 nm. de large, à bords fortement relevés; semences brunes,

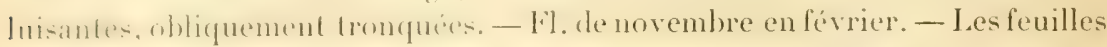
sont souvent employées comme sudorifiques. - Très abondant dans les pmbrots difriches, dans les savanes herbeuses. le loner des routes, autour des maisons, sur les décombres, etc., de la région inférieure. Alt. 0-600 mèt. [N०3047.]

MArtinique. Vulgo : Sou marqué. - Très abondant. - On en emploie les fenilles en infusion, aussi bien que celles du G. bicapsularis, pour aider à la dentition des enfants. $\left[N^{\circ} 824.\right]$

G. nicticans L.; Casse clignotante. Vulgo : Balai-savane, acacia-balai. Innuel ou bisannuel, suffrutescent à la base, infléchi au sommet, laut de f1-7) (m., habituellement sans branches: la partie supérieure de la lige, les putioles, les stipules el les gousses sont gramis de duvet. Feuilles ovales, à 1.2-1s paires de foliolesobliques a la base, oblongues-linéaires, mucronulées ef fuliformes au sommel, penninerviées, très brièvement pétiolées, à pétioles nniratres; pétiole enmmun garni d'une ghlande tronquée, au-dessous de la paire infericure des folioles; stipules appliquées contre le pétiole, lancéoléesacuminées, obliques à la base. Fleurs jaunes, axillaires, réunies par 3 à laisselle des feuilles, quatre à cinq fois plus courtes que les feuilles. Gousses longues de $3 \mathrm{~cm}$. sur :3 mm. de larare, arquées, comprimées, imprimées entre les graines, munies, au sommet, d'un petit mucro; semences aplaties, obliquement obovoïdes, tronquées au sommet. - Cette herbe, quand elle est jeune et tendre, constitue un bon fourrage. - Vit en société dans les savanes herbeuses, le long des routes : Camp-Jacob, Gourbeyre, Montéran, Troislivières. Iamentin (Ravine-Chaude el savanes voisines), Sainte-Rose, etc. Alt. 50-700 mèt. [Nos 2625, 3060.]

Martingte. Vulgo: Petil balai-savane, petite diotine. - Abondant : savane entre Case-Pilote et Fort-de-France, Lamentin, Ducos, Robert, etc. [No 1121.]

NoтA. - La plupart des casses, surtout les C. bicapsularis, obtusifolia, niclicans el ylandulosi, ont des feuilles mobiles qui se ferment pendant la nuit, et quand il pleut durant le jour.

1. Cassia spectabilis 1). (., arbre d'assez grande taille, a fleurs jaune vif, en panicules larges, dressées, à gousses pendantes, est cultivé au Jardin botanique de Saint-Pierre et sur quelques habitations de l'île : sa patrie est le Mexique. [No 826.]

Tamarindus L. (de l'arabe " tamar ", datte, et "hindi ", indien, c'est-à- 
dire datte de l'Inde, nom que domnerent les drabes aux lruits du lamarinior. lorsqu'ils les virent pour la première fois.)

T. indica L.; Tamarinier de l'Inde. Vulgo : Tamarinier. - Grand et bel arbre, généralement très branchu, à fronde arrondie, à tronc droit, anfractueux, surtout dans le bas, à écorce grise, fortement feudlillé at crovassie, it racines traçantes et fortes. Feuilles paripennées, de 10-1s folioles oblongues, glauques des deux côtés, légèrement échancrées ou arrondies au sommet; pétiole commun épaissi et noir à la base. Fleurs légèrement odorantes, en grappes courtes ou plus ou moins allongrées, axillaires et frminales : les axillaires, toujours pendantes; calice à tube turbiné, quadripartite, ¿ segments blanc jaunâtre, d'inégale longueur, fortement repliés et appliqués contre le pédicelle, après l'ouverture de la tleur; pétales 3 , à moitié ouverts, les 2 latéraux de même grandeur, panachés-striés de rose brun et crépus sur les bords : celui du milieu, dressé, plus étroit et plus court, naviculaire, plus crépu et plus coloré; étamines fertiles 3, rarement 2, monadelphes, subulées, divergentes, ascendantes, soudées à la base, sur une étendue de 3-1 mm. : partie soudée, large, comprimée, munie, souvent, de petilesdents: les autres étamines, nulles ou avortées, on rudimentaires; ovaire stipité, gynophore adné au tube du calice; style subulé, légèrement tordu et barlun d'un côté. Fruits indéhiscents, long de $11-15 \mathrm{~cm}$. sur une larôneur moyenne de $2 \mathrm{~cm} .$, plus ou moins oblongs, comprimés, mucronés, légèrement arqués ou droits, imprimés entre les graines, quelquefois difformes; épicarpe rude; fragile, brun, subéreux-crustacé; semences 1-8, lisses, très dures, brun foncé, trapézoïdes-arrondies, comprinées, marquées, de chaque côlé, d'un area circonscrit par une lige verte, enveloppées chacune séparément d'une membrane mince, solide, qui représente l'endocarpe, lui-même entouré d'une pulpe noirâtre qui est le mésocarpe. - Fl. en juin ou juillet. - Le tamarinier est un arbre des plus utiles qui joue un grand roble dans la médecine domestique. Les feuilles sont acidules : jeunes et employés en infusion, elles calment les inflammations des yeux; l'écorce est bomme contre lasthme; lat pulpe est un purgatif doux, que tout le monde connait; avec du sucre, on en prépare une limonade rafraîchissante el légèrement laxative ; avece la mòme pulpe, on prépare encore des confitures agréables. Mélée avec un pen de sel de cuisine, cette pulpe forme un tonique dont on se sert en friction contre les douleurs rhumatismales. Ie bois est tres dur, mais nest gruere utilise ni pour la construction ni pour la menuiserie. - La irbere pousse lentement el, (onmme on a remarqué que rien ne vient à son ombre épaisse, on en a conclu que son voisinage est malsain: la vérité, cest qüil est dangereux de s'arreter longtemps sous un tamarinier, quand on est en sueur. - (priginare des Indes Orientales; naturalise dans toutes les parties chamdes de l'Imerique. $\left[N^{\circ} 2618.\right]$

Martinique. Vulgo : Tamarinier. [No 1126.] 
Hymenæa L. (du gree " humenaios ", chant nuptial, mariage, parce que les dens loblinler, éloignées l'une de l'autre pendant le jour, se rapprochent pendant la nuit.)

H. Conrtharil L. Vulen: Courbaril imot tiré de la langue des Indigènes de MAmérique du Sud.) Desc., vol. V, t. 359, p. 208. - Un des plus beaux et des plus grands arbres des lutilles, is fronde majestuense, large, arrondie, a trone droit, cylindrique, peu anfractueux à la base, à feuillage d'un vert comble of agreable, it branches nombreuses, tries rapprochées et richement feuillues : les inférieures, très étalées, horizontales et souvent penchées, à écorce épaisse, raboteuse, d'un roux noirâtre. Feuilles alternes, bifoliées, à folioles coriaces. luisuntes, obliquement oblongues-lancéolée, tris inégales it la base, munies d'un certain nombre de grands points transparents, très visibles, avec une infinité d'autres, invisibles à l'œil nu. Fleurs d'une odeur suave, en grappes corymbiformes, terminales, bractéolées; calice urcéolécampanulé, ligneux, a $\mathbf{1}-5$ segments caducs, ovales, imbriqués, pubescents, tombant d'une seule pièce en se détachant de bas en haut; corolle blanche, à 5 pétales presque égaux, ovales-oblongs, très blancs, très concaves, insérés, avec les étamines, au sommet du tube du calice et alternant avec ses lobes; étamines 10. libres, subulées, is filets filiformes, à anthères oblongues, longritudinalement déhiscentes; ovaire stipité; style subulé; stigmate obtus; pédicelles courts, à f angles oblus. Gousses indéhiscentes, longues de 10-1.5 $\mathrm{cm}$. sur 5-6 cm. de large et sur une épaisseur d'environ $2 \mathrm{~cm}$, ruguleuses, chagrinées, ligneuses, dures, arrondies au sommet; semences ovoïdes, à testa dur comme la pierre, nichées dans une pulpe sèche, farineuse et jaunâtre. Le courbaril est un wégétal utile : son trone, droit, peut mesurer jusqua ia $1^{\text {"n }} 80$ de diametre; il fournit des arbres de couche et des roles pour les moulins, etc.; le bois ressemble beaucoup au mahogani, mais il est plus dur, plus résistant, sa texture est libreuse el enchevetrée; il ne se fend presque jamais el se conserve indéliniment. En dehor's des usages déja indiqués, il est généralement employé pour les meubles. Il laisse exsuder une gomme-résine uniritre, qui brule comme le camphre; elle serait, selon Descourtilz, aromatique ${ }^{1}$ - Fl. en juin et juillet: la floraison ne dure guère plus de quinze jours; les fruits restent sur pied pendant plus d'une année. - Assez abondant dans la région inférieure de la Guadeloupe; plus rare à la Grande-Terre. Alt. 0-550 mèt. [No 3044 .

Martinique. Vulgo : Courbaril. [No 1525.$]$

1. MM. les professeurs Heckel et Schlagdenhauffen ont publiẻ en 1588, dans le Naturaliste, un travail détaillé sur ce végétal, sur son fruit et sur sa résine. La résine, extraite des racines par incision, est employée à la Guyane en liniment contre les rhumatismes. L'écorce y est réputéc purqative et carminative à petite dose en infusion. La résine fraiche est un topique de toutes les plaies: on l'emploie aussi comme celle du cedre blane (Icica allissima Aubl.). C'est la résine animé tendre d'Amérique ou copal du Brésil, copal de Cayenne. (E. H. 
Bauhinia L (dédié aux deux frères Bâlois, Jean Bauhin 1.511-161:3, méclecin

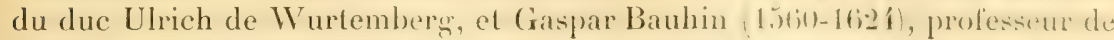
médecine à Bâle. Tous deux ont bien mérité de la bolanique.)

B. Krugii Kr. et Urb.; Bauhinie de Krug. Vulgo : Petit flamboyant. Petit arbre essentiellement ornemental, n'excédant quire ti mil. délévittion, plus ou moins droit, à écorce grise, à branches très divariquées : les inférieures, horizontales on penchées. Fenilles alternes, palminervies, rondâtres, tronquées a la base, un peu plus larges que longues, bilobiens, à lober courts, obliquement arrondies. Fleurs larges, en corymbes nombreux, pauciflores, terminaux et axillaires ou réunies par 2, el siluées at l'extrémité des rameaux ; calice vert, ì tube allongé, obconique, creux, renfermant le support de l'ovaire, en se prolongeant inférieurement sur une longueur de $2-3 \mathrm{~cm}$., pubescent en dehors et terminé, au sommet, par une bractée large, spathiforme et bifide à l'extrémité, pubescente en dehor's et verte ou blanc verdâtre en dedans, renfermant completement la fleur avant son éclosion; pitales 5, larges, subégaux, insérés au sommel et sur le bord du lube élargi du calice, a limbe obovale et arrondi au sommet, passant assez brusquement it un onglet très long : 3 de ces pétales sont finement ponctulés-striés de me tendre sur fond blanc pâle; le 5e et linférieur sont fortement panachés-striés de carmin foncé, ce qui tranche nettement avec la couleur des autres; étamine lértile 1 , blanche, subulée, ascendante, vigoureuse, cylindrique-lancéolée, s'amincissant graduellement vers le sommet, longue de pres de $\mathbf{f}$ cm., presque aussi longue que les pétales : les autres étamines manquent complètement ou se trouvent représentées par 1-5 filaments capillaires, le plus souvent sans anthères; anthères noires; style robuste, subulé; stignate terminé par deux lamelles épaisses ; ovaire arqué, ascendant, longuement stipité; stipe dont les trois quartsinférieurs sont renfermés dans le tube du calice. Dans un grand nombre de fleurs, l'ovaire n'est pas fécondé ou fait complètement déliut. Gousses longues de $16-22 \mathrm{~cm}$. sur $2-2,3 \mathrm{~cm}$. de large, tardivement déhiscentes, mucronées, coriaces-ligneuses, polies, convexes-compriméres, droitrs, légèrement imprimées entre les semences; semences $2-6$, transversalement situées, noires, polies, comprimées-ovoüdes, nichées dans une pulpe farinense. brune, peu copieuse; funicule court, noir, portant, à son point d'altache it la graine, un prolongement pointu; pédicelles robustes, cylindriques, articulés près du sommet, bibractéolés à la base. - Fl. en juin et juillet. Originaire des Indes Orientales; naturalisé et cultivé fréquemment duns les cours, les jardins et autour des habitations: Basse-Terre (ville at banlicue . Pointe-à-Pitre, Moule, Gourbeyre, Camp-Jacob, etc. [No 2619.

M.ntriece. Vulgo: Petit tlamboyant. - Aseez abondant dans les jartins el autour des habitations: Saint-Pierre (ville el banlieue), Fort-de-trance, Lamentin, Prêcheur, Marin, etc. 「No 102.2. 
I. Bauhinia fomentosa L., vulun : Fleur du Sacré-Cưur, arbrisseau droit,

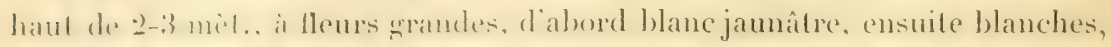
puis rose pourpere est cultivi dans divers jardins comme plante d'ornement. [No 30.6.

Mantinique, Vulgo : Fleur du Sacré-Coeur. - Marin, Saint-Pierre, elc. [No 1123.] - Le B. megalandra Gr., grand arbuste très toulfu, est cultivé au Jardin botanique de Saint-Pierre. [No 1124.]

Schnella Radd. (dédié à Schnell.)

S. splendens Benth., Bauhinia (Jutimontou Aubl.; Schnelle it fleurs splendides. Vulgo: Liane-boudin tordu. Aublt., t. 144. - Puissante liane, dont les branches s'étendent au loin el s'élalent fièrement sur les cimes des arbres les plus élevés, a tige complitement nue dans le bas, très aplatie, de 7-9 cm. de large, sur une épaisseur de 3-12 mm., anfractueuse, à jeunes branches eylindriques, it rameaux flexibles tournant autour des branches des autres arbres pour trouver des appuis. Feuilles larges, plus larges que longues, coriaces, palminerviées, it ! nervures, bilobées, a lobes pointus ou subarrondis, peu profonds : les adultes, glabres des deux côtés; les jeunes, garnies d'un duvet court, doré-argenté; pétioles de longueur très variable, contournés et jouant le rôle de vrilles. Fleurs très belles, rouges, en grappes simples, allongés, terminales; tube du calice campanulé, à 5 lobes obtus; pétales pubescents en dehors, inézaux : le plus large, obové, deux fois plus long que le calice; élamines 10 , distinctes, Loutes fertiles, insérées, avec les pétales, près de la base du calice; ovaire sessile; stigmate capité. Gousses bivalves, déhiscentes, très comprimées. - Fl. en juin, juillet. - Assez abondant dans les bois sees de Gourberre (mornes Goblin et Dos-d'Ane), dans les forêts entre la Pointe-Noire et la Ravine-Chaude, etc. [No 3222.]

De la tribu des Ceesalpiniées, on cultive au Jardin botanique de la Martinique et sur beancoup) d'habitations des plantes introduites, très omementales, dont les principales sont :

Brownea grandiceps Jacf., vulgo : Rose de Venezuela [No 1129], et B.

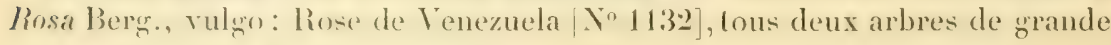
laille, originaires du Venezuela;

Ionezia Asoca Roxb., petit arbre de l'Asie tropicale [ $\left.\mathrm{N}^{\circ} 1130\right]$;

Swartzia lomenlosa . Iubl. Iubl., 1. 5y; De Candolle, Lég., 1. 59. (No 11:27), petit arbre originaire de la Guyane.

S. grandiflora W., petit arbre de la Dominique et de la Trinidad $[\mathrm{No} 679]$;

Copaifera "ffeinalis Jace. V'ulgo: Copahu, Coumarouna, dont le sue oléorésineux donne le baume de Copahu, originaire du Brésil. [No 1128.$]$ 


\section{TROISIEME TRIBU. - MIMIOSEES.}

Entada Ad. (nom de la plante à Malabar.

E. scandens Benth.; Entada grimpant. Vulgo: Lame-onanda, liane-bonde Tuss., Fl., III, 21; Desc., vol. III, t. 200, p. 226. - Gigantesque liane, ¿̀ trone droit, élevé, mesurant jusqu'à $70 \mathrm{~cm}$. de diamètre, cylindrique, à branches extrèmement allongées, montant sur les arbres voisins, les couvant completement, retombant ensuite, pour prendre racine of remonter plus loin, sur d'autres arbres, de manière à occuper un espace considérable, à écoree noirâtre, ruguleuse, à branches striées, à jeunes rameaux munis de vrilles doubles, portées sur un longr pédoncule. Fenilles paripennées, longuement pétiolées, à pétiole commun noir et épaissi à la base, à 2-3 paires de folioles, petites, fermes, oblongues ou elliptiques-oblongrues, inézales a la base. luisantes. Fleurs régulières, blanc pâle, polygames, petites, en „rappes minces. pendantes, sourent très allongées, solitaires, quelquefois géminées, axillaires. naissant a l'aisselle des feuilles, tout le long des rameaux; calice a j dents ; élamines 10; antheres ovoüdes, oblongues, munies d'une glande. (iousses indéhiscentes, pendantes, longues de $0^{m} 80$ - $1^{m} 20$ (rarement plus longrues sur 10-12 cm. de large, ligneuses, sinuées entre les semences, aplaties, renflées à l'endroit des graines, contenant autant d'articulations transversales qu il y a de semences et pouvant se détacher en laissant intact le cordon ou le prolongement du pédoncule, qui forme autour de la gousse un cadre complet; semences jusqu’à 12, roudâtres, comprimées, larges de j-ficm. sur une épaisseur de $2 \mathrm{~cm}$., polies, à testa crustacé, brun noir. - Les jeunes graines peurent se manger róties, bien qu'elles soient ameres; dans les campaynes. on en fait, après avoir enlevé les cotylédons blancs et éburnés, des petites bourses et des tabatières. - Cà et là dans les falaises et endroits boisés, marécageux ou secs du Lamentin, de la Goyave, de Baic-Mahault. etc. - Il fleurit en octobre et novembre. [No 3530.

Martinique. Vulgo : Liane-ouaoua. - Autrefois abondant dans les bois de la Régale et des hauteurs de Sainte-Luce. En 1889, il n'existait plus qu un seul pied de cet arbre intéressant dans les bois de Sainte-Luce, prós de l'hitbitation Montravel. [No 1153.$]$

E. polystachya D. C. : Entada à nombreux épis. Vulgo: Liane à apoulis. 1)

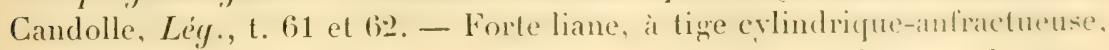
d'un diamètre de $10-15 \mathrm{~cm}$, à rameaux pourvus de vrilles, à racines tragantes, grosses, formant des nouds tres grands. spongienses of hanchitres en dedans. Feuilles deux fois composées-pennées, à $4-6$ paires de pennes, 
contenant dist prires de folioles. petites. oblongues, armondies au sommet ou lescrement idhaneres, of trés somvent mucronées, tres pâles ou blanchatres

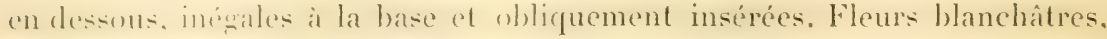
en panicules terminales, longues de $20-25 \mathrm{~cm}$., composées d'un très grand momber pedites grappes secondaires. spiciformes, souvent unilatéralement

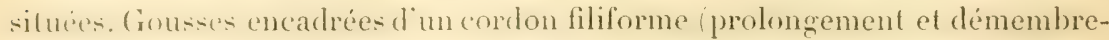
ment du pédoncule), très aplaties, longues de $12-18 \mathrm{~cm}$. sur 6-7 cm. de large, indihiscentes, membraneuses, transversalement articulées, a articulations libres, en forme de parallélogranme, et se détachant en laissant le cordon intact; semences longues de $15 \mathrm{~cm}$. sur $7 \mathrm{~mm}$. de large, obovoüdes, comprimées-convexes, lisses, brunes, marquées d'un aréole elliptique, circonscrit par un petit sillon. A la maturité, l'épicarpe se détache par plaques du mésocarpe. - Les racines coupées par morceaux et mises dans l'eau froide ne tardent pas à produire une masse d'écume (saponine?): cetle eau est un des meilleurs diurétiques-rafraichissants quon connaise: dans le pays, on en fait grand usage. - Vit dans les monceaux de pierres du littoral et sur les mornes inférieurs : bord de mer de la Basse-Terre au Baillif et de la basse-Terre au lienx-Fort, Capesterre Guadeloupe, Pigeon. Deshaies, elc. [N०3029.

Mantineve. Vulgo : Manioc-Lachapelle. - Mornes du Jardin botanique, Basse-Pointe, Grande-Rivière, Macouba, Trois-Ilets. [No 1154 .

Adenanthera L. du wrec " aden ", whinde, el " anthera ", fleur, allusion ì la glande qui termine les anthères.)

A. pavonina L.; Adenanthère pavonine. Vulgo : Arbre à réglisse, arbre graines réglisse. - Grand arbre à branches peu nombreuses, étalées horizontalement, à écorce lisse, grisâtre. Feuilles deux fois composéesparipennées, larges, à $3-4$ paires de pennes, distantes, portant 5-13 paires de folioles alternes, également distantes, ovées ou rétuses au sommet, subtronquées à la base. Fleurs régulières, jaunes, en rrappes axillaires, confinées aux extrémités des branches et longuement pédonculées; calice à 5 dents; pétales 5; étamines 3 , incluses, à anthères munies d'une grlande stipitée, terminale. Gousses longues de $20-25 \mathrm{~cm}$. sur 14-16 $\mathrm{mm}$. de large, recourbées en forme de faucille, déhiscentes, imprimées à l'endroit des graines, rétrécies à la base, pointues au sommet; semences 3-8, laissant des espaces vides entre elles, rondes, biconvexes, très luisantes, d'un rouge écarlate, très vif'. Après la déliscence, les valves se fordent ef lomrnent con ypirale: l'endocarpe, hlane en dedans, se detache des

1. Ces graines, sous le nom de faux jérfuirity, ont été étudiées en détail par MIN. Hec$\mathrm{kel}$ el Schlagdenhaufien, dans un travail qui a paru au journal de pharmacie de Recber, le Progfès (Genève, 1882). Elles se substituent quelquefois aux graines d'Abrus precalorins l. 
autres parties du péricarpe; les graines se montrent en dehors et restent longtemps altachées, pour faire admirer leur belle couleur. - Fl. en juin et juillet. - On ramasse souvent les graines pour en fabriquer des bracelets, des colliers, etc. - Originaire des Indes Orientales: naturalisi at alonndant dans nos deux colonies. Alt. 0-400 mèt. [Nos 3225, 3532.]

Martixique. Vulgo: Graines rouges, arbre à graines rouges. - Prêcheur, Carbet, Trois-Ilets, Macouba, Trinité, etc. A été introduit au Jardin botanique, d'où il s'est répandu dans le pays. [ Y $^{\circ} 820$.]

Le Pentaclethra filamentosa Benth., grand arbre, originaire de la Trinirlarl et de la Guyane, à feuilles très larges et très belles, deux fois composéesparipemées, de 10-20 paires de pennes, ornées de 30-50 paires de folioles. très rapprochées et luisantes, est cultivi au Jardin botanique de Saint-l’ierre, d’ou il śest répandu dans l’ile; il pousse dejà spontanciment dans plusicurs endroits, aux environs de la ville. Xo 1152. Les graines doivent etre grasses (à vérifier).

Neptunia L. (de "Neptune ", dieu des eaux, parce que ces plantes recherchent habituellement le milieu aqueux.)

N. plena Benth.; Veptunie pleine. Vulgo: Pompon jaune. -.. Suffrutescent, ghlabre, haut de $0^{m} 70-1^{\text {m }} 80$, droit ou tortueux, ordinairement peu branchu et peu feuillu, à rameaux comprimés. Feuilles bipennées ; a :3-5̆ paires de pennes, portant 12-10 folioles irritables, délicates, linéares-oblongues: pétiole long, garni d'une stande large, elliptique, sessile, entre la premiere paire de pennes : stipules plus ou moins larges, obliquement insérés, cordées a la base, pointues ou mucronées an sommet. Fleurs jaune vil, en capilules: obovales, très longuement pédonculés, axillaires; pécloncule arqué portant 1- $\mathbf{f}$ bractées, irrégulierement distancées, lareges, cordiformes, ovales, pointuesmucronées; calice à 5 dents : fleurs inférieures du capitule, stériles, arec des filets pétalö̈les et longss; étamines fertiles 10, avec des anthires noires et surmontées d'une glande stipitie. (sonssess stipitées, arquées, infléchiess mucronées, longues de $4-5 \mathrm{~cm}$. sur $5-7 \mathrm{~mm}$. de large, comprimées-convexes. ordinairement au nombre de $\mathbf{1}-\mathbf{f}$, imprimées entre les semences oboroïder. noires, lisses, transversalement situées. - Assez aboudant a la Grande-Terre, sur les bords des étangrs et des mares. - Il arrive parfois que ces plantes vivent complètement dans l'eau. Les parties inférienes des liges devirmnent

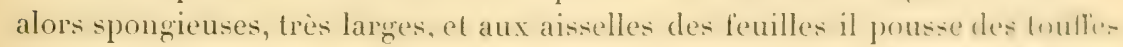

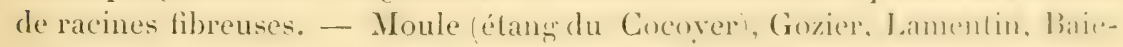
Mahault, Marie-Galante, Port-Louis, etc. [Nos 3030, 352\%.

Martixique, Vulgo : Pompon jaune. - Vauclin, Mariu, Sainte-Anne. [Nos $830,831$.

Desmanthus 17 . (du gree " desmé $)$, lien, fascicule, c'est-it-dire fleurs rotunies en capitules.) 
D. virgatus W., variété strictus Benth.; Desmanthe à bagueltes. Vuigo: Petit acacia. - Sous-arlorisseau, droit, haut de $0^{\mathrm{m}} 50-1^{\mathrm{m}} 80$, à ume seule ou plusicurs tiges cylindriques, sourent très branchues, striées-anguleuses, noirâtres el lisses. Fenilles deux fois composées-paripennées, à 2-4 paires de pennes, comptant 10-25 paires de folioles linéaires ou oblongues-linéaires; pétiole principal muni d’une glande aplatie et rougeâtre, entre la première paire de pennes; stipules obovales-sétacées. Fleurs blanches en capilules pédonculés, axillaires, situées dans les parties supérieures des rameaux; calice à 5 dents; pétales subdistincts; étamines 10; anthères ovoüdesoblongues, sans glandes. Gousses réunies le plus souvent par 4-5, longrues de 4-6 cm. sur 2-3 mm. de large, sessiles, mucronées; semences 10-25, ovoüdescomprimées, noires, polies, longues de $2 \mathrm{~mm}$. - Très abondant dans les halliers et dans les savanes sablonneuses de la région inférieure : Montéran, Vieux-Fort, Trois-Rivières, Sainte-Rose, Deshaies, etc. [No 2630.

Martinele. Vulgo : Petit acacia, pompon blanc. - Abondant : Parnasse, environs de Saint-Pierre, savanes de Ducos, hauteurs de la Rivière-Salée. ete. $\left[\mathrm{N}^{\circ} 1150\right.$.

D. depressus Kth.; Desmanthe à tiges couchées. Tulgo: Acacia courant. - Suffrutescent et frutescent, glabre, couché, long de $40-70 \mathrm{~cm}$., à racines pirotantes, allongées, fortes, à tiges très nombreuses, cylindriques dans le bas, subtétragones dans le haut et souvent ascendantes aux extrémités. Feuilles à 3 paires de pennes, portant 8-12 paires de folioles, très petites, linéaires, obtuses. Fleur's blanches, en capitules pédonculés, peu nombreux, axillaires el terminaux; pétiole commun muni d'une glande arrondie, entre la demière paire de pennes; calice trifide, pétales linéaires-oblongs, deux fois aussi longrs que le calice; étamines deux fois aussi longues que les pétales; pédoncule presque aussi long que les feuilles. Gousses de $\mathbf{4} \mathrm{cm}$. de long sur $2 \mathrm{~mm}$. de large, droites, pointues au sommet, contenant 8-15 semences ovales, noirâtres. - Les bestiaux sont friands des feuilles el des jeunes tiges. - Assez abondant dans les savanes sablonneuses, sèches, où il forme souvent

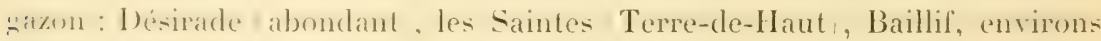
de la Basse-Terre, Vieux-Habitants, etc. [No 3032 .

Mantrigee. Vulgo : Acacia-terre. - Assez abondant dans les savanes des environs de Fort-de-France, de l'Adillon, de Case-Navire, etc. [No 1151.

Mimosa l. du latin " mimus ", pantumime, comédie, allusion à la contraclion des feuilles quand on les touche.

M. pudica L.; Mimeuse pudique. Vulgo: Sensitive, zerbe-mamzelle, honteuse femelle. Plum., édit. Burm., t. 202. - Suffrutescent, à tigre herbacée, grêle, rampante ou ascendante, parfois grimpante, peu branchue, à tige el rameaux armés de piquants jaunâtres : les uns, infra-stipulaires, au nombre

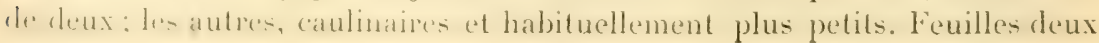


fois composées-paripennées, à 1-2 paires de pennes, très rapprochées, de manière à simuler une feuille palmée, portant 15 -25 folioles oblontrueslinéaires, pointues, ciliées sur les bords; pétiole secondaire garni de poils roux, sétacés; pétiole commun comprimé, glabre, souvent muni de spinules; stipules ciliées-frangées. Fleurs pourpres, ou purpurines, plus rarement blanches, en capitules oroüdes, axillaires, pédonculés, runis par -2-3: predoncule souvent poilu, aussi long ou sourent plus longr que le pétiole commun; calice avorté ou rudimentaire; étamines 4 ou 8 , trois ou quatre fois plus longues que les pétales. Gousses indéhiscentes, longues de 12-18 mm. sur $3 \mathrm{~mm}$. de large, sinuées, imprimées entre les graines, à $2-\hat{t}$ articulations, convexes, orbiculaires, se détachant, à la maturité, du cordon qui les encadre el qui est hérissé de soies rigides, jaunatres et droites; semenees lenticulaires. brunes, comprimées-convexes. Cette plante est célèbre à cause de l'irritabilité de ses feuilles. - La racine de la sensitive est purgative, émétique et en même temps alexitère; dans le pays, on se sert uniquement de la décoction de la racine en gargarisme contre l'irritation de la gorge et contre la coqueluche, en y ajoutant un peu de miel pour corriger son astringence. Répandu dans toutes les Antilles, jusqu'it une altitude d'environ 700 mit. [No 3034 .

Martixeqe. Vulgo: Amourelte, Marie-honte, sensitive, zherbe-zamuser. [No 1149.]

M. casta L.; Mimeuse chaste. Vulgo : Zamourette. Desc, vol. II, t. 119, p. 203. - Suffrutescent, grimpantou rampant, glabre à tignes, rameaux, pédoncules et pétioles armés de piquants jaunes ou jaunâtres, élarwis à la base, droits ou recourbés, placés à rebours. Feuilles irritables. à 1 paire de penues. longues de $5 \mathrm{~cm}$., divergentes, munies de 3-5 paires de folioles opposées, oblongrtes, semi-elliptiques, coriaces, pointues, marginées, frarnies de poils rigides et couchés, surtout sur les bords; pétiole commun plus longr que les pennes. Fleuirs purpurines, ou blanches, en capitules axillaires et terminaux : les axillaires, solitaires; les terminaux, en grappes corymbilormes. Gousses longues de $3 \mathrm{~cm}$. sur un peu plus de $12 \mathrm{~mm}$. de large, droites, membraneuses-coriaces, arrondies aux extrémités, à $3-\hat{f}$ articulations se délachant isolément du cadre fibreux hérisse de piquants jaunes, droits ou plus souvent recourbés en crochet; semences comprimées, obovoïdes, marquées, de chaque côté, d'un aréole circonscrit par une ligne blanchâtre. - Assez répandu dans la basse région de la Capesterre Guadeloupe. de la Conave. de Sainte-MIarie, du Petit-Bourg. [No 3763.]

Martinique. Vulgo: Amourette. - Abondant : environs de Saint-Pierre. Trou-Vaillant, Carbet, Trois-Ilets, Prêcheur, Trinité, etc. 「Yo 1147.

M. camporum Benth.; Mimeuse des champs. Vulgo : Sensitive, petite amourette. - Suffrutescent, droit, très branchu, haut de $511-94$ cm. . rarement 
plus haul, herisis the toutes parts despinules droites, blanchitres, ol depoils

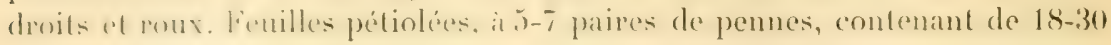
paires de folioles très petites, pubescentes, sensitives, linéaires, obtuses au sommet. Fleurs pourpres,ou purpurines, ou (si elles se trouvent à l'ombre)

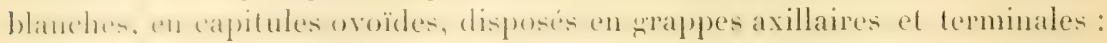
ces deruières sont allongées et interrompues. Gousses longues de 7-11 mm.

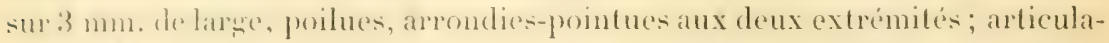
tiuns: 2-33 so détachant du cordon-cadre, qui, apres la chute des articulations. se rompt au sommet; semences noires, obovoïdes, comprimées. - Fl. en juin, juillet. - Peu répandu : environs de Saint-Pierre, sur les bords des chemins des champs de canne, entre l'Flise de la Consolation et lihabitation Périntell: sà et lit dans les champs du Trou-Vaillant. - Celte espéce a dù itre introduite arec les engrais. [No 1148.] - Elle n'est pas à la Guadeloupe.

M. asperata I..; Mimeuse rude. Vulgo : Amourette-rivière, zamourette violet. - Arbrisseau très ornemental, haut de $1^{m} 50$ à 3 mèt., habituellement droit, it branches nombreuses, distiques, à tige, jeunes branches, pétioles, rachis hispides-ruguleux el garnis de piquants acérés, subulés, at pointe noire: coux de la tige, plus grands ed latéralement élaryis à la base ; ceux des pédoncules el des pétioles, plus petits. Feuilles a $8-15$ pennes, pourvues de 20-60 folioles tris petites, tris rapprochécs, linéaires, obliquement pointues au sommet, ulabres en dessus, hispidulées en dessous; pétiole commun garni de piquants larges insérés par paires sur les parties qui séparent les pemes, el d'une spinule dressée, subulée, entre chaque penne; stipules subulées. Fleurs purpurines, en capitules larges ovoïdes-allongés, géminés, pédonculés, alternes, formant une large grappe feuillue, terminale el allongée ; ćtamines en nombre louble des pélales; pédoneules hispides, ruynuleux, longs de 23 cm. Gousses longues de 6-7 cm. sur 8-9 mm. de large, mucronées, très arquées, hérisseres de toutes parts, mais surtout sur les bords, de poils tres roux, imprimés ('ntre les z)-20 articulations étroites, lesquelles tombent sans entrainer le cordon encadrant qui forme un rebord de chaque côté; semences brunes, ovoïdes-allongées. — Fl. en avril, mai, juin. — Le long des rivières de la basse région et dans les endroits aqualiques voisins des cours d'eau : RavineChatude riviere brats-de-sable, Jamentin, Baic-Mahault. Nos 3228, 3118.

Mantingue. Vulgo : Amourette-rivière. - Bords de la rivière du Carbel (cours inférieur), rivière des Pères, rivière sèche, rivière du Prêcheur, etc. $[\mathrm{N} \cup 910$.

M. ceratonia I.; Mimeuse à épines corniculées. Vulgo : Amourette, grattejimbe, croc-chiens. - Puisint arbrisseau-liane, ornemental, nrimpant it une grande hauteur el couvrant les arbres de ses branches et de ses belles fleurs, i) lige fres lordueuse. plus ou moins cylindrique, ì rameaux striés-anguleux, à tige, branches, rameaux el pétioles armés de piquants noirs, subulés ou droits, placés a rebours ot latiralement chargis a la base, de grandeur variable. 


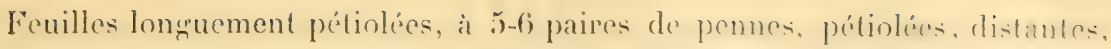
portant 2-3 paires de folioles également distantes et pétiolées, obovales, arrondies au sommet et î la base, très glauques en dessous; pélioles secondaires filiformes, noirs avec ou sans piquants. Fleme purpurines, en capilute:

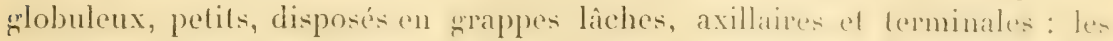
dernières, souvent très allongées; corolle trifide. Gousses longues de $5-6 \mathrm{~cm}$. sur $2 \mathrm{~cm}$. de large, oborales, non articulées, noires, membraneuses, à bords formant cadre et armés de $8-10$ piquants subulés, courts, placés à rebours: semences 3-5, longues de $2 \mathrm{~mm}$., brunes, comprimées. - Endroits secs, pierreux et calcaires: Moule (environs de l'habitation Malettre), Vieux-Fort. Courbere morne Dos-dilne, Le Baillif, Yreux-Habitants. Pigeon, Bonillante. - Fl. en septembre et octobre. [ $\left.\mathrm{N}^{\mathrm{o}} 3033.\right]$

Mantixique, Vulgo: Amourette grand-bois, croc-chiens. - Abondant dans les hauteurs des Trois-Ilets, de la Régale, de Case-Pilote, etc. [Yo 1146.$]$

Schrankia I. dédié à lex-Jésuite allemand Schrank 1747-18:35, né it Varnbach en Baviere, professeur d'agriculture et de botanique économique à Ingolstadt, directeur du Jardin botanique de Munich; a laissé un grand nombre d'ouvrages de botanique.)

S. leptocarpa D. C.; Schrankie à fruits longs et minces. Vulgo : Sensitive. - Suffrutescent, ressemblant beaucoup, quant au port, au feuillage et aux fleurs, à la sensitive ordinaire, à racines tubériformes, à tiges et branches quadrangulaires, armées, ainsi que le pétiole commun, d'aiguillons crochus. Feuilles irritables au mème denré que le Mimosa pudica, it :-3 paires de pennes, contenant 10-20) paires de folioles linéaires, obliquement insérées. Fleur's purpurines, en capitules axillaires, presque toujours solitaires, petites. pédonculées: étamines libres, 8-10. Gousses très droites ou parlois légierement arquées, longues de 6-9 cm., tétragnnes-sillonnées, sourrant en quatre valves hérissées sur les bords de piquants jaunes, subulés, très acérés, et terminées en une longue pointe aiguë; pédoncule vigoureux, longr envirom de $1 \mathrm{~cm}$.; semences obliquement tronquées-subtétragones, longues de $2 \mathrm{~mm}$., situées longitudinalement. - Fl. en septembre, octobre et novembre. Abondant daus les savanes entre Fort-de-France et Case-Xavire, surtoul sur Thabitation Sainte-Catherine el aux environs du Marigot. $x " 103 t .,-J e$ me l'ai pas vu à la Guadeloupe.

Leucæna Benth. du gree "leucaïno ", blanchir, allusion a la couleur de: fleurs, qui sont presque blanches.)

L. glauca Benth.; Leucæene à feuilles glauques. Vulgo : Monval, tamarin bâtard, macala. (Mimosa L., Acacia W., - Arbrissean ou petit arbere pur branchu, à trone nu, à branches étalées, à tiges couvertes de petites écailles et de lenticelles roussatres, à rameaux, pretioles, pédoncules finement pulue- 
cents ou commesaupoudrés d'une poussière blanche. Feuilles de $8-13 \mathrm{~cm}$. de long, it 8 paires de pennes, portant $10-20$ paires de folioles oblongueslinéaires, obliquement pointues, obliques it la base, glabres, glauques en dessous; pétiole commun chargé, au milieu, d'une glande large, sessile, aplatie. Inflorescence axillaire et terminale, en capitules globuleux, larges, presque blancs, formant ensemble une grappe lâche; calice à 5 dents; étamines 10. Gousses stipitées, longues de $12-17 \mathrm{~cm}$. sur $2 \mathrm{~cm}$. de large, glabres, déhiscentes, très aplaties, atténuées à la base, pourrues d'un bec court el recourbé au sommet; semences 12-22, transversalement placées, obovaleselliptigues, brunes, luisantes. altachées à un funicule filiforme et droit. - On se sert des graines pour fabriquer des petits travaux d'art, comme bourses, porte-montres, bracelets, etc. - Très commun dans les terres inféricures, sèches et sablonneuses de toute la Guadeloupe, de la Grande-Terre et des dépendances. Alt. 0-350 mèt. $\left[\mathrm{N}^{\circ} 3042.\right]$

Mantinique. Vulgo : Nacatta, macatta-bourse. - Très abondant dans toute l'île. [ $\mathrm{N}^{\circ} 834$.

Acacia L. (du grec "akakia ", épine, pointe : la racine est dans le mot celtique " ac.", pointe, allusion aux épines que portent la plupart des plantes de ce nom.

A. Iamarindifulia W: . Acacia à leuilles de tamarinier. Vulğo: Cóte-lézard. Plum., édit. Burm., t. 7. - Arbrisseau tantôt sarmenteux, tantôt plus ou moins droit, haut de $1-6$ mèt., à branches allongées, à rameaux quadrangulaires, at branches et rameaux garnis de piquants noirs, droits ou recourbés, à écorce presque toujours noire. Feuilles longues de 7-8 cm., à $4-6$ paires de pennes, de 12-20 paires de folioles de $3 \mathrm{~mm}$. de long, oblongues, obliques à la base: pútiole commun garni d'une glande entre la dernière paire de pennes. Inflorescence en grappes terminales et axillaires; fleurs blanc pàle, en capitules larges, pédnnculés, réunis par -2-5, à pédicelles enreloppés, à la base, de deux grandes bractées foliacées, cordées, largement ovales, pointues, caduques: :aractère qui distingue facilement cette espèce de toutes ses congénères; calice à 5 lobes; corolle à 5 lobes, deux fois plus longs que ceux du calice; étamines nombreuses, en nombre indéfini. Gousses stipitées, suboblongues, atténuées à la base, longues de $7-11 \mathrm{~cm}$. sur $2 \mathrm{~cm}$. de large, très aplaties, coriaces, sèches; semences 5-8, transversalement placées. - Abondant dans les quartiers secs, chauds, pierreux de toute la côte, de la BasseT'erre jusqu'à Deshaies. - Fl. en août, septembre et octobre. - Alt. 0-150 mèt. [ Y'o 3261.

Mantixique. Vulgo: Grand amourette. - Environs de Saint-Pierre, Carbel, Case-Pilote, Trois-Hlets, Marin, etc. $\left[\begin{array}{ll}N^{\circ} & 1145\end{array}\right]$

A. riparia II. B. et Kith., A. sarmentosa Desv.; Acacia des bords des riviore. Vulgo: Amouretle - Ressemble beaucoup au précédent; il en 
differe par ses branches tonjours sarmenteuses, plus qrites at blanchithepar ses folioles plusétroites et plus nombreuses. par sur piquants luancom plus étroits, plus courts et souvent réduits ì de petites spinules, par ses capi-

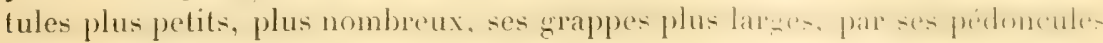
plus courts et non enveloppés dans des bractées, ou an ant des brackeses ludimentaires ou avortées, par ses grousses plus étroites et un peu plus longues. - Surtout abondant le long des rivières, jusqu' à une altitude de 180 mèt. depuis la Basse-Terre jusqu’a I deshaies, et de la Basse-Terre jusqu ia la Capenterre (Guadeloupe), Marie-Galante, les Saintes, et dans toute la GrandeTerre. [No 3041 .

Martixique. Vulgo : Amourette, fleurs d'amour, fleurs du bien-aimé. Abondant : environs de Saint-Pierre, Fond-Coré, Canonville, Prêcheur, Grande-Rivière, Case-Pilote, Marin, Trois-Ilets, etc. [No 1141.

A. paniculata W., A. martinicensis Prl.; Acacia ì fleurs en panicules. Vulgo : Amourette. - Arbrisseau sarmenteux, haut de 5-12 mèt, armé de petits aiguillons crochus. Feuilles longues de $12-18 \mathrm{~cm}$., à $12-17$ paires de pennes, longues de $4-6 \mathrm{~cm}$., portant 30-60 folioles petites, très rapprochées, linéaires, sessiles, obliquement arrondies au sommet; pétiole commun chargéd d'une ghlande ì peu près ì son milieu. Inflorencence en petits capitules globuleux, très nombreux, formant une panicule terminale sans bractées; fleurs blanc pâle ou blanches. Se distingue facilement de ses congénères par le nombre des pennes, la finesse et le grand nombre de ses folioles. Gousses déhiscentes, très aplaties, pointues aux deux extrinitís. très coriaces; graines 6-8, noires, très comprimées, longues de $7-9 \mathrm{~mm}$.; funicule long de $3 \mathrm{~mm}$., robuste, noir. - Fl. en mai, juin, juillet. - Peu abon-

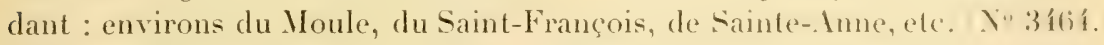

Martnique. Vulgo : Amourette, acacia blanc. - Abondant aux environs de Saint-Pierre (Boulevard, Trois-Ponts), Carbet, Prêcheur, Trinité, etc. Alt. 0-300 mèt. [No 1140.]

A. macrantha II. B. Kith.; Acacia à grosses épines. Vulgo: Acacia piquant. acacia-savane. - Petit arbre très touffu, à branches toujours divariquées, horizontales, et les inférieures toujours penchées, it trone, branches et rameaux grarnis d'épines stipulaires, droites, acérées, très souvent blanches, surtout les adultes, insérées à angle droit, réunies par deux à la base. Fenilles de 1:$15 \mathrm{~cm}$. de long, ayant de 20-25 pennes de $3-4 \mathrm{~cm}$. de long., portant 15-34 folioles, petites, linéaires, émoussées au sommet le nombre des penures es

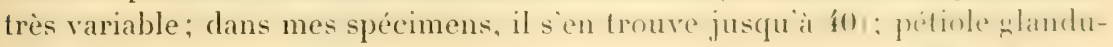
lifère. Inflorescence axillaire, en capitules arrondis, pédonculés: Mére jaunes. odorantes. Gousses indéhiscentes, plus on moins moniliformes, lignentuse. tantit droites, tantot courbes, sessiles, vertes, longues de 9 ('m., hiconveres. couvertes de poils rudes, très serrés et très courts, lénerement pulpeuses en 
dedans: semences 10-13, brunes, convexes, ovales, longues de 4 mm. - Fl. surtout en mai, juin, juillet. - Très abondant sur toute la côte entre la BasseTure (1) llates, entre la Basse-Terre et Vieux-Fort, Gozier, Moule, MarieGalante, etc. Alt. 0-250 mèt. [No3416.]

Mantivece. Vulgo: Acacia-savane, - Rare dans les environs de SaintPierre: plus abondant aux environs de Fort-de-France, notamment entre le collewe el lo fond Tartanson, lo long de la rivière Madame el de la rivière de La Dillon. [No 838.]

A. arabica $\mathrm{W}$.; Acacia de l'Arabie. Vulgo : Acacia de Cayenne. - Petit arbre, plus rarement assez grand arbre, à branches inclinées, à rameaux pédonculés, pétioles et fruits couverts d'un duvet tomenteux, fin, blanc ou blanchatre. Findilles fasciculées, a $1-8$ paires de pennes, portant 10-20 paires do folioles oblonenus-linéaires, obtuses; pétiole habituellement zami d'une whande, pres de la base; épines géminées, tantot courtes, tantôt tres longues, droites, blanches. Fleurs lasciculées, à pédoncules longs, bibractéolés au milicu. Gousses stipitées, de 7-9 cm. de long sur 13-15 mm. de large, couvertes d'un duvet fin et blanchâtre. - Çà et là dans les savanes sèches des environs de la Basse-Terre, Baillif, Vieux-Habitants, etc. [Nos 2635, 341.5.]

Martixique. Vulgo : Acacia-savane. - Rare : dans les savanes sèches de Sainte-Anne. [No 840 .]

A. Farnesiana IV.; Acacia de Farnèse. Vulgo: Acacia jaune, acacia odorant. Desc., vol. I, t. 1, p. 1. - Arbuste ou petit arbre, le plus souvent tortueux, à branches très divariquées, d'un port peu élégant, à rameaux et pétioles glabres. Feuilles à 1-8 penmes, charéés de 10-20 folioles obtuses, oblenurue-linéaires; pétiole conmun muni d'une glande scutelliforme, entre la derniere et sourent entre la première paire de pennes. Fleurs jaume d'or vif, fasciculées, fortement nusquées; étamines en nombre indéfini, subdistincles; épines stipulaires 2, sétacées. Gousses longues de 6-9 cm. sur 7-12 mm. de larere, fortement arquées, cylindriques, atténuées aux deux extrémités, brièvement stipitées ou sessiles, terminées par un bec allongé et recourbé. Avec les gousses vertes et la gomme qui suinte de l'arbre sans incision, en y joinnant un peu de bois de campêche et du jus de citron, on peut préparer à chaud une enere très noire et indélébile, si on a soin de fixer la couleur avec un peu de sulfale de cuivre ou de zinc. Le bois est dur et résiste longtemps à l'humidité. Il sert à faire de petits meubles. Avec les fleurs, on prépare une excellente tisane contre les dyspepsies. Les racines, qui sont courertestume écorece brune ou noirâtre, ont une odeur d'ail tris prononcée:

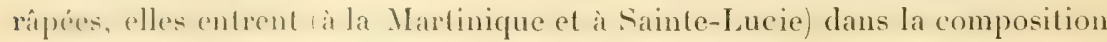
des remèdes contre la morsure du serpent; avec la décoction des gousses, pilées, on peut noircir les cuirs. - Fl. à peu près toute l'année. - Cultivé dans les jardins de la ville el aulour des habiations; abondant dans les terres 


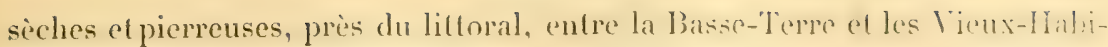
tants, Vieux-Fort, Capesterre, etc. [ $\mathrm{N}^{\circ} 2638$.

Martingue. Vulgo : Acacia jaune, acacia odorant, pompon jaune. - Cultivé et à l'état sauvage, dans toute l'île, mais surtoul au Carbet, ì CasePilote, au Diamant, à Sainte-Anne, etc. [No 1141.

A. parvifolia W.; Acacia à petites feuilles. Vulgo: Acacia bord-de-mer, acacia-savane. - Arbrisseau ou grand arbuste, quelque fois petit arbre, habituellement très touffu, souvent tortueux, nu dans le bas, à branches inclinées et divariquées. Feuilles de 20-4 pennes, contenant de 10-1.5 follotes pubescentes en dessous, finement ciliées sur les bords, linéares, whtuses. longues de 2-3 mm.; pétiole commun marqué d'une glande sessile, elliptique, entre la plus basse paire de pennes (quelquefois un peu au-dessous de cetle paire); pétioles secondaires finement duvetés. Fleurs jaunes, solitaires, odorantes, pédonculées, à pédoncules pubescents; épines variables, ziminées. pubescentes; étamines monadelphes. Gousses longues de $12-15 \mathrm{~cm}$. sur $5 \mathrm{~mm}$. de large, linéaires, légèrement moniliformes, arquées. Ressemble au précídent, avec lequel on peut le confondre de prime abord; il en dillère surtont par la pubescence des pétioles, l'étroitesse el la longueur de ses gousses. Fl. presque toute l'année. - Abondant dans les sables secs du bord de mer, de Saint-François, du Inoule, de Sainte-Amne, du Petit-Canal, ete. et aussi dans les mornes secs, près du littoral. [Nos 3037,3525 .

Martinique. Vulgo: Acacia bord-de-mer. - Abondant, entre Sainte-Anne et le François. [No 839.]

A. Vincentis Gr., Pithecolobium Vincentis Benth. ; Icacia de Saint-Vincent. Vulgo : Acacia blanc. - Arbrisseau tortueux, haut de 2-3 mèt., à écorce blanchâtre. Feuilles longues de $3-4 \mathrm{~cm}$., à 3 paires de permes, de $2 \mathrm{~cm}$. de long, portant 5 -6 paires de folioles, de $5 \mathrm{~mm}$. de long, oblongues; pétiole garni d'une glande pointue, au-dessus de sa base: pétioles primaire ef secondaire, pubescents; stipules petites, caduques: aiguillons droits, solitaires ou réunis par deux, dont un toujours plus grand. Flenrs en capitules: blancs, globuleux, axillaires, brièvement pédonculés; étamines 10-12. connées à la base. Gousses longues de 12-15 cm. sur 1,5 cm. de large, plus ou moins arquées, ligneuses, indéhiscentes, sinuées, aplaties: semencés 11)-1.5. obovales, comprimées-convexes. - Endroits secs, pierreux des environs du bourg de Case-Pilote; çà et là au Vauclin, à Sainte-Anne et au Marin. Alt. 0-80 mèt. [No 837.] (Spécimen imparfait.) - Je ne lai pas (rouvé at la (iuatdeloupe.

A. Lebbeck W. ; Vulgo : Bois noir, vieille fille. Tuss., Fl., IV, t. 29. Arbre de taille moyenne, rarement grand arbre, droit, sans piquants. whathe dans toutes ses parties, à écorce noire, presque lisse, at branches infériempes

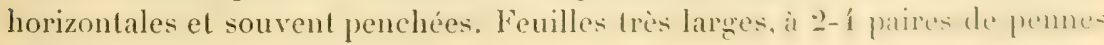


distantes, portant 3-9 paires de folioles laryes, obovales-oblongues, inégales it la base. Fleurs en capitules, grandes, purpurines ou blanches, axillaires et alors solitaires, ou géminées ou terminales, disposées en une sorte de corrmbe ombelliforme; capitules pédonculés, à pédoncules longs, filiformes; étamines en nombre indéterminé, soudées à la base. Gousses longues et larges, pourant atteindre jusqu'à $32 \mathrm{~cm}$. de long sur $4-5 \mathrm{~cm}$. de large, droiles, très membraneuses, minces, blanches, toujours pendantes, atténuées aux deux extrémités, brièvement stipitées et munies d'un crochet au sommel; valves tardivement déhiscentes, concaves d'un côté et convexes de l'autre, it l'endroil des graines, - Les gousses restent longtemps sur pied, et, quand le rent les agite, elles produisent beaucoup de bruit. - Le bois est recherché pour la construction, mais surtout pour le charromnage. - Originaire du Bengale. Naturalisé et abondant dans les environs de la Basse-Terre, Baillil, Capesterre (Guadeloupe), Pointe-à-Pitre, Moule, etc. lil. en arril, mai, et aussi en septembre et octobre. [Yo 2636.

Mantineve. Vulgo : Bois noir. - Abondant : Fort-de-France (environs de la maison de campagne du gouverneur), Saint-Pierre (place Bertin), Prêcheur, Carbel, etc. $\mathrm{N}^{\circ} 1143$.

Parmi les espèces d'acacia introduites et sur le point de se naturaliser, on rencontre : $1^{\circ} 1^{\prime}$ Acacia cornigera W., vulgo : Acacia à cornes de bouf, apporté du Mexique à la Martinique par l'horticulteur Louis Hahn, en 1867. C'est un arbrisseau ou un grand arbuste, remarquable par ses grands piquants connés ì la base, divergents, géminés, ayant exactement la forme de cornes de bouf, par son beau feuillage rert, dont les folioles portent, à l'extrémité, un appendice arrondi, et par ses fleurs jaunes disposées en épis courts, à fleurs très serrées. - On l'emploie pour faire des haies impénétrables, aux environs de la Basse-Terre, du Camp-Jacob (habitation Rollin), de Gourbeyre, de Pointe-ì-Pitre, etc. [No 3226.] Martinrque. Vulgo : Acacia arrêteboufs, acacia à cornes. [No 114 f́.

2 LAcacia Sundra Roxb., originaire des montagnes du Coromandel, introduit, pour la formation de haies impénétrables, par le comte de Lautrec, sur son habitation Grand-Fond-Balata au Marin. No 836.

3' L'Acacia Suma Kunz, arbre assez élevé, très ornemental, ì fleurs blanches, en épis très nombreux, axillaires et terminaux. Naturalisé près de la BasseTerre (La Pintade) el au bord de mer, entre la Basse-Terre et la rivière des I'Pres. N" 31139.

Calliandra lienth. (du grec "kallos ", beau, et " aner ", homme, allusion i la belle couleur des étamines.)

C. purpurea Benth.; Calliandre à fleurs rouges. Plum., édit. Burm., t. 10 , 1. 2 - Pelit arbre, souvent tortueux, très touffu, haut de 2-4 mèt., à écorce

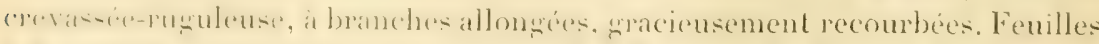
is I paire de fremes diverzentes portant 3-7 paires de folinles tres vertes, 


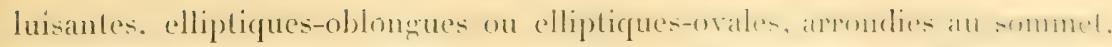
inégales à la base; pétiole commun pubescent. Inflorescence axillaire el terminale, en capilules pédonculés; étamines 10, écarlates, quatre fois plus longues que le calice. Gousses élastiquement déhiscentes, à $4-5 \mathrm{~cm}$. de long sur $4 \mathrm{~mm}$. de large, glabres, oblongues, droites ou arquées, slipitées, valves cornées, à rebords épaissis; semences 3-5, légèrement anguleuses, convexes, tachetées. - Il est cultivé comme plante d'ornement, mais existe it l'état sauvage ì Deshaies (sommet du Gros-IIorne, seul endroit ou jaie rencontré cette espèce $).\left[\mathbf{N}^{\circ} 3038\right.$.

Mantinique. Vulgo: Pompon rouge. - Abondant sur la côte sèche entre le Carbet et Case-Pilote. - Fi. a toutes les époques de l'année. [X゚o 1161.

Nota. - L'espèce de Deshaies dilfère de celle qui est cultivée et de celle de la Martinique par les ramuscules qui portent, dans toute leur étendue, quatre rangées de squamules imbriquées et très rapprochées; c'est peut-ètre une espèce particulière. [No 3227.

G. tergemina Benth.; Calliandre trigéminée. Vulgo: Bois-patate (ì cause de ses racines noueuses). Plum., édit. Burm., t. 10, I. 1. (Inga $W^{2}$.) Arbrisseau ornemental, haut de $0^{\text {" }} 90-1^{\mathrm{m}} 70$, à tiges grêles, à rameaux penchés, parfois un peu sarmenteux, à écorce blanchâtre, à racines traçantes, noueuses, très allongées. Feuilles solitaires, ou géminées ou fasciculées, ì une paire de pennes, portant le plus souvent une paire et demi de folioles ou 1-2 paires (la foliole intérieure de chaque penne avortant), obliquement ovales, arrondies au sommet, folioles terminales plus grandes et plus rapprochées; pétioles tiliformes. Fleurs axillaires, pédonculées, purpurines rémien par 2-4, en capitules globuleux; étamines 10, trois fois plus longues que le

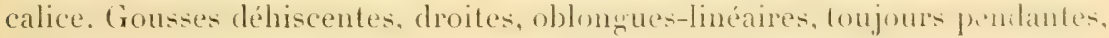
stipitées, cartilagineuses. - Abondant dans les endroits secs, pierreux et chauds: Saint-Pierre (Boulerard), Case-Pilote, Trois-llets, etc. Alt. 5-70 mèt. $\left[\mathrm{X}^{\circ} 1165.\right]$ - Je ne l'ai pas trouvé à la Gruadeloupe.

G. Iatifolia $\mathrm{Gr}_{\mathbf{r}}$; Calliandre à larges feuilles. Vulgo : Acacia-rivière, poisdoux bâtard. Br., Jam., t. 22, f. 3; Plum., éd. Burm., t. 9. - Grand arbuste ou petit arbre, à branches très divariquées, horizontales ou penchér.s. Fenillé it une, souvent à deux paires et demi de folioles, larges : celles de la première paire, alternes; celles de la dernière paire, opposées, rapprochées, longues de $8-13 \mathrm{~cm}$. sur $1-5 \mathrm{~cm}$. de large, chacune pourvue de quatre nervures arquées

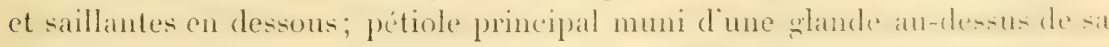
base et d'une autre entre la dernière parre. Inllorescence caulinaire; fleur's purpurines ou rouge cramoisi, ou plus rarement blanches, en fascicules nombreux, situés tout le long des branches; étamines 20 , soudées it la base. Gousses arquées, plus ou moins sinuées, biconvexes, longues de $10-13 \mathrm{~cm}$. sur $2 \mathrm{~cm}$. de large; semences 5-11, orbiculaires, biconvexes. - Asse\% abon- 
dant le long des rivières de Case-Pilote, dans leur cours inférieur. - Cet arbre a beaucoup de ressemblance avec le pois-doux (Inga laurina W.). Alt. 0-120 mèt. [No 1162.] - Je ne l'ai pas v'u à la Guadeloupe.

C. portoricensis Benth.; petit arbre à branches sarmenteuses tombantes, à feuilles vert foncé, d'une grande beauté; est cultivé comme plante d'ornement à la Martinique, [No 835.$]$ - Originaire de Porto-Rico.

Le G. Saman Gr., Inga Saman IV., vulgo : Samana, arbre gigantesque, originaire du lirécil, es cultive au Jardin botanique de la Base-Terre N"3036;, à la Martinique au Jardin botanique de Saint-Pierre, et sur plusieurs propriétés du pays, comme arbre d'ombrage. [Nº 1163.

L. Enterolobium cychearpum Mart. (Inga W.), arbre énorme, originaire de la Jamaïque et du Venezuela, très remarquable par ses gousses larges, noires. sinnés-angulenses sur le bord extérieur. aplaties, indéhiscentes, formant un corcle complet el laissant au milieu un petit espace vide. Lintérieur du fruit contient une pulpe blanche. comestible. - Cultivé au Jardin botanique de Saint-Pierre. $\left[\mathrm{N}^{0} \cdot 1160.\right]$

Pithecolobium Mart. (du grec " pithex ", singe, et " ellobion ", anneau d'oreille, parce que les fruits, par leurs spirales, rappellent la forme de l'oreille du singe.)

P. unguis-cati Benth., Inga guadalupensis Desv. Vulgo: Griffe-chat, lendre at caillou riviere, hois trainant aux Saintes), collier diable. Desc., vol. I, 1. 11, p. 51; Plum., édit. Burm., t. 4 (Mimosa L.) - Arbrisseau ou petit arbre, selon le terrain, habituellement très toulfu, muni daiguillons géminés. très courts ou inerme, à écorce blanchâtre. Feuilles à une paire de pennes, portant une paire de folioles obovales, inégales à la base, échancrées au sommet; pétiole commun long de $3 \mathrm{~cm}$. folioles longues de $3-5 \mathrm{~cm}$. sur $2-1 \mathrm{~cm}$. de laree Inflorescence en capitules ghblubleux, formant des grappes axillaires ef terminales: comble blanc jaunatre; fleurs sessiles; étamines monadelphes. Gousses comprimées, sinuées, décrivant deux ou trois tours de spirale; graines noires, rondâtres, comprimées, en forme de lentilles, très lisses, luisantes, entourées, à un tiers près, d’un arille copieux, blanc, charnu. L'écorce est amère, astringente et fébrifuge. - Endroits secs, rocailleux, près de la mer. - Abondant sur la côte, entre Le Baillif et Deshaies, les Saintes

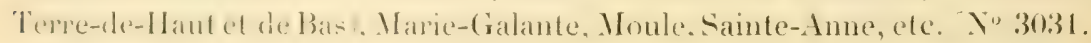

M.nntixigte. Vulgo: Diaballe, acacia à bracelets. - Sur la côte sèche,

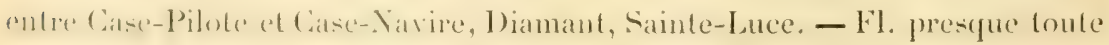
l'année. [No 1161 .

P. micradenium linnth.; P'illécolobe a petiles glandes. Vulgon: Fougère. - L. plus souvent arbe de stande taille, droit, à branches très divariquées. 
étalées, horizontales ou penchées, à écorce grise, peu gocrcée. Fenilles de 4-7 pennes, longues de 5-9 cm., portant 3-12 paires de folioles, longues de $1-2,5 \mathrm{~cm}$. sur $1 \mathrm{~cm}$. de large, luisantes, blanchâtres en dessous, rhomboïdes ou trapézö̈des, ce qui distinğue cet arbre facilement de son congúnere; pétionl.

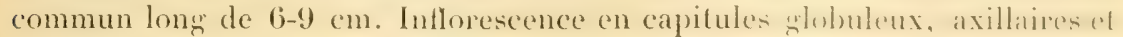
terminaux, portés sur un pédoncule long; fleurs blane jaunâtre. Gousses rouges, comprimées-aplaties, formant deux ou trois tours de spirale, sinuces sur les bords; semences rondâtres-ovoïdes, grises, enveloppées, sur les deux tiers de leur longueur, d'un arille charnu, blanc. - Fl de décembre à mars. - Abondant dans les hauteurs pierreuses et sèches du Vieux-Fort, Houëlmont, Gourberre mornes Goblin et Dos-d'Ane , hauteurs der Trois-livieres. el des Vieux-IIabitants, etc. [No 3375.$]$

Il n'existe pas à la Martinique, mais abonde dans les bois secs de la Dominique et de Sainte-Lucie.

Inga W., Mart. (nom caraïbe de la plante.)

I. laurina W.; Inga à feuilles de laurier. Vulgo : Pois-doux, pois-doux blanc. (Mimosa L.) - Arbre de taille moyenne, plus rarement de grande taille, à tronc généralement droit, cylindrique, anfractueux, très branchu, à écorce grise ou blanchâtre, unie. Feuilles à 1-2 paires de folioles: celles de la paire inférieure, plus petites ou réduites à une foliole, luisantes, coriaces, elliptiques, ou elliptiques-oblongues, terminées par une pointe obtuse. Inflorescence en grappes axillaires, spiciformes, souvent allongées, très nombreuses, situées le long des branches, surtout vers l'extrémité; fleurs blanchers. odorantes, subsessiles; corolle infundibiliforme; etamines soudées it la batse. Gousses renflées à l'endroit des graines, arquées, de longueur tris variable. mais ne dépassant guère $13 \mathrm{~cm}$. de long, vert jaunâtre; semences placées transversalement, nichées dans une pulpe blanche, abondante, d'une saveur douce et agréable, dont les enfants, les oiseaux, les rats et les fourmis sont très friands. - Très abondant dans toute la Guadeloupe, jusqu'ì une altitude de 650 mèt. - On le plante en lisières pour abriter les caféiers, les cacaoyers, les bananiers, etc. - Fl. en mars, avril. [No 2633.]

Mlartinique. Vulgo : Pois-doux, - Abondant, - On en fait également des haies pour abriter les plantations; on prélère cependant les haies de valloat No 1157.]

I. martinicensis Prl.; I. coruscans W. Vulgo : Pois-doux-montagne. Petit arbre tortueux, d'un port peu élézant, à hranches divariqués. horizon-

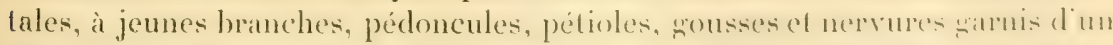

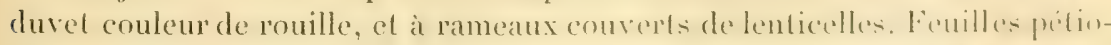

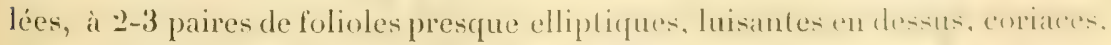
longues de 6-12 cm. sur í cm. de large; pétiole principal muni d une tamb. concave, sessile, nu ou maryiné, an-dessus du sommed. Inflonescence en cph- 
axillaires, courts ou allongés; calice pubescent, comme dans la précédente espèce; corolle blanche, hérissée de poils, deux fois plus longue que le calice et renfermant le tube staminal. Gousses longues de $8-10 \mathrm{~cm}$. sur $2 \mathrm{~cm}$. de large, droites, à bords relevés, terminées par un bec tantôt droit, lantôt recourbé. - Fl. en mai et juin. - Rare. Çà et lì dans les hautes montagnes, aux endroits exposés aux grands vents : Savane aux Ananas, morne du Matelyane, coulée de la Ravine-à-Déjeuner (au pied de la Grande-Découverte). Alt. $800-1000$ mèt. [No 3230 .

Martriguce. Vulgo : Pois-doux-montagne. - Cà et là dans les grands bois de la Montagne-Pelée et des Pitons-du-Carbet. [No 1155.$]$

I. ingoides W., Mimosa Inga L.; Inga ressemblant au vrai Ingra. Vulgo: Pois-doux poilu. - Assez grand arbre, souvent arbre de grande taille, ì branches très étendues et fortement penchées, à trone droit, à écorce grisâtre, à pédoncules, pétioles el nervures revêtus d'un duvet épais, couleur de rouille. Fenilles de $3-5$ paires de folioles elliptiques; pétiole primaire ailé et portant des glandes entre les folioles. Inflorescence en grappes corymbilormes; calice couvert d'un duvet laineux et roux, tubuleux, à 5 dents pointues, courtes; corolle blanche, en entomnoir, une fois plus longue que le calice, à 5 lobes; étamines environ 30 , soudées en un tube long de $5 \mathrm{~mm}$., d'un beau rouge; pistil plus long que les étamines. Gousses de longueur variable: les plus longues ne dépassant pas $16 \mathrm{~cm}$., garnies d'un duvet laineux, épais, court, couleur de rouille, droites ou arquées, à quatre côtes arrondies dont deux plus larges ; semences 10-15, noires, de forme irrézuliere, nichées dans une pulpe sucrée et rafraichissante. - Le bois est dur et se fend facilement : on l'emploie pour faire des merrains. - Fl. en août, septembre et octobre. - Abondant dans les bois du Gommier, des mornes Goblin el Dos-d'Ane Gourberre, de Ilouëlmont, des Vieux-IIabitants, de la Capesterre (Guadeloupe), des Trois-Rivières. [Nos $3035,3229,3601$.

Martixique. Vulgo: Pois-doux gris. - Assez abondant dans les bois du morne Saint-llartin bois de Galbiac, du Champflore, du Parnasse; abondant dans les environs de la fontaine Didier, etc. [No 1158.]

SOLXINE-ONZİME FAnLLE. - CONNARACELS.

Connarus L. (du grec "konnaros ", arbre inconnu, qui, selon Athenceus, se trouvail dans les environs d'Alexandrie.)

G. grandiflorus Planch.; Connarus à grandes fleurs. Vulgo : Liane à barriques. - Puissante liane, sans vrilles, pouvant s'élever sur des arbres très grands, à écorce unie, noirâtre, à rameaux et panicules garnis d'un duvet 
couleur de rouille. Feuilles très grandes, imparipennées, à 5-11 folioles ovales ou ovales-oblongues, obtuses au sommet, arrondies it la base. Inflorescence en panicules axillaires, sou vent très allongées, pouvant atteindre jusqu ì $35 \mathrm{~cm}$. de long; fleurs petites, subsessiles; calice à lobes imbriqués; pétales blancs 5 ; étamines 10 , alternativement grandes et petites, unies it la base. Fruils folliculaires, biconvexes, obovales, longs de $3,5 \mathrm{~cm}$. sur ' $2 \mathrm{~cm}$. de large, droits du côté de la suture dorsale, recourbés du côté de la suture ventrale ; valves dures, noires; endocarpe rouge en dedans; semences noires, lisses, olivilormes, enveloppées dans à peu près le tiers de leur longueur d'un arille blanc, charun, souvent frangé sur les bords. - Assezabondant le long des rivières et dans les falaises des boisinférieurs des Bains-Jaunes (rivières Noire et liouge), de Gourbeyre (Dolé), des Trois-Rivières, etc. - Fl. en juin, juillet, aoûl. [No 2411 .

Martrique. Vulgo: Liane-barrique. - Rare : çì et lì dans les bois du Champtlore avoisinant le Lorrain. [No 833.

SOTXXTE-DOUZIÈMe FAMLLE. - CHR YSOBALANÉES.

Chrysobalanus L. (du gree "chrusous", couleur d'or, et "balanos ", gland. parce que les fruits ont la forme d'un gland et sont jaunâtres avant d'être mùrs.)

C. Icaco L.; Chrysobalan Icaco (mol carä̈be). Vulgo : Icaque, zicaque. Petit arbrisseau droit, touffu, ou grand arbuste, rarement petit arbre, à branches fastigiées dans les jeunes pieds, divariquées ou parfois penchées dans les pieds adultes ou vieux. Feuilles ovales, arrondies au sommet. Inflorescence en corymbes axillaires et terminaux, plus courts que les feuilles; lleur's blanches; étamines unilatérales, jusqu’ì 20, gynophore court, adné an tube du calice. Drupe obscurément marquée de 5̆-6 côtes, bleu foncé ou pourpre, ou parfois blanche, ovale, de la dimension d'une prune; comestible. - La pulpe est blanche, adhérente au noyau, d'une saveur donce el astringente; on la mange crue ou confite arec du sucre. Toutes les parties de la plante contiennent du tanin; l'écorce, prise en infusion, est un excellent remède contre les cours du ventre et la dysenterie 1. - Abondant sur le bord de mer, où il vit souvent en société sur une grande étendue, el sur les mornes secs inférieurs. Alt. 0-350 mèt. [No.2730.]

1. Cette plante, connue ì la Guyane sous le nom de prune-colon, prune de l'anse, iो cause de la nature el de la forme de son firuit, y est employée dans ses rácines, écorces el feuilles, à titre d'astringent dans les cas de diarphe on de leucorrhée. Le suc des feuille. et des racines battu avec de l'huile est employé par les matrones pour resserier les muqueuses du vagin et simuler la virginité. (L. II.) 
Mantringue. Vulgo : Icaque, zicaque. - Hauteurs de Base-Pilote, Diamant (bord de mer et hauteurs), la Régale, etc. [ $\mathrm{N}^{\circ} 154$.]

G. cuspidatus Grisb.; Chrysobalan à feuilles cuspidées. Vulgo : Icaquemontagne, icaque grand-bois. - Petit arbre, haut de 3-5 mèt., droit, très hranchu, at branches ef rameanx couverts de lenticelles blanches et de rugosités. Feuilles coriaces, elliptiques, cuspidées, nettement obovales. Fleurs pédonculées, blanches, solitaires ou réunies par 2-3, axillaires. Drupe obovale presque sieche, munie de J-ficoles saillantes. - Fl. presque toute l'année. - Dans les bois de l'As-de-Pique, des Bains-Jaunes et du-Gommier. [Nos 3476,3633 .

Martinique. Vulgo : Zicaque-montagne. - Assez abondant au Piton-Gelé, sur les mones qui entourent le Champllore, et dans les hauteurs de CasePilote (Savane Saint-Cyr). [No 154.$]$

Hirtella L. (du latin " hirlus ", rude au toucher, allusion à la nature des feuilles et des jeunes branches, qui sont très scabres.)

H. Iriandra Sw.; Hirtelle à trois étamines. Vulgo : Icaque à poils, icaque poileux. - Le plus souvent petit arbre, rarement arbre de taille moyenne, droit, it branches lastigiós, ou horizontales ou penchées. Feuilies très scabres, poilues en dessous, surtout sur les nervures, elliptiques, cuspidées. Inflorescence en grappes ou en panicules; fleurs grandes, blanches ou pourpres; calice Jofide: pétales J; étamines 3, unilatérales. Fruit drupacé, bleu foncé ou noir, poilu, obové-oblong, comestible. - Le bois est dur et sert pour la construction à l'extérieur et à l'intérieur. - Fl. presque toute l'année. Abondant dans les grands bois inférieurs des Bains-Jaunes, des environs du Canmp-Jacol), du Gommier, des Trois-hivieres, des hauteurs du Baillil, des Vieux-Habitants, de la Bouillante et de la Pointe-Noire, etc. Alt. 400800 mèt. [No 2214 . $]$

Martixique. Vulgo: Icaque poileux, bouis poilu, icaque grand-bois. Morne-liouge, (irand'Anse, hauteurs du Prècheur, hauteurs de Case-Navire. [No 2140.

H. pendulat sol.; I Tirtelle it grappes pendantes. Tulgo: Leaque grand-bois, icaque poilu. - Arbrisseau ou petit arbre, haut de 4-5 mèt., à branches inféricures très inclinées ou pendantes, à grappes verticalement pendantes. Finilles tries sabres, surtout en destous, oblongues-lancéolées, insensible-

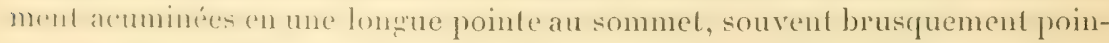
Lues, nervures très saillantes en dessous et garnies de poils courts, rudes et roux. Inflorecence le plus souvent en srappes composés, surtout a la base, Lomenteuses, couleur de rouille, très allongées, atteignant souvent $32 \mathrm{~cm}$. de long; calice persistant; étamines 5-6. Drupe obovée, pubescente. - Cà et là dans les bois de Houëlmont, de Sainte-Rose (Sofaya). [No 3255.] 
Il n'existe pas à la Martinique, mais il est très abondinut dans bes hauteur. de Castries (île de Sainte-Lucie). [No 1904.]

Licania Aublet (anagramme du mot "Calignia ", nom de l'athre à lal (iuyane.)

L. Ternatensis Hook.; Licanie de Ternate. Vulgo : Bois-diable, bois gris, bois de fer. - Très grand arbre, souvent arbre gigantesque, droit, très anfractueux à la base, à tronc cylindrique dans le haut, à fronde très large et arrondie, it rameaux presque toujours couverts de lenticelles blanchatret ou rouges. Feuilles très coriaces, épaisses, ovales-elliptiques, cuspidies, blanches en dessous, à côte et nervures très saillantes à la face inférieure, et rouges. Inflorescence en grappes terminales, courtes, pubescentes, blanchatres; calice a 5 dents; pétales nuls; étamines 3 ou f. Drupe sèche, obovale, tomentruse, souvent sillonnée ou striée; semence 1. - Le bois est rouge en dedans, extrêmement dur et incorruptible; il sert pour les constructions it l'extéricur et surtout pour les constructions sous terre et dans l'eau. - Assez commun dans les bois du massil de Houëlmont, des Vieux-IIabitants, de la lionillante, de la Pointe-Noire, des Trois-Rivières. - Fl. de mai en août; fruits mûrs en octobre et novembre. - Alt. 300-700 mèt. [Nº 2868.

Martinique. Vulgo : Bois de fer, bois gris, bois résolu. - Bois des FondsSaint-Denis, du Camp de l'Alma, des hauteurs de la Grandilnse, du GrosMorne, du Lorrain, etc. [No 1902.]

Le Licania pyrifolia Gr. existe à la Dominique el a été introduil ì la Marrtinique, sur l'habitation Pécoul. [Nº 153.$]$

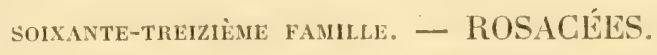

Prunus L. (du latin " prunus »; prunier, qui vient du grrec "prouné ».)

P. Dussii Kr. et Urb. (n.sp.); Vulgo: Bois-noyau. - T'antôt petit arbre, tantôt arbre de grande taille, d'un port élégant, à branches suprérieures lasligiées, les inférieures horizontales, à tronc très droit, cylindrique, at incorece brune, légèrement grercée, à feuilles très vertes, toujours a moitie fermén. Feuilles longues de 5-9 cm. sur 3-5) cm. de large, ovales-elliptique's on orées. fermes, luisantes, terminées en pointe obluse ou souvent réluse, wu lénererment échancrée, arrondies à la base et souvent munies de deux taches, ou brusquement rétrécies en un pétiole cannelé, longr de $(i-10)$ mm. Intleréserencer axillaire, en grappes spicilormes, extremement nombertses. hmbles de :3-

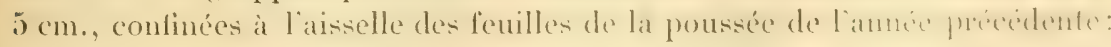
fleurs blanches, petites, odorantes; calice infundibiiforme, ch:mbu, hlanc pathe.

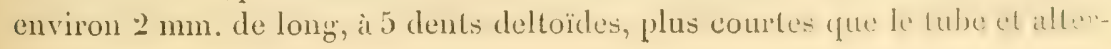


nant avec les pétales; pétales 5 ou plus rarement 6 , concaves, arrondis, longs de $3 \mathrm{~mm}$, ; étamines en nombre double des pétales, insérées sur le rebord du calice, cing ou six d'entre elles sont penchées en dehors et plus longues, elles alterment arec les pétales, les autres, plus courtes, sont opposécs aux pétales et penchées vers le pistil; filet blanc, subulé, coniquealloneré; ovaire libre, sessile ou subsessile au fond du calice; ovules collatéraux; style droit, aussi long que les étamines les plus courtes; stigmate troncqué, obscurément trilobé; pédicelles de la base de la grappe plus longrs que le calice: les supérieurs, plus courts. Drupe plus large que longue, 12-14 mm. de large sur 8-9 mm. de long, à péricarpe sec, brun en dehors; cotrlédons très larges, sans albumen. - Cà et là dans les parties inférieures des bois des Bains-Jaunes, du Gommier, des environs du Camp-Jacob, du Matouba. - Fl. en mai, juin. - Le bois est dur, élastique et très recherché pour le charronnage; on peut extraire des feuilles une essence qu'on emploie en ruise de créosote contre les maux de dents. - Alt. 280-600 mèt. [No 2731.$]$

Martixique, Vulgo : Noyau de France. - Bois inférieurs du morne SaintMarlin, hauteurs du Prêcheur (Céron), de Case-Pilote, de Case-Navire, etc. $\left[\mathrm{N}^{\circ} 1907.\right]$

Rubus I. (du latin " ruber ", rouge, à cause de la couleur rouge des fruits dans un grand nombre des espèces de ce grenre.)

R. rosifolius Smith.; Ronce à feuilles de rosiers. Vulgo : Framboisier, framboise, - Arbrisseau ou sous-arbrisseau buissonnant, très toulfu, torlneux, parfois samenteux, a liges el rameaux garnis de petits aiguillons, droits nu crochus, souvent implantés à rebours. leuilles à folioles orales-elliptiques, doublement serretées, pubescentes, à dents mucronulées; pétioles communs et pédoncules armés d'aiguillons erochus. Fleurs blanches, solitaires ou en cymes pauciflores et terminales; calice 5-partite; pétales 5; étamines nombreuses, en nombre indéterminé; ovaires nombreux, insérés sur un réceplacle charnu, conico-cylindrique, surmontés d'un style caduc; carpidium rouge, ovoïde, charnu. - Les fruits se mangent soit sans apprêl, soit dans le vin blanc sucré. - Fl. surtout d'octobre en mai. - Abondant le long des chemins, dans les clairières et sur les lisières des bois de la moyenne région de Loute la Guadeloupe. [No 2203.

Martineue. Vulgo: Framboisier. - Abondant. [No 152.]

R. jamaicensis Sw.; Ronce de la Jamaïque. Vulgro: Grand framboisier, lramboisier blanc. - Vivace, grimpant, haut de $3-5$ mèt, à racines stolonilères, à tiges el rameaux hérissés de poils droits, roux, entremêlés de rares piquants crochus, à pétioles primaires, secondaires, et pédoncules également poilus et granis de nombreux aiguillons recourbés et implantés à rebours. lieuilles palmées, a 3-5 folioles d'inégale grandeur, ellipliques, acuminées, 
finement et inégalement serretées, munies en dessous d'un duvet court el blanc; pétiole commun long. Fleurs petites, blanchâtres, en panicules terminales, laineuses; pétales obovales, aussi longrs que les segments du calice; carpidium presque sec, noir à la maturité. Fruil obovale. - Fl, en mars, avril, mai. - Rare : Haut-Matouba (bord de la rivière Rouge, près du pont). [No 2215.] - Il n'existe pas à la Martinique.

De celte famille, on rencontre, sans parler des nombreuses et belles espèces et variétés de rosiers, qui ornent les parterres et les jardins : l'Eriobotrya japonica Lind., vulgo : Néflier du Japon [No 3477], Martinique [No 2141], quon cultive pour ses liruits; le Raphiolepis indical Lind, pelil buisson, li'es beau; se trouve au Jardin botanique de Saint-Pierre.

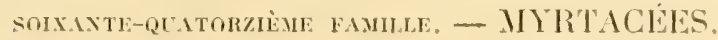

Psidium L. (clu gree " psicin », donner à manger, indiquant l'usage quion fait de ces fruits propres à ces plantes.)

P. Guajava L. (mot de la langue des Indigènes de l'Amérique du Sud.) Vulgo: Goyavier. Dese., vol. II, 1. 72, p. 30. - Le plus souvent petil arbre, Lortueux, nu dans le bas, à branches très divariquées, à écorce très lisse, mince, verte ou rougeâtre, à jeunes rameạx tétragones et pubescents. Feuillesopposées, membraneuses, fermes, oblongues ou elliptiques-oblongues. légèrement veloutées en dessous et pâles, à nervures saillantes en dessous, imprimées en dessus. Fleurs blanches, le plus souvent réunies par deux, ¿ l'aisselle des feuilles et opposées; calice diabord fermé el renfermant la flent. ensuite 1-denté après l'ouverture de celle-ci; pétales 5; ovaire à 2-5 logres multiovulées. Fruil baccien, ovoüde, couronné par les lobes persistants du calice; semences très nombreuses, nichées dans une pulpe succulente. - Les fruits sont recherchés pour la table. Verts, ils sont astringents; à l'état de parfaite maturité, ils sont au contraire laxatifs. Les graines sont dures à ce point qu elles ne subissent aucune alteration dans l'estomac de l'homme des oiseaux, qui en sont friands. Restituées, après digestion, elles grardent leur faculté germinative. Aree les fruits on fail d'excellentes compotes el des confitures; avec les fruits débarrassés des graines, on prépare des goelées universellement appréciées. L'écorce de la racine, les jeunes leuilles et les boutons sont toniques et astringents, et s'emploient souvent dans le pays contre la 
dysenterie! Le bois est dur et sert pour la menuiserie. - Par la culture, on a obtenu une assez grande variété de goyaves dont les principales sont : la goyave-poire (P. pyriferum L.), la goyave ronde (P. pomiferum L.), la grosse

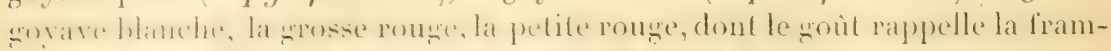
boise. - Les goyaviers fleurissent habituellement d'avril en juillet. - Alt. $0-700$ mèt. [No 2992.

Martingue. Vulgo: Goyavier. - Très abondant. [No 1850.]

P. Callleyanum Sabine, variété coriaceum O. Berg. Vulgo : Goyavierprune, originaire de la Chine et du Brésil, arbrisseau ou grand arbuste, à lenthes tris tables, coriaces, subcharnues el luisantes, à petits fruits ronds et rouges. [Nos 2993, 2198.]

Mantinique. [No 1848 . ]

P. Araça Radd., P. guineense Sw. Vulgo : Goyavier-fraise, originaire de la Trinidad et de l'Amérique tropicale, arbuste ou petit arbre, a fruit de la

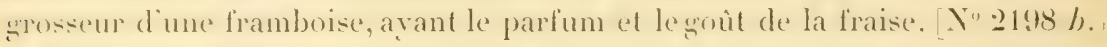

Martixieve. Vulgo : Goyavier-fraise. [Nos 595, 65\%.] - Sont cultivés dans les cours et les jardins.

Amomis Berg. (du grec " amomos », irrépréhensible, de " a ", privatif, et " momos », blâmable, c'est-à-dire des plantes dont l'odeur et le parfum ne laissent rien a desires. Genre corrige par Krü ef Lrban dans : Addimenta ad cognitionem florx Indix occidentalis, particula II, anno 1895.

A. caryophyllata Kr. et Urb., Pimenta acris Sw.; Amomis dont les dillérentes parties tiennent de la nature du giroflée. Vulgo : Bois d'Inde. - Arbre

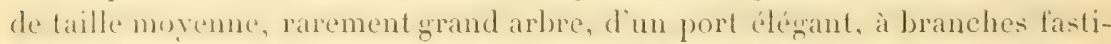

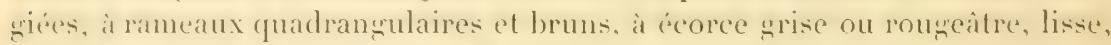
sc détachant par plaques minces. Fenilles presque toujours fortement roulées. oblemguts un lanceolexs-oblongutes, ou elliptiques. échancrées au sommet, très coriaces: les jeunes, garnies d'une infinité de points transparents; les audulter, opatques. Fleurs blanches, tresodorantes, en cymes corvmbilormes, terminales, dépassant de beaucoup les feuilles; calice à $\mathbf{1}-5$ lobes, tube turhini: preales 1-j); waire a deux cellules biovules. Drupe ovoüde, noire, pulpeuse, contenant une semence. _ Toutes les parties de la plante exhalent

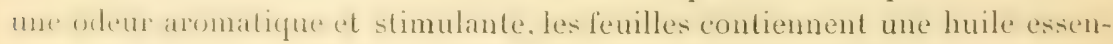

1. Le goyavier a été l'objel de recherches botaniques, chimiques et pharmacentiques, dans un remarquable travail de MI. Ḱhouri, qui a paru aux Annales de l'Instilut colonial de Marseille, 1895. Cet auteur y a démontré dans les feuilles l'existence d'une huile essentielle antiseptique et d'un tanin spécial (acide psiditanique), qui justifient scientifiquement remploi populaire de cette plante contre les diarriées atoniques des pay's chauds. (E. II.) 
lielle 1. - Relativement peu abondant a la Guadeloupe p pluc commun it lie Grande-Terre, sur les mornes calcaires el a la Desirale a Marie-(ralantr, aux Saintes (Terre-de-Bas), etc. [No 2209.]

Martinique. Vulgo : Bois d'Inde. - Abondant: Anses-d'Arlet (morne Larcher, où il forme des forêts), hauteurs des Trois-llets, de Case-Pilote, du Diamant, etc. [Nos $1210,1843$.

Mitranthes Berg. (du grec "mitra ", mitre, turban, et "anthos ", fleur, parce que les lobes du calice forment une coiffe qui couvre les fleurs avant leur épanouissement.)

M. Egyersii Viedenzu.; Mitranthe dEgrers baron danois, capitaine de vaisseau, qui a publié la flore de Saint-Christophe, de Sainte-Croix, de Saint-Thomas, etc.). Vulgo : Cerisier-montagne petite-feuille. (Marlieriopsis Kiersk.). - Petit arbre, élégant, droit, rarement assez grand arbre, à branches très nombreuses, fastigiées, à écorce grise ou noirâtre, lisse. Feuilles petites, ovales-elliptiques, coriaces, terminés en pointe obtuse,

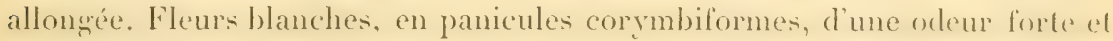
agréable. Drupe petite, ovoïde. - Fl. en juillet, août. - Assez rare : bois de la Grande-Citerne, des Bains-Jaunes partie supérieure), hois du Maldrane, etc. $\left[\mathrm{N}^{\circ} 3463.\right]$ - Il n'existe pas à la Martinique.

Myrcia D. C. (du grec «muriné », myrte, parce que ce genre était autrefois confondu avec le genre Myrtus.)

M. paniculata Kr. et Urb., M. coriacea D. C.; Myrcie à feuilles très membrancuses et fermes. Vulgo : Bois-Fustet, bois de sante-Jucic merister bois petite-feuille. - Arbrisseau, ou grand arbuste, haut de 2, 5-3 mèt., rarement petit arbre, à branches étalées ou fastigiées, à écorce lisse et grise, à jeunes rameaux rougeatres, légerement pubescents ou glabres. Feuilles fris coriaces. très variables quant aux dimensions, tantôt brièvement pétiolées, tantôt presque sessiles, ovales ou obovales, échancrées au sommet ou non, très luisantes en dessus. Fleurs blanches, odorantes, en panicules corrmbiformes. Fruit pulpeux, noir, plus grand qu'une graine de poivre. - On en rencontre deux variétés bien distinctes :

$\alpha$, variété Jacquiniana Gr. Vulgo : Merisier, arbrisseau ou petit arbre, faiblement feuillu, à feuilles larges, très luisantes, coriaces el polies, à

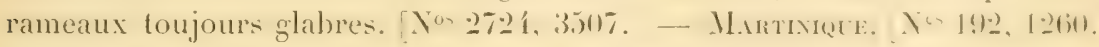

1. Cette essence, très agrréable mais d'arrière odeur poirrée, pourrait ètre employece surtout dans la parfumerie anglaise et devenir, en raison de l'abondance de ce vérgétal, une source de revenus importante pour la colonie. I.es feuilles de cel arbre sont stimulantes, et, distillées aree du rhum, elles sont inscrites dans la pharmacopée des litatsUnis sous le nom de Bay-rum et Spirilus Myrcia. (E. H.) 
G, variété Imrayana D. C. Vulgo: Merisier bois petite-feuille, arbrisseau ou grand arbuste, très ornemental, à branches très fastigiées, grrèles, à feuilles plus petites, ternes des deux côlés, légèrement échancrées au.sommel, ì jennes rameaux el pédoncules garnis de duvet couleur de rouille, ì panicules moins allongées. [Yos 2199, 2207, 3516, 3517.] - Mantixique. [No 201.]

Les deux variétés fleurissent en mai, juin, juillet. - Abondant dans les mornes inférieurs, secs, de toute la Guadeloupe : Vieux-Fort, Baillif, V̈ieuxIIabitants, Deshaies, etc.

M.nmtinqui, - Case-Pilote, Diamant, Sainte-Anne, Vauclin, Caravelle, etc.

M. dumosa Kr. et Urb.; Myrcie buissonneuse. Vulgo : Merisier-montagne, goyavier-montagne petite-feuille. - Arbuste on petit arbre, droit, très feuillu, ¿̀ branches fastigiées. Feuilles très coriaces, épaisses, obovées, obtuses au sommet ou très brièrement acuminées, rétrécies à la base en un pétiole trìs court : les jeunes, rouges en dessous; les adultes, grises du même côté. Baie mûre, noirâtre, ruguleuse, peu pulpeuse, globuleuse, pouvant atteindre la grosseur d'une petite cerise. - Fl. en juin, juillet. - Abondant dans les endroits ventés des grands bois du Gommier, des hauteurs du Matouba, des Vieux-Habitants, du massif de Houëlmont, de Pigeon, de la Savane aux Ananas, de la Grande-Découverte, du morne de la Madeleine (Trois-Rivières). - Sur ces hauteurs, il est rabougri et n’atteint souvent pas 1 mèt. d'élération. - Alt. 300-1080 mèt. [Nos 2727, 3207, 3514, 3588.]

Martixique. Vulgo : Merisier. - Pitons-du-Carbet, hauteurs de CasePilote et des Trois-Ilets (abondant). [No 1250.

M. edulis Kr. et Urb.; Myrcie at fruits comestibles. Vulgo : Goyarierbois. - Grand arbuste ou très petit arbre, élégant, droit, à branches fastigiées ou divariquées, à rameaux très glabres, à écorce lisse et grise. Feuilles longues de 6-12 cm. sur $4-7,5 \mathrm{~cm}$. de large, obovales ou elliptiques, très coriaces, ì côte très forte, à côte et nervures imprimées en dessus, saillantes en dessous el reliées à un are qui court parallèlement au bord et à peu de distance de ce bord; pétiole de $\breve{-}-8 \mathrm{~mm}$. de long. Fleurs en grappes corymbiformes, axillaires et terminales. Fruit noirâtre, ruguleux, globuleux, de la grposseur diune petite cerise. - Assez abondant dans les bois de la lavineChaude. [N०3510.] - Il n'existe pas à la Martinique.

M. leptoclada 1). C.; Myrcie à branches faibles, Vulgo : Bois-gruépois. Petil arbre, peu élégant, presque toujours tortueux, ì branches divariquées, it rameatrx minces, faibles el inclinés, à écorce noirâtre. Feuilles membraneuses, très vertes, elliptiques ou ovales-elliptiques, terminées en pointe allongée et obluse. Fleurs b) lanches, en panicules axillaires et terminales. Baie noire, globuleuse, un peu plus grande qu'me graine de poirre. - Fl. en mai, juin, anût. - Abondant sur les lisières des bois inférieurs: Gouberre, 
Camp-Jacob, Trois-Rivieres, hauteur's du Baillif, Mone̊lmont. All. 300600 mèt. [Nos 20201, 3514.

Martineue. Vulgo: Pelit merisier. - Hauteurs el plateau des 'Trois-Ilets el du Diamant (abondant), hauteur's de Case-Pilote et de Case-Navire. [Xo 193.

M. splendens D. C.; Myrcie brillante. Vulgo: Bois petite-feuille, boisbaguette. - Grand arbuste ou petit arbre, élégant, droit, ì branches fastigiées ou plus ou moins élalées. Ressemble beaucoup au précédent; il en diflère par son port, ses rameaux plus lermes, son écorce grise, ses grappes plus nombreuses, plus allongées et plus fournies, par ses flemrs plus grandes et surtout par ses baies plus volumineuses et ovoïles. - Fl. en mai, juin, juillet. - Cet arbuste fait l'ornement des savanes de Gourbeyre, des Palmistes, des environs du Camp-Jacob, des bords inl'érieur's des rivières liougge et Yoire, des 'Trois-Rivières, etc. - C'est l'espèce la plus abondante du genre. - Alt. $50-600$ mèt. [Nos 2994, 3515.

Mantrigel. Vulgo : Bois-baguette: - Abondant : hauteurs et plateau des Trois-Ilets, de Case-Pilote et Case-Navire, des endroits boisés de Ducos, elc. No $19 \%$

M. divaricala Gr., M. berberis D. C.; Myrcie à branches divariquées. Vulgo: Petite-feuille du haut, pelit goyavier bâtard montagne. - Petilarbre, droit, ¿t branches divariquées, souvent horizontales, à rameaux grlabres, ì écorce grise el fendillée. Feuilles très coriaces et rigides, fortement roulées sur les bords, souvent en forme de cuiller, ovales-elliptiques, brièvement pétiolées. Fleurs blanches, très odorantes, en cymes terminales, très nombreuses. Baie ovoïde-allongée, longue de 7-12 $\mathrm{mm}$. sur 4-8 mm. de diamèt. - Abondant dans les bois supérieurs des Bains-Jaunes; plus rare dans les parties inféricures, chemin des Bains-Jaunes à la Savane à Mulets plus ou moins rabougri), hauteurs du Baillit, ete. Alt. $400-950$ mèt. [Nos 2720, 2721.

Mantmique. Vulgo : Goyavier bâtard. - Assez commun : Parnasse (morne de La Croix), Morne-Rouge (Calvaire), bois de l'Ajoupa-Bouillon el de la Calebasse, endroits boisés de Ducos, etc. [Nos 194, 196.]

M. marlinicensis Lir. el Urb. (n. sp.). Vulgo: Bois de basse blanc, bois de fer blanc. - Petil arbre, droit, haut de 3-4 mèt. Feuilles très coriaces el fermes, vert brun, longues de 3,5-6,5 cm. sur 1,5-1 cm. de large, ì pétioles de 1,5-3 mm. de long. Inflorescence en grappes, longues de $3-5 \mathrm{~cm}$., presque glabres, naissant aux aisselles des dernieres feuilles des rameaux, presque aussi longues que les feuilles; pédoncules longes de $1-2 \mathrm{~cm}$., subcomprimés; sépales 5, arrondis au sommet, 1-1,2 mm. de long, dont deux plus longes; lleurs manquent. Baie cylindrique-ovoïde, pulpeuse, longue de $10-1.1 \mathrm{~mm}$. - Peu abondant : sà et là aux Pitons-du-Carbet, au Piton-Gelé, au morne Jacob. No 191 . 
M. deflexa D. C., variété Dussii Kr. el Urb.; M. ferruginea Berg.; Myrcie pliée. Tulgo: Goyavier queue-de-rat, goyavier-montagne. - Générale-

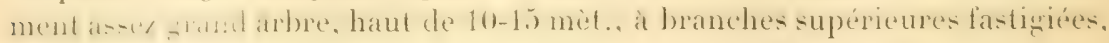
les inférieures divariquées et horizontales, à tronc nu dans le bas, à écorce lisse. Feuilles larges, très variables quant aux dimensions, ovales ou ovées, ou ovées-oblongues ou elliptiques, roulées sur les bords, garnies d'une infinité de points transparents (cryptes); pétiole court, couvert d'un duvet couleur de rouille. Fleurs très blanches et très odorantes, en panicules nom-

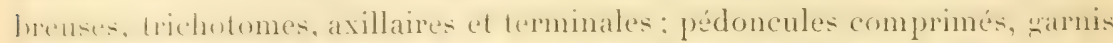
d'un durel cunterur de ronille: bourgerons de feuilles et jeunes feuilles ćmalement munis d'un duvet fin, long et de même couleur que celui des pédoncules. Jeune baie duretée, verte; baie mûre blanche, glabre, subglobuleuse ou ovale-oblongue. - Fl, de mai en juillet. - Abondant dans les bois supéricur: de- Bains--Janes, du Matouba, du (rommier, dans la partie inlérienere de la Savane à Mulets, où il est rabougri et couvert de mousse, hauteurs des Vienx-Habitants, de Pigeon, de la Pointe-Yoire et des environs de la RavineChaude. Alt. 150-1000 mèt. [Nos 2726,3674 .]

Martinique. Vulgo : Goyavier bâtard. - Hauteurs des Trois-Ilets, ravine

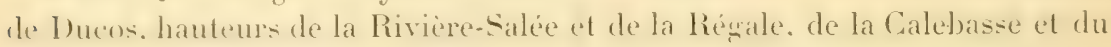
morne Saint-Martin. Alt. 80-600 mèt. [Nos 195, 619, 658. 1]

Calyptranthes Sw. du grec " kaluptra ", couverture, et "anthos ", tleur, parce que le calice forme une sorte de coiffe qui tombe d'une seule pièce à l'éclosion de la fleur.)

G. pallens Griseb.; Calyptranthe à feuilles pâles en dessous. Vulgo : Bois de basse. - Arbuste élégant, haut de 3-4́ mèt., droit, fastigié, nu dans le bas. Fonilles clliptiques. on elliptiquestovales, terminées en pointe allongée et obluse. Fleurs blanchâtres, en cymes trichotomes, axillaires et terminales;

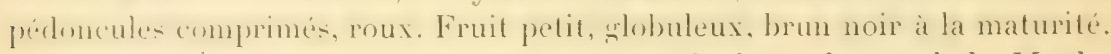
- Rare : dans les terres sèches et pierreuses, le long du canal du Moule. [No3512.] - Il n'existe pas à la Martinique.

G. elegans Kr. et Urb. (n. sp.); Calyptranthe élégant. Vulgo: Boisbaguette, bois petite-feuille. - Grand arbuste ou petit arbre, très élégant, glabre dans toutes ses parties. Feuilles petites, longues de $2-5 \mathrm{~cm}$. sur 1, 3-2 $\mathrm{cm}$. de large, ovées ou ovales, ou subrhomboïdes-ovales, très brièvement acuminées en une pointe obtuse, rétrécies à la base; pétiole long de 1-2 $\mathrm{mm}$. Fleurs blanches, en panicules terminales, longues de $5-9 \mathrm{~cm} . ;$ pédoncules

1. Tous les reprisentants de ce grenre se font remarquer par la présence dans les feuilles d'une quantité notable d'une huile essentielle, à odeur poirrée et très excitante, qui fait rechercher ces feuilles pour les usages culinaires; à titre d'épices, certains Myrcia (M. acris D. C., p. cx.) sont cultivés pour cetemploi aux lndes et à la Réunion. (L. H.) 


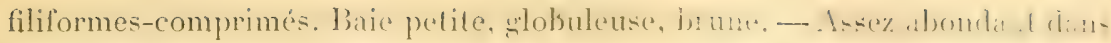
les hauteurs de Case-Pilote (Fond-Layette et Fond-Brulé), Marin (morne Gommier). [No 205:] - Je ne l'ai pas trouvé à la Guadeloupe.

C. sericea Griseb.; Calyptranthe à feuilles soyeuses en dessous. Vulgo: Bois de basse rouge, bois étti. - Arbrisseau très élégant, droit, souvent très

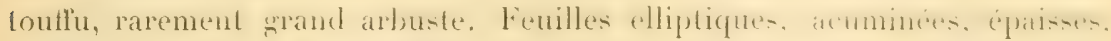
coriaces, d'un vert rouge en dessus, garnies, en dessous, d'un duvet couleur

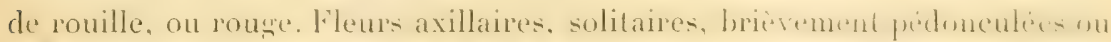

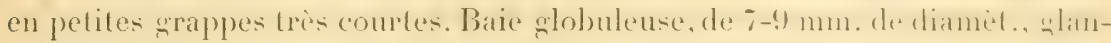
duleuse et soyeuse entre les glandes. - Assez abondant sur les crêtes des Pitons-du-Carbet et des mornes qui environnent les Deux-Choux. - On se sert des tiges pour faire des cannes tres belles, flexibles et fortes. - . 1l. tom880 mèt. [Nos 618, 1243] avec la variété Hahnii. Kr. et Urb. [No 203.] - Je ne l'ai pas vu à la Guadeloupe.

Le C. Forsteri Berg., petit arbre élégant, ne se trouve pas dans nos deux colonies: je l'ai trouvé à l'île de Sainte-Lucie, au fonds Saint-Jacques. $\left[\mathrm{N}^{\circ} 213.\right]$

Marlierea Camb. (dédié à Guido Thomas Marlière, qui, en 18:23, a introduit la culture du maïs, du riz et du café dans les déserts du fleuve Rio Doce au Brésil.)

M. Dussii Kr. et Urb. (n. sp.). Vulgo : Cerisier-montagne. - Petit arbre, haut de 6-10 mèt. ou arbuste rabougri dans les endroits exposis au frand vent, élégant, très branchu, à branches lastigiées ou étalées a tronc nu dinn: le bas. Feuilles très vertes, longues de $2-4 \mathrm{~cm}$. sur $0,2-8 \mathrm{~mm}$. de large, à

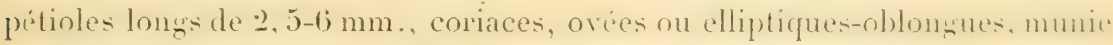
d'une infinité de points transparents (cryptes à essence), rétrécies à la base obtusément acuminces au sommet. Inflorescence axillatire et caulinaire sn whmérules sessiles ou subsessiles composies de 1-t) lleurs, ondoranter, hanc paile: base de la glomérule entourée de bractés suboploculaires. Batie manque. lil. en mai, juin ou juillet. - Dans les grands bois supérieurs du Matel rane.

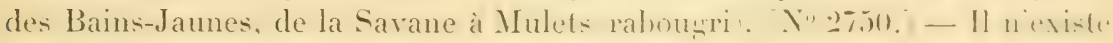
pas à la Martinique.

M. glomerata Berg.; Marlière à fleurs en glomérules. Vulgo : Bois-mus-

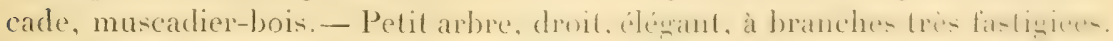

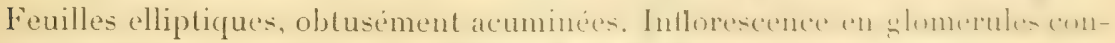

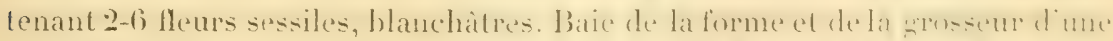

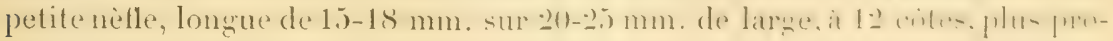
noncées au sommet qu'à la base, à péricarpe de $1 \mathrm{~mm}$. d’épaisseur. - Fi. en novembre et décembre; fruits mûrs en avril, mai. - Le fruit exhale la mème odeur que la muscade proprement dite. - Assez rare : çi et lit dans les 


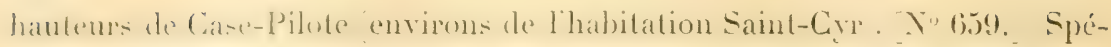
cimeis impartail.

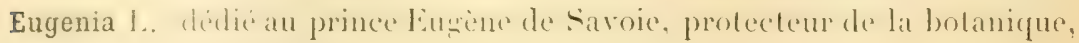
né en 1663, mort en 1736.

E, albicans Rich,; Eugrénie ì feuilles blanchâtres en dessous. Vulgo : Bois-cendre. - Grand arbuste ou petit arbre, haut de 1-5̃ mèt., à branches flexibles, étalées. Feuilles ovées ou ovales, brusquement et obtusément acuminées, blanchâtres ou glauques en dessous, longues de $\mathbf{1}-7 \mathrm{~cm}$. sur 2,5$3,5 \mathrm{~cm}$. de large ; pétioles ruguleux, larges, noirâtres, lonğs de $5-6 \mathrm{~mm}$. Inflorescence axillaire comme dans tous les Eugenia. Fleurs blanches, solitaires

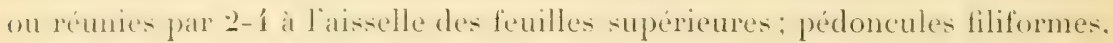
longs de 4-12 mm.; pédoncules, bractées, ovaire et l'extérieur du calice garnis d"un dured grisithe ou couleur de rouille. Baie subghlobuleuse-oroüde, de la grosseur d'une petite cerise, couronnée par les lobes persistants et recourbés du calice; péricarpe sec el dur. - Cà̀ et là dans les grands bois sombres des Fonds-Saint-Denis, de la Grand'Anse et du Camp de l'Alma. N Nos 211 , 212, 1244.] - Je ne l'ai pas vu à la Guadeloupe.

E. ligustrina Villd.; Lugénie à feuilles de troëne. Vulgo : Merisier noir, cerise noire. - Grand arbuste, très élégant et très touth, ou petit arbre, haut de 4 -6 mèl., à branches supérieures fastigiées, les inférieures souvent horizontales ou penchées. Feuilles très luisantes et d'un vert noir foncé en dessus, lancéolées-oblongues ou ovales-elliptiques, longues de $2,5-5 \mathrm{~cm}$. sur $1-2 \mathrm{~cm}$. de large, obtuses au sommet, rétrécies à la base en un pétiole long de $3-5 \mathrm{~mm}$. : les jeunes, pourvues d'une masse de points transparents; les adultes, opaques. lileurs larges, blanches, très odorantes et très nombreuses, solitaires ou réunies par 2-3 a l'aisselle des feuilles, portées sur des pédoncules longs de $\tilde{\jmath}-6 \mathrm{~cm}$., filiformes, roussâtres, pubescents, accompagnés, à la base, de bractéesspatulées, lonğues de $9-10 \mathrm{~mm}$. Baie noire, glabre, luisante, lisse, surmontée des lobes allongés et persistants du calice, d'un diamèt. de $6-8 \mathrm{~mm}$. - Les fruits sont comestibles. - Très abondant dans les terres sèches, calcaires ou graveleuses des Saintes (Terre-de-Haut), Vieux-Forl, Marie-Galante, Désirade, Port-Louis, Petit-Canal, etc. Alt. J-100 mèt. $\mathrm{N}^{\mathrm{N}} 22 \mathrm{2} 10$.

Mantrivel. Vulgo: Crosse merise. - Abondant à Case-Pilote, à la Rivière Pilote (bord de mer), etc. [Nos 198, 1254.]

E. miflora L., E. Michelii Lam.; Eugénie à une seule fleur à l'aisselle. Vulgo: Cerise-côte, cerise à côtes. - Arbuste ou petit arbre, haut de 2-1 mèt., Lies souvent tortueux. Feuilles membraneuses, ovées-lancéolées, obtuses : les jeunes, ganies de nombreux points transparents; les adultes, opaques. lileurs blanches, très souvent solitaires, plus rarement réunies par 2, portées 
sur des pédoncules filiformes, longs de 1, $5-2 \mathrm{~cm}$; lobes du calice linéarresoblongs. Baie d'abord rouge clair, noir brun à la parlaite malurité, aciduléc, pourvue de huit côtes. - Les fruits sont comestibles el rafraîchissants. Fl. en mai, juin, juillet. - On en fait souvent de très belles haies, qui, sous l'influence de la taille, deviennent très épaisses. - Très abondant au CampJacob, à Gourbeyre, au Matouba, ele. It. 10-700 mèt. [No 2201.]

Martinique. Vulgo : Cerise de Cayenue, cerise à côles. - Abondant. On en fait aussi des haies vives. [Yos 1211,1255 .

E. chrysobalanoides D.C.: Eugénie ressemblant au chryobalanus. Vulgur : Grand merisier. - Très grand arbre, droit, très branchu, à branches très étalées-divariquées. Feuilles larges, ovées ou obovales, acuminées, très vertes, surlout en dessus, légèrement rougeâtres en dessous; pétiole court, comprimé-cannelé. Fleurs blanches, odorantes, en grappes trichotomes, tantôt très courtes, tantôt allongées, portées sur des pédoncules longs de $\mathbf{4}-6 \mathrm{~mm}$., bibractéolés au sommet, unibractéolés à la base. Baie ylobulense, moire il la maturité, de la grosseur d'une petite cerise, ou plus petite. - Fl. en mai ou juin. - On met les fruits dans le tafia et le rhum pour leur domner un bouquet particulier. - Planté autour des habitations: Basse-Terres habilation Saint-Aude Gall, Baillif habitation Sainte-Sophie, ete. Y" 2725 b.

E. Trinitatis D.C.; Eugénie de la Trinidad. Vulgo : Bois pelite-feuille. - Arbuste ou petit arbre, élégant, haut de 3-J̌ mèt., droit, à branches fastigiées, à rameaux effilés. Feuilles petites, ovales, acuminées, terminées en une pointe obtuse. Inflorescence en pelites grappes contenant lo-20) llems blanches, odorantes, portées sur des pédoncules filiformes, bibracténlis au sommet, unibractéolés à la base. Baie noire, petite, globuleuse. — Cáa et là dans les hauteurs des Trois-Hets et de Case-Pilote, Caravelle. $\left[\mathrm{Y}^{\circ}\right.$ 199. $]-$ Je ne l'ai pas rencontré à la Guadeloupe,

E. monticola D. C., E. baruensis Ballo, Eugénie des montagnes. Vulgo : Merisier petite-feuille. - Arbrisseau ou grand arbuste, rarement petil arbre, à branches fastigiées, à écorce grise et ruguleuse. Feuilles petites, elliptiques, cunéiformes à la base, très coriaces, vert clair en dessus, grises en dessous, à nervures à peine perceptibles, reliées à un are qui court ì peu de distance le long des bords. Inflorescence en petites cymes, contenant f-s fleurs blanches, petites, odorantes: pedicelles bractentis an milien. loms de $3-5 \mathrm{~mm}$, aussi lougs que les pétioles. Baie petite, noirâtre à la maturité. - Fl. en mai, juin. - Abondant dans les terrains montueux, secs el pierreux : bois inférieurs des Trois-Rivières, hauteurs du Baillif, Gourbeyre, Iouëlmont, Deshaies, Pointe-Noire. Alt. 100-480 mèt. [Yos 2723, 2723 b.

Martivique. Vulgo : Merisier, - Commun : hauteurs el plateau des l'roisIlets, de Case-Pilote, de Case-Navire et de Fort-de-France, du Marin, cte. [Nos $189 \mathrm{~b}, 209,1253$. 


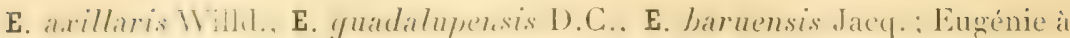
lleurs axillaires. Vulgo : Merisier. - Petit arbre, droit, élégant, touflu, à branches fastigiées, à écorce gris blanchâtre, lisse. Feuilles très coriaces, opaques, ovées ou orales-elliptiques, très obtusément pointues; pétioles noirs ou rouges, cannelés, longs de $2-4 \mathrm{~mm}$. Baie ghlobuleuse, brun noir à la malurité, ruguleuse, peu pulpeuse ou sèche, très souvent monstrueuse et dépourvue de semence, surtout dans les pieds qui poussent près de la mer. - Endroits habituellement pierreux et sees : Vieux-Fort, Gourbeyre (rare), les sinter murne dni Chamean. Marie-Galante abondant dans les sables du

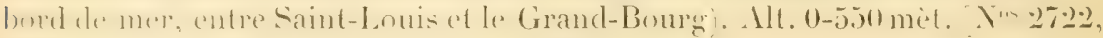
3639.] - Je ne l'ai pas rencontré à la Martinique.

E. Dussii, Kr. et Urb. (n. sp.). Vulgo : Merisier-montagne. - Petit arbre rabougri, couvert de mousses, de fougères, haut de 2-4 mèt., ou petit

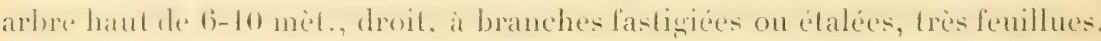
Feuilles larges, longues de $4-5 \mathrm{~cm}$. sur 2-3,5 cm. de large, ovées ou ovales, très obtuses ou arrondies au sommet, brusquement rétrécies en un pétiole long de fä) nun. Fleurs manquent. Baie déprinée-globuleuse, lonğue de $5 \mathrm{~mm}$. sur 6-7 mm. de diamèt. - Fl. très rarement. Assez abondant aux environs des Bains-Jaunes et dans les bois inférieurs de la Savane à Mulets. Alt. 900-1200 mèt. [N²200.] — Il n'existe pas à la Martinique.

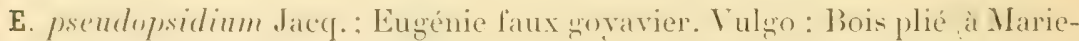
Galante), ailleurs goyavier-montagne. - Arbre haut de 10-16 mèt., rarement plus élevé, droit, à tronc erlindrique, nu dans le bas, a fronde arrondie, at branches nombreruses, fastigiées ou plus on moins étalés, à écorce lisse et rongerilre. Feulles membraneuser, minces, ovées-elliptiques, terminées en une pointe triss olduse, brievement pétiolées. Fleurs blanches, larges, d'une odeur tres agréable. réunies par 2- el opposedes. naissant aux aisselles supérieures des levilles: pédicelles longes de 1-2,3 cm., filiformes. bibractéolés an sommet. Raic brun noir, pulpeuse, mangeable, globuleuse-ovoüle, couronnée par les 4 larges lobes persistants du calice. - Assez rare : çà et là dans les beris inferienus du massif de Hoü̈hont mornes Goblin et Dos-d'Ane), du Gommier et des Bains-Jaunes. Alt. 150-600 mèt. [X゚o 2729.

Mantnique. Vulgo : Goyavier-montagne, goyavier bâtard. - Bois de l'. joupa-bunilmon, hanteurs de Case-Pilote (assez abondant, fontaine Absalon, etc. $\mathrm{N}^{\circ} 190$.

E. Latmlertiana D.C.. E. smaraydina Bero., E. nigropunclata L., Eugénie

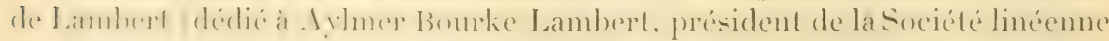
de Londres, mort en 1842). Vulgo : Merisier jaune. - Grand arbuste ou a- déceratim, tres glabre dans toutes ses parties, droit, parfois tortueux, a 
écorce blanchatre. Feuilles ovales, tres coriaces. anmondies on prinfures it la base, brièvement et obtusément acuminées au sommel; pétioles longs de 7-10 mm. Fleurs blanches, très odorantes, réunies par 2-12 à l'aisselle des

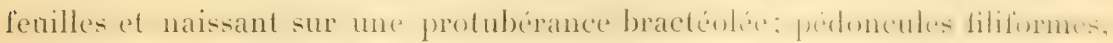
longs de 4-6 mm., bibractéolés. Baie sphérique, jaune orangre avant d'être mûre, bleu foncé à la parfaite maturité. - Les fruits sont comestibles. - F1. en avril, mai, juin. - Le bois est dur et rouge en dedans: on l'emploie pour la construction. - Assez abondant dans les haies el sur les lisières des bois infé-

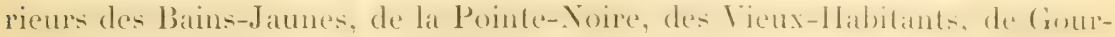
beyre, etc. Alt. 50-600 mèt. [Nos 2208, 2211, 3447.

Martinique. Vulgo : Merisier. - Caravelle, Marin, morne Gommier, hau-

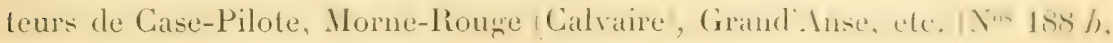
1259 .

E. Tapacumensis Berg.; Eugénic de Tapacuma. Vulzo : Bois grillé. - P'etit arbre peu élécant, le plus souvent tortueux, wlaber dans foules les parlies, a branches très divariquées, souvent penchées, à écorce noirâtre et rude. Fenille- longues de $7-12 \mathrm{~cm}$. sur 3-1́ cm. de large, nettement elliptiques ou elliptiques-ovales, brièvement rétrécies à la base en un pétiole long de 5-11 mm., à côte saillante en dessous, non imprimée en dessus, à nervures écalement saillantes en dessus et en desous. Fleurs hanches remies par Z-6 et naissant sur une protubérance bracténlée: pédnncules fermes, Inngis: de $7-8 \mathrm{~mm}$., bibractéolés au sommet. Baie sphérique, de $9 \mathrm{~mm}$. de dianèt. - Fl. en septembre et octobre. - Endroits secs et rocailleux : Caravelle (environs du Phare), Marin (morne Gommier, Sainte-Anne), mornes calcaires) Alt. 10-200 mèt. [Nos 188, 1243]. - Je ne l’ai pas trouvé à la Guadeloupe.

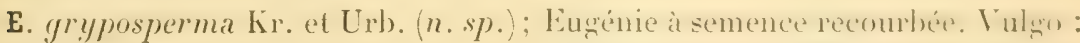
Cerise-montagne. - Arbuste haut de 2-3,5 mèt., très touffu, élégant, droit. Feuilles larges, sessiles, légèrement ovées, en cour à la base, ce qui le distingue facilement de ses congeneres, tris brierement of whturiment acuminées, longues de $5-9 \mathrm{~cm}$. sur 3,5-8 cm. de large, à côte noire et épaissic vers la base du limbe. Fleurs....... ; pédicelles longs de 5-15 mm. Baie large, sphérique, de $12-15 \mathrm{~mm}$. de diamèt., bleu noir loncé à lá maturité, à pulpe violacée, copieuse et très savoureuse. - Très rare. De cette belle espèce, je nai pu trouver que quelques pieds au milieu de la grande pente de la monlagne du Vauclin (Martinique). Alt. 390 mèt. [No 1242.]

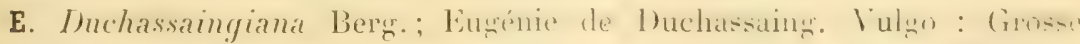
merise, prunier des bois. - Assez grand arthe tres droil. a trome cylindrique mesurant jusqu’à $35 \mathrm{~cm}$. de diamèt., à écorce grise, ruguleuse, se détachant

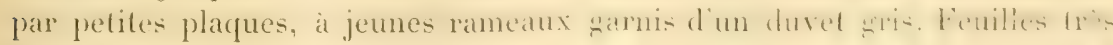
lareses, ovales-elliptiques, brierement acuminés an sommet. subarmondies is 
la base : les jeunes, pubescentes et argentées en dessous; les adultes, glauques du mème côté; nervure médiane très forte et très saillante en dessous et garnie d'un duvet couleur de rouille; pétioles longs de $3-4,3 \mathrm{~mm}$., couverts d'un duvet roux. Fleurs très nombreuses, blanches ou légèrement violacées, disposées en glomérules caulinaires, contenant jusqu'à 55 pédoncules, qui naissent sur une grosse protubérance couverte de bractéoles plus ou moins arortées; pédoncules filiformes, longs de 1,5-2,5 mm. et bibractéolés au sommet. Baies elliptiques ou oblongues, de $15-20 \mathrm{~mm}$. de longueur sur 8-12 mm. d'épaisseur, jaune avant la maturité, bleu foncé ensuite, pulpeuse et bonne à manger. - lil. en juin et août. - Cuà et là sur les lisières des bois et dans les falaises de la région inférieure : bords de la rivière Noire, Vieux-Fort, Gourbeyre (morne Goblin). Alt. 200-500 mèt. [Nos 2725, 3671.

Martiniqe. Yulgo: Grosse merise. - Bois inférieurs de la Calebasse, Morne-Rouge (Savane Chazot et Calvaire), Grand'Anse, ete. [Xos $210,1252$.

E. Gregii Poir.; Eugénie de Greggg. Vulgo : Goyavier-bâtard. - Pelit arbre, élégant, droit, haut de 5-9 mèt., ì branches supérieures fastigiées, les inférienres datees parfois tres penchés et tres allongees a jeunes branches garnies d'un duvet roux et court, à écorce rougeâtre et lisse. Feuilles larges, rigides, blanches-tomenteuses en dessous, nettement elliptiques ou ovales, nu ovales-elliptiques, trés brievement et obtusément acuminées au sommet. longues de 6-11 cm. sur 4-5 cm. de large, rétrécies, à la base, en un pétiole longr de 4-7 mm. Inflorescence en glomérules courtes portant 2-8 fleurs sur des predoncules pubercents el bibracténlés. longs de $5-8 \mathrm{~mm}$. : calice pubercent en dehors. Baie longue de $2 \mathrm{~cm}$., oblongué, garnie d'un duvet gris avant d'ètre mûre, bleu foncé à la maturité. - Fl. en mai, juin ; fruits mûrs en octobre et novembre. - Le bois est très flexible et élastique : on le recherche pour en faire des manches de houes, de pelles, etc. - Peu abondant : ravine de Belost (près de la Basse-Terre), bords de la rivière Rouge, Ifoü̈lmont pentedu Yord, Trois-Rivieres, Matouba, Pointe-Xoire pres de l'habitation Longease), etc. [Nos 2205, 3445.]

Mintisique. Vulgo : Goyavier bâtard. - Prêcheur (Céron), Fort-deFrance (Marigol), hauteurs de Case-Navire et de Case-Pilote, elc. Alt. 10400 mèt. [Nos $187,1218$.

B. brachystachya Berg.; Eugénie à épis courls. Vulgo : Merisier. - Petit arbre, à branches étendues, penchées, à écorce lisse, blanchâtre, à jeunes rameaux comprimés, couverts d'un duvet court et roux. Feuilles larges, ovales-elliptiques ou elliptiques-allongées, longues de $8-15 \mathrm{~cm}$. sur 4,3-6,3 $\mathrm{cm}$. de large, à nervures principales reliées à un arc bien prononcé, à 3-6 $\mathrm{mm}$. de distance des bords, et les nervilles secondaires à un arc plus faiblement marqué courant tout près du bord. Inflorescence en grappes 
longues de $3-4 \mathrm{~cm}$; fleurs blanches, odorantes; calice brun, dureté en dehors: lobes du calice, warnis de cils courts, blanchatres et fins: puitales 4-5. orbiculaires-obovales; jeunes pédicelles garnis diun duret blancluitre. Fruit inconnu. - Fl. en juillet ou en août. - Peu abondant : çi et lì dans les bois de la Ravine-Chaude, dans les bois supéricurs des Bains--Iatume:

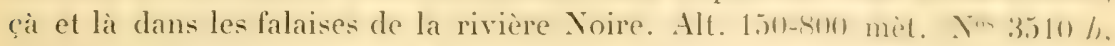
3771.] - Il n'existe pas à la Martinique.

E. octopleura Kir. et Urb., E. ferruginea Griseb. ; Eugénic à huit côtes. Vulgo : Gueppois bâtard, koumaré (au Camp-Jacob). - Arbre haut de 10-16 mèt., élancé, à branches tantôt lastigniées, tantot divariquéés el horizuntales, à jeunes rameaux comprimés, garnis d'un duvet enuleur de rouille. Feuilles membraneuses, tres vertes, surtout en dessus, of luisantes, longues de $7-13 \mathrm{~cm}$. sur $3-5 \mathrm{~cm}$. de large, deux fois et demi plus longues que larges. ovales ou ovales-elliptiques, tantôt longuement, tantît brievement ef hrusquement acuminées, lentement rétrécies à la base en un pétinle hong de 7-13 mm., à cote imprimée en dessus, saillante en desionus. Intloresence en grappes ombelliformes, longues de près de $20 \mathrm{~cm}$., tres nombreuses. contenant 2-8 fleurs blanches, odorantes; pédicelles environ de la mème lonezueur que le pétiole, garnis d'un duvet couleur de rouille, bibractéclés atu sommet: calice garni d'un duvel couleur de rouille, a $f$ lobes: pétales $\{$. orbieulaires; ovaire biloculaire. Baie obovale, longue de 1.2-1.5 mm. sur $8-10$ mm. d'épaisseur, pulpeuse, bleu noir à la maturité, pourvo de liuit coiles, laiblement marquées au sommet et au milieu, plus prononcées ver's la base. .- I. (e bois est rouge en dedans et dur; il est recherché pour la construction. Fl, en mai, ou juin ou juillet. - Assez abondant dans les bois des BainsJaunes, de Gourberre (mornes Dos-d'. Ine et Boucanier . 1lt. f(00)-1006) mil. [Nos $2759,3270,3600$.]

Mantivece. Vulgo : Govarier bâtard grand-bois. - Buis de la Calchaste et de l'Ajoupa-Bouillon, du Morne-Rouge Calvaire et habitation Petil ence [Nos $200,619,125 \%$.

E. floribunda West., E. disticha Bello: Eungénie lloritère. Vulgyo: Conencarette, bois de basse bâtard. - Grand arbuste ou petit arbuste, élétunt, liststigié, haut de 3-5 mèt. Feuilles petites, coriaces, elliptiques-ovales, longurment acuminées. Fleurs blanches, en glomérules nombrenses, subsestiles it l'aisselle des feuilles, bractéolées à la base. Baie rouge avant dibre mure. jaune à la maturité, globuleuse, de $8-10 \mathrm{~mm}$. de diancel., luisante, acidulise. mangeable. - Peu abondant : Pitons-du-Carbet morne d'.lmour . morme

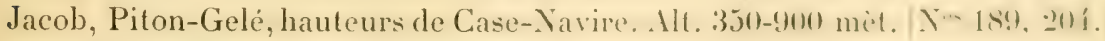
- Je ne l'ai pas trouvé à la Guadeloupe.

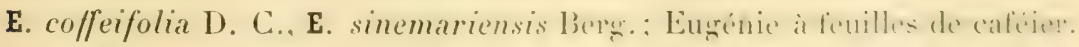
Vulgo: Merisier-bois. - Grand arbuste on petit arbere. haut de $1-5$ mit.. a 
branches peu nombreuses, allonges, llexibles. Fenilles membraneuses, minces, longues de $8-17 \mathrm{~cm}$ : sur $4-4,6 \mathrm{~cm}$. de large, brusquement et le plus souvent lonenument acuminécs, anondies à la base, lraversées par deux ares, dont le premier est à $6-8 \mathrm{~mm}$. et le second à $2-3 \mathrm{~mm}$. du bord du limbe; pétiole noir, long de 3-1 mm., ruguleux. Fleurs pelites, blanches, en glomérules sessiles, pauciflores, situés tantôt a laisselle des fenilles, tantôt le longr des branches dépourvues de feuilles. Fruit inconnu. - Fl. en mai ou juin. Eudroits ombratés des rrands bois de la Ravine-Chaude, el ça et là dans les bois entre la Pointe-Noire el Deshaies. [No 3448.$]$ - II n'existe pas à la Marlinique.

E. fragrans Willd., variété hrachyrhiza Kr. et Urb., E. emarginata Macf., Amomis fragrans (arisel), : Eugénie odorante. Vulgo: Bois d'Inde hatard, bois pelé, goyavier-montagne. - Arbre droit, haut de 16 mèt., très glabre dans loutes ses parties, il tronc anliractueux-eylindrique, à écorce verdâtre et lisse, à rameaux comprimés. Feuilles ovales-arrondies ou obovées, très luisantes en dessus, tres palles en dessous, ou blanchitres et marquées de points noirs: les jeunes, pourvues d'une masse de points transparents (cryptes). Fleurs blanches, d'une odeur exquise, en cymes, ou solitaires ou réunies par 2-3; calice 4-5-lobé; pétales 4-ว̃; pédoncule bibractéolé, longr d'environ $2 \mathrm{~cm}$.; pédicelles longs de $4-5 \mathrm{~mm}$., bractéolés au sommet, à bractéoles souvent

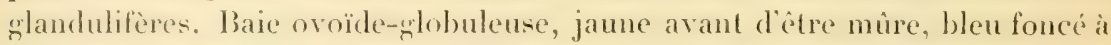
la maturité, couronnée par les lobes persistants du calice; semences 1-3, réniformes. - Fl. en mai, ou juin ou juillet. Les feuilles et l'écorce sont aromatiques presque au mème degré que le bois d'Inde. - Issez abondant : çà et là dans les bois inférieurs des Bains-Jaunes et à Marie-Galante (bois de Folle-Anse). [Nos 2758, 3269.] - Je ne l'ai pas vu à la Martinique.

E. Malaccensis L., Jambos Malaccensis D. C.; Eugénie de Malacca. Vulgo: Pomme de Taïti, pomme d'Haïti. Tuss., Fl., III, t. 25. - Petit arbre, droil, haut de 6-9 mèt., à branches toujours horizontales, à fleurs rouge poupre fonce, disposies en cymes trichotomes tres nombreuses, qui courrent les branches dépourvues de feuilles, à fruits turbinés pourpre foncé, plus protití qu une pomme, a chair blanche, d'une odeur légère de rose, mais d'une saveur assez insignifiante. - Se rencontre çà et là autour des maisons : Gourbeyre (morne des Palmistes), Trois-Rivières, Lamentin, elc. - Originaire de l’île de Malacca. - L'écorce est astringente et s'emploie contre la dysenterie. [No 3733.$]$

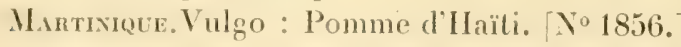

E. Jambos L., Jambosa vulgaris D. C. (du mol des Indiens d'Orient "chambu ».) Vulgo: Pomme-rose. Dese., vol. V, t. 314, p. 49. - Grand arbre, fres branchu, introrluit autrefois pour abriter les plantations de caféiers et de cacaoyers; s'est naturalisé et est devenu très abondant dans les quar- 
liers supérieurs du Matouba el dans le Gommier, nil il forme de virilables forêts; abondant à Gourbeyre, au Camp-Jacob, au Mas-.Matouba, dans les hauteurs du Baïllif, aux Trois-Rivières, etc. [No 2206.]

Mantinique. Vulgo : Pomme-rose. - Abondant: Morne-Rouge, AjoupaBouillon, Champflore, Parnasse, hauteurs de l'habitalion P'́roul, ete. - Fl. surtout en avril, mai, juin. [No 1855.$]$

E. Javanica Lam.; Eugénie de Java. Vulgo : Frambroisier, pomme de Malacea. - Grand arbre, à branches fastigiées dans le haut, horizontales el souvent très penchées dans le bas, a fleurs blanches en cymes frichotomesallongées, nombreuses, à fruits rose pourpre ou plus rarement blancs, oben, niques el tronqués au sommet, d'une saveur aqueuse et insipide. - Fil. ('n arril ou mai, ou juin. - Originaire de l'Asie centrale et des îles de l'Océanie. Environs de la Basse-Terre, Gourbeyre, Capesterre, Trois-Rivières, etc. [Nos 20202, 2990.] - Dans cette espèce d'Eugenia, il est rare de trourer des graines qui germent.

Martinieve. Tulgo: Pomme de Java. - Cultivée au Jardin botanique el sur quelques propriétés de l'île. [Nos 206, 20\%.]

E. aromatica Baill., Garyophyllus aromaticus I..; Eucrénic aromaticque. Vulgo: Giroflier. Desc., vol. VIII, t. 566, p. 214. - Arbre de taille movenne. - Fl. en avril et mai. - On cueille les boutons de fleur, on les sèche et on s'en sert comme épice sous le nom de "clous de girolle ». Dans le pays, on emploie les feuilles contre la dysenterie et contre les colicques; le bois est recherché des menuisiers et des tourneurs. - Plante nrigrinaire des Mnluques. - Cultivée çà et là dans le pays : Capesterre (Guadeloupe, habitation Longmont), Sainte-Marie (habitation La Caféière), Pigneon, (inurbeyre, Lamentin, etc. [No 2203.

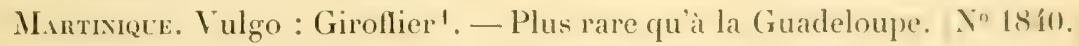

Parmi les plantes introduites et cultivées appartenant a la famille des Myrtacëes, on rencontre souvent, outre l'espèce précédente :

I' Punica granatum L. Tulgo : Grenadier. - Introduit el cultive dans les jardins comme plante médicinale. Les feuilles sont antiscorbutiques; f lécores des lruits est employée contre la diarrée chronique; la décoction concentríc de l'écorce râpée de la racine constitue un souverain remècle clasisique "ontro' le ver solitaire, par la pellefiérine (principe titniluge) qui y esol enntenue et qui a été découverte par Tanret.

1. L'huile essentielle, qu'on extrait par distillation des clous de girolle $\langle 16$ i $170 j 0\rangle$, est formée d'eugénol ou acidc eugénique et d'un hydrate de carbone plus léger que l'eau (essence légère de clons de girofle. Liessence laisse diposer un camphre analugue it colui des Laurinées, appelé caryophyllène; l'essence renferme aussi de l'acide salycilique el les clous de girofle ont encore du tanin. Employé comme éclaircissant dans la technique du microscope. (E. II.) 
$2^{\circ}$ Couroupita gnyanensis Aubl. Tulgo : Boulet à canon. Aubl., Guy.. t. 282; Desc., vol. V, t. 340; Tuss., Fl., II, t. 10 et 11. - Assez grand arbre, originaire de la Guyane.

$3^{\circ}$ Myrtus communis L. Vulgo: Myrte de France. - Fl. difficilement.

10 Gustavia augusta L. - Grand arbre de la Guyane. Cultivé au Jardin botanique de Saint-Pierre et sur quelques propriétés. [No 1854 .

5 Barringtonia speciosa L. fils. Vulgo: Arbre à barrefte, bonnet de prêtre. - Origninaire des côtes occidentales d'Al'rique. [No 1853.] Cultivés aux Jardins botaniques de la Basse-Terre el de Saint-Pierre, et planté en bordure à la Savane de Fort-de-France (beaux spécimens). - Les graines, toxiques, servent à enivrer le poisson.

$6^{\circ}$ Eucalyptus rohusta Smith, E. amygdalina Labill, et E. grandiflora L'Hér. - Originaires de l'Australie. Le dernier est assez répandu à la Guadeloupe : Pointe-it-I'itre (hospice de Saint-Jules), Vieux-IJabitants (habitation Rollin), Pigeon (Gendarmerie), Basse-Terre (La Jacinthe et la Gendarmerie), Camp-Jacob (habitation Rollin), Sainte-Rose, etc. - Il est beaucoup plus rare à la Martinique ${ }^{4}$.

70 Syzygium Jambolanum D. C. Vulgo : Tété-négresse. [No 1852.] Grand arbre, originaire de l'Asie centrale, qui est cultivé au Jardin botanique de Saint-Pierre, et an Marin, sur l'habitation Grand-Fond-Balata. - Il lleurit et rapporte tous les ans ${ }^{2}$.

$8^{\circ}$ Lecythis yrandiflora Aubl. Vulgo: Canari”macaque. - Se rencontre à la Basse-Terre, sur l'habitation Saint-Aude Gall. - Il est originaire de la Guyane. - Fl. de mars en juillet et rapporte des fruits.

\section{SOIXANTE-QUinzì̀me FaMille. - MÉLASTOMACÉES.}

Henriettella Cogn. (diminutif de "Henriettea ", qui, à la Guyane, porte le nom de "caca-Henriette ».)

1. Les feuilles et l'écorce d'E. globulus doivent au tanin qui y existe les propriétés toniques et astringentes qu'on leur connait; le même principe les rend sans doute fébrifuges. En Australie, en Corse, les feuilles sont administrées à la dose de 4 à 16 gre. par jour, en poudre, contre les fievres intermittentes; on en fait aussi des cigarettes antiasthmatiques. Ces feuilles donnent, ì la distillation, une huile essentielle, dont un des éléments composants, l'eucalyptol (cloëz), a été employé avec succès contre les bronchites. L'E. amygdalina (pepermint-tree des Anglais), moins répandu que le précédent dans l'Australie mais plus odorant par ses feuilles, riches en huile essentielle, est souvent préféré à l'E. globulus pour le pansement des plaies et le traitement des fièvres. (E. H.)

2. Dans ces dernières années, les médecins anglais de l'Inde ont attiré l'attention sur' cette plante dont, d'aprés eux, les graines seraient non seulement capables de diminuer la quantilé énorme d’urine émise par les diabétiques, mais encore de faire disparaitre le sucre rapidement dans ces urines. L'expérimentation méthodique faite en Europe n'a pas justifié ces aftirmations. Ces graines, analysées par M. Elborn (1888), ont donné une résine soluble dans l'alcool et l'éther', de l'acide gallique et un extrait soluble dans l'eau. (E. H.) 
H. Lateriflora Triana; Henriettelle à fleurs caulinaires. Vulgo : Caca-ravel. - Grand arbuste, haut de 4-5 mèt., à branches très ćtalíes et penchées. it tige cylindrique, à rameaux tétragones, à tige et branches nues. Fruilles elliptiques, ramassées aux extrémités des rameaux, pointues aux deux bouts, à 3 nervures principales (les 2 latérales prenant naissance an-desisus de la base de la médiane), pourvues d'un are partant de la base du limbe et courant prís du bord, à nervilles transversales parallèles. Inflorescence axillaire en fascicules nombreux et petits, disposés tout le long des branches, contenant 1-8 tleurs, petites, blanches, brièvement pédonculées; calice conné avec l'ovaire, campanulé, grabre, tronqué au sommet ou obscurément 5-denté, formant une coilfe pointue, tombant d'une seule pièce à l'ouverture de la lleur; itaminess: style droit, plus longr que les étamines; stigmate capité. Baie ghlobuleuse, deux ou trois fois plus petite qu'une graine de poivre, lurbinée, couronnée par le rebord annulaire du calice; ovaire à 5 loges multiovulées. - Fl. en octobre en novembre. - Cà et là au milieu des grandes forcts humides des Bains-Jaunes et du Matouba. Alt, 500-800 mèt. [No 2265 .

Martnique. Vulgo : Crécré grand-bois. - Çà et là dans les bois inférieurs des Pitons-du-Carbet. [No 1176.$]$

H. Dussii Cogn. (n. sp.); Crécré grand-bois. - Grand arbuste ou petit arbre, droit, haut de 3-5 mèt., à rameaux à quatre angles obtus, renflés aux nœuds, à tige et branches nues, à feuilles ramassées aux extrémités des branches, à jeunes rameaux, pétioles, calice et face supérieure des feuille's hérissés de soies subulées, couchées, tuberculées à la base el jamâtres. Feuilles longues de $12-17 \mathrm{~cm}$. sur $6-7 \mathrm{~cm}$. de large, elliptiques-ovales, acuminées au sommet, rétrécies el subarrondies à la basc, a 5 nervures principales et 2 ares courant parallèlement sur le bord, à nervilles transversales parallèles; pétioles comprimés, longs de $1,8-2,8 \mathrm{~cm}$. Inflorescence axillaire, en grlomérules de 1-3 fleurs sessiles, naissant sur une sorte de tubérosite, tout te longr des branches; calice campanulé, longr de 7-8 mm., obscurément quadridenté, garni de soies plus courtes que celles des rameaux; pétales blances. insérés sur le bord intérieur du calice, longs de $7 \mathrm{~mm}$. sur $7,2 \mathrm{~mm}$. de largé, arrondis au sommet et lacérés, très rétrécis à la base, caduc's, formant une coiffe conique et tordue avant l'éclosion de la fleur; étamines 8. Baie inconnue. - Rare : ça et là dans les grands bois du Lorrain et du Gros-.Yorne. [No 1180.] -Je ne l'ai pas vu à la Guadeloupe.

Glidemia Don. (dédié à Clidemus, médecin srrec de l'antiquité, qui a ícrit sur les maladies des plantes. (Théophraste, V, 12.)

c. guadalupensis Griseb.; Clidemie de la Guadeloupe. Vulwo : Bois-critelette. - Arbrisseau ou grand arbuste, haut de $2-3$ mèt., habituellement pe'n

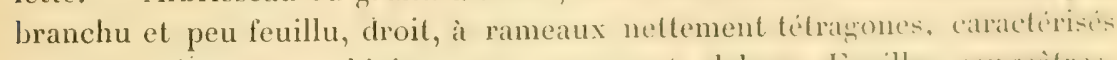
par une pubescence rubigineuse ou rarement glabres. Fenilles rougenters. 
tris scabres, ovales-clliptiques, longuement acuminées au sommet, arrondics ou fortement rétrécies à la base, très finement erénelées-dentées, longrues de 17-18 cm. sur 5-7 cm. de large; nervures principales 3 , très saillantes en dessous et légerement pubescentes. pourrues de deux ares, dont le premier est de $2 \mathrm{~mm}$. de distance, el le second, plus faiblement marqué, est trés mappreché du bord; pétioles lonens de 2-33 cm., comprimés-subquadrangulaires. Fleurs blanches ou légèrement roses, en petites cymes très lâdues, racémilomes, axillaires, pauciflores, confinées dans la partie supérieure des raneaux, géminées et opposées, plus courtes que les feuilles, à divisions souvent verticillées par ł; pédicelles délicats, comprimés-filiformes, d’inézale Iongueur, pubescents ainsi que le pédoncule; calice pubescent; lobes du calice linéaires, subulés, plus courts que le tube; pétales 1, obtus; étamines 8: anthères jaunes, linéaires, dressées; stigmate petil; ovaire à f lognes. Baie mûre bleu foncé, poilue, sphérique, un peu plus grosse qu une graine de poivre. - Assez abondant dans les bois supérieurs des Bains-Jaunes, du Matouba, de la Ravine-ì-Déjeuner (au pied de la Grande-Déconrerle e ete. - Fl. toute l'année. - Alt. 700-1000 mèt. [No 3203.]

Mantiviqe. Yulgo : Crécre-montagne. - Assez rare : Morne-Jacolo lentre le Champflore et Sainte-Marie), Piton-Gelé, etc. $\left[\mathrm{N}^{\circ} 667\right.$.

C. hirta 1)on., variété elegans, C. crenata Mey.-Lsseq.; Clidémie hérissée de poils. Vulgo : Herbe-cótelette. Aubl., Guy., t. 167. _ Irbrisseau élégant, haut de 0,70-1 mèt., rarement plus haut, droit ou plus ou moins incliné, it rameaux, feuilles, pétioles, calice et pédoncules entièrement grarnis de poils roux, rigides, droits, serrés et tuberculés à la base. Feuilles ovées ou plus rarement ovées-oblongues, subcordées il la base, ciliées sur les bords, netlement crénclées, à 3 nerrures principales et 2 ares. Fleurs en cymes subsessiles, corymbiformes, courtes, aussi longues que les pétioles, contenant 2-20 pédoncules; lobes du calice filiformes, subulés, aussi longs que le tube; pétales 5, blanes ou rosés, obovés: étamines 8-10, tuberculées a la base, du côté antérieur, s’ouvrant au sommet par un pore; ovaire à jognes, libre dans le bouton, ensuite adhérent au calice; style filiforme; stigmate obtus. Baie poilue, de la grosseur d'une graine de poivre et portant au sommet un loner rebord annulaire. - Fl. toute l'année. - Peu abondant : çà et là dans les savanes herbeuses des Trois-Rivières et du Lamentin. [No 2261.]

Martineve. Vulgo: Herbe-crécré. - Très abondant dans les savanes de Ducos, du Lamentin, de la Rivière-Salée; assez abondant au Parnasice et aux environs du Morne-Rouge, etc. [Nos $106,1181$.

C. Iatifolia D.C.. C. nmbrosa Cognn.; Clidémie a larges feuilles. Vulgo : Coeur it beut, groseiller mrand-leuille. - Arbrisseau trés droit, élégant, haut de 1-2 mèt, d̀ rameaux tétragones-sillonnés, à tige cylindrique, à branches, pétioles, pédoncules, pédicelles et calices hérissés de poils roux blancs, rudes, 


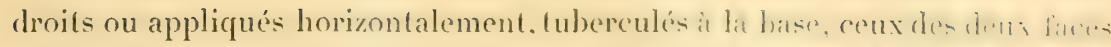

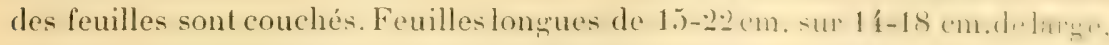

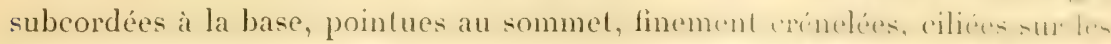
bords, à 5 nervures principales, ef deux ares, distant-, a lat base, de $3-4 \mathrm{~mm}$. 1.

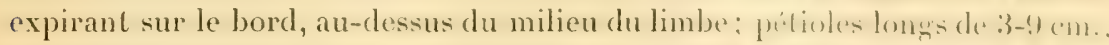

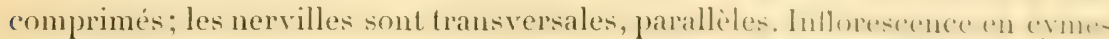

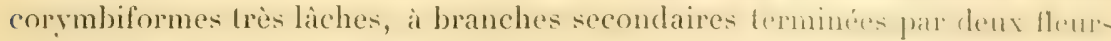
pédonculées, et les branches tertiaires par trois, dont (olle du milien est solivent sessile; calice bibractéolé; lobes du calice brièvement mbulís, de muiti: plus courts que le Lube; pétales blancs, obovés; ovaire it 4 logere; ; sle filiforme: stigmate arrondi-capité. Baie mùre hérissée de quelques poils, bhen foncé it la maturité, sphérique, d'un diamèt de $5-7 \mathrm{~mm}$. - Abondant dans les savaneet les clairieres des quartiers du Camp-Jacob, de Bagatelle, du (rommiere. du Matouba, de la Ravine-Chaude, des Trois-Rivières. - Fle presque toul. l'annęe. - Alt. 150-800 mèt. [No 2268.]

Martinete. Vulgo : Crécré grand-feuille. - Abondant au Mome-lionge.

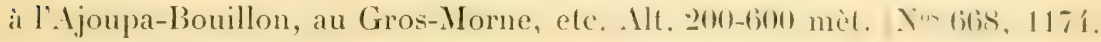

Conostegia Don. (du grec "konos", cône, et "steges ", couverture, paree que la partie supérieure du calice forme un cone qui coure complietrment les organes de la fleur et se détache d'une seule pièce au moment de l'anthesese.

C. subhirsuta D.C.; Conostégie peu velue. Vulgo : Bois-côtelette. Grand arbuste ou petit arbre, haut de $-\mathbf{f}-6$ met., a branches souvent tris divatriquées, à tige anfractueuse, à écorce verte, presque lisse, à jeune brincher: obtusément quadrangulaires, renflées aux neuds et couvertes d'une pubescence roux brun, ainsi que les pétioles et les panteules. F'enilles colliptiques. ou elliptiques-oblongues, pointues, longues de $11-15 \mathrm{~cm}$. sur 6-8 cm. de large, glabres en dessus, grisattres en dessous, ì 3 nerrures principales arence un are distant de $2 \mathrm{~mm}$. du bord, subentières ou crénelées-dentés an-desists: de la base; pétiole subeomprimé, fort, long de 3-5 com. Inflorescence an panicules corymbiformes, a 7 divisions portant 3-7 fleurs; calier plus un moins glabre; coiffe arrondic, convexe; pétales 6 , blancs, ohliequement obovés; anthères 20 ; ovaire à 12-20 loges; stigmate peltí. Baire lurbince, ruguleuse, verte avant d'être mûre, bleu foncé ì la maturité. - . 1ssoe abondant dans les mornes sees de Gourberre mornes Dos-d'. Ine el Bumeanier: çà et là aux Palmistes. [ $\left.\mathrm{N}^{0} 3472.\right]$

Martinique. Vulgo : Crécré-falaise. - Bois de l'Ajoupa-Bouillon, des hauteurs de la Basse-Pointe, du Champflore bords de Lat Capmlte we. $\left[\mathrm{N}^{\circ} 1170\right.$.

G. calyptrata Don.; Conostégie coiffée. Vulgo : Côtelette grandl-bois.

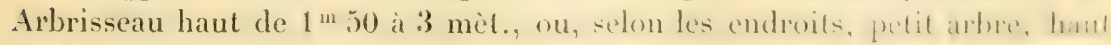

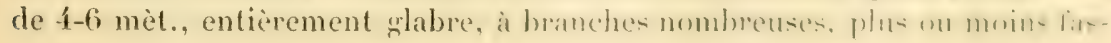


licriées. llexibles, à rameaux obtusément quadrangulaires, épaissis aux noxuds. Feuilles longues de $8-13 \mathrm{~cm}$. sur 1.2-j cm. de large, oblongues ou elliptiquesoblongues, acuminées, luisantes, it 3 nervures principales, avec un arc; nervilles transversales ef paralliles. Intlorescence en grappes composées, dressées, souvent pramidales-allongées. portant des cymes à 3-7 fleurs blanches: pédicelles de longueur inégale; opercule allongés. deux fois plus long que le tube du calice. conique, mucroné: pétales 5, elliptiques, à peu près aussi longrs que le calice; anthères 11-15; ovaire à 5 loges. Baie petite, verte, munie d'un large rebord. - Assez abondant dans les mornes secs de Gourberre imornes Goblin et Dos-d Anei, Hoü̈lmont, Matouba, Sainte-Rose. Deshaies, Ravine-Chaude. - Fl. de mai en août. - Alt. 150-500 mèt. [No 2267.

Martixique. Vulgo : Crécré. - Abondant : Parnasse, Morne-Rouge, Carbet, hauteurs de Case-Pilote, Trois-Ilets (plateau). [No 108.

Tetrazygia Rich. (du grec "tetra", quatre, el zugon ", liaison, parce que, dans les espèces-types, la fleur est construite sur le type tétramère.)

T. angustifolia D. C. : Tetrazygie à feuilles étroites. Vulgo : Palissade à Jacques (au Gozier), ailleurs bois-cotelette petite-fenille. - Grand arbuste ou petit arbre, haut de $3-6$ mèt.. très élégant, à cause de son port et de son feuillate, à branches très nombreuses el noirâtres, à rameaux eylindriques. garnis d'un duvet blanchâtre et fin. Les feuilles, ramassées aux extrémités des branches, sont longrues de 2,3-4,3 cm. sur 3-6 mm. de large, linéaireslancéolies, acuminées au sommet, pointues à la base, garnies en dessus d'un duvet blanc, court et serré, grisâtres en dessous; nervures 3. Inflorescence en panicules courtes, corymbiformes, terminales, moins longues que les feuilles, à divisions portant 3-5 fleurs rosies, ou blanchatres ou blanches; anthères 8 . Baie noir brun à la maturité, deux fois plus petite qu'une graine de poivre. - Fl. en avril, mai, juin; dans certains points, il fleurit toute lannée. - - Hondant dans les terres pierreuses, argileuses, plus ou moins siches: Gourberre imorne Goblin), hauteurs seches et pierreuses du VieuxFort, etc. Alt. 200-100 mèt. [No 2260.]

Martisice. lulgo: Crécré petite-feuille. - Hauteurs et plateau des TroisIlets, Marin (morne Gommier), Sainte-Anne (mornes calcaires, abondant). [No 1169.$]$

T. discolor D. C... variété villosa; Tétrazygie à deux couleurs différentes. Vulgo: Cotelette blane. - Grand arbuste ou petit arbre, haut de 5-8 mèt. ¿ branches divariquées, à rameaux, pétioles, pédoncules et le dessous des feuilles rarnis d'un duvet tomenteux, blanc et court. Fenillesovées, ou ovéeslancéolées, acumineses au sommet, arrondies ou inégales à la base, subentières ou faiblement crénelées-dentées au-dessus de la base: nervures 3-j, rougeatres, avec un arc peu distant du bord. Fleurs en panicules corymbiformes, contractées, arrondies, multiflores: pétales blanchâtres, ou blane jaunâtre; 
étamines 8; anthères jaunes; ovaire à ́l loges. - Fl. en avril, mai, juin. Assez abondant dans les basse el infra-moyenne repinns: Monteran, "minonde la Basse-Terre (ravine de Belost, Ducharmois, (jourberre, I)ole, TroisRivières, Moule, Gozier, etc. Alt. 40-600 mèt. 「No 22\%0.

Martineze. Vulgo: Crécré blane. - Mbondant: Parnasise, Morne-liouser, Carbet, hauteurs du Prècheur, de la Trinité, route de liort-de-linance an Gros-Morne, etc. [No 1170.

Miconia R. P. (dédié à Micon, médecin espagnol.)

M. guyanensis Cogn., variété ovalis; Miconie de la Guyane, variété ì feuilles ovales. Vulgo: Bois-còtelette. - Petit arbre, haut de 1-7 mirt., rarement arbre de 15-18 mèt., et alors très anfractueux ou à grosses côtes, à branches horizontales et souvent penchées, à rameaux tetragones, ipatisis aux nouds. Feuilles elliptiques, ou légèrement ovales, acuminées au sommet.

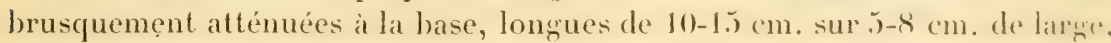
vertes en dessus, pâles et rougreâtres en dessous, a j nervures et un are pris du bord, subentières; pétioles longs de 2-4 cm., comprimés. Inllorescence en grappes terminales, composées, allongées, longues de 13-16 c'm., à divisions courtes, terminées par des cymes trillores; bouton de la theur entirement enveloppé de deux bractées, obovales, opposées et complètement garniess d’un duvet épais et blanchâtre; calice campanulé, jaunâtre, rétréci au-dessous du sommet; pétales 4-5, blanes, environ deux fois plus longs que le calice ; ctamines 10; anthères jaunes, transversalement tuberculées du colté mlirrieur, munies d'un appendice en bee à la base et d'une petile busse pris de ceotle base (du côté extérieur), longues de 4-5 mm., subulées, terminées an pointe: pédicelles quadrangulaires, striés et duvetés comme les bractées; pédoncule comprimé-quadrangulaire, rarement strié, à durel fin et roux. Baic lurbinces, d'abord jaunâtre, ensuite noire. - Fl. en mai, juin et juillet. - Ce petit arbre fait lornement des savanes du Camp-Jacob, de Gourbeyre, des bois inférieurs des Bains-Jaunes, du Gommier, des hauteurs du Baillif, des Vienx-

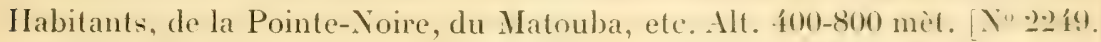

Martingle, Vulgo: Crécré-falaise. - Abondant: Champllore, tjoupaBouillon, Grand'Anse, Gros-Morne, Fonds-Siant-1)enis, fontaine I)idier, ef(e. $\left[\mathrm{N}^{\circ}\right.$ 109.]

M. lavigata D. C. ; Miconie à feuilles lisses. Vulgo : Bois-côtelette. Arbrisseau ou grand arbuste, entierement ghabre, haut de 2-23 met. a branches dressées, minces, à feuilles ternes des deux cotes. Ces feuilles, orales-enllip)tiques, crénelées-dentées, irrégulières, ou arrondies ou subcomblires a la hase. ont cinc nervures et un are à peu de distance du bord. Inllorescence en patnicules terminales, latches, longues de $9-13 \mathrm{~cm}$, a branches lermindes en eymes triflores. Baies brunes, petites, turbinées-ghbulenses. - Tris variable, quinl aux dimensions des feuilles, des panicules et des baies. - Mbondant dans l.t 
basse régrion : environs de la Basse-Terre, Montéran, Baillif, Deshaies, Dolé (Gourbeve), Trois-Rivieres, Lamentin, Grande-Terre, ete. Alt. 10-100 mèt. $\left[\mathrm{N}^{\text {os }} 1158,215 \%\right.$.

Martivique, Vulgo : Petil crécré. - Abondant dans la basse région. [No 1182 .

M. ambigua D. C., M. prasina D. C., M. collina D. C. ; Niconie ambigu. Vulgo : Bois-côtelette. - Ressemble beaucoup au précédent, quant aux feuilles, aux panicules el aux baies; il en diffère par ses feuilles plus ternes, ses nervures légèrement pubescentes en dessous, ses baies plus larges. C'est de tous les Miconia celui qui offre le moins d'éclat. - Même habilat que le précédent. [No 2250.]

Martinique. Vulgo : Crécré-savane. - Abondant comme le précédent : environs de Saint-Pierre, Prècheur, Carbet, Case-Pilote, Trois-Ilets hauteurs, la Régale, etc. [ $\left.\mathrm{N}^{\circ} 2148.\right]$

M. globulifera Cham.; Miconie à fruils grlobuleux. Vulgo : Bois-côteleltemontagne. - Arbrisseau ou grand arbuste, très ornemental, haut de 1-3 mèt, entièrement wlabre, a branches très nombreuses, formant une tète arrondie el large, nu dans le bas, it feuilles confinées aux extrémités des rameaux quadrangulaires. Feuilles longues de $\mathbf{4}-11 \mathrm{~cm}$. sur 2-4,3 cm. de large, elliptiques, finement crénelées-dentées, à dents fermes, ou subentières, acuminées au sommet, rétrécies à la base; nervures 3 , saillantes en dessous et légèrement violacées. lleurs petites, blanches, en panicules courtes, arrondies, très nombreuses; anthères jaunes. Baies globuleuses, sphériques, blanches avant dìtre mûres, bleu foncé à la maturité, plus petites qu'une graine de poivre. - Fl. en mai, juin, juillet. - Abondant dans la région supérieure des montagnes: Savane ì Mulets, Soufrière (cône et plateau), Grande-1)écouverte, Savane aux Ananas, Savane du Nez-Cassé. Alt. 1000-1400 mèt. [No 2448.

Mantixigue. Vulgo: Crécré-montagne. - Abondant au plateau de la Montagne-Pelée et des Pitons-du-Carbet. [No 671.]

M. Letrandra Naud.; Miconie à 4 étamines. Vulgo : Bois-côtelette. Arbuste haut de 0,90-2 mèt., rarement plus haut dans la région élevée, souvent petit arbre dans les bois de la région infra-supérieure, toulfu, très élézant ef ornemental, à rameaux obtusément tétragones, à rameaux, pétioles, pédoncules et nervures garnis d'un duvet très court, fin et gris. Feuilles longues de 10-14 cm. sur :2-1 cm. de large, à nerrures imprimées-cannelées en dessus, très saillantes en dessous; pétiole long de $2-4 \mathrm{~cm}$. Inflorescence en panicules pyramidales serrées, à branches terminées en cymes triflores, brièvement pédonculées; pétales blanc ou très souvent couleur de soufre. Baies ylobuleuses, environ deux fois plus petites qu une graine de poivre. - Assez commun dans les environs des Bains-Jaunes, dans le bas de la Savane i 


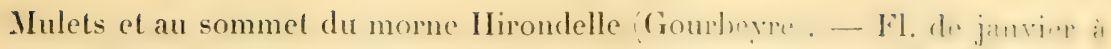
mai. - Alt. 700-1200 mèt. [No 3469.] - Ne se trouve pas à la Martinique.

M. martinicensis Cogn.; Miconie de la Martinique. Vulugo : Crére-montagne. - Arbrisseau haut de $1^{\text {m }}$ 80-2 mèt., droil, très ornemental, entièrement gitabre. Feuilles extremement coriaces, presque tonjours fortement romlées sur les bords, parfois en forme de cuiller, ovales-ellipliqunes, noiriller. très glabres, entières, à 3 nervures et un arc près du bord. Inflorescence en panicules allongées, à branches très divisées, étagées, atree des perdicilles: unilatéraux et tournés vers le haut. Baies noires, globuleuses, du volume d'une graine de poivre. - Très rare. - De cette belle espèce, je n'ai trouvé que quelques pieds dans la petite savane de la Montagne-Pelée Marlinique. [No 672 .

M. furfuracea Griseb.; Miconie couleur de son. Vulgo : Bois-côtelette. - Grand arbuste, haut de 3 - $\mathbf{f}$ mèt., peu branchu, richement feuilhu, a branches: et rameaux cylindriques, à jeunes rameaux, pétioles, pédoncules, pédicellés. nervures, nervilles el calices revêtus d'un duvet gris brun, dense, poulreux. Feuilles vert noiratre, longues de $12-25 \mathrm{~cm}$, parfois de $32 \mathrm{~cm}$. sur $5-13 \mathrm{~cm}$. de large, obovées, acuminées au sommet, rétrécies a lis base, dentée-crénelées au-dessus de la base; nervures 3 : les deux latérales très écartées de la médiane, et un are près du bord; nevilles transversales paralletes et ícilrtées; pétioles de longueur variable, nexcédant jamais $6 \mathrm{~cm}$. de long. Iullnrescence en panicules lâches, allongées, portant des divisions le plus sonvent triflores, avec des fleurs solitaires à l'aisselle des pédicelles; calice conique. long de $\mathbf{f} \mathrm{mm}$.; pétales blanes, une fois plus courts que le calice. Biries critelées, noires, globuleuses. - Çà et là sur les lisières des grands bois : Capesterre (Guadeloupe), aux environs du Grand-Etang el de listany-\%mbi. Gommier; rare au Matouba. Alt. 300-600 mèt. [No 2263.]

Mırtinique. Vulgo : Crécré grand-bois. - Fonds-Saint-Denis, Calebasse, Champflore, fontaine Absalon. $\left[\mathrm{N}^{\circ} 1175\right.$.

M. coriacea D.C.; Miconie it feuilles coriaces. Vulgo : Boris-cotelette-montagne. - Arbrisseau d'une grande beauté, haut de $0^{\mathrm{m}} 80-1^{\mathrm{m}} 80$, nu dans le bas, à feuilles confinées aux extrémités des branches, à rameaux quadranggulaires, grisattres, très ruguleuses, portant de nombrenses cicatrices al unn faible couche de poils rigides el courts. Fenilles tries rigides, épaissus, luntr-

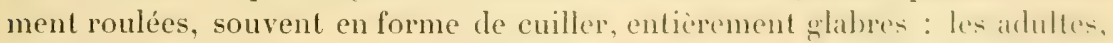
vert jaunâtre en dessous, longues de $7-12 \mathrm{~cm}$. sur $4-5 \mathrm{~cm}$. de larpe, fine-

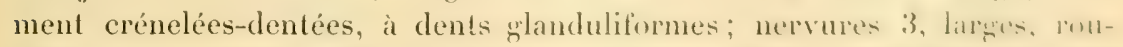

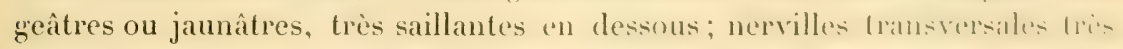
rapprochées, avec un are près du bord; pétioles larpes, comprimés, lons der 1-2 cm. Inflorescence en panicules trichotomes, corvanhiformes, pramiditearrondies, plus courtes que les feuilles : les dernières divisions portim? 
2-3 tleurs blanches sessiles; pédoncules et pédicelles ghlabres, quadrangulaires, robustes. Baies petites, noiritres, globuleuses, couronnées par les bords lacérés du calice. Ciest de tous les Miconia la plus brillante espèce. - Asser abondant ì la Soufriere (cone et plateau, ou il est souvent rabougri). Savane aux Ananas, plateau de la (irande-Découverte. - Fl. presque toute l’année, mais surtout de février à juillet. [No 2252.]

M. impetiolaris Don.; Miconie sans pétioles. Vulgo : Bois-côtelette rouge. - Arbuste haut de 2-4 mèt., très droit, à tige cylindrique, à rameaux, pétioles, pédoncules, calice et le bas de la côte médiane revêtus d'un duvet rude, court, couleur de rouille. Feuilles longues de $20-35 \mathrm{~cm}$, sur 10-16 cm. de large, ovées-oblongues, pointues ou obtuses au sommet, auriculées it la base, brièvement pétiolées ou subsessiles, faiblement crénelées-dentées, ou subentieres, wlabres en dessus, garnies en dessous d'un duvet glanduleux, court, brun clair; nervures 3, avec un are double : le premier, peu marqué, i 3-4 mm. de distance, et l'autre prìs du bord; côte non imprimée en dessus et trìs saillante en dessous. Inflorescence en panicules trichotomes, longues de $111-17$ cm., à branches primaires très allongées, spiciformes, interrompues, portant des cymules sessiles à 3-ว̆ fleurs blanches, petites. Baies mûres bleu foncé, poilues, globuleuses, obscurément marquées de 7-8 côtes. - Fl. en juin, juillet, anût. - Abondant dans les environs de la Ravine-Chaude, du Trou-aux-Chiens, de Gourbeyre (Valcanar et Grande-Savane), Pigeon (le long de la rivière Lostau, etc. - Alt. 12-400 mèt. No 2264.] - Cette belle espèce n'existe pas à la Martinique.

M. Irichotoma Cognn.: Miconie à panicules trichotomes. Vulgo: Bois-côtelette rouge. - Grand arbuste ou petit arbre, haut de 3-8 mèt., entièrement glabre, à branches presque toujours penchées, à rameaux obtusément tétrawones el renflés aux nœuds. Feuilles membraneuses, rougeâtres, longrues de 10-18 cm. sur 6-9 $\mathrm{cm}$. de large, acuminées au sommet, subcordées à la base, ou atténuées ou arrondies, à 3 nervures et un are près du bord. Fleurs en panicules trichotomes, longues de $10-15 \mathrm{~cm}$., pyramidales, allongées, it branches très divisées, à pédoncules secondaires cylindriques, faibles, à pédicelles filiformes, pourvus d'une petite bractée à la base; pétales blanes; anthères 8 ; nvaire biloculaire. Baies globuleuses, plus petites qu'une graine de poivre, à huit côtes. - Fl. en mai, juin, juillet. - . thondant dans presque tous les grands bois humides de la Guadeloupe jusqu'à une altitude de 880 mèt. N $^{0} 2254$.

Martinique. Vulgo : Bois crécré rouge. - Abondant dans tous les grands bois. [No 669.$]$

M. striata Cogn.; Miconic ì fruits striés. Vulno: Du bon matin à Gourbeyre), il cause de la bonne odeur que les fleurs émettent le matin. - Arbrisseau ou grand arbuste, haul de $3-4$ mèt., très droit, ornemental, entièrement 
glabre, à rameaux cylindriques. Feuilles tres variables quant anx dimensions, d'une longueur moyenne de $9 \mathrm{~cm}$. sur $3 \mathrm{~cm}$. de large, généralement vert pâle sur les deux faces, ovales-elliptiques, armminés an sommel. altinuées à la base ou pointues; pétioles longs de 1-2 cm., cannelés. Fleurs blanches, en panicules terminales, it branches pen division. Baites pelitu. élargies à la base, d'un bleu noir à la maturité, pourvues de huil petites côtes. - Abondant sur les lisières des bois et dans les savanes de la région inférieure : hauteurs inférieures du Baillif, des Tienx-Hahitante, de l beshairs.

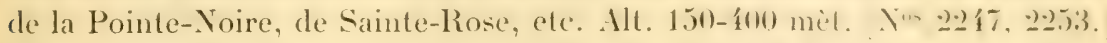

Mantringue. Vulgo : Crécré blane. Très abondant: Parnasse, plateau des Trois-Ilets, Carbet, hauteurs de Case-Pilote, etc. [Nos 108 h, 670, 1179.

Gharianthus Don. (du gree " charis ", beauté, et "anthos s, fleur, allusion it la beauté des fleurs dans les espèces de ce genre.)

G. coriaceus D. G.; Charianthe à feuilles coriaces. Vulgo: Fuchsia-montagne. - Superbe arbrisseau, haut de $1-1^{\mathrm{m}} 50$, rarement plus haut, souvent rabougri, toujours couvert de mousses et de petites plantes épiphyters, entierement glabre, à branches obtusément tétragones, noueuses, grisâtres. Feuilles très coriaces, entières, longues de $7-10 \mathrm{~cm}$. sur $3-5 \mathrm{~cm}$. de larige, ovées, acuminées au sommet, subarrondies ou rétrécies à la base, it 3 nervures non imprimées en dessus, très saillantes en dessous, arec un are près des bords du limbe; pétioles longs de $6-9 \mathrm{~mm}$. Inflorescencer en panicules corymbiformes, penchées ou pendantes, arrondies, axillaires et plus rarement terminales. Fleurs pourpres, d'une grande beauté, longues de $11 \mathrm{~mm}$; pétales 5, longs de $5 \mathrm{~mm}$., oblongs; étamines 8, dépassant les pétales de $6 \mathrm{~mm}$.; pédicelles fermes, munis d'un noud articulé près du sommel, bibractéolés ou biglanduleux à la base. Baies noirâtres, turbincés, conronnées par les lobes persistants du calice, à $f$ loges. - Assez abondant dans les terres volcaniques de la Savane à Mulets, pente du Gation à la GrandeCiterne,-Grande-Décourerte, etc. [No 2229.] - Il n'existe pas à la Martinique.

C. nodosus Triana; Charianthe is branches tres noueuses. Vulwu : Fuchitid. - Arbrisseau très beau, dont les fleurs, comme celles du précédent, rappellent les fleurs du fuchsia de France, haut de $0^{\mathrm{m}} 90-1^{\mathrm{m}} 40$, a branches subtétragones, très noueuses, charyées de mousises ef diuntrés plaules ippi-

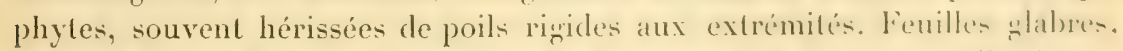
longues de 4,5-6 cm. de large, tantiot largement et netlement elliptiquues. lantòt légèrement ovées, très oblusément pointues an sommet, sunvent prorlongées à la base; pétioles longs de $6-8 \mathrm{~mm}$., finement ef neltement dentedie--

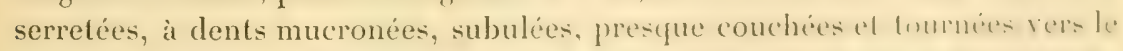

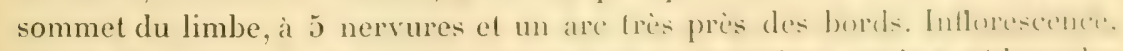
forme et couleur de la corolle comme dans le précédent, mais a pédoncule- 
et pédicelles plus minces, presque filiformes. Baies tétrayones, élaryies vers le sommet, roses, caracteres qui distinguent facilement cette espece de la précédente. [No 666.$]$

C. nodusus. Tr., variété crinilus. Yaud., présente des feuilles trìs nettement elliptiques-orbiculaires, grisitres en dessous, très brièrement et obtusiment pointues au sommel, à branches hérissées de soies rudes et couchées, qui, a l'extrémité des rameaux, forment une couche épaisse, laquelle devient moins accusée sur les cinq nervures, du côté inférieur, et se réduit, sur le côté supérieur du limbe, à des soies éparses. - Cette belle espèce avec sa variété nexistent pas à la Guadeloupe; elles sont assez abondantes dans la région supéricure de la Montagne-Pelée. [No 665 .]

C. corymbosus Cogn.; Charianthe à fleurs en corymbes. - Grand arbuste, plus rarement petit arbre, n'excédant guère 5 mèt. de haut, à branches peu nombreuses : les supérieures, lastigiées; les inféricures, divariquées, horizontales ou penchées, entièrement wlabre. Feuilles d'un vert noiràtre, à 5 nervures et un arc, acuminées au sommet, rétrécies ou subarrondies à la base. Inflorescence en corrmbes larges, arondis ou allongés, selon la variété. Flenrs jaune verdatre. Baies globulenses, d'un noir bleu foncé à la maturité, deux ou trois fois plus volumineuses qu'une graine de poivre.

x, variété grandiflorus Cogn. - Abondant dans les hauteurs de TroisRivières, morne Gommier, etc. $\left[N^{\circ}\right.$ 22269.

$\beta$, variété diffusus Cogn. - Bois supérieurs des Bains-Jaunes, Matouba, Vieux-Habitants, elc. [Nos 2250, 3204 .

Martinique. - Variété glaberrimus D. C. Vulgo : Crécré noir. - Abondant is la Calebasse, dans les endroits exposés aux vents, Prècheur hauteur du Céron et à la Sibérie), fontaine Absalon, etc. $\left[\mathrm{N}^{05} 666,1164\right.$.

Mouriria Aubl. (de "Mouriri ", nom de la plante à la Guyane.)

M. domingensis Walp.; Mouriri de saint-Lomingue. Vulgo : Mele. Tuss., Fl. , III, t. 37. - Petit arbre élégant, à feuillage très vert et luisant, haut de 5-7 mèt., très branchu, à branches supérieures fastigiées, les inférieures horizontales et penchées aux extrémités, flexibles et allongées, à rameaux tétragones. Feuilles cartilagineuses, ovées-oblongues, petites, pétiolées, entières, à nervures secondaires presque imperceptibles. Inflorescence en corymbes umbelliformes, axillaires, pédoncules, nombreux, situés tout le long des branches, a laisselle des feuilles, contenant p-10 fleurs blanches. petites; pédoncules filiformes, longés de $4-8 \mathrm{~mm}$., plus lonès que les pétioles, bibractiolés et articulés au-dessus de la base; calice campanulé, a f-5 dents deltoïdes: corolle it f pétales tordus, avant lanthese, en un bouton pointu; clamines 8 ; antheres jaunes i deux pores an sommet. Baie gitnbuleuse, conromere par les lobes el par le prolongement du lube du calice, de la grosseur 


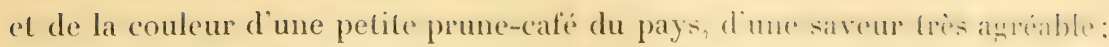
semences grosses, dures, 2-4, anguleuses. - Peu abondant : çà et là dans les endroits pierreux, secs el chauds des bois inferimus du masif de Honëlmont. -Fl. en mai, juin el juillet. $\left[X^{\circ} 1299\right.$. $]$ - Il niexiste pas à la Martinique.

Blakea L. (dédié à l'Anglais Stephan Blake, de lihe d'Antizua, róli bolaniste, auteur de l'ouvrage : Le Jardinier pratique.)

B. pulverulenta Vahl; Blackea pulvérulent. Vulgon: Govarier rose, moyave rose, framboisier (au Camp-Jacob), petit figuier blanc. - Irforisuean sarmenteux, épiphyte, très beau et ornemental, à branches nombreuses, dichotomer, très divariquées: les adultes toujours penchées, à jeunes rameaux quadrangulaires (à quatre angles aigus). Feuilles petites, situées à l'extrémité des branches, coriaces, glabres, souvent couvertes d'une couche pulvérulente et glaurgue, nettement obovées, cunéiformes à la base, brusquement rétréciess au sommet en une pointe très courte, à 3 nervures et un are sur les bords. Fleurs larges, odorantes, roses, très belles, solitaires ou réunies par deux aux aisselles des feuilles et opposées; bouton de la fleur enveloppé de quatre bractées, elliptiques, d'inégale grandeur, tombant après l'anthése: calice is fidents: pétales 6 , obovés; anthères 12 , dressées, s'ouvrant par deux pores terminaux; pistil droit, beaucoup plus long que les étamines. Baic larwe, de la forme d'une nèfle, mais beancoup moins volumineuse, comestible, à odeur de groseille; péricarpe pulpeux. - Abondant dans les quartier's infériérurs des Bains-Jannes, Gommier, bords de la rivière Rouge, du Malouba, hords de l'Étang-Zombi et du Grand-Étang (Capesterre). - Fl. en juin, juillet. août, et souvent aussi en septembre et octobre. [No 2147.] - Il n'existe pas à la Martinique, mais il est assez commun il la Dominique environs de Lauda. [No 113.$]$

Le Bellucia grossularioides Tr., vulgoro: Néflier du Mexique, introduil du Mexique a la Guadeloupe par le Dr Lillerminier, est cultivé dans beancoup' d'endroits à eause de ses fruits, qui sont blanes et qui ont la forme mais non pas le volume d'une nèfle de France. - Ravine-Chaude abondant, Lomgmont (Capesterre, Guadeloupe), Lamentin (près des marais), ete. [ $\left.\mathbf{N}^{\circ} 3205.\right]$

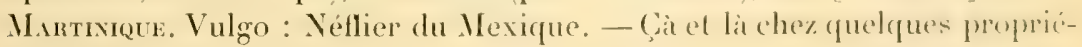
taires. $\left[\mathrm{N}^{\circ} 1167.\right]$

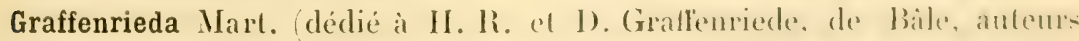
d'un ouvrage sur les arbres fruitiers el éditeurs de Mistoria plantarum, de Bauhin.)

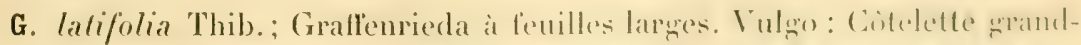

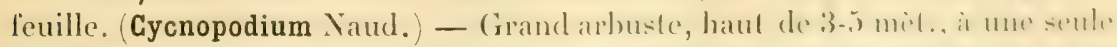

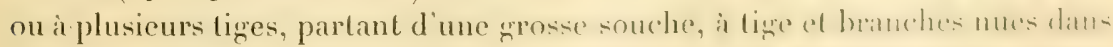
le bas, marquées de larges cicatrices, à écorce lisse et verte. Feuilles orbicu 
laires, coriaces, très glabres, entières, longues de 10-15 cm. : les jeunes, un peu moins laryes; les adultes, plus larges que longues. Fleurs petites, blanches, en paniculeslarges, terminales, trichotomes et corymbiformes. Fruit inconnu. - Rare : dans les bois inférieurs du morne Desboulais, au-dessus de l'habitation Pagesis, à Pigeon. [No 3714.

Martingere. V'ulgo : Crécré grand-feuille. - Prêcheur (bois de la Sibérie), Basse-Pointe, dans les hauteurs, sur la pente de la Montagne-Pelée (assez abondant). [No 110 .

Tibouchina Aubl. (nom indigène à la Guyane.)

T. chamiecistus Cogn.; Tibouchina petit ciste. V'ulgo: Thrm violet, thym de montagne. - Arbrisseau haut de $\mathbf{1 5 - 4 0} \mathrm{cm}$., tortueux, flexible, branchu ou presque dépourvu de branches, à ramuscules tétragones. Feuilles longues de 4-7 mm. sur $2-4 \mathrm{~mm}$, de large, roulées sur les bords, ovées ou ovales, terminées au sommet par une soie, garnies en dessus de 10-16 soies courtes, adnées dans toute leur longeur: nervure 1. Fleurs pourpre foncé, larges, d'une grrande beauté, solitaires ou réunies par 2-4; calices et pédoncules hérissés de soies; pétales obovés, ciliés sur les bords; étamines 8-10; ovaire à 4 logres. - Fl. presque toute l'année. - Vit dans les sphagnums, sur le cône et le plateau de la Soufrière, de la Grande-Découverte, de la Sarane aux Ananas, etc. [No 2251.]

Martixiele. - Chætogastra chamcecistus Gr. Vulgo: Thym de montagne. - Ressemble exactement à l'espèce guadeloupéenne, quant à la couleur, la forme et les dimensions des feuilles et des organes floraux; il en diffère : par sa taille beaucoup plus élevée $\left(0^{\mathrm{m}} \%(0-1 \mathrm{~m}\right.$.) , ce qu'explique sa station sur un sol volcanique couvert d'une couche d'humus très riche; par ses branches et ses fleurs très nombreuses; par ses feuilles pourvues aussi, mais à la face inférieure, de soies adnées; par ses pédoncules plus longs et le plus souvent disposés par ombelles de 3-4 rayons. - Il constitue un des plus beaux arbrisseaux que la Providence ait créés. - Fl. surtout de mai en juillet. - Vit solitaire ou en société à la Montagne-Pelée (Petite et Grande-Savane), sur la pente du morne Lacroix (plus ou moins rabongri); plus rare aux sommets des Pitons-du-Carbet. $\quad I^{\circ} 112$.

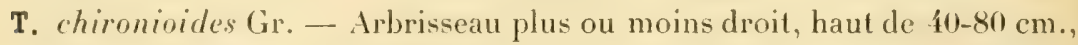
¿ branches allongées, ì fleurs larges, pourpre pâle; se rencontre ì la Dominique (environs de Lauda). [No 1172.

Arthrostemma 1). C. (du gree "arthron ", articulation, el "stemma ", étamine, à cause de l'état articulé de ces organes.)

A. glomeratum Naud., Pterolepis capitala Miq., P. glomerata Crueg; Arthrostemme à fleurs en glomérules. Vulgo: Herbe à vaches mâle. - Herbe annuelle, très sourent sulfrutescente à la base, ornementale, haute de 30- 
$80 \mathrm{~cm}$., droite, peu branchue, vert pâle dans toutes ses parties, ì ligye et branches tétragones, garnies de poils couchés, roux jaunâtre, ainsi que les pétioles et la lace inféricure des feuilles, mais surtout les ramuscules. Fenilles entières, petites, lancénlées, pointues, à 3 nerrures. Fleurs roséesou blanches, larges, caduques, en whomérules terminales, contenant rarement plus de deux rayons; tube du calice à huit sillons, narni de poils sétilormes, longs, rigides el étoilés à l'extrémité; lobes du calice longns, persistants; élamines 8 ; anthères jaunes, luberculées à la hase, subulíes; nvaire mûr libre, surmonté de plusieurs soies droites. Fruit sec. - Extrèmement abondant dans toutes les savanes humides, depuis environ 300-1000 mèt. d'élévation (jusque dans la petite savane autour de la case des Bains-Jaunes). -- Fl. toute l'année. [No2266.]

Martingee. Vulgo: Herbe à mouches. - Très abondant dans toutes les savanes jusqu'à altitude de 680 mèt. [ $\mathrm{N}^{\circ} 1173$.

Nepsera Naud. (anagramme du gr. Spennera de Martius el de I). C. I'rod.. III, p. 115.)

N. aquatica Naud. Nepsera aquatique. Vulge : Herbes it mouches. Aubl, 1. 169. - Annuel, droit, à base souvent couchée el lignense, d'une élévation moyenne de $70 \mathrm{~cm}$., très ornemental, a tige crlindrique, très fragile. branchue ou à branches peu nombreuses, allongées, à jeunes rameaux tétragones. Feuilles petites, ovées-lancéolées, opposées, peu nombreuses, brièvement acuminées, finement serretées, à 3-5 nervures. Fleurs violettes, nu violacées ou blanches, disposées en un large panicule trichotome, feuillue ì la base; pédicelles loners, fililormes; calice à é lobes linéaires; ćtaniness; anthères violettes, lancéolées-linéaires. Fruit mûr seec, non adhérent au calicer. - Fl. presque toute l'année, mais surtout d'arril a juillet. - Endroits aquatiques ou très humides, pas rarement dans les savanes sèches et aryileuses: TroisRivières (chemin du Trou-aux-Chiens), Capesterre, Matouba: (si el lii au morne Gommier et à Gourbeyre (environs du Valcanard). Alt. 270-7mo mèt. $\left[\mathrm{N}^{\circ} 2261\right.$.

Martingere. Vulgo : Ilerbe ì mouches. - Fonds-Saint-Denis, Champtlore, La Régale, Rivière-Salée, etc. [No 1168 .

SotXANTE-SEIZIÈME FAMILLE, - LYTIIRARIEES.

Cuphea P. Br. (du gree "kuphos ", vouté, bossu, parce que le calice cest bossu à la base.)

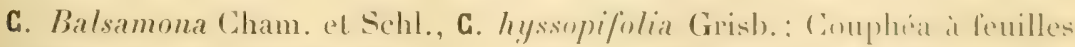
d'hysope. Vulgo : Herbe-savane. - Herbe sulfrutescente ou lirutescente, 
haute de 15-70 cm., scabre, plus ou moins visqueuse, droite; à branches alternes, situées sur le même plan : les inférieures, longues; les supérieures, graduellement plus courtes; it tige, branches et pédoncules plus ou moins garnis de poils rudes, tuberculés à la base, et plus ou moins crochus au sommet. Feuilles orées-oblon ruues ou oblongues-lancéolées, petites, à pétiole très court. Fleurs très petiles, pourpres ou plus rarement blanches, axillaires et terminales : les axillaires habituellement solitaires ou réunies par -.5; calice tubuleux, à 12 sillons, bossu à la base; pétales 5 , inégaux; ovaire supère, à deux logres inégrales et garnies d'une glande du côté supérieur. Fruit capsulaire, s'ourrant latéralement. - Plante de peu d'utilité. - Abondante dans les endroits lomides ou atquatiques: Bagatelle, morne Grommiers, route de la Basse-Terre ì Gourbeyre. Alt. 80-700 mèt. [No 2234.]

Martineue. Vulgo: Petite violette. - Route de la Trace (Deux-Choux), environs de Fort-de-France (dans les chemins peu battus), Gros-Morne. $\left[\mathrm{N}^{\circ} 1495\right.$.

(On cultive asser fréquemment dans les parterres le G. micropelala Kunlh. (C. platycentra Benth.), joli sous-arbrisseau à tleurs larges, jaunâtres. ГNo 2233.

Martinique. [ $\mathrm{N}^{0} \mathbf{2 1 4 9 .}$

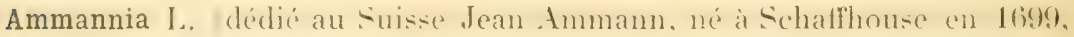
mort en 1741, professeur d'histoire naturelle à Pétersbourg; a écrit sur les plantes russes rares. - Paul Ammann a écrit sur l'histoire du Pérou en 1663, et a laissé plusieurs ouvrages ayant trait à la botanique.)

A. lalifolia L. ; Ammannie à larges feuilles. Vulgo: Herbe-mare. Sl., t. 7, f. 4. - Herbe annuelle, entièrement glabre et glauque, très droite, haute de $25-80 \mathrm{~cm}$. Feuilles opposées, décussées, lancéolées-linéaires, sessiles, cordées à la base, avec deux lobes semi-amplexicaules. Fleurs petites, blanches, axillaires, réunies par 2-5 aux aisselles des feuilles, depuis la base de la tige jusqu'au sommet; calice à $\mathbf{f}$ dents, doublées de dents accessoires; pétales f́, rouges; étamines 4 ; ovaire à 4 loges; style filiforme. Fruit capsulaire, renf'ermé dans le calice, s'ourrant irrégulièrement. - Cù et là dans les mares d'eau douce et dans les fossés le long des routes : environs de la BasseTerre, route de la Pointe-d-Pitre au Gozier, les Saintes Terre-de-Haut, autour de la mare située derrière le cimetière, où cette plante vit en société avec d'autres herbes). [No 3053 .

Martingue. Vulgo : Herbe-mare. - Marin, environs de Fort-de-France. $[N \circ 1303]$.

A. humilis Mich., A. ramosior L., A. occidenlalis D. C., Rotala ramosior liochne; Petite Ammanic. Vulgo : Herbe-mare. - Pelite herbe annuelle, à base couchée, radicante, à branches très allongées et plus ou moins relevées anx extrémites, hate de $2(1-35$ cm. Fenilles lancéoles-lineares, spatuleses, 
très rapprochées. Fleurs sessiles, solitaires ou réunies par 3 aux aisselles des feuilles, tout le long de la tige; étamines $\mathbf{t}$; style très court. Fruit globuleux. plus petit que dans le précédent. - Rare: Pointe-Noire (sur le bord de la grande mare, à côté du bourg. [Yo 3387.] - Je ne l'ai pas Lrouvé à la Martinique.

Lawsonia L. (dédié à John Lawson, médecin à Grand-Strickland, au commencement du xrır siècle; a voyagé en la Caroline dans un intérêt bolanique, et a publié la description de cette contrée.)

L. inermis L.; Lawsonie sans piquants. Vulgo : Réséda de France, réséda du pays. Desc., vol. VIII, t. 596, p. 365. - Arbrisseau ou grand arbuste, plus rarement petit ardere, a branches lortement inclinexs triginate d' Irat bie et des Indes Orientales, naturalisé et cultivé à cause de la bonne odeur de ses fleurs, qui se rapproche beaucoup de celle du réséda de lrance: On en

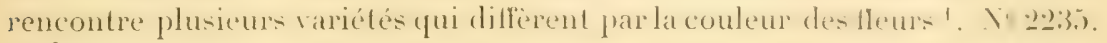

Également abondant à la Martinique.

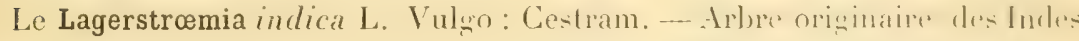
Orientales, qui, soumis à la taille, se couvre de fleurs d'avril en septembre; est très fréquemment cultivé dans les jardins des Antilles $\left[\mathrm{N}^{\circ} \varphi(02]\right.$, et le $\mathrm{L}$. Reginz L., grand arbre, originaire de la côte de Malabar, à fleurs lareses. pourpre foncé; se rencontre aux Jardins botaniques de la Basse-T'ere et de Saint-Pierre (Martinique), d'où il s'est répandu dans plusieurs localités de lîle. [ $\left.\mathrm{N}^{\circ} 903.\right]$

SOIXANTE-DIX-SEPTIÈME FAMILE. - ONAGRARIÉLS.

Jussieua L. (dédié par Linné au célèbre Bernard de Jussieu, né ì Paris en 1699, mort en 1777 , médecin; en 1775 , directeur du jardin royal du l'rianon,

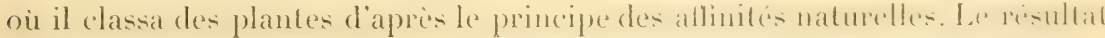
de ses travaux fut publié dans un simple catalogrue, sous le tilre: Ordines naturales in Ludovici XV horto Trianonensi dispositi.

J. su/fruticosa L. ; Jussiée suffrutescente. Vulgo: Girofle-mare. Sl., L. 11, f. 1; Plum., édit. Burm., t. 175, f. 1; Lam., Ill., t. 280, I'. 1. - Herbacé. haut de $0^{\mathrm{m}} 70-1^{\mathrm{m}} 50$, à base suffrutescente, à tige glabre, grosse, angruleuse,

1. Les feuilles de cet arbuste forment le IIenné d'Égypte et d'Arabic, employé depuis la plus haute antiquité, comme cosmétique colorant, par les femmes et les enlants pour augmenter la beauté et assurer la santé. Ils se servent de la poudre de leuilles fraticlues pour se colorer les ongles, ce qui est un signe de dignité. Il est aussi employé comme topique contre toutes les blessures par les Arabes. L'industrie l'utilise entin pour teindre la soie et pour donner au bois blanc une belle couleur d'acajou. (E. II. 
noire, at branches habituellement chalés. Feuilles lancéoles-oblongues ou lancénlées ou lancéolées-linéares, rétrécies à la base en un pétiole très court. Fleurs jannes, laryes, brierement pédonculees, solitaires ef axillaires; calice ¿l Jobes largement ovés ou elliptiques. cuspiclés. Capsule rétrécie vers la base. - Assez abondant le long des rivières, sur le bord des mares et des étangs. , variété à fleurs plus larges : environs de la Basse-Terre, Pointe-Noire, Capesterre $[$ Nos 2917,2245 .

Martinique. Vulgo: Gironflé, herbe ì pique. - Carbet, Fort-de-France, 'Trinité. $\left[\mathrm{N}^{\circ} 805\right.$.

B, variété angustifolia. Lam., Ill., 1. 280, f. 3. - Lamentin, Baie-Mahault, Pointe-à-Pitre, etc. [Nos 2918,3247.]

Martinique. - Lamentin, Ducos, Rivière-Salée, etc. [No 1385.]

J. erecta L., J. palustris Miq.; Jussiée droite. Vulgo : Giroflé-mare. Annuel, très droit et élégant, nu dans le bas, branchu dans le haut, d'une élévation de $0^{\mathrm{m}} 80-2^{\mathrm{m}} 50$, à tige anguleuse, à branches fastigiées. Feuilles elliptiques-linéaires. Fleurs petites, jaunes. Capsules courtes el grosses, nombreuses. - Endroits humides ou aquatiques, dans les fossés remplis d'eau et sur les bords des étangs : Sainte-Rose, Lamentin, Morne-à-l'Eau, les Saintes (Terre-de-Haut), Marie-Galante, etc. [No 2246.

Martixique. Vulgo: Géronflé, herbe à pique. - Abondant: Rivière-Salée, Marin, Caravelle, Trois-Ilets. [N॰ 1386.$]$

J. linifolia Vahl; Jussiée ì feuilles de lin. Vulgo : Gérolle-mare. - Suffrutescent, haut de $0^{\mathrm{w}} 90-2$ mèt., très droit, nu dans le bas, à branches fastiwies: les inférieures, longues: les supérieures, successivement plus courtes. Fenilles infirieures beaucoup plus larges el plus longues, lancéolées, celles des branches plus courtes, linéaires-lancéolées. Capsule courte, linéaire, léxèrement recourbée. - C'est l'espèce dont les capsules sont les plus minces. Eudroits humides, marécageux ef aqquatiques; vit souvent en société sur une grande étendue : Sainte-Rose, Lamentin, Morne-itl'Eau, Petit-Canal, etc. [No2919.

Martingue. Vulgo : Gironflé, herbe à pique. —Ducos, Trois-Ilets, Lamentin, Saint-Esprit, François, etc. [No 802.$]$

SOIXANTE-DIX-IUUTIVie FAMILLE. - RHIZOPHORÉES.

Rhizophora L. (du grec "rhiza ", racine, et "phero ", je porte, allusion aux nombreuses racines adventives qui supportent la plante.)

R. Mangle L. (mol de la langue malaise). Vulgo: Manglier, palétuvier rouse, manglè rouge, mangle-chandelle, mangle noir. Desc., vol. I, t. 10, 
p. 45. - Petit arbre ou assez souvent arbre d'assez grande laille; it branches très nombreuses, allongées, très inclinées, souvent pendantes; it racine principale courte, sourent presque nulle; it trone soutenu par des racines adrentives, arquées, nombreuses, plongeant dans l'eau; ì écorce noire et lisse. Feuilles ramassées aux extrémités des branches, épaisses, très glabres, entieres, ovales ou ovales-elliptiques, arrondies an -mumel: - lipule-interpitiolaires, tantôt longues, tantôt courtes. Fleurs axillaires, solitaires ou en

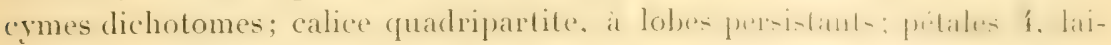
neux à l'intérieur; étamines 8 , sur deux verticilles. Fruit ovale, couronné, à la base, par les lobes persistants et durs du calice; semences 1. - Dìs que le fruit est arrivé à maturité, il commence à germer sur pied, la radicule en perce le sommet, s'allonge peu à peu, atteint quelquefois une longueur de $30 \mathrm{~cm}$, devient pendante et, entraince par son poids. alle linit par w ditither de la capsule. Dans sa chute, elle s'enfonce verticalement dans la vase. - Le

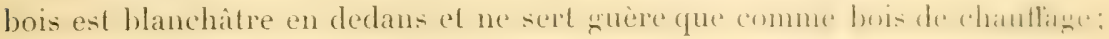
l'écorce et le fruit sont riches en tanin, et dans le pays on en fait souvent usage, surtout pour les tanneries de la Basse-Terre '. Fl. principalement de juin à septembre. - Vit en société sur une grande étendue, dans les marécages du Morne-à-l'Eau, de la Pointe-ì-Pitre, de Baie-Mahault, du Lamentin, de Sainte-Rose; moins abondant aux Saintes Trepre-de-llant, an Gozier, etc. [No 2961.]

Martinique. Vulgo: Mangle-chandelle, palétuvier rouge, mangle rouge. - Vit en société sur une large échelle : au Lamentin, Ducos, Rivière-Salée, Robert, François, Trinité, Galion, etc. [N॰1836.]

Cassipourea Aubl. (nom indigène de la plante à la Guyane.)

C. elliptica Poir.; Cassipoure it feuilles elliptiques. Vulgu : Bor--th-lail. - Arbre élégant, de taille moyenne, parfois grand arbre, selon les endroits.

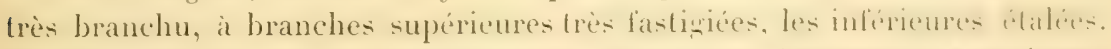
Fenilles entieres, coriaces-subchamues, elliptiques. Lépirement atmonimes. opposées. Fleurs très nombreuses, en fascicules axillaires de -2-6 rayons pédonculés; calice aussi long que les pétioles, à 4-6 lobes deltoïdes; pétales כ-4, blancs, délicatement frangés et laineux en dedans. Capsule petite, ì 3 valves. - Les fleurs, en s'ouvrant, émettent un parfum agréable; plus tard. ces mèmes fleurs exhalent une mauvaise odeur. Les feuilles, froissées entre les doigts, répandent une odeur rappelant bien celle de lail. 1\% habiludment en mai et juin, et aussi en octobre et novembre. - Assez abondant

1. L'emploi de cette écorce, riche en tanin, a pris aujourd'hui une place marqu e dans: l'industrie de la tannerie et surtout des matieres colviantes. Elle sert surtout it la fah iciation des extraits tannants aujourd'hui presque exclusivement employés au lieu et place des écorces abandonnées. (E. H.) 
dans les bois inférieurs du Matouba, des Bains-Jaunes, de Houëlmont, des Trois-Rivières, etc. $\left[\mathbf{N}_{0} 2737 .\right]^{1}$

Mantineue. Vulgo : Bois-de-l'ail. - Était encore assez abondant, en 1878, dans les bois de la Régale et dans ceux de quelques mornes de la Rivière-Salée; les déboisements l’ont fait disparaître. - Assez abondant enenre dans les bois du Prêcheur (Géron et la Sibérie). [No 2149.

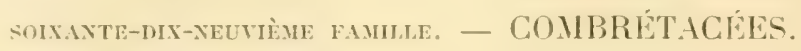

Terminalia L. (du grec « terma ), en latin " terminus », terme, pointe, parce que les feuilles sont confinées aux extrémités des branches.)

T. Calappa L. (du mot " catapan ", nom de l'arbre aux Moluques.) Vulgo : Amandier. Dese., vol. IV, t. 279, p. 217. - Arbre de taille moyenne, plus rarement arbre de grande taille, droit, à branches étagées, horizontales, à écorce rude et gercée. Feuilles obovales, subcordées et portant deux glandes à la base du limbe, arrondies au sommet. Fleur's polygames, en grappes elfilées, réunies en groupes, axillaires, situées aux extrémités des branches : les femelles, mélangées avec les mâles dans le bas de la grappe et distantes; les mâles, plus haut et rapprochées. Fruit ovale-oblong ou elliplique, biconvexe-comprimé, muni de deux ailes longitudinales et étroites. Le bois est recherché pour le charronnage; l'amande est blanche et très goûtée des créoles, son goût approche de celui de la noisette. On peut retirer des amandes une huile qui ne rancit jamais. Selon Descourtilz, le lait des amandes est émulsif, et l'huile, extraite à froid et mêlée à du sirop de l'herbedi-charpentier, est recommandée contre les toux opiniâtres². - Originaire de l'Asie et de l'Afrique, naturalisé dans les deux colonies; on les plante habituellement dans les cours et le long des routes comme arbres à ombrage. - Fl. toute l'année dans la basse région; dans la région supérieure, la floraison a lieu de mai en août, et les grappes sont souvent très allongées el composées. [No 3100.$]$

Mantiniqee. Vulgo: Amandier. [No 1800.$]$

Laguncularia D. C. (du latin "laguncula ", diminulif de "lagena ", bouteille, parce que le limbe du calice, qui couronne le fruit, a un peu la forme d'une bouteille ou d'une cruche renversée.)

1. Plante riche en tanin, astringente : teinture et lannage des peaux.

2. La racine est employée contre la dysenterie, la diarrhée; l'écorce contre les fièvres gastriques et bilieuses. Elle contient un tanin qni lui donne ses propriétés astringentes et ges matieres colorantes qui en permettent l'emploi dans la teinture. L'huile des amandes est comestible. (E. II.) 
L. racemosa G.; Lagunculaire ì fleurs en grappes. Vulgo: Mangle blanc (à cause de la couleur de la lace inférieure de la feuille). - Pelit arbre, droit, très branchu, it branches horizontales, très souvent penchées ou tombantes, à rameaux cylidriques-comprimés, à écorce grise el lisse. Feuilles coriaces, subcharnues, ovales ou elliptiques, ou ovales-oblonğues, souvent échancrées et mucronulées au sommel, blanchâtres-duvetées en dessous; pétiole longr, portant habituellement deux glandes en dessus, près de la base ou au milieu. Fleurs polygames, en cymes trichotomes et à branches spiciformes; pédoncules pubescents; calice à 5 lobes persistants; pétales 5 , blancs ou légèrement rosés, caducs, petits; étamines 10 , bisériées. Fruil petit, ì deux ailes étroites, pubescent, gris, rappelant un peu la forme d'une bouteille de genièvre de Hollande. - Très abondant dans les marécages du bord de mer, où il vit en société avec d'autres palétuviers. YYo 3097.]'

Martixique. Vulgo : Mangle gris, palétuvier gris. - Rivière-Salée, Lamentin, Ducos, Trois-Ilets, François, Robert, etc. [ $\left.\mathrm{N}^{\circ} 1798.\right]$

Conocarpus L. (du grec "konos ", cône ", el "carpos ", \{ruil, parce que les fruits affectent une forme conique.

G. erectus L.; Conocarpe droit. Vulgo : Palétuvier rouge, mangle rouge, mangle gris, olivier bord-de-mer. Jacq., Sel. Am. stirp. hist., 1. 52 ; Sl., t. 161, f. 2 ; Desc., vol. VI, t. 399, p. 68. - Petit arbre, entièrement glabre. habiluellement droit, plus rarement torlueux, a branches horizutates. allongées, penchées ou tombantes, à ramuscules triangulaires, à écorce grise ou rougeâtre, fortement gercée dans les vieux pieds. Feuilles lancéolées ou elliptiques, brièvement pétiolées, garnies de deux glandes, situées ì droite el it gauche, à égale distance du sommet du pétiole. Inflorescence en grappes courtes, simples, à branches terminées par des capitules d'abord sphériques, devenant ensuite coniques; divisions du calice 5, rudes, caduques; pétales nuls; étamines $5-10$; akènes imbriqués, petits, recourbés, ressemblant it de petites écailles d'un cône de sapin ; capitule mûr conique, long de $5-\bar{t} \mathrm{~mm}$.. souvent tout à fait rond. - Le bois n'est employé que pour le chaullage 2Très abondant dans les endroits marécageux du bord de mer, où il vit en société avec d'autres palétuviers; plus rare dans les sables secs : les Saintes (Terre-de-Haut), Port-Louis, Petit-Canal, Anse-Bertrand, Moule, etc. [No 3098.]

Martiniqce. Vulgo: Palétuvier gris, palétuvier rouge. - Abondant dans les endroits marécageux du bord de mer : Trinité (Galion), Robert, François, Lamentin, Sainte-Luce, Rivière-Pilote, etc. $\mathrm{N}^{\circ} 1797$.

1. Plante à tanin, astringente, usitée contre la dysenterie.

2. Plante amère et astringente : on l'a proposće comme succédanée du quinquina ef comme utile dans le traitement du diabète el de la syphilis. (A étudier.) 
Le Conocarpus latifolius Roxb, urand arbre, est cultivé au Jardin botanique de Saint-Pierre, où il fleurit el rapporte des fruits tous les ans. No 1802 .

Bucida L. (du grec " bous ", bœuf, paree que, dans les espèces-types, le fruit est long et recourbé en forme de corne de bœuf.)

B. capilata V.; Bucida à fleurs en capitules. Vulgo : Bois gli-gli ou grigri (oiseau de l'ordre des rapaces). - Arlore souvent énorme, à tronc très anfractueux, surtout à la base, à branches nues, très irrégulièrement étalées, plus,ou moins horizontales, souvent penchées, à rameaux régulièrement et nettement dichotomes, à écorce grise ou blanchâtre, peu crevassée. Feuilles ramassíes ì l'extrémité des branches, spatulées nu ovées-oblongues, coriaces: les jeunes couvertes en dessous d'un duvet couleur de rouille. Inflorescence en capitules pubescents, allongés, axillaires, wilues à l'extrémité des branches, longuement pédonculés. Jeunes feuilles el capitules d'abord renfermés dans une masse de bractées luisantes, garnies d'un duvet fin, couleur de rouille. Fleurs vertes, très petites; calice à 5 petites dents; pétales nuls; étamines 10 , dont 5 plus grandes et insérées plus haut. Fruit ovoüde, pointu aux deux bouts et muni de f-6 côtes longitudinales et de côtes accessoires plus courtes. - Lors de la germination, le fruit s'ouvre en deux moitiés égales. - Fl. en janvier, mars ou avril. - Peu abondant : çà et là dans les bois du massif de Houëlmont, des bois inférieurs des Bains-Jaunes, des bords de la rivière liouge, etc. [No 3095 .

Martinique. Vulgo : Bois-arcoqois. - Rare : hauteurs de l'habitation Pécoul; çà et là dans les bois de la Régale (Saint-Esprit) et des bois de la fontaine Absalon. [ $\mathrm{N}^{\circ} 660$.]

B. buceras L. (de "bous ", bœuf, et " keras ", corne.) Vulgo : Bois gligli. Sl., 1. 189, f. 3 ; Br. Jam., t. 23, f. 1. - Grand arbre, à frondaison large et allongree is branches étalées. Feuilles comme dans le précédent, mais habituellement plus larges. Fleurs en épis courts, très nombreux, soyeux, cylindriques, interrompus, situés à l'extrémité des branches, habituellement plus courts que les feuilles; étamines exsertes. Fruit inconnu. - Les deux espèces de shi-sli lournisisent pour la charpente un bois serré, résistant, très élastique, se travaillant facilement; il passe pour être inatlaquable par les termites ${ }^{1}$. Assez abondant dans les environs du Moule; ça et là à Port-Louis, etc. [No 3096.] - Il n'existe pas à la Martinique.

Le Quisqualis indical L., vulgen a la (ruadeloupe) : Fleur is trois couleur's, est trés fréquemment cultivé pour la sarniture des treillis, des grillages cl des

1. Écorce à tanin et à matière colorante, employée en médecine et dans la teinture. Sous l'influence de la piqûre de certains insectes, le B. buceras fournit des galles riches en tanin. 


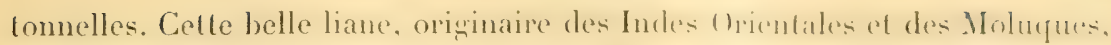
a des grappes simples, pendantes, à fleurs longuement tubulées, blanches en s'ouvrant, ensuite blanc rose, puis rouge pâle et enfin rouge sombre. Fl. sans cesse mais ne produit pas de fruits. [No 3777.] - Martinique. No 954 .

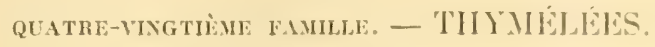

Daphnopsis Mart. Zuce. (du gree " daphné ", laurier, el "opsis ", aspect, c'est-ì-dire ressemblant à un laurier.)

D. caribiea (rr.; Daphnopsis des Caräbes. Vulgo : Mahol-piment, pimenti. mahot pimenté. - Petit arbre, habituellement droit, haut de 4-10 mèt., très variable quant à la disposition des branches, à écorce grise, lisse, très fibreuse. Fenilles subcoriaces, lancénlesesoblongues. Inthorecence terminale, en cymes arrondies, pédonculées, plusieurs fois dichotomes, i branches terminces par des ombelles. Fleurs blane pàte, diö́ques, apcitales; lube du calice de la fleur mâle en forme de massue, celui de la fleur femelle d'abord infundibiliforme, ensuite campanulé. Baies mûres tris blanches, cllipuödes, il pen près de la grosseur d'une graine de poivre, contenant une semence rondâtre. - Fl. en avril, mai, et aussi en octobre et novembre. - Le bois a peu de valeur, mais l'écorce fournit des fibres très longues et très fortes : les habitants en fabriquent des cordes et des liens '. - Assez abondant it Gourbeyre (Dolé, mornes Goblin, Dos-d'Ane, Boucanier), Vieux-Fort, Moule, Gozier, etc. Alt. 20-480 mèt. [ $\mathrm{N}^{\circ} 3220$. $]$

Martinique. Vulgo : Mahot-piment. - Parnasse, morne Saint-Martin, Prêcheur, Grande-Rivière, Robert, hauteurs du Carbet, etc. [Xo.2103.]

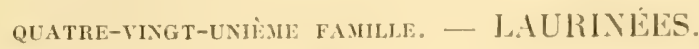

Cinnamomum Bl. (du gree " kimnanomon ", iecorece de camnelle, de " kineinn", rouler, et " amomon ", amone; selon d'autres, du mot " china ", c'est-ìdire écorce de Chine, parce que les Arabes, qui les premiers apportaient la cannelle en Grèce, croyaient qu'elle venait de la Chine.)

C. zeylanicum Bl.; Cinnamome de Ceylan. Vulgo : Cannellier. Desc.,

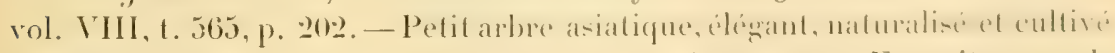
dans le pays à cause de son écorce. - Fl. en février, mars. - Fournil un excel-

1. Celte écorce, comme les feuilles, est âcre el détermine, par la mastication, d'abord une vive brûlure dans la bouche (d'où le nom de piment), puis de la vésication. 
lent bois pour l'ébénisterie. - Capesterre (habitation Longmont), CampJacob, Gourbeyre, Lamentin, etc. To 3194.

Martixiqu. Vulgo: Cannellier. - Camp Balata, Saint-Pierre, Fort-deFrance, Marin, etc. $\mathrm{N}^{\circ} 1947$.

Phœbe Nees (parce que le genre "Phobe " était fondu autrefois dans le genre "Laurus " proprement dit, qui était dédié à Phœbus ou Apollon.)

P. elongata Nees; Phœbé à grappes allongées. Vulgo: Bois-doux, boisChypre. - Grand arbre, droit, à branches étalées et allongées, à écorce noirâtre. Feuilles coriaces, ovales-elliptiques. Inflorescence en panicules allongées, axillaires, confinées aux extrémités des branches. Fleurs blanches, orlorantes; calice large, à 6 lobes persistants. Fruit ovale-clliptique, long de 10$1: 3$ con.. supporté par une cupule obeonique-allongée, muni des lobes persistants du calice. - Le bois est recherché pour la construction. - Forêts des hauteurs de Deshaies, de Sofaya, et des environs de la Ravine-Chaude. Fl. en mai et juin; fruits mûrs en août et septembre. [ $\mathrm{N}^{\circ} 3196$. ]

Martixique. Vulgo : Laurier-cannelle, cannelier sauvage. - Bois del'AjoupaBouillon, des hauteurs du Prêcheur (bois de Galbiac et du morne SaintMartin), Champtlore, etc. [N०216.]

Persea L. (nom donné par Théophraste à un arbre d'Égypte.)

P. gratissima L.; Persée très agréable au croût. Vulgo : Avocatier, avocat (du mot des Indiens du Brésil "Aguacate », que les Brésiliens modernes ont changé en " arocate ", et les Espagnols en " avocato ", et les Français en " avocat ».) Tuss., Fl., III, t. 3; Desc., vol. VIII, t. 577, p. 280; Sl., t. 222, f. 3. - Petit arbre, originaire de l'Amérique tropicale et subtropicale, et de l'Asie, naturalisé et cultivé dans toutes les Antilles à cause de l'excellence de son fruit. C'est une drupe brune en dehors, pyriforme-obovale, pouvant atteindre jusqu'à $16 \mathrm{~cm}$. de long. sur 9-12 cm. de diamèt., polie et luisante, abritant, sous un épicarpe mince qui se détache facilement à la maturité, un

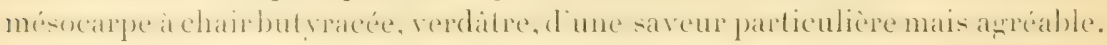
Il renferme une seule grosse graine, enveloppée par un endocarpe ou une pellicule blanche, qui s'enlève facilement. La semence est globuleuse, déprimée à la base, d'un diamèt. de $4-6 \mathrm{~cm}$., très souvent un peu plus large que longue; les deux cotylédons sont charnus et hémisphériques. - Le fruit se sert ì table en hors-d'ceuvre. Les Européens le trouvent fade, les créoles en sont friands. Il passe pour être aphrodisiaque. Descourtilz le classe dans les

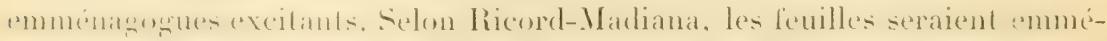
nagogrues, antihystériques et antidysentériques ${ }^{1}$. La graine contient un suc

1. Celte dernière propriété, seule bien reconnue aux feuilles jusqu’ici, tient à la présence dans ces organes d'une quantité notable de tanin. (E. II.) 
laiteux, qui rougit peu à peu à l'air et tache le linge d'une manière presque ineffaçable. Dans le pays, on se sert de l'eau, dans laquelle on a infusé les boutons de feuilles et de fleurs, comme apéritive el béchique. Les agoutis sont extrêmement friands des graines. Le bois est sans raleur pour la construction. - Fl. en avril, mai; fruits mûrs en août, septembre, octobre et novembre. $\left[\mathrm{N}^{\circ} 3195\right.$.

Martinique. Vulgo : Avocalier. [Yo 1948.

P. Urbaniana Mez; Persée d'Urban. Vulgo : Laurier-avocal. - Arbre de

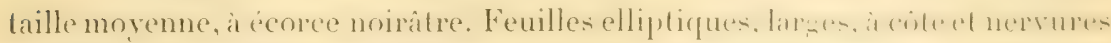
imprimées en dessus, très saillantes en dessous. Inflorescence en grappes axillaires, courtes, situées à l'extrémité des branches. Fleurs el fruits inconnus. - Hauteurs de l'habitation Pécoul, morne Saint-Martin et bois de Galbiac. [No 218.] - Je ne l'ai pas trouvé à la Guadeloupe.

Hufelandia Nees (dédié à Hufeland?.)

H. pendula Nees; Iufelandie à grappes pendantes. - Petit arbre ou arbere de taille movenne, is branches pendantes. Fevilles efliptiques on whip-

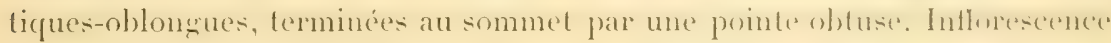
en panicules pendantes; tleurs inconnues. Fruit long de $3-4 \mathrm{~cm}$, ovalecylindrique, inséré sur un petil disque. - Assez rare : çà et là dans les bois du morne Saint-Martin, des hauteurs du Pécoul et du Prechenr lovis de (ialbiac). [No 222.] — Je ne l'ai pas ru à la Guadeloupe.

Acrodiclidium Nees (du grec "akros", pointe, et- " diklis ", porte à double battant, en raison du mode de déhiscence des anthères.)

A. salicifolium Gr.; Acrodiclidium à feuilles de saule. Vulgo: Bois-fourmi, bois-chique. - Petit arbre, n'excédant guère 7 mèt. de haut, droit, à écorce lisse, à jeunes branches couvertes d'un duvet très léger el gris. Feuilles très coriaces, lancéolées, acuminées, à nervures formant des ares près du bord. Inflorescence en grappes courtes, pauciflores, axillaires. Fleurs verdâtres. Fruit ovoïde-oblong, long de 11-13 mm., inséré dans une cupule moitié plus courte que ce fruit, munie d'une double marge, dont la première lorme un petit rebord près du sommet, tandis que la seconde est siluée plus haut et appliquée contre le fruit ' - Arbre croissant exclusivement dans les terres calcaires ou pierreuses, sèches et peu élevées : Port-Louis et Anse-Bertrand, mornes calcaires des environs du Moule, de Sainte-Anne, etc.; rare it la Guadeloupe proprement dite (çà et lì sur le bord de mer, entre Deshaies el Sainte-Prose). [Nos 3197, 3382.] - Je ne l'ai pas trouvé à la Martinique.

A. sericeum G.; Acrodiclidium à feuilles soyeuses endessous. T'ulgo: Bois

1. Le bois est amer et aromatique; les fruits, desséchés, sont employés pour combaltre la dysenterie. (A étudier.) 
à pian. - Petit arbre, très droit, haut de 6-12 mèt., à branches fastigiées, à écorce grise et lisse. Feuilles petites, elliptiques, brièvement acuminées au sommet, pointues à la base, pâles et légèrement pubescentes en dessous; calice soyeux, à 6 dents. Fruit inconnu. - Était, en 1878, encore très abondant dans le- hanteure entre la Riviere-satée et la Réprale : les débnisements sont la cause de sa rareté. [No 1903.] - Je ne l'ai pas vu à la Guadeloupe.

Nectandra Rottb. (du grec "nectar ", nectar, et " aner" ", homme, parce que sur les neuf étamines fertiles, les trois intérieures sont grarnies sur le dos de denx mectaires plobuleux: quelquefois les trois étaminesstériles portent atisi des nectaires.)

N. Inminicana Mez: Vectandre de la Dominique. Vulgo: Muscadier-boisdoux-muscade. - Arbre droit, de taille moyenne, haut de 12-18 mèt., entièrement stabre, à trone fort nu, cylindrique, it écorce épaisse, verdâtre, lisse : les

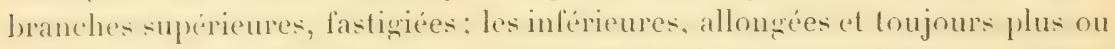
moius (ombantes. Feuilles larges, fris vertes et luisantes en dessus, jaunitres en desinns, clliptiques ou elliptiques-oblongues. brievement et obturément pointues au sommet, à côte noirâtre, très large, aplatie en dessus, très saillantes en desons. Inflorescence en wrappes larses, dressées, axillaires. continées dans les aisselles des cing ou six dernieres feuilles de la branche. Fleurs vertes; grappes mûres pendantes. Fruit long de près de $4 \mathrm{~cm}$. sur $13-14 \mathrm{~mm}$. de diamètre, légèrement obovale, noir et pulpeux à la maturité, glauque avant d'être mûr, inséré dans une cupule large, verruqueuse à l'extérieur, munie des dents persistantes et émoussées du calice. C"est le laurier indigène dont les feuilles soient les plus larges. - Fl, en août et septembre. - Le trone, qui peut atteindre jusqu a $\mathrm{fl} \mathrm{cm}$. de diamèt, foumit un excellent bois de construction. - Assez abondant dans les bois des Bains-Jaunes, du Natouba et du Gommier. Alt. 400-800 mèt. [No 2226.]

Martinieve, Vulgo : Laurier-gombo. - Bois de l'Ajoupa-Bouillon, du Lorrain, des Fonds-Saint-Denis, etc. [N ${ }^{\text {os }} 224,228$.]

N. Antillana Meiss.; Nectandre des Antilles. Vulgo : Bois de laurier. - Arbre de taille moyenne, élancé, entièrement glabre, ì branches étalées, relativement courtes. Feuilles très coriaces, elliptiques-ovales, acuminées, à pointe terminale obtuse, à $3-5$ paires de nervures irrésulierement alternes. Intlorescence en grappes confinés aux extrémités des branches: flemrs blanches. Fruit splérique, de la grosecur d'une petite cerise. souvent monstrueux et sans noyau, piqué qu'il est par des insectes. - Abondant dans les bois inferieurs des bains-James, des Tieux-Habitants, du Gommier, de Deshaies, etc. - Le bois est mou et est employé tout au plus pour les constructions à l'intérieur. [No 2222.]

Mantixque. Vulgo: Laurier à cerise. - Abondant dans les quartiers infé- 
rieurs de la fontaine Didier et de la fontaine Absalon, de la Calebasse, du Lorrain (côté de la Grand'Anse), etc. [ $\left.\mathrm{N}^{\circ} 221.\right]$

N. coriacea Gr.; Nectandre à feuilles très coriaces. Vulgro : Bois-négresse. - Arbre haut de 9-17 mèt., à branches très étalées, à jeunes branches rougeâtres, lisses et luisantes, à écorce lisse et noirâtre. F'euilles elliptiquesoblongues, cartilagineuses, très luisantes en dessus. Inflorescence en panicules axillaires, courtes, plus ou moins pendantes, plus courtes que les feuilles; fleurs blanches, très odorantes. Fruit obovoïde, inséré dans une cupule tronquée. - Fl. en juillet, août. - Le bois de celte espèce de laurier est excellent pour la construction. - Bois des Bains-daunes, du Matouba, du

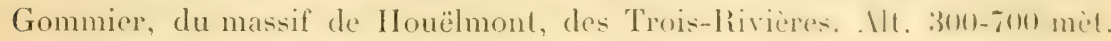
[Nos $3199,3200,3528$.

Martinique. Vulgo : Laurier-fine. - Bois du Lorrain, du Camp de l'Alma, de la fontaine Absalon, de la Grand'Anse, etc. [Nos 227, 23:2.]

N. patens Gr.; Nectandre à grappes ouvertes. Vulgo : Laurier doux. Arbre de 15-20 mèt. de haut, a trone cylindrique, a ecorer noiritre a jeunes branches gris brun. Feuilles ovées ou ovales, cunéiformes-arrondies à la base, à côtes et nervures très imprimées en dessus, saillantes en dessous el portant de petites touffes de poils courts à l'angle d'insertion des nerveres. Inflorescence en panicules axillaires et à branches très ouvertes. Fleurs blanches, odorantes; cupule large. Fruit oliviforme. - Fl. en mai, juin, juillet. - Bois de Gourbeyre mornes Goblin, Dos-d lue el boncanier , bois des environs du Grand-Étang (Capesterre, Guadeloupe), ete. L.'.2.216 a, 3618$.

Martinique. Vulgo: Bois petit Jean, laurier Isabelle rouge. - Fontaine Absalon, hauteurs de sainte-Luce, de la Rivière-salée el de la hermale. $\left[\mathrm{N}^{\circ} 229.\right]$

N. membranacea Gr.; Nectandre à feuilles très membrancuses. Boisdoux.- - Arbre de 12-22 mèt., ressemble au précédent quant au port, à la forme des feuilles et à la couleur des fleurs; il en diffère par ses jeunes branches, pédoncules et pédiceller pubescents, par ses nervures autrement disposées, par ses panicules deux ou trois lois plus allongéeses, par ses fleurs plus petites. - Le bois est poreux et blanchàtre on dedans et ne sert que pune les constructions à l'intérieur; sa racine contient une teinture violetle. On trouve souvent sur le mème pied des lleurs et des fruits murs. - lonis infirieurs de la Pointe-Noire, bois de la liavine-Chaude, de Solaya, de. .11t. 51)400 mèt. [No 3381.$]$

Martixique. Vulgo : Laurier-Chypre. — Basse région boisée de l'île: Prêcheur, Parnasse, Rivière-Pilote, environs de Fort-de-France, ctc. [No 2.20.]

Ocotea Aubl. (nom indigène de l'arbre ì la Guyane.) 
0. cernua Mez, Oreodaphne marlinicensis Sieb.; Ocotée penché. Vulgo :

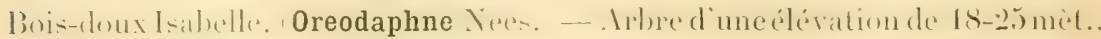
a trone nu sur une longue étendue, cylindrique dans le haut, anfraclueux à la base, à frondaison large, à écorce noirâtre. Feuilles cartilagineuses, oblongues ou oblongues-lancéolées, ou elliptiques, à nervures principales parallèles, au nombre de $\mathbf{4}-5$ et formant un arc sur les bords. Panicules plus courtes ou plus longues que les feuilles, à pédoncules minces et noirs; fleurs b)anches, odorantes, habituellement dinïques. Fruil ovö̈léoliviforme, inséré dans une cupule tronquée et large. - FI. en mai, juin, juillet. - Abondant dans les bois inlériens du Gommier, des lanins-daunes, des Vieux-IIabitants, de l'îlet Lajaille, des environs du Saut-de-Constantin, des hauteurs de Baillit, ete.

Mantiveue, Vulgo : Laurier Isabelle. - Prêcheur (fontaine Chaude), Grande-Rivière, hauteurs de Pécoul, Champłlore. $\left[\mathrm{N}^{\circ} 223\right.$.

0. lencoxylon Mez; Ocotée à bois blanc. Vulgo: bois-doux jaune, bois-doux pimente, bois-doux-courome. - Arbre de taille movenne, haut de 15-18 met..à branches divariquées et souvent couvertes de lenticelles blanches, et toujours garnies d'un duvet poudreux et blanc. Feuilles cartilagineuses, oblongues ou elliptiques, le plus souvent acuminées. Fleurs blanches, odorantes. Fruits sphériques, noirs, de la grosseur d'une très petite cerise, insérés dans une cupule tronquée, verruqueuse et souvent couverte de lenticelles blanches. - Abondant dans les bois inférieurs des Bains-Jaunes, de la Pointe-Noire, de Deshaies, de Sainte-Rose, etc. - Le bois est jaunâtre; il est employé pour la charpente et pour les boiseries ${ }^{1}$. [Nos $\left.3202,3203,3482.\right]$

Martingue. Vulgo: Laurier-fine, laurier-madame. - Calebasse, Lorrain, Champllore, Fonds-Saint-Denis, Gros-Morne, etc. [No 231.]

0. Martinicensis Mez; Ocotée de la Martinique. Vulgo : Laurier bord-demer. - Arbre haut de 16-22 mèt., à trone nu sur une grande hauteur, à frondaison élancée. Feuilles obovales, larges, très obtusément pointues au sommet, à 5-10 paires de nervures formant un arc sur les bords du limbe. Infloresernce en panicules axillaires, habituellement aussi longues que les leuilles, lomgunement pédincules. Fleurs blanches, exhalant une forte el bonne odeur. Fruit ovoïde-oliviforme, large, très pulpeux, inséré dans une cupule large et verruqueuse-sillonnée, s'amincissant peu à peu jusqu'au pédoncule. - Dans les régions inférieure et infra-moyenne de l'île : Ajoupa-Bouillon, Carbet, Parnasse, Saint-Esprit, Rivière-Salée, etc. [No 234.] - Je ne l'ai pas trouvé à la Guadeloupe.

0. Ełygersii Mez; Ocotée d'Eggers. Vulgo: Peste-à-pou. - Arbre haut

1. Cette espéce, comme toutes celles du scenre Ocotea propres aux Antilles, est aromatique; son fruit renferme, dans sa partie pulpeuse, une huile fixe et une essence employécs dans le traitement du rhumatisme. (E. II.) 
de 14-18 mèt., élancé ou à l'rondaison très large, arrondie, selon qüil est seul ou en société avec d'autres arbres, entièrement grlabre, à écorce lisse el noirâtre. Feuilles cartilagineuses, d'un vert sombre en dessus, glauques en dessous, elliptiques, obtusément pointues au sommet, it nervures reliées ì un arc, près des bords du limbe. Panicules comrtes, axillaires, plus longrues que les feuilles; pédicelles quadrangulaires. Fruil sphérique, bleu foncé, de la grosseur d'une cerise, inséré dans une cupule tronquée. - Le bois est excellent pour la charpente. - Cà et là dans les bois secs du massif de IJouëlmont. des hauteurs pierreuses de Deshaies, route de Deshaies à Sainte-Rose, elc. $\left[N^{\circ} 2220\right.$.

Martinique. Vulgo : Laurier noir. - Bois de Saint-Joseph, plateau des 'Trois-llets (endroits secs et pierreux), Anses-d'Arlet, ctc. [No 12-4.

0. falcata Mez; Ocotée à feuilles en forme de l'aux. Vulgo : Bois-doux Desbonnes. — Grand, bel arbre, entièrement glabre, haut de $20-25$ mèt., à écorce épaisse et lisse. Feuilles plus ou moins pliées en deux et falciformes, roulées sur les bords, ovales, cartilagineuses, très luisantes, d'un vert sombre en dessus, à nervures à peine perceptibles à l'état vert, rougeâtres en dessous. Panicules axillaires, confinées aux extrémités des branches plus ou moins pendantes; fleurs inconnues. Fruit long de $2-3 \mathrm{~cm}$. sur $15 \mathrm{~mm}$. de diamèt. inséré dans une cupule peu profonde, tronquée, noire, verruqueuse-sillonnée. Le bois de cette espèce de laurier est très recherché : avec le tronc, on fait de belles planches. - Dans les bois des Bains-Jaunes, bord de la rivière aux Écrevisses. [No 3661.] — Je ne l'ai pas trouvé à la Martinique.

0. floribunda Mez; Ocotée à fleurs abondantes. - Arbre élancé, très glabre dans toutes ses parties. Feuilles lancéolées-elliptiques, d'un vert pâle des deux côtés. Inflorescence en grappes spiciformes, interrompues, axillaires. Fruit inconnu. - Dans les bois du plateau des Trois-Ilets (rare). - Le spécimen de cette espèce me manque; j’en possède un du Musée botanique de Berlin, sous le $N^{0} 6522$. - Je ne l'ai pas vu ì la Guadeloupe.

0. Jacquiniana Mez; Ocotée de Jacquin. Vulgo: Laurier-gland. - Arbre haut de 12-17 mèt., à rameaux légèrement pubescents, à ramuscules garnis d'un duvet roux doré, soyeux, à calice soyeux, à fruil très gros, inséré dans une cupule profonde, dont l'ouverture mesure jusqu'ì $22 \mathrm{~mm}$. de diamètre. J'ai trouvé cette belle espèce à l'île de Sainte-Lucie, dans les bois de Barabara, entre Castries et la Grand'Ause. [No 215.$]$

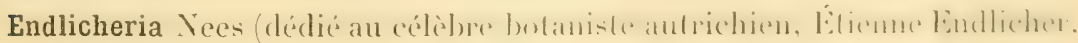
né en 180-4, à Pressbourg, professcur de botanique ì Vienne, mort en 1819; a écrit, entre autres ouvrages : Prodomns florac Norfoll, el surtout : Generá plantarum secundum ordines naturales disposila.)

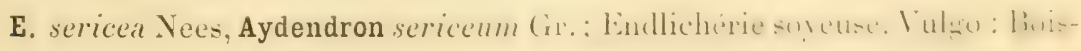


doux blanc, cayali-cayari, bois-doux grand-feuille. - Arbre haut de 1020 mèt., à branches inférieures étalées, longues, penchées à l'extrémité, à jemes branches et panicules soyeuses. Fenilles cartilagineuses, laryes, elliptiques-oblongutes nu ovées-oblongues, terminées par une pointe obluse, aignës à la base, garnies en dessous d'un duvet soyeux et argenté, qui est plus long el plus fourni che\% les jeunes, caractire qui distimgue facilement celte esprece de lous ses congeneres. Panicules axillaires: calice à $(i$ dents caduques: tleurs blanches, dioïques. Fruit ovale, inséré dans une cupule tronquée, souvent verruqueuse. - Assez abondant dans les bois des Bains-Jaunes, rivières Noire et Rouge, Trois-Rivières, etc. [Yos 2217, 3624.]

Martixique. Vulgo : Laurier-caillé, bois-montagne. - Bois du Lorrain, des Fonds-Saint-Denis, du Camp de l'Alma, de la fontaine Absalon, etc. [No220.

Aniba Aubl. (nom indigène de l'arbre à la Guyane.)

A. hracteata Mez, Aydendron bractealum Nees; Anibe à fleurs enfermées dans des bractées avant l'éclosion. Vulgo: Bois jaune. - Arbre très droit, haut de 7-12 mèt., rarement arbre de 15-18 mèt. d'élévation, à trone nu, raboteux, á écore grrise, à jeunes branches et pétioles couverts de cicatrices et de lenticelles, à ramuscules et panicules garnis d'un duvet gris et poudreux. Feuilles très coriaces, scabres, elliptiques ou elliptiques-allongées, cunéiformes at la base, ramassées en rosettes ou en faux rerticilles, silués a l'extrémití des branches, caractère distinctif par lequel on reconnait facilement cette espèce. Panicules à fleurs blanches et petites. Fruit ovoïdeoliviforme, brun noir à la maturité, assis dans une cupule verruqueuse et tronquée au sommet. - Fl. en mai, juin. - Le bois est jaune à l'intérieur, très dur et recherché pour les constructions et la menuiserie. - Gourbeyre (morne Goblin, abondant), rivière Rouge, bois inférieurs des Trois-Rivières. etc. $\left[\mathrm{N}^{\circ} 3433\right.$.

Martinieve. Vulgo: Bois jaune. - Abondant à l'Ajoupa-Bouillon et dans les hauteurs du Nacouba. [No 233.]

A. Ramageana Me\%; Anibe de Ramage. Vulgo : Laurier-falaise. - Arbre de taille moyenne, haut de 12-16 mèt, à branches étalées, à rameaux noirs. Feuilles ovales ou ovées, très glabres et luisantes en dessus, à nervures presque impereptibles a l'état frais. Inflorescence en panicules; fleur's inconnues. Fruit long de $2 \mathrm{~cm}$., ovoüde-oliviforme, inséré dans une cupule tronquée. - Peu abondant : hauteurs de la Grande-Rivière et du Prêcheur. [No217.] - Je ne l'ai pas vu à la Guadeloupe.

Misanteca Mez. (de "Palo-misanteco ". nom donné à la plante par les habitants des forts de Misantla, du Mexique, dans le district de Vera-Cruz.

M. triandra Mez; Misantèque à trois étamines. - Arbre de taille 
moyenne, souvent petit arbre. Feuilles elliptiques, obovées, acuminées au sommet, coriaces, petites. Inllorescence en grappes composées de cymes. Fleurs inconnues; calice à six petites dents. Fruil petit, oliviforme, inséré dans une cupule tronquée. - liare : trouvé dans les hauteurs des Troisllels. [No 85.] - Je ne l'ai pas vu à la Guadeloupe.

Hernandia Plum. ex. L. (dédié à Francisco Hernandez, qui, vers la fin du

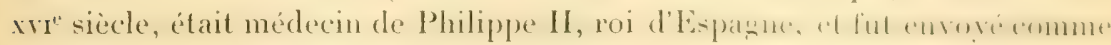
naturaliste dans les Indes Uccidentales; il a écrit : IItistoria naluralis mexicana.)

H. sonora L. ; Hernandie sonore. Vulgo: Mirobolan bâtard, Desc, vol. II. 1. 143, p. 309. - Arbre de $20-28$ mèt. de haut, à branches étalées el souvent horizontales : les inférieures très penchées. Feuilles larges, peltinerviées, ovées, arrondies à la base, pointues au sommet. Inflorescence en panicules corvmbiformes, allongées, plus longues que les feuilles, a branches lermineres par des ombelles triflores : fleur du milieu de l'ombelle, sessile et lemelle; les deux latérales, males et longuement pédoneulées, base de charque branche entourée de quatre bractées foliacées el pubescentes. Fruil ovale, marqué de huit cotes longitudinales, entièrement renlemé dans un caliee vesiculaire et ouvert au sommet. Quand le vent agite l'arbre et s'engoulfire dans le calice, il se produit un sifllement qu'on entend au loin, de là le nom spécifique de la plante. - Fl. en janvier et décembre; fruits mûrs en octobre et décembre, et il arrive souvent aux pieds qui poussent dans la basse région de porter des tleurs el des fruits mûrs en même temps 1. - Bois du Gommier el des BainsJaunes, embouchure de la rivière de Baillif, ele. $\mathrm{N}$.220219.

Martinique. Vulgo : Mirobolan. - Cà et là dans les mornes inférieurs entre Saint-Pierre el les Fond-saint-Denis, hauteurs de l'habitation P'inoul. Jardin botanique de Saint-Pierre, etc. [No 235.

Gassytha L. (du grec "kassutha " ou "kaduta ", synonyme de " cuscuta ". parce que ces plantes ont quelque ressemblance extérieure avec la cuscute.

G. americana Nees, G. filiformis L. ; Cassyte d'Amérique. V'ulgo : Corde ì violon, liane-ficelle. - Liane parasite sans feuilles, vivace, à tigre de l'épaisseur' d'une ticelle, d'une longueur indéfinie, at branches filiformes, a lige be brancheextrêmement enchevêtrées, pubescentes, se nourrissant et s'accrochant par des suçoirs. Inflorescences en épis très courts, axillaires, pédonculés; lleurs blanches, distantes. Fruit sessile ou subsessile, globuleux, de la grosseur d'une graine de poivre, renfermé dans le calice qui laisse au sommet une

1. Sous le nom de myrobolan, le fruit de ce végétal est employé anx Antilles comme it la Guyane pour son amande, qui entre dans la composition d'une émulsion purgative. L'écorce, les graines et les jeunes feuilles sont du reste fígrement purgatives it itudier le principe cathartique. Frais, le suc des feuilles est, dit-on, un puissant épilatoire : arei la partie charnue du fruit, on prépare une liqueur de table assez agrénble, li. Il. 
petite ouverture entourée de six lobes persistants. - Fl. en avril, mai, juin. Vit sur les arbres et les buissons, dans les endroits secs et rocailleux : environs du Moule savane de l'habitation Mercier, sainte- Mnne, saint-Francois. No3:301. 1

Martinique. Vulgo : Liane-sans-fin. - Uniquement dans le sud de l'île: Marin, Vauclin, Sainte-Anne, etc. $\left[N^{\circ} 1770.\right]$

Le Tetranthera laurifulia Jaeq. Litsea sebiferal Pers.. pelil arbe i fleurs dioïques, est cultivé au Jardin botanique de Saint-Pierre ${ }^{2}$. [No 3 I 3.

\section{QUATRE-VINGT-DEUXième FAMILLE。 - CUCURBITACÉES.}

Sechium P'. Br. (nom modifié de "Sicyos ", genre auquel la plante appartenait autrefois.)

S. edule Sw, ; Sechium comestible. Vulgo : Christophine. Desc., vol. V, t. 328, p. 94. - Voluble, à racines larges, charnues, à tiges à cing angles ${ }^{3}$, grimpant par le moven de vrilles liliformes, 3-j fideset opposées aux feuilles. Feuilles larges, rudes, à 5 lobes deltoïdes peu profonds, cordées à la base avec un sinus profond. Inflopesence en yrappes simples, longruement pédonculées. Fleurs blanches, pelites, monoïques: corolle rolacée, a tube garni de 10 glandes nectarifères. Fruit large, obovale, operculé au sommet, long de 11-15 cm. sur 4-6 cm. de diamèt., pourvu de côtes longitudinales et garni de piquants : sa forme rappelle un peu celle d'un fruit de cacao (cabosse). Dès que ce fruit est mûr, la graine, unique, située à la base, se met à grermer sur pied. - Cultivé dans tout le pays à cause de ses fruits, qui constituent un aliment sain : on les mange cuits; ils sont rafraîchissants et émulsifs. Fl. pendant l'hivernage. $\left[N^{\circ} 2295\right.$.

Martinique. Vulgo: Christophine. $\mathrm{N}^{\circ} 1793$.

1. Cette plante parasite est employée en Cochinchine comme dépurative et antisyphilitique.

2. Cette laurinée, d'origine asiatique (Inde, Cochinchine, Iles de la Sonde), est introduite actuellement dans toutes nos colonies tropicales, où ses feuilles constituent (à la Réunion surtout) un précieux aliment pour les bêtes à cornes laitières. Les feuilles et les rameaux renferment un mucilage qui les fait employer comme émollients dans la diarrhée et la dysenterie. Le fruit, très petit malheureusement, contient une graisse solide, appréciable, et qui pourrait prendre, avec le produit du T. monopelala lioxb. de l'Inde, une place dans l'industrie des corps gras en France. (E. H.)

3. Avec cette plante, on prépare à la Réunion, après fente longitudinale, grattage et dessication de la tige, des rubans de paille qui servent à la fabrication de chapeaux et de forts jolis objets de luxe : cette industrie est développée dans cette colonie à un point qu'il serait désirable de voir atteindre dans nos autres possessions tropicales, ou cette Cucurbitacée se développe et croît sans soins spéciaux. (E. II.) 
Gayaponia Silva Manso (nom indigène de la plante à la Guyane.)

C. americana Cognn; Cayaponie d'Amérique. Vulgo : Concombre-marron. - Voluble, annuel, à tige très grêles, à $4-5$ angles obtus, à vrilles simples,

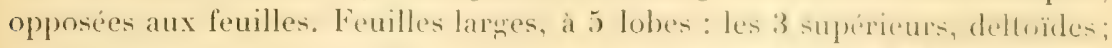
les 2 basilaires, arrondis. Fleurs blanches, en grappes simples et nombreuses. Fruit mûr jaune, sphérique, du volume d'une cerise, contenant plusieurs semences noires. - C Cà et là dans les halliers des lisières des bois des basse et moyenne rézions. Alt. 10-990 mèt. - Camp-Jacob, (ionrberre, Cappesterre (Guadeloupe), Sainte-Marie. [No 2293.]

Martivere. Vulgo: Concombre bitard, concombre-hallier. - I'lus abondant qu ì la Guadeloupe : environs de Saint-P'ierre (Trois-Ponts, lunterard, Carbet, Trois-llets, ete. [ $\left.\mathrm{N}^{\circ} 766.\right]$

Sicydium Schlechtd. du gree " sikudion", diminutil de "sikuns ", (nurwel.

S. Lamnifolium Cognn., variété Dussii Cogn, ; Sieydium ì feuilles de Tamnus. Vulgo: Petit concombre-hallier. - Annuel, grimpant, haut de -1-6 mèt., à lige très grêle, sillonnée-anguleuse, à vrilles simples. Fenilles cordilormes, palminerviées. Fleurs diö̈ques, extrèmement petites, blanches, en prnicules allongées et très branchues, à pédicelles filiformes. - Fl. en mai, juin. Très rare : trouvé daus trois endroils au Camp-Jacob, route de la cascade de Vauchelet). [No 2294.]

Martinique. Vulgo : Liane-hallier. - Assez rare: Prêcheur (ģà et là sur le bord de la rivière Claire). [ $\mathrm{N}^{\circ} 93$. $]$

Momordica L. (du latin " mordeo", " momordi ", mordre, parce que, dans les espèces-types, les graines sont irrégulierement aplaties comme si on les avait mâchées à moitié, et parce qu'en outre elles contiennent un suc àcre. mordicant.)

M. Charantia L. Vulgo: Pomme-coolis, concombre-coolis, pomme-z Indiens. Dese, vol. VIII, t. 594, p. 355. - Annuel, srimpant par le moyen de simples ou doubles vrilles, à tiges nombreuses, très flexibles el très cuchevetrés, a tiges, branches et feuilles scabres-hispides : les jeunes branches souvent tres hispides. Feuilles à $5-7$ lobes sinués-serretés. Flenrs munö̈pues, jaunes, délicates, larges. Fruit muriqué, d'un bean jaune orange, ellipsoide, sinurant en trois valves de haut en bas, rempli d'une pulpe brun jaune; graines aplaties nichées dans la pulpe. - Les fruits se mangent confils dans le vinaigre; dans le pays, on emploie souvent les feuilles et les fruits, écrasis. en tisane contre les fières et les derangements de ventret. Extremement commun

1. Cette espèce, peu utilisée aux Antilles, l'est davantage ḋ la Guyane. Ses fruits mûrs, dépouillés de leurs semences et macérés dans l'huile d'amandes douces, y forment. un vulneraire populaire. Les feuilles, contusćes et mêlées à un corps gras, donnent un onguent contre la gale et les maladies de la peau. (E. II.) 
dans les halliers de la région littorale de toute la Guadeloupe et de la Grande-Terre. [No 2292.]

Martinique. Vulgo : Mexicaine, pomme de merveille. - Abondant. $\left[N^{\circ} 1795.\right]$

Luffa L. (du mot arabe "Luff».)

L. acutangula Roxb. ; Lulfa à angles aigus. Vulgo: Torchon-Liane. à tiges anguleuses, grimpant au moyen de vrilles trifides. Feuilles scabres it is lobes, cordées à la base, a limbe prolongé dans le sinus. Fleurs très prandes. jaunes, délicates, monoïques : les mâles, en srappes; les femelles, solitaires. Fruit loner de $25-30 \mathrm{~cm}$. sur un diametre de $7-8 \mathrm{~cm}$. cylindrique-oblong. s'ouvrant au sommet par un opercule; ovaire à 3 loges : semences nombreuses, aplaties, noiratres. - Les fruits, encore tendres, peuvent se manyer; avec le fruit mùr. réduit aux fibres, après ablation de l'enveloppe, de la pulpe et des graines, on tabrique des paniers, des bourses, des franges, des bonnets de nuit et mème des éponges. Les graines mûres et crues provoquent des vomissements et deséracuations alvines; pour être purgé, il suffit d'en avaler une quinzaine, après les avoir épluchées'. - Assez abondant dans la basse réénion de toute l'île. - Fl. en août, septembre, octobre et novembre. [No 1796.] Je ne l'ai pas trouvé à la Guadeloupe.

L. cylindrica Roem. L. xgyptiaca Mill.; Lutfa à fruits cylindriques. Vulgo : Torchon. - Ne diffère du précédent que par ses fleurs plus larges, ses fruits cylindriques et plus longs, pouvant atteindre jusqu a $37 \mathrm{~cm} .^{2}-$ Dans les halliers, autour des maisons: Morne-ì-l'Eau, Moule, les Abymes, environs de la Basse-Terre, etc. [No 2965.] — Je ne l'ai pas trouvé à la Martinique.

Lagenaria Ser. (du latin "lagena ", bouteille, allusion ì la forme du fruit.)

L. vulgaris Ser.; Gourde commune. Vulgo : Calebasse musquée; calebasse douce. - Voluble ou rampant, à tige cylindrique, molle; a tigre, feuilles, pédoncules, calice et jeune lruit garnis d'un duvet gris et soyeux. Feuilles cordées, arrondies, subentières ou dentelées, largées. Fleurs blanchàtres, très longuement pédonculées, solitaires, monoïques. Fruit oblonğ, courbe. arrondi au sommet, long de $30-10 \mathrm{~cm}$. - Sauvage el cultivé à cause de ses fruits, qui constituent un excellent légume. [No 2287.]

Martivicte. Vulgo: Calebasse douce, avec la variété calebasse-herbe, dont on emploie les racines et les feuilles contre la morsure du serpent. No 789 .

1. Cette espèce, originaire de l'Inde, est utilisée dans sa patrie : les racines comme drastiques et émétiques, les tiges comme amères et diurétiques.

2. Cette plante, en Arabie et en Égypte, est utilisée dans sa racine comme purgative et hydragogue; le fruit, très mucilagineux, pourrait être employé comme émollient : son squelette fibreux sert aux mèmes usages que celui du fruit de l'espèce précédente. (E. H.) 
Melothria L. Idu gree " melothron ". qui répond is Bryonia crelical 1.. Vitis alba, de Pline, XXIII, 16, à cause de la ressemblance de la plante avec la Bryone d'Europe.

M. guadalupensis Cozn., M. perraga Griseb. : Metolhria de la (inadeloupe. Vulgo : Petit concombre-hallier. - Liane très délieate el faible, courant au loin dans les haies et les broussailles a tiges filiforme-sillommes-quadrangulaires, pourvues de vrilles bi ou trifides. Feuilles en coeur, ì sinus pro-

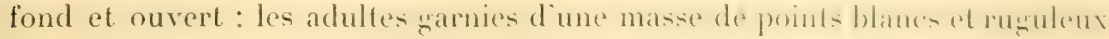
(poils cystolithiques), à 3-5 lobes, grossièrement dentés : celui du milieu beaucoup plus grand que les 2 ou les $\mathbf{A}$ lateraux. Fileurs pulites, jannes, sulitaires, pendantes, pédoncules longrs, tiliformes. Fruit sphérique ou oreöde. Cà et là dans les haies et les broussailles de la basse région : Capesterre (iuadeloupe), Gourbeyre, Pointe-Noire, etc. Alt, 10-400 mèt. [No 2377.

Martinique. Vulgo : Concombre-diable. - Plus abondant qu à la Guadeloupe: environs de Saint-Pierre, Carbet, Parnasse, hauteurs de la hiviereSalée. $\left[\mathrm{N}^{\circ} 2070\right.$.

Ceratosanthes Burm. (du gree "lieras ", colne, et "anthos ", fleur, parce que les parties intérieures du calice sont couronnéps par une petite corne.

G. corniculata Cogn., C. Auberosal spreng.; Ceratosanthe cornicule. Vulwo : Pomme-hallier bâtard. - Petite liane, tris délicate, whlabre, à tigen tiliformes. Feuilles at trois segments très profonds, formant presque une fenille trifolite. les deux latéraux portant chacun un lobe court près de la base. Fleurs et fruits inconnus. - Très rare : trouvé une fois dans un sol pierreux et sec de Case-Pilote. [N 748.$]$ - Je ne l'ai pas trouvé à la Guadeloupe.

Anguria L. (du grec " aggourion ", melon d'eau, "aggos ", vase creux, allusion à la forme du fruit.)

A. Plumieriana Schlecht.; Angurie de Plumier. Vulgo : Concombre bâtard. - Liane annuelle, haute de 2-4 mèt., à tige sillonnée-comprimée. Feuilles à trois lobes, faiblement dentés, à dents très distancées : lobe du milieu beaucoup plus grand; rrilles simples, opposées aux leuilles. Fleurs jaunâtres, axillaires, réunies par 22-3, situres a l'alisselle des feruilles. Fruit ovoïde, long de $4 \mathrm{~cm}$., sur $16 \mathrm{~mm}$. de diamèt. - De celte espèce, je n'ai que des fleurs femelles. - Rare. Cà el là dans les broussailles de la région inférieure : 'Trois-Ilets (dans les halliers du bord de mer), SaintPierre, Trois-Ponts, Trou-Vaillant. [No 750.] - Je ne l'ai pas trouvé à la Guadeloupe.

Gucumis L. (de " cucuma », vase creusé; racine du celtique " cucc ", creux, ventru, allusion à la forme du fruit.)

C. Anguria L.; Cucumis-concombre. Vulgo: Petit cornichon, petit con- 
combre. - Lampant et grimpant, annuel, at tige molle, sillonnée, hispide. Feuilles garnies de poils rudes, couchés, surtout à la face inférieure, à trois lobes arrondis, qui sont eux-mêmes trilobés, à sinus arrondis et dentelés. Fleurs blane jaunitre, monoïques. Fruit ovö̈de, de la grosiseur diun axuf, hérissé de pointes arrondies. - Il constitue un bon lézume. - Probablement introduit; cultivé à la Guadeloupe et à la Grande-Terre: on le rencontre sourent aussi à l'état sauvage dans les savanes et les broussailles de la région inférieure. [No 2962.]

Martwique. Vulgo : Concombre-comichon. [No 1791.$]$

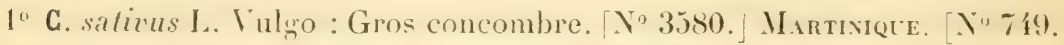

2o Cucurbita Pepo L. Vulgo : Giromont. [No 35j1.] M.artinece. [No 1750.]

3" Cucurbita maxima Duch. Vulgo : Potiron: sont toutes trois un objet de culture dans les deux iles, où elles ont été introduites depuis tris longtemps.

$4^{\circ}$ Citrullus vulgaris Schrad. Vulgo: Citrouille. [No 751]: se rencontre plus rarement.

$\jmath^{\circ}$ Trichosanthes colubrina Jacf.. Tr. Inguina L., d'Asie tropicale, se voit çà et là dans les jardins des cultivateurs indiens '. [N०3778.]

\section{QUATRE-Tingt-TRoisiène FAMLle。 - PAPA IACÉS.}

Carica L. (du nom "Caria », Carie, ancienne province de l'Asie Mineure, particulièrement riche en figues.)

C. Papaya L. (de " papara-maram ". nom de la plante a Malabar.) Vulg̈o : Papayer. Desc., vol. I, t. 47, 48; Tuss., Fl., HI, 1. 10, 11. - Arbre haut de 9-16 mèt., rarement plus élevé, à tronc nu, souvent sans branches, marqué de cicatrices ammulaires laissies par les feuilles. Feuilles ramassées aux extrémités de la tige ou des branches, très larges, glabres, à 7 lobes profonds, pinnatifides et pointus; pétioles suberlindriques, creux, très longs. Fleurs dioïques, blanc jaunâtre : les mâles, en panicules axillaires, interrompues, portées sur des pédoncules très longs, de même couleur que les lleurs; les femelles, plus larges, cyalement axillaires, en corymbes courts. Fruit larese, meloniforme, comestible : semences sphériques, très nombreuses. completement entoures d'un arille transparent. - Fl. presque toute l'amnée. - Le lait qui découle du fruit, par incision, a la propriété de ramollir les viandes. La papä̈ne (principe actif) qu'on en extrait a le pouvoir de dis-

1. Cette plante est réputée laxative et fébrifuge. comme ses conæénèes $\mathrm{Tr}$. cueumerina L., très appréciée des Indous, et Tr. palmata Roxb. 
soudre les matières albuminoüdes et entre dans les préparations pharmacentiques digestives ou antidyspepsiques. Selon Descourtilz, le suc de la racine serait vermifuge. Dans le pays, on se sert des racines macérées dans le talia contre les douleurs rhumatismales. - Abondant dans toutes les Antilles. No 2980 .

Martinique. No 201.

Quatre-vixgt-Quatrièe fimlle, - PASSIlilolielis.

Passiflora L. (du latin " pessio », passion, et "flos », fleur, parce qu'on a

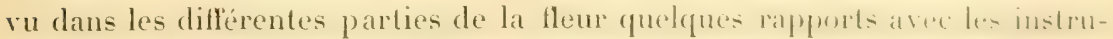
ments de la Passion de N.-S. Jésus-Christ.

P. minima L.; Passiflore très petite. Vulgo : Pomme-liane bâtard. Petite liane, à rrilles simples comme dans toutes les Passiflores, ì feuilles arrondies à la base, trilobées, à lobes profonds : celui du milieu plus grand: pétiole garni de deux glandes subsessiles, au-dessus du milieu. F'leurs 1-2, petites, pédonculées. - Fl. en septembre et octobre. - Rare : dans le bois du plateau des Trois-llets. [No 886.] (Spécimen imparfail.) - Je ne l'ai pas trouvé à la Guadeloupe. - Cette espèce pourrail se fondre peut-être dans lis suivante.

P. suberosa L.; Passiflore subéreuse. Vulgo: Pomme-liane à rat. Cav., Diss., 10, t. 265. - Haute de 3-5 mèt., à racines et tiges subéreuses. Feuilles extrêmement variables, arrondies à la base, peltinerviées ou palminerviées dans le même pied, à lobes lancéolés ou deltoïdes, plus ou moins longrs;

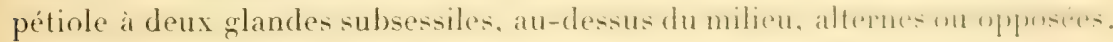
Fleurs blanchâtres ou blanc verdâtre, à couronne courle. Fruit ovoïde, de la grosseur d'un ceuf de-pigeon. - Abondant dans les halliers des basse el infra-moyenne régions de l'île; plus abondant à la Grande-'lerre. Y Yus 2626, $3538,3539,3616,3540,3562,3563$.

Martixque. Vulgo: Pomme-liane bâtard. - Abondant. [No S76.

P. hederacea Cav.; Passiflore à feuilles de lierre. Vulgo: Pomme-lianehallier. Pl., édit. Burm., t. 84. - Tige glabre. Feuilles à 3 lobes courts, del-

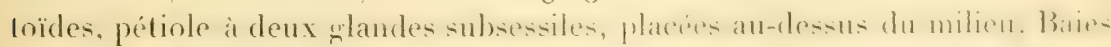
légèrement pubescentes, bleu foncé à la maturité. - Cì et lì dans les broussailles des basse et infra-moyenne régions: Moule, Morne-ì-l'Lau, Ciapesterre (Guadeloupe), Gourbeyre, etc. $[$ To 3616 h. $]$ - Pourrail se l'ondre pentêtre dans la précédente espèce.

Martinieue. Vulgo: Pomme-liane-źoiseau. - Vallée du Carbel, lauteurs des Trois-Ilets, Anses-d'Arlet. Alt. 0-100 mèt. No S7r. 
P. pellala Car.; Passitlore à cing̣ feuilles peltées. Vulgo: Liane à couleurres. Cav., Diss., 10, t. 274. Feuilles peltinerviées près de la base, à 3 lobes larges, divergents, ovales lancéolés. Baies globuleuses, pendantes, bleu foncé. Dans les haies et les halliers de la régrion inférieure: Carbet, Caravelle, Robert, La Régale, etc. [ $\mathrm{X}^{\circ}$ 873.] - Je ne l'ai pas trouvé à la Guadeloupe. - Pourrail peut-être se fondre dans P. suherosa L.

P. rubra L., P. capsularis Lk.; Passiflore à feuilles et tige rouges. Yulgo: Pomme à rals, Mariegougeat, pomme-liane bâtard. Plum., Descript., t. 83 ; Cav., Diss., 10, t. 268. - Tiges et feuilles garnies d'un duvet fin, soyeux, rougeâtre. Feuilles arrondies, à 2 lobes divergents, pointus, mucronés, tronquées entre les 2 lobes et mucronulées; pétiole sans glandes. Fruil déhiscent, marqué de six stries rouges ou noirâtres, longitudinales. Cette espèce se distingue facilement de ses congénères. - Fl. en mai, juin, juillet, août. - Abondant dans les moyenne et infra-moyenne régions : lisières et clairières des Bains-Jaunes, de Gourbeyre, du Gommier, des Vieux-Habitants, etc. Alt. 300-700 mèt. $\mathrm{N}^{\circ} 2231$.

Martinique. Vulgo: Pomme-liane rouge hallier, Mariegougeat. - Hauteurs de Fort-de-France, des 'l'rois-Ilets, de Case-Pilote, etc. No $^{\circ} 82$.

P. rotundifolia L.; Passiflore à feuilles rondes. Vulgo : Liane-à-l'encre. Cav., Diss., 10, t. 290 ; Plum., éd. Burm., t. 38, f. 1. - Tige pubescente, striée. Fenilles rondatres a i 3 lobes tres courts, légèrement arrondis-trongués. mucronés. Facile à distinguer des autres à cause des deux rangées de points transparents ou des petits yeux (ocelles) qui se trouvent entre les nervures. Baie obovoïde, oliviforme. - Sur les lisières des bois de la Capesterre (Guadeloupe), des Trois-Rivières, de Gourbeyre, etc. [No 2228.]

Martingee. Vulgo: Patte-de-canard. - Fonds-Saint-Denis, hauteurs de Case-Pilote et de l'habitation Pécoul, etc. $\left.\mathrm{N}^{\circ} 271.\right]$

P. laurifolia L.; Passiflore à feuilles de laurier. Vulgo : Pomme-liane, Desc., vol. I, t. 56, p. 242; Plum., Descript., t. 80. - Entièrement glabre. à tige cylindrique. Feuilles ovales, entières; pétiole à deux glandes près du sommet; feuilles involucrales, larges, au nombre de 3, dentées; couronne florale a 3 series de filaments. Fleurs larges, a odeur aromatique, tres belles. Fruit ovoïde, a 3 côtes, alternant avec 3 stries. - Sauvage et cultivé à cause de ses fruits et pour garnir les tonnelles et les grillages. -- Le fruit, un peu plus gros qu'un ouf de poule, cache, sous un péricarpe mou et spongieux, une pulpe très légèrement acide, très agréable au goût, rafraîchissante, apéritive, stomachique et vermifuge. Avec les tiges dépouillées de l'écorce, on peut labriquer des paniers et autres ouvrages. - On en rencontre une variété ì fruits plus petits, a pulpe plus exquise : elle est connue sous le nom de llarietambour. - Abondant dans toutes les Antilles. [No 3249.]

Martiniple. Vulgo: Pomme-liane. $\mathrm{N}^{\circ} 883$. 
P. maliformis L.; Passiflore is fruits ronds comme une pomme. Tulgo : Liane à agouti. - Tige et branches cylindriqués. Feuilles ovées-oblongrues, pointues au sommet, d'un vert sombre; pétiole à deux glandes, au-dessus de la base. Fleurs larges. Fruits sphériques, d'un diamètre de $3,5 \mathrm{~cm}$., it péricarpe dur. - L'intérieur se mange, mais il n'a pas le parfum de la pomme-liane ordinaire. - Rare : cultivé çà et là dans les jardins; très rare à l'état sauvage : Basse-Terre (jardins de la ville), Gourbeyre, Capesterre, etc. $\left[\mathrm{N}^{\circ} 2229.\right]$

Martinique. Vulgo : Pomme-liane de la Guadeloupe, - Dans les jardins : Saint-Pierre, Fort-de-France, Lamentin. $\mathrm{N}^{\circ} 879$.

P. quadrangularis L. ; Passiflore à lige it quatre andeles. Vulgo : Barhadim. Cav., Diss., 10, t. 283. - Tige forte, à quatre ailes courtes. Feuilles larges. ovées, subcordées à la base, mucronées au sommet, entières, nervures reliées par des ares, près du bord. Fleurs larges, très belles, à filaments de la couronne placés sur cinq rangs. Fruit melonilorme, long de $20-25 \mathrm{~cm}$. sur $15-18 \mathrm{~cm}$. de diamètre; péricarpe succulent, charnu, d'un diamètre de 3-4 cm. - Le fruit se mange confit; il est stomachique et vermifuge; les graines, entourées d'un arille pulpeux, se servent ì table dans du vin blanc sucré et constituent un dessert recherche; la racine passe pour tris fovique: mais le fait est contesté. - Cultivé dans toutes les Antilles. - Ml. de juillet en novembre. [No 3779 .]

Martinique. Vulgo : Barbadine. [No 884 .

P. serrata L; Passiflore à feuilles dentées en scie. Vulgo: Pomme à agouti. Plum., Descript., t. 179; Desc., vol. V, t.349, p. 119. - Forte liane, at tige cylindrique-striée. Feuilles larges, at 5-7 lobes profonds el serretés ; pitiole portant deux ghandes presque en son milieu, et deux autres pres du sommet. Forrilles involucrales trifides. Fleurs presque ausis grandes que celles de l'spree prictidente, mais à couleurs plus pâles. Fruit de la grosseur d'une pomme manetle. sphérique, à péricarpe dur. - Les graines, pulpeuses, se mangent. - Fl. en aout, septembre, octobre. - Asse\% abondant dans les halliers et les cafitiones

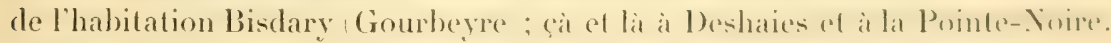
[No 2232.$]$

Martingue. Vulgo : Pomme-liane-manicou. - Très rare. Je n'en ai trouvé que trois pieds sur les lisieres des bois de l'habitation saint-Martin (Prêcheur). [No 882.]

P. foetida L.; Passiflore fétide. V'ulgo : Mariegougeat. - Tige velue, annuelle, glandulifère. Feuilles anguleuses ou à 3 lobes, cordées a la base. visqueuses, garnies de poils glanduleux, ciliées sur les bords. leuilles involucrales 3, multipartites, formant comme une garniture qui entoure le fruil. caractère qui le distingue facilement des autres congénères. Fruit ovoüde, comestible. - Fl. d'octobre à avril. - Assez abondant dans les halliers, les 
haies el les broussailles de la rénion inférieure: envirous de la Basse-Terre. Baillif, Pointe-Noire, Gozier, Noule, les Abymes, etc. [No 2230].

Martingue. Vulgo: Pomme-liane collant. - Abondant. [Nos 885 b, 1936a.]

P. Murucuja L. (nom de la plante chez les Indiens du Brésil.) - Vulgo: Pomme-liane-hallier. Cav., Diss., 10, ᄂ. .287; Tuss., Fl., II, t. 62 ; Desc., vol. I, 1.62, p. 265. - Tige délicate, glabre. Feuilles bilobées, transversalement obliques, trimucronées, ocellées aver denx rangées de glandes en dessous. Assez rare: Champllore, Pamasse, Trois-llets (plateau), ete. [Yo $880 . \mid$ - Je ne l'ai pas vu à la Guadeloupe.

NотА. - Toutes les passillores des Antilles sont volubles et grimpent au moyen de vrilles simples; les graines sont scrobiculées et entourées d'un arille pulpeux.

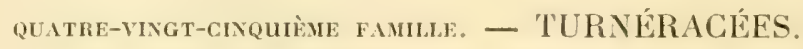

Piriqueta Aubl. (nom indigène de la plante à la Guyane.)

P. cistoides G. F. W. Meyer, P. villosa Aubl.; Piriquète villeuse. Vulgro : Bouton d'or. Sl., t. 127, 1. 7. - Herbe annuelle, ornementale, haute de 15$80 \mathrm{~cm}$., ressemblant assez exactement à lhélianthème des champs en France, branchue ou non, à tige, branches et pédoncules garnis de poils roux, luisants el droits. Feuilles lancéolées-linéaires, poilues, grossierement serretées, à dents obluses el distantes. Fleurs larges, jaune vif. Fruit capsulaire, rondatre. garni d'un duvet roux jaunâtre, une fois plus petit qu'une graine de poivre. - Assez abondant dans les savanes supérieures des Vieux-Habitants; çà el là dans les savanes sèches entre la Basse-Terre et Baillif, etc. - Fl pendant l'hivernagre. - La fleur s'ouvre au lever du soleil et se ferme après midi. [No 2438.]

Martinique. Vulgo: Bouton d'or. - Dans les savanes des environs de Case-Pilote. No 180.1 .

\section{QUATRE-VINGT-SIXIÈME FAMILLE, - HOMALINÉES.}

Homalium Jacq. (du grec "homalos ", égal, parce que les vingt-une élamines sont divisées en sept faisceaux égaux.)

H. racemosa Jacq.; Homalium à fleurs en grappes. Vulgo : Acomat-hêtre, acomat franc, bois de hêtre. Sw., Fl., t. 17. - Arbre de taille moyenne, haut des-16 met., rarement plus haut, à branches tris divariquées : les infé- 
rieures horizontales et souvent plus ou moins tombantes, à écorce rude brune

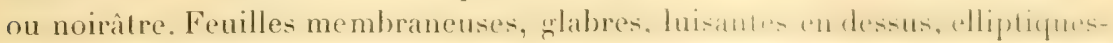
oblongues. Fleurs blanc pâle, rolacées, en grappes simples ou composées ì la base, axillaires et terminales. - Assez abondant dans les mornes inférieurs;

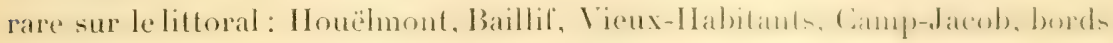
de la rivière Noire, etc. - Fl. en mai el juin. - Le bois sert pour les constructions à l'intérieur; avec le tronc, on fait de belles planches pour les boiseries; exposé à l'air et à l'humidité, il pourrit facilement'. [N'2 2q27, 2998.

Martrnique. Vulgo : Acomat. - Saint-Pierre (Boulevard), Parnasse, Anses-d'Arlet, la Régale, fonlaine Didier. ¡No 1806.$]$

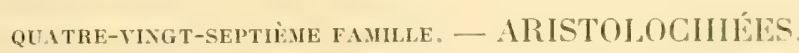

Aristolochia Tourn. ex L. (du grec "aristos", très bon, et "lochia ", lochies, plante autrefois employée pour les accouchements.)

A. obtusala Sw.; Aristoloche a feuilles obtuses. Vulgo : Liane fer it cheval. Pl., éd. Burm., 1. 33. - Tige voluble, comure dans toutes les. . Aristutuches ". du pays, glabre, cylindrique. Feuilles cordées-oblongues, armondies an smmmet, pédatinerviées, à sinus ouvert. Tube de la fleur terminé par un appendice arrondi, couvert de poils, noir à la face supérieure. Firnit long de í.) ('m. - Fl. presque toute l'année, mais surtout en mai, juin et août. — Les feuilles el les tiges répandent une mauvaise odeur. - Peu abondant ; ça et là dans les halliers des basse el infra-moyeme répions: Camp-bacol) Bayalelle, dans les caféières), morne Gommier, environs de la Basse-Terre, Lamentin, elc. [Nos 2957, 3573.] - Je ne l'ai pas trouvé à la Martinique.

A. trilobata L.; Aristoloche à trois lobes. Vulgo: Trèlle, pipe vécgétale. Feuilles arrondies a la base, pédatinervies, glanques en desous a lube oblongs ou ovés-oblongs, obtus: stipules cordées-rondatres; bate du calice entourée, à l'extérieur, d'une rangéé de six filaments ou éperous de lontrue inérale; calice campanulé, brusquement tronqué du cotésuprérieur, muni d'une lèvre portant un prolongement ou une queue filiforme, pouvant atteindre jusqu'à $25 \mathrm{~cm}$. Fruit long de 6-7 cm. - Fl. de juin en novembre. - Peu abondant. Çà et là dans les broussailles des basse et infra-moyenne

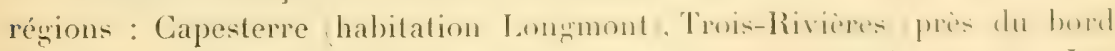
de mer), environs de la Basse-Terre (ravine de Belost), etc. - Les racines de cette espèce, épaisses, d'un diamèt. de $2-3 \mathrm{~cm}$., sont ramifiées

1. Sous le nom créole de mavévé ou matévé et indigine d'dcoma, les latines de ce végétal sont employées à la Guyane française contre la gonoridéc et à titre d'astringent. (tanin?). 
et contournées. Toutes les parties du végétal sont réputées alexitères ef employes intérieurement et extériesurent contre lesmorsures du serpent '. Le suc de la racine enivre, dit-on, ce reptile :il suffirait d'en introduire dans sa gueule deux ou trois gouttes pour l'enivrer au point de pouroir le manier sans danger pendant quelque temps. A plus forte dose, il éprouverait de fortes convulsions et mourrait bientot apries. I la Martinique, on cultive souvent cette aristoloche auprès des maisons. $\left[\mathrm{N}^{\circ} 2585\right.$.

Martisique. Vulgo: Trèlle-caräbe. - Parnasse, hauteurs du Carbet, Prêcheur, ele. $\left[\mathrm{N}^{\circ} 582.\right]$

A. anguicida Jacq.; Aristoloche tue-serpent. Vulgo : Liane douce. Dese., vol. III, 1. 202. p. 1'4. - Racines grosses, noueuses, blanchâtres en dedans. spongienses-ligneuses. Feuilles cordiformes, ovales, it sinns ouvert; stipules cordées. Fleurs petites, longues de $3,3 \mathrm{~cm}$. - Fl. presque toute l'année. Toutes les parties de cette liane exhalent une mauraise odeur, qui chasse, diton, le serpent, el la décoction des feuilles est dite alexitère et antisyphilitique par excellence. La racine s'emploie de préférence contre les tumeurs vénériennes. - Assez abondant dans les halliers des environs du bourg de Sainte-Anne, seule localité où j’aie trouvé cette plante. [No887.] - Je ne l'ai pas rencontrée à la Guadeloup̉e.

A. constricta Griseb.; Aristoloche resserrée. Vulgo : Liane amère. - Forte liane pouvant monter sur des arbres très élevés, al lige noiratre, striée-crlindrique. Feuilles larges, oborales-elliptiques, pointues au sommet, cordées it la base, à sinus ouvert (quelquefois fermé : les lobes basilaires se couvrant l'un l'autre). Fleurs et fruits inconnus. - Baie-Mahault (dans les bois de la Digue, hauteurs de Pigeon bois de l'habitation Maler, oi elle abonde. [No 3660.] - Elle n'existe pas à la Martinique.

L'A grandiflora Sw., Vulgo : Cou-de-canard (Tuss., Fl., t. 27; Desc.. vol. III, t. 157, p. 35 , a été introduite de la Jamaïque à la fontaine Absalon, ou elle fleurit régulierement tous les ans, mais ne donne pas de fruits. No 210 f́.

L'A. odoratissima L. (Sl., t. 104; Desc., vol. V, t. 356, p. 196), introduite de la Jamaïque, est cultivé it la Martinique chez quelques propriétaires, ni elle fleurit toute l’année et donne des fruits; l'A. galeala Mart. el Zucc., du Brésil, Aristoloche à casque, se rencontre dans quelques jardins de la Pointe-ì-Pitre et du Moule. (Lindley, The vegetal Kingdom, p. 794.)

QuATRE-viNgT-Heitrìne FAMLLe. - C.ACTEES.

Melocactus Link et Otlo (du latin "melo ", melon, et "cactus ", cactéc,

1. Elle passe aussi pour très sudorifique; sa racine renferme une huile volatile, une résine amère et une substance âcre à laquelle on rapporte ces proprićtés. (E. H.) 
parce que ce végétal, qui alfecte la forme ronde du melon, est aussi pourvu de ciiles.

M. communis Link et Otto; Mélocactus commun. Vulgo : 'Téte-i-l'Angrlais, têle d'Anglais. 'Tuss., Fl., II, 1. 27; Dese., vol. VII, t. J15, p. 269. - Tige

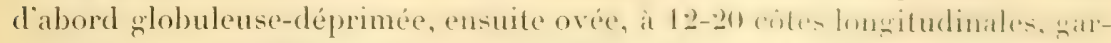

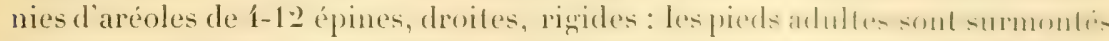

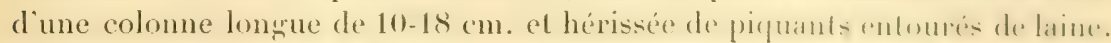

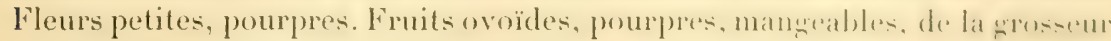
d'un ouf de moineau. - Fl. de juin en novembre. - Ve vénète que dans les terres extrêmement sèches, pierreuses, près de la mer ou sur les rochers du

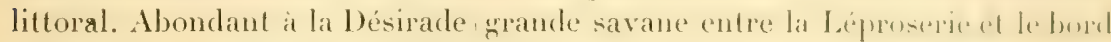
de mer), les Saintes (Terre-de-Haut). Le spécimen manque. - Il n'existe pas à la Martinique.

Cereus Mill. (du latin " cereus ", bougie de cire, parce qu'en Amérique les liges desséchées et trempées dans l'huile servent de tlambeaux.

C. Lriangularis Haw, G. compressus Mill.; Cierge ì lige triangulaire. Vulgo : Pomme-jardin, cierge-lézard. Desc., vol. VII, 1.519, p. 291; Plum., éd. Burm., t. 199, l’. 2, et 200, f. 1, 2. - Tige triquètre, radicante, grimpante,

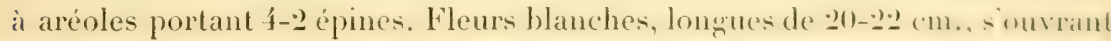
le soir et se fermant le matin pour ne plus s'ouvrir. Fruil ovoïde, plus grand qu'un ouf de poule, blanchâtre à la maturité, couvert d’aréoles munis de 5-8 épines droites. - Assez abondant sur les vieux murs de la ville de la Basse-Terre, de la Pointe-à-Pitre, du Moule, etc. - Fl. en juin, juillet, aoùt. [No 3076.$]$

Mirtingue. Vulgo : Cierge-liane. - Cà el là sur les vieilles souches el sur les rochers: Francois, Roches-Carrés (Lamentin, vallée du Carbel. N"loní.

C. grandiflorus Mill.; Cierge à grandes fleurs. Vulgo : Fleur d'amous, cierge rouge. Pl., éd. Burm., t. 199, f. 1. - Tiges rampantes ou grimpantes,

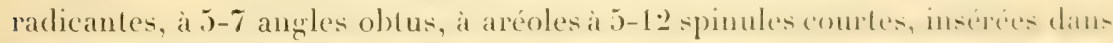

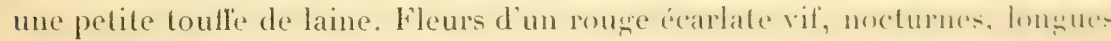
de 20-21 cm., garnies en dehors d'une masse d'aréoles portant de 10-15

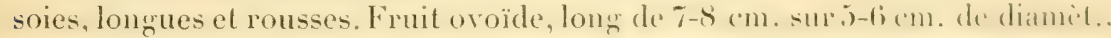
revêtu d'aréoles épineuses et petites. - Fl. en juin, juillet, août. - Sur les vieux murs de la ville de la Basse-Terre, de la Pointe-Noire; çi et là à la Pointe-ì-Pitre, au Moule, etc. [No3077.]

Martingue. - Introduit de la Guadeloupe el cullivé sur quelques vicux toits de la ville de Saint-Pierre et de Fort-de-France.

C. Curtisi Otto; Cierge de Curtis. Vulgo : Cierge. - 'l'iges droiles. souvent cespiteuses, hautes de 2-5 mèt., d'un diamèt. de 7 -9 cm., it 8-1() côtes continues, saillantes, garnies d'aréoles laineuses et portant des épines longues de 2-1,5 cm., droites ou subulées. Fleurs jaumes, larges. Fruil 
ovoïde, pourpre, mangeable, mais d'une saveur fade, de la grosseur d'un wuf de poule. - Fl. en juin, juillet, août et septembre. - Cette espèce forme souvent des toulfes énormes, composées de 15 à 20 tiges. - Sur la côte sèche entre Baillif et les Vieux-Habitants, Désirade, Marie-Galante, les Saintes ('Terre-de-Haut). No 3506.

Martixique. Vulgo: Chardon, charderon. - Saint-Pierre /sur les rochers du Mouillage), Case-Pilote (près du bourg), Diamant, etc. [No 903.]

Opuntia T. (du nom " d'Opuntia ", contrée de l'ancienne province grecque de la Phocide, ayant pour capitale Opus, parce que ces sortes de plantes y poussaient en abondance.)

0. Tuna Mill. (du mot arabe "Tyn", arbre à figues.) Vulgo: Raquette bord-de-mer, raquette à piquants. Desc., vol. VII, t. 513 , p. 261 ; Tuss., Fl., II, t. 30. - Haut de 0, 60-2 ${ }^{\mathrm{m}} 50$, droit, à tige cylindrique, à pattes ou à articulations larges, obovales, garnies de tubercules laineux, pourvus d'une toulfe de poils courts, jaunatres, rigides, et de piquants droits ou subulés. tres acérés. Fleurs larges, jaunes. Fruit ovö̈de, pourpre-glauque, de la grosseur d'une figue de France. - Ce fruit est rafraîchissant, mais d'une saveur fade. - Fl. surtout de mai à août. - Bord de mer entre la Basse-Terre et Baillif, Pigenn, Bouillante, Pointe-Yoire, Désirade, les Saintes. 1lt. 11-jo mèt. $\left[\mathrm{N}^{\circ} 3074\right.$.

Martixige Vulgo: Raquette bord-de-mer. - . Bondant: Case-Pilote, Caravelle, Prêcheur, etc. [No $175 \%$.

0. spinosissima Mill.; Opuntia très épineux. Vulgo : Raquelte volante. Haute de $0^{m} 50-1^{\text {m }} 50$, à articulations plus petites que dans le précédent, ì tubercules ou aréoles laineux, dans lesquels sont insérés 2-4 piquants, très droits, blancs, noirs à l'extrémité, en forme d'aiguille et très acérés, de longueur inégale : les plus longs mesurant de $3-3$ à $\mathbf{i}$ cm. Fleurs jaune orange. Fruit ovoïde, mangeable, de la grosseur d'une figue de France. - Désirade (très abondant dans la grande savane pierreuse et aride qui s'étend entre la Léproserie el la meri. les Saintes (Terre-de-llaut); çà et là entre Baillif el les Vieux-lIabitants. Yos $3071,3457$.$] - Elle n'est pas à la Martinique.$

0. cochinelifera Mill., Nopalea coccinellifera Salm-Dyck.; Opuntia à cochenilles. Vulgro : Nopal, raquette sans piquants. - Haut de 3-5 mèt., forme quelquefois de petits arbres à branches divariquées et tombantes. Articulations à aréoles laineuses sans piquants, à fleurs peu ouvertes, à étamines exsertes, pourpres, ramassées en pinceau. - Introduit du Mexique el cultivé autour des maisons. - On se sert des entre-nxeuds dépouillés de leur épiderme, soit sans préparation, soit pilés dans du lait, en cataplasmes émollients et résolutifs sur les tumeurs inflammatoires. [ $\mathrm{N}^{\circ} 3072$.]

Martinique. Vulgo: Raquette sans piquants. [No 1796.$]$ 


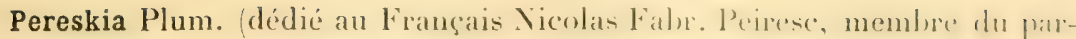
lement d'Aix; a laissé des écrits sur la culture des plantes.)

P. aculeata Mill.; Pereskia à piquants. Vulgo : Groseiller du pays, groseiller de la Barbade. Desc., vol. IV, t. 294, p. 289. - Liane sarmenteuse,

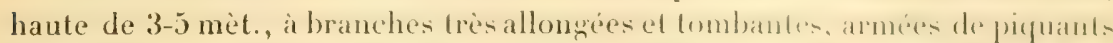

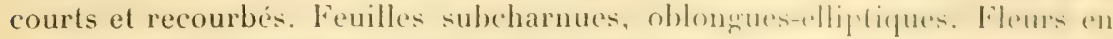
cymes larges, racémiformes, terminales, d'un blane pâle. Fruil jaunâtre, à épiderme membraneux, pourvu de petits enfoncements d'où sortent de petites feuilles charnues et oblongues. - Le fruil se mange : sa chair est molle, succulente, rafraîchissante, d'une saveur aigrelette qui rappelle celle de la groseille de France. - Fl. en juin et juillet. - Rare. (ja et lit dans les endroits secs de la basse région : environs de la Basse-Terre /rivière Sence), Baillif, Vieux-Fort. - (In le cultive quelquefois antour dex mairons. [No3073.]

Martinique. Vulgo : Groseille du pays. - Rare : Case-Pilote FondLayette), Trois-Ilets (route des Anses-d'Arlet). [No 958.]

Le Pereskia grandifolia Haw., arbuste très branchu ou petit arbre, à fleurs larges, pourpre foncé, se rencontre assez souvent dans les jarlins de: deux colonies. - Introduit du Brésil.

QUatre-ringt-neurième faMlle. - CRASSUlaclies.

Bryophyllum Salisb. (du gree "beruein ", pouscer, et "phyllon ", lenille, à cause de la facilité avec laquelle les feuilles charuues domnent des boutures.)

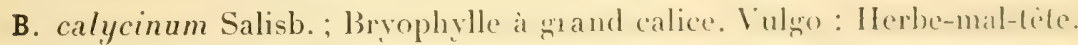
- Haut de $0^{\mathrm{m}} 80-1^{\mathrm{m}} 20$, à base souvent suffrutescente, à racines grosses, stolonifères, à tige cylindrique, grosse, rouge ou panachée. Fenilles clliptiques, charnues, grossierement crénelées : les inférieneres, trifolices. Inflerescence en panicules larges, terminales: lleurs pouges, tres belles, prochée: calice campanulé, tubuleux, ventru, à 4 lobes courts; corolle monopétale. tubuleuse, à 4 lobes courts; étamines 8. - Fl. de juillet en décembre. Abondant dans les endroits sees, pierreux, chauds de la basse region : mvirons de la Basse-Terre, Vieux-Habitants, Pointe-Noire, leshaies. dt dans toute la Grande-Terre. [No 2955.

Martrique. Vulgo : Herbe-à-mal-tête. - Très abondant dans toute lîle. Xंo 1808. - Probablement introduit du Mexique dans Les deus iles. 


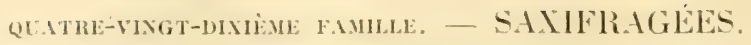

Weinmannia L. dédié a l'Allemand Jean Guil. Weimmann, apothicaire at Regrensbourg, mort en 1737, auteur du Phylanthosa iconographica.)

W. pinnata L.; Weinmannie à feuilles pennées, Vulgo : Bois-sitlleur. Lam., Ill., t. 313, ґ. 1. - Pelit arbrisseau rabougri et très ornemental, haut

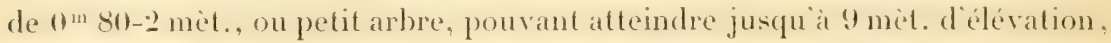
très branchu, à jeunes branches couvertes d'un duvet court, couleur de rouille, à lige nue à feuilles ramassées aux extrémités des branches. Feuilles petites, imparipennées, à ${ }^{2}-9$ paires de folioles elliptiques-nblongues, obluses. serretées au-dessus de la base; pétiole aile entre les folioles. Fleurs blanches, en grappes spiciformes, très nombreuses, terminales. - Fl. presque toute l'année, mais surtout d'avril à août. - Abondant dans les bois supérieurs de la Montagne-Pelée, de la Calebasise, des Deux-Choux, des Pitons-du-Carbet. $\left[\mathrm{N}^{\circ} 1797.\right]$ - Je ne l'ai pas v'u à la Guadeloupe.

W. hirla šw. : Weinmannie a branches hirsules. Tulgo : Tamarinier des montagnes, bois-tan rouge. - Ne diffère du précédent que par la couche plus épaisse de duvet qui couvre les jeunes branches, et par les ailes qui sont rhomboïdes-obovées, tandis que dans le précédent elles sont spatulées. - Abondant dans les bois supérieurs des Bains-Jannes, du Matelyane. des environs de la Ravine-à-Déjeuner. $\left.\mathrm{N}^{\circ} 2426.\right]$ — Je ne l'ai pas trouvé à la Martinique.

QU.ıTRE-VINGT-ONZìne FAMLLE. - BEGONIACELS.

Begonia L. dédié a Mich. Bézon, né enn 16i38, intendant de Saint-Domingues, zélé promoteur de la botanique.)

B. dominicalis A.DC.; Bégonia de la Dominique. Vulgo: Oseille-bois. - Herbe à tige succulente, souvent tortueuse, glabre, luisante, haute de

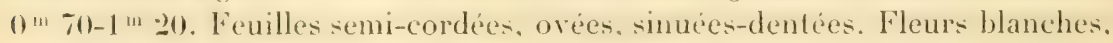
monoïques, en eymes dichotomes, longruement pédonculées : les máles à pétales inégaux. Capsule a trois ailes, dont deux étroites, la troisième arrondie et beancoup plus grande. - Tres abondant dans tous les bois humides des deux rigrions movenne et supérieure. Alt. 1.50-900 mèt. Tos 3069, 3070. 3460 . 
Martinique. Vulgo : Oseille-bois. - Également très abondant. All. 300S00 mèt. [Nं0 973.]

B. martinicensis A. DC.; Bégonia de la Martinique. Vulğo : Oseille-bois. - Haut de $0^{\text {m } 90-1}$ " 80 , droil ou souvent sarmenteux. Feuilles velues, sur

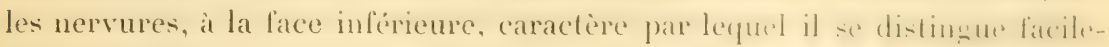
ment des autres. - Mbondant. - Même habilat que le précédent. [Yo:3781.]

Martinique. Vulgo : Oseille-bois. [No 976.

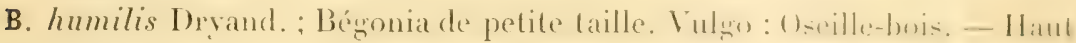

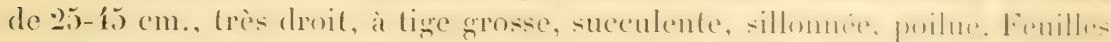

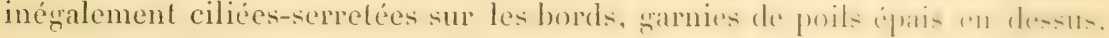
semi-cordées-oblongues; pétioles très velus. Fleurs blanches, en crmes axil-

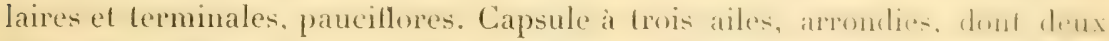
d'égrale grandeur et la troisième plus large. - Peu abondant : (ammp-olanto. Bas-Matouba autour des maisons), Basse-Terre (hospice de lillate . I :37in).

Martingue. Vulgo: Petile oseille-bois. - Environs de Saint-Pierre (TroisPonts, Jardin botanique et Trou-Vaillant). [ $\left.\mathrm{N}^{\circ} 994.\right]$

QUATRE-VINGT-DOUZİ̀E FAMLLE。 - ARALIACEES.

Sciadophyllum P. 13r. du grrece "sciadion ", parasol, ombrelle, al . phullon ", feuille, parce que les feuilles, ramassées et étalées à l'extrémité des branches, suggèrent l'idée d'un parasol ouvert.)

S. capitatum Griesb.. Oreopanax capilalum Dene et Pl. : Sciaduphylle it fleurs en capitules. Vulgo : Figuier-aralie, figuier-hêtre. Jacq., Sel. Am. stirp. hist., t. 61. (Aralia Jacq.) - Arbre ornemental, haut de 10-18 mèt.. très droit, à écorce brune ou noirâtre, ou rougeâtre lisse. Feuilles simples, longuement pétiolées, confinées aux extrémités des branches, ovées ou elliptiques, ou elliptiques-oblongues, longuement atuminess. Inthresconer en panicules terminales, réunies par 22-5), a branches temincés par descipritules d'abord ronds, ensuite ovoïdes. - Assez abondant dans les bois des Bains-Jaunes, du Matouba, du (rommier, des Trois-livieres. - Fl. liaril à juillet, et souvent d'octobre en janvicr. - Alt. 100-900 mèt. [ 102548 .

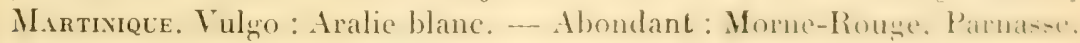
hauteurs de Pécoul, Basse-Pointe, Ajoupa-Bouillon, etc. [N¹761.

Panax L. (du grec "pan », et " akos », remède, c'est-ì-dire remède universel contre toutes les maladies. Le "panax ", "panace " ou " panakes " des anciens auteurs srees et latins n'est pas le "panax " de Lime; mais ils

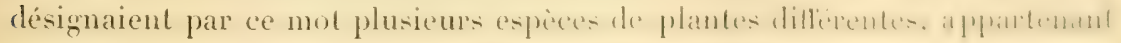
à la famille des Ombellifères. — Pline, XIV, 11-14.) 
P. Morototoni Aubl. (nom de la plante à la Guyane.) Vulgo : Bois-flol (au Lamentin). Aubl., t. 360. - Petit arbre, très droit el très ornemental, à trone nu, haut de 5-9 mèt., très peu branchu (souvent même sans branches, ou ne se divisint que quand il esl dejugrand), marque de cicalrices lareses et annulaires qui persistent après la chute des feuilles. Feuilles ramassées au sommet de la tige et à l'extrémité des branches (s'il y en a), digitées, très longuement pétiolées, à $7-11$ folioles, larges, oblongues, acuminées, longuement pétiolées, pendantes dans la journée, sous l'influence du soleil : les adultes couvertes en dessous d'un duvet fin, rougeâtre doré, qui, dans les jeunes, est rouge doré el très luisant. Inflorescence en panicules pubescentestomenteuses, très larges, à branches terminées par des ombelles de 12-15 rayons, - Fl. en mars, arril, mai, juin'. - Assez abondant dans les plaines du Lamentin et de Baje-Mahault. [N³378.]

Celte belle plante n'existe pas à la Martinique.

Oreopanax Lindl. (du grec " oros ", " oreos ", montagne, el " panax ", panacée.)

0. Dussi lir. et Unt).; Oreopanax de Duss. Vulgo : Bois-llot. - Arbre haut de 6-14 mèt., très ornemental quand il est jeune, à cause de son beau et riche feuillage; à tige et branches complètement nues dans l'âge adulte, à branches très divariquées el penchées, de manière à perdre toute son élégance. Feuilles larges, cordées, couvertes en dessous d'un duvet épais, farineus, blanc, à nervures rouges en dessous et garnies d'un duvet roux, à 5 lobes pointus, les 3 supérieures largement ovales. Inflorescence en panicules terminales, pyramidales, à branches terminées par des capitules ronds; pédoncules et pédicelles vigoureux, garnis d'un duvet farineux et blanchâtre. - Fl. en mai, juin, juillet. - Assez abondant dans les bois du Haut-Matouba (Matelyane, coulée de la Ravine-à-Déjeuner), des Bains-Chauds; plus rare dans les bois supérieurs des Bains-Jaunes. Alt. 800-1000 mèt. [Nं 2986.$]$

Martixique. Vulgo : Bois-llol. - Rare : çà et là sur les sommels et dans les falaises du massil des Pitons-du-Carbet, morne d'Amour. [ $\left.\mathrm{N}^{\circ} 186.\right]$

Didymopanax Decne et Planch. (du gree “ didumos », double, jumeau.)

D. attenuatum March,; Didymopanax à feuilles alténuées. V'ulgo : Trompelte à canon, mapou blanc. - Petit arbre, habituellement tortueux, plus rarement arbre de taille moyenne, haut de $8-13$ mèt, à écorce lisse, rou-

1. Cette plante, qui n'est pas utilisće aux Antilles, jouit d'une répulation considérable í la Guyane. On lui attribue les merveilleuses propriélés analeptiques que les Chinois accordent au ginseng (Aralia quinquefolia Dec. et Pl.) et lui doment le nom de "SaintJean", par transposition des consonnes de ce nom. Il y aurait intéxèt à faire l'étude de la racine de eette plante. (E. II.) 
geâtre, à tige el branches nues. Feuilles digitées, it 3-5 lolioles, pétiolées. ovées, ondulées, souvent crénelées au-dessus de la base; pétiole commun. long, se terminant à la base en une ligule semi-amplexicaule. Inflorescence en srappes allongées, spiciformes, terminales, reunies par 2-5. at branches lerminées par des ombelles de 5 - 10 rayons. Fruil mir mir. pulpeux, arroudi. contracté au milieu par deux sillons longitudinaux. - FI. presque toute l'année. - Très abondant dans la régrion supérieure : buis de Bains-tanmeSavane à Mulets (rabougri), Savane aux Ananas (rabougri), coulée de la Ravine-à-Déjeuner, Matelyane, etc. Alt. 800-1400 mèt. [No2587.

Martixique. Vulgo : Aralie-montagne. - Montagne-Pelée, Pilons-duCarbet (abondant). [ $\left.\mathrm{N}^{\circ} 185.\right]$

D. Lrbanianum March.; Didymopanax d'Urban. Vulgo : Aralie, - Arbre

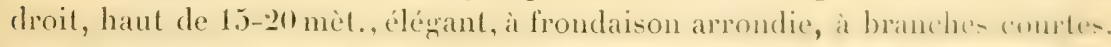
plus ou moins horizontales. Fenilles digitées, à 3-5) folioles ellipliques, arouminées, coriaces, obtuses à la base. Inflorescence en panicules terminales, partant des branches, réunies par 5 -10, courtes, terminés par ti-10 mubeller- Rare : çà et là dans les grands bois du Lorrain et de la Grand'Anse. [No 434.]

De cette lamille on cultive dans les jardins comme plantes d'ornement plusieurs espèces introduites, telles que : Aralia filicifollia IIort.. haut de -23 mèt. No 200. , Panax /ruticosum L. Vulgo : Romarin (X" 17.5.) : Panax cochleatum D.C. (a feuilles en forme de cuiller). Vulgo: Couis [No 1751]: Polyscias pinnata Lam. Vulgo: Petit romarin. ICe spécimen me manque.

QUATRE-VINGT-TREIZİMe FAMILLE, - OMBELLIFÈRES.

Hydrocotyle L. (du grec "hudor ), eau, et "kolulé ", écuelle, parce que ces plantes poussent habituellement dans liau et que les feuilles sont plus ou moins creuses au milieu.)

H. umbellata L;; Hydrocotyle à fleurs en ombelles. Herbe it poutbois. Desc., vol. I, t. 3, p. 165. - Herbe aquatique, vivace, it racines fibreuses. à tiges rampantes, stolonifères et radicantes. Feuilles peltées au milieu,

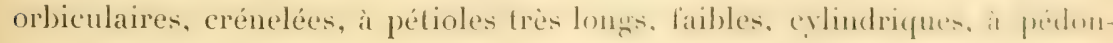
cules aussi longs que les feuilles, portant au sommet une ombelle étalée. contenant jusqu'à 30 rayons. - Vit en sociélé avec d'autres herbes, dans les endroits aquatiques: Capesterre (Guadeloupe pres du bord de mer. Puintrà-Pitre (abondant). Alt. 0-20 mèt. [No 23308 .

Je ne laai pas trouvé à la Martinique. 
H. verticillata Thumber: Hydrocotyle a tleurs en verticitles. Vulgo: Herhemare. - Herhe arpuatique, it tiges concheses, radicantes, filiformes, stoloniferes. Feuilles comme dans le précédent. mais plus petites a pétioles plus tlexibles et plus minces: pédoncules aussi longs on plus courts que les leuilles et portant, de distance en distance, 2-5 fleurs verticillées et subsessiles. Rare : trouvé en petite quantité dans la mousse, sur une pierre, dans le Grand-Ltang/Capesterre-Guadeloupe. Xo 2873. - Il nexiste pas a la Martinique.

H. asiatica L., Centella asiatica Urb.; Hydrocotyle asiatique. Vulgo : Herbe-pru-bois. - Herbe it liges radicantes, rampantes greles, filiformes. stohniferes, sétendant à une distance indéfinie. Feuilles cordées-arrondies ou cordées-ovées, avec un sinus très ouvert, crénelées-dentées, à pétioles longs et velus. Infloresence en ombelles nombreuses, contractées, paucillores, portées sur des pédoncules beancoup plus courts que les pétioles. Fruil réniforme. - Dans le pass, la plante jouit d'une srande réputation et semploie fréquemment, comme un puissant dépuratif, en lisane contre la frale. la gratelle. les dartres, les ulérations. les engorgements des ylandes. les affections scrofuleuses. syphilitiques el rhumatismales, of meme contre le cancer, - Très abondant dans les saranes humides du Matouba, du CampJacob, du Gommier, du Parnasse, sur le bord du chemin et dans les clairieres des Bains-daunes, de (sourberre. du Honëhmont, des Trois-Rivieres, de la Ravine-Chaude, etc. Alt. 150-800 mèt. $\mathrm{X}^{\circ} 2297$.

Martuxigee. Vulgo : Véronique. - Plus rare qu’à la Guadeloupe. Emplove sourent contre les maladies de peau el contre les fluxions de poitrine, comme sudorifique!. - Saint-Joseph (dans beaucoup de champs de manioc). $\left[\mathrm{I}^{\circ} 1753\right.$.

Eryngium L. du gree " erruguion ", rejet, parce que ces plantes seraient éminemment sudorifiques.)

E. fatidum L. : Errngium létide. Vulgn: Herbe à fer, herbe puante, chardon béni. Sl., t. 156, f. 3, 4; Desc., vol. VIII, t. 585, p. 319. - Herbe bisannuelle, droite, haute de $10-45 \mathrm{~cm}$., glabre, a racine pivotante, forte. blanche wu rougeatre, ì tigestriée. Feuilles rosulées dans les jeunes pieds, appliquées contre la terre, amplexicaules, spatulées-lancéolées, nettement serretées, ì dents épineuses. Inflorescence en crmes dicholomes, larges, it lleurs en capitules brièvement pédonculés : capitules entourés d'une collerelte de bractées

1. Cette plante a joui dans l'Inde d'une véritable célébrité comme médicament ranté contre la lépre; aujourd'hui, complètement déchue, elle n'est plus qu'un vulgaire dépuratif tonique, même altérant. Le principe actif (vellarine), qui avait été extrait par Lépine, pharmacien de la marine, et auquel on attribuait des propriétés merveilleuses, est aujourd'hui plus que douteux, Fluckiger en ayant nić l'existence. Cependant c'est une plante qui, à haute dose, peut occasionner des accidents dus à son âcreté et à l'action spèc ciale qu'elle exerce sur le systimenerveux. (E. H. 


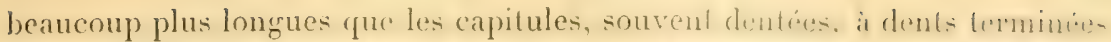

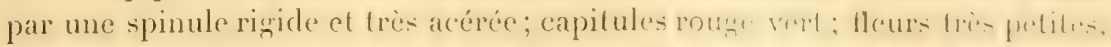
blanches. - Abondant antour des maisons, dans les chemins pen batlus, an pied des vieux murs, etc. Alt. 5-800 mèt. [N²296.]

Martinique. Vulgo: Charderon ou chardon béni. - Abondant. [Yo 1752.] - Toutes les parties de la plante, mais surtout les raciurs, "shatent une odedur très forte, fétide el nauséabonde; elle n’en est pas moins très estimée el

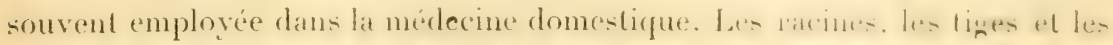

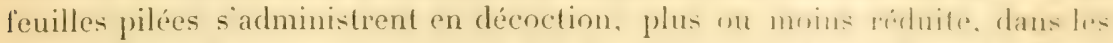

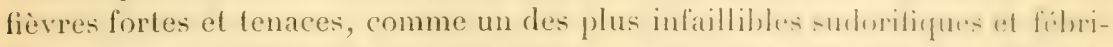
fuges connus. Cette herber, puante, entre aussi dans la compuntion du lamenx "looch ", connu à la Guadeloupe sous le nom de: "Looch de M"me Parizet." - A la Martinique, on se sert des feuilles et des racines pilées contre la morsure du serpent; arec ces feuilles, cuites dans l'eau, et de feuilles pilex-s de gros coton, on prépare encore une tisane contre les fluxions de puitrine.

Apium IIoffn. 'nom donné par les Latins à plusicurs ombelliferes, probablement de "apis ", abeille, parce que ces insectes recherchent plusieurs espèces de ce genre.)

A. Ammi Urb. (du grec "ammos ", 'sable, parce que beaucoup d'espèces poussent dans le sable), Helosciadium leptophyllum 1). (2. - IIerde annuelle, délicate, hante de $25-3.5 \mathrm{~cm}$., at tige striée, plus ou moins diroite. Feuilles triternatiséquées, à segments comprimés-linéaires. Inflerescesncer en ombelles axillaires, opposées aux feuilles, à 6-10 rayons filiformes. - Pen répandu: Camp-Jacob (habilation Michaux), oì il est abondaut. .16. isul mèt. [Nं 2874.]

Martisiqle. - Abondant aux Trois-Ponts el dans les terres de Tivoli, du Jardin botanique. [ $\left.\mathrm{N}^{\circ} 961.\right]$

De cette famille, on cultive plusieurs herbes introduites pour les besine domestiques, comme : Petroselinum satirum [Ioff, rulgo : Persil, miginaire de la Grèce et de la Sardaigne; Fœniculum vulgate Adans, vulgn : lenouil:

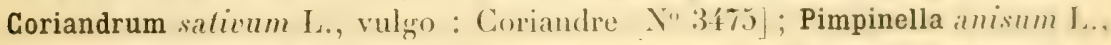
vulgo: Anis; Daucus carola I., vulgo: Carotte, et plus rarement Arrechacha esculenta D. C., vulgo : Arrachacha ou navet de Jérusalem, originaire du Pérou et de la Colombie, dont la srosse racine tubériforme constitue" un légume délicat et recherché, entin l'Ammi majus L., qui est cultivé comme plante d'ornement. $\left[\mathrm{N}^{\circ} 420 \mathrm{~h}\right.$.

\section{QUATRE-VINGT-QUATORZIÈME FAMILLE. - BALANOPHORÉES.}

Helosis Rich. (du grec "helos ", clnu, parce que les fatilles qui enveloppent d'abord les fleurs ont la forme d'un clou.) 
H. guyanensis Hook; Hélosie de la Guyane. Vulgo : Clampignon. Pelite plante, aphylle, parasite sur les racines de plantes virantes ou mortes. et ressemblant it un champignon. Fleurs ramassées sur un spadice terminal, arrondi au sommet, long de 2-3 cm. - Cù̀ et là dans les bois humides el sombres des régions moyenne el infra-supérieure : bois de la MontagnePelée, de l'Ajoupa-Bouillon, du Lorrain. [No 1106.$]$ - Je ne l'ai pas trouvé à la Guadeloupe.

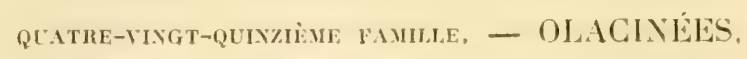

Ximenia L. dédié a l'Espagnol Franç. Ximenes, naturaliste, qui, en 1615, a écrit sur les plantes et les animaux employés en médecine.)

X. americana L.; Ximenia de l'Amérique. Vulgo : Bois puant (à MarieGalante), prune bord-de-mer, prune-épine. Desc., vol. II, t. 132, p. 266: Tuss., Fl., III, 1. 30. - Grand arbuste, buissonneux et très toulfu, haut de 3-4 mèt., ou petit arbre, de 4-6 mèt. d'élévation, à tige et branches avec ou sans épines, à écorce noire, lisse. Feuilles elliptiques-orales, alternes, subcharnues, à nervures peu marquées. Inflorescence en corymbes axillaires, pauciflores; fleurs blanches, très odorantes, approchant de l'odeur du girofle, couvertes en dedans de nombreux poils laineux. Fruit drupacé, rempli d'un suc laiteux, de la grosseur el de la forme d'une olive. - Comestible. - Fl. en novembre, décembre et janvier. - Peu abondant. Çà et là dans les terres pierrenses et sèches: Desirade, Gozier, Saint-François, Marie-(ralante (Capesterre), les Saintes (Terre-de-Bas). [No 3245 .

Mantiniqee. Vulgo: Prune bord-de-mer. - Case-Pilote, Sainte-Anne. [No 1914.]

Heisteria L. dédié a l'.lllemand Laurent Heister, né en 16833, a Frankfortsur-le-Mein; en 1706, professeur à Altclorf, mort en 17.58; a laissé des écrits sur la botanique, dans lesquels il se déclare adversaire du systeme de Linné.

H. coccinea Jacq. ; Heisterie à fleurs rouges. Vulgo : Bois-perdrix, boislélé. - Grand arbuste ou petit arbre, haut de 1-5̃ mèt., à écorce grise el lisse. Feuilles coriaces, oblongues, acuminées. Fleurs trè petites, axillaires. solitaires ou portées sur des pédoncules bi-triflores; calice rouge, d'abord petit, ensuite très élaryi, en un bord ondulé ou à jobes peu distincts. Fruit drupacé, inséré dans le calice sur les deux tiers de sa longueur. - Le bois est très flexible et recherché pour des manches d'outils, pour de petits meubles. - Assez commun dans les grands bois de Case-Pilote (surtout de ceux du Plateau militaire, des Fonds-Saint-Denis, du Camp de l'Alma, du 
Lorrain, etc. Alt. 400-800 mèt. [Y0 573.] - Je ne l'ai pas trouvé ì la Guadeloupe.

Schœpfia Schreb. (dédié au Bavarois Jean Day. Schcepf, né en 1572, it Wunsiedel, mort en 1800; a écrit son voyagre en Amérique et sur les îles de Bahama.)

S. arhorescens R.S.; Schapfie arborescente. Vulgo: Café-bois. - Arbrisseau ou grand arbuste, ou petit arbre élancé, fastigié, ì écorce noire el lisse.

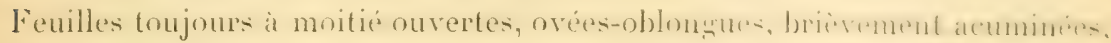
arrondies à la base, à nervures très peu marquées. Inflorescence en petites

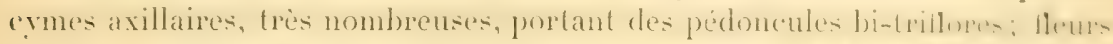
petites, blane verditre; lube de la enolle campanulé, à f lubes arromlio et rélléchis. Fruit drupacé, à peine pulpeux, ovoïde, de la grosseur d'une graine de poivre. - Endroits secs et pierreux : Ilouëlmont, hauteurs des Vieux-Habitants. Peu abondant. [No 3246.

Martinique. Vulgo: Petit café-bois. - Rare: dans les mornes entre le Carbet et les Fonds-Saint-Denis, dans le bas du morne Saint-Martin. [No 103.]

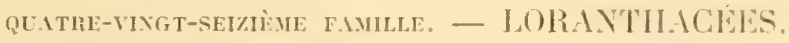

Loranthus L. (du gree "loros ", lanière, et "anthos ", lleur, allusion aux parties linéaires qui composent la corolle.)

L. americanus Jacq. : Loranthe ditmérique. Vulgon: Pimprenelle che les bûcherons des Vieux-Habitants). Plum., édit Burm., t. 166, 1'. 1; Desc., vol. VI, t. 390. - Parasite vivace, comme le sont toutes les Loranthacées des Antilles, vivant sur les arbres, qu'ils tuent avec le temps et auxquels ils se substituent. Feuilles ovées ou ovales, obscurément veinées. Fleurs en corymbes terminaux, d'un beau rouge vif, larges. Fruit de la forme et de la grosseur d'une olive, inséré dans une cupule. - Peu abondant : dans les grands bois humides comme aussi sur les coteaux secs et pierreux; lorèts des Bains-Jaunes (rare), de Deshaies, Morne-îl-l'Eau (bois du canal des Rotours), etc. - Fl. en août, septembre, octobre et novembre. Alt. 0-850 mèt. [No 2970.]

L. uniflorus Jacq., L. parviflorus Lam, ; Loranthe it une fleur ouverte. Vulgo : Teigne bord-de-mer. - Racines rampant sur l'écorce, très allongcées,

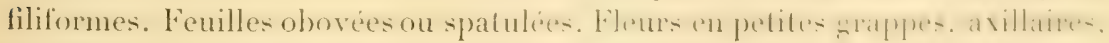
spiciformes, nombreuses; pied haut de $40-60 \mathrm{~cm}$. - Fl. toute l'année. -

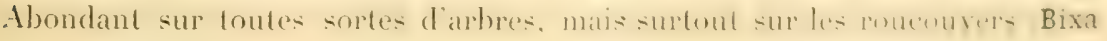


Orellana L.), qu'il faut nettoyer tous les ans : Gourbeyre, Trois-Rivières, vallée entre Gourberre et le bord de mer, habilation Bisdary, elc. No 2417. Il n'existe pas à la Martinique.

L. emarginatus Sw.; Loranthe ì feuilles échancrées au sommet. Vulgo : Teigne. - Très touffu, haut de $0^{\mathrm{m}} 50-1 \mathrm{~m}$ 80, rarement plus haut. Jeunes branches comprimées. Feuilles obovées, arrondies, petites. lileurs vertes, en grappes axillaires et courtes. - Bois des Bains-Jaunes, du Matouba, conlée de la Ravine-ì-Déjeuner, etc. Alt. 500-800 mèt. [No 2967.]

Je ne l'ai pas trouvé à la Martinique.

Phoradendron Nutt. (du grec " phoreo ", porter, et " dendron ", arbre.)

P. hexastichum Griseb), Phoradendre à six rangées de fleurs surl'épi. Vulğo: Haut-bois. Pl., éd. Burm., t. 258, f. 1. - Haut de $0^{m}$ 7-1 ${ }^{\mathrm{m}} 50$. Branches comprimées-létragones. Feuilles larges, ovées ou elliptiques, obtuses au sommet, contractées ì la base. Fleurs en épis interrompus, placées sur six rangs. Fruits mùrs trè blanes. - Bois des Fonds-Saint-Denis, de la Grand Anse, du Macouba, etc. Alt. 200-600 mèt. [No 1375 .] - Je ne l'ai pas vu à la Guadeloupe.

P. martinicense (iriseb).; Phoradendre de la Martinique. Vulgo : Graine it perruche (au Camp-Jacob). - Très touffu, haut de $0^{m} 80-2{ }^{m} 50$, à branches flexibles, très allongées, tombantes. Feuilles oblongues-lancéolées, à -nervures secondaires, unies ì la côte, près de la base du limbe. Inflorescence en grappes spiciformes. Fleurs vertes, placées sur quatre rangs. - Çà et là dans les bois humides el secs: Camp-Jacob, Matouba, Houëlmont, Gourbeyre (les Palmistes). Alt. 400-900 mèt. [No 2966.]

Martingeve, Vulgo: Haut-bois. - Abondant: Fonds-Saint-Denis, Carbet, Trois-Ilets (plateau), Case-Pilote, etc. Alt. 100-600 mèt. [No 1374.]

P. trinervium Griseb.; Phoradendre à feuilles à trois nervures. Vulgo: Jiane is perruche (au Camp-Jacoh). - Très touffu, haut de $t^{\mathrm{m}} 80-1^{\mathrm{m}} 90$, rarement plus grand, à branches allongées, souvent pendantes. Fenilles petites, obovales, a 3-5 nervures peu marquées. Fleurs en épis axillaires el géminés ; graines mûres vertes. - Camp-Jacob, Matouba, bois de la Pointe-Noire et des hauteurs de Deshaies. Alt. 50-800 mèt. [No 2968.]

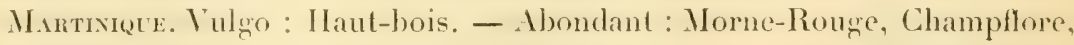
Gros-Morne, Sainte-Luce, etc. [No 1373.$]$

Dendrophthora Eichl. (du gree "dendron ", arlse, ef phtheirein ", détruire, c'est-ì-dire des plantes qui détruisent les arbres.)

D. macrostachya Eichl., Viscum macrostachyum Jaeq.; Dendrophthore it épis allongés. Vulgo: IIaut-bois. - Ilaut de (1m 80-1 mèt., à jeunes branches 


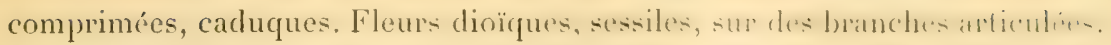
- Assez abondant dans les bois du Champllore, des fonds-saint-l).nis, d. la Calebasse, etc. [ $\left.\mathrm{N}^{0} 1371.\right]$ - Je ne l'ai pas trouvé à la Guadeloupe.

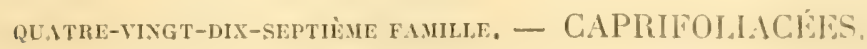

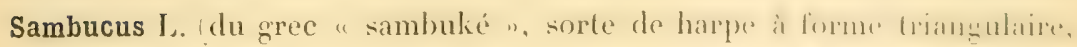
qu'on fabriquait avec le bois de cette plante, ou encore de "sambux " ou " sandux », couleur rouge, parce que les fruits contiennent un suc rouge foncé.)

S. canadensis L., variété pinnata Cham. et Schl.; Sureau du Canada. Vulgo : Suriau ou suyau. - Grand arbrisseau, buissonneux, haut de ¿-1 mèt.; introduit de l'Europe et fréquemment cultivé dans les jardins el autour des maisons comme plante ornementale el médicinale. - (1n empluit souvent les fleurs en tisane contre les rhumes et les fluxions de proflume. an décoction contre les fortes fièvres, à cause de ses verlus sudorifiques. - Fl. durant toute l'année. $\left[N^{\circ} 2429\right.$.

Martinique. Vulgo : Suyau, suriau. [No 1911.]

Le Caprifolium pubescens Goldie, vulgo: Chevrefenille de Chine, est (-ultivé dans les jardins des deux colonies, a cause de la richessese de de lexpuise odeur de ses fleurs, qui sont blanches au moment de l'anthisese et qui passent ensuite au jaume clair. Elle est originaire de la Chine et llemrit en tout templs. [No2428.

Martinique. [No 1911.]

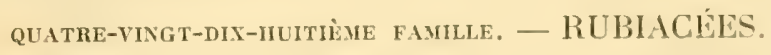

\section{TRIBU I. - CINCIIONACÉES.}

Genipa L. (de "Jenipalea ", nom de la plante au Brésil.)

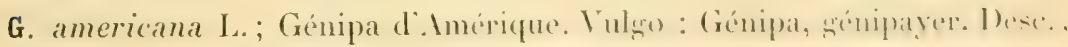

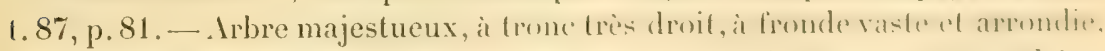
à branches nombreuses : les inférieures horizontales, souvent penchées.

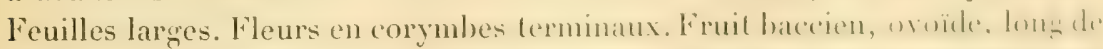

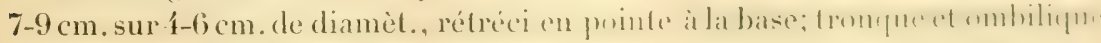
au sommet. - Fl, en septembre et en octobre, el souvent en juin el juillet. 
- Rare. Dans la coulée au pied de Houëlmont; ça et lì dans l'intérieur des terres du Lamentin, de Sainte-Rose, ctc. ${ }^{+}\left[\mathrm{N}^{0} 2729.\right]$

M.ntaxique, Vulgo : Génipa. - Plus abondant qü ì la Guadeloupe. PetitBourg, Fort-de-France, La Dillon et rivière Monsieur, Rivière-Salée, ele. $[\mathrm{X} 0901 \mathrm{~b}$.

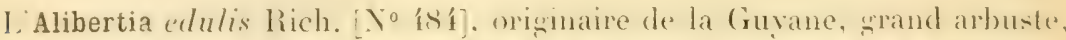

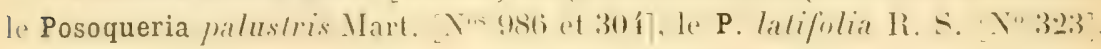
petits arbres de la Guyane, sont cultivés à la Martinique chez quelques amaleur's de plantes et au Jardin botanique de Saint-Pierre.

Randia I. (déchié à l'Anglais Isaac Rand, pharmacien, né en 1730; a publié un catalogue des plantes pharmaceutiques du jardin de Chelsea ${ }^{2}$.)

$R$. aculeata L.; Randia à piquants. Vulgo : Petit coco, bois-quenouille. Sl., t. 11, f. 1.; Br. Jam., t. 8, f. 1; Desc., vol. II, t. 92, p. 101. - Arbuste haut de 1-3 mèt., rarement plus haut, élégant, quand il est jeune; tortueux, souvent subsarmenteux, à branches divariquées, horizontales ou pendantes. quand il estrix. Fenillesoboves, luisantes. Flemssolitaires, subsesiles, tres blanches, odorantes. Baies jaunes à la maturité, oroïdes. - Dans la basse région sèche : environs de la Basse-Terre, Baillif, Yieux-Fort, Pointe-Noire.

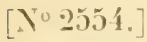

Martineue. Vulgo : Bois-lance. - Abondant : Case-Pilote, Caravelle, Sainte-Anne, Prêcheur. [No 990.

R. armata D. C., Basanacantha armata Hook fils; Randia armé de piquants. V’ulgo: Petit coco. - Arbuste élégant, haut de 1-2" jo 0 , très branchu, extrémités des branches armées de quatre piquants plus ou moins longs, quelquefois inerme. Fenilles elliptiques. Fleurs blanches. Bate ovoüde, de lat grosseur d'une prune, rude en dehors. - Endroits secs et pierreux : hanteur's du Prêcheur, des Trois-llets (plateau), Sainte-Luce, etc. [No 988.] - Je no l’ai pas trouvé à la Guadeloupe.

R. Moussiendae D. C. (de "Moussenda », nom de la langue des Indižènes de Ceylan.) Vulgo : Petit coco. - Arbuste élégrant, haut de 1-2 mèt., droit.

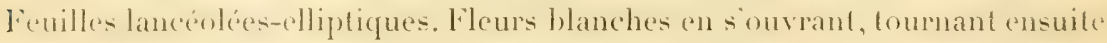
au jaune légèrement pourpré, à tube long et pubescent. Baie ovoïde. - Je

1. Cette plante, dont l'emploi n'est pas indiqué aux Antilles, est utilisc̉e à la Guyane. L'ícorec, astringente, est un bon reméde contre les cliarrhées atoniques. Aree les racines. $n$ fait une tisane dépurative trés recommandée contre la gonorrhée.

2. Les Randia américains n’ont aucun emploi; ils mériteraient cependant d'être étudiés par comparaison arec Randia dumetorum Lam., de l'Inde, qui, sous le nom de Mainphal, est utilisé par les llindous comme vomitif et employé au mème titre que la coque du Levant (Menispermum Cocculus L.) pour eniver le poisson. La pulpe du fruit jouit de propriétés émétiques dues à une saponine spéciale et à un acide randique, d'après Vogtherr. (E. H.) 
n’ai trouvé cette belle espèce que sur la pente de la montacrne du Tauclin of dans quelques jardins du voisinage. - Fle de juin a octobre. - Introduil i la Guadeloupe et cultivé sur l'habilation Sainte-Sophie, Baillil. [X" (184).

Le Randia grandiflora Lam., arbrisseau d'une beaulé remarquable, il fleurs longues de $7-12 \mathrm{~cm}$. [Y० 101$]$, est sourent cultivé dans les jardins de Saint-

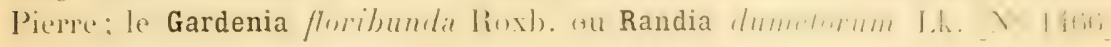
se rencontre sourent dans les parterres de la Guadeloupe et de la Martinique: le Mussænda frondosa L., superbe arbrissean it teuilles florales blanches

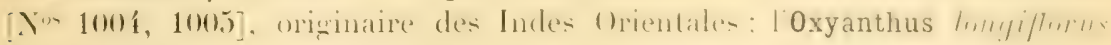
Lem., 0. versicolor Lindl. [Y 102], petit arbrisseau; le Leptactinia Mannii Hook. fils [ $N^{\circ} 101$ font l'omement du Jardin botanique de Saint-Pierre.

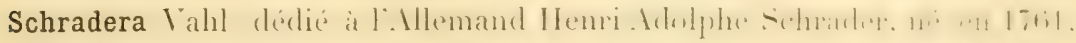

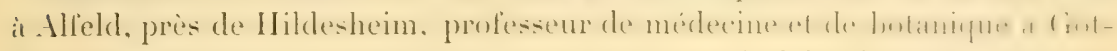
lingue, mort en 1836; a écrit entre autres choses: Spicilegium Florie germilnicre; Flora germanica; Description systématique des plantes cryplogramiques, etc.; Nova genera plantarum horti Guetlingensis.

S. capitata Vahl; Schradère à fleurs en capitules. Vulgo : Liane blanche. Vahl, Eclog., t. 5. - Liane épiphyte, à branches allongées, pendantes nu

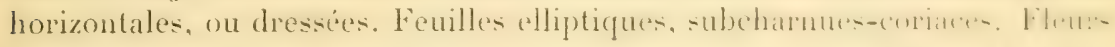

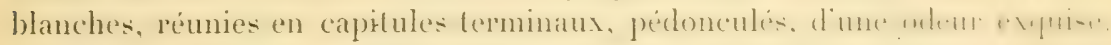
- Abondant dans la plupart des grands bois humides : Gommier, lbainsJaunes, Matouba, Trois-Rivières, ete. Alt. 400-900 mèt. [No 25.17].

Martixiece. Vulgo : Liane-jasmin, jasmin-bois. - Montagne-Pelé. Calebasse, Champflore, Lorrain, etc. [No 14 f́.

Hamelia Jacq. (dédié à H. L. Duhamel du Monceau, né en 1700, à Pilliviers, près de Paris, inspecteur de la marine, mort en 178:2; s'est occupé beau-

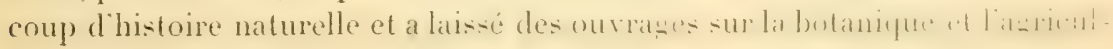
(ure.)

H. patens Jacq. ; Hamélie à grappes ouvertes. Vulgo : Fleur corail, Dese..

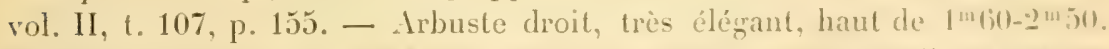

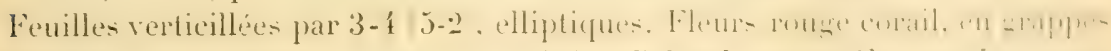
terminales, à branches scorpioides. Baies d'abord rouge påle, cnsuite rouge sombre foncé. - Rare : morne de la Fontaine-Chaude, seul endroil ou jaic rencontré cet arbuste. On le cultive fréquemment dans les jarlins. [ yo y.).3. - Je ne l'ai pas ru à la Guadeloupe.

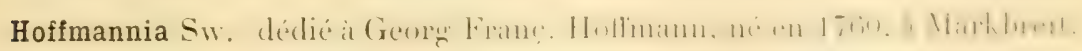
dans la Franconie, médecin, botaniste, prol'esseur de botanique it ciöllingur. et en 1804 à Moskou, mort en 1826; a écritsur les lichens, les champipnons: et les Ombellifères.) 
H. pedunculala sw. : Hoflmannie it lleurs pédonculées. Vulggo: Herbe grandbois. - Frutescent, droit ou plus ou moins tortueux, haut de $0^{\mathrm{m}} 90-1 \mathrm{mg0}$, at tige grosice, renflée anx nueuds, tres glabre. Fenilles larges, elliptiques, poinlues aux deux bouts. Fleurs verdatres, rémies par -2-8 à l'aisselle des feuilles, pédonculées, répandues tout le longr de la tige et des branches. Fruit pulpeux, poune foncé. - Peu commun. Endroits aquatiques ou très humides et ombragés des srands bois: Bains-Jannes le Jong du canal de Montéran;. Matouba: cà et là au Gommier le long du Galion. T"1595. - Il n'existe pas à la Martinique.

H. Inhiftora (rriseb.); Hoffmannie à fleurs tubulées. Vulgo: IIerbe grandbois. - Ne diffère du précédent que par ses fleurs sessiles, à tube plus allongé et de couleur jaune pâle. - Rare : endroits aquatiques des bois entre les Fonds-Saint-Denis et les Deux-Choux. [No325.] - Je ne l'ai pas trouvé it la Guadeloupe.

Gonzalea Pers. (dédié au botaniste espagnol F. Gonzales Laguna.)

G. spicata D. C.; Gonzalée à fleurs en épis. Vulgo: Bois-foufou (nom d'une espece de colibri. - Petit arbrisseau, haut de $0{ }^{\mathrm{m}} 90-\mathrm{1}^{\mathrm{m}}$ 80, habituellement peu branchu, ilancé. Feuilles elliptiques-obovales ou lancéolées-oblongnes, acuminces au sommet. Fleurs blanches, en grappes simples, spiciformes, très allongées, d’abord droites, ensuite penchées. Baies petites, légèrement poihtes, d'abord vertes, ensuite blanches, puis bleu foncé. - Très abondant sur les lisières et dans les clairières des bois et dans les savanes des moyenne et infra-moyenne régions: Camp-Jacob, Bagatelle, Gommier, Matouba, VieuxHabitants, Ravine-Chaude, Sainte-Rose, ete. Alt. 300-900 mèt. [No 25661.]

Martinique. Vulgo : Bois-colibri. - Abondant : Champllore, Parnasse, hauteurs de Pécoul et de Périnell. Case-Pilote, ete. Alt, 40-550 mèt. No 952.]

Chimarrhis Jace. idu gree "Cheimarros ", fleuve, parce que cet arbre pousse principalement le long des rivières.)

C. cymosa Jacq. ; Chimarrhis à fleurs en larges cymes. Vulgro: Bois-résolu. — Grand et bel arbre, haut de 16-25 mèt., à cime arrondie et à branches inférieures très dalées, longues. Feuilles larges, glabres, obovées-oblongues nu elliptiques, pointues au sommet, rétrécies à la base. Fleurs blanc pâle, en cymes larges, arrondies ou allongées. - Fl, de mai à août. - Le bois est jaunatre nuancé, flexible et recherché pour la charpente, les boiseries et les meubles. - Issez abondant dans les régions inférieure et infra-supérieure de

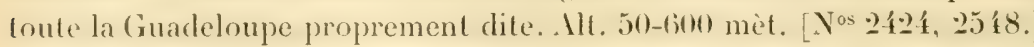

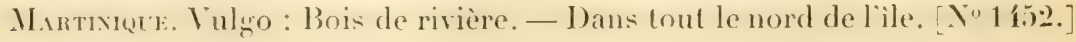

Le Coutarea speciosa Aubl. (Gomy., t. 122, petit arbre originaire de la 
Guyane, à fleurs larges et pourpres, est cultivé sur quelques habitations.

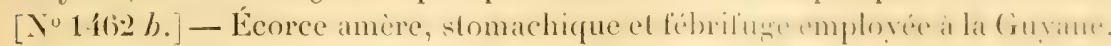

Exostemma D. C. (du grec " exo ", en dehors, el "stemon " ou "stema

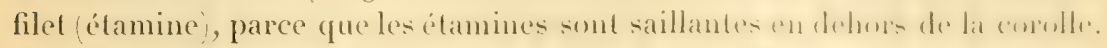

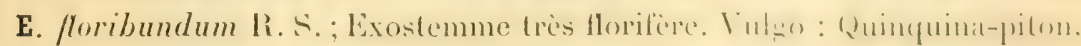
quina-montagne, tabac-montagne, bois-tabac. Desc., vol. I, L. 13, p. 507. Petit arbre, rarement arbre de taille moyenne, haut de 8-1.4 mèt., droil, ì

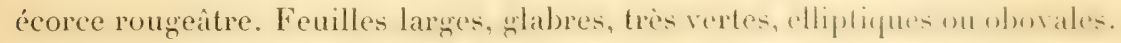
Fleurs rouge jaunâtre, en corymbes terminaux et axillaires : ces derniers partant des aisselles des trois ou cinc dernières feuilles de la branche; élamines exsertes. Capsule oblongue, longue de 2-3 cm.; graines ovales, ailées, petites. - Assez abondant dans tous les bois de la Guadeloupe proprement dite, mais surtout dans le massif de Houëlmont. - Le bois sert pour la construction, et, à cause de son amertume, les insectes ne l'atlatpuent pats: linomere est très amêre, astringente et fébrifuge. Dans le pays, on en fait un usagre

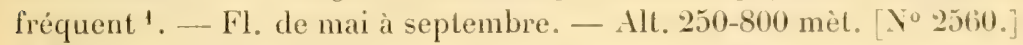

Martixique: Vulgo: Quinquina-montagne. - Dans tons les bois de l'île, surtout de ceux de la Calebasse, de la Basse-Pointe, du Champllore, etc. [No 1458.$]$

E. carihrum R. S.; Exostemme des Caraïbes. Vulgo : Quinquina-caraïbe, tendre, en gomme. - Arbrisseau élégant, rarement tout petit arbre, haut de 2-1 miet., très branchu ou presque sans branches, selon lew lencalitio. Femilles

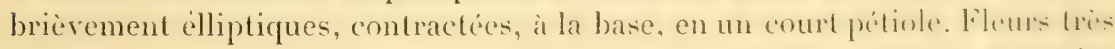
odorantes, blanches ou légèrement rosies, en corrmbes axillaires. Capsules obovoïdes-oblongues. Assez abondant dans les terres sèches et pierreuses, entre Baillif et les Vieux-Habitants, entre Deshaies et Sante-lieme pris du

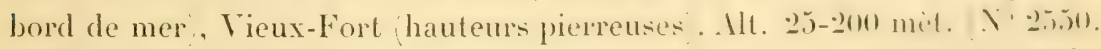

Martineue, Vulgo : Quinquina-caraïbe. - Rare: Caravelle (habitation Leferré, sur le bord de mer), variété à piquants. [No 951.]

Le Portlandia gypsophila Mace, superbe petit arbee a lleurs blanches.

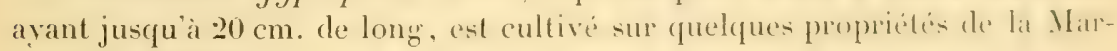
tinique. $\left[N^{\circ} 991.\right]$

Hillia Jacq. (dédié à John Irill, né à Peterborough, aponthicaire el bontanist. à Londres, mort dans celle ville, en 177.) a larise des écrits sur la butanique

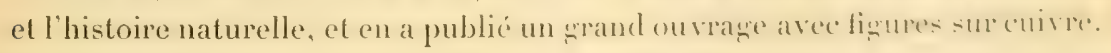

1. Cette espéce et la suivante constituent par leurs écorces tris iméres el léhrifures: des faux quinquinas trés appréciés. L'E. floribundum contient un alcaloüde nommé monlanine (exostemmina de Bocquillon-Limousin) qui en est le principe actif. - L.E. caribreum a une saveur d'abord mucilagineuse et sucréc qui devient ensuite trés ancire cl trés désagréable, nauséeuse mème, dans liune comme dans l'autre écorce. (A étuclieravec soin.) (E. H.) 
H. longiflora Sw., H. parasilica Jacq.; Hillie à longues lleurs. Vulgo: Jasmin-bois. Sw., Observ., 1. 5, f. 1; Jacq., Sel. Am. stirp. hist., 1. 66. Arbrisseau épiphyte, vivant sur les arbres, les roches et les souches pourries, ¿ branches allongées, droites, souvent pendantes. Feuilles épaisses, très luisantes, elliptiques, brièvement pointues au sommet. Fleurs blanches, solitaires ou géminées, terminales, à long tube cylindrique, a lobes rotacés, à odeur forte et exquise. Fruit en forme de silique, long de 9-1:3 cm., ressemblant it une petite gousse de vanille. - Dans les bois humides: Matouba, Bains-Jaunes, Gommier, Trois-Rivières, etc. Alt. 400-900 mèt. [No 2546.

Martineue. Vulgo: Jasmin des bois, - Bois du Camp de l'Alma, de la fontaine Absalon, de la Montagne-Pelée, etc. Alt. 500-800 mèt. [No 1462.]

Rondeletia Plum. (dédié à Guil. liondelet, né en 1507. a Montpellier, professeur à la faculté de médecine en 1545 , mort en 1566, à Réalmont, près d'Alby.)

R. stereocarpa Griseb. ; Rondelétie à fruits secs. Vulgo : Bois-résolu-monlagne, petit résolu. - Grand arbuste ou petit arbre, haut de 2-5̃ mèt., nu dans le bas, à écorce rude, presque toujours couverte de mousses et de lichens. Feuilles larges, lancéolées-oblongues, pointues au sommet, contractées à la base, à nervilles très anastomosées et aréolées. Fleurs en cymes pédonculées, d'abord blanchâtres, passant ensuite au jaune brun. Capsule subglobuleuse, loculicide; semences petites, ovales, aplaties, entourées d'une aile membraneuse el dentelée. - Abondant dans les bois du Gommier, des BainsJaunes, de la Savane aux Ananas (rabougri), du Matelyane, de la Ravine-àDéjeuner, etc. Alt. 450-900 mèt. [No 2552.]

Marmivinue. Vulgo : Bois-montagne. - Calebasse, Montagne-Pelée, fontaine Absalon, Lorrain. TNos $210,941$.

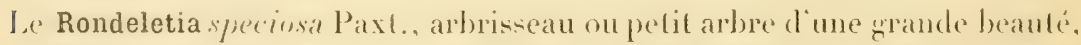
est cultivé gà et là dans quelques jardins de la Basse-T'erre et du Camp-Jacob [No 3253), et à la Martinique dans beaucoup de jardins privés et au Jardin botanique de Saint-Pierre. [No 604.]

Le Pentas carnea Benth., vulgo: Maladrière (i la Basse-Terre) No 2552 ], Martinique, vulgo: Corbeille d'argent [No 1 t́61], est très lréquemment l'objet de culture comme plante d'ornement; il est originaire de l'Afrique.

Manettia L. (dédié à l'Italien Xav. Manetti, né en 1723, à Florence, directeur du Jardin botanique de celte ville, zélé propagateur du système de Linué.)

M. calycosa Griseb. ; Manettie à grand calice. Vulgo : Liane blanche monlagne. - Pelite liane, annuelle, très branchue, à lige el branches blanchâtres,

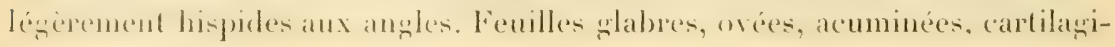


neuses. Inflorescence en cymes axillaires, contenant 2-5 fleurs blanches. Cá et là dans la haute région: Savane à Mulets, Grande-Découverte, elc. Alt. 900-1300 mèt. [No 2563.

Martingue. Vulgo: Liane-colibri-montagne. - Monlagne-Pelée PelileSavane), Pitons-du-Carbet, etc. $\mathrm{N}^{\mathrm{u}} 1003$.

Oldenlandia L. (dédié aux Danois Henri Beruh. Oldenland, botaniste: a royagé dans l'Afrique du Sud, où il est mort à la fin du xrro sièce.)

0. corymbosa L. ; Oldenlandie a fleurs en corymbes. Vulgo: Mille-graines. Desc., vol. I, 1. 50, p. 225. - Petite herbe, annuelle, hate de $10-201$ cm., délicate, droite ou plus ou moins difluse, à tige grêle. Fénilles lancéoléeslinéaires, à une nervure. Fleurs blanches, petiles, en corvmbes unbellilormes, terminaux. - Répandu dans toute la Guadeloupe et dépendances, sans èlre très abondant nulle part '. Alt. 5-600 mèt. [No 2542.]

Martingue. Vulgo: Mille-graines. - Abondant. [No 1.156 a.]

0. herbacea D. C.; Oldenlandie herbacée. Vulgo : Mille-graines. - Merbe très délicate, flasque, dilluse, quand elle est solitaire; droite ou grimpante. quand elle pousse dans les hautes herbes, haute de $25-70 \mathrm{~cm}$. à tige tétragrone. Feuilles linéaires ou linéaires-lancéolées. Fleurs petites, blanches, disposées comme celles de la précédente espèce. - Endroits aquatiques ou très humides : Lamentin dans les savanes marécageuses el couvertes de hautes herbes), T'rois-lívières (çà et là dans les champs sablonneux). [Xu 3385.]

Martingue. Vulgro: Mille-graines. - Cà et là dans les chemins peu batlus des environs de la fontaine Absalon. $\left[\mathrm{N}^{\circ} 1456 \mathrm{~b}.\right]$

0. IIalei Chap.; Oldenlandie de Hale. Vulgo: Mille-craines. - Herbe annuelle, rampante ou grimpante, extrêmement flasque el délicale, haule de $0^{m}$ 20-1 ${ }^{\prime \prime} 40$. Feuilles lancéolées. Fleurs blanches ou rosées, en crmes ombelliformes. - Assez abondant dans les jardins et les saranes herbeuses des environs de la Pointe-ì-Pitre. [No 2761.] - Je ne l'ai pas vu à la Marlinique.

Mitreola L. (diminutif du gree "mitra ), bonnet, mitre, allusion it la petite calotle qui couronne le fruit et qui tombe après la déhiscence, comme dans les pourpiers.)

M. petiolata Torre et Gray; Mitréole à feuilles pétiolées. Vulgzo: Mille-

1. Cette espèce, abondamment répandue dans l'Inde, yest employée comme föbrifuge:

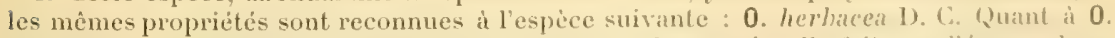
umbellata L., également de l'Inde, sous le nom de chaya-vair, elle fuit, par lécorée de sal racine, l'objet d'un grand commerce en tant que matiere colorante tres appricice dres Indiens pour la teinture de leurs étofles en jaune orange. Ce trafic se lít surtout sur lis côte de Coromandel. Les feuilles y sont appréciées comme expectomantes et antiasthmiatiques. On pourait peut-ètre retrouver les mèmes propriétés dans les racines et les feuilles des Ohlenlanclia des Antilles. (E. II. 
graines. - Iterbe anmuelle, droite, grèle, haute de $30-60$ cm. entierement grisâtre. Feuilles opposées, petiles, ovées-lancéolées. Fleurs roses, en cymes terminales, unilatérales; pédonculées. - Fl. en juin, juillet, août. - Peu répandu : le long de la route et dans les savanes entre la Pointe-a-Pitre et le Gozier; çà et là dans les champs sablonneux de Marie-Galante. [Nْ 3614.$]$ - Je ne l'ai pas trouvé à la Martinique.

Spigelia 1. dédié à Adrien Van der Spigel, né en 1558, i Brüssel, médecin à Mähren; en 1616, professeur d'anatomie à Padoue, mort en 1625; a écrit. entre autres choses : Isagoge in rem herbarariam.)

S. Inthelmia L. : Spigélie anthelminthique. Vulgo : Brinvillière, herbe ì la Brinvilliers, poudre à vers. Br. Jam., t. 37, f. 3; Tuss., Fl., IV, t. 8; Dese., vol. I, t. 61, p. 261. -- Herbe annuelle, droite, haute de $25-70 \mathrm{~cm}$., branchue ou simple, nue dans le bas. Feuilles ovées-lancéolées, subsessiles, réunies par:2-1. dont deux toujours plus grandes. Fleurs pourpre brun, en crmes unilatérales, axillaires et terminales. Capsules muriquées. - Celte herbe est vénéneuse à l'état frais. Les graines et les feuilles sont stomachiques et vermifuges 1. - - bondant dans les champs en friches, le long des routes et dans les terres cultivées : environs de la Basse-Terre, Gourbeyre, Lamentin, Moule, Les Abymes, etc. Alt. 0-500 mèt. [No 2762.].

Martinique. Vulgo : Herbe Brinvilliers, herbe-poison. - Abondant dans la région inférieure de toute l'île. [No 1459.$]$

\section{TRIBU II. - COFFÉACÉES.}

Guettarda Vént. idédié à François-Jean-Étienne Guettard, né en 1715, ¿ F́tampes, médecin el minéralogiste, mort en 1786 , a Paris ; a écrit entre autres choses : Flore des environs d'Étampes.)

G. crispiffora Viahl: Guettarde à fleurs crépues. Vulgo: Bois-flot-montagne, bois-flot-des-hauts. - Grand arbuste ou petit arbre, dont le maximum de taille ne dépasse guère 7 mèt. de haut, à branches divariquées, à jeunes branches médulleuses, à écorce blanchâtre, à bois mou et fragile. Feuilles larges, elliptiques, flasques, pubescentes en dessous et blanchâtres. Fleurs

1. Cette plante est mieux classée dans les Strychnées ou Loganiacées avec le genre auquel elle appartient. Le rhizome est employé contre les vers intestinaux. A haute dose, c'est un poison violent. La plante répand une odeur vireuse très accentuée et possède une saveur nausécuse et amère persistante. Elle contient, daprès Dudley, un alcalo de volatil (qui serait le principe actif de la plante (spigéline) et qui présenterait d'étroites affinités avec la nicotine et la lobéline. Cette drogue, bien que constituant un bon vermifuge, doit être employée arec la plus grande prudence, à cause de ses propriétéséminemment toxiques. (E. H.) 
odorantes, en cymes nombreuses, axillaires, confinćes aux extrémilés des

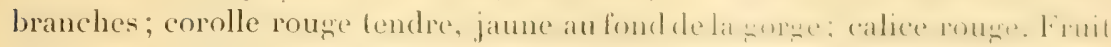
Iriquètre. - Fl. toutel'année. - Peu répandu : dans la coulée de la Ravine-ilDéjeuner, et bois des Bains-Chauds. Alt. 800-1000 mèt. [No 2763.]

Martineue. Vulgo : Bois-flot-montagne. - Plus abondant qu' it la Cruade-

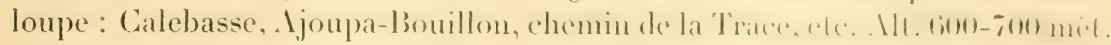
[No949.]

G. scahra Lam.; Guettarde à feuilles rudes. - Vulgo: Bois-madame, boisgoyavier. Lam., Ill., t. 154, fleurs à gauche, en bas. - Grand arbuste et très souvent petit arbre, haut de 5-9 mèt., à trone droit, à branches allongées, fastigiées ou étalées, à écorce blanchâtre et rude. Feuilles très scabres el ruguleuses, blanchâtres en dessous, obovales ou oblongues-edliptiques. Inthrescence en cymes très contractées sur des pédoncules pubescents presque aussi longs que les feuilles. Drupes globuleuses, gris noir at la maturité.

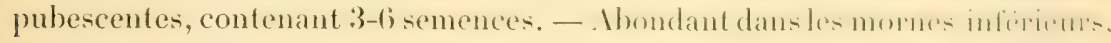
secs et rocailleux de tout le massif de Houëlmont, Gozier, Moule, SainteAnne. Alt. 200-450 mèt. [No 2555.]

Martinique. Vulgo : Goyavier bâtard. - Endroits secs des hanteurs de Case-Pilote, de la Rivière-Pilote, des Trois-Ilets (plateau). [No 1 163.3.]

G. parvifolia Sw.; Guettarde à petites feuilles. Vulgo: Bois puant, boiscaca. - Grand arbuste ou petit arbre, ornemental, ne dépassant guère -í mèt. d'élévation. Feuilles petites, ovées ou lancéolées. Fleurs blanches, très nombreuses, en petites cymes pédonculées, axillaires, portant 2-3 lleur's. Drupe globuleuse, pubescente, plus petite qu'une graine de poivre. - Fl. en juin. juillet, août. - Région sèche du littoral :.environs de la Basse-Terre, coite entre Baillif et les Vieux-Habitants, Vieux-Fort, ete. Alt. 10-140 mèt. [No 2362.]

Martinique. Vulgo : Bois-de-fer blane. - Côte sèche de Case-Pilote, route de Fort-de-France au fort Desaix, Trois-Ilets (bord de mer). [No 913.$]$

Stenostomum Gartn. (du gree " stenos," court, el "stoma ", bonche, parce que les lobes du calice persistant se réunissent au-dessus du liruit et y laissent une petite ouverture.)

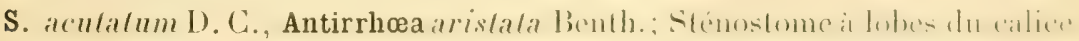
acuminés. Vulgo : Mapou noir. - Arbre d'assez grande taille, haul de 10-15 mèt., à écorce noire et lisse. Feuilles elliptiques, pointues, vert sombre en dessus. Fleurs blanches, odorantes, en eymes terminales. Drupe noire, ellipsoïde-oblongue, pointue. - Fl. en octobre. novembre el décembre. - Peu abondant : è̀ et là dans les bois sees du massil de Houëlmont, hauteurs de Deshaies. Alt. 250-100 mèt. TNos $2807,32600$. 
Martineve. Vulgo : Mapou noir. - Assez abondant dans les hauteurs des Trois-Ilets, de la Rivière-Salée et de la Rérgale. [No 251.]

S. resinosum Griseb., Laugeria resinosa Vahl; Sténostome résineux. Vulgo : Bois-fer blanc. (Laugeria V.) Vahl, Eclog., t. 10, f. 6, analyt. - Grand arbuste ou petit arbre, ornemental, haut de 3-6 mèt., à tige et branches nues, noirâtres. - Feuilles petites, ramassées aux extrémités des branches, très rapprochées, oblongues-lancéolées, résineuses, grises en dessous. Fleurs blanchâtres, en cymes axillaires. - Abondant dans les endroits secs du massif de Ilonëlmont, des hauteurs du Vieux-Fort, elc. Alt. 200-450 mèt. [No 2543.]

Martinique. Vulgo: Bois-de-fer blanc, - Abondant dans les hauteurs de Case-Pilote sarane saint-Crret environs. de Case-Navire el des Trois-Ilets (plateau). [No 1457.$]$

Chione D.C. (du gree " chion », neige, parce que les fleurs sont d'un blane de neige.)

C. glabra D.C.; Chione glabre. Vulgo : Grand branda. - Petit arbre, haul de 6-12 mit. droit, à trone nu, id branches étalées ou fastigrées. Fenilles lancéoléesoblongues plus ou moins molles, a nervures secondaires peu márquées. Inflorescence en cymes larges, trichotomes, terminales, portées sur

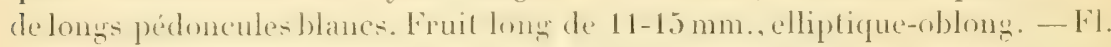
d'août à septembre. - Bois de Gourbeyre (morne Goblin), hauteurs de Deshaies et bois entre Deshaies et Sainte-Rose (bord de mer), etc. - Alt. 40-500 mèt. [No 3252.] - Il n'existe pas à la Martinique.

Strumpfia Jacef. dédié a l'Dllemand Charl. Strumpl, qui sonceupa beaucoup de l'édition des ourrages de Linné.)

S. maritima Jacq.; Strumpfie du bord de mer. Vulgo : Romarin bord-demer. Desc., vol. III, t. 208, p. 260. - Arbrisseau très rabougri, très élégant et ornemental, ou arbuste haut de 1-2 mèt., droit, très branchu et richement feuillu, ressemblant it un grand pied de romarin, par le port, la couleur et la forme des fenilles. Fleurs blanches en trè petites grappes axillaires. Drupe blanche à la maturité, globuleuse, plus petite qu'une graine de poivre. - Fl. Loute l'année. - Fait l'ornement des rochers et des sables du bord de mer, de Marie-Galante (Capesterre), de la Désirade, de Saint-François, etc. [No 2764.] - Il n'est pas à la Martinique.

Erithalis P. Br. (du grec " eri ", très, beaucoup, et " thallein ", verdir, c'est-ì-dire des arbrisseaux à feuilles très vertes.)

E. fruticosa L.; Erithale frutescent. Vulgo : Bois d'huile bord-de-mer, bois-chandelle noir. Desc., vol. IV, 1. 242, p. 40. - Arbrisseau ou grand arbuste, haut de $2-3{ }^{\mathrm{m}} 50$, à écorce noire, à branches et feuilles bien fournies. Feulles obories ouspatules-lancéolés, arrondies au sommet, subcharnues, 
luisantes en dessus. Fleurs blanches, diune odeur forte of exquise, en eymus frichotomes, assez courles ol terminales. Fruil whoblenx, marequi de dix

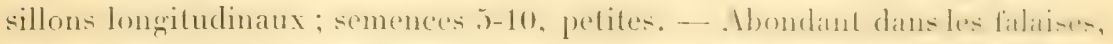
sur les rochers et les sables du bord de mer ou sur les mornes secs et pierreux près du littoral. - Fl. toute l'année avec plus ou moins d'abondance.-

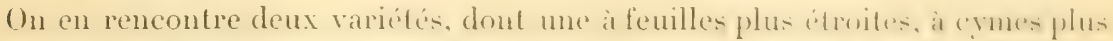

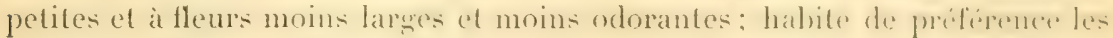

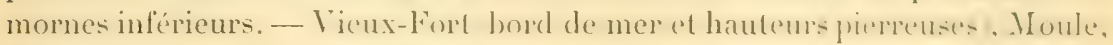
Marie-Galante, Désirade. [No 2557.]

Martivieue. Vulgo: Flambeau noir, bois-chandelle noir. - Abondant : basse-Pointe, chemin de la Grolte, Grand' Ause, Sainte-Luce, Caravelle, ele. $[\mathrm{Nos} 9 \mathbf{4 5}, 9 \mathbf{4 6 .}]$

E. angustifolia D. C. ; Erithale à fenilles étroites. Vulgon : liob-flambean'montagne. - Arbrisseau très élégant, droil, haut de 1-2 mil. Fenille- lancéolées, acuminées aux deux bouts. - Infloresence encrmes allongéres, ans-i longues que les feuilles, d'abord droites, ensuite penchées. - Fl. de décembe en mars. - Assez abondant à la Montagne-Pelée. Alt. 900-1000 mèt. [No 1724.] - Je ne l'ai pas trouvé à la Guadeloupe.

Chiococca P. Br. (du grec " chion ", neige, et "kokka ", baie, parce que les baies de cette liane ont la blancheur de la neige.)

C. racemosa Jacq.; Chiococca à fleurs en grappes. Vulgo: Bois-branda .

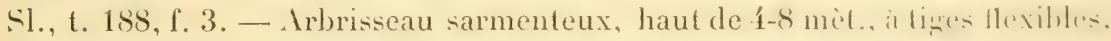
à branches horizontales ou pendantes. Feuilles coriaces, petifes, elliptipuenou ovées, ou ovées-lancéolées, plus rarement ovales-oblongues. Inllorecormer en cymes racémiformes, unilatirales, souvent pendantes. Filutr- il ouleur exquise; corolle d'un blanc pale ou légerement jambitre. lprupe dialmer verte, ensuite d'un blane tres pur. - Commun dans les mormes infericurs.

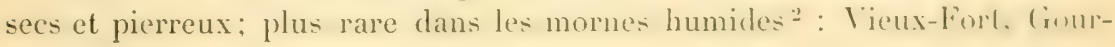

1. Ces deux espèces d'Erithalis, dont la première porte à la Guyane le nom de hoisflambeau et fournit, par son bois résineux, une matic̀re a confectionner des torches, doivent jouir des mêmes propriétés et peuvent, sans doute. se supplíer l'une l'autre. Il y aurait intérêt à étudier cette résine et à la rapprocher de celle des gardenia de la Nơvelle-Calédonie (fournie par les feuilles), qui tient le milieu, d'aprés des recherehes que j'ai faites avec M. Schlagdenhauflen, entre les résines et les tanins. Astringente el aromatique, cette résine est employée contre les atrections des reins et de lat ressie.

2. Cette plante, dite " caiça des Antilles ", constilue, par ses racines, un violent drastique. Elle se rapproche sensiblement de la Chiococca anguifuga Mart., dite "cainça du Brésil ", dont quelques botanistes font une simple variété de C. racemosa, et dont les racines constituent un émétique drastique violent, employé avec succés contre les lỵdropisies essentielles. En Allemagne, on emploie de préférence contre la mème affection la racine de Chrococca racemosa, qui se distingue de sa congénére par l'abondance d'une matiere colorante jaune. Celle-ci donne à l'écorce une teinte gris jaunâtre et au bois unc couleur' franchement jaune. Aême composition chimique dans les deux caïnģa. (L. II. 
bevre mornes Goblin, Dos-d Ine. Boucanier), Trois-livieres, Grands-Fonds du Moule, du Gozier, du Morne-ì-1'Eau, ete. Alt. 470-150 mèt. No 25j9.

Martixique. Vulgo : Jasmin-bois. - Très abondant: Parnasse, hauteurs du Précheur, Trois-Ilets el Anses-d'Arlet, Marin (morne Gommier), ete. Alt. 50-340 mèt. [No948.]

Vangueria Vahl ide "Voa-vanguier ", nom de la plante à Madagascar.)

V. edulis Vahl, V, madagascariensis Gmél.; Vanguérie comestible. Vulugo: Tamarin des Indes, néflier des Indes. - Petit arbre, à branches dirariquées et étalées, à leuilles larges, à fleurs vertes, en cymes axillaires disposées tout le long desbranches, a fruits de la forme d une nèfle, mais moins volumineux. - Fl. en juin, juillet, août. - Originaire de l'Afrique tropicale. Cultivé pour ses fruits blets dans toutes les colonies chaudes. [No 2765.

Martineve. Vulgo: Tamarin des Indes. [No 1465.

Ixora L. (nom d'un dieu de Malabar.)

I. ferrea Benth.; Ixora à bois dur comme le fer. Vulgon : Bois-de-fer rougre. - Grand arbuste ou petit arbre, haut de 3-J mèt., à tronc droit ou tortueux. a branches étalées et souvent tortueuses, à écorce noire et rude. Feuilles oblongues, pointues au sommet, brièvement pétiolées. Fleursblanches, exhalant une odeur exquise, en corymbes axillaires et latéraux, tres courts, disposés tout le long des branches. I)rupe subglobuleuse, noire, contenant deux semences. - Assez rare : çà et là dans les bois humides ou secs des mornes inférieurs du massil de Ilouëlmont et des hauteurs du Vieux-Fort: disséminé dans les bois inférieurs des Bains-Jaunes. Alt. 200-700 mèt. No 2547.

M.nтrirgev. Vulgo: Bois-baguette, bois-piquet. - Bois des Fonds-SaintDenis, des hauteurs de Case-Pilote et de Case-Navire, de la fontaine Didier, etc. [No 1460 .

I. coccinea L., I. Bandhuca Roxb., vulgo : Bois-pintade, arbrisseau touffu, oripinaire des Indes Orientales, i fleurs rouges, en corrmbes umbelliformes, est fréquemment cultivé dans les jardins. [No 2769.$]$

Martinique. [No 1008 .

(In rencontre à la Gruadeloupe et surtout à la Martinique, l'Ixora blanda Ker.-Gawl. et l'I. odorata Hook., qui font l'ornement des parterres. Les I. javanica D. C., salicifolia D. C., ternifolia Cav. et Pavelta Roxb. [No 1006] sont cultivés au Jardin botanique de Saint-Pierre.

Coffea L. [peut-être du mot arabe " kakueh ", qui signifie force, vie, allusion aux eflets toniques de la plante; selon le voyageur Ritter, du mot " caffa ", parce que le caféier pousse à l'état sauvagre sur une très grande

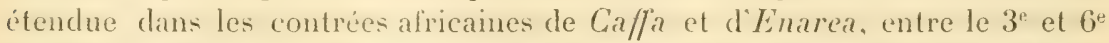
degré de latitude nord, eomme aussi au sud du Niger jusqu à Tombouktou; 


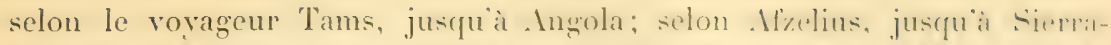

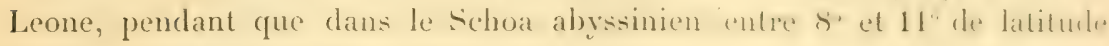
nord) il existe à l'état de culture.]

C. arabica L.; Calé arabique. Vulgo : Cafier, caféier (selon toutes les

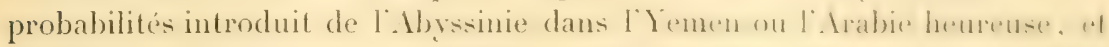
cultivé là sous le nom de "calé Moka "). Implanté à la Martinique, en 1720,

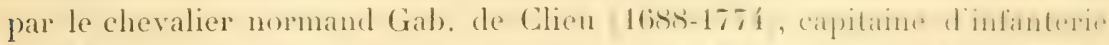

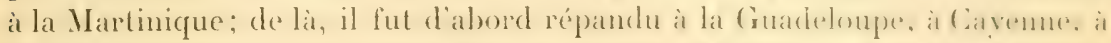

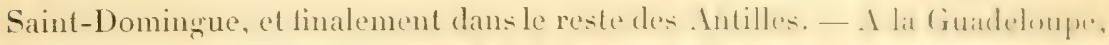
les cultures du caféter oceupent foon hectares de leme: lexporlation side-

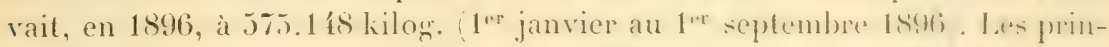
cipaux centres de culture sont : les Trois-Rivières, (sombere, saint-clemle. Vieux-Habitants, Boullante, Pointe-Voire, Deshates, Capesterere, SainteMarie, etc. - La récolte a lieu de fin septembre en janvier ou février. [No 3766.$]$

Martinique. [ $\left.\mathrm{y}^{\circ} 212.\right]$ - On y cultive principalement trois variétés: $1^{\circ}$ celle d"Abyssinie, la plus ordinaire, à cerises ovoïdes, contenant deux semences; : celle de Bourbon, à fruits ovoüdes pointus: 3" le cale Muka a fruits subglobuleux, ne renfermant qu'une semence. $\left[\mathrm{N}^{\circ} 2766 \mathrm{~b}\right.$. $]$

C. liberica Hiern. Café de Libéria. - Petil arbre, originaire de la côte

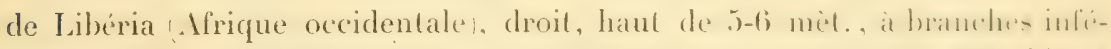

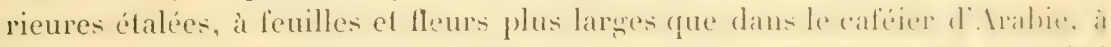
fruils longs de $9-11 \mathrm{~mm}$. sur 7-9 mm. de large, qui restent attachés au pied jusqu'à ce qu'ils soient secs. [No 4323.$]$

Martivique. Vulgo : Café Libéria. - Les premiers pieds de cette Rubiacée ont été recus, en 1870, par M. Ch. Belangers, directeur du .ardin butanique: ils provenaient du Jardin botanique de Paris. [ $\mathrm{N}^{\circ} 987$.

Faramea Rich. (nom de la plante à la Guyane.)

F. odoratissima D. C. ; Faramée à fleurs très odorantes. Vulgo : Caliémarron, café bâtard. Br. Jam., l.6, f. 2; 'I'uss., Fl., II, ᄂ. 16; Jacq., Sel. Im.

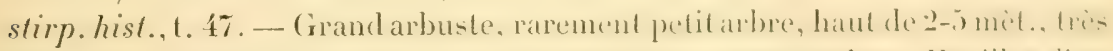

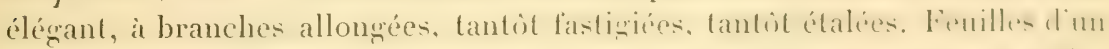
vert sombre en dessus, elliptiques ou oblongurs. pointues atl sommel. pritin-

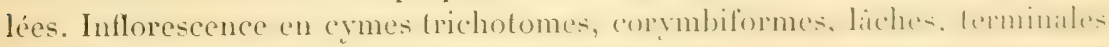
et axillaires. Fleurs d'un blanc pur, exhalant une odeur expluise al linte yni se fait sentir au loin. Baie noire, globuleuse-déprimće. - Rare : endroits

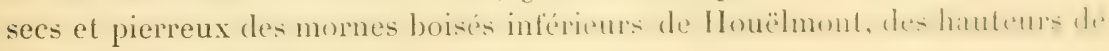
Vieux-Fort, etc. $\left[\mathrm{N}^{\circ} 2767.\right]$

Martinique. Vulgo : Bois-flèche. - Fl. presque toute l'année. - Cril et lii dans les hauteurs de Case-Pilote (savane Saint-Cyr), de Case-Navire, des environs de la fontaine Didier. Alt. 100-300 mèt. 「No 14.jol. 
Rudgea Salish. dédié au botaniste anglais kd. Rudge. qui, le premier, a fait connaître les plantes de la Guyane dans son ouvrage : Plantarum Guianx rariorum icones et descriptiones. Londres, 1606.)

R. caribiea Benth.; Rudgée des Caraïbes. V'ulgo : Café bâtard-montagne, bois-mêle jaune, bois cassant. - Grand arbuste ou petit arbre, haut de 2-6 mèt., droit ou tortueux. Feuilles subcharnues-cartilagineuses à l'état frais. très luisantes en dessus, elliptiques. Inflorescence en panicules courtes. terminales. Fleurs d'un blanc pur, à odeur exquise. Drupe obovoïdewhongue, longue de $2 \mathrm{~cm}$. sur $8.9 \mathrm{~mm}$. de diam., a 6 -8 cotes longitudinales, jaune à la maturité. - Fl. en mars, avril, mai. - Très abondant dans tous les bois humides, surtout dans ceux de Sante-Rose, de la Ravine-Chaude. du Gommier, des hauteurs des Vieux-Habitants, etc. [No 2556.

Mantinique. Vulgo : Café-montagne. - Abondant : hauteurs de CasePilote (sarane Saint-Cyr et Plateau militaire), de Case-Navire, de la GrandAnse, etc. Alt. $300-600$ mèt. $\left[N^{\circ} 601\right.$.

Ronabea Aubl. (nom indigène de la plante à la Guyane.)

R. latifulia Aubl., Psychotria axillaris Willd.; Ronabée à largere leuilles, Branda grand-bois, café blanc. Aubl., Guy., t. 59. - Arbrisseau herbacé, haut de 40-90 $\mathrm{cm}$., rarement plus haut, à tige unique, très épaisse et succulente, cylindrique, épaissie aux noxuds, souvent couchée et radicante it la base, quelquelois munie de racines adventives. Feuilles opposées très larges, elliptiques ou oblongues, brièvement mucronées au sommet, contractées à la base en un long pétiole cylindrique. Inflorescence en cymes axillaires, très serrées, glomérulées-allongées, à pédoncules et pédicelles blancs; fleurs blanches, odorantes, laineuses en dedans (sur une cyme, on trouve rarement plus de 3-5 fleurs ouvertes en même temps). Drupe ovoïde-globuleuse, très blanche à la maturité, à pulpe assez copieuse et spongieuse. - Fl. toute l'année. - Peu abondant : çà et là dans les endroits trèshumides, ou sur les bords des ruisseaux, dans les grands bois. - BainsJaunes le longe du canal de Montéran), Matouba icoulée de la Ravine-íDéjeuner), Capesterre (bois des environs du Grand-Etang). [No 2768.]

Martinique : Vulgo: Café-montagne. - Abondant : hauteurs de CasePilote et de Case-Navire, bois du "Bambou-gouverneur ", environs de la fontaine Absalon, du Camp de l'Alma, bois du Lorrain, etc. [No 601.$]$

Psychotria L. Ilu gree "psyché", vie, àme, el "tropho n, je nourris, parce que, arec les fruits du Psychotria herlacea Vell., on prépare à la Jamaïque. d'apres Browne, une boisson agréable, semblable ì celle du café. Limné a contracté le nom primitif de Psychotrophum en celui de Psychotria.

P. uliginosa Sw.; Psychotrie des endroits humides et ombragés. Yulgo: Pelit café bâtard. - Sulfrutescent ou frutescent, haut de $0^{\mathrm{m}} 50-1$ mèt., 
droit ou plus souvent tortueux, it tige parfois couchée el radicante. F'enilles larges, horizontales ou penchées, subcharnues, obovales ou elliptiques, pointues au sommet, cunéiformes à la base, longuement pétiolées. Intlorescence en panicules trichotomes, axillaires, courtes; lleur's d'un blanc pâle. Baie ovée, pulpeuse, rouge foncé à la maturité. - Issez abondant dans les endroits très humides et ombragés des grands bois des lBains-Jaunes, du Gommier, des Trois-Rivières, de Samte-Rose, ete. Alt. fo(1-Son) mèt. [No 2528.]

Mantrineve. Vulgo: Café-bois. - Calebasse, Montagne-Pelée, Lorrain, Fonds-Saint-Denis, Camp de l'Alma, etc. [No $130 \mathrm{~b}$.

P. floribunda H. B. et Kth.; Psychotrie très florifère. Vulgo: Calé-bois marron. - Arbuste haut de 2-3 ${ }^{\mathrm{m}} 50$, droit, élégant, it branches plus ou moins divariquées. Feuilles subcharnues-coriaces, oblongues. Inllorescence en panicules trichotomes, contractées, terminales; fleurs blanc pâle. Drupe oroüde. - Assez abondant dans les bois des environs du Camp-Jacol, des bois inférieurs des Bains-Jaunes, du Gommier, des 'Trois-Rivières, de la Ravine-Chaude, elc. Alt. 400-700 mèt. [No 2527.

Martinique. Vulgo : Calé-marron. - Très abondant dans les bois du Champflore, ceux de la fontaine Didier, de la fontaine Absalon, des Fonds-Saint-Denis, etc. [No 2144.

P. lanceolata Nutt., P. chimarroides D.C.; Psychotrie à feuilles lancéolées. Vulgo : Petil café-marron. - Arbuste haut de 1-1 ${ }^{\text {m }} 50$, rarement plus haut, droit, toulfu. Feuilles lancéolées, acuminées, ternes en dessus, grisâtres en dessous. Inflorescence en panicules courtes; fleurs petiles, blanc pâle. - Fl. en mai, juin, juillet. - Endroits secs, rocailleux de la région inférieure: Vieux-Fort, Gourbeyre, Trois-Rivières, Moule, Gozier, Monneà-l'Eau, etc. [No 2531 .

Martinique, Vulgo : Petit café bâtard. - Parnasse, Prêcheur, Carbet, Trois-Ilets (plateau), Anses-d'Arlet (morne Larcher). [No 124.]

P. tenuifolia Sw.; Psychotrie à feuilles minces. Vulgo : Café-marron. Arbrisseau haut de 2-3 mèt., touffu. Feuilles cartilagineuses, elliptiques ou oblongues, à veines saillantes en dessous. Fileurs en panicules brièvement pédonculées, trichotomes. Drupe ellipsoïde. - Cà et lì dans les haies el les endroits boisés de la région inférieure : Lamentin, Ducos, Trois-llels, elce. Alt. 50-300 mèt. [No 126.] - Je ne l'ai pas vu ì la Guadeloupe.

P. pubescens Sw.; Psychotrie pubescente. Vulgo : Café-marron grandbois. - Grand arbuste, rarement petit arbre, haut de $3-\hat{i}$ mèt, droil, it branches étalées, it quatre angles arrondis. Feuilles larges, llasques, elliptiques ou lancéolées-oblongues: les jeunes pubescentes, grisitres en dessous. Inflorescence en panicules pubescentes, longuement pédonculées, axillaires et terminales, pyramidales, trichotomes, at branches leminées en pelites. 
cymes; corolle verdâtre passant ensuite au jaune pâle. Drupe marquée de huit côtes longitudinales. - Abondant dans les bois des Bains-Jaunes, du Gommier, du Matouba, des Vieux-Habitants, etc. [No 2529.

Mantrique. Vulgo : Petit café-marron. - Bois des Fonds-Saint-Denis, des hauteurs de Case-Pilote et de Case-Navire, de la Montagne-Pe!ée, etc. I. 125.

P. horizontalis Sw.; Psychotrie à branches horizontales. Vulgo : Café bâtard. - Arbrisseau droit, à branches fastigiées, quand il est jeune; i branches tortueuses, parfois sarmentenses, tres divariquées, horizontales on pendantes, quand il est vieux. Fenilles elliptiques ou elliptiques-oblongues. luisantes en dessus. Inflorescence en cymes contractées, arrondies, à branches terminées par trois rayons; fleurs d'un blane pur. Drupe globuleuse-ovée, pulpeuse, rouge à la maturité. - Assez commun dans la basse région sèche : environs de la bas-e-Terre, Vieux-Fort, Baillit, Détrade, Marie-Galante. les Saintes. Moule, Gozier, Grand-Fonds-du-Morne-itl Eau, ete. 11t. (1-306) met. [No 2253.$]$

Martixique. Vulgo : Café-marron. - Abondant : Prêcheur, Fond-Coré, Lamentin, Trois-llets près du bord de mer, Carbet le long de la rivieres. Case-Pilote (bord de mer), etc. [No126.]

P. parasitica Sw.; Psychotrie parasite, Vulgo: Graine rouge. Jacq., Sel. Am. stirp. hist., t. 56, f. 1. - Arbrisseau épiphyte vivant sur les arbres, les vieilles souches et les troncs pourris, vivace, sarmenteux, long de $0^{\mathrm{m}} 40$ 1 mèt., à branches souvent très nombreuses, allongées, pendantes. Feuilles épaisses, ovées ou ovées-lancéolées, d'un vert sombre en dessus, grisâtres en dessous. Inflorescence en cymes trichotomes, terminales; fleurs blanches. Fruit pulpeux, ghlobuleux, rouge fonce a la maturité - Dans tous les grands bnis humides de la Guadeloupe proprement dite. 11t. 480-950 met. Y"2.534.

Martixique. Vulgo: Graine ì perdrix. - Abondant dans tous les grands bois. $\left[N^{\circ} 1468\right.$. $]$

P. crassa Benth.; Psychotrie à feuilles très épaisses. Vulgo : Graine à perdrix, graine rouge montagne. - Épiphyte et radicant comme le précéclent, auquel il resisemble de prime abord. Fenulles tres épaisses, elliptiques, pointues au sommet, marginées, à nervures imperceptibles à l'état frais. Fleurs blanches, en cymes trichotomes, multillores, corymbiformes; corolle hérissée de poils. Drupe comme dans le précédent. - Fl. toute l'amnée. Abondant dans les bois supérieurs des Bains-Jaunes et du Haut-Matouba, comme aussi à la Savane à Mulets, à la Soufrière, à la Grande-Découverte et à la Savane aux Ananas. Alt. 700-1480 mèt. [Xo 2533.] - Il n'existe pas ì la Martinique.

Palicourea Aubl. (nom indigène de la plante à la Guyane.) 
P. crocea DC., Psychotria subcrocea Muell. Arg.: Palicourćc ì fleurs couleur de safran. Yulgo : Bois-cabrit noir, bois-foul'ou (au Camp-Jacob), arbre à l'encre. Br. Jam., t. 13, f. 1, 2. - Arbrisseau d'une grande élégance, haut de 1-3 mèt., à branches le plus souvent fastigiées, à jeunes rameaux

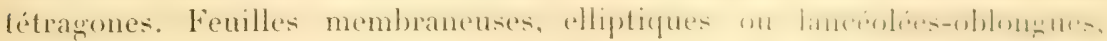
pointues au sommet. Inflorescence en grappes corymbilormes, allongées; drupe ovée, arrondie, latéralement comprimée; fleurs de couleur très variable, tantôt d'un jaune de citron, tantôt d'un jaune orange, tantôt d'un jaune safran, selon qu'il pousse dans les régions basse, moyenne ou supérieure. - Abondant dans toute la Guadeloupe proprement dite. All.

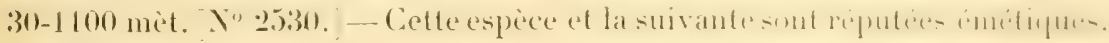

Martinique. Vulgo : Bois-cabrit. - Très abondant dans toutes les parties boisées de l'île, à l'exception de celles de Sainte-Anne, du Vauclin, de la Caravelle. $\mathrm{X}^{\circ} 602$.

P. Pavelta D.C.; Palicourée à feuilles de Pavetta (autre Rubiacée). Vulgo: Bois-cabrit. Plum., édit. Burm., t. 156, f. 1; Sl., t. 202, 1, 2. - Arbrisseau buissonnant, haut de $1^{m} 50-2$ mèt, à tiges très glabres, entlées aux nueuds.

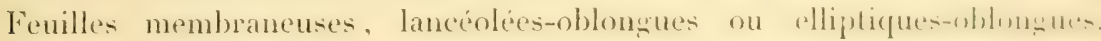
Fleurs blanchâtres. Fruit inconnu. - Fl. en septembre, octobre et novembre - Rare : cà et là dans les Grands-Fonds-du-Gozier. [No 3667 . _ Je ne l'ai pas trouvé à la Martinique.

Cephælis Sw. (du gree "kephalé ", tête, et " cilein ", prendre, réunir. c'est-à-dire fleurs réunies en capitules.)

C. axillaris Sw.; Céphélis à fleurs axillaires. Vulgo : Ipéca bàtard, looismarguerite, graine bleue. - Petit arbrisseau élégant, peu branchu, toujours nu dans le bas, haut de $0^{m} 80-1^{m} 40$, à rameaux tétragrones. Fenilles elliptiques, pointues, fermes. Fleurs blanches, en glomérules larges, axillaires,

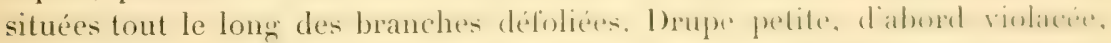
ensuite bleu foncé. - Fl. en janvier, février, mars et avril. - Endroits ombragés de tous les bois supérieurs de la Guadeloupe, surtout de ceux des Trois-Rivières et du Matouba. Alt. 600-900 mèt. Xo 2535.

Martingue. Vulgo : Graine bleue. - Abondant dans les bois de la Calebasse, de la Montagne-Pelée, des Pitons-du-Carbet, etc. No 1453.

C. muscosa Sw.; Céphélis mousseux. Vulggo : Ipéca bâtard, bois-marýgue-

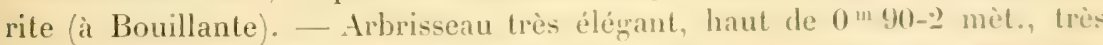

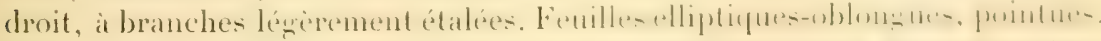

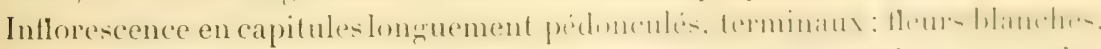
chacune entourée de cinq bractées ovées-arrondies. Drupe large, at pulpe copieuse, spongieuse ou mousseuse et blanche. - Très abondant dans tout les grands bois humides de la Guadeloupe. 11t.500-900 met. X" 2.537. 
Martinique. Vulgo : Bois-marguerite. - Dans tous les bois humides. [Nos $13 \dot{4}, 135$ a.]

C. Swartzii D.C.; Cephélis de Swartz. Vulgo : Faux ipéca, bois-marguerite. - Ressemble au précédent; il en diffère : par ses capitules brièvement pédonculés, beaucoup plus petils; par ses drupes plus arrondies, peu pulpeuses et bleu foncé à la maturité. - Également très abondant dans tous les bois humides, où il vit en société avec l’espèce précédente. [ $\Upsilon^{\circ} 2536$.

Martinique. Vulgo : Bois-marguerite, graine bleue. - Abondant. [No 135 b.]

Morinda Vahl (du latin "morus », mûrier, et "indicus », de l'Inde, parce que ces plantes sont originaires de l'Inde et que leurs fruits, composés, ont quelque ressemblance avec ceux du mûrier.)

M. citrifolia L., M. macrophylla Desf.; Morinda à feuilles de citromnier. Vulgo : Rhubarbe-caraïbe, bilimbi (au Morne-à-l'Eau). - Arbre haut de 5-12 mèt., à branches étalées: les inférieures penchées. Feuilles très larges, ovées-elliptiques. Inflorescence en capitules subglobuleux, larges, aréolés; fleurs blanches, insérées sur le réceptacle charnu dont se compose le capitule. Baie ovoïde à la maturité, lougue de $1-\tau \mathrm{cm}$., jaune en dehors, contenant 10-40 semences aplaties, nichées dans une pulpe blanchâtre. - Cet arbre ne devient pas grand à la Guadeloupe à cause de la nature du terrain dans lequel il pousse; ses fruits restent également petits ${ }^{1}$. - Fl. en août, septembre, octobre. - Ne se rencontre qu'à la Grande-Terre, ou il a été introduit de l'Asie et où il s'est naturalisé. - Mornes calcaires du Morne-il-l'Ean, du Moule; çà et là dans les Grands-Fonds-du-Gozier et de Sainte-Anne; rare dans les environs de la Pointe-à-Pitre. - Originaire des Indes Orientales. - Alt. 0-150 mèt. [No 2770.$]$

Martinique. Vulgo: Pomme de singe, pomme-macaque. - Introduit et cultivé au Jardin botanique, où il devient un très grand arbre. $\left[\mathrm{N}^{\circ} 1005\right.$.

Geophila Don. (du grec "gué ", terre, et " phileo ", jaime, parce que ces plantes se plaisent à ramper sur la terre.)

G. reniformis 1)on., Mapouria herbatea Müll. Aro., Psychotria herlaceat Jacq.; (reophile a fenilles en forme de rein. Vulgo : Ipéea noir. graine dorée à Deshaies). Jacq., Sel. Am. stirp. hist., t. 46; Tuss., Fl., I, t. 8. - IIerbe annuelle, radicante, rampant à une distance indéfinie, en tous sens, à tiges délicates, filiformes. Feuilles longuement pétiolées, cordiformes, un peu plus longues que larges (du moins dans mes spécimens). Inflorescence en petites

1. Le fruit de cette espèce est employé dans l'Inde, sa patrie, comme emménagoguc, ses feuilles sont toniques et fübrifuges, propriétés dues sans doute à un glucoside, la morindine. Celte écorec fournit, en outre, une matière colorante rouge écarlate foncé, employée dans l'Inde et en Nouvelle-Calédonie (oủ ce végétal croît spontanément) pour la teinture des étolles par les indigènes. Il est probable aussi que ses racines sont purgatives comme celles du M. Royoc L., espèce du continent américain. (E. H.) 
cymes axillaires, pédonculées; fleurs d'un blane tries pur. Baie d'abord rouge écarlate, ensuite d'un jaune doré. - Des personnes dignes de foi m'ont aflirmé que les fruits sont un poison pour les volailles. - Assez abondant dans les bois secs et humides: Deshaies dans les bois voisins de la mer, ou il forme souvent un vrai gazon, sur une grande étendue), bois des environs

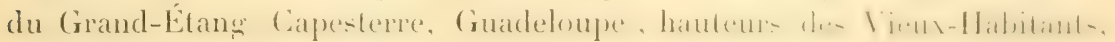
etc. Alt. 60-450 mèt. [No 2771 .

Martinique. Vulgo : Liane-terre, herbe à terre, graine dorée. - Bois de l'Ajoupa-Bouillon, hauteurs du Macouba, de Case-Pilote, etc. $Y^{\prime} 145.5$.

Ernodea Sw. (du grec " ernos », rameau, jeune branche, parce que la plante a des rameaux très nombreux.)

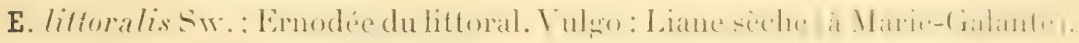
Sl., t. 189, f. 1, 2; Sw., Fl., t. 4, fig. int., analyt. - Arbrisseau plus ou moins couché, très glabre, haut de $9^{\mathrm{m}} 80-1^{\mathrm{m}} 20$, à tige très rameuse, à ligre el

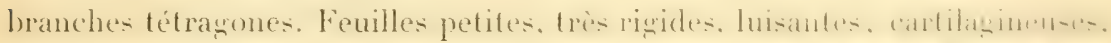

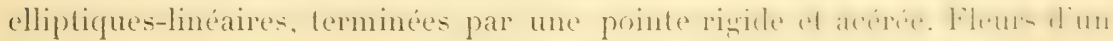
blanc pur, solitaires à l'aisselle des feuilles, tout le long des rameaux. Drupe jaune, subglobuleuse. - Uniquement dans les terres calcaires, trìs sèches de la Désirade, de Marie-Galante. [No 2772.] - Il n'existe pas à la Martinique.

Diodia L. (du grec " diodeuein », voyager à travers; " dia ", à travers, et " odos ", chemin, c'est-à-dire des plantes qui rampent à travers les chemins.)

D. sarmentosa Sw.; Diodie sarmenteuse. Vulgo : Liane-hallier. - Annuel,

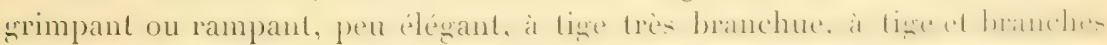

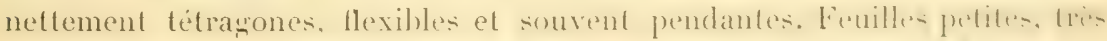

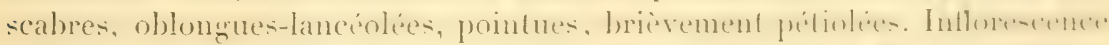

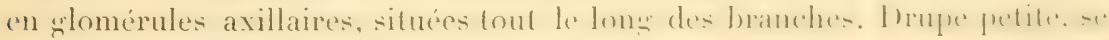
divisant,- à la maturité, en deux petites coques. - Çà et lì dans les hallier: des régions inférieure et basse : Capesterre, Trois-Rivières, Baillil, elc. Alt. 0-300 mèt. [No 2773.

Martingue. - Liane à cornette. - Hauteurs de Sainte-Luce (habilation

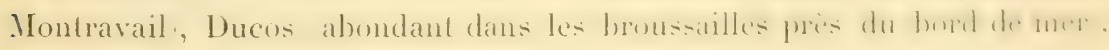
Trois-Ilets. [No 979 .

Spermacoce L. (du grec "sperma ", semence, et "akoke ", pointu, parce

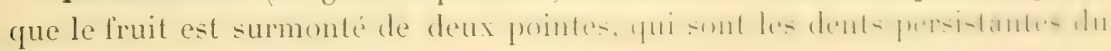
calice.)

S. tenuior L.; Spermacoce plus délicate que les autres. Vulgo: Iterbe à macornet. Lam., Ill., t. 62, f. 1; Sl., t. 91, I. 2. - Herbe annuelle, odorante, très grêle, peu feuillue, d'abord très droite, ensuite pen- 
chée ou plus ou moins infléchie, haute de $15-90 \mathrm{~cm}$., it tiwe anguleuse. pubescente ou unlabre. Feuilles petites, lancéolées, ou souvent lancéolées-linéaires. Inflorescence comme dans le précédent. Fruit très pelit, composé de deux cariopses. - Abondant dans les terres sablonneuses, cultivées ou incultes de la région inférieure de toute la Guadeloupe et dépendances. Alt. 0-f00 mèt. No 2539 .

Martinique. Vulgo : Herbe à cornette. - Abondant dans toute l'île. [No 982 .

S. portoricensis Balb.; Spermacoce de Porto-Rico. Vulgo : Herbe à macornet. - Annuel, très droit, rigide, branchu ou simple, haut de $30-70 \mathrm{~cm}$., à tige cylindrique, noirâtre, it branches a quatre angles obtus. Feuilles ovaleslancéolées, très scabres sur le bord; glomérules nombreuses. Fleursblanches, très petites. - Abondant dans les régions humides ou sèches supérieure et moyenne: Camp-Jacob, Gourbeyre, Vieux-Fort, Trois-Rivieres, Vieux-Habitants, etc. - Herbe de peu d'utilité ${ }^{\text {. }}$ - Alt. 400-800 mèt. [No 2540.]

Martinique. - Herbe à cornette. - Marin, Sainte-Luce, Diamant, CasePilote, Gros-Morne (très abondant). [No2146.

Borrera Miq. / dédié à W. Borrer, collaborateur de Turner pour la monographie des lichens d'Angleterre.)

B. laevis Irisb; Spermacoce à feuilles lisses. Vulgo : Herbe à macornet. Herbe fourragère très utile, annuelle, haute de $20-65$ cm., presque toujours couchée el radicante à la base, dressée à l'extrémité. Feuilles elliptiques-lancéolées, acuminées. Fleurs blanches, velues en dedans, ramassées en gtomérules verticillées, axillaires. Fruit petil, s'ourrant en deux petites coques. Abondant dans les terres humides et fertiles des basse et moyeme régions. Alt. 0-800 mèt. [No 3444 .]

Martinique. Vulgo : Herbe à cornette. - Abondant dans toute l'île. No 980 .]

B. spinosa Cham. et Schl.; Borrère épineux. Vulgo : I Ierbe à macornet.-Annuel, très droit, rigide, branchu ou simple, haut de $40-70 \mathrm{~cm}$., rarement plus haut, it tige cylindrique dans le bas, à quatre angles obtus dans le haut. Feuilles scabres, lancéolées-linéaires ou lancéolées-allongées, muriquées en dessous sur la nervure médiane. Inflorescence en lares glomérules axillaires; fleurs blanches. Fruit septicide. - Assez abondant dans les terres fertiles, sablonneuses, le long des routes de la basse région : environs de la Basse-

1. Les Spermacoce des Antilles ne reçoivent aucun emploi, celles du continent américain, par contre, et notamment S. longifolia Aublet, Poyan A.S. H., crerulescens Aublet, radicans Aublet, aspera Aublet, sexangularis Aublet, prostrata Aublet, ont des propriétés éméto-catarthiques très marquées qui les font employer (racine) comme romitives. Il y a lieu de supposer que ces propriétés sont aussi communes aux espèces des Antilles. 


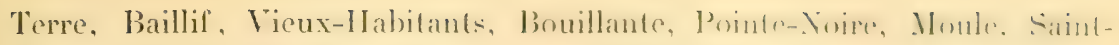
François, Désirade, Marie-Galante, etc. [No 25 11.]

Martinique. Vulgo: Herbe à cornetle. - Prêcheur, Case-Pilole, Carbel. elc. $\mathrm{X} 37 \mathrm{~s}$.

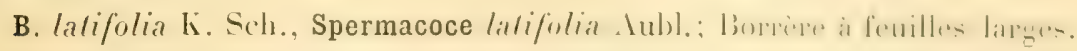
Vulgo : Herbe à macornet. - Annuel, rampant, rarement dressé aux extrémités, long de $20-90 \mathrm{~cm}$., à tige à quatre angles aigus el poilus. Feuilles garnies de poils couchés et roux, ovées, pointues. Inflorescence en grlomérules contractées, petites. - Mondant is Baie-Mahault cmirmo de lusine "La Retraite ", où il forme gazon, dans les champs de cannes du Lamentin. [ $\left.\mathrm{N}^{\circ} 3519.\right]$ - Il n'existe pas à la Martinique.

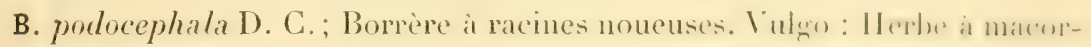
net. - Suffrutescent, haut de $30-60 \mathrm{~cm}$, a racine pivolante-nonense, horizntale ou verticale, longue, à tiges souvent nombreuses, toujours droites, el létragones vers le sommet. Feuilles linéaires, sessiles. Fileurs blanthes, en glomérules sessiles, axillaires. - Peu répandu. Lniquement dans les terres calcaires de la Désirade el de Marie-Galante. W"277. - Il n existe pas a la Martinique.

B. parviflora Mey.; Borrère à petites fleurs. Vulgo : Herbe à macornet. - Annuel, diffus, haut de 15-25 cm., droit, souvent cespiteux, à tiges tétragones. Feuilles oblongues-lancéolées ou elliptiques. Flems blanches, pretites. calice el dents roux jaunatre: ghlomérules verticillées. - Issez alumedant danles champs des régions inlérieure el basse : environ de la Basse-Terre, ( beyre (abondant), Camp-Jacob, Matouba, Vieux-Habitants. [No 2977.]

Mantrige. Vulgo: IJerbe à cornette. - Abondant dans touter les savanehumides de la basse région, où il constilue une bonne herbe lourragiere. [No 2147.]

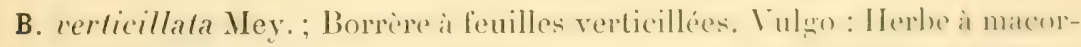
net. - Suffrutescent, haut de $30-\mathbf{4 0} \mathrm{cm}$., à racine forte et grosse, à tiges nombreuses, très branchues, tétragones, droites ou couchées, à la base. Fenilles linéaires ou lancénlées, le plus souvent réunies par quatre. Filenes en glomérules axillaires et terminales. - Je n’ai trouvé celle espèce qu'aux Saintes (Terre-de-Haut, chemin du morne du Chameau). Alt. 0-170 mèt. [No 2886.] - Elle ne se trouve pas à la Martinique.

Mitracarpu Zuce. (du grec "mitra", bonnel, mitre, el "karpos ", lruit. parce que la partie supérieure du lruil śenleve par déhisemes circulitire comme une petite calotte.)

M. hirtus DC., Spermacoce hirla Limn.; Mitracarpelaineux. Vulgo : Herbe à macornet. - Annuel, haut de $25-60 \mathrm{~cm}$., habituellement droit, souvent cespiteux. Feuilles petites, oblongues ou lancéolées. Fleurs 
blanches, en ylomérules globuleuses, axillaires ef terminales. Fruit ovale, à 4 lobes. Ressemble au Borrera parviflora Mey. - Dans les savanes herbeuses, dans les terres cultivées et incultes, le long des routes, etc. - Cette herbe forme un bon fourrage. - Environs de la Basse-Terre, Gourbere, Camp-Jacob, Lamentin abondant, dans toute la Grande-Terre. Désirade, Marie-Galante, etc. [No 2776.$]$

Mantinique. Vulgo: Herbe à cornette.-Régions basse et moyenne de toute like. [No

Noта. - Toutes les herbes connues sous le nom vulgaire de " herbes ì macornet " et "herbes à cornette » répandent, après dessiccation, une bonne et forte odeur de coumarine (?), et toutes sont douées de vertus sudorifiques que les habitants mettent souvent à profit. Elles mériteraient une étude attentive.

Rubia Tourn. (du latin "ruber ", rouge, allusion aux propriétés tinctoriales de la plante.)

R. guadalupensis Spreng., Galium hypucarpium Endl.: Garance de la Guadeloupe. - Petite liane, flasque, délicate, haute de 1-2 mèt., à tige et à branches tétragones. Feuilles plus ou moins glabres, verticillées par 4, ovales-oblongutes, mucronées, à une nervure. Inflorescence axillaire: lleurs solitaires, jaunes. Fruit inconnu. - Très rare : trouvé une fois près du sommet de la Grande-Découverte. [No 2778.] - Il n’est pas à la Martinique.

QUATRE-VINGT-DIX-NEUVì̀E FAMLLE. - SYNAXTIIÉRELS.

TRIBU I. - CORYMBIFËRES.

Sparganophorus Taill. du gree "sparganon ", bande, et "pherein ", porter, paree que les semences portent au sommet un petit appendice entouré d'une bandelette.)

S. Vaillantii (ir.. Ethulia sparganophora L. : Sparganophore de Vaillant (célèbre botaniste français). Vulgo : Oreille-mouton. Br. Jam., t. 34, f. 1, analyt. - IIerbe annuelle ou bisannuelle, habituellement droite, haute de 15-70 $\mathrm{cm}$., à racine forte, pivotante, blanche ou rouge, à tige grosse, le plus souvent très branchue, médulleuse. Feuilles vert pâle, lancéolées ou elliptiques. serreties on irrexulièrement dentelies. Fleurs petites, blanches on rosées, en capitules sessiles et axillaires. - Assez abondant dans les fau-

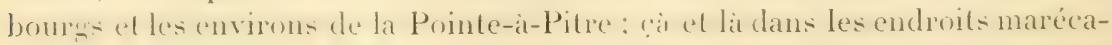
genx ou aqualiques du .loule, du Norne-it-l Ean; très rare à la Guadeloupe proprement dite. $\left[\mathrm{N}^{\circ} 2811\right.$. $]$ - Je ne l'ai pas vu à la Martinique. 
Vernonia Schreb. (dédié an botaniste français Guillaume Vemon, cílèbre par ses voyages en Amérique du Sud, entrepris dans un intérèt bolanique.

V. cinerea Less.; V'ernonie cendrée. Vulgo : Boulon violet. - IIerbe

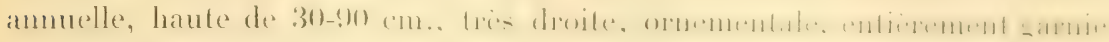
d'une pubescence fine et grise. Feuilles ovales, subentieres nu prossierement dentées. Fleurs violet pâle ou blanches, en cymes dichotomes, lâches, terminales, longuement pédonculées; capilules petits, cylindriques, - Mbondant dans les endroits cultivés ou incultes de la basse réuion : cnvirons de la Basse-Terre, Baillif, Vieux-IIabitants, Deshaies. Alt. J-200 mèt, ГXos 2.181. 2517.] - Il n'est pas à la Martinique.

V. arborescens Sw., V. icosantha D. C.; Vernonie arborescente. Vulgo : 'Tabac à jacot petil, tabac ì jacot bâtard. (Conyza L.) Plum., édit. Burm., 1. 130. - Arbrisseau élégant, ornemental, haut de 2-3 mèt., souvent buissonneux, à écorce grise, à branches fastigiées, à liges nues dans le bas. Feuilles grises, pubescentes, ovales-elliptiques. Capitules généralement sessiles, disposés en cymes scarpioïdes, feuillues ou non; involucre long de $6 \mathrm{~mm}$. Fl. de janvier en mai. - Abondant dans les endroits marnenx, secs et pierreux de la basse région: Vieux-Fort, Pointe-Noire, Deshaies, YY 2812.

Martivique. Vulgo : Casser-coutelas. - Case-Pilote (très abondant),

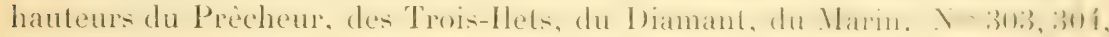
$305,984$.

V. punctata Sw.; Vernonie à feuilles pointillées. Vulgo: Tabac it jacol bâtard. - Arbrisseau ornemental, droit, buissonneux, haut de 2-33 mèt., frris dans toutes ses parties, à tiges eylindriques, à rameaux striés. Feuilles coriaces, parsemées, sur les deux faces, de poils couchés, courts el gris, garnies en dessous de pellictiles blanches. Capitules longs de $7-11 \mathrm{~mm}$., réunis par 2-4, en cymes partielles, nombreuses, courtes, scarpiö̈des, formant collectivement une large panicule fastigiée; lleurons violets, plus rarement

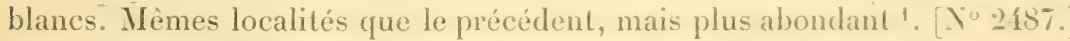

Martinique. Vulgo : Grande violette. - Abondant. ['*302.

Centratherum Cass. (du grec "kentron ", pointe, et "ather" ", barbe d'épi, allusion aux pointes rigides qui terminent les écailles de l'involucre.

1. Les Vernonia arborescens et punctala sont répulés digestif's et stomachiques. par. leurs feuilles prises en infusion; mais queleques espéces de ce grente jouissent de propriétés plus actives, tels : V. nigriliana Ol. et IIiern. du Soudin, dont la vernonine principe actif) peut être rapprochéc, d'aprés mes (ravaux (en commun avee M. Schlaýrdenhauflen), de la digitaline; le V. anthelmentiea $W$. de l'Inde, dont les raines sont anthelmintiques; le V. cinerea Less, est un fébrifuge des Inclous; le V. squarrosal Laur., de Cochinchine, est utilisé comme emménagogue; enlin V. prealla $\mathrm{WV}$. el allissima Null. sont considérés comme alexipharmaques. Il y aurat done lieu de mieux étudier lé espèces des Antilles. (E. H.) 
C. muticum Less.; Centrathère à capitules avec réceptacle dépourvu de pailletles. Vulgo : Grande violette, grande marguerite. - Sutfrutescent, ligneux a la base. toulfu, plus ou moins couché-diffus, haut de $25-60 \mathrm{~cm}$. Feuilles spatulées-oblongues. glandulenses, gaufrées, irrécrulièrement serretées. Capituleslarges, ventrus a la base, plus larges que longs: fleurons pourpre foncé. Aliène léxèrement poilu, glanduleux, tronqué au sommet et muni d'une petite touffe de poils courts. - Originaire de la Trinidad, naturalisé et cultivé comme plante d'ornement. - Pointe-à-Pitre, Gourbeyre, BasseTerre, Camp-Jacob, etc. [No 2526.

Martinique. Vulgo : Grande marguérite. - Abondant dans les jardins. No 1734 .

Elephantopus L. (du gree " elephas ", éléphant. el " pous ", pied. allusion ¿ la forme des glomérules, rappelant un pied d'éléphant.)

E. scaber L.; Eléphantope à feuilles rudes. Vulgo : Langue à vache. Herbe vivace par la base, haute de $0 \mathrm{~m} 90-1 \mathrm{~m} 40$, rarement plus élevée, à racine zrosse, pirotante, à lige droite, rigide. Feuilles spatulés, subentières ou crénelées, poilues en dessous : les inférieures, rosulées et appliquées contre la terre, dans les jeunes pieds: les supérieures, éparses et plus petites; capitules longs de 7-9 mm., cylindriques, glomérulés, enveloppés par trois srandes bractées. Inflorescence en panicules très làches, longuement pédonculées; corolle blanche ou plus souvent rosée. - Fl. toute l'année, mais surtout pendant la saison des pluies. - Plante de peu d'utilité : cependant, jeune et mélangée avec d'autres herbes, elle peut servir de fourrage. - Très abondant dans le sol sec ou humide des basse el moyenne régions de toute la Guadeloupe et de la Grande-Terre. [No 2515.

Martinique. Vulgo: Grand'oreille-mouton. - Dans toute l'île. [No 14 f́.

E. angustifolius I.; Eléphantope ì feuilles étroites. Vulgo: Langue it bœuf femelle. Sl., t. 148, f. 4. - Vivace par sa base, très droit, à tige finement striée, médulleuse, laineuse, haute de 70-90 cm., peu branchue et peu feuillue. Feuilles en rosette, lancéolées-oblongues, finement serretées, semiamplexicaules, engainantes. Capitules blanes, sessiles, glomérulés, constituant un épi interrompu et allongé. - Peu répandu : çi et là dans les savanes herbeuses des hauteurs des Vieux-Habitants. [ $\mathrm{N}^{\circ} 3535$. ]

Martinique. Vulgo: Oreille-mouton long. - Assez rare : dans le haut des lerres de l'habitation Fond-Lavette Case-Pilote, el au Marignt, près de Fort-de-France. [No 308.]

E. spicalus Juss., Distreptus nudicaulis Less. Sl., t. 1.50, f. 3, 4; Eléph. ¿̀ épis. Vulgo : IIerbe à vache mâle, herbe à vache noire. Distreptus Cass.j - Vivace par la base, haut de $0^{\mathrm{m}} 40-1^{\mathrm{m}} 10$, droit, rigide, glabre, à tige striée dans le bas, velue dans le haut. Glomérules entourés de 2-3 brac- 
tées, disposées en épis, droits, composés, terminaux; corolle blanche. -

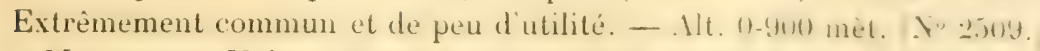

Martinique. Vulgo: Petile oreille-mouton, oreille-lapin. Trie abundant dans tous les coins de l'île jusqu'à une altitude de tim) mêt. To 14 fr.

Rolandra Rottb. (dédié a liolandre, cleve de Limne; a voyagé a surinam, dans un intérêt botanique.)

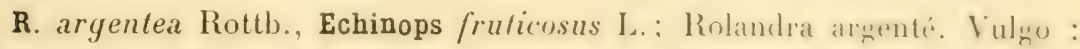
Herbe-pilori. Sl., t. 7, f. 3; Sw., Fl., t. 17, analyt. - Vivace par sa base, souvent stolonifère, haut de $0^{m} 60-1^{m} 20$, droit, rigride, at tige noire. Fenilles tomenteuses, blanc argenté en dessous, elliptiques-oblongutes nu lancénléroblongues, pointues. Capitules unillores, ramassés en whlomérules ghlobuleuser. axillaires; écailles de l'involucre luisantes, membraneuses, carénés: Irs extérieures, terminées par une pointe rigicle at acérée. - Fl. presque toute l'année. - Herbe de peu d'utilité. - Assez abondant dans les endroits incultes des régions moyenne et infra-moyeme: Camp-Jacob. Trob-Rivièrés. Vieux-Habitants. Alt. 250-700 mèt. [No 2500.]

Martixique. Vulgo: Bouton piquant, herbe argenté. herbe blanche, dos blanc, - Fonds-Saint-Denis, Gros-Morne, Trois-Ilets, ete. No 1 f33.

Ageratum L. (du gree "agreratos"), qui ne vieillit pas, parce que les tleurs conservent longtemps leur fraîcheur.)

A. conyzoides L.; Ageratum à feuilles de Conyza. Tulgo : Petit pain-doux. herbe à pisser, herbe aux sorciers, herbe à la vierge. - Ammel, droit, très branchu, haut de 4 (1)-90 cm. Feuilles vert pàle, ovales. wrosicrement dentées. trinerviées, parsemées de poils couchés. Cilpitules multilloress. en corymbes terminaux, pédonculés: corolle lilas, plus rarement blanche. Herbe fourragère, quand alle est jeune; les lapins surtout en sont friands. - Dans la médecine domestique, elle jouit dime rande réputation comme plante diurétique; on l'emploie, en outre, en tisane contre les rlumes, la toux et les refroidissements '. - Très répandu dans toute la Guadesoupe, la Grande-Terre et les dépendances. Alt. 0-800 mèt. [No 2520.]

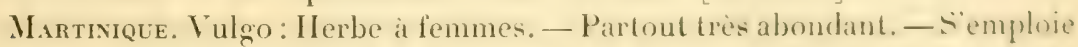
dans les campagnes pour les femmes en couches: les feuilles el lés jeunes tiges se mettent dans les bains tiedes pour favoriser les éruptions de la freau: elle est en outre préconisée contre les coliques. [N॰931.]

Hebeclinium DC. du gree "hébé ", puberti, et "cline n, lil, allusinu a la pubescence dont est couvert le réceptacle.'

H. macrophyllum D C., Eupatorium pepulifilium Matl. Ageratum conen!

1. A la Guyane, l'infusion de cette plante est donuce dans les cas d'atonie du tube digestif. (E. H.)

Düss. - Pluntes Guarleloupe pt Ifurtinique. 
lieum Sieb. : Hébéclinie à largres feuhles. Vulgo: Grande guimauve. Pl., éd. Burm., t. 129. (Eupatorium L.) - Herbe aromatique, haute de $0^{\text {"n }} 80-1^{\text {"n }} 80$, rarement plus haute, simple ou branchue, à base sous-ligneuse, couverte, dans toutes ses parties, d'une pubescence fine, grise et courte, à tige grosse, cylindrique-striée, remplie de moelle blanche. Feuilles opposées, larges, cordées, deltoïdes-arrondies, pointues, irrézulièrement crénelées. Capitules nombreux, en corymbes arrondis, contractés, terminaux et axillaires; corolle violacée ou blanche. - Répandu dans toute la Guadeloupe et la GrandeTerre, sans ètre abondant nulle part. Alt. J-600 mèt. [No 2516.] - On le rencontre quelquefois à l'état de culture comme plante médicinale; elle sert surtout aux femmes en couches; avec les feuilles et les rameaux, on prépare, en outre, des tisanes très rafraîchissantes.

Martinique. Vulgo : Herbe à chat. - Dans toute lîle, avec plus ou moins d'abondance. [No 309 .

Eupatorium DC. (dédié à Mithridate, roi du Pont, surnommé Eupator, qui, le premier, employa des plantes contre les maladies du foie. - Pline, XXV, 29.)

E. punctatum L.; Eupatoire à feuilles pointillées. I'ulgo : Amourette. Arbrisseau ornemental, aromatique, haut de $1^{\mathrm{m}} 50$ à $2^{\mathrm{m}} 50$, entièrement glabre, a tige cylindrique striée, a branches sourent inclinées, à rameaux à quatre angles émoussés. Feuilles ovales-lancéolées, pétiolées, fortement serretées, glanduleuses en dessous. Capitules en corymbes composés, multiflores, pédicellés. - Abondant sur les lisières et dans les clairières des grands bois des Bains-Jaunes, du Matouba, des Vieux-Habitants, des Trois-Rivières, de la Ravine-Chaude, etc. Alt. 280-900 mèt. [No 2528.]

Mantixique. Vulgo : Amourette. - Abondant : hauteurs du Prècheur. Fonds-Saint-Denis, fontaine Didier, Trois-llets. [No 299.]

E. odoratum L., E. Brachiatum Wickst; Eupatoire odorant. Vulgo : Guérit-tout, guérit-trop-vite, langue a chat, fleurit Noël. - Annuelle ou bisannuelle par la base, aromatique, haute de $0^{\text {ш }} 30-1$ m 30 , entièrement garnie d'une pubescence fine, grise et plus prononcée à la face inf'érieure des feuilles. Branches nombreuses, insérées à angle droit, décussées. Feuilles pétiolées, ovées ou ovées-lancéolées, acuminées. Capitules à 15-25 tleurs, en corymbes trichotomes, serrés. - Fl. en décembre, janvier, février. Répandu dans toute la Guadeloupe; plus rare i la Grande-Terre. Alt. 0-500 mèt. [No 2518.] - Cette herbe est très appréciée dans la médecine domestique, et s'emploie fréquemment en décoction ou en tisane contre les coliques; les feuilles et les jeunes tiges, écrasées, sont émollientes et sappliquent en cataplasme sur le ventre contre les douleurs intestinales ${ }^{1}$.

1. Cette plante donne des infusions aromatiques et stimulantes, propriétés qu'elle doit aux essences contenues dans les glandes dont ses feuilles sont couvertes. (E. H.) 
Martnique. Vulgo: Fleurit Noël. - Abondant dans toute l’île. IY" 1711

E. integrifolium W. Eupatoire is feuilles entier. l ulgo: Violetle bordde-mer. - Arbrisseau très ornemental, haut de 1-3 mèt., très rameux, ì rameaux étalés, très fragiles, souvent tortueux. Fenilles vrées-deltuides. ondulées sur les bords. Inflorescence en corymbes arrondis, terminatux: corolle violet foncé. - Fl. presque toute l'année. - Findroits sablonneus. secs, rocailleux du bord de mer ou un peu à l'intérieur: l'ieux-Fort, linker. Désirade, les Saintes (Terre-de-Haut). No g193. - Nir se trouve pas at la Martinique.

E. Vahlianum Lirb.; Eupatoire de Vahl célibre bolaniste danois. Vuluno: Grande violette. - Arbrisseau très beau, haut de 1-3 mit. rameux, droil ou tortueux, duveté, à tige cylindrique, noire, nue dans le bas. médullenter. Feuilles glabres, rigides, fortement réticulées, ovales. Capitulesen corrmbes trichotomes, ombelliformes, terminaux, pédonculés; corolle lilas foncé. Fl. de janvier à mai. - Cette belle plante, avec son feuillage sombre et ses nombreuses fleurs, tranche fortement sur les répétaux d'un vert páte ou wris. avec lesquels elle vit en société; elle ne se trouve que sur les hautes montagnes, dans les endroits exposés aux grands vents: Savane it Mulets. GrandeDécouverte, Savane aux Ananas, montarne de la Madeleine. I/t. S100-1/(11) mèt. $\left[\mathrm{N}^{\circ} 2483.\right]$

Martiviele. Vulgo : Grande violette. - Pitons-du-Carbel, MontagnePelée. $\left[\mathrm{N}^{\circ} 295.\right]$

E. ivxfolium L.; Eupatoire à feuilles d'Irette. Vulgo: Vinhelte-savane. Herbacé, très droit, ornemental, haut de 0$)^{\mathrm{m}} 70-1^{\mathrm{m}} 20$, simple on branchu, at rameaux trichotomes, fastigiés. Feuilles opposés, lanciolés-linéaires. pmintues aux deux bouts, serretées au-dessus du milieu. Inlforesences en (onrymles: lâches et larges, terminales; capitules à 10-20) Heurous: corolle violette mu violacée. - Dans les savanes et champs de canne du Lamentin, de la laaieNahault; plus rare dans les environs de la basse-Terese savane de l'hnopice de Tillac). - Fl. en août, septembre, octobre. No Nol3. - Il n' ét pat: à la Martinique.

E. canescens Vahl, E. sinuatum Lam.; Eupatoire blanchitte. Vul_u: Boinsavane. Plum., éd. Burm., t. 128, f. 1; Lam., Ill., t. 692, f. 5. - Arbrisseau buissonneux, ornemental, à tiges en haguetles. entierement warni diun duvet blanchâtre, haut de 1-2 mèt. Feuilles overs-arrondies. sinuies-erinklées. Inflorescence en corymbes simples, ombelliformes, terminatux, i brameles racémiformes; capitules à 10 fleurons. - Rare et peu répaudu : cite calcaire de la Désirade. [No 3241.] - N'existe pas à la Martinique.

E. iresinoides H. B. Kth., E. Sieberianum I)C.; Eupaloire Pes-emblant a une

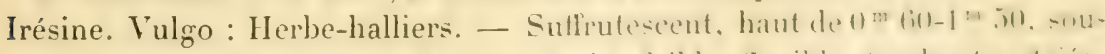
vent sarmenteux et ligneux a la base, at tige faible, llexible. Lmmbante, strich 
duvetée dans le haut. Fenilles diun vert très clair, finement réticulées, ovales-deltoüdes. cunéiformes à la base, acuminées an sommet. Inflorescence en corvmbes umbelliformes, nettement trichotomes, portés sur des pédoncules velus; capitules petits, contenant 3-5 fleurs blanc pâle. - Çà et là dans les haies et broussailles des hauteurs pierreuses de Case-Pilote. $\mathbf{X}^{0} 577$. - Je ne l'ai pas trouvé à la Guadeloupe.

E. cellidifolium Lam. : Eupatoire à feuilles de micocoulier. Vulgo : Amourette blanc, tabac à diable. - Arbrisseau ornemental, haut de 3-4 mèt., rarement tout petit arbre, glabre, strié, habituellement très branchu, à branches inclinées ou tombantes. Feuilles membraneuses, ovées-lancéolées, acuminces au sommet et se terminant en une longue pointe souvent recourbée, quintuplinerviées, glanduleuses en dessous. Inflorescence en corymbes allongés, trichotomes; capitules ì 10-1.2 fleurons; corolle blanc pâte. - Fl. de novembre à février. - Assez abondant dans les mornes inférieurs boisés, secs et pierreux, ou humides : Houëlmont, Vieux-Fort, hauteurs des VieuxHabitants, Grands-Fonds du Morne-à-l'Eau, du Gozier, de Sainte-Anne. [N०2503.]

Martiniere. Vulgo : Amourette. - Prêcheur, Trou-Vaillant, Trois-Ilets, Marin (morne Gommier), Vauclin. [No 300.]

E. paniculatum Schrad., E. guadalupense Spreng., E. urticifolium Hb. Bks. : Eupatoire à fleurs en panicules. Vulgo: Tabac à jacot petit. - Herbe annuelle, flasque, grêle, aromatique, haute de $60-95 \mathrm{~cm}$., à tige simple, le plus souvent droite, à tige et feuilles couleur de paille. Fenilles deltoïdes, serretées au-dessus de la base, trinervices. Inflorescence en corymbes larges, lâches, paniculés: capitules à 12-20 fleurs blanc pâle. - Cià et là dans les haies; plus abondant dans les savanes et endroits en friches du Camp-Jacob, des hauteurs de Baillif, des Vieux-Habitants. [No 2494.]

Martivique. Vulgo : Tabac à diable bâtard. - Trou-Vaillant, MorneRouge, Parnasse, Grande-Rivière, etc. Alt. 0-600 mèt. [No 1740.]

L'Eupatorium Ayapana Veut. inom de la plante chez les indigènes voisins du fleuve des Amazones;, E. triplinere Vahl; Vulgo: Ayapana (Ava-pana), herbe à thé, herbe contre fièvre. (Desc., vol. III, t. 203, p. 240.) Herbe couchẹe, à base radicante, à tige branchue, à branches et tige relevées aux extrémités, à feuilles lancéolées, à fleurs purpurines. - Est souvent cultivé dans les jardins comme plante médicinale; les racines et surtout les feuilles ont une saveur aromatique et légèrement astringente. Elle est originaire du bassin des Amazones, dont les habitants vantaient ses vertus comme capables de guérir toutes les maladies qui aflligent le corps humain. Sans avoir tant de propriétés, elle reste cependant une plante des plus précieuses. Descourtilz l'employait arec succès, comme stimulante, contre les affections scorbutiques: comme sudo- 
rifique, contre les fievres occasionuees par len hem-ures. Dans les hipitaus de Cayenne, il est d'usage de servir aux malides, fous les soirs, une tasse de the fait avec l'ayapane. - A la Guadeloupe, m prepare avec les feuilles et les jemes tiges une lisane contre les fievres linach of rebelles, ef les personnes anémiées, qui font usare de celte herbe, losuent heaucrup ses vertus toniques'. - L'herbe se propage facilement par brulures; les semences avortent presque trujours, ec qui l'empêche de se naturaliser. $x^{\circ} 2506$.

Martixique. Vulno : Ayapana, herbe vulnéraire. - Emalement cultivé dans beaucoup dendroits. - (O) se sert des leuilles en infusion dans les digestions difficiles, les dérangements de ventre at les fluxions de poitriue: on les écrase et on les fait macérer dans le vin. ou le tafia nu le miel, pour panser les blessures, les contusions ef les luxations, soil dhez l'homme, snit chez les animaux, les mulets ef les chevaux surlout; il entre aussi daus les remèdes contre la morsure du trigonocéphale. [No 1737.

Critonia P. Br. (dédié à Crilon, médecin grec de l'antiquité.)

C. macropoda D. C.; Critonia à grosse racine. Vulgo : Tabac-diable bâtard. - Arbrisseau ou grand arbuste, ornemental, haul de 3-4́ mit., a tige vigoureuse, à branches et jeune tige médulleuses, stríes-cylindriques. glabres. Feuilles larges, membraneuses, ovales-lancéolées, inésalement et grossièrement serretées. Inflorescence en corymbes composés, il branches portant des capitules aglomérés. brièvement pédicellés. - Rare : hauteurs du Prêcheur, vallée de la rivière Claire (Champllore. Yus 19., 298., -... Je ne l'ai pas trouvé à la Guadeloupe.

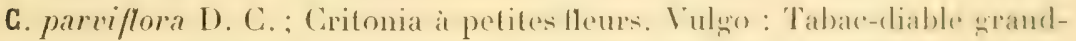
bois. - Arbrisseau haut de 2-3 ${ }^{\text {m }} 50$, très droit, à branches inférieures hori-

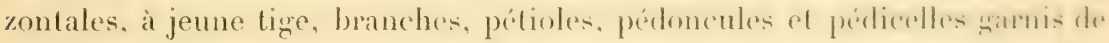

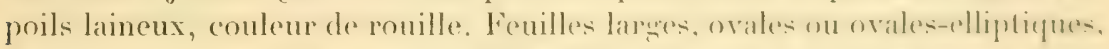

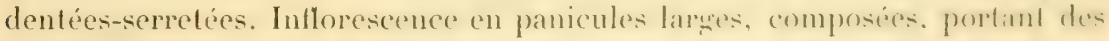
branches terminées par 3-7 capilules: llenr's blumches. - Fl. de matrs it mai. -

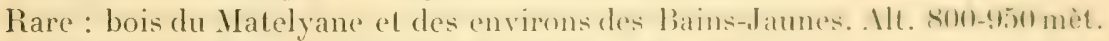
[No 3615.$]$ - Je ne l'ai pas trouvé à la Martinique.

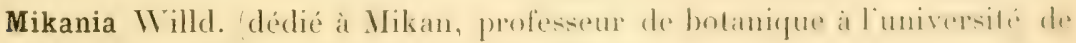
Prague; il a exploré le Brésil, mort en 1811.

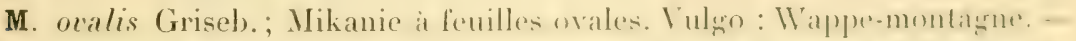

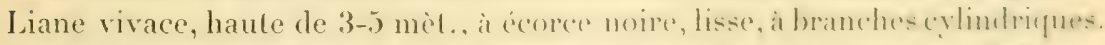
Feuilles ovales, brievement pointues, antieres, diun wert somber. Inthrescence en corymbes trichotomes, racimilomes corolle blane piate. - l'en

1. Toutes ces propriétés ont été singulièrement exagérées; elle n'est en réalité que digestive et sudorifique, propriétés qu'elle doit it l'existence d'une huile essentielle abondante, d'un principe amer et d'une matière grise, soluble dans l'éther (W'uatlart). (E. II. 
abondant: cà et lit dans les bois supérieurs et sur les hautes montagnes: Ravine-a-Déjemer (au pied de la Grande-Découverte), Savane aux Ananas, montanne de la Madeleine Capesterre, Guadeloupe. To 2 198.: -- Il n'est pas à la Martinique.

M. latifolia Sm., M. Badieri D. C. : Mikanie à larges leuilles. Vúngo : Gros-fort, chez les bûcherons du Matouba), liane gaufre, liane à eau. - Puissante liane, à tige grosse comme le bras, glabre, nue dans le bas, sur une grande étendue, pourve d’anneaux dans le haul, à branches très enchevètrées, finement striées-subanguleuses, tombantes. Feuilles épaisses, orées, luisantes, entières ou subentières. Capitules réunis par trois en grlomérules constituant ensemble un corymbe allongé fleurs blanches ou blanc verdatre. à odeur aromatique. - Fl. de septembre à mars. - Abondant dans les grands bois supérieurs des Bains-Jaunes, du Matouba, du bassin Bleu et du Gommier. [No 2501.

Martinique. Vulgo : Liane tordue. - Abondant dans les bois de la Montagne-Pelée, des hauteurs de la Basse-Pointe, des Fonds-Saint-Denis, etc. [No 312 .

M. Imrayana Griseb.; Mikanie d'Imray médecin de la Dominique, qui s'est occupé de la flore de cette île. Vulgo: Liane tordue, liane à eau, lianegaufre. - Se confond à premiere vue avec le précédent, auquel il ressemble par la vigueur de la tigre, la couleur des feuilles, le parfum et la couleur des fleurs, l'enchevêtrement des branches; il en diffère par ses feuilles ovales, d'un vert sombre en dessus, par les branches deltoüdes et nombreuses de la panicule, par ses capitules plus longrs, réunis par 5-3, par les lobes du calice moins profonds, et par les écailles ciliées, oblongues-linéaires de l'involucre. - Même habitat, mais moins abondant. [No 2815.]

Martinere. Vulgo: Liane tordue. - Forêts du Macouba, de la Basse-Pointe. des environs du Camp de l'Alma, elc. [No 313.$]$

Nor.. - Celte espèce et la précédente ont des tiges spongieuses, remplies d'une eau limpide et potable; les chasseurs et les bûcherons en boivent souvent le contenu; les vieilles tiges sont en outre pourvues de longues racines adventives, cylindriques, pendantes.

M. cordifolia IVilld, Mikanie à feuilles en coeur. Vulgo : Wappe.-Forte liane, pouvant monter sur de très hauts arbres, à tige grise, cylindriquenoueuse, à branches extrêmement enchevêtrées, tombantes, à jeunes branches, tiges et feuilles garnies d'une pubescence grise ce qui donne à la liane un aspect particulier et la distingue de loin de toute autre plante. Feuilles molles. plus ou moins gaufrées, cordiformes-deltö̈des, à sinus basilaire largement ouvert. Fleurs odorantes, surtout le soir, en corymbes composés, nettement trichotomes, terminant la tige principale, avec $8-10$ corymbes axillaires formant ensemble une large panicule. - Abondant aux environs du Camp- 
Jacob, hauteurs de Baillif el de Gourbeyre insirms du lialcanard. TroisRivières, bois de la Capesterre. [No 2814.]

Martwete. Vulgo: Liane-serpent, Guaco. Mbondant dans la rierion moyenne : Champllore, Camp-Balata, Gros-Mrome.4c. Mlt. 306--7nt mit. [No 310.$]$

M. congesta D. C., M. scandens Willd.; Mikanie à fleurs ramassées. Vulgo : Wappe. - Assez qrande liane, haute de . -7 mil. a tiges fries allon„ées, pendantes, à rameaux glabres, striés-anguleux, firmis de qurlequpoils épars sur les stries. Feuilles membraneuses, diu verl clair, corrlexs. it lobes basilaires, tantot divergents, tantit parallides, of alors aver un siunétroit et profond, pédatinerviées, grossierement el insintement dentionsinuées ou dentées : les jeunes entières. Corymbes ramassie, plus petit- qu. dans le précédent, en ombelles composes et tres longuemont pidunculises. à pédoncules nettement tétragones. - Abondant dans les endroits humides des basse et infra-moyenne régions : environs de la Basse-lerre, Gourbeyre, Capesterre (iuadeloupe, Trois-Rivieres tres commun, ete. X 2!ntu.]

Mantixique. Tulgo : Liant-serpent. - Abondant: envirnis desaint-l'ierre. Prêcheur, Carbet (le long de la rivière), Parnasse, etc. Alt. 5-100 mèt. $\left[\mathrm{N}^{\circ} 311.\right]$

Nota. - Les deux dernières espèces posséderaient à un haut degré des propriété alexitères et sudorifiques; les panseurs en appliquent les feuilles et les jeunes rameaux, pilés, ainsi que le sue de la racine ef de la lige sur les morsures du trigonocéphale pour en neutraliser le venin. Ces propriélés rapprochent ces plantes du Mikania Guaco II. el Bp. propre au contintent americain.

Erigeron L. du gree " eri ", printemps, de bonne heure, el "gernu", vieillard, parce que les akènes avec leurs soies zrises disparaissent de suite apris la chute des fleurs et que ces plantes ressembloul dejat dans leur jeunuse a des plantes fanées.)

E. jamaicensis L., E. cuneifolius D. C.; Vergerette de la Jamaïque. Vulgo: Petite marguerite. Sw., ()bsere., t. 8, 1. 2. - Herbe vivace, ormementale, a racine pivotante, blanche, émettant an colled j-lo liges rampantes.

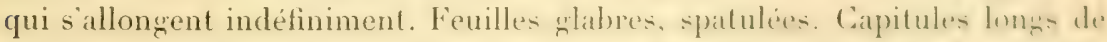
f-5 mm., solitaires, terminaux, portes sur des pédoncules tries lungs. tiliformes et flexibles; ligules blanches placess sur deux rangs. - l'eu repandu : Basse-Pointe près du bord de mere et dans le tazon des amirmus dés mazasins, du câté de la grotte de N.-D. de Lourdes). [No 669.] - Je ne l'ai pas trouvé à la Cruadeloupe al létat sauvage, maison le cultive friguemment diuns les jardins. [ $\mathrm{N}^{\circ} 2951$.]

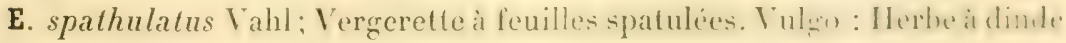
- Annuel, très droit, haut de $80-95 \mathrm{~cm}$., rarement plus haut, entièrement 
poilu, branchu dans le haut, banches fastigiées : les inférieures longues. Feuilles alternes, rugruleuses, spalulées-lancéolées. Capitules nombreux, constituant un corvmbe lâche et laroxe. - Abondant le long̣ des routes et dans les savanes sablommeuses en friches: (rourbeve. environs de la Basse-Terre, Trois-Rivières, Lamentin, etc. [No 2507.]

Mantixece. Vulgo : Ilerbe-lapin. - Environs de Saint-Pierre, Parnasie, Carbet, etc. [No311.]

E. bonariensis I. ; Vergerelle de Buenos-Ayres. Vulgo : Herbe-con d'Inde. Dill., Hort. Elth., vol. II, t. 331. - Annuel, droit, haut de $70-95 \mathrm{~cm}$, rarement plus haut, à tige strièe, légèrement poilue, nue dans le bas, tres branchue dans le haut. Feuilles supérieures lancéolées, les inférieures plus larges, presque toujours pinnatifides-sinuées. Capitules longs de $5 \mathrm{~mm}$., disposés en une large panicule racémiforme. - Assez abondant aux environs du CampJacob (chemin de la cascade de Vauchelet, le long du chemin et dans les clairières des Bains-Jaunes. Matouba, etc. 1lt. $100-900$ mèt. No 2707.

Martinece. Vulgo: Herbe-coy d'Inde. - Morne-Rouge, Fonds-SaintDenis, fontaine Didier, Ajoupa-Bouillon, etc. [No314.]

E. canadensis L.; Vergerette du Canada. Vulgo : Herbe-coq d'Inde. Annuel, tries droit, haut de $30-90 \mathrm{~cm}$, à tige striée, très feuillue et sans branches. Feuilles très rapprochées, lancéolées-linéaires : les inférieures fanées avant l'éclosion des fleurs. Capitules nombreux, longs de $\mathbf{t}-5 \mathrm{~mm}$. constituant une panicule racémiforme allongée. - Abondant dans toute la région inférieure de la Guadeloupe el dépendances; répandu dans presque toutes les parties du monde. [No2565.)

Martinique. Vulgo: Herbe-coq d'Inde. - Abondant. [No 1142.$]$

LiAster chinensis 1.., vulgo : OEil du Christ, à fleurs violet poupre el i feuilles glauques, originaire de Chine, est cultivé dans beaucoup de parterres. [No 3389 .

Martineue. Vulgo: OEil du Christ. [Nº 322.]

Baccharis L. (dédié à Bacchus, dieu du vin, à cause de l'odeur agréable de la plante.)

B. speciosa D. C. ; Baccharis brillant. Vulgo : Bois Guillaume. - Arbrisseau très ornemental, haut de 1-2 mèt., a branches fastigriées, nombreuses, rigides, ì lige grosse, striée. Feuilles elliptiques ou elliptiques-oblongues, mucronées, à trois nervures. Capitules en corvmbes contractés, arrondis; fleurs diö̈ques. - Fl. d’aoùt à janvier. - Peu abondant. Région supérieure des hautes montagnes : Savane aux Ananas, Savane à Mulets, Grande-Découverte. [Nos 2512, 2952.]

Martixige. Vulgo: Bois Guillaume. - Pilons-de-l'Alma, route de l'Alma. route de l'Alma aux Deux-Choux. [N 935.]

B. nervosa 1). C.: Baccharis à feuilles fortement nervés. Vulgro : Liane ou 
bois Guillaume. - Sarmenteux, haut de 3-5 mèt., tris branchu, a branches allongées, plus ou moins droites, d'abord dressées, ensuite tombantes.

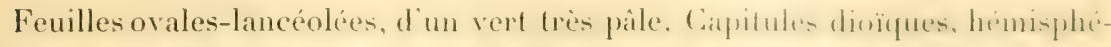

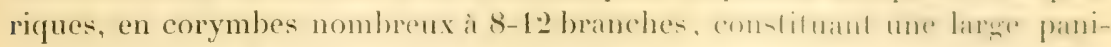
cule terminale; fleurs blanc pâle. - De l'espèce gruadeloupéenne, je n'ai pu

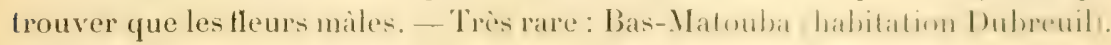
$\left[\mathrm{N}^{\circ} 3598.\right]$

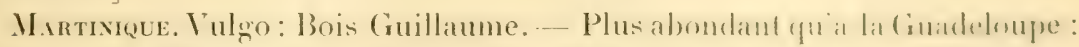

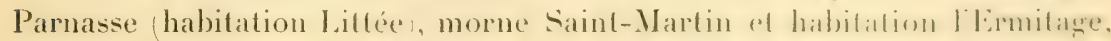
près de Saint-Pierre, etc. No 936.] - Je nài trouvé que les lleurs lemelles.

B. dioica Vahl; Baccharis à lleurs diö̈ques. Vulgo : Bois Guillaume. Liane des plus belles et des plus florileres, haute de 2-1 mit. a lige movitre,

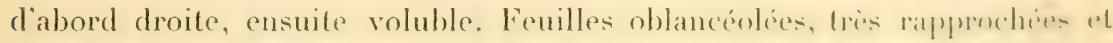
frès visqueuses, mucronées au sommet. Fleurs blanches, en corvmber larmes. lastigiés, longuement pédonculés, à pédicelles bractónlis at la base. - Fl. de juillet a novembre. - Ne se trouve qüa la Désirade, dams la ravine Cruble. où elle abonde. $\left[\mathrm{N}^{\circ} 2810.\right]$ - Elle n’existe pas à la Martinique

Pluchea Cass. (dédié à l'abbé Franc. Pluche, auteur de : Spectarlés de la nature. - Paris, 1732.)

P. odorala Cass., Conyza odorata I., C. carolinensis Jacr. : Pluchere odorante. Vulgo: Tabac à Jacot, bois-liège, grande sauge. Desc., vol. III, 1. 217, p. 300. - Arbrisseau ou grand arbuste, touffu, haut de 2-3,50 mèt., couvert dans toutes ses parties, sauf le bas de la tige, d'un duvet court el blanchàtre, à branches étalées, divariquées, finement striés. Fiailles elliptiques ou elliptiques-oblongues, pointues aux deux extrémités, subentieres ou légirement dentelées. Capitules multiflores, hémisphériques, en corymbes arron-

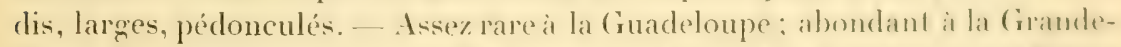
Terre, dans les sables du bord de mer ou daus les savanes interienres : saintFrançois, Moule, Sainte-Anne, Marie-Galante. - Cette plante passe pour jour de nombreuses vertus alexitire ef stimulantel. Pour l'avoir plus lacilement sous la main, on la cultive sonvent autour des maisons, dans les cents et les jardius. On l'emploie dans les bains chauds et en fomentations contre la paralysie: Iinfusion des fenilles est stomachique of les sommitis mèlées aux aliments excitent l’appétit et facilitent la digestion: dans le pays.

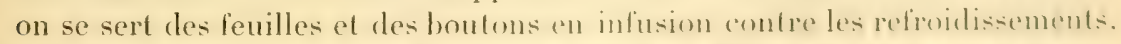

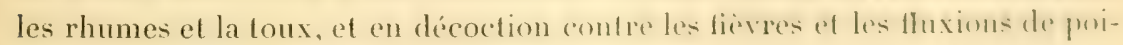
trine. $\left[\mathrm{N}^{\circ} 2523\right.$.

Martinique. Vulgo : Tabac-diable. - Assez abondant. - Il entre souvent dans les remèdes contre la morsure des serpents. On met les leuilles el l'écorce des racines pilées dans du tafia lort, on en exprime le suc et on le donne à boire : le marc s'applique sur la plaie. [No 575. 
P. purpurascens D. C.: Pluchée it fleurs purpurines. Vulgo: Sauge rouge. guérit-tout. Sl., t. 152, f. 1. - Herbe annuelle ou bisannuelle, souvent stoIonifère. surtout quand elle pousse dans l'eau, haute de $30-80 \mathrm{~cm}$., à lige noire, simple ou garnie d'un petit nombre de branches, a jeune tige el branches revètues d'un duvet très court, fin el blanchâtre. Fenilles d'un vert très pâle, lancéolées ou oblongues-lancéolées. Capitules en corrmbes terminaux, Ionquement pédonculés: fleurs purpurines ou pourpres, ou plus rarement blanches. - Endroits aquatiques ou marécageux près de la mer: les Saintes, Terre-de-Haut (derrière le cimetière, ou il abonde), Pointe-Noire, Moule. [No 2953.] - Je ne l'ai pas trouvée à la Martinique.

Pterocaulon Ell. idu grec "pteron ", aile, et "kaulon ", tige, parce que les feuilles décurrentes forment des ailes sur la tige.)

P. virgatum I). C., Conyza alopecuroides Lamk.; Pterocaulon droit comme une baguette. Vulgo : Langue à vache femelle. S1., t. 152, f. 2. - Herbe sulfrutescente, très droite, haute de $40-80 \mathrm{~cm}$., simple ou touffue. Feuilles elliptiques ou elliptiques-oblongues, vertes et grlanduleuses en dessus, garnies d'un duvet laineux et blanc en dessous, ainsi que les ailes formées par les pétioles décurrents. Capitules en glomérules formant un épi oblong : les glomérules inférieurs distants; corolle blanc pâle. - Fl. de novembre à juin. - Çà et là aux Saintes (Terre-de-Haut); assez abondant dans les savanes et les terres en friches des hauteurs des Vieux-Habitants. Alt. 20-350 met. ${ }^{\top 0} 2949$.

Martingeve. Vulgo: Oreille-mouton. - Rare : Fort-de-France Marigot;, hauteurs de l'habitation Fond-Layette (Case-Pilote). [No 1440.$]$

Clibadium L. (nom emprunte d'une plante que les Grees appelaient " klibadion ", dont on n'a pas pu trouver la signification.)

C. asperum D. C., Cl. surinamense L., Trixis scabra Sw.; Clibadie à feuilles rudes. Vulgo: Bois enivrant. Aubl., Guy., f. 313. (Bailleria Aubl.) Arbrisseau haut de $2-3$ mèt., droil, a tige cylindrique, nue dans le bas, a branches nombreuses dans le haut, fastigiées, a tige et branches grises et hispides. Feuilles ovales-lancéolées, grisatres, surtout en dessous, finement serretées, scabres-hispides des deux côtés. Capitules en panicules corrmbiformes, terminales; corolle blanche. - Rare : hauteurs des Trois-Ilets quartier de la Plaine), où il fleurit presque toute l'année. $\left[N^{\circ} 317.\right]$ - Je ne l'ai pas trouvé à la Guadeloupe.

C. Badieri Griseb), (Clibadie de Badier. Vulgo: Herbe enivrante. - Plante herbacée par le haut, suffrutescente à la base, haute de $0^{\mathrm{m}} 60-1^{\mathrm{m}} 30$, très feuillue, vénéneuse. Feuilles ovales-lancéolées ou ovées, subentières ou serretées au-dessus de la base, ruguleuses en dessus. hispides-laineuses en dessous, surtout sur les nervures. Capitules pédicelles. en corymbes terminaux. — Peu abondante : çà et làdans les bois de l'Ajoupa-Bouillon. — Les pêcheurs 
la plantent quelquefois a crite de lesurs cases et sen servent pour eniver le poisson '. Elle passe pour tonique et est employere pour combaltre l'animit. et la chlorose. [No315.] — Je ne l'ai pas vue à la Guadeloupe. Espèce probablement à fondre dans la précédente.

C. erosum D. C.: Clibadie à feuilles frangées. Vulgo : Bois enivrant. (Trixis Sw.) - Grand arbuste, haut de 2-1 mil . ramement plus haut it lige

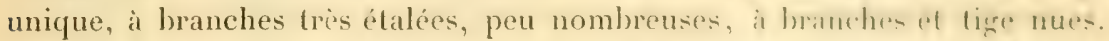

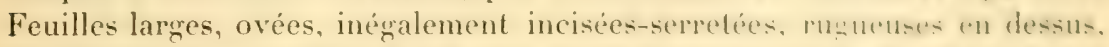
pourvues en dessous d'un duvet gris, court, legerement hispide. Cappilules an corymbes étalés, arrondis, larges; corolle blanche ou lose purpurine. - Fi. presque toute l'année. - Dans les bois, le longr des rivieres det des ruisseanx: Bains-Jaunes, Matouba. [No 2491.$]$

Martinique. Vulgo : Bois à enivrer. - Bois des Fonds-Saint-Denis, che-

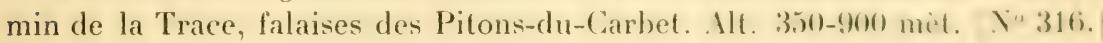

Ogiera Cass. (dédié à Ogier?.)

0. ruderalis Griseb., Eleutherantera ouala Poit; () wierie des décombres. Vulgo: Herbe-savane. - Herbe annuelle, haut de 15 -for) ('m. pubescente, à tige simple, très branchue, cylindrique dans le bas, tétragone dans le haut, à branches très longues, insérées à angle droit, tombantes ou penchées aux extrémités. Feuilles ovales, triplinerviées, glanduleuses en dessons. (Capitules solitaires ou géminés à l'aisselle des feuilles; corolle jaunitre. - Herbe fourragère de médiocre valeur. - Abondante dans les savanes herbeuses et plates du Lamentin, de Sainte-Rose, etc. [To 3264.] - Elle nexiste pas i la Martinique.

Melampodium L. (du çrec " melas ", noir, et " podion " pous ", pied, allusion à la racine noire de la plante, ce qui est vrai du Melamporlium des anciens, Helleborus niger (Hellébore noir\%, qui n'a ancune ressemblance avec le Mélampode de Limmé. - Pline, XXV,21, dit qu'un discur d'aventures, appelé Melampus, ou un berger de ce nom, avait le premier découvert les propriétés de l'Hellébore.)

M. perfoliatum H. B. et Kunth; Melampode a feuilles perfolices. Vulgu : Bouton jaune. - Petite herbe plus ou moins droite, haute de 25) a 30 c cm . a tige noire, nue dans le bas, nettement dichotome dans le haut. Feuilles lareres. en forme de losange, opposées, śélargissant a la base pour derenir amplexi-

1. Les Clibadium sont probablement tous doués de propriétés toxiques qui en font utiliser quelques-uns, notamment Cl. asperum (à la Guyane) ou Cl. Badieri (aux Antilles), pour enivrer le poisson. Ils sont désignés i la Guyane, en raison de cet emploi, sous le

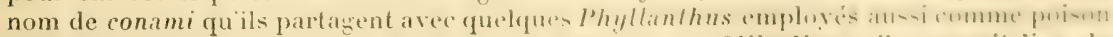
enivrant. On ignore la nature des principes actifs de ces Clibadium; il y aurait lieu de faire sur les espèces de ce genre un travail de recherches semblable d̀ celui de feu Geoffroy sur le Robinia Nicou, qui est aussi un poison enivrant de la Guyane. Cc dernier travail a paru dans les Annales de l'Institut Colonial en 1889. (L. H. 
caules ef connées avec la feuille opposée. Capitule solitaire, radié, multiflore, terminal. porté sur un long pédoncule : lleurs de la périphérie femelles;, au nombre de 20; celles du centre mâles, entourées de paillettes diaphanes: fleurs involucrales sur deux rangs, ovales, ciliées, - Rare : çà et là dans les savanes et champs de cannes entre la Basse-Pointe et la Grande-Rivière. $\left[\mathrm{N}^{\circ} 320.\right]$ - Je ne l'ai pas trouvée à la Guadeloupe.

Acanthospermum Schrk. (du gree "akantha ", épine, el "sperma ", semence.

A. xanthioides 1). (... A. hrasilum Schrk: Acanthosperme a feuilles de lampourde. Vulgo: Herbe-savane. -- Annuel, couché, hispidulé dans toutes ses parties, at tige trichotome et it branches dichotomes. Fenilles opposées. pétiolées, obovées, inégalement dentelées, ylanduleuses en dessous. Capitules subsessiles, terminaux, souvent fixés dans la bifurcation de deux branches: écaille ligneuse renfermant lakène, munie de piquants erochus ef de 8-10 côtes longitudinales 1. - Peu répandu : Carbet dans une savane herbeuse du haut de l'habitation Crassous . $X^{\circ} 1042$. _- Je ne l'ai pas trouvé à la Guadeloupe.

Xanthium L. du gree " xanthos ", jaune, parce que l"infusion de la plante doit, selon Dioscorides, IV, 133, teindre les cheveux en jaune.)

$\mathbf{X}$. orientale L.; Lampourde à gros fruits. Yulgo dans le pays : gros cousin ।. - Annuel ou vivace, à racine grosse, longue, pivotante, à tige très bran-

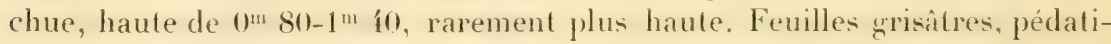
nerviées, ovées, inciso-dentées, larnes: les adultes, penchées. Inflorescence en corymbes allongés, composés de capitules agoglomérés et monö̈ques: les mâles dans le haut et les femelles dans le bas du corymbe; involucre des capitules mâles uniserié, libre; réceptacle cylindrique et garni de pailleltes; corolle tubuleuse, a 5 lobes trìs courts; involucre des capitules femelles ovoïde, épineux, dur, surmonté de deux pointes fortes, très crochues au sommet, épines crochues au sommet: corolle filiforme-tubuleuse; stigmates 2 . - Fl. de juin à octobre. - Assez abondant dans les usines " La Retraite ", à Baie-Mahault. - Introduit d'Europe par les marchandises ou les engrais, car elle se rencontre dans toutes les parties chaudes et tempérées du monde entier ${ }^{2}$. [No 2816.

Martinique. Vulgo : Gros cousin. - Environs de Fort-de-France et port des Transatlantiques. [N०918.]

Parthenium L. (du grec "parthenos ", vierge, jeune fille, ćest-i-dire plante à guérir les maladies des femmes.)

1. Cette plante est usitée sous le nom de Picaío de Praya comme fébrifuge et diurétique. (E. H.)

2. Cette plante qui, comme toutes les autres lampourdes de France, est réputée jouir de propriétés mirifiques, n'a aucun emploi aux Antilles, et c'est avec raison. 
P. Ilysterophorus L.; Parthénium matricaire. Vulgo : Absinthe batard, herbe à pian, matricaire. - Annuel, ornemental, très droit, haut de

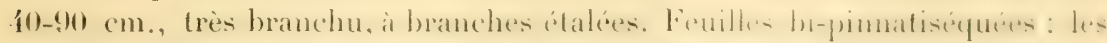

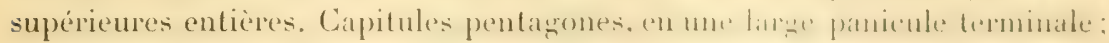
fleurons blanes. - Très abondant sur les décombres, le long des routes et

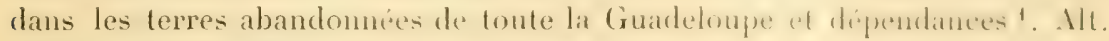
0 -500 mèt. [No 2502.]

Martinique. Vulgo : Matricaire, - Abondant dans toute l'ile. Yo 261.

Ambrosia L. (du grec "ambrosia ", nourriture des dieux, paree que les feuilles froissées répandent une agréable odeur.)

A. artemisifolia L.; Ambroisie ì feuilles d'Artémise. Vulgo: Absinthe anglaise, ambroisie. - Suffrutescent, droit, haut de $0^{\mathrm{m}} \quad 40-2$ mèt., velu. Feuilles bi-pinnatisequées. Capitulesumbreux, multillores, chn repis allongis. nombreux et terminaux; fleurons verdâtres. - Cù et là dans les savanes: Gourbeyre (Dolé), Vieux-Fort. - On le rencontre plus souvent autour des maisons à l'état de culture. - Descourtilz le vante comme un excellent vermifuge: dans le pays, on s'en sert comme lel et ausi comme sudorifique, fébrifuge et antigoutteux. [No 2511.]

Martinique. Vulgo : Absinthe de la Dominique. - Cà el là dans les champs, et à l'état de culture dans les jardins; il est emploré comme vermifuge : Sainte-Anne, Vauclin, Ducos, etc. [ $\mathrm{N}^{\circ} 218$.

Zinnia L. dédié a Jean Gotffrid Zinn, né en 1717, as Schwablach, près de Nuremberg; en 1753. professeur de médecine it Göttingue, mort an 17.59: a écrit, entre autres choses: Descriptiones plantarum horti el atgri (inctlingensis.)

Z. multiflora L.; Zinnia multiflore. Vulgo: Brésine. Lam., Ill., 1. 585, lig. inf. - Annuel, très droit, haut de $25-35 \mathrm{~cm}$. à fleur's rouges. Trouvé it l'état sauvage sur plusieurs mornes calcaires de la Désirade. Xosiz. I - I n evi-te pas à la Martinique.

Z. elegans Jacq.; Zinnia élégant. Vulgo: Brésine. - Ilaut de $40-70 \mathrm{~cm}$. - Pousse spontanément autour des maisons, dans les cimelières el dans

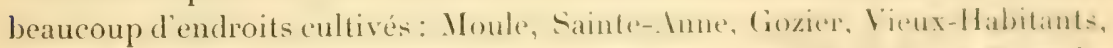

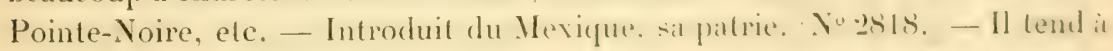
se naturaliser à la Martinique.

Eclipta I. (du grec " elieipsis ", isclipse, ahsence, manque. parce que les

1. Cette plante est citée dans nos classiques conme employée de lemps immémorial aux Antilles à titre de fébrifugre et dans le traitement de l'herpès : elle contient un principe actif cristallisé, la Parthénine, qui a été donnée avec succís contre lés névalyies crâniennes el de la face: la plante passe aussi pour astringente et emménagogue. 
fleurons blanes de la périphérie du capitule font, pour ainsi dire, disparaitre les fleurons verts du centre.)

E. alba L.; Eclipte blanche. Vulgo : Herbe à l'encre. - Annuel, droit, haut de f(0-8j cm.. branchu, entièrement scabre, à tige presque toujours noiràtre. Feuilles lancéolées ou elliptiques-lancéolées, subsessiles. Capitules solilaires, axillaires el terminaux, pédonculés, hémisphériques. - Abondant dans toute la Guadeloupe et dépendances. Alt. 0-600. [N²495.]

Martivique. Vulgo: Herbe à l'encre. - Commun. [No 1436.$]$

Borrichia Ad. Idédié it Olof Borrich, botaniste du xvir siècle; a laissé : De somno el somniferis maxime papavereis, 1683, et De usu plantarum indigenarum in medicina, 1690.)

B. arborescens DC.; Borrichie arborescente. Vulgo : Pourpier bord-demer, tiraille. Plum., éd. Burm., t. 106, f. 2. - Arbrisseau haut de $0^{\mathrm{m}} 40-$ $1^{\mathrm{m}}$ 90, rarement plus haut, droil, rarement tortueux, très branchu et tris feuillu, à branches fastigiées et à feuilles très rapprochées, à écorce grise. Feuilles épaisses, blanc argenté ou grises, spatulées ou lancéolées, entières. Capilules radiés, larges, solitaires, terminaux; fleurs jaunes. - Fl. toute l'année. - Sur les roches madréporiques ou dans les sables, ou aussi dans le gazon du bord de mer: Désirade, Marie-Galante, Moule, Saint-François, Sainte-Anne, etc. [No2819.] - Il n'existe pas à la Martinique.

L'Helianthus luberosus I., vulgno: Navet de Jérusalem, topinambour de France, à capitules larges, radiés, à corolle jaune, est souvent cultivé à cause de ses racines tubériformes qui constituent un excellent légume. - Originaire du Brésil. [Nº 3265.]

Martinique. Vulgo : Navet de Jérusalem. [No 1735.$]$

Wedelia Jacq. (dédic à l'Allemand Georg Wolfgang Wedel, né en 1645, à Golzen, dans le Viederlansitz; en 1667, ingénieur à Gotha; en 1673, professeur de médecine à léna, mort en 1721; a écrit, entre autres choses, sur les plantes des anciens.)

W. carnosa Rich.: Wédélic à feuilles charnues. Vulgo : Herbe à couresse à l'emme, patte-de-canard, herbe-soleil, bouton d'or. Sl., t. 155, f. 1. Herbe couchée, radicante, stolonifère, rampant à une distance indéterminée, élevée aux extrémités. Feuilles sessiles, obovées, trilobées, grossièrement dentées, offrant dans leur ensemble un peu la forme diune patte de canard. Capitules jaunes, radiés, larges, axillaires et terminaux. - Très abondant dans les savanes humides ou sèches et sablonneuses, où il forme souvent grazon sur une grande étendue : Vieux-Fort, Gourbeyre, Camp-Jacob, Lamentin, Baie-Mahault ef dans toute la Grande-Terre, ete. Alt. 0-800 mèt. [N०2524.] 
Martrique, - Vulgo : Herbe-soleil, bouton d'or. - Extrêmement abondant. $\left[\mathrm{N}^{\circ}\right.$ 1434. $]$

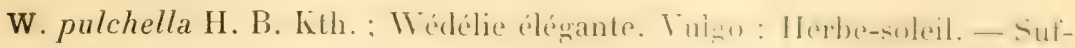
frutescent, à tige couchée, radicante, it extrémités dressées, haut de

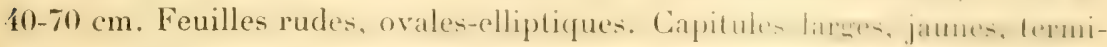
naux. - Peu répandu : Fort-de-France, aux environs du port des Trans-

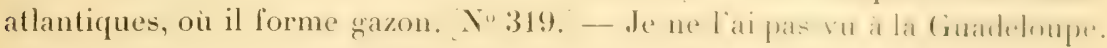

W. frutescens Jacq.; Wédélie frutescente. Vulgo: IIerhe ì vache. Vivace par le bas, à branches herbacées, haut de 1-1 $\mathrm{ml} 90$, rarement plus élevé, droit ou tortueux, peu ou fortement branchu, à branches et jeune tige médulleuses, garnies de soies courtes et rudes. Feuilles pétiolées, ovales-elliptiques, acuminées, serretées, très scabres-hispider. Citpitules jaunes, solitaires ou géminés, terminaux. - Abondant dans les endroits secs des mornes inférieurs ou dans les falaises et les sables du berd de mer. où il vit en société : Carbet, Case-Pilote, Prèchenr, Cirande-livirire. ‥31s. — Je ne l'ai pas vu à la Guadeloupe.

W. buphthalmoides Gr.; Wédélie il fleurs de Buphlhahum. Vulsu: Herbe à vache. - Frutescent dans le bas, herbacé par les branches haut de

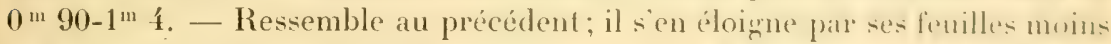
rudes, par ses jeunes branches velues, et par la longueur des ficailles de l'involucre. Plante variable quaut au port, à la taille et it la dispurition dernervures, selon qu'elle pousse dans les endroits ombragés ou exposés au soleil et au vent. - Abondant: Vieux-Fort, Gourbeyre, Ciapesterre, Moule, Gozier, Saint-François, Marie-Galante, etc. [No 2525.]

Martinique. Vulgo: Herbe-soleil. - Abondant. (Spécimen manque.)

Le Tithonia speciosa IIook, herbe annuelle, très ormementale, hauke de

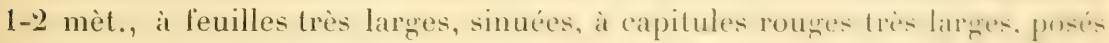
sur de longs pédoncules terminaux, est cultivé dans les jardins de la Désirade, du Moule, du Morne-itl'Eau, du Petil-Canal, ete. al antsit it la Martinique. - Originaire du Mexique. [No 2806.

Melanthera Rich. (du gree "melas ", noir, et "anthera ", authere, paree que les anthères sont naturellement noires.)

M. deltoidea Mich.; Melanthère à feuilles deltoïdes. Vulgo : Bouton blanc. - Vivace par la base, herbacé par le haut, stolonilère, haut de $0^{\mathrm{m}} 70-1^{\mathrm{m}} 20$, d'abord droit, ensule inflechi an tombant, ou partioin sarment-

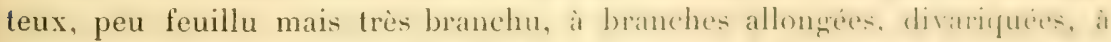

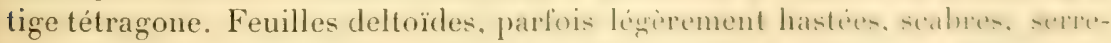

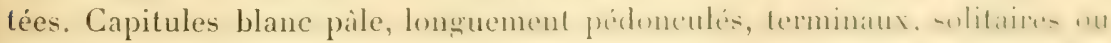
géminés, ou ternés. - Très abondant sur le bord de mer et un peu dans l'intérieur. Vit souvent en société sur une grande étendue : Désirade, Marie- 
Galante, les Saintes, Moule, Saint-François, Petit-Canal, Port-Louis, etc. [No 2820 .

Martinique. Vulgo : Bouton blanc, - Abondant: Prêcheur, Carbet, Caravelle, Trinité, Sainte-Aune. [ $\left.\mathrm{N}^{\circ} 1431.\right]$

Wulffia Neck. (dédié à J. C. Wulfi, qui, en $174 \hat{4}$ et 1765, a écrit sur les plantes de la Prusse.)

W. stenoglossa DC.; Wulflie à capitules pourvus de ligules courtes. Vulgo: (iros bouton. - Ilerbe sulfrutescente, grimpante, haute de 2 -4 mèt. ¿ tige subtétragone, peu branchue, à branches étalées. Feuilles très rudes, ovées-lancéolées ou ovées, brièvement acuminées. Capitules jaunes, arrondis, terminaux, portés sur de longs pédoncules géminés ou ternés. - Dans les haies et les broussailtes de la régrion inférieure: environs de Saint-Pierre, Parnasse, Carbet, Prêcheur, Marin (morne Gommier), etc. [No 929.J - Je ne l'ai pas trouvé à la Guadeloupe.

W. havanensis DC.; Wulffie de la Havane. Vulgo : Gros bouton. Suffrutescent, sarmenteux, haut de 1-3 mit., it tige subanguleuse. Feuilles rudes, ovées-oblongues, acuminées, faiblement hispidulées ; écailles de l'involucre non apprimées comme dans le précédent, foliacées, oblongues-lancéolées, pointues, un peu plus longues que les fleurons du contour. - Çà et là dans les haies et les broussailles de Camp-Jacob el de Gourbeyre (les Palmistes). [No 2486.] - Je ne l'ai pas trouvé à la Martinique.

Bidens L. (du latin " bis ", deux, et " dens ", dens, parce que les akènes sont surmontés de deux arêtes.

B. leucanthus W.; Bidens à fleurs blanches. Vulgo : Herbe-z'aiguille, persil bâtard. Desc., vol. VIII, t. 583, p. 308. - Herbe annuelle, glabre, droite, haute de $0^{\mathrm{m}} 30-1 \mathrm{~m} 50$, rarement plus élevée, à tige tétragone. Feuilles penniséquées at 1-3 paires de segments grossièrement serretés-denlés. Capitules à fleurons blanes, radiés, à anthères jaunes : pédoncules longs. Akine surmonté de 2 - - arêtes divergentes. - Très commun dans les champs de cannes, le long des routes et sentiers, dans les terres en friches, etc. Alt. 5-900 mèt. [No 2504.]

Martinique, Vulgo : Herbe-z'aiguille. - Abondant. [No 1444.]

B. coreopsidis I)(.; Bidens a fleur's de Coréopsis. Vulgo : Liane jaune, herbe zaiguille-liane. Pl., éd. Burm., 1. 53, f. 1. - Suffrutescent, grimpant, très ornemental, haut de $3-5$ mèt., à tiges el branches très nombreuses, ¿ branches souvent pendantes. Feuilles pinnatisequées, à 1-3 paires de segments serretés. Fevilles larges, jaunes, en larges corymbes le plus souvent pendants ou penchés, terminaux. - Plus répandu : çà et là dans les mornes seeset pierreux des hauteurs du Prècheur: plus abondant aux Anses- 
d'Arlet, surtout sur la pente occidentale du morne Larcher. [No 1045. _ _ Je ne l'ai pas trouvé à la Guadeloupe.

B. bipinnata L.; Bidens à feuilles bipennées. Vulğo : Ilerbe-z’aiguille. Annuel, droit, glabre, haut de $20-90 \mathrm{~cm}$., très branchu ou simple. Feuilles

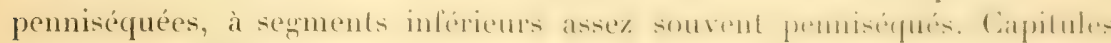
jaunes. - Très abondant dans les terres cultivées on laissées en friches de Loute la Guadeloupe ; plus rare à la Grande-Terre, à Marie-Galante et à la Désirade. Alt. 5-600 mèt. [No 2492.

Martinique. Vulgo: Herbe à aiguilles. - Très abondant. TNo 1-14ti.

Cosmos Cav. (du gree "kosmos ", ornement, allusion ù la beauté des fleurs.)

C. caudatus H. B. Kith.; Cosmos à quene, en parlant des deux arotes horizonLales des akènes). Vulgo: Herbe-z aiguille. - Herbe droite, tris ormementales

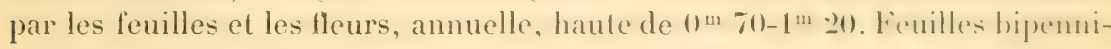
séquées, à 3-5̆ paires de segments entiers. Capoilules pourpres un purpurins, portés sur de longrs pédoncules terminaux. - I)ans les champes de loner des routes, dans les endroits pierreux et secs : route de la Basse-'Terre à Gourbeyre, Camp-Jacol), Monteran, Ducharmois, Lamentin, Baic-Mahault, (iozier. Moule, etc. Alt. 20-560 mèt. [No 2499.]

Martinique. Vulgo : Herbe-z'aiguille. - Assez abondant : environs de Saint-Pierre, Parnasse, Trou-Vaillant, Carbet, Marin, elc. 「No 1143.

Verbesina L. (du latin “verbena », verveine, parce que les feuilles de ces plantes ont une assez grande ressemblance avec celles de la verveine.)

V. gigantea Jacq. : Verbésine grigantesque. Iulgo : Camomille. — Sullirutescent, très droit, haut de 1-2 mèt., à tige grosse, striée-cylindrique, nue dans le bas, très branchue dans le haut, glabre. jeme lige of branches pubucentes. Feuilles grisâtres, rudes : les inférieures, très laruges et penchées,

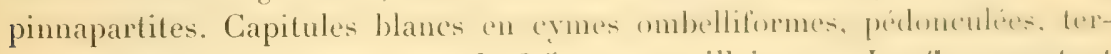
minales, larges, accompagnées de 3-5 cymes axillaires. - Les fleurs restenl

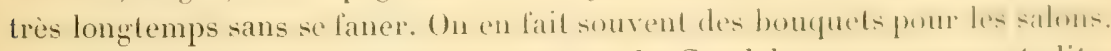
- Caa et là dans les champs de toute la Guadeloupe proprement dite,

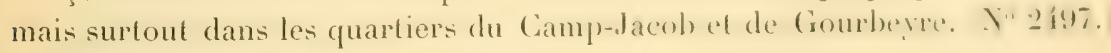
- Plante aromatique et stimulante.

Martinique. Vulgo : Grande camomille. - Plus abondant qu'ì la Guade

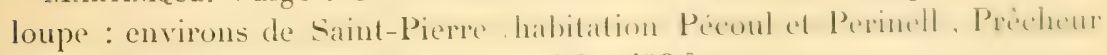
Carbet, Trois-llets. Alt. 10-400 mèt. [No 1438.]

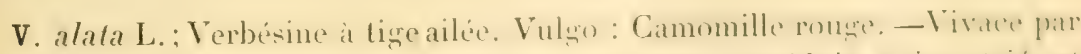

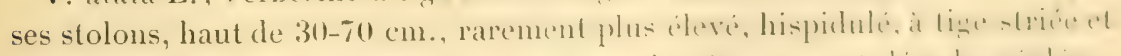

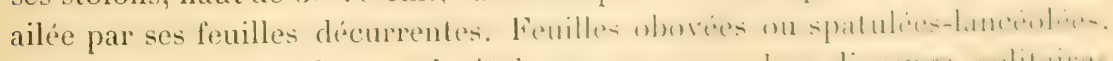

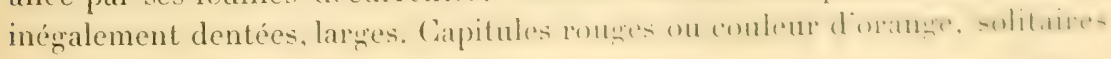


nu zéminés. portés sur de longss pédoncules. Arêtes de l'akène, de longueur inégale : les plus longues crochues au sommet. - Abondant dans les faubourgs de la Pointe-â-Pitre, Mnule. Morne-a-l'Eau; cá et là dans le bouror des Trois-Rivières. - Plante stimulante et aromatique. [No 2821.] - Il n'existe pas à la Martinique.

V. hetianthoides II. B. Kth.; Verbésine ressemblant a l'Helianthus. Vulgo: Fleur jaune montagne. - Arbrisseau très ornemental et florifère, haut de 0 ${ }^{\text {10 }}$ 90-2 mèt., nu dans le bas, très branchu dans le haut, souvent tortueux, à hranches fastigieses, hispides, midulleuses. Fenilles larges, épaisser, rigides. très fragiles, dentées en scie, obovées-lancéolées, pointues au sommet, contracties, à la base, en un conrt petinle. Capitules jaunes, larpes, radiés, disposés en cymes allongées. - Fl. d'août en octobre. - Uniquement sur les hautes montannes : Sarane it Mulets et Savane aux Ananas, Grande-Découverte, ete. [No 3308 .

Martrique. - Cultivé au Jardin botanique, d'où il s'est répandu dans le pays; et se rencontre assez fréquemment. [No 971 .

Spilanthes Jacq. (du gree "spilos ", tache, et " anthos ", fleur, parce que les fleurs portent des taches noires.)

S. uliginnsa sw, S. Lemella Murr.: Spilanthes des lieux humides. Vulgo : Créosote du pays, herbe mal-aux-dents. - Annuel, haut de $20-60 \mathrm{~cm}$., délicat, droit ou couché, ou plus ou moins couché, à tige souvent radicante. Feuilles npposées, petites. ovées-lancénlées, sourent crénelées. Capitules à liguules blanches; réceptacle conique. - Dans les endroits très humides ou aquatiques, dans les fosses remplies d'eau, sur les bords des étanges et des mares, etc. - Les capitules sont très âcres et piquants. - Quand on souffre des dents par suite d'une névralgie, on écrase un ou deux capitules et on les met sous la dent malade; la douleur disparaît souvent instantanément. - Alt. 5-700 mèt. 「 「o 2521.

Martingue. Vulgo : Créosote du pays, bouton d'or. - Dans toute l'île.

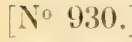

S. urens Jacq.; Spilanthe brûlant. Vulgo : Créosote. - Herbe annuelle, haute de $50-80 \mathrm{~cm}$. i tige souvent couchée a la base, ensuite droite. Feuilles lancéolées, a trois nervures. Cappitules jaunes, petits, Ionguement pédonculís, solitaires terminaux. - Fl toutel'année. - Peu répandu : dans les savanes herbenses du bord te mer, entre Fort-de-France et le Lamentin. [X"1733.] - Je ne l'ai pas trouvé à la Guadeloupe.

S. exasperata Jacq. : Spilanthe très rude. Vulgo : Cresson de Para, bouton d'or. - Annuel, haut de $30-90 \mathrm{~cm}$., très droit, à tige et branches scabres. Feuilles ovées ou lancévlées, crénelées, caractère qui le distingue facilement de ses deux congénères. Capitules trìs coniques, portés sur des pédoncules longs, filiformes, droits, axillaires et terminaux. - Assez rare. Dans les 


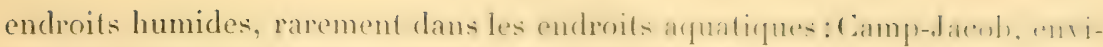
rons de la Basse-Terre, Gourbeyre, ete. [No 2822.

Martinique. Vulgo : Bouton d'or, créosole. - Issez abondant dans les

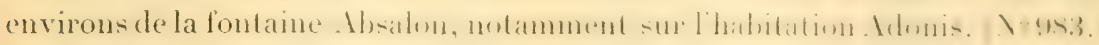

S. oleracea Lin., S. Acmella Murs. Vulgo : Zerbe-bouton, bouton d'or. Desc., vol. I, t. 52, p. 231. - Herbe plus ou moins couchée, souvent radicante à la base, à feuilles larges, ovées, crénelées. - Est sourent cultivée dans les jardins comme plante vermifuge ' Yo \.198.

Martinique. Vulgo: Bouton d'or, créosote. [No 1.1.19.

Synedrella Gartn. (du gree "sunedra », réunion, à cause de l’agrrloméralion des capitules.)

S. nodiflora Gartn.; Synédrelle à capilules réunis. Vulgo : Herbe à feu; cochon gras (parce que cet animal en est friand et s'en engraisse). Sl., t. 155, 1. 3; Sw., Observ., 1. 8, f. 2.- Annuel, droit, rarement a base couchéc, haut de $50-85 \mathrm{~cm}$., scabre ou glabre, à branches trichotomes dans le bas, dicho-

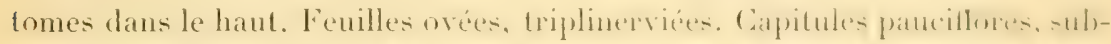

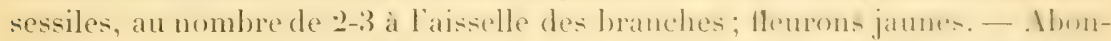
dant dans toutes sortes de terrains, et constitue un assez bon fourrage pour le bétail. Alt. 0-600 mèt. - Dans toute la Guadeloupe et dépendances. No 2496.

Mantinique. Vulgo : Herbe à feu. Abondant dans toute l'île. [No 1-141.]

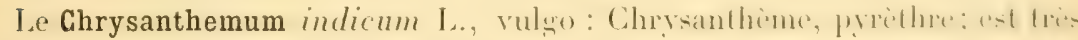
fréquemment cultivé dans les jardins, oil il themil presfue tumb lanmer. [No 2823.] - Originaire de l'Inde Orientale.

Martinique. Vulgo: Chrysanthème. [No321.

Pectis L. (du grec " pectos ", épais, solide, parce que les akènes sont enflés ou épaissis à la base.)

P. punctata Jacq., P. linifolia L.; Pectis à feuilles pointillées. Vulgo : Lin bâtard. Sl., t. 149, f. 3; Lam., Ill., t. 681. - Herbe amuelle, délicate, haute

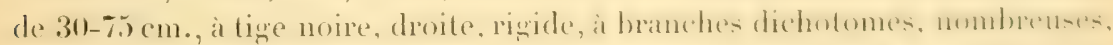

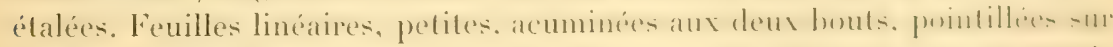

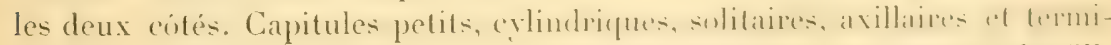
naux, ne contenant que trois ou cinq fleurs, jaunes, radiées; pédoncules fili-

1. Cette plante est plutôt considérée comme un excellent antiscorbutique; elle peut remplacer le cochlearia et le cresson; du reste, elle est connue sous le nom de " cression du Para ". Elle renferme une huile volatile, odorante, àcre, une gomme, de l'extractif. du malate et du sulfate de chaux, enfin une matiére colorante jaune. Celte composition doit être peu différente dans les autres espéces des Antilles qui ont aussi des vertus antiscorbutiques. - Seul le Sp. uliginosa parait avoir des propriétés syalagogues lrí éneryiques et une âcreté qu'on ne retrouve pas au mème degré dans les autres esprét: du genre. (E. H.) 
formes. - Mbondant dans les terres siches et pierreuses de Baillif, VieuxHabitants, etc. Alt.40-150 mèt. [No 2519.] - Je ne l'ai pas trouvé à la Martinique, mais il est abondant is la 1)ominique el a Sainte-Lucie. No 932.

P. carthusianorum Less.; Pectis des Chartreux. Vulgo : Lin bâtard. Annuel, haut de $30-65 \mathrm{~cm}$., plus ou moins incliné, rarement couché, très branchu, à tige noire et lisse. Feuilles spatulées, garnies d'une infinité de petits points transparents sur les deux faces. Capilules sesiles, terminaux, réunis par 2-5, pidoncules. - 1sse\% abondant dans les savanes maritimes de Sainte-Anne, du Vauclin et du François. [No 933.] — Je ne l'ai pas trouvé à la Guadeloupe.

P. humifusa sw.; Pectis couché et appliqué sur le sol. Vulgo: Marguerite bord-de-mer, petite marguerite jaune. -- Annuel ou suffrutescent, radicant, rampant, à une distance indéterminée, en tous sens. Feuilles petites, épaisses. spatulées, arrondies au sommet et mucronulécs. Capitules jaunes, sessiles, ne contenant que 10-15 fleurons. - Tress abondant sur les playes sablonneuses, sur les pierres madréporiques du bord de mer, et un peu à l'intérieur, ou il forme souvent un gazon superbe: Désirade. Marie-( Sainte-Anne, Moule, etc. $\mathbf{N}^{\circ} \supseteq \mathbf{4 8 7}$.

Martinique. Vulgo : Marguerite bord-de-mer. - Vauclin, Sainte-Anne, Diamant, ete. $\left[\mathrm{N}^{\circ} 970\right.$. $]$

Porophyllum Vaill. (du grec " poros n, trou, et "phyllon ", feuille, parce que les feuilles ont une infinité de petits trous.)

P. ruderale Cass.; Porophylle des décombres. Vulgo: Herbe à soie. Jacq., Sel. Am. stirp. hist., t. 129. - Annuel, très droit, haut de $0^{\mathrm{m}} 60-1^{\mathrm{m}} 10$, nu dans le bas, très branchu dans le haut, à branches fastigiées. Feuilles glauques. pétiolées, lancéolées, pointues, entieres ou crénclées. Capitules longs, cylindriques, blanc pâle, terminaux, pédonculés, formant ensemble une large panicule. - Dans les savanes herbeuses, sur les décombres et le long des routes de la région inférieure : Vieux-Fort, Pigeon et Bouillante, Moule, Gozier, Marie-Galante, etc. [No2514.]

Martixique. Vulgo: Herbe soyeuse, herbe à soie. - Environs de SaintPierre, Parnasse, Trois-Hlets, Trinité, etc. $\left[\begin{array}{lll}\mathrm{N}^{\circ} & 1435 .\end{array}\right]$

Helenium L. 'du gree "elios", soleil, a cause de la forme des capit ules, dont le centre représente le soleil, et les fleurons radiés les rayons du soleil. - Pline dit XXI. 33 i que la plante est née des larmes d'Hélène, épouse de Ménélas, roi de Sparte, enlevée par Pâris.)

H. quadridentatum Labill.; Helenium a ligules it quatre dents. Vulgo : Bouton d'or, œil-de-bœuf. - Annuel, haut de $45-80 \mathrm{~cm}$., à tige faible, souvent couchée dans le bas, peu branchue. Feuilles décurrentes, lancéolées, acuminées. Capitules allongés, blanes, solitaires ou géminés, portés sur des 


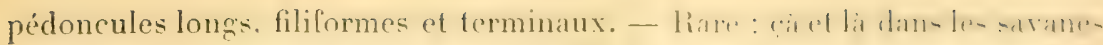
maritimes de Ducos et du Lamentin. [No 480.] - Je ne l'ai pas trouvé à la Guadeloupe.

Egletes Cass. du greec " aiglelis ", brillant, lay younul, allusinu aux belles fleurs jaunes au centre, el blanches à la circonférence.)

E. domingensis Cass.; Égletès de Saint-Domingue. Vulgo : Bouton d'or, herbe-soleil, matricaire-savane: - Annuel ou vivace (selon les endroits),

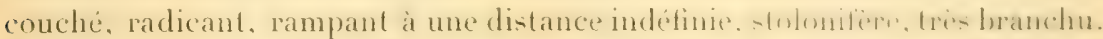

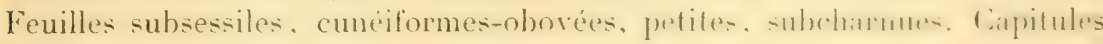
larges, très nombreux, axillaires, pédonculés : fleurons du contour blancs. -

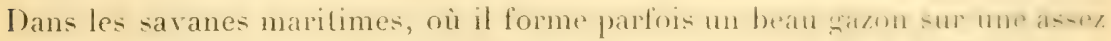
grande étendue : Saint-François, Marie-Galante entre le hois de lenlle-Anse: et le Grand-Bourg), etc. [No3386.]

Martinique. Vulgo : Bouton d'or, matricaire bord-de-mer. - Basse-Pointe, Grand'Anse (environs de l'hospice), Sainte-Marie, etc. [No 1435.]

Gnaphalium Lin. du wree "quaphalon ", bourre cotomneuse diun matedas. allusion au duvet laineux et blanc qui garnit les inflorescences.)

G. americanum Mill., G. purpureum Lin.; Gnaphale américain. Vulgo : Herbe-coton. - Annuel, haut de $50-70 \mathrm{~cm}$., plus ou moins droit, entièrement

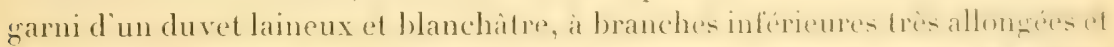
pendantes. Feuilles spatulés-allongées, rélrécies vers la bare. Capitules laineux, nombreux, disposés en épis corymbiformes-allongés. - Nl. en mai, juin, juillet. - Rare : çà et là dans le haut du bourg du Camp-Jacob et aux environs. [No 3664 .

Neurolæna R. Br. (du grec " neuron ", nervure, et "laina ") ou " chlaina ", manteau qu'on jetait par-dessus la tmique, allusion a la maniere dienter bractées à trois nervures qui entourent les capitules.)

N. Tobata R. Br.; Neuroliene à feuilles lobées. Vulgo: Herbe à pique. tabac à diable. Sl., t. 154, f. 4. - Annuel, haut de $0^{m} 80-1^{\mathrm{m}} 80$, très droit et ornemental, à tige grosse, striée, médulleuse, branchue. Feuilles vert clair,

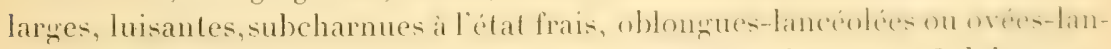
céolées, rétrécies à la base : les adultes, presque toujours à 1-3 lobes, au-

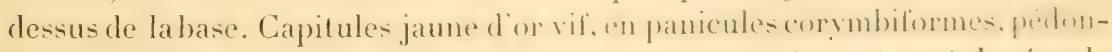
culées. - Toutes les parties de la plante sont très amères et sont douées de

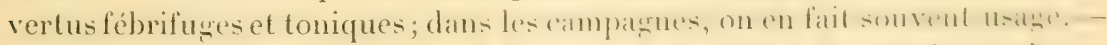
Assez abondant dans les mornes inférieurs, humides, et dans les ravines:

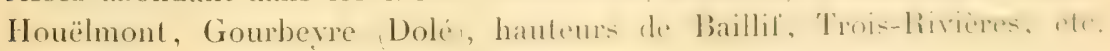
[No 2824.]

Martineve. Vulgo: Ierbe à pique. - Roule du Mome-Rouge à l'AjompaBouillon, bois des Fonds-Saint-Denis, de la lontaine Didier, ete. [No 1.637 . 
Erechthites Raf. (du grec "erechthites", qui est un "Senecio " de Dioscorides, genre auquel appartenait autrefois notre plante.)

E. hieracifolia Raf., E. priealta Raf.; Erechthite à feuilles d'épervière. Vülgo: Herbè à lapin, laitue sauvage. - Amnuel, droit, haut de $45-80 \mathrm{~cm}$, ¿t tigestries. Fouilles oblongues-lancénlés, inciso-dentées, seabres en dessous (sur la nervere médiane). Capitules blancs, en corrmbes terminaux. - Abondant dans les terres cultivées ou en friches, le long des routes, etc. Alt. 50500 mèt. No 2825 .

Martineue. Vulgo : Laitue saurage. - Abondant dans les terres cultivées. No 1437 .

Emilia Cass. Cassini, qui emploie ce nom grénérique, n en fait pas commatre les origines.)

E. sonchifolia 1). C. ; Émilie à feuilles de lailron. Vulgo : Salade à lapins. - Annuel, haut de $25-60 \mathrm{~cm}$., délicat, plus ou moins droit, à base souvent couchée et radicante. Feuilles adultes en forme de lyre: les jeunes, sagittées et amplexicaules. Capitules blancs, en corymbes tres laches, paucillores, portés sur des pédoncules longs et filiformes. - Aboudant le longr des routes, au pied des murs, dans les champs de cannes et de maninc, etc. Alt. J-7on mèt. [N०2510.]

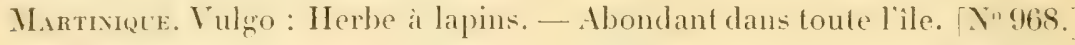

E. sagillala DC., E. flammea cass.; Émilie à feuilles sagilées. Vulgo: Herbe à lapin, goulte-de-sang. - Annuel, ornemental, haut de 30-70 cm., droit, à lige poilue dans le bas. Fenilles ovales-lancéolées, sagittées-amplexicaules, poilues sur la nervure médiane, en dessous. Capitules rouge de sang, en corymbes très lâches et très longuement pédonculés. — Cà et là dans les champs autnur des maisnus; aboulant dans les cimstieres : Gourbeyre. I isuxHabitanls, Sainte-Rose, Moule, Morne-à-l'Eau, etc. [No 2485.]

Martinique. Vulgo: Goutte-de-sang. - Abondant au Parnasse, aux cimetières du fort de Saint-Pierre, du Carbet, du Morne-Rouge, de l'AjoupaBouillon. Alt. 5-500 mèt. [No967.]

Nota. - Tous les Emilia des colonies constituent un bon fourrage.

Senecio L. (du latin "senex ", vieux, vieillesse, à cause des aigreltes qui ressemblent à des cheveux blancs.)

S. lucidus D. C. ; Séneçon à feuilles luisantes. Vulgo: Ilerbe à lapin. Plum., éd. Burm., t. 154́. - Suffrutescent, très ornemental, droit, très rarement sarmenteux, haut de $1^{m} 50-3$ mèt., rarement plus haut, à tige grosse, striée, médulleuse, très glabre. Feuilles larges, luisantes, subcharnues, dentées en scie : les supérieures, lancéolées et acuminées; les inférieures, elliptiques. Capilules radiés, jauns:- en éorvmbes larges, arrondis, pédoneulés, axillaires ef terminaux. - Fl. de mai a aout. - Assez abondant dans les falaises, sur les 


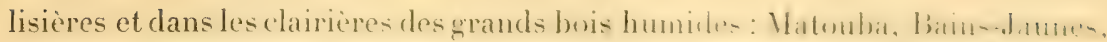
Gommier, Gourbeyre, Trois-Rivières, etc. Alt. 300-900 mèt. No 2954 .

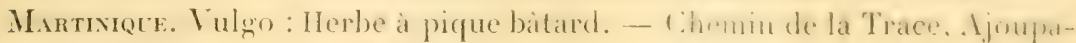
Bouillon, Grand'Anse, etc. [No 966.

\section{TRIBU II. - LABIATIFLORES}

Lerya D. C. (dédié au Français Jean Lery, qui a écril : Voyage dans la Terre de Brésil, Larochelle, 1578.)

L. nutans D. C. Chaptalia mulans Hemsl. ; Lerya it capritule junche. Vulen:

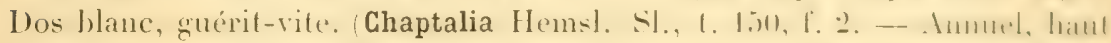
de 1.5-30 cm., sans tige. Feuilles rosulées, completement appliquíde cont r la

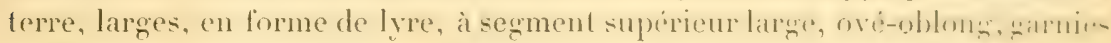

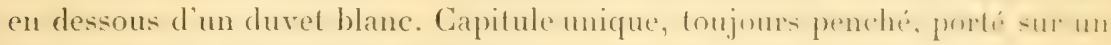
pédoncule de $15-30 \mathrm{~cm}$. de haut, pubescent; aigrettes blanches. - Sur les talus, dans les champs de toute la Guadeloupe el dépendaners. - Cotfre herhe est souvent employée dans le pays comme vulnéraire et comme détersive. Alt. 5-800 mèt. [No 2470.]

Martinique. Vulgo: Dos blanc. - Dans toute l'île. [No 1439.

\section{TRIBU III. - LIGULIFLORES.}

Sonchus L. dugrec "sogrchos " ou " somphos", mou, tendre, spongienx. par allusion à la consistance de la tige.)

S. oleraceus L.; Laitron maraîcher. Vulgo: Laitue sauvage, herbe à lapin. - Annuel, haut de $30-60 \mathrm{~cm}$. Feuilles roncinées, ou subentières ou dentées,

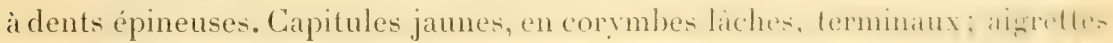
blanches. Akènes à trois stries et transversalement rugulenx. - Le long deroutes, au pied des murs et dans les terres cultivées '. [No 2483.]

Martinieue. Vulgo : Herbe à lapin, laitue sauvage. [No 306.

S. asper Vill.; Laitron âpre. Vulgo : Laitron épineux, herbe à lapin. Annuel, très droit, haut de $30-70 \mathrm{~cm}$., à racine grosse, pivolante, à tige

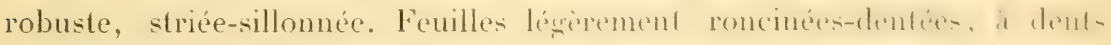
molles. Capitules jaunâtres ou jaunes, en corymbes ramassés, arrondis;

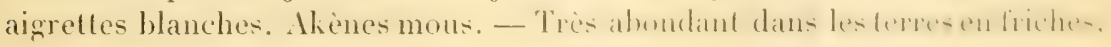

1. Cette plante, évidemment introduite aux Antilles, donne un sue épraisisi qui, à la dose de 15 à $20 \mathrm{cg}$., jouit de propriétés cathartiques comparables à celles du sue delaterium (Ecballium agreste Reich.); on en tire aussi un caoutchouc en épuisint la plante par te sulfure de carbone et en faisant bouillir dans de l'alcool ce résidu de l'évaporation. (li. II. 
dont il compose sourent l'unique végétation, et dans les champs de manioc de la rérion movenne; moins abondant dans la région du littoral, $\Upsilon^{\circ} 3387$.

Martisique. Vulgo : Herbe à lapin. - Abondant. [No 306.] - Introduit d'Europe comme le précédent.

Le Taraxacum officinale Wigk. vulgo : Pissenlit, tend a se naturaliser en

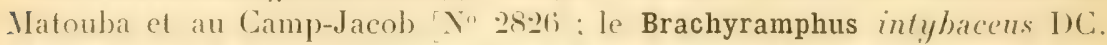
Lactuca Jaç. . rulgo: Chicorie. et le Lactuca sativa L., vulgo: Laitue, fleurissent facilement et se rencontrent çà et là à l'état sauvage.

De la tribu des Corymbiferes, on cultive très souvent l'Artemisia valyaris L. [No 1737] et l'A Absinthium L., les deux connus sous le nom vulgaire d'" absinthe "; le Tanacetum rulgare L., vulgo: Herbe aux vers, menthe glaciale, amande glaciale. [No 3694 .

Martinique. [No 1732.]

\section{CENTIÈMe FAMILLL. - LOBÉLIACÉES.}

Centropogon Presl (du grec "kentron ", éperon, pointe, et " pogon ", barbe, parce que les anthères sont velues et que les deux inférieures sont terminées en pointes.

C. surinamensis Presl; Centropogon de Surinam. Vulgo : Bois-poison. Fl. des Jardiniers, Amateurs et Manufacturiers, vol. III, t. 19. - Arbrisseau, haut de $0^{\mathrm{m}}$ 90-2 mèt., tantôt très touffu, tantôt sans branches et nu daus le bas, droit ou tortueux, ì rameaux remplis de moelle. Feuilles brièvement péliolées, ovées ou orées-oblongues. Inflorescence axillaire; fleurs rouge fonce, i deux livres. Baie globuleuse, large, couronnée par les lobes persistants du calice. - Fl. presque toute l'année. - Rare. Çà et là dans les haies de la rérion movenue : Camp-Jacob, Matouba. Alt. Joo-son mèt. [No 2409 .

Martinique. Vulgo : Orégine. - Rare : Morne-Rouge, Champflore. [No 921.$]$

Siphocampylus Pohl idu grec "siphon ", tuyau, et "kampulos ", courbe, parce que le tube de la corolle est courbe.)

S. Berterianus (G. Don, Centropogon Berterianus I)C.; Siphocampylos de Bertero. Vulğo: Liane rouge. - Herbe délicate, plus ou moins voluble ou tortueuse, haute de $0^{m} 80-1^{m} 40$, à tige blanchàtre, striée. Feuilles ovéeselliptiques, flasques, acuminées au sommet, arrondies à la base. Fleurs rouge pàle, axillaires, solitaires, portées sur de longs pédnncules. - Disséminé dans les endroits ombrazés et sur le bord des rivières des grands bois: Matouba. Bains-Jaunes. Alt. $500-800$ mèt. [No 2407.] - Je ne l'ai pas trouvé à la Martinique. 


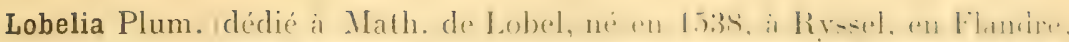

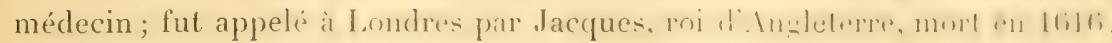
à Highgate; a laissé des écrits ayant trait à la bolanique.)

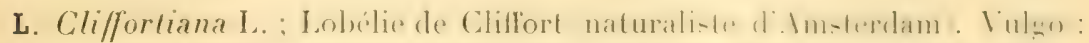

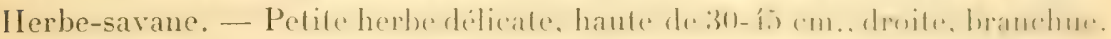
Feuilles ovées, inégalement et srossièrement dentées, pétiolées, petites. Fleurs blanches, petites, en grappes lâches, allongrées, terminales. -

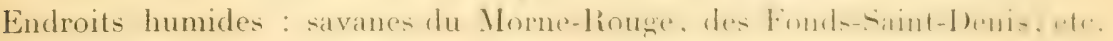
Alt. 350-600 mèt. [No 1748.] -- Je ne l'ai pas vu à la Guadeloupe.

Tupa G. Don (nom indigène de la plante au Pérou.

T. flavescens A. DC.; Tupa à fleurs tirant sur le jaune. Vulgo: Fleur-

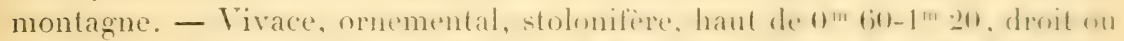
tortueux, toujours nu dans le bas, sans branchen on pen banchu. Fenille-

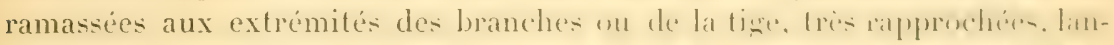

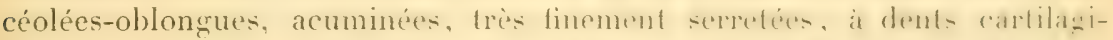
neuses et pointues. Inflopescence en wrappes simples allongins, poptice un long pédoncule: fleurs jaunitres, pédicellees: predicelles farnis de dear bractéoles au milieu et d'une grande bractée à la base. - Haute région des montagnes : abondant à la Savane it Mulets, au coine et ou platesu de la sinufrière, Savane aux Ananas, Grande-Découverte, etc. [No 2408.$]$

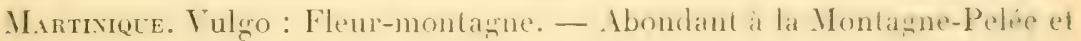
aux Pitons-du-Carbet. [No 504 .

T. stricta A. DC. ; Tupa à tiges en baguette. Vulgo : Fleur-montagne. -

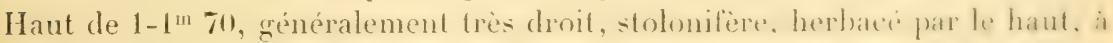
tiges simples ou multiples, grosses, cylindriques, complitement nues dans le. has. Feuilles rigides, lancéolées-oblongues, printues aux deus extrinite-

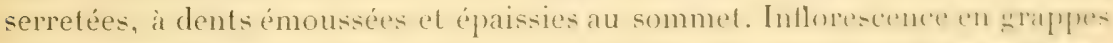

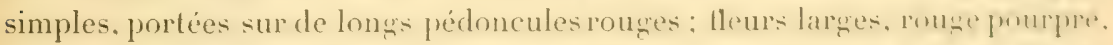
longuement pédicellées tres belles, caracteres par lesquels il ar distingue

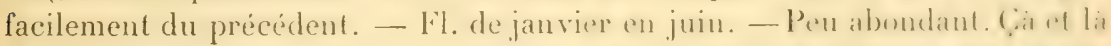
dans les endroits humides ou aquatiques de la rimion supérieure des standbois : Bains-Jaunes environsl. Matelyane, coulee de la havine-ti-l hejen-

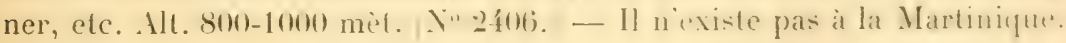

T. cirsiifolia A. DC.; Tupa à feuilles de cirsium (sorte de chardon. Vulgo: Fleur rouge montagne. - Vivace par la hase. herbace par le haml.

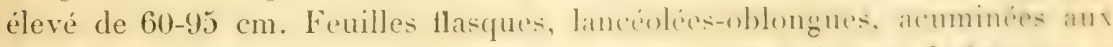

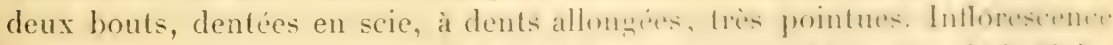
comme dans le précédent. - Cà ef là dans lesendroits humides de la Cate-

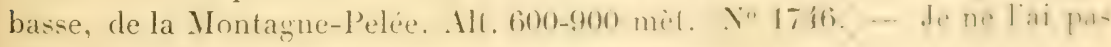
trouvé à la Guadeloupe. 
T. persiciefolia A.DC.; Tupa à feuilles de pêcher. Vulgo: Herbe-poison. Annuel, ornemental, hant de $0^{m}\left(60-1^{m} \cdot 20\right.$, à tige très feuillue, au-dessus de la base. Feuilles flasques, pétiolées, ressemblant, quant à la forme, à celles du pècher. Inllorescence en grappes feuillues; fleurs rouges, pédicellées, bibractéolées pris de la base. - . Dondant sur les talus el le long des chemins dé bois de: Bains-ataunes, du Matouba. - Fl. en tout temps, mais surtout d'octobre à mai. - Alt. 450-800 mèt. [No 2405.]

Il n'existe pas à la Martinique.

T. conglobata A. DC.; Tupa à boule allongée. Vulgo : Fleur-boule-montagne. - Annuel, parfois vivace par les stolons, haut de $30-60 \mathrm{~cm}$., droit ou it base couchée, ì lige inférieurement nue. Feuilles laręes, pendantes ou non, lancéolées, fortement dentées ent scie, acuminées au sommet, brusquement rétrécies à la base, à pétioles longs, décurrents. - Assez abondant dans les ravines de la Calebasse. - Fl. en septembre, octobre et quelquefois en janvier. [N506.] - Je ne l'ai pas vu à la Guadeloupe.

Isotoma Lindl. (du grec " jsos ", égal, et “ lomé ", section, allusion à la régularité de la corolle.)

I. longiftora Presl; Isotome à fleurs à long tube. Vulgo: Quidec-z'erbepoison, mort aux cabrits, mort aux vaches. Pl., éd. Burm., t. 253; Tuss., Fl., IV, t, 25; Desc., vol. III, t. 156, p. 30 ; Sl., t. 104, f. 2. - Bisannuel ou triannuel, haut de $15-45 \mathrm{~cm}$, à tige branchue ou sans branches, rarement bien droite. Feuilles lanciolées ou oblancéolées, sinuées-dentées, ressemblant assez bien ì celles du pissenlit d'Europe. Inflorescence en cymes axillaires, pédonculées; fleurs d'un blane pur, à tube long, cylindrique, à lobes rotacés. - Fl. de novembre en août. - Herbe dangereuse pour les animaux qui la mangent; elle contient un suc laiteux et très corrosif, aussi a-t-on soin de la détruire le plus possible. - Critet la dans les endroits humides et aquatiques ef dans les savanes herbeuses des basse et moyenne régions: environs de la Basse-Terre (ravine de Belost), ravines de IIouëlmont, TroisRivières, etc. Alt. 20-700 mèt. [ $\mathrm{N}^{0} 2410$. $]$

Martinge. Vulgo : Herbe-poison, mort aux cabrits. - Environs de SaintPierre, Trois-Ilets, Marin, etc. [ $\mathrm{N}^{\circ} 47 \%$. $]$

Cent uniène fanille, - GOODÉNIACÉES.

Scævola I. (du latin "scitvus ", sanche, parce que le pistil se trouve du côté gauche, par rapport à la lèvre unique de la corolle.)

S. Plumieri Vahl; Scevola de Plumier. Vulgo: Prune ou cerise bord-demer. Desc., vol. VII, t. 474, p. 92. - Arbrisseau haul de $0^{\mathrm{m}} 60-1^{\mathrm{m}} 40$, à tige 
grosse, souvent couchée el radicante à la base, dressée aux extrémilés, a

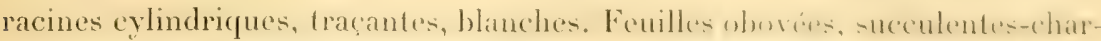

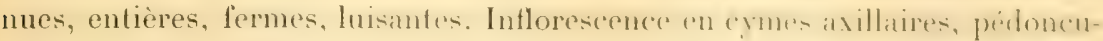
culées, paueiflores; tleurs blanches. Fruil drupacé, noir, pulpeux, rempli d'un sue blane, de la grosseur et de la forme d'une olive. - Vit en société sur les plages sablonneuses de la Désirade. - Fl. toute l'année, avec plus ou moins d'abondance. [No 2997.] — II n'existe pas at la Martinique.

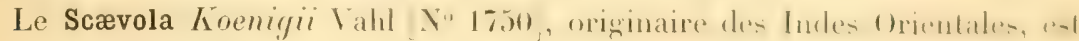
cultivé au Jardin botanique de Saint-Pierre.

De la famille des Loganiacées, qui trouve ici sa place, on rencontre au Jardin botanique de Saint-Pierre les Fagræa ceylanica Thunl). X" 11.5 el F.

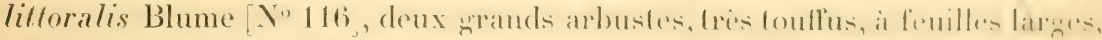

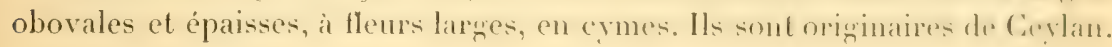

Gent deuxiène fanille. - PLANTAginlées.

Plantago L. (du latin "planta ", plante du pied, el "ago ", je me montre, à cause de la ressemblance de la figure laisiée par les lentilles presies contre la terre avec la trace d'un pied d'homme.)

P. major L.; Plantain majeur. Vulgo : Millet. - Herbacé, vivace, haut de 9-15 cm., sans lige, a rhizome souterain, stoloniliere dans les espiece que jai observées). Fenilles larges, radicales, rosulées, alternes, longument pétiolées, palminerviées, ovées, souvent dentées à la base, un peu plus

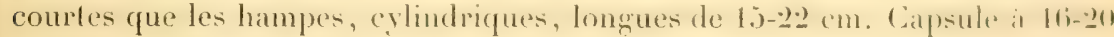
semences, convexes du côté placentaire, plates du côté extérieur. - Probablement introduit d'Europe.-- Assez abondant dans les champs des environs du bourg des Trois-Ilets, dans les jardins et aux pieds des murs et vieilles maisons de Saint-Pierre, de Fort-de-France, du Morne-liouge, ete. - On se sert du sue des feuilles contre les ophtahnies; des feuiltes, feratives, comme vulnéraires; on donne enfin les épis mûrs aux petits oiseaux en cage. - Alt. 5-600 mèt. [No 1920.] — Je ne l'ai pas trouvé à la Guadeloupe.

P. virginica L.; Plantain de la Virginie. Vulgo : Millet. - Annuel, haut de 2.5-33 cm. Feuilles spatulées-oblonerues, drescíes: les inférieures, hom-

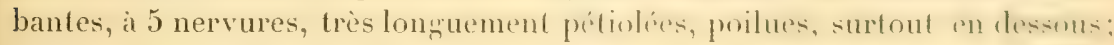
pétioles poilus; hampes considérablement plus longues que les firuilles: pyxides à trois semences seulement, concaves du côté placentaire et convexes du côté extérieur. - Les épis mûrs servent de nourriture aux petits oiseaux. - Assez abondant aux pieds des murs, des vieilles cases, el dans les endroits abandonnés et fertiles: Basse-'Terre, Gourbeyre, Camp-Jacob, Matouba, Moule, etc. [No2424.] - Je ne l'ai pas vu à la Martinique. 
Le P. lanceolata L., vulgo : Plantain lancéolé (herbe à cinq côtes), petit millet, est naturalisé à la Martinique. - Dans les champs des environs du bourn des Trois-llets, dans les environs de Saint-Pierre et dans quelques jardins de cette ville, et du Morne-Rouge. [ $\left.N^{\circ} 1921.\right]$ - Il est très rare à la Guadeloupe.

$$
\text { Cext troisième famlle. - PLUMBAGINÉES. }
$$

Plumbago Tournf. (du latin " plumbum ", plomb, et "agere ", se conduire, parce que la racine contient une matière qui laisse sur les mains une couleur de plomb.)

P. scandens L.; Dentelaire sarmenteuse. Vulgo : Herbe $\mathbf{I}^{\mathrm{me}}$ Bihoret, sinapisme (à cause de ses vertus vésicantes), collant (à cause de ses fruits visqueux), moutarde du pays (à cause de son âcreté). Desc., vol. III, 1. 172, p. 94; Sl., t. 133, f. 1. - Vivace, touffu, très feuillu, haut de 1-3 mèt. el davantage, is tiges glabres, strićes, condées en zig-zag, sarmenteuses-grimpantes. Feuilles ovẻes ou ovées-lancéolies, acuminées au sommet : les inférieures, à base amplexicaule; les supérieures, brièvement pétiolées, légèrement pointillées en dessous; elles ressemblent assez bien à celles de la bette de France. Fleurs blanches, presque sessiles, en épis terminaux, formant ensemble une large panicule allongée ; calice à 5 còtes, garnies de glandes stipitées et visqueuses. - Fl. de décembre en juin. - Toutes les parties de la plante ont une saveur âcre et brûlante. Dans le pars, les habitants se servent des feuilles, froissées, comme vésicantes, en guise de sinapisme. Abondant sur le littoral : Basse-Terre, Baillif, Capesterre (Guadeloupe), Pointe-à-Pitre, Deshaies, Pointe-Noire, Désirade, Marie-Galante, etc. $\left[\mathrm{N}^{\circ} 2430\right.$.

Martinique. Vulgo: Sinapisme, herbe brûlante. - Abondant: Saint-Pierre, Prêcheur, Carbet, etc. [Nº 1919.

Un cultive souvent dans les parterres des deux colonies le Plumbago cnccinea Salisb.. [ $\left.\mathrm{N}^{\circ} 2432\right]$, vivace, stolonifère, à tiges presque couchées, à fleurs rouge foncé, en panicules spiciformes, très allongées, et très souvent le $\mathbf{P}$. capensis Thunb., arbrisseau vivace, stolonifère, grimpant, à fleurs d'un bleu azuré. Originaire du Cap. [No 2430.

Martinique. [No 1918.

CENT QUATRIÈme FaMLLE. - LENTIBULARIÉES.

Utricularia L. (du latin " utriculus ", diminutif de " uter ", outre, allusion aux renflements des segments foliaires, qui ressemblent id de petites vessies.) 
U. montana Jacq.; Utriculaire des montagnes. Jacq., Sel. Am. stirp. hist., t. 6. - Petit herbe, haute de 15-35 cm., sans feuilles ou avec 1-3 feuilles, lancéolées-oblongues ou ovées-lancéolées, arrondies an sommet, contratcliom it lat

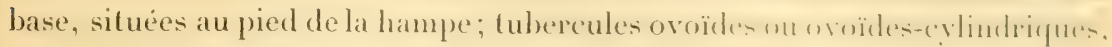
blanes, transparents, luisants, au nombre de 1-3; hampe droite. Fleurs grandes, solitaires, ou plus rarement en cymes uni-trillwes, blanches, munied'une large tache jaunâtre, au milieu. - Fl. surtout de janvier à août. Sur les arbres, dans la mousse ou à terre : bois supérieur's des Bains-Jaunes, du Matouba, montagne de la Madeleine (Trois-Rivieres. Soufrime. (irandeDécouverte, etc. Alt. 700-1480 mèt. [No 29:4.

Martinique. - Bois des Fonds-Saint-Denis, de la Montagne-Pelée, de la Calebasse, des pitons de Fort-de-France, du Lorrain. $\left\lceil\mathrm{N}^{\circ} 1228\right.$.

CENT CINQUì̀me FAMILLE. - MYRSINÉES.

Myrsine L. (du frrec " myrsine ", myrte, paree que ces plantes ressemblent aux myrtes par leur feuillage.)

M. Leta A. DC.; Myrsine à feuillage d'un vert agréable. Vulgo : Cacaravet. - Grand arbuste ou petit arbre, haut de 2-5 mèt., nu dans le bas, très branchu et feuillu par le haut, à branches presque toujours divariquées et étalées, à écorce lisse et gris noirâtre. Feuilles petites, cortiaces, lancroblieson

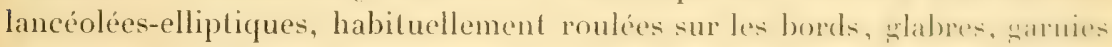
en dessous d'un grand nombre de points transparents. Fleurs très petites,

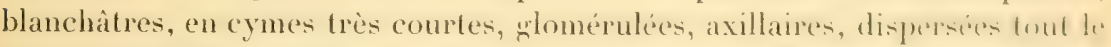
long des rameaux. Drupe oroüde-ghobuleuse, deux fois plus petite qu une graine de poivre, surmontée du style persistant. - Fl. de février en mai. Abondant: Bains-Jaunes, Matouba, (rommier, Trois-Rivières. Mll. Lon900 mèt. [No 2282.]

Martinique. Vulgo : Caca-ravet. - Ajoupa-Bouillon, Champllore, Piton Gelé, Case-Pilote, etc. [No 611.

M. coriacea R. Br.; Myrsine à feuilles coriaces. Vulgo : Caca-ravet. Petit arbre, plus rarement arbed assez grande tailfe, d'une blivation moreme, de 4-8 mèt., à écorce lisse et grise, à branches souvent lastigiées. Feuilles

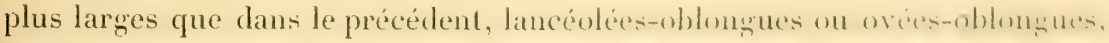
roulées sur les bords, garnies en dessous de nombreux points ot de lizmes transparents. Fleurs glomérulées, insérése sar de petites branches contuleet avortées. Drupe plus volumineuse que dans son congénere prétedent. -

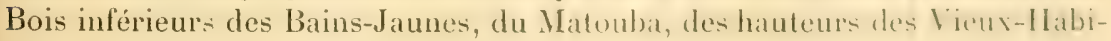
tants. [N $\mathbf{N}^{\circ} 3219$. $]$ 
Martixute. Vulgo: Caca-ravet. - Calebasse, Montagne-Pelée, Piton Gelé, Case-Pilote. $\left[\mathrm{N}^{\circ} 146\right.$.

M. floribunda R. Br. : Myrsine al lleurs abondantes. Vulgo: Caca-ravet-montagne. - Arbrisseau rábougri et très touffu, ou grand arbuste ì tête arrondie, élégant. droit. Feuilles petites. ohlongrues ou elliptiques-lancéolées, cichancrées ou réluses au sommel, fortement roulées sur les bords : les adultes, opaques. Drupes très petites. - Fl. de septembre à février. - Plateau de la Soufrière, Grande-Découverte, Savane aux Ananas, etc. [No 3703.$]$

Martinique. Vulgo : Caca-ravet. - Assez abondant dans le massif des montagnes entre les Deux-Choux el les Pitons-du-Carbet, notamment sur le morne d'Amour. [No 610.$]$

Grammadenia Benth. (du wree "gramma ", ligne, et " aden ", rnlande, parce que les feuilles sont zarnies en dessous de nombrenses glandes linéaires.)

G. parasitica (rriseb. : Grammadénic parasite. - Plante épiphyte, ornementale, longue de $0^{\mathrm{m}} 60-1^{\mathrm{m}} 20$, à branches pendantes ou horizontales, à écorce grise. Fenilles oblancéolées, sessiles, brièrement acuminées, entières. Fleurs blanchàtres, tachetées de points noirs, en petites grappes axillaires, confinées aux aisselles des dernières feuilles des rameaux, deux ou trois foisplus courtes que les feuilles. Drupe petite, noire. - Rare : çà et là sur les arbres du Matelyane el de la coulée de la Ravine-à-Déjeuner. Alt. 800-950 mèt. [No 3479.] - Il n’existe pas à la Martinique.

Ardisia Sw., Miq. (du grec " ardis », pointe, épine, parce que les différentes parties de la fleur sont pointues.)

A. laurifolia 1. I)C., A. lateriflora, var. lalifolia Sieb. ; Ardisier it feuilles de laurier. - Grand arbuste, élégant, très branchu, droit, à branches et tige nues dans le bas. Feuilles coriaces, lancéolées-oblongues ou elliptiques, terminées en pointe, arrondie, rétrécies, à la base, en un largée pétiole marginé. Fleurs blanches, d'une odeur très suave, en corrmbes composés, axillaires, ombelliformes. - Hil. presque toute l'année. - Peu abondant : sà et là dans les bois humides des Bains-Jaunes, du Matouba, des Trois-Rivières, des Vieux-Habitants. Alt. 400-900 mèt. [No 2283.]

Martixique. Vulgo : Aralie-z'abricol. - Fonds-Saint-Denis, Case-Pilote (bois de la savane Saint-Gyr), Camp de l'Alma, Lorrain. [No 236.]

A. guadalupensis Duchass.; Ardisier de la Guadeloupe. Vulgo : Bois petit chique. - Arbuste haut de 2-3 mèt., rarement plus élevé, élégant, a branches nombreuses, fastigiées. Feuilles cartilagineuses, obovées-oblongues ou elliptiques-oblongues, contractées, à la base, en un court pétiole. Inflorescence en grappes composées, pyramidales, terminales; fleurs tantôt orangées, tantôt jaunâtres, tantôt vert jaunâtre. - Fl. de décembre en férrier et sourent de 


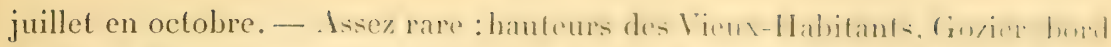
de mer), Marie-Galante (bois de Folle-Anse). Alt. J-100 mèt. [No 2.281.

Martinique. Vulgo: Bois-chique. - Assez abondant dans les hauteurs infé-

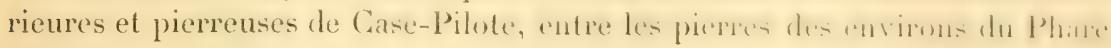
de la Caravelle, des mornes calcaires de Sainte-Anne, clc. $Y^{\circ} 1.17$.

Les A. crenulata Vent. [No 1732], petit arbrisseau des plus élégrants, el A.

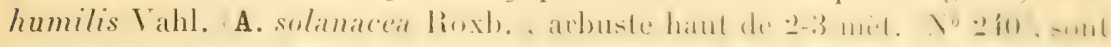

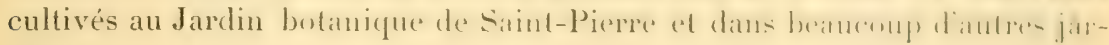
dins.

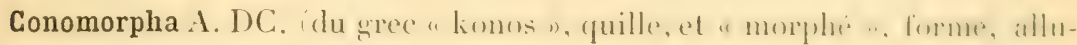
sion au pistil, qui est court et en forme de quille.)

C. peruviana A. DC.; Conomorphe du Pérou. Vulgro : Bois-chique. Arbuste ou petit arbre, peu branchu, nu dans le bas, haut de $2-1$ mèt., it jeunes rameaux couverts de petites pellicules. Feuilles ovales, ou obovéeselliptiques, très brusquement rétrécies, au sommet, en une pointe courte,

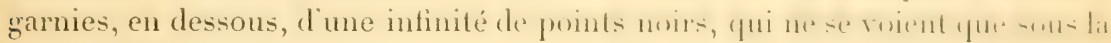
loupe. Inflorescence en grappes simples, axillaires, plus courtes que les

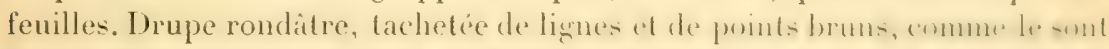

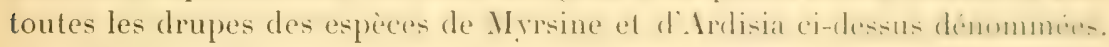
- Fl. en mars, avril. - Rare: Pigeon (dans les grands bois, sur une crête au pied du morne Desboulais, au-dessus de l'habilation Maler. 1o 373 í. Il n'existe pas à la Martinique.

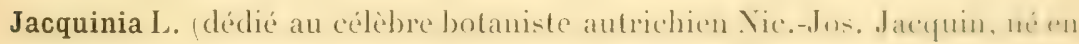
1727, à Leyden, médecin, a collectionné, de 1751 à 1759 , dans les Indes

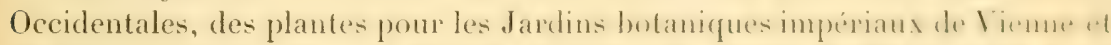

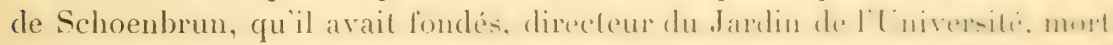
en 1817. A écrit : Enumeratio systematica plantarum quas in insulis caribxis vicinoque America continenti detexil; Selectarum americanarum

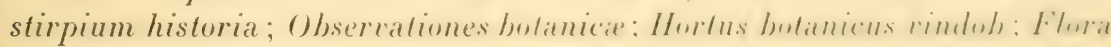
austriaca, etc.)

J. armillaris Jacq. ; Jacquinie à bracelets. Vulgo : Bois-casse-cou, olivier

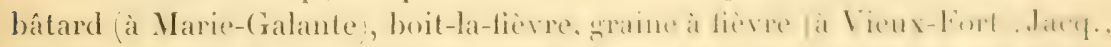
Sel. Am. stirp. hist., t. 39; Sl., t. 190, f. 2. - Arbuste haut de 1 "' $50-2{ }^{m} \mathrm{SO}$,

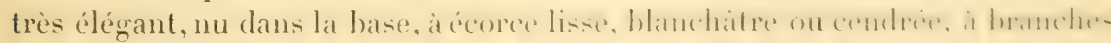
nues, verticillées par 4-5, nombreuses, courtes. Feuilles d'un vert très pâle,

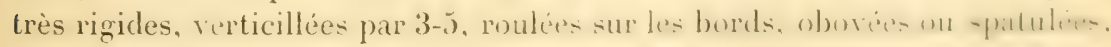
arrondies au sommet et souvent mucronulées. Inflorescence en grappes courtes, ombelliformes, terminales, tris monbrenses flem-hlame frile, limant

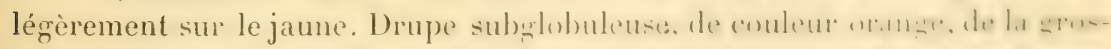

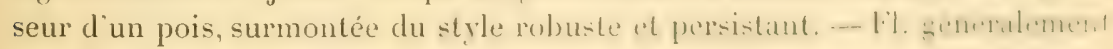


de février en avril et d'octobre en décembre. - Les Caraỉbes, après avoir enlevé la pulpe, peręaient les novaux et en fabriquaient des bracelets. Arec les feuilles et les jeunes tiges, macérées et mises dans l'eau, on peut enirrer les poissons. - Assez abondant dans les falaises et entre les rochers du bord de mer, et souvent un peu à l'intérieur : Vieux-Fort, Marie-Galante (Capesterre, sur les mornes calcaires), Gozier (bord de mer), Saint-François, elc. $\left[\mathrm{N}^{\circ} 2280\right.$.

Martinique. Vulgo : Bois-bouc (à la Caravelle), bois-bracelet. - Caravelle (habitation Le Ferré et environs du Phare. [No 1730.]

Le J. ruscifolia Jacq. [ $\mathrm{N}^{\circ} 1727$ ], petit arbrisseau, très élégant, à feuilles très piquantes, origninaire des montagnes de la Havane, et J. arislata Jacq. No 1731 , grand arbuste, à leuilles émalement piquantes, à lleurs de couleur orange, sont cultivés au Jardin botanique de Saint-Pierre.

CENT SIXiène FAMILLe, - SAPOTAGÉES.

Chrysophyllum L. (du tgree " chrusous ", d'or, et " phyllon ", feuille, parce que les feuilles sont dorées en dessous.)

C. Cainito L.; Chrysophylle kämite. Y'ulgo : Kä̈mitier ou kä̈nitier. Desc., vol. II, t. 70, p. 13 ; Jacq., Sel. Am. stirp. hist., t. 37. - Petit arbre ou arbre de taille movenne, à écorce noirâtre, gercée. Feuilles ovales on oblongues, ou ovales-oblongues, dorées, soyeuses en dessous. Inflorescence en fascicules axillaires, disposés tout le long des branches, it l'aisselle des feuilles, comme cela a lieu dans toutes les Sapotacées du pays. Fruit large, ovoïde ou sphérique, selon les variétés, de la grosseur d'une pomme, rempli d'un sue blane et gluant; semences 8-10, dont 2-4 seulement se développent. - Fl. en mai. juin, juillet. - Les fruits sont stomachiques et astringents; l'aubier est tendre, mais le ceur est dur et noirâtre 1. - Rare ì la Guadeloupe : BasseTerre, Camp-Jacols (habitation Rollin), Trois-Rivières. [No 3672.]

Martingue. Vulgn: Kä̈mitier, kä̈mitier blane. - Abondant: Sant-Pierre, Carbet, Prêcheur, Trinité, François, etc. [No 264.] - Par la culture et la greffe, on a obtenu plusieurs variétés, supérieures à l'espèce-type par le volume de leurs fruits; la variété Martinicensis Pierre, vulgo : "La grosse blanche ", en est une des plus appréciées. [ $\mathrm{N}^{0} 262$.

C. cxruleum Jacq.; Chrysophylle à fruits bleus. Vulgo : Kämitier noir, gros bouis. Jacq., Sel. Am. stirp. hist., t. 3\%. - Grand arbre, cultivé çà et là à la Martinique. - Le fruit est sphérique, beaucoup plus petit que celui clu

1. Écorce tonique excitante, amande amire à étudier. 
précédent, de couleur bleu foncé. Rare: Jardin botanique, fontainc Didier. Parnasse. [ $\left.\mathrm{N}^{\circ} 263.\right]$ - Cet arbre ne tardera pas di disparailre du sol de la Martinique.

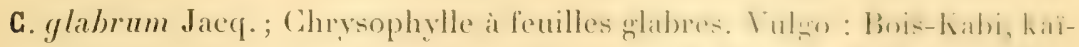
milier-bois, bois de bouis. Jacq., Sel. Am. stirp. hist., 1. 38, 1. 2. - Petit arbre, haut de 6-12 mèt., rarement plus grand, très branchu, ¿ branches

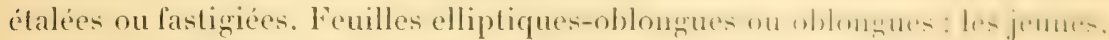

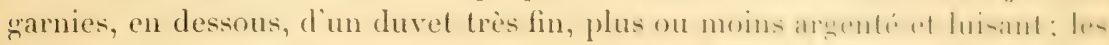
adultes, ylabres en dessous. Drupe mûre, bleu fonce en delun- renlimmint

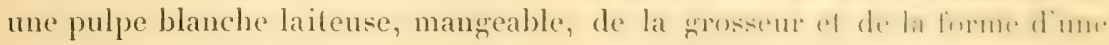
grande olive ou plus grosse. - Fl. en mai, juin, juillet. - I te bois est recher-

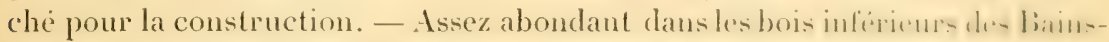
Jaunes, du Matouba, du Gommier, hauteurs des Vieux-llabitanls. ole. Ill. 200-700 mèt. [No 2911.]

Martinique. Vulgo : Bois-Couis, petit bouis. - Abondant dans les bois inférieurs : Parnasie, morne Saint-Martin, lontaine Didier, Champllore, ate. $\left[\mathrm{N}^{\circ} \mathbf{2 6 5}, 266,269\right.$.

C. argenteum Jace.; Chrysophỵlle à feuilles arenentées en desinus. Vulen : Petit bouis, prune, bois-glu (a Marie-Galante), acomat ì la ciomde-Terre. - Ressemble au précédent; il en diflère par son écorce plus blanchitre, ses feuilles habituellement plus petites et garnies, en dessons, d'un duvel serriot fortement argenté. - Ses fruits se mangent également. — Se plaît dans la basse région sèche : Vieux-IIabitants, Morne-itl'in, Monle rare, (forier

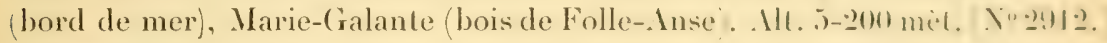

Martinique. Vulgo : Bouis. - Parnasse, bord de mer, entre le boure de la Trinité et le Robert, Trois-Ilets, etc. [No 747.

Sapota Plum. (du nom indigène au Mexique " cochit-zaboil ».)

S. Achras Mill, Achras Sapola L. idu wrece "achmas", poirier, parce que

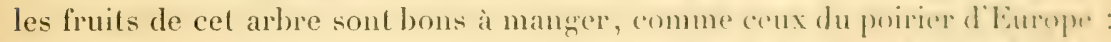
"achras" sapplique réellement au poirier saurage, dont les fruits n iataient pas mangeables; de "achraios ", inutile, sans usage. lulwn: Silpulillier. Tuss., Fl., I, t. 5; Desc., vol. IV, t 259, p. 112; Br. Jam., 1. 19, 1. 5; Sl., 1. 69. - Grand arbre, tres branchu, a frondatison arrondie, a branches inferieures horizontales, à jeunes rameanx, pédicelles el pélioles garnis d’un duvet couleur de rouille. Feuilles ramasses amx extremiles des hranches. très rapprochées, lancéolées-oblongues on plus on moins ellipliques. Fleurs

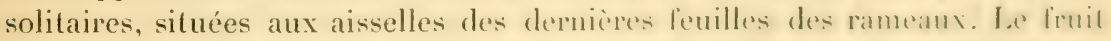
est une pomme dont le volume et la forme varient heaueoup, selum lexpusi-

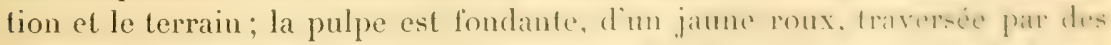

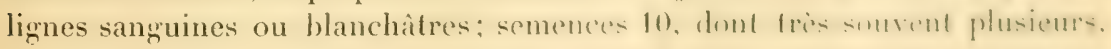
rarement toutes, avortent. - Ce lruit est diurétique, mais les granines le 
sont a un degré plus élevé; dans le pays, on les écrase, après les avoir débarrassées du testa, et on en prépare une tisane. L'arbre contient, comme la plupart des plantes de cette famille. un latex blane, résinoöde, analogute à la gutta. Le bois est rougeâtre, dur et incorruptible; il sert pour la menuiserie, le charronnage, et pour construction dans l'eau et dans la terre. - Il fleurit habituellement deux fois par an. - A la Basse-Terre, on mange de sesfruits presque toute l'année: les chauves-souris leur font une guere acharnée. - Abondant dans la basse région de toute la Guadeloupe et dépendances. [No 2914.]

Martivique. Vulgo: Sapotillier. - Abondant dans toute l'île. [No 1909.]

Sideroxylon L. (du grec " sideros ", fer, et "xulon ", bois, parce que le bois est très dur.

S. Mastichodendron Jacq.. Bumelia pallida sw.; Sidéroxỵlon produisant du mastic (du grec "mastiché ", mastic). Vulgo : Acomat, acomat franc, acomat bâtard. Desc., vol. II, t. 88, p. 86..-Grand arbre, à tronc droit, à fronde élancée, a branches peu étendues : les inférieures, pendantes ou trìs penchées, à écorce peu gercée. Feuilles ovales, membraneuses, ondulées sur les bords. Inflorescence en fascicules axillaires, très nombreuses, situées tout le long des rameaux; fleurs petites, jaune verdâtre, à odeur forte et agréable; pédoneules courts. Drupe jaunâtre, lisse, de la forme et de la grosseur d'une olive, contenant un suc jaunàtre, très visqueux ef d'une saveur trèsamère; semence 1, dure, polie, amère. - Fl. de septembre à novembre; fruits mûrs en février et mars. - Cet arbre est devenu rare à cause de lexcellence de son bois pour la construction; il est dur. compact, jaunatre en dedans. Son incorruptibilité dans la terre et dans l'ean tient sans doute à son amertume, qui le rend inattaquable par les insectes. - Vieux-Fort iquelques pieds, environs de la Basse-Terre (ravine de Belost); çà et lì au Moule, Marie-Galante (bois de Folle-Anse). [No 2915.]

Martixique. Vulgo : Acomat. - Très rare : Caravelle (environs du Phare, quelques pieds), hauteurs inférieures des Trois-Ilets. [No 1920.

S. chrysophylloides Mich. Bumelia tena Willd; Sidéroxylon ressemblant au chrysophylle. Vulgo : Kaïmitier-bois. - Arbre parfois énorme et très ḋancé, à tronc très anfractueux, surtout it la base, à branches horizontales, ¿ écorce grise et crevassée. Feuilles rigides, obovales, assez brusquement rétrécies, au sommet, en une pointe courte, contractées a la base : les jeunes. dorées en dessous et luisantes; les adultes, blanchàtres argentées. Fruit cylindrique, obtus aux deux bouts, long de $3-1,5 \mathrm{~cm}$. sur $1-7 \mathrm{~mm}$. d'épaisseur: comestible. - Cà et là dans tons les grands bois inférieurs des Bains-Jaunes, du Gommier, du Natouba, de la Pointe-Noire au-dessus de l'habitation Longcase), etc. - Alt. 400-700 mèt. [No 3379.

Martinique. Vulgo: Bois à rames. - Çà et là dans les bois des hanteurs 
de Case-Pilote et de la fontaine Absalon, où je l'ai trouvé à l'étal de petil arbre. $\left[N^{\circ} 268\right.$.

Mimusops L. (du grec " mimo ", singe, et " ops ), aspect, parce que les fleurs ont l'aspect d'une tête de singe.)

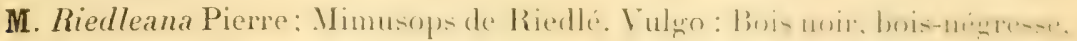
sapotillier marron. - Arbre de taille moyenne, à trone peu élevé, à branches

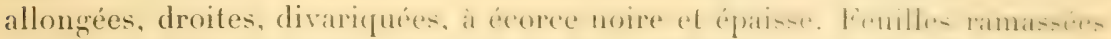

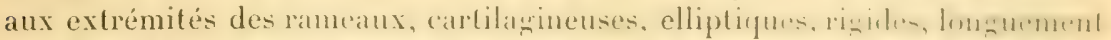

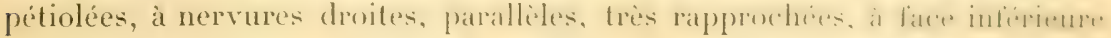

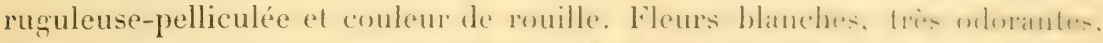

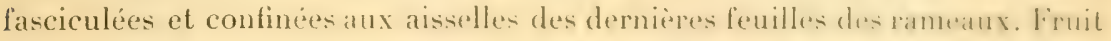
légèrement ruguleux, sphérique, pédonculé, de la grosseur d'une prune, surmonté du gros style persistant. - Fl. en juin, juillet. - Assez abondant

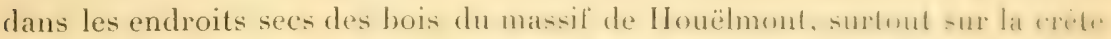

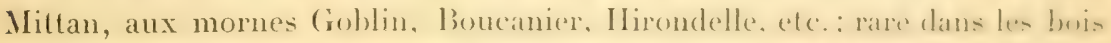
des Bains-Jaunes, du Matoulaa plus abondant dans les hauteres des lieusHabitants. [No 3263 .]

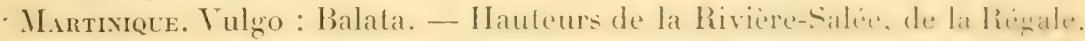
- Le bois est recherché pour la construction. [N०252.]

Le Mimusops Elengi L., est cultive au Jardin botanique de Sitinl-l'ierre. [No 1908.]

Oxythece Miq. Lucuma Juss., du gurec "oxus ", porintu, et "thehe ". linerreau, étui, allusion aux étamines soudées en tube aminci au sommet.)

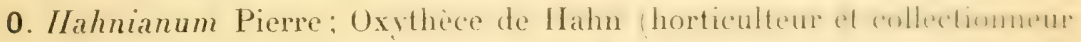
martiniquais). Vulgo : Balata rougge. - Très grand arbre, à tronc droil,

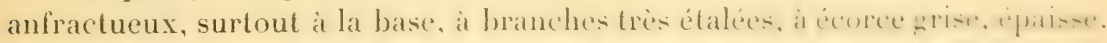
Feuilles cartilagineuses, larges, olwreses, arromdies au sommet, blandhitre-

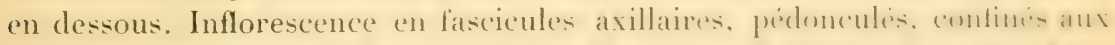

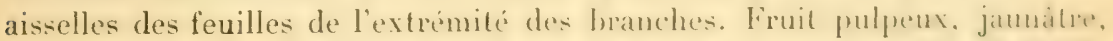

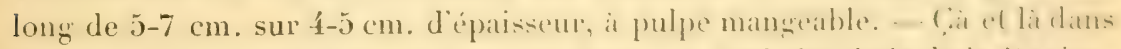

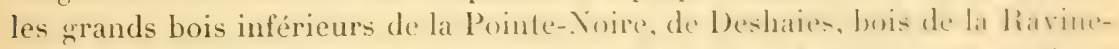
Chaude, de Sofaya, ete. - Le bois est recherehe pour la construclion: il e-t dur, élastique, doune teinte ronge brun, et se conserve indeliniment dan- la terre el dans l'eau. [No 3493.$]$

Martinique. Vulgo : Bois Balata, bois Balate: - Dans tous les grands bois des Fonds-Saint-Denis, du Cimp Balata, de l'Ama, du lanrran, ete. [Nos 253, 254.]

Guapeba Gomez inom de la plante au Brisil, | Guapebeira limm. Lucuma Juss.)

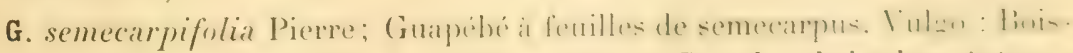
contrevent. Desc., vol. V, t. 346, p. 160. - Grand el bel arbre, it trome 
élevé, très branchu, à branches inférieures très étalées et horizontales, à écorce noirâtre, gercée. Feuilles larpes, obovales, subcordées à la base et rétrécies en un pétiole large el court. Inflorescence en fascicules axillaires, sessiles, très nombreux, situés tout le long des rameaux. Fruit inconnu. - Fournit un bois recherché pour la construction. - Çà et là dans les grands bois de l'Alma, du Lorrain, de la fontaine Absalon. [No 255.] - Je ne l'ai pas trouvé à la Guadeloupe.

Dipholis A. DC. (du gree "dis ", deux fois, et "pholis ", écaille, pellicule, parce que la corolle est garnie d'une double rangée d’appendices, dont les extérieurs se trouvent entre les divisions de la corolle, et dont les intérieurs alternent avec les filets.)

D. salicifolia A. DC.; Dipholis à feuilles de saule. Vulgo : Acomat bâtard. Sl., t. 205, f. 2 ; Br., Jam., t. 17, f. 4; Rich., Cuba, t. 54, f. 2. - Petit arbre, plus rarement arbre de taille moyemne (dans nos colonies), à trone droit, très branchu, à branches habituellement courtes, infléchies ou plus ou moins horizontales, à rameaux garnis, à l'extrémité, d'un duvet soyeux. Feuilles lancéolées, pointues aux deux bouts. Inflorescence en fascicules axillaires, très rapprochés et nombreux, disposés tout le long des rameaux; lleur's verdàtres, très odorantes. Drupe ovoïde-allongée, noire, de la grosseur d’une petite cerise. Fl. en mai, juin; fruits mûrs en août et septembre. - Abondant sur les mornes calcaires de toute la Grande-Terre, de Marie-Galante. No 2913. Il n'existe pas à la Martinique.

Bumelia Sw. Gaerl. (du grec "boumelia ", c'est-ì-dire le grand Mfelia des anciens auteurs, qui est le Fraxinus excelsior L. et qui n'a aucun rapport avec notre plante; l'auteur a voulu perpétuer le nom antique d'une plante à haute tige, parce que les Bumelia sont souvent des arbres de grande taille.)

Lucuma Molina (nom indigène de la plante au Pérou.)

L. Dussiana Pierre. Vulgo : Pomme-pain. - Arbre de taille moyenne, plus rarement de grande taille, droit, à branches plus ou moins étalées, à tronc nu jusqu à une grande hauteur. Feuilles obovales-elliptiques, coriaces, rétrécies ì la base, arrondies ou rétuses au sommet. Inflorescence en lascicules axillaires, pédonculés, disposés tout le long des rameaux. Fruil ovoïde, ou sphérique-déprimé, environ une fois plus volumineux qu’un aul' de poule, lisse en dehors et jaunâtre, à pulpe brun jaunâtre; mangeable. - Fl. en octobre, novembre, janvier, comme aussi en juin et juillet. - Le bois est très apprécié pour la charpente. - Assez abondant dans les bois du massif de IIouëlmont, des hanteurs de Bouillante, de Pigeon, de la Pointe-Noire; plus rare au Gommier et dans les bois des Bains-Jaunes. Alt. 300-700 mèt. [No 2916.]

M.ırtixique. Vulgo: Bois de pain d'épice. - Morne-Rouge, Champflore, Fonds-Saint-Denis, Grand'Anse, etc. [Nos 257,258 . 
L. mammosa Gærtn.; Lucuma à fruits en forme de mamelle. Vulgo : Sapole, grosse sapote. Sl., t. 218. - Habituellement arbre de petite taille, assez

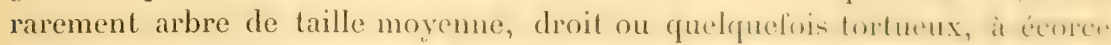

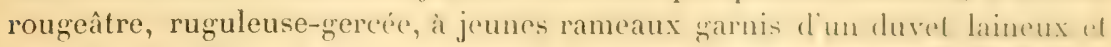

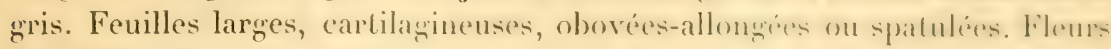
fasciculées, sessiles, disposées tout le longr des rameaux. Fruit mammifirme. volumineux, contenant une semence. - Il est dime salveur fidte of frineratement peu apprécié. L'amande est ayréable au goutl, mais un pen amere: gragée, elle entre dans la confection des cremes. Le fruit, avant sat maturite, est doué de vertus astringentes et peut servir contre les diarrhies rebebles et chroniques. - Fl. en août, septembre et octobre. - Peu abondant. Cultivé çà et là autour des maisons : Camp-Jacob (Choisy), Montéran,

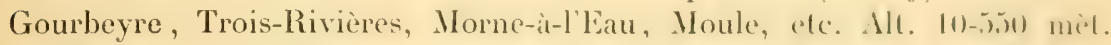
[No 3734.$]$

Martixieue. Vulgo: Sapote à crème. - Cà et là dans toute l'île. [No1901.

CEXT SEPTIÈn: FAMULE. - STYYRACÉS.

Styrax L. (du grec "sturax ", nom de la gomme résineuse qui découle de ces arbres.)

S. glabrum Sw.; Styrax nu. Vulgo : Oranger des bois, cypre-orange. - Le plus souvent petit arbre, plus rarement arbre de taille moyenne, droit, à branches très divariquées, nombreuses, étalées, à écorce gris blanchâtre. Feuilles elliptiques ou elliptiques-oblongues, subentieres, pmintues, garnies en dessous d'une couche de petites squamules blanches. Fleurs blanches, très odorantes, en cymes axillaires, raccimiformes; ditamines monadelphes; anthères jaunes. Fruit ovö̈de, hong de 201-2.5 mm., surmonté du style persistant, posé dans une cupule formice par le calice persistant. - Fl. souvent deux fois dans l'année, en juin et juillet, ct auswi en octobre et novembre. - Le bois est dur, d'une teinte jaune foncé el

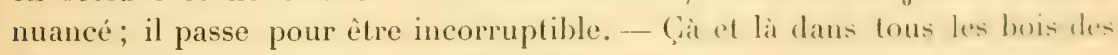
Bains-Jaunes et du Gommier. [Nos 3262,3707 .]

Martinique. Vulgo : Laurier caraibe, bois-madame. - Bois de la Calebasse, de l'Ajoupa-Bouillon, de fontaine-Chaude, de Case-Pilote savame Saint-Cyr). Alt. 250-650 mèt. [No 1728.]

Symplocos Jace. (du gree "sumploké ", noué, parce que le- filets stamiminaux sont concrescents avec la base de la corolle.)

S. martinicensis Jacq. : Symploce de la Martinique. Vulwe : Ciraine hene. Sw.; Observ., t. 7, f. 1; Jacq., Sel. Am. st. hist., t. 175, 1. 68, la Ileur. 
- Petit arbre, haut de 6-9 mèt., à branches nombreuses, le plus souvent fastiriés. Feuilles jamais complietement ouvertes, elliptiques, subentières ou crénelées. Inflorescence en cymes axillaires, avec branches à 3-7 fleurs blanches odorantes. Drupe pulpeuse, bleu fonce, cylindrique-oblongue ou obovée-elliptique, ou ovale, longue de 9-12 cm. sur 5-7 mm. d'épaisseur. - Fl. principalement d'octobre en janvier. - Abondant : Camp-Jacob, Bains-Jaunes (bois inférieurs), Gommier, Vieux-Habitants, Pigeon, Bouillante, etc. [No 2236.$]$

Martinique. Vulgo : Graine bleue, caca-rat. - Abondant : Morne-Rouge, Champflore, Fonds-Saint-Denis, Case-Pilote, Case-Yarire, Ja hígale, ete. Alt. 350-700 mèt. [Nos 1494-1727.

S. guadalupensis Kr. et Urb.; Symploce de la Guadeloupe. Vulgo : Graine bleue de montagne. - Arbre de taille moyenne, assez souvent de grande taille, droit, entièrement glabre, à écorce noirâtre ou grise, lisse, à branches peu allongées, horizontales ou penchées. Feuilles rigides, lancéolées, acuminées aux deux extrémités, plus petites que danş le précédent; vert pâle. Inflorescence en petites srappes plus courtes que les feuilles, ne portant environ que huit fleurs blanches, très odorantes. Drupe ovée-elliptique, rétrécie à la base, longue de $12-15 \mathrm{~cm}$. sur $8 \mathrm{~mm}$. d'épaisseur. Fl. de févier en mai. - Dans les bois supérieurs du IIaut Matouba (Ravineà-Déjeuner), chemin du Matelyane à la Sarane aux Ananas, où il est sourent rabougri. Alt. $800-1100$ mèt. [N ${ }^{\text {us }} 2989,340 \%$. - Il ni existe pas à la Martinique.

\section{CENT Huttièue FAMILLE. - ÉBÉNACÉES.}

Diospyros L. (du grec " dios ", divin, et "puros", nourriture, parce que les principales especes de ce grenre ont des fruits d'une saveur agréable.)

D. Ehenaster liet\%; Plarqueminier-ébène. Vulgo : Barbacoar, bois-négresse. - Arbre de taille moyenne, souvent plus ou moins tortueux, à branches très divariquées, lıorizontales, à écorce noire, extrêmement crevassée et se détachant par plaques. Feuilles cartilagineuses, luisantes : les adultes, obovées; les jeunes, elliptiques. Fleur's diö̈ques, blanches, axillaires : les mâles, caduques, en petites grappes beancoup plus courtes que les feuilles: les femelles, solitaires. Fruit déprimé-ronditre, de lat grosseur et de la forme d'une petite pomme reinette, contenant 2-4 graines aplaties-convexes. L Lintérieur est rempli d’une pulpe noirâtre. - Les grraines, écrasées et mises dans l'eau, enirrent les poissons. Le bois est très amer et aussi dur que le chéne; il a une leinte tris foncé; à cause de son incorruptibilité, on l'emploie pour les constructions dans l'eau et dans la terre. - Fl. en juin, juillet, anût. - Issez abondant dans les bois du massif de Houëlmont: plus rare 
dans les bois des Bains-Jaunes el du Gommier; se rencontre aussi dans les hauteurs de Bouillante (Trou au Trois-Diables), el dans les bois inlérieur: de la Pointe-Noire. [No 2573.] — Il n'est pas à la Martinique.

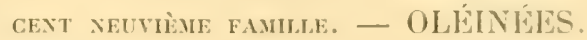

Mayepea Aubl. ide "Marepé " nom indigine de la plinte a la Ciuyante.

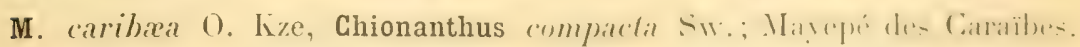
Vulgo : Bois de fer, bois de fer blanc. (Linociera Sw.) - Pelit arbre, haut de 8-10 mèt., droit, à branches fastigriées ou divariquées, à écorce cendrée. presque lisse. Feuilles coriaces, presque jamais ouvertes, elliptiquesoblongues. Inflorescence en panicules pramidales, latres. axillaires confines ¿l l'extrémité des branches, quelquefois terminales. Fleurs d'un blanc très

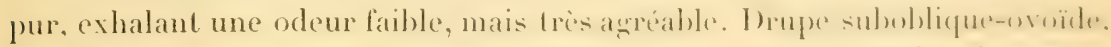
allongée, brun noir. - Fl. en avril, mai, juin. - Le bois est dur, incorruptible et sert pour les constructions souterraines. - Croît dans tous les bois inférieurs plus ou moins sees, sans être abondant nulle part : Vieux-fiort

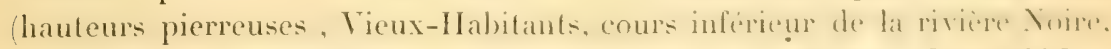
Pointe-Noire, Trois-Rivières (bord de mer). Alt. 10-700 mèt. 1 [No 22-14.]

Martineue. Vulgo: Bois de fer. - Morne-Rouge (Calvaire), hauteurs du Prêcheur, et des Anses-d'Arlet, elc. [No 1234.]

M. Dussii Kr. et Urb. Vulgo : Acomat du pays. - Petil arbre, haul de 4-7 mèt., droit, très branchu. Feuilles coriaces, ovales ou elliptiques, acuminées au sommet. Inflorescence en panicules axillaires, latress : lhems hlanches.

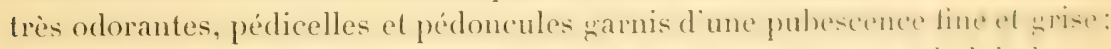
lobes de la corolle plus larges que dans le précédent. Drupe sulmblubuleuse. - Fl. en juin, juillet. - Assez rare : dans le bois entre la rivière de la Capote-et le versant occidental du Champllore. [ $\left.\mathbb{N}^{\circ} 336.\right]$ - Je ne l'ai pas trouvé à la Guadeloupe.

Forestiera Poir. idédié au Français Charles le forentier. collaturateme de

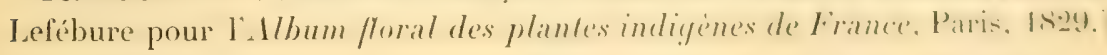

F. rhamnifolia Griseb., variété Martinicensis lir. el Urb.; Forestiere à feuilles de Rhamnus. - Grand arbuste, haut de 2-1 mèt., tries branchu, it

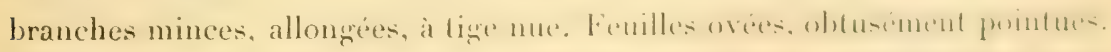

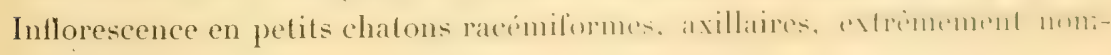

1. Le Mayépé de la Guyane (M. guyanensis Aubl., Linociera letrandra 11. 13\%) est utilisé dans son fruit, dont l'enveloppe est amére ef Lonique. Colui du Marépé dés Antilles a sans doute les mêmes propriétés et devrail être étudie de ce proint de vur: comme celui de la Guyane. (L. II.) 
breux; fleurs vertes, polygames. Irupe petite, bleu foncé, Inngue de 5 -7 mm. sur $3 \mathrm{~mm}$. d'épaisseur. - Fl. en septembre et octobre. - Rare : çà et là sur les mornes pierreux et secs de Vieux-Fort. NNo 3244.

Martixique. Vulgo : Caca ravet, graine bleue bâtard. - Sur les mornes calcaires de Sainte-Anne. $\left[\mathrm{N}^{\circ} 640\right.$.

CEXT DIXILME FAMHLE, - JASMINEES.

Jasminum I. (de "Jasmin ", nom de la plante chez les Arabes.) (nn cultive fréquemment les espèces suivantes, mais dont aucune n'est indigène :

J. Sambac dit. Vulgo: Jasmin double. - Arbrisseau sarmenteux-tortueux, it lleurs presque toujour's doubles, d'une odeur forte et exquise. - Dans les jardins abandonnés, on le rencontre quelquefois avee des fleurs simples. Originaire des Indes Orientales. [No 2286.] - Martinique. [ $\mathrm{N}^{\circ} 342$.

J. humile L. Vulgo : Jasmin jaune. - Arbrisseau buissonneux, haut de 2-4 mèt., à feuilles imparipennées de 5-7 folioles, à fleurs jaunes, à odeur faible. [ $\left.\mathrm{N}^{\circ} 2287.\right]$ - Martinique. $\left[\mathrm{N}^{\circ} 345\right.$.

J. grandiftorum L. Vulgo : Jasmin odorant. - Sarmenteux, grimpant, à feuilles imparipennées de 5-11 folioles, a fleurs blanches, diune odeur forte et très agréable. [ $\mathrm{N}^{\circ}$.2284.] - Martinique. [No 641 .

J. azoricum L.; Jasmin des Açores. Vulgo : Jasmin à bouquet. - Sarmenteux, grimpant, ì fleurs blanchâtres ou rosées, en panicules terminales, it odeur des plus suaves. - Rare à la Guadeloupe : Basse-Terre, Pointe-àPitre. [No 3697.] - Plus abondant à la Martinique. [No 341.

J. undulatum Ker-Gawl. Vulgo :Jasmin blanc. - Arbrisseau d'abord droit, ensuite sarmenteux, à feuilles ondulées sur les bords, à fleurs blanches, odorantes, laryes, en cymes ombelliformes, it corolle rotacée. $X^{0} .2055$. - Martinique. $\left[\mathrm{N}^{\circ} 642\right.$.

J. puhescens Willd., J. multiflorum Andr. - Arbrisseau d'abord droit, ensuite sarmenteux, très branchu, à jeunes tiges, feuilles, pédoncules, pédicelles et pétioles garnis d'un duvet gris ou roux, à fleurs blanches, sans odeur, en crmes courtes, terminales, très nombreuses. Cest l'espèce la plus commune : elle se propage avec une grande facilité par ses racines stolonifères; on la rencontre souvent aussi dans les cimetières. $\mathbf{X}^{2} 288$. - Martinique. [No 339.

Tous les jasmins ci-dessus dénommés fieurissent sans interruption, mais ne produisent pas de fruits.

Au Jardin botanique de Saint-Pierre et dans quelques jardins de cette ville, on cultive le Nyctago arber-tristis L.., arbrisseau droit, qui fleurit tout le temps et rapporte des fruits, Originaire de l'Asie tropicale. $\left[\mathrm{N}^{\circ} 343\right.$. 


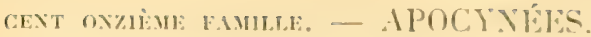

Allamanda L. (dédié au Dr Fr. Allamand, qui, dans la seconde moilié du xvm $^{e}$ siècle, était professeur d'histoire naturelle at Leyde. Il a entrepris en Amérique un voyare marequé par la découverte de beatenup de planter muvelles; il a aussi publié une édition des ouvrages d'histoire naturelle de Buffon.)

A. cathartica L., Orelia grandiffora Aubl.: Allamata purpative. lulers : Liane à lait. - Arbrisseau-liane, haut de 3-6 mèt. à écorce noire ou noirâtre.

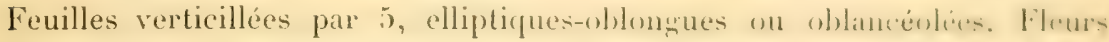
jaunes, larges; corolle à tube intumdibiliforme, brusquoment dilati. - cintle belle liane est constamment couverte de lleurs, mais ne produil pas de linil=:

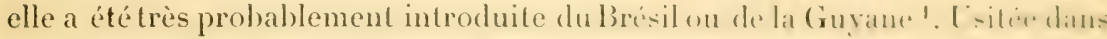
tous les jardins de l'ile pour la gramiture des treillis, des prillatures des tonnelles. [No 2613.]

Martinique. Vulgo : Liane à lait. - Dans toute l’île, soit à l'état de culture, snit à l'état sauvage, dans les broussailleset les hairs: linbert, I.amentin, ete. $\left[\mathrm{N}^{\circ}\right.$ 1869.]

L'Allamanda Schottii Pohl, du Brésil, arbrissean toullu, it lranches lortueuses, allongées, est cultivé au Jarlin botanique el dans beancoup d'antres= jardins du pays; il fleurit abondamment et donne une riche recolle de linils. [No 1870.$]$

Rauwolfia Plum. (dédié à Léonard liauwoll, gui a vorag̨i (en (1)ínt, de 1573-76, et a écrit, en autres choses : Flora orientalis, el son voyarre en Orient.)

R. Lamarckii A. DC.; Raumolfie de Lamark. Vulgo : Bois-lait pelil. Limm. Ill., t. 172, f. 1. - Arbrisseau buissonneux, élégant, haut de 1-2 ${ }^{m} 50$, à suc laiteux, comme le sont la plupart des plantes de celle lamille. Fenilles verticillées par 3-4, elliptiques-oblongues ou elliptiques, pointues, trim vertes. Inflorescence en crmes ombellilormes, axillates et forminales : les a dillatres. situées à l'extrémité des branches; fleurs blanches, pelites. I) rupe trin verte. arrondie, plus large que longue, rétuse-tronquée au sommet. - Fl, en tout temps. - Assez abondant sur les côtes sèches et pierreuses prís de la mer: Vieux-Fort, Baillif, Vieux-Habitants, Pointe-Noire, Bonillante, Corier, Moule, Désirade, Marie-Galante, etc. [No 2611.$]$

1. Cette plante donne, par incision, un latex abondant qui constilue un purzatif iner-

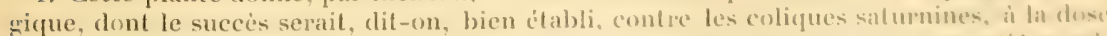
de 8 à 10 grouttes. Les feuilles, en infusion aो 10 pour 1000 , domnent un purpalif excellent: à dose plus forte, c'est un purgatif émétique violent. (k. H. 
Martingle. Vulgo : Bois-lait petite-feuille. - Environs de Saint-Pierre, Case-Pilote, Marin, Sainte-Anne, Caravelle, etc. [No1225.

R. bianriculata J. Iuell.; Rauwolfie à corolle biauriculée. Vulgn : Arbre ì lait. - Petit arbre, très élégrant, haut de $4-6$ mèt., à frondaison arrondie, à branches nombreuses, at trone droil, à écoree noiratre ef lisse. Feuilles cartilayineuses, verticillées par 3, elliptiques-oblongrues ou lancénlées-oblongues, terminées par une pointe obtuse. Fleurs rosées, en cymes long̨uement pédonculées, läches, umbelliformes. Drupes elliptiques, réunies par 2 et cohérentes jusqu'au delà du milieu, ensuite divergentes. - Fl. de décembre en mars. - Rare : cia el lid dans les bois inférieurs des Bains-Jaunes. No 2541. - Il n’existe pas à la Martinique.

Thevetia L. (dédié au moine français And. Thevel, mort en 1590 ; a royaçé dans le Brésil ; a écrit sur la Guyane française, oủ ce genre est représenté.)

T. neriifolia Juss, Gerbera Theretia L.; Thévétie à feuilles de laurier-rose. Vulgo: Arbre à lait. Desc., vol. III, t. 158, p. 40; Tuss., Fl., IV, t. 7; Jacq., Sel. Im. stirp. hist., t. 34, p. 48. - Petit arbre, souvent tortueux, tris branchu, at branches divariquées, et penchées dans les vieux pieds, à trone et branches nus. Feuilles d'un rert clair, luisantes, longues, tres rapprochées et ramassées aux extrémités des rameaux, linéaires. Fleurs laryes, solitaires. axillaires, d'un jaune de safran, odorantes. Fruit transversalement élargi, obeonique-comprimé. quadrangulaire. - Fl, surtout d'octobre à mai. - Peu alondant : environs de la Basse-Terre, Morne-i-l Vaches), route de la BasseTerre à Gourbeyre, Lamentin, etc. ${ }^{1}$ Alt. 0-120 mèt. [No 2611.]

Martinique. Vulgo : Noix de serpent, bois à lait. - Assez rare : Diamant, Vauclin, Marin. [No 1867.]

Tabernæmontana Plum. [dédié a Jac. Théodore Tabernemontanus, ainsi nommé de son lieu de naissance, Berrzabern, dans le Palatinat mot à mot taverne de montagne; botaniste, médecin du prince-électeur-évèque de Spire, de l'électeur du Palatinat et de la ville libre de Worms; a publić un ouvrage sur les herbes médicinales, avec de belles gravures; mort en 1590.$]$

1. Ce végétal, qui est l'Ahouaï de la Guyane, donne un fruit et une graine toxiques (narcotico-âcres). La mort survient après des convulsions riolentes et des désordres gastro-intestinaux. Une amande, mâchée ou broyće dans le lait, amène rapidement (en un quart d'heure) une purgation violente, souvent suivie de vomissements : on emploie une demi-amande comme purgatif contre les hydropisies et le rhumatisme. C'est surtout à titre de fébrifuge qu'elle est usitée, ainsi que l'éoorce. Pilée avec du rhum, c'est un alexitére recommandé. Deux graines, broyées dans ce liquide. donnent un breuvąe qui est absorbé par fraction; la partie fibreuse, pressée, est appliquée sur la blessure. La dose maxima en poudre, décoction, macération, teinture, extrait aqueux, doit ne pas dépasser la valeur de 0 gri. 25 d'extrait. - De Vrya isolé de cette graine la thévétine : c'est un glycoside cristallisé dont l'action est tétanisante: il est très amer, a un frout métallique et piçote la langue, qu'il finit par engourdir. La graine contient, en forte proportion, une huile fixe, qui est purgative; on $y$ trouve, comme dans toutes les autres parties de la plante, du pseudo-indican. (E. H.) 
T. citrifolia L.; Tabernæmontane à feuilles de citronnier. Vulgo : Boislait, Desc., vol. I, 1. 9, p. 4; Jacq., Sel. Am. st. hist., 1. 175, f. 13, p. 38. Grand arbuste ou petit arbre, laiteux, haut de 3-5 met. Feuilles oblongues

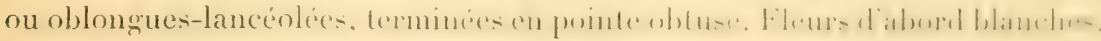
tirant ensuite sur le jaune, odorantes, en cymes axillaires, pauciflores. Fruits

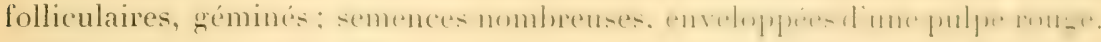
- Fl. presque toute l'année, avec plus ou moins d'abondance. - Abondant

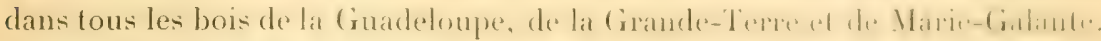
Alt. 40-700 mèt.' 'No 2617.

Martixique. Vulgo: Bois-lait. - Abondant dans toute l'île. [N" 1886.

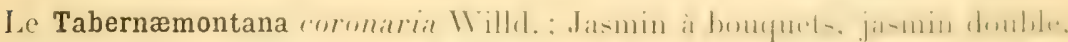

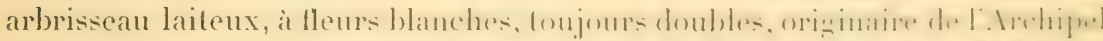

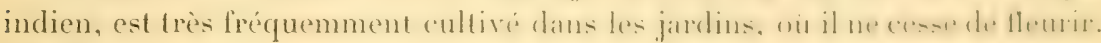
[No 2612.] - Martinique. No 1872.

Vinca L. (du latin " yincere ", vaincre, triompher, parce qu'il reste vert pendant le froid de l'hiver, ou de "vincire ", lier, ì cause de ses ligres allongées et flexibles.)

V. rosea L.; Pervenche à fleurs roses. Vulgo: Herbe aux sorciers._Sullru-

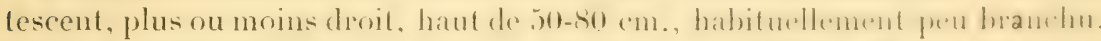

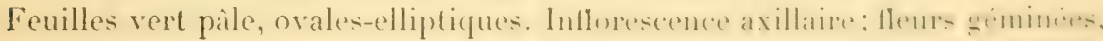
ou réunies par 3, le plus souvent roses, plus rarement blanches, larues, situées tout le long des branches: follicule comprime-crlindrique. long- de. $2-3 \mathrm{~cm}$. sur $2,4 \mathrm{~mm}$. d'épaisseur. - Fl. toute l'année. - Très abondant dans les sables du bord de mer et sourent un peu it linteriene : Bas-s-Terre. Baillit.

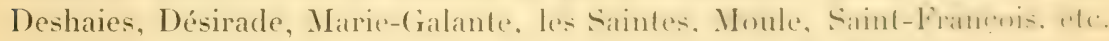
On le cultive souvent dans les jardins. Alt. 0-60 mèt. [No 2615 .

Martripue. Vulgo : Caca-poule (à cause de son odeur désagréable). Très abondant sur toutes les plages sèches et aussi un peu à l'intérieur. [No 1864.]

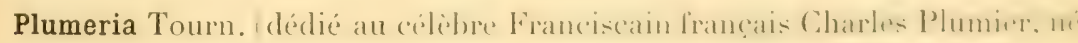
en 1646, à Marseille, qui fut envoyé trois fois par Louis XIV en Amérique pour chercher des plantes médicinales. sur le print de siombarquer pour un

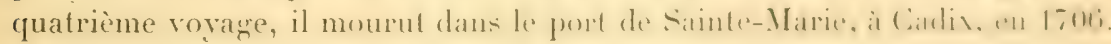
Ses ouvrages sont énumérés dans l'introduction de ce livre.)

P. alba L. ; Plumière à fleurs blanches. Vulgo : Frangipaniel blanc, frangipan blanc. Plum., éd. Burm., 1. 231; Desc., vol. 111, 1. 178, p. 1:8. -

1. Cet arbuste, dont toutes les parties sont aromatiques, est employé il la finyme, wi

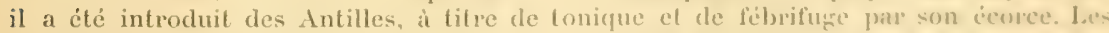
feuilles, prises en infusion, sont purnatives: linissces et introduiles dans les bains, elle's passent pour fébrifuges. Le latex, très actil, est il éludier comparalivement avec celui de T. utilis Arn., qui est alimentaire sur le continent de l'Amérique tropicale. (E., II.) 
Arbuste rabougri, haut de $1^{12} 50$, ou petit arbre, haut de 6-9 mèt., selon les terres dans lesquelles il pousse. Feuilles allongées, linéaires ou oblancéolées, le plus souvent acuminées au sommet, roulées sur les bords, surtout les jeunes, blanchâtres en dessous. Fleurs d'un blane pur, d'un parfum suave, en crmes larges. Ionguement pédonculées; follicules longrs de 12-15) cm. sur 7-9 mm. d'épaisseur, géminés, à forme d'un vanillon. - Fl. de juillet à novembre. - Assez abondant sur les mornes rochéux et secs, voisins de la mer : Vieux-Fort, Vieux-IIabitants, Bonillante, Wésirade, Marie-Galante, ete. Alt. 0-250 mèt. - On le cultive quelquefois dans les cours et les jardins; il devient alors un assez grand arbre. et ses feuilles se moditient consiclérablement 1 . [N०2838.]

Martinique. Vulgo : Frangipanier blanc. - Prêcheur, Anses-d'Arlet, Diamant, Caravelle, etc. [No 1863.$]$

P. rubra L.; Plumière à fleurs rouges. Vulgo : Frangipanier rouge, laurier rouge bâtard. Desc., vol. IV, t. 297, p. 301 ; Tuss., Fl., III, t. 20; Sl., t. 185. 186, f. 1. - Petit arbre, souvent plus ou moins tortueux, à branches divariquées et étalées horizontalement, à tige et branches nues. Feuilles obovéesoblongues ou oblongues, pointues, pétiolées, glabres. Fleurs rouges, en cymes larges, pubescentes; follicules géminés, pendants, longs de 15 à $22.2 \mathrm{~cm}$., noirs, lisses. - Fl. d'arril en juillet. - Originaire du Mexique; il est cultivé et naturalisé dans toute la Guadeloupe et la Grande-Terre: on le rencontre fréquemment sur les cimetières ${ }^{2}$. [No 2839.]

Mantinique. Vulgo : Frangipanier rouge. - Dans toute l'île. [Nos 1184 , 1185.]

Le P. pudica Jacq. ; Frangripanier jaune. - Petit arbre, originaire du Pérou, ¿̀ fleurs jaunes, qui ne s'ourrent qu'à moitié, est cultivé au Jardin botanique de Saint-Pierre et dans le parc de l'habitation Pécoul. [ $\mathrm{N}^{\circ} 1868$. $]$

Echites P. Br. (du grec " echis ", coulcuvre, par allusion aux tiges volubles et flexibles de la plante. - Pline, XXII, 89, appelle "Echites " différentes espèces de clématites et de liserons.)

E. hiflora Jacq.; Echite à deux fleurs à l'aisselle des feuilles. Vulgo: Lianemangle. Desc., vol. VII, t. 510, p. 250; Jacq., Sel. Am. st. hist., t. 21, p. 30.

1. A la Guyane, on emploie le latex de frangipanier blanc (suc gommo-résineux caustique et partant suspect) dans le traitement des ulcères, des dartres et de la gale. Les graines sont préconisées, d'après Descourtilz, contre les flux sanguins. L'écorce des racines. qui est purgative, est donnce surtout contre la blennorrhagie; on l'administre sous forme de décoction ou de macération, de poudre ef mème d'extrait. On la donne encore, à l'intérieur, contre l'herpès et la syphilis; à l'extérieur, en lotion contre les ulcères syphilitiques. C'est un médicament à étudier sćrieusement. (E. H.

2. A la Guyane, le frangripanier rouge fournit à la médecine des fleurs, qui sont réputées béchiques, aromatiques, et employées dans un sirop pectoral renommé. Le latex est usité contre les rages de dents déterminées par la carie. L'écorce est drastique : on l'emploie comme celle de l'espèce précédente. (E. H.) 
- Vivace, volubile, haut de 1-ว̃ mèt., grêle, trìs flexible, à écorce lisse el

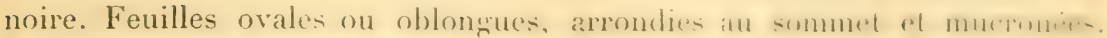

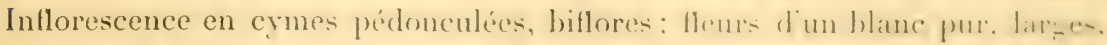
odorantes; follicules erlindriques, linéaires, printus an summel. - Vit en

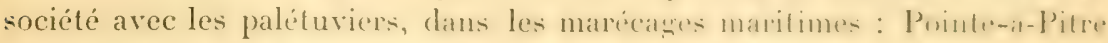
(environs), Sainte-Anne, Baic-Mahault, etc. [No 2810.]'

Martrisique. Vulgo : Liane-mangle. - Abondant : Rivière-Salcie, Ducos, Trois-Ilets, etc. [No $186 \%$.

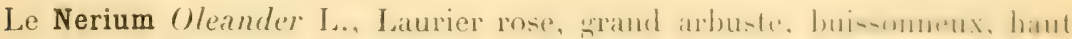
de 3-4 mèt., introduit de la région méditerranéenne, sa patrie, est très fréquemment cultivé à la Martinique, plus rarement is la Cinadeloupe. [ $\mathrm{N}^{\circ}$ 1873.] Il contient un suc caustique, très amer et très vénéneux. I.es feuilles et l'écorce séchées, pulvérisées el mêlées à de la graisse ou à de

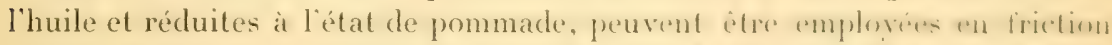
contre la gale et la teigne; la décoction des fonilles bouillies dans lihuil. présente les mémes avantages; l'écorce of le bois, riduils en poudred melés à de la graisse, servent encore à tuer les rats.

De cette famille, on cultive au Jardin botanique de Saint-Pierre un certain nombre de plantes très intéressantes, entre autres :

Kopsia fruticosa A. DC., arbrisseau des Indes ()rientales, qui lleurit suncesse, mais ne produit pas de fruit $\left[\mathrm{N}^{\circ} \mathrm{A}\right]$;

Roupellia grata Wall. et Hook, arbrisseau samenteux, it grandes Heurs: doubles, très parfumées, originaire de l'Afrique tropicale $\left[\begin{array}{lll}N^{\circ} & B\end{array}\right]$;

Tanghinia renenifera Poir., petit arbre on grand arbuste (étithere it -uc laiteux et à graines très toxiques, originaire de Madagascar [ $\left.\mathrm{N}^{\top} \mathrm{C}\right]$ :

Alstonia scholaris R. Br., grand arbre, tries désant, quii. an wetobre nu novembre, se couvre d'une toison de fleurs. mais ne produit pas de fruit: originaire des Indes Orientales $\left[\mathrm{N}^{\circ} \mathrm{D}\right]$;

Carissa Carandas L., Lam., Ill., t. 118, I. 1, arbrisseau épineux, dont les Pruits, laiteux, de la forme el de la grosspur diune prune, sont comestibleet ont une saveur très agréable, originaire de Malaisie $\left[\mathrm{N}^{\circ} \mathrm{E}\right.$ ];

Serissa foetida L., tries petit arbrissean, it lleurs blanches, doubles, a feuilles petites, exhalant une odeur tres déstgrable quand on les froiste $\left[\mathrm{N}^{\circ} \mathrm{F}\right]$, originaire de Chine et Japon ; appartient aux Rubiacées.

Beaumontia grandiffora Wall., liane puissinte, it Meure trie largers. blanches, originaire des Indes Orientales $\left[\mathrm{N}^{\circ} \mathrm{G}\right]$;

1. Cette espèce est utilisée d la Guyane : $1^{\circ}$ dans son latex, amer, puryalif et vomitif: $2^{\circ}$ dans ses feuilles, appliquées comme topiques sur les ulcéres, et usitées, en outre, comme purgatives. (E. H.) 
Dipladenia Harrisii Ilook., (Odontadenia speciosa Benth., Echites grandiflora Mey.), liane à très larges fleurs james, originaire de la Trinidad et de la Guyane $\left[\mathrm{N}^{\circ} \mathrm{H}\right]$, etc.

\section{CENT DOUZième FAMILLE. - ASCLÉPIADÉES.}

Metastelma R. Br. (du grec "meta ", entre, et " stellein ", placer, parce que la corolle est garnie de cing dents accessoires, alternant avec ses lobes.)

M. parviflorum R. Br.; Metastelme à petites fleurs. Vulgo: Liane it corde. - Liane haute de 3 - 1 mèt., sulfirutescente, très branchue, à tige adulte subéreuse, à jeunes tiges et branches filiformes, très allongées, extrêmement enchevêtrées. Feuilles petites, ovales, elliptiques, mucronées. Fleurs blanches, très pelites, en fascicules ombelliformes, axillaires, très nombreux, à pédicelles plus longs que le pédoncule commun; follicule long de $4,5 \mathrm{~cm}$. sur $2 \mathrm{~mm}$. d'épaisseur, terminé par une pointe droite et rigide; semences couronnées par une longue touffe de soie blanche. - Fl. de juin en août. Assez abondant dans les halliers des basse et infra-movenne régions de l'île. - Environs de la Basse-Terre, Baillif, Désirade, Marie-Galante, GrandeTerre, les Saintes, etc. Alt. 0-300 mèt. [No 2616.

Martixigle. Vulgo: Corde à violon, liane-corde. - Abondant : environs de Saint-Pierre, Carbet, Prècheur, Trois-Ilets, Marin, Caravelle, etc. [No 347.]

M. Schlechtendalii Dene; Metastelme de Schlechtendal. Vulgo: Vanille bâtard. - Liane vivace, très élevée, à tige adulte subéreuse, à jeune tige et branches trìs allongées, flexibles et fortement enchevêtrées. Feuilles ovéeslancéolées, brièvement acuminées, deux ou trois fois plus grandes que dans le précédent; follicule long de $13-15 \mathrm{~cm}$. sur $1-7 \mathrm{~mm}$. d'épaisseur, cylindrique, terminé, au sommet, par une pointe longue et forte, aminci à la base, ressemblant, à l'état vert, à un petit vermillon; semences imbriquées, surmontées d'une toulfe de soie blanche. - Fl. en juillet, août et septembre. Rare : çì et lì dans les bois des Bains-Jaunes et sur les bords de la rivière Noire. [No 3774.$]$ - Il n'existe pas à la Martinique.

Asclepias L. dédié à "Asclepios ", Esculape, dieu de la médecine, ou à Asclépiade, célèbre médecin grec de Pruse, en Bithynie, qui vivait à Rome environ 100 ans avant $\mathbf{J}$.-C.)

A. curassavica L.; Asclépias de Curaçao. Vulgo : Herbe à I $^{\text {me }}$ Boivin, herbe à ouate, ipéca bâtard, ipéca-savane. Sl., t. 129, f. 4, 5; Dese., vol. II, t. 116, p. 191. - Vivace par sa base et ses racines stolonifères, herbacé par le haut, d'une élévation de $40-80 \mathrm{~cm}$., droit, peu branchu ou sans branches, pubescent. Feuilles opposées, oblongues-lancéolées, pointues. lileurs en 
ombelles pédonculées, terminales et axillaires : les dernières, situćes i

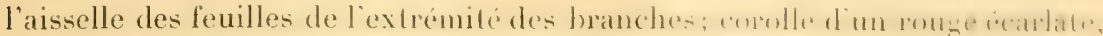
à cornets d'un jaune orange; follicule long de $5-6 \mathrm{~cm}$., oblong-lancéolé, mou; graines garnies, au sommet, d'une touffe de soie blanche. - Herbe

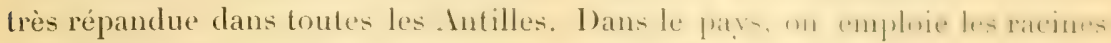
contre le syphilis et les maladies cutanées. Descourtil\% dit: "La racine

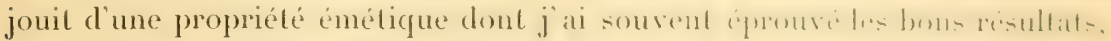
surtout dans les diarrhées si communes aux colonies el quelquefois si rebelles. " Les racines, qui sont, selon la dose, vomitives ou purgatives, offrent

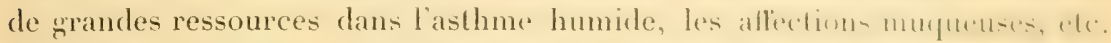
- Fl. toute l'année. - Alt. 0-600 mèt. [No 2811.]

Martinique. Vulgo: Zerbe-papillon, quadrille. - Abondant. [Yo 1858.$]$

Calotropis R. Br. (du gree "kalos ", beau, et "tropis ", quille de vaisseau, parce que les cornets de la corolle, d'un beau violet clair, sont en forme de quille de navire.)

G. procera Ait.; Mudar de grande taille. Vulgo: Arbre à soie, coton de France (a Marie-Galante). - Arbrisseau ou grand arbuste, haut de-2-3 met. rarement plus hant, droit, quelquefois tortueux, habituellement trie hramehu dans le haut, à jeunes tiges et branches : le dessous des feuilles, les pédoncules et pédicelles garnis d'un duvet cotonneux qui donne à la plante un aspect particulier qui le distingue, de loin, de tout autre végétal. Feuilles

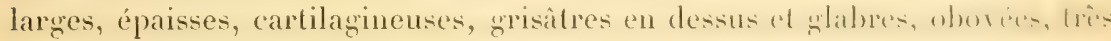
brièvement acuminées au sommet, cordées, sessiles, à lobes amplexicaules. Fleurs blanches ou rosées, à cornets violet clair, en corymbes larges, pédonculés, terminaux; follicules pendants, gris, srands, vericulenx, qui, quint

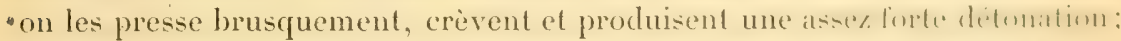
ils ressemblent, quand a la forme el au volume, it un mango: s'menters mombreuses, aplaties, imbriquées, surmontées d'une toulle de solie hlanchel. Fl. toute l'année. - Cet arbrisseau, ornemental, est exclusivement propre aux terrains secs, pierreux ou calcaires, chauds et arides : Baillil, environs de la Basse-Terre La P'intade, Maric-Galante, les Santes, Desirade, Monle, etc. Alt. 0-200 mèt. [No 2846 .

Martingue. Vulgo: Bois-pétard, bois-canon. - Fond Canonville, Prècheur. Anses-d'Arlet (morne Larcher), Diamant, etc. [No 1859.

1. Cette espéce est une de celles qui lournissent à la médecine les écorees de Mudar. réputées toniques, diaphrétiques et antisyphilitiques, el jouissant d'une grancle renomméc dans l'Inde. On emploie cette écorce a la dose de 15 a $20 \mathrm{cg}$. par jour comme tonique alterant, et à la dose de 2 à ír. comme émétique. Duneau en a extrait un alcalüle, le mudarine, qui n'a pas été retrouvé; Fluckigrer en a reliré $120 / 0$ d'une résine itere qui parait être le principe actif de cette drosue; Warden et Weddel, en 1 ss 1, en ont extrait me natiére cristallisable analogne à l'albane de la gutta, une résine jatue trís amére, the résine noire et du caoutchouc. (L. II. 
Gonolobus Mich. (du grec " gonos", coin, angle, et "lobos", gousse, parce que les fruits de ces plantes sont anguleux en dehors.) .

G. marlinicensis Dene: Gonolobe de la Martinique. Vulgo : Liane noire. - Liane vivace, haute de 4-8 mèt., à tige adulte subéreuse, à jeunes tiges el branches habituellement poilues, allongées, flexibles et très enchevètrées, it écorce noiràtre. Feuilles ovales, cordées, a sinus très ouvert. Fleurs rouge de sang, en corrmbes ombelliformes et pédonculés; follicule grand, ovoüdeventru, long de 12-14 cm. sur 6-7 cm. d'épaisseur, pourvu de quatre ailes longitudinales, aboutissant it la base du fruit, deux de ces ailes prenant naissance au sommet et les deux autres à peu près au milieu; semences aplaties, nombreuses, imbriquées, surmontées d'une touffe de soie blanche. - Peu abondant : șà et là dans les mornes de la Pointe-Noire, bords de la rivière Rouge. $\left[N^{\circ} 3714\right.$.

Martixique. Vulgo: Liane-serpent. - Parnasse (habitation Litté), hauteurs du Prècheur, hauteurs de l'habitation Pécoul. [No 1862.

Ibatia Dene (nom arabe de la piante.)

I. muricata Griseb., I. maritima Griseb. ; Ibatia à fruits garnis de piquants. Vulgo : Corosol à chien. Desc,, vol. III, t. 189, p. 171; Jacq., Sel. Am. st. hist., t. 56, p. 83. - Liane suffrutescente, bi ou trisannuelle, haut de 2-4 mèt. à tige adulte subéreuse, glabre. jeune tige, branches et feuilles garnies d’un duret laineux et grisâtre. Feuilles cordées-deltoïdes, cuspidées. Fleurs rougeatres, en fascicules subsessiles ou brièvement pédonculés, situés tout le long des branches; follicule ventru-ove, pointu, long de 5-7 cm. sur 2,9-3,2 cm. dans sa plus grande épaisseur, légèrement duveté, garni de protubérances nombreuses, spiniformes, pointues ou émoussées; semences convexes-aplaties, imbriquées, surnontées d'une toutfe de soies blanches. - A lépoque de la maturité des fruits, les leuilles se sont flétries et ont disparu; on ne voit que des tiges complètement nues. - Fl. de juin en novembre. Exclusivement propre à la région aride, sèche et pierreuse des côtes maritimes : environs de la Basse-Terre, Baillif, Vicux-Habitants, Pointe-Noire. Deshaies, Marie-Galante, etc. [ $\left.\mathrm{N}^{\circ} 2843.\right]$

Mantineze. Vulgo : Corosol-diable, corosol-chien. - Carbet, Case-Pilote, Trois-Ilets, Marin, Vauclin, etc. [ $\mathrm{N}^{\circ} 1860$.

Marsdenia R. 13r. dédié à l'Anglais Guill. Marsden, secrétaire de l'amirauté anglaise: a visité l'ìle de Sumatra et a écrit : Mistory of Sumatra, 1783.)

M. elliptica Dene; Marsdénie à feuilles elliptiques. Vulgo : Liane it vache à cause de l'abondance de son suc laiteux). - Liane haute de $4-6$ mèt., à tige aclulte subéreuse, à jeune tige et branches allongées, lisses et noiràtres. Feuilles larges, cartilagineuses, d'un vert très foncé, elliptiques. Fleurs blanches, en cymes courtes, axillaires; follicule inconnu. — Rare : çà et là 
dans les broussailles des mornes sees de Case-Pilote. [Yo 185\%. I - Ie ne l'ai pas trouvé à la Guadeloupe.

De cette famille, on rencontre très souvent dans les jardins, pour l'orne-

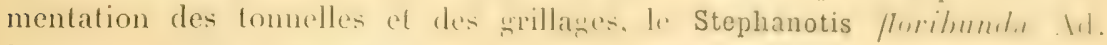
Brongn., vulgo : Stephanotis, liane at bouquet, origninaire de Marlarascal,

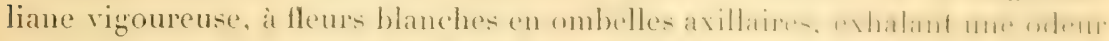
exquise, à follicule de la forme, de la couleur et du volume d'un manno (fruil du manguier) [No 2837], Martinique [No 1861]; le Hoya carnosa R. Br.. vulgo: Liane-porcelaine, à feuilles elliptiques, charnues, polies, à fleurs en

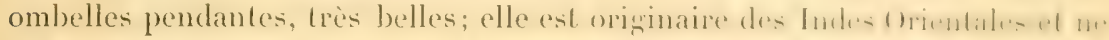

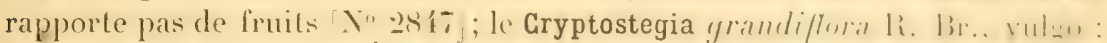

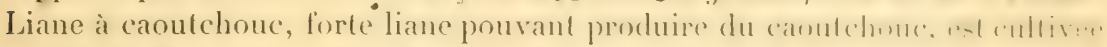
au Jardin botanique de la Basse-Terre, où elle lleurit d'octobre à janvier et

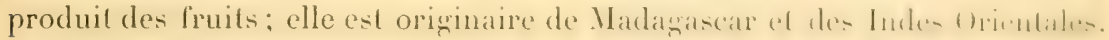
$\left[N^{0} 3067\right.$.

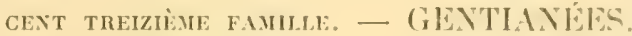

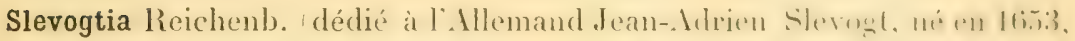
mort en 1726, professeur d'anatomie el de chirurgie ì léna, auteur d'un grand nombre de traités sur différentes plantes et drogues.)

S. occidentalis (Briseb., Gentiana verlicillata L.. Enicostema lillurale lilum. ; Slevogtie des Indes Occidentales. Balai-savane bâtard. Desc., vol, I, L. 16, p. 76; Plum., éd. Burm., t. 81, f. 2. - Herbe annuelle, plus rarement sulfrutescente et bisannuelle, haute de 40-60 cm., droile, sans branches ou peu

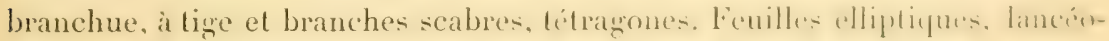
lées, acuminées aux deux bouts. Fleurs petites, blane pâle (jamais bleues.

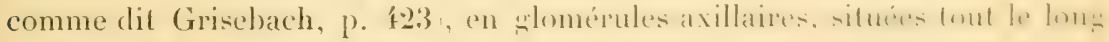
des tiges. Fruit capsulaire, long de $3-5 \mathrm{~mm}$., sessile. - La plante toul entière est employée dans le pays comme stomachique el fébrifuge. - Le longr des routes et dans les savanes sèches de la bassé région : Baillif, Vieux-Habitants, Pointe-Noire, Gozier, Moule. Alt. 5-120 mèt. No 2855.

Martinique. Vulgo : Balai-savane. - Case-Pilote, Case-Navire, environs de Fort-de-France, Marin, etc. No $^{\circ} 1330$.

Coutoubea Aubl. (nom de la plante chez les indigènes de la (ruyane.)

G. densiflora Mart.; Coutoubée à fleurs très serrées. Vulgo : Mugnel des savanes. Dese, vol. VIII, Ł. 58\%, p. 325. - Herbe ornementale, annuelle on bisannuelle, à racines pivotantes-fasciculées, à tige très droite, rigide. branchue dans le haut ou sans branches, haute de $15-80 \mathrm{~cm}$. Fenilles npposeces,

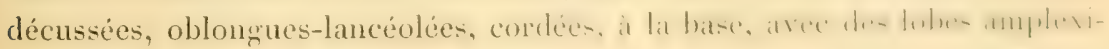


caules. Inflorescence en épis denses, allongés: flenrs blanches on trós légèrement violacées. - Fl. toute l'année avec plus ou moins d'abondance. Abondant dans les savanes herbeuses, humides et graveleuses de la régrion infra-moyenne : Vieux-Fort, Baillif, Vieux-Habitants (abondant), TroisRivières, etc. - Bien que Descourtilz range la plante parmi les emménagogues, dans le pays on n'en fait aucun usage. Alt. 200-500 mèt. [No 2305.] Il n'existe pas à la Martinique.

Lisianthus Lin. (du grec " lis " ou lissos ", lisse, et "anthos ", lleur, parce que, dans ce genre, toutes les parties des plantes sont lisses.)

L. frigidus Sw.; Lisianthe des endroits froids. Vulgo : Lis-montagne, gueule-de-loup-montagne. - Vivace, haut de $25-90 \mathrm{~cm} .$, très ornemental, plus ou moins droit, à tige carrée, sans branches ou très peu branchue. Feuilles elliptiques, coriaces, brievement pétioleses, pointues. Fleurs blanc verdâtre, larges, solitaires ou en cymes bi-triflores, terminales, très longuement pédonculées; corolle penchéc, ì tube largement campanulé au-dessus du calice. Capsule ovoïde-oblongue. - Fl. à peu près toute l'année. - Cette belle plante n'habite que les montagnes les plus élevées de l'île : Savane à Mulets, cône et plateau de la Soufrière, Savane aux Ananas, Grande-Découverte, etc. [No 2305.] - Elle n'est pas à la Martinique.

Voyria Aubl. (nom de la plante à la Guyane.)

V. uniflora Person.; Voyere uniflore. Vulgo: Mugnet jame, muguel grandbois. Jacq., Sel. Am. st. hist., t. 60, f. 3. (Gentiana Jacq.) - Herbe parasite, ormementale, haute de 15-2.2 cm.. sans feuilles el sans branches, ou a feuilles représentées par de petites squamules, droite, jaunitre, dépourve de chlorophylle. Fleur unique, jaune, terminale. - Pousse à terre sur le bois pourri, dans les endroits ombracés et humides des grands bois. - Assez rare : Bouillante (bois du Trou-aux-trois-Diables), Trois-Rivières. [No 2837.]1

Martixleue. Vulgo: Muguet jaune. - Bois du Lorrain, des Deux-Choux, etc. $\left[\mathrm{N}^{\circ} 1331\right.$.

Limnanthemum Gmel. (du gree " limné ", ćtang, et "anthemon ", fleur. paree que ces plantes vivent dans les étangrs.)

L. II nmboldtianum Griseb.: Iimmanthème de Humboldt. Vulgo : Follet femelle, petit follet. Desc., vol. I, t. 24, p. 112. - Herbe aquatique, vivace, ¿ lacines cherelues, très allongées, blanches. Fexulles flottantes, cordésorbiculaires et a peine peltées, très longuement pétiolées, succulentes, tris vertes et luisantes. Inflorescences axillaires, en ombelles de j-lo ravons d’inégale lomgurur, it pédicelles filiformes, concreseents avec le pétiole jusqu un

1. Cette plante doit avoir despropriétés amères ef toniques des voies grastro-intestinales, voisines de celles qui sont reconnues, à la Guyane, à V. cervulea Aubl. ou royère bleve : est à étudier. (E. II. 


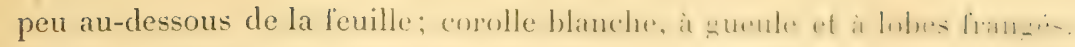
Sur une ombelle, on ne trouve jamais plus d'une fleur ouverte; des que la fleur est fanée sur son pédoncule dressé, ce dernier orgune s'abaisse sous la feuille, le lendemain un autre le remplace. - Fl. surtout de juin is janvier. - Vit dans les étangs peu profonds ou sur le bord des étangs profonds: étang Cocoyer (Moule). [N०3507.] - Il n'existe pas à la Martinique.

\section{CENT QUATORZIÈME FAMLLE, - SCROPIULARINEES.}

Scoparia L. (du latin « scopa ", balai, parce qua aree cees plante- on lint di.. balais aux Antilles.)

S. dulcis L.; Scoparia doux. Vulgo : Balai-savane, thé-savane. Sl., L. 10s, I. 3 ; Desc., vol. II, t. 106, p. 162. - Herbe annuelle ou sulfiulescente.

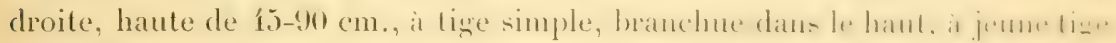

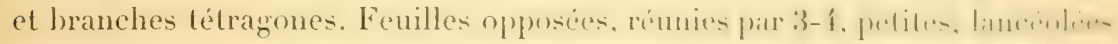

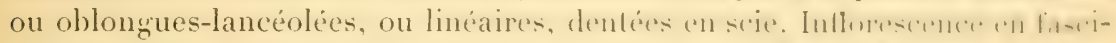

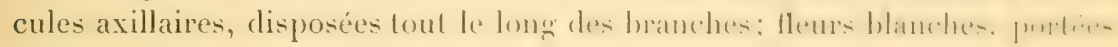
sur des pédoncules filiformes, à moitié aussi longs que les feuilles. - Trìs abondant dans toutes sortes de savanes des basse el infra-moyeme r'ínions. de la Guadeloupe et de la Grande-Terre. - A cause de ses vertus astrin-

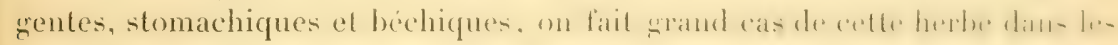
campagnes; on l'emploie en tisane contre les maux d'estomac, les rhumes, la

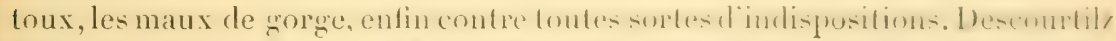
dit, entre autres choses, quavec le sue on pripare une pommade contm. l. hémorroïdes et que, contre la chute du rectum, on se sert de sal décoction ferrée '. - Alt. 5-600 mèt. 「 Nº 2304 .

Martinique. Vulgo: Balai-doux. - Dans toule l'ile. No 1336.

Gapraria L. (du latin " capra ", chèrre, parce que ces animaux en sunt (riands.)

C. biflora L.; Capraria à deux fleurs à l'aisselle de chaque l'euille. l'ulgoo: Thé du pays, thé-muraille. Desc., vol. IV, t. 300, p. 313; Jacq., Sel. Im. st. hist., t. 115, p. 182. - Sulfrutescent, ligneux it la base, droit, haut de ("' 45 -

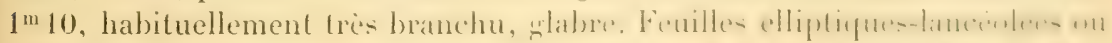

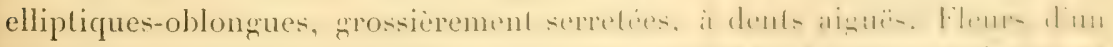

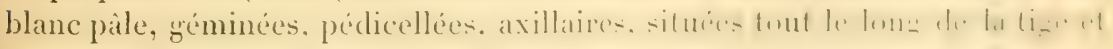

1. A la Guyane, sous le nom de balai-doux, herlye it balais, cette espéce est stutuut employée, toutes les parties de la plante étant émétiques, à faire vomir les enfints. Idefeuilles sont amères et usitées en infusion dams les affections fúbriles. La décoction de la racine, astringente et mucilagineuse, qui entre clans la composition d'une firanc antilolennorrhagique, est l'ecommandée aussi contre l'écoulement trop abondant des régles. Li. $\$ 1$. 
des branches. Capsules oroüdes-subghlobuleuses, à déhiscence septicide el loculicide. - Abondant sur les vieux murs, autour des maisons, sur les décombres et endroits abandonnés de toute la Guadeloupe et de ses dépendances. - La plante est aromatique et fébrifuge: elle s'emploie dans les campagnes contre toutes sortes d'aflections, mais surtout en tisane contre les rhumes, bronchites, fluxions de poitrine, ete. 1 - Alt. 11-600 mèt. No 2853.

Martineue. Vulgo : Thé-muraille, thé du pays. - Dans toute l'île. [No 1357 .

Alectra Thunb. du gree "alector ". coq, parce que, dans les especes-types. les. fleurs, par l'ensemble des pièces qui les composent et par leur couleur, ont quelque ressemblance avec la crête d'un coq.)

A. hrasiliensis Benth. : Aleetre du Brésil. Vulgo: Herbe fragile, queule-deloup. - Annuel, haut de 35-45 cm., droit, rigide, sans branches ou peu branchu, tris hispide dans toutes ses parties et très fragile. Feuilles subsessiles, rigrides, subcordées el élargies à la base, acuminées au sommel, grossièrement et inéralement dentées, dents émoussées et souvent blanchàtres. Fleurs: les unes, axillaires et solitaires: les autres, terminales, géminées, ou solitaires ou réunies par trois; corolle d'un jaune de citron, caduque, large, très belle. - Vit habituellement en parasite sur les racines d'autres herbes. - Fl. surtout de juillet à décembre. - Issez abondant dans les savanes herbeuses et sablonneuses des environs de la Ravine-Chaude et des Trois-Rivières. [No 2984.] - Il n'existe pas à la Martinique, mais je l'ai vu récolté à la Dominique.

Stemodia L. (du grec " stemon ", étamines, et " dis ", double, parce que les étamines didynames ont chacune une anthere partagéée en deux parties distincles et divergentes.)

S. parviftora Ait., S. arenaria H. B. et Kth.; Stémodie à petites fleurs. Vulgo: Petite véronique. - Petite herbe, dilfuse, à branches longues de 5$12 \mathrm{~cm} .$, plus ou moins dressées à l'extrémité, quelquefois tout ì fait dressées. Feuilles petites, opposées, ovées, crénelées-serretées au-dessus de la base. longuement pétiolées. Fleurs violettes, panachées de blanc, ou violet paile, brièrement pédonculées, axillaires et solitaires, situées tout le longr des branches; comlle à deux lères. Capsule à quatre valves. - Cia et là dans les chemins peu battus, le long des routes, dans les endroits sablonneux . envimons de la Basse-Terre, Gourberre, Baillif, Trois-Rivières. Moule ${ }^{2}$. Alt. 10400 mèt. [No 2852.]

1. Sous le nom de thé de la Guadeloupe, cette espèce est employée à la Guyane surtout comme diurétique, comme tonique à faible dose, et antipériodique à dose plus élerée. On utilise les feuilles en infusion théiforme.

2. Le St. pusilla Benth., sous le nom de basilic sauvage, est employé à la Guyane contre la mizraine (infusion théiforme des feuilles et des tleurs). La décoction des racines est recommandée en rarrarismes contre les inflammations buccales; elle passe aussi pour vulnéraire. Le St. parviflora Ait. doit avoir des propriétés analogues. (E. II.) 
Martinique. Vulgo : Petile violette. - Saint-Pierre (Jardin bolanique el Trois-Ponts], Trou-Vaillant, Trinité, etc. [No 1351.

Herpestis Gertn. (du gree "erpein ", ramper, parce que les plantes de ce genre sont rampantes.)

H. Monnieria II. B. Kth.; Herpeste de ILonnier. Vulgo : Pelite véronique. Sl., t. 129, f. 1; Br., Jam., t. 28, 1. 3. - Ilerbe radicante, rampant en tous:

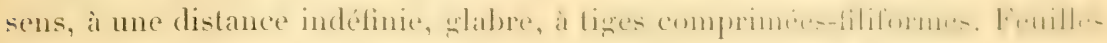
petites, très vertes, spatulées ou obovées, subentières. Fleurs violelles,

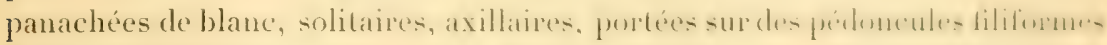
et bibractéolés au sommet. - Les fleurs ne s'ouvrent que vers neul' heures el se lerment de bonne heure dans l'après-midi. Cette plante forme souvent un gazon superbe. - Cà et lì dans les endroits humides et aquatiques de la basse région : Capesterre (Guadeloupe), Pointe-ì-Pitre. Alt. (1-2000 mèt. $\left[\mathrm{N}^{\circ} 2851\right.$.

Martinique. Vulgo : Véronique. - Fort-de-France (dans les jardins), Lamentin (bord de mer), Ducos, etc. [No 1353.

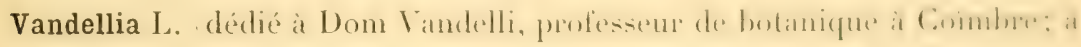
publié, entre autres choses, un ouvrage sur les plantes du Porlugal el du Brésil, 1788.)

V. crustacea Benth.; Vandellie à fruits crustacés. Vulgo : Cresson bâtard. - Petite herbe, glabre, aquatique, délicate, à tige rampante, radicante,

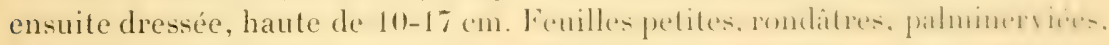
it 3-5 nervures à peine perceptibles. Fleurs axillaires, blanches, lachetées de violet, ou violettes et tachetées de blanc. - Très abondant dans les endroits très humides ou aquatiques, autour des fontaines, sur le bord des ruisseaux et des rigoles: Basse-Terre, Camp-Jacob, Gourbeyre, Lamentin, Ravine-Chaude, Matouba, Gozier, Moule, ete. Alt, 0-900 mèt. [X" 28.50.

Martivique. Vulgro : Cresson bâtard, petil cresson. - Dans toule liile. $\left[N^{\circ} 1355\right.$.

V. diffusa L.; Vandellie couchée. Vulgo : Ilerbe à tisane. - P'etite herbe,

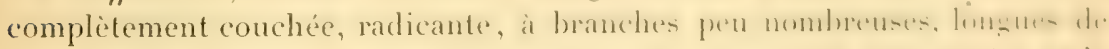
5-25 cm., filiformes. Feuilles orbiculaires, brusquement contractées, it la base, en un court pétiole, palminerviées, serretées au-dessus de la base, opposées : les paires, distantes. Fleurs axillaires, 1-2 à l'aisselle de chaque

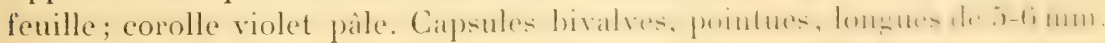
- Assez rare. Cà et là dans les chemins humides el peu fréquentés : environs de Saint-Pierre, Carbet, Fonds-Saint-Denis, Marin I. [No 135.5.] - te ne l'al pas trouvé à la Guadeloupe.

1. Cette plante, amère et mucilagrineusc, est employéc dt la (iuyane, sums lo num d"her/he du Paraguay, en décoction contre les fievres continues ed intermitentes. Contre les mali- 
Angelonia Humb, et Bonpl. ide "angelon ", nom de la plante à Caracas.)

A. angustifolia Benth.; Angélonie à feuilles étroites. Vulgo: Gueule-deloup. - Herbe suffrutescente, à tiges nombreuses, haute de $40-85 \mathrm{~cm}$., plabre. Feuilles lancéolées ou linéaires-lancéolées, pointues au sommet, acuminées, à la base, en un pétiole très court, serretées au-dessus de la base, à dents distantes. Fleurs larges, violet foncé, en grappes simples, allongíes, terminales. - Plante d'ornement, cultivée dans un grand nombre de jardins. — Fl. à toutes les époques de l'année. - Alt. 5-700 mèt. [No 2300.] — Introduite de l'Amérique continentale et tropicale (Mexique).

Martingue. Vulgo: Gueule-de-loup. - Dans beaucoup de jardins el parterres. $\left[\mathrm{N}^{\circ} 1350.\right]$

Le Russelia juncea Zuce, vulgo: Goutle-de-sang fNo 2845, Martinique $\left[\mathrm{N}^{\circ}\right.$ 1347 $]$, arbrisseau sarmenteux, sans feuilles, à branches et tiges très nombreuses, striées, à rameaux verticillés par 5-10, à fleurs d'un rouge de sang très vif, disposées en panicules laryes, allongées et tombantes, est souvent cultivé dans les jardins. Originaire du Mexique.

CENT QUINZIÈME FAMLLE. - SOLANEES.

Browallia L. (dédié à John Browallius, né en 1707, à Westerise, en Suède. écrivain, mort évêque et chancelier de l'Université d'Abo, en 1755; a écrit un ouvage remarquable contre les adversaires du systime de Limé.)

B. demissa L.; Browallie de petite taille. Vulgo : Grande violette. Iferbe annuelle, ornementale, droite, sous-ligneuse at la base, haute de 50$90 \mathrm{~cm}$., raneuse dans le haut, ì tigne et branches grrêles. Feuilles flasques. distantes, entières, longuement pétiolées, ovées, légèrement poilues ou glabres. Fleurs riolettes, plus rarement blanches et it gorye violelte, distantes. en crmes racémiformes, axillaires et terminales: les dernières allongées. Capsule striée, septicide, à valves trifides. - FI. presque toute l'année, mais surtout d'octobre à mai. - Très abondant au Camp-Jacob, à Bagatelle, à Choisy, Montéran, etc. 「ํo 2593.

Martinique. Vulgo : Ne m'oublie pas. - Abondant: Saint-Pierre, TroisPonts, Carbet. Precheur assez rare', Ajoupa-Bouillon. Alt. 10-500 mit. $\left[\mathrm{N}^{\circ} 2125.\right]$

dies du foie, elle entre dans le médicament brésilien connu sous le nom de haimerada. Elle est surtout recommandable comme éméto-cathartique et fébrifuge. Le V. crustacea jonit des mèmes propriétés. Sous le nom de "Hachaa ou Mataura ", c’est une des plantes médicinales dont les indigènes font le plus fréquent usage à Tahiti; elle y tient la place de la digitale. Elle donne de bons résultats aux débuts des affections bilieuses, dans la dysenterie, l'aménorrhée. (Voir E. Heckel, Hist. mẻd. et ph. des nouv. méd., 1874.) 
Brunfelsia Plum. (dédié à Otto Brunlels, né à Mayence vers la fin du $\mathrm{xv}^{\mathrm{V}}$ siècle, mort médecin à lierne, en 1531 ; a été le premier bolaniste qui ait écrit sur les plantes. Il a laissé entre beaucoup d'autres choses : IIerbarium vive icones.)

B. fallax Duchass.; Brunfelsie trompeuse. Vulgo: Bois it plier (at VieuxFort). - Grand arbuste ou petit arbre, haut de 3-1 mèt., très peu leuillu. nu dans le bas, à écorce brune. Feuilles coriaces, elliptieques-obovées. arrondies au sommet. Fleurs larges, a long tube, d'abord blanches, tournant ensuite au jaune pâle, très parlumées, surtout pendant la nuit, solitaires: ou géminées, axillaires et terminales. Fruit sphérique, déhiscent, de la grosseur d'une cerise, jaune à la maturitét. - Fl, de novembre ì mars. - Un le cultive quelquefois dans les jardins, où il devient plus branchu et plus feuillu. - Endroits secs, pierreux, chauds, près de la mer : Vieux-liort.

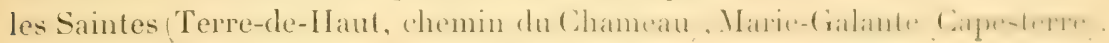
$\left[\begin{array}{ll}\mathrm{N}^{\circ} & 2594 .]\end{array}\right.$

Martinique. - Cultivé au Jardin bolanique. [No 12:33.]

Solandra Sw. (dédié à Daniel C. Solander, né en 1736, ¿t Stift Nordland, en Suède : voyagea à travers la Laponie jusqu'ì Archangel el it SinintPétersbourg; passa ensuite en Angleterre, aux îles Canaries; fut employé, après son retour, au Musée britannique; accompagna Cook dans son premier voyage, de 1768-71; obtint, après son retour, une place de hibliothécaire au musée; mort en 1782.)

S. grandiflora Sw.; Solandre à larges fleurs. Vulgo : Liane-pomme, liane-trompette. Sl., t. 9, Analyt.; Desc, vol. III, 1. 171, p. 101. - Puissante liane, montant sur les arbres les plus élevés et les couvrant de ses

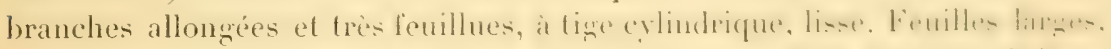

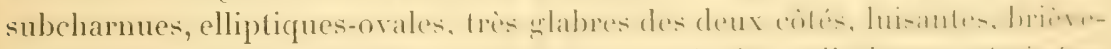

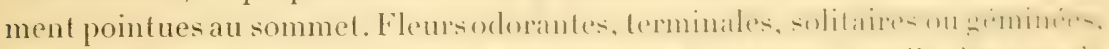

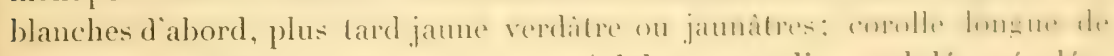
16-18 cm., à tube infundibiliforme, à 5 lobes arrondis, ondulés-crénclés: calice à 3-5 lobes longs de $10 \mathrm{~cm}$., pointus et persistant encore longtemps après la chute des fruits; pistil subulé, dépassant la corolle. Fruit ovoüdemammiforme, rétréci au sommet, surmonté du pistil fané, très vert, de la grosseur d'une pomme reinette, contenant un grand nombre de semences, nichées dans une pulpe brune. - Toute la plante est toxique, aucun animal n'en mange les fruits. - Fl. de décembre à mars. - Cà el lit dans les:

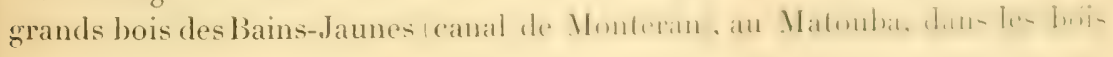

1. Les fruits de cette espèce paraissent être bans usigre aux Antilles, mais ceux du B. americana L. servent, à la Guyane, à fare un sirop astoingent employéconlru les diarrhers rebelles. (E. H.) 
entre la Pointe-Noire et la Ravine-Chaude, et dans ceux des Trois-Rivières. Alt. 500-900 mèt. [No 3-409.]

Mantrioge. Vulgo : Liane-chasseur. - Cà et là dans les bois de l'Ajoupa-

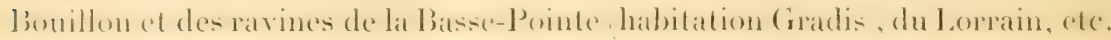
No 2129.

Datura L. (selon les uns, du mot arabe "Datora "; selon d'autres, du mot persan "Tatula " (de "lat ", piquer), c'est-ì-dire des plantes ì fruils piquants.

C. suaveolens Humb. et Bonpl,; Datura à fleurs suares. Vulgo : Fleurtrompette, trompette-du-jugement. - Cirmel anbuste on petit ambre, peu élégant, haut de 3-4 50 , à écorce grise, branches divariquées, sourent penchés. Feuilles flasques, glabres on sonvent légirement pubescentes en dessous, ovées ou ovées-oblongues, larges, pointues au sommet, souvent inégales a la base, entières. Fleurs toujours pencheses. blanches, solitaires ou géminces, naissant dans les lifurcations des rameaux supérieurs, odorantes. longues de $20-25 \mathrm{~cm}$.; corolle infundibiliforme-cylindrique à jo Intes dentés-subulés; calice ventru, d'un tiers plus court que la corolle. - Fl. de janvier à juin. - La plante ne produit pas de fruits dans nos colonies. Introduit el cultive, originaire du Mexique. - Camp-Jacob el environs. Alt. 450-600 mèt. [No 2598.

Martixique. Vulgo : Fleur-trompetle. - Morne-Rouge, fontaine Absalon, etc. $\left[\mathrm{N}^{\circ} 1924\right.$.

D. Metel L. (du mot arabe "methel ».) Vulgo : Concombre à chien. Ammel, droit. haut de 30-9.) cm., a lige ef branches pouges ou blanchatres, elatés, a jeunes liges, branches, feuilles, pédoncules et pétioles garnis d'un duret wris, tendre, plusoumoins visquenx. Fenilles ovés. entieresou ì dents peu nombreuses. - Fleurs larges, d'un blanc pur; corolle à tube cylindrique. brusquement dargi au sommet et muni de cing dents courtes. Fruit gros, couvert de piquants subulés ou droits. - Fl. pendant et après l'hivernage. - Les fleurs s'ourrent le soir et se ferment de bonne heure dans la matinée. - Dans le pays, on emploie les feuilles de cette espèce indienne, flambes au préalable sur une flamme, comme topiques contre les inflammalions, les enflures, etc ${ }^{1}$. - Abondant sur les décombres et dans les endroits

1. Il est a peine besoin de rappeler que les feuilles et les graines du D. Stramonium L. sont employées en médecine comme narcotiques, à cause de leur prineipe actif qui est un mélangre d'itropine et d'hyoscyamine, mélange plus abondant dans les graines que dans les feuilles. Les autres Datura indiqués ici participent évidemment des mèmes propriétés : D. fastuosa L., remarquable par l'ampleur de ses fleurs, fizure dans la pharmacopée de l'Inde comme plante sédative; D. Metel L., espéce indienne, donne des graines employées comme narcotiques dans sa patrie; D. Tatula L. est employée au Pérou (feuilles et graines) contre les maladies de la peau et contre l'asthme. A la Guyane française, le D. ceratocaula Jacq. est couramment employé et de la méme façon que D. Stramonium L. Les feuilles, chaudes, servent en application contre la sciatique. La 
abandonnés de la basse région: Basse-Terre (ville el envirnns), Baillil. Lamentin; ẹ̀ el lì dans toute la Grande-Terre, it Marie-Galante, it la Désirade, ete. Alt. 0-100 met. [X0 2877.] - Introduit raisemblablement de l'Inde. Martrique. Tulgo : Concombre à chien, concombre-diable, - Euvirons de Saint-Pierre, Carbet (cimetière), Prècheur, Marin, Trinité, ele, [N" 19:2(j, ]

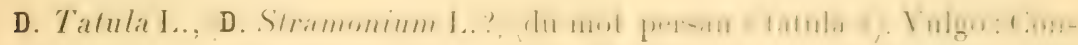
combre à chien. Desc., vol. III, t. 173, p. 99. - Annuel, droil, branchu dans le haut, à branches très étalées, it tige et branches tantôt rouges, tantit blanches, grosses, succulentes. Feuilles ovées, sinuées-dentées, largés. Fleurs grandes, violettes ou violacées, glabres. Fruil garni de piquants droils. - Cil et là autourdes maisons, sur les décombres, dans les champs en friche, etc. :

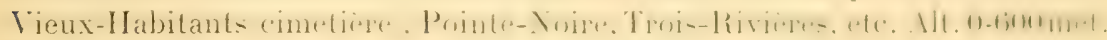
[No 2596.]

M.ntrique. Vulgo: Concombre à chien. - Assez rare : Sainte-Anne, Trinite. [ $\mathrm{N}^{\circ}$ 1925.]

On rencontre quelquefois à la Guadeloupe et à la Martinique le Datura Stramonium L. [No 2996 b.] qui se confond, d'après certains auteurs, arec D. Tatula L.

D. fastuosa L.; Datura fastueux. Vulgo : Concombre à chien grand, carapate bâtard (au Moule). - Annuel, tortueux, haut de $0^{\text {m }}$ (9)-2 mèt. Feuilles larges, ovées, subentières ou dentées, ì dents peu nombreuses. Fleurs longues de 15-18 cm., jaunâtres ou violet panaché, ou blanc sale; corolle toujours double, à tube subcylindrique et terminé par cinq dent:

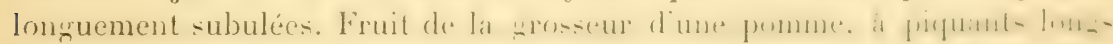
et droits. - Fl. de novembre à mars. - Cuà et là sur les décombres, dans les endroits abandonnés de toute la Guadeloupe et de la Grande-Terre. - Toutes les parties de la plante exhalent une odeur désagréable; lefeuilles s'emploient extérieurement contre les douleurs rhumatismales et contre les maux de tête. [Yं 255\%.] - Introduit de la régrion tropicale de l'ancien continent.

Martinque, Vulgo : Trompelte-du-jugement. - Cá el li dans la basse régrion de toute l'île. [Nos 1927,2128 . ]

Nicotiana L. (dédié à Jean Nicot, né en 1530, à Nimes; mort en 16un, à Paris, ambassadeur a la cour du Portugal; apporla, en 1.560, des graines de tabac en France, et $y$ introduisit. en 1561, l'usage d'en fumer les feuilles.

N. Tabacum L. Vulgo : Tabac. - Introduit autrefois de l'Amérique tro-

teinture des feuilles est recommandée contre les palpitations. Liextrait alemolique, mélé i l'huile, ou encore les feuilles, pilées et macérées dans l'huile, servent en frictions contre les rhumatismes et contre le prurit des parties finitales. On recommande le firuit vert. écrasé, en application contre les pustules charbonneuses. (E. II. 
picale pour la culture en grand, qui a été ensuite abandonnée; se rencontre encore cultivé çà et là pour l'usage personnel. Naturalisé dans toute la Guadeloupe et la Grande-Terre. [ $\mathrm{N}^{\circ}$ 2878.] '

Martingue. Vulgo: Tabac. - Naturalisé et cultivé çà et là en petit. [No 338 .

Acnistus Scholt. (du gree " aknistès ", plante des Anciens, qu'on ne connaît pas.)

A. arborescen.s Schlecht., Cestrum cauliftorum Jace. : Icniste arboreseent. Vulgo: Surio, suyau (corruption du mol sureau). Pl., édit. Burm., t. 46, f. 1; Desc., vol. III, t. 177, p. 119. (Atropa L.) - Petit arbre, haut de 4-5 mèt., peu détyant, à branches tress divariquées, souvent penchées à écorce grise, feuilles laryes, llasques, elliptiques-oblongues, pointues aux deux extrémités. Inflorescence en fascicules latéraux, penchés, très nombreux, situés tout le long des branches; conolle blane pâle. wraduellement dilatée du sommet it la base. Fruit sphérique, jaune à la maturité, de la grosseur d'une très petite cerise. - La plante est toxique-narcotique, cependant les enfants en mangent impunément les fruits. Dans le peuple, on se sert des fleurs séchées en tisane contre les maux d'estomac, et comme sudorifiques contre la toux et les refroidissements; on les ramasse souvent pour les vendre aux pharmaciens du pars: les feuilles semploient avec le curage Commelyna nudiflora L.), comme émollientes dans les bains tièdes, et à l'extérieur contre les névralgies, au même titre que les feuilles des concombres à chien. - Assez abondant dans les basse et infra-moyenne régions de toute la Guadeloupe et de la Grande-Terre. Alt. 10-600 mèt. [No2589.]

Martinique. Vulgo: Suyau, sureau. - Pour enivrer les poissons, on se sert des feuilles, froissées, à cause de leurs vertus narcotiques. - Abondant dans tout le nord de l'île; plus rare dans le sud. [No 1929.]

Physalis L. (du gree " phusalis ", vessie, allusion au calice accru qui forme une vessie entourant et cachant le lruit.)

P. foetens Poir; Coqueret puant. Vulgo : Herbe à cloques. - Annuel, haut de $2.5-4.5$ ('m., délicat, visqueux, at tige hlanche, a branches très étalées et dichotomes, à tige, branches et pétioles garnis de poils mous et blanchatres. Feuilles ovées, anguleuses-dentées, molles. Fleurs solitaires dans la bifurcation de deux branches, jaunâtres avec une tache noire à l'entrée de la gorge; anthères violettes; calice accru, ì cinq angles, s'effaçant plus ou

1. En dehors des usages connus du tabac, qui est une plante médicinale en Europe (employée en lavements pour favoriser la réduction des hernies et pour combattre les obstructions alvines), citons ce fait qu'à la Guyane la feuille, écrasée avec du rocou (Bixa Orellana L. préserve des piqûres de la chique (Pulex penetrans) et cicatrise les plaies déterminées par l'extraction de l'insecte parasite. Les feuilles, huilées et tièdes, s'appliquent sur les blessures récentes. (E. H.) 
moins avec la maturité du fruit, qui est sphérique, mangeable, de la crosseur d'une petite cerise, et rouge l'oncéquand il est mur. - Dans les savanes herbeuses et humides, dans les endroits défrichés, ele., de Ioute la Guadeloupe et de la Grande-Terre. Alt. 0-700 mèt. [No 25!)1.]

Martinique. Vulgo : Poc. - Dans toutes les savanes de l'ile. [Yu 19:31.]

P. angulata L.; Coqueret anguleux. Vulgo: Herbe ì cloques. Dill., Eilh.. t. 12, f. 12. - Herbe annuelle, glabre, haule de $\mathbf{1 0 - 9 0}$ cm., tris divisé dans le haut, à rameaux lastigiés ou étalés, à ligre quelquefois couchéce à ligre el branches anguleuses-striées. Feuilles llasques, plus larges que dans le précédent, ovées ou orées-elliptiques, irrégulièrement sinuées-dentées, contraclées, au sommet, en une pointe allongée; ressie du calice ì cinq angles airus. Fruit jaune à la maturité, et bon à manger. - Très abondant sur les décombres. les endroits abandonnés et cultivés, et le longr des routes des basse el inframoyenne régions de la Guadeloupe et de la Grande-Terre. Alt. (0-jon) mèt. $\left[\mathrm{N}^{\circ} 2590.\right]$

Martinique. Vulgo: Herbe à poc. - Abondant dans toule l'île. [Yo 1930.]

Capsicum L. (du grec "kapto », futur "kapso », mordre, ¿̀ cause de sa saveur piquante.)

C. frutescens L.; Capsicum frutescent.Vulgo : Piment-z'oiseau, piment enragé, piment cabresse, piment caraïbe. Desc., vol. VI, t. 113, r. 21. Arbrisseau grêle, délicat, glabre, haut de $0^{m} 30.1^{m} 20$, peu branchu, i branches dichotomes et un peu en zig-zac. Feuilles ovées, pointues, llasques. Fleurs blanchâtres, petites, en cymes réduites, courtes el latérales. Firuit conico-cylindrique, long de 6-8 mm., ronge foncé à la maturité. - Fil. en août, septembre et octobre. - Assez rare ì l'état sauvagre : basse régrion de Bouillante, de Pigeon; ç̀ et là à Baillif, aux Vicux-Habitants. All. 15400 mèt. [No 2595.$]^{1}$

Mantinique. Vulgo : Piment-oiseau, piment enragé. - Caí et là dans les haies et les broussailles, des hauteur's inl'érieures de Case-Pilote, morne Gommier (Marin) [No 351 , avec ses variétés [ Yos 352, 353, 351.]

On a transplanté celte espèce dans les jardins, et, par la culture, on est arrivé à obtenir des variétés qui dépassent. de beaucoup la taille de l'arlrisseau primitif et le volume normal des fruits; entre autres : le piment ordinaire ou piment blane, dont le pied peut atteindre jusqu'it 2m jo (), et le fruit dépasser le volume d'une grosse cerise. [Nos $1603,2604$.

C. baccatum L.; Capsicum ì fruits ronds, Vulgo : Piment rond, piment-

1. Les fruits de ce Capsicum (qui est officinal) doivent leur iereté, comme cerux de tums les piments, à un liquide oléo-résineux el à une substance cristalline, la capsicine. I.e's piments, en dehors de leur action stimulante des voies digestives, gui en rend l'emploi voisin de l'abus dans toutes nos colonies chaudes, ont été vantés, ainsi que leurs extraits. comme un reméde merveilleux contre les hímorrhoïdes. (L. H.) 
poivre. Sl., t. 246, f. 2. - Arbrisseau haut de $0^{\mathrm{m}}$ 80-1 ${ }^{\mathrm{m}} 50$, faiblement branchu, à branches en zigr-zac. Fleurs comme dans le précédent, mais plus longuement pédoncųlées. Fruil sphérique, rouge foncé, plus petit qu'une graine de poivre. - C Cà et lì dans les halliers et les haies des basse et inframoyenne régions de la Guadeloupe et de la Grande-Terre. [ $\mathbf{I}^{\circ} 3681$.]

Martinique. Vulgo: Piment-poivre, piment à grives. - Parnasse, vallée du Carbet, Trois-Ilets (plateau), morne Gommier (Marin), etc. ${ }^{2} N^{\circ} 349$.

La culture a donné des variétés nombreuses, dont les fruits diffèrent beaucoup, par le volume, de ceux de l'espèce-type, mais affectent toujours la forme ronde; les principales sont :

$1^{\circ}$ Piment moka, fruit de la grosseur d'un liruit de café moka [ $\left.\mathrm{N}^{\circ} 3575\right]$;

$2^{\circ}$ Piment rouge, piment cerise, de la grosseur d'une cerise ordinaire $\left[\mathrm{N}^{\circ}\right.$ 2602];

30 Piment bonda Madame Jacques, à fruits subsphériques, du volume d'une grande cerise. $\left[\mathrm{N}^{\text {os }} 348,3574\right.$.

C. conoides Roem. et Schult, C. frulescens I.. Capsicum it fruits conoïdes. Vulgo : Piment-café, à fruits du volume et aussi un peu de la forme d'un café ordinaire $\left[\mathrm{N}^{0} 3567\right.$ ], el la variété plus grosse. [Nos 355 el 3559.] - Introduit.

C. ceratocarpum Fingerhut. Vulgo: Piment-z indien, a fruits conico-cylindriques, blancs ou rouges à la maturité, longs de 5-6 cm., légèrement recour-

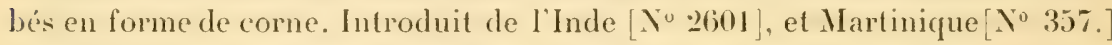

On rencontre aussi le C. dulce Hort. Vulgo : Piment-doux [Xo 353], el le G. annuum L., vulgo : Gros piment, tous deux introduits de l'Europe.

Les Lycopersicum cerasiforme Dun., vulgo: Tomadose [Yo 3785], Marti-

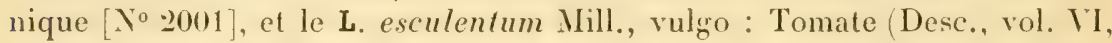
t. 303, et vol. $\mathrm{T}$, t. 875), introduits et naturalisés, sont cultivés dans toutes les Antilles. On les rencontre à l'état sauvage, échappés des cultures.

Solanum L. (du latin " solamen "), consolation, tranquillisation; de "solari ", allusion aux vertus adoucissantes el soporifiques de ces plantes.)

S. nodiflorum Jacq., S. caribeum Dun.; Morelle, a fleurs axillaires. Vulgo : Agoman ou agouman planter). - Herbe annuelle, droite, glabre, hautede () "'60-1 "' 10, à branches rrêles, lisses, noires, habituellement penchées au sonmet. Feuilles flasques, ovées, contractées en coin à la base, entières ou sinuées-dentées. Fleurs blanches, en ombelles latérales et axillaires. Fruit sphérique, rouge, un peu plus petit qu'une graine de poivre. - Abondant dans les terres cultivées ou laissées en friches de toute la Guadelonpe el de la Grande-Terre. On en rencontre une variété à feuilles larges, toujours sinuées-dentées, à tige tétragone, garnie de protubérances spinescentes. Alt. $0-700$ mèt. [No 2604 . 
Martineue. Vulgo : Herbe amère, herbe il calalou. - Dans foute lile. avec les mêmes variétés qui existent à la Guadeloupe. [N" 2130.]

S. Seaforthianum Andr.; Morelle de Seaforth (lord anglais). Iulgo : lat douce-mère, lilas grimpant, liane-lilas. - Liane vivace, flabre. Fenilles ovées, flasques : les inférieures, penniséquées, à 3-5 segments; les supé-

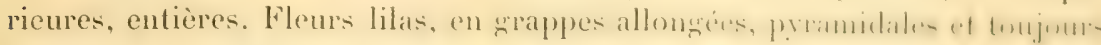
pendantes. Baie sphérique, jaune à la maturité, de la grosseur d’une praine de poivre. - Cultivé dans les jardins pour l'omementation des grillages. des tonnelles, ete. On le rencontre quelquefois à l'état sauvare. [ $X^{\circ} \geq 0066$.

Martinique. Vulgo : La douce-amère. [No 367.$]$

S. triste Jacq.; Morelled'un aspect triste. Vulgo : Bois-caca. Desce, vol. III. t. 185, p. 155; Jacq., Sel. Am. stirp. hist., l. 40, f. 2, p. 50. - Arbrisceau

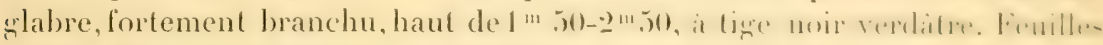
larges, flasques, d'un vert noirâtre, elliptiques-oblongrues ou oblonğnues-

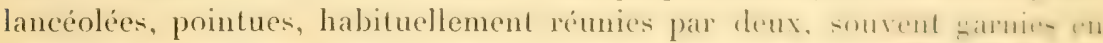

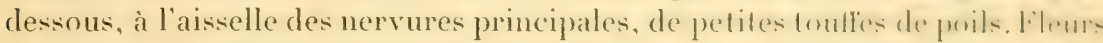
blanchâtres, petites, en crmes umbelliformes, laterales. pridnuculien. Bate sphérique, jaune à la maturité, de la grosiseur d'une pelite corise. - Tumbles parties de la plante exhalent une odeur désagréable; on n’en lait aucun usage dans la médecine domestique. - Fl. d'octobre à mai. - Cia et lì dans les halliers et les broussailles des régions inférieure et basse : environs de Saint-Pierre, Carbet, Marin, Trois-llets, ete. [No 2366.] - Je ne l'ai pas trouvé à la Guadeloupe.

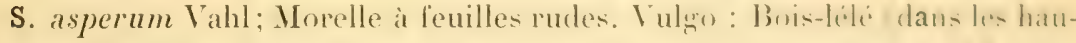
teurs de Baillif), ailleurs Bélangère petit. - Graud arbuste, hat de-2-3 mil. très branchu dans le haut, à écorce rougeâtre, rude, à ligge et rameaux très scabres, garni d'aspérités lenticulaires, blanchâtres el très nombreuses. Feuilles scabres, elliptiques ou elliptiques-oblongues, acturninces an smmus. rétrécies, à la base, en un pétiole ailé. Fleurs d'un blane sale, en cymes arrondies, contractées, poilues, longuement pédonculées, terminales, ì pédoncules et pédicelles revêtus de poils courts, roussâtres. Baie scal)re, jaunâtre à la maturité, sphérique, de la grosseur d'une pelite cerise. - Vl\% de février à mai. - Peu abondant : çà et la le long des rivières, et dans les

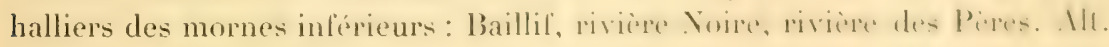
50-300 mèt. [No 2607.]

Martinique. Vulgo : Mélongène bâtard, - Basse-Pointe (environs du bourg), Macouba, fontaine Didier. Alt. 50-100 mèt. [No 370.]

S. neglectum Dun.; Morelle nérligée. Vulgn : Mélongène-liane bailard. $\mathrm{Pl}$, édit. Burm., t. 245, f.4. - Liane sullrutescente nu frutescente, š́lendant en tous sens sur les branches des plantes voisines, it ligo eylindrique, 
glabre, à rameaux plus ou moins pubescents à l'extrémilé. Feuilles très llasques, ovées ou ovées-oblongues, pointues, laineuses en dessous, et grisâtres. Fleurs d'un blane pâle. en crmes ombelliformes, pauciflores, pédonculées; calice garni, au sommet, de dix appendices droils, courts. Fruit subglobuleux-oliviforme, surmonté du style persistant. - Fl. de mai a juillet, et aussi d'octobre à janvier. - Peu abondant. Sur les lisières et dans les clairites des grands bois inféricurs: Camp-Jacob, rivière Noire, Capesterre (Guadeloupe, habitation Longmont, etc.). Alt. 150-600 mèt. [No 2884.]

Martinique. Vulgo : Mélongène bâtard, mélongène-liane-razier. - TroisIlets, hauteurs de Case-Pilote, fontaine Didier, etc. [ $\left.\mathrm{N}^{\circ} 364.\right]$

S. racemosum Jacy.; Morelle ì fleur's en grappes. Vulgo: Picanier femelle. a, variété inerme. Jacq., Sel. Am. stirp. his .., t. 36, p. 50. - Grand arbuste, haut de 2-3 mèt., peu branchu, nu dans le bas, à écorce cendrée, à rameaux pulvérulents-pubescents, grris. Fenilles allongées-lancéolées, acuminées au sommet, légèrement pubesbentes et grises en dessous. Fleurs blanches, pédicellées, unilatérales, en çrappesterminales et axillaires : ces dernières confinées aux aisselles des fenilles de l'extrémité; pédicelles penchés. Baie rouge de feu à maturité, sphérique, de la grosseur d'une graine de poivre. Fl. d'août à mars. - Abondant sur les côtes sèches du littoral, entre Baillif et Deshaies, Désirade, Moule, Saint-Francois, Sainte-.Mne, Gozier, MarieGalante, les Saintes, elc. Alt. 0-120 mèt. [No 2605.]

Martinique. Vulgo : Mélongène-diable bord-de-mer. - Aboitdant : Prêcheur, Case-Pilote, Diamant, Sainte-Anne, Vauclin, etc. [No 1131.$]$

h, variété épineuse. Vulgo : Picanier mâle. Sl., t. 11, f. 3. (S. igneum L.) I) iffère de la précédente par sa taille moins élevée, par les tiges dont l'extrémité supérieure est garnie de piquants forts, droits et jaunes, par les feuilles, les pétioles et le dessous de la nervure médiane également dépourvus de piquants recourbés et latéralement comprimés et plus courts que ceux de la tige. - Environs de la Pointe-à-Pitre, Moule, Gozier, etc. - Cette variété est loin d'être aussi abondante que lautre. No 288:- J - Je ne l'ai pas vue à la Marlinique.

S. lancerefolinm Jacq.; Morelle à feuilles en fer de lance. Vulgo: Bélangère piquante. - Liane vivace, rampante et grimpante, courant mollement sur les branches des végétaux voisins ou montant à une faible hauteur, à tige, branches, pétioles et nervure médiane warnis de piquants recourbés ou droits, acérés, courts, nombreux. Feuilles lancéolées ou ovées-lancéolées, longuement pétiolées. Fleurs blanches, plus rarement violacées, en cymes latérales. Baie sphérique, rouge, de la grosseur d'un pois. - Fl. de novembre à mai. - Peu abondant. Crit et li dans les haies des savanes, sur les lisieres el dans les clairieres des gronds bois inférieurs : rivières Noire et Rouge, Natouba, Camp-Jacob, etc. [No3408.] 
Martixique. Vulgo : Mélongène-razier, mélongène piquant. - Plus abondant qu'à la Guadeloupe : hauteurs de Fort-de-France, fontaine Didier. Trois-Ilets (plateau), Anses-d'Arlet (morne Larcher), etc. [Yo 365.]

S. torvum Sw., S. ferrugineum Jacq. ; Morelle is cymes contournées. V'ulgno : Bélangère bâtard. Desc., vol. III, t. 188, p. 167. - Arbrisseau droit ou tortueux, frutescent par la base, herbacé par le haut, d'une élévation de 1 m.j)$2^{\mathrm{m}} 50$, à branches peu nombreuses, presque étalées el souvent penchées, à

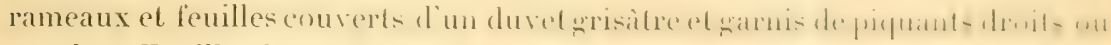
courbés. Feuilles larges, ovées, sinuées-dentées : les jeunes souvent entières. Fleurs d'un blanc pâle, en cymes dicholomes, tournées de côté, latéralés. Fruit jaune à la maturité, sphérique, de la grosseur d'une petite cerise. Très abondant dans les basse et infra-moyenne régions de toute la Guadeloupe et de ses dépendances. - Fl. presque toute l'année, mais surlout pendant et après l'hivernage. - La plante est, comme la plupart des Solanum, toxique-narcotique. Dans le pays, on emploie les racines, macérées dans l'eau et prises en lisane, contre les coliques néphrétiques, la racine et l'écorce en décoction contre les fièvres gangréneuses. Les cultivateurs se servent souvent

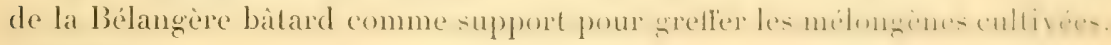
[No 2885.]

Martinique. Vulgo : Mélongène-diable. - Très abondant dans toute l'ile. [N.2123.]

S. Melongena L. Vulgo : Mélongène (du grec. " melon ", pomme, el "genein ", produire, qui produit des fruits semblables à une pomme), aubergine. Dese, vol. III, t. 107, p. 163. - Originaire de l'Asie tropicale, cultivée comme légume dans toutes les parties chaudes el tempérées du monde entier. [ $\mathrm{N}^{\circ} 2880$.]

Martinique. Vulgo: Mélongène, aubergine. [No 21:27.]

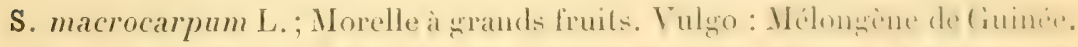

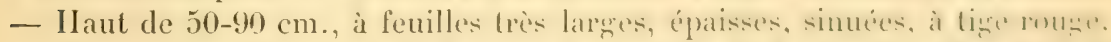
ou blanche ou noiritre, it fruits d'un jaume d'or, de la grosseme d'un wat de poule ou d'une petite poire; se rencontre assez souvent dans les deux colonies. - Originaire de l'Afrique (La Réunion, Madagascar). - Les fruits sont délicats et se mangent comme les mélongènes ordinaires'. Un les grelfe habituellement sur la Bélangère bâtard. [Y 2881 .

S. mammosum L.; Morelle à fruits mammiformes. Vulgo : Pomme-poison. Sl., t. 12, f. 1; Desc, vol. III, t. 186, p. 159.-Amnel, omemental, haul de

1. On emploie, à Madagascar, la décoction de la racine ou le linit de celle plante nommée, à la Réunion, frosse anghine contre les fievies paludécnnes. hat dínetimn. aqueuse ou vinense, se prépare avec 15 grammes de racines concissés pum mu litre d'eau ou de vin rouge; on prend cette décoction par verréce en "zi hetures, diapres Bocquellon-Limousin. (E. II.) 
$0^{\mathrm{m}}$ 60-1 mèt., tortueux ou droit, à branches étalées et divergentes, à tiges, hranches, pétioles, pédoncules et faces des feuilles garnis de piquants jaunes. droits ou recoubésel très acérés. Feuilles laryes, sinuées-anzuleuses, flasques, velues des deux côtés, à poils dorés et couchés. Fleurs violet foncé, en cymes latérales, seorpiö̈des, plus ou moins cachées par les feuilles. Fruit mammiforme, long de 5-6 cm., nu, de 4-4,5 cm. d'épaisseur, muni de son calice persistant. - A l'époque de la maturité des fruits, les feuilles se sèchent et tombent : on voit alors l'arbrisseau chargé de 10-\{1 capsules, très lisses, d'un jaune d'or vif et brillant de tout leur éclat au milien des savanes sèches, ce qui produit le plus bel effet. - La plante est éminemment toxique-narcotique et pourrait rendre de trands services dans la médecine domestique. Descourtily dit : "Je l'ai administrée avec succès à dose fractionnée, dans de violentes cardialgies, dans plusieurs autres douleurs nerveuses, et dans beaucoup d'alfections locales douloureuses, dans la cure des dartres rongeantes et des autres maladies de la peau, rebelles aux moyens ordinaires. C'est par sa vertu sédative qu'elle convient en topique dans les cas d'ischurie spasmodique, la strangurie et les douleurs néphrétiques. ()n en recommande les topiques contre les brúlures et pour le soulagement des hémorroüdes. On applique le feuillage de cette plante calmante, soit en bains, soit en fomentation ou en cataplasmes, sur les abcès douloureux, les furoncles et les panaris, et particulièrement la décoction dans les pansements des ulcérations douloureuses des seins et dans ceux des ulcères cancéreux, etc. "Dans le pays, on ne fait guère usage de cette herbe : on se sert cependant des fruits verts pour empoisomner les ravets (eancrelatsi. I)ans quelques endroits, on détruit la plante, de peur que les enfants et les animaux n’en mangent les fruits. - Fl. habituellement pendantlhivernage. - Cuà et lì dans les régions inféricure el basse de toute la (ruadeloupe et de ses dépendances, sans ètre abondant nulle part. [ $\mathrm{N}^{\circ} 3367$.

Martinique, Vulgo: Pomme-zombi. - Çà el là dans toute l'île. [N 1214.]

Gestrum L. (du grec "kestron ", marteau, parce que les étamines sont pourvues d'une dent qui les fait ressembler à un marteau avec un manche; le "kestron " de Dioscoride, IV, 1, est une Labiée qui a reçu ce nom dans le sens de pilon, parce que l'ensemble de la fleur visée présente une certaine ressemblance avec cet instrument.)

G. laurifolium L'Hérit.; Cestreau à feuilles de laurier. Vulg̨o: Citronnier, bois-savon (à Bouillante), bois-poison (au Camp-Jacob). - Arbrisseau ou grand arbuste, haut de $1^{\mathrm{m}} 50-3$ mèt., très glabre, droil, très feuillu. Feuilles cartilagineuses, très vertes, luisantes, elliptiques ou obovées, a nerrures a peine perceptibles it létat frais. Fleurs odorantes, jaune verdâtre, en cymes contractées, axillaires, très nombreuses, situées tout le loner des branches. Baie ovö̈de, noire ou bleu foncé à la maturité. 
- Toutes les parties de la plante, surtout les feuilles, froissées, émettent une odeur désagréable. - lil de janvier à avril. - Asse\% abondant dans les buis inférieurs des Bains-Jaunes, de la rivière Noire, des hauleurs de laibllif.

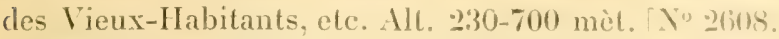

Martinique. Vulgo: Bois-poison, - Un se sert des liruils, écrasés el mélé: à de la graisse, pour tuer les ravels (cancrelats) el les rats. - Moundinul Grande-Rivière, la liégale, Trois-llets, Roches-Carrées (Lamentini), cle. [No 361 .

C. nocturnum L.; Cestreau nocturne. V'ulyon: Jasmin grand-bois. Dill., Elh., t. 186. - Grand arbuste ou plus rarement petit andre, haut de 34 mèt. Feuilles ovales-elliptiques, cartilagineuses', pointues au sommel. brusquement rétrécies, à la base, en un pétiole ailé, de coulenr vert pâle. Fleurs en eymes racémiformes; corolle blanc pâle, à lobes bosés, it lube graduellement élargi de la base au sommet. Baie ovoüde, blen foncé i la maturité. - Cà et là dans tous les grands bois : Bains-Jaunes, rivière Ronune, Gommier, Vieux-Habitants, etc. Alt. 400-900 mèt. \'0 2610.

Martixique. Vulgo : Jasmin des bois : hauteurs de Case-Pilote el de CaseYarire, fontaine Didier, etc. [Xos 167,359 a.

C. vespertinum L.; Cestreau du soir. Vulgo : Jasmin bâtard, suyau bitlard. - Arbuste haut de 2-3 mèt., à branches flexibles, peu nombreuses. Feuilles ovales-elliptiques, minces. Fleurs odorantes, surtout le soir après le coucher du soleil, purpurines d'abord, ensuite blanc pâle, en cymes axillaires, pauciflores; diffère du précédent : par les lobes du calice subulés-deltö̈des; par le tube filiforme de la corolle, qui s'élargit brusquement au sommet: par ses étamines insérées dans la gorge de cette corolle, et leurs filets aussi longrque les anthères. Baie bleu foncé. - Fl, de septembre en jauvier. - Išse abondant aux mornes Sulpice et Pérou (Marin). Yo 360.] - Je ne lia pas trouvé à la Guadeloupe.

C. Ialifolium Lam.; Cestreau à larges feuilles. Vulgo : Jasmiu-bois. Arbrisseau haut de 2-3 mèt, peu branchu. Feuilles membraneuses, orées. glabres. Fleurs blanc pâle, odorantes, subsessiles, en cymes contractéc: tube de la corolle graduellement dilaté de la base au sommet. - (jai et lis dans les endroits ombragés des grands bois : Bains-Jaunes, Trois-Rivieres. hauteurs de Baillif, etc. Nos $^{\top} 609,3410$.

1. Ces feuilles sont sans usage aux Antilles: foulefuis a la fiurame celles mul servi

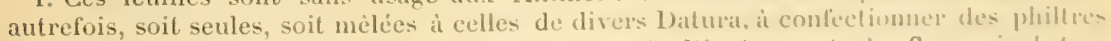

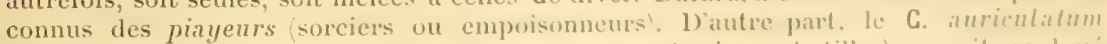
L'Iérit. (de l'Amérique australe, qui nexiste pás spontanć aux Antilles) y s'rait e'mpluyé comme fébrifuge, d'après 130 crfuellon-J,imousin . Yat. méd. dudes de plantes desconlunies

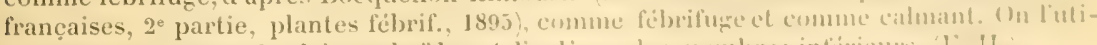
liserait aussi contre les hémorrhoides el lodeme des membres infírieurs. "1: II

Duss. - Plantes Guadeloupe et Martinigum. 
- Mantinique. Vulgo : Jasmin sauvage. - Environs de Saint-Pierre, morne du Jardin botanique), Fonds-Saint-Denis, Case-Pilote, vallée du Carbet. $\left[N^{\circ} 1900\right.$.

De la famille des Solanées, on cultive au Jardin botanique de Saint-Pierre et dans d'autres jardins un superbe arbuste à fleurs en cymes terminales, violet foncé, a corolle longue, tubuleuse, c'est Iochroma lubulosa Benth., introduit de la Nouvelle-Grenade.

\section{CENT SELZIVE HMULE, - BIGNONIACÉLS.}

Grescentia I. udédié à l'Italien Pierre Crescenzi Petrus de Crescentiis, ué en 1230, à Bologne, mort dans cette ville à un âge très arancé; a ecrit : Opus ruralium commodorum. C'est le premier auteur qui ait écrit sur l'agriculture depuis les anciens Romains.)

G. Cujete L. (Cujete, nom brésilien de l'arbre). Vulgo : Calebassier, calebasse. Tuss., $\mathrm{Fl}$., II, t. 9; Desc., vol. IV, t. 244, p. 47. - Arbre de la taille d'un pommier de France, habituellement très branchu, à rameaux droits, allongés, peu divisés, à écorce grrisatre, crevassée. Fenilles fasciculées par 3-10. cartilayineuses, subsessiles, spatulées, les fascicules de feuilles naissant sur des protubérances. Fleurs larges, couleur de crime, latérales, solitaires, nais-ant sur le trone, les grosses branches et les rameaux; calice bipartite, spathacé, caduc; corolle à deux lobes dentés-ondulés. Fruit, nommé calebasse, très variable quant a la forme et aux dimensions: les plis petits ne mesurant que $5 \mathrm{~cm},-5,2 \mathrm{~cm}$., et les plus grands jusqu'à $32 \mathrm{~cm}$. de long. - C'est une sorte de baie, à péricarpe dur, ligneux et vert dent l"intérieur est rempli d'une pulpe aigre, contenant une masse de semences comprimées-cordiformes. Arrivé a maturité, on le vide et on en fabrique des ustensiles de ménage, que les Créoles appellent "Couis ". Sclon l)escourtilz, la pulpe est diurélique-excitante, el cet auteur recommande le jus pasé à travers un linge et mòlé à du sirop contre les maladies de pnitrine, contre la diarrhée chronique el certains catarthes intest inaux. Dans le pays, on se sert de la pulpe, quion applique a froid, pour la guérison du crabe (crevasses de la plante des pieds), contre les coups de soleil, en y ajoutant un peu de vinaigre, et contre les blessures et les fortes contusions : avec les jeunes fruits, pilés, on prépare aussi des "loochs". Le bois est blanc et compact, mais il se laisse facilement attaquer par les insectes. - Le calebassier tleuril presque toute l'année, mais ne produil que peu de fleurs a la fois. - Abondant dans les basse et infra-moyenne régions de toutes les Antilles. Alt. 0-700 mèt. [No 3066.]

Martixique. Vulgo : Calebassier. - Abondant. Alt. 0-500 mèt. [ [ $\left.{ }^{\circ} 1236.\right]$

C. cucurbitina L.; Crescentie it fruits en forme de concombre. Vulgo : 
Calebassier bâtard, calebasse-poison. Desc, vol. III, 1. 182, P. 143; P1., édit. Burm. ; t. 109. - Grand arbre, ì fronde ample, ì feuilles larres. cartilagineuses, obovées-oblongues ou ovales-oblongues, it liruit de lit srosseur et un peu de la forme d'un petil arocat. - Existait autrefois it la Martinique. dans les bois de la Régale et des Trois-Ilets; il a disparu de ces stations et on en a conservé un seul pied au Jardin botanique de Saint-Pierre. . Y" 1231. - Il n'existe pas à la Guadeloupe.

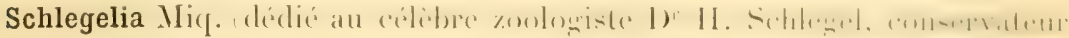
du musée zoologique de Leide.

S. Urbaniana K. Sch.; Schlégélie d'Urban. Vulgo: ORil de crabe. Liane puissante, s'élevant sur des arbres très hauts, at écorce lisse et grise, it

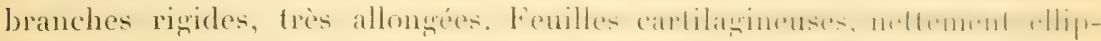
tiqques, luisantes en dessus, vert très pâle en dessous. Fleurs violacées, en grappes courtes, axillaires et caulinaires, très nombreuses, disposées tout le long des branches. Fruit subglobuleux, de la grosseur d'une petite cerise, bleu foncé à la maturité. - lil. de février ì mars. - Peu abondant : çi et là dans les bois de Houëlmont et dans les bois inférieurs des Bains-launes et du Matouba. [No 2118.] - Il n’existe pas ì la Martinique.

Catalpa Scop. (nom de la plante chez les Indigènes de la Caroline.

C. Iongisiliqua Cham.; Catalpa ì longues siliques, Vulgo : Chène d'Amirique. Desc., vol. I, t. 18 ; Tuss., Fl., IV, t. 37. - Grand arbre, droil. anfractueux, surtout vers la base, à trone nu à une grande hauteur, ì frondaison peu fournie, à fleurs violet pâle, en petites grappes terminales. Était autrefois abondant dans la basse région de la Martinique. - I cause de son bois recherché pour la construction, on a fait abattre tous les pieds, il n'en existait plus que deux ou trois au Jardin botanique de Saint-P'ierre en 1889. - Il est indiqué, par Mazé ', comme laisant partie de la flore de la Guadeloupe; mais il n'y jamais existé.

Tecoma Juss. (du nom mexicain "T'ecomaco-chill.

T. pentaphylla DC.; Tecome à feuilles à cinq folioles. Vulyo : Poiriel du pays. - Arbre de grande taille, peu élégant, peu branchu, trìs anfraclueux, surtout les vieux pieds dont le trone peut atteindre un diamètre de 81)$95 \mathrm{~cm}$; ; à écorce blanchâtre. Feuilles composées-palmées à 3-5 folioles, longuement péliolées, luisantes, cartilagineuses; pétioles communs, longs; ne portant quelquefois qu'une seule foliole. Fleurs rosées ou blanches, ou it peine rosées; siliques pendantes, à 3 valves, longues de $12-27 \mathrm{~cm}$. sul , j-s mm. de large, droites ou légèrement courbes; semences de 30-\{0), très aplaties. plus larges que longues, pourvues de deux ailes latérales, tramsinarentes.

1. Contribution da la flore de la Guadelonpe, Basse-'Terre, 1s9:. 
minces, frangées et blanches. - Le bois est gris, dur, à texture fibreuse, tenant de l'orme, du chêne et du châtaignier de France : il sert avantageusement pour la confection des canots, des bateaux de cabotage, des moulins a manioc, pour les constructions dans l'eau et dans la terre; il.est également recherché pour l'ébénisterie et la confection de jantes de roues. A cause de son bois flexible et de ses longues et fortes racines, il se laisse difficilement renverser par les coups de vent. Pendant la saison sèche, l'arbre perd habituellement ses feuilles. - Abondant dans toute la région du littoral et ì l'intérieur jusqu'à une altitude d'euviron 350 mèt. [No 3061 .]

Martixique. Vulgo : Poirier. - Abondant. [No 1917 a.

T. leucoxylon Mart.; Tecome à bois jaune. Vulgo : Bois d'ébène. Desc., vol. III, t. 204, p. 241. - Arbre de grande taille, à feuilles composées-palmées, à cinq folioles ressemblant à celles du précédent, à fleurs larges, d'un jaune très vif, en bouquets terminaux très nombreux. - Était autrefois abondant à la Martinique. On en conserve encore quelques pieds au Jardin botanique. - A l'époque de la floraison, il perd complètement les feuilles. (Spécimen en maurais état.)

T. stans Juss.; 'T'ecome droit et solidement attaché. Y'ulgo : Bois-pissenlit, fleurs jaunes, bois à enivrer (au Baillif) (Bignonia L.) - Grand arbuste ou petit arbre, droit ou souvent tortueux, haut de $2-4^{\text {m }} 50$. Feuilles imparipennées, à 3-.5 paires de folioles oblongues-elliptiques, acuminécs, dentées en scie. Fleurs larges, james, en grappes simples ou composées à la base, pyramidales, dressées; siliques linéaires, pendantes, longues de $12-15 \mathrm{~cm}$, droites ou légèrement courbes, pointues à l'extrémité; semences nombreuses, aplaties, à deux ailes latérales. - Il fleurit toute l'année. - On se sert, en quelques endroits, des feuilles et des jeunes tiges, froissées, pour enivrer les poissons 1. - Très abondant dans la région sèche du littoral de toute la Guadeloupe et des dépendances. Alt. $0-350$ mèt.; rare à une plus grande altitude. $[\mathrm{X} 02117$.

Martisique. Vulgo : Fleur jaune. - Abondant dans toute l'île. [No 1915.]

1. Tous les Tecoma des Antilles sont sans emploi médicinal; mais il faut signaler toutefois que T. undulata Bon. y serait utilisé, dans son écorce, ses fleurs et ses feuilles, comme fébrifuge et astringent. Poupée-Desportes recommande l'usage du sirop fait avec l'écorce et les fleurs au mème titre que le sirop de quinquina du commerce auquel il pourrait être substitué. La poudre d'écorce s'administrerait à la close de 8 à $15 \mathrm{gr}$., en cachets ou en infusion dans le vin. On préparerait un électuaire miel, poudre d'écorce et sirop d'écorce) (qui répugnerait moins aux fébricitants. Les fleurs, qui seraient aussi fébrifuges, s'emploieraient en poudre à moitié dose de la poudre d'écorces. Enfin, l'infusion faite arec $30 \mathrm{gr}$. de feuilles pour un litre d'eau serait employée en lavements fébrifuges. M. Bocquellon-Limousin (loc. cit.) s'est occupé de cette plante et n'y a trouvé que du tanin, ce qui confirmerait cette opinion dont je me suis souvent fait le propagateur après l'étude de certaines plantes coloniales, nettement fébrifuges et ne renfermant que de l'acide tannique, que ce principe est doué de propriétés fébrifuges. A étudier comparativement tous les Tecoma des Antilles. E. H.) 
Le T. capensis Lindl., Tecome du Cap de lionne- Espéranee, vulgo : Jasmin-trompette, est un arbrisseau sarmenteux, it leuilles imparipenmés, it fleurs rouges, en grappes courtes, terminales, à élamines exsertes, it cornlle en tube comprimé et courbe, qui est naturalisé et cultivé pour lonmementation des tonnelles, des grillages, etc. [N०3062.]

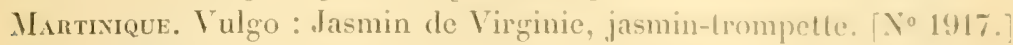

Bignonia L. (dédié à Jenn-Paul Bignon, né à Paris, con 166.2, ablué de SaintQuentin, bibliothécaire du roi, ami et protecteur de tons les savants de ton temps; mort en 1743, dans son château d'Isle-Belle.

B. equinoctialis L., B. spectabilis V.; Bignone fleurissant it l'époque de l'équinoxe. Vulgo : Liane-crabe, liane à paniers, liane-corde. Desc., vol. II, t. 100, p. 130. - Forte liane, grimpant au moyen de vrilles partant du sommet du pétiole commun, à tige nue dans le bas, à rameaux allongrís, flexibles et pendants. Feuilles à deux folioles ovées-oblongues, on ovées. pointues, entières. Fleurs axillaires, géminées on en corymbes panciflores; corolle violette avee des stries jaunes à l'entrée de la gorye; silique Iongue de $30-15 \mathrm{~cm}$. sur $2 \mathrm{~cm}$. de large, plus ou moins courbes; semences aplaties, noires, à ailes opaques. - Fl. de septembre à mars. - Avee les sarments

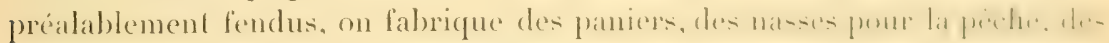
cordes, etc. - D'après Descourtilz, cette liane est stomachique, astringente: mais dans la médecine domestique du pays, on n'en fail pas usarge. - Vil en société avec les palétuviers de toutes sortes, dans les marécayes maritimes: Lamentim, Baie-Mahault, Pointe-à-Pitre, cte. $\mathrm{N}^{\circ} 3065$.

Martinique. Vulgo : Liane à crabes. - Rivière-Salée, Trois-Ilets, Lamentin, Ducos, Robert, etc. [No 1239.]

B. unquiscati L.;Bignone à racines adventives en forme de grifles de chat. Vulgo : Griffe-chatte. - Liane ne dépassant guère 5 mèt. d'úlévation, it tige d'abord rampante, radicante, pourvue de racines adventives ayant asse\% exactement la forme de griffes de chat. Feuilles adultes dans les lomohes libres, à deux folioles larges, luisantes, membraneuses, elliptiques ou clliptiques-lancéolées: celles des tiges radieantes, plus petiles. Fleurs laures, d'un jaune brillant, en grappes nombreuses, courtes ou allongées, axillaires el terminales; silique linéaire longue de $60-85 \mathrm{~cm}$. sur $1.5 \mathrm{~cm}$. de larye, toujours pendante, droite ou courbe; semences ailées. - I l'époque de la lloraison, la liane se dépouille souvent entièrement de ses leuilles. - La planter a des vertus alexitères internes, el Descourtilz la place, en ellet, dalns celle catégorie. - Fl. de juin à août. - Cà et là dans les ravines, dans les condroits boisés de la basse région de la Guadeloupe el de la Grande-T'erre: Monte. Saint-François, environs de la Basse-Terre (ravine de Belust), Baillit, cle. [ $\mathrm{N}^{\circ}$ 3069.]

Martinique. Vulgo: Griffe-chatte. - On se sert des racines, piliess, comme 
remède contre la morsure du serpent '. - Case-Pilote fond Layette et fond Brûlé), Trinité, Trois-llets, etc. [T̃o 1914.]

La Bignonia alliacea Iam., vulgo : Bignone a l'ail Adenscalymna alliacum Miers), forte liane, dont les feuilles froissées exhalent une forte odeur d'ail, est cultivée au Jardin botanique de Saint-Pierre : elle est originaire de la Guyane. La B. radicans L. se trouve à l'habitation Rollin, au Matouba.

Amphilophium Kith. (du grec "amphi ", autour, et "lophion ", diminutif de "lophos ", crinière, crête, parce que la partie extérieure du double limbe calcinal est ondulée-crêpue et rappelle en quelque sorte le bord diune crête de coq.)

A. paniculatum II. 13. Kith.; Amphilophe à fleursen panicules. Vuluno: Liano à canot. Pl., éd. Burm., t. 56, f. 1; Jacq., Sel. Am. st. hist., t. 116, p. 183. - Forte liane, vivace, grimpant au moyen de vrilles sur des arbres très élevés el les courrant complètement, pour y étaler ses nombreuses srappes: à branches, jeune tige et rameaux à six angles, légèrement velus. Feuilles opposées, le plus souvent à deux folioles, rarement à trois, ovées, pointues, pétiolées. larges et garnies en dessous d’un léuer duvel snyeux el pris. Inflorescence en panicules pramidales médiocrement allongées; fleurs odorantes: calice à limbe double : l'extérieur formant, au-dessous du sommet du premier, un collet ondulé quis applique contre la comolle; celle-ci est blanche. ou violacée ou blanche dans le haut, et violacée ou violette à la base; silique longue de $11-14 \mathrm{~cm}$. sur $6 \mathrm{~cm}$. de large, et $3-4 \mathrm{~cm}$. de diamèt, elliptique, échancrée au sommet; valves dures, ligneuses, épaisses, formant deux écuelles; semences lareges imbriquées, it deux ailes laterales, minces et transparentes. - Peu abondant. Cà̀ et là dans les falaises et endroits abrupts, d'un accès souvent difficile: Basse-Terre (ravine de Belost), rivières Voire et Rouge, Vieux-Habitants, etc. Alt.10-100 mèt. YNo 3060 .

Martiniqe . Vulgo : Liane-canol. - Parnasse (habitation Litté), morne du Jardin botanique, vallée du Carbel, Fonds-sant-I tenis pres de la Portede-l'Enfer), ele. [No 1238.]

Tanæcium Sw. (du grec “tanakès », ce qui est allongé, par allusion aux branches droites et allongées, qui plus tard deviennent sarmenteuses.)

T. crucigerum Seem. (Tanacie dont la coupe transversale de la tige montre les faisceaux disposés en croix.). Vulgo: Liane à barrique. Pl., éd. Burm., t. 58. - Liane puissante, s’élevant sur les arbres les plus hauts, ¿ branches dabord droites, devenant ensuite sarmenteuses, a tige cylindrique-

1. A la Guyane, le suc de toutes les parties de cette plante est réputé alexitère. Èn infusion, les feuilles et les bourgeons sont utilisés en bains médicamenteux, et comme sudorifiques dans les fièrres d'accès. Ils entrent dans la composition d'un sirop béchique adoucissant. (E. H.) 
anfractueuse, à rameaux souvent couverts de nombreuses aspérilés lenticu-

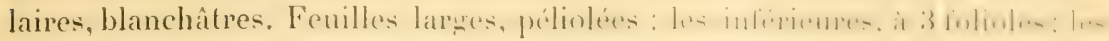
supérieures, très sourent it deux folioles senlement, folioles ovales, cartila-

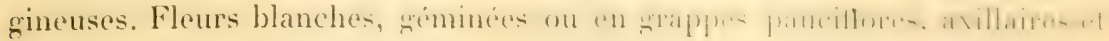
terminales; corolle à tube long el infundibulilorme, pubescente, it Inbes

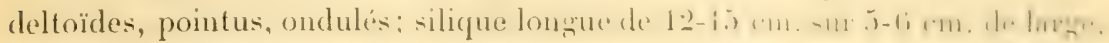
convexe, elliptique, arrondie aux extrémités, formant, aprís déhiscence,

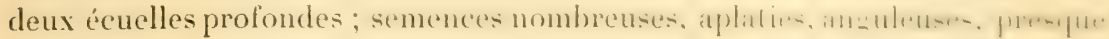
quadrangulaires, à surface lisse, ondulée. - Peu abondant : environs de

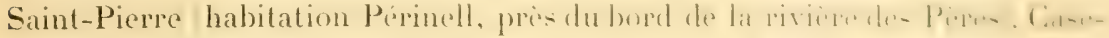
Pilote (le long de la rivière du Fond Layette). - Ses tigres servent il laire des cercles pour les barriques. [ $\mathrm{Y}^{\circ}$ 1237.] - Je ne l'ai pas vu al la Cuadeloupe.

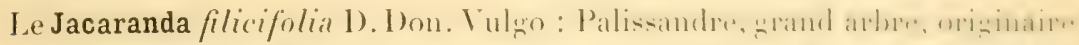

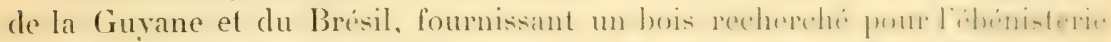

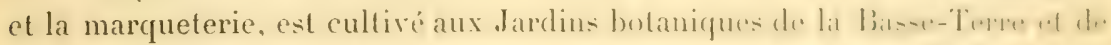

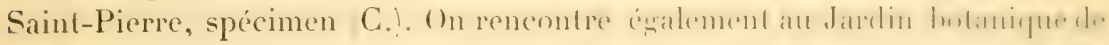

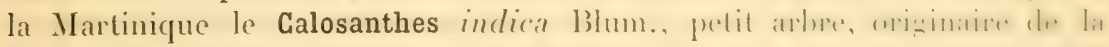

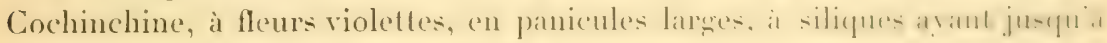
$30 \mathrm{~cm}$. de long, et le Phyllarthron comorense DC., petit arbre des iles Comores, qui fleurit presque constamment, mais ne produit pas de fruits.

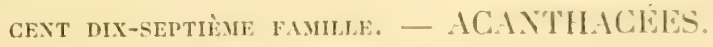

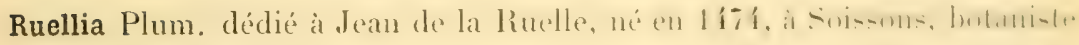
et médecin de François Ier, entra plus tard dans un ordre religieux ; mort it Paris, en 1537; a publié plusieurs ouvages des anciens, fratinal de-plint:médicinales, entre autres ceux de Dioscoride. Il a aussi écrit : le nalura stirpium.)

R. tuberosa L., R. clandestina L.; Ruellie à racines tubéreuses, lúgo : Chandelier. Desc., vol. II, t. 113, p. 180 ; Sl., 1. 95, 1. 1. - Vivace par ses racines fasciculées, fusiformes-allongées, prolondement enterrex-a a lizsouvent multiples, droites, branchues, tétragones el velues dans le haut,

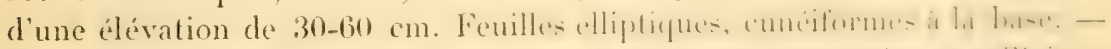

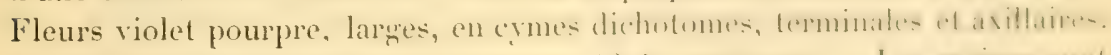

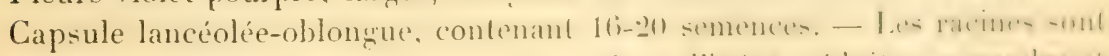

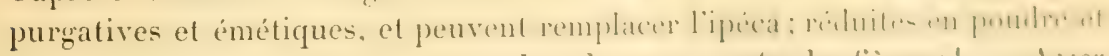
prises en décoction, elles servent, dans le pays, contre les lièvess 1. - Assey

1. A la Guyane, le sirop obtenuavec les racines est trés vanté contre la coqueluche. (L. II 
abondant dans les environs de la Basse-Terre, Vieux-Fort, Moule, SaintFrançois, Lamentin, Désirade, Capesterre (Guadeloupe), etc. [No 2366.]

Mantmirie. - Ipéca bâtard, patate-macaque. - Trois-llets, Ansesd'Hrlet, Marin, V'auclin, etc. [No 2013.]

R. geminiflora H. B. Kth. ; Ruellie à deux fleurs aux aisselles des feuilles. Vulgo: Herbe-hallier. - Sullrutescent et frutescent, haut de 30-70 cm., droit ou tortueux, à tiges sourent nombreuses, grêles. Feuilles lancéolées, ovées, subsessiles. Fleurs violet pâle, petites, très caduques. - Assez rare. Dans le sol sec, pierreux et en pente de la basse région : environs de SaintPierre (ravine de Belost), Houëlmont. [No 3808.] - Il n'existe pas à la Martinique.

Blechum P. Br. (du gree “blekon ”, mot par lequel les Grees désignaient une espèce de marjolaine : notre Blechum a une inflorescence semblable.)

B. Brownei Juss., Justicia marlinicensis Sieb.: Blechum de Browne. Vulgo: Herbe-savane. Sl., t. 109, f. 1. - Herbe annuelle ou bisannuelle, haute de $25-80 \mathrm{~cm}$., à tige souvent couchée et radicante, habituellement nue dans le bas. Feuilles ovées. Inflorescence en épis tétragonaux, terminaux, réunis par 2-3; corolle violet pâle, pédicelles courts, munis, à la base, de trois bractées ovées, ciliées. Capsule ovoïde, contenant huit semences. - Très abondant dans les savanes sèches et humides de la basse rézrion, où il vit souvent en société et forme une sorte de gazon; il constitue un assez. médiocre fourrage. - Environs de la Basse-Terre, Baillif, Lamentin, Moule. Désirade, Marie-Galante, les Saintes. Alt. 0-400 mèt. T To 2363.

Martinece. Vulgo: Herbe-savane. - Abondant dans toute l'île. [No 1212.

Lepidagathis Willd. idugree "lepis", ceaille, el "ayalhis ", pelote, parce lesfleurs sont en glomérules, et les segments inférieurs de ces fleurs en forme d'écaille.)

L. alopecuroides R. Br.; Lépidagathis à queue de renard. Vulgo : Queue de renard (Teliostachya Nees). - Herbacé, annuel ou vivace, ou parfois suffrutescent, selon les endroits, à tigre couchée, allongée, radicante, ensuite relevée, haute de $20-75 \mathrm{~cm}$. Feuilles elliptiques, cunéiformes à la base. Fleurs en glomérules verticillées, formant ensemble un épi serré, ovoïde-allongé; bractésscarieuses, elliptiques, pointues, wristres; corolle vinlet pale, pelite. - Dans les endroits aquatiques ou très humides et le long des ruisseaux des "rand bois : Bains-Jaunes, Matouba, Vienx-Habilants, Trois-livieres', ete. Alt. $400-900$ mèt. [No 2365.$]$

1. Dans l'Inde, on emploie comamment le Lepid. cristata Willd. contre les fières intermittentes : on en prépare une décoction aqueuse ou une infusion vineuse, à la dose de 45 gre de plante pour un litre de liquide. Il y aurail à voir si l'espèce des Antilles n'a pas les mêmes propriétés. (E. II.) 
Mantmique. Vulgo : Queue-de-renard. - . Dondant: Bois de la MontagnePelée, du Lorrain, de l'Alma, etc. $\left[Y^{\circ} 1213\right.$.

Pachystachys Nees (du gree "pachus », épais, scréé, cl "stachy's ", cipi. allusion à la forme de l'inllorescence.)

P. coccinea Nees; Pachystachys ì lleurs écarlates. V'ulso : Plumel d'ullicier. Aubl., t. 3. - Arbrisseau élégant, haut de $1^{\text {"II }}$ J)-3 mét, chroit, très ornemental. Feuilles larges: les adultes, penchées; les jeunes, drescies. elliptiques ou elliptiques-oblongues, pétiolées. Hleur's larges, serrées, en épis cylindriques, longs de $8-12 \mathrm{~cm}$. - Introduil de Cáyenme, naturalisé el cultivé à la Martinique, au Jardin botanique el dans beaucoup d’autres endroits de l'île; se rencontre rarement dans les jardins de la Gutaleloupe. [No 2371.$]$

Thyrsacanthus Yees (du gree "thyrsos ", thyrse, panache, el "akantha ", épine, pointe, probablement parce que les grappes en forme de thyrsesont allongées et pointues.)

T. nitidus Nees; Thyrsacanthe à fleurs brillantes. Vulgo : Bois indien. Sl.. 1. 10, f. 2. - Arbrisseau suffrutescent el souvent frutescent, tris frabre, droit, haut de $0^{m} 70-1 \mathrm{~m} 40$, ornemental, peu branchu, a bois trè cassint. Feuilles oblongues ou lancéolées-oblongues, acuminées au sommet, rétrécies. à la base, en un pétiole court. Fleurs violet pourpre, ou violacées ou plus rarement blanches, et panachées de violet, en thyrses allongés, formant, le plus souvent, une large panicule terminale. - Abondant dans les bois inl'cirieurs, humides el rocailleux : Camp-Jacob, Iouëlmont, Gourbeyre (mornes Boucanier et Hirondelle), Trois-Rivières, Vieux-IJabitants, etc. Alt. (1-\{1)600 mèt. [No 2361 .

Martinique. Vulgo: Bois genou, à cause des renflements des nexuds. - T'rè: abondant dans presque tous les grands bois, mais surtout dans les mivirns: de la fontaine Didier et dans les hauteurs des Trois-llets et du l)iamant. [Nos 2004,2005 .

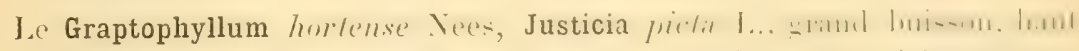
de 2-4 mèt., à feuilles panachées de blanc sur fond vert, est fréquemmenl cultivé dans les jardins des deux colonies. [No 1996.

Dianthera Gronor. (du gree " dis ", double, et "anthera ", anthire, allusion aux loges de l'anthère, qui sont séparées par le connectif, de maniere it paraître doubles.)

D. androsamifolia Griseb, Dianthère is feuilles d'Androsema. Vulgon : Violette-savane, - Sulfrutescent et frutescent, haut de - fil-(i) cm.. nu dims le bas, à tige grêle, à branches peu nombreuses, plus ou mons inclinces an sommet. Feuilles ovées ou ovées-lancéolies. Fleurs violettes, parachées des 
blanc, en épis pauciflores el allnngés. - Peu abondant. Endroits secs, chauds el pierreux : les Saintes (chemin du Chameau), Deshaies (Gros-Morne?. $\left[\mathrm{N}^{\circ} 2895\right.$.

Martixique. Vulgo: Violette des bois. - Assez abondant dans les broussailles pierreuses et en pente des hauteurs du Fond Layette Case-Pilote. [N०2008.]

D. pectoralis J. F. Gmel.; Dianthère pectorale. Vulgo : Herbe aux chaipentiers. Tuss., Fl., III, t. 2; Jacq., Sel. Am. stirp. hist., t. 3, p. 3.- - Sulfrutescent, haut de $20-70 \mathrm{~cm}$., à racines fibreuses, à tige grèle, allongree, peu branchue ì l'état saurage, et sourent garnie d'une ligne de poils gris. Feuilles ovées ou ovées-lancéolées, petites. Fleurs violettes, en épis allongés, formant ensemble une panicule terminale, làche. Rare it l'état sauvage; se rencontre très fréquemment dans les jardins, ou il est cultivé comme plante médicinale et aussi en bordures, qui, par la taille, deviennent très touffues et trìs belles. - Dans la médecine domestique, nn emploie les feuilles et les branches en infusion contre les maux d'estomac: mêlées à du sirop, contre les maladies de poitrine; macérées avec du sel, pour la guérison des blessures. [ $\mathrm{N}^{\circ}$ 2362.]

Martixique. Vulgo: Herbe à charpentiers, - Cù et là dans les haies et surtout dans le cimetière de l'Ajoupa-Bouillon. - ()n en lait auswi des bordures. [Nos 2001, 2132.]

D. sessilis J. F. Gmel.; Dianthère à feuilles sessiles. Vulgo : Petite maryuerite. - Suffrutescent, haut de $30-80 \mathrm{~cm}$., souvent très branchu, à branches rigides, droites, lastigiées, peu feuillues, quelquefois presque sans feuilles. Feuilles ovées, pointues, brièvement pétiolées. Fleurs larges, violet loncé, sessiles, axillaires. - Endroits secs, chauds, pierreux, arides. - Fl. en arril, mai. - Assez abondant sur la còte de Baillif, entre le bourg et l'habitation Bovis. [No 3625.] - Il n'existe pas à la Martinique.

Justicia Iloust. (dédié à l'horticulteur Écossais James Justice, qui a écril : The scots gardener director, 1745; The british gardener director, 1767.)

J. eustachiana Jacq. : Justicie de Saint-Eustache. Vulgro: Grande marüuerile. Jacq., Sel. Am. st. hist., t. 4, p. 4. - Suffrutescent, ornemental, haut de $50-95 \mathrm{~cm}$., droit, à tige et branches rétrécies aux nuxuls. Feuilles lancéolées, acuminées, terminées par une pointe obtuse, pointues à la base. Fleurs rose foncé, en épis axillaires et terminaux. - Fl, d'août à janvier. - Environs du Noule, seul endroit où jaie pu trouver cette belle plante, mais elle y est assez abondante. [ $\mathrm{N}^{0} 2894$. ] Elle n'existe pas à la Martinique.

J. carthaginensis Jacq.. Beloperone violacea Planch. et Linden; Justicie de Carthage. Vulgo : Grande marguerite. Jacq., Sel. Am. st. hist., t. 5, p. 5. - Suffrutescent, haut de $50-95 \mathrm{~cm}$., droit, quelquefois tortueux et subsar- 
'menteux, à tige noirâtre, lisse, à branches courles, ì lige ef branches pútrícies et noirâtres aux nouds. Feuilles ovées ou ellipliques-lancéolées. Inllorescence en épis courts, terminaux; bractées obovales, spalulées, plus lonerues: que le calice; corolle violet foncé, très belle, it lèrre supérieure larye el it deux stries blanches. - Abondant dans les environs de la Basse-Terre Inne-ilVaches), Baillif, Pigeon, Moule, Morne-itl'Lau, etc. YY" Đ36í.

Martixleve. Vulgo: Grande violette. - Environs de Saint-l'ierre iTmis-

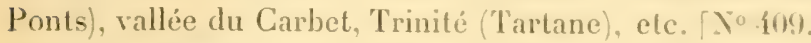

Le Grossandra infundibuliformis Nees, sous-arbrisseau haut de (1) "96$4^{m} 20$, droit, à fleurs d'un jaune d'ocre, en épis carrés el allongrés, a été introduit au Jardin botanique de Saint-Pierre, d'ou il s'est répandu et naturalisé dans les deux colonies ( $\mathrm{N}^{\circ}$ 2368), Martinique [ $\mathrm{Y}^{\circ}$ 408]; il est originaire de Madagascar.

On rencontre également dans les doux îles le Justicia Adhaloda I. (J. caracassana Sieb.), sous-arbrisseau à branches tombantes, relevées aux extrémités, à fleurs d'un bleu noir, panaché de blane, en laruges cymes axillaires: il est originaire de Caracas. $\left[\mathrm{X}^{\circ} 411\right.$.

Anthacanthus Nees (du gree "anthos ", fleur, el " aliantha ", ippine, it cause des épines qui se trouvent à la base du pédoncule floral.)

A. spinosus Nees; Anthacanthe épineux. Vulgo : Picanier jaune. - Arbrisseau haut de $0^{\mathrm{m}}$ 60-1 mèt., droil ou tortueux, le plus souvent fortement branchu. Feuilles ovées ou ovées-elliptiques, pointues au sommet, alténtées à la base en un pétiole tantôt long, tantôt court. Inflorescence en épis courls, terninaux et axillaires : les derniers très courts, épines it 3-5 branches acérées, droites ou légèrement recourbées, blanches, situces a l'aissclle der branches et des fleurs; corolle large, d'un jaune pâle; bractées ovales-lancéolées, terminées par une épine rigide et très acérée. - Peu répandu : via et là dans les terres sablonneuses des environs de la Basse-T'erre (quartier de l'Arsenal et embouchure de la rivière du Galion). [Yo 23660.] II existail autrefois à la Martinique : je n'ai pas pu le retrouver'.

A. microphyllus Nees; Anthacanthe it petites feuilles. Vulgo: Amourette. - Buisson très touffu et très ornemental, haut de 1-2"' 50, à branches allongées, flexibles, infléchies ou tombantes. Feuilles très petites, spatulées nu obovales, solitaires ou fasciculées par 2-5. Fleurs violelles, axillaires, solitaires ou plus rarement fasciculées. - Fl. de septembre at mars. - Mondant dans les terres calcaires de la côte oecidentale de la Désirade; ma it MarieGalante. [No 2899.] - Il n'existe pas à la Martinique.

Dicliptera Juss, (du gree " diklis ", double porte, el "pleron », aile, paree que les deux valves de la capsule sont ailées el se séparent it la hase.

D martinicensis Juss.; Dicliptère de la Martinique. Vulgo : Herbe-savane 
Jacq., Sel. Am, st. hist., t. 2, f, 3, p. 2 (une feuille et une fleur). Justicia Jacy. - Herbe géniculée, rameuse, slabre, haute de $50-80 \mathrm{~cm}$. plus ou moins droite. Feuilles ovées ou ovées-oblongues, rétrécies, à la base, en un pétiole mince. Inflorescence en épis allongés, interrompus, terminaux et axillaires; Hleurs fasciculées par 3-5 : chacune enveloppée par deux bractées larges; corolle ì deux lèrres, violet pâle. - Assez abondant. Dans les endroits ombragés et dans les haies de la basse région : environs de Saint-Pierre, Candet, Precheur, Trois-Ilets. Alt, 11-300 mèt. No 2002. - Je ne lai pas trouvé à la Guadeloupe.

Thunbergia Retzius dédié à Charles-Pierre Thunberg, né en 1743, à Jönköping, en Suède ; étudia, sous Linné, les sciences naturelles ; après de nombreux voyages au Cap, a Batavia et au Japon, devint professeur de botanique, et mourut en 1822, sur sa propriété de Tunaberg, près d'Upsal. Il a écrit : Flora japonica; Icones plantarum japonicarum; Prodromus planlarum capensium; Flora capensis, etc.)

T. fragrans Roxb.; Thunbergie à fleurs odorantes. - Liane annuelle, haute de 2-4 mèt., à tige flexible, filiforme, cylindrique. Feuilles ovées ou ovées-lancéolées, subcordées ou hastées à la base. Fleurs d'un blanc pur, inodores (dans nos colonies), axillaires, larges, pédonculées ou réunies par 2-3; corolle à 4-5 lobes deltoïdes-renversés, tronqués ou tridentés au sommet; calice entouré de deux bractées spathacées, caduques, vertes. Capsule ovoüde, s'ouvrant élastiquement en deux valves, dont chacune terminée par une pointe longue, large, obtuse; semences subglobuleuses, tronquées aux deux extrémités et percées d'un trou de part en part. - Fl. surtout pendant et après l'hivernage. - Naturalisé et très abondant dans les haies et les broussailles des basse et infra-moyenne régions de la Guadeloupe et de la Grande-Terre. - Origninaire des Indes Orientales. Alt. (1-60) met. [Y" 2.370.]

Martinique, Vulgo : Abondant dans toute l'île. [No 2014.]

T. alata Boj., Bot. mag.; Thunbergie à pétiole ailé. Vulgo : Fleur jaune savane. - Liane annuelle, rampante et grimpante, haute de 3-5 mèt., ì tige ef branches tries enchevêtrées, flexibles, filiformes. Feuilles velues, en cour, à sinus ouvert et profond. Fleurs jaunes, ornementales, larges, disposées comme celles de la précédente espèce, marquées d'une tache pourpre noir i la gorne: corolle it cing lobes arrondis; calice, bractées et fruits comme dans le précédent. - Fl. surtout pendant et après l'hivernage. - Dans toute la Guadeloupe et ses dépendances, Marie-Galante, les Saintes Terre-de-Haut, etc. Alt. 0-700 mèt. [No 2367.]

Mantixrece. Vulgo : Fleur jaune savane. - Abondant dans toute lî̀le. [No 2015 .

T. grandiflora Roxb.; Thunbergie à grandes fleurs. Vulgo : Liane-fleur violette. Illust. hortic. Belge, pl. xxxir, anno 1895. - Très forte liane, à 
branches extrêmement nombreuses, allongées, llexibles, pendantes, frlabres el noires. Feuilkes larges, ovales, cordées, antuleuses. Intlorescence en grappes pendantes, terninales, nombreuses; corolle larene, violette, plus rarement violacée ou blanche, renlermée, avant l'anthèse, dans deux bracters spathacées el caduques, tube ventru, à 5 lobes arrondis el inégraux. (appsule ovö̈de, terminée par un bec large, droit, environ denx lois plus lone qu'elle; déhiscence élastique; semences 2, arrondies, convexes-concaver. noires, sillonnées-ruguleuses. - Fl. toute l'année. - Originaire de la Chine et des Indes Orientales, introduite en Lurope en 1820). Naturalisée et cullivie comme plante d'ornement dans les jardins de la Basse-I'erre, de Courbeyre, du Camp-Jacob. No 2367.

Mantraque. Vulgo : Liane de Chine. - Introduite an Jardin bolanigute, oì elle s'est naturalisée, et pousse arec une vigueur et une rapidite telle: qu'elle envahit tout et qu'il faut détruire de temps en temps les vieux pieds. La racine devient très grosse el prend la forme d'une souche; elle est subéreuse et spongieuse.

Sesamum L. (du grec " sesamon ", ou de l'arabe "sem-sem ",

S. orientale L., S. indicum L.; Sésame de l'Orient. I'ulgo: (Gigiri. Desc. vol. IV, t. 268, p. 155. - Herbe annuelle, pubescente, droite, haute de 601-, $95 \mathrm{~cm}$., rarement plus élevée. Feuilles ovées-lancéolées, acuminées, grossièrement dentées, longuement pétiolées : les inférieures, opposées; les supérieures, alternes. Fleurs axillaires, brièvement pédonculées, siluées tout le long de la tige; corolle rosée. Capsule ovoüde-oblongue, hrusquement terminée par un bee court et droil, traversée de quatre sillons, souvrant au sommet en deux valves, par le dédoublement d'une fausse cloison. - Yaluralisé et cultivé. - Fl, en mai, juin, juillet. - Les fenilles el surtout les fleurs sont émollientes et ont des vertus béchiques adoucissantes; dans le pays, on les emploie souvent contre le rhume et la Loux. L'eau froide ou tiède, dans laquelle on a infusé soit les feuilles, soil les fleurs, soil les deux ensemble, sert de collyre pour les yeux malades ou latignés; l'huile, quion extrait des graines, sc conserve longtemps et rend les mèmes services que l'huile d'olive; avec les graines, grillées, mêlées a du sirop, on fail de: galettes ou des tablettes très appréciées des Créoles. [10 2898.]

Martixique, Vulgo : Gigiri. - Cullivé et naturalisć. (Spécimen manque.

De cette famille des Acanthacées, si riche en arbrisseaux d'ornement, Ioujours faciles à propager à cause de leur bois mou, on cultive dans lé dena colonies les espèces suivantes:

Eranthenum nervosum R. Br. (Ruellia marians lent.), buisson hatut de 1-1 m50, à fleurs bleues, serrées, en épis Leminaux el nombrenx, orizinaire des Indes Orientales. [No 838.] - E. bicolor Spr. Vulgo : l’ensice crécole. 
arbrisscau grèle, haut de $50-90 \mathrm{~cm}$., ì fleurs blanches, ponctuées de noir, originaire de Java. [No 1999.] - Meyenia erecta Benth. Vulgo: Gueule-deloup, buisson à tiges très nombreuses, à lleurs violettes, larges, originaire de la Guinée. [No. 2372.] Martinique. [No 1996.] — M. alha Hort. Vulgo : Guenle-de-loup-blane, buisson comme le précédent, mais a tleurs moins lariés el blanches. [No 2373.] Martinique. X's \$31, 8333.] — Sanchezia mobilis Hook. arbrisseau, tortueux, à fleurs jaunes, en épis terminaux, originaire de la liépuhlique de l'Équateur. [No 835. - On rencontre plus souvent le Stephanophysum rentricosum Nees de la Nouvelle-Grenade, arbrisceau à fleurs rouges, en cymes lâches et larges [N* 1995]; - le Barleria cristata I.., de l'Inde ()rientale, sous-arbrisseau, fort ilinant el touffu, originaire de Pondichéry [No 1992]; le B. cærulea Roxb., à fleurs bleu céleste, originaire du Népaul. [No 1993.

LAphelandra pectinata Willd. No 2000 ], de l'Amérique australe et le Gendarussa vulyaris Nees, de l'Asie tropicale [X"19919], sont cultivés au Jardin botanique de Saint-Pierre ${ }^{1}$ et dans l'île de la Martinique.

\section{CExt mi-huttìne Famle. - GESNÉRIACÉES.}

Pentarhaphia Lindl. ।du gree " penté ", cinq, et "raphia ", couture, parce que le tube de la corolle présente cinq côtes.)

P. longiflora Lindl., P. Swartzii Decne., Gesneria ventricosa Sw.; Pentaraphie à longues tleurs. Vulgo: Gueule-de-loup-montagne. - Arbrisseau ornemental, droit, haut de $0^{m} 90-5^{m} 50$, à écorce lisse, se détachant par petites plaques. Feuilles rigides, souvent visqueuses, entières ou serreties au-dessus de la base. lancéolées-elliptiques ou lancéolées-oblongues, alténuées à la base. Fleurs axillaires, très longuement pédonculées, en cymes nmbelliformes de 2-j rayons: corolle rouge foncé, bilabiée, à tube arqué; cétamines exsertes; pistil plus long que les étamines; calice herbacé, à dix côtes, à 5 lobes subulés, longs, linéaires; ovaire infère. Fruit médianicide au sommet; semences nombreuses, petites. - Fl. en juin, juillet. - Rare : dans les hauteurs sèches et pierreuses de Vieux-Fort et des VieuxHabitants. Alt. 200-400 mèt. [No 2375.

Mantixique. Vulgo: Gueule-de-loup-montagne. - Plus abondant qu’à la Guadeloupe, Pitons-du-Carbet, morne des environs de l'Alma. Alt. 700800 mèt. [Nos 330 a et $\mathbf{b}$ ], avec la variété Lindleyana Decne, à feuilles plus petites, elliptiques-ovales. [No 329.$]$

1. D'après Limousin-Bocquellon (loc. cil.) on emploierait, aux Antilles, souvent cette plante, le G. vulgaris, contre les fièvres intermittentes. On en prépare une décoction aqueuse ou une infusion vineuse it la dose de $30 \mathrm{gr}$. de plante pour un litre de vélicule. (E. II.) 
Episcia Mart. (du grec " episkos », ombragé, parce que ces plantes se plaisent dans les endroits couverts et humides.

E. melittifolia Mart.; Episcie à feuilles de mélisse. Vulyo : Ilerbe it miel. - Herbe flasque, pubescente, droite ou ascendante, à tige succulente, grosse. carrée dans le haut, d'une élévation de $15-60 \mathrm{~cm}$. Feuilles larges, plus ou moins pubescentes, elliptiques, pointues, crénelées, à base toujour's inégale.

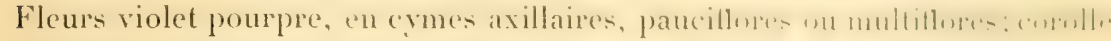
infundibiliforme, droite, à 5 lobes arrondis, presque émanx. Capsule médianicide. - Fl, presque toute l'année. - Cetle herbes'emploie souvent en tisane comme sudorifique contre les fièvres, ies bronchites, la toux el les rhumes. - Abondant dans les anfractuosités des roches humides. sur les lalus des chemins des grands bois : Houëlmont, Camp-Jacob, 'Trois-Rivières, Ravine-Chaude, Sofaya, etc. Alt. 150-900 mèt. [No 3381.

Mantrique. Vulgo: Herbe à miel. - Abondant: Morne-Rouge, Champflore, Fonds-Saint-Denis, Chemin de la Trace, fontaines Didier el Absalon. etc. $\left[\mathrm{N}^{\circ} 327\right.$.

Tussacia Reichb. (dédié au botaniste français G. Rich. de 'l'ussac, qui it écrit : Flora Antillarum, en 4 grands volumes, avec des fignures coloriées.)

T. pulchella Reichb.; Tussacie gracieuse. Vulgo : Herbe it miel batard, (Besleria Plum.) Episcia Mart. - Sulfrutesent, it tige inferientement cunchu et ensuite dressée, grosse, carrée-sillonnée, pubescente dans le haut, d'une hauteur de $40-80 \mathrm{~cm}$. Feuilles tlasques, larges, plus ou moins pubescentes, ovées ou ovées-oblongues, pointues, fortement crénelées au-dessus de lá base et rétrécies en un pétiole court. Fleurs jaunes, solitaires ou en cymes axillaires, pédonculées; calice rouge jaunâtre. - Dans les bois humides el rocailleux : Ravine-Chaude (bord de la rivière Bras de Sable). [Yo 338 1. \}On le cultive quelquefois dans les jardins comme plante médicinale, ef on emploie feuilles et fleurs en décoction contre les fortes fières, les bronchites. les fluxions de poitrine, etc.

Martingue, Vulgo: Herbe à miel. - Environs de la lontaine Didier, du Camp de l'Alma, et dans les bois du Gros-Morne. [ Y 30328.

Besleria Plum. ex L. (dédié à Basile Besler, né en 1501, à Nurember.

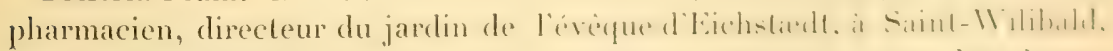
mort en 1629; a décrit les plantes du jardin de l'évèché, avee des ligrures gravées sur cuivre. Son frère et son neveu ont égralement publie des ouvrages de botanique.)

B. Intea L.; Beslérie à fleurs jaunes. Vulgho: Herbe at piqque ballard. Plum. éd. Burm., t. 49. - Sous-arbrisseau, droit, frlabre, stolonilere, haut de $0^{m}$ 90-1 ${ }^{m} 50$, à tige grosse, succulente, remplie de molle blanche. Feuilles larges, pétiolées, a veines très lortes el saillantes en dessous, limbe cllip- 
lique ou elliptique-oblong, pointu, serreté au-dessus de la base. Fleurs jaunes, axillaires, solitaires ou en cymes ombelliformes à $2-8$ rayons; corolle tubuleuse, à tube droit, suberlindrique el légèrement bossu à la base. Fruit mûr rouge foncé, subgrlobuleux-comprimé, luisant, de la grosseur d'une très petite cerise, contenant une masse de pelites semences noires. - Peu abondant. Cà el là sur les lisières et dans les clairières des grands bois, dans les haies des savanes : Camp-Jacob, Houëlmont, Trois-Rivières, Sofaya, etc. Alt. $400-800$ mèt. [No 2379. ${ }^{1}$

Martinele. Vulgo : Bois-graine rouge. - Plus abondant qu'à la Guadelonge: Morne-linuge. Calebaree. Ijoupa-bonillon, hauteurs de Care-Pilote. fontaine Didier, etc. $\mathrm{N}^{\circ} 326$.

Alloplectus Mart. (du gree " allos ", autre, et "plectos ", noué, entortillé, allusion à l'état de torsion des étamines.

A. cristatus Mart.; Alloplectes ì calice en crête de coq. Vulgo : Fuchsia saurage (au Camp-Jacob). Jacq., Sel Am. st. hist., 1. 119, p. 188. - Vivace, ornementai, grimpant, à tige radicante, ì branches libres et velues. Feuilles petites, elliptiques, flasques, laineuses, entières ou serretées au-dessus de la base. Fleurs laineuses, très belles, d'un rouge jaunâtre, solitaires, axillaires, pédonculées, à pédoncules presque aussi longs que les feuilles; calice ì 5 folioles herbacées, inégales, cordées, serretées, laineuses, persistantes. Fruit baccien, subglobuleux ou nettement globuleux, très blanc à la maturité, de la grosseur d'une cerise, contenant une infinité de petites semences nichées dans une pulpe bianche. - Assez abondant dans tous les bois

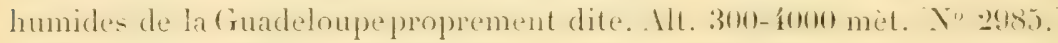

Martnique. Vulgo: Fuchsia sauvage. - Dans tous les grands bois du nord de l'île. $\boldsymbol{N}^{\circ} 187 \%$.

Columnea Plum. dédie à Fabin Colonna en latin Fabius Columua . né en 156 , a Naples, fut d'abord jurisconsulte, étudia ensuite la botanique, apres avoir été guéri du haut mal par l'usage prolongré de la valériane; devint plus tard gouverneur de la Calabre et ensuite professeur à Naples, où il mourut en 1650 ; a écrit: Phylobasanos ou entretiens sur les plantes), accompagné de fravures sur cuive: Ecphrasis description minus cugnilarum rariorumque nostro cœlo orientium stirpium.)

G. scandens I.; Columnea grimpant. Vulgo: Fuchsia des bois. Plun., édit. Burm., t. 89, f. 1. - Vivace et grimpant comme le précédent. Feuilles laineuses. épaisises, elliptiques, subentieres, petites. Fleurs larpes. rouges, très

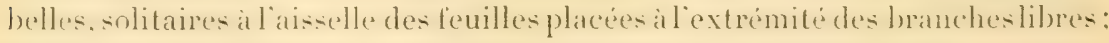

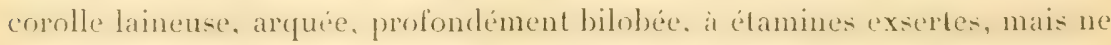

1. Sous le nom d'Ortie d'ean, le B. violacea d'Aublet est employé à la Guyane comme sudorifique par ses feuilles (infusions chaudes). (E. H.) 


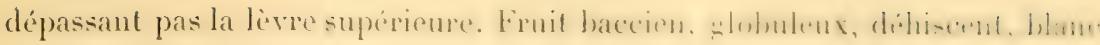
à Ia maturité, de la grosseur d'une pelite cerise, contenant une masse de petites semences. - Fl. de mai à août. - Rare. Caì el là dans les bois

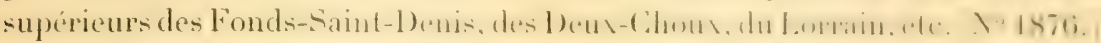
- Il n'existe pas à la Guadeloupe.

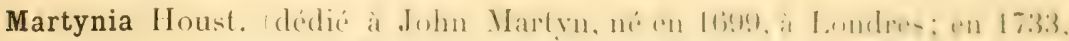

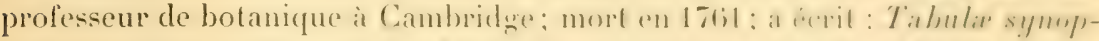

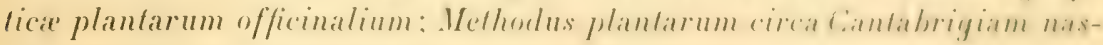
centium; Historix plantarum rariorum decades $T$.)

M. diandra Glox.; Cornaret à deux étamines. Vulgo : Téte-de-mort. Desc., vol. IV, t. 272, p. 180. - Herbe amuelle, droite, haule de $50-80 \mathrm{~cm} .$,

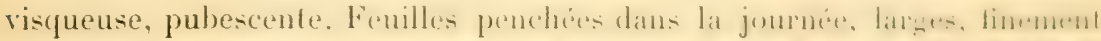

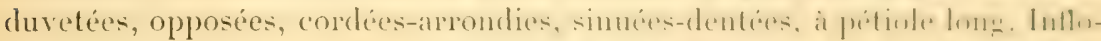

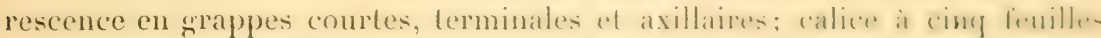

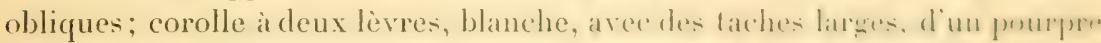

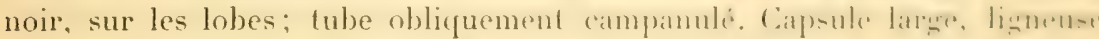
et dure à la maturité, souvant, au sommes, par dehisceme midianicite en

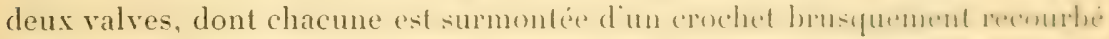
et acéré. - Fl. pendant et après l'hivernage. - Durant la nuit, par un beau clair de lune, les feuilles se dressent verticalement et s'abaissent vers le matin. - Dans les terres seches ou humides et ombragers pris du hord de mer : Prêcheur, Fond-Canonville. [No 187f.] - Je ne l'ai pas trouvée à la Guadeloupe.

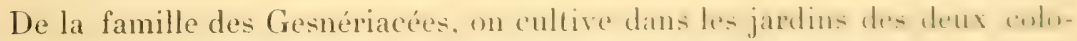
nies, où elles se sont pour ainsi dire naturalisées, les espèces suivantes Achimenes longiflora DC. du Mexique X" 22:36: A. gramlifmir IX.

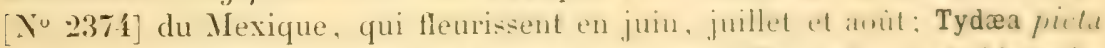

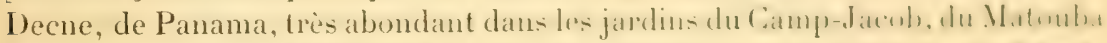

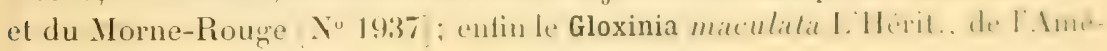
rique Australe. Vulgo: Gueule-de-loup. [ No 2378.

\section{CENT DIX-NeUTLìe FAMLLE. - CONVOLIULAClíS.}

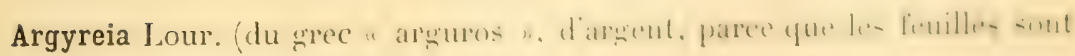
habituellement argentées en dessous.)

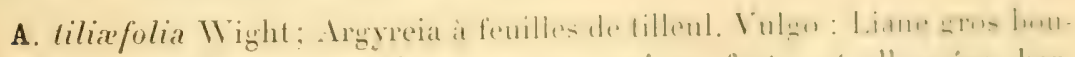
din, bois-patate marron. - Vivace par ses racines, fortes et allongées, her-

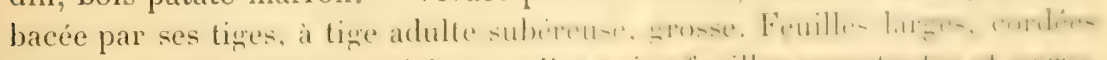

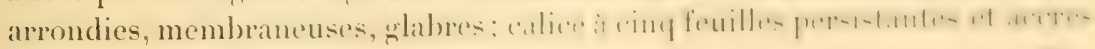

Duss. - Plantes Guadeloupe et Martinique. 
centes. Fruit large, indéhiscent, niché dans le calice; ovaire à quatre logettes. contenant chacune une semence brune, lisse, de la grosseur d'un pois. - Fl. de septembre à février. - Assez abondant le long des ruisieaux, des rivieres et dans les savanes humides de la basse résion : environs de la Basse-Terré, Trois-Rivières, Baillif, Sainte-Rose, Lamentin, Moule, Sainte-Anne, ele. [Nos 2476,3503 .

Martixiqle. Vulgo: Gros boudin, liane d'argent bàtard. - Grande-Rivière (abondant près du bord de meri. Grand Anse, Trinité. Fort-de-France. ete. [No 1883.$]$

LiArgyreia bracteala Chois. de l'Inde Orientale, vulgo : Liane d'argent, is feuilles larges, cordées, garnies, en dessous, d'un duvet soyeux, blanc argenté, à fleurs en grappes terminales. est cultivé dans les jardins des deux colonies. [ [No 3480.] - Martinique. [No 1884.]

Ipomøa L. (du grec "ips ", ver, et "omoios ", semblable, plante qui marche comme un ver, c'est-à-dire plante semblable au liseron.)

I. Bona-nox L., Calonyction megalocarpum Rich.; Ipomée boune nuit. Vulgo: Belle-de-nuit. Sl., t. 96, f. 1; Rich., Cuba, t. 63. - Annuel, voluble, at tige adulte subéreuse, jeune tige et branches filiformes. Feuilles larges, cordées-rondâtres, pointues. Inflorescence axillaire: fleurs pédonculées, larges, blanches, tries odorantes, it odeur suave et tris aureable, solitaires ou réunies par trois; corolle ì tube cylindrique, Iong, sélargisisant brusquement au sommet; sépales 5, inégaux : les deux intérieurs, ovales-oblongs, oblus; les trois extérieurs, ovés-lancéolés et terminés par un appendice filiforme; ovaire à deux loges quadriovulées. Capsule entourée des sépales persistants, s'ouvrant de la base au sommet et ne contenant que quatre semences blanchâtres, glabres: les autres ovules avortent. - Fl. d'août à décembre. - Peu abondant. Cà et lia dans les halliers du Morne-itl' Eau el du Moule. N" 3 199.

Martingue. Vulgo : Belle-de-nuit, liane douce. - Dans les halliers du Parnasse, des Trois-Ponts et des hauteurs de l'habitation Pécoul. "X" 128.

I. Iuba (i. 1)on, Calonyction grandiflorum Chois, Ipome it fleurs a long lube. Vulgo : Liane douce bord-de-mer. - Voluble, grimpant, peu branchu, haut de 5-7 mèl., lige grosse, subéreuse, adulte quand elle est jeune, tige et branches striées. Feuilles cordées-rondâtres, pointues, entières. Fleurs blanches, pédonculées, réunies par trois aux aisselles desfeuilles, nombreuses: cinq lobes courts et à peine distincts; sépales el capsule comme dans le prícédent: semences $\mathbf{t}$, angruleuses, pubescentes, laineuses autour du hile et le long des angles. - Fl. de juin à novembre. - Abondant sur les lisières des bois du bord de mer : Sainte-Anne habitation Les Anglais), Vauclin, ete. [N 1892, spécimen imparfait.] - Je ne l'ai pas trouvé à la Guadeloupe.

I. ventricosa Chois.; Ipomée à fleurs ventrues. Vulgo : Liane blanche, 
liane d'argent. - Vivace, grimpant et rampant, extrêmement branchu, \&̀ branches très allongées, glabres. Feuilles cordées, rondîtres : les adultes,

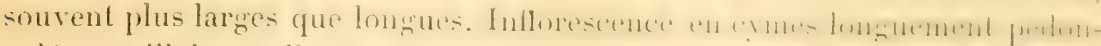

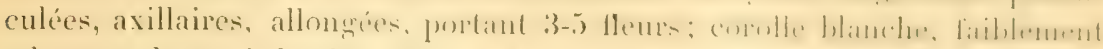

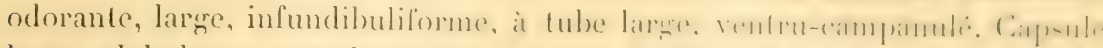

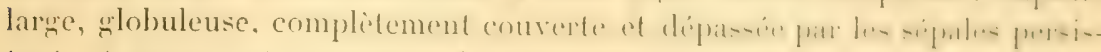
lants et accrescents; semences $\mathbf{4}$, globuleuses, convertes d'un duvet court et noir. - Rare à l'état sauvage : se rencontre souvent dans les cours et les jar-

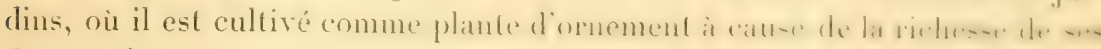

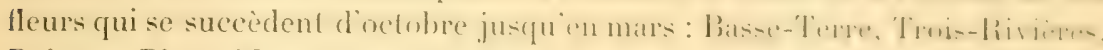
Pointe-à-Pitre, Moule, etc. [No 3081.

Martixique. Vulgo : Liane-serpent, liane bord-de-mer. - Assezrare : Grande-

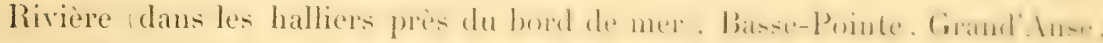
elc. $\left[\begin{array}{ll}N^{\circ} & 427 .\end{array}\right]$

I. tuberosa L.; Ipomée à racine tuberculeuse. Vulgo : Liane ì Innnelle, liane à courtine, bois-patate. Sl., t. 96, f. 2. - Forte liane, montant sur des arbres très élevés, dont elle atteint le sommet, rivace par ses racines tuber-

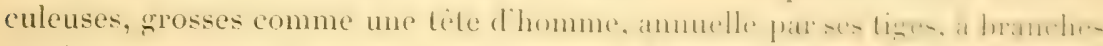

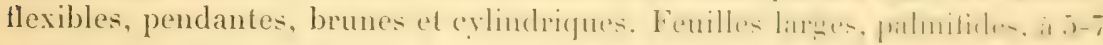

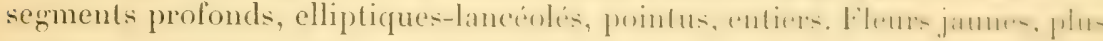
petites que dans les trois espèces précédentes, en cymes longuement pédon-

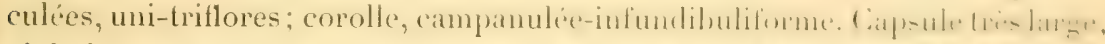

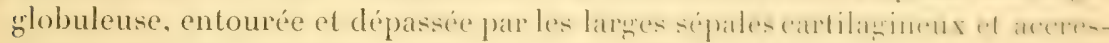
cents; semences rondâtres, pubescentes. - Fl. de septembre ì janvier. - - C.i et là dans les halliers des falaises de la basse région: Basse-Terre (ville et

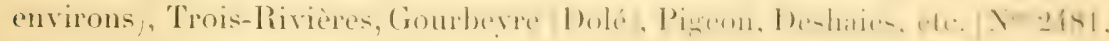
3010.] - Il n'existe pas à la Martinique. - Tubercule énorme, drastique.

I. dissecta Pursh, I. sinuata Orteg.; Ipomée à feuilles découpées. Vuluro: Liane-amande amère, liane à noyau (de cerise sous-entendu), - Aunuel,

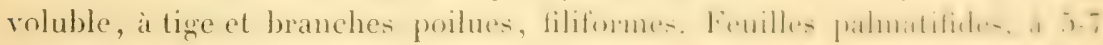
segments profonds, elliptiques-lancéolés, pennitides ou sinués-dentés;

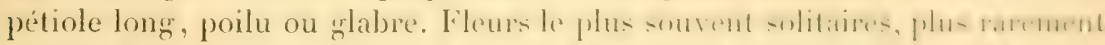

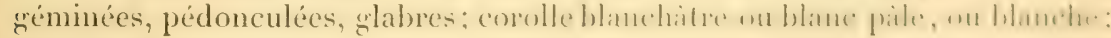

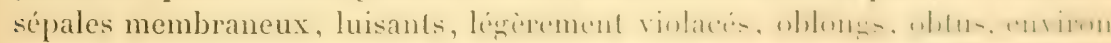
une fois plus courts que la corolle; semenees 1, rondes, glabres, brunes. -

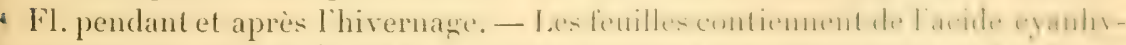

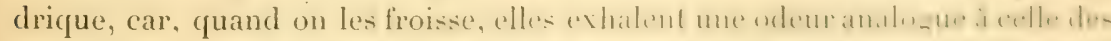
noyaux de cerise. - Abondant dans les halliers de la basse rérgion : environs

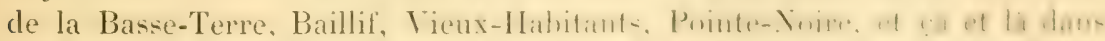
tous les grands fonds de la Grande-Terre, de la Désirade et de MarieGalante, etc. [No 24\%?.] 
Martingete. Vulgo: Pâte d'amande. - Abondant dans la basse réegion de l'île. [Nº 1886 .

I. pentaphylla Jacq.; Ipomée à cinq feuilles. Vulgo : Liane poilue. Annuel. grimpant, à branches filiformes, tombantes: à tige, branches, pédoncules, pétioles et sépales garnis de poils longs, roux, droits, sétiformes. Feuilles à einq lobes elliptiques on lancéolés-elliptiques, pointus, entiers. Fleurs blanc pâle, peu odorantes, en crmes très liches, axillaires el très lonquement pédonculées: sépales 5, ovés-oblongs, obtus: les trois extérieurs plus longs et garnis de poils très développés: ovaire à quatre logettes. Capsule à quatre semences globuleuses et brunes. - Dans les halliers de la région inférieure de toute la Guadeloupe et de ses dépendances. [No 2481.$]$

Martinique. Vulgo : Liane poilue. - Dans toute l'île. [No 1889.]

I. Batatas Poir., Batatas edulis Chois. (du mot espagnol "batata " ou "patota ", pomme de terre, allusion i la saveur et ì lusage des racines de la plante.) Vulgo : Patate douce. Tuss., Fl., IV, f. 1; Desc., vol. VIII, t. 545 , p. 70. - Rampant ou roluble, à racines tuberculeuses, allongées. leuilles très variables : lantot cordées ou hastées à la base, lantôt entières ou sinuéesdentées, tantôt ì 3-7 lobes pointus ou arrondis, tantôt très longuement, tantôt brièvement pétiolées. Fleur's violettes nu violet pâle, ou blanches, en cymes paucillores, pédonculées, à pédoncules de Inngueur variable. - On croit que !a patate est originaire de l'Amérique : elle est cultivée dans presque toutes les parties chaudes et tempérées du monde entier. On en rencontre plusieurs variétés, entre autres : la patate "Maley "), à racines violettes en dehors et en dedans; la patate "Créole ", à racines violettes en dehors et blanches en dedans; la patate "Samana ", à racines jaunâtres; la patate "moyenne " ou patate "suif ", à racines napiformes, grasses; la patate de la "Barbade " ou " gros bois ", à racines blanches; la patate "rouge ", etc. Celles qui ont des racines blanches sont généralement plus sucrées et sont préférées aux autres. - Les patates se mangent rûties dans le four ou cuites avec du sel, ou en confitures avec du sirop. Dans le pays, on se sert de la patate, gragée ou mêlée au lait froid, comme d'un remède infaillible contre les démangeaisons des vieillards prurictus senilis); il suflit d'en frictionner les parties malades pendant trois ou quatre jours. La patate rouge, gragée et mèlée à l'huile d'olive, s'emploie intérieurement contre les empoisonnements causés par les crabes, les moules, les écrevisses, ete. On fait encore usage de la patate blanche, crue et gragée, contre les brûlures. Les patates produisent très rarement des graines : les pieds se multiplient surtout par les tronçons de la partie inférieure de la tige. [No 3452.]

Martinique. Vulgo: Patate douce. [Nos 436, 1881.

I. fastigiata Swl.; Ipomée a fleurs en cymes ramassées. Vulgo: Patate marron, patate bâtard, patate sauvage, liane douce. - Vivace par les racines 
tuberculeuses, annuelle par les tiges, qui sont, comme les Jranches, fric vertes, lisses, cylindriques. Fenilles variables, gimeralement cordies, at smo

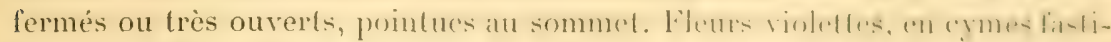

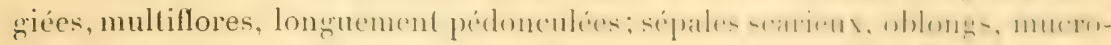
nés, quatre ou cinq fois plus courts que la corolle. Capsule it $2-1$ semences

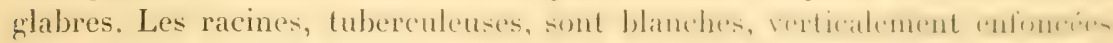

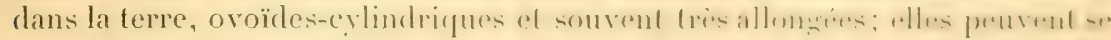
manger cuites, mais elles n'ont pas la saveur des patates cultivées. - Fil.

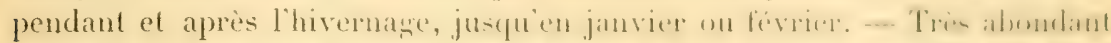

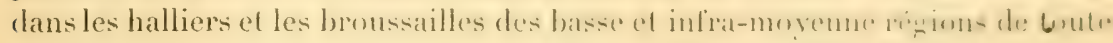
la Guadeloupe et de ses dépendances. Alt. 0-700 mèt. [No 2. 179.

Martinique. Vulgo: Liane douce, patale sauvage. [No 132.]

I. violacea L.; Ipomée à fleurs violetles, Vulgo: Liane douce. Plum., édit. Burm., t. 193, f. 1; Sl., t. 98, f. 1. - Annuel, rampant el grimpant, entièrement glabre. Feuilles cordées, rondâtres, pointues, pédatinerviées, rare-

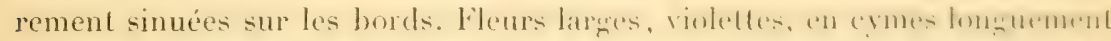

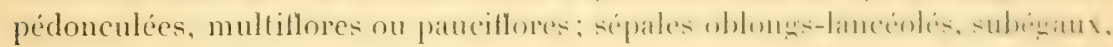
six ou huit fois plus courts que la corolle. Capsule ovoüde-conique, surmon-

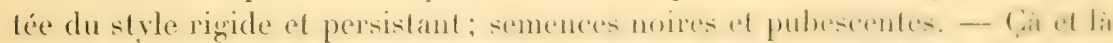
dans les halliers propres aux endrots seres pel piereux : vieille mule de Baillit aux Vieux-Habitants. Pigeon, Bouillante, ete. . ."3.991. - Je ne l'ai pas trouvée à la Martinique.

I. selifera Poir.; Ipomée à calice setifere. Vulgn : Liaue à laux. -- liampant un

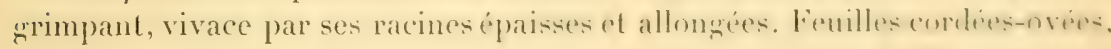
terminées en une pointe large, échancrée et mucronulée. Inflorescence en crmes triflores, pédonculées; sipales 5, lapges, incyanx : les tmis exlérieurs. imbriqués, herbacés, verts, ovales, carénés, a carène murque of terminim par un bec long el rigide ; les intérieurs, menbraneux, leaucoup plus stmits et un peu plus courts; corolle violet loncé, infundibuliforme, veinese a cime dents aiguës. Capsule enfoncéc dans les séplales persistants. - lit diofulme à mars. - Extrêmement abondant dans les savanes et terres cultivées des

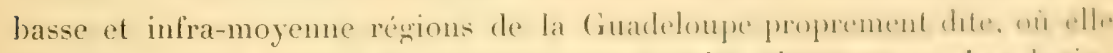

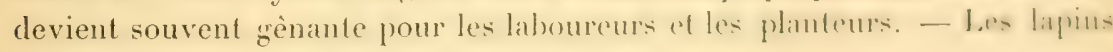
sont friands de ses feuilles. [ $\mathrm{N}^{\circ} 2474$.]

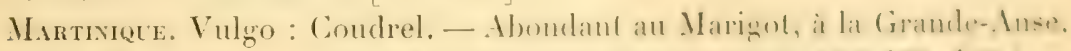

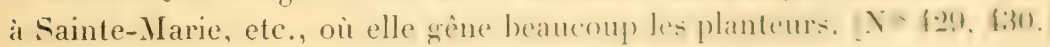

I. triloba L.; Ipomée à feuilles trilobées. Vulgo: Petite patate marron. Si., t. 97, f. 1. - Petile liane, anunelle, rampante el grimpante, haute

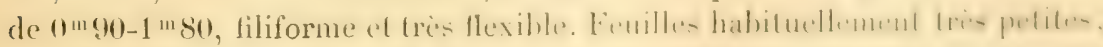
cordées-deltoïdes, à trois lobes : les deux inférieurs, courts, silués près de la base, peu profonds et arrondis; celui du milieu, deux ou trois fois 
plus long. Fleurs petites, violet pâle ou roses, en cymes ombelliformes à 2-3 rayons ou solitaires; sépales orés-oblongs, velus sur les bords, environ trois fois plus courts que la corolle infundibuliforme; semences glabres, brunes. Cai et lì dans les savanes inférieures de Baillif. des Vieux-Habitants; très abondant sur les mornes calcaires du Gozier. [Nos 3084, 3559.]

Martinique. Vulgo: Petite liane douce. - Mornes calcaires de SainteAnne, endroits pierreux du plateau des Trois-Ilets. [No 433.$]$

I. umbellata G.F. W. Mey. I. mollicoma . Niq.; Ipomée it fleurs en ombelles. Vulgo: Liane à malingres, liane-berceau. Desc, vol. VII, t. 52' p. 305; Miq., Stirpes Surinam, t. 37. - Annuel, grimpant, ornemental, haut de 3-5 mèt. Feuilles cordées-deltö̈des, pointues, plus ou moins gaufrées, à pétiole grarni, it la base, de deux stipule's de longueur variable. Fleur's jaunes, en ombelles pédonculées, de 5-12 rayons; corolle obconique au-dessus du tube cylindrique; sépales ovales, obtus, subézaux, imbriqués, trois ou quatre fois plus courts que la corolle. Capsule globuleuse, souvrant en qualre valves igales: semences 1, garnies d'un duvet noir et de poils longs sur les angles. - Fl. vers la fin de l'hivernage jusqu'en février. - Issez abondant dans les hasse el infra-moyenne régrions : environs de la Basse-Terre, Montéran, Gourbeyre, Vieux-Forl, Capesterre (Guadeloupe), Lamentin, Sainte-Rose, etc. Alt. 10-600 mèt. [No 3082 .]

Martixique. Vulgo : Liane douce, jaune. - Abondant : environs de SaintPierre, Prêcheur, Carbet, Parnasse, Basse-Pointe, Trinité, etc. [No 1891.

I. pes-capra Roth: Ipomée pied-de-chève (parce que la feuille reproduit à peu près la forme que laisse la trace d'un pied de chèrre). Vulgo : Patate bord-de-mer, passe-pierre (aux Saintes). Desc., vol. II, t. 130, p. 255 . Vivace par ses racines volumineuses, très allongées, grimpant ou rampant it une distance indéfinie, quelquefois à plus de 15 mèt., à rameaux blancs, cylindriques, vigoureux. Feuilles cartilagineuses, très vertes, penfinerviées, verdâtres, émaryinées au sommel, cunéiformes ou tronquées el sarnies de deux glandes à la base. Fleurs violettes ou violacées, en cymes triflores, pédonculées: sépales orés-oblongs, mucronés, cinq fois plns courts que la corolle; semences pubescentes. - La plante est rangée, par Descourtilz, parmi les purgatives laxatives. Dans le pays, on s'en sert rarement pour se purger, mais on emploie les racines en décoction contre les coliques et les fièves intermittentes; les feuilles, bouillies et macérées, en topique contre les tumeurs et les cedèmes des jambes. - Fl. presque toute l'année. - Abondant sur les sables du bord de mer et aussi dans les savanes sablonneuses près de la mer : toute la Guadeloupe et ses dépendances. [Nº 3501.]

Martixique. Vulgo : Patate bord-de-mer. - Sur toutes les plages sèches et sablonneuses et dans les savanes du bord de mer. [ $\left.\mathrm{N}^{\circ} 1888.\right]$

I. acetosefolia R. S.; Ipomée à feuilles d'oseille. Vulgo : Liseron rampant. 
Plum., Descript., t. 105; Desc., vol. II, t. 145, p. 317. - Vivace, rampant,

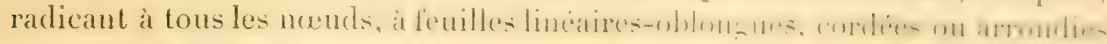

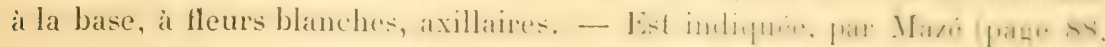

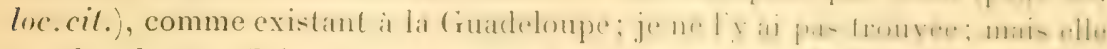

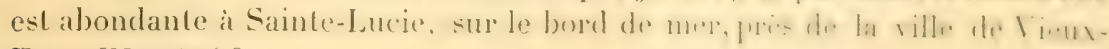
Fort. [No1885.]

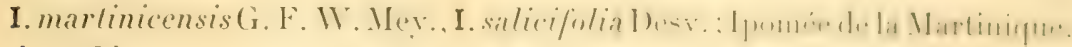
Vulgo: Liseron-savane. Jacq., Sel. Am. stirp. hist., t. 17, p. 26. - Annuel,

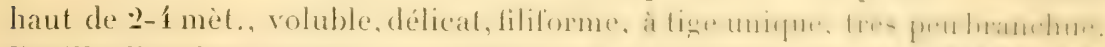

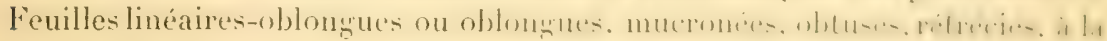
base, en un court pétiole. Fleurs solitaires ou géminées, axillaires, pédonculées, garnies de deux bractées; sépales 5, pointus, veinés el rétieulé: :

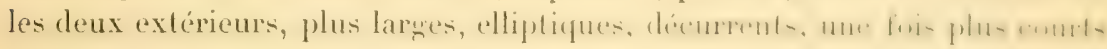
que la corolle; les trois intéricurs, ovés; corolle blanche, se rélrécissant graduellement vers la base, à plis garnis de poils. Capsule ì deux logres, contenant chacune deux semences arrondies. - Fl. de mars ì juin. - Peu abondant : dans les marécages de Port-Louis, et it Marie-Galante (environs

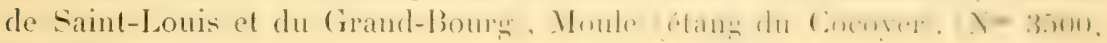
3638$.

Martinique. Vulgo: Petit liseron. - Peu abondant : endroits marécageux du Robert et du François. [N 1996.

I. repanda Jacq.; I pomée à feuilles ondulées. Vulgo : Liane-patate, patate grand-bois. Jacq., Sel. Am. st. hist., t. 20, p. 28. - Voluble, vivace par ses

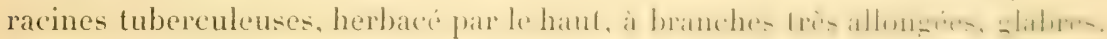
Feuilles luisantes, cordées, acuminées, entières ou ondulées sur les bords. Fleurs très belles, rouge carmin, en cymes très nombreuses, situées tout le

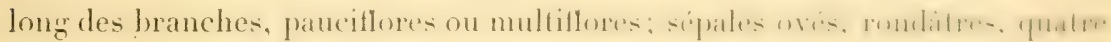
ou cing fois plus courts que la corolle, dont le tube est infundibuliforme,

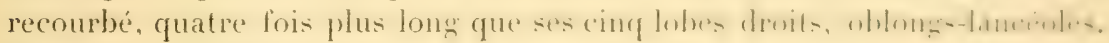
Capsule à deux loges à la base et à quatre logettes au sommet. - Jacquin ne fait pas mention de ses racines; Grisebach, p. 472 , dit: "Koot with small tubers. "J'ai vu de vieux pieds dont les tubercules presque lisneux ont $70 \mathrm{~cm}$. de long sur $40 \mathrm{~cm}$. de large; ils sont pointus aux deux extrémites, tantot rondatres, tantit plus ou moins eylindrinues. - Fl. de janvin a avril. - Assez abondant dans les bois inférieurs secs : Vieux-Fort, Vieux-llabi-

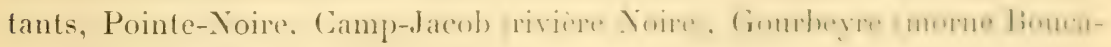
nier). Alt. 180-180 mèt. [No 2478.]

Martinique. Vulgo: Patate grand-bois. - Abondante: hauteurs des TroisIlets, Marin (morne Gommier), Trinité, Grand'Anse. [Xo 1890.]

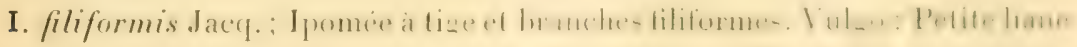
bleue. Jacq., Sel. Am. stirp. hist., t. 19, 1. 27. - Vivace par ses racines, 
herbacé par les tiges, voluble, haut de 2 -4 mèt., à tiłre adulte subéreuse, à branches filiformes très enchevêtrées. Feuilles petites, ovées-oblongrues, légèrement cordées à la base, nucronées-obluses au sommel. Inflorescence en crmes courtes et lâches, pédonculées, très nombreuses: corolle pourpre noir. a tube infundibuliforme-cylindrique. environ quatre lois plus long que ses lobes; sépales ovés-ronditres, terminés par une pointe. Capsule grlobuleuse, de la grosseur d'une graine de poive : semences f. - Assez abondant dans les endroits pierreux, sees, chauds, pris de la mer : Marie-Galante bois de Folle-Anse), Moule, Gozier, Désirade, etc. [No 3085.]

Martwece. Vulgo : Liane razier hord-de-mer. - Dans les broussailles du bord de mer de Sainte-Luce. [No 425.$]$

I. pendula R. Br.. I. palmala Forsk.; Ipoméc a fleurs pendantes. Iulgro: Liane rouge à tomelles. - Vivace, glabre, à feuilles à cinq folioles elliptiques, pointues aux deux extremités, a tleur rouge carmin très foncé, fleurissant toute lannée, mais ne produisant que tris rarement des craines; a été introduit d'Érpte et est cultivé dans les denx colonies pour l'omementation des tonnelles, des grillages, etc. [No 3086.$]$ - Mantixique. [No 1822.]

I. Quamoclit L. (du grec “Kuamos », fève, et “ klitos », bas, petit, c’est-àdire une petite plante grimpante comme le haricotl: Quamoclit inlgaris Chois. Vulgo: Cheveux de Vénus, herbe a éternuer. Desc.. vol. VI. t. 415 , p. 1ff6. - Annuel, voluble, très délicat, haut de 3-f mèt., à tiges et branches filiformes, très encherêtrées. Feuilles subsessiles, palmipartites, à segments filiformes, pointus, entiers, ou les inférieurs bifides. Fleurs pelites, rouge cramoisi ou écarlates, pédonculées, solitaires ou en cymes bi-triflores; tube de la corolle trois ou quatre fois plus long que ses lobes; sépales ovés, obtus. mucronés, quatre fois plus courts que le tube de la corolle; semences comprimées, ylabres, brunes. - Fl. de septembre à décembre. - Descourtilz classe la plante parmi les sternutatoires irritantes; dans le pays. on n'en fait pas usage. - Elle est à l'état sauvage et à l'état cultivé : environs de la Basse-Terre, Vieux-Fort, Capesterre très abondant au cimetièe), Moule (cimetière), Sainte-Anne, Baillif, etc. [No 2473.

Martingete. Vulgo: Cheveux de Vénus. - Abondant, surlout dans les cimetières. [ $\left.\mathrm{N}^{\circ} 1887.\right]$

I. coccinea L. : Ipomée à lfeursécarlates. Vulgo: Liseron-hallier. - Annuel, grimpant, à lige et branches filiformes. Feuilles flasques, cordées-deltoüdes, sinuées dentées ou entières, ondulées sur les bords ou trilobées. Fleurs petites, écarlates, en cymes trés longuement pédonculées et très làches; tube de la corolle trois fois plus long que ses cinq lobes: sépales subégaux, cuviron cing fois plus courts que le tube de la corolle. Capsule ì quatre semences trigones, anguleuses. pubescentes. - Dans les halliers et les haies de la basse région: 


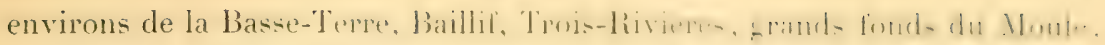
du Gozier, etc. [No $247 \%$.

Martiveue. Vulgo: Liseron rouge. - Cuil el li dans les halliers de la basse région de toute l'île. [N०1230.

I. Nil Roth, I. hederacea Jacq.; Ipomée Nil. Vulgo : Liseron bleu. -

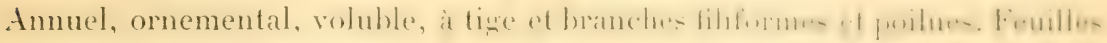
cordées, trilobées, pointues au sommet; péliole long, velu. Inflorescence en cymes billores, à pédoncule long el velu; corolte délicate, large, bleu azur

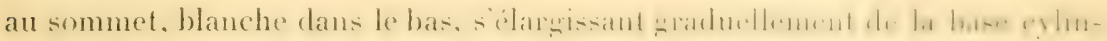

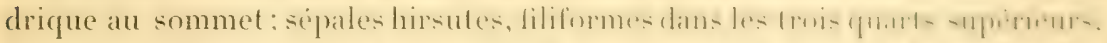

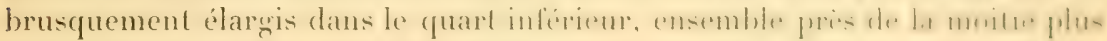

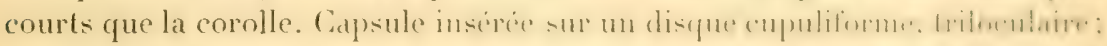
semences $\mathbf{4}$, obovales ${ }^{1}$. - Abondant dans les haies el les broussailles de la région inférieure : Basse-'Terre (ville el environs), Gourbeyre, Capesterre (Guadeloupe), les Abymes, Moule, Marie-Galante. [Xos 2180, 34.150.

Martineve. - Liseron bleu. - Saint-Pierre, Trois-Ponls, Carbel. Pricheur, Trinité, Marin, etc. [No 1231.] - On en rencontre une variété it

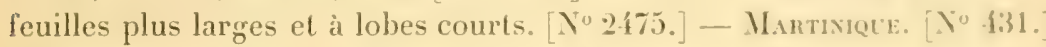

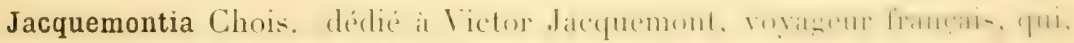

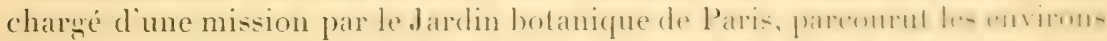
de Rio-Janeiro, l'île Bourbon, la région du Nord-Esst des provinees de Kachmir, le Sud-Ouest du 'T'ibet; mort en 183:.)

J. Lamnifolia Griseb.; Jacquemontie à feuilles de T'amnus. Vulgo : Liseron-

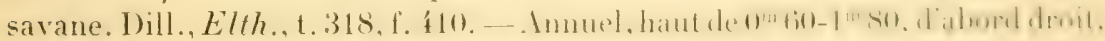

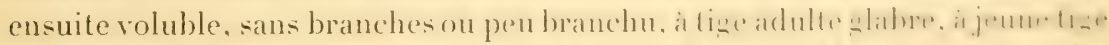

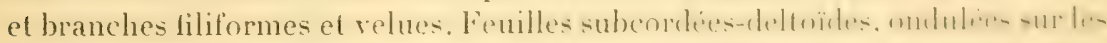
bords. Fleurs bleuâtres, petites, en cymes ombellitormes, trìs contractées,

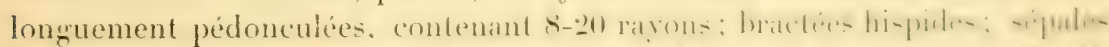

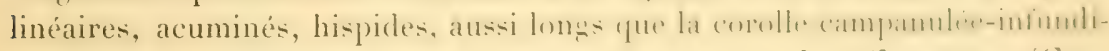
buliforme. - Fl. presque toute l'année. - Peu répandu : Ciapesterre (Ciuadeloupe): abondant dans le cimetière el dans les champs de cannes et les haies des environs. $\left[\mathrm{N}^{\circ} 2-480.\right]$ - Il n'existe pas à la Martinique.

1. L'Ipomæa Nit, originaire des montagnes de l'Inde, donne des graines inscriles suns le nom de Kaladana dans la Pharmacopée anglo-indienne et qui possédent les proprictes cathartiques du jalap; elles s'emploient i la dose de 2 à 3 fr. comme pumatives. liluckiger, qui a fait l'analyse de ces graines, en a retiré : $1 \mathrm{i} \%$ d'une huile épaise, brunilre. de saveur âcre, se solidifiant à 18\%; une forte proportion de mucilage, dès maticues albuminoïdes, de l'acide tannique et surtout $8.2 \%$ d'une résine qui en constitue le principre actif cathartique. Il a reçu le nom de Pharbilisine, suus lequel celle résine a cite introduile dans la médecine indienne. C'est une masse friable, jaunitre, douce d'un fontil icre. nauséeuse et d'une odeur désagréable, qui s'acentue par liaction de la chaleur : clle fund à $160^{\circ}$ et se dissout dans l'alcool absolu, l'acétone, l'éther acétique. Cotle résine al lat plus grande analogie avec la convolvuline, qui, comme on le sait, est un des deux principes bien définis qui constituent la résine purgative du jalap. (L. I1.) 
J. violacea Chois. Convolvulus pentanthus Jacq. - Suffrutescent ì la base, voluble, glabre, très ornemental, à tige et branches filiformes, très enchevêtrées, haut de 3-4 mèt. Feuilles petites, cordées-ovées, pointues, entières ou ondulées. Inllorescence en cymes contractées, bractéolées, pédonculées, axillaires, très nombreuses; sépales de moitié moins longs que la corolle : les trois extérieurs, plus larges, ovés, pointus; les deux intérieurs, ovés-lancéolés et acuminés: corolle campanulée-infundibuliforme, beancoup plus large que dans le précédent, violet foncé. Capsule à quatre valves, glabre, globuleuse; semences glabres. - Fl. pendant et après l'hivernage. Il fait l'ornement des haies et des broussailles de la région inférieure de toute la Guadeloupe et de ses dépendances. [No 2480.]

Martinique. Vulgo : Liseron bleu. - Dans la région inférieure de toute l'île. $\left[\mathrm{N}^{\circ} 1879\right.$. $]$

Evolvulus L. (du latin " evolvere ", dérouler.)

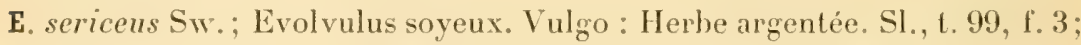
Br., Jam., t. 10, f. 3. - Herbe annuelle, plus ou moins diffuse, rarement droite, à tiges nombreuses, grêles, hautes de $15-35 \mathrm{~cm}$., à racine pivotante, forte. Fenilles petites, garnies d'un duvet blane el soveux, subsessiles ou brievement pétiolées, lancéolées-linéaires, mucronées. Fleurs blanches ou légèrement violacées, solitaires, portées sur un pédoncule beaucoup plut court que les feuilles; sépales à cinq lobes ovés-lancéolés, acuminés, un peu plus courts que la corolle rotacée-infundibuliforme. - Fl. pendant l'hivernage. - Assez abondant dans les terres sablonneuses, sèches, arides près de la mer ou tout ¿ lait sur le hord de la mer : entre Baillif et les Vieux-Habitants, Désirade, Moule. [No 2451.] - Je ne l'ai pas vu à la Martinique.

E. linifolius L.; Evolvulus à feuilles de lin. Vulgo : Herbe grrise. Br., Jam., t. 10, 1. 2. - Ressemble de prime abord au précédent; il en diffère: par ses tiges plus élevées et plus droites, ses feuilles plus étroites, non argentées; par ses pédoncules filiformes, beaucoup plus longs que les feuilles, unibractéolés au-dessus du milıeu, et infléchis au-dessus de la lracléole; par ses sépales plus étroits. - Endroits secs, arides de la côte du 1)iamant, Vauclin, Caravelle. Y' 1810.] - Je ne l'ai pas vu ì la Guadeloupe.

E. nummularius L.; Evolvulus à feuilles en pièce de monnaie. Vulgo: Véronique. Sl., 1. 99, f. 2. - Petite herbe, ornementale, complètement couchée, radicante, rampant en tout sens à une distance indéterminée, à tige filiforme, un peu en zig-zag, a racine forte, pivolante. Feuilles petites, orbiculaires ou ovales-orbiculaires, subcordées à la base, arrondies ou rétuses au sommet. Fleurs solitaires, à pédoncules plus courts que les feuilles et disposés lout le long des branches; corolle blanche nu légèrement violacée; sépales oblongs, obtus, de moitié moins longe que la corolle. - Cetle herbe vit habituellement en société et forme alors un magnifique tapis qui, dans la journée, 
est émaillé de lleurs innombrables; quand il pleut, les fleurs ne sourrent pas; quand il fait beau temps, elles s'ouvrent vers 9 heures du matin ct se ferment l'après-midi. - Abondant dans les endroits sablonneux, plats et secs du bord de mer, el aussi dans les saranes sèches peu éloignées du littoral: Port-Louis, Anse-Bertrand, Marie-(Galante, Désirade, les Saintes, etc. $\left[\mathrm{N}^{\circ} 3003.\right]$

Martinique. Vulgo: Petite véronique, véronique bord-de-mer. - Diamant, Anses-d'Arlet, Sainte-Anne, Marin, Vauclin, Caravelle. $N^{\prime} 1881$.

Guscuta L. (du mol arabe "liechout ", c'est le "kadulas " de T'héophraste, mot modifié de "kattuein ", attacher, parce que les plantes s'atlachent, par leurs suçoirs, aux autres végétaux.)

G. americana L.; Cuscute américaine. Vulgo: Vermicelle, herbe-zamilié, corde à violon. Sl., t. 128, f. 4. - Ilerbe parasile, annuelle, sans leuilles, h liges jaunes, filiformes, cylindriques, très entortillées, s'accrochant, iu

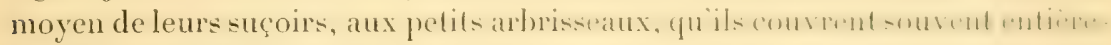
ment et finissent par tuer. Inflorescence en pelites grappes courtes, très

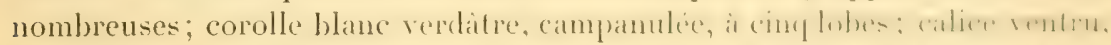

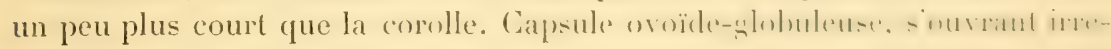
gulièrement par déhiscence pyxidaire. - Fl. en juin, juillet, el aussi en octobre et novembre. - Peu abondant: environs de la Basse-Terre, Baillil,

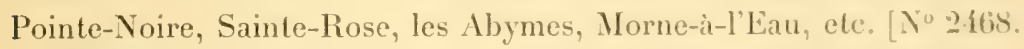

Martinique. Vulgo : Liane à cordon, liane sans fin, cordon de violon, vermicelle. - Rare dans les années pluvieuses; assez alondant dans les annèes sèches : environs de Saint-Pierre, Carbet, Trois-llets, Casc-Pilote, Vauclin, etc. [No 1878.$]$

De la famille des Convolvulacées, ou cultive, pour fornement des murs

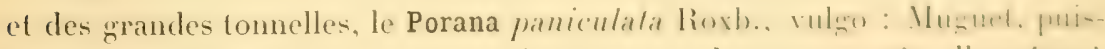
sante liane, à écorce grise, à branches très nombreuses el très allontruéce, ì

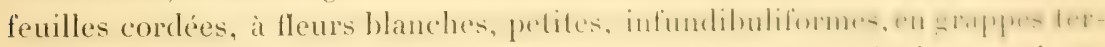
minales et axillaires : ces dernieres formant avec les terminales une larye

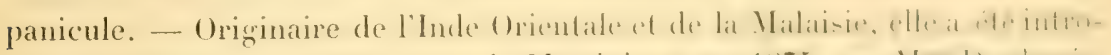

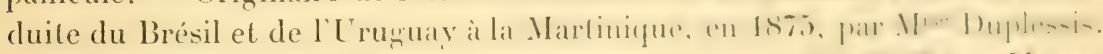

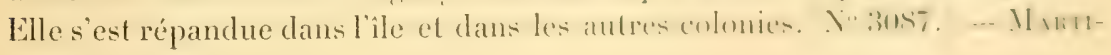
NIQUE. [No 247.$]$

$$
\text { CENT VINGTIÈ FAMLLE. - IIDDROLE.LCLES. }
$$

Nama L. (du grec " nama ", cau courante, de " nacin ", couler, allusion i l'habitat de la plante.) 
N. jamaicense L.; Name de la Jamaïque. Vulgo : Herbe couchée. Br., Jam., t. 18, f. 2. - Petite herbe, annuelle, couchée, longue de 10-20 cm., entierement garnie diun duvet grisâtre. Feuilles obovées. contractées à la base, décurrentes, entières. Fleurs violet pâle ou blanches, petites, obliquement tournées. brièvement pédonculées, naissant, sur de petites cymes it la bifurcation de deux branches: segments ducalice, linéaires, acuminés; tube de la corolle infundibuliforme, un pen plus long que le calice; étamines incluses. Capsule oblongue-linéaire, médianicide. - Assez rare : sà et là dans les endroits humides des environs de Saint-Pierre. Trou-Vaillant, Trois-Ilets, Marin, etc. [No 1894.] - Je ne l'ai pas vue à la Guadeloupe.

\section{CENT Vixgt-LNiÈME famille. - BORAGINÉES.}

Cordia I. dédié à Eurich el Valérien Cordus : le premier, né en 1486, à Simmershausen, dans la Hesse, professeur à Erfurt, ensuite à Marboury. mort médecin à Brème, en 1535 : a écrit : Bolanologicum; son fils, Valérien, né à Erfurt, en 1515, médecin et botaniste, mort à Rome, en 1544, a laissé : Innotationes in Dioscoridem; Liber quintus stirpium descriplionum quas in italia sibi risas describil: Dispensatorium 'pharmacorum omnium, publié et annoté par Conrad Gesner.)

c. Gerascanthus Jacq. (du grec " geraskein ", vieillir, et " anthos ", fleur, parce que la gorge de la corolle est warnic de poils gris ou blancs.) Vulgo : Bois de Rhode, bois de rose (à cause de l'odeur des fleurs), bois Chypre. Rich., Cuba, 1. 59: Jacq., Sel. 1m. stirp. hist., 1. 175, 1. 16. - Arbre de taille movenne, à tronc léxèrement anfractueux, à écorce grise, rude. Feuilles oblongues-lancéolées nu ellipticues-oblongues, pointues. entières, coriaces. grisâtres en dessous. Fleurs blanches. parfumées, en panicules élalées, à branches terminées par des glomérules ombelliformes; calice ì dix côtes. oboroïde-cylindrique, tomenteux, à cinq dents petites et égales. Fruit sec. - Fl. en janvier, février et mars. - Le bois sert pour les constructions à l'intérieur et à l'extérieur. - Dans les bois secs du littoral et les mornes pierreux inférieurs: Pigeon, Bouillante. Pointe-Noire, Deshaics, VieuxFort, etc. [No 2585 .]

Martinque. Vulgo : Bois de Chypre. - Prêcheur, Anses-d'Arlet, Troisllets, Rivière-Salée, etc. $\left[N^{\circ} 1415.\right]$

C. alha Roem. et Schult.; Cordia à fleurs blanches. Vulgo: Herbe à cou-

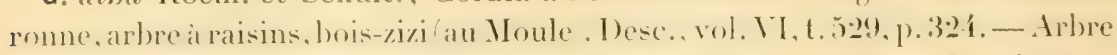
de taille movenne, a branches inclinées et souvent très penchées, divarifuées. at tronc anfractueux it la base. Feuilles mhabes en dessus, scabres en dessous, elliptiques-arrondies, dentées-onduléc. Fleurs blanches, lareses, odorantes. 
en cynes corymbiformes, larges, tiès nombreuses; calice cupulilormeturbiné, à lobes irrégulièrement émarrinés et arrondis, deux lois plus court que la corolle, qui est plissée, infundibuliforme, ì cincq lobes courts. Drupe

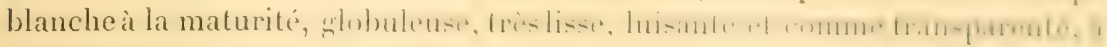
pulpe gluante, d'une saveur douceâtre, de la grosseur d'un mrain de raisin. -

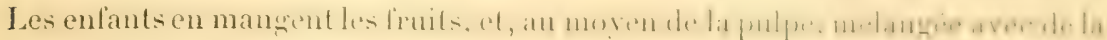
terre glaise, ils préparent une grlu pour prendre les petits niscaux. - 'Prouvé en fleurs et en fruits en août et septembre: Moule (le longr du canal et

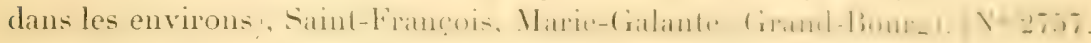

Martixique. Vulgo: Mapou blanc, mahot blane, mapou-baril. - Asses. rare: hauteurs inférieures el sèches de Case-Pilote, seul endroit ou jaie trouvé cet arbre. $\left[\mathrm{N}^{\circ} 285\right.$.

C. Sebestena L. (du mol persan "Sébestan " ou de Súbesta ", ville de la Samarie, dans les environs de laquelle celle plante pousse en abondance, C. speciosa Salisb. Vulgo : Bois-rape (à cause de la rudesse de ses feuilles). Desc., vol. IV, t. 277, p. 205; S1., 1. 161. - Petil arbre, droil, ou quelquefois tortueux, haut de $\mathbf{4}-6$ mèt., à écorce rude, gercée, bruntre, à branches fitalés. Feuilles très scabres, larges, ovées, subentières. Inthoresence en cymes corymbiformes, terminales; lleurs pédicellées; corolle écarlate, plissie, i six lobes ovés-rondâtres. Drupe blanche à la maturité, suburlobuleuse, pointue au sommet, de la grosseur d'une petite noix, it noyau pourru de 5-ti sillons profonds et longitudinaux. - Fl. durant toute liamée, - Descourtil\% en range les fruits parmi les béchiques adoucissants; dams le pays, on n'en fait pas d'usage et l'arbre est à peine connu. - Se rencontre sit et lit autour des habitations, où il est cultivé comme plante d'ornement : environs de la Basse-Terre (habitation l'Espérance), Sainte-Rose (cimetière), Désirade (planté en allée à l'extrémité nord du bourg), Port-Louis, elc. [X" 27.51.]

Mantinique. Vulgo : Sébestier, mapou rouge. - Environs de Samt-Pierren. Jardin botanique, Carbet, Lamentin, 'Trinité. [Y 15s.

G. Collococea L. (du gree "kolla ", colle, et "kokka ", baie, paree que les

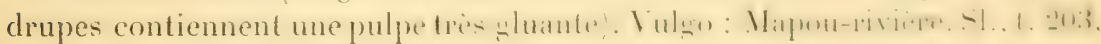
f. 2. - Arbre de taille moyenne et souvent au-dessus de la moyenne, à trone fort, court, à cyme arrondie, à branches horizontales, divariquées, it écorece

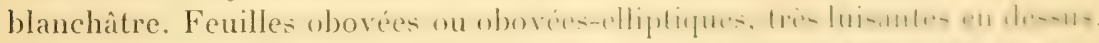

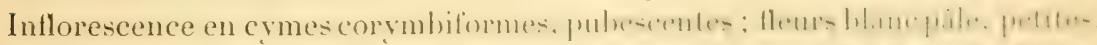

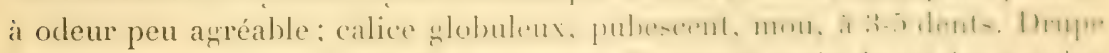

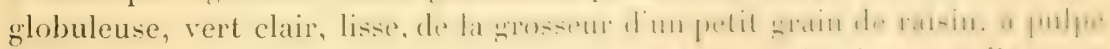
très gluante, dont les enfants se servent pour laire de la glu. - I l'époque

1. Tous les Cordia à fruits succulents ont été employés en médecine contre les atliections de la poitrine : on utilisait ces fruits sous le nom de sébestes, nutamment cem de C. Myxa L., Sebestena L., ete., qui sont émullients et lígirement laxatifs. IL. H. 
de la floraison, l'arbre se dépouille partiellement, et, sur les vieux pieds, entièrement de ses feuilles. - Fl. en mai, juin, juillet. - Le bois est mou et n'a pas de valeur pour les constructions, car les insectes l'attaquent facilement. - Assez abondant le long des rivières et cours d'eau de la basse région: Moule, les Abrmes, Gozier, Baillif, Marie-Galante, etc. [No 2575.]

Martixique. Vulgo : Mahot-bré, bois puant. - Abondant le long des rivières du Lamentin, de Ducos, de la Rivière-Salée, des Trois-Ilets, ete. [No 282.]

C. Ixvigata Lam. : Cordia à feuilles lisses, Vulgoo : Mapon-lélé (au CampJacob). - Arbre approchant de la taille moyenne, droit, a branches habituellement fastigriées, les inférieures élalées ou inclinées. Feuilles d'un vert sombre, luisantes en dessus, légèrement gaufrées, elliptiques, pointues, entières, à veines réticulées des deux côtés. Inflorescence en cymes corymbiformes, petites, garnies d'un duvet couleur de rouille. Fleurs blanches, odorantes; calice ellipsoïde, strié, à 3-5 lobes; corolle à 5 lobes ovés, trois fois plus courts que son tube. Drupe blanche à la maturité, ovoüde-ventrue, légrèrement courbe, terminée par une pointe allongée. - Fl. et fructifie presque toute l'année. - - Abondant dans tous les grands bois de la Guadeloupe proprement dite, mais surtout dans les bois inférieurs des Bains-Jaunes el du Matouba. Alt. 300-800 mèt. [No 2584 .

Martinique. Vulgo : Mahot siflleur. - Abondant dans tous les grands bois de la partic nord de l'île, et dans les hauteurs de la Riviere-Salée et de la Régale. $\left[\begin{array}{ll}\mathrm{N}^{0} & 1422 .\end{array}\right]$

C. elliplica Sw.; Cordia ì feuilles elliptiques. Vulgo: Mapou grand-bois. - Arbre de taille moyenne, rarement de grande taille dans nos colonies, droit, très branchu, à rameaux allongés, droits : les branches inférieures, souvent tombantes. Feuilles d'un vert très sombre, rigides, ovées-elliptiques, arrondies it la base. Fleurs blanches, petites, tres odorantes: lobes de la corolle recourbés, ovés-oblongs, une fois plus courts qne son tube. Drupe shlobuleuse, blanchâtre, terminée par une pointe courle; ressemble de prime abord au précédent; il en dillere : par ses feuilles plus petites et $110 n$ graufrées; par sa corolle cylindrique et plus allongée, mais surtout par la forme de ses drupes, plus petites et globuleuses. - Fl. en juin, juillet, août. - Rare, Çà et là dans les hauteurs des Trois-Ilets, de la RivièreSalée, de la Régale, de Sainte-Luce, etc. - Le bois se fend facilement : on en fait des merrains. $\left[\mathrm{N}^{\circ} 212.\right]$ - Je ne l'ai pas trouvé à la Guadeloupe.

C. macrophylla L. ; Cordia à larges feuilles. Vulgo : Mahot grand-feuille, bois-flot, bois de liège. Sl., t. 221, f. 1. - Le plus souvent petit arbre, rarement arbuste de taille moyenne, à branches inférieures toujours étalées horizontalement, à rameaux striés; i rameaux, pétioles, pédoncules, pédicelles, calice et face inférieure des feuilles revètus d'un duvet plus ou moins long. 
plus ou moins serré, loujours brun. Feuilles très larres, seabres cn dessus, ovées ou ovées-oblongues, pointues, entières ou subendées a la base. Intlorescence en panicules corymbiformes étalées, it branchessouventscorpioüdes: lleurs blane pâle, petites; calice obové, shlobuleux. Fruit rondâtre, blanc it la maturité, lisse, de la grosseur d'un pois. - Fl. cn juin, juillet, aout. - Assez

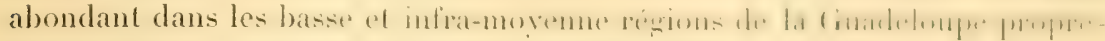
ment dite; çà et là dans les gorges des grands fonds, du Moule, du Goxier. des Abymes, etc. Alt. 50-700 mèt. [No307t.

Martinique. Vulgo : Mapou ou mahot grand-feuille, - T'rou-Vaillant, Carbet, Parnasse, Champltore, Fontaine Didier, etc. TYos 1:206, If26.

C. salviefolia H. B. el Kith.; G. cylindristachya lioem. el Scluult..

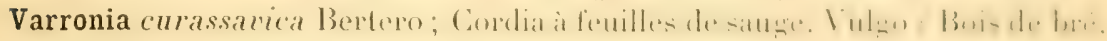
mapou noir. - Grand arbuste, habituellement très branchu, nu dans le bas. haut de 1-3 mèt. Feuilles hispides-tuberculées en dessus, pubescentes el blanchâtres en dessous, à poils épaissis a la base, ovées-lancéolécé, acuminées, terminées en pointe courte, dentées en scie. Fleur's en cymes corym-

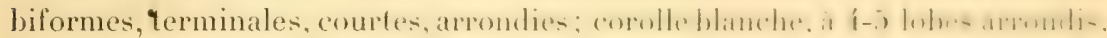
quatre ou cinq fois plus courts que son tube; calice obové, hirsute, it t-5 dents courtes. Drupe ovoïde-globuleuse, de la grosseur diune graine de poirre. - Abondant dans les endroits marécageux ou sees de la basse régrion Désirade, Moule, Saint-François, Marie-Galante, les Saintes. Mlt. (1)-30 met. $\left[\mathrm{N}^{\circ} 2749\right.$.]

Mantivique. Vulgo: Mahot noir. - Très abondant dans les endroits pierreux, sees ou humides près du bord de mer. - Trinité (Galion), Cararelle. Carbet, Case-Pilote, Trois-Ilets, etc. $\left[\mathrm{N}^{\circ} 287\right.$.

C. ulmifolia Juss.; Cordia à feuilles d'orme. Vulgo : Pelitmahol. Sl., 1. 191, f. 3. - Grand arbuste, à branches alternes, disposées sur le mème plan,

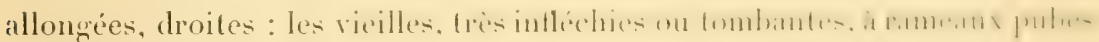
cents-Feuilles rigides, pubescentes-scabres, ovées ou ovées-lancéolées, acuminées, pubescentes et blanchatres en dessous, dentées en scie all-dessus de la base, à dents aiguës. Inflorescence en panicules courtes, it branches lerminées par des glomérules de 10-15 fleur's; pédoncules communs adnés it la base des pétioles; fleurs petites, blane pâle; calice ovoïde, strigreux, it cinç dents, de moitié plus court que la corolle, qui est infundibuliforme, lerminée par cinq crénelures. Drupe globuleuse, beaucoup plus pelite qu'une sraine de poivre. - Abondant dans les haies et les broussailles des rigions inférieure et infra-moyenne: Gourbeyre, Trois-Rivières, Ravine-Chande, Lamentin, Moule, Morne-à-l'Eau, Marie-Galante, ele. X No 2576.

Martinque. Vulgo: Mahol fin. - Très abondant : Parmitsies. MomeRouge, Carbet, hauteurs des Trois-Ilets, du Diamant, Lamentin (RochesCarrées), Marin, etc. [No 1 f2:1. 
G. cylindristachya lioem. el Schult., G. macrostachya Spreng.; Cordia it fleurs cylindricues. Vulgo: Mahol bord-de-mer. - Grand arbuste, trés branchu, nu dans le bas, à écorce noirâtre et rude, à rameaux pubescents, souvent couverts de lenticelles blanches. Fenilles oblongues-lancéolées ou lancéolées, dentées en scie au-dessus de la base ou crénelées. Fleurs blanchâtres, en épis allongés, terminaux; corolle petite, infundibuliforme, deux fois plus longue que le calice, qui est globuleux, a cing dents deltoüdes. Drupe grobulegse-ovoïle, rouge. On en rencontre deux variétés : a) C. cinerascens. DC..

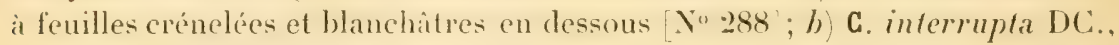
à épis interrompus, à feuilles plus larges et verdâtres en dessous. [No 289.] - Abondant à la Trinité (Galion), Caravelle, Sainte-Anne, Marin. - Je ne les ai pastrouvées à la Guadeloupe.

C. martinicensis linem. et Schult.; Cordia de la Martinique. Vulgo: Mahot noir. (Varronia P. Br. Sel. Am. stirp. hist., t. 32, p. 41.) - Grand arbuste, ornemental, scabre dans toutes ses parties, haut de $2-3^{\mathrm{m}} 50$, it branches inclinées et souvent tombantes. Feuilles très rudes, ovées, acuminées, pubescentes en dessous, inégalement serretées, à dents très aiguës; pétiole articulé au milieu. Fleurs blanc pàle, en épis terminaux, serrés, plus grands que dans le précédent; corolle infundibuliforme, exserte, à cinq lobes courts, arrondis; calice obovoüde-ylobuleux et pubescent. Drupe subglobuleuse, complètement renfermée dans le calice persistant et gonflé. - Les racines et les feuilles, pilées, sont employées comme vulnéraires. - Abondant dans les haies et les broussailles de la région inférieure : Parnasse, Case-Pilote, Marin (mornes Sulpice et Pérou), Prêcheur, Grande-Rivière. $\mathrm{N}^{\mathrm{N}} 1$ 123.1 Je ne l'ai pas trouvé à la Guadeloupe.

G. dasycephala H. B. et Kith. : Cordia à fleurs serrées en capitules ghobuleux. Vulgo: Ilerbe à bouc (aux Saintes), Guérit-tout, bonbon rond (au Baillif) (Varronia $\mathrm{P}$. Br.). - Grand arbuste, droit ou tortueux, extrèmement branchu dans le haut, a frondaison arrondie, à branches et rameaux hispides-ruguleux, warnis de lenticelles blanches, a ramuscules courts el pubescents. Feuilles petites, scabres, ovales-elliptiques, acuminés, couvertes, en dessus, de nombreuses lenticelles, pubescentes en dessous, surtout sur les nerrures, dentées en seie au-dessus de la base. Fleurs blanc pâle, en capitules globuleux, terminaux, brievement pédonculés ; calice ì cinc lobes filiformes, garnis de longrs poils et de cils; corolle infundibuliforme, deux fois plus longue que le tube du calice, it lobes très courts. Drupe subglobuleuse, incluse aux deux tiers dans le calice persistant. - Fl. de mars en juillet. - Assez rare : endroits secs, pierreux et arides de la basse région: Baillif, route de la Basse-Terre ì Gourbeyre, Capesterre Guadeloupe), Capesterre (Marie-(ialante), les Saintes (Terre-de-Haut). [No 2575.]

Martnique. Vulgo : Bonbon rond. - Plus abondant qu'à la Guadeloupe : Carbet, Case-Pilote, Marin, Sainte-Anne, Caravelle. [No 1424. 
Le Cordia amplifolia A. DC., vulgo: Teli d'Arabie, est cullivi dans les mornes du Jardin botanique de Saint-Pierre, oì il fleurit avec une mrande abondance en avril el mai. \No 281.] - Patrie inconnue.

Beurreria Jacq. (dédié à J.-A. Beurrer, pharmacien it Vurembers.

B. succulenta Jacq., Ehretia Beurreria Linn.; Beurérie it fruils pulpeux. Vulgo: Acomat-côtelette. - Grand arbusteou petil arbre, entiérement rylabre. droit, à écorce rougeâtre, ì branches allongées, droites, halituellement lastigiées, à bois très fragile. lieuilles membraneuses, obovées-obfongues ou oblongues, ou obovées-arrondies, pétiolées. Fleurs blanches, odorantes, en corymbes larges, nombreux, élalés, souvent penchés, pédonculés; calicé cupuliforme, à 5 lobes valvaires; lube de la corolle aussi long que ses lobes obovés, lesquels sont plus longs que le calice. 1)rupe globuleuse, obtusément mucronée, jaunâtre à la maturité, pulpeuse, de la grosseur d'une trio petile cerise; semences 4, tétragones. - Très abondant dans les endroits morneux, secs et pierreux : Vieux-Fort, 'Trois-livières, liavine-Chande, Sainte-Rose, Moule, Morne-it-l'Eau, les Abymes, Gozier, Maric-Galante, ele. $\left[\mathrm{N}^{\circ}\right.$ 2 2752.$]$

Martixique. Vulgo: Bois-cabril bâlard. - Abondant : cuvirons des 'l'roisPonts, Carbet, Trois-Ilets (plateau), Marin (morne Gommier, saint-lisprit (Régale), hauteurs de Sainte-Luce, etc. No zqu

Rochefortia Sw. (dédié à François César de Rochelort, qui, en 1(i3), it publié une histoire naturelle des Antilles.)

R. cuneata Sw; Rochefortie à feuilles cunces. Vulgo: Bois vert, loois d'ébène vert (aux Saintes). - Arbrisseau élégant, très toulfu, à ligres nombreuses, ou plus rarement petit arbre, haul de $3^{m} 50$, i branches listigices, étroites. Feuilles très vertes, luisantes, obovées, arrondies au sommel el souvent émarginées, rétrécies, à la base, en un court pétiole. lileurs hlanches, petites, en cymes pédonculées, terminales et axillaires, naissant sur des protubérances ligneuses; calice à trois lobes ovés, arrondis, ciliés, aussi lontris que le tube de la corolle, à segments orés, obtus, deux fois plus lonirs que son tube. Drupe jaunâtre à la maturité, un peu plus petite qu'une çrainc de poivre verte. - Fl. en juin, juillet, aoûl. - Peu abondant. Endroils pierreux, secs, arides de la basse région: les Saintes (Terre-de-Haul), sur le chemin

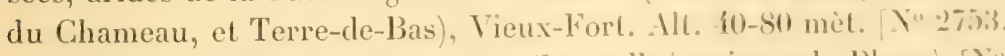

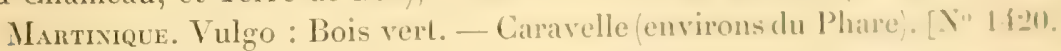

Tournefortia L. (dédié à Jos. Pitton de Toumelort, ué un llisti, it lix : an

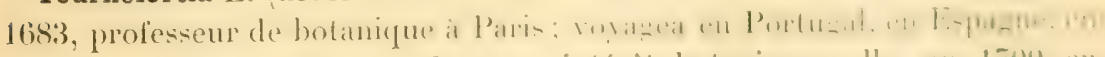
Angleterre et en Hollande, dans un intérèt bolanique; alla, en 17(1), ('n Grèce, en Roumélie, dans l'archipel grec, en Asic Mineure, e’n syrio et en Égyple; de retour, en 1702 , il devint professenr de midecine il lix, at 
mourut en 170s. Il a écrit : Éléments de butanique: Ilistuire des plantes qui naissent aux environs de Paris; Institutiones rei berbaria; Voyage du Levanl.)

T. gnaphalodes R. Br.; Tournelortie à feuilles de Gnaphalium. Vulgo: Bois de lance noir. - Arbuste haut de $60-95 \mathrm{~cm}$., rarement plus haut, droit ou tortueux, ornemental, très rameux, à branches, rameaux, feuilles, pétioles, pédoncules el calices rarnis diun duvet blanc argenté, a tige glabre ot moire dans le bas. Fenilles spatulées-linéares, épaisses, allongées, obtuses au sommet, sessiles. Fleurs blanches, en épis terminaux, scorpioïdes, formant souvent un corymbe peu branchu; corolle petite, à tube laineux, à lobes arrondis, ovés. Drupe ovée-conique. - Fl. en toute saison. - Sur les pierres et les rochers calcaires ou madréporiques du bord de mer : Désirade, Moule, Marie-Galante (Capesterre). [No 2748.

Martineue. Vulgo : Romarin blane bord-de-mer. - Rare : Vauclin (sur un petit îlot, à l'entrée du port du Macabou). [No 246.

T. hirsulissima I.., T. corymbosa sieb. : Tournefortie tris hirsute. Vulgo: Liane à chique poilue. Sl., t. 212, f. 1; Desc., vol. IV, t. 253, p. 89; Plum., édit. Burm., t. 229. - Arbrisseau sarmenteux, à tige et branches d'abord droites, devenant peu ì peu volubles et i la fin tombantes, pourant atteindre 4́-5 mèt. d'élévation, à jeune tigre, branches, pédoncules, pétioles ét calice revetus d'une couche de poils rudes, brun foncé. Feuilles elliptiques, lareces. pointues, garnies en dessous d'un duvet roux, scabres en dessus. Fleurs blanches, petites, en épis courts, scorpiö̈les, nombreux, formant ensemble un large corrmbe. Drupe tris blanche a la maturité, subghobuleuse et velue. - Fl. en août, septembre, octobre et novembre. - La plante a, selon Descourtilz, des vertus diurétiques excitantes; dans le pays, on ne fait aucun usage de cette liane. - Assezabondant dans les falaises des mornes inférieurs et dans les grandes haies qui bordent les savanes: Vieux-Fort, Capesterre (Guadeloupe), les Abymes, Morne-à-l'Eau, elc. [No 2747.]

Martivique. Vulgo: Herbe malingre. - Vallée du Carbet, hauteurs de la Rivière-Salée, Anses-d'Arlet, etc. No 1207.

T. foelidissima L.; Toumefortie tris puante. Vulgo : Mapou puant, żerbe à chiques. Plum., éd. Burm., t. 130. - Suffrutescent, arbuste touffu,

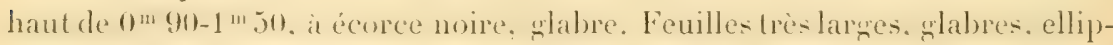
licpues, à base lentement rétrécie en un courl pétiole. limbe de lo-1 t nervures. lileurs blanches, en épis allongés, corrmbitomes, formant une panicule plus ou moins penchée. Irupe subghbulense. wabre, blanchitre a la maturité. - Fl. de mai à juillet. - C Cà et là dans les ravines profondes de Houëlmont. [No 2818.] - Il n'existe pas à la Martinique.

T. filiflora Griseb., T. cymosa Griseb. Pl. caraïbes); Tournefortie à épis filiformes. Vulgo : Zerbe à chiques. - Ressemble de prime abord au précé- 
dent. Il en diflère: par ses lleurs en épis allongés, divariqués, formant un corymbe paniculé, toujours pendant; par sa corolle liliforme, quatre ou cinc| fois plus longue que le calice, dont les lobes sontovés-arrondis el muncrunés: par ses drupes plus petites, ghlobuleuses, d'un blanc pur il la malurile.

Rare : gà et là sur les lisières des bois du Morne-Rouge, du Prèchenre de:

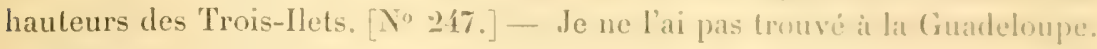

T. bicolor Sw. ; Tournelortic à feuilles bicolores. Vulyo : liane il chicpues. - Arbrisseau samenteux, haul de 2-1 míl., il branches d'abord droiles. ensuite sarmenteuses, peu tlexibles, glabres, cylindriques. Fenilles elliptiques ou elliptiques-oblongues, ou ovées, péliolées, at f-(i pares de nervures. Fleurs blanc verdâtre, en épis terminaux el axillaires, plus ou moins allongrio.

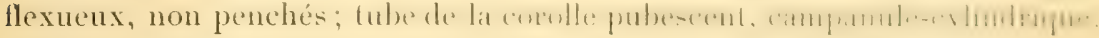
trois fois plus long que le calice. Drupe blanchatre. - lil. d'arril a juin. Capesterre Guadeloupe, habitations Longmont et Saint-Saveur), environ: de la Pointe-à-Pitre, etc. [No 2579.

Martinique. Vulgo: Liane à chiques. - Iauteurs de l'habilation Pícoul. Diamant (près du bord de mer), Trois-llets et livière-Salée. No IS.

T. volubilis L.; Tournelorlie voluble. Vulgo: Liane moire, pelit chique. Sl., t. 143, f. 2. - Vivace, voluble, haut de 2-5 mèl., a tiges el hranche-

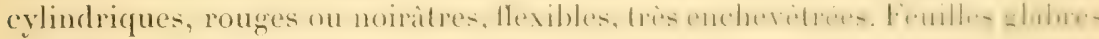
(dans mes spécimens), ovées ou oblongues. Fleurs vertes, trispeliles, en épis allongés, nombreux, filiformes, lormant ensemble des corymbes pendants : tube de la corolle pubescent, filiforme. Drupe petite, rouge, tris souvent marquée de quatre taches, très blanches et rondes. - Hl. diaril it juillel. Cette plante est douée, dit-on, de vertus vulnéraires. Les habitants en pilent les feuilles el les jeunes tiges, y ajoutent un peu de sel al appliquent le tout sur les blessures, les écorchures, etc. - Assez abondant dans les haies ét le:broussailles de toute la Guadeloupe el de ses dépendances. [ Y va :582.

Martinique. Vulgo : Liane caraïbe. - Abondant : Lamentin, I)uens, Marin (morne Sulpice), Sainte-Anne, Robert, Caravelle. Alt. 15-300 mit. $\left[\mathrm{N}^{\circ} 350.\right]$

T. ferruginea Lam., T. scandens Mill, Tournefortie i poils conleur de rouille. Vulgo : Liane caraïbe. - Vivace, voluble, pen rameux, ì rameaux.

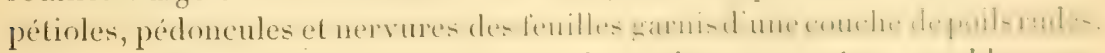
de couleur brum foncé. Feuilles ovées-lancéolées on ovées, ou oblonerues. pointues. Fleurs petites, verdâtres, en épis courts, lormant ensemble un corymbe plus ou moins contracté; tube de la corolle liliformes environ den fois plus long que les lobes linéaires-filiformes du calié. 1)rupe dépriméglobuleuse, à l'état rert; à 3-1 semences. - Peu abondint : cia cl lit dims leo haies de la basse région du Lamentin (environs de l'usine), Cianavelle, sainle-

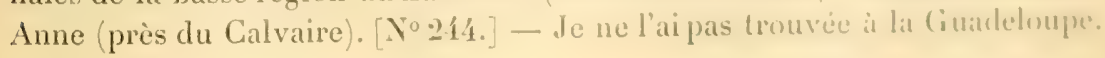


T. tomentosa Mill.; Tournefortie à feuilles tomenteuses en dessous. Vulyo: Liane a chiques. - Tivace, voluble, haut de $2-4^{\text {in }} 80$, a tige cylindrique, peu rameux, à rameaux el pédoncules garnis d'un duvet grisâtre, fin, court et couché. Feuilles ovées-lancéolées ou ovées-oblongues, acuminées, revètues, en dessous, d'un duvet blanchatre el court. Fleurs vertes, en épis allongés, minces, constituant un corymbe arrondi; tube de la corolle pubescent, un peu plus long que les lobes filiformes du calice. Drupe petite, à deux semences. - Fl. en mai, juin, juillet. - Çà et là dans les haies des TroisRivières. [No2582 b.] - Je ne l'ai pas trouvée à la Martinique.

Heliotropium L. (du grec " helios ", soleil, et " trepo ", je tourne, parce que, d’après Dioscoride. IV, 185, el Pline, II, 12. ; X.II, 2, I'Heliotropium villosum Desf. se tourne du côté du soleil.)

H. indicum L.; Héliotrope de l'Inde Occidentale. Vulgo : Crête à coq, crête co-d'Inde, verveine à pians, grosse verveine, verveine crête à coq. Desc., vol. VII, t. 483, p. 135. - Herbe annuelle ou bisannuelle, droite, grosse, haute de $35-90 \mathrm{~cm}$., très feuillue, d'un aspect gris, à racine pivotante, allongée, forte et blanche, à jeune lige, pélioles et feuilles garnis de poils longs, dressés sur la tige el les pétioles, plus courts et couchés sur les feuilles. Feuilles larges, gaufrées, ovées, contractées à la base en un long pétiole, ondulées sur les bords ou irréyulièrement el wrossièrement crénelées au-dessus de la base. Inflorescence en épis courbes, très allongés; fleurs bleuâtres, rarement blanches, disposées sur quatre rangs tournés en haut. Fruits 4, unis par la base, en deux paires bilobées. Selon Descourtilz, les leuilles seraient détersives, désicatives et résolutives '. - Assez abondant dans les savanes fertiles et les terres cultivées, sur les décombres et le long des routes des régions inférieure et basse de toute la Guadeloupe et de ses dépendances. $\left[\mathrm{N}^{\circ} 2581\right.$.

Mantrique. Vulgo: Herbe à verrues, herbe à malingres, herbe à pians. Abondant dans toute l'île. [No 1419 .

H. parviftorum L.; Héliotrope à petites fleurs. Vulgo: Herbe scorpion, petite verveine. Dill., Elth., t. 146. - Annuel ou suffrutescent, haut de $0^{\mathrm{m}} 30-1{ }^{\mathrm{m}} 40$ : les jeunes pieds, droits, sans branches; les pieds adultes, très branchus, à branches inclinées, souvent sarmenteuses, à tiges et branches brunes, veluesdans le haut. Feuilles flasques, fraufrées, vert clair, ovées-ellipliques ou orées, ou lancéolées oblongues, pointues. Inflorescence en épis

1. D'après Bocquillon-Limousin (loc. cit.), on ferait, dansl'Inde et en Afrique, des applications de suc de feuilles sur la morsure des serpents renimeux, en méme temps qu'on ferait infuser le résiclu de l'expression et qu'on le donnerait á boire au patient. On emploierait aussi le suc contre les furoncles, dans la pharyngite et la tonsillite. En Cochinchine, is la Réunion, à Rio Nunez, on emploierait les feuilles en cataplasmes comme maturatifs contre les plaies et l'anthrax, et pour provoquer de la diurèse; le suc serait employé contre l'ophtalmie. (E. H.) 
scorpioïdes, allongés, axillaires et torminaux; lleurs blanches, petites, disposées sur quatre rangs, à la surface supérieure de l'épi. Fruits 1 , unis par lin base. - Fl. pendant et après l'hivernage. - Très abondant sur les décombres, dans les terres abandonnées et cultivées, sur les vienx murs, ele.. des bisise et infra-moyenne régrions de toute la Guadeloupe el de ses dépendinces. Alt. 0-700 mèt. [ $\mathrm{N}^{\circ}$ 2583.]

Martinique. Vulgo: Petite rerreine. - Abondant dams toule l'ile. Ale. 0-600 mèt. [ $\left[\mathrm{N}^{\circ} 1418\right.$.

H. curassavicum L.; Héliotrope de Curaçao. V'ulgon : V'erveine bond-de-

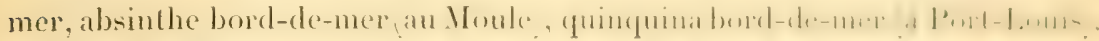
verveine blanche, romarin blanc. Sl., t. 132, l. 3. - Sulfrulescent ou vivace. d'un aspect gris, très branchu, à tige et branches noires, a ligre plus nu moins couchée et radicante, relevée à l'extrémité, haute de 20(1)-6.5 cm. Feuilles lancéolées ou oblongues, subsessiles, charnues, glauques, ce qui leur donne un aspect qui tranche fortement avec les herbes vertes ambiantes. Inflorescence en épis scorpiö̈des, simples ou bifides; fleur's petites, blanches ou très légrerement violacées. Fruit comme dans l'espèce précédente, mais noir. - F'orme souvent gazon dans les endroits arrosés par l'eau de mer el dans les savanes humides ou lieux aquatiques situés près du bord de mer, oì il fleuril toule l'année : Moule, Saint-François, Sainte-Amne, Port-Louis, Anses-Bertrand, Petit-Canal, Marie-Galante, les Saintes. $N^{0} \cdot 2755$.

Martinique. Vulgo: Verveine bord-de-mer. -- Vauclin, Sainte-Inne, Marin, Trinité (Galion), François, etc. [No 1416.$]$

H. fruticosum L.; Héliotrope frutiqueux. Vulgo: Verveine blanche salvane. Pl., édit. Burm., t. 227, f. 2. - Frutescent, ornemental, tortueux ou droit, d'un aspect gris, haut de $60-90 \mathrm{~cm}$, 11 dans le bas, très branchu dans le haut, à branches inclinées et divariquées, à rameaux garnis d'une pubescence grise, qui s'étend aux pétioles, à la face inlérieure des feuilles, aux pédoncules et aux calices. Feuilles petites, grisâtres : les adultes, scabres en clessus et garnies de poils courts tuberculés ì la base, lancéolées-linéaires, acuminées, subsessiles, roulées sur les bords. Inflorescence en épis courts, scor-

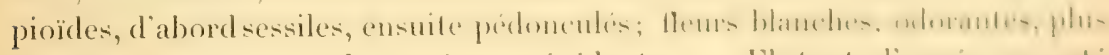
larges que dans toutes les espèces précédentes. - Fl. toute l'amnéce, exceplti pendant les sécheresses prolongées. - Vil en société, sourent sur d'assey grandes étendues, dans les savanes sèches, arides, pierreuses de la hatsiet région : Désirade (très abondant sur le plateau); şit el lit sur lit côte entre Baillif et les Vieux-Habitants. $\left\lceil N^{2} 2570,2756\right.$.

Martivique. Vulgo : Verveine-savane. - Ciase-Pilote (abonclinut), Ciarivelle (rare). $\left[\mathrm{N}^{\circ} 141 \%\right.$. $]$

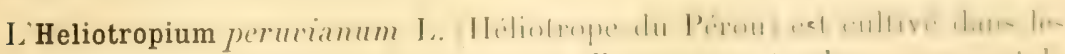
jardins des deux colonies comme plante d'ornement, it odeur surve, at le 
Symphytum officinale L. (grande consnudé comme plante médicinale; cette dernière fleurit abondamment. [No 3511.] - Mantimique. [No 1415.$]$

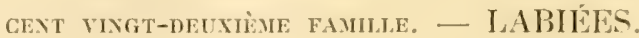

Ocimum L. (du grec « okimon ", de " ozein », sentir, parce que ces plantes émettent une odeur forte et agréable.

0. Basilicum L. (du gree " basilicos ", royal, digne d'un roi.) Vulgo: Basilic. Desc., vol. II, t. 301, p. 317. - Sullrutescent, toulfu, haut de $30-75 \mathrm{~cm}$, originaire de l'Asie occidentale et tropicale, naturalisé et cultivé dans toutes les Antilles comme plante médicinale et culinaire. - Elle fleurit toute l'année. $\left[\mathrm{N}^{\circ} 2151.\right]$

Martnigue. Vulgo : Basilic. [No 27.] - On en cultive deux variétés : la srande et la petite; la dernière est moins haute, les fenilles en sont plus petites, les branches plus ramassées et moins longues; elle forme un joli sous-arbrisseau.

0. micranthum Willd.; Basilic à petites fleurs. Vulgo: Petit framboisin, petit basilic. - Annuel ou plus rarement suffrutescent, ligneux dans le bas, haut de 20-60 cm., droit, peu branchu, à branches fastigiées. Feuilles ovées, pointues, serretées, contractées à la base en un court pétiole. Fleurs blanches, en grappes courtes, spicilormes, interrompues; calice élargi à la base; dents de la lèvre supérieure, ovées, obtuses, concaves, décurrentes jusqu'à la base dutube : les quatre dents inférieures, subulées. - Assez abondant dans les savanes et les terres en friches des basse et infra-moyenne régions de toute la Guadeloupe et de ses dépendances. - Toute la plante est aromatique, et, clans les campagnes, on fait avec les feuilles et les jeunes liges un extrait qu'on emploie avec succès contre toutes sortes d'indispositions. $\left[N^{\circ} 2155\right.$.

Martineue, Vulgo : Petit framboisin. - Abondant dans les savanes. $\left[\mathrm{N}^{\circ} 399.\right]$

0. gratissimum L.; Basilic ì odeur très agréable. Vulgo: (Frand framboisin, grand baume. - Herbe annuelle, très droite, haute de $0^{\mathrm{m}} 90-1^{\mathrm{m}} 60$, à tige forte, carrée-sillonne, branchue dans le haut, it branches fastigiées. Fénilles ovées-lancéolées (les jeunes lancéolées), dentées en scie, rétrécies, à la base, en un pétiole, lankot long, lantót court, légèrement pubescentesen dessons. Flenrs blanches, en qrappes spiciformes, allongées, formant ensemble une panicule souvent très large. - Toute la plante, surtout les fleurs, exhalent une odeur aromatique, forte et agréable. - Abondant sur les décombres, les vieux murs, dans les endroits abandonnés de la région inférieure : envi- 
rons de Saint-Pierre, Carbet, Prêcheur, Marin, Sainle-Anne. All. 0-fon mit. [No 400.] - Je ne l'ai pas vu à la Guadeloupe.

Coleus Lour. (du gree "koleos ", élui, foureau, parec que les élamines sont concrescentes inférieurement en un tube qui entoure le pistil.

C. amboinicus Itour., G. aromaticus Benth.; Coléts d'Ambnine. Vulern : Gros thym. - Vivace, aromatique el stolonilère, d'ahord plus nu moin: couché, ensuite samenteux, ì lige grosse, cylindrique. streculente, it branches velues. Fenilles épaisses, charmues, velues des deux coltés, móer. pointues, brusquement rétrécies a la base. Fleurs violeltes, en grappes spiciformes, très allongées, simples nu composées al la base, lerminales. - Fil. (2n juin, juillet, août. - Naturalisé et cultivé comme plante sudorifique ol insecticide. - Se rencontre souvent à l'état sauvage dans les endroils autredin. habités et maintenant abandomnés : Basse-Terre. Baillif (ballerie La Madoleine. où il est devenu envahissant), Vieux-lort (batlerie), Moule, (iozice, cte. [No 2936.$]$

Mantineve. Vulgo : Thym de l'Inde. - Cai el lì dans les jardins el a l'ulal sauvage. $\left[N^{\circ}\right.$ 1975.] Les beaux Coleus lerschaffellii Lem. et J3/umei Benth., vulgo: Robe à l’évêque, introduits des élablissements horticoles d'Europe, sont derenus communs daus les jardins el dans les cudroits abandonnés de la région humide du Camp-Jacob, du Matouba, de Gonuberre, cle.. où ils viennent spontanément. [Nos 215\%, 2129.]

Martinique. Vulgo : Herbe panachée. - Morne-lionge, Gros-Morne. Lamentin, Saint-Pierre, Fort-de-lirance, etc. [No -101.]

Marsypianthes Mart. (du gree " marsupion ", bourse, el "anthos ", lleur, allusion à la lèvre supérieure de la corolle qui forme une sorte de petit salc.

M. hyptoides Mart.; Marsypianthe ressemblant à un Hyptis. Vulgn : Verveine-terre. - Herbe annuelle, couchée, molle, plus nu moins relevéc aux extrémités, à tiges et branches nombreuses el carrées. Fieuilles llasques, wréc ou ovées-lancéolées, dentées en scie. Fleurs pourpres, en capilules whlouleux, nombreux, habituellement pédonculés; calice 5-fide, laineux; corolle rentermée dans le calice persistant; élamines f. Fruits 1, cymbilormes, entoure d'un bourrelet. - Dans les mornes sablonneux el herbeux de la rérion infirieure: Baie-Mahault, où il forme souvent gazon, Sainte-liose, les. Mromes. Moule, etc. [No 2938.]

Martinique. Vulgo: Herbe couchée, herbe courante, 'Trou-l'aillant, SaninleAnne, Trois-Ilets, Marin, Saint-Esprit, Rivière-Pilnte, elc. (X' y)1!).

Hyptis Jacq. (du gree « huptios ), replic, allusion ì la forme de la comolle.

H. capitata Jacq. ; Iyptis à fleurs en capilules. Vulgo : Mélisse à lumbuns. Si., t. 109, f. 2; Desc., vol. VHI, 1.576, 1). 172. - Ilerbe annuclle, trie

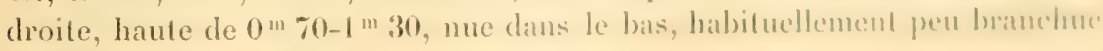


al peu feuilhe à branches distantes et décussées, à tige grosse et virnoureuse. à tige et branches carrées. Feuilles pétiolées, ovées-oblongues, pointues, rétrécies à la base, grossièrement dentées en scie : les florales, oblongues-lancónles. Fleurs petites, en capitules ghtouleux, longuement pérloneulés, axillaires, opposés par deux, confinés dans les parties supérieures de la tige et des branches; dents du calice 5, subulées, sétilormes et dressées; corolle blane pâle, souvent tachetée de petits points ronds. - On se sert des parties tendres de celte herbe en décoction comme sudorifiques contre les lières, les rlumes, les fluxions de poitrine, la toux, etc. - Fl. pendant et après l'hivernage. - Assez abondant le long des cours d'eau, dans les endroits humides et ombragés de toute la Guadeloupe et de ses dépendances. Alt. 0-700 mèt. [No 2159.$]$

Mantinique. Vulgo : Pompon blanc, mélisse à tête. - Dans les endroits humides et ombragés de toute l'île. $\left[N^{0} 920.\right]$

H. atrorubens Poit.; Hyptis à lleur pourpre noir. Vulgo : Herbe à miel, bouton à vonvon, petit thym it lapins a Gourbeve), véronique au Lamentin , blanc mauve au Moule). - Iferbe flasque, à tige d'abord couchée, rampante et radicante, ensuite ascendante, à branches nombreuses, à branches et tige pubescentes dans le haut. Feuilles petites, brièrement ovées ou ovéesoblongues, dentées en scie: les florales toujours ovées. Fleurs en capitules ghobuleux, axillaires, brievement pédonculés, à pédoncules aussi longrs que les cappitules: corolle pourpre noir, panachée de blanc; dents du calice sétiformes et hispides. - Cette plante est sudoritique au mème litre que la précédente et s'emploie souvent dans la médecine domestique. - Extrêmement abondante dans la région supérieure, où elle constitue souvent presque l'unique herbe fourragère des savanes; plus rare dans les savanes sèches inférieures. Alt. 5-900 mèt. [No 2159.]

Martingee. Vulgo: Herbe à mouches (parce que les insectes ailés les fréguentent pour sucor le nectar des lleurs, herbe à miel. - Fort abondante dans toutes les savanes. [No 404.]

H. spicata Poit.; Hyptis à inflorescence en épis. Vulgo : Herbe-mélisse, framboisin. - Annuel, très droit, haut de $0^{\mathrm{m}} 80-1^{\mathrm{m}} 50$, rarement plus haut, a tige forte, carrée, nue dans le bas, a branches distantes, décussés. Fenilles petiles: les canlinaires, ovées, pointues, inégalement dentées en scie; les Ilorales, lancéolées. Fleurs en grappes simples ou composées, allongées, terminales, constituées par des glomérules pauciflores, un peu distantes; corolle blanchatre, tachelie de violet, à tube eylindrique, à lère largement ouverte; calice ventru à la base, à dents courtes, sétiformes et droites, beaucoup plus courtes que le tube de la corolle. - Abondant dans toutes sortes de terrains, le long des ruisseaux, sur les vieux murs, sur les décombres dis la région inférieure: Basse-Terre et environs, Baillif, Pointe- 
Noire, Anse-Bertrand, Port-Iouis, Moule, Gozier, Marie-Galante, de. [No 215\%.]

Martinique. Vulgo : Framboisin. - Abondant: Saint-Piepre, Casc-pilnte, Marin, Vauclin, Trois-Ilets, etc. [No 1217 a.]

H. suaveolens Poit.; Hyptis ì odeur suave. Vulgo: Cons baume, démarré, gros du thym. Sl., t. 101, 1. 2; Br., Jam., t. 18, 1. 3; 1)ese, vol. I, 1. I1s, p. 282. - Annuel, très droit, haut de $0^{m} 70$-1" ${ }^{m}$ 80, quelquelonis plus haul, sonon le terrain, nu dans le bas, très feuillu et branchu dans le haut, à jeune lige el branches plus ou moins carrées, toujours lortement grarnies de poils gris el longs. Feuilles caulinaires, ovées, doublement servetées: les inlérienres, cordées; les florales, petites, lancéolées, sétilormes. Fleurs petites, en „rln-

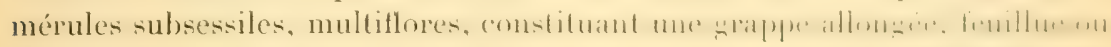
non feuillue; corolle bleu pâle, brièvement exserte; calice brievement púdicellé, à tube garni de dix côtes, à dents subulées, rigrides, spinescenten el acérées. - Fl. de décembre à mars. - Toute la plante est aromalique, el on se sert des feuilles et des parties tendres des branches pour partumer les bains. - Vit souvent en société dans les terres arides, sèches et pierreuses des côtes de la basse région: environs de la Basse-Terre, Baillif, Vieux-Habitants, Vieux-Fort, Pointe-Noire, Marie-Galante, les Saintes, ele. TY Iflil.

Martingue. Vulgo: Baume. - Saint-Pierre (envirous de la batlerie SainteMarthe), Carbet, Case-Pilote, Vauclin, Sainte-Anne, Marin. [N 197:.

H. pectinata Poit.; Hyptis à fleurs en glomérules, disposées en peirne. Vulgo : Baume-z'anglais camphré, guérit-tout. - IIerbe très droite, haute de $0^{\mathrm{m}} 80$ à $1^{\mathrm{m}} 80$, et parfois de $2^{\mathrm{m}} 80$, à tige netlement carrée, forte, nue dans le bas, à branches décussées, à jeune tigre et branches souvent pubescentes. Feuilles petites : les caulinaires, ovées, inégalement dentées en scie, velues

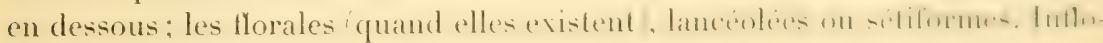
rescence en petites cymes contractées, nombreuses, tournées en biais, consti-

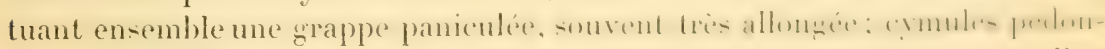
culées, multiflores, à fleurs disposées sur deux rangs, tournés en haul el d'un seul còté; calice brièvement pédicellé, à tube à dix stries, it dents aigruës ef légèrement courbes, plus courtes que son tube : ouverture du tube du calice tronquée et garnie de poils laineux; corolle blanc pâle, petite, it lìves larrement ouvertes et souvent ponctuées de noir. - Fl. pendant ot après l'hivernage. - Abondant dans les terres sieches, tufières ou sablommenses de la région inférieure de toute la-Guadeloupe el de ses dépendances. Y Y" 216ti.

Martixique. Vulgo: Baume-savane, herbe-muraille. - Nondant dans: toute l'île. $\left[\mathrm{N}^{\circ} 402.\right]$

H. verticillati Jacq., Stachys palens. Vulgo: Grand baume. - Suffrutescent et frutescent, haut de 22 à 2 m sil), droil. ornemental, très branchu dans le haul, à branches droites, ílalies. Inmerues. 
Fevilles brievement pétiolées, oblongues-lancéolées, dentées en scie : les florales trè petites, sétiformes ou avortées. Intlorescence en glomérules verticillés. tris nombreuses, disposies sur des srappes spiciformes, interrompues, allongés, axillaires et terminales. formant ensemble une très large panicule'. - Peu répandu : environs de Saint-Pierre (Trois-Ponts et dans le lit de la Roxelane). [No 1217.] - Je ne l'ai pas trouvé à la Guadeloupe.

Salvia L. (du latin "salvare ", sauvér, conserver, par allusion aux vertus médicinales de ces plantes.

S. occidentalis Sw.. Hyptis glandulosal Sieber: Sauge de l'Inde Occidentale. Vulgo : Herbe à couleurre. Sl., t. 107, f. 2. - Herbe annuelle, à tige couchée, radicante, rampant en tout sens, longue de $0^{\mathrm{m}} 40$ à $90 \mathrm{~cm}$., rarement plus longue, très branchue, cylindrique, rougeâtre ou noirâtre. Feuilles gaufrées, ovées, pointues, cunées à la base, dentées en scies, garnies de poils épars sur les deux faces. Fleurs en glomérules verticillées, à 2-6 rayons, distantes, constituant une grappe spiciforme, mince, allongée, terminale; tube du calice garni de poils glanduleux, courts, risqueux, de moitié moins long que le tube de la corolle, qui est bleue. - Fl. à toutes les saisons. Dans beaucoup de savanes humides des basse et infra-moyenne régions de toute la Guadeloupe et de la Grande-Terre. - Est considérée comme un assez bon fourrage. Dans le pays, on se sert du suc (extrait des feuilles el des tiges quion instille par gouttelettes dans les yeux pour laire disparaitre les taies de la cornée. Alt. 10-700 mèt. [No 2153.]

Martinique. Vulgo: Petite violette. - Dans toutes les savanes de l'île. [No 1978.]

S. micrantha Vahl, S. lenella Sw.; Sauge à petites fleurs. Vulgo: Herbemuraille. - Suffrutescent, aromatique, haut de $20-35 \mathrm{~cm}$., nu dans le bas, très touffu par le haut. Feuilles deltö̈des. garnies des deux cotés d'un duret soyeux el sris. Intlorescences en verticilles de 2-1; fleurs, disposées en sirappess courtes, interrompues et terminales. - Peu répandu : çà et là sur les décombres et les vieux murs du bourgr de Saint-François. [No 2160.] - Il n'existe pas à la Martinique.

On cultive souvent dans les jardins : $1^{\circ}$ le Salvia splendens Ker.-Gawl, du Brésil, vulgo : Sauge rouge, sous-arbrisseau à fleurs écarlates, subspontané

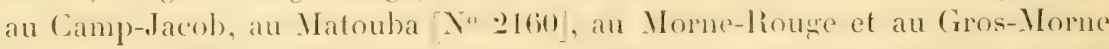
Martinique X" $197 \%$ : 2" le S. farinacea lienth., du Mexique, vulgo : Sauge blanche, it tignes plus ou moins couchées, à leuilles et pédoncules d'un blance

1. Sous le nom vulgaire d'Azier maringouin, Ragnet maringouin, cette plante, qui a été introduite à Cayenne venant des Antilles, est employée en Guyane comme pectorale, emménagogue, céphalique. On la donne aussi en infusion contre les indigestions, comme excitant diffusible au même titre que les autres Hyptis signalées ci-dessus comme aromatiques.

(E. 11.) 
farineux, à fleurs violetles, en glomérules verticellées sur de lonģs épis nnmbreux $\left[\mathrm{N}^{0} 2934\right] ; 3^{\circ}$ le $\mathrm{S}$. coccinea Juss, d'Amérique tropicalè, herbe annuelle, droite, haute de $40-60 \mathrm{~cm}$, ì tige el branches carrés, poilues ou

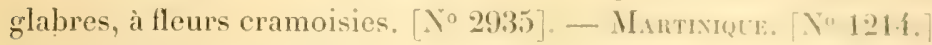

Le S. lamiifolia Jacq., suffrutescent, plus nu moins droit, haut de bio$90 \mathrm{~cm}$., à fleurs d'un violet très foncé, se trouve dans la région mon lagncuse dé l'île de Sainte-Lucie. [No 1218.

Stachys L. (du gree "stachys ", épi, allusion ì la forme de l'inflorescence.)

S. arvensis L.; Épiaire des prés. Vulgo : IIerbe graine-roisenu. - Petite herbe flasque, très branchue, plus ou moins difluse, haute de 1(1)-1.5 ('m. : s'est naturalisée dans les jardins du Morne-Rouge. - Introduite sans doute de France par les graines de plantes potagères. $\left[\mathrm{X}^{\circ} 397\right.$.

Leonurus L. (du gree "leon ", lion, et "oura ", queue, par allusion plus ou moins forcée aux glomérules florales rappelant un peu une quene de lion.)

L. sibiricus L.; Agripaume de Sibérie. Vulgo : I Ierle-saron (it la liasseTerre), herbe Madame Lalie. - Herbe annuelle ou bisannuelle, droile, ornementale, haute de $60-95 \mathrm{~cm}$., à tige carrée-sillonnée, fortement branchue dans le haut. Feuilles palmipartites ou les supérieures entières. Fileurs pourpres, en glomérules verticillées, axillaires; calice it cinq dents spinescentes et à cinq nervures; corolle ì deux lèvres: lèvre supérieure, concave, entière, droite; lèvre inférieure, à trois lobes; étamines didynames, parallìtes: les deux inférieures plus longues. - Herbe très répandue dans la rénion inférieure de toutes les Antilles, originaire de la Sibérie. - Fl. surtout pendant et après l'hivernage. - Arec les feuilles, mêtées à celles du curage

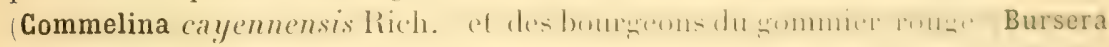
gummifera L.), on prépare une décoction contre la toux invétérée. [Y.-2l(t:-2]

Mantinique. Vulgo : Chandelier. - Abondant. [No 1976.

Leucas Burm. (du gree "leucas ", blane, it cause de la couleur des flemr.)

L. martinicensis R. Br., Phlomis caribea Jacq. ; Leucas de la Martinique. Vulgo: Herbe à boutons. (Phlomis I.) Jacer., Sel. Am, si. hist., 1. $17 \%$. f. 75. - Herbe annuelle, haute de $20-60 \mathrm{~cm}$., droite, peu branchue, d'un aspect grisâtre. Feuilles flasques, ovées-lancéolées ou ovées, obturimuent dentées en scie. Fleurs en frlomérules larges, verticillées, multillorés. distantes, à bractées linéaires-acuminées; calice oblique, recourbé, it dix dents spinescentes el sétacées, subulées at la base; corolle hlanche, renfermée dans le tube du calice. - Dans le pays, on se sent des lecuilles con décoction contre les fluxions de poitrine. - Assez abondant daus les lerres sablonneuses et fertiles de la basse région : environs de la lasse-therre. 
Bailif, Pigeon. Vieux-Habitants, Déwirade, Moule, Pointe-it-Pitre, elc. Alt. 5-180 mèt. [Nº 2165.]

Martivique. Vulgo : Bouton blane, pompon blanc. - Carbet, Case-Pilote, route du Lamentin à la Trinité, Robert. [No 1221.]

Leonotis R. Br. (du grec "leon », lion, et " ous », oreille, parce que la lèvre supérieure de la corolle, large, dressée, concave et laineuse, aurait une certaine ressemblance avec une oreille de lion.

L. nepetirfolia R. Br.; Léonotis à feuilles de Népéta (autre espèce de Iabiée). Vulgo: If(rbe is mouton, gros bouton au Moule - - Ierbe annuelle, très droite, ornementale, haute de $60-95 \mathrm{~cm}$., rarement plus élevée, glabre, à tige carrée-sillonnée. Feuilles ovées, crénelées-dentées, longuement pétiolées. Fleurs en gylomérules solitaires, globuleuses, très larges, axillairesverticillíes, distantes; corolle écarlate, large, pubescente en dessous, deux fois plus longue que le calice, à lèvre supérieure allongée, beaucoup plus longue que l'inférieure, qui est trifide; calice à dix nervures, à 8-10 dents inézales, spinescentes, très rigides el acérées, lancéolées-linéaires: les supérieures, beaucoup plus longues et subulées. - Abondant dans les terres sablomneuses, ou calcaires ou tulieres de toute la Guadeloupe el de ses dépendances. Alt. 5-600 mèt. [ $\mathrm{N}^{\circ}$ 2164.]

Martinieve. Vulgo : Herbe-chandelle, pompon rouge, gros pompon. - Alt. 5-350 mèt. [No 1958 .

Scutellaria Riv. (du latin " scutella ", écuelle, assiette, tasse, à cause de l'appendice en forme d'écuelle que porte la lèvre supérieure du calice.)

S. purpurascens $\mathrm{Sw}_{\mathrm{w}}$; Scutellaire à fleurs tirant sur le pourpre. Vulgo : Violette-savane, toque de la Havane. - Annuel ou bisannuel, ornemental, haut de 15-30 cm., stolonifère, plus ou moins diffus, quelquefois très droit. Feuilles relativement larges, ovées ou deltö̈des, dentées en seie, ì dents peu nombreuses et larges. Fleurs pourpres, panachées de blane, en stomérules verticilleses, distantes, paucithores, formant ensemble une grappe courte, terminale; calice à deux levres entières: la supérieure portant sur le dos un appendice scutelliforme; corolle it deux lèves: In supérieure fortement voutée et rapprochée de linféricure; tube de la corolle allongé, dilaté vers le sommet. - Fl. presque toute l'année. - Peu répandu. Cà et là dans les endroits ombragés, sablomeux, secs ou humides : environs de la Basse-Terre (Ravine de Belost), Pointe-Noire (au Gommier et au Pérou). Alt. 50-600 mèt. [No 2163.]

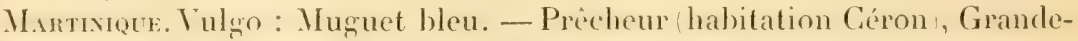
Rivière, etc.; se cultive quelquefois dans les jardins. [No 1974 .]

De la famille des Labiées, on cultive dans les jardins des deux colonies, comme plantes condimenteuses ou médicinales : le Rosmarinus "fficinalis L...

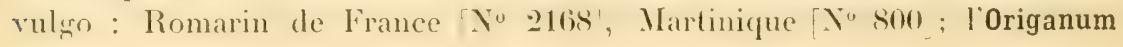




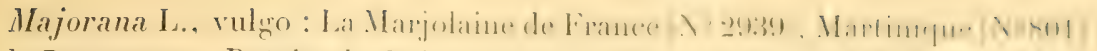

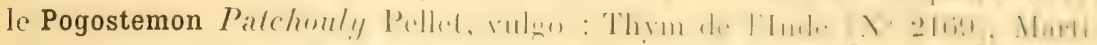
nique [No 1222]; le Mentha piperiti L., vulgo: M[enthe poivere, avec les variétés à tiges rouges ou vertes, vulgo : Petil thym. Y, 319:3]. - T'oute: ces plantes fleurissent facilement, à l'exception du patchouly.

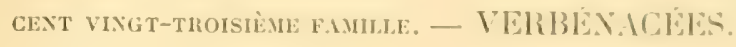

Priva Adans. (anagramme d'un nom inconnu.)

P. echinata Juss,; Priva à fruits hispides. Vulgo : Collant, trmérittout. Sl., t. 110, f. 1. - Herbe annuelle, d'un aspect gris, pubescente ou glabre, à tige souvent couchée, ensuite ascendante, haute de $6(0-90 \mathrm{~cm}$. habituellement très branchue. Feuilles ovées, pointues, rétrécies à la base on subtronquées, crénelées-dentées, flasques. Fleurs violet pâle, en grapje: spiciformes, courbes, allongées; calice ventru, à cing dents, garni de prils crochus, gris et visqueux; corolle obliquement 5-lobéc. Fruits it quatre angles, composé de deux coques cohérentes, ì angles fortement muriqués. Constitue un bon fourrage pour le grand bétail. - . Mondant le lonér des routes, dans les savanes sablonneuses et humides des basse et inlira-moyenne

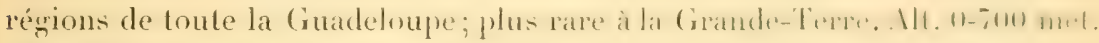
[No 2393.]

Martinique. Vulgo: Herbe à l'angine. - Abondant dans toule l'ile, - Avec les feuilles el les tiges, on prépare une décoction, qui est employée en gargat-

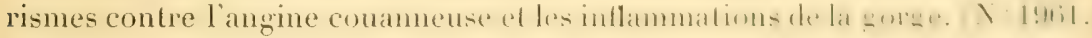

Stachytarpha Link. (du gree " stachys ", épi, el " Larpha ", épais, dru, serré, parce que, dans les espèces-lypes, les inflorescences sont en ćpis doućde ce caractère.)

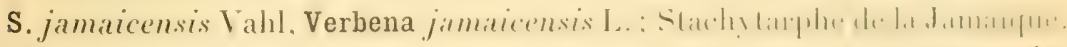
Vulgo: Verveine queue-de-rat. SI., $1.107,1$. 1; Desc, vol. VI, 1. 39!2, 1, 42. - Herbe annuelle, droite, haute de $25-90 \mathrm{~cm}$, at racine pivotante, lonte, blanche, à tige grosse, nue dans le bas, généralement peu branchue dans le haut. Feuilles larges, d'un aspect grisître, gaufrées, ovales, grrossièrement serretées, contractées en coin à la base. Fleurs bleu tendre, en épis légèrement courbes, allongés, pouvant atteindre jusqu' à $30 \mathrm{~cm}$. de Inugr; bractéce recourbées, subulées; calice à quatre dents; corolle it tube lérgèrement contrbe. à cinq lobes arrondis. Fruits linéaires, conchés dans de petites fosectles. Abondant dans les basse el inlra-moyenne régions de loute la Gundeloupe et de ses dépendances'. Alt. 0-700 mèt. [N" 2393.]

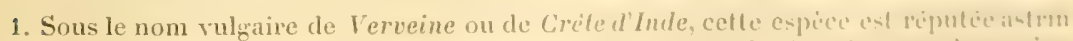
gente it la Guyane et y rend, avec la suivante (St. cayennensis), lés plus framels serviru 
Martixique. Vulgo : Verveine queue-de-rat, verveine caraïbe. - Dans toute l'île. [No 1963 . $]$

S. cayennensis Vahl; Stachytarphe de Cayenne. Vulgo : Petite verveine quene-dle-rat, petite queue-dle-rat. - Suffrutescent, slabre, pouvant alteindre $1^{\text {th }}$.o de haut, à tigne d'abord droite. ensuite tortueuse, à branches nombreuses, à tige et branches grêles, quelquefois subsarmenteuses, penchées ou tombantes. Feuilles vertes, beancoup plus petites que dans le précédent, ovées. obtuses, dentées en scie, contractées it la base. Fleurs violettes ou violet pâle, en épis très allongés, filiformes, léwèrement courbés; bractées linéaires-acuminées, séteuses vers l'extrémité; calice à 4 dents. Fruit disposé comme dans le précédent. - Abondant dans les savanes et les haies de la moyenne région; plus rare dans le bas. Toute la Guadeloupe et ses dépendances. Alt. 5-800 mèt. [ $\mathrm{N}^{0}$ 3282.]

Marmingee. Vulgo : Petite verveine queue-de-rat. - Commune dans toute l'île. Alt. 0-600 mèt. [ $\mathrm{N}^{\circ} 1962$.

Lippia Houst. (dédié à Auguste lipp, né en 1678, à Paris; alla, en 1707, comme médecin, avec une société de savants, à IIabbech, en Afrique, pelit port sur la mer Rouge, où il fut massacré. A laissé plusieurs écrits ayant trait à la botanique et à l'histoire naturelle.

L. nodiflora Rich.; Lippia ì lleurs portées sur des pédoncules naissant it l'aisselle des feuilles. Vulgo : Verveine courante. - Herbe suffrutescente ou annuelle, à tige couchée, radicante, rampant en toul sens à une distance de plusieurs mètres, à extrémitís souvent relevées. Feuilles petites, spatulées, dentées en scie au-dessus de la base, à dents aiguës ou émoussées. Fleurs en capitules d'abord ovoüdes, ensuite ovoüdes-allongés, portées sur des pédoncules filiformes solitaires, et trois fois plus longs que les feuilles; bractées ovales, armondies, cunées à la base, un peu plus courtes que la corolle qui est blanche ou très légèrement violacée; calice bifide du côté postérieur, bipartite du côté antérieur, un peu plus court que le tube de la corolle. Fruit à deux coques cohérentes. - Fl. toute l'année. - Abondant dans les endroits humides ou secs du bord de la mer et souvent aussi un peu dans les terres : environs de la Pointe-a-Pitre, Port-Lonis, Anse-Bertrand, Saint-François, etc. $\left[\mathrm{N}^{\circ} 2941\right.$.

Ifartixique. Vulgo: Verveine courante. - Commun au Vauclin, à SainteAnne, à la Caravelle, etc. $\left[\mathrm{N}^{\circ} 415.\right]$

L. reptans H. B. Kth.; Lippia rampant. Vulgo : Verveine courante. IIerbe suffrutescente, couchée, radicante, s'étendant en tout sens à une dis-

contre la dysenterie : ses feuilles sont aussi employées en cataplasmes résolutifs. Une cuillerée du suc récent de ses feuilles suffirait pour apaiser les coliques et les tranchées dans la dysenterie. (E. H.) 
Lance indéterminée. - Feuilles comme dans le précédent. - Fleurs en capritules d'abord ovoïdes, devenant plus tard ovoüdes-allongés, portés sur des: pédonculescomprimés, un peu plus courts que les feuilles; corolle visted pâle ou blanche. Ressemble beaucoup au précédent; il s'en dillérencie surtout : par ses pédoncules constamment beaucoup plus courls; par son calicu bicaréné-comprimé, bidenté au sommet, et par les cils qui garnissent les deux carènes. - Mème habilat que l'autre, mais moins abondant. Y. -29:37.

Martinique. Vulgo: Petile verveine. - Vauclin, Sainte-Anne, Trois-Ilets. liobert. INo flí.

L. geminata H. B. et Kunth; Lippia à glomérules géminées a l'aisselle des feuilles. Vulgo: Sauge du Brésil. - Arbrisseau ornemental, d'un aspect fris: blanchâtre, très droit, haul de $0^{\text {min }} 80-1^{\text {mI }} 30$, it une ou plusieur's lifres, frès peu branchues (à l'élat sauvage), à liges et branches pubescentes. Feuilles petites, ovées ou ovées-oblongues, finement dentées en scie, scabres-pubescentes. Fleurs en capitules suly

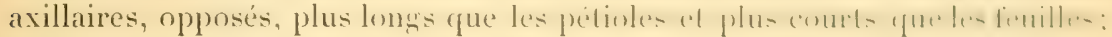
bractées ovées, pointues, un peu plus courtes que la corolle qui est rose: calice bifide, trois fois plus court que la corolle. - Rare : cit et lit aux Abymes, au Morne-â-l'Eau et dans les environs de la Basse-'Terre (quartier de l'Arsenal). [No 3281.$]$

Martinque. Vulgo : Sauge de la Barbade. - Plus abondant qua ì la Guadelonpe. - On se sert des feuilles et des jeunes tiges en lisanes sudoritique: contre les refroidissements, les rhumes, la toux, etc. - Grande-Rivière (pris du bord de mer); Case-Pilote, Marin. [ Yo 116.

Le Lippia citriodora H. B. et Kith, d'Amérique australe, vulgo: Citronnelle, sous-arbrisseau à branches plus ou moins couchées, it feuilles rudes. lancéolées, ì fleurs en panicules spiciformes, est cultivé dans beaucoup de

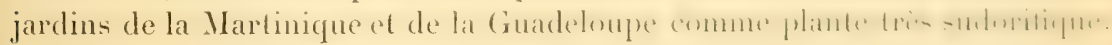
- Originaire de l'Amérique australe. [ $\mathbf{X}^{\circ} 212.4$.

Lantana L. (du latin "lentare ", plier, parce qu'un grand nombre de ces: espèces ont des branches flexibles comme le Lantana des Anciens, qui appartient au genre Viburnum, et qu'en outre les feuilles et les l'ruits noirs lui ressemblent aussi.)

L. Camara L., L. aculeata L. (nom de la plante che\% les indigienes de l'Amérique du Sud.) Vulgo: Mavisou (a la Basse-Terre), mille-flenr's, saluze. herbe à plomb. Sl., t. 195, f. 2; Desc., vol. IV, t. 301, 1).330, et rol. I. 1. 370 , p. 250 ; Pl., éd. Burm., 1. 71, l. 1. - Irbrisseau ou grand arbuste, ne dépassant que rarement 3 mèt. d'élévation, nu dans le bas, it hranchere nombreuses, divariquées, penchées ou tombantes, ou parfois un preu sarmenteuses, à tige el branches quadrangulaires, garnies sur les angles de piquant: recourbés, acérós, jaunes ou jaunitres. Fieuilles orées ou ovécs-oblongrues. 
dentées en scie, à dents obtuses. Fleurs odorantes, en capitules axillaires, solitaires ou géminés, ou réunis par 3 , portées sur des pédoncules plus longrs, ou aussi longs et plus courts que les feuilles; calice à 2 dents, quelquefois à 4, petit; bractées lancéolées, une fois plus courtes que la corolle. Drupes noires, luisantes, souvent épineuses. - Sur les mèmes capitules, on trouve toujours des fleurs de deux, souvent de trois couleurs différentes: celles du centre sont jaunes d'abord, deviennent ensuite lilas, et avant de tomber elles tournent très souvent au blanc; la gorge des fleurs, lilas et blanches, demeurant du reste jaune 1. - Fl. d'un bout à l'autre de l'année. Extrèmement abondant dans la basse région sèche de toute la Guadeloupe el de ses dépendances. $\left[\mathrm{N}^{\circ} 2380\right.$.

Mantinique. Vulgo : Bois-genou. - Très abondant dans toute l'île. Nos 418, 687.

L. croceatacq. ; Lantana ì fleurs couleur de salran. Vulgo: Pelit baume, bois mille-fleurs jaunes. - liessemble beaucoup au précédent; il en difrère : par sa taille plus élevée, ses branches plus allongées et souvent sarmenteuses; par la corolle, qui est constamment d'un jaune de safran, passant ensuite à l'orangé ; par ses bractées linéaires-acuminées, enriron trois lois plus courtes que la corolle. - Moins abondant, mais même habitat que le précédent. No2383.

Martineue. Vulgo : Baume safran. - Abondant. 「No 687.

L. involucrata L.; Lantana à fleurs enveloppées de larges involucres. Vulgo : Petit baume, baume blane. - Arbrisseau ornemental, d'un aspect grisâtre, très droil, haut de 1-2" 50 , tantit peu, tantit fortement branchu, it rameaux droits, grêles, plus ou moins fastigiés. Feuilles petites, ovées ou ovales, crénelées, pubescentes, grisâtres. Fleurs d'un blanc pur ou lilas tendre, odorantes, portées sur des pédoncules droits, plus longs ou aussi longs que les fenilles, situés un de chaque crité des qualre dernières feuilles de la branche; capitules 3-1, plus petits que dans les deux précédentes espéces, a bractées involucrales largement ovées, pubescentes, aussi longues que les lleurs. - Fl. en août, septembre, octobre et novembre. - Abondant sur la côte sioche et aride entre Baillif et les Vieux-Habitants: Deshaies, Moule, Gozier, Marie-Galante, les Saintes, etc. ${ }^{2}$. [Nos 2391, 2945, 2746.]

1. Cette plante est utilisée à la Guyane, sous le nom de Marie-Crabe ou de Marie-Crabe épineux, comme aromatique et antispasmodique. La décoction de toute la plante est préconisée en bains contre le tétanos, les rhmmatismes, la fievre palustre. C'est un tonique puissant très employé contre l'atonie des viscères abdominaux. L'infusion des feuilles est stomachique, digestive; elle faciliterait, dit-on, le travail intellectuel. Les bourgeons, macérés dans le vin de Malaga, servent de topique contre les aphtes des enfants. On en fait un thé sudorifique un peu amer, et avec les feuilles, froissées et bouillies, des bains fortifiants: l'infusion est donnée contre les coliques. Negrete en a extrait la lantanine, alcaloïde qui, à la dose de $2 \mathrm{gr}$., serait plus actif que la qquinine contre les fièvres. (E. H.)

2. Cette espèce pourrait recevoir sans doute les mèmes emplois médicinaux que $\mathbf{L}$. 
Martinique. Vulgo : Baume blane : Carbet, Case-Pilole, Sainle-Anne, Caravelle. $\left[N^{\circ} 417.\right]$

Citharexylum Mill. (du gree "kithara », guitare, ef "xulon ", bois, parce

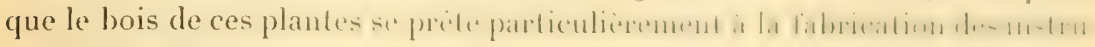
ments de musique, comme violons, violoncelles, guilare, ete.

C. quadrangulare Jacq., C. coriaceum Desf., C. cauditum Sw:; Cithiréxylon à branches quadrangulaires. Vulgo: Bois carré, bois de fer blanc. St., t. 200, f. 3, 4. - Arbre de taille moyenne, it trone anfractueux, it branche: tantôt fastigiées, tantôt divariquées, tantôt penchées, surtout les inférieures. à écorce grise, à jeunes branches constamment quadrangulaires. Feuilles

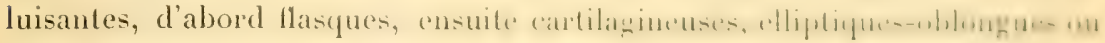
elliptiques, pointues ou obtuses au sommet, glabres des deux cítés. Fleurs

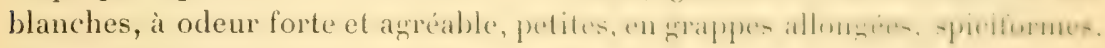
noueuses, axillaires et terminales, souvent réunies en groupe; calice à cinq

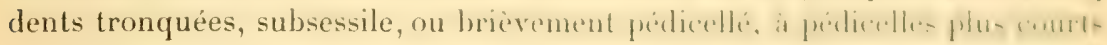
que la bractée; corolle en forme d'assiette. Drupe d'abord rouge, ensuite noire, luisante et polie, ovoüde. - Le bois, mou, n'est gruère employé pour la construction. - Fl. d'août à novembre et aussi en mai, juin et juillet. - (Wii et là dans les grandes haies, dans les falaises, le long des rivières des basse

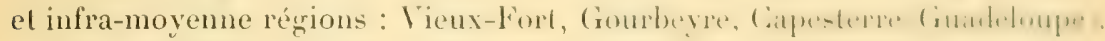
les Abymes, Morne-ì-l'Eau, Moule, Marie-Galante. No 2941.

Martinique. Vulgo : Bois-cotelette. - Plus abondant qu'it la Guadeloupe. - Dans tous les bois inférieurs du nord et du sud de l'ile. No.21:27 at.

C. lucidum Cham. et Schlecht., C. caudalum L.; Citharéxylon it leuilles luisantes. Vulgo : Bois-côtelette. - Ressemble au précédent; il en ditterére : par ses rameaux, qui sont d'abord quadrangulaires et deviennent ensuite

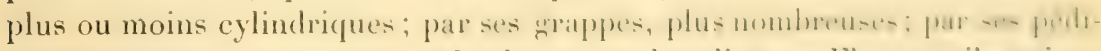
celles, aussi longs et souvent plus longs que le calice. - Hl. en avril, mai. -

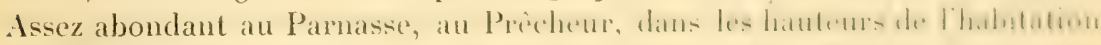
Pécoul, dans le haut de la vallée du Carbet, de la Riviere-salée, ele. [No 2027.] - Je ne l'ai pas vu à la Guadeloupe.

Duranta L. (dédié à Castor Durante, médecin à Rome, mort en 1590, it Viterbe; a écrit: Herbario nuovo in versi latini.)

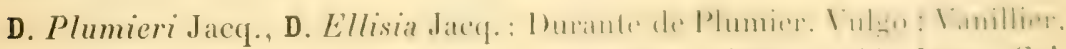
fleurs vanille. Br., Jam., t. 29 ; Desc., vol. VII, t. 488, p. 155; Jaceq., Sel. Am. st. hist., t. 176, f. 76 . - Grand arbuste ou petit arbre, droil ou

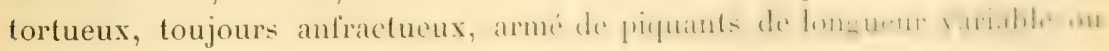

eamera; elle est usitée, sous le nom vulgaire de Monjoly en bains aromatiques que l'on prépare au moyen de la décoction de ses feudlles (it étudier comme comprasition chi mique). (E. H.)

Duss, - Plantes Guadeloupe et Martinique, 
inerme, à branches divariquées : les inférieures presque toujours pendantes. Feuilles elliptiques-lancéolées, on obovées-arrondies, subentières ou serretées-crénelées. Fleurs lilas, en grappes penchées ou pendantes, simples ou composées, terminales et axillaires : les dernières naissant à l'aisselle des feuilles de l'extrémite des branches; calice cylindrique, une fois plus court que le tube de la corolle, d'abord tubuleux, sélargissant ensuite ef renfermant completement la drupe : corolle en forme d'assiette; tube de la corolle cylindrique, courbe; lobes 5, légèrement irréguliers : les deux supérieurs plus étroits et parcourus d'une strie pourpre qui tranche fortement sur le fond lilas. Drupe ovoüde-ventrue, surmontée des cinq dents persistantes du calice, au milieu desquelles se dresse le style, persistant et droit; péricarpe jaune à la maturité; semences 4.- Rare à l'état sauvage, cultivé souvent dans les jardins et les cours comme plante d’ornement, état qui lui fait perdre habituellement les épines. - Selon Descourtilz, les feuilles sont détersives; dans le pays, on n'en fait pas d'usage : on se sert seulement des grappes florales pour la confection de bouquets. [No 2394.]

Martixique. Vulgo : Vanillier. - Se rencontre à l'état sauvage et armé de piquants dans les hauteurs de l'habitation Pécoul, du Prêcheur, et au Champflore, enfin à l'état de culture dans beaucoup de jardins. [No 1960 .

Petrea Houst. (dédié au lord anglais R. J. Pètre, né en 1710, mort en 1742, possesseur d'une grande collection de plantes rivantes exotiques.)

P. volubilis L.; Pétréa voluble. Vulgo : Liane rude, liane violette, liane Saint-Jean, liane ì cercles, liane Pentecôte. Jacq., Sel. Am. st. hist., t. 114, p. 180. - Forte liane, très ornementale, pouvant atteindre les sommets de grands arbres, à tige anfractueuse, à écorce grise, à branches et grappes pendantes. Feuilles tries rigides et scabres, elliptiques ou elliptiques-oblongues, luisantes en dessus; pétiole court. Fleurs bleues, très belles, en grappes lâches, allongées, nombreuses; calice double : l'extérieur, large, 5-partite, persistant et renfermant plus tard le fruit, à tube scabre; l'intérieur, petit, a cing dents arrondies; corolle bleue, infundibuliforme; étamines $\mathbf{4}$, incluses; akène unique, par avortement de l'autre ovule. - Fl. de janvier à juillet, et souvent d'octobre à janvier. - Abondant dans les mornes inférieurs, le long des falaises et des rivières : Vieux-Fort, Houëlmont, Gourbeyre, Monléran, rivières Noire et Rouge, Pigeon, Bonillante, Deshaies, etc. [No 2390.$]$

Martinique, Vulgo : Liane rude. - Abondant : hauteurs du Prêcheur, Trois-Ilets, la Régale, hauteurs du Diamant, etc. [No 1964.]

ÆEgiphila Jacq. (du grec " aix ", chèvre, et "philein ", aimer, c’est-à-dire plantes aimées des chèvres.)

Æ. marfinicensis Linn., Æ. glabra Lam., A. Manabea Sw.; AEgiphile de la Martinique. Vulgo: Bois-cabrit, bois de fer, sureau gros. Lam., Ill., t. 70, f. 1. - Grand arbuste, haut de 2-3" 50), généralement assez peu branchu, à 


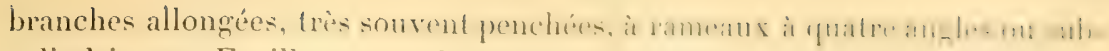
cylindriques. Feuilles assez larges, membraneuses, lancéolées-oblongués, pointues ou acuminées, rétrécies à la base. Fleur's jaunâtres ou blanc sale, en

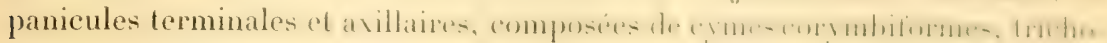
tomes; calice turbiné-infundịbuliforme, à 1 lobes tronqués, deux ou trois fois plus court que le tube de la corolle; étamines t, exsertes. Drupe jaune it la maturité, lisse, ovoïde-ghobuleuse, contenant quatre semences, - [i]. presque toute l'année. - Assez abondant dans toute la rénion inféricure: Gourbeyre, Montéran, Vieux-Fort, Deshaies, Pointe-Yoire, Sainte-Rose, Ravine-Chaude, Moule, les Abymes, Morne-itl'Eau, Marie-Gralante, etc. Alt. 20-100 mèt. [No 2389.

Mantinique. Vulgo: Bois-cabril. - Abondant. Environs de Saint-Pierre: Carbet, Grand-Anse, Macouba, Basse-Pointe, Marin (mone Gommieri'. [No 1966.]

Clerodendron L. (du grec "kleros ", sort, hasard, et " dendron ", arb)re, allusion aux vertus bonnes ou mauvaises qui sont propres aux différentes espèces de ces plantes.)

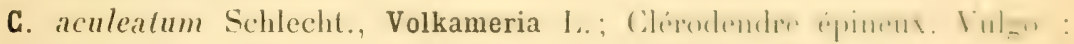
Amourette. Sl., t. 166, f. 43; Br., Jam., t. 30, 1. 2. - Buison ornemental,

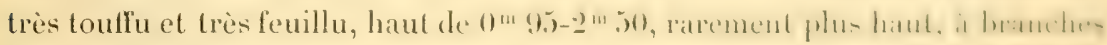
droites, fastigiées, armées de piquants courts el subconiques. Fieuilles

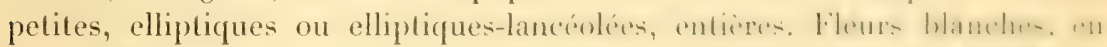

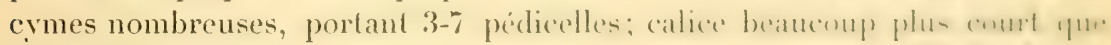

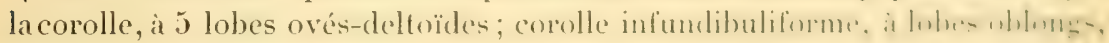

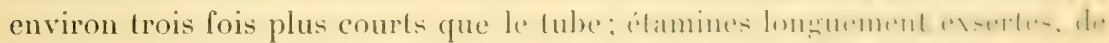

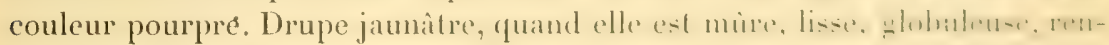
fermant quatre semences. - Fl. surtout de décembre ì avril. - Triès abon-

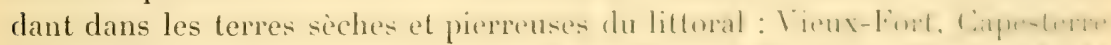

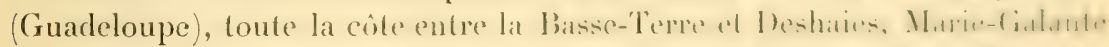
(Capesterre et Saint-Louis), les Saintes, Moule, Gozier, Saint-liançois, Petit-Canal, etc. [No 2387.]

Martinique. Vulgo : Thé bord-de-mer. - Abondant : Saint-Pierre, Pré-

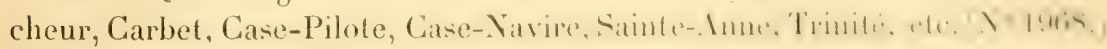

G. fragrans Willd, Clérodendre ì forte odeur. Vulgo: Herlue puante, herbe à Madame Villaret. - Arbrisseau haut de $0^{m} 60-1^{\prime \prime}$ 4, herhace par la

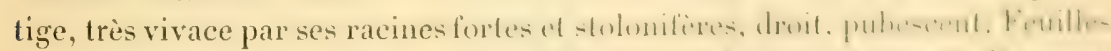

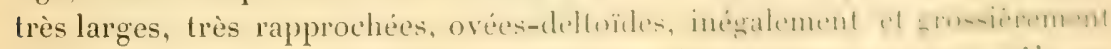
dentées, longuement pétiolées, pointues. Fleur's roses, ou rose pâle ou

1. Cette espèce se différencie peu d'AE. villosa Vahl, qui, sout le nom vulfatire de hois-

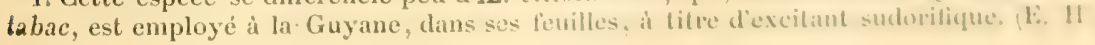


blanches, en ermes courtes, ramassies: corolle toujours double. - Originaire de la Chine, naturalisé et très envahissant. - Les feuilles émeltent une odeur forte et désagréable; les fleurs, au contraire, sentent bon. - Fl. presque toute l'année, mais surtout pendant et après l'hivernage. - Environs du Camp-Jacob, Montéran, Sainte-Liose, Iamentiu, Pointe-à-Pitre, Morne-à-l'Eau, les Abymes, etc. [ $\left.\mathrm{N}^{\circ} 2386.\right]$

Martixique. Vulgo : Herbe puante. - Abondant sur les décombres et le long des cours deau : Saint-Pierre, Trois-llets, Carbet, Marin, ete. Yo 1969.

C. siphonanthus R. Br. : Clérodendre at fleurs at long tube. Vulgo : IJerbe it long cou. - Vivace par ses racines fortes et stolonifères, herbacé par la tige, haut de $0^{\mathrm{m}} 80-1^{\mathrm{m}} 60$, droit, peu fenillu, à tige grosse, carrée, remplie de moelle blanche. Feuilles verticillées par 3, lancéolées, acuminées : les supérieures, oblongues-linéaires. Fleurs blane pâle, en cymes feuillues, axillaires et terminales, formant ensemble une large panicule; pédicelles droits: calice long de $5-6 \mathrm{~mm}$., à lobes arrondis; tube de la corolle cylindriquefiliforme, long de 6-8 cm., à lobes obovés, rétléchis; étamines exsertes. Fruit noir, grand, pulpeux, luisant, contenant quatre semences. - Fl. en mai, juin, juillet. - Dans les savanes et terres cultivées, ou on est obligé de déraciner les pieds pour empecher leur trop grand envahisiement : Lamentin, Sainte-Rose, Gourbeyre ,Dolé, environs de la Basse-Terre, Trois-Riviures, etc. $\left[\mathrm{N}^{\circ} 2943.\right]$

Martinique. - Herbe à long cou. - Saint-Pierre (cimetière du Fort), Prêcheur, Trois-Ilets, Parnasse, Lamentin. [No 1229.]

De ce genre, on cultive fréquemment dans les jardins des deux colonies le C. nutans Wall. Bot. May., vol. LXXXVII, t. 5313), grand arbuste, droit, it écorce noire, ì branches et grappes pendantes, à lleurs blanches [ $\mathcal{X}^{\circ} 3280$ ], Martinique $\left[N^{\prime \prime} 1970\right]$; C. Thompsonie Balf., liane, à fleurs rouges, avec un calice grand et blanc, plante très florifère et ornementale (Bot. Mag., vol. LAXXVIII, 1. 5313; III. horlicole, anno 1863, 1.358; C. Kaempferi Fisch. (IIl. horticule; anno 1863, t. 10 Nos 1971, 2375), sons-arbrisseau, haut de 1-2 ${ }^{m}$ 40, à feuilles larges, pubescentes, à tleurs écarlates, en larges panicules terminales.

Au Jardin botanique de Saint-Pierre, on rencontre le C. squamalum Vahl, Bot. Reg., vol. V'III, t. 649, qui tend à se naturaliser [No 1972] C. violaceum Hort. et G. Balfouri Hort. : le premier tleurit continuellement et rapporte des fruits; le second est aussi toujours en fleurs, mais ne produit pas de graines.

Cornutia L. (dédié au médecin français Jacq.-Phil. Cornuti; a exploré le Canada; mort a Paris. en 1651: a écrit : IListoria plantarum Canadensium: Enchiridium botanicum parisiense.) 
C. pyramidata L.; Cornutie ì fleurs en srappes pyramidales. Vulero: Bois de savane, bois-cac, bois-caral (a Vicux-Forl). Plum., did. Burm., 1. Iofi, f. 1. - Grand arbuste, très toulfu, d'un aspect gris, it liges mombreuses, nu petit arbre pouvant alleindre jusqu' ì 6 mèt. d'élévalion, it écoree gris blan-

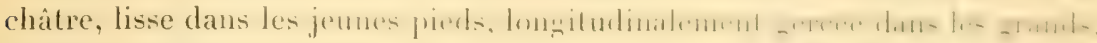
à rameaux carrés, droits, fastigiés el Lrès cassants. Fenilles lonfruement elliptiques, pointues, en coin à la base, vert grisatre en dessus, frarnies un dessous d'un duvet blanchâtre et fin. Fleurs odorantes, ch cymes dicholones, constituant une large panicule pyramidale, pédonculée, teminale; cornllu: bleue, à deux lèvres: la supérieure, subentiere; l'inféricure, is is lobes. I rupe bleu foncé à la maturité, globuleuse, de la grosseur d'une granine de porive. et légèrement duvelée. - Fl. de mai à juillet. - Celte belle plante se se plaît que dans les endroits secs, pierreux ou rocailleux des mornes inférieurs:

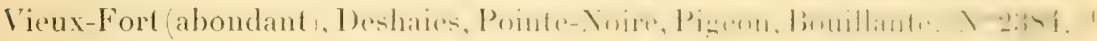

Martineue. Vulgo : Bois-cassave, mouri-deboul (i) la Caravelle, parece que les pieds morts restent longtemps debout). - Abondant : Casc-Pilote, TroisIlets, hauteur de la Rivière-Salée, Prêcheur, Caravelle, etc. [X 1965.

Vitex L. (du latin "viere ", lier, tresse, parce que les branches servent it faire des paniers el que les feuilles ont de la ressemblance avec celles du saule, lequel sert par excellence à lier; le saule s'appelait autrelois Vililia: Pline, XXIV, 38.)

V. divaricata Sw., V. multiflora Miq.; Gattilier à branches divariquécs. Vulgo : Bois à agouti. - Le plus souvent arbre de laille moyenne, trìs nrnemental, à cause de la richesse de ses belles fleurs, anfractueux, il branches divariquées, plus rarement fastigiées, droites, très l'ragiles. Feuilles mem-

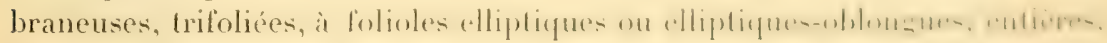
brièvement pétiolulées. Fleurs bleues, très nombreuses, en cymes axillaires.

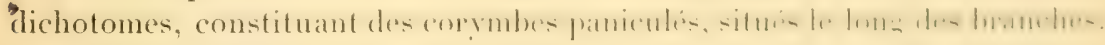
Drupe jaunâtre, lisse, luisante, de la forme et de la grosseur d'une olive. Fl. en mai, juin, juillet. - Peu abondant. Cá et là dans les momes el les falaises des basse et infra-moyenne régrions : Camp-Jacob, Montéran, bonds des rivières Noire et Rouge, Gourbeyre, Trois-Rivières, Sainte-liose, cle. -

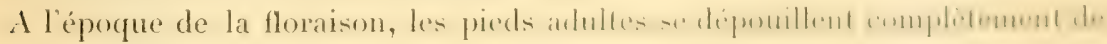
leurs feuilles; le bois est résistant el élastique, assez facilo à travailler : il se conserve longtemps dans l'eau et clans la tere, el les termites ne l'atlacjuent pas; il est recherché par les charpentiers, par les menuisiers el surtoul par les charrons. Alt. 10-500 mèt. [No 2385.

Martingue. Vulgo : Bois-lézard. - Parnasse, Case-l’ilote, Cindoet (vallée), Trois-Ilets, La Régale, Rivière-Pilote, elc. ¡Ỹ 1967.

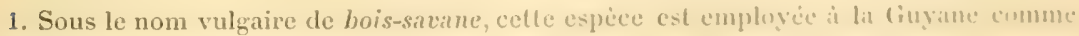
ćmolliente et rafraichissante. (L. II.) 
Le Vitex agnus-castus L., Gattilier-agneau chaste, vulgo : Muguet bleu, petit arbre (dans nos colonies), ornemental, à feuilles à $5-7$ folioles entières ou incisées-dentées, blanches, tomenteuses en dessous, ainsi que les calices, les jeunes branches et les pédoncules, à fleurs bleuatres, en petites grappes, presque sessiles, formant une panicule allongée, a été introduit aux Jardins botaniques de la Basse-Terre et de Saint-Pierre, d'ou il s'est répandu dans les jardins et y fleurit abondamment de mai à octobre. Yo 2396.] - MartiNique. [No 422.] - Originaire du Midi de la France.

Avicennia I. (dédié à Avicenne, né en 980, à Afschana, petite ville de la Perse, médecin, mort vizir, en 1036, à IJamadan; a écrit plusieurs ourrages sur la médecine.

A. nitida Jacq.; Avicennie à feuilles luisantes en dessus. Vulgo : Bois de mèche, mangle blanc (à la Grande-Terre), palétuvier blanc. Jacq., Sel. Am. st. hist., t. 112, p. 177. - Petit arbre, haut de 5-7 mèt, rarement plus haut, à branches nombreuses, souvent fortement inclinées, à écorce gris bleuâtre, lisse ou un peu gercée dans le bas. Feuilles coriaces, lancéolées ou lancéoléeselliptiques, garnies, en dessous, d'un duvet farineux blanc. Fleurs blanches. en cymes trichotomes, contractées, terminales et axillaires : les dernières confinées aux extrémités des branches; calice quadripartite; corolle subrotacée, à $\mathbf{f}$ lobes, dont un plus grand; étamines $\mathbf{1}$, brièvement exsertes. Fruit cordiforme, comprimé, coriace, souvant tardivement en deux valves; semence 1. - Dès que les graines tombent à terre, elles se mettent à germer. - Le bois est excellent pour le chaulfage; l'écorce contient du tanin : on l'utilise pour les tanneries de la Basse-Terre. - Vit en société avec les palétuviers rouges, dans les marécages maritimes. - Fl. surtout de mai à juillet. - Pointe-àPitre, Port-Louis, Petit-Canal, Saint-François, Marie-Galante, les Saintes (Terre-de-Haut, Marigot), etc. [No 2942.

Martineue. Vulgo: Mangle blane, mangle gris, paléluvier gris. - Lamentin, Rivière-Salée, Robert, François, Trinité (Galion). [ $\left.\mathrm{N}^{0} 1224.\right]$

De la famille des Verbénacées, on cultive aux Jardins botaniques de la Basse-Terre et de Saint-Pierre, le Tectona grandis L. fils, vulgo : Tek, grand arbre, très droit, anfractueux, à écorce blanchâtre, à branches fastigiées, à feuilles très larges, coriaces, garnies, en dessous, d'un duvet farineux blanc, à fleurs blanc pâle, en cymes larges, formant une énorme panicule pyramidale; étamines 6 . - Fl. en juin ou juillet; fruits mûrs en octobre-novembre. - Le bois est dur el compact; c'est le meilleur qu'on connaisse, pour les constructions navales. - Originaire des montagnes de Malabar et du Pégou. [N०3786.]

Le Hastingia coccinea Sm. (Halmskioldia Retz.), vulgo : Chapeau chinois, grand arbuste à branches allongées, très inclinées ou tombantes, à fleurs rouge orangé, avec un calice en forme de chapeau chinois, se rencontre souvent 


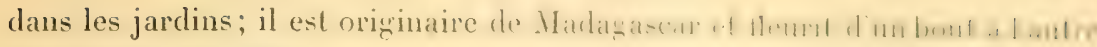
de l'année. [No 2391.

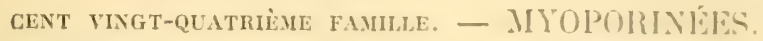

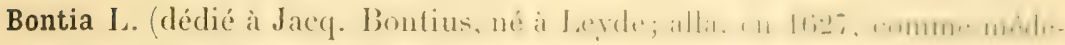
cin à Batavia, où il mourut en 1631 ; a écrit : Iristoria nalturalis el medica india orientalis.)

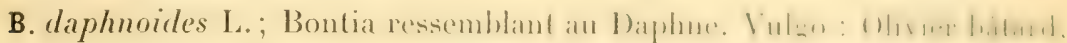
olivier bord-de-mer (à Marie-Galante). Desc., vol. VI, 1. 386), p. 22. J Jacy., Sel. Am. stirp. hist., t. 173, f. 16 (la fleur et le fruit). - Grand arbuste nu petit arbre, souvent tortueux, à écorce rude, gercée dans les vieux pieds: les branches inférieures, horizontales et divariquées. l'cuilles lancéolées. acuminées, glabres, subcharnues-flasques. Fleurs solitaires ou greminécs it l'aisselle des feuilles; calice à cinq segments subulés el ciliés; corolle rourine jaunâtre et panachée de pourpre, à deux lèves laincuses en dedans : l'jnlérieure penchée en avant et roulée. Drupe ovée, jaunâtre à la maturité, de la grosseur et un peu de la forme d'une petite olive, surmontée du style persistant. - A la Guadeloupe, on cultive quelquefois ce petil arbere dans les jardins; il devient alors très beau, et par la taille on lui donne toutes les lormes voulues. - Selon Descourtilz, les feuilles passent pour un excellent vulnéraire; l'huile, extraite des fruits, est très émolliente, et la décoction des fleurs

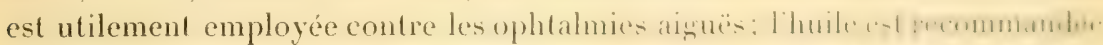
dans les lavements qu'on administre contre les colicpues, le- irritations intetinales même, causées par la présence d'un tienia, el contre le lénesme el les douleurs dysentériques. - Peu abondant: Anse-Bertrand (hord de mer), Port-Louis. [No 3788.]

Martineue. Vulgo : Olivier bord-de-mer, olivier de pays. - Beaucoup plus abondant qu’à la Guadeloupe. - On en fait souvent des haies vives, qui, soumises à une taille régulière, deviennent très belles et très toullues. - Fl. toute l'année. - Rivière-Salée, Lamentin, Ducos, Trois-llets, Précheur, Trinité. Alt. 0-120 mèt. [No 1959 .

\section{MONOCOTYLEDONES,}

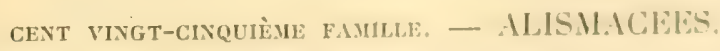

Echinodorus Rich. (du gree "echinos ", hérisson, ef " dorns", nutre cul cuir, sac, parce que les fruits, de la consistance du cuir, forment un cappilute heri-si de pointes.) 
E. cordifolins Griseb., E. rostratus Engel.; Echinodore à feuilles en creur. Vulgo: Plantain d'eau. Pl., éd. Burm., 1. 234, l. 2. Alisma Berteroanum Balb.) - Herbe aquatique, haute de $30-70 \mathrm{~cm}$., très droite, it racines fibreuses, trìs nombreuses et longues. Feuilles radicales, rosulées, cordées-rondâtres, ondulées ou subcrénelées sur les bords, un peu plus larges que longues, à sinus très ouvert, à 7-9 nervures, très longuement pétiolées, à pétioles creusés en gouttière vers la base. Fleurs blanches, en capitules oroüdes, pédicellés, verticillés par 3-9 sur des branches opposées-décussées et terminées par des ombelles, formant ensemble une large panicule pyramidale, portée sur une hampe radicale, pentagone, vigoureuse, lisse ; sépales 3 ; pétales 3 , imbriqués; étamines 12-15; ovaires très nombreux, insérés sur un réceptacle ovoïde; carpide à 10-12 sillons, surmonté du style persistant, durci, qui forme une pointe crochue. - Fl. de janvier à juillet. - Peu répandu. Dans les mares d'eau douce : à Marie-Galante Grand-Bourg, habitation Maréchal, et à la Capesterre.) [ $\left.\mathbf{N}^{\circ} 3652.\right]$ - Il n'existe pas à la Martinique.

\section{CENT Vingt-sixiène FAMLLE. - HYDROCHARIDÉES.}

Limnobium Rich. (du grec " limné ", étang, et " bioun ", vivre, c'est-à-dire plantes qui vivent dans l'eau.)

L. stoloniferum Griseb, ; Limnobie à racines stolonifères. Vulgo : Herbeétang, herbe-mare. - Vivace, llottant, stolonifère, d'un aspect gris, long de 10-15 cm. Feuilles petites, flottantes, ovales-oblongues ou ovées-rondâtres, spongieuses en dessous et faites pour flotter ainsi que les longrs pétioles. Fleurs unisexuées, petites, blanchàtres, solitaires, portées sur des hampes filigranes; sépales 3 ; pélales 3 , presque filiformes et une fois plus longs que les sépales; étamines 6 . - Çà et là dans les petits étangs d'eau douce de Sainte-Anne et de la Caravelle. Alt. 10-80 mèt. [No 1959.] - Je ne l'ai pas trouvée à la Guadeloupe.

\section{CENT Vingt-SEPTIÈme FAMille, - NAJADÉES.}

Potamogeton L. (du grec "potamos ", fleuve, et "geiton ", voisin, parent, parce que ces plantes ont une vie essentiellement aquatique.)

P. fluitans Roth; Potamol nageant. Vulgo : Herbe d'eau, herbe-rivière. Vivace, vivant immergé dans l'eau douce courante, à tige prolifère, filiforme, s'étendant à une distance indéterminée. Feuilles cartilagineuses, longuement pétiolées : les plus proches de la racine, flottantes; les autres, submergées. lancéolées-oblongues, garnies de stipules. Fleurs glomérulées, en épi inter- 
rompu, porté sur un long pédoncule vigoureux, comprimé. - 1)ans le canal

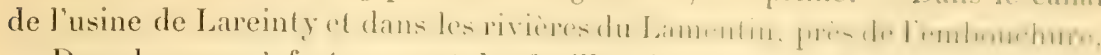
- Dans les eaux à fort courant, les leuilles sallongrent el deviennent lancén-

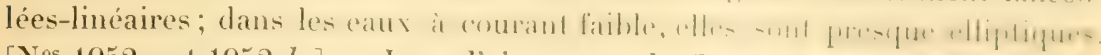
[Nos 1952 a et 1952 b. — Je ne l'ai pas vu it la Guadeloupe.

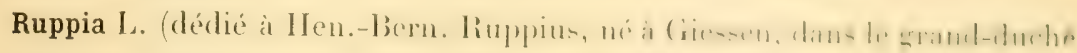
de Hesse-Darmstadt, mort en 1719; a écrit la Flore d'léna.

R. maritima L.; Ruppie maritime. - Petite herbe vivace, it rhizomu

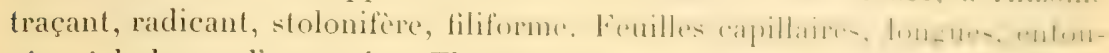
rées, à la base, d'une gaine. Fleurs et fruits incomnus. - V'il dans l'eau de mer, dans les endroits peu profonds et vasenx : Marin, Sainte-Anne. SainteLuce, Trois-Ilets, etc. [No 1953.] - Je ne l'ai pas vue à la Guadeloupe.

Gymodocea Koen. (du grec "kuma », onde, el "dokeuin », observer, parce que ces plantes se rencontrent dans l'eau de mer.)

C. manatorum Aschers.; Cymodocée des Lamantins (manalus, lamantin). - Herbe vivace, stolonifère, à rhizome rampant et articulé. Feuilles très nombreuses, linéaires, longues de $40-48 \mathrm{~cm}$, engrainées à la base. Fleurs ef

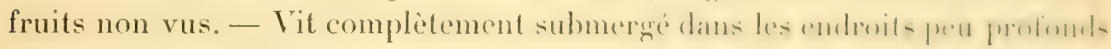
et vaseux : Saint-François, Sainte-Anne, Cul-de-Sac (Pointe-ì-Pitre), elc. [No 3801.$]$

Martinique, - Trois-Ilets, Robert, François, Rivière-Salée, elc. TXo 19.4.

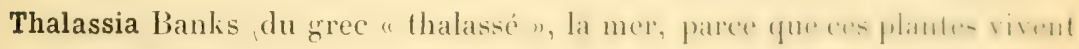
dans l'eau de mer.)

T. testudinum Koen.; Thalassie des tortues, - Vivace, it rhizome rampant, gros, d'une longueur indéterminée. Feuilles rosulées, en forme de ruban, longues de 17-35 cm. sur 4-5 cm, de large, très vertes, enveloppées, à la base. d'une gaine membraneuse. Fleurs dioïques. Fruits non vus. - Extrèmement abondant dans l'eau de mer, près du bord et dans les endroits peu profonds

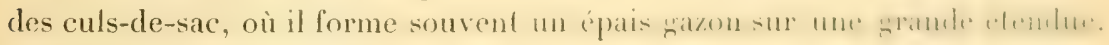
[No 3803.$]$ - Martinique. [No 1956.]

$$
\text { CENT VINGT-HUITIÈE FAMHLE. - AROIDDlíS. }
$$

Anthurium Schotl (du grec "anthos ), lleur, et " oura ", quetre, parce que ces plantes ont une inflorescence en spadice allongé el cylindrique, ressemblant à une queue de serpent.)

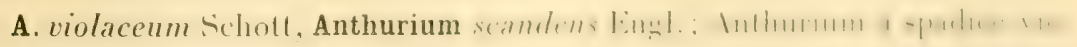
let. Vulgo : Siguine violet. - Vivace, rampant ou grimpant sur les arbresel 
les pierres, haut de $30-70 \mathrm{~cm}$. Feuilles longues de $250-32 \mathrm{~cm}$. sur $7-9 \mathrm{~cm}$. de larre, enveloppées, à la base, d’une bourre fibreuse, elliptiques-lancéolées, entières, pointues au sommel, rétrécies à la base, it nervure unique, très large et aplatie en dessus, en carène en dessous, nervilles communiquant avec deux ares filiformes, dont le premier est tries près et le second ì quelque distance du bord; pétiole court, amplexicaule épaissi el géniculé au sommet. Pédoncule axillaire, court; spadice violet, droit, long de 12-13 cm., cylindrique, graduellement atténué vers le sommet obtus; spathe verte, entière, plane, presque aussi longue que le spadice, réfléchie, lancénlée, brusquement pointue au sommet. - Peu abondant : cà et lì dans les hauteurs pierreuses de Deshaies et des Vieux-Habitants. [No 3787.] - Il n'existe pas à la Martinique.

A. lanceolatum Kth; Anthurium à feuilles lancéolées. Vulgo: Petite Siguine. Pl., Descript., t. 62. - Se distingue du précédent, auquel il ressemble: par l'abence de la tige; par ses feuilles vert päle. plus longues, plus larges, nettement lancéoléer et lentement rétrécies ì la base; par les arcs, dont l'un est aussi près du bord que possible, et l'autre à une assez grande distance; par sa spathe, plus courte et plus étroite. - Abondant dans les endroits secs, pierreux des hauteurs des Trois-Ilets. X's 22143, 2144. - Je ne l'ai pas trouvé à la Guadeloupe.

A. Inegelii Schott: Anthurium re Iluegel. Vulgn : Sirnine rouge. - Plante très ornementale, épidendre, à tige très courte, à racines nombreuses, vertes. cylindriques, de l'épaisseur d'un crayon : les unes pendantes, les autres altachées au tronc, souvent longues de 10-12 mèt., si les pieds se trouvent dans le haut diun arbre. Feuilles rosulées, nombreuses, longrues de (1) 601-1 met. sur 15-37 cm, de large, cartilagineuses, très vertes, obovales-oblongues : celles du centre, plus courtes: toutes formant ensemble une raste corbeille, à ouverture de $60-80 \mathrm{~cm}$. de diamè., a nervure médiane. tris large, aplatie en dessus, fortement caréne et saillante en dessous, à nervures secondaires de 9-12 paires, courbes, alternes, distantes: are maryinal aussi pres que possible du bord; pétiole robuste, court, bossu au sommet, du côté du dos; pédoncule radical, latéral, un peu plus court que les leuilles, relativement faible, d'abord plus court, ensuite plus long que le spadice. Spadice violet. uni à la base, d'une odeur très suave à l'époque de la floraison, long de 30$40 \mathrm{~cm}$., d'abord droit, ensuite penché en dehors de la corbeille. - Fleurs stériles, dans la partie supérieure et terminale; étamines vert clair. Fruit long de $3 \mathrm{~mm}$. sur $1 \mathrm{~mm}$. d'épaisseur, violet avant la maturité, laissant voir, a travers la pulpe gluante et transparente, les deux semences noires, juxtaposées el munies, au sommel, d'une tache verte. - Fl. de février à mai ; fruits mûrs en juin, juillet. - Avec les racines, on fait des liens, des paniers, quelquefois des nattes grossieres; certains niseaux des bois se servent de la hourre fibreuse qui enveloppe les pétioles pour construire leurs nids, et des 
pédatinerviés: à $7-9$ paires de nerrures qui, ainsi que la grande côte, sont plus saillantes en dessous qu en dessus: pétiole viroureux, pourant mesurer jusqu ì $81 \mathrm{~cm}$. de longr, légèrement cannelé en haut: pédoncule plus court ou plus long que le pétiole. Spathe longue de 18 -2: $\mathrm{cm}$., lancéoléc-linéaire, pointue au sommet, rétrécie à la base, pendante; spadice long de $74 \mathrm{~cm}$., effilé, violet, d'abord droit, ensuite pendant. Fleurs à odeur suave : les fertiles situécs sous le premier quart inférieur du spadice. Fruit violet avant maturité ensuite blanc, - Tree ses racines, longues et filiformes, on fabrique aussi des panier's et quelquefois des natles. - Abondant dans les bois des Bains-Iaunes, du Matouba, des Trois-Rivières, des hauteurs de Bouillante, ete. Dans les bois des Bains, jai trouvé plusieurs pieds à spadices jaunatres. Alt. 380-800 mèt. [Nos $3296,3606$.

Martinique. Vulgo : Grande Siguine. - Dans tous les grands bois. [No 524.]

A. palmalum kunth: Anthurium à lenilles palmées. Vulgon: Bénéfice (au Norne-àtl'Eau et à la Ravine-Chaude), Gagne-Petit (partout ailleursi. Pl., Descript., t. 64, 65. (Pothos L.) - Vivace, grimpant, radicant, haut de 3-5 met., très ornemental, sans branches ou rarement branchu, à tige cylindrique-comprimée. Feuilles très vertes, ramassées à l'extrémité de la tige. coriaces : celles des jeunes pieds, entières, petites, elliptiques, ensuite ovéeselliptiques, pointues, puis trilobées, plus tard 5-lobées, à l'âye adulte 7-9, et plus rarement 11-partites, à segments lancéolés, pointus : les plus longs mesurant jusqu à $\mathbf{~} \mathbf{l} \mathrm{cm}$. de longr; pétiole rigoureux, légèrement cannelé en dessus, variable quant à la longueur, habituellement plus long que les feuilles: pédoncule délicat, cỵlindrique, penché, environ de la mème lonğneur que le pétiole. Spathe linéaire, acuminée. Iongue de $14-16 \mathrm{~cm}$. sur $6-7 \mathrm{~cm}$, de large, d'abord aussi longue que le spadice, ensuite plus courte. Spadice riolet, odorant, recourbé au sommet, nu à la base, sur une petite étendue. - Fl. en avril, mai, et aussi en octobre et novembre. - Grands bois humides : Ravine-Chaude, Trois-Rivières, Pointe-Yoire, Morne-it-l'Eau bois marécageux du canal des Rotours et Vieux-Bourg). Alt. 0-600 mèt. [No 3274.]

Martnique. Vulgo : Bénéfice. - Bois de la Grandl Inse, de Sainte-Marie. de la Régale: çà et là dans les bois des environs de la fontaine l)idier, etc. $\left[\mathrm{N}^{\circ} 520\right.$.]

LiAnthurium gracile Lindl., petite espèce très belle, originaire de la Trinidad, est cultivé au Jardin botanique de Saint-Pierre.

Noтa. - Les fruits de tous les Anthurium que j’ai observés sont, avant de tomber, surpendus, pendant plusieurs jours, à un fil mince, qui s'allonge peu à peu et peut atteindre jusqu’à $11 \mathrm{~mm}$. de long.

Monstera Ad. (l'origine de ce nom nous est inconnue.)

M. pertusa de Vriese; Monstera at feuilles percées de trous. Vulgo : Bois 
de couleuvre, liane franche, liane percée, carnal. Pl., Descripl., 1. ät, st; Desc, vol. III, t. 229, p. 351 . - Vivace, rrimpant, it lige colin-

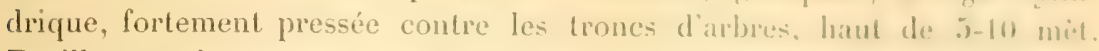
Feuilles membraneuses, orées, entières : les plus grandes mesurant jusqu ia $45 \mathrm{~cm}$. de long; les jeunes, sans trous; les adultes, percées de 3-7 trums oralesarrondis, obliquement situés; pétioles longrs, engainants, ḋirrís du sommel à la base. Spathe pédonculée, verte dans sa partie inférieure et grosice, blanc jaunâtre par le haut et large; spadice d’abord blane, ensuite trè̀ lérèrement jaunâtre, libre, portant des fleurs fertiles de la base au sommet, environ une fois plus court que la spathe; étamines '́l'. - Assez abondant sur le's arlorés de la région inférieure des grands bois des Bains-Jaunes, du (rommier el derbords des rivières Noire et liouge. - Fl. de septembre it janvier. - L.eracines, filiformes et longues, servent ì faire des cribles, des natles et des liens, - Alt. 300-600 mèt.; rare it une altitude moindre. [X 33301.

Martinique. Vulgo: Siguine-couleuvre. - Le suc de la racine est un alexitère interne, et sert dans le pays contre la morsure du serpent. - Parnasise.

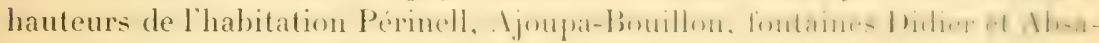
lon, la Régale, etc. $\left[\mathrm{X}^{\circ} 522\right.$.

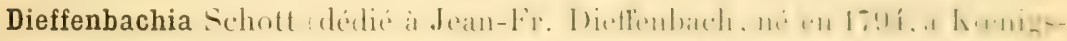

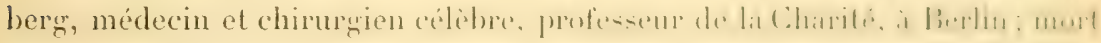
en 1842.)

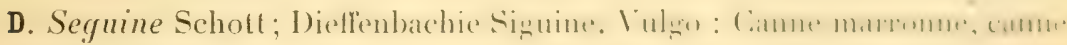
brûlante, canne-rivière, canne-siguine. Pl., Descript., t. 61, 51; Jacq., Sel. Am. stirp. hist., t. 151. - Vivace, stolonifère, généralement droit, haut de $0^{\mathrm{m}} 90-1^{\mathrm{m}} 90$, rarement plus haut, à tige cylindrique, marquée de cicatrices

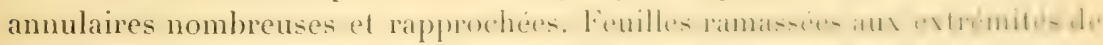
la tige, larges, ovées-oblongues, pointues, souvent marquées de taches blanches, engainantes, peu nombreuses, à 9-15 paires de nervures; spathe

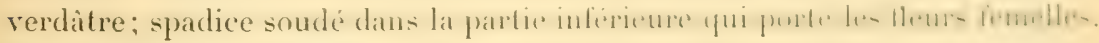
libre dans la partie supérieure qui contient les fleurs mâtes. - loe sue de toute la plante est extrêmement caustique ${ }^{2}$. - Abondant et vivant sourent en société dans les lits et sur les bordsdes rivières, dans les mares, les útangs et endroits aquatiques: environs de la Basse-Terre, Camp-dacob, PointeNoire (le long de la rivière), Pigeon, Lamentin (canal et marécagres), Pointeà-Pitre, Gozier, Sainte-Anne, etc. Alt. 0-600 mùt. [No 3790 .

1. Ce spadice derient, à l'égal du fruit de l'ananas, succulent dans toutes se's parties et si agréablement parfumé (odeur de fraise et d'ananas), qu'on le consumme injinurd hui conramment, même quand la maturation de ce fruit a dít obtente artilicieflement dans nom serres chaudes de l'Europe. (E. II.)

2. Cette espèce, conmune de Cayenne, entrerait, d'aprés Baillon, dans la compuntum du curare de la Guyane française. Elle est comme dans ce pays sous te nom de canne-fen.

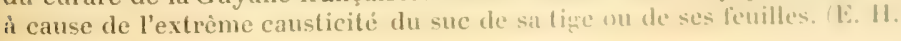


Martmeue. Vulgo : Siguine d'eau, canne d'eau. - Très abondant. $\left[N^{\circ} 2149 \mathrm{~b}.\right]$

Le Dieffenbachia Barraquiniana Vessch. el Lem. (IIl. horlicole, anno 1864), a feuilles panachées, a été introluit d'Amérique tropicale et se cultive dans beaucoup de jardins comme plante d'ornement.

Montrichardia Crueg. lorinine de ce nom zénérique nous échappe.)

M. arborescens Schott: Arum arborescens L.: Montrichardie arborescente. Vulgo : Malanga-gratter, malanga-rivière. Pl., Descript., t. 60, 50 g. - Vivace, stolonifère, droit, haut de $2-2 \mathrm{~m} 80$, à tige cylindrique, nue, d’une épaisseur de $\mathbf{1}-\mathbf{J}$ cm.. marquée de cicatrices annulaires. Feuilles ramassées au sommet de la tige, très vertes, luisantes, polies, membraneuses, sagittées, à lobes arrondis-pointus, plus longs que la nervure médiane, divergents; pétiole plus long que la feuille, portant une gaine large, qui prend naissance au milieu de ce pétiole et se dilate graduellement vers la base, à veines communiquant avec un are marginal. Spathe verte en dehors, blanche en dedans et pourpre à la base, à moitié enveloppée par une bractée. Syadice longr de 7-9 cm., libre, pédonculé, à pédoncule presque aussi long que la spathe, entierement couvert de fleurs: les mâles, dans le haut, et les femelles, dans le bas. - Après la chute de la spathe et des fleurs mâles, la partie dı spadice portant les fleurs femelles forme, une sorte de cone ovoïde, grand, contenant des semences anguleuses, blanches et farineuses en dedans, de la grosseur d'une prune. Elles sont comestibles 1. - Fl. d'arril à juillet; mais en certains endroits, les pieds fleurissent toute lannée. Il faut environ six mois pour la maturation des fruits. - Vit en société dans les endroits inondés et aquatiques, le long des rivières et des fossés remplis d'eau de la basse région : environs de la Pointeà-Pitre, grand fond du Gozier, où il abonde. [Nº 3791.$]$

Mrntixice. Vulgo: Malanga bàtard. malanga deau. - Endroits aquatiques, de Duçns, du Petit-Bourç, du François, du Robert, etc. [No 999.]

M. aculeatum Crueg. ; Montrichardie à piquants. Vulgo : Malanga sauvage. - Ressemble au précédent quant à la taille, au port, ete.; il en diffère par les tiges garnies de petits piquants et par les lobes basilaires des feuilles plus divergents. - Mème habilat et mème époque de floraison. [No 3792.]

Martinique. Vulgo : Malanga d'eau. - Ducos, Sainte-Luce, RivièrePilote, etc. $\left[\mathrm{N}^{\circ} 1000\right.$.

Philodendron Schott (du grec "philein n, aimer, et "dendron ", arbre, parce que ces plantes grimpent sur les arbres.)

1. Cette espéce, connue d̀ la Guyane sous le nom vulgaire d" "Arum du pays ", donne un suc corrosif employé contre les cors et les verrues : les ménagères s'en servent aussi pour marquer le linge. (E. H. 
P. dispar Schott, P. Karstenianum Schotl; Philodendre dissemblable. Vulgo : Siguine rouge, liane à hébichet. Sl., t. 27, f. 3; Plum., édit. Burm..

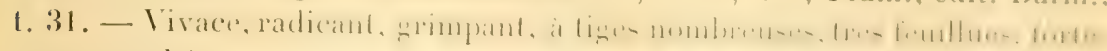
ment attachées aux trones des arbres, haut de $1-6$ met. Fenilles allernes, lar-

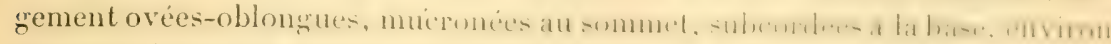

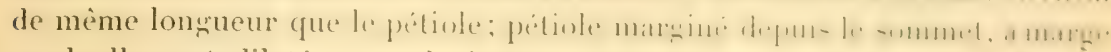
graduellement dilatée vers la base el formant une larrge gouttière. Spathe verte en dehors, concave, blanc jaunâtre en dedans, longue de $17-19 \mathrm{~cm}$.; spildice blane, libre, un peu plus court que la spathe, acuminé vers le sommet. Fleurs mâles, situées dans la partie supérieure; les femelles, i la base, sépatrées des mâles par un espace contenant des fleurs stériles; pédoncule frarni

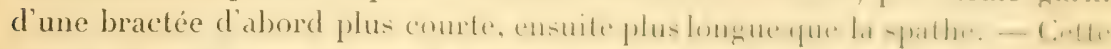

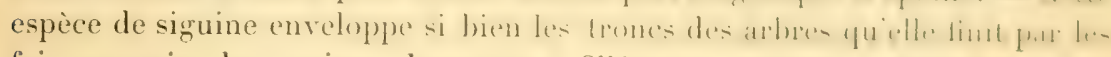
faire mourir; les racines, longues el filiformes, servent it faire des petit:

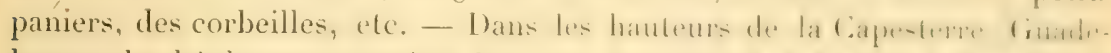

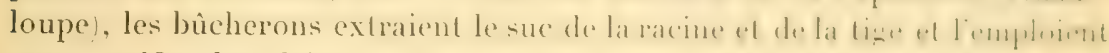
pour purifier les plaies. - Fl. à diverses époques de l'année. - Assez ahon-

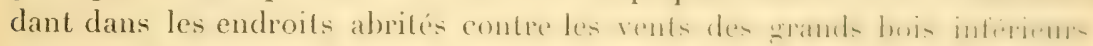
Camp-Jacob (environs de la cascade de Tauchelet), falaises de la rivière Rouge, Gommier, Trois-Rivières. Alt. 300-700 mè. [No 3297.]

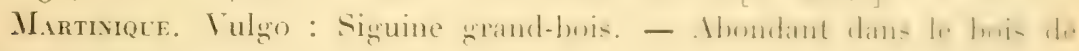
l'Ajoupa-Bouillon, près des bords de la Capote, Champflore, fontaine Didier, ete. $\left[\mathrm{N}^{\circ} 2149 \mathrm{~b}\right.$. $]$

P. hederaceum Schott; Philodendre grimpant comme le lierre. Vuleno: Liane brûlante, herbe à méchant. Desc., vol. III, L. 168, p. 71; Plum., Descript., t. 55, 51 d; Jacq., Sel. Am. stirp. hist., t. 159. - Vivace, grimpant, haut de 15-20 mèt.; à tige glabre, cylindrique, d'une épaisseur de

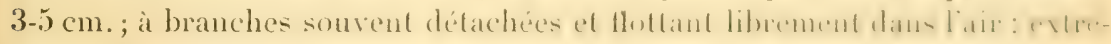
mités des rameaux terminées par un bourgeon pointu el allongé. Feuilles

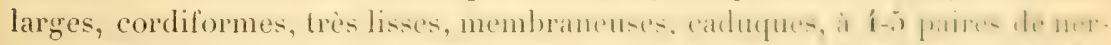

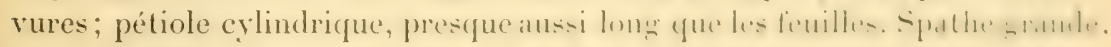

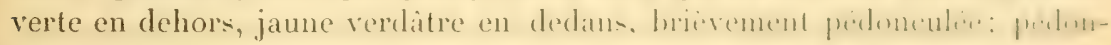
cule axillaire, naissant à la base des feuilles, long de $111-12 \mathrm{~cm}$., plus longr que le spadice; spadice cylindrique, un peu plus court que la spathe. - Ia plante est toxique, corrosive; dans le pays, on n'en fail aucun usagre. - lil. en avril, mai, juin. - Çà et là dans presque tous les grands bois : Camp-

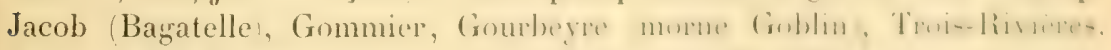
hauteurs des Vieux-Habitants. All. 400-800 mèt. [X 103791.$]$

Martinique. Vulgo : Siguine-liane, siguine rouge. - Asse abondant.

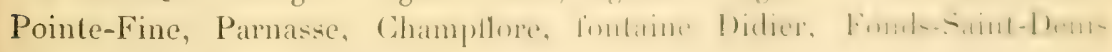
(Porteade-l'Enfer). [No2119c. $]$

P. giganteum Scholt; Philodendre géant. Vulgo : Siguine blance- 
Vivace, terrestre ou arboricole: it tige couchée, longue de $20-30 \mathrm{~cm}$., souvent plus longue, très épaisse et volumineuse; à racines funiformes, vertes, très longues, quand les pieds sont grimpants. Fenilles vert bronzé, luisantes, atteignant jusqu’à $85 \mathrm{~cm}$. de long sur $25-30 \mathrm{~cm}$. de large, cordées à la base; à sinus profond, arrondi; a lobes arrondis, larnes: i nervures médianes carénées en dessous : les nervures secondaires, à cinq paires, aplaties en dessus, saillantes en dessous; pétiole cylindrique, gros, diminuant de volume du sommet a la base, un peu plus court que le limbe de la feuille et enveloppé, à la base, d'un tissu fibreux qui, en mème temps, courre partiellement la tige. Spathe d'abord sessile, ensuite brièvement pédonculée, enveloppée d'une bractée très larre, bifide, roussâtre et portant sur le dos une large aile Inngitudinale : partie inférieure de la spathe, verte, ventrue-ovale; la partie supérieure, très blanche. Spadice tres blanc, exhalant une odeur forte et suave, longr de 15$18 \mathrm{~cm} .$, un peu plus court que la spathe. Fleurs disposées comme dans les précédents. - Fl. rarement et ì des époques indéterminées. - Les feuilles, membraneuses et de consistance forte, se récoltent et se vendent dans les magasins dépicerie, où elles servent à envelopper toutes sortes de denrées. - Très abondant dans les bois supérieurs : Savane à Mulets (source du Galion), cone de la Soufriere, oi il est souvent rabougri, Matouba, Matelyane, Savane aux Ananas, etc. Alt. 400-1400 mèt. [Nos 3303, 3626.]

Martixieve. Vulgo : Malanga bâtard, chou caraïbe sauvage. - Plus rare qu'à la Guadeloupe : Prècheur habitation Céron, sur les rochers), vallée du Carbet, Lamentin Roches-Carréesi. Rocher du François. Alt. 150-400 mèt. $[\mathrm{N} \circ 517$.

Acontias Scholt idu gree "akontias ", mol par lequel on désignait une espèce de serpent, allusion à la longueur du pédoncule qui porte le spadice, ou aussi à la couleur des pétioles.)

A. helleborifolius Schott, Xanthosoma helleborifolium Schott: Acontias a feuilles d'Ellébore. Vulgo: Malanga bâtard, malanga-poison, malanga-cochon. - Herbe acaule, virace par ses tubercules, droite, ornementale, haute

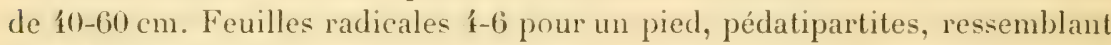
bien à celles de l'Ellébore de France, sauf la couleur; à 5-11 segments lancéolés-oblongs, pointus : les extérieurs beaucoup plus petits; a nervures communiquant avec un arc marginal; pétiole panaché ou bariolé de blanc pâle, de brun et de vert; pédoncule radical, plus court que les feuilles. Spathe dressée, blanc pâle, corymbiforme, allongée et pointue; spadice blanc pâle, plus court que la spathe. Fleurs mâles, à anthères connées au milieu. - Les tubercules sont arrondis, jaunes en dedans et ne se mangent pas. - Dans le pays, on les pile, et avec le sue on se frotte les parties du corps affectées de douleurs rhumatismales.- Dans les caféières de Ilouëlmont, du Camp-Jacob, du Gommier, de Gourbeyre, des Trois-Rivières, ete. Alt. 20-600 mèt. [No 3295.] 
Mantisique. Vulgo : Chou-diable, calalon-diable, - Truis-P'mes pare du

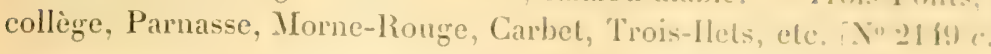

Xanthosoma Schotl (du gree "xanthos", jaune, el "soma ", corp)s, paree que les stigmates sont couverts d'une sorte de mative jaune et visquense.

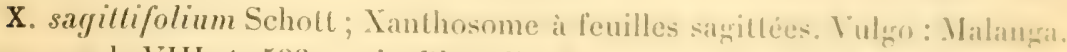
Desc., vol. VIII, t. 533, p. 4; Pl., édit. Burm., 1. 3.5. p. 21. - Vivace, it tige nulle ou très courte. Feuilles très larges, vert clair, satrillés, it lobes basilaires, pointus, presque en triangle; spathe jaune serin, acuminé, plus longue que le spadice, blanc pâle, teinté de jaune. - H. habituellement de septembre à décembre. - Cultivé dans toutes les Antilles comme plante

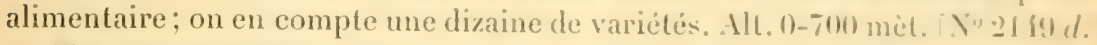

- Martixique. Vulgo: Chou-caraïbe.

$\mathbf{X}$ hastifolium C. Kioch, $\mathbf{X}$. hastatum Eirg.; Xanthosome it lenilles an forme de hallebarde. Vulgo: Calalou, zherbe it calalou. - Vivace, it feuilles

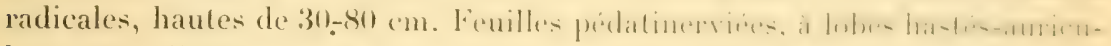
lés et très divergents, à sinus très ouvert. Spathe, blanche dans sa partie supérieure, longue, pointue; verdâtre, slans sa partie ventrue; spadice hlanc. un peu plus court que la spathe. - Les tubercules sont blanchattres, as:ien. gros el légèrement rugueux; cuits, on les donne habiluellement aux pores:

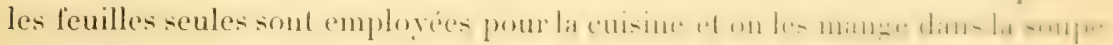
comme le chou ordinaire de lrance; elles servent, en outre, anec les leuilles de l'espèce précédente, de base à plusieurs mets particuliers aux colonies. entre autres au fameux Calalou. - ( )n appelle Calalnu un met exquis pri-

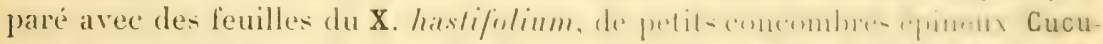

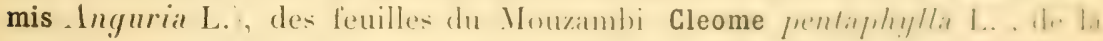
petite valériane, à feuilles argentées en dessous, vulgrairement nomméc l'ata-

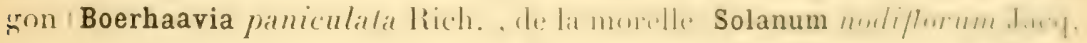
du pourpier, de l'oseille de France, des feuilles tendres de patate, des jeunes

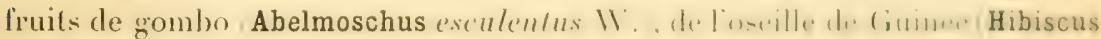

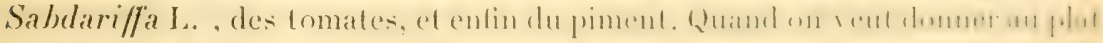
encore plus de relevé, on ajoute un peu de vin blance, quelques clous de girofle, un peu de muscade et d'écoree de eamnelle ràpés. On doit cuire le tout avec du lard, un os de jambon, du beeul salé on des crabes vulpon: Ciriques). Le Calalou est toujours servi avee du riz cuil, en grains. - H. ch

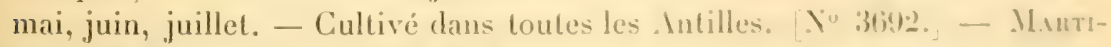
sigue. Vulgo: Calalou. [No 2149.

X. atrovirens C. Koch el Bouché: Xanthosome it leuilles d'un noir vert. Vulgo : Malanga sauvage, malanga bâtard, malangritcochen. Sl., I. Illi. f. 2 (ex parle). - Vivace, a tige nulle ou tres courte, meme is liatat adulte. Feuilles d'un vert noirâtre, sagrittées, à lobes pointus et divergents, limbeà huit paires de nervures, reliées par un are marginal. Spathe ruse; ya- 
dice blane, odorant, latéralement comprimé. -- I.estubercules de cette espèce sont assez fortement rugueux, mais cuits ils peuvent servir de nourriture aux porcs. - Dans les haies, et le long des routes et des ruisseaux : route de la Basse-Terre à Montéran et à Gourbeyre, Trois-Rivières, Lamentin, BaieMahault, Pointe-à-Pitre, Marie-Galante, ete. Alt. 10-500 mèt. 「Yo 3795.

Mantixiger. Vulgo: Chon-cochon, chou batard. - Saint-Pierre Boulevard, Grande-Rivière, Basse-Pointe, Trinité, etc. (Spécimen manque.)

Colocasia Schott (de "kolkas " ou "kulkas ", mot arabe pour désigner une espece de colocasia. Le vari holokasion des Anciens est le Nelumbo speciosus, composé du mot "kolon ", nourriture, et "kazein ", orner, c'est-àdire racine qui sert de nourriture, et fleur qui sert à orner.)

C. esculenta Schott, C. antiquorum Schott: Colocasie mangeable. Vulgo: Madere. (Arum 1.) - Introduit des Indes ()rientales el cultivé dans toutes les Antilles; is lubercules pondatres el noirâtres en dehors. Feuilles radicales, très difléreutes de celles du Malaza. peltées, cordées à la base, oblongues, pointues, à veines principales reliées par un are maryinal. Spathe légèrement jaunatre; spadice odorant, libre, nu it la base. F'leurs miles dans le haut et les femelles dans le bas, les unes séparées des autres par un espace à fleurs stériles, visqueuses, noires. - Fl. de septembre à décembre. - Cultivé dans toutes les Intilles comme plante alimentaire. - Les feuilles de cette espèce ne se mangent pas. Du corps du tubercule qui, comme celui du Malanga Xanthosoma sagfllifulium, peut devenir très gros, partent une masse de tiges soulerraines, allongées, pyriformes-obconiques, pouvant alteindre jusqu à $35 \mathrm{~cm}$. de long : les grosses se détachent pour être livrées à l'alimentation; les petites, on les laisse en terre pour aroir de nouveaux pieds. L'extérieur des tubercules de Madères est uni et presque poli; celui du Malanga est rugueux. Les Madères aiment les endroits frais et humides. Alt. 0-700 mèt. [No3796.]

L'Alocasia macrorhiza Schott, variété foliis variegalis (Ill. hort., ammo 1861), a leuilles larges, panachées de blanc sur fond vert it lige cylindrique, marquée de gros anneaux, haute de $0^{m}$ in-1 met. et au delì, ì suc tres caustique, a été introduit comme plante domement et est devenu extrémement abondant. Il est originaire des Indes Urientales, particulicrement de l'île de Ceylan.

Galadium Vent. imol indien employé d'abord par lihumphius pour désigner lArum esculentum ou Madere, el dont Ventenat s'est servi pour faire le genre Caladium.)

C. bicolor Yent.; Calidium a deux couleurs. Vulgo : Madère bâtard, petit Madire. - Vivace, haut de 15-35 cm., très ornemental et remarquable par ses feuilles diun rouge cramoisi très vil au milieu du limbe, passant assez 
Lemna L. (du grec " limné », étang, allusion à l'habitat de la plante.)

L. paucicostata IIegelm.; Lemna à peu de côtes. - Très petite plante flotlante, d'un aspect criss, qui forme ì la surlace des étangs et des mares d'eau douce une couche plus ou moins épaisse qui conserve l'eau fratche el limpide. Fenilles 2-3, longues de $1.5 \mathrm{~mm}$, ovales, épaisses; racines capillaires longues de 3-6 mm. - Etangs de Sainte-Amne, hauteurs des Trois-llets, Vauclin, etc. [YYo 2148.] - Il n'existe pas à la Guadeloupe.

L. Valdiviana Phil. - - Jifrère extéricurement du précédent par ses racines plus longues et ses feuilles plus minces. -- Camp-Jacob) (ruisseaux de la ravine Malanga, où il abonde), Marie-Galante (Cipesterre), les Saintes. No 330.2.] - Je ne l'ai pas vu à la Martinique.

\section{Cent Ingt-Neuviène paslle, - CICLANTHÉES.}

Garludovica R. P. (dédié à Charles IV, roi dWespanne, né en 1748, a Naples, mort en 1819, à Rome, el à son épouse, Marie-Louise, née en 1751, ¿̀ Parme, morte en 1819, tous deux protecteurs des botanistes.)

C. Plumieri Kith.; Carludovice de Plumier. Vulgo : Ailes à mouches. Pl., Descript., t. 59, f. c. - Vivace, radicant, grimpant à une grande hauteur, à racines libreuses, longues, à tige comprimée, verte. Feuilles rosulées, allongées, rétrécies à la base, de longueur variable, selon que les pieds viennent it l'ombre ou au soleil : les plus longues mesurant 70-78 cm. sur 11-17 cm. de large, fendues dans les deux premiers tiers en deux segments, à nervure propre allant jusqu a la bilurcation; pétiole camnelć, environ trois fois plus court que les feuilles; spathe à cinq parties, blanches, distantes, alternes, concaves: les inféricures, plus longues; spadice blanc. Fleurs màles, disposées par quatre phalanges opposées aux femelles; filaments stériles f, blanes, longs, cadues, accompagnant les fleurs femelles groupées par 4 ; ovaire mûr noir, tétragone, contenant de nombreuses petites semences. - Fl. de lévrier a mai. - Mbondant dans tous les grands bers de la Guadeloupe proprement dite. Alt, 380-900 mèt. [No 3607 .

Martixigue. Vugo : Cachibou, peltau. - Dans lous les grands bois. $\left[\mathrm{N}^{\circ}\right.$ 2008.]

G. gracilis Sieb). C. angustifolia Seem.; Carludovice grêle. Vulgo : Ailes a monches. - Difrère du précédent par les lobes des feuilles plus étroites el le spadice entouré d'une spathe à trois éléments seulement. - Dans les srands bois et de préférence dans les endroits plus ou moins sees : Honëlmonl, Gommier, Trois-Rivières, etc. [No 3312.$]$

Martinece. Vulgo : Cachibou. - Fontaine Didier, Camp de lidma, bois du Gros-Morne, etc. (Spécimen absent.) 
C. insignis Duchass.; Carludorice superto. Tulun : Siguine bâtard, langüe à bouf: - Vivace, terrestre, haut de 1-2 mèt., it ligre urrosse, inrtueuse on droite, rarement couchée, garnie de nombreuses racines adventives, filiformes, grises. Feuilles beaucoup plus larges que dans les deux préceidentes espèces et mesurant (avec le pétiole) jusqu'it 1 mèt. de longr el davantage, sur $12-15 \mathrm{~cm}$. de large, bifides au sommet, it lobes arrondis, longes de $16 \mathrm{c}$ con.. et à trois côtes principales dont les deux latérales expirent au-dessonus du milieu du limbe; spathe it quatre parties, disposées comme dins les précédentes espèces, mais plus larges et plus longues. - Abondant dans les: endroits humides des grands bois : Bains-Jannes, Matouloa, Trois-Riviites, etc. $\left[\mathrm{N}^{\circ} 3804\right.$. $]$

Martinique. Vulgo : Cachibou. - Bois des Fonds-Saint-1)enis, du Camp de l'Alma, du Lorrain, elc. Yo 2$\}$.

Cyclanthus Poit. (du gree "kulilos », cercle, el "anthos ", fleur, paree que les fleurs des deux sexes sont disposées alternativement en cercles sur le spadice.)

C. Plumieri Poit.; Cyclanthe de Plumier. - Vivace, haut de $2 \mathrm{~m} 50-3$ mil.

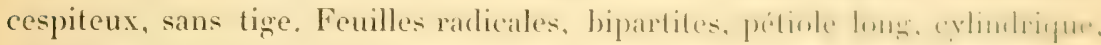
en forme de baguette, de l'épaisseur du petit doigt, lisse, verdàtre; pédon-

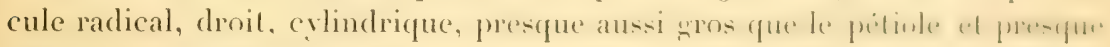
aussi long; spathe formée de quatre parties : les deux extérieures plus laryes et munies d'un appendice au sommet: spadice crlindrique, verditre, whinant. Fleurs monö̈ques : les mâles et les femelles disposées en croles alternants. - De cette plante intéressante, je n'ai trouvé que quelques grandes toulles: le long de la rivière de Ducos, près du sentier qui conduit au Petil-Bourr, et quelques touffes moins grosses sur la rivière de Sainte-Luce. - Spécimen manque. - Je ne l'ai pas vu ì la Guadeloupe.

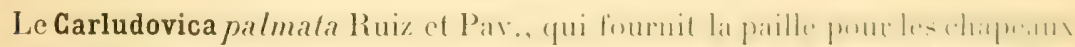

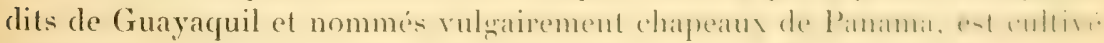
aux Jardins botaniques de la Basse-Terre et de Saint-Pierre.

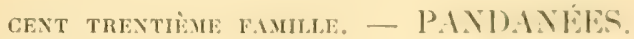

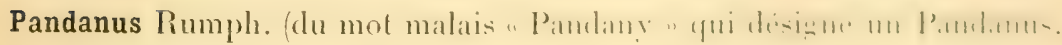

P. utilis Bory; Pandanus utile. Vulgo: Vacoua ou Bacoua. - (Ornemental : jeunes pieds, sans branches, à feuilles très rapprochées finmant une spirale autour du tronc; pieds adultes, hauts de 6-9) mil., pyramidaux, it branches nues, peu nombreuses : les inférieures horizontalement italies. marquées de cicatrices très nombreuses, très mpprochéces, it cionce griser, unie, à trone garni, à la base, de nombreuses racines adventives, crlindrique's. 
Feuilles droiles el lermes, ramassies aux extrémités des branches, imbrifuées sur trois rangrs et tournant en spirale, linéaires-lancéolécs, graducllement acuminées de la base au sommet, sessiles, finement dentelées en scie, de couleur frise. lileurs diö̈ques, situées près de lextrémité des branches : les miles apérianthées, en chatons rameux, pendants, a odeur forte et agréable. ¿ branches renfermées avant l'ouverture dans une bractée large, blanche, membraneuse, caduque, acuminée, ciliée-dentée au-dersus du milieu; étamines $8-12$. insérées au sommet sur un pédicelle long de $7-9$ mm., filiforme: pédicelles très nombreux couvrant les branches d'une extrémité à l'autre; anthires a denx loges, at déhiscence longitudinale, tournées en tire-bouchon it la maturité : les femelles insérées sur un spadice grlobuleux ou ovoïde, a stigmates sessiles, distincts. Fruits constitués par des drupes fibreuses, contenant 2-5 semences allongres, nichées séparément dans une substance très dure. In spadice peut contenir 100-180 fruits: ceux du sommet commencent à mûrir les premiers: la surface nue du spadice est converte diune matière sucrée qui attire une masse d'abeilles. - Tree les feuilles, fendues en lanieres au préalable, on fabrique des sacs, des chapeaux grossiers, des nattes, ele. - Originaire des iles de la mer du sud, introduit, naturalisé et cultivé çà et lit autour des maisons: Camp-Jacob Choisy, habitation Rollin, Capesterre (Guadeloupe), Sainte-Rose, Baie-Mahault, etc.

Mantriere. - Beaucnup plus abondant : environs de Saint-Pierre, AjoupaBouillon, Morne-Rouge, Parnasse, Fort-de-France, Trinité, ete, [Yo $2009 \%$.

Le Pandanus odoratissimus L., Desc, vol. VIII, t. 540, est cultivé aux Jardins botaniques de la Basse-Terre et de Saint-Pierre.

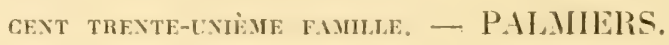

Thrinax I. f. du gree " hrinax ", éventail, allusion it la forme des feuilles.)

T. barbadensis Iondd.: Thrinax de la Barbade. Vulgo : Latanier, palmier à balai. - Très ornemental, pouvant atteindre jusqu'à 15 mèt. de haut et davantage, à stipe cylindrique, de $1 \mathrm{f}-17 \mathrm{~cm}$. de diamèt., souvent beaucoup plus mince dans les vieux pieds. Feuilles lareses, flabelliformes, palmifides, a segments loners de 10-1.2 cm., acuminés: pétiole inerme, comprimé-convexe des deux côtés, environ de la mème longueur que les feuilles, enveloppé, à la base, par un tissu fibreux, fort. Régrimes larges, unilatéraux, longs de 25-45 cm., composés de panicules partielles, pyramidales, alternes, au nombre de 4-10, très glabres, blanc mat, contenant chacune de 10-23 grappes simples, spiciformes : panicule partielle renfermée dans une graine membraneuse, fermée dans sa moitié inférieure; ouverte, acuminée, coneare dans sa partie supérieure. Fleurs hermaphrodites, blane mat, à 
odeur forte et peu agréable, altirant néanmoins une masse diabeilles: puifuncule court, un peu plus long que les étamines; périgone nul; ctamines \$-12. hypogynes, à filets subulés, élargis, comprimés el connés it la bises, un preu plus courts que l'ovaire; anthères droites, biloculatres, basifixes, bilides antix deux extrémités; pistil un peu plus court que lonvitre, dressé, lubulaxx. ćlargi et creux au sommet; oraire unique, it un soul orule. liruil frlobulaxy. de la grosseur d'un pois nu, dims les jeunes pieds, de lit dimension diune petite cerise, pulpeux, à chair noire, contenant un sue muge unir : surfice de la coque irrégulièrement sillonnée-fendillée. - Fl, deux fois dans l'annér. souvent cinq fois dans l'espace de deux ans. - Assez abondant sur les momes calcaires et sees des grands fonds du Morne-itl'Eau, du Grover, de MarieGalante, de la Désirade, etc. - Se rencontre souvent a l'état de culture: les jeunes pieds servent à l'ornementation des salons et des autels pour le:grandes fêtes religieuses. [ $\left.\mathrm{N}^{\circ} 3797.\right]$

Martixique. Vulgo: Palmier ì balai. - Hauteurs des t'rois-llets : yát et lii sur les mornes calcaires de Sainte-Anne. - Lst souvent cullive daus ler jardins.

On cultive dans les deux colonies : le T. argentea Lodd., haut de . - 10 mi. . à feuilles plus ou moins argentées en dessous; le T. radlitid londd., mrigi-

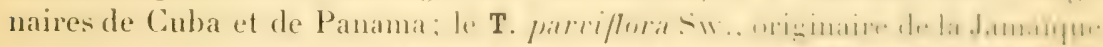

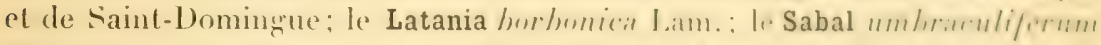

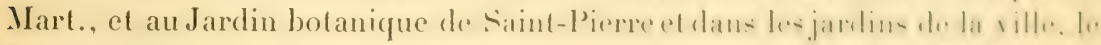

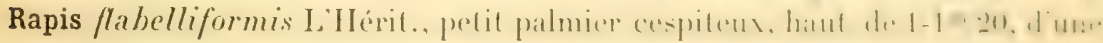
grande beauté.

Oreodoxa Willd. (du gree " oreos ", montagne, et "doxa ", grloire, cest-itdire arbre qui fait la beauté des montagnes.)

0. oleracea Mart. Areca L.); Oreodoxa dont les jeunes fleurs et leuilles: servent de légumes. Vulgo : Chou-palmiste, chou-colonne, palmiste franc. Sl., t. 215 (la leuille et le fruit); Dese., vol. IV, 1. 265 , p. 1.40; . Tact. Sel. Am. st. hist., t. 110, p. 278. - Palmier majestueux, le plus deve des

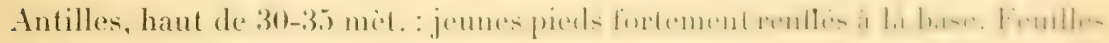
lo gues de 2m 50-3 mèt. et même au delì, penniséquées, à sergments lungst,

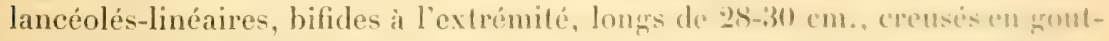
tière à la base; pétiole long, creusé ansisi en goutlière, engainant it lat hases of terminé par un tissu fibreux, très lort. Flenrs monoïques dans le mime spadice, situées à la base du cylindre formé par les gaines, disposées en larpes panicules, d'abord renfermées hermétiquement dans une spathe homgue de 60-80 cm., renflée au milien en forme de lusenu, verditre, liste, caduque: panicule blanche au sortir de la spathe, a tranches denx ou trois fois ramifiées, à ramuscules déliés; périgone double: l'extérieur ul'intérieur, lriphylles; l'intérieur, un peu plus longr; celui des fleurs mile's, imbriquí; colui 
des fleurs femelles, valvaire: itamines $6-9$; stiomates 3 , sessiles, ovaire assis sur une petite cupule 6-denté. Fruit baccien, monosperme, oblong, obtus, lexirement recourbé, blesu pourpere, de la grosscur diune pelite olive; coque dure, adhérente ì l'albumen corné, brun. - La partie extérieure du stipe, sur une épaisseur de $6 \mathrm{~cm}$., est dure, compacte et brune, et se délache facilement de la partie molle et fibreuse de l'intérieur : on s'en sert pour faire des bâtons, des lattes pour les clotures, elc. La plus jeune feuille, centrale, dont les segments ne se sont pas encore déroulés el qui émerge verticalement comme une sorte de baton, prend le nom de fleche de chou-palmiste; elle est toujours penchée du côté du vent. - Avec les feuilles, encore tendres et blanches, renfermées dans le creur de la touffe qui couronne laarbre, on prépare un aliment sain ef tres apprécié, connu sous le nom de "chou-palmiste "; il est d'un goût délicat, analogue à celui de la noisette de France, tout en rappelant un peu le gotut de l'artichaut : on peut le manger cru, mais le plus souvent on l'apprête en salade ou bouilli avec du sel et servi avec du beurre frais ou une sauce mayonnaise. A la Guadeloupe et surtout a la Marlinique, on trouve des coupeurs de chou-palmiste qui montent régulierement dans les grands bois élevés et reviemnent avee de lourdes charesesüils vendent à bon prix sur le marché. Environ deux mois après qu'on a coupé la tête du choupalmiste, on trouve, dans le stipe, une zrosse larve blanche, appelée vulgairement ver-palmiste (Calandra palmarum Fabric.) C'est celle d'un coléoptère qui pond dans la moelle: on la mange crue ou simplement rôtie, ou rôtie arec du jus de citron, du sel et du piment. Certains gourmets font grand cas de ces vers cuits sur le gril. Arec les fleurs, encore renfermées dans la spathe, on fait aussi une bonne salade, mais elle est un peu amère et ne vaut pas celle qu on compose arec les feuilles tendres. - Ce palmier n’atteint sá plus zrande dimension que dans les basse et infra-basse récions : au milieu des bois élevés, il n’arrive quà une élévation de $8-12$ mèt. - Abondant dans toutes les grandes forêts de la Guadeloupe : çà et là dans les bois des grands fonds de la Grande-Terre. Dans la basse région, on le plante souvent en allées. [No 3797.] - Mantixique. (Spécimen absent.)

Areca (nom indien " arec ", de l'arbre qui donne la noix d'Arec, et qui est Areca Catech $и$ L.)

A. regia Kith. ; Areca royal. Vulgo : Chou franc, chou-palmiste franc, choupalmiste-montagne, chou amer. - 1)roit, haut de $1^{m} 50-3$ met., dans les endroits escarpés et exposés aux grands vents, de 5-6 mèt. dans les endroits plats et abrités contre les vents, dans les régions infra-moyenne et basse, où on le renentre quelquefois. Il peut śélever à 12 mèt. de haut et même davantage. Stipe d'une épaisseur de $13-20 \mathrm{~cm}$. Feuilles longues de $0^{\mathrm{m}} 50-1^{\mathrm{m}} 80$ et au delir. à segments tres rigides et très rapprochés, surtout dans les pieds rabougris des hautes montagnes. Quand le vent soufle à travers les segments 


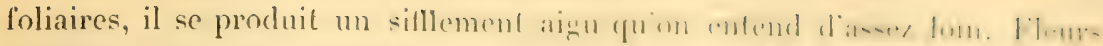

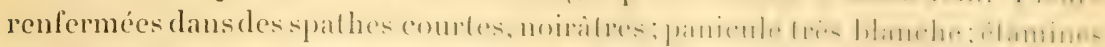

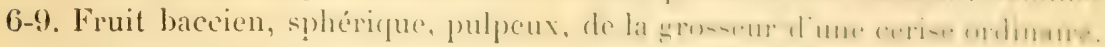
- Abondant dans la haute région aérée, où il reste raboungi. Dans la rérion

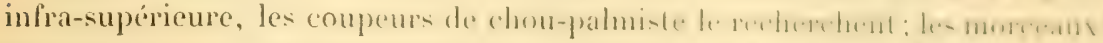

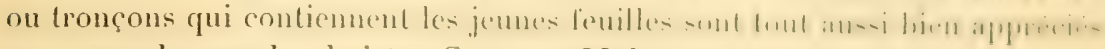
que ceux du grand palmiste: Savane a Mulets, Grande-l)écouverte. Sarane aux Ananas, Nez-Cassé, etc. [No3800.]

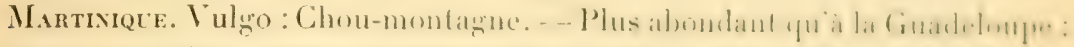

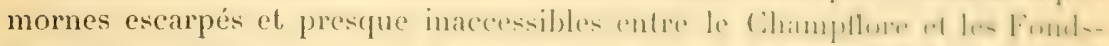

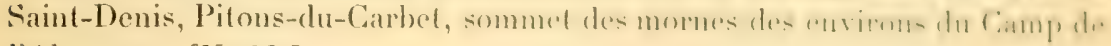
l'Alma, etc. [No 23.]

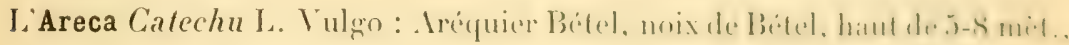
à stipe marqué d'anneaux, à fruits jaumes d'or, de la trosseur d'un pelil ceuf de poule, est assez fréquemment cultivé dans les jardins el les cours

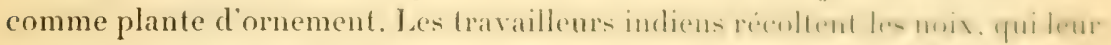

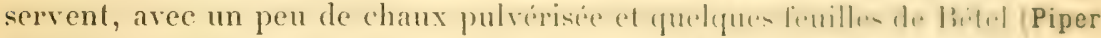

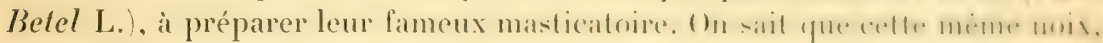

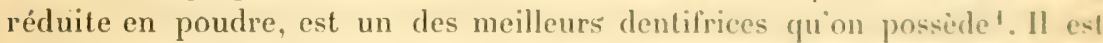

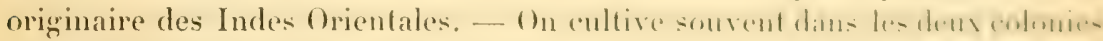
l'Areca rubra Bory, beau palmier, haut de $5-8$ mel., il slipe annele el it feuilles rougeâtres.

Acrocomia Mart. (du gree "akron ", pointe, et "liomé n, chevelure, parce

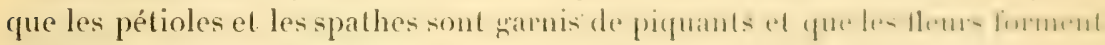
de larges bouquets dans les inflorescences.)

A. sclerocarpa Mart.; Acrocomia à fruits durs. Vulgo: 1)indé, palnier-

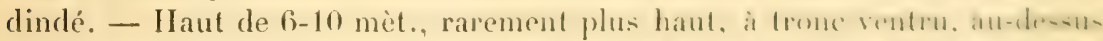
de la base dans les jeunes pieds, peru ventru ou eylindrigue dans lue pients

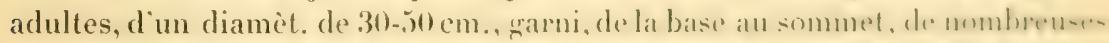

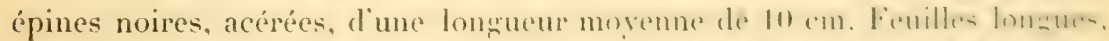

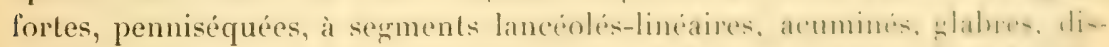

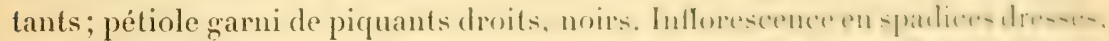

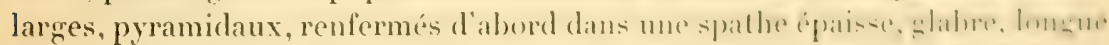
de $40-50 \mathrm{~cm}$, revêtue de piquants brun noir, très acérés, longrs de $3-$ timm. $^{2}$

1. On sait de plus que, outre ces proprictés, la graine de cet Aréguier est un excellent vermifuge : elle donne, par des ébullitions successives dansl'eau, des extraits aupux qui sont des cachous dépourvus de catéchine (Fluckiger). Cutte grane contient une luté lanrine et myristine, d'après Fluckiger), une matière tannique ronge et cimy alcaloüles isolé par Jahns, 1892), parmi lesquels l'arécoline (liquide huileux) est trés actif of donme un bromhydrate cristallisant facilement. Ce serait le principe tienifize of il arirat comme lit pelletiérine, la muscarine et la pilocarpine. Il serait intéressunt de voir si fes A. reyiat rubra, etc., renfermeraient les nèmes principes. (L. H.) 
Fleurs monnöques, insérées dans de pelites alvéoles : les mâles, siluées à lexIrémité des 80 -100 divisions de la panicule, la partie inférieure élant réservée aux lleurs lemelles, sessiles, dont deux ou trois seulement se développent; branches de la panicule droites, non ramifiées: périgone intérieur et extérieur a trois écailles; étamines 6 ; stigmates 3. Fruit see, dur, de la forme et de la grosseur d'une pomme-reinette, marqué de trois ouvertures, pres du sommel: lalbumen est blanc et peut se manger comme celui du coco. - Issez abondant : environs de la Basse-Terre (habitation Ia Jacinthe, Lamentin, SainteRose, Baie-Mahault. [No 3805.$]$

Mantinece, Vulgo : Glouglou. - 1)ucos, environs du Petit-Bourę, François. (Spécimen manque.)

Martinezia Ruiz el Pav. dédié à Balth. Martinez, archerèque de la Vouvelle-Grenade, naturaliste, et à (uer Josef y Martinez, professeur à Cadix, mort en 1764; il a écrit la flore de l'Espagne.)

M. corallina Mart, : Martinezia à fruits couleur de corail. (Aiphanes Wendl.) Vulyo: Palmier grigri. - Palmier élancé, triss droil, haut de 6-8 mist., at stipe d'une épaisseur de $7-10 \mathrm{~cm}$. à lầze adulte, grarni, de la base au sommet. de piquants noirs disposés en spirales. Feuilles très vertes, longues de 2 mèt., à segments longs de $14 \mathrm{~cm}$. sur $7 \mathrm{~cm}$. de large, revêtues des deux côtés de piquants longrs, séteux, droits; spathe couverte de piquants couchés; spadice droit, à branches non ramifiées; pédoncule court, pourvu de piquants droits, noirs, de longueur variable. Fleurs monoïques dans le mème spadice : les mâles, dans le haut des branches; périgone double; étamines 6; ovaire triloculaire. Drupe sphérique, lisse, luisante, de la grosseur d'une cerise, à pulpe rouge corail; coque dure, garnie de nombreux petits sillons irriguliers et de petites cavités. - ( )riginaire du Brésil; introduit et naturalisé : Camp-Jacol) (habitation Michaux), Basse-Terre, Pointe-à-Pitre. [No 3815.]

Martixique. Vulgo : Grigri, glouglou rouge. - Carbet cinetiere et jardin du presbrtèrei, Saint-Pierre, Prêcheur, Trinité (habitation Saint-Josephl, etc. $\lceil\Upsilon 19$.

Sagus Rumph. (nom indien de ce palmier.)

S. vinifera Pers.; Sagoutier vinifère. Vulgo : Sagouier, palmier-sagou. (Metroxylon Rollb, Raphia 1'al. de Beaur.) 1)esc., vol. I, 1. 33, 1. 15\%. Palmier ineme, haut de 8 -10 mèt. à stipe fusiforme, surtout dans le jeune âge, plus gros vers le summet. Feuilles très longues et très nombreuses, à pétiole garni de petits pirquants dans loute sa longueur et entouré, à la base, d'une masse fibreuse épaisse; régime pendant mesurant 2-3 $3^{\mathrm{m}} 50$, divisé en un grand nombre de régimes partiels, rappochés, inégaux, long de $28-33 \mathrm{~cm}$, à pédoncules lnngs de $7-8 \mathrm{~cm}$. el enveloppés d’écailles, glabres, luisantes, membraneuses; branches du régime partiel 50-60, très rapprochées, latéralement situées sur deux rangs : les inférieures, longues de 13-15 cm. ; les supé- 
rieures, graduellement plus courtes. Fleurs monoïques sur le mime riorime, disposées alternativement et latéralement tout lo longr des brandese : les mâles, plus nombreuses, occupant la partie supérieure; les femelles. au nombre de 1-3, situées i la base; les màles al les femelles entonres. a la base, de bractées orbiculares, membraneuses, fres apprimées, imbriquées; périgone 6-phylle: les 3 ćcailles extérieures formant unc alviols: les 3 intérieures et supérieures, plus longues, exsertes, lancénlies, concaves, pointues; étamines 6 , à anthères dressées, sariltées; slimmiles: 3 ,

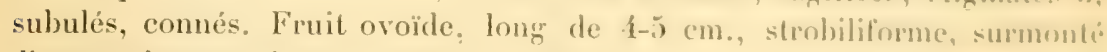
d'une pointe conique et forte; écailles du strobile soudées, renversées. polies, luisantes : celles du sommet graduellement plus petiles el plus rapprochées; amande ou albumen dur, délaché ì la malurilé, frarmi, i la surface, de cavités et de petits enfoneements irréruliers. - (t) obtient le vin de ce palmier en perforant la tige jusqu'à la moelle; it deux piecls audessus de la terre, il coule presqu'à linstant une liqueur agréable, stomachique et antiscorbutique. - Route de Fort-de-France au Camp-laalata,

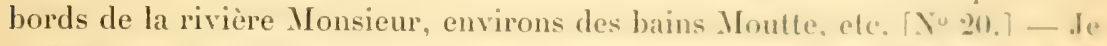
ne l'ai pas vu à la Guadeloupe, mais on ma assuré qu'il existe à Sitinte-lhnse et ailleurs.

Geonoma Willd. (du gree " geonomos "), experrimenté dans l'art de l'arri-

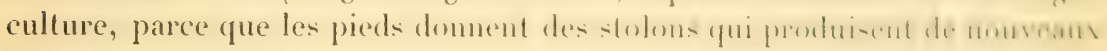
pieds.)

G. vaga Gr.et Wendl.; Géonome vagabond, Vulğo : Coen-macaquue. - Haul de 3-4 mèt., solitaire et alors droit, ou en toulfe de \{-7 pieds et alon's plus nu moins tortueux, à stipe cylindrique, lisse, marque de cicatrices ammulaires, distancées, très régulières, de l'épaisseur d'une forte canne it sucre, plein cl ne fournissant pas de substance larineuse eomme les autres palmiers, it bois

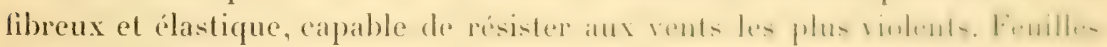

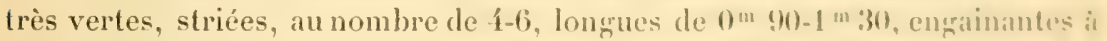
la base, penniséquées, à 6-10 segments adnés à la base, les uns laryes, les autres étroits, obliquement acuminés: les inférieurs, distants; les suprérieurs. rapprochés; spathes 2 , longues de $7-10 \mathrm{~cm}$. l'une couvant l'aulre con partie, et revêtues d'un duvet ferrugineux : l'extérieure, plus frrande et concase: l'intérieure, fusiforme, beaucoup moins concave: spadice, dans les spathes entrouvertes, gros comme un oul d'oie blanc, ressemblant ì une bunle de

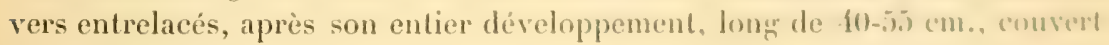
d'une pubescence roux noir ou roux grisitre; branches du spadice nombreuses,

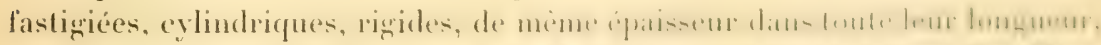

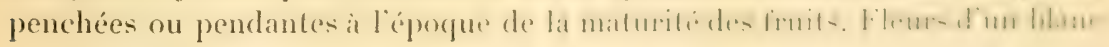
pur, petites, à odeur forte el suave, monoïques, inséries chacume dams un. alvéole tri-quadridentée : les mâles el les l'emelles mélangrés, disposiés sur 
quatre rangss. Ies mâles pourvues d'un carpelle rudimentaire: pérignne double : l'extérieur de la fleur mâle, à 3 écailles concaves; l'intérieur, à 3 ¿́cailles plus longues, plus ou moins plates: les 3 écailles extérieures de la tleur femelle distinctes, les 3 intérieures zomopétales trifides: étamines 6. monadelphes, à tube staminal plus longr que les filets noiruttes: styles 3 . ayant chacun son sitigmate. Fruil assis dans une cupule forme par les lobes profonds el durcis du périgone intérieur, monosperme, sphérique, à pulpe mince, rougre foncé. - Fl. de férrier à mai; graines mûres de juillet à décembre. - Avec les stipes de ce palmier, on fabrique des bâtons très solides. - C.a et li dans tous les grands bois de la Guadeloupe proprement dite, mais plus abondant dans les bois des bains-daunes que partout ailleurs. Alt. $600-950$ mèt. $\left[\mathrm{N}^{\circ} 3313\right.$.

Martinique. Vulgo : Aile à ravet. - Pitons-du-Carbet, où il forme souvent de grandes touffes; çà et là dans les bois du Lorrain, etc. [ $\left[\mathrm{N}^{\circ} 22.\right]$

Cocos L. (du grec "Kokios », noix.)

C. nucifera L.; Cocos à grosse noix. Vulgo: Cocotier. Desc., vol. I, t. 21, 22, p. 99; Tuss., Fl., IV, t. 34. - Haut de 18-20 mèt., à stipe flexueux, relativement grêle, sourent incliné et tortueux, très rarement droit, quelquefois aminci au milieu, toujnurs épaissi a la base, marqué de cicatrices demicirculaires, rapprochées, composé de paquets de fibres qui le rendent souple et capable de résister aux vents les plus violents. Feuilles au nombre de 1014, longrues de 2 in 50-3 mì. it segments nombreux, lancéolés-linéaires, acuminés, a pétiole très large à la base et semi-amplexicaule; spathe oborale, pointue, épaisse, verdatre. Iongitudinalement fendilléc en dehors, blanchâtre

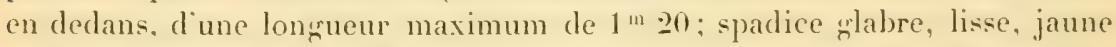
verdâtre, paniculé, à 20-35 branches simples, droites, garnies de deux bosses au point d'insertion; pédoncule très vignureux et en rapport arec la charge qüil doit porter plus tard, légèrement comprimé. Fleurs sessiles, monoïques sur le mème spadice : les mâles très nombreuses, avec un carpelle rudimentaire petit ia 3 styles subulés, courts et dépourvus de stigmates), situées sur six rangs irrégulierement disposés: les femelles 1-3, placées vers la base des branches, formant un corps arrondi, déprimé. plus large que long, du volume d'une grosse châtaigne: périgone double, fiphỵlle: les 3 écailles extérieures de la fleur mâle très petites, inégrales, souvent avortées: les 3 écailles intérieures six ou huit fois plus longues, valvaires, ovées, fermes, souvent difformes; écailles de la fleur femelle imbriquées. arrondies, très épaisses à la base, plus larges que longues, fortement apprimées : les 3 extéricures plus courtes, les 3 intérieures beaucoup plus longues et courrant complètement lovaire, toutes acrescentes et formant plus tard la cupule sur laquelle le fruit est assis; étamines 6, dont 3 fortement courbées en dehors dans les lleurs ourertes. entre les écailles f́carties: les 3 autres dressées el opposées à ces 
mêmes écailles; filet comprimé, noirâtre; anthères d'abord dressces ensule horizontales, submédianifixes, subsagitlées; ovaire lérierement pubescent au sommet; stigmates nuls ou indiqués par hois petiles sallies it peinc pereep)tibles, tant que lovare est enfermé sous les écailles. Plus tard, les trois stigmates rigides se forment el la fécondation sinpere. Firnit oroüde-oblonr. légèrement triangulaire, it saillies angulaires, plus prononcées vers le sommet, long de $22-25 \mathrm{~cm}$. sur $11-16$ cm. d'épaisseur, posiédant un brou ferme. filandreux, élastique, plus ou moins spongieux, épais, que reconver une peatu vert pâle ${ }^{1}$; coque ou noix monosperme, ovale ronditre, ligneusc-cornce, creusée autour de l'extrémité altachée it la base de trois trous ronds, dont un plus grand, de perforation lacile, et deux plus petils, durs il percer. - Lin débouchant une de ses ouvertures, il coule de la moix un liquide blanchatre. un peu sucré, parfois légèrement acidulé, selon les fariélés, très frats et trie agréable à boire. Un coco de taille moyenne peut en fournir environ un demi-litre : il en contient le maximum quand il est at moitic mùr. Le jeune fruit ne renferme que de l'eau; à mesure qu'il grandil, il se dépnse, sur les parois encore peu épaisses el molles de la coque, une matière blanche, de la consistance du lail caillé, d'un aspect gélatineux (endosperme), quion mange à la cuiller. Au bout d'environ huit mois, le firuit est devenu sec.

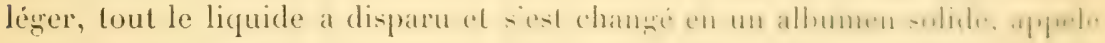
vulgairement amande de coco (Coprah); elle se mange crue, ou ripéce el rútic ou de toute autre manière. L'eau de coco est stomachique, antiscorbutique el

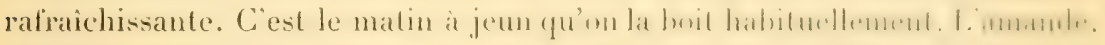
séchée el mangée à jeun plusieurs jours de suite, détruil, dil-()n, le línia mu ver solitaire. En incisant la spathe a la base, al lépoque ou la theur nest pas encore sortie de cette enveloppe, comme cela se pratique dans cerlanines

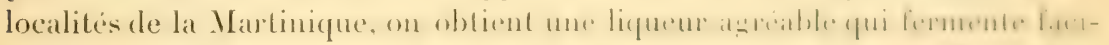
lement el quion appelle vin de cocolier. Dapres Cossigny (rol. 111, p. 2:35. . il constitue, après qu'on a ajouté des graines de coriandre, un remeide

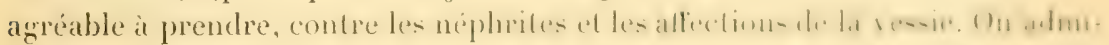
nistre au malade ce remede, dit cel auteur, plusicurs l'ois dans la jomrnée, pendant plusieurs jours de suite, et il provoque l'expulsion part les urines d'une quantité considérable de graviers. La noix de coeo, bruilé sur lé: cendres chaudes, laisse exsuder une matiere huileuse dout lodeur approche beaucoup de celle de la créosole et qui est employée contre les matux de dent. Le brou du coco (fibres) peut servir à calfater les canots el at líre des cordages; arec la coque, dure, on peut fare toutes sortes d'ustensiles el de

1. Ce brou, d'aprés les observations du D- Martialis, serail un anthelminthique ale pre-

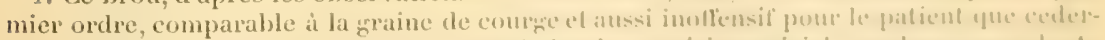

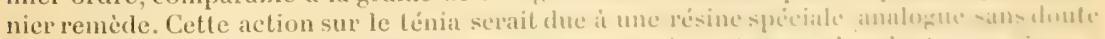

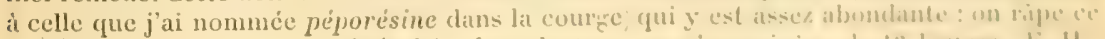

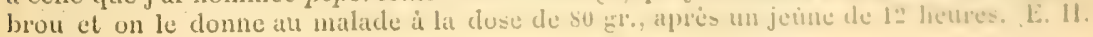


petits travaux. Ice bois du stipe est assez dur pour servir a la construction. Les feuilles, encore tendres, peuvent se mangrer en salade au méme titre que celles du chou-palmiste; elles ont cependant une saveur beaucoup moins agréable . - Dans les pays chauds, le cocotier fleurit et rapporte toute lannée. - (1n le croit indigìne de la côle oceidentale de Panama: il se plait de préférence dans les sables du bord de mer, mais il pousse également bien dans l'intérieur et sur les mornes inférieurs exposés au vent. - Cultivé dans tous les pays chauds et subtropicaux du monde entier. [ $\mathrm{X}^{\circ} 386$.

Syagrus Mart. du gree "stls ", pore, et "agrios ", sauvage. Pline, XIII, 9, désigne par ce mot une expece de palmier, sans donner dautres explicat linns.:

S. amara Mart.; Syarre amer. Vulgo : Petil enco. Cocos Lin.) - Palmier élancé, très droit, dépassant rarement 15 mèt délévation dans nos colonies, à stipe diune épaisseur de $1 \mathbf{1}-16 \mathrm{~cm}$. : celui des jeunes pieds est plus gros. Semblable au cocotier par les feuilles, la spathe, les fleurs, le spadice, mais les écailles du pérignene snnt plus épaisses : les intéricures de la fleur mâle sont linéaires-oblongues. Fruit ovoïde, deux ou trois fois plus grand qu un a uf de poule, jaune en dehors, possédant un brou drupacé-filandreux, aree un suc jannatre: coque dure, un peu plus grosse qu un ceul de poule, marquée de trois sillons plus ou moins prononcés. - L L amande se mange conme celle du coco ordinaire. - Çà et là à l'état sauvage dans les mornes inférieurs; se rencontre plus souvent a l'état de culture dans les pares et autour des maisons, comme arbre d'ornement: Camp-Jacob, Matouba habitation Rollin et la Joséphine, ou it y en a toute une allée) Gourberre (Dolé, les Palmistes. Trois-Rivières. [No 3817.

Martinique. Vulgo : Petit coco. - Assez abondant à la Rivière-Salée habitation La Reprise). Petit-Bourę, La Regale, Saint-Esprit, François. [N"18.]

L'Elaeis ynineensis L.., vulgo: Palmier de Guince, palmier is l'huile (Jacq. Sel. Am. stirp. hist., t. 173, p. 280; Tuss., Fl., IV, t. 31), originaire de 1.Afrique chaude, haut de 9-11 mèt., a stipe droit, marqué de laryes cicatrices demi-amnulaires, at feuilles longues, nombreuses, qui ne tombent pas d'une seule pièce, comme dans les autres palmiers, mais se flétrissent et pourrissent à partir de l'extrémité, de sorte que la partie supérieure du trone est toujours

1. Il est à peine besoin de rappeler ici que l'amande de cocotier fournit, sous le nom de coprah, une matière oléagineuse de première utilité pour l'industrie des savonneries et des stéarineries en Europe. Cette amande renferme de 40 à $500 / 0$ d'une huile dite de coprah qui sert encore comme matiere aliment aire quand clle est fraiche et qui, quand elle at ranci, est transforméce en une axonge végetale tris ayréable, qui est encore journellement utilisée dans l'alimentation publique sous le nom spécial de Taline. On peut dire que le cocotier est, par ses produits, un des végétaux les plus utiles à l'homme non sculement dans les climats où il végete, mais encore a l'industrie de tous les peuples civilisés. E. II.) 
garnie de vieilles leuilles et de vieux pétioles, à pétioles gramis sur les deus bords d'une rangée de piquants, ì fleur's monö̈ques, sur des spadices distincts et renfermés dans une double spathe, at lruits pourve d'une musloppe jaune à l'état frais, huileuse, à coque très dure, a allumen dur of creux, et le Phœnix dactyliferal l... vul et de l'Afrique septentrionale, à fleurs diö̈ques, et dont les fruits arrivent en plusieurs endroits ì une parfaite maturite, se rencontrent couranment danles deux colonies.

Les palmiers étant des arbres d'ornement par cxcellence, les directenrs de: Jardins botaniques, les amateurs de plantes se sont appliqués a en introduire un certain nombre des plus belles especes. Citons parmi ceux dont he:

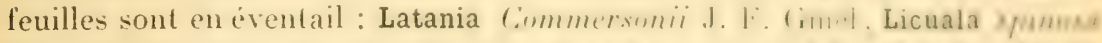

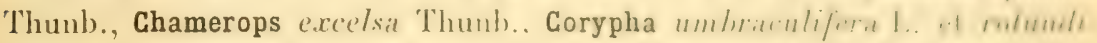

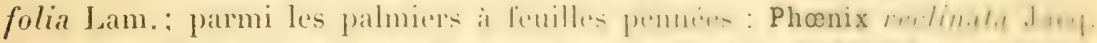
et syleestris Roxb., Attalea .Maripa Mar. ', Euterpe chlulis M.nt., Arenga

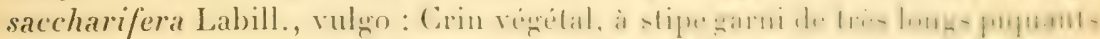

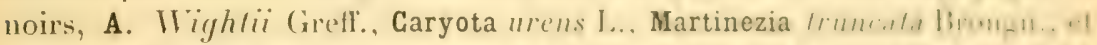
caryotefolia II. B. Kth., de Java, Maximiliana reylit Marl. Bactris muahe Mart., Seaforthia elegans R. Br., etc.

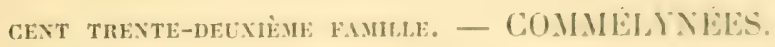

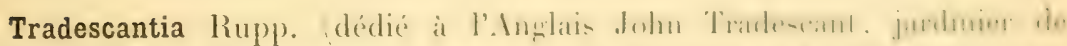

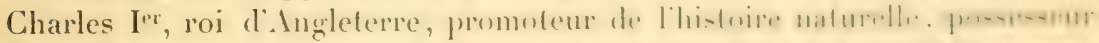

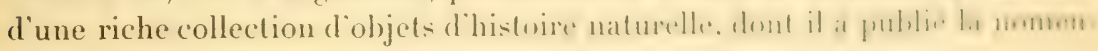
clature en 1656.$)$

T. geniculata Jacq. ; Tradescantia à ligres géniculées. Vulgro: Cumize der bois. Plum., édit. Burm., t, 116, 1. 2. - Ilerbe anmulle, diffuse, velue,

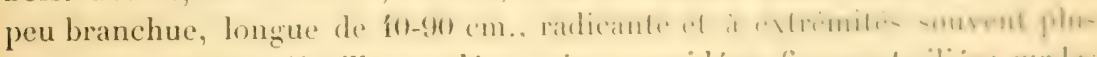
ou moins relevées. Feuilles cordées-ovées, cuspidées, finement cilices sur les bords, à gaine lâche, revêtue, sur le bord supérieur, de longrs poils solveux. ou plus rarement saus poils. Fleurs purpurines fou blanches dans les endroits ombragés), en cymes ouvertes, terminales el axillaires: (celles-ci naissant dans les deux ou trois dernières feuilles des rameanx; pédicelles

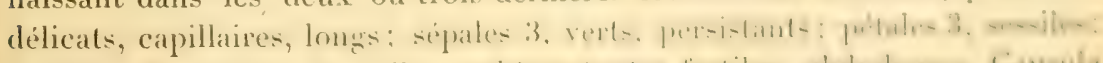

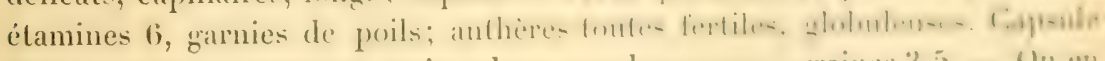
triloculaire, s'ourant en trois valves membraneuses ; graines $3-5$. - (11 t"n rencontre trois variétés :

1. A la Guyane française, sa patrie, lhuile extraite de la graine de ce pratmier est employée en frictions contre les rhumatismes. (E. H.) 
a, variété e/fusa Mart. T. florihunda Kith.), à feuilles ovées-obtuses, laryes, à fleurs en cymes larges. - Ibondant dans les caféières et le long des chemins it travers les bois peu élevés, inférieurs : Ilouëhmont, Camp-Jacob, les Palmistes, Gourbeyre Dolé. Gommier, Bagatelle, etc. - Fl, darril a juillet. [Nं 3292.$]$

Martixique. Vulgo: Herbe grasse des bois. - Prêcheur, Macouba, dans les caléières des hauteurs des Trois-Ilets. Fonds-Saint-Denis, ete. No 1014.

b, variété à feuilles courtes, cordées-ovées, à cymes courtes, petites. Sur les rochers humides: Marin morne Gommier, valle du Carbet, ete. $\left[Y^{\circ}\right.$ 1016, 1021.] - Je ne l'ai pas vue à la Guadeloupe.

c, variété à feuilles el cymes très petites, poilues. - Sur les rochers humides et très ombragés : vallée du Carbet. Parnasse (le longr des rivieres), Morne-Rouge (entre le bourg et le Champtlore. X" 10.20.] - Je ne l'ai pas troụvée à la Guadeloupe.

T. elongata G. F. W. Mey.; Tradescantia à tige allongée. Vulgo : Curagerivière. - Vivace par ses stolons, haut de $70-95 \mathrm{~cm}$, , radicant et souvent couché it la base, droit ou tortueux par le haut; la tige et souvent le dessous des f'euilles sont bleu verdâtre, toujour's glabres. Feuilles oblongues-lancéolées, pointues, at gaine très làche, laineuse-ciliée. lileurs pourpres, en ombelles contractées, beaucoup plus courtes que dans le précédent; pédicelles filiformes; élamines poilues, à poils pourpres. - Peu répandu. Cà el là en sociéte dans les lits des rivieres et des ruisseaux : Capesterre habitation Longmont), Trois-Rivières (Trou-aux-Chiens). No 3619.

Mantriges, Vulgo: Herbe grasse riviere. - Carbet le long de la riviere, Gros-Morne, 'Trinité (rivière du Galion). [No 1024.]'

T. discolor Sw.; Tradescantia à feuilles à deux couleurs. Vulgo : Gros curage. Rhoeo Hance., - Vivace par ses stolons, haut de $30-70 \mathrm{~cm}$. droit, à tige grosse, succulente, nue dans le has. Feuilles charnues, ramassées au sommel, longrues, noir bleuâtre en dessus, pourpre foncé en dessous, oblongues-linéaires, pointues, élargies à la base et amplexicaules, mesurant $2.5-37 \mathrm{~cm}$. de long sur $4 \mathrm{~cm}$. de larue. Fleurs bractéolées, en ombelles sessiles, multiflores, renfermées dans deux bractées pourpres, veinées, très larges, plus larges que longues, cordiformes, opposées : l'extérieure couvant en partie lintérieure; pédoncules communs, longs de $3-1,8 \mathrm{~cm}$.. solitaires, plus rarement néminés, renfermés dans une gaine cylindrique, qui s'élarvit au sommet, se fend latéralement et forme deux plis: ombelles 2, multillores, d'abord soudées at la base, ensuite distinctes, chacune entourée

1. Cette espèce, comme la suivante, passe pour jouir de propriétés diurétiques et rafraichissantes; c'est à ce titre qu'elle est employée, sinon aux Antilles, du moins da la Guyane française, sous le nom vulgaire de Raguet-crapaud. (E. II.) 
d'une braclée purpurine, mince, transparente, plus combleque les peidicellen pédicelles longrs de $8-18 \mathrm{~mm}$; sépales petils, étroils, pnurprés end dehor:largement ovales, plus courts que les pétales blance : étamimes do fommun

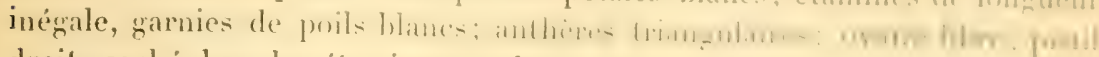
droit, caché dans les élamines el plus court quielles ; sligmale capriti. Fruil capsulaire, sourrant en trois valves comme dans tontes les aspines de co.

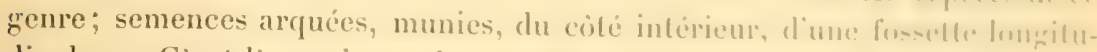

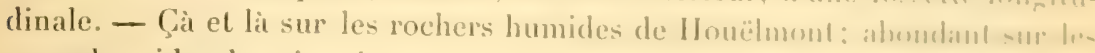

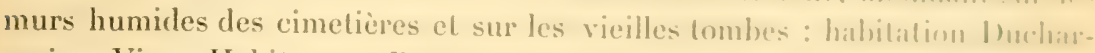
mois, Vieux-Habilants, Basse-Terre, Pointe-loire, Sainte-Innc, we. $[\mathrm{N} \circ 3291$.

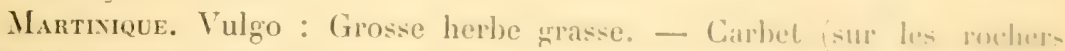
humides, dans le haut de la vallée, le long de la rivière, livirire-pilulı. Lamentin (Roches-Carrées), - On le cultive souvent dans les jarlin- comm. plante d'ornement et aussi pour ses rertus diuréliques. [1" 1015).

Callisia L. (du gree "kallos "), beau, parce que les feuilles sont pruppurines sur les bords.)

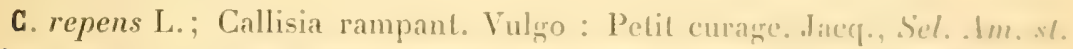
hisl., t. 11, p. 11. - Pelite herbe fourragère, annuelle, dílicale, rampramt.

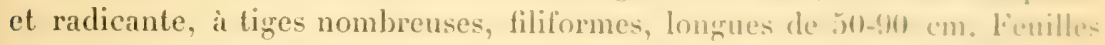
petites, cordées-deltoïdes, cuspidées, ciliées sur les borls, plus contés que les entrencuds, souvent pourprées sur les bords, amplexicaules-engrainantes: les supérieures plus petites et plus rapprochées. Flenus en frlumerules sersiles.

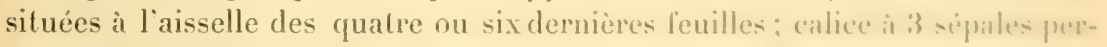
sistants; corolle blanche, à pétales très cadues; étamines 3. Fruil at 3 loger. - Cà el la sur les rochers humides, sur les vieux toils, ele : emvirms de la

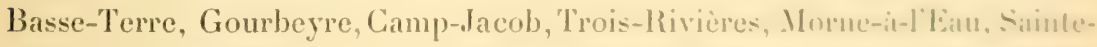
Anne, ete. [No $328 \%$.

Martmique. Vulgo: Pelite herbe grasse. - loncos (mavine), Marin mecherhumides du Gommier), Vauclin (montagne), cle. [X Iofs.

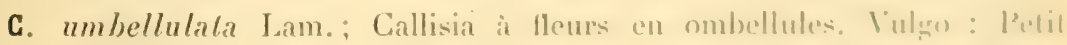
curage. - Port et taille du précédent. Feuilles nvales, irruguliores at ha hare el arrondies, cuspidées au sommel : celles de la base des mubellube berauconup

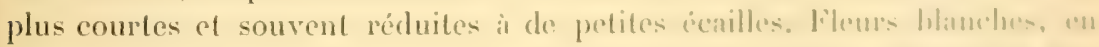

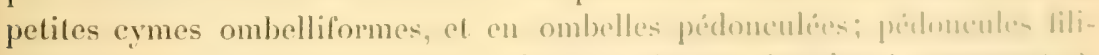

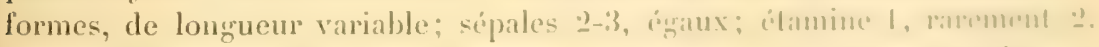

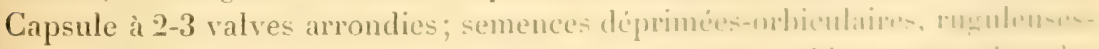

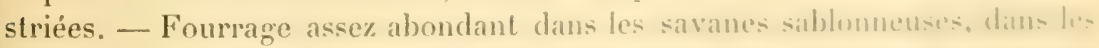
plantations de Malangas el de Madieres, dans les duanylit de camme

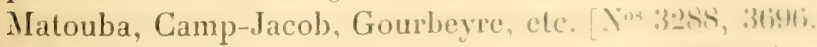

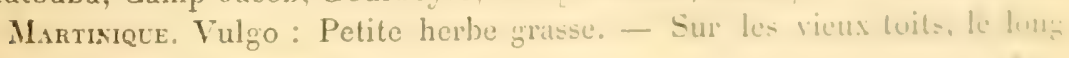

Duss. - Plantes Guadeloupe et Martinigue. 
des routes el dans les champs de cames: Marin. Lamentin, Trois-Ilets, Grande-Rivière. [ $\left.\mathrm{N}^{\circ} 1086.\right]$

Commelyna Plum. dédié à Commelyn, né en 166i, it Amsterdam, prolesseur de botanique dans cette ville. mort en 1731 : a écril : Flora malabarica; Prieludia bolanica: Horti med. Amstel. plantie rariores; Bolanographia malabarica.

C. cayennensis Rich.; Commelyne de Cayenne. Vulgo : Curage. - Herbe

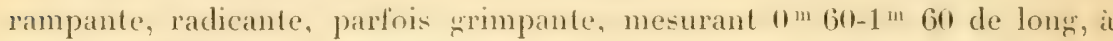
tize molle. Feuilles ovées-oblongues ou oblongrues-lancéolées; gaine lâche, striéc, ciliée au sommet. Inflorescence en cymes pédonculées, 3-5-fiores; lleurs renfermées dans deux bractées cordées-ovées, pointues, pliées en deux; pétales bleus, plus rarement blanes: élamines $5-6$ dont 3 plus longrues, fertiles, - 2-3 stériles arec des antheres rudimentaires en forme de crosse. Fruit at trois loges, dont deux contiennent deux semences et l'autre une seule. Fl. toute lannée. - Très abondant dans les endroits fertiles, humides des basse et moyenne régions de toute la Guadeloupe et de ses dépendances. Elle constitue un succulent fourrane pour le bétail, mais surtout pour les lapins et les pores; on s'en sert souvent dans les bains et aussi en cataplasmes, à cause de ses vertus émollientes. [ $\mathrm{N}^{\circ} 3290$.

M.nrmence. Vulgo: Herbe grasse. - Abondant dans toute l'ile. [Yo 1017.]

C. elegans Kith; Commelyne élégante. Vulgo : Curage. - Petite herbe d'abord droite, ensuite plus ou moins diffuse, haute de $15-40 \mathrm{~cm}$. Fenilles petites, subcharnues, lancéolées, finement ciliées sur les bords : la derniere leuille de l'extrénité nvée, scsile; gaine courte, ciliée-velue. Fleurs en petites cymes terminales, sesiles a l'aiswelle de la dernière feuille, renfermées dabord dans deux el en dernier lieu dans onze paires de hractées semi-lunaires, cuculiformes, pointues, horizontalement placées, làchement imbriquées: sépales concaves, carénés au sommet, à l'extérieur; pétales bleus; étamines 6 , dont 3 fertiles el 3 stériles toutes enveloppées, à la base, de poils bleus laineux; ovaire dépassé par les 3 sépales persistants; semences anguleuses, coniques, tronquées aux deux extrémités, scrobiculées. - Assez répandue dans les jardins: plus rare dans les savanes des basse el movenne régions : Basse-Terre, Camp-Jacob, Trois-Rivieres, Morne-itl'Ean, elc. $\left[\mathrm{N}^{\circ} 3: 89.\right]$

Mantixique. Vulgo: Herbe grasse. - Carbel (cimetière), Prêcheur (cimetière), Parnasse, Morne-Rouge, Saint-Pierre, etc. [ $\left.\mathrm{N}^{\circ} 1022.\right]$

Dichorisandra Mik. (du "wree " dis ", double, " chorizein ", séparer, et "aner ", oryane mâle. parce que les six étamines sont toutes lertiles, mais séparées en deux groupes de trois, dontl'un, l’intérieur, est formé d'étamines plus grandes.) 
D. Aubletiana Schult.; Dichorisandre d'Aublet. Vulero : Merfuravinr, Sarmenteux, grêle, haut de 1-2 mét., peu branchu, it fraine ot predieclles poilus. Feuilles oblongues, pointues, arrondies at lit hase. flabros, finement ciliées sur les bords. Fleurs bleu foncé, en grappes courtes, pramidales, terminales; calice à 3 sépales persistants; corolle al 3 pétales obuvés, éralement persistants; ovaire à 3 loges; semences grarnies d'un arille ronge oramiri. - Très rare : Basse-Pointe (ravine de l'habilalion Gradis'. |Y" 101!?.

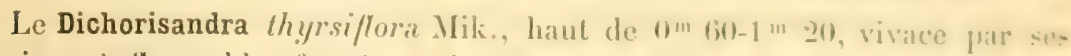
racines, à fleurs bleu foncé, en thyrse terminal, longuement pidencule, est cultivé aux Jardins botaniques des deux colonies el daus d"autres jardincomme plante d'ornement. Origrinaire du Brésil.

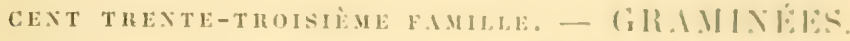

Les ospeces maryuées d'un " sont fourrazire"-

TRIBU 1. POACEES. - sots-Tumu 1, m.иm:si:s.

Bambusa Schreb (des mots indiens “ bambos, ou bambu ou manlus

B. vulgaris Schrad., B. arundinacea Ail., B. Thonarsii kilh: Bambon commun. Vulgo: Bambou. Desc, vol. IV, t. 293, p. 281. - Ilaut de 1.i20 mèt, rarement plus haut, cespiteux, formant avec le tempes des sonches

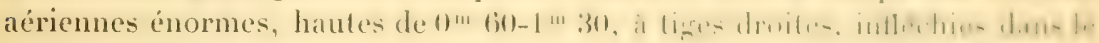
haul, très glabres, luisantes, rameuses des la bise, noneuses. cornses entre les entrenouds et marquées en dehors par des anneaux sillants. Feuillealternes sur le même plan, linéares-oblongues, acuminés, arrondies it lit base, brièvement pétiolées, engainantes. liamean naissunt pal :3-5) : celui du milieu toujours très allongé et plus lort, tous très épaissis il ha base ed rnver-

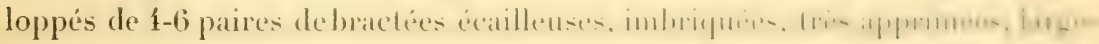
ment ovées et pointues; bourgeon produisant les ramean foros, complidement entouré d'ume spathe mesurant jusqu'à 37 em. de long sul prespule autant de large, membraneuse, polie en dedans, granie en dehors d'une couche de poils séteux, couchés, roussitres, longs de 2 mm. : spallhes des

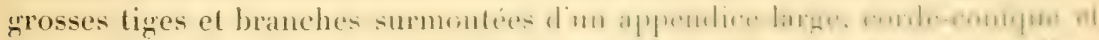

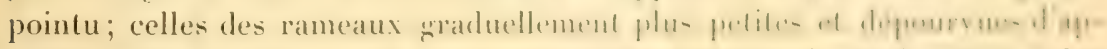
pendice. A mesure que les bourgeons se développent, la spithe protectrice tombe. Inflorescence en panicule longue, souvent de plus d'un mitre, prit-

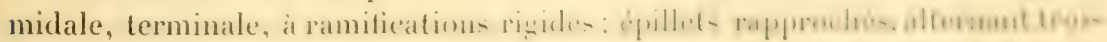
par trois, sessiles, comprimés, lancéolés: chacun muni, it lat haste, de lrois

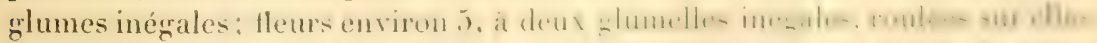
mêmes; étamines 6 , très courtes, à anthères oblongues; stigmales 3 , velus ; 
style long, velu; ovaire à deux glumellules membraneuses et pubescentes; caryopse oblong, ressemblant à celui de l'avoine cultivée.

Le bambou des. Intilles ne produit que tris rarement des fleurs, encore ne les trouve-t-on que sur des pieds qui poussent dans les endroits sees. Les jeunes pousses renferment une moelle spongieuse, d'une saveur agréable et sucrée, et lorsqu' elles ont acquis plus de solidité, il découle naturellement de leurs nouds une liqueur miclleuse, qui se coagule el se convertit en larmes concrètes constituant un véritable sucre dont on faisait grand usage avant la culture de la canne à sucre. Avec les jeunes pousses, on prépare aussi une salade atrréable et saine. - Les mallaiteurs, sous l'empire d'un désir de venzeance, grattent les poils qui recourrent les spathes, les ramassent et les mèlent aux herbes destinées au bétail : ces poils se fixent dans la grorge et le tube digestif de l'animal qui ne tarde pas à dépérir pour mourir enfin d'inanition au bout d'un certain temps. On se sert des noxuds de bambou en guise de pots à fleurs; avec les tiges, on fait des zouttieres, des clôtures, des cercles, des ustensiles à boire, des mâts pour les petits canots, des graules pour la pèche, etc. Les feuilles forment un bon lourrage pour les animaux. La décoction des feuilles est employée, en beaucoup d'endroits, contre les rhumes et les catarhes. Abondant dans la basse el surtout dans la moyeme région jusquà une altitude de 700-950 mèt. [ $\Gamma^{\circ} 3135$. $]$

Mantinque. Vulgo : Bambou. - Plus abondant qu'à la Guadeloupe. $[N \circ 1285$.

sous-tnibu II. restucées. - fre Division. - Bromées.

Arundo Tournf. idu mot celte " aru ", cau, allusion it lhabitat de la plante, ou de "arere ", ètre sec, à cause de la tigne sèche qui caractérise ce genre de végétaux, ou de " ruere ", faire du bruit.)

A. Donax L. (du grec "donax ", roseau.) Vulgo : Bambou indien. Ornemental, haut de $2-\mathbf{t}$ mèt., stolonifère, d'un aspect gris, souvent torlueux, a panaches blancs, prramidaux, allongess. - Probablement introduit. naturalisé : cà el lit it létat sauvage et cultivé dans les jardins comme plante dornement: Moule, Baie-Mahault, environs de la Pointe-it-Pitre. [Xus 3145 , 3471$.

Mantixique. Vulgo: Roseau des mares. - Prêcheur (rivière du Céron), Carbet (emhouchure de la rivière), Lamentin, ete. [No 561 .

Phragmites Trin. du wree "phragmis ", haie, paree que, dans le Midi de la France, on fait des haies avec ces plantes.)

P. marlinicensis Trin., Arundo occidentalis Sieb. ; Phragmites de la Marlinique. Vulgo : Petit roseau. Sl., t. 67. - Haut de 2-4 mèt., droit, stolonilêre. Feuilles linéaires, acuminées, légèrement scabres sur les bords; bord de la ligule cilie; panache large, penche, branches du panache verticillées. 
- Endroits marécageux près de la mer : Anses-d' Arlet, Carbet irarei, Kolmert. François, Trinité (Tartane). [Yo 1283.] - Je ne l'ai pas su it la Guadeloupe.

Gynerium Humb. et Bompl. (du grec "gruné ", lemme, el " erion ", laine. parce que les fruits sont garnis d'un duvet laineux.

G. saccharoides Humb. el Bonpl.; Gynérium ressemblant it une canne : suere. V'ulgo: Roseau d'Inde, grand roseau, mseru de riviere, - Vivace par ses stolons, haut de f-fi mèt., très droit. Fenilles de. canne it sucte; panache très long, penché, à branches unilatérales. Fileurs pelités. - (1) 11 w sert des tiges pour latter les toits des chaumières, pour palissader les cases: on en fait aussi des nasses et des paniers ì capturer le poisson. - Isis\%

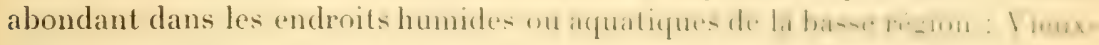
Habitants, Pointe-Noire, Sainte-Rose, Jamentin, Morne-itl'lan, ele. $\left[N^{\circ} 3138.\right]$

Martinique. Vulgo: Grand roseau, - Prêcheur (Cúron), Carbel, Marin. Anses-d'Arlet, etc. [ $\left.\mathrm{N}^{\circ} 1284.\right]$

Orthoclada Pal. Beauv. (du gree "orthos w, droil, el "klados ", hranches. parce que les branches de la panicule sont droites et rigicides.:

* 0 . rariflora Nees; Orthoclade à lleurs peu nombreuses. - Vivace, slolonifère, cespiteux, haut de 60-80 cm., droit. Feuilles longrues de 1 f $-16 \mathrm{~cm}$. ovales-lancéolées, acuminées, à pétiole long de $3 \mathrm{~cm}$; panicule ramassien. allongée, à branches filiformes, rigides, nues dans le bas. - Vit en societie dans les endroits ombragés et souvent inondés, ou marécagreux : BaieMahault (dans la vaste forêt de l'îlet La Jaille, seul endroit où jaie trouvé cette belle graminée). [No 3522.] - Elle n’existe pas à la Martinique.

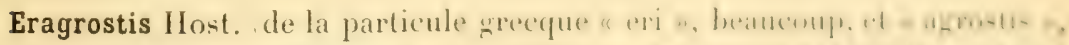

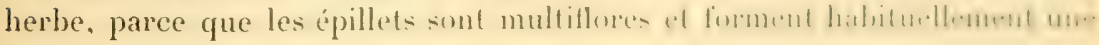
grande panicule.)

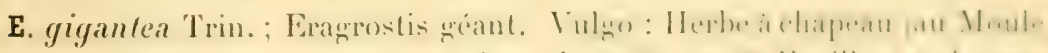

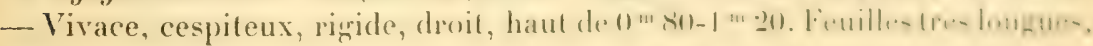
rapprochées dans le bas, distancées dans le haut, linéaires, longruement acuminées, souvent roulées; panieule longue de $30-13$ cm., allongéce, forlument penchée, portée sur un chaume nu dans le haut; épillets bruns.

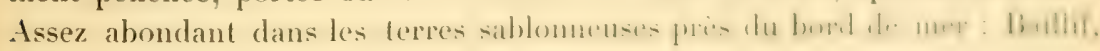
Moule, Gozier, Marie-Galante, etc. [Yo 31. 12.$]$

Martivique. Vulgo: Herbe it chapeau, - Precheur fembouchure de la

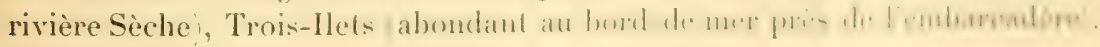
Marin, etc. $\left[\mathrm{N}^{\circ} 565.\right]$

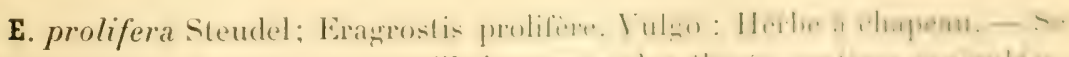

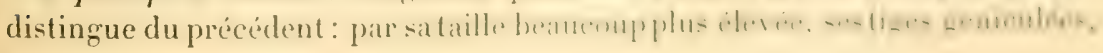


branchues; par ses feuilles inférieures courtes; par sa panicule làche, ses épillets plus larenes et plus brums. - Pointe-Noire (près du bord de mer), Baillif, Vieux-Habitants, ete. Y"3422. - Je ne l'ai pas trouve a la Martinique.

*E. plumosa Link; Eragrostis plumeux. Vulgo : IJerbe à bouquets. Annuel, cespiteux, plus ou moins droit, haut de $12-18 \mathrm{~cm}$. , ornemental, Feuilles peu nombreuses, ovales-lancénlées, acuminées, courtes: chaume filiforme, zénicule: panicule dresiée, ramassée, ovoïde, lomgue de f-7 cm. : partic nue du chaume trois fois plus longue que la panicule. - Autour des maisons, dans les jardins el les champs cultivés : Basse-Terre. Baillif, VieuxHabitants, Moule, Saint-François, etc. [No 3143 b.]

Martivele. Vulgo : Herbe à bouquets. - Dans les jardins abandomés el les terres cultives : Saint-Piere, Carbet imetiere), Case-Pilnte. ¿ ${ }^{\prime \prime}$ jofi.

*E. pilosa Beauv .: Eragrostis a épillets poilus. Vulgo: Herbe a bouquets. Anmel, cespiteux, de taille et de port tres variables, tantot diffus et haut de

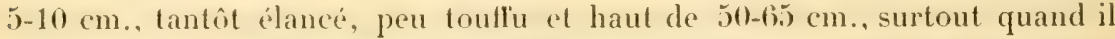
vit en société avec d'autres herbes. Fenilles assez courtes, linéaires, roulées ; épillets souvent pourprés. - Mbondant dans les rues peu fréquentées, dans les terres sablonneuses, dans les savanes humides des basse et movenne régions de toute la Guadeloupe et de ses dépendances. [No 3143.$]$

Martivique. Vulgo : Herbe à bouquets. - Abondant dans toule l'île. [No 793.] - Introduit probablement du Midi de la France.

*E. reptans Vees; Kragrostis rampant. Mich., Fl. de I'Imérique boréale, rol. I1, 1. 11. - Haul de f-6 cm., cespiteux, à tiges gréniculées, filiformes, dilfuses. Fenilles courtes, linéaires, acuminées. Fipis au nombre de 6-12, longs de 1-7 mm. formant ensemble une petite srappe simple. - Diamant el Marin (dans les savanes sèches pres du bord de mer. “o 739 b.] - Je ne l'ai pas trouvé à la Guadeloupe.

E. ciliaris Jink: Eragrostis à épillets ciliés. Vulgro : Herbe à bouquets. - Innuel, cespiteux, haut de $30-42 \mathrm{~cm}$. plus ou moins diffus, plus rarement droit. Feuilles ovales-linéaires, acuminées; panicule contractée, longue de $4-6 \mathrm{~cm}$. : partie nue de la tigre, entre la dernière feuille et la panicule, longue de 8-10) ('m. - Hbondant autour des maisons, dans les cultures des basse et infra-movemne régrions de toute la Guadeloupe et de ses dépendances. [No 2706] (avec la variélé à panicules minces et allongées.)

Martineve. Vulgo: Herbe à bouquets. - Abondant dans toute l'île. [Nos 1305, 2710, forme ordinaire.] [Nos 1307, 2707, forma minor.]

\section{2e Division. - Agrostidées.}

Sporobolus R. Br. (du sree "spora ", semence, et " ballein ", jeter, parce que les caryopses se détachent lacilement et de bonne heure.) 


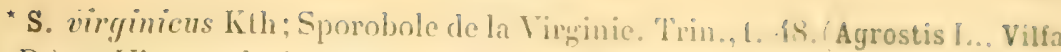
P. B.) - Vivace, droit, haut de $40-75 \mathrm{~cm}$., à stolons rampants. Feuilles di-

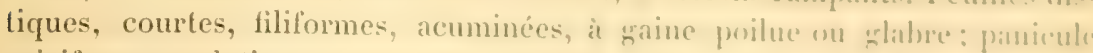

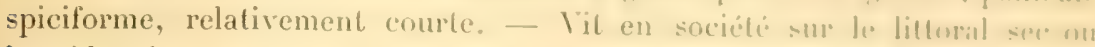
humide, pierreux ou non, el souvent dans les sables. YX 3 I $\{$.

Martixique. - Extrêmement abondant sur presque toules les pliges of souvent un peu à l'intérieur. [Nº $12 \%$.

S. littoralis Kith; Sporobole du bord de mer. - Virace droil, hamt de 1-2m 50, à stolons nombreux, très longrs, profondément enterrís. firuilles: toujours roulées, linéaires-séliformes, très acuminces; fraine cylindrique. légèrement poilue ou glabre; panicule allongée, spiciformes, renfurmé it lit base par les dernières feuilles du chanme. - Fl. rarement. - Vit monciali sur les plages, où il maintient les sables, que le vent impituenx lend it purter dans l'intérieur des terres: Moule, Saint-Francois, Sainte- Inme, Purt-I.nuis. etc. $\left[N^{\circ} 3162.\right]$

Mantrique. - Diamant (loute la plane), Trois-livieres, Marin, siniuluAnne. $\left[N^{\circ} 562.\right]$

* S. indicus R. Br., S. tenacissimus P. B.; Sporobole indien. Vulın : Mrile. foin (au Moule), Mabouge. S1., t. 73, 1. 1; Trin.. Ic., 1. (30). - I)rnil, (espiteux, haut de $\mathbf{4 0 - 8 0} \mathrm{cm}$, à chaume sec, tenace. Fevilles rnulés, linciniresacuminées, longues. Fleurs purpurines, plus rarement blanches; paniculte contractée, longue de $25-35 \mathrm{~cm}$. : les branches infúrieures distantes: - Vit en société dans la région sèche, inférieure et basse, où il constilue sonvent l'unique herbe des savanes; moins abondant dans la rigion movennc. Jeune, il forme un bon fourrage pour les moutons el les cheraux. - l'inute la Guadeloupe et ses dépendances. 1lt, 0-800 mèt. [X 31 î.

Murtineve. Vulgo: Cabouya. - Tres abondanl dans toules less savanes sèches de l'île. $\mathrm{N}^{\circ} 1278$.

* S. Jacquemontii Kith; Sporobole de Jacquemont. Vulero : Maboume. Ne diffère du précédent que par ses graines eylindriques et striées, par sus panicules plus ouvertes et à branches moins allongrées, - Moins abondant.

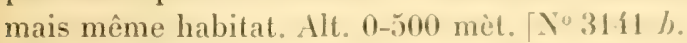

Martixique. Vulgo : Cabouya. - Mème habilat que le précéclenul. i X" 1:19?.

\section{3e Dixision. - Stipnetips.}

Aristida I. (du latin " arista ", bart)e d'épi, arite, pareo que les iplilletont des glumes terminées par trois arêtes trilides.

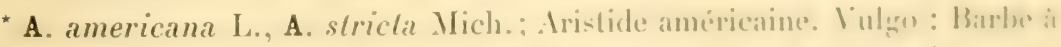
blé. - Annuel, cespiteux, stolonilère, plus ou moins droil. me dípassant

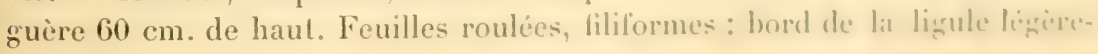


ment cilié; épillets unillores, barbus, ì harbes trifides, capillaires, droites, terminant la stume fertile; panicule droile, eflilée, làche, délicate. - Endroits secs, chauds, sablonneux et pierreux de la côte entre la Basse-Terre et la rivière des Pères, Pigneon, Bouillante, Baillif. Alt. 40-350 mèt. [No 3159.]

Mantixique. Vulgo : Barbe à blé. - Abondant aux Fonds-Saint-Denis (dans les friches), hauteurs des Trois-Ilets et du Robert, etc. [No 1326.$]$

\section{q Dixision. - Oryzies.}

Oryza sativa L. Vulgo: Riz. - Haut de $0^{\mathrm{m}} 80-\mathrm{1}^{\mathrm{m}}$ 20, droit, à épillets en panicule contraclée, penchée. est cultivé ça et lit à la Guadeloupe [No 3111$]$ et à la Martinique, au Gros-Morne, dans les hauteurs de Fort-de France. [No 1287.] - La récolle se fait habiluellement en septembre et octobre.

Leersia Soland. dédié a John Daniel Leers, né en 17.27, à WI unsiedel, apothicaire de l'université de Herborn, mort en 1774; a écrit: Flora herbornensis.

L. monandra Sw.; Leersie à une seule étamine. Vulgo : Riz bâtard. Cespiteux, formant des touffes compactes, hautes de $601-90 \mathrm{~cm}$. Feuilles lancéolies-linéaires, acuminées, scabres; ligule courte: panicule d'abord étroite, courte, ensuite allongée, à branches étalées, subunilatérales, distantes; épillets pilles. Fleurs ì une d́tamine; glumessans arêtes. - Peu répandu : çì et lit dans les bois sees des hauteurs du Diamant (habitation Kiliandon'. Alt. 300-450 mèt. [No775.] - Je ne l'ai pas trouvé à la Guadeloupe.

\section{̈̈ Division. - Phalarideses.}

Olyra I. (dlu gree " oluein ", avoir peu de valeur, parce que les semences contiennent peu de farine. L'Olyra d'Homère, Iliade V et VIII, était une espece dorye, qui servat it nourrir les chevaux. Link et Sprengel croient que le Triticum zea Hort. actuel est l'Olyra des anciens.)

0. latifolia L., 0. paniculata Sw.; Olyre à feuilles larges. Vulgo: Calumet. Sl., t. 64, f. 2; Trin., Ic, t. 346. - Vivace, sarmenteux, haut de 35 mèt., à tige ligneuse, cylindrique, polie, d'une épaisseur de $8-9$ mm., contractée aux meuds, à branches pendantes. Feuilles verl pâle, membraneuses, ovées-oblongues ou ovées-lancéolées, acuminées, inégales à la base. Inflorescence en panicule pramidale, leminale; fleurs monö̈ques sur la mème panicule : les femelles, solitaires, pédicellées et situées aux extrémités des branches; les mâles, dans le bas; wlume de la fleur femelle très acuminéc et Ierminée par une longue barlse, lautre ì barbe plus courte; caryopse blane, libre, ellipsö̈le, dur, poli et tres luisant. - . Dondant dans les mornes sees ou humides: ( Gourberre Dole, mornes Boncanier, Dos-d Ane, les Palmistes), 


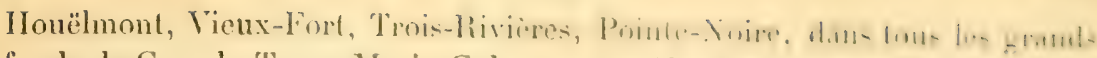
fonds de Grande-Terre, Marie-Galante, etc. All. 40-480 mèt. [Y, 2701.

Martixigue. Vulgo : Calumet. - Abondant : hauteurs du Préeheur, de

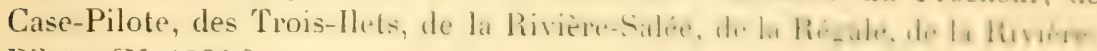
Pilote. [No 1286.$]$

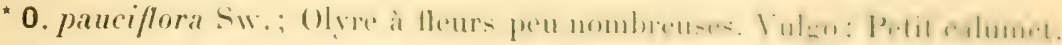
- Vivace ou annuel, stolonilère, cespiteux, at fi-fo ligres, hautes de fll-

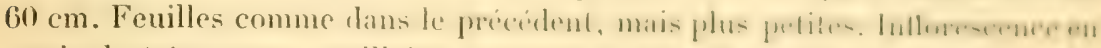

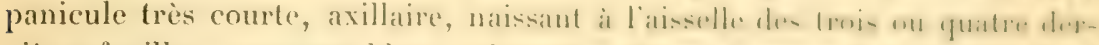

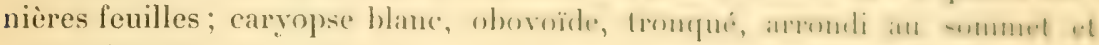
muni d'un bec latéral très court. - Dans les momes inférieurs, secs et pier-

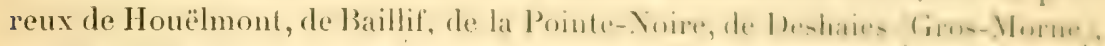
etc. Alt. 150-400 mèt. [No 3148.$]$

Martixique. Vulgo: Petil calumet. - Manheurs du Princhenr, de la CiramuleRivière, du Fort-de-France, des 'Trois-Ilets, du Diamant, ele. [X̃o 733.

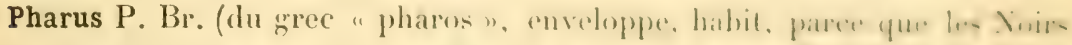
de la Jamaïque se servaient autrefois de ses feuilles pour se courrir.

P. latifolius L., P. scaber II. B. Kith, P. walifulius IIam. : S.. 1. 73, I. 2: Br., Jam., t. 38, f. 3. - Vivace, stolonilère, peu cespiteux, haut de f1)$85 \mathrm{~cm}$. Feuilles distiques, larges, scabres en dessous, vert noir, souvent

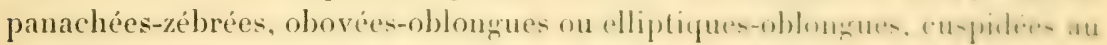

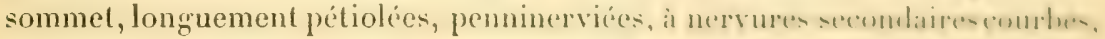

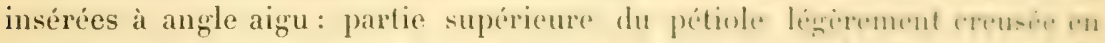

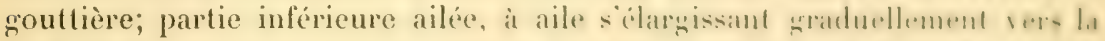

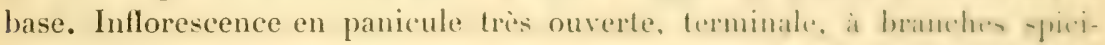

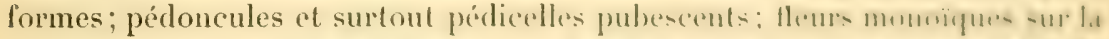
mème panicule; épillets biflores : les fleurs miltes portions sur un pridicelle. filiforme; les femelles, sessiles; élamines 6 ; stigmates 3 : Flume- fertile-

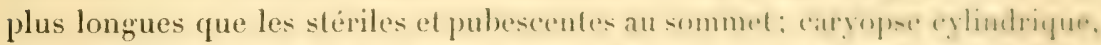
libre, noirâtre, long de 9-11 mm., zarni de prils courts, crochus, muni au sommet d'un bec dur et crochu. - Fl. d'arril it juillet. - Mbondant dans

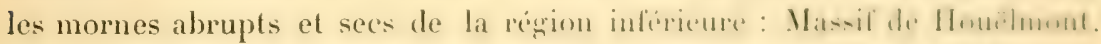
Vieux-Habitants, Pointe-Noire, Baillil, Deshaies. Ale. 3(0)-f(t)0 mil. [No 3147.$]$

Martingeve. Vulgo: Avoine bâtard, collant. - Hauteurs boirées el sèches du Diamant, des Trois-Ilets, de la Grande-Rivière. $X^{\circ} 781$.

P. glaber H. B. et Kith; Pharus a leuilles glabes lulgen: I wine a thich Tuss., Fl., II, t. 8; Desc., vol VI, t. 398, p. 65. - Ve dillère du precident

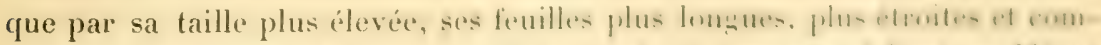

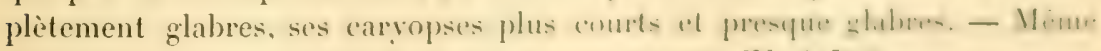
habitat et tout aussi abondant que son congénere. [X" 3150. 
Martingers. Vulyon: Aroine bâtard. - Variété à pédoneules el pédicelles glabres.-. Plus abondant que le précédent. Alt. 350-600 mèt. [No 780.

\section{$6^{\mathrm{e}}$ Division. - Pappophorées.}

Pappophorum Schreb. idu gree " pappos ", aigrette, duvet, et " pherein ", porter.)

P. laguroideum Schrad., P. alopecuroideum Vahl; Pappophore à queue de lièvre. Vulgo : Queue-de-renard, herbe à laine. Vahl, Symb., t. 51. Vivace par ses rhizomes, droit, très cespiteux et très ornemental, haut de 60$90 \mathrm{~cm}$, rarement plus haut, entièrement glabre. Feuilles très longues, étroitement linéaires-acuminées, roulées, rapprochées de la base du chaume. Intlorescence en panicule allongée, blanche, longue de 2.5-30 cm., cylindrique, spiciforme, composée d'épis courts el simples, dans les pieds maigres, fastigiée et constituée dépis longs et composés, dans les pieds uras; épillets: les uns, sessiles; les autres, pédicellés, presque toujours réunis par paire, triflores. La première fleur, hermaphrodite, est sessile ou pédicellée; la deuxième, plus petite, pédicellée, est imparfaite; un peu au-dessus de celle-ci, la troisième, est énalement stérile, ou réduite à un simple rudiment de fleur; les deux stériles, sont itroitement adossées contre l'hermaphrodite. Glumes stériles de la fleur complite ou hermaphrodite, membrancuses, transparentes, orées-lancéolées, uninervices, a arêtes, et restant attachées au rachis après la chute de l'épillet : l'extérieure, légrèrement plus longue; toutes les autres glumes, tant celles de la fleur complète que celles des stériles, garnies de 7-1í poils, plus longrs que l'épillet, rigides, de longueur inégale, blanes et formant comme une aigretle semblable à celles des Synanthérées. - Peu répandu. Endroits sees ou sablonneux de la réngion inférieure et de la région du littoral : Basse-Terre (La Pintade où il vit ent société sur une petité élendue), Pointe-Noire (entre le bourg et le bord de mer). - Alt. 5-100 mèt. [No 3164 . ]

Mantinger. V"ulgo : Herbe quene-de-renard. - Fond-Canonville, Prêeheur. Alt. 0-50 mèt. [ $\left[\mathrm{N}^{\circ} 1329.\right]$

SOUS-TRHzU HI. CHI.ORIDÉES.

Bouteloua Lag. dédié à l'Espaynol Boutelou, de Madrid, botaniste; a écril un ouvrage sur l'horticulture, en 1813.)

* B. litigiosa Lag. Vulgo: Herbe sèche. Sw.,Observ., t. 2, f. 2. 一 Haut de 15-60 cm., cespiteux, plus ou moins droit, à chaume sec, géniculé, filiforme. Feuilles inférieures, courtes, plates ; les supérieures, plus longues. Inflorescence en panicule allongée, étroite, composée d'épis courts; ligule brièvement ciliée; épillets distants, à 6-12 sur un épi. - Trìs abondant dans les 
endroits sees, pierreux ou rocailleux, ou sablonnenx des bastes chiles di. Baillif, des Vieux-Habilants, de Pigeon, de Boullante, oi il forme Firon.

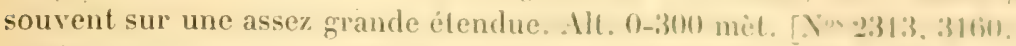

Martinique. Vulgo: Merbe-savane, - Linvirons de Saint-Pierre. CasoPilote, Grande-Rivière. IYo 779.

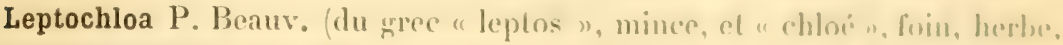
c'est-ì-dire herbe à épis minces et allonènés.

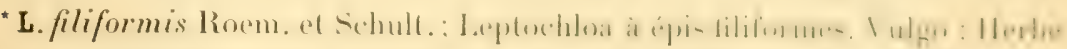
fine. - Annuel, très droit, cespiteux, haut de 15 -80 cm. Feuilles thasques, plates, peu nombreuses, linéaires-acuminées; chaume sec, à nueuds mirs 1.1 contractés; panicule lâche, pouvant atteindece fl) cm. de longh. it ippis longrs.

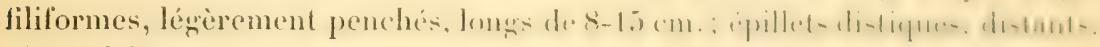
bi-quadriflores; glumes barbues; pédicelles glabres. - Cai ul li dans leterres sablonneuses des basse et infra-moyenne rérions de luule la fiuadeloupe et de ses dépendances. $\left[x^{\circ} 380 \%\right.$.

Mantineve. Vulgo: Herbe fine. - Dans toute l'île, sans etre abondanl nulle part. [No 532.$]$

* L. virgata P. B.; Ieptochloa droit comme une baguelte. lubeo : Piedpoule de Saint-Domingue. S1., 1. 70, 1. 2. - Amurel, haul de (1) très vert, cespiteux; panicule longue de 10-14 cm., it épis rapprochés, pen-

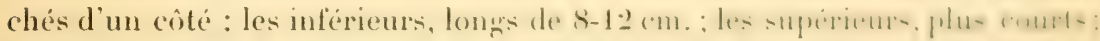

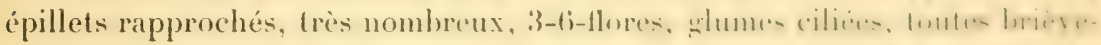
ment barbues. Variable quant à la couleur, au nombre el ì la longurur des épis, - Répandu dans la régrion inférieure de toute la Ciuadeloupe el do sis dépendances. Alt. 0-500 mèt. No 3156.

Martixeve. Vulgo : Herbe droite, herbe aux chevaux, - Dims Inute l'ile. mais surtont aux environs de Saint-Pierre, Carbet, Parnasie, Basse-Poninte. $\left[\mathrm{N}^{\circ} 531.\right]$

Chloris Sw. (du gree " chloros », vert jaune, parce que la pluparl de's espèces ont cette couleur.)

*C. radiata Sw.; Chloris à épis disposés en ombelle. Vulern: Peotil piedpoule. - Annuel, droit, cespiteux, haut de 30-5) cm. Leuilles courtes. mem-

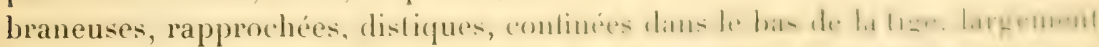
linéaires, plates, obtuses au sommet, souvent cilieses at la hase: chatume it

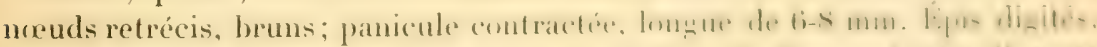

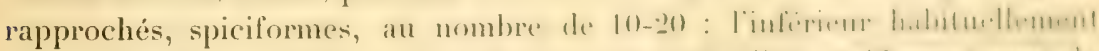

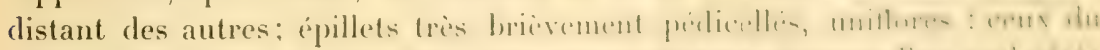

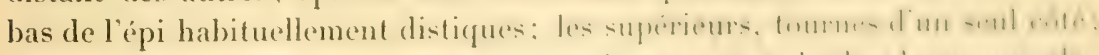

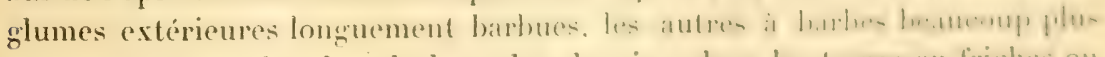
courtes. - Très abondant le long des chemins, dans les terres en liviches on 
cultivées de toute la Guadeloupe et de ses dépendances. Alt. 0-500 mèt. $\left[\mathrm{N}^{\circ} 2708.\right]$

Martinique. Vulgno: Petit pied-poule. - Très abondant dans la région inférieure de toute l'île. [No 1272 .]

* C. barbala Sw, ; Chloris à épillets barbus. Vulgo: Petit pied-poule. Trin., Ic.. t. 306. - Annuel, haut de $10-70 \mathrm{~cm}$., droit, rarement couché à la base, à chaume grrêle. Feuilles situées vers la base du chaume, linéaires-acuminées, plates: panicule très contractée, comptant 5-8 épis longos de $4 \mathrm{~cm}$.; épillets tronques au sommet, it trois barbes noiritres, longues. - Peu abondant : chemin de la Basse-Terre à Gourberre, Baillif, Vieux-Ilabitants. Alt. $0-300$ mèt. [No 3158.]

Martixiqle. Vulgo: Herbe à barbes. - Environs du port des Transatlantiques, de Fort-de-France, Trois-Ilets (environs du bourg). [No 78:.

*C. ciliata Sw.; Chloris à épillets ciliés. Vulgo: Petit pied de poule, Trin., Ic., t. 307. - Annuel, droit, haut de $\mathbf{1 0 - 6 0} \mathrm{cm}$. Feuilles plus longues et plus larges que dans les deux précédents. Épis digités, au nombre de $\mathbf{1}-\mathbf{6}$, longs de $5-7 \mathrm{~cm}$.; épillets triflores; glumes garnies de cils soyeux, blanchâtres tout le long du bord; barbes courtes. - Peu abondant. Cá et là dans les endroits abandonnés et le long des routes : Trois-Rivières (environs du bourg), Capesterre (Guadeloupe), Marie-Galante (Saint-Louis). Alt. 5-308 mèt. [No 3158 b.]

Marminete. Vulgo: Petit pied-poule. - Plus abondant qua it la Guadeloupe : Rivière-Salée (bord des chemins), Rivière-Pilote, Marin, SainteLuce. $\left[N^{\circ} 1273\right.$.

Dactyloctenium W"illd. (du grec " dactylos ", doigt, et " ktenion ", diminutif de "kteis ", peigne, parce que les épis sont disposés comme les doigts de la main et les épillets comme les dents d'un peigne.)

* D. sgypliacum Willd.; Dactyloctène d'Égypte. Vulgo : Trin., Ic., t. 69. — Annuel, très cespiteux, diffus ou plus ou moins droit, haut de $30-45 \mathrm{~cm}$. Feuilles plates, rigides, garnies de poilsfins et droits. Épis 2-4, digités, longs de $12-15 \mathrm{~mm}$; épillets bruns noirs, bi-quadriflores, sessiles, étroitement imbriqués sur deux rangs, du côté supérieur du rachis; glumes brièvement barbues: péricarpe du caryopse utriculaire. - Dans les endroits sablonneux et les savanes sèches des basse et infra-movenne régions de toute la Guadeloupe : Marie-Galante, les Saintes, etc. [ $\left[\mathrm{N}^{\circ} 2711.\right]$

Mantixique. Vulgo : Herbe fine. - Basse région de toute l'île. [ $\left.\Gamma^{0} 1271.\right]$

Eleusine Gaertn. (du nom de la ville grecque "Eleusis ", où Cérès, la déesse du blé, fut particulièrement honorée; les semences de cette graminée donnent de la farine comme les grains de blé.)

"E. indica Gaertn.; Eleusine indien. Vulgo : Pied-poule. Trin., Ic., t. 71. 


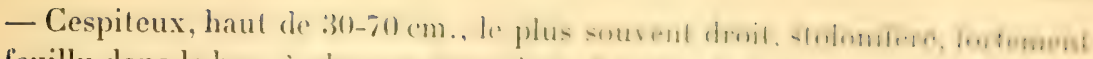

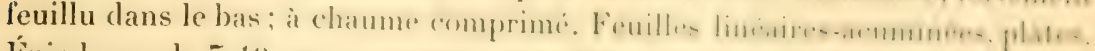

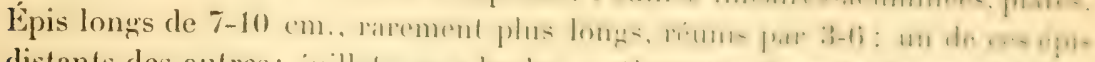

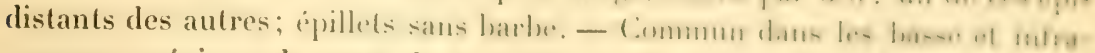
moyenne régrions de toute la Gruadeloupe el de ses dípendances. - I.es racines, prises en infusion ou en décoction dans du riz, sont, dans lone endro-

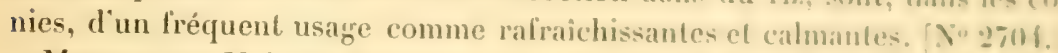

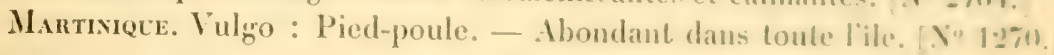

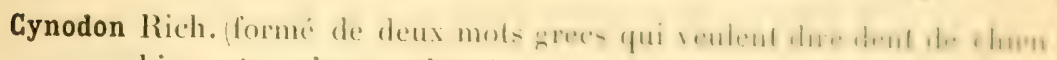
" xuon ", chien, et " odous ", dent.)

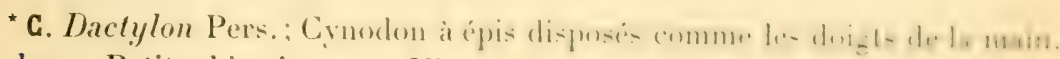
Vulgo : Petit chiendent. - Vivace, très stolonifere, hatut de Zn-(it) (mm.

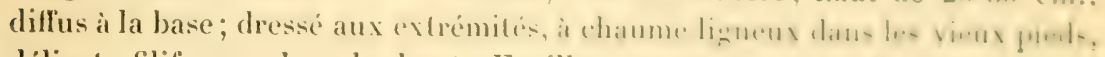
délicat, filiforme dans le haut. Fenilles très vertes, courtes, limeairos-acti-

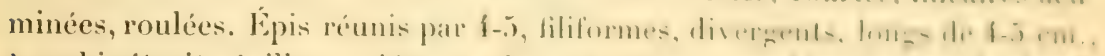

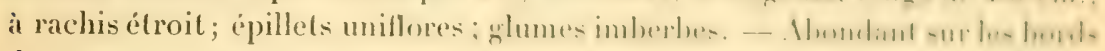
des chemins, dans les rues peu fréquentées, sur les vieux murs des basse el infra-moyenne régions de toutes les Intilles. Xo 27.5., - Probablement introduit d'Europe.

Martinique. Vulgo: Chiendent. [N*1:27.]

TRIBU II. PANICÉES. - sots-Tmm: 1. P.ASI.ATIS.

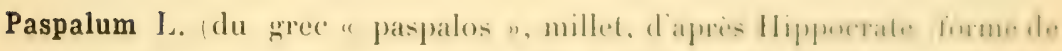
"pas ", entier, et "palé ", larine), c’est-à-dire plante dont lés senuences donnent beaucoup de farine: le genre Paspalum est wisin du form mallel.

* P. platycaule Poir., P. compressum Nees, P. guadalupense Steud. : Paspale à chaume large. Vulgo: Herbe-süe male. Trin., le, 1. 118. - Jiflu-

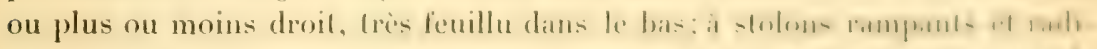

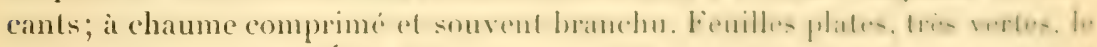

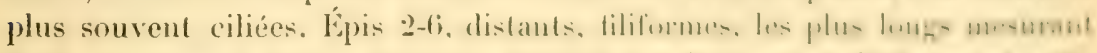

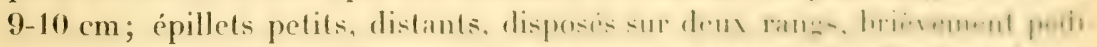

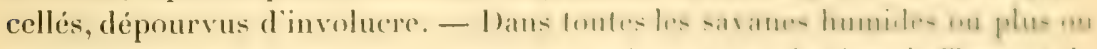

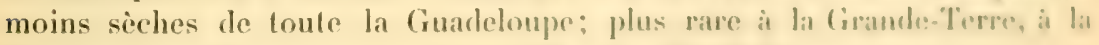

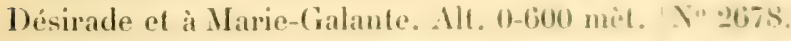

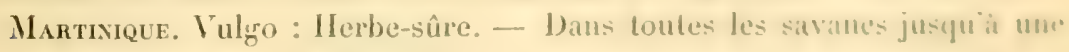
altitude de 530 mèt. [Nos $776,77 \%$.

* P. conjugalum Beror, P. cillatum I.am.; Palspale a ípillets conjugrucis. Vulgo: Herbe-sûre, herbe-sure mâte, herbe fine, herbe-mouton firmelle. herbe-gazon. Trin., Ics, t. 102. - Stolonifiere, radicant a lat base; a chamme 
faible, grele, haut de $40-60 \mathrm{~cm}$. Feuilles plates, ciliées; gaine comprimée; nueuds rétrécis, noirs. Épis 2, rarement 3 , longs de $8-12 \mathrm{~cm}$., filiformes, divergents, courbes, dont 1 toujours placé à distance; épillets très brièvement pédicellés, disposés sur deux rangrs qui se touchent; rachis linéaire, légèrement cannelé sur le dos; glumes stériles à 2 nervures; caryopse ové, aplati. - Constitue une des meilleures herbes fourrageres des Antilles. Tris abondant dans toutes les savanes, où il forme souvent grazon. Alt. $0-850$ mèt. [No 3151.$]$

Mantivele. Vulgo: Ierbe-mouton, herbe line. Alt. (1)-700 mèt. X" 1276.

* P. distichum L.; Paspale ì feuilles distiques. Vulgo : Herbe à cabrit. Trin., Ic., t. 112 et t. 120. - Vivace ou annuel, haut de $35-60 \mathrm{~cm}$., à rhizome rampant, stolonifère, gros, a chaume droit ou plus ou moins conché. Feuilles courtes, roulées, glabres ou poilues at la base. Épis 2 , longs de 4-J cm.. divergents d'abord, ensuile convergents, dont 1 toujours situé plus bas; épillets sur deux rangs, ovés, larges; ghme stérile, à 3-5 nervures; rachis linéaire, aplati sur le dos. - Dans les savanes et endroits humides, ou aquatiques : Gourberre, Camp-Jacob, Trois-Rivières, etc. Ilt. 0-600 mèt. [No 3609 .

Mantixique. Vulgo : Ilerbe-mouton, herbe-cabrit. - Pamasse, Fort-deFrance, Lamentin, Ducos, Rivière-Salée, Case-Pilote, Robert, François, etc. [No 545.$]$

* P. pusillum Vent. : Paspale petitet mince. - Rampant, radicant, à chatume filiforme, long de $30-60 \mathrm{~cm}$. Feuilles petites, vert tris pâle, plates, souvent pubescentes, aussi longues que les entrencuds. Fip 2-5, rapprochés, longs de 5-7 mm.; rachis linéaire, plat sur le dos; épillets sur deux rangrs, brièvement pédicellés, rondâtres. - Peu abondant. Çà et là le long des chemins, dans les champs de cannes, les plantations de manioc, etc. : Fontaine Didier, Prêcheur, Parnasse, Carbet, ete. Alt. 10-400 mèt. [No 565. - Je ne l'ai pas trouvé à la Guadeloupe.

*P. notatum Flüngr.: Paspale très caractéristique. Vinggo : Herbe-sûre femelle. Trin., Ic., t. 111; Sw., Observ., t. 2, f. 1. - Herbe à rhizome stolonifère, plus ou moins rampant, à chaume droit ou incliné, haut de $35-55 \mathrm{~cm}$. Feuilles distiques, nhlauques, confinées vers la base : les supérieures peu nombreuses, distantes et courtes; chaume comprimé. Ejpis 2, diveruents, longs de $6-8 \mathrm{~cm}$. : le terminal plus haut; épillets ovés, obtus, whlabres, larges: „̈lume lertile, a 3-5 nerrures, insérées sur deux rangs ; rachis linéairé, plat sur le dos. - Cette espèce ressemble de prime abord au P. distichum; mais il en differe surtout par ses leuilles vert wlauque, ses stolons tris longs, et ne se rencontre que le Iong des ruisseaux, dans les lits des rivieres et sur le bord des mares: environs de la Basse-Terre, Gourbeyre, Iamentin, Baie-Mahault, Moule, Marie-Galante, elc. Alt. 0-600 mèt. [Nos 2675, 3610.] 
Martixique. Vulgo: Zerbe at mouton. - Endroils aquatiques, berds dis ruisseaux, le long des canaux, elc. [Yo 558.$]$

* P. setaceum Mich.; Paspale séteux. 'Trin., Ic, 1. 129 et 130). - Innuel. délicat, à rhizome rampant, radicant, long ; chaume frénicule. couch

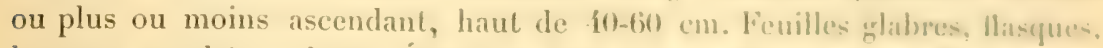
Jongues, penchées, plates. Épis 1-2, dont un très distant, lomps de f-i) (mo... arqués, portés sur un chaume grêle et filiforme, nu naissinul a l'aisselle du dernier noud; épillets glabres, insérés sur trois ranź; rachis grlabre, plat sur le dos. - Peu abondant. - Endroits ombragese et humides des cuvirmodu Camp-Jacols (chemin de la Cascade de Viuchelet), (iommier, Matunba.

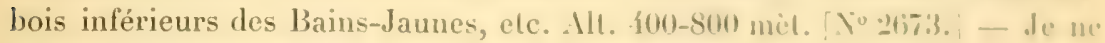
l'ai pas trouvé à la Martinique.

*P. fimbrialum H. B. Kith; Paspale à épillets franerés. - Annuel, ornemental, cespiteux, très droit, haut de $40-60 \mathrm{~cm}$. lienilles plates cilies: épis 2-5, rarement 7, longs de $\mathbf{4}-5 \mathrm{~cm}$. : les inlérieurs, très distants; lés supérieurs, plus courts et plus rapprochés; rachis tringone, plat sur te dos, larre:

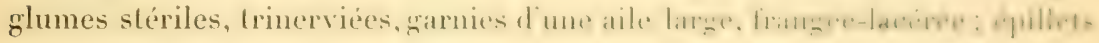
ovés, obtus, mucronés, pédicellés. - Assez abondant sur la route de lia Basse-Terre à Gourbeyre et du Camp-Jacob, Trois-livières dans les chemins des caféières $\}$, etc. Alt. 10-100 mìt. [ $\mathrm{N}^{\circ} 0679.7$

Mantmigue. - Environs de Fort-de-lírance, route du lamentin ì lucens. hauteurs de la Rivière-Salée, Marin, etc. [No 1.276.

P. glabrum Poir.; Paspale glabre. Vulgo: Herle-calé. Trin., Ke., 1. 12ti. - Cespiteux, haut de 50-70 cm., plus ou moins dilfus. Fenilles lnufrues,

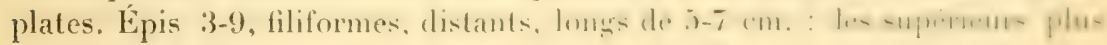
courts; rachis linéaire, convexe sur le dos; épillets sur quatre rangs, plus

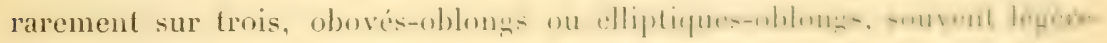
ment pubescents. - Abondant dans les terres sèches, sablonmenses nu cailcaires-des mornes inférieurs : Vieux-Fort, Vieux-Habitants, Deshaies, I hisi-

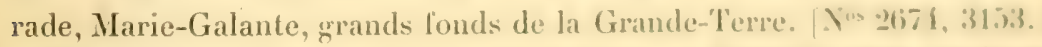

Mantrivive. Vulgo: Herbe-sûre bâtard. - Endroits sec's dés himuleur: inférieures de Case-Pilote, de Case-Navire, du Marin, des Trois-Hels, cle. IN०5 50 .

*P. plicatulum Mich., P. undulatum Poir.: Paspale it leuilles lingirement

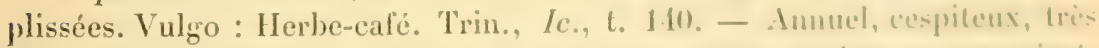
droit, haut de $50-80 \mathrm{~cm}$; it racines filiformes, fortes; it chanme comprimé. Feuilles ondulées sur les bords, rigides, droites, lamres, ciliées it la basere: ligule garnie au sommet et sur les deux bords de poils plus ou moins numbreux. Épis 5-7, un terminal, les autres distants, loners de f-li cm. : les suprerieurs plus courts ; rachis trigone, plat sur te dos; épillets sur qualtre ranks.

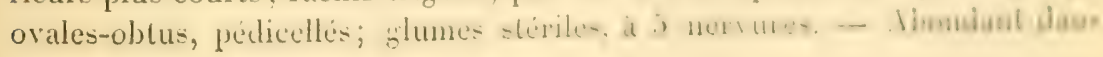


les savanes herbeuses et sablonneuses, dans les chemins des caféières, dans les plantations de manioc des régions moyenne el basse : Basse-Terre ichamp d'Arbaud, Gourbeyre, Baillif, Trois-Rivières, Montéran, etc. Alt. 30400 mèt. [Nos 2676,3608 .

Mantingce. Vulgo: Herbe i cheval. - Parnasse, hauteurs de Périnell, Trois-Ilets, Anses-d'Arlet abondant, La Régale, Saint-Esprit, etc. Yus 5 is, 720.

* P. virgalum 1.. : Paspale trés droit. Vulgo : Herbe rude. Trin., Ic., 1. 1333; St., I. 69, f. 2. - Cespiteux, formant de grandes toulfes, haut de 0"' 81)-1 "' 30. Fenilles larges, longues, ylabres, plates, scabres sur les bords; gaine assez souvent ciliée. Épis 8-12, d'une longueur moyenne de $10 \mathrm{~cm}$. : les supérieurs souvent plus courts, un terminal, les autres distants; rachis vigoureux, trigone: épillets obovés ou rondâtres elliptiques, quelquefois pubescents surr les bords. - C'est de tous les Paspalum l'espece la plus vigoureuse, possédant les caryopses les plus volumineux. - Endroits fertiles et le long des chemins de campanne des basse et infra-moyenne régions de toute la Ciuadeloupe proprement dite: plus rare it la Grande-Terre. Alt. (1)-500 mèt. [\$o 2680.

Martisigle. - Herbe a cheval. - Case-Pilote Fond Layelle el liond Brûlé), Case-Navire, Lanentin, Fort-de-France (emvirons), 'Trois-Rivières, Robert, etc. [No 552.]

* P. paniculatum L.; Paspale à épis en panicule. Vulgo: Herbe à cheval. Trin., Ic., t. 127; Sl., t. 72, f. 2. - Droit, cespiteux, ornemental, haut de $70-95 \mathrm{~cm}$., à chaume comprimé. Feuilles longues, relativement larges; gaine couverte de poils luisants, couchés; ligule longuement ciliée et garnie de poils courts et luisants. Eipis droits, 30-40): les inférieurs, longs de .j-fi cm.; les supérieurs, plus courts et plus rapprochés, constituant ensemble une belle panicule pyramidale: épillets petits, insérés sur quatre rangss, arrondis ou ovés-rondâtres: rachis trigone, légèrement convexe sur le dos : épillets petits, insérés sur quatre rangs, arrondis ou ovés-rondatres. - Espece lacile it reconnaitre à cause de sa panicule ì épis nombreux. - Ibondant dans les terres sablonneuses et les savanes humides de la rénion inférieure : route de la Basse-Terre à Montéran, Camp-Jacob, Gourbevre grande savane près du Valcanardi, Trois-Rivières, Lamentin, Sainte-liose Sol'ava), Morne-à-l'Ean, Moule, Sainte-Anne, etc. $\left[N^{\circ} \mathbf{2 6 7 \%}\right]$

Martinele. Vulgo : Ilerbe a mulet, herbe a cheval. - Mbondant : Carbet (vallée, Case-Pilote fond Layelte, Fond Brüli, Belle-fonntaine, CaseNavire, Lamentin, Ducos, 'Trinité, Robert, etc. [Nus 549, 55 1.]

P. saccharoides Nees; Paspale à panache de canne à sucre. Vulgo : Calumet. Trin., Ic., 1. 107. (Tricholæna Schrad.) - Vivace par ses slolons, à chaume fort, ligneux, creux, trois fois plus gros a la base qu'une plume d'oie, renflé aux nouds, toujours tortueux, géniculé, branchu, presque tou- 
jours à branches penchées, haut de $1^{\text {m}} 50-3$ mèt. Fenilles disticues, pelativement courtes, laineuses en dessus, linéaires-acuminces, cincp it sept linis plus

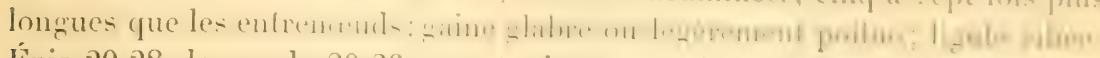
Épis 20-28, longs de $20-26 \mathrm{~cm}$, Loujours penchés, filiformes. formant ume panicule corymbiforme, courte; épillets blancs, laincux-soyeux, lancindlís, acuminés, brièvement pédicellés; rachis grlabre, - Abondint : m le: lalus al dans les falaises abruples el humides des régions moyeme el in fri-moyemue : Camp-Jacob, Bagatelle, Gommier, Matouba, Trob-livieres (movions du Trou-au-Chien). Alt. 350-900 mèt. [No3366.

Martingue. Vulgo : Calumet blane, - Très abondant: Inute de la trace. Camp de l'Alma, fontaine Absalon, route des Deux-Choux an Cros-Mone. et à la Trinité, etc. [No 131\%.]

Eriochloa H. B. et Kith (du gree "erion ", laine, el "chloat ", foin, parce que les épillets sont garnis de poils fins et laineux.)

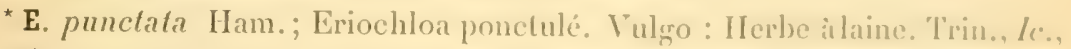
t. 153. - Vivace par ses rhizomes, ornemental, droit, eespiteux, haut de $0^{\mathrm{m}} 80-1^{\mathrm{m}} 10$, à chaume cylindrique. Feuilles largement linéaires-acuminés. glabres, souvent pubescentes aux nowds, it gaines el lirrules frlabres. Inllorescence en grappes dressées, allongées, longues de $10-1$ f cm., composies de 10-14 épis: les inférieurs, distants, longs de $3-5$ cm.; les supérieurs, plus courts et plus rapprochés; rachis et pédicelles pubescents; épillets subsessiles, alternes, ovés-lancéolés, garnis d'un duvet fin, soyeux et luisant. - Le long des routes, dans les savanes herbeuses, humides et fertiles de la réfion inférieure et basse : environs de la Basse-Terre, Montéran. Duchamnis, Gourbeyre, Trois-Rivières, Vieux-Fort, Pointe-Noire. Alt. f(1)-foll mèt. $\left[\mathrm{N}^{\circ}\right.$ 2709.]

Marmineve. Vulgo : Ilerbe à laine. - Peu abondant : environs de Furl-

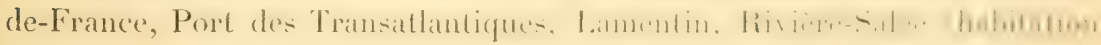
Saint-Pée. $\left[\mathrm{N}^{\circ} 5 \mathrm{k} 0\right.$.

Stenotaphrum T'rin. (du gree "stenos ", court, el "laphros ", losse, parce que les glumes sont concaves et les épillels couchés dans les petites fossetle: du rachis.)

* S. americanum Schrk, S, glabrum 'Trin.; Stenotaphre américain. l'ulyon: Gros chiendent. - Vivace, très stolonifère, rampant et radicant it la hatie, plus ou moins dressé aux extrémités, haut de 30-90) (mon., branchu, à chaume comprimé. Feuilles rigides, distiques, obtuses, courtes, naissant par deux it l'aisselle des nouds; gaine comprimée, grlabre; ligule glabre. lipis solitiares, longs de 6-7 cm., axillaires el terminaux : ces derniers, plus lumps: cpillels bilatéraux, bitrisériés, couchés dans les cavilés du rachis: glumes trís concaves, imberbes, pointues, dures, oblongues-lancéolées.

- Abondant dans les basse et infra-moyenne régrioni, oú il lorme souvent 
gazon sur d'assez grandes étendues : Vieux-Fort (près du bord de mer), Camp-Jacoh, Monteran, Matouba, Pigeon. Troi-Rivieres, et dans les grands fonds de la Grande-Terre. Alt. 10-640 mèt. [Yo 3151.]

Martixigce. Vulgo: Gros chiendent. -- Savanes du Morne-Rouge, hauteurs de Périnell, du Prêcheur, du Lamentin, du Saint-Esprit, etc. No 1324.

Oplismenus Beaur. (du gree "hoplizein ", armer, parce que les glumes sont pourvues de longues arêtes.)

0. selarius R. el Sch.; Oplismène séleux. Vulgo : Herbe à barbes. Orthopogon R. Br.) - Annuel (ou virace dans les endroits humides), rampant, radicant, long de $0^{m} 40-1{ }^{m} 20$, souvent ascendant aux extrémités, à chaume grểle, branchu, filiforme dans le haut. Feuilles ovées-lancéolées ou lancéolées, brièvement acuminées, parsemées en dessus de quelques poils; gaine ciliée. Épis 5-9, longs de $1-3 \mathrm{~cm}$., très distants, en panicule terminale, longue de 10-13 cm.; épillets 丂̆-11, dans un épi; glumes stériles 3, ciliées, longuement barbues: les 2 supérieures à barbes plus courtes; rachis commun, glabre; le secondaire, hispidulé. - Très abondant dans les chemins des caféières, cacaoyères, dans les clairières des grands bois : Matouba, CampJacob, lingatclle, Gommier, les Palmistes, hauteurs des Vieux-Habitants, des Trois-Rivières, etc. Alt. 400-800 mèt. [No 3826.]

Martingece. Vulgo: Z'erbe à barbes. - Abondant : fontaines Didier et 1bsalon, hauteurs de Care-Pilote, Parnasse. Champllore. Baste-Pointe, etc. TX" i⿱⺈

0. Loliaceus beaur. ()plismène ressemblant it livraie. Orthopogon R. Br. - Ressemble beaucoup au précédent quant au port et à la forme des feuilles; il en diffère surtout par sa taille et ses leuilles plus petites, ses épillets non ciliés. - Peu abondant : endroits ombragés de Montéran, de Gourbeyre, des mornes inférieurs de Houëlmont, etc. Alt. 100-300 mèt. [N०2714.]

Mantuxque. - Plus abondant : environs de Saint-Pierre (Trois-Ponts et Jardin botanique), Prêcheur, Grande-Rivière, etc. [No 778 b.]

L'Oplismenus africanus Beauv, 0. compositus Beauv, vulgo : Herbe panachée, vivace, radicante, rampante, à feuilles ovales-lancéolées, zébrées de blane, a tiges filiformes, est naturalisé et cultivé dans les jardins et les pares comme herbe d'ornement. - Originaire de l'Afrique. [No 3155.] Martinique. [N'o 1325.]

Panicum L. (du latin " panis ", pain, parce quantrefois on fabriquail du pain avec ses semences; le Panicum de Pline, XVIII, 10, 25, est le Holcus Sorghum L. actuel.

* P. paspaloides Pers, P. truncalum T'r.; Panis ressemblant à un Paspalum. Vulgo: Herbe à riz. Trin., Ic, 1. 168, - Tivace, cespiteux, plus ou moins 


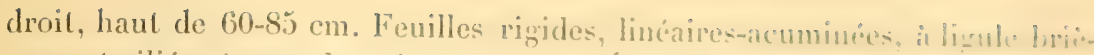

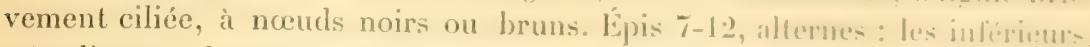
très distants, long's de 2-3 cm.; les supérieurs, fraductlement phus mppurechés et plus courts, formant ensemble une panicule torminale, tres allonirus:

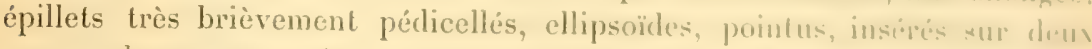
rangs; glumes sans arêtes. - Peu abondant. (Ca ot lit dans lus rígims infé-

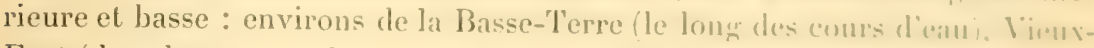
Fort (dans les savanes herbeuses), Lamentin (environs de hat livine-('hatude). Baie-Mahault, etc. Alt. 0-300 mèt. [No 3381.

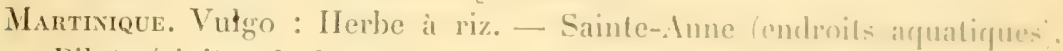

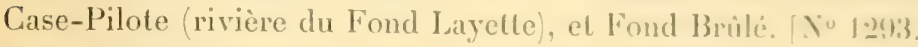

P. colonum L., P. pseudocolonum Roth, P. Dalloni Pinlal.: Panis the colons, Vulgo : Herbe à riz. Trin., Ic., t. 160. - Annuel, droil, hant de 30$80 \mathrm{~cm}$., rarement plus haut. Feuilles flasques, glabes, linéaires-icumines. sans ligule; nouds bruns, rétrécis. lis environ de mème longuenr que le:entrenceuds, en panicule longue de $8-12 \mathrm{~cm}$, ;épillets insérés sur quatre rants: glumes stériles, mucronées. - Abondant dans les saranes fertiles, le lonn des routes de la basse région de toute la Guadeloupe el de ses dipendances. Alt. 0-300 mèt. [No 2681.]

Mantrique. Vulgo : Herbe à riz. - Mbondant dans loule lile. . IIt. $0-300$ mèt. [No 1322.]

* P. Crus-galli L.; Panis à crête de coq. Vulugo: IIerbe ì riz. Trin.. IC.. t. 161. - Annuel, cespiteux, haut de 50-80 cm., stolonilëre, primicule it lit base et haut de $1^{\mathrm{m}} 20$ dans les endroits arquatiques. Fenilles flabres, linétiresacuminées; ligule nulle. Épis longs de 2, $5-3$ cm., plus longs que les mulrenœuds, en panicule terminale; épillets sur quatre ou six rangs, lorievement pédicellés, hispidulés; glumes stériles mucronées, la troisième grmpic d'une arête qui devient souvent très longue dans la variélé aquatique. - Isice rare. Cả et là sur le bord des fosses el des ruisenux, souvent dans les muisseaux peu profonds: Baie-Mahault, Pelit-Canal (environs du bumper Alt. 0-300 mèt. $\left\lceil\mathrm{N}^{\circ} 3161\right.$.

Mantrigue. Vulgo: Herbe à riz'. - Plus abondant qua ia la ciuadeloupe el

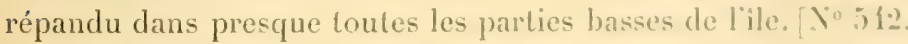

${ }^{*}$ P. prostratum Lam., P. procumbens Necs, P. umh hrosum lhel\%. P. insu. larum Steud.; Panis couché. Trin., Ic., 1. 181, 185. - Innucl, conche, malicant à la base, long de $25-60 \mathrm{~cm}$, à nexuds gréniculés, it chaume filitin'me.

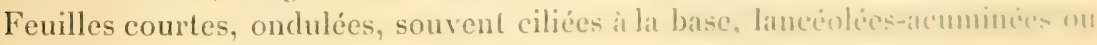

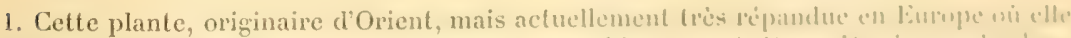

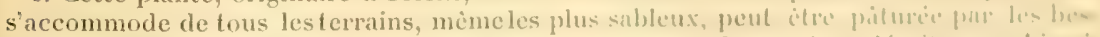

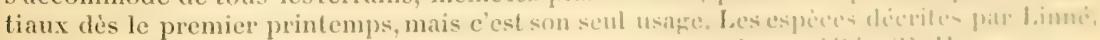
sous le nom de P. colonnm el P. crus-corvi, n'en sont yue des villiclín. (1.. II. 
orées-lancéolées, amplexicaule; waine tinement ciliée au sommet. Épis 8-12, fastigiés, en panieule courte, ne dépassant wuère $7 \mathrm{~cm}$. de long: épillets prlabres. sur trois rangs: lumes de la fleur fertile lexèrement mucronces, toutes les autres obtuses; la deuxième à 7 et la troisième à 5 nervures. - Assez abondaul sur le bord des chemins, dans les champs de cannes du Monle, de sainteAnne, de Saint-François, de Port-Louis, etc. Alt. 5-90 mèt. [No 3529.]

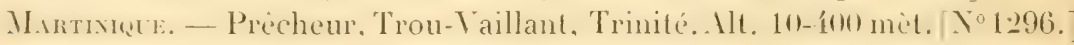

* P. grossarium L.; Panis à gros caryopses (de grossus, petite figure). Trin., Ic., t. 169. - Petit, annuel, haut de 20-10 cm., cespiteux, souvent couché à la base, ensuite ascendant. Feuilles courtes, lancéolées, cuspidées, ciliées à la base; gaine souvent ciliée sur les bords. Épis 3-7, longs de 1-2 cm., (n panicule courte: ipillets slabres. dresses, irrewulierement situes diun seul côté ; première glume à 5 nervures très prononcées. - Peu abondant. Cià et lì dans les endroits secs. sablonneux et calcaires: environs de la Basse-Terre, Baillif, Vieux-Habitants où il forme quelquefois un gazon epais, Deshaies. Alt. 5-300 mèt. [No 3180.] - Je ne l'ai pas trouvé à la Martinique.

P. frumentaceum Roxb., L.; Panis à blé. Vulgo: Herbe queue-de-renard. - Vivace par ses rhizomes, droit, vert pâle, très ornemental, haut de $1^{\text {m } 50-2}$ mèt., rarement plus haut, à chaume glabre, cylindrique, rétréci aux nœuds; nœuds bruns. Feuilles longues, plates, linéaires-acuminées, deux fois plus longues que les entrencuds; ligule garnie de longs et de nombreux poils soyeux; taine striée, poilue sur les bords. Epis juequ it 46 , en panicule allongée, terminale, prourant atteindre jusqu it $40 \mathrm{~cm}$. : rachis primaire anguleux, wlabre: épillets pédicellés, oroüles, trisériés : les deux glumes inférieures mucronées, à 1 nervure 1. - Assez abondant sur le bord des lossés. dans les laubourgs de la Pointe-ì-Pitre el dans les endroits humides ou aquatiques des environs : les Abymes (rare). Alt. 0-30 mèt. [No 3176.] Il n'existe pas à la Martinique,

*P. fuscum Sw, ; Panis jaune noirâtre. Vulgo : Herbe à riz. - Annuel, plus ou monins droit, at base souvent conchée et radicante, haut de $35-6.5 \mathrm{~cm}$. Fenilles linéaires-acuminées, glabres; lizule courte, ciliée; gaine finement striée, snurent pubescente sur les bords. Épis 7-13, simples. allongés : les supérieurs, plus longs. en panicule racenurcie, longrue de $7-11 \mathrm{~cm}$ : épillets gros, jaunes nu noiratres it la maturité, irrégulierement tournés d’un culé: slume extérieure deltoïle, à 3 nerrures ; caryopse transtersalement sillonné. - Peu abondant. Hans les terres et savanes fertiles, le long des routes au pied des murs : environs de la Basse-Terre, Gourbeyre, Trois-Rivières, Moule, les Abymes, Vieux-Fort, etc. Alt. 0-200 mèt. [No 2691.]

1. C'est le Schamalo ou Blé du Deccan, originaire de l'Asie méridionale, plante très fourrageuse et produisant beaucoup de graines, aujourd'hui très répandue et aussi bien cultivée comme céréale pour son grain que comme fourragère. (E. H.) 
Martinique, - Rivière-Saléc, Saint-Esprit, Trois-Ilets, Suinte-Luce. [Nos 387,537 .

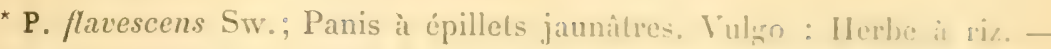
Annuel, plus ou moins droil, flasque, it base assez souvent couchn of radicante, à chaume mou, haut de 60-90 cm. Feuilles elliptieques-lancionlés, lon-

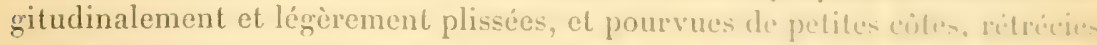
ì la base, poilues en dessous el quelquefois en dessus ; lifule atroite, frirnie d. poils fins; gaine pubescente. Épis simples, 10-20) : les interieurs, sunsent composés; les supérieurs, graduellement plus courts, en panteule pramidale, longue de $7-15 \mathrm{~cm}$; ; épillets insérés sur deux rangrs; ratchis primaires ol secondaires pubescents et portant, en outre, de petites snies druite: flum inférieure ovée, à 3 nervures; la deuxième, à is nervures; caryopse printuellipsoïde, comprimé sur le dos, transversalement sillonné et ponctulé. Abondant dans les haies, le long des routes et dans les savanes herberuses de la région inférieure: Basse-Terre, Capesterre (Guadeloupu'), Trois-livieres. Lamentin (Ravine-Chaude), Sainte-Rose; sia et là dans les grands londs de la Grande-Terre. Alt. 0-300 mèt. [Nos 368:-3175.

Martinique. Vulgo : Herbe à riz, - Dans toute l'ile, mais plus alondant dans le Nord et surtout aux environs de Saint-Pierre et au Pamasee. $x$.ifl.

*P. palmifolium Poir., P. plicatum hailiense Kith; Panis it leuilles de palmier. Vulgo: Petit bambou, herbe it bambou. 'Trin., Ic., 1. 2.2.3. - Iivace par ses rhizomes et stolons, glabre, droit, plus ou moins sarmenteux cyuand

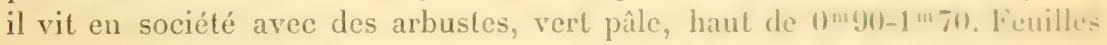
longues de $25-52 \mathrm{~cm}$. (le pétiole compris) sur $4-6 \mathrm{~cm}$. de linrye, Iongitudinalement plissées et pourvues de côtes, elliptiques-lancéolées, étroitement acuminées, légèrement et lentement atténuées vers la base : les jeunes.

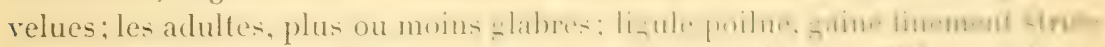

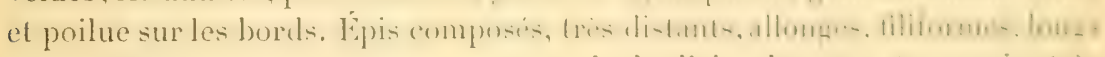
quelquéfois de $30 \mathrm{~cm}$, formant une panicule d'abord compacte, ensulte trie-

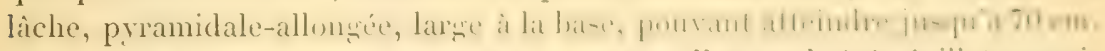
de long et au delà, à branches à la fin tournées d'un seul ciolé; ṕpillets apprimés contre le rachis, glabres, irrégulièrement tournés d'un cité. (ìlume infírieure, ovée-oblongue, oblusément pointue, it $3-5$; la deuxième, it i- it; la troisième, à 5 nervures. Rachis secondaires el tertiaires frarnis de soies peru rigides et presque droites, - C'est de toutes les Graminées des Inlitlés celli. qui a les plus larges feuilles. - Peu répandu : sia el lit aux environs de .1ontéran; abondant dans la ravine de la rivière Noire (habitation l)ucharmeis. Alt. $250-400$ mèt. $\left[N^{\circ} 3185.\right]$

Martineqe. Vulgo : Petil bambou. - Introduil au Jardin bolanilgue, ni il

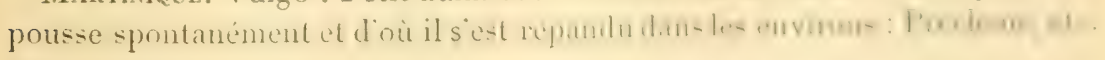
$\left[\mathrm{N}^{\circ}\right.$ 1292.] 
${ }^{*}$ P. molle Sw., P. barbinode T'rin., P. sarmentosum Roxb., P. guadaloupense Steud.; Panis à chaume mou. Vulgo: Herbe de Para. - Vivace par ses rhizomes. rampant it la base et radicant, ensuite plus ou moins ascendant, à chaume cylindrique, mou dans le haut, à nouds renflés et garnis de poils droils, fius el blanchâtres. Feuilles molles, relativement courtes, linéairesacumines, whabrescentes; yaine linement strice et le plus sourent pubescente, ciliésur les bords; ligule glabre, brune. Epissimples : les inférieurs, souvent composés à la base et longs de 5 -6 cm.; les supérieurs plus courts, tous beaucoup plus longs que les entrenueds, en panicule prramidale longrue de $10-20 \mathrm{~cm}$; épillets glabres, tournés d'un côté; glume inf'érieure, deltoïde, étroite, uninerviée; les deux supérieures, à 5 nervures; caryopse demicylindrique, légèrement ponctulé. - Introduit du Brésil, naturalisé et eultivé pour la nourriture des chevaux et du bétail. - Abondant dans nos

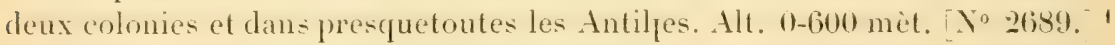

Mantrique. Vulgo : Herbe de Para. [No 539.]

*P. diffusum Sw.; Panis dilfus. Vulgo : Herbe-cabrit. 'Trin., Ic., t. 263. Anmel, très cespiteux, glabre, haut de $15-55 \mathrm{~cm}$., toujours plus ou moins couché ¿ la base, ensuite ascendant, à chaume filiforme. Feuilles étroites, linéairesacuminées. Épis solitaires ou réunis par 2-7, étalés, souvent branchus à la base, formant une panicule courte, tres làche, prramidale, terminale, niexcedant jamais $8 \mathrm{~cm}$. de long: épillets bruns, irrégulièrement tournés d'un côté. - Propre au terrain sec, rocailleux ou sablonneux, ou calcaire de la basse région, où il forme souvent gazon sur une assez grande étendue : Baillif, Vieux-Habitants, Bonillante, Pigeon, Pointe-Noire, Deshaies, Vieux-Fort. - Constitue un fourrage recherché des chèvres et des moutons. Alt. 5240 mèt. [No 3181 .

Mhrtivique Vulgo: Herbe à cabrit. - Endroits secs entre les Anses-d'Arlet et le Marin. [No 536.

P. rivulare 'Tr.; Panis des rivières. - Vivace par ses rhizomes, très droit, ornemental, haut de 1-1 "1"20. Feuilles glabres, lancéoles, longuement acuminées. graduellement rétrécies à la base, longue de $15-25 \mathrm{~cm}$. sur près de $3 \mathrm{~cm}$. de large: gaine finement striéc : celles des feuilles inférieures, zarnies de poils serrés, couchés et de cils droits. Epis nombreux, composés, en panicule fastigriée, dressée, rétrécie à la base, élargie au sommet, longue de $30 \mathrm{~cm}$; rachis principal, walne, robuste; rachis secondaires et tertiaires filiformes; épillets irrégulièrement unilatéraux, petils. - Rare: sur les bords de quelques pelites rivieres, dans les hauteurs entre la Riviere-Salée el Sainte-Luce. Alt. 280-35̌0 mèt. [No 708.] - Je ne l'ai pas trouvé à la Guadeloupe.

1. Cette grande espèce fourragère, originaire de I'Amérique chaude, de l'Afrique et de l'Asie méridionale, constitue un superbe et excellent fourrage, atteignant jusqu'à deux mètres de haut; elle donne un produit abondant dans les terres arrosées, mais ne peut prospérer que dans les régions chaudes. $\langle$ E. H. 


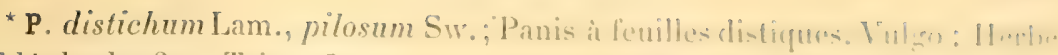

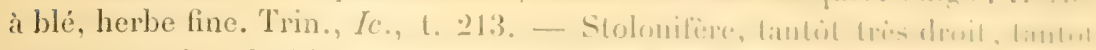

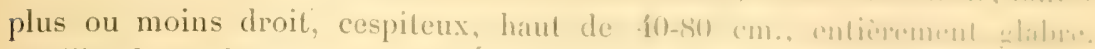

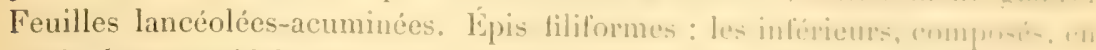
panicule pyramidale, large à lal base, pouvant alleindre jusqu

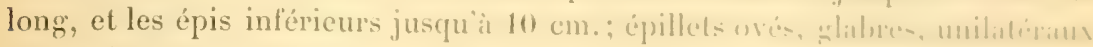

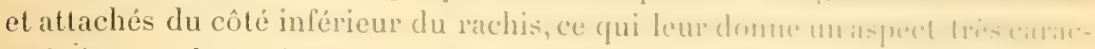

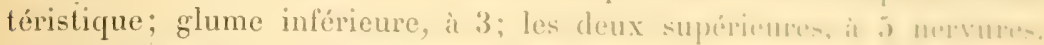

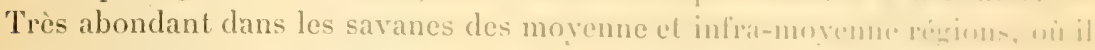

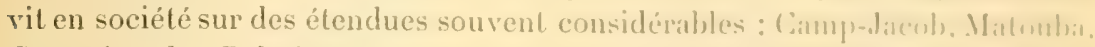

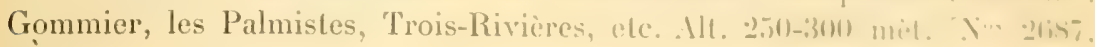
3179.

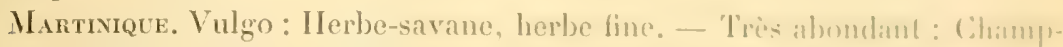

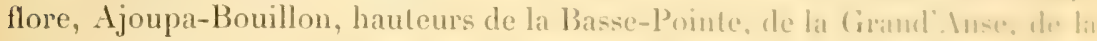
Rivière-Salée, etc. INos 534, 735, forme uberior.

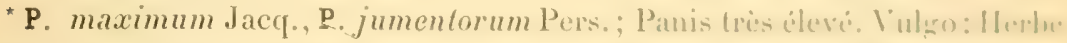

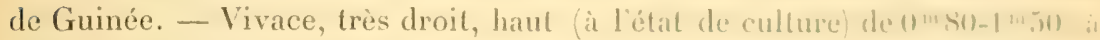

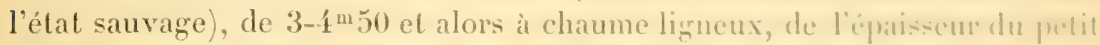

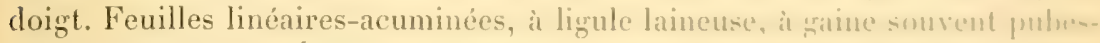
cente dans le haut. Épis d'une longueur movenne de 3 cm... citales, verticillis.

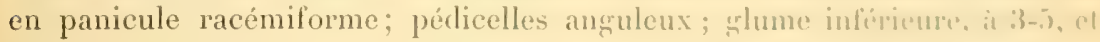
les deux supérieures, à 7-9 nervures; caryopse ellipsoüde, frlalure, luisant. Originaire de la Guinée 1. - Introduit dans les colonies pour la momiture des chevaux de la Gendarmerie. - Naglumalisé el cultive dans touler les Antilles. Alt, 0-750 mèt. [No3186.

Martivece. Vulgo: Herbe de Guinéc. [Yo 1288.

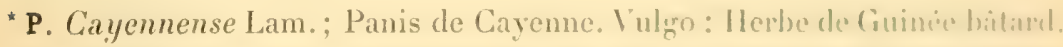
- Droit ou légèrement incliné, quelquefois conché it la basts. surtout diurles endroits aquatiques, haut de $10-70 \mathrm{~cm}$. Feuilles rigides, élroiles, smusml roulées, longuement acuminées, très pubescentes, surtout en dessons. phus rarement glabres, glauques en dessous; gaine poilue, il poils fris at druils.

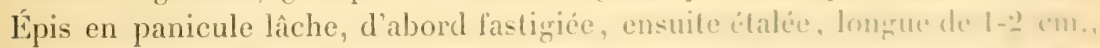
à branches non verticillées : les inl'érieures, composées el plus courlé que. les supérieures; pédicelles filiformes, rigides; pédicellules catpillatires ; friltretellipsoïdes; première glume, deltö̈de, tronquée, trois fors phtus centhe que l'épillet; les deux supérieures, stériles, de mème longucur dit is nemrume:

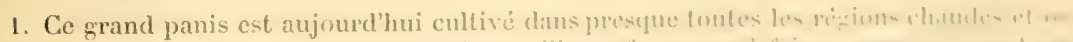

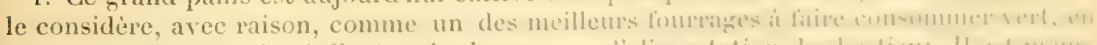

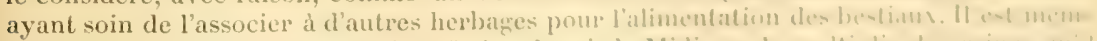

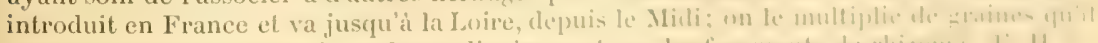

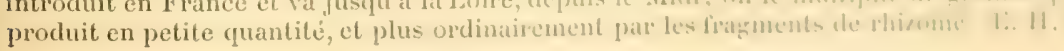


caryopse convexe sur le dos, poli el luisant, blanchâtre, comprimé el pourru de sillons du coté du ventre. Ressemble de prime abord à des pieds maigres de l'herbe de Guinée. - Assez abondant dans les endroits sablonneux des (mvirons de la Basse-Terre: çì et lì à Gourbeyre bords du Vaicanard); beancoup plus abondant dans les savanes des environs du Moule, où il forme grazon sur une étendue souvent considérable. 1lt. (1-350 mèt. N"3181, variété it feuilles pubescentes.j [N"3178, variété à feuilles slabres.] - Je ne l'ai pas trouvé à la Martinique.

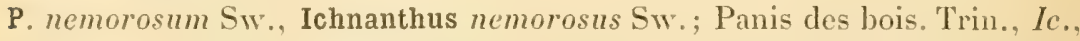
t. 210. - Annuel, rampant, radicant, long de $35-70 \mathrm{~cm}$., branchu, glabrescent, délicat. Feuilles ovéesou ovées-lancéolées, pointues, obliques à la base, demi-amplexicaules; saine légèrement pubescente. Épis simples, rarement composés, solitaires ou en panicule courte, pyramidale; épillets assez volumineux, elliptiques-oblongs, dressés, à pédicelles courts : les trois glumes stériles, subégales, l'extérieure à 3 , les deux supérieures à 5 nervures, et la troisième munie de glumellules. - Assez abondant dans les chemins des cafeiceser cacanyeres, des bois de petite fulaie, sees ou humides : fontaines Diclier et . 1)salon, Morne-Tert, La Régale, Gros-Morne. Alt. 300-650 met. [No 773.] - Je ne l'ai pas vu à la Guadeloupe.

P. pulchellum Raddi; Panis petit et gracieux, - Annuel, rampant, radicant, délicat, glabre, peu feuillu, long de $30-50 \mathrm{~cm}$., à chaume filiforme. Feuilles courtes, ovées, pointues; gaine courte, ciliée. Épis 7-21, allongés, simples : les inférieurs, très distants; les supérieurs, plus rapprochés el plus courts, constituant ensemble une panicule très làche, fastigiée, étroite, longue de $10 \mathrm{~cm}$.; épillets distants, unilatéraux, souvent avortés, ovoïdes-pointus; glume inférieure, deltoïde, deux fois plus courte que l'épillet, à 1 nervure; les deux supérieures, à 3 nervures. - Rare : çà el là dans les endroits ombragés des environs de la fontaine Didier et des hauteurs du Carbet. 1lt. 201400 mèt. [No 767.] - Je ne l'ai pas trouvé à la Guadeloupe.

*P. pallens Sw.; Panis à couleurs pâles. Trin., Ic., t. 211. - Annuel, branchu, rampant, radicant, souvent ascendant, long de $30-90 \mathrm{~cm}$. Feuilles nombreuses, rapprochées, ovées-lancéolées ou lancéolées, brièvement ou longnement acuminées, sessiles, inégales, nhlabres ou ciliées à la base; ligule "rlabre (dans fous mes spécimens); gaine wabrescente. Epis racémiformes, le plus souvent légèrement composés, en panicule axillaire et terminale, acuminese à la base ef ́largie au sommet, longue de $7-10 \mathrm{~cm}$. : les panicules axillaires plus courtes; pédicelles anguleux; épillets elliptiques-oblongs. Glume extéricure, trois fois plus courte que l'épillet, à 3-5; les deux supéricures, à 5-7 nervures. Fleurs fertiles, munies, à la base, de deux appendices liguliformes; caryopse à base garnie de deux petits prolongements. - Abondant dans les sentiers des caféières el cacaoyères, des bois humides, etc., de toute 
la Guadeloupe proprement dite; assez raresur les mornes des Grand-FondAlt. 90-800 mèt. [No 2686.

Martinique, - Abondant dans les cheminsides plantations, maí sultoul dans celles de la fontaine Didier, du Monne-Vert el du Morne-Konge. . Mt. ju600 mèt. [No 773.

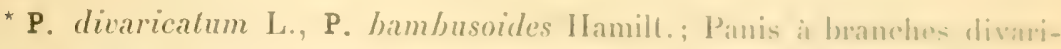
quées. Vulgo : Pelit bambou, calumet. Lam., /ll., 1. 13, 1. 33 sty. - Vivace par ses rhizomes, sarmenteux, pouvant alteindre jusqu i miel, d'ariation, très branchu, à branches tombantes, grểles, divariguere, it chamme ligneux dans le bas, plus gros qu'une plume d'oice, lonfli: aux mumels. Feuilles étroites, lancéolées-linéaires, acuminées, courles, disliques, frlabre ou légèrement pubescentes. Épis en panicule peu branchue, a hranche simples ou composées (selon la fertilité du terrain); pédicelles incinaux; épil. lets obovés, très verts; glume inférieure, trìs concive-ventrue, dêvicr mu souvent presque horizontale, à 7 nervures; les deux superiures, stiriles. polies et luisantes, de même longueur, surmontées d'une petite toulle de: proil: soyeux, blanes; caryopse convexesur le dos, aplati du cóté ventral. - Mburdant dans les bois sees, pierreux des mornes inférieurs de loule la ciunte loupe et de ses dépendances. Alt. 5 -100 mèl. $\left[N_{0} 318: 2\right.$.

Martinique. Vulgo: Pelil calumel. - Ilauteurs de Case-l'ilote, du Líntel. des Trois-Hets, de la Régale, du Diamant, ete. [No 76!).

P. Sloanei Griseb., P. arborescens Sieb,; Panis de Sloane. lulgo Calumet. Sl., t. 71, f. 3. - Vivace par ses rhizomes, sarmenteux, hatul de 3-5 mèt, et au delà, branchu, à branches pubescentes; chaume limpux, denx fois plus gros dans le bas qu'une plume d'oie, à nuxuds larges, renllis. lieuilles obovales-lancéolées, acuminées, finement pubescentes en dessous at fraturues. souvent inégales à la base; gaine pubescente ou seulement cilice stur lex bords, à l'état adulte, fortement poilue dans la jeunesse, linement strice ol garnie-de nombreux petits tubereules au fond des stries. lipis en panicule obovée ou pyramidale, lâche, longue de $13 \mathrm{~cm}$., à hranches diverperntés, peut distantes et peu composées : les plus basses souvent renlermés dams la zanim de la dernière feuille; épillets obovés-obtus, verts ou moirilres; frlmun: stériles, arrondies : les deux supérieures, légerement incigales ct it 11 morrores. - Abondant dans les haies el les lisieres des momes inferients, stest mu humides, dans les clairières des bois de toute la Guadeloupe el de sers déprudances, Alt. 0-600 mèt. [No 3613.

Martinique. Vulgo: Calumet. - 1)ans tous les hois jusqu'it une allitude de 550 mèt. $\left[\mathrm{N}^{\circ} 770.\right]$

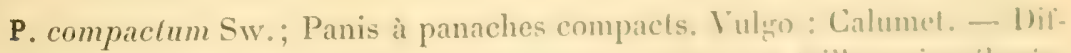
fère du précédent, auquel il ressemble beaucoup : par sal laille moins ibevic.

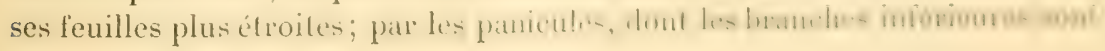


toujours renfermées dans la derniere gaine du chaume. - Mime habitat et tout aussi abondant. [Nos 3683, 3183.] - Je ne l'ai pas trouvé à la Martinique.

* P. brevifolium L.; Panis à feuilles courtes. Vulgo : Petite avoine. Sl., 1. 72, 1.3 - - Annuel, délicat, très ornemental, droit, cespiteux. Feuilles courtes, confinées vers le bas du chaume, oblongues-lancéolées, acuminés. arrondies à la base: gaine pubescente. Épis en panicule pyramidale, droile. longue de 11-14 cm., à branches distantes : les inférieures, deux fois; les supérieures, une fois composées: pédicelles longrs, capillaires: épillets obovés. confinés aux extrémités des pédicelles. pelits, légèrement pubescents: unlume inférieure à moitié aussi longue que les épillets; les deux supérieures énales, it 3 nervures; la troisième, étroite, garnie diune petite glumellule. - Endroits ombracés des basse et infra-moyeme régions de toute la Guadeloupe et de ses dépendances, sans ètre abondant nulle part. Ilt. (1-600 mèt. TYo 2681.

Martinique. Vulgo: Herbe fine. - Cà et là dans les terres en friches el les savanes de toute lî̀le, [Nं 1321 .

P. lencophaeum H. B. et Klh, P. Mnchassaingii Steud., Tricholæna insularis Griseb. . P. lanatum Roltb.; Panis à panicule d'un blancéclatant. Vulgro: Herbe à blé. Sl., t. 14, f. 2; Trin., Ic., t. 220 ; Desc., vool. IV, t. 238, p. 11. Andropogon L. - Vivace par ses stolons, cespiteux, droit, haut de (1) 80 $1^{\prime \prime \prime}$ 20. Fenilles flasques, glabres, linéaires, acuminées ou lancéoléc-linéaires : les inférieures, plus longues, toujours plus ou moins penchées. Épis tournés d'un coté, verticillés, en panicule terminale, Inngrue de 1.5-20 ('m., penchée au sommet; pédicelles inéwaux, séminés; épillets arliculés à la base. lancéolés-acuminés, imberbes: glume inférieure. petite, wlabre: les deux supérieures, de longueur écale, membraneuses et garnies de poils soveux el blanc argenté. - Descourtilz place, avec raison, cette plante parmi les diurétiquesexcitantes. Dans les Antilles, les racines, prises en infusion, sont d un usare fréquent comme très rafraîchissantes et diurétiques. - Mondant dans les basse et infra-moyeme régions de toute la Guadeloupe el de ses dépendances. Alt. 0-600 mèt. [Nos 2507, 3187.]

Martinique. Vulgo: Herbe à blé. - Dans toute l'île. No 1318.

P. sanguinale Lin., Milium digitalum $\mathbf{N}$; ; Panis couleur de sang. Vulgूo : Herbe fine mâle. Trin., Ic., t. 93. - Annuel, couché à la base ; à rhizome rampant, radicant, génicule, à chaume ascendant ou plus ou moins droit, filiforme, délicat. Feuilles lancéolées-acuminées, peu nombreuses, confinées dans la partie inférieure du chaume. Épis 5-13, filiformes, allonsés, étalés. longs de $8-9$ cm., en panicule courte, digitiforme: épillets étroits, disposés par deux dans chaque paire, l'un est pédicille et plus haut. l'autre subsessile', lancéolés nu oblongs-lancéolés, pointus: plume inférieure, petite ou rudimentaire: la deuxieme, plus longue que les fleurs; la troisieme, pubescente sur les 


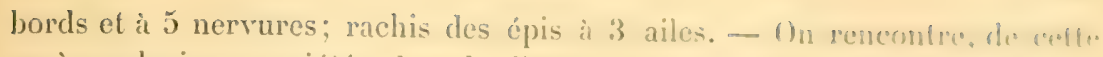
espèce, plusieurs variétés, dont la dillérence porte : sur les lenilles, qui - mul tantôt glabres, tantòt finement pubescentes; sur la gaine, qui est pubencente. ou garnie de longs poils droits; sur le nombre et lat longueur dés épis dont les premiers sont souvent verticillés par 3-1; la largeur des arles des rate-hi-: la grosseur des épillets et des caryopses. - Abondant daus les lorres silflunneuses, humides des basse el infra-moyenne régions de tonte la ciurde-

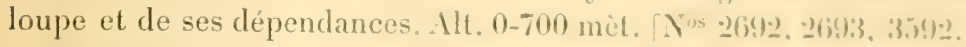

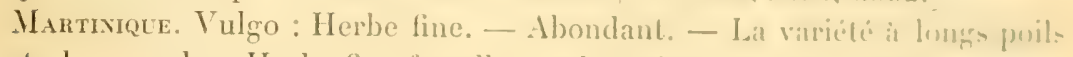
porte le nom de "Herbe fine femelle ". Alt. (1- 150) mèt. To 1:32:3.

P. amplexicanle Rudge; Panis à feuilles embrassantes. lulgo : Herbe queue-de-rat. Trin., Ic., 1. 205. - Vivace, à rhizomes rampants, malicints. très allongés, à chaume couché dans le bas, ensuile atscendant. haut de 1-2 ${ }^{m}$ 10. Feuilles larges, glabres, cordées a la base el amplexicaules, lancénlées-acuminées ou les supérieures lancéolées-linéaires; traines et ligules glabres; noeuds contractés, noirs. Épis en panicule spiciforme, acmmine, allongée, étroite, cylindrique, longue de $25-32 \mathrm{~cm}$; ; épillets petils, lrièrement pédicellés, lancéolés-acuminés; glume inférieure, deux fois fulus courte que l'épillet; les deuxsupérieures, inégales, à $3-5$ nervures : grlume de la lleur. fertile, cartilagineuse, ne durcissant pas avec la maturite du caryopse. - - Vil en société dans les étangs et les mares: Gourberre / Valcinard'. TroisRivières (étang de l'habitation Roussel), Moule (élamg du Conconere ele. All. 0-400 mèt. [Yo 3372 .

Mantixique. Vulgo: Herbe queue-de-rat. - Find-de-liance, Lat Ijillon, Lamentiñ, Rivière-Salée, etc. đỸo 1313.

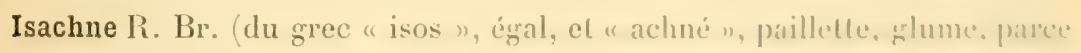
que les deux premières glumes inl'érieures sont de meme longruerur.

I. arundinacea Griseb., Panicum arundinaceum Sw., P. dispermum l.amk. : Isachne roseau. Vulgo: Petit bambou, calumet, - Olnemental, vivace par ses stolons, sarmenteux, haut de 1 -í mèt. très branchu; it chame lizmer. très glabre, cylindrique, un peu plus gros dans le bas quime plume dine ; it nouds bruns, rentlés; à branches toujours plus ou moins inclincis ou fombantes. Feuilles lancéolées, longruement ou brièvement acuminces, trieglabres. Epis nombreux, rapprochés, jaunitre doré, componsts, filifinmer,

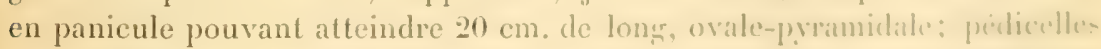
courts, inégaux, capillaires; épillets petils, ovoüdes; les dexx fumes inlirieures, de longueur égale, à 5 pelites cútes, frlabres. - Herthe camatiritique par ses glumes et par ses panicules jaune dure, lincile it distingure der autres Panicum samenteux, auxquels il ressemble par le port. - Iscer ahumdant dans les clairières et les falaises, sur les lalus des hois supirionr: de toute la Guadeloupe proprement dite. Alt. 50)(1)-110(1 mèt. X" :31s!?. 
Mantinique. Vulgo : Calumet, petit bambou, - Abondant. - Alt. 100 1000 mèt. [No 1341 .

I. rigens Trin.; Isachné à feuilles rigides. Vulgo : Petit calumet. - Omemental, rivace par ses rhizomes, haut de $26-50 \mathrm{~cm}$., très branchu, d'un aspect wrisou vert très pâle: a racines fortes, longues el très nombreuses : à chaume souvent couché a la base et radicant, ensuite droil. Feuilles distiques, courtes, tress rapprochées, rigides, linéaires-acuminées, scabres; waines courtes, laissant après la chute des feuilles des protubérances annulaires. Épis courts. en panicule courte, rigide, droite, ovale-pyramidale, longue de $6-8 \mathrm{~cm}$.; pédicelles courts el inégaux; épillets oboroïdes; les deux glumes inférieures, inégales, à 7 nervures. - Assez abondant dans la haute région où il vit souvent en société sur d'assez grandes étendues: Savane à Mulets, Savane aux Ananas, Grande-Découverte, Nez-Cassé, etc. Alt. 1200-1480 mèt. $\left[\mathrm{N}^{\circ} 2705\right]$ et $\left[\mathrm{N}^{\circ} 3190\right]$ la grande variété.

Martinique. Vulgo : Petit calumet. - Montagne-Pelée, Pitons-du-Carbet. [N०1312.]

Setaria P. Beauv. (du latin " seta ", soie de porc, parce que le rachis des épis porte de nombreux faisceaux de soies droites et rigides.)

S. glauca P. Beaur, variété penicillala Griseb.; Sétaire à feuilles ghlaucues. Vulgo : Herbe-salon. Trin., Ic., t. 195. - Annuel ou bisannuel, cespiteux, d'un aspect grisâtre; à racines souvent rampantes dans les vieux pieds; ì chaume le plus souvent penché, haut de $10-70 \mathrm{~cm}$.; a nouds presque toujours séniculés dans le bas. Feuilles glauques, rigides, droites, étalées, plates, linéaires-acuminées, rétrécies in la base; gaines et ligules glabres. Inllorescence en épis vert jaunatre, cylindriques, loners de $8-13 \mathrm{~cm}$., solitaires, terminaux; épillets rapprochés, solitaires, subverticillés, uniflores, insérés sur quatre ou sir rangs, pédicellés, chaque pédicelle portant, à la base, un faiseeau de soies jaunâtres (à la maturité), quatre ou cinq fois plus longues que lépillet, et barbelées, a barbules tournées de bas en haut; glume extérieure deux fois plus courte; la deuxième, carénée et une fois plus courte que les épillets; glumes fertiles égales; étamines 3 , at antheres brunes; caryopse transversalement sillonné, convexe sur le dos, plat sur le côté ventral. Assez abondant dans les basse et infra-moyenne régions de toute la Guadeloupe et de ses dépendances. - Les épis se conservent longtemps : on les cueille pour en faire des bouquets de salons. Alt, 0-600 mèt. [N" 2094.]

Martinique. Vulgo : Herbe-salon, herbe à bouquets. - Dans toute l'île. Alt. $11-500$ mèt. [N" 131.4.] Introduit probablement de France dians les deux colonies.

S. italica P. Beauv.; Sétaire d'Italie. Vulgo : Petite queue-de-renard. Trin., Ic., t. 198. - Annuel, glabre, droit, ornemental, haut de $60-80 \mathrm{~cm}$. Feuilles plus larges et plus longues que dans le précédent. Épis rapprochés, 
courts, formant une panicule serrée, longue de $11-1: 3$ cm. str \& cm, de dian mèt., oblongue; soies involucrales 5-8, cing lois plus lomerues que les ipil. lets, réunies à la base sur une longueur de $1,5 \mathrm{~mm}$; iprillets alliplique. oblongs; caryopse finement pointillé. Facile it distinguen du précident : part son port, sa panicule courte el épaisse; par sa taille beancoup plus vipun-

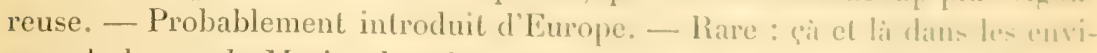
rons du bourg du Marin, dans les terres fertiles el cullivirs, Xu 1:31.5. _ I. ne l'ai pas vu à la Guadeloupe.

S. verlicillata P. Beauv.; Sélaire verticille. - Annucl, falome, haut de 35-45 cm., droit, beaucoup plus délicat que les deux précedents; chame it noeuds noirs. Épis très courts, en glomérules verticillés par f, limmant ensemble une panicule longue de $\{-6 \mathrm{~cm}$, serrée, cylindrique: ípilleds stosiles, cinq ou six dans un glomérule; soies involucrales -2-1, droifés, conterte. inégales: la plus longue dépassant une lois lépillet. - Proloullement introduit de France. - Assez rare : terres sablonnes des emvirons du Marin at dim-

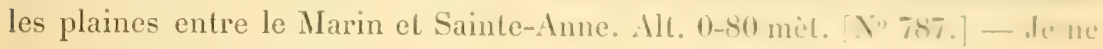
l'ai pas vu à la Guadeloupe.

S. setosa P. Beauv,; Sétaire séteux. Tulgo : Avoine-silvanc. Trin.. le... t. 96, A 95. - Annuel, grêle, haut de 50-85 cm., rarement plus haıt: it rhizome rampant dans les vieux pieds; à chaume d'alonel droil. omenile incliné, nu dans le haut, sur une étenclue de $6-20$ (cm. Fenilles pern numbreuses, linéaires-acuminées, roulées. Épis courts : les inférieurs, frís distants, longs de $2-3 \mathrm{~cm}$; les supérieurs, graduellement plus rapprochio al plus courts, formant ensemble une panicule tris allongere, somvent lumstre de $20 \mathrm{~cm}$., fastigiée; épillets elliptiques, pointus; caryopsce transwersilement strié; soies involucrales $1-3$, trois ou quatre lois plus longues que les iquilluts. quelquefois presque nulles; axe des épis garni de petils poils. - Trís abundant dans les terres sèches, arides, calcaires ou sablomenses de liaillil, de Bouillante, de Pigeon, de Deshaies, de Vieux-Forl, des saintes linte-de-

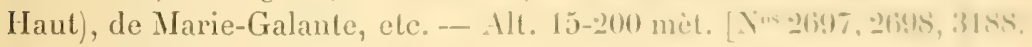

Martinique. Vulgo: Avoine bâlard, - I Iauleurs du l)iamanl, (imo-lleds des Trois-Ilets, rochers du bord de mer de sainte-Iace. Ill. \{-2sil met. [No 511.$]$

Pennisetum Rich. (du latin " perna ", p)lume, el "sela ", soic de frore. parce que les soies involucrales sont plumeuses à la liatse

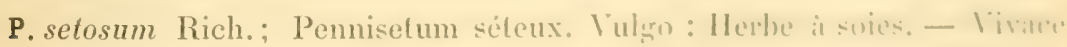

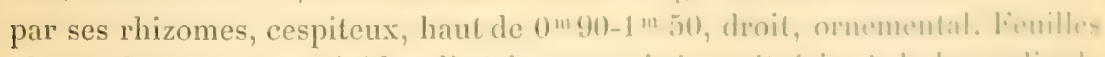

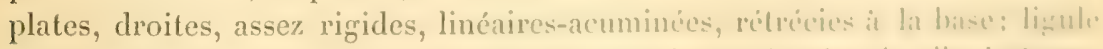

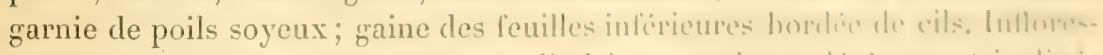
cence en épis longs de 12-18 cm., cylindriques, pointus, hiziremunt imclimis

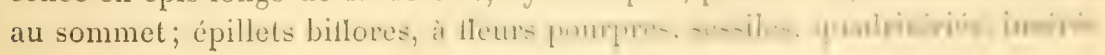


sur de petites protubérances du rachis, chacun niché au fond d'un faisceau de soies; soies unies à la base : les quatre extérieures, longues, dont une très longue; les intérieures, plus courles, toutes plumeuses à la base; glumes inégales, concaves, mutiques : l'inférieure, petite ou avorlée; les glumes stériles, au nombre de 3 ; glumellules 3 ; étamines 3 ; style 2; étamines et styles pourpres. - Assez peu répandu : cà el là dans les terres sablonneuses des environs de Saint-Pierre (Boulevard), de Fort-de-France, Trois-Ilets (rare). Alt. 5-150 mèt. [No 1316.] - Je ne l'ai pas vu à la Guadeloupe.

Cenchrus L. (du grec " kenchron », millet, à cause de la ressemblance du caryopse avec un grain de millet.)

* C. echinatus L.; Cenchrus hérissé de piquants. Vulgo : Herbe rude, herbe-collant, herbe picpunte aux Vienx-IIabitants), herbe-ponle male au Moule). - Annuel, haut de $40-70 \mathrm{~cm}$., presque toujours couché et radicant à la base, ensuite ascendant; à chaume mou, supérieurement branchu, très feuillu. Fenilles relativement larges, allongées, linéaires-acuminées. Inflorescence en épis terminaux, cylindriques, longs de 7-9 cm.; épillets bi-quadrillores, inserés sur quatre rangs, renlermés dans un involucre large, ventru, très dur; à 9 lobes linéaires, séteux et spinescents, inégaux : les uns, droits; les autres, infléchis et se croisant entre eux; involucre entouré, à la base, de 18-20 soies adhérentes, infléchies, seteuses: les unes, plus courtes: les autres, plus longues que cet involucre; glumes 2, minces, transparentes, renfermant un caryopse libre, sessile, comprimé, presque aussi large que long, et surmonté d'une pointe courte, émoussée et brune. - Assez abondant dans les savanes herbeuses de la basse récion de toute la Guadeloupe proprement dite : plus rare à la Grande-Terre, à la Désirade et à Marie-Galante. Alt. 0-250 mèt. [No $2 \% 18$.]

Mantinque. Vulgo : Herbe rude. - Dans la région inférieure de loute l'île. $\left[\mathrm{N}^{\circ} \mathrm{790.}\right]$

* C. tribuloides I.; Cenchrus dont les épillets ressemblent à un fruit de 'Tribulus. Vulgo : Ilerbe rude, pied-poule mâle (au Moule). Sl., t. 65, f. 1. (C. spinifex Cav.). - Diffère du précédent: par sa taille moins élevée; par son chaume plus couché et moins branchu; par ses épillets moins volumineux; par ses soies involucrales, moinsnombreuses, multisiriées, noiritres, diverenentes, lres acérées, droites ou subuliformes, Iancéolées: par les lobes de l'involucre plus courts, fendus jusque près de la base, plus rigides el moins nombreux. - Espéce variable quant a la longueur des soies. - Les fruits mûrs des deux espèces de Cenchrus se détachent facilement et saltachent fortement i tout ce quiles fouche, au moven des pointes propres aux feuilles involucrales. - Plus petit que le précédent et abondant dans loutes les savanes des base el inlira-moyenne régious de toute la Guadeloupe et de ses dépendances. Alt. 0-600 mèt. [No 3173.] 


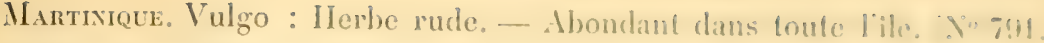

Anthephora Schreb. (du gree "anthos ", lleur, ol "phercin ", prorter, parce que, dans les espèces-types, les épillels portent une fleur neulro ol num lleur hermaphrodile.)

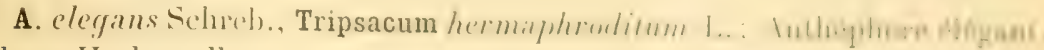
Vulgo: Herbe-collant. - Annuel, élégrant, très droit, hant de :3(1)-lie) ("ml.. rarement plus haul; à chaume mou, glabre; il ligules of maines chlahwes. Feuilles linéaires-acuminées. Inflorescence en ejpis cylindriques, mincer, allongés, solitaires, longs de $9-12 \mathrm{~cm}$; épillets allernes, inscrus sur deux rangs, sessiles, tous hermaphrodites; involucre uniserie, divisc prespue jusqu’a la base en quatre segments ovés-lancéolés, rélrecis il lal hased, durs. presque osseux, lormant quatre fentes; fleurs it deux frlumes memluamenses. plus courtes que l'involucre; stigmates 2, courts, frlabres, cappillaires, presfur sessiles, très aigus; caryopses petits, glabres. - Asse\% abondant dans loule: les savanes herbeuses, humides de toute la Guadeloupe el de ses dipendances. Alt. 0-500 mèt. [Nं 2717.$]$

Martixique. - Abondant dans toute l'ile. [Yo 131?."

Arundinella Raddi (diminutif de "arundo ", roseau.

A. martinicensis Trin.; Arundinelle de la Marlinique. Vulgur : P’elil roseau. - Vivace par ses Hhizomes forts et longrs, lris droil, haul de 1 m 2) -11I" 80 ; à chaume ligneux dans le bas, deux ou Lrois fois plus gros qu ume plume d'oie. Feuilles longues, peu nombreuses, linénires-acuminies, scalores: graine à peine pubescente. Fleurs en panicule allongée. lastipieve druite. longue de 30-35 cm., constituée par des épis filiformes, légerement compusis. disposés par faisceaux subverticillés; épillets billores, jammitres, distants. lancéolés, petits, géminés; glumes inégales, à 3-jonerrures ; frlumes stiviles. 3 : celles des fleurs fertiles, cartilagineuses, surmonties d'une arite drote (dans mes spécimens). - Peu répandu : hauteurs du liond Jalyelle CarsPilote), route de Fort-de-France it la lontaine Didier. Mlt. 2.j(1-3un mil. [No 559.] - Je ne l'ai pas trouvé à la cruadeloupe.

$$
\text { Sous-tnme II. Sil:cirdutis. }
$$

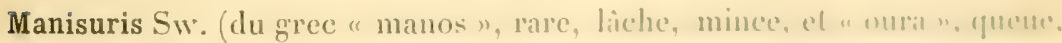

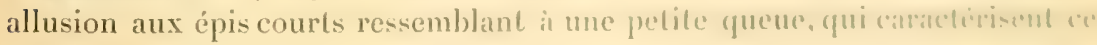
genre de plantes.)

M. granularis Sw; Manisure granuleux. Vulino: Petil millol. S1.. 1. S1).

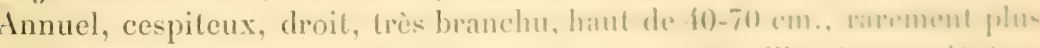

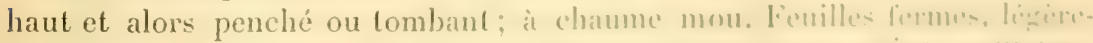

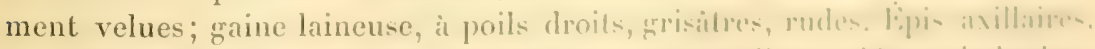

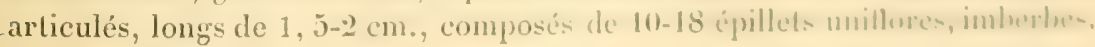


féminés, alternativement fertiles et neutres: fleurs fertiles à denx glumes concaves, dures, dont l'une inférieure et l'autre supérieure et plus longue; Ileur stérile, à deux slumes presque ézales : étamines.3; (aryoper orhiculaire. comprimé. scrobiculé, blane ì la maturité, de la srosseur d'une tète d'épingle. - Cà et là dans les champs sablonneux, fertiles de la région inférieure: route de la Basse-Terre a Gourbeyre, Trois-Rivières, Moule, Gozier, elc. Alt. $0-360$ mèt. [No 3172 .]

M.artixigte. Vulgo: Ierhe queue-de-souris, petit millet. - Plus abondant qu'à la Guadeloupe: Trou- $T$ aillant, chemins des champs de cannes de la Basse-Pointe, Macouba, Parnasse, Ajoupa-Bouillon. [N०1275.]

Andropogon L. (du gree " aner ", homme, et " pogon ", barbe, allusion aux poils et arêtes des épillets et de l'axe des épis.)

A. saccharoides sw : Andropogon à ípillets semblables à ceux de la tlèche de la canne à sucre. - Annuel, haut de 45-70 cm., droit, grêle, rarement couché à la base; à chaume nu dans le bas. Feuilles distiques, courtes, très rapprochées, glabres ou plus rarement velues: ligule poiluc: gaine glabre. Épis articulés, longs de $3-5 \mathrm{~cm}$., au nombre de $5-7$, formant un faisceau paniculé, long de $1-7 \mathrm{~cm}$; ; epillets fertiles, sessiles, munis d une longue arete: ¿pillets neutres pédicellés: axe de lépi garni de poils fins. - l-sez abondant dans les endroits rocailleux et secs de la basse région: Baillif, falaises du Galion, les Saintes (Terres de Haut et de Bas). Alt. 0-200 mèt. [No 3170.$]$

Martingue. - Diamant, Sainte-Luce (sur les rochers près du bord de mer, Trois-Ilets rochers de la pointe Salomon!, Anses-d'Arlet pente du morne Larcher). [ $\left.\mathrm{Y}^{\circ} 1296.\right]$

A. contorlus L. (ex parte)., A. secundus Willd.; Andropogon à barbes longues et entrelacées. - Annuel, cespiteux, droit, haut de $45-90 \mathrm{~cm}$., branchu, à zaine el liģule glabres. Feuilles allongées, linéaires-acuminées. Ép solitaires, longs la barbe y comprise de $11 \mathrm{~cm}$. : épillets allongés, 121.), chnt les (j-9) inférieurs sont mâles et à glume extérieure lancéolée-acuminée, à deux ailes ciliées sur les bords; les 6-7 supérieures, fertiles, chacun muni d'une arête légèrement géniculée, brune, longue de $7-10 \mathrm{~cm}$.; arêtes sentrelaşant en spirale dans la moitié -upérieure, poilues et libres dans la partie inférieure, au-dessous du genou. - Peu répandu : dans la partie basse, le long de la route qui va du bourw à l'habitation Sainte-sophie (Baillifi. [No 3137.] - Je ne l'ai pas trouvé à la Martinique.

A. condensatus H. B. et Kth, variété paniculatus Hack.; Andropogon à panicule dense. Vulgo : Herbe à bonhomme. - Vivace par ses rhizomes, très

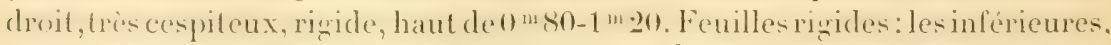
assez courtes; les supérieures, très courtes. Épis alternes, en partie cachés dans une bractée très étroite, latéralement comprinée, allongée, longue de $3 \mathrm{~cm}$. el garnie, à la base, d'une petite touffe de poils très fins; pédicelles 
capillaires, élargis et épais au sommet; panicule lonque de $2.5-30$ em : arliculations du rachis élargies, garnies de poils funs, soyeux et blance; frlumes extérieures de la fleur fertile acuminées el munies d'une arête lúgirement géniculée. - On se sert des panaches pour orner les salons et du chaume pour couvrir les cases. - Assez abondant sur les coteaux secs des hasece d infra-moyenne régions de toute l'île : Vieux-Fort, Vieux-llabitants, l)e-hairs. Bouillante, etc. Alt. 50-100 mèt. [Yo 3817.

Martinique. Vulgo: Herbe-panache. E Environs de Saint-Pierre, sainteAnne, Marin (mornes Sulpice el Gommier). Ilt. 0-110 mil. (X" 1 10 (1)!

A. Nardus L., variété cerifera Hack., A. cillalus D) C. Vuleno : Cilronnelle. - Vivace parses rhizomes stoloniferes, plusou moins rampants, hlanes. durs, ligneux et épais; a chaume droit, haut de $1-i^{m} 70$. Fenilles longues, penchées, étroiles. Fleurs en panicule tries lâche, allongréc, Iongrue de :30$45 \mathrm{~cm}$, composée d'épis courts, peu nombreux, géminés, sarnis, it la baste. d'une bractée spathacée, concave, très aiguë, rougeatre, apprimée, pliée cu deux; pédicelles filiformes, noirs, articulés près du sommet; articulations: du rachis garnies de poils à la base. - Fl. en aout, septembre el octobre. Introduit et cultivé comme plante sudorifique; originaire de l'Inde et de l'Arabie. - Basse-Terre, Moule, les Abymes (aboudant an cimetiere). $\left[N^{\circ} 3169 .\right]^{1}$

Martinique. Vulgo: Citronnelle. - Cultivé dans les jardins commo planla médicinale. $\left[\mathrm{N}^{\circ} 560\right.$.

A. squarrosus L. fils, Vetiveria arundinacea Griseb., V. odurala lirey...

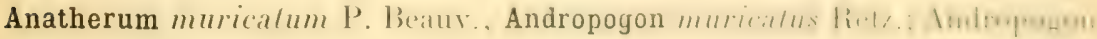
muriqué. Vulgo : Vétiver. - Vivace par ses rhizomes, trís cosplecux. haut de $1^{m} 50-2$ mèt., à leuilles très lonerues, inclinées; it ípis cu panicule large, pyramidale; à épillets muriqués. - Se cultive it la (iuadeloupe, ois on le plante à côté des routes pour fixer les terres. - L'odenr forte déracines chasse la vermine qui, dans les pays chauds, atlaque si facilement leo vêtements de laine: cette particularité vaut à la racine un emploi jummaliem dans les deux colonies: son chaume, dur, sert il couvir les cares. - (1riginaire des Indes Orientales. $\left.\mathrm{N}^{\circ} 3167.\right]^{2}$

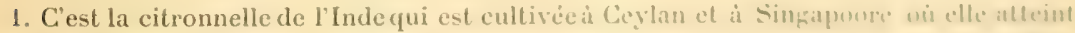
une hauteur de 1 m 80 et davantage. Elle se distingne des espéces voisines par sat conlem

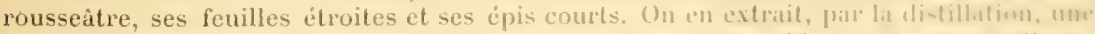

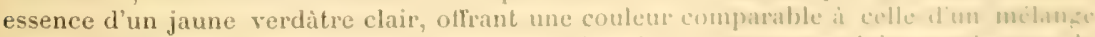

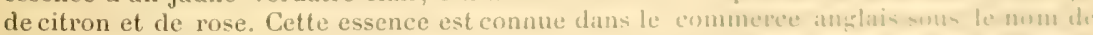

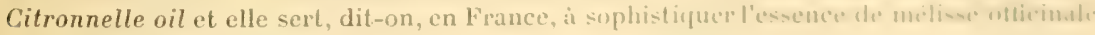
dont elle a un peu l'odeur. (E. H.

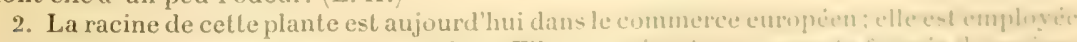
soit comme drogue, soit comne parfum. Elle se presente en palquets finmes de ratime

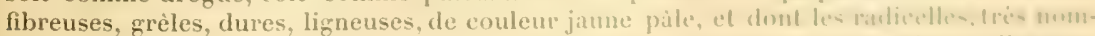

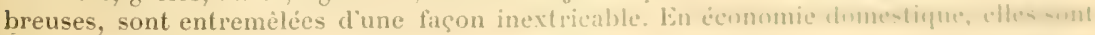


Martinele. Vulgo: Vétiver : çà et là dans les jardins et autour des maisons. $\left[N^{\circ} 1303\right.$.

A. imberbis Hack., variété muticus Hack.; Andropogon sans arêtes. Vivace par les rhizomes, plus ou moins droit, haut de $40-60 \mathrm{~cm}$. Feuilles extremement nombreuses, imbriquées à la base, confinées dans le bas du chaume, tres longues, roulées. linéares-acumineses, slabres. Epis solitaires. longs de $7-8 \mathrm{~cm}$., axillaires et terminaux, renfermés it la base dans la gaine; épillets ghabres, alternes, couchés dans les cavités du rachis imberbe et articulé. - Abondant. Endroits secs et rocailleux près de la mer : Vieux-Fort, Baillif. $\left[\mathrm{N}^{\circ} 3171.\right]$

Martinique. - Rochers du bord de mer entre Sainte-Luce et RivièrePilote. $\left[\mathrm{N}^{\circ} 784.\right]$

A. bicornis I., Anatherum bicorne P. Beauv.; Andropogon à épillels bicornés. Vulgo: Herbe au paurre homme. S1., t. 15. - Vivace par ses rhizomes, très cespiteux, droit, haut de $0^{\mathrm{m}} 80-1^{\mathrm{m}} 20$, rarement plus haut. Feuilles distiques, linéaires-acuminées, très longues, rigides, souvent légèrement poilues vers la base, scabres sur les bords : les inférieures, tombantes, tres nombreuses et rapprochées de la base du chaume; les superieures, distantes, plus courtes; ligule souvent ciliée; gaine glabre. Inflorescence en panicule trés large, rétrécie i la base, supérieurement élarwie, composée de panicules secondaires formés d'épis digités par 2-3. verditres, renfermés d'abord complètement dans une bractéc cylindrique-compriméc, acumince, verte, longue de :2-3 cm. : pédoncules secondaires longs, filiformes, rigides; rachis des épis articulés, chaque articulation munie de poils fins, trìs soyeux, et d'une fleur mâle et femelle : la mâle, avortant ou se réduisant à un simple pédicelle: la femelle, dépourve darêtes. - (In se sert, pour la couverture des cases. du channe qui est tris tenace et dure longtemps. - Abondant dans les savanes sèches, souvent arides des basse et infra-moyenne régions de toute la Guadeloupe et de ses dépendances. Alt.90-900 mèt. [N०3168.]

Martinique. Vulgo : Herbe-panache. - Abondant dans toute l'île. Alt. $50-600$ mèt. [ $\left.\aleph^{\circ} 1302.\right]$

A. lencoslachyus H. B. et Kith, Anatherum domingense Rom, et Schult. ; Andropogon à épis blanes. Vulgo: Herbe au pauvre homme, paille du paure homme. Sl. 1. 68, f. 2.- - Diflère du précédent, auquel il ressemble beaucoup : par sa taille moins èlevie, ses épis et ses panicules plus courts,

employées pour parfumer le linge, les étoffes et en éloigner les insectes. En médecine, c'est surtout un stimulant. Dans l'Inde, on en fait mème des paniers et des stores odorants. On y a trouvé une résine, une matière extractive amère et une huile essentielle employée en parfumerie. Cetteplante est cultivée depuis longtemps en Algérie pour les besoins de la parfumerie locale. (E. H.) 
ses bractées plus larges, mais surtout par la longue aréte, droile, que portu. la fleur femelle de chaque épillet. - Mêmes localités et même altitude. mais moins abondant. No 35 . 18.

Martingue. Vulgo: Herbe à panache. - Trois-llets, Morne-Rnuge, Diamant, Gros-Morne, etc. [No 1301.]

A. Sorghum Brol., Sorghum vulyare Pers, Vulgo: Sormh it mil, wros millet. Desc., vol. VII, t. 511. - Haut de 2-3 mèt. - Introduil el cultivi: çà et là en petite quantité, principalement pour la nourrilure des niscaux 1. [No 3191]: $1^{\circ}$ à caryopses blanchâtres, variété e//usus llack, J 3191 h;: 2o à caryopses noirs, variété niger Hack.

M.ntrineve. Vulgo: Sorgho, gros millet: [Nu 1:32\%], varicte e/[usus,

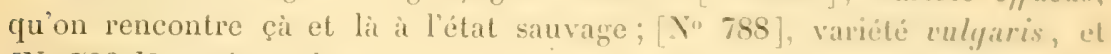
$\left[N^{\circ}\right.$ 78S h], variété niger.

\section{Arthraxon P. Beauv.}

A. ciliaris P. Beauv., variété: Quintinianus Hack, Arthraxnn cilié. Vulero : Herbe-savane. - Vivace par ses rhizomes, Inngrs, rampants el moueux, couché et radicant à la base, ensuite plus ou moins ascendant, haut de :2()$45 \mathrm{~cm}$. ; à chaume branchu, mou, délicat, capillaire daus le haut. Feurilles petites, cordées à la base, ornées, pointues, ciliées à la base : lirrules cel gaines glabres. Intlorescence en panicules digitiformes, axillaires et lerminales, composées de trois ì huit épis d'inégrale longrueur, les plus longr mesurant $3 \mathrm{~cm}$; épillets alternes, allongés, sessiles, noiritres ; flume extérieure noire, surmontée d'une arête géniculée au-dessus de la bast. Très abondant dans les savanes herbeuses du Gommier et de l'habilation Mousine, où il vit en société sur une grande étendue: 13agatelle, Parnassec. etc. Alt. 400-600 mèt. [No3136.] - Il n'existe pas à la Martinique.

Themeda Forsk. (du mot amabe "Thremed n.)

T. ciliata Hack.; Théméde à leuilles ciliées. (Anthistiria I..) - llaut de $50-80 \mathrm{~cm}$., vivace, plus ou moins droit, très branchu, rarement enuché a lis base et alors radicant el géniculé ; à chaume ligrneux daus le has : a ligrule cl gaine glabres (daus mes spécimens). leuilles étroites, frlabres. Inflorescence en épis longs de $7-8 \mathrm{~mm}$. (sans l'arête), solitares, chacun renfermi, aviant son épanouissement, dans une leuille spathilorme, ovale-lancénléc, puintur, garnie, à la base, de cils long's, droits, qui sortent d’un qraud basilature : çuis

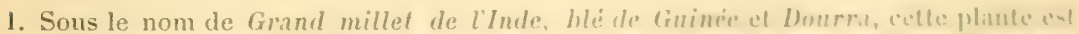
cultivée dans l'Inde et en Afrique, où elle forme la base de l'alimentalion des imbigene(Couscous des Arabes et des nègres). Sous les climals chatuds et en lerre ammeic, celle graminée est trés productive. Coupée avant la formalion du gratin, elle con-litue mu

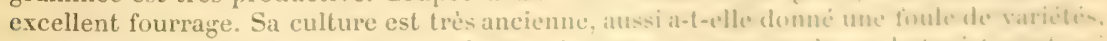
notamment une d'entre elles, nommée Sorgho cernum par quelyues lutanister, ret qui est remarquable par la blancheur et la grosseur de son train. Li. 11. 
lormant des faisceaux paniculés, pédonculés, distiques, qui, à leur tour, constituent une panicule allongée, interrompue et toujours penchée; pédoncules et pédicelles glabres. Épis à sept épillets : les quatre premiers ì tleurs mâles, sessiles, verticillées, couvrant les autres, chacune ayant deux glumes extérieures rigides, aiguës, roulées sur les bords et quelquefois ciliées, qui restent attachées au rachis après la chute de l'épillet, el deux glumes intérieures, ovales, minces et transparentes: au-dessus des épillets mâles, un épillet hermaphrodite, cylindrique, sessile, à une ghlume extérieure, coriace, roulée, velue à la base, et à deux glumes intérieures, oblongues, presque égales, lérèrement obtuses; à trois étamines pourvues de filets courts portant des anthères droites, oblongues; ì deux styles arec des stygmates pileux et en massue; à un ovaire de la base duquel part une arête légèrement pubescente, longue de $40-\mathbf{1 3} \mathrm{mm}$., tortueuse et filiforme dans sa moitié inférieure, géniculée un peu au-dessus du milieu, capillaire et droite audessus du genou; de chaque côté de la fleur hermaphrodite, un épillet stérile, pédicellé : l'un, légèrement plus court et plus étroit que l'autre, les deux, lancéolés et pointus aux deux extrémités; base de la fleur hermaphrodite garnie d'une touffe serrée de poils courts; caryopse mûr très brun, dur, oblong, enveloppé par la glume. - Peu répandu : assez abondant sur les terres argileuses de l'habitation Sainte-Catherine, pris de Fort-de-France. Alt. 40-130 mèt. [Nos 333, 1304.]

Ischæmum Lin., du gree " ischein ", arrêter, et " aima ", sang, parce que la plante servait autrefois à titre d'hémostatique.)

I. latifolium Kth; Ischieme ì larges feuilles. (Ischæmopogon Griseb.) Yulgo: Pied-poule-falaise. - Vivace par les rhizomes rampants, haut de $0^{\mathrm{m}} 90-1^{\mathrm{m}} 40$, quelquefois sarmenteux et haut de plus de 3 mèt.; at chaume géniculé, rentlé aux noxuds, rarement droit, le plus souvent tortueux. Feuilles largement lancéolées-linéaires, glabres, lisses, plates, acuminées ; à ligule garnie de poils droits, blancs; graine glabre. Intlorescence en panicule digitée, composée de 8-15 épis racémiformes, de longueur variable: les plus longrs mesurant $9 \mathrm{~cm}$; épillets billores, pourpres, lancéolés, pédicellés, it pédicelles articulés au-dessus du milieu et zarnis de poils très fins aussi longr's que les pédicelles mèmes: les deux glumes inférjeures, stériles, cartilagineuses, cuspidées, noirâtres, sans arêtes; la troisième, mâle, avec une ğlumellule; la quatrième, femelle, avec une glumellule et garnie d'une arête tordue ou droite, légèrement géniculée ; étamines 3 , pourpres, à anthères dressées. - Abondant dans les endroits non boisés, humides et aquatiques des régions infra et supra-movenne de toute la Guadeloupe proprement dite. Alt. 200-1000 mèt. [ $\mathrm{N}^{\circ} 3366$. $]$

Martinique. Vulgo: Herbe à laine. - Dans les clairières et falaises humides de toute la partie montagneuse de l'île. [No 783.] 
Saccharum L. (du grec "sakchar, sakcharon", sucre, en arabe "soukar".)

S. officinarum L.; Saccharum officinal. Vulgo: Canne à sucre. Tuss., Fl., I, t. 23-25; Desc., vol. IV, t. 287; vol. I, I. 193. - Vivace par ses stolons,

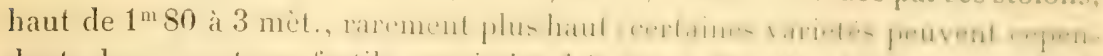

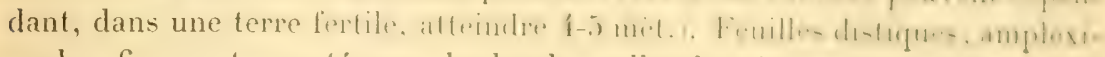
caules, finement serretées sur les bords : celles du milieu, longues de $1-1$ m jo)

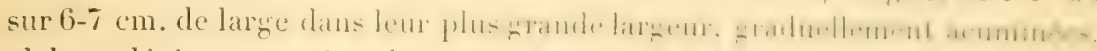
glabres, légèrement rétrécies vers la base et souvent garnies de poils, par-

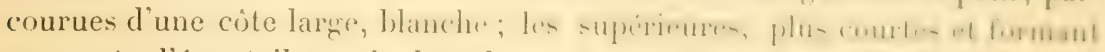
une sorte d'éventail terminal et dressé; celles du milieu el du bas, penchées

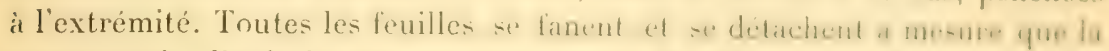

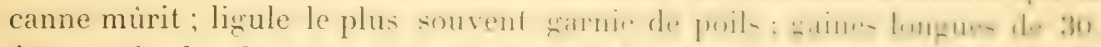

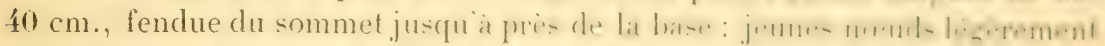

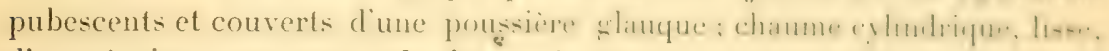
d'une épaisseur moyenne de $1 \mathrm{~cm}$; intervalle d'un noud à l'autre, d'une longueur moyenne de 11 cm. Infloresence en pranicule pramalales nom-

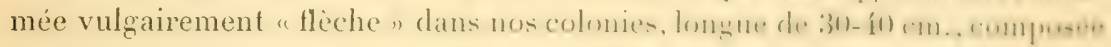
d'épis ramifiés à la base, longs de $15-30 \mathrm{~cm}$., articulés, à articulations

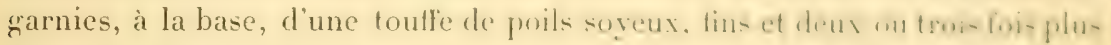

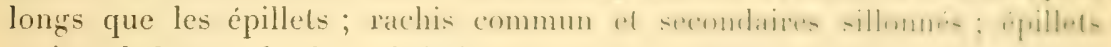
petits, biflores: la fleur inférieure, sessile, mâle, renfermée dans deux

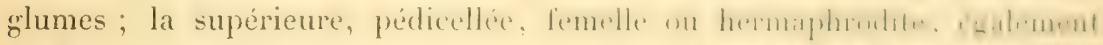

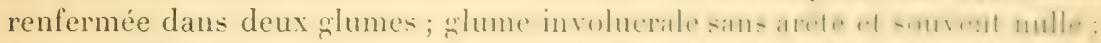

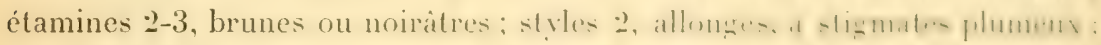
caryopse sessile, très pelit, ou manquant ou avorté. - Les leuilles constituent un bon fourrage pour les chevaux et le bétail. - Uriginaire de l'. Isic

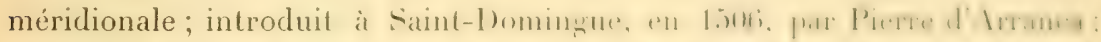

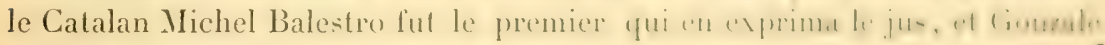
de Celosa le premier qui en fit du sucre. - On en cultive plusieurs varieté, dont les principales sont: la canne créole, la canne violette ou de Batavia, la canne noire, la canne de Salangor, la camne blanche el la canne de laiti: c'est cette dernière qui est le plus souvent cultivée. - Dans l'annéc I SH, la Guadeloupe a exporté $-13.299 .757 \mathrm{kilog}$. de suere d'usine. All. (1-.7)(1) mit. [No 1328.] - Martinique. Vulgo: Canne il sucre. (Spécimen mancque.)

Imperata Cyr. [dédié à I'Italien lerrante Imperate, qui vivail au

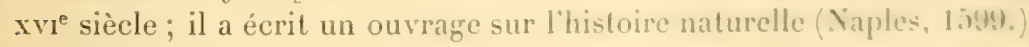

I. caudata Trin., I. contractum II. 13. el Kith; Imperata en panicule it

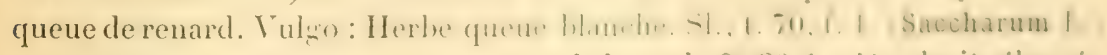
- Vivace par ses rhizomes, ornemental, haut de $0^{m} 80-1$ miel, droil, clanci ; à chaume sous-ligneux à la base, cylindrique. Feuilles peu mombenses. lancéolées-linéaires, plates; ligule glabre (dans mon spécinen : Finine izile- 
ment glabre. Inflorescence en panicule droite, pyramidale-allongée, longue de $20-26 \mathrm{~cm}$., composée d'épis plus longs dans le bas de la panicule que dans le haut; rachis des épis non articulé; épillets non articulés, laineux, géminés, biflores, inégalement pédicellés. garnis, il la base, dinne touffe de poils soyeux, blancs, et quatre ou cinq fois plus longs que les épillets : les deux slumes inféricures, stériles, membraneuses; les deux glumes fertiles, sans arêtes; la troisième renfermée, dépourvue de glumelles; étamine 1; syles 2, a stygmates plumeux; caryopse oblong, libre. - Peu abondant et peu répandu : çà et là dans les terres sèches et rocailleuses des environs du bourg du Diamant. Alt. 10-80 mèt. [No 1306.] — Je ne l'ai pas trouvé à la Guadeloupe.

Coix L. (du grec " koïx " (Théophraste), qui est un palmier: Hyphaene coriacea Gaertn. - Linné croyait que Théophraste arait voulu désigner par ce nom une graminée.)

C. Lacryma L. ; Coïx-larme (par allusion aux caryopses blanchàtres, luisants et ovoüdes rappelant la forme d'une larme.) Vulgo: Larmes de Job. Vivace par ses rhizomes, plus rarement ammel, droit, haut de $0^{\mathrm{m}} 60-1^{\mathrm{m}} 60$, branchu dans le haut; ì chaume ligneux dans le bas. Feuilles comme celles de la canne à sucre, mais plus courtes, alternes, glabres, traversées par une côte blanche, cordées à la base : ligule glabre, marquée de chaque côté d'une tache brune; gaine courte, lâche, élargie au sommet. Inflorescence en panicule extrêmement làche, feuillue, terminale, composíe d'épis longuement et inégalement pédicellés, sortant par 2-3 des gaines des fenilles de la panicule; fleurs monoïques: les femelles $1-2$, rarement 3 , situées à la base de l'épi; à 3 glumes stériles, membraneuses; à style bipartite; à stigmates longt, saillants, corniculés et pubescents ; à caryopse entouré par la glumelle durcie, osseuse, luisante, ovale-conique, on en forme de toupie, de la grosseur d'un pois, traversée par l’axe qui porte les fleurs mâles; épillets à lleurs mâles, biflores, sessiles, it deux glumes ovales-oblongues, mutiques, et à deux glumelles glabres, mutiques, presque aussi longues que les glumes; étamines 3, ovaire, sessile. - On se sert des fruits pour fabriquer des colliers, des chapelets, etc. - Originaire des Indes Orientales; introduit et naturalisé. Cà et là autour des maisons, dans les savanes et les lieux abandonnés: environs de la Basse-Terre, Gourbeyre, Trois-Rivières, Moule, Sainte-Anne, MaricGalante, etc. Alt. 0-600 mèt. [No 2702.

Martinique. Vulgo: Larmes de Job. - Saint-Pierre, Prêcheur, Carbet, Sainte-Anne, Trinité, etc. [No 1280.

Zea L. (du gree "zaein ", vivre, c'est-à-dire plante fournissant une bonne nourriture. Le Zea ou Zeia des anciens est le Triticum Spella L.)

Z. Mays L. V'ulgo: Maïs (nom de la plante che\% les Indigènes de l'Amé-

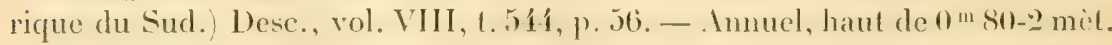
et quelquefois au delà, droit, branchu; à feuilles ressemblant ì celle de la 
canne à sucre; à fleurs monoüques séparées sur le méme pied : los mailes.

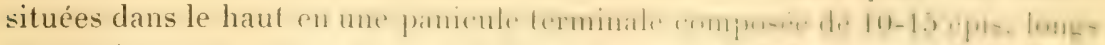

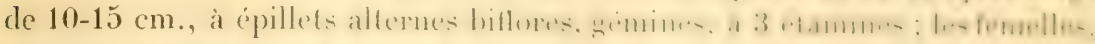
axillaires, situées au-dessous des mâles, appliquées en dix rangrées, sur une

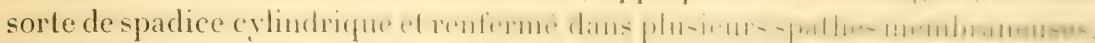
blanchâtres; spadice surmonté d'un faisceau de filaments loners, d'alonrl droits, ensuite pendants, qui ne sont que des étamines superthes. - Originaire de l'Amérique continentale chaude; cultivé dans les deux colonies principalement pour la nourriture de la volaille. All, 0-600 mét. Yo 3163.3.

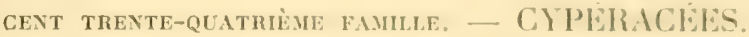 \\ Les espèces marquées d'un "sont fourratriré.}

\section{TRIBU I. CYPÉRÉES.}

Gyperus L. (du mot "kuperos ou kuperon ") des anciens, probablement dérivé de "kupris", Vénus, ì cause des vertus aphrodisiacques du Cyporus rotondus L., localisées dans les racines odorantes. Bauhin croil que le mot vient de "kupuros ", vase, à cause de la forme ovale du tubercule de ce même souchet comestible.)

C. polystachyus Rottb.; Souchet à épis nombreux. Rottb., Jesc., 1. II, f. 1. - Annuel ou bisannuel, droit, cespiteux, tris vert, haut de f(1)-(j) cm. : a rhizomes courts ; à chaume triangulaire, nu dans le haut. Feuilles continées dans le bas. Inflorescence en ombelle contractée, composéc de 7-4) épis,

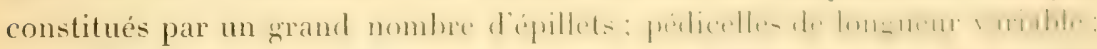
feuilles involuerales longues de $3-6 \mathrm{~cm}$. - Abondant dans les savines humides et sablonneuses des récrions inférieure et basse de toute la Guadeloupe et de la Grande-Terre. Alt. 0-300 mèl. [Nos 3101, 3669).

Martixique. - Variété major. - Abondant dans toute l'ile. [Y (i!)1.

C. compressus L.; Souchet à épis comprimés. Sl., 1. 76, I. 1: 1Rotlh.. Desc., t. 9, f. 3. - Annuel, plus ou moins couché, très leuillu, haut de :2) $30 \mathrm{~cm}$., cespiteux; à chaume triangulaire. Feuilles étroites, plates. Inthrescence en ombelles à $3-5$ rayons pédicellés, de longueur inégale, une des ombellules sessile au centre de l'ombelle; ombellules paniculés portant 3-1; épis, longs de 10-14 mm. - Rare dans les champs; plus abondant daus le: rues peu fréquentées et le longr des roules: Basse-Terre, chemin de la BasseTerre à Gourbeyre, Pointe-a-Pitre, Trois-Rivières, clc. 1/1. (1)-1S1) mét. [No 3818.$]$

Martingue. - Saint-Pierre, Trois-Ponts, Fort-de-France (dans les rues peu fréquentées), Marin (abondant), Trinitć. [ Y 700 a $t$.

C. alopecuroides Rottb.; Souchel it queue de renard. Riollb., Mese., l. s,

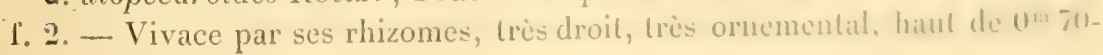


1:-21). nu dans le haut. Fenilles longues. confines dans le bas, tres dargies a la hase : a chaume triguetre. Inthresenese en ombelles trois fois compo-

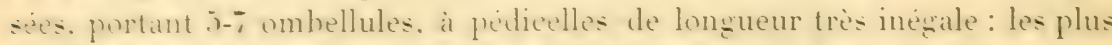
longs mesurant $13 \mathrm{~cm}$ : ombellules a $7-11$ ejos inequax : le plus long mesu-

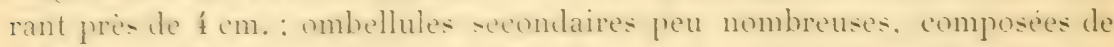

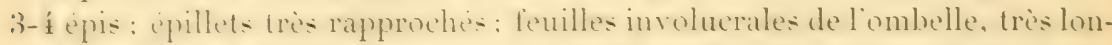

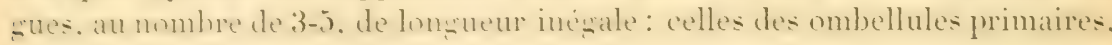
3-1. sétiformes, courtes; celles des ombellules secondaires, nulles. - Ne se trouve a la Guadeloupe que dans les fosses remplies deau de certains fau-

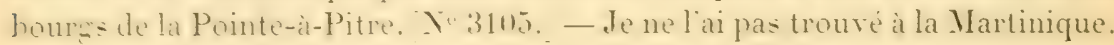

C. confertus $\mathbf{S w}_{\text {: }}$ : Souchet à épis courts et ramassés. - Vivace, droit, délicat: à chaume comprimé, haut de $40 \mathrm{~cm}$. à feuilles longues, nomhreuses. enntinces a la base. Intloresence en ombelles simpless à iti branches

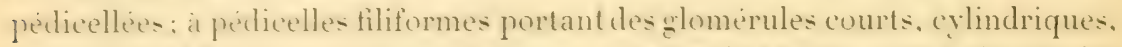
longs de $11-1: 3 \mathrm{~mm}$. : composes d epis au nombre de $18-25$ : quatre ghomérules sesiles. Fenilles involucrales fiti. plus courtes que les feulles caulinaires. Cat el lit dans les saranes humides de la rérion inferieure: Carbet. Pamasse. environs de saint-Pierre. Lamentin. Saint-François. 11t. 0-280 mèt. X" 153. - Je ne laai pas trouvé à la Guadeloupe.

c. umbellatus Benth.; Souchet à épis en ombelle. Rottb., Desc., t. 4, f. 2. - Droit, ornemental, haut de $\$ 5-60 \mathrm{~cm}$; à chaume nu dans le haut, tres feuillu dans le bas: a feuilles rapprochees. Infloresence en ombelle simple. a 11-1:3 ravons portes sur des pédoncules fermes, d’inégale longueur: epis cylindriques: les plus longs mesurant $13 \mathrm{~mm}$. Feuilles involucrales $;-11$, inevales, alternes-distiques. - Peu repandu : abondant dans les terres sablomneuses du (2uartier-Monsieur Carbet. Alt. 25-1201 mèt. Nu695.Je ne l'ai pas trouvé à la Guadeloupe.

C. elegans Walt. C. flaciermus schlecht. : Souchet dewant. - Vivace par ses rhizomes, très droit, haut de $35-50 \mathrm{~cm}$.; à chaume comprimé, nu dans le haut. Feuilles lancéolexes. brusquement acumines. Inflorescence en une ombelle trois fois composée, larece, tres lache, à (1-12 rayons, dont le plus long mesure jusqua $15 \mathrm{~cm}$ : ombellules a 7 -9 rarons, tris inépaux : le plus Inny avant $5 \mathrm{~cm}$. : ombellules seenndaires a $3-6$ ravons. dont $2-3$ plus longs; épis des ombellules secondaires. longs de it mm. Feuilles involucrales de l'ombelle lancénlées. presque aussi longuesque les caulinaires, incigales, au nombre de 7 plus longues que lombelle; celles de lombellule primaire $\overline{7}$. inérales: les plus plus petites. sétifnmes: les plus grandes, linéaires acuminées: celles de l'ombellule secondaire, réduites à 2-3, sétiformes, très courtes. - Pesu repandu el peu abondant: environs de Saint-Pierre TroisPonts, Jardin botanique, Trou-Vaillant). Alt. 15-90 mèt. [No 147.$]$ - Il n'existe pas à la Guadeloupe. 


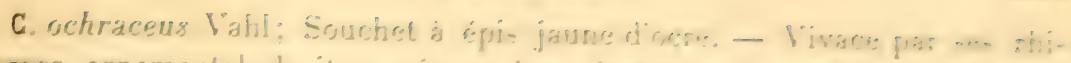

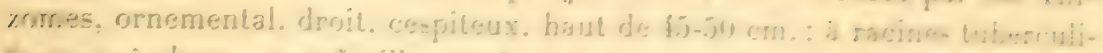

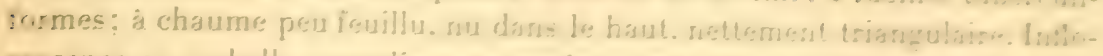

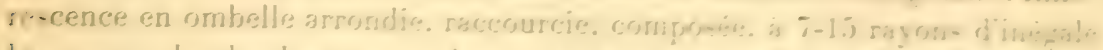

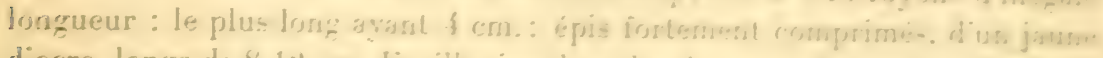

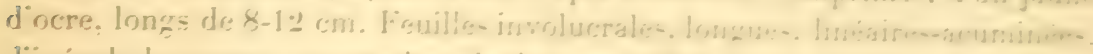

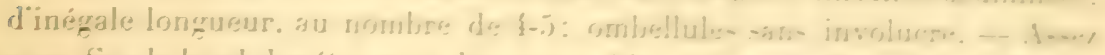

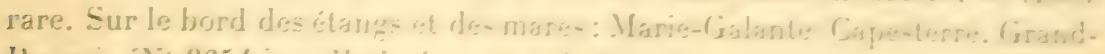

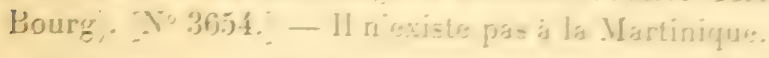

C. alternifrolius L. : Souchet is reuilles alternes. - Vimace tri- ormumentul.

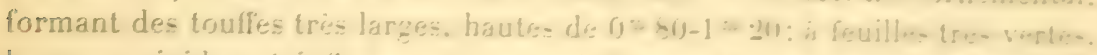

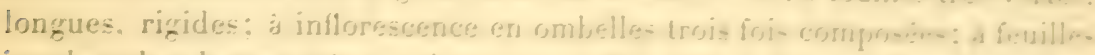

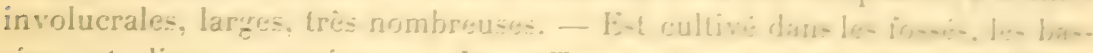

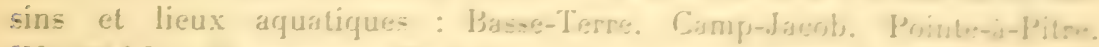

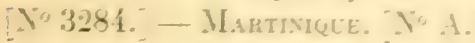

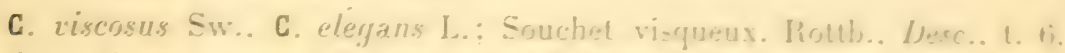

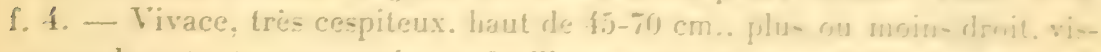
queux dans toutes ses parties: a feuilles peu nombreu-es: as chamm ribtumment triangulaire. Inflorescence en rmbelles trois froi- crmprome- it $4-11$

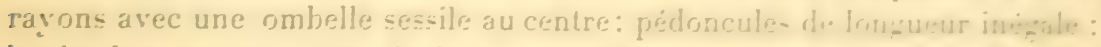
le plus long ayant $11 \mathrm{~cm}$. de long: ombelle secrndaire is -2-3 ravou dati:

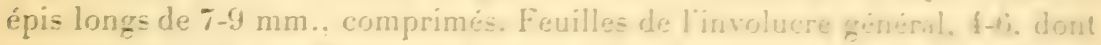
1-2 très longues. - Abrondant dans les endroits marecazeux rum inondis par leau de mer: Deshaies. Pointe-a-Pitre. Grozier. etc. Y 33 \{11.

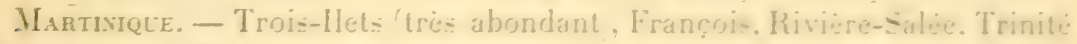
(Galion), etc. 692 a.

C. surinamensis Rottb.. varietétiridis Boek. ; Souchet de Surinam. Moth).. Desc., t. 16, f. 5. - Vivace, haut de $70-51) \mathrm{cm}$. peu ce=piteux, droit nrmemental, peu feuillu. Feuille- lonfues: chaume comprime, nu dan-1e haut.

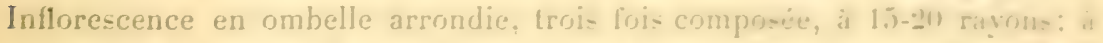
pédicelles filiformes. fermes. tres ingux: ombellules frimaim. a s-1n

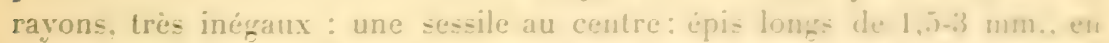
\%lımérules arrondis: épillets imbriqués, tri- rapproché-. - Peu almudant. Dans les savanes humides et aquatiques de la basse région : Moule mairons de l'usine Duchassaing!, Gozier. Jes Abynet ete. Alt. 11-11m mit. INo3jef.

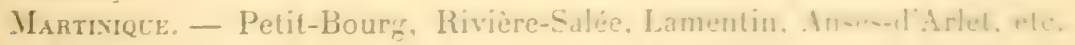
$[\mathrm{X} \circ 690$.

C. Luzula Rotth.. C. Trinilatis Steud.: Souchet semblable an I.mmia

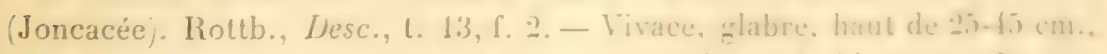

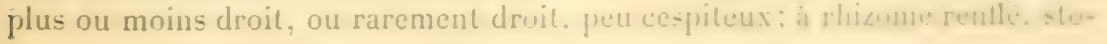


lonifère: à chaume vigoureux, triangulaire: à feuilles très vertes, glauques en dessous, plates. Inflorescence en ombelle simple, à $\mathbf{t}-8$ rayons courts, portant des glomérules oroïdes-coniques; à épis très nombreux, petits, ramassés. - Peu répandu. Endroits très inondés et sur le bord des étangs: Gourheve 'bords de l'étang de Valcanard', Trois-Rivières, etc. Alt. 5-350 mèt. [No $310 \%$.]

Martinere. - Saint-Eeprit, Fort-de-France bords de la rivière Madame Trois-Ilets. Alt. 0-380 mèt. [ $\mathrm{N}^{\circ} 705$ a.]

C. articulatus L.; Souchet à chaume articulé. Sl., t. 81, f. 1. - Haut de 0' 80-1 mèt., vivace: à rhizome gros: à chaume cylindrique, dépourvu de feuilles, enveloppé, à la hase, de 3 -í gaines graduellement plus longzues; à noxuds partitionnes et rapprochés. Inflorescence en panicule ombelliforme, it 6-9 ravons inégaux, chacun portant J-6 épis minces, pointus, bruns, longs de 9-13 mm. ; épillets imbriqués. - Endroits aquatiques, bords des mares el des étangs, et fossés remplis d'eau : Trois-Ilets, route de Fort-de-France au Lamentin, Trinité, etc. Alt. 0-400 mèt. [No 851.] - Je ne l'ai pas vu à la Guadeloupe.

C. rotundus L.. C. hexastachyos Rottb., C. IIydra Michx., G. olivaris Targ. : Souchet à tiges souterraines globuleuses. Vulgo: Petit coco. Rottb., Desc., t. 14, f. 2. - Vivace par ses tiges souterraines en forme de tubercules ronditres ou ovoüdes, de la grosseur d'une petite noisette; à racines fibreuses. noires; à feuilles très vertes; à chaume triangulaire, droit, haut de $25-30 \mathrm{~cm}$. Inflorescence en ombelle composée, paniculiforme, à f-6 rayons, très inégaux, avec une ombelle sessile au centre; onbellules a $4-6$ épis comprimés, longs de 9-20 cm. - Extrèmement commun dans les terres cultivées, dans les savanes, le long des routes. - Ce snuchet est une plante très nuisible et difficile à détruire; plus on en arrache les tiges, plus on en multiplie les pieds, quand on n'enlève pas en mème temps les tubercules profondément enterrés. Alt. 0-800 mèt. [No 3102.$]^{4}$

Martivique. Vulgo : Coco-chat, chien-coq. [ $\mathrm{N}^{\circ}$ 852.]

C. sphacelatus Rottb., C. Balhisii Kith: Souchet ergoté. - Ressemble au précédent quant aux feuilles, au port et a l"inflorescence; il en diffère par sa taille plus élevée. labsence de tubercules, ses épis beaucoup plus nombreux. - Abondant dans les savanes humides, dans les terres cultivées des

1. Ce Souchet donne des tubercules ovoüdes unis par des prolongements radiciformes. lizneux. Noirs à l'extéricur et marqués d'anneaux circulaires, ces tubercules sont blancs. spongieux et comme subéreux à l'intérieur; leur saveur est un peu aromatique et leur saveur douce. Ils passent pour excitants et peut-être même aphrodisiaques. On les a employés en médecine sous le nom de Souchet rond. - Le C. hexastachyos Rottb. donne, d'après Holmès, un rhizome usité dans l'Inde contre le choléra, sous le nom de llootha.

(E. II.) 
régions inférieure et infra-moyenne de toute la Guadeloupe et de sus dépendances. Alt. 0-700 mèt. [No365.

Martinieue, - Très abondant. 「yos $452,460$.

G. brunneus Sw., C. purpurascens Vahl, C. planifolius Rich. : Souchel it épis d'un brun foncé. Sl., 1. 7f, f. 2, 3. - Vivace, it snuche trosece, meiritre. droit, haut de 60-80 cm., oruemental, cespiteux; il leuilles lapers. mombreuses, glauques en dessous, rigides, scabres sur les bords, plates, carcinéen dessous, aussi longues ou plus longues que le chamme triangrulaire el

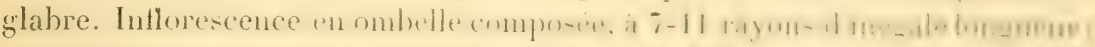

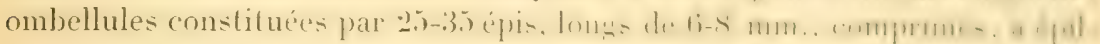
lets brun foncé. Feuilles involucrales 5-6, dont deux tris lonrues. - Mbondant dans les sables secs du bord de mer et dans les endroits inondés par lia mer: Vieux-Fort, Baillif, Vieux-Habitants, Bouillante, l'ipeon, l'ointeNoire, sur toutes les plages sèches de la Grande-T'erre, de la Désirade, de Marie-Galante. Alt. 0 mèt. [No 3103.$]$

Martinique. - Sur toutes les plages sèches. [N"765 h.

G. purpureo-variegatus Boekeler; Souchel brun panache. - Vivace, haul de $45-50 \mathrm{~cm}$, droit, à feuilles flagsques, lancéolées-linćaires, un pen plus courtes que le chaume et confinées dans le bas. Intlorescence comme dans le Cyperus rotundus; épis comme dans le précédent. - Asse rate. (ai et la dans les sables secs, près du bord de ner et aussi dans lintérieur, jusqu' i une altitude de 100 mèt, : Prêcheur, Case-Pilote, Ducos (dans les clairières des Mangles). [No 449.] - Je ne l'ai pas trouvé ì la Guadeloupe.

G. Ottonis Boekeler; Souchet d'Otton. - Ressemble au C. Jrunneus sw: : il en diffère par sa taille svelte, ses feuilles plus étroites el beaucoup moins nombreuses, ses ombelles plus courtes el peu fournies, ses épis moins allun-

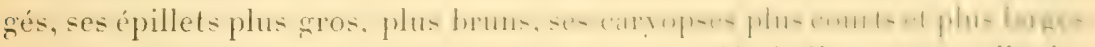
- Savanes humides ou sèches près de la mer : 'Trois-llels, Insis-d'. Mrlel. Sainte-Luce, Marin, etc. Alt. 0-20 mèt. [No 695.] - Je ne l'ai pas lmuve it la Guadeloupe.

C. acicularis With.; Souchet à épillets à pointe acéréc. - Vivace par sers

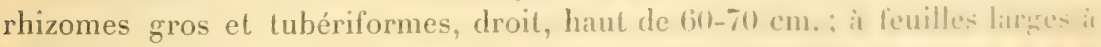
la base; à chaume triangulaire. Inflorescence en ombelle compusio, it it ombellules paniculées, constituées par des épis allongés; iprillets it fhmme très pointue. Feuilles involucrales 5-7, larges : celles des ombellules, antisi longues que ces ombellules. - Assez rare : sai et lit dans less savines humilec

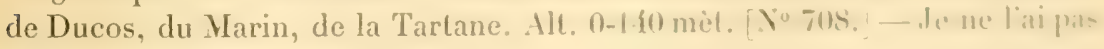
trouvé à la Guadeloupe.

C. IIartii Boekeler; Souchet de Hart. - Virace par ses somche's Luberiformes; à chaume svelte, triquètre, haut de $20-25 \mathrm{cms}$; it fouilles fera mum- 
breuses, très étroites. Inflorescence en ombelle composée; à rayons paniculés, brièvement pédonculés, à ombelles allongées; épis minces, cyylindriques, pointus. - Dans les savanes humides du Lamentin, de Ducos, du PetitBourre. des Anses-d'Arlet. Alt. 0-200 mèt. No $450 \mathrm{~b}$. - Je ne l'ai pas vua à la Guadeloupe.

C. esculentus L. : Souchet comestible. - Vivace, droit, haut de $40-50 \mathrm{~cm}$. : it souche yrosse, tubériforme, subglobuleuse: à chaume vigoureux, triangulaire: à feuilles peu nombreuses, plates; à chaume et feuilles vert jaunâtre. Inflorescence en ombelle composée, dressée, à i-9 pédicelles très inérgaux, portant chacun une petite panicule constituée par 5-13 épis. longs de 1,5-2 $\mathrm{cm}$., sessiles, comprimés, lineaires, souvent courbes. Feuilles involucrales 4-5. dont la plus longrue ne dépasse pas l'ombelle. - Assez abondant dans les plaines humides ou aquatiques de la basse région : Marin. Sainte-tnne, Lamentin. Anses-d Arlet. Alt. 0-300 met. Nos 459, 470. - Je ne l'ai pas vu à la Guadeloupe'.

C. distans L., C. elatus Rottb. ; Souchet à épis et épillets distancés. Rottb.. 1. 10. - Virace, à souche épaisse et noiràtre, haut de $60-75 \mathrm{~cm}$., très droit : à chaume nettement triangulaire; à feuilles longues, penchées, plates, glauques en dessous. Inflorescence en une large ombelle jusqu à trois fois composée. à $7-11$ rayons, dont $2-3$ longs de $15-23 \mathrm{~cm}$. les autres plus courts, d'autres très courts: ombellule primaire à ravons nombreux; ombellules secondaires, paniculées, prramidales: épis cylindriques, allongés, au nombre de 13-23: épillets linéaires, bruns. - Dans les savanes humides des basse et inframoyenne régions de toute la Guadeloupe et de ses dépendances. Alt. 0-300 mèt. [Nos $3365,3668,3576,3377$.]

Martrique. - Dans toutes les parties basses de l'île. Alt. 0-200 mèt. [N० 451 .

C. odoratus L.; Souchet odorant. Vulgo: Herbe-couteau. Sl., t. 74, f. 1. Vivace par ses rhizomes, à souche grosse, tubériforme, à chaune très droit. robuste, triangulaire, haut de $30-(60) \mathrm{cm}$., rarement plus haut. Feuilles lourues. tombantes. glauques en dessous, larges. Inflorescence en ombelle simple dans les pieds maigres. composié dans les pieds grats et triés étalée, arrondie, a 5-6 pédicelles comprimés, très fermes : les plus longs mesurant 12. cm. ; ombellules paniculées, à épis lonģ, cylindriques, à épillets distants, jaunàtre ou jaune doré; feuilles involucrales 6-12, très longues. - Cuí et lì

1. Le tubercule du Souchet comestible est ovoïde, de la grosseur d'une olive, marqué d'anneaux circulaires, jaune au dehors, blanc au dedans, et doné d'une saveur sucrée, huileuse, très agréable, qui rappelle celle de la noisette. On en fait grand cas en Espagne, en Italie et mème dans le Midi de la France, où ces tubercules sont couramment vendus sous le nom de soufflet, ou chouflet (notamment à Marseille), altération du nom de Souchet. On lui prête encore aujourd'hui des propriétés aphrodisiaques plus que douteuses.

E. H.) 
dans toutes les savanes humides de la région infericure: Lamuntin, BainMahault, Moule, les Abymes, Petit-Canal, etc. Mlt. 0.200 mel. Xo 310ri.

Martimeve. Vulgo: Herbe-razoir. - Ducos, Lamentin, Riviere-salie. Anses-d'Arlet, Carbet, Trinité, etc. To 158.

C. ferax Rich.; Souchet lertile. Yulgo: Herbe-couteau, _ Vivace par as souches tubériformes, très droit, haut de $5.5-75 \mathrm{~cm}$. : it chaume ohturiment triangulaire, cannelé d'un côté; à feuilles linéaires, longrues, plaltes. Intinrecence en ombelle de 5-6 rayons, dont les plus grands seulement portent t-i ombellules allongées, à épis courts, cylindriques, lnners de 1-7 cm. : iprillets cylindriques, distants, 3-1 dans chaque épi; fenilles involucrales ti-s, dont 3-4 très longues. Facile à distinguer des congrénères de la méme section par sa taille svelte, la couleur pâle des feuilles, la petitesse des ombellen et la brièveté des épis. - Dans toutes les savanes humides ou aquatiques, sur l.

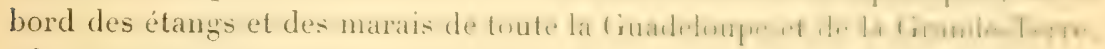
Alt. 0-700 mèt. [No $35 \% 8$.

Mantrique. Vulgo : Herbe-razoir. - Dans toutes les plaines de la halsite

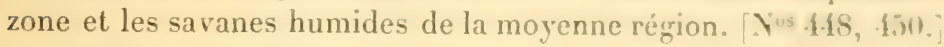

C. nitidus Boekeler; Souchet luisant. - Ressemble au pricident par sa taille, son port et son inflorescence; il en diffère: par son chaume profon-

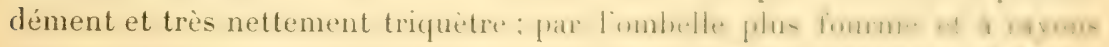

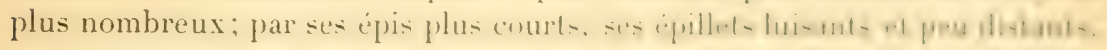
ses caryopses plus allongés. - Dans les savanes humides de la ringinn inferieure: Lamentin, Robert, François, Vauclin, etc. Alt. ()-300 miet. lo (ifis.)

- Je ne l'ai pas vu à la Guadeloupe.

C. Irispicatus Boekeler; Souchet à trois épis. - Vivace par sil sonche grosse, stolonifère, épaisse, arrondie; à chaume triangulaire, svelle. haul de $28 \mathrm{~cm}$. ; à feuilles glauques en dessous, très nombreuses, plus courtes que le chaume, très rapprochées. Inflorescence en ombelles compuscés at y-11 rayons, dont 2-3 des plus longs portent deux épis lateraux plus pelits et un central beaucoup plus grand. Épis minces, cylindriques, pointus, hugs de 6-8 cm.; feuilles involuerales 4-8, dont i-6 plus longues que l'nmbelle. Assez rare: çà et là dans les savanes humides du Parnasse, du Murne-liert. du Gros-1Morne. Alt. 250-500 mèt. [No 45.5$]$. Je me l'ali prats trume at la Guadeloupe.

C. Dussianus Boekeler; Souchet de Duss. - Innuel, haut de f(1)-71) ('m. à feuilles longues, étroites. Inflorescence en ombelles, protant der raýmfiliformes; épis peu nombreux, cylindriques; épillels bruns, puintur, a glume extérieure brun foncé sur le dos, blanche sur lés hords. - l,i.t et la sur les coteaux secs ou humides des Trois-Ilets. Alt. $20(1)-31)(1)$ mit. A 1.61 h. (Spécimen très imparfait.) - Je ne l'ai pas trouvé a la (inadeloupe. 
G. Martinicensis Boekeler: Souchet de la Martinique. - Vivace par ses rhizomes tubériformes, plus ou moins rampant, à chaume triquètre, haut de

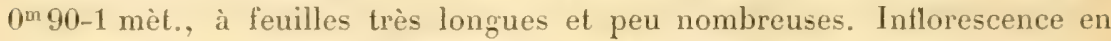
ombelle à 5-7 rayons très inégaux, portant des épis cylindriques simples ou composés: épillets triflores, orientís de tous côtés: feuilles involucrales $5-\overline{7}$, longues, carénées, trois ou quatre fois plus longues que lombelle. — Savanes humides de la Basse-Pointe, du Lamentin. du Saint-kiprit, de La Riénale, etc. Alt. 0-300 mèt. [No 471.$]$-Je ne l'ai pas trouvé à la Guadeloupe.

G. flacamariscus Griseb., Mariscus flavıs Vahl : Souchet à épis jaunâtres. - Vivace par ses souches rampantes, nombreuses, tubéreuses-ovoïles, cespiteux, haut de 25-70 $\mathrm{cm}$., peu feuillu; à feuilles étroites, tombantes; à chaume nettement triangulaire. Intlorescence en ombelle simple at $2-3$ rayons, portant des épis courts, cylindriques-oblongs: épillets jaunes ou jaunâtres, orientés de tous cotés, très rapprochis: feuilles involucrales deux ou trois fois plus longues que l'ombelle. - Abondant dans toutes les savanes humides de toute la Guadeloupe et de ses dépendances. Alt. 0-600 mèt. [No 3653.] - Мartixique. - Dans toute lîle. [Nos 473, 564.$]$

Le Cyperus Papyrus: L., de l'. Afrique tropicale, haut de $1^{\mathrm{m}}$ 50)-2 met., sans feuilles, à ombelles composées, tries vastes, avec des pédicelles longs étalés et engainés at la base. est cultivé dans l'eau chez quelques amateurs de plantes: Camp-Jacob (habitation Rollin). [N॰3829.]

Martinique. - Jardin botanique, Saint-Pierre, Fort-de-France, etc. (Spécimen B.)

Mariscus Grertn. du celtique " mar n, marécage, parce que ces plantes se trouvent dans les endroits marécageux.)

M. rufus H. B. Kth; Mariscus roux. Vulgo : Herbe-couteau, - Vivace par ses souches renflées, noirâtres, courtes, à chaume robuste, triquètre, strice, haut de fio-i5 cm., quelquefois plus long, nu sur une longueur de fo$48 \mathrm{~cm}$. Feuilles aussi longues que le chaume, glauques en dessous, striées, tuberculées et fortement carénées, très finement serretées sur les bords, brunes à la base. Inflorescence en ombelle composée, à $7-11$ pédoncules comprimés, tres inergax, portant 3-5 épis, gros, coniquesobtus, a epillets bruns, rapproches, verticalement insérés sur l'axe, tres nombreux, 3-j-flores, orientés en tous sens. - Abondant dans les marécages d'eau salée, dans les terres inondées par la mer et dans les sables du littoral: Pointe-à-Pitre, Sainte-Anne, Baic-Mahault, Saint-François, etc. [No 3683.$]$

Martinique. Vulgo: Herbe-razoir. - Fort-de-France (habitation de l'Échelle), Sainte-Anne, Marin, Trinité, etc. [No 456.]

Kyllinga Rottb. dédié au Danois Peter Kylling, mort en 1696; a écrit: Viridarium danicum, 1628.) 


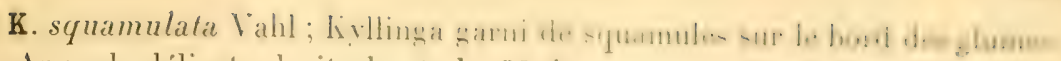
- Annuel, délicat, droit, haut de $32-10 \mathrm{~cm}$.; it feuilles llasques, lineairesacuminées; à chaume filiforme, nu sur une étendue de $25-30$ cm. Influrecence en un glomérule arrondi, sessile, composé de 10-12 épillelo, cntonte: de trois feuilles involucrales; glumes garnies, sur les bords, de squamulenombreuses formant une sorte de frange. - Isse\% abondant dins les emblerit. ombragés près du bord de mer: Carbet (près de l'embonchure de lia rivière), Prêcheur. Alt. 0-20 mèt. [No 4́61.] - Je ne l'ai pas trouse it lit Guadeloupe.

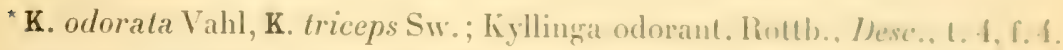
- Annuel, cespiteux, haut de 5-20 cm., droit ou plus ou mone dilfus: is feuilles linéaires-acuminées, plates, peu nombreuses; it chatume filifirme. nu. Inflorescence en capilules oblongs-obtus, réunis par tronis : les deux liatiraux beaucoup plus petits; feuilles involucrales relativement plus hngues. Abondant dans les prairies, dans les savanes herbeuses des basse ot infrarmoyenne régions, où il forme souvent gazon sur d'asse\% frandes cetendues: environs de la Basse-Terre, Gourbeyre, Matouba, Lamentin, Gorict, Sininte-

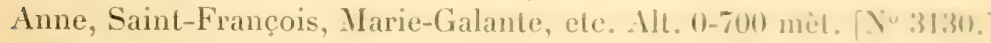

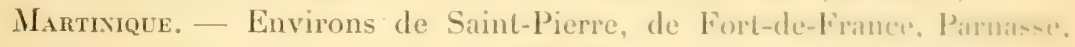
Lamentin, Robert, Gros-1Iorne, etc. [No 17 ita. $]$

* K. brevifolia Rottb.; Kyllinga à feuilles courtes. lin(t), , l)esce, 1, 1, I. 3. — Haut de $30 \mathrm{~cm}$.; à rhizome rampant, vivace, noueux; a fenilles conder. rigides, linéaires: une ou deux seulement pour chaque chaume : chatume triquètre, droit, svelte, filiforme-rigide. Inflorescence en capitule: sersiler. petits, arrondis-solitaires ou géminés, entourés de trois leuilles involucratedressées, dont une plus longue. - Peu répandu : asser abondiant sur te lomat des mares d'eau douce et dans les savanes aquatiques des envirnns de samLouis. Alt, 0-30 mèt. [No 3579.] - Je ne l'ai pas vu it lat Martinique.

K. cxspitosa Ness, variété elatior Boekeler; Kyllinga céspiteux, .... Innuel ou vivace (dans les endroits très humides); it thizome ramprant a it furulles nombreuses, linéaires-acuminées, longues; it chitume filiforme, limme, sillonné, nu, haut de $20-22 \mathrm{~cm}$., rarement plus hatut. Intlurescencer con capitules solitaires, largement ovoïdes, sessiles; feuilles involuerales 3-1, dunt

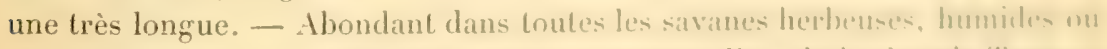

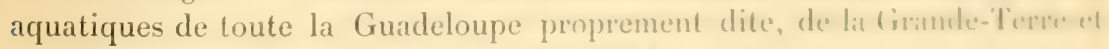
de Marie-Galante. Alt. 0-800 mèt. [ Y0 31:29.

Martinique. - Abondant dans les savanes humides on inquatiques: 'T'mis-

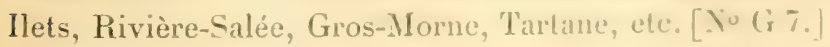

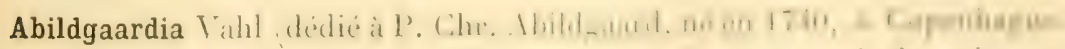
professeur d'histoire naturelle et secrétaire de la socieli myate des science- 
fondateur de l'École vétérinaire, en 1773, et de la Société d'histoire naturelle de Copenhague ; mort dans cette ville en 1801.)

A. monostachya V'ahl; Abildgaardie à un seul épi. Vulgo: Barbe à nègre, Sl., t. 79, f. 2: Rottb., Desc., t. 13, f. 3. Cyperus L.; Scirpus Boekeler.) Petite herbe, très cespiteuse, vivace, droite, haute de $5-30 \mathrm{~cm}$.; à feuilles très étroites, roulées, presque filiformes: à chaume filiforme, nu, dépassant de beaucoup les leuilles. Inflorescence en épis comprimés-ovoïdes, pointus, longs de 6-13 mm. : épillets imbriqués, couleur de paille, plurillores ; les deux glumes extérieures vides, mucronées, les trois autres carénées et à trois nervures ; rachis ailé. - Assez abondant dans les clairières d'endroits sees et humides des mornes de (rourbere, du Camp-Jacob, de Bagalelle, du Gommier, du Matouba, des Vienx-IIabitants, de Houëlmont. Alt. 200-150 mèt. $\left[\mathrm{N}^{\circ}: 31: 27.\right]$

Martinique. Vulgo: Herbe fine, herbe à cheveux. - Sur les talus des routes et dans les endroits humides ou secs du Champflore, chemin de la Trace, fontaine Didier, hauteur de Fort-de-France, etc. [No 466.$]$

\section{TRIBU II. SCIRPÉES.}

Heleocharis R. Br. (du grec " helos ", marécage, et " charis ", charme, beauté, c'est-ì-dire plantes qui font l'ornement des marécages.)

H. chxtaria Roem. et Schult,; Héléocharide à feuilles fines comme des cheveux. Vulgo: Herbe à cheveux. - Annuel, haut de $12-20 \mathrm{~cm}$., cespiteux ; à feuilles capillaires, plus longues que le chaume également capillaire. Inflorescence en épis courts, terminaux, solitaires, longs de 1,5-2 mm. - Forme gazon sur le bord des mares el dans les endroits aquatiques des montagnes: Camp-Jacob, Bagatelle, Matouba, Gommier, Vieux-Habitants, etc. Alt. fon800 mèt. [No 3737 . ]

Martinique. Vulgo: Herbe-cheveu. - Chemin de la Trace, environs du Camp Balata et de la fontaine Absalon, du Camp de l'Mma, etc. Now 470 at, 468. - On le rencontre aussi sur le bord de l'étang de la Montagne-Pelée, à une altitude de 1250 mèt.

H. punctulata Boekeler, forma major: Héléocharide pointillée. Vulgo : Barbe à mulâtre. - Cespiteux, vivace, haut de $8-32 \mathrm{~cm}$, droit, sans feuilles ou avec quelques feuilles radicales et courtes; ì chaume filiforme, strié, terminé par un épi ovoïde-pointu, couleur de paille, long de $3-5 \mathrm{~mm}$. Se distingue du précédent, en la société duquel on le rencontre souvent, par l'absence de ses feuilles, son chaume plus long, deux ou trois fois plus gros, ses épis plus longset plus gros. - Mares et endroits aquatiques des montagnes : Savane a Mulets, Haut-Matouba, chemin du Matelyane a la Savane aux Ananas, etc. Alt. 400-1480 mèt. [No 3124.$]$ 
Martinique. Vulgo: Barbe de mulitre, - Champlfore, Cime-Momm. Cihe-

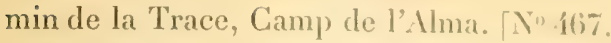

H. Dussiana Boekeler; Héléocharide de 1)uss. Vulgo: Barbe i mulitu.

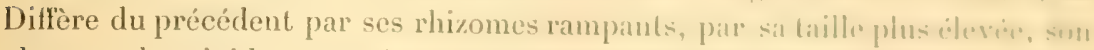

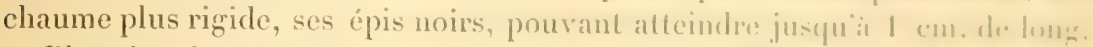
- Plus abondant : mares el endroits aquatiques du (Whampllore. I" friti it. (Spécimen imparfait.)

H capitata R. Br.; Héléocharide à épillels en capilules arrnoli- liulen: Barbe à mulâtre. Sl., t. 75, 1. 2; Rottb., l)ese., 1. 1\%, 1. 3. Scirpus 1. Vivace dans les endroits très humides, amuel dans les emdroils serent rilhan. neux, très cespiteux, omemental, droit, ou plus on moins penchi:, hant de. 4-32 cm., à chaume sans feuilles, strié. Infloresconce en épis rfobuleuxconiques, multiflores ; glumes orales-arrondies, obluses; corvopse brum. luisant, biconvexe. - Assez abondant dans les maréciteres et condroils immoli:par la mer : Port-Louis, Anse-Bertrand. Alt, 0 miet. Tu 3124i.

Martinique. Vulgo: Barbe-mulâtre. - Prinité (Galion), Robert, 'lartane. Fort-de-France, etc. $[\mathrm{N}$ os 457,752 .

H. maculosa R. Br.; Héléocharide à épis mouchelés. Vulero : Herhuecheveu. (Scirpus L.) - Haut de 10-4́ em., à rhizomes rampants, it fenillenulles. Épis noirs ou bruns, Iongs de $8-12$ mm., ovö̈les-coniques. compuri-

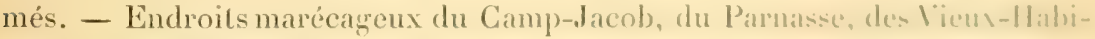
tants, de Bouillante, où il vit souvent en société. - l)ans les Sphatrum - du cône de la Soufrière, à la Savane à Mulels el à la Savane anx Inanar. cefle même herbe peut atteindre jusqu'a $8.1 \mathrm{~cm}$. de hatut. Mlt. f(nt)-l foll) mit. $[$ Xus $3125,3595$.

H. plantaginea R. Br.; Héléocharide lenant de la nalume du flantain.

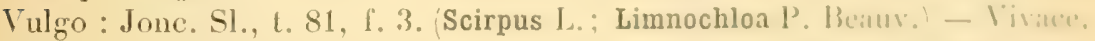

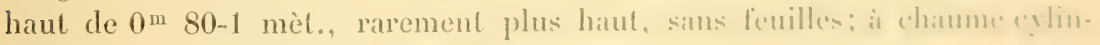
drique, noueux, engainé en son quart inférieur dans une frame terminte pin

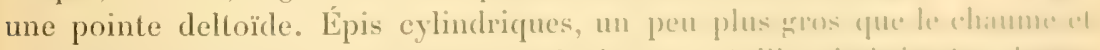

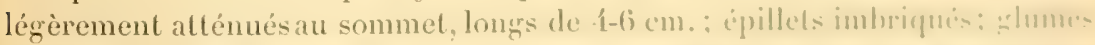

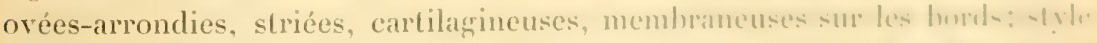
trifide; caryopse obové, biconvere, Inngiludinalement stric, muni, an smm-

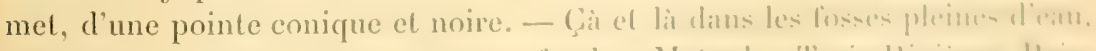

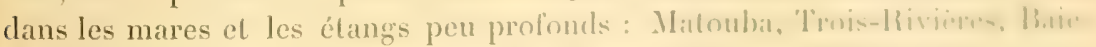

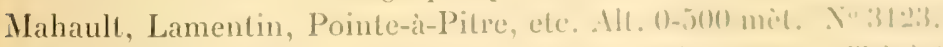

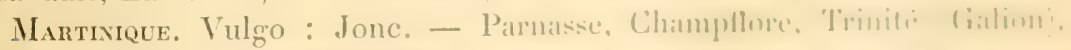
Gros-Morne, elc. $\left[\mathrm{N}^{\mathrm{os}} 696,753.\right]$

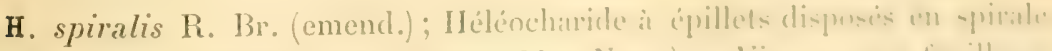

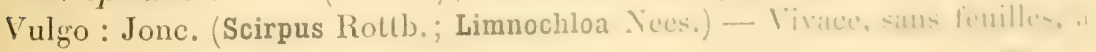
Duss. - Plantes Guadeloupe et Ifartinique. 
chaume nettement triquètre, inséré à la base dans une gaine courte, terminée par une pointe deltö̈de. Épis cylindriques, longs de 3-5 cm., presque aussi gros que le chaume contracté au sommet; glumes deltoüles, cartilagineuses, minces et membraneuses sur les bords; carropse comme dans le précédent. - Cál et là dans les mares d'eau douce près du littoral : Pointe-à-Pitre, Gozier, Anse-Bertrand, Moule. Alt. 0-100 mèt. [No 3441.

Martiveve. Vulgo: Jonc bâtard. - Trois-Ilets, Marin, Robert, etc. $\left[\mathrm{N}^{\circ} \mathrm{75} 4.\right]$

Fimbristylis Vahl (du latin " fimbria ", frange, et " stylus ", style, parce que les styles sont finement frangés ou ciliés.)

F. autumnalis R. et Sch. (emend.), Trichelostylis mucronulata Torr.; Fimbristylis d'automne. (Scirpus L.) - Cespiteux, haut de $45-75 \mathrm{~cm}$., rarement plus haut, droit, à feuilles longues, linéaires, plates, nombreuses, dépassées par le chaume comprimé. Inflorescence en cymes composées, terminales, ombellitormes, plus longues que les feuilles involucrales dresées; épillets bruns, lancéolés-oblongs, pointus; glumes ovées, mucronées; style trifide; caryopse obové-rondâtre, trigone. - Abondant dans toutes les savanes humides de la basse et surtout de l'infra-moyenne région de toute la Guadeloupe et de ses dépendances. Alt. 150-600 mèt. [No 3134.]

Martinique. - Abondant dans toute l'île. [No 755.

F. polymorpha Boekeler; Fimbristylis à formes variables. - Cespiteux, haut de $45-65 \mathrm{~cm}$., à feuilles nombreuses, flasques, couvertes d'un duvet frlauque, plus contes que le chaume. Infloresence en cymes ombelliformes. petites; épillets bruns, ovoïdes-pointus, petits, au nombre de 10-13 seulement sur chaque épi; caryopse brun, longitudinalement strié, ovoïde, comprimé, surmonté d'une pointe courte. Feuilles involucrales 3-5, dont 2 plus Inugrues que la crme. Se distingue facilement du précédent par sa taille plus petite et ses feuilles velues. - Abondant dans presque toutes les savanes humides. dans les mornes peu boisés de toute lat Gruadeloupe et de ses dépendances. Alt. 40-700 mèt. [No 3288 .

Mantiviqle, - Dans toutes les savanes et les endroits peu boisés. [No 759.]

F. spadicea Vahl; Fimbristylis a épis allongrés el eylindriques, en forme de spadice. Sl., L. 76, 1. 2. (Scirpus L.) - Très cespiteux, formant des Loulfes très larges, virace, haut de $60-80 \mathrm{~cm}$., à feuilles filiformes, rigrides, camnelées, brunes à la base; à chaume trigone-comprimé, le plus souvent penché. Inflorescence en cromes inégatement ombelliformes, composés. larges, Inngues de 10-14 cm. Feuilles involucrales de la cyme le plus sourent 2, dont l'extérieure beaucoup plus longue el l'intérieure plus courte que la cyme: les 2, brunes et élargies à la base. Épis longs de $7-9 \mathrm{~mm}$., noirs, ovés, subcylindriques; feuilles involucrales des cymules 2-3, dont 1 plus longue; épillets predicellen: syle bifide, cilie: carvopse brun, obové-biconrexe, Iongitudina- 


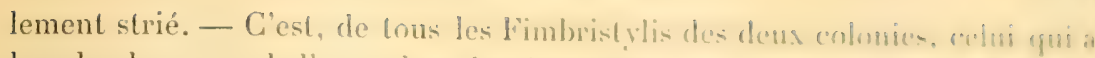

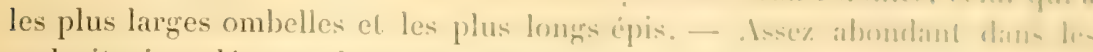
endroits inondés par la mer et les saranes lás sablumenses du lillomal : Fort-de-France, Trois-llets, Lamentin, Francoix, Trinile fialion cte. Alt. 0 mèl. [Nos $756,757$.$] — Je ne l'ai pas lonuve at la Ciuadeloupue.$

F. ferruginea Vahl; Fimbristylis à épis couleur rouille de lex. S1., 1. 7. 1. 2. - Vivace, très cespileux, à feuilles très élmiles, rlatugues, lizider. cinnnelées, souvent visqueuses, à chaume subcomprime, hatut de 71)-7i) (mo. Inllurescence en cymes ombelliformes, courtes, simples, plus ratrenent compmeres. compactes. Feuilles involucrales 2, plus courtes que lit cyme, ibarries ct sims taches, brunes à la base; épillets bruns, pédicellés, ovés-coniques, langres: glumes ovées-rondâtres, mucronées, pubescentes sur le dos : caractime par lequel il se distingue facilement du précédent; caryopse obovi. hiconveve. poli et sans stries. - C'est l’espèce dont les épillets sont les plus lankero, maira non les plus longs. - Très abondant dans les terres bassecs inondén par la mer et dans les savanes sablonneuses el marécigeuses, voisines du lithral :

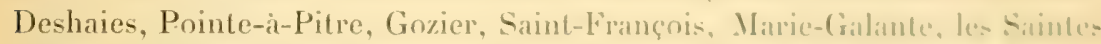
('Terre-de-Haut, Grand'Anse), elc. Alt. ()-3 mèt. [X" 31:3:3.]

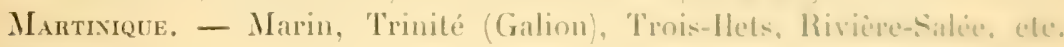
[No 704.$]$

F. obtusifolia Kth; Fimbristylis a l'euilles courles, - Droit, (erpitenx,

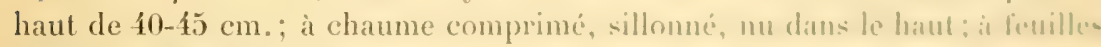
courtes, rosulées, très rapprochées, fortement cannelies, obluses atu sommet.

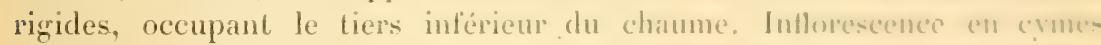
simples ou composées, plus ou moins contractees, plus longues que les dems

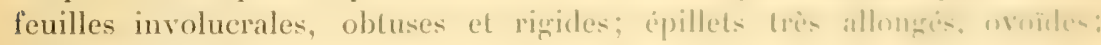

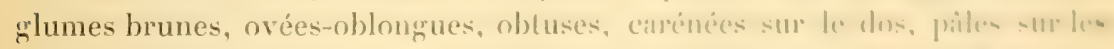

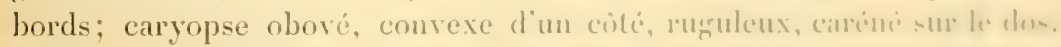

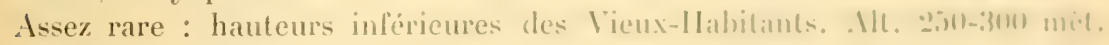
[No 3594.] - Je ne l'ai pas trouvé à la Mamlinique.

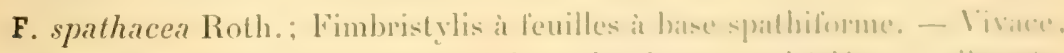

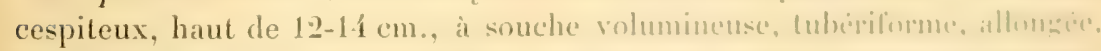
noire; à feuilles rosulées, cannelées, contes, fries rigides, ohluses an smmmet:

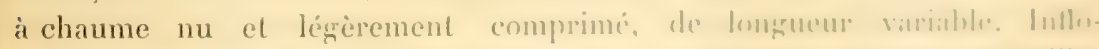

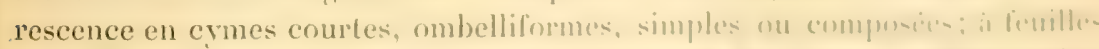

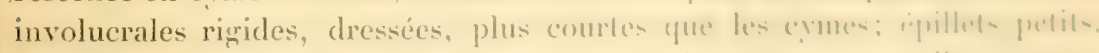

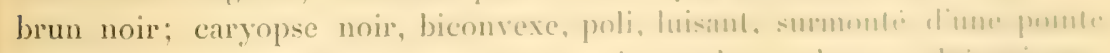

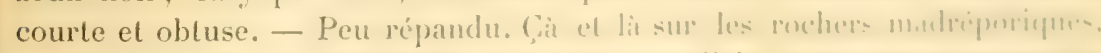

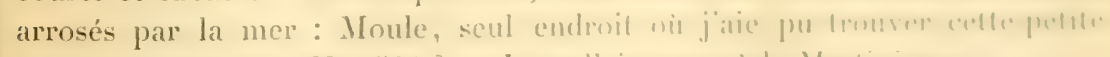

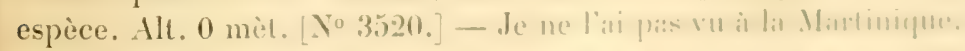

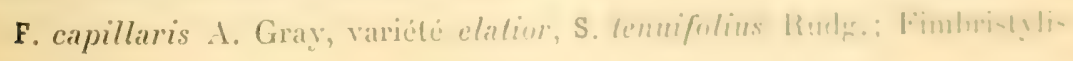


à leuilles capillaires. (Scirpus L.; Isolepis R. Br.) - Amnuel, cespiteux, droit, très ornemental, haut de $40-45 \mathrm{~cm}$; à feuilles rosulées, filiformesséteuses, réfléchies; à gaine velue: à chaume filiforme, uu, tantôt plus longr, tantôt plus court que les feuilles. Inflorescence en cymes très petites, inégalement ombelliformes, à 5-9 épis brums, ovés-oblongs, obtus: glumes ovées, carénées, obtuses; caryopse trigone, obové, transversalement tuberculé et surmonté d'un petit tubereule mammiforme. - Issez abondant sur les talus des routes, dans les endroits sablonneux et peu boisés: Champflore, route de la Trace, des Fonds-Saint-Denis aux Deux-Choux, etc. Alt. 3001-660 mèt. [No 758.] - Je ne l'ai pas trouvé à la Guadeloupe.

Scirpus L. (du mot celte "Sirs ", jonc. Cette racine celtique vient de "scirpare ", lier, tresser.)

S. Dussianus Boekeler; Scirpe de Duss. - Annuel, cespiteux, très droit, haut de $15-20 \mathrm{~cm}$. à fèuilles filiformes-capillaires, séteuses, peu nombreuses, plus courtes que le chame filiforme. Inflorescence en petits grlomérules arrondis, composés de 8-15 épillets, courts, couleur paille. - Rare: çà et là quelques pieds dans le Champ de Pétrification, à Sainte-Anne. Alt. \{15 mèt. [N०478.] - Je ne l'ai pas trouvé à la Guadeloupe.

Hemicarpha Nees et Arn. (du gree "hemi ", à moitié, "karpha n, brin de paille, parce que les épillets n'ont qu une paillette à l'axe de l'aisselle de la glume au lieu de deux.)

H. sulsquarrosa Nees; Hemicarpha garni de pelites pustules. Scirpus micranthus V'ahl. - Petite herbe très délicate, plus ou moins droite, haute de $15-18 \mathrm{~cm}$., cespiteuse: à chaume capillaire, portant à la base une feuille courte, capillaire. Inflorescence en capitules ovoïdes-comprimés 2-3, petits, dépassés par l'unique l'euille involucrale dressée; glumes vert pâle, lancénlées, terminées en une pointe recourbée: étamine 1 ; (aryopse sulbeylindriqueoblong. - Assez abondant dans les basse et infra-movenne rémions : endroits très humides des Trois-Ponts, dans les friches du Carbet, des Fonds-SaintDenis, du Gros-1Inrne, du Robert, ete. Alt. (1-450 mèt. [No 460, 1) 4.] - Je ne l'ai pas trouvé à la Guadeloupe.

Fuirena Rottb. (dédié au Danois Georg Fuiren, né en 1581, à Copenhague, médecin ; a exploré la Scandinavie dans un intérèt botanique; mort en 1628.)

F. umbellata Rottb.; Fuirena à épis en ombelles. Rottb.,Dese, t. 19, f. 2. - Vivace par ses rhizomes, droit, haut de $0^{\mathrm{m}} 80-1^{\mathrm{m}} 80$, rarement plus haut; à chaume mou, glabre; a feuilles grlabres, relativenent courtes, lancéolées, brièvement acuminées; à gaine à 5 angles, ligulée. Inflorescence enombelles arrondies, axillaires et terminales, portées surdes pédonculeshispides: glumes pourves d'une arète, it 3 nervures; caryopse trigone, supporté par 3 écailles obovées et dépourvues d'arêtes. - Très abondant dans les marécages et 
endroits aquatiques des basse et moyenne regions ou il vil sonvent en société sur une grande étendue : Camp-Jacob, Batratelle, Iammentin, Baire-

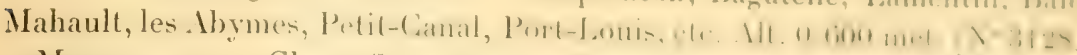
Martineue, - Champflore, Ducos, Gros-Morne, linamegis, Mobert, che, $[\mathrm{N} \times 853$.

Gladium P. Br. (du gree " kladion ", diminutil de "klados ", masseaus allusion au grand nombre de panicules très branchues de linflorescencer.

G. occidentale Schrad., Schœnus Cladium Sw.; Cladium des Imbles (teci-

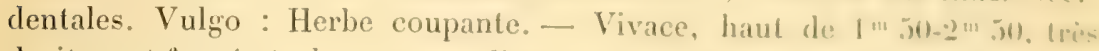
droit, vert foncé; à chaume sous-ligneux à la base, obtusément triangularir.

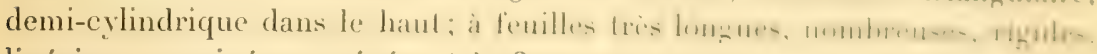
linéaires-acuminées, carénées, très finement serretées sur les bouls: it dents rigides, distantes; à gaine apprimée. Inflorescence en panicules (on) vmbiformes, interrompues: les inféricures, courtes; les supérieures el terminile's.

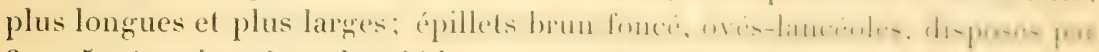

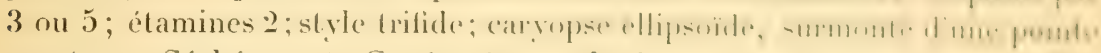
courte. - Séchée, cette Cypéracée sert de chaume ponr couvrir les Inits.

Vit en société sur de grandes étendues, dans les endroils marécigenx dims

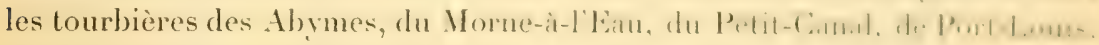
qui avoisinent la mer; à Marie-Galante (entre le bois de liolle-luse ot les terres de l'usine de Retz); à Trois-Rivières (étang de Roussel au-dersus du bourg), Gourbeyre (étang du Valcanard). Alt.0-350) mit. [Y :3108. - 1) cette plante, si commune à la Guadeloupe, on ne trouve pas trace it la Martinique, mais elle existe à Sainte-lucie dans un étaner au-dessus de la soufrière. $\left[N^{\circ} 469.\right]$

Machærina Vahl (du gree "machaira ", couleau, sabre, allusion is la forme des feuilles, qui sont recourbées, larges el polies.)

M. restioides Vahl; Macharine ressemblant ì un Restin, - Vivace par so: souches, droit, cespiteux, haut de $55-65 \mathrm{~cm}$., tres ormemental; it chamme

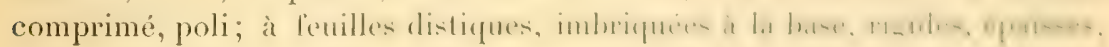
ensiformes, légèrement courbées, très polies et luisuntes : les suprivicures.

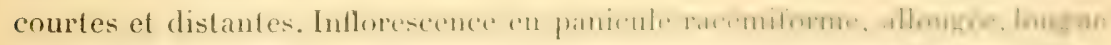
de 13-15 cm., large; panicules partielles alternes, entources, a la hase, d'um gaine ferme, comprimée, brune à la base; épillets paucillores, moirs: frume:

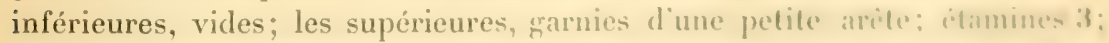
style trifide; caryopse trigone, noir, smmonte d'un hec conique, - Rare dans la région des grands bois; abondant dans la réginn supripieure : Silvint

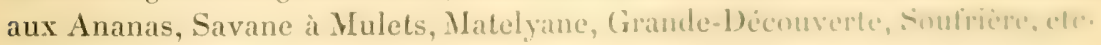
Alt. 600-1480 mèt. [No 3130 . $]$

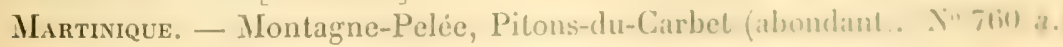


Rynchospora lahl (du gree "rhynchos ", bec, et "spora ", semence, parce que les caryopses sont surmontés diun long bee, qui est le style persistant.)

R. cyperoides Marl., R. polycephala Wydl., Schœnus polycephalus Pers.. S. triceps Vahl: Rinchospore ressemblant at un Cyperus. Schœnus Lin., Vivace, très droit, svelte, ornemental, haut de $0^{\mathrm{m}} 80-1^{\prime \prime} 20$, à feuilles peu nombreuses, très longues, linéaires, rigides, carénées; à carène très scabre ; ¿̀ gaine Iongrue, apprimée: ì chaume triangulaire. Inflorescence en capitules globuleux, disposés en une ombelle tres inégale, à 1-3 capitules sessiles ou presque sessiles, les autres pédicellés. Feuilles involucrales du capitule sétiformes; épillets ovés, acuminés. Fleurs supportées par plusieurs barbes; glumes inférieures ovées, les supérieures ovées-lancéolées; caryopse obové, articulé avec le bec qui le surmonte; bec pâle, subulé, linéare, environ de la même longueur que le caryopse. - Cà et là sur le bord des fosses remplies d'eau et des mares : Petit-Bourg, Petit-Canal, Goyave. Alt. 0-300 mèt. [No 3821 .]

Martinique. - Ducos, Gros-Morne, Trois-Ilets. [No 761.]

R. aurea Vahl; R. surinamensis Nees; Rynchospore à épillets dorés. Vulgo : Paille-mare, herbe-razoir mâle. Rollb., I)esc., t. 21, f. 1. (Schœnus Lin.) - Vivace, haut de $0^{\mathrm{m}} 90-1^{\mathrm{m}} 50$ et quelquefois au delà; à feuilles longues, largement linéaires, scabres sur les bords et sur la carène; a chaume it trois angles aigus. Inflorescence en panicules corvmbiformes, intermmpues, larges, arrondies, terminales et axillaires, dépassées par les feuilles; épillets jaune doré (à l'état f'rais); glumes inférieures ovées, les supérieures ovéeslancéolées; caryopse obové, brun, traversé longitudinalement de chaque coté d'un sillon profond, surmonté d'un bec conique, pointu, plus zros et un peu plus long que le caryopse lui-même. - Abondant dans les marécages dı Lamentin, de la Baie-Mahault, du Pelit-Canal, des Abymes, du Morne-ìl'Eau, ou il vit en société avec le Fuirena umbellata lintth.. Gommier, Gourbeyre (Valcanard), Trois-Rivières, etc. Alt. 0-600 mèt. [Nos 3118, 3523, 3612 .

Martingue. Vulgo: Herbe à couleau. - Ducos, Trois-Ilets, Anses-d'Arlel, Gros-Morne, etc. $\left[\mathrm{N}^{\circ} 761\right.$ a.

R. corymbifera Nees; Rynchospore à inflorescence en corymbes. Virace par ses stolons, cespiteux, droit, très glabre, ornemental, haut de 65-75 cm. ; à chaume triangulaire; à gaine lerme, liche au sommet; ì feuilles longues, plates, très légèrement carénées; a tignes et fenilles conleur de paille. Inflorescence en corymbes composés, axillaires et terminaux : les derniers beaucoup plus longrs et larges ; épillets cylindriques, allongés, bruns ; caryopse brun, biconvexe, court, surmonté d'un bec conique-comprimé, qui lui-même est surmonté d'une barbe géniculée, longue de près de $1 \mathrm{~cm}$. Se distingue facilement de ses congénères parses longues feuilles, ses épillets et ses barbes 


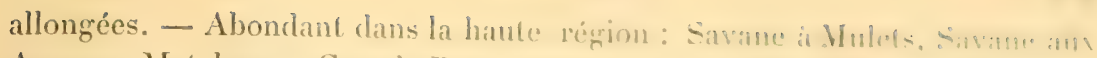

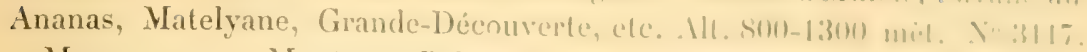

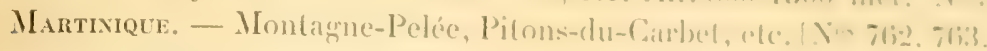

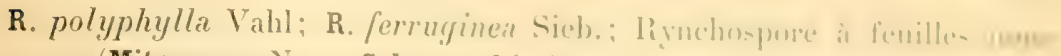

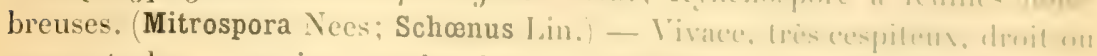

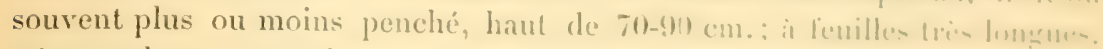

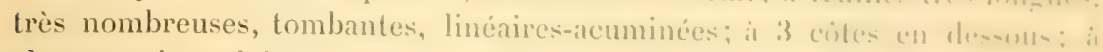
chaume triangulaire. Inflorescence comme dans le precident: ipillet atlun-

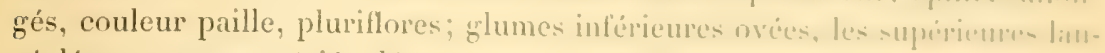
céolées; caryopse strié, dépourru de barbe, finement tuluerculi: an-i lom:

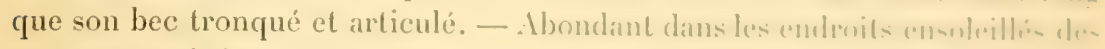

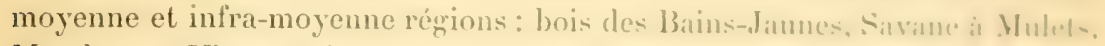

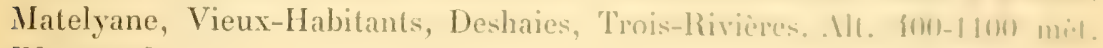
[No 3116.$]$

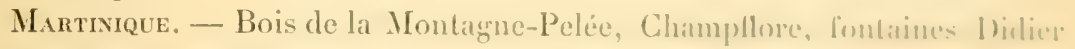
et Absalon, Trois-Ilets, la Régale, Gros-Jorue, ele. YX" tifi.

R. setacea Boekeler, R. spermodon Griseb.; Rynchuspore ì leutles sitiformes. (Schœnus Rott)., Desc., t. 21, 1. 2.) (Dichromena Kilh. Cespiteux, annuel, haut de $32-10 \mathrm{~cm}$, droil ; it chatume rigride, filiformue : it

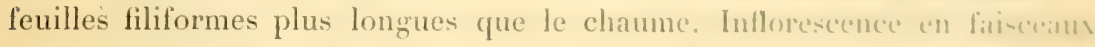
corymbiformes, petits, axillaires el teminaux, plus conts que les feruillen h l'aisselle desquelles ils naissent; épillets bruns, allongrés, pelils, lamequateacuminés; glumes inlérieures elliptiques, leminées pitr une conte printe.

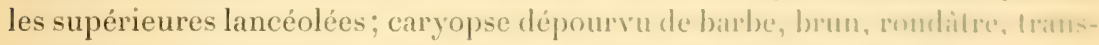
versalement sillonné, bidenté au sommet, plus long el plus lampe que le lue. comprimé-conique, qui le surmonte. - Endroils sees, menillemx mu piemrens

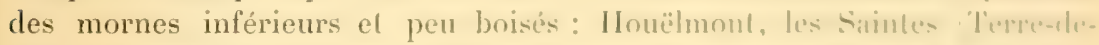
Haut, route du Chameau), Marie-Galante: asser man dans le's melroil-

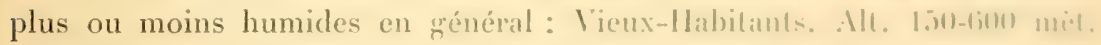
[No3121.]

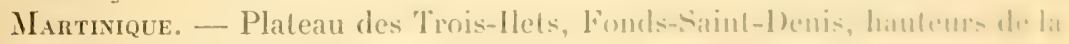
Grand'Anse, Caravelle. [No 760.]

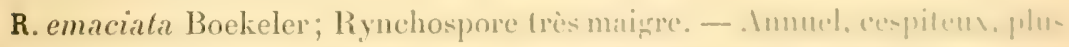

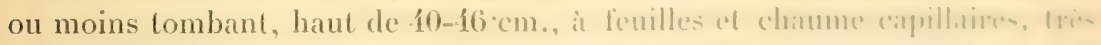
tenaces. Inflorescence en 1-3 laisceaux corymbilmmes, fermimam at and-

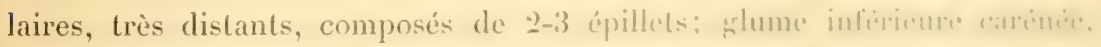

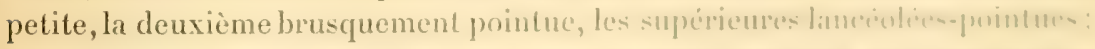

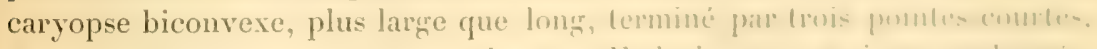

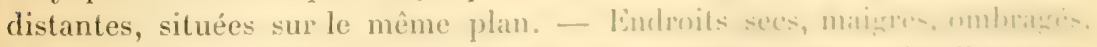

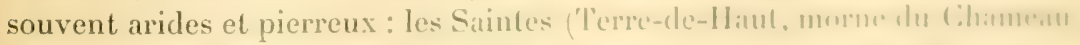
Abondant, Alt. $80-250 \mathrm{mèt}$ [ [Y' 31:2. 
Martinigle. - Hauteurs du Diamant, chemin des Fonds-Saint-Denis aux Deux-Choux, Caravelle, hauteurs de Fort-de-France. [No 693.$]$

R. micrantha Vahl, R. sparsa Sieb.; Rynchospore à petites fleurs. Vulgo : Herbe à chereu. (Dichromena Kth.) Annuel, haut de $25-55 \mathrm{~cm}$., délicat, flacide, plus ou moins droit; à chaume triangulaire, branchu; à feuilles linéaires, plates, nombreuses. Inflorescence en corymbes courts, délicats, divariqués, axillaires et terminaux, à pédicelles filiformes; épillets ovésarrondis, petits; glumes lancéolées, obtuses; caryopse brunâtre, rondâtre, transversalement sillonné, marginé, trois fois plus longet plus large que son bec, court, comprimé-conique, pointu, el brièvement décurrent. - Endroits humides et peuboisés, bords des mares et des étang"s, savanes aquatiques, où il vit souvent en société et forme gazon : Bains-Jaunes, Matouba, CampJacob, Bagatelle, Parnasse, Gourbeyre, Trois-Rivières, Vieux-ILabitants, ete. Alt. 300-900 mèt. [No 3119 .

Martrnque. Vulgo : Herbe à cheveu. - Champflore (abondant), TroisIlets, Ajoupa-Bouillon, Grande-Rivière, ete. $\left[\mathrm{N}^{\circ} 463\right.$.

R. pubera Boekeler, forma clatior; Rynchospore pubescent. - Vivace (habituellement, cespiteux, plus ou moins droit, haut de 35) (m. ; ithizomes rampants; it feuilles nombreuses, linéaires-acuminées: les unes plus courles, les autres aussi longues ou plus longues que le chaume comprimé, souvent tacheté de brun; à feuilles, gaines et chaume pubescents. Inflorescence en capitules arrondis, sessiles, terminaux, composés d'un petit nombre d'épillets et entourés de 3-5 feuilles involucrales, dont 2-3 très longues; épillets et shlumes carénés; caryopse subglobuleux, transversalement sillonné-tuberculé, plus long que son bec obtus. - Abondant dans les terres cultivées et en friche de la rénion infra-moyenne de toute la Guadeloupe proprement dite. Alt. 300-600 mèt. [Nos 3122, 3611 .

Martinique. - Fontaine Absalon, Camp Balata, Gros-Morne, ete. [N०706.]

R. Jelskiana Boekeler'; Rynchospore de Jelske. - Vivace par ses rhizomes rampants, droit, haul de 35)-38 cm. cespiteux, a leuilles peu nombreuses : les inl'érieures courtes, lessupérieures plus longues, Inutes flasques, réfléchies, légerement pubescentes vers l'extrémité, plus pubescentes ver's la base; gaine courte, ciliée sur les bords; chitume sillonné, filiforme, rigide, dépassint de beaucoup les feuilles. Inflorescence en capitules arrondis, larges, blanes, composés d'épillets 5-6-flores; glumes inférieures larges, ovées-membraneuses, les autres ovées-lancéolées, toutes carénées sur le dos; caryopse ovoïle, lézèrement comprimé, transversalement sillonni-tubereulé, un peu plus court que son bec blanc, artieulé, comprimé et surmonté d'une pointe brune et courte. Se distingue facilement de ses congénères par son chaume noirâtre et ses feuilles courtes. - Environs des fontaines Didier et Absalon, 


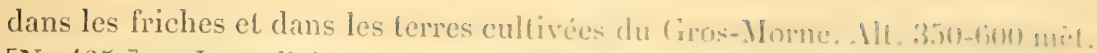
[No -165.] - Je ne l'ai pas trouvé à la Guadeloupe.

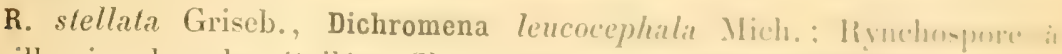

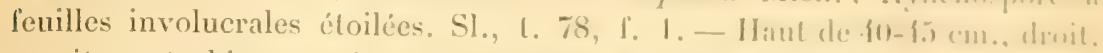
cespiteux, à rhizomes vivaces, rampants, à fenilles frabres, limenire-suminées, peu rigides: les unes plus courtes, les autres plus longues qun hi dhamm. anguleux. Inflorescence en capitules compacts, lamper, hemisphirigum.

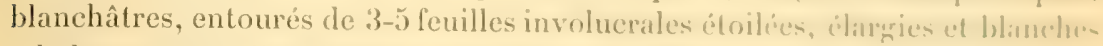
à la base, sans cils, vertes à l'extrémité : 2-33 lompues, les autres conder: épillets blancs, ovés-oblongrs; caryopse obové-ponditre, di sillons tranversaux, fins, deux fois aussi large et aussi lomgr que snu bec comprimiconique et pointu ; barbe longue, noire. - Mbondant dins lus sivanes hrebeuses, très humides ou aquatiques des basse el infratmoneme rininn:

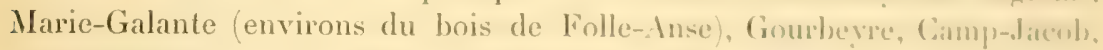
Pointe-à-Pitre, Gozier, Moule, les Abymes, Matnuba, ofć. Nlt. (1)-7mu mil. [No 3131.$]$

Martinique. - Abondant: Saint-Esprit, La Regale, Riviere-l’ilole, TroisIlets, Marin. [ $\mathrm{N}^{\circ} 665 \mathrm{~s}$ a. $]$

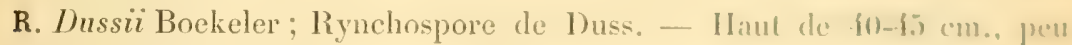

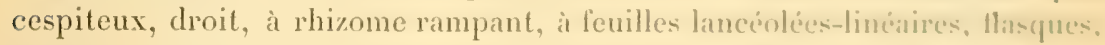
glabres, 6-8-nerviées, très vertes: celles de la base, conrles, avere une finine également courte; les supérieures, plus longues que le chaume liliforme. comprimé-anguleux. Capitules arondis, composés de fi-s épillets, hlane pâle, allongés, cylindriques, pointus, 1-5-flnese ; feuilles involucrales vertes. au nombre de 5, dont 1-3 longues; caryopse brun, ovö̈le, transversalement silloniné-strié, deux fois plus lnng et plus large que son bee obtus, el sumunti: d'une barbe noire un peu plus longue que les deux arotes qui narisent it la base du caryopse. Facile à distinguer de ses congénimes de la meme sertion par ses feuilles larges. - Peu répandu : assez abondant dans une riviun du

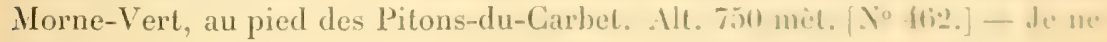
l'ai pas vu à la Guadeloupe.

TRIRU III. SCLERIEES.

Scleria Berg. (du gree « skleros", dur, paree que les caryopeses soul durs.

S. pratensis Lindl., S. commumis Kilh; Sclérie des pris. linlen : Herlue-

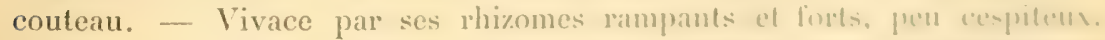

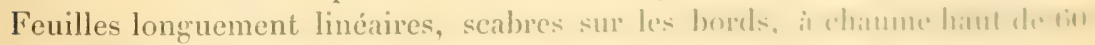

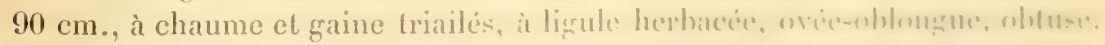

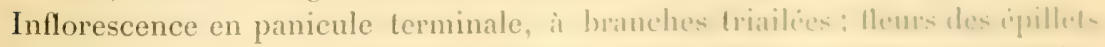
mâles, à 1 étamine; glumes inféricures vides; lleur lemelle it 1 s lyle ; 
carvopse golouleux, blane it la maturité, très poli et luisant, d'un diamet. de 1-5 mm., niché dans un double disque dont l'extérieur, à 3 lobes terminés en pointe allongrée, se sépare facilement du second, qui est it 2 lobes et adhérent à ce caryopse. - Cà et là dans les savanes herbeuses, dans les haies, sur le bord des chemins des basse et infra-moyenne régions de toute la Guadeloupe, de la Grande-Terre et de Marie-Galante. Alt, 0-600 mèt. [No 3824.]

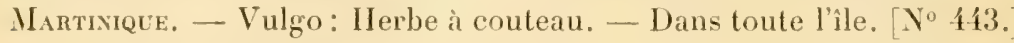

S. microcarpa Nees, variété latifolia macrocarpa. Vulgo: Herbe-razoir. - Vivace par ses rhizomes, haut de 1-2 met., rarement plus haut, droit, ornemental, à feuilles lancéolées-linéaires, scabres sur les bords, rigides, penchées à l'extrémité, ì yaine fendue, au sonmet, en deux lobes, garnie de trois ailes larges, allant en climinuant du sommet it la base et formant finalement trois carènes, à ligule deltoüle. Inflorescence en panicule souvent très allongée, étroite, interrompue, à branches trigones; épillets mâles situé dans le bas des branches, chacun contenant trois fleurs avec trois étamines: les tleurs supérieures, femelles; earyopse grlobuleux, blane à la maturití, très poli et luisant, surmonté d'une pointe très noire; disque double: l'extérieur, tronqué ; l'intérieur, trilobé. - Vit en société dans les endroits marécageux de lintérieur des terres et dans les terres marécageuses el inondées du bord de la mer: Gourbeyre étang du Valcanard, où il abonde, PetitCanal (près du bord de mer), Baie-Nahault, Gozier, Lamentin. Alt. 0-350 mèt. [No 3112.$]$

Martnique. Vulgo : Herbe-razoir. - Ducos, Lamentin (près de l'embarcadère de l'usine de Lareinty, etc.). [ $\left.\mathrm{N}^{\circ} 445.\right]$

S. scindens Nees; Sclérie coupante. Vulgo : Herbe coupante. - Vivace par ses rhizomes, haut de $1^{\mathrm{m}} 50-2^{\mathrm{m}} 50$, à feuilles rudes, très scabres sur les bords, longues, linéaires, étroites, penchées; à gaine non ailée, mais ì trois carènes finement serretées-scabres; it ligule courte, arrondie-obtuse. Inflorescence en panicule longue de $7-9 \mathrm{~cm}$., naissant pris de la dernière leuille du chaume, à branches triquètres, étalées; épillets mâles à trois fleurs, chacunà trois étamines; caryopse comme dans le précédent : disque intérieur trilobé, supporté par un petit carpophore: l'extérieur, ondulé. - Dans les bois secs, ou plus ou moins humides de l'infra-moyenne région de toute la Guadeloupe proprement dite, surtout dans le massif de Itouëlmont, dans les hois de Deshaies, des Trois-Rivieres, de Pigeon, des Vieux-Habitants, ete. Alt. 50-670 mèt. [ $\mathrm{N}^{\circ} 3111$.]

Martinque. Vulgo: Herbe à couteau. - Dans les clairières et sur les lisières des bois inférieurs. [No 446.$]$

S. latifolia Sw.; Sclérie à larges feuilles. Vulgo : Herbe à couteau. Vivace par ses rhizomes forts et volumineux, haut de $0^{m} 70-1^{m}$ (60, i feuilles larges, oblongues-lancéolées, ou lancéolées: a chaume triangulaire: saine it 


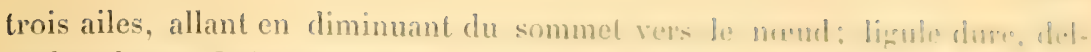
toïde, obtuse. Inflorescence en panicule compacte, plus langer que dans he

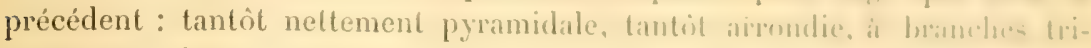

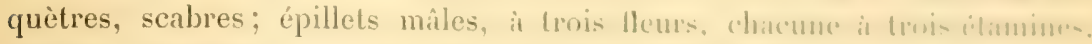

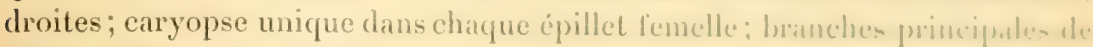

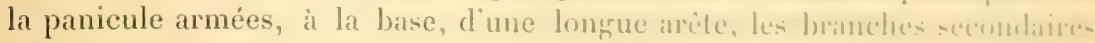
d'une arête courte, subulée, celles des épillets mailes ol femellen d'ume irrate.

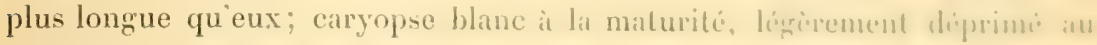
sommet et terminé par une petite protubérance; disque interient inciondenté et à trois lobes plus longs que le discpue extérieur onvert al mululi.

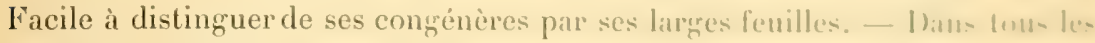
bois plus ou moins humides de la région infrit-moyeme de lonte lat (iniuleloupe proprement dite. - On en rencontre deux varide : l'une dunt lex branches de la panicule et les épillets sont d'un blane paile ou content pritle:

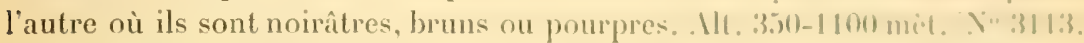

Martinique. Vulgo : Herbe à couleau. - Dans Inus les boris humides mu plus ou moins sees. $\left[\mathrm{N}^{\circ} 443 \mathrm{a}\right.$. $]$

S. reflexa H. B. el Kith, S. flagellum Grisel, ; Sclerie it branches lombantes. Vulgo: Herbe à couteau. S1., 1. 77, 1. 1. - Vivace, mrimpant, ponvant monter sur des arbres très élevés; it branches pendantes; it leuille-

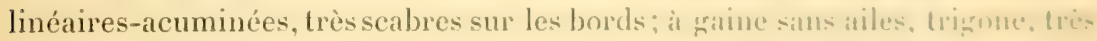

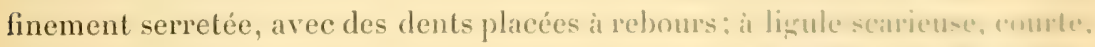
obtuse, noirâtre, souvent oblitérée. Les leuilles des S. reflexal II. I3, ct lith, latifolia Sw. et scindens Nees sont tris tranchantes : efles ncominimment de: blessures profondes et douloureuses. Inflorescence en pintenter terminater et axillaires, toutes courtes, compactes, pyramidales, it hranches triquition.

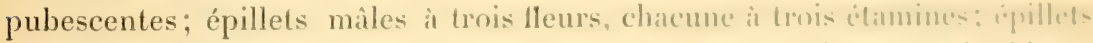

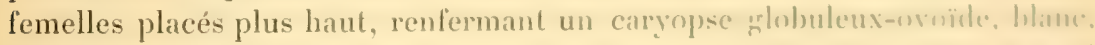

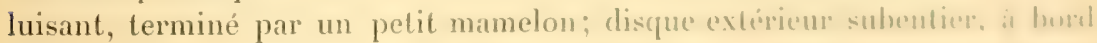

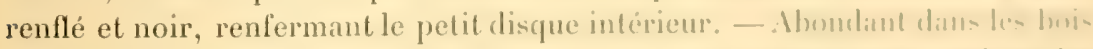

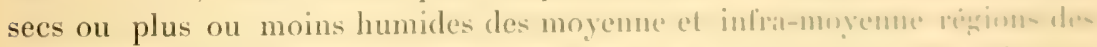

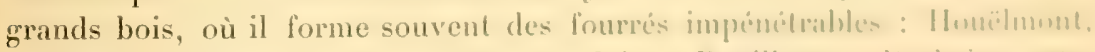
Gourbeyre, Vieux-Habitants, Pointe-Noire, Bonillanle, Deshated, che Alt. 300-800 mèt. [No 3825 .

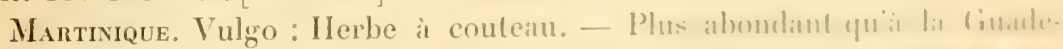

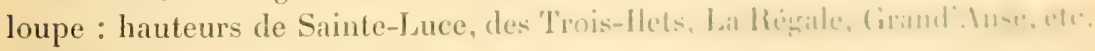
[No 41.

S. lithosperma Sw. (emend), S. filiformix Sw... S. purpurcil 1'uir. : Schinu

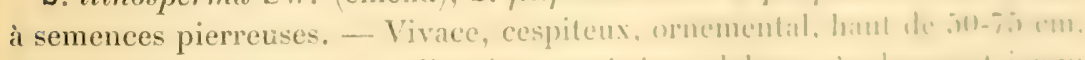

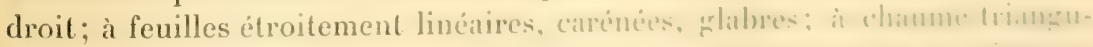

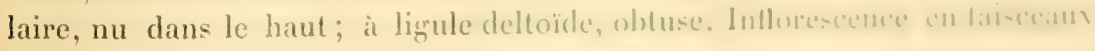


courts, pédonculés, axillaires et terminaux, très distants, composés d'un petit nombre d'épillets: bractée mère, longue, séteuse, rigide, droite ou subulée; épillets màles à une étamine; caryopse globuleux, blane, obtusément trigone à la base; disque trigone, noirâtre, simple, petit. - Abondant. dans les mornes inférieur's peu boisés, sees et rocailleux de Vieux-Fort, des Vieux-IIabitants, de Bouillante, de P'igenn, de leshaies, etc. 1tt. 10-400 mèt. [No 3114 .]

Martixique. - Hauteurs du Diamant, des Trois-Ilets, Sainte-Luce près du bord de mer.) [ $\left[\mathrm{N}^{\circ} \mathbf{4} 46 \mathrm{a}\right.$.]

\section{TRIBU IV. CARICINÉES.}

Carex L. du latin "carere ", manquer, parce que les épillets supérieurs sont mêlés et ne portent pas de semences.)

C. Dussiana Boekeler; Laiche de Duss. - Vivace, haut de $55-75 \mathrm{~cm}$.; à chaume mince. penché, triangulaire; à feuilles très Inngues, très glabres, plates, beaucoup plus longues que le chaume, lancéolées-linéaires, très acuminées et graduellement rétrécies vers la base, presque toutes radicales, bitricaulinaires; ligule nulle; gaine triangulaire. Inflorescence en épis formant des panicules làches, allongrées, longuement pédonculées, fastigiées, biaxillaires et triteminales, toutes d’inérrale longueur; épis longes de 8-12 mm., sessiles, obovés-allongés, garnis, à la base, d'une arête droite, barbelée, tantit plus courte, tantot de moitié moins longue que l'épi, et à 2-3 bractées vides : épillels distiques : les huit premiers renfermant des fleurs femelles, à trois st yles, à caryopse comprimé-nvoïde, pointu, renfermé dans un utricule, persistant, ovoïde-allongré et muni, à la base, d’une écaille légèrement carćnée, pointue, uninerviée; fleurs mâles dans la partie supérieure de l'épi, à trois étamines. - Peu répandu : çà et là dans les hauteurs du Morne-Vert. Alt. 500-700 mèt. [No 763 b.] — Je ne l'ai pas trouvé à la Guadeloupe.

CENT TRENTE-QUATRIÈye FAMILLE. - LILIACÉES.

\section{ASPHODÉLÉES.}

Aloe I. (du grree ". Iloé ", mot qui vient de la langue orientale, ou du mot arabe "Alhoch ", en hébreux " Alal ", brillant, amer.)

A. vulgaris Lam.; A. harbadensis Mill.; Aloé commun. Vulgo : Aloès. Dese., vol. II, t. 130, p. 160. - Vivace, stolonifère, à tige généralement courte. Fenilles rosulées, extrèmement épaisses, remplies d'un suc filant, verdâtre brun, lancéolées-acuminées, dentées; dents distantes. plus ou moins 


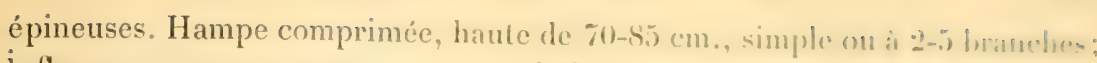

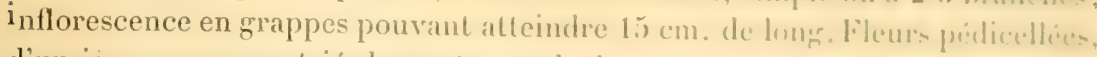
d'un jaune orange strié de vert, en clechetles fi-fides, pendindes, suluevlin-

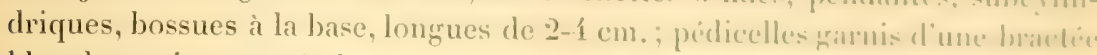

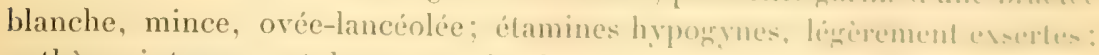
anthères introrses; style exsert, simple; stirmate trilobi. - lil. de firrier it mai, mais ne produit pas de fruits. - Introduit probablement de lit rizion méditerranéenne. - Gultivé comme plante médicinate, mais sc rencontre assez souvent à l'état sauvage dans les endroits très seces, pierrems ol arides : cote entre Baillif et les Vieux-Habitants, hord de la riviere des l'ires. mume calcaires du Petit-Canal, environs du Moule. - Dans mos denx columiun. on met rarement à profit les propriétés purratives bien commues de ced alorio. mais on en emploie souvent les feuilles comme très imollientes: on lex pri-

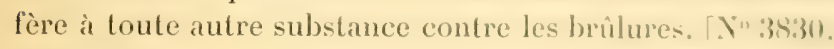

Martingue. - Cultivé çà el là à l’étal sauvage. - Hauleurs inlérieurés de Case-Pilote et du Diamant. Y Yo 13 ín.

On cultive fréquemment dans les deux colonies le Yucca yloriosil L... qui montre sa belle et large panicule pyramidale en mai, juin ou juillet; il esl originaire de l'Amérique; on rencontre plus rarement les Yucca filamenlusia L., flaccida Haw et aloifolia L., enfin l'Aspidistra elatior Blum., ote.

Dans les jardins potagers, on voil partout: l'Allium I'orrmm I... vulgo Poireau ou Porreau; l'Allium fistulosum L., vuliro : Ciboule: l'Allium walivum L., vulgo : Petit ail; l'Allium cepa L., vulgo : ()ignon: l'Allium ascialunicum L., vulgo : Échalotte ou Chalotte. - Dans les hauteurs, les vignon:fleurissent assez souvent.

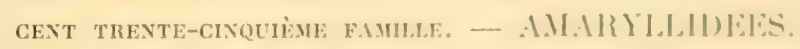

Agave L. (du gree "Agauos ", beau, fier, par allusion au prort de lit plante et à la beauté de ses fleurs.)

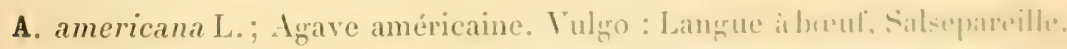
Lindley, Vegetable Kingdom, f. 116, 1). 15\%, - Plante majestueduce, sams lige

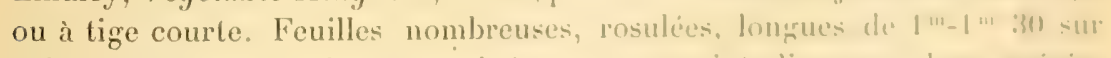

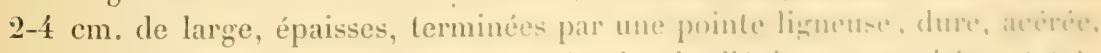

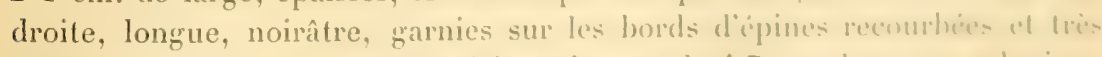

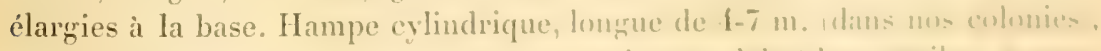

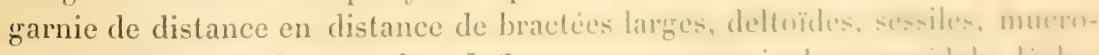
nées, tournées de haut en bas. Inflorescence en panicule prymadale, liuche. longue de $1^{\mathrm{m}} 50-2^{\mathrm{m}} 50$; branches de la panicule tris comprimies : lés infirieures, horizontales, longues de $55-75 \mathrm{~cm}$, el deux livis lrichulumes: lin 
dernieres divisions, courtes et terminées chacune par une ombelle contenant 5-10 fleurs. Fleurs d'un jaune très vif d'orange, longues de $8-9 \mathrm{~cm}$.; ovaire infère, long de près de $3 \mathrm{~cm}$. : périanthe à 6 serments nvés-lancéolés, obtus, crarni au foud de plusieurs nectaires sécrétant une matiere brune, mielleuse, demi-liquide qui attire des nuées d’insectes ailés: étamines exsertes, fixées à la hase du tube, lérerement arquées: anthères dorsifixes: style plus longr que les étamines, at sligmates trilubés-trigones. Capsule longue de 5 cm. sur $2 \mathrm{~cm}$. de diamèt., s'ourrant au sommet en 3 valves; graines très aplaties, nnires en dehors, blanches en dedans, laryement obovées ou irrégulièrement subquadrangulaires-arrondies. - Fl, en février, mars ou arril. - Endroits secs, rocailleux, souvent arides du bord de mer ou dans les mornes voisins de la mer: Moule, Sainte-Anne, Iésirade, Marie-Galante, les Saintes Terrede-Bas). - Spécimen manque. Alt. 0-150 mèt. ${ }^{1}$

Mantrique. Vulgo: Langue a boruf, - Case-Pilote (Belle-Fontaine), Diamant, Caravelle. $\left[N^{\circ} 2136\right.$.

On cultive souvent dans des pots ou en pleine terre, l'A. americana foliis variegatis. - Je ne l'ai jamais vu fleurir.

Fourcroya Vent. dédié an Français Ant.-François Fourcroy, né à Paris, en 1755: en 1781. professeur de chimie au Jardin du roi, collaborateur de la nouvelle nomenclature de chimie, membre du comité de l'instruction publique et du salut public, fondateur des écoles de médecine de Paris, de Strasbourg et de Montpellier; mort en 1809.)

F. gigantea Vent., Agave fotida L.; Fourcroya géant. Vulgo : Karatas. Tuss., Fl., II, t. 25 et 26. - Sans tige ou à tige peu élevée. Feuilles rosu-

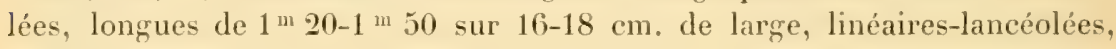
droites, épaisses, avec ou sans piquants sur les bords, terminées par une pointe acérée, cylindrique, ligneuse. Hampe longue de 7-10 m., cylindrique, très droite, garnie de hractées larges, deltoïdes, apprimées. Inflorescence en une panicule nettement prramidale, longue de $2^{m}\left(60-33^{m} 50\right.$, à branches paniculées, distantes, alternes: les inférieures, horizontales; les supéricures, fastigiées. Fleurs à odeur lorte et désagréable, hlanc verdatre. pendantes après léclosion, longues de près de $6 \mathrm{~cm}$. : tube du périanthe filiforme, long de $2-5 \mathrm{~cm} .:$ lobes du périanthe, elliptiques, finement veinés. plus courts que le tube : les 3 extérieurs, plus étroits; les 3 intérieurs, plus larges: étamines 6 . incluses, inférieurement dilatées; ovaire presque loujours transformé en un bulbille ové-lancéolé, acuminé. - Les racines, mises dans l'eau, sont purgatives, mais on s'en sert rarement; le sucdes feuilles est

1. Cette plante reçoit des usages divers: ses fenilles donnent un textile apprécié; ses racines sont dites sudorifiques et antisyphilitiques (contiennent peut-c̀tre de la saponine); la tige laisse exsuder, ainsi que les feuilles, après incision, un suc sucré qui, par fermentation, donne un liquide alcoolique (poulqué des Mexicains), qui serait, dit-on, laxatif.

(E. $\mathrm{H}_{\text {.) }}$ 
légèrement caustique, et aree des fragments de fenilles pilées on pripare une sorte de pâte à lacquelle on ajoute du sel el du tafia, el qui inn applique contre les plaies, les blessures et les foulures des cheraux el des mulets: les bulbilles sont acides el astringents : on en fail, it la Martinique, une cepiece de sirop contre les dysenteries chroniques. Avec le bois mou el sponerieux de la hampe, après dessication, on fabrique, dans les Antilles, d'excellents reppissoirs pour les rasnirs, les instruments de chirurrie el les canifs. Toul te monde sait que les feuilles de cette espèce el de la précédente contiennent une filasse forte semblable à celle du chanvre. - Hil. en juin, juillet, incit. Assez abondant dans les mornes inférieurs, secs, arides el pierreux : crite de Baillif el de Deshaies, Vieux-Forl; şi el lit au Mnule, an (inzier, it Marie-

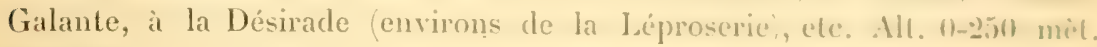
[Yo 3602 .]

Martixique. Vulgo : Karalas, langue à bocul, bois-chique. - Coiles siches entre le Carbet, Case-Navire, Diamant, Inses-d Arlet, Carravelle, GrnsMorne (où on en fait des haies). $\mathrm{N}^{\circ} 2125$.

Hymenocallis Salisb. (du gree "hymen ", pellicule, et "kallos ", beanti. allusion aux segments long's, tendres et délicats du périanthe qui font lit beauté de la tleur.

H. caribea Herb., Pancratium caribeum L., P. amanum Salisb. P. declinatum Jacq.; Hyménocalle des Caraübes. Vulgo : Lis blanc, nignon de lis. lis à l'huile. Desc, vol. VIII, L. 556 , p. 135. - Haut de $45-80 \mathrm{~cm}$. a it bullse rondâtre, blanc. Feuilles lancéolées-oblongues, inclinées, se rétrécissant lentement en un pétiole largement cannelé. IIampe comprimée, plus longue que les feuilles, surmontée d'une ombelle de $6-12$ lleurs; ombelle enveloppée, it la base, de deux spathes foliacées, blanches en dedans, vertes en dehors. deltoïdes, allongées. Fleurs longues de $15-22 \mathrm{~cm}$., d'un parlum tries suave el fort, sessiles; tube du périanthe droit, filiforme, tanteit plus court, tantit plus long que les lobes étroits, inclinés et plus langes au milieu qu’aux extrémités; étamines insérées sur une cournnne infondibuliforme el alternant avec ses dents pointues; filets filiformes, vert loncé dans la moilié supérieure: anthères fixées un peu au-dessus du milieu; style fililorme, dépassint un peu les étamines, rert foncé dans la moilié supéricure; ovaire triłgone. - Ial décoction des bulbes est romitive, et s'emploie contre l'asthme. - lit. haluituellement deux fois dans l'année. - Dans loute la Guadeloupe el ser

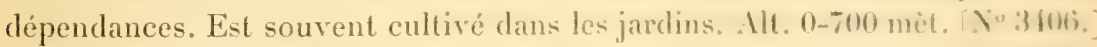
Martixique. Vulgo: Lis blane, lis à l'huile. - Dans toute l'ile. [10.1333.

Grinum L. (du gree " lirinon ", lis.

C. amabile Don, - Crinole aimable. Vulgo: Grand lis rougre. - Haut de 1-1' 40 , à bulbe blanchâtre, gigranterque, formant au-dessus du sol une

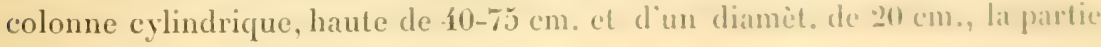


souterraine étant plus grosse et arrondie. Feuilles longues de $0^{\mathrm{m}} 85-1^{\mathrm{m}} 20$ sur 12-18 cm. de large, inclinées, vert très tendre, épaisses, ondulées sur les bords, cannelées et rétrécies à la base, terminées au sommet par une pointe ferme. Hampe latérale rouge, plus Inngue que les feuilles, droite ou sourent tortueuse et tombante, large de $3-\mathbf{4} \mathrm{cm}$., comprimée, portant une ombelle composée de 15-25 fleurs. Ombelle entourée, à la base, de deux spathes concares, allongées, blanches en dedans, d'abord dressées, ensuite fortement rejetés sur la hampe. Fleurs à ndeur forte el exquise, longuement pédicellées, it lube mince, long de $5-7$ am.. legerenent infondibuliforme: segrments longrs de 20-25 cm., rose foncé, striés de rose moins foncé, lancéolés-linéaires, linement veinés: les 3 extérieurs moins larges: élamines insérées au sommet du tube, plus courles que les segments: ovaire allongé, ne produisant pas de semences. - Fl, principalement de janvier à mai. - Originaire de Sumatra. - Très répandu dans l'île. On le plante rarement dans les parterres, parce qu'il est trop encombrant, mais il abonde souvent dans les cimetières, dans les pares, dans les grandes cour's et dans les environs des maisons de campagne. Alt. 0-500 mèt. [No 3831.$]$

Mantixique. Vulgo: Gros lis rouge. - Dans toute l'île. [No 2141.]

G. longiflorum Herb.; Crinole à longues fleurs. Vulgo : Lis panaché. Haut de $65-75 \mathrm{~cm}$, ì bulbe rondatre, très filandreux-spongieux, très profondément enterré, trois ou quatre fois plus grand qu'un ceuf' de poule. Feuilles fortement infléchies-tombantes, ondulées, oblongues-linéaires, lentement acuminées, légèrement seabres sur les bords, à nervures parallèles. Hampe droite, latérale, dépassant de beaucoup les feuilles, comprimée, rouge ou rouge vert, surmontée d'une ombelle sessile de 5-7 fleurs, longues de 18$22 \mathrm{~cm}$, toujours penchée, renfermée, à la base, dans deux spathes herbacées, deltoïdes, très allongées, pointues, presque aussi longues que le tube de la fleur. Tube du périanthe filiforme, plus court que les lobes, graduellement dilaté vers le sommet en six segments oblongr-lancéolés, acuminés, blanchâtres en dedans, rose foncé, et traversés de deux stries longitudinales blane paile: étamines recourbées au sommet, plus courtes que les segments. - Fl. de mars à août. - Çà et là dans les endroits aquatiques ou très humides et le long des ruisseaux : environs de la Basse-Terre, Gourbeyre (habitation Saint-Charles), Trois-Rivières, Lamentin. Alt. 0-300 mèt. [No 3833.]

Martinique. Vulgo : Lis penché. - Parc du Collège, habitation Pécoul (grand parc), Carbet, Ducos, Sainte-Anne, etc. [ $\mathrm{N}^{0}$ 2134.]

On rencontre encore çà et là dans les deux îles le Grinum americanum L., vulgo : Grand lis blanc, haut de $0^{\mathrm{m}} 90-1^{\mathrm{m}} 40$, à feuilles allongées, assez étroites et rigides, à fleurs blanches, peu odorantes, disposées en ombelle X's 3191, 3716], et le Grinum giganteum Andr., vulgo: Grand lis blane, qui diffère de l'americanum par ses fleurs à tube plus allongé et plus mince, à 


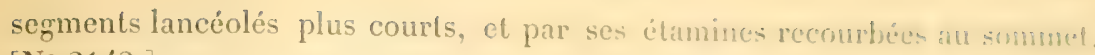
[N०2142.]

Hippeastrum Herb. (du gree "hippos ", cheral, ch "astron ", itrille, firrec

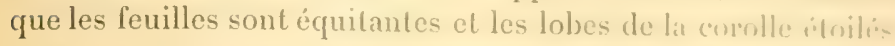

H. equestre Herl), H. occidenlale Roem., Amaryllis erquestris . Lil. : Hip-

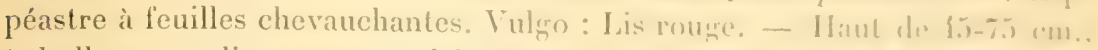

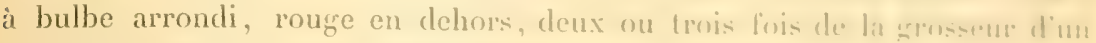

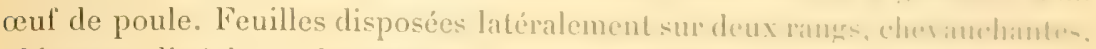
oblongues-linéaires, obtusément pointues, inclineses, peut allemmes it lat hal-1 Hampe creuse, droite, glauque, dépassant les fenilles, subeylindriqum, rifricie au sommet, très sourent munic de deux sillons longiludinamx, profinullatéraux. Ombelle à 2-1 fleurs pédicellées; pédicelle vert morritro. Inug de. 3-3,5 cm., dressé jusqu'au niveau de l'ovare nù il tomme it ample droil al fait prendre à la fleur une direction horizontale; spathes de limmluello frívertes, deltoïdes, aussi longues que la partic droite du pridicelle: luhn du périanthe long de $2-3 \mathrm{~cm}$., obtusément trigone, se dilatant rradueflement in

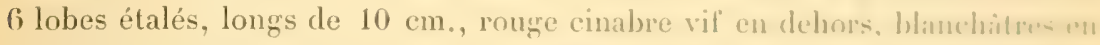
dedans vers la base et garnis d'une toulte longritudinale de proils hanchiller. sépales ovales-elliptiques, subégaux; pétales plus élroils, ch to lroisimme. opposé aux étamines, bien plus étroit el lancéolé; élamines plus courter que les lobes, horizontales, redressées à l'extrémité : les trois externé = un pru plus courtes et plus minces; anthères semilunaires, sulmédiatixes: pristil suivant la direction des étamines, plus long qu'eltes et redressic it l'a lrimiti: stigmate trilobé, triangulaire. - Répandu dans loute liı Ciuadeloupe ol ses dépendances, mais particulièrement abondant dius less savanes de's limi:-

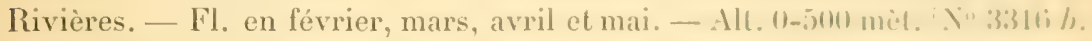

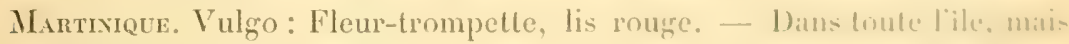
moins abondant. [No2143.]

Amaryllis L. (dédié à la belle nymphe Amaryllis, de "amaru-crin briller.)

A. tubispatha L'Hérit.; Amaryllis à spathe tubuleuse. I'ulino : l’elil liblanc. (Zephyranthes Herb.) - Haut de 25-30) cm., à Julbe owïle-ronditre et noirâtre en dehors, deux ou trois fois plus volumincux qu'um आrul d: pigeon. Feuilles plates, linéaires-rubanées. Hampe filitorme, it pren prí-di. la même longueur que les fenilles; spathe simple, fubulense, siture andessous de l'ovaire, bifide, égalant à peu près én longruen la moiliv de prialicelles; tube du périanthe très court; lobes de ce périandhe d'mu hlane dimé-

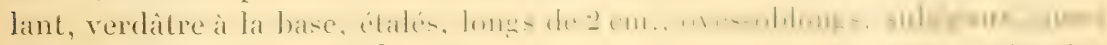
longs que le pédicelle. Étamines incluses: lrois plus longrues à lmi- fllucourtes, les longues deux l'ois plus courtes que les lnhes: pristil imelus. dépassant un peu les étamines; style trifide. - lil, habiluellement de juillè

Duss. - Plantes Gradeloupe et Martinique. 
à octobre. - Abondant dans les jardins, où on le plante en bordures ; cà et là dans les savanes et les terres cultivées: Moule, Gozier, les Abymes, Morne-i-l'Eau, Gourbeyre, Marie-Galante, etc. Alt. 0-600 mèt. [No 3314 b.]

Martingue. Vulgo: Petit lis blanc, lis-savane. - Dans les jardins et à l'étal saurage. Tro 2138.

A. carinata Spreng. ; Amaryllis à spathe carénée. Vulgo: Petit lis rose. Zephyranthes II(x)., - Diffire du précédent: par sa taille un peu moindre, ses feuilles un peu plus élroiles; par sa spathe fendue et légèrement carénée, enveloppant la moitié inférieure du pédicelle; par son périanthe rose, à lobes obovés-oblongs et pointus, un peu plus longs que le pédicelle et une fois plus longs que les étamines subégales. - Fl. de juillet à octobre. - Plus abondant que son congénère; cultivé et à l'état sauvage, on en fait souvent des bordures dans les parterres: Basse-Terre, Gourbeyre (dans les terres cultivées de I'habitation Saint-Charles), Vieux-Fort, Trois-Rivières (environs du Bourg). Alt. 0-500 mèt. [No3313 J.]

Martaxique. Vulgo: Petit lis rose, lis à bordures. - Dans les jardins et à l'élat saurage. [No 2138 b.]

On cultive fréquemment dans les jardins des deux colonies: $1^{\circ}$ le bel Eucharis yrandiflora Planch. E. amazonica Linden), vulgo : Couromme de la Vierge, lis de saint Joseph, originaire des bords du fleuve des Amazones 「X"3:334, Martinique [To 21:37; 2" le Lilium longifforum Thunb., variété IIarrisii Hort., vulgo: Lis de France [No 3850$]$; $3^{\circ}$ un peu moins souvent, l'Amaryllis villata L. Ileril. ; " les Hemerocallis fulva L. el flaca I. ; 5" l'Amaryllis L Lamasco I. . a feuilles evlindriques el creuses. [N"3315 bj, Martinique

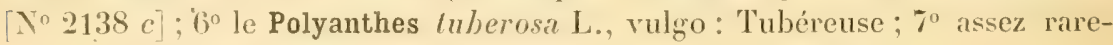
ment l'Agapanthus umbellatus Ait., qui fleurit difficilement.

Hypoxis L. (du grec "hypo", avec la signification de quelque peu, et " oxus ", pointu. Les feuilles et les lobes du périanthe sont pointus.)

H. procumbens L.; Hypoxide à feuilles tombantes. Vulgo: Petit safran. - Vivace par son bulbe ovoïde-obconique, arrondi à la base, jaunâtre en dedans. Feuilles radicales, rosulées, flasques, tombantes, linéaires-acuminées, ressemblant à celles d'une Graminée, légèrement poilues: les plus longues mesurant de 20-23 cm. sur 4-8 mm. de large. Hampes 1-6, tombantes, filiformes, comprimées, très flexibles, pubescentes, plus courtes que les leuilles. Inflorescence en cyme lâche, bi-triflore (lleur rarement solitaire); périanthe jaune vif, petit, supporté par deux bractées filiformes plus longues que le pédicelle; tube du périanthe complètement adné à l'ovaire, divisions 6-partites, rotacées, ovés-lancéolées, pointues; étamines courtes, incluses. Capsule longue de 1,6-2 cm., oblusément quadrangulaire-oblongue, légèrement recourbere ; semences noires, subghlobuleuses, atlachées par un large lumicule. - Fl. en tout temps. - Dans les savanes humides, dans les sentiers des 


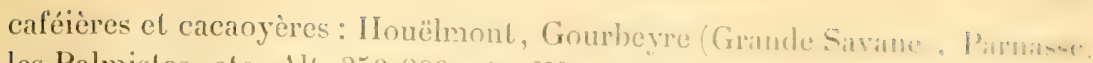
les Palmistes, etc. Alt. 350-800 mèt. [Yo:331\% h.

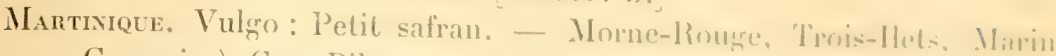
(morne-Gommier), Case-Pilote, ele. Yo 20111. ' '

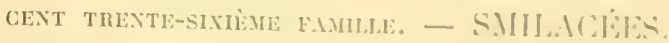

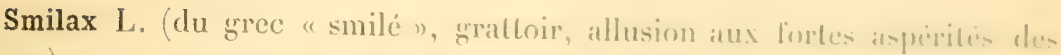
tigres.)

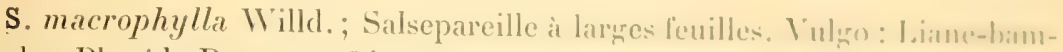
boche. Pl., éd. Burm., t. 81. - Liane virace pourant illeindre le summel de très grands arbres, à tige inférieurement anghuleuse, rarement mbevlindrique et armée de forts aiguillons, longs nu courts, distancés nu rapprochio. noirs ou jaunâtres, pointus ou émoussés, rarement sans piquants, supericurement cylindrique, très lisse el garnie de pelits aiguillons, it hanches lissés: vrilles stipulaires, ligneuses, longrues, insérées au-dessus du milieu du péliule. Feuilles larges, obtuses ou brusquement pointues, lisses, luisantes, rigrides, du:

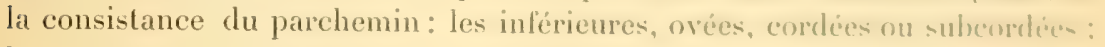
les supérieures et les florales, ovées-lancéolées: les jennes, lancéntées, fontur palminerviées, à 3-5 nervures principales et it nombreuses nervilles divariquées el saillantes des deux côtés. Inflorescence en ombelle i $18-21)$ flont:pédicellées, à pédicelles un peu plus courts que le pétiole ; boutons des fleur:lancéolés. Fleurs dioïques, pelites, vertes. I.es males, périanllués a li lubes: étamines insérées à la base du périanthe filets dressés; antheres frises, plus longues et aussi larges que les filets. Fleur l'emelle a style trilide. Fruil baccien, rondâtre, d'abord très vert, devenant noir à lat maturité, envirun deux fois plus grand qu'une graine de poive verte; semences 2-33, rondex.Fl. en juillet et août. - Assez abondant sur les lisières et dans les clirrières des bois de la région infrámoyenne: Honëhmont, (inurbeyre, ('armpJacob, Bagatelle, Gommier, Trois-Rivieres, Vieux-ILabilants, l)eshaies. Sainte-Rose, etc. Alt. 250-600 mèt. [Nं03311.

Martingue. Vulgo: Boyau-chat, liane-boyau, - Prois-llels. Care-l’ilule.

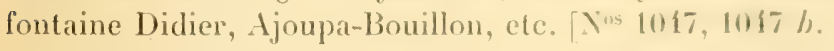

De cette famille, on rencontre en abondance, comme plantes intrutuiles et cultivées, le Dracæna Sieberi Planch., vulgo: Roseau des ludes, hatul de:-2-3 mèt., à fleurs roses, en panicule droite, terminale; l'Aletris fratyran.s l... hant

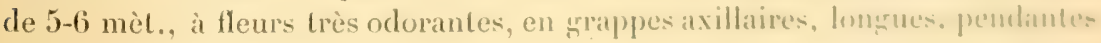

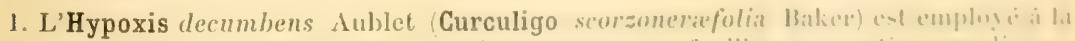

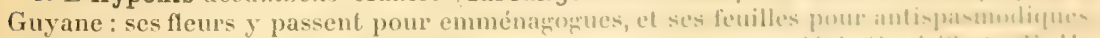
Il est probable que l'espèce des Antilles jouit des mènes proprictio fit véritier). L.. 11. 
et interrompues. - Avec ces deux espèces, on fait très souvent des clôtures. On cultive plus rarement le Dracæna umbraculifera Jacq. - Au Jardin botanique de samt-Pierre, on remarque le Dracæna stricta Sims. le D. marginata Lam., le D. indivisa Forst., le D. Guilfoylei Veitch, le D. draco L. Plusieurs de ces espèces se sont répandues dans le pays, mais n'y fleurissent que rarement.

Le Sanseviera zeylanica Milld.. a feuilles panachées a tleurs dime odeur forte et exquise, portées sur une hampe radicale presque aussi longue que les feuilles, orne souvent les jardins; il se multiplie très rapidement par ses stolons.

\section{CENT TRENTE-SEPTIÈy FAMLLe. - DIOSCORÉES.}

Dioscorea L. dédié au Ciree Dinsonides Pedanius. d'Inazarbe, dans la Cilicie, qui vivait dans le $x^{\text {er }}$ siècle de l’ère chrétiemne. Il a écrit un traité de botanique en cinq volumes et un traité sur la Matiére médicale.)

D. alata L.; Ignane à tige ailée. Vulgo: Ignane blanc. Desc., vol. VIII, t. 537. - Grimpant, voluble, à tige garnie de quatre ailes, plus ou moins larges, très sourent ondulées. Feuilles très ternes, opposées, longuement pétiolées: les adultes, oblongues, cordées, ovées, à sinus profonds, à $5-7$ nervures principales; les jeunes, ovées et à 3 nervures, toutes brusquement terminées en pointe. Bulbes aériens, ruguleux, noirâtres, arec ou sans piquants. Fleurs diö̈ques. blanchatres : les males. tries petites. en panicules axillaires et terminales, verticillées, quelquefois géminées et opposées: étamines 6 ; les femelles, en épis simples, géminés ou vericellés par 3, pouvant atteindre $\mathbf{4} \mathrm{cm}$. de long; ovaire infère; stigmate tripartite, large. Capsule elliptique. longue de $1.6-2 \mathrm{~cm}$. . subsessile, a trois ailes, dont une ou deux fois plus étroite que les autres. - Originaire de l'Archipel océanien. - Çà et là à l'état saurage et cultivé dans toute la Guadeloupe, la GrandeTerre et à Marie-Galante.

() nen rencontre plusieurs variétés sous les noms de : Iyname déan, à bulbes aériens, muriqués, à tubercules tendres et faciles à cuire; Igname portugrise, à tige épineuse dans le bas, à tubercule large et noir en dehors: Ifname Pacala, à tubercule très large. - Fl. habituellement en septembre. Alı. 0-500 mèt. [Nos 3309,3511 .

Martivique. Vulgo: Igname Saint-Martin. - Cultivé dans toute l'île. Cà et là dans les halliers à l'état sauvage. [Ỹo 512.

D. pilosiuscula Berter.; Igname pubescente. Vulgo: Igname bâtard. Grimpant, a tige mince. tris tlexueuse. subcylindrique. strie finement et 


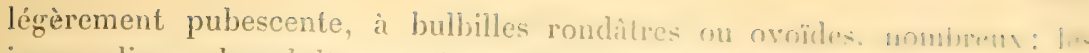

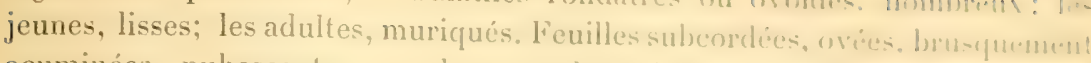
acuminées, pubescentes en dessous : les adulles, it i-j: les jumm. is : nervures principales. Fleurs diö̈ques: les femelles, distanter, on ipri- suli-

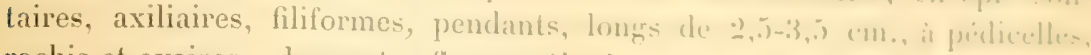
rachis et ovaires pubescents; fleurs mates inconnms.

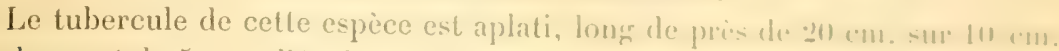
de large et de $5 \mathrm{~cm}$. d'épaisseur; il peut se manger, mais il wa pren appuriti:

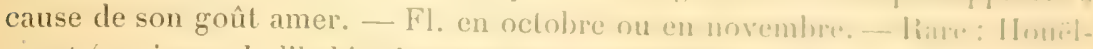

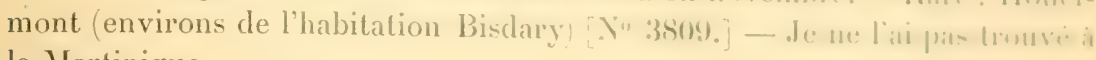
la Martinique.

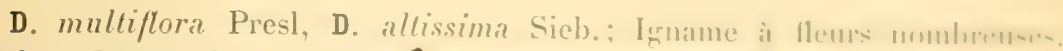

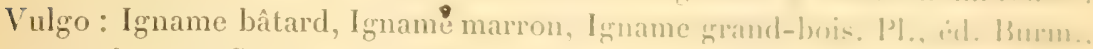

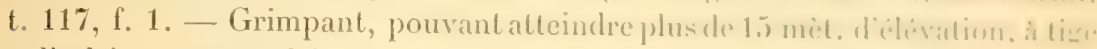
cylindrique, très glabre, ì branches très allongrés, pendauter, filifumm. Feuilles larges, ternes, quelquefois panachees en dessus of violethen end desous, cordées, deltoïdes, cuspidées: les adultes, it 5i-7: les jemmes, it is mmvures principales; bulbilles grands, peu nombreux, mantrableles, muditren. ou ovoïdes-allongés, jamais muriqués. Fleurs dioïques : les males tri-s petilen. en glomérules sessiles, distants, disposés en épis liliformes, allongís, solitaires ou géminés, ou en panicule très làche el très hngre: itamine li. 3 fertiles et 3 stériles, insérées a la base des lobes rotaciés du pririanthe: fleurs femelles en épis simples, solitaires ou rémis en griplpe. (Cippoule.

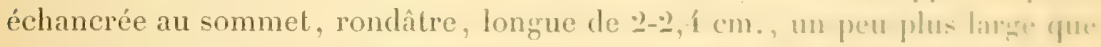
longue, à 3 ailes inégales; semences très aplaties, complitemunt entomitud'une aile membraneuse et très fragile. - Ses tubercules sont altongés, sonvent presque cylindriques, à chair blanche el comestible. - fil. en nomembre et décembre. - Assez abondant dans tous les bois sees on humides de lit région infra-moyenne de toute la Guadeloupe proprement dite. AH. :3nu600 mèt. [Nos $3547,3565$.

Martinieue. Vulgo: Igname maron. - Dans Lous les bris. Y" $1013 . j$

D. Cayennensis Lam., D. Berleroana Kith; Iername de Calyeme. Vuliro: Ignamë-Guinée. - Grimpant, à lige souvent noire ou moritre. cylindrique ou anguleuse ou anfractueuse dans le bas, ligneuse, furnice diagnil-

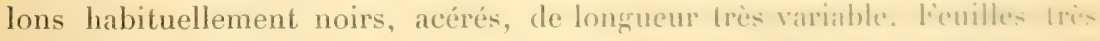
vertes, luisantes, membraneuses: les adultes, cordées-molitres of it i-i nervures; les jeunes, cordées-deltö̈des et it 3 nervures. Lileurs disügues: lemâles en épis simples, solitaires ou plus souvent deux oppusíes, naimsint it l'aisselle de chaque feuille, tout le long des jemes tranches, rarement on

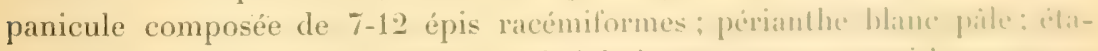

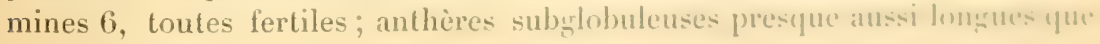


les filets courts. - Je n'ai jamais pu trouver des pieds à fleurs femelles. Originaire de la côte occidentale d'Afrique. Généralement cultivé dans toutes les Antilles, on en rencontre de nombreuses variétés qui dilfèrent entre elles par la couleur et la forme des tubercules, le nombre des épis. Les principales sont : Iyname careme, parce quion les ricolte habituellement pendant le carême, à piquants noirs, et les branches garnies, à la base. d'une bractée charnue, épaisse, ovale ou ovale-deltoïde, à tubercule jaune; l'Igname Grand Monsieur ou Monsieur, parce que ses tubercules l'emportent en excellence sur les autres variétés; l'Igname jaune grosse-tête, ¿ tubercules jaunes et larges, etc. [Nos $3286,3543,3546,3564$.

Martixigue. Vulgo: Igname-Guinée, igname-ouaoua. [Nos 5 510, 513, 514.]

D. Irifida L. ; Ignane à feuilles trilobées. Vulggo : Cousse-couche, couchecouche. - Grimpant, rigoureux, à tige anguleuse ou pourvue de quatre ailes courtes; bulbilles arrondis, whabres. Feuilles alternes, larges, ternes, fendues jusqu'au delà du milieu du limbe en trois lobes ovés-oblongs et pointus: celui du milieu, beaucoup plus large et plus long; les deux latéraux, à un lole basilaire, arrondi. Fleurs diö̈ques, axillaires: les mâles, pédicellées, distantes, vertes, en grappes allongées racémiformes et réunies par 3-7, pendantes; étamines 6 , toutes fertiles, insérées sur le tube très court du perianthe infondibuliforme: les femelles distantes, en épis pendants, toujours séminés, pourant atteindre jusqu à fol cm. de longr; rachis légèrement pubescent. Capsule longue de 2,7-3 cm., triailée, surmontée du style persistant. Fl. en novembre et décembre. - Introduit, origine incertaine. Cultivé dans toutes les Antilles. - Cette espèce produit habituellement un grand nombre de tubercules allongés ou fusiformes, attachés à un fil comme ceux du Topinambour et fournissent un aliment délicat, très appétissant et recherché. qui l'emporte de beaucoup sur les autres ignames par sa raleur. X" 3560."

Martingue. Vulgo: Cousse-couche. [No 996.$]$

D. tuberosa Vell.; Igname tubérifère. Vulgo: Patte à cheval, IgnameBonda. - Diffère du précédent par ses tiges moins élevées, les lobes de la feuille beaucoup moins allongés, ses fleurs moins nombreuses. ses tubercules plus lareses. blanes en dedans et aplatis comme le dessous d'un sabot de cheval. - Cultivé dans toute la Guadeloupe et aussi a la Martinique. (Spécimens manquent.

Rajania L. dédié a l'Anglais John Ray IVray, né en 1622, à Blak-Totley, dans l'Essexhire, théologien et naturaliste; mort en 1705, dans son lieu de naissance; a écrit: Catalogus plantarum circa Cantabrigiam nascentium; Catalogus planturum Inglix ef insularum adjacentium: Melhodus plantarum, etc.)

R. cordata L.; Rajanie à feuilles en cour. Vulgo: Igname-pas-possible, igname-bamboche, igname-bamboche bitard. - Gimpant, ornemental, it 
tige cylindrique, sans épines. Feuilles membrancuses, vert pille, deillöl....

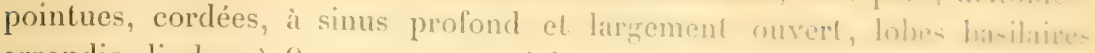
arrondis, limbes à 9 nervures; pétiole plus court que le limbe : bullillu.

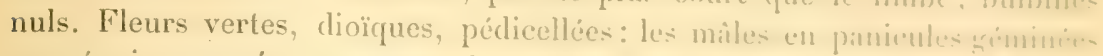

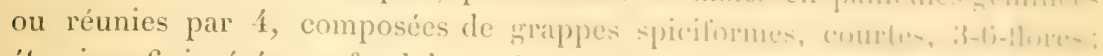

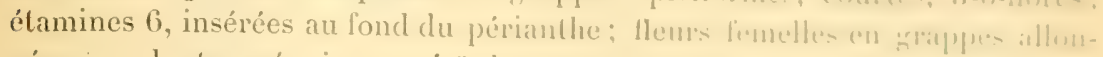

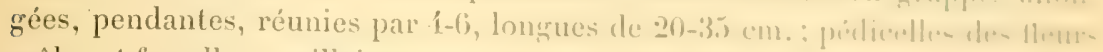

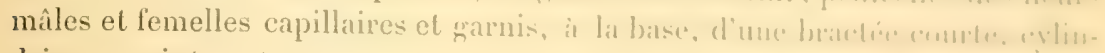

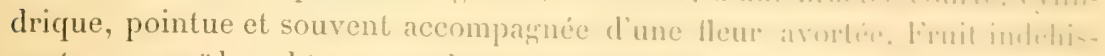
cent, samaroïde, obtus, membrancux, blanchitre, protant infertempment un bec latéral, qui est le style persistant, el superiommment mme aile membraneuse, obtuse, semi-ovale, longue de 1,5$)-1-f$ em a a

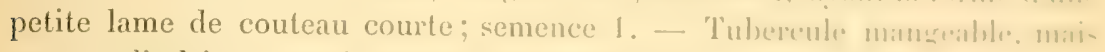

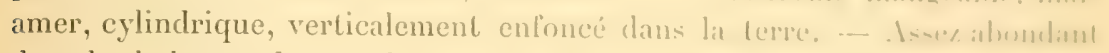
dans les bois sees de tout le massif de IIouëhmont ; plus rane dams le- lui-

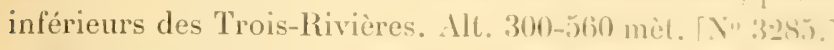

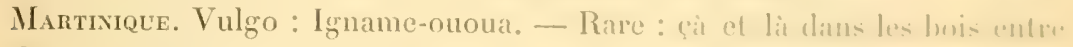

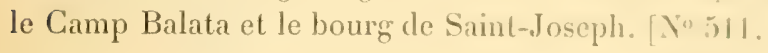

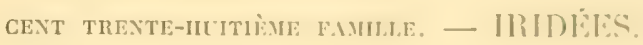

Cipura Aubl. (nom indigène de la plante il la Guyane linucaice.

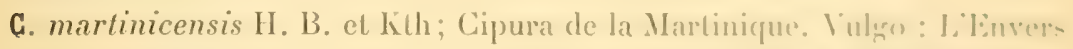
mâle. Pl., édit. Burm., 1. 261, 1. 2; 1)esc., vol. 11. 1. 2.2. 1). 1, (Iris 1.. . Haut de 40-80 cm., ornemental, très droit, vivace par son tulerembe conipue. Feuilles radicales, équitantes, lancéolées-linéaires, plates, 3-ti pnur chatue pied, plus courtes ou plus longues que la lige: leuilles caulinarers 1-2. spathiformes, engainantes à la base. Infloresence en une sorte de crme hiquadriflore, portée sur un pédoncule nu, subcylindrique: "yns firmin, iो

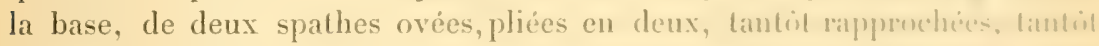
distantes l'une de l'autre et couvrant partiellement ou cutienement tes pirli-

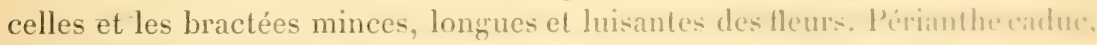

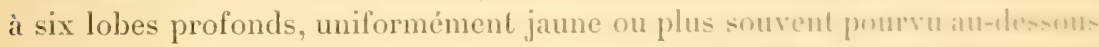
du milieu d'une large strie noire, transverse : les trois lobes atirinu(calice), plus grands, obovés, rélléchis, longes de $11-1$ s mm.: lé- tmi- imlirieurs (corolle), plus étroits et environ une fois plus courts. Átanines 3.

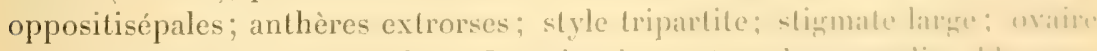

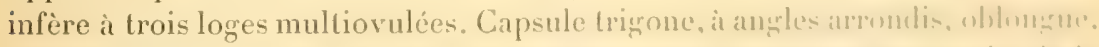
s'ouvrant au sommet par trois ouvertures moles; semences lmum moir, de lit grosseur d'une graine de radis. - Selon l)escourlil\%, la plante and dimm- 
tique-excitante, et les racines, employées comme purgatives, vomitives et astringentes, seratent, selon le I)' lienaud, un puissant emménagozue. D'après des renseignements précis, cette herbe ne jouit d'aucun crédit ni à la Guadeloupe ni it la Martinique, nù som usage dans la médecine domestique est nul. - Fl. presque toute l'année dans les endroits lıumides. - Abondant dans toutes les savanes de la Guadeloupe et de ses dépendances. Alt. 0-700 mèt. [No3312 b.]

Martinique. Vulgo: Lis jaune savane. - Abondant dans toute lîle. [No 1951.]

C. plicala Griseb., Sisyrinchium latifolium Sw.; Cipura d feuilles plissces. Vulyon: L'Envers femelle, chance. Moræa Sw., Marica Curt.1 - Haut de 40-60 cm., formant des touffes larges, vivace par son tubercule ovoïdeanguleux, noirâtre en dehors, blane en dedans, long de 4-6 cm. Feuilles radicales, rosulées, plissées, à six côtes, longuement lancéolées-acuminées au sommel et lentement acuminées à la base, plus longues que la tige, 4-5 pour chaquepied : les adultes, tombantes; les jeunes, dressées. Tige sillonnée. Inflorescence en une cyme terminale naissant à l'aisselle d'une feuille allongée, spathiforme el portant un nombre variable de fleurs très inégalement pédicellées, dont chacune est entourée, à la base, d'une bractée courte et très concave. Périanthe à six lobes blancs, subégaux. - Les orules de celte espèce avortent presque toujours. - Fl. de juin ì novembre. Abondant dans les savanes argilo-l'errugineuses du Lamentin et de BaicMahault. Alt. 10-150 mèt. [No3836.]

Martinique. Vulgo : Chalolte-bois, chalotte-savane. - Les bulbes, réduits en pâte et mis dans le tafia, sont employés en friction contre les rhumatismes 1. - Cà et là dans les bois et les savanes inférieurs de Case-Pilote et des Trois-Ilets. Alt. 200-300 mèt. [No 1950.]

L.e Belamcanda chinensis lied. Pardanthus sinensis Van-IIoutte), vulgro:

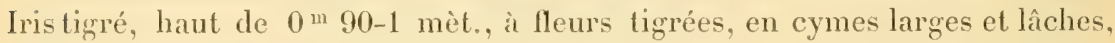
est assez souvent cultivé dans les jardins des deux colonies. Originaire de la Chine. $\left[\mathrm{N}^{\circ} 1949\right.$.

Cent trente-Neutik̀me famlle. - PONTÉdÉRIACÉES.

On cultive dans les étangs, les bassins et les mares d'eau douce des deux colonies, l'Eichhornia crassipes Solms, vulgo : Gayeul bleu Pontederia Lin. ,

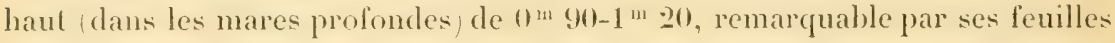

1. A la Guyane, on utilise, sous le nom d'Envers, le Cipura paludosa Aublet comme un antispasmodique éprouvé; on l'emploie, mèlé au laudanum, contre les convulsions des enfants. Si ces propriétés étaient bien établies, on les retrouverait, probablement à un égal degré, dans les deux espèces des Antilles. (E. II.) 
très vertes, luisantes, réniformes-corclées, sces pétinles gros. vésiculcux, renuliau-dessous du milieu, mais surtout par ses grandes fleurs blenes en ipi ling-t terminal. - Il se multiplie si facilement que, Inus les ans, il fiut (mi ditruite une masse de pieds. - Fl. de mars à juillel. - Originaire dusul de litat -

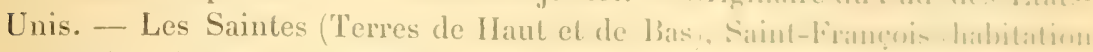
Richeplaine), etc. [No 3331.] - Mantsxuese - Ismentin, lint-cle-limane. Saint-Pierre, etc. (Spécimen manque.

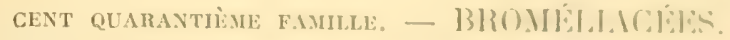

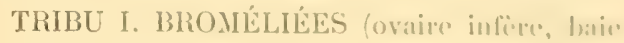

Ananassa Lindl. (de Anana, Anassa ou Nana, chez les 'T'upis du Bricil pour désigner une Broméliacée semblable ì l'Ananis.)

A. sativa Lindl.; Ananas cultivé. Vulgo: Ananas, - Mriginaire de l'Amirique continentale équatoriale, répandu maintenant dins foutes les partieintertropicales du monde entier, cultive en serres dans les pays lemprime el

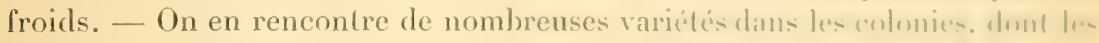
principales sont: l'Ananas jaune ordinaire, l'Ananals anylais, l'. Inanalsbouteille, l'Ananas vert, l'Ananas pain-de-sncre, l'Ananas pri-i-ean. l'Ananas Barbade, l'Ananas de Cayenne ou Barol, l'Amanas-purcelaine'. (Spécimen manque.)

Bromelia L. (dédié à Olaüs Bromel, né en 1639), à Gothemboury, en suide.: médecin et botaniste; mort en 1705 ; a écril Chloris golhica.)

B. Karatas L. Vulgo : Karatas (du nom indigrène brésilien " Kinrazuatiacanga ».) - Terrestre, vivace par ses stolons. Feuilles radicales nombrenses. longues de $1^{\mathrm{m}} 20-1^{\mathrm{m}} 50$ sur $3,3 \mathrm{~cm}$. de large, graciensemsent reconthere. acuminées, glauques-pulvérulentes en dessous, élaryies it la base, lífirement cannelées, et bordées d'aiguillons courts, recourbés, acérée, distints at tumrnés vers le haut; base de la feuille, garnie de poils mux, brillants, comuchir. Fleurs nombreuses, roses, sessiles, insérées sur un réceptacte on une tite large, -située au fond de la corbeille formée par les feuilles. 'l'ube du calice,

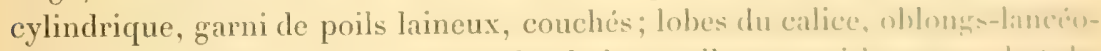
lés, une fois plus courts que le tube de la corolle et aussi longs que le lutu

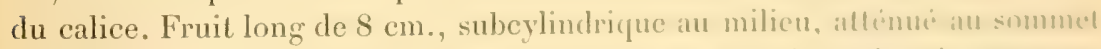
et à la base, à trois loges contenant chacune un grand momber de semences

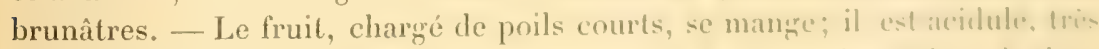

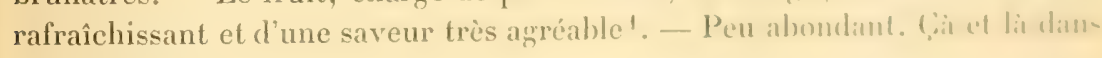

1. Sous le nom vulgaire de Carata, on utilise de celte plante it la linsine frampatise: le sue des feuilles et de la tige pour la cicalrisation des plates récenters: la teinture aldem 
les endroits secs, rocailleux, peu boisés près de la mer et dans les mornes inférieurs : Deshaies, Pigeon, Pointe-Noire, Bouillante. Alt. 5-300 mèt. [No 3319.]

Martinique. Vulgo : Karatas, - Case-Pilote, Case-Navire, Trois-Ilets. [No 994.]

\section{Wittmackia Mez.}

W. lingulata Mez; Wiltmackic à pétales munis d'un appendice linguliforme. Vulgo: Ananas sauvage. Pl., édit. Burm., t. 64, f. 1. Chevalliera Gaudich.) - Haut de 60-9.5 cm. Feuilles larges, rigides, brusquement acuminées au sommet, bordées de dents noires, crochnes, acérées, courtes. IIampe plus longue que les feuilles, zarnie de bractées apprimées, lancénlées-acuminées. Inflorescence en une panicule large, composée de 5-7 branches allongées, distantes, cylindriques, longues de $15-18 \mathrm{~cm}$., et munies, à la base, d'une bractée semblable à celles de la hampe, mais plus petite. Fleurs subsessiles, beaucoup plus longues que la bracténle subulée de chacune d'elles. Calice rigide, plus long que la bracténle, it bobes obliquement obovés, arrondis et plus longs que la pointe qui les termine. Corolle blanchâtre ou rose; pétales distincts. munis d'une sorte d'appendice linguliforme et dilaté à la base. Baie ovoüde, surmontée des trois pointes rigides, acérées et persisLantes du calice. - Fl. en avril et mai. - Çà et là dans les bois humides ou sees: (Gourbevre imorne Golbin), Ilouëlmont (environ de la batterie), CampJacob, Pointe-Noire, Ravine-Chaude. Alt. 200-700 mèt. [No 331\%.]

Martinique. Vulgo : Ananas-marron. - Champflore, plateau des TroisIlets, hauteurs de La Régale, etc. [ $\left.\mathrm{N}^{\circ} 273.\right]$

Æchmea R. P. (du gree " aichmés", piquant, parce que les lobes du calice sont terminés par une arête et les feuilles sont bordées de piquants.)

A. serrata Mez, A. dichlamydea Baker; Aechmea ì feuilles serretées. Vulgo: Ananas sauvage. - Haut de 70-85 cm., très ornemental, arboricole. Feuilles rigides, ovales-lancéolées: les plus longues mesurant jusqu'à $85 \mathrm{~cm}$. sur $5 \mathrm{~cm}$. de large, très élargies à la base, brusquement mucronées au sommet, ghlauques en dessous, bordées dans loute leur Inngueur de dents noires ou noirâtres, acérées, élargies à leur base. Hampe un peu plus longue que les feuilles, noirâtre, garnie de bractées blanches, alternes, renversées, lancéolées, membraneuses. Inflorescence en panicule cylindriquepointue, longue de 28-35 cm. sur une épaisseur de 9-12 cm., composée d'un grand nombre d'épis comprimés, longs de $5-7 \mathrm{~cm}$. et portant 1-4 paires de fleurs distiques et sessiles; pédicelles des épis zarnis d'une bractée blanche. laineuse, presque aussi longue que l'épi; rachis et pédicelles couverts d'un

lique des feuilles est employée comme détersive des ulcères. Le suc, qui est amer, pourrait, dit-on, remplacer le savon et contient peut-ètre de la saponine. $(\mathbf{E}$. $\mathbf{H}$.) 
duvet laineux, court, caduc, brun; fleurs pourpere foncé, peu anvertes, chacune entourée d'une bractéole très concave, oviale, pointue, concente d'us: duvet farineux et caduc. Baic bleu foncé at la maturiti, nvale, primlue.

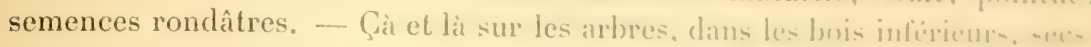
et aussi dans les endroits boisés près du bond de mer : (iourlente mume

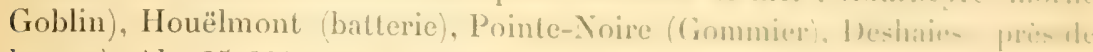
la mer). Alt. 25-600 mèt. $\left[\mathrm{X}_{0} 33325\right)$.

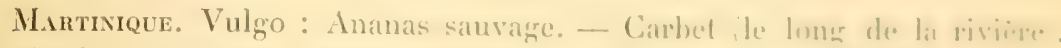

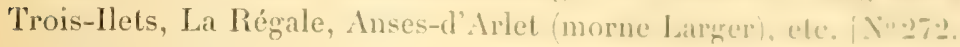

Dans les jardins, on cultive fréquemment l'Aechmea fulyens lírongn.

TRIBU II. TILLANDSIEES forare supiere, capsulei.

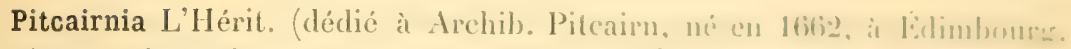

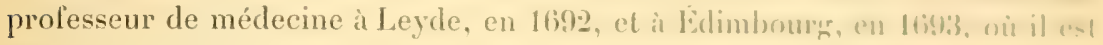
mort en 1713.)

P. penduliflora A. Rich.; Pitcaimie à lleurs pendantes. Vulero : Anamar grand-bois. - Haut de $0^{m}$ 90-1 ${ }^{\text {m }}$ 60, et exceptionnellement hien an delis. droit. Feuilles rigides, souvent longues de plus de 1 mit, sur If ('m. de large. peu recourbées. Hampe grosse, très vigoureuse, frarnic de lumclies larbers. rapprochées dans le bas, graduellement plus petites daus le haul. Inflowecence en panicule large, nettement pyramidale, it branches inl'irieures horizontales ou souvent penchées; fleurs confinces aux extremiles des branche: nues et cylindriques, disposées en épis distiques, f-ti-flores; comolle jamme. très peu ouverte. C'est de toutes les Broméliacées arboricoles des Intillés. celle qui offre les plus grandes dimensions. - Assez aboudant dans les framdbois humides des Bains-Jaunes, du Matouba, des 'lirois-livirops. efe. Alt, 400-900 mèt. [No 3837 .

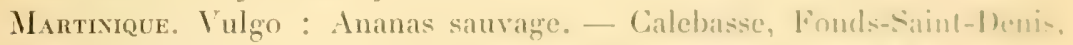
Gros-Morne, Grand'Anse, bords supérieurs du Lorrain. Yo yo-7s.

P. bracteata Dry., P. latifolia Red., P. sulfurea Indr. : Pilcairnic it Menr:garnies de larges bractées. Vulgo: Ananas rouge montagne, hemle rouge mon-

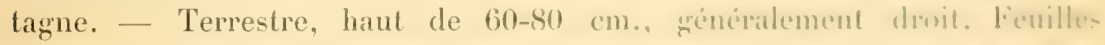

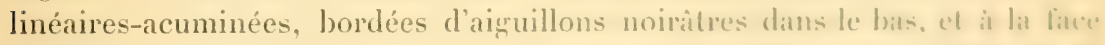
inférieure, revêtues, vers la base, d'une poussiere blanchitre: cedtús de lir

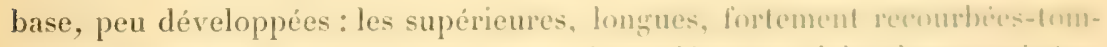

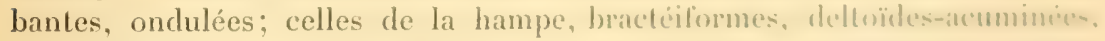
graduellement plus courtes. Iampe dépassint de beatucoup les foruilles. Inlln

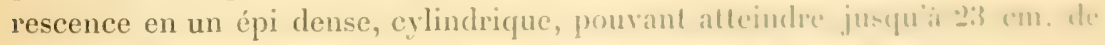

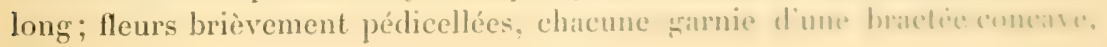


rouge foncé pluscourte que la corolle: corolle lomgue de 1-jén. écarlate, diune srande beauté, quelquefois d'un jaune desoufre dans les régions où émerenent des sourecesulfurenses, exceptionnellement blanchatre jaune. Indes du calice pointus, une fois plus courts que la corolle, beaucoup plus longs que le pédicelle. Pétales distincts, voûtés au sommet et garnis, à la base et à l'intérieur, dine écaille deltoide-arondie, larye, longue de pries de $3 \mathrm{~mm}$. : filets fililormes: antheresquatre fois plus courtes que les dilets: slimmate tordu. ()vare frigne: semences fusiformes, portant i chaque extremité un prolongement filiforme. - Fl. surtout de férrier à juillet. - Très abondant dans la haute région des montagnes : Savane anx Ananas, Savane a Mulets. cone et plateau

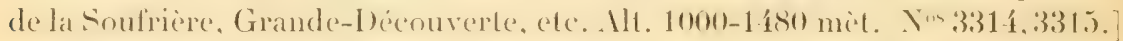

Mantinique. Vulgo : Ananas-montagne. - Montagne-Pelée, Pitons-du-

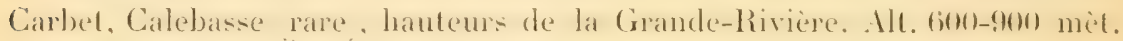
[No 995.]

P. ramosa Jacq.; Pitcairnie à hampe ramiliée. Vulgo : Ananas rouge bâtard. - Le plus souvent terrestre, cespiteux, haut de $70-90 \mathrm{~cm}$, droit. Feuilles recourbées-penchées, longuement acuminées, à bords garnis d'aiguillons à la base. Hampe munie de 5-6 bractées serretées, deltoüdes-acumimies. graduellement plus petites. Inthresence en une panicule tres liches. large, à branches longues, peu nombreuses, distantes : les inférieures hori-

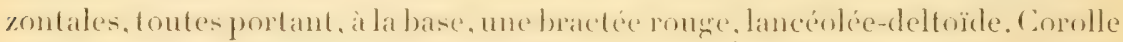
rouge foncé ou rouge pâle, à deux lèvres; pétales étroits, longs de $2-4 \mathrm{~cm}$.;

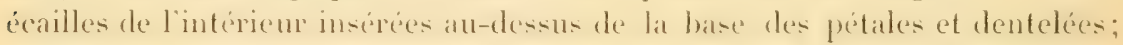
segrments du calice rouges, lancéolés. plus counts que la corolle: appendices des semences tronqués. - Fl. de février à juillet. - Abondant sur les terres

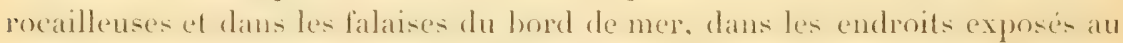
grand vent, sur les rochers humides ou sees et dans les falaises des mornes des basse et infra-moyenne régions; rare au delà de 500 mèt. d'altitude :

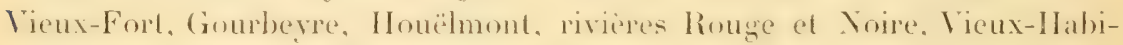
tants, Pointe-Noire, Deshaies, etc. [No 3461.$]$

Martivique. - Rocher du Diamant, hauteurs de Case-Pilote, des 'T'roisIlets, rochers de Sainte-Luce et de Riviere-Pilote, etc. [No 994 a.]

Tillandsia L. (dédié à Elias Til-Lands, professeur de médecine à Abo, dans la Finlanrle; publia en 1673son catalogue desplantes des environs di. Who.

T. fasciculata Sw.; Tillandsie à épis fasciculés. Vulgo: Ananas sauvage. - Arboricole, trés beau, haut de fo-jol cou. Feuilles rigides, épaisses, longuement ef fraduellement acuminées, élaryes a la base, entierement couvertes. en dessus et moins en dessous, de squamules grises. Inflorescence en pani-. cule composec de 3-7 épis trés comprimés, rapprochés, longs de 14-16 cm. : les latiraux presque aussi longs que le terminal. Hampe plus longue que les feuilles. Bractées llnrales imbriquées, distiques, orées-nblongues, pointues, 
aussi longues que le calice. Corolle peu ouverte, d'un ponpre fonce tris riche dans sa portion exserte; pétales linéaires; étamines tordues en spiralu. au sommel; anthères exsertes; pistil plus long que les étamines: sigmale gros, pourpre, roulé en spirale. - Fl. de décembre à mai. - P’eu rípandu. Dans les falaises le long des rivières: Rivière-Noire, Vienx-IJabilanl- mute

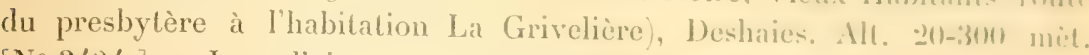
[No 3404.] - Je ne l'ai pas trouvé à la Martinique.

T. polystachya L.; Tillandsic à épis nombreux. Vulget : Anamas samvinge. - Épidendre, haut de $-40-60 \mathrm{~cm}$. Fenilles vertes, acuminies: celles de la base très courtes, les supérieures plus longues, loutes lanroment avere it la base; celles de la hampe graduellement plus pedites, lincionles-lincinireacuminées. Hampe verte, dépassant de beaucoup les feuilles. Indlorescrnce ent épis composés de 3-7 branches courtes, inégales el renfermies dans une bractée. Corolle inconnue. Endocarpe de la capsule trés noir, luisint et puli. - Peu répandu : assez abondant dans les bois des marcicares du lillomil de: Port-Louis. Alt, 0 mèt. [No3102.]

Martinique. Vulgo: Ananas sauvage. - Lamentin, Jucos (dans les: endroits boisés près du bord de mer). [No 280.

T. bulbosa Hook.; Tillandsia bulbeux. Vulgo : Ananas-marron.- - Irlonricole, haut de $35-40 \mathrm{~cm}$. Feuilles vertes, rosulées, brusquement dilitées it la base, autour de la tige fortement renllée : les supéricures allongres. acuminées, roulées. Hampe plus longue que les leuilles. Inflorescence en pinicule composée de 2-7 épis comprimés, longs de $1-6 \mathrm{~cm}$; ; bractées llorales distiques. imbriquées; sépales du calice beaucoup plus courts que la corolle: pitales spatulés-linéaires, violets au sommel; anthères exsertes. - P’eu répandu: çà et là au Camp-Jacob, à Bagatelle, à Choisy, au P'amasse, dans les hauteurs de Deshaies, etc. Alt. 400-600 mèt. [No3316.] - II n'existe pas il lil Martinique.

T. ulriculata L.; Tillandsia à feuilles utriculées. Vulgo : Ananas sauvarge. Pl, édit. Burm., t. 237. - Arboricole, très variable quant à la laille, de $0^{\text {m }} 25 \mathrm{~cm}$. jusqu'à 1 m 20 d'élévation. Fenilles rigrides, lancéolées-acuminées. se rétrécissant graduellement à partir de leur base, ovéc, vert gris, courerter de nombreuses petites squamules. Ilampe nue, beaucoup plus longre (fut les feuilles. Inflorescence en une panicule pyramidale, lrès litche, it branches paniculées: les inférieures, horizontales; les supérienres, finstiriéc; hracté de chaque branche Iancéolée, embrassante. Fleurs distiques, distantes, confinées aux extrémités des branches; bractées florales linement striécs, un foriplus courtes que le calice, vertes avec une marge mince ef rentige; lobers du calice verts bordés de rouge; corolle hlane verdatre; lilets tordus en spirite: stigmate tordu. Capsule deux fois plus longrue que le calice _- C"ust de loules les Broméliacées la plus commune. Elle se rencontre surtout sur les fromagrers 
(Bombax), les orangers, les citromiers, les calebassiers Cescentia), et les immortels bâtards de toute la Guadeloupe et de ses dépendances. Alt 0-600 mèt. [No 3320 .]

Martinique. Vulgo : Ananas sauvage. - Très abondant. [No 280.]

T. pulchella Hook.; Tillandsie gracieux. Vulgo : Petit ananas sauvage. Haut de 20-25 cm., arboricole, à tige recourbée et nue dans le bas, à 2-3 branches dans le haut; partie nue longue de $15 \mathrm{~cm}$. Feuilles confinées aux extremités des branches, imbriquées, linéares-acuminées à partir de la base élargie, rigides, droites, couvertes de squamules brunes. Inflorescence en un épi portant 4-8 lleurs. Bractées florales rosées, oblongues-lancéolées, membraneuses: sépales deux lois plus courts que les pétales blancs, spatuléslinéaires; étamines inégales, droites. Capsule aussi longue que le calice; semences dépourvues d'aigrette. - Rare : sur les petits arbres, dans les mornes inférieurs, sees et pierreux du Fond Layette (Case-Pilote). Alt. 280 mèt. [No 179.$]$ - Je ne l'ai pas trouvé à la Guadeloupe.

T. recurvata L. ; Tillandsie à feuilles fortement recourbées. Vulgo : Barbe à nègre. Sl., t. 121, f. 1.- Arboricole, cespiteux, haut de 10-23 cm. Feuilles filiformes-comprimées, nombreuses, confinées à la base de la tige, fortement recourbeses et entiorement recouvertes de squamules blanchâtres ainsi que les liges et les bractes. Tige unique, courte, donnant naissance a 3-6 branches rapprochées dont chacune porte une hampe nue, filiforme, droite et plus longue que les feuilles. Inflorescence en 1-2) épis uniflores, dont un situé plus haut que l'autre, tous les deux sont entourés, à la 'base, de deux bractées embrassantes et couvrant la bracténle de l'épi supérieur. Calice à trois segrments membraneux, minces, rigides, deux fois plus courts que la corolle; étamines incluses, à filets droits, at antheres dressées; stigmate tribló, porté sur un style court. - Fl. en janvier et février. - Assez peu répandu. Cà et la sur les calebassiers ou sur d'autres petits arbres des mornes inférieurs secs : Vieux-Habitants, Pointe-Noire. Alt. 60-150 mèt. [No 3401.]

Martinique. Vulgo : Barbe-z'arbre. - Plus abondant qu'à la Guadeloupe : collines sèches de Fond-Canonville, du Prècheur, de la livière-Pilote, du Marin (morne Gommier). Alt. 40-220 mèt. [No 992.]

T. usneoides I.; Tillandsie ressemblant à un Usnea (genre de lichen). Vulgo : Barbe à l'arbre. Sl., t. 122, f. 2, 3. - Épidendre, pendant, d'une Inngueur trés variable, formant des toulfes très enchevètrées, qui, dans certains endroits abrités contre les vents, peuvent atteindre 5 -6 met. de long et ressemblent à d'immenses queues de cheval. Feuilles et tiges courertes d'écailles grrisâtres. Feuilles distiques, filiformes, recourbées. Tizes filiformes, recourbees, dnmunt successivement et alteruativement naissance à d'autres ligres, dont chacune porte une branche latérale garnie de 3-6 feuilles d'inégale longueur. Hampe unitlore, plus courte que les leuilles. Calice à trois segments 
plus longs que la corolle; pétales pourpres, spatules: filamines inclu-ce : slizmates 3. Capsule trois fois plus longue que le calice: coutocarpe pmurn. trum en dedans. - Fl, rarement. - Abondant dans les falaises alurupler de l

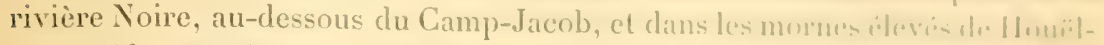
mont. Alt. 200-700 mèt. [No 332:2.]

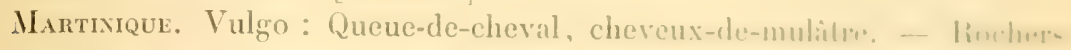

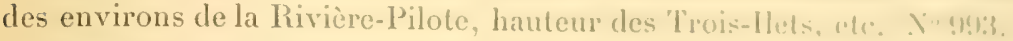

Le Tillandsia splendens Brongn, espèce introduite de lin (invane, wr rencontre souvent dans les jardins où il se proparge avec beancentu de: linciliti:

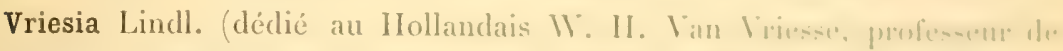
botanique à Amsterdam; a écril sur la physiolorio dé phlantes un Chloris medica, et a collaboré à un joumal botaniçue.

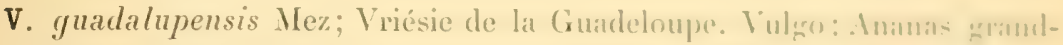

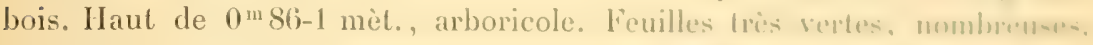
rosulées, lancéolées, brusquement pointues, se rétrécissant lentement in partir de la base élargie, les plus longues mesurant $6.5 \mathrm{~cm}$. les superieures pim-int graduellement à l'état de gaines apprimées, amplexicaules, deltrïdes-alcuminées. Hampe toujours inclinée, dépassant de beaucoup lés feruilles. Inllonescence en un épi long de $30-38 \mathrm{~cm}$., portant de I0-120 paires de flenrs distiques: fleur entourée de 4 bractées, dont l'extérieure tris verte, plus stante. largement ovée-pointue, longue de 4,3 cm. sur presque intint de lingrenr, les trois autres plus petiles, toutes imbriquées. Calice benuenup plus cont que la corolle; pétales écarlates, concaves, longss de $1,3 \mathrm{~cm}$. : le praterieur voûté au sommet et un peu plus long" que les deux autres. Btimnines presque aussi longues que les pétales, à filets filitormes, dressís; style un peu plus

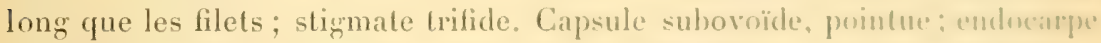
pourpre foncé en dedans; semences brunes, fusiformes, fonfrues de :3 mm...

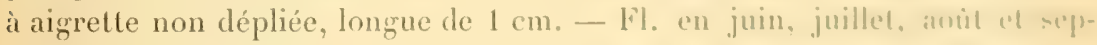
lembre. - Abondant dans les bois du Gommier, des environs de Batziledle.

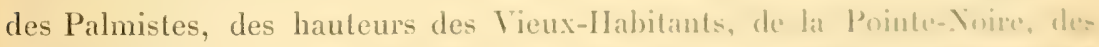
Trois-Rivières, etc. Alt. $400-900$ mèt. [No 3321.$]$ - Je ne l'ai pals trompi at la Martinique.

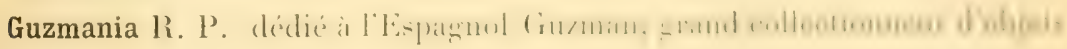
d'histoire naturelle.)

G. Dussii Mez; Guzmannie de Duss. Vulgro: Ananas frand-buis. - Irburi-

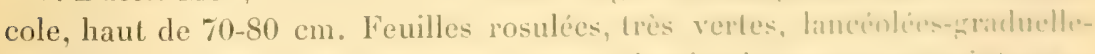

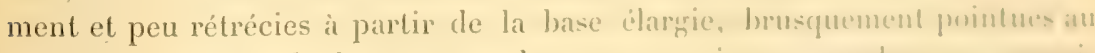

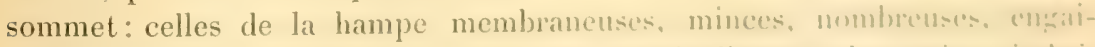
nantes à la base, longuement acuminées, fraduellement plus petiles, imbriquées. Hampe plus longue que les fouilles inférieures. Inlloresconce on une 
panieule longue de 1.5-30 cm. à 3-5 branches très inégales ; fleurs solitaires, distantes, alternes, chacune à moitice enveloppée d'une bractée large, concave, rougealre, pointue, plus longue que le calice; lobes du calice droits, pointus, de un tiers plus courts que les corolles; pétales écarlates, longs de $4 \mathrm{~cm}$.: le postérieur, un peu plus long, à sommet voûté et arrondi; étamines dressées, un peu plus courtes que les pétales; anthères deux fois plus courtes que les filets; style exsert, épaissi au sommet, à stigmate trifide, penché. Capsule inconnue. - Rare: çà et là dans les bois du Haut-Matouba, du Gommier, des Bains-Jaunes, etc. Alt. 500-900 mèt. [No 3326.] — Je ne l'ai pas trouvé à la Martinique.

Guzmania R. et Pav.

G. lingulata Mez: Gusmanie à pétales munis d'un appendice linguliforme. Vulgo: Ananas-bois. Sl., t. 120. - Arboricole, haut de $45-50 \mathrm{~cm}$. Feuilles nombreuses, très vertes, rosulées, oblongues, mucronées, dilatées à la base, recourbées: celles de la hampe, courtes, imbriquées, el entourant la base de la hampe. Hampe un peu plus courte que les feuilles. Fleurs en un capitule large, chacune garnie d'une bractée rouge aussi longue que la corolle; lobes de la corolle jaunes, inférieurement soudés en un tube cylindricque; sépales du calice lancéntes-acuminés, éralant en longuenr la moitié du tube de la corolle. Capsule longue de $3 \mathrm{~cm}$, atténuée à la base. - Assez abondant dans les bois inférieurs de Houëlmont, des Trois-Rivières. Alt. 300-700 mèt. [No 3403.$]$

Martinique. Vulgo: Ananas-marron. - Bois de la Calebasse, de l'AjoupaBouillon, du Lorrain, du Camp de l'Alma, etc. [No 275.

G. megastachya Mez; Gusmanie à grand épi. Yulgo: Ananas-bois.- Haut de (iofol) con. Fenilles comme dans le précédent, mais beaucoup plus lareses et plus longrues: celles de la hampe graduellement plus courtes. Ilampe plus longrue que les feuilles inférieures. Inflorescence en un épi composé, loner de 14-22 cm., portant de 12-18 faisceaux bi-quadriflores : chaque faisceau enveloppé à moitié dans une bractée large, ovée, cymbiforme, pointue, plus longue que le laisceau lui-mème: chaque fleur granie d'une bractée secondaire ovale-lanciolée, aussi longue que la capsule. Segments du calice membraneux, lancenlés-acuminés, aussi longs que la capsule. Corolle inconmue. - Capsule longue de $3 \mathrm{~cm}$., obtusément trigone, pédonculée. - Assez abondant dans la région supra-moyenne des bois humides: Bains-Jaunes, Matouba (Matelyane), bois supérieurs du Gommier; rare au-dessous de 500 mèt. d'altitude. [No 3405.] - Je ne l'ai pas trouvé à la Martinique.

G. Plumieri Mez; Gusmanie de Plumier. Vulgo : Ananas sauvage montagne. - Terrestre, haut de $0^{\mathrm{m}} 80-1$ mèt. Feuilles lancéolées, brusquement teminées en une pointe rigide: celles de la hampe passant brusquement a l'état de feuilles bractéiformes, amplexicanles. IIampe deux fois plus 


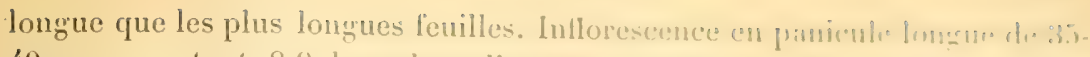
$40 \mathrm{~cm} .$, portant 8-9 branches distantes, alternes: colles du milinu plu-

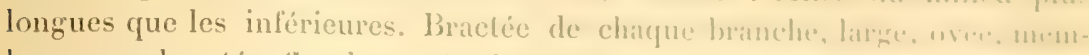

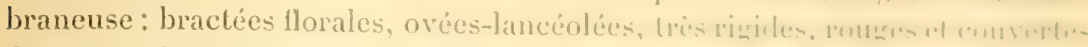
de squamules écailleuses; rachis principal nouend, rachis menulaim anzu-

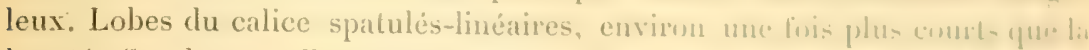
bractée florale; corolle jaune brun, plus longue que le callice at me cimwant

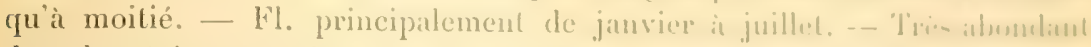

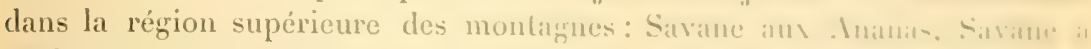

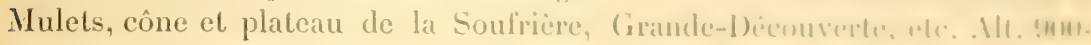
1810 mèt. [No 3443.

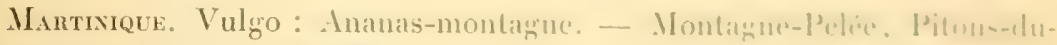
Carbet, Piton-Gelé. [No $27 \%$.

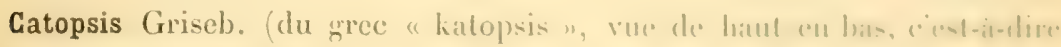
plante à hampe penchée.)

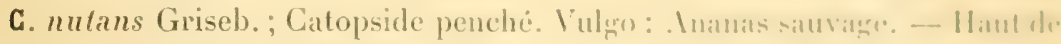

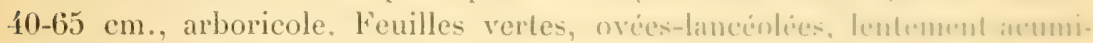

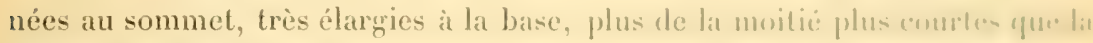

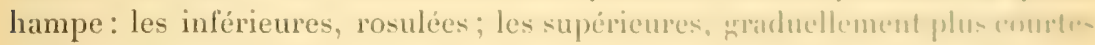

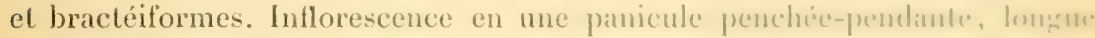

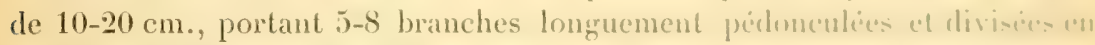
deux épis; rachis glabres. Bractées des branches, wies-lancionteren, plupetites que les feuilles de la hampe: les bractées flomales, longtses de :3-1 mmm. Fleurs petiles; sépales spatulés, plus courls que la tractionle; pritales spralulés, blanes, ou souvent légèrement roses; stimmate subsessile. Ciapunte deux fois plus longue que le calice; aigretle deux lois plicestur wle-mime. Fl. presque toute l'année, mais principalement d'octobre it matr.- - Mmondant sur les arbres épineux, de petile laille, comme les citrominers ot le-

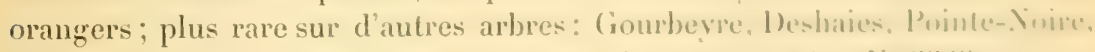

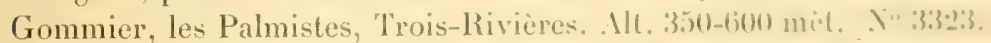

Martinece. Vulgo: Aranas sauvage. - Hauleurs de Caise-Pihute de de Case-Navire. $\mathrm{N}^{0} 270$.

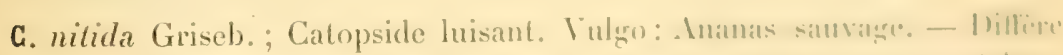

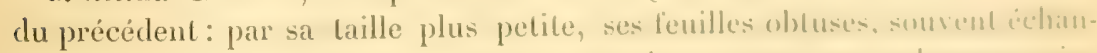
crées au sommet, glauques en dessous, el plus courtes ; fir sal hampe mon-

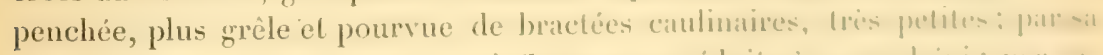

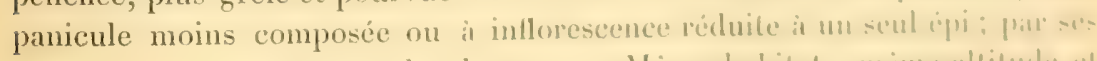

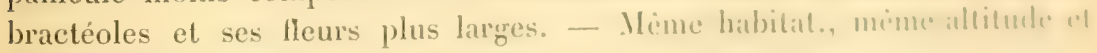
même époque de floraison. [No 3321.

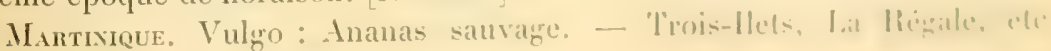
$[\mathrm{N} \circ 270 \mathrm{~b}$.

Duss. - Plantes Guadeloupe et Mentinique. 


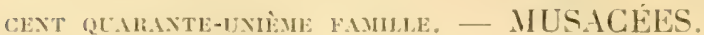

Musa L. (de l'arabe "Mauz ", mais Limné a dédié ce genre au l'rère d'Fuphorhus, midecin du roi Juba. Intonius Musa, lui-mème médecin de l'empereur Auguste; il a écrit: De botanica.)

De celte famille, on cultive en abondance comme plantes alimentaires dans les Intilles et dans fous les pars intertropicaux du monde entier, les especes suivantes :

a. - Musa paradisiaca L.; Bananier du paradis terrestre 1. Vulgo: Bananier, banane. - On en rencontre de nombreuses variétés, dont les principales sont: banane franche, banane Potau, banane-serpent, banane jaune, banane blanche, etc. - I la Martinique, on cultive les variélés: banane colossale, ou banane d'Aris ou banane d quatorze paltes, elle est tres productive et la plus élevée de toutes. ses rérimes onl quatorze à quinze pattes, dont chacun porte jusqu'à 22 bananes: un seul régime pèse en movenne tol libs, et il laut pres de deux ans pour qu il parvieme à maturiti: la banane noire, à régrime de 8-10 pattes, dont chacune compte environ Is bananes: la banane-puce, a récime de 5-7 pattes, dont chacune comple environ 15 bananes tachées de noir; la banane sans nombril, à régime de 9-10 paltes, contenant environ 18 bananes effilées; la banane à cornes, à 1-j palles, portant 5-fi bananes diune wrosseur el diune longueur considérables.

b. - Le Musa sapientum L., Bananier des sages. Vulgo: Banane-figue ou figue-banane, banane sucrée. — Ses variétés sont également nombreuses. ce sont: figue-ca/é, ou grosse figue, figue naine, figue Raimbaud, figuepomme, figue rose, figue Jacob, etc. - I la Martinique: figue-créole, figueprume. figne-pumme. figne-cochon. figue verle, figne-ipjere ou Ciacanboury. figue naine, etc.

c. - Le Musa Gavendishii Lamb. Vulgo: Banane naine, banane de Chine.

Les bananes se mangent habituellement cuiles ou frites, tandis que les bananes-figues se mangent crues.

Comme plante lextile ou dionement. on cultive : le Musa tertilis Vée, Bananier Lextile, vulgo: Banane-corde, Abaca, qui foumil des fibreslongues, fines el très tenaces; Martinique, vulgo: Banane-corde; le Musa rosacea Jacq., vulgo: Bananier rose; enlin le Musa coccinea Andr., vulgo: Bananier rouge,

1. Cette espèce et le M. sapientum L., oririnaires d'Asie, sont employés à la Guyane française: les feuilles pour panser les vésicatoires; le fruit vert à titre d'astringent et même d'abortif par son épicarpe; la séve est considérée comme astringente et hémostatique. (E. II. 


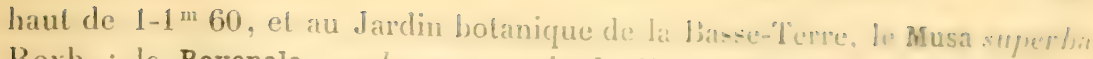
Roxb.: le Ravenala madagascarensis .\% F. (imel. Imom indigine de la plante à Madagascar), vulgo: Arbre du voyageur. Orania speciurat Millil

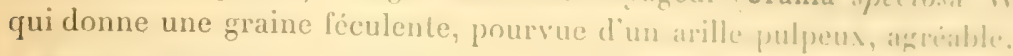

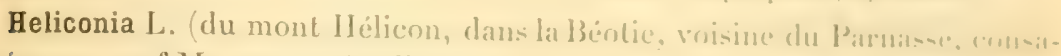
crée aux neuf Muses et à Ipollon.

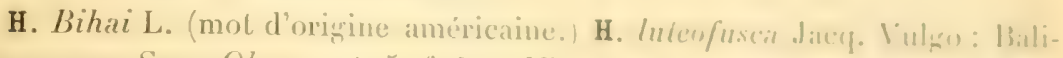

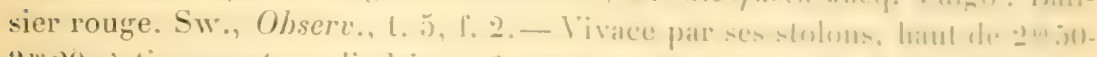

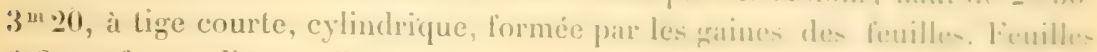
6-8, en forme d'éventail, beaucoup plus longues que la hampe, a limbe longe de $0^{m} 90-1^{m} 30$ sur $20-23$ cm. de large, hrusquement puintues an mommet. atténuées à la base, à nervures parallèles, insérés presqu il andro druit: péliole longuement engainant et presque aussi long que le limbe : pridumcule. de la hampe nu, lisse, légèrement comprimé, inséré entre les dens derniome feuilles. Inflorescence en un épi long de 25-30 cm., droil, portant 7-!) bure. tées, rouge carmin vif, épaisses, horizontales, cymbiformes, dintiques, launes à la base, pointues au sommel, embrassantes: les infiorienres, distanter. longues de $18 \mathrm{~cm}$., teminées en une pointe lres allonere: les supripienter. graduellement plus courtes, imbriqueses it la base. Fileurs situres stu deut rangs, disposées en épis, longrues de 6-8 cm., el renlermées dans lestratelier. au nombre de 5-6, blanches: chaque paire renfermée dans une hractiole blanche, membraneuse, délicate, lérèrement concave, lomrue de F-tem. Périanthe inférieurement tubuleux, largement cannele, divis suprétenrment en cinq dents insérées sur deux rangrs: les deux dents de la liore pur tirieure, recourbées; les trois dents de la lère antérienre, plus conder. dressées; étamines 6 : l'inférieure, stérile; les autres, fertiles, toutes hlancher. exsertes, recourbées el ensuite dressées a l'extrémité; ovaire it śloger unimulées, ovules avortant, à l'exception de 2-3. Fruit bleu loncé, drupacti. Lri-

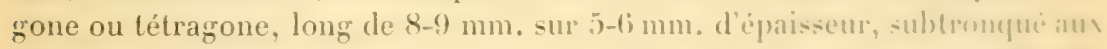
deux extrémités, divisé en 2-3 coques, bosselies-rugulenses. - lil. de février à juillet - Abondant dans les bois humides de la cinadedoupe proprement dite. Alt. $400-900$ mèt. [X" $38: 38$.

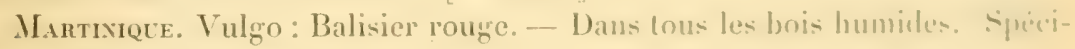
men manque.

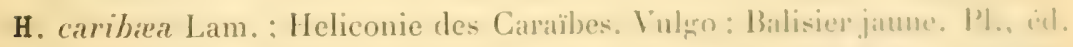

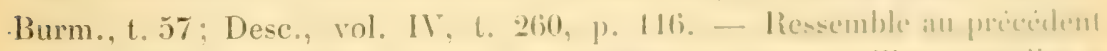
par la taille, le port et les fruits; il en dillère: pare ses leuilles artundies it

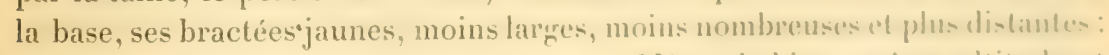
par sa lèvre supérieure, à trois dents. - Méme habilat. mime altilude al même époque de floraison '. [N" 3839.

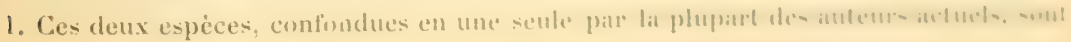


Mantregce. Vulgo: Balisier jaune. - Dans tous les grands bois humides. - On en trouve une variété à pétioles couverts d'une poussière blanche et farineuse. (Spécimen manque.)

L. Heliconia psillacorum Sw.; Ileliconie des perroquets, vulgo : Petil balisier H. cannoidea 1. Rich., Floredes Jardiniers, vol. II, 1.67, tries ornemental, vivace par ses stolous traçants, haut de $0^{\mathrm{m}} \mathrm{g} 0-\mathrm{I}^{\mathrm{m}} \mathbf{2 0}$, à feuilles lancéolées-elliptiques, longuement pétiolées, à hampe longue et filiforme, à fleurs larges, jaune rougeâtre, noires au sommet, est cultivé dans beaucoup de jardins, où il fleurit abondamment et se propage avec une grande rapidité. - Originaire du Brésil. [No 3318.] - Mantinique. Vulgo : Petit balisier. $\left[\mathbf{N}^{\circ} \mathrm{D}.\right]$

\section{CENT QUARANTE-DEUxiÈe FAMLLE. - SCIT'AMINÉES.}

\section{TRIBU I. ZINGIBÉRACÉES.}

Renealmia L. fils / dédié au Français Paul Reneanlme, botaniste, qui, en 1611, publia un ourrage sous le titre de: Specimen historie plantarum.

R. caribra Griseb.; R. racemosa R. el Sch.; Rénéalmie des Caraïbes. Vulgo: Lavande blanche, Lavande grand-bois. Plum., édit. Burm., 1. 20. Haut de $1^{\text {m }} 10-1^{\text {m }} 75$, herbacé, amuel par la tige, vivace par ses stolons gros et traçants. Tige toujours plus ou moins penchée. Feuilles largement lancéolées ou oblongues, ou plus rarement elliptiques, ligulées, longruement engainantes, longues de $30-40 \mathrm{~cm}$. sur $7-9 \mathrm{~cm}$. de large, glabres, à nervures se detachant a angle très aign. Inflorescence en panicule terminale, lâche, longue de 18-25 cm. dépassée par la dernière feuille de la tige: pédoncule ¿́paissi au sommel et dommant naissance à une bractée verte, demi-embrassante. longrue de $7-8 \mathrm{~cm}$. el souvent terminée par une feuille rudimentaire: branches de la panicule courtes, à pédicelles garnis, a la base, d'une bractée blanche, membraneuse, habituellement plus longue que la branche; rachis et pédicelles blancs. Fleurs blanches, odorantes, le plus souvent géminées, entièrement renfermées, avant leur épanouissement, dans une bractéole blanche. très mince, caduque; calice lubuleux, apprimé, a 3 lobes obtus el écartés: corolle infondibuliforme; labelle obové, i 3 lobes arrondis; élamine presque sessile: slyle filiforme; stigmate échancré, comnivent avec l'anthère. Capsule longue de près de 2 - cm., ovoüde, à déhiscence loculicide : les valves restant unies au sommel surmonté des débris du périanthe; semences jaune brun, rondâtres-anguleux, arillées, percéesd'un trou à la base. - Très abondant dans

employéces à la Guyane française : les feuilles pour en extraire des fibres textiles, et les racines comme diurétirques. $\mathrm{E}, \mathrm{II}$.) 
tous les bois de la Guadeloupe proprement dite. - Fl, de férner it juilled! - Alt. 400-900 mèt. [No 3328.]

Martinique. Vulgo: Gingembre grand-bois. - Alondant dims toun l... bois. $\left[N^{\circ} 2117 \mathrm{~b}.\right]$

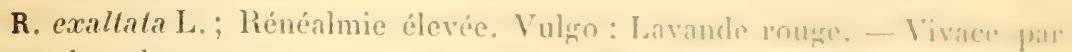

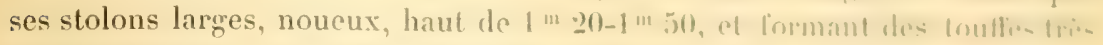
amples. Feuilles très vertes, mucronées, oblonerues nu ellipliques, sumpul

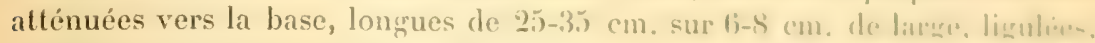

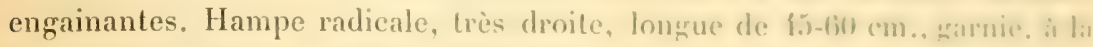

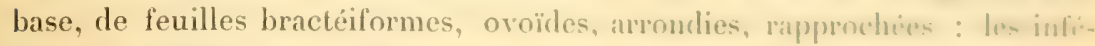
rieures, courtes; les supérieures, graduellement plus Inurues, lancriolian. toutes engainantes et rouges. Inflorescence en grappe longur du 12-18 (am,

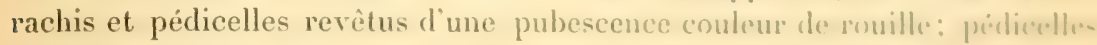
longs de 8-12 mm., porlant à la base une bractic vert mugreitre. plus lungum. que la fleur. Fleurs solitaires, rouge brum; bractée spirale de lia fleur rentrusetubuleuse, brièvement bifide; calice tridenté; corolle presqu ausi hrupur que le calice; lobes de la corolle oblongrs-ovales, plus courls qur lu lulu:

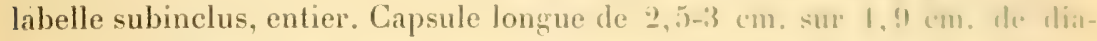
mèt., loculicide, surmontée des débris durcis du périanthe: semences romp. foncé (à l'état frais), lisses, luisantes, faiblement abillés, plus pertiter que dans le précédent, mais à ouverture basilare plus larene. - liare. (ait el li dans les endroits aquatiques des basse of infra-noyenme rérions, exeeptionmellement dans les endroits secs : Capesterre (le longr le la riviere, sour lu pont de l'usine du Marquisat), Deshaies (près du presbylire dans un sul sece

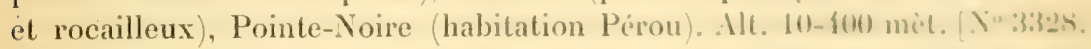

Martinique. Vulgo: Grand gingembre. - Sainte-Luce pris de lat more. bois inférieurs du Lorrain, sur le bord d'un endroit aquatique . | Y" -2f(1)!.

Costus L. (du gree "Kostos ", mot par lequel tes anciens disignaicul une. plante aromatique, en arabe "lioost.).)

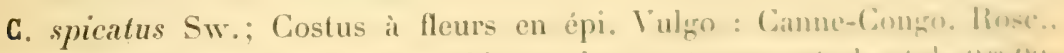
Monand., t. 77. - Vivace par ses rhizomes larges et rampiants, haut de (1) !n : $2 \mathrm{~m} 50$, a tige cylindrique, droite ou souvent plus nu moins tortueuse. Finilles

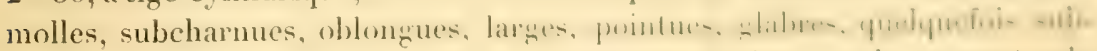
cordées à la base; pétiole court, large, altaché au-dessous dus sommet suhtronqué d'une gaine longue de $1-5 \mathrm{~cm}$., longuement cilice sur hes hords, it cils

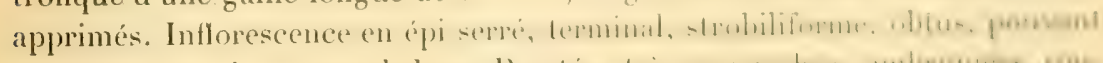

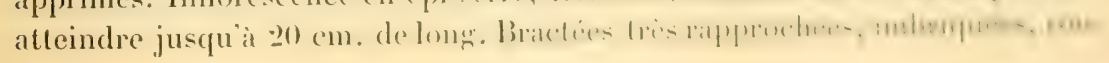

1. Sous le nom rulgaire de Balisier grenipa, cette espece est rmphyse an mederine it th

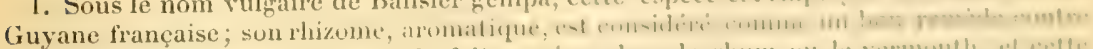

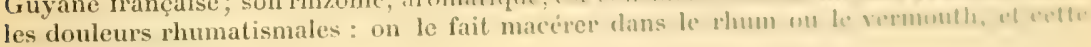
boisson est absorbce à jeun. (L. II. 
geatres. Iongues de $f$ cm. sur à peu près autaut de large, légèrement carénées sur le dos, au sommet. Corolle longue de $3,3 \mathrm{~cm}$, jaune pâle, à moitié exserte, tubuleuse: labelle rejeté en arriere, obtusément trilobé; ctamine pétalö̈le. spatulée; slimmate yarni de deux petites cornes sur le dos, au sommet. Capsule légirement pulpeuse. Ioculicide, triloculaire: semences petites, arillées, nombreuses, violet pâle à l'état frais). - Fl. en mars, avril, mai. - Peu abondant. Cis et li dans les bois humides et le long des ruisseaux des basse et infra-moyenne régions : Vieux-Fort (ravine du haut de la rivière Blondeau, Capestere (environs du Grand-Etang, riviere Noire au-dessous du Camp-Jacob). Alt. 200-500 mèt. [Nos 3701, 3704.

Mantixate. Vulgo: Pelit dégonflé. - Ijoupa-Bouillon, roule des FondsSaint-Denis aux Deux-Choux, Camp de l'Alma, etc. [No 2109.

On rencontre souvent dans les deux colonies le Costus speciosus Smith., it lleurs très larges, blanches, en épi globuleux, garni de braclées d’un mouge vif noiratre. ()riginaire des Indes ()rientales, introduit en Angleterre en 1791. (Illust. horlicole, de Linden, t. III, avril 1896.) [No 3329.]

Hedychium koenig du gree "hedus ", doux, agréable, allusion à l'orleur agréable des tleurs.)

H. coronarium Koenig; Hedychium à fleurs en bouquet. Vulgo: Canne d'eau. Rose., Monand., L.51. - Haut de 0m 80-1 mèt., rarement plus haut, a rhizome rampant et noueux. Tige tres droite, evlindrique, grosse. Feuilles distiques. lancénlées-acuminées, glauques, imbriquées, à limbe long de 25$33 \mathrm{~cm}$. sur 5-7 cm. de large; ligule deltoïde, large, membraneuse, mince; zaine fendue. Inflorescence en épi raceourci, obovoïle, strobiliforme, terminal, naissant à l'aisselle de la dernière feuille, long de 10-12 cm. Bractées de l'épi spathiformes, imbriquées, vert pâle, minces el blanchâtres sur les bords, obovales, arondies, plus longues que larges; bractées basilaires de l'épi pointues, de 1 à 3 prolongées en un limbe foliiforme souvent long. Fleurs d'un blane tres pur, extremement odorantes, a odeur exquise el forte. Périanthe lubuleux, à tube cylindrique, filiforme, longr de $5-6,5 \mathrm{~cm}$. , renfermé, a la base, dans trois bractéoles minces, membraneuses, longues de $2-3 \mathrm{~cm}$. : les trois segments extérieurs du périanthe, longs de $3 \mathrm{~cm}$. sur $2 \mathrm{~mm}$. de large, éxaux, pointus, étalés: les deux segments latéraux intérieurs, larźes, obovés. obtus, plus longs que les trois extérieurs; labelle tres large, obcordé, hrusquement ef étroitement rétréci ì la base, long de $4,2 \mathrm{~cm}$, plus large que Iongr; élamine ì filet comprime; anthère longue, jaune, toujours penchée: sligmale infondibuliforme; nvaire subsessile, triloculaire. Capsule large.

1. Sous le nom de Canne-Congo on utilise à la Guyane française les rhizomes du Costus arabicus L., originaire des Indes Orientales; ce rhizome, à fine odeur de violette, y sert à faire une tisane dépurative et diurétique. II est probable que les deux Costus ci-dessus décrits jouissent des mèmes propriétés. (E. H. 
obovoïde, loculicide; semenees jamnatres, arillés. _ lil. d'amil it juillel.

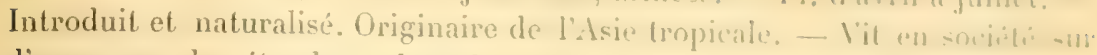

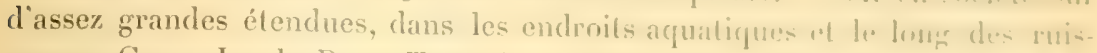
seaux : Camp-Jacob, Basse-Terre (raviue de T3elost fiomberme itang du

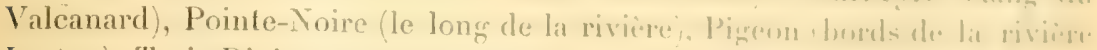

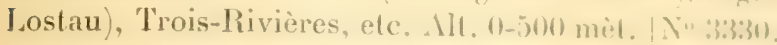

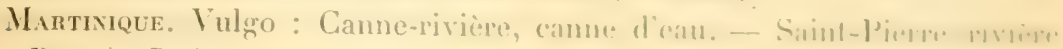

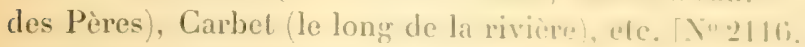

Au Camp-Jacob el dans beaucoup de jardins de la Mantinique, un culdive.

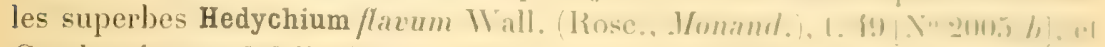
Gardneriamum Wall. (Rose., Monimd., 1. (i2) [X" 2)(x)f ; ils llenri-cent an mai, juin et juillet, et sont originaires de l'. lsie tropicale.

De la tribu des Zingibéracées, on rencontre snuvent:

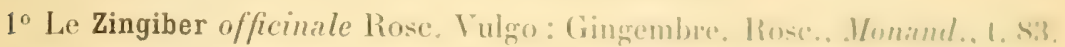
- Ses racines, excitantes, servent dans la médecine donestiqur. - 1.1. en septembre ou octobre, ou novembre, mais ne produil pats de fruil. - Il - a Lrouve aussi à l'état sauvage autour des vieilles habilatinns an ruine; il m.

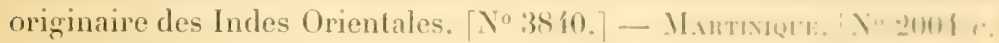

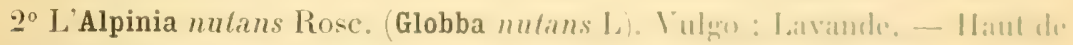

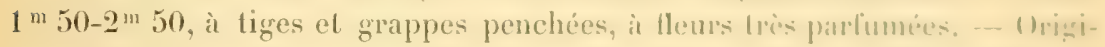

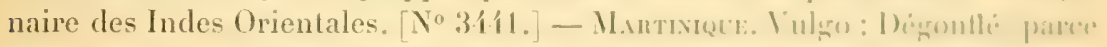
quion emploie la décoction des feuilles contre le métionisme. Y" -2mu h.

$3^{\circ}$ Le Kaempferia longa Jacq. Vulgo : Fleur de mai, qui, pn arril, mai mu juin, époque de la floraison, perd complètement ses leublles panatheres. ul dont les fleurs, radicales, blanches, striées dot laves de vinted carmimi.

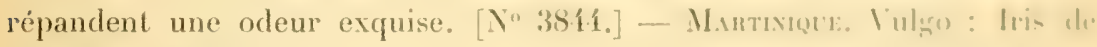
Florence. $\left[\mathrm{N}^{\circ} 2111 \mathrm{~b}\right.$. $]$

$4^{\circ}$ Le Curcuma longa L. Vulgo: Curcuma. - I lleurs d'un hlance jurt.

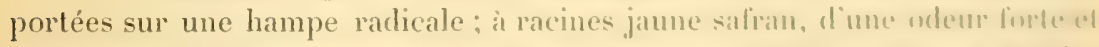
pénétrante. - Elles entrent dans la préparation du lamenx mets aroule. nommé à la Guadeloupe le “Colombon, - Le suc des rilcines us employi chez les femmes de la campagne pour teindre les mouchoirs. Les foulards, he toques, appelées vulgairement " Madras w) il constitue un cxcedlent anli-(") -

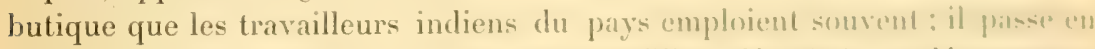

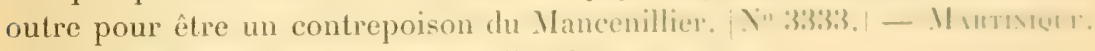
Vulgo: Safran du pays, safran-cooli. [N"2117.]

\section{TRIBU II. MIR.ANTIES.}

Calathea Mey. (du gree "kalathos w, corbeille, allusion it la linme piationlière du labelle.) 
C. discolor. Mex., Maranta Cachibon Jacq., M. Iutea I.am, : Calathie ì feuilles pourvues de deux couleurs. Vulgo: Cachibou, roseau-mare. Rosc., Monand., t. 43. - Vivace, cespiteux, à racines stolonifères, formant une masse compacte, à tiges hautes de 3-4 ${ }^{m} 50$, en baguettes très droites, nues, creuses, lisses, cylindriques, de l'teasseur d'un doigt. Feuilles continées aux extrémilés des ligres, ovales, obtuses au sommet, habituellement arrondies i la base.

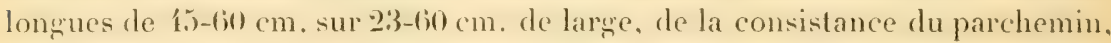
vert pille en dessus, blanches, poudreuses en dessous; pétiole légèrement comprimé, pouvant atteindre jusqu a $70 \mathrm{~cm}$. de lomge, renflé prés de la base du limbe. Inflorescence en -2-1 épis strobiliformes, naissant de la waine de la dernière ou des deux dernières feuilles, comprimés-cylindriques, longs de (1-11 cm., pédonculés, a pédoncules Jongss, trisinédaux. entourés diune bractée générale extérieure, tries longue, courrant les bractées intéricures beaucoup plus courtes, el spéciales it chaque pédoncule. Bractées du strobile brunes sur les bords, tres coriaces, plus larges que longues, largement obovoüdes, subtronquées au sommet, imbriquées. Fleurs james, de moitié moins longues que les bractées, fasciculées: le faisceau rami d'une bracténle cannelée sur le dos: calice à trois segments; corolle à tube filiforme, et à six lobes: les trois extérieurs, lancéolés; les deux intérieurs, obtus; labelle larone, en forme de cuiller ; étamine pétaloïde ; stigmate rond. - Fl. presque toute l'année. Endroits aquatiques : cà et là dans l'étang de Valcanard, Gourbeyre); plus abondant dans les maréeages du Lamentin et de la Baie-Mahault. Alt. ()-400 mèt. $\left[N^{\circ}\right.$ 3334.]

Martineue. Vulgo: Cachibou. - Rare: Champflore (sur le bord de la Capolte), Sainte-Marie (endroits marécageux des bois inférieurs), etc. Y". 2117 h.]

Le Galathea Illonia Lindl., Maranta Allonia Aublel., vulgo: Topitambourg (pour Topinambourg) (Rosc., Monand., t. 38 ; Desc., vol. I, t. 26, p. 1:27), a racines portant des tubercules alimentaires, ovoüdes, slobuleux, linerement hirissés de petits piquants, il lleurs blanches disposées en tête. ovoüde, naissant de la gaine de la demiere feuille, est eultivé dans les deux colonies et dans toutes les Antilles. - Fl. en juin, juillet. - Alt. 10 600 mèt. [No 3812.] ' - Martixeve. Vulgo: Topitambourg. [No $2110 c$. $]$

Ischnosiphon Koern. (du grec "ischnos ", mince, maigre, et "siphon ", lube, allusion aux bractées tubuleuses des épis.)

I. Arouma lineru., Maranta juncea I.am., M. peliolata liudge. Tulgo: Irouma ide " aruna ", nom de la plante chez. les Garipons et les Galibis de la Guyane.) Maranta Jacq.) Vivace, formant des touffes tris larges, compactes

1. Sous le nom vulgaire de Galanga, cette espèce est employće d la Guyane française: ses rhizomes, tubéreux et féculents, y donnent un excellent salep. (E. II.) 
et très ornementales par leur port, hautes de 2 m 50)-3 mit. it tiges comme duns

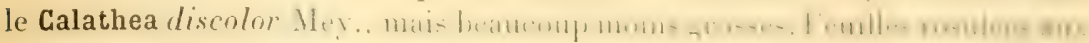

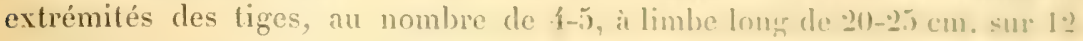
$14 \mathrm{~cm}$. de large, ovale, obliquement pointu au sommet el it critr midime déviée et courbe; pétiole long de 23-30 cm., engatuml dans les troi- quart-

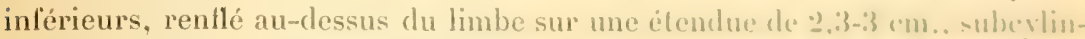
drique entre le renflement el la gaine. Inflorescence an ipjis cylindriques. très minces, fasciculés ou solitaires, très inégatux en Inuruen : les plu- long: mesurant jusqu' ì $11 \mathrm{~cm}$, naissant tous des gaines disposcies sur un pridomente qui s'élève du noud formé par le finisceau des pélioles. Braclés des ipjir alternes, imbriquées, obliques au sommel ef rouges sur lo brord. Fileurjaunes, avec de nombreux points rouge brun; calice renlermé dams la luaction et garni de plusieurs bractéoles; corolle à tube filiforme, dilatí atu sommol.

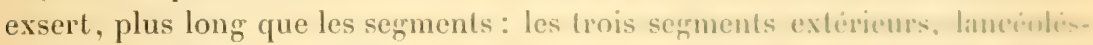
linéaires; les deux internes, latéranx, aussi fongrs, mais lanciobés: labullu. spatulé; étamine filiforme, à anthère libre. Capsule inconnuc. - 'l'mosti as fleurs en août. - Peu abondant : ça el là dans less grands mátreages d’oau

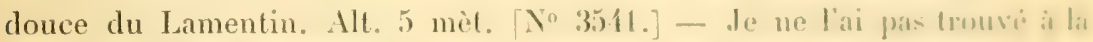
Martinique ${ }^{1 .}$

Maranta L. (dédié au Vénitien Barlh. Maranta, médeciu, monl en 17.j): a écrit: Méthode pour connaîle les plantes.)

De ce genre, on cultive dans les deux colonies, comme: du reste damloutes les Antilles:

$1^{\circ}$ Le Maranta arundinacea I., vulgo: Dictame (l' "Arrow-lool " des Anglais) (Sl., t. 149 Rose., Monand. 1. 25), ì lleurs blanches, ('n cymes terminales, très lâches et dichotomes. - Origrinaire de l'Amérique méridinnale. [No 3843.] - Mantixigue. Yulgo: L'Luvers blanc. [Y'2167, 21111.

$2^{\circ}$ Le Maranta indica Tussac, vulgo: Diclame de la Barbade. Moussichu de la Barbade (Rose., Monand., 1. 26; T'uss., Fl., 1, 1. 26; I)esc.. vol. 1111. t. 549$)$; il ressemble au précédent, mais est plus élevé. - (Mrigrinatire dé Indes Orientales.

Les rhizomes de ces deux espèces produisent des fubercules comprimís. écailleux, allongés, pointus, qui contiennent une fécule blane narere, trí: appétissante, nourrissante et facile à digérer : elle est commue daus lés conto-

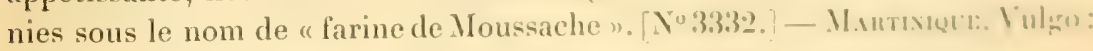
Moussache de la Bardade. $\left[N^{\circ} 2110 \mathrm{~b}.\right]$

1. Cette espèce, très commune à la Guyane française, y est commue vulgairement sum le nom d'Arouman: le suc de ses feuilles et de sal lizge serait camstiqume comme oetu

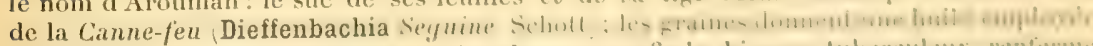
¿̀ Cayenne conme cosmétique pour les cheveux; enfin le rhizume, Inherculeux, renfieme une fécule alimentaire. (E. II.) 
On rencontre souvent dans les jardins de nos deux colonies le beau Maranta zebrina sims, remarquable par ses larges feuilles rayees de brun velouté et de jaune en dessus, d'un beau violet en dessous. - Il est originaire du Brésil.

\section{TRIBU II. CANNÉES.}

Canna I. (du mol celte " can ou cana ", roseau, en grec "kanna », en hébreu «kanak».)

C. indica L. ; Canna de l'Inde occidentale. Vulgo: Balisier rouge. Dese.. vol. IV, L. 240, p. 30 ; Rose., Monand., t. 1. - Vivace par ses rhizomes, a tigre haute de (1) ${ }^{\text {mo-2 }}$ mèt. - Feuilles ovées ou ovées-oblongues, pointues. engainantes, sans liçule. Inflorescence en une grappe simple, terminale, plus rarement composée, quelquefois en deux grappes par la division du pédoncule primaire: pédoncules primaires et branches de la grappe garnis de 1-3 gaines. Fleurs rouges, striées de jaune; bracte de la fleur, wlauque, cymbiforme, plus long que lovaire. Périanthe à six segments : les trois extérieurs, inégaux, lancénlé-acuminés ; les trois intérieurs, formant deux lèves : levrer supérieure, ì segrments lancéolés, subégaux, un des segments bipartite; la lèvre inférieure, entière, projetée en avant, roulée en dedans et plus vivement coloréc que la supériéure; style pétaloüde, large, spatulé; ovaire inlère. surmonté de trois appendices glauques, dressés, deltoïdes-acuminés persisLants. Capsule triloculaire, loculicide, hérissée, noire a la maturité ; semences noires, sphériques. - Fl. en juin, juillet, août. - ( )n se sert des graines pour faire des chapelets. -- Cultivé el ì l'élat sauvage : Basse-Terre, (rourberre, Trois-livieres, Capesterre. Marie-Calante, Pointe-̀-Pitre, ete. Alt. O-fon mèt. [No3554.]

Martinique. Vulgo: Balisier rouge, balisier à chapelets. - Cà et là dans toute l'île. [No $2112 \mathrm{~b}$. $]^{1}$

C. coccinea Mill. ; Camma ì tleurs écarlates. Vulgo: Balisier rouge. Rosc., Monand., 1. 11. - Ressemble au précédent quant aux racines et à la taille; il en differe: par ses feuilles mucronées, par les segments de la livre supérieure, échancrés, lancéolés, inégaux el surtout par la lève inférieure échancrée, striée de jaune, tandis que dans le précédent tous les segments des deux lèvres sont striés de jaune. - Même habitat et même altitude. No $3554 \mathrm{~b}$.

Martinique. Vulgo: Balisier rouge. - Cultivé çà et lì et à l'état sauvage dans toute l'île. [ $\mathrm{N}^{\circ}$ 2112.]

1. Cette espèce, bien connue et largement cultivée en France et en Europe, est réputée diurétique et diaphorétique par son rhizome qui contient une fécule connue et exploitée comme aliment sous le nom d'Arrow-rott de Queensland. (E. H.) 
C. edulis Ker Gawl; Canne comestible. Vulgo : Toloman. Mosce, Monaml., t.5. - Vivace par ses rhizomes tubérifiés, volumineux el allongés, it lige haute de $1^{\mathrm{m}} 50-2 \mathrm{~m} 50$. Feuilles larges, ovées ou ovées obhmprues, printue- ou arrondies au sommet, contractées, ì lat base, cn une gaine lompur, mon apprimée. Corolle écarlate; segments de la lère supérienre, subutraux, Aresmí. sans échancrure; lèvre inférieure, échancrée, projelér, - lit. principalement en septembre, octobre et novembre. - Issez sonvent cultive pour sе

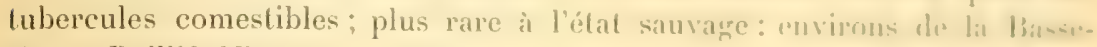
Terre, Baillif, Vieux-Fort, Capesterre, Morne-iil'Lau, (iofier, (1) .111. 11-bu) mèt. [No 3558 .

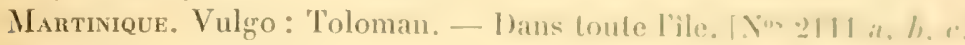

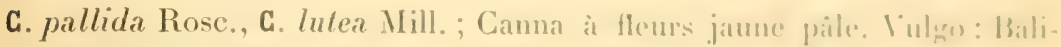
sier jaune. Rosc., Monand., 1. 19, 20. - Haut de L-1" 80 , rarement juluhaut. Feuilles larges, ovées-oblongues ou ovécs, labituellement trits filanque:en dessous, à gaines et bractées ghlauques. Corolle larre, jaune pille, in liever supérieure dressée, ses deux segments égaux et entiers, souvent liurirrment rétus, à lèvre inférieure tachetée d'orange brun. Cilpsule muriquíe, - I-no abondant. Cultivé et à l'état sauvage dans les endroils humides et aqual tique-:

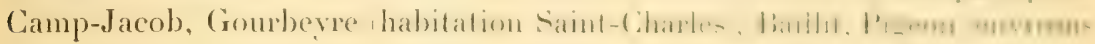
de l'usine), Trois-Rivières (habitation Roussel), Pointe-Noire, Mnule, Mante-

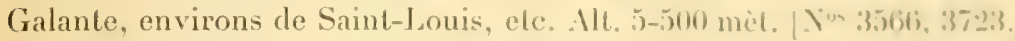

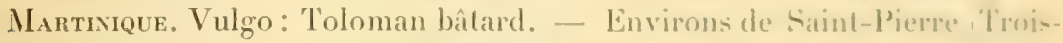
Ponts), Carbet, Case-Navire, Marin, Gros-Morne, ele. Y 2111.

C. glauca L.; Canna à leuilles très glauques. Vulgo: Balisier jaune. Mrose.. Monand., t. 17. - Haut de $0^{\mathrm{m}} 80-1^{\mathrm{m}} 50$. - l'euilles plus étroites que

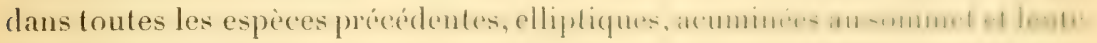
ment atténuées, à la base, en une longue gaine élroite. Fileurs larpeśs, d'un jaune assez vif; segments de la lève supérieure, obovés-spalulés, inchatux.

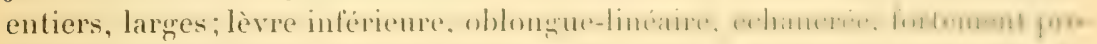
jetée et roulée. Capsule muriquée. - Cultivé el it l'élat samvange dans les

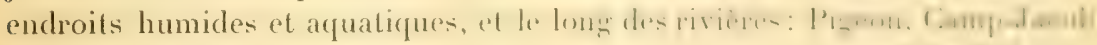
(Montéran), Baillif, Capesterre, Lamentin, etc. Alt. 1)-500) mit. [X" 33:33\%.

Martingue. Vulgo: Balisier jaune. - Rivière-Pilote le lone de lia riviere. Ducos (ravine), Trinité, La Régale, elc. [No.2113.

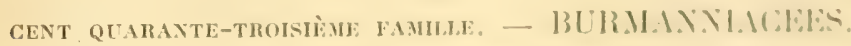

Apteria Nutt. (du grec "apteros ", saus ailes, parce yuc lil calpsule wht couverte, à la base, par le périanthe non ailé.)
A, selacea Nutt.,
A. lilacina Miers,
A. hymenantherat Miq. : Ipterie a 
l'euilles séteuses. Traité général de Bolanique descriptive, de Le Maout et Decaisne, 1876, 2e édition, p. J66, figure. - Haut de $4-15 \mathrm{~cm}$.. à tige droite. filiforme, sans ou arec -2-3 branches. Feuilles réduites, it quelques écailles engainantes, linéaires. Fleurs bleues, 1-3, longues de 3-4 mm., terminales. Périanthe infondibuliforme, adne it la base de lovaire, it 6 lobes d'inéyale largeur ; etamine 3, incluses, at filets très courts, insérées un peu au-dessus du milieu du périanthe et grarnies sur le dos d'un petit appendice obeordé: strle inclus, trifide: oraire uniloculaire. multinrulé. Capsule médianicide au sommet. - Trouvé fleuri en août. - Très rare: Trois-Rivières (sur les racines d'un manguier, non loin de l'habitation Trou-aux-Chiens). Alt. 340 mèt. $\left[\mathrm{N}^{\circ} 28556\right.$.

CINT QUARANTE-QUATRIEME FAMILLE, - ORCHIDÉES.

\section{TRIBU I. MAIAXIDÉES.}

Pleurothallis R. Br. du wree "pleura ", côte, flanc, et "thallos ", branche. parce que les fleurs naissent sur le côté au sommet de la tige.)

P. ruscifolia R. Br.; Pleurothalle à feuilles de Ruscus une espèce de Fragron de la famille des Asparagrinées . Jacq., Sel. Am. stirp. hist., t. 133. f. 3. (Dendrobium Sw.) - Arboricole, haut de 8-30 ( $\mathrm{cm}$., sans bulbe: a racines rampantes; a tige cylindrique, droite, rigide, garnie, a la base et au-dessous du milicu, d’une raine. Feuille 1. elliptique-lancéolée, atténuée au sommet et ì la base, pétiolée. Inflorescence en un fascicule arrondi, situé latéralement au sommet de la tige, plus longr ou aussi long que le pétiole et entouré, à la base, d'une bractée bifide, engainante, de laquelle sortent 3-16 fleurs, petites, pédicellées, verdâtre pâle. Divisions extérieures du périanthe lancéoléesacuminées, dont deux sont cohérentes jusqu'au sommet : divisions intérieures, une fois plus courtes el libres; livre tris petite, ovée-oblongue, articulée avec le grnosteme. - Fl. durant les mois de mars et octobre. - Abondant dans les bois humides de la Guadeloupe proprement dite. Alt. 300-900 mèt. [No3313.]

Martixique. - Dans tous les bois. [Nos 395, 2069.]

P. aristata IIook.; Pleurothalle à divisions extérieures terminées par un prolongrement en forme d'arête. - Arboricole, haut de 1-5 cm.. cespiteux. Feuilles naissant près de la racine, longues de $1.2-2 \mathrm{~cm}$. . spalulées, assez. brusquement atténuées vers la base. Inflorescence en crrappe droite, dépassant de beaucoup la feuille. Rachis en zigzacs tris réguliers : rachis, pédoncules et pédicelles capillaires. Fleurs pourpre noir. Divisions extérieures du périanthe larges ì la base, brusquement atténuées, à partir du milieu, en 
arète allongée : divisions intérieures, une lois plus courtes, ovees-lancéculios: lèvre ovée-oblongue, avec deux petils lobes lateraux, - Isem rare. Sur le: trones à une faible hauleur, vil souveut dans la mousco : Camp-Jacoh), Batrit-

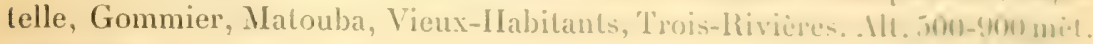
INo 3311 .

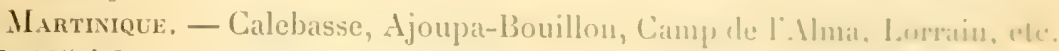
$[\mathrm{N} \circ 395 \mathrm{~b}$. $]$

Stelis Sw. (du grec "stelis ", par lequel les ancions disinnatent unc pedil. plante parasite. Théophraste, Gaus., 2, 23; Pline, XV1, 113.

S. ophioglossoides Siv.; Stélide ì leuilles en forme de langrue de serpent. Jacq., Sel. Am. stirp. hist., t. 133, 1. 2. Epidendron 1., - Arbnricrole, sul:

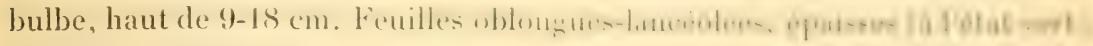
obtuses, lentement atténuées vers la base, plus longrues yue la tiget at plu-

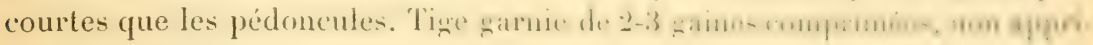
mées et élargies au sommel. Inflorescence en $1-1$ grappes cflilées, spiciformes, lâches, longues de $\mathbf{1}-5 \mathrm{~cm}$., naissant ì la basec du pétiole. P'édoncule:

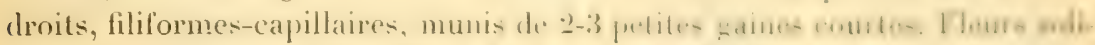

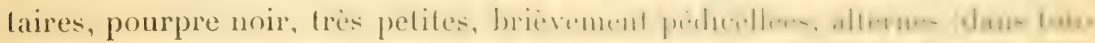
mes spécimens), assises dans une petite bractéce concave el pointue; rachidisposé en zigzag. Caractères généraux de la fleur les mémes que ceux de: Pleurothalles : divisions extérieures, deltojdes, d'égate lonfrucur; les interieures, tronquées; lèvre deltoïde-tronquée. - Asse\% abondant sur les troned'arbre à une faible hauteur el souvent couverts de mousises : Camplatacob),

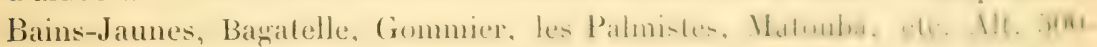
1000 nièt. [No 33340.$]$

Martixique. - Deux-Choux, Piton-Gelé, Montarne-Pelie, ele. ! Xo :3\$il.

Octomeria R. Br. (du grec " octo ", huit, et "meros ", partic, division, parce que ce genre a huil masses polliniques.)

0. graminifotia R. Br.; Octomérie à feuilles de graminces. - Hatul de 11 $13 \mathrm{~cm}$. à rhizomes rampant au loin, noueux et garmis de grines. fienille 1.

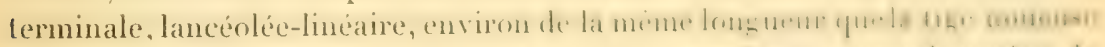

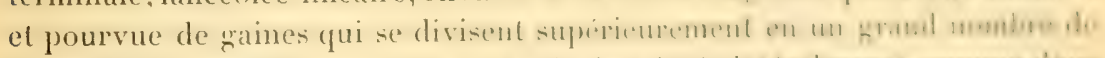

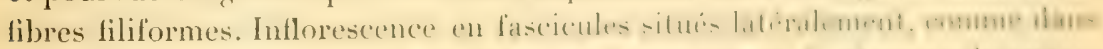

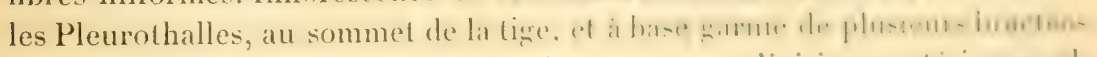
Fleurs 1-5, jaunes, tachetées de points rouges : divisions cxlirieures du

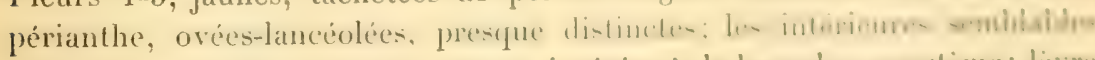
aux extérieures, mais plus courtes el insérées à la base du frymostime: lierre

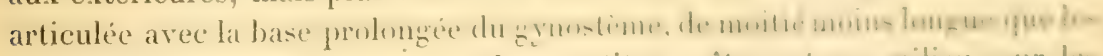
divisions intérieures, granie de deux petites crêtes, et atu milien, sur les côtés, de deux petits lobes. - Dans le bas conme aussi sur le haul des arbren. où il forme souvent une sorte de gazon recouvant des trunc: enticre: dims: 
tous les bois humides de la Guadeloupe proprement dite. Alt. 500-900 mèt. [No 3699 .

Martinique. - Dans tous les bois. [No394.]

Microstylis Nutt. (du gree "micros ", petil, el "stulos ", style, allusion ì la petitesse du gynostème.)

M. spicata Lindl.; Microstyle à fleurs en épi. Sw., Fl., t. 28, inf. analyt. - Terrestre, haut de $35-46 \mathrm{~cm}$., très droit, éléxant. Feuilles 2, flasques, dont une plus grande que l'autre, opposées, nettement ovées, larges, trìs vertes, siluées à 7-9 cm. au-dessus du sol, engainantes jusqu à la base. Hampe lerminale, subquadrangulaire, nue, radicale, filiforme, latérale, à un pseudobulbe blanchâtre, petit, légèrement comprimé. Inflorescence en racème long de 3-4 cm., teminal. Fleurs jaune verdatre, petites, pédicellées, à pédicelles capillaires, garnis, à la base, d’une petite bractée subulée-lancéolée : divisions extérieures du périanthe, ovées; les intérieures, linéaires, toutes distinctes; lèvre sessile-embrassante, presque carrée, à trois lobes courts : celui du milieu, obtus. - Assez abondant dans les endroits humides et ombragés des grands bois : Bains-Jaunes, Gommier (partie supérieure), Matouba (Matelyane et Ravine-à-Déjeuner), etc. Alt.600-900 mèt. 「No 33-18.

Martinique. - Bois des Pitons-du-Carbet, des environs du Camp de l'Alma et de la fontaine Absalon. [No383. $]$

\section{TRIBU II. ÉPIDENDRÉES.}

Epidendrum L. (du grec "épi ", sur, et " dendron ", arbre, parce que la plupart des espèces de ce vaste grenre végètent sur les arbres.)

E. ciliare L.; Épidendre à lève zarnie de longrs cils. Plum., édit. Burm., ᄂ. 176, f. 1; Jacq., Sel. Am. stirp. hist., t. 179, f. 89. - Haut de $30-10 \mathrm{~cm}$. Tige à 3-4 noeuds, allongée en un pseudobulbe revêlant la forme d'une massue et loug de 6-120 cm. Feuilles 2-3, épaisses, rigides, oblonğues-lancéolées, presque toujours légèrement échancrées au sommet, plus courtes que la hampe. Hampe garnie de bractées oblongrues-lancéolées, alternes-distiques, imbriquées : les inl'érieures, stériles; celles de la grappe beaucoup plus courtes que l'ovaire. Inflorescence en grappe étalée, aussi longue ou plus longue que la lige; fleurs blanches, larges, a odeur exquise : divisions du périanthe, linéaires-acuminées, étalées; lèvre adnée au gyuostème, divisée en trois segments profonds : les deux latéraux, larges, longuement frangésciliés; le segrment médian, étroitement lancéolé-linéaire, dépassant les autres en longueur. - Fl. habituellement d'octobre à janvier. - Assez abondant sur les arbres el les rochers, dans les endroils sees des mornes inférieurs: Houëlmont (environs de la batterie), Vieux-Fort (ravine Blondeau, rivière Noire, hauteurs des Vieux-Habitants, etc. Alt. 150-400 mèt. [No 3358.] 
Martineve. - Trois-llets (plateau, hès abondant), hanteurs du linhert. Gros-Morne, etc. No 2077.

E. fuscalum Sm.; Épidendre à fleurs sombres. Jacy., Sel. Am, stirp. hive.. L. 138. - Haut de 70-80 cm., sins bulbes. Tirge fenillue, Imrizmntale m penchée. Feuilles elliptiques-oblongres, ou oblongues-linéares, distiquer.

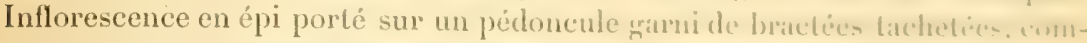
primées, scarieuses. Fleurs pédicellées, brun verdatre un morrilles : divivinu-

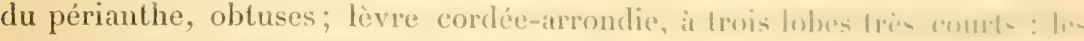
lobes extérieurs, arrondis; celui du milieu, émarriné - IH. de dermbre is mai. - Assez abondant daus les bois supérieurs du Matunba, du (iommier.

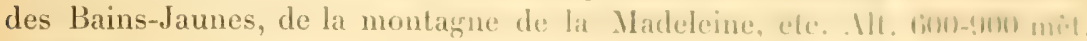
[No 3486.]

Martingue. - Calebasse, Ajoupa-Bouillon, Cliampifore morme de la Croix), Gros-Morne, Morne-Rouge. [N" 1028.]

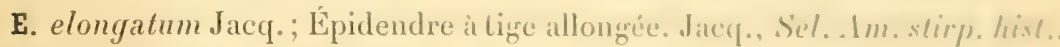
t. 137. - Très beau, terrestre, plus rarement anboricole, haut the firl-thl (mo. à ligedroite, nue dans le bas et feuillue au milieu. leuilles rigrides, nhlongrumlancéolées, habituellement obtuses. Hampe alloneré, lisse. Inforescenco en grappe terminale, simple ou branchue. Fleurs roses ou roses pilles, ou plurarement blanches : divisions du périanthe, spatulées-lancétécs : livre puluecente en dedans, garnie, à la base, de deux tubérosités, trilubee, it lat)edentelés : celui du milieu, plus large el bifide. (iymosteme tridenti an sommet, dilaté. - Fl. de janvier à août. - Très abondant daus toute la reginin

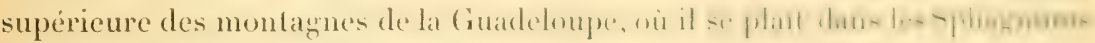
humides; moins abondant dans les bois inférieurs : sai cel lit dins les sarvane:

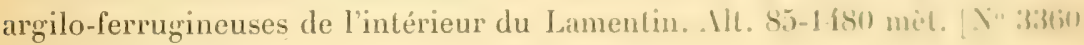
avec une variété à lobes de la lève frangés.

Martinique. - Bois de l'Ajoupa-Bouillon, du Gros-Morme, du l'ilm-lichi. de la Calebasse, des Deux-Choux, etc. [ Y 1029 .

E. rigidum Jacq. ; Épidendre à leuilles rigides. - Jacq. Sel. Im. xlip). hist., t. 134. - Arboricole, haut de 30-10 cm, à tige comprimie, lienillue. Feuilles rigides, oblongues, obtuses. Inflorescence en épi allongi, c'mmprimi. Fleurs alternes, vert jaunâtre, naissant solitaires de l'aisselle d'unc bratedir eymbiforme, amplexicaule, voutée, carénce, ì carènc décurrente : divisinn: extérieures du périanthe, ovales; les intérienres, lancéolées-lincianés: livere entière, ovée, obluse. Gynostème denticulé alu sommet. - fil. prespum lonte l'année. - Asse\% abondant dans les bois humides des Bains-launes, dés lmiintérieurs de Sofaya, de la Pointe-Noire, de la Ravine-Chaude. Mll. Mint. 900 mèt. [No 3845 .]

Martrigee, - Bois du Lorrain, de la Cillebasse, du Pilub-Ciche. de la Grand'Anse, etc. $\left[N^{\circ} 1031\right.$. 
E. strobiliferum Rehb; Épidendre en épi strobiliforme. - IJaut de 1622 cm.. ì tige branchue. comprimée. Feuilles distiques, petites, épaisses au milieu, plus minces sur les bords, lancéolées ou ovées-lancéolées, échancrées au sommel. Inflorescence en épis droits, strobiliformes, courts, terminaux ou axillaires, très comprimés. Fleurs distiques, blanchâtres ou verdâtres, petites: bractées florales, voûtées-ovées, obtuses. non décurrentes. plus courtes que l'ovaire. Divisions extérieures du périanthe, ovées-oblongues : les internes, oblongues-linéaires; lèvre entière, cordée-ovée, pointue, aree un disque concave sans callosités. - Dans la région basse, sur les tiges de petits arbres, surInut sur les cacaoyer's: Ajoupa-Bouillon, Grand'Anse, Champtlore, etc. Alt. 300-500 mèt. [No 1033.] - Je ne l'ai pas trouvé à la Guadeloupe.

E. ramusum Jacq.; Epidendre rameux. Jacq., Sel. Am. stirp, hisl., 1. 13:2. - De hauteur très variable : les plus longs pouvant atteindre $70-95 \mathrm{~cm}$. et au delà, ì tige très branchue, it branches toujours penchées ou pendantes dans les pieds adultes. Feuilles linéaires-lancéolées. Inflorescence en épis terminaux: bractées florales, distiques, Jjlanchâtres, ovées-oblonğues, coriaces, concaves, obtuses, non décurrentes, plus longues que l'ovaire. Fleurs petites, vertes : divisions extérieures du périanthe, ovées-lancéolées: les intérieures, linéaires: lève indivise, cordée-ovée. Gynostème à disque concave avec deux petites bosses a la base. - Issez abondant sur les arbres. dans le bas comme dans le haut des troncs : Bains-Jaunes, Gommier, Matouba, Pointe-Noire, etc. Alt. 250-800 mèt. [No 3361.]

Martixique, - Très abondant : Parnasse. Morne-Rouge, Prècheur, FondsSaint-Denis, fontaines Didier et Absalon, etc. [ $\left.\mathrm{N}^{\circ} 2075.\right]$

E. difforme Jacq.. E. umbellatum Sw.; Épidendre difforme. Jaeq., Sel. Am.stirp. hist., t. 136. - Haut de 14-18 cm., tortueux, à tige comprimée. Feuilles oblongues ou ovées-oblongues, obtuses on émarginées, engainantes: saine comprimée, pius large au sommet, persistant apres la chute des feuilles. Intlorescence en ombelle terminale, sessile, composée de 3-10 lleur's verdâtres, odorantes; bractées florales, ovales, pointues. Divisions du périanthe, veinées : les extérieures, lancéolées ou oblongues; les intérieures. linéaires, légèrement spatulées; lère it trois lobes plus larges que longs, réniformes, portant en dedans deux callosités: lobe du milieu, légèrement échancré. Gynostème tronqué-dentelé. - Fl. d'arril à juillet. - Issez abondant sur les arbres des régions moyeune et infra-moyenne, exposées au grand air: Camp-Jacob, Bagatelle, Gommier, hauteurs de Pigeon el des TroisRivières. Alt. 350-800 mèt. [No 3362.]

Martingez. - Plus abondant : bois de l'Ajoupa-Bouillon, de la Calebasse, du Champflore, hauteurs de la Basse-Pointe, etc. [No 1048.]

E. paniculatum R. P. : Fidendre a fleurs en panicule. - Arboricole, haut de $60-70 \mathrm{~cm}$. a tige très feuillue, inférieurement grosse. cylindrique. supé- 


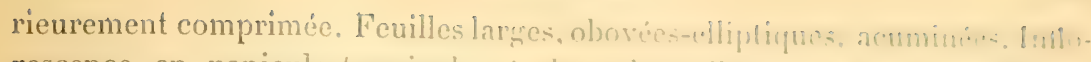

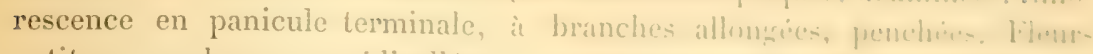

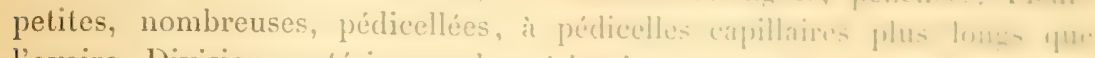

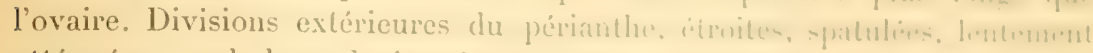

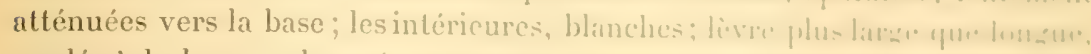

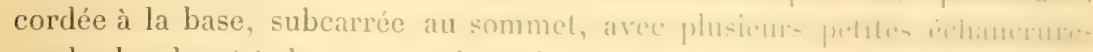

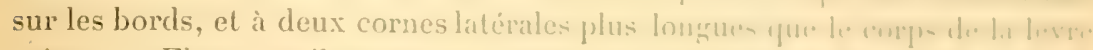

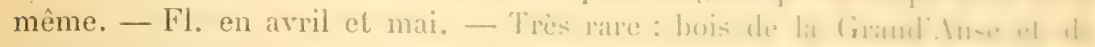

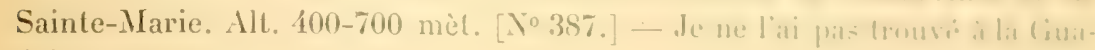
deloupe.

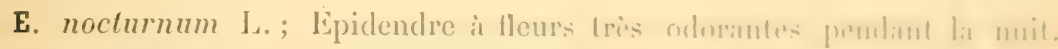

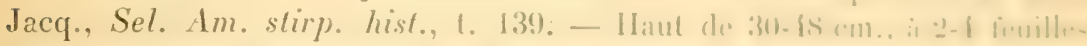

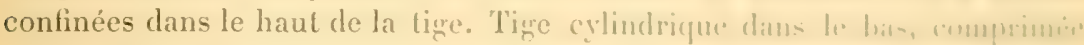

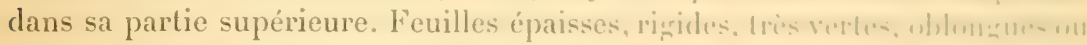

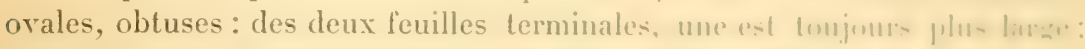

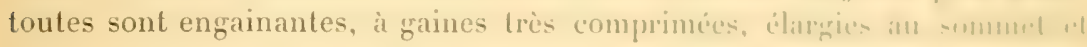

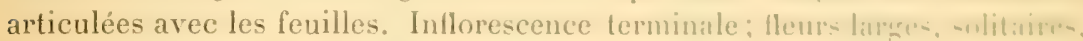

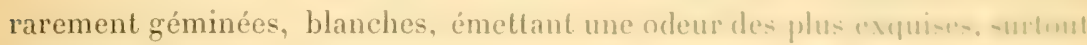

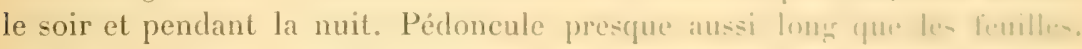
Bractées tlorales, ovées-lancéolées, très conrtes ou réduites at qurlyum

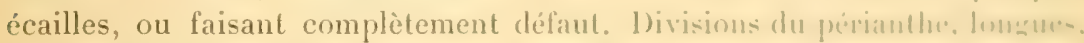
linéaires-acuminées; lèvre à trois lobes: les deux latirams, wris-ubluma-

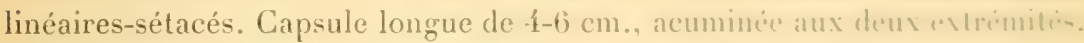
- A la partie inférieure des trones d’arbre, dans les endruil= flus on muimhumides et très aérés: Houëlmont, Gourbeyre, lienx-lont maime Mhndeau), Pointe-Noire. - On en rencontre deux varietes : une plus mamble a

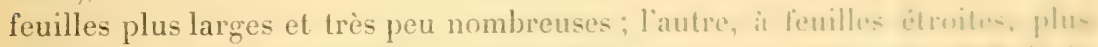

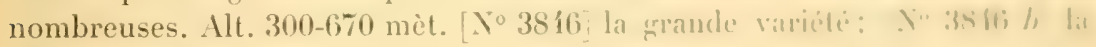
petite variété.

Martingue. - Morne-Rougre, Ajoupa-Bouilhon, Champllure, ete. [No2074] la grande variété; [No 1032] la pelite vilriéte.

E. vincentinum Lindl.; Epidendre de Saint-V̈̈ncent. - Hant de T-I f crn...

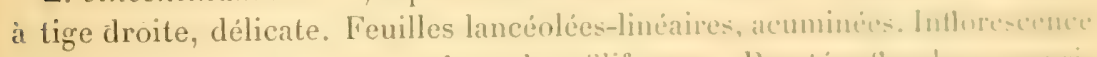
en panicule lâche, allongée, à branches liliformes. Braclies floriles, comprimées, engainantes, très petiles. Fleurs rert jaunilre, it pidiculles beamump plus longs que les bractées. Divisions extérieures du pritinthe. lamcialice:

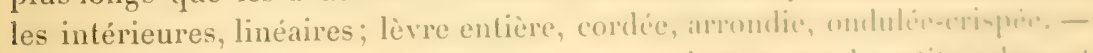

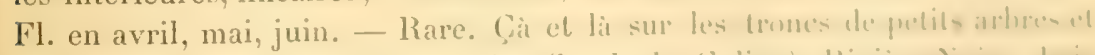

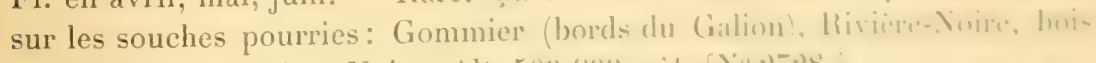

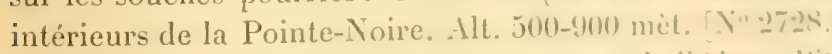

Martingue, - Fontaine Absalon, Camp de l'. Mma. Pitum-(ivi: 
E. terefifolium sir : Épidendre a fenilles cylindriques. - Ilaut de $18-23 \mathrm{~cm}$., a ligre jaune. ligierement comprimée, droite, a vant une épaisseur égale de la base au sommet. Feuilles jaune verdâtre, recourbées, distiques-alternes, obtuses, charnues, triquètres-subcylindriques; une seule fleur terminale, jaune verdâtre, brièvement pédicellée, à pédicelle garni, à la base, de 2-4 bractées scarieuses, blanchâtres, ovées. Divisions extérieures du périanthe, lancéolées, pointues, rigicles: les intérieures, elliptiques, de moitié plus courtes que le calice; lèvre libre, entière, d'un bleu violet foncé, épaissie et triquètre à l'extrémité. - Rare : çì et là sur les arbres du Matouba et des Bains-Jaunes. Alt. 680-900 mèt. [No 3597.] — Je ne l'ai pas trouvé à la Martinique.

E. globosum Jacq. ; Épidendre à capsule globuleuse, Jacq., Sel. Am. stirp. hist., t. 134, P. 4. - Haut de $4-12 \mathrm{~cm}$. Tige feuillue, droite, ayant la même épaisseur, de la base au sommet. Feuilles recourbées ou droites, distantes, alternes-distiques, obtuses, cannelées-cylindriques. Inflorescence en une petite ombelle sessile, terminale, entourée de bractées membraneuses, ovées, obluses. Fleurs petites, jaunitres, panachées de rouge. Divisions du périan the, ovées: les intérieures, plus étroites; lèvre entière, pointue, concave. F1. habituellement de mai a juillet. - Abondant sur les arbres des grands bois de toute la Guadetoupe proprement dite. Alt. 500-980 mèt. Yo 3698.

Martinique. - Dans tous les grands bois. [No 2076.$]$

Brassavola R. Br. (dlédié à I'Italien Ant. M. Brassavola, né en 1500 , à Ferare, professeur de physique et de médecine dans cette ville, médecin particulier de plusieur's papes, médecin consultant de plusieurs princes, mort en 1555 ; a laissé plusieurs ouvrages ayant trait aux matières qu'il enseignait.)

B. cucullata R. Br.; Brassavola à lèvre en forme de cuiller. - Haut de 25-30 cm., cespiteux. Tige courte, noueuse, cylindrique à la base, supérieurement comprimée, garnie de ?-3 gaines blanches, membraneuses, dont la supérieure est beaucoup plus longue, fendue dans le haut et dépasse la base de la hampe courte. Feuilles solitaires, plus rarement géminées, charnues, slauques, subcrlindriques, linéaires-acuminées, unisillonnées, naissant de la gaine supérieure. Fleur 1, terminale, d'un blanc très pur, exhalant, surtout pendant la nuit et le soir, une odeur des plus agréables; hampe courte, zarnie de - -3 saines blanches de grrandeur inégale, située au-dessus de l'insertion de la feuille; pédoncule de la fleur, long de 11-13 cm., filiforme, plus court (que la feuille. Divisions du périanthe, longues de $8-9 \mathrm{~cm}$., lancéolées-linéaires, très acuminées, subégales; lèrre libre, onguiculée, cannelée, en forme de cuiller, frangée sur tout le bord, et garnie, au milieu, d'un long appendice, linéaire-acuminé. Masses poliniques 8. - Fl. habituellement d'août à janvier. - Assez abondant sur les rochers et les arbres dans les endroits sece de la basse région : Vieux-Fort, Houëlmont, Désirade, ete. - 


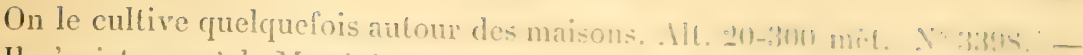
Il n'existe pas à la Martinique.

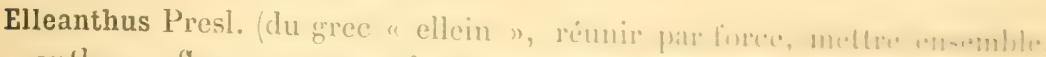

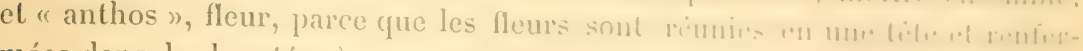
mées dans des bractées.

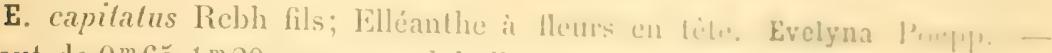

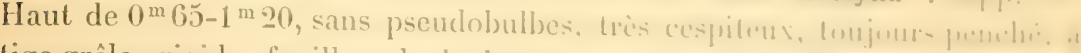

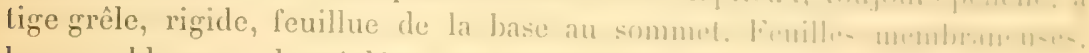

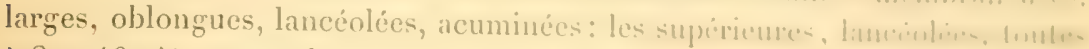

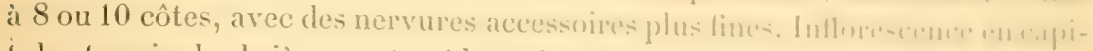

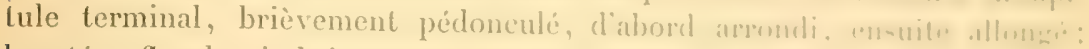

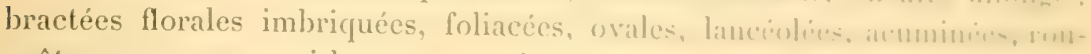

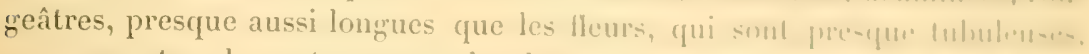

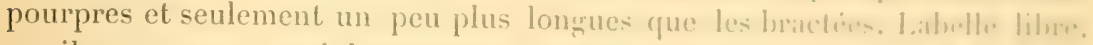

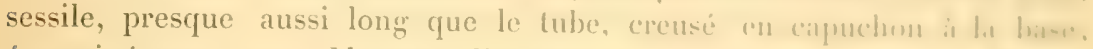
émarginé au sommet. Masses poliniques 8. - Fl. de mai i juin. - Sur In-

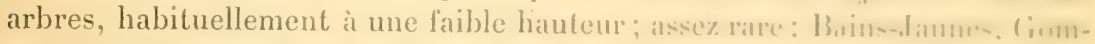
mier. Alt. 450-900 mìt. [No 3732.

Martingue. - Bois de l'Ajoupa-Bonillon fasco\% abondant, the finmeSaint-Denis, etc. [No 1037.$]$

Bletia Ruiz el Pav. (dédié à l'Lespagnol L. Blel, phanmacion tholani-l. à Madrid.)

B. verecunda R. Br.; Blétie modeste. - Haul de 30-7l; ('m., rarement pluhaut (et à l'état de culture seulement), terrestre, tres beau, it parmulubultu.

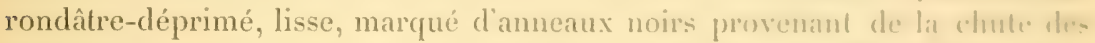
feuilles, de la grosseñ d'un oignon, teminé par une tontle dhe f-is finille-

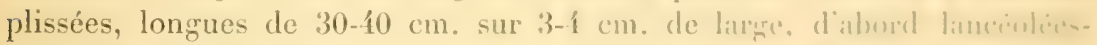
acuminées, ensuite linéaires-acuminées. Inlorescence en frapple terminate. longue finalement de $20-30 \mathrm{~cm}$, toujours penchéc. portic sur um hamp. latérale, panachée, plus longue que les leuilles, plus mu moins purtuip.

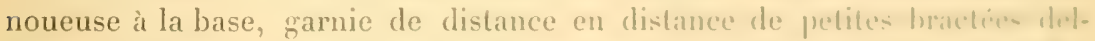
toüdes-subulées. Fleurs lilas, demi-penchées, subunilatérates: hraction- Horales semblables à celles de la hampe, mais beaucoup plus peliter. friture du

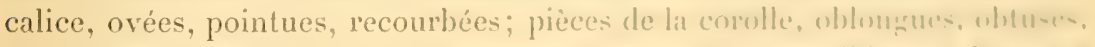
plus larges, légèrement plus longrues ef droites: livre semsiblement humar i la base, libre, courbe, presque tubuleuse-cylindrique dans sil montio mbli-

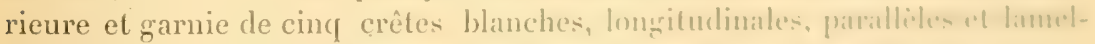
leuses, élargie vers le sommet en trois lobes: celui du milind, heamenu'

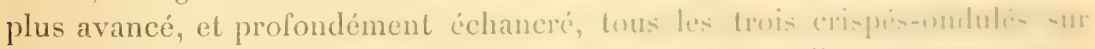

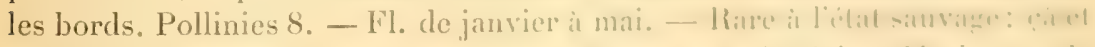

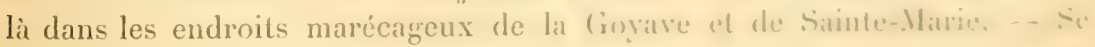


cultive frécuemment en pot, dans les jardins: les fleurs deriennent alors plus grandes, et la hampe, sourent vivement panachée, se termine par une panicule lâche. Alt. $0-50$ mèt. [N"3395.] - Elle n existe pas it la Martinique.

Isochillus $\mathrm{R}$. Br. (du grec "isos"), égal, et "cheilos ", lèvre, parce que la lève est presque de méme forme que les autres divisions du périanthe.)

I. linearis R. Br. Vulgo: Lin bâtard. - Arboricole, sans bulbe, très cespiteux, haut de $60-5 \mathrm{~s}$ cm., à tiğe grêle, rigide, très feuillue. Feuilles distiques, plates. linéaires, courtes, émaryinées au sommet qui est obtus. Inflorescenceen épi court, brièvement pédonculé : bractées florales, ovées-lancéolées. Fleurs petites, unilatérales, pourpre fonce ou pourpre clair. Divisions du périanthe, égales; lèrre spatulée-linéaire, libre, à onglet courbe. Pollinies 6 , dont 4 plus larges et 2 plus petites et sessiles. - Fl. de mai à octobre. - Abondant, formant des touffes souvent très larges et très compactes: Gommier, Bains-Jaunes, Natouba, V'jeux-Habitants, Bouillante, ete. Alt. 180-900 met. [No 3349.$]$

Martixiqce. Vulgo: Lin bâtard. - Dans tous les bois humides. [No 2075.]

\section{TRIBU III. VANDÉES.}

Dichæa Lindl. (du grec " diché ou dicha ", double, parce que les tiges portent deux rangées de feuilles très rapprochées.)

D. echinocarpal Lindl., Limodorum pendulum . Lubl. : l lichée à capsule hérissée. Aubl., Guy., 1. 322. - Arboricole, cespiteux ou non, sans pseudobulbe, à tigesimple ou hranchue. pousiant de haut en has, lésèrement radicante, ou sourent non radicante, flexible, comprimée. Inngue de f(0-60 cm. Feuilles $n 10 \mathrm{~m}-$ breuses, très rapprochées, oblongues, très mucronées, longues de $12-15 \mathrm{~mm}$. sur 4-5 mm. de large; pétioles larges, engainants, équitants. Fleurs solitaires, toujours très nombreuses, portées sur un pédoncule aussi long que les feuilles. Divisions du périanthe distinctes, toutes de même longueur, jaune pâle; lèvre libre, entière, sagittée-oblongue, d'un bleu très vif; Eynostème 11 ; masses polliniques 4 : caudicule rétréci à la base. Capsule ovoïde, muriquée et velue. - Peu abondant : çà et là dans tous les grands bois humides de la région supérieure de la (suadeloupe proprement dite. Alt. 600-1000 mèt. [ $\mathrm{N}^{\circ} 3354$.]

Martinique. Vulgo: Mille-pattes. - Calebasse, bois du Lorrain et des Pitons-clu-Carbet. [No 2068.]

Ornithidium Salisb. du grec "ornithidion ", petit oiseau, parce que les fleurs sont petites et offrent, dans l'ensemble des différentes parties, une certaine ressemblance avec un oiseau.)

0. coccineum Salisb. (1)ruithidie à fleurs rouge vif. - Haut de $15-45 \mathrm{~cm}$., 


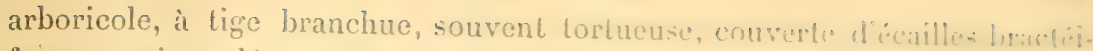

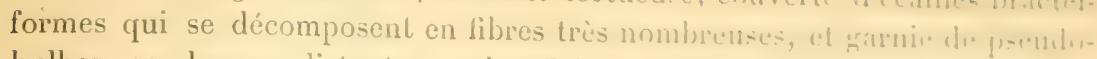
bulbes nombreux, distants, quelquefois rapprochis, ovales-compurimi- du

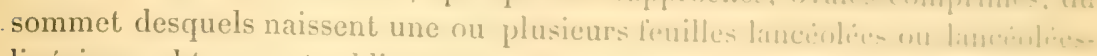

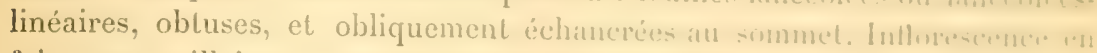
faisceaux axillaires; fleurs rouge vif, petifes, lompmement prifomentara, a

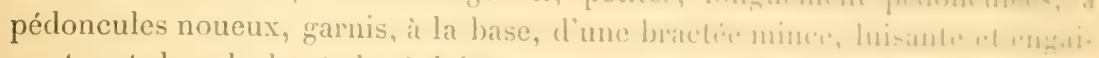

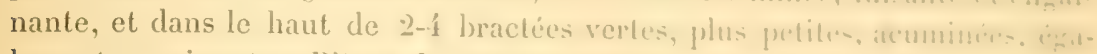

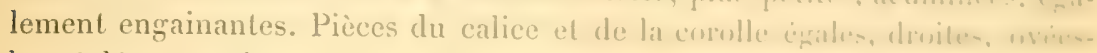

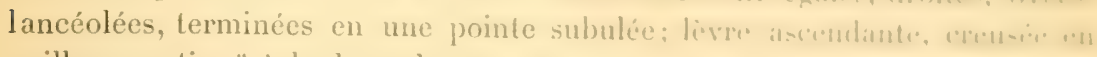

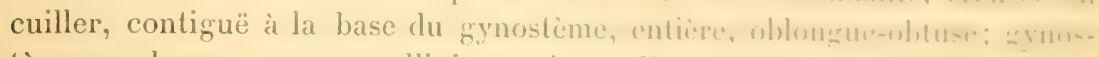
tème nu, bossu; masses polliniques 1, caudicule linciare. . fil. dr mate a juillet. - Assez abondant dans tous les lonis élevis al lummiles de la

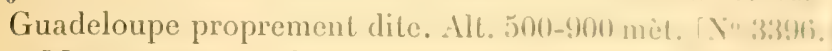

Martunique, - Abondant dans (ous les frands bois. Y"2071).

Polystachya Hook. (du gree "polus n, beaucoup), cel "slachus", ifi, c"ulà-dire fleurs en panicule composéc de beaucoup) d'ëpis.

P. luteola Hook.; Polystachye à fleurs jaunitres. - Mlum., édit. Murm.. 1. 185, f. 1. - Haut de 17-12 cm. Tige it pseudohulle it lat hase, druile, peru

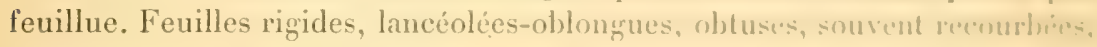

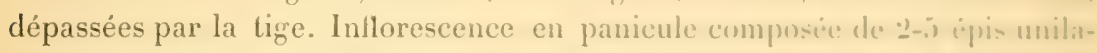
téraux; fleurs vert jaunâtre, petiles. Divisions extericures el lintirates du

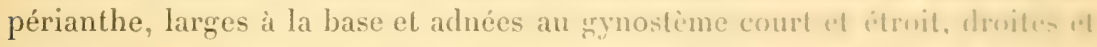
dressées : les pièces de la corolle, plus courtes; labelle sissile. plat, articule

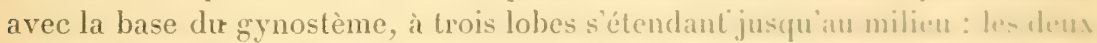

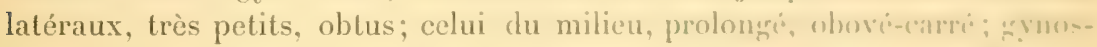

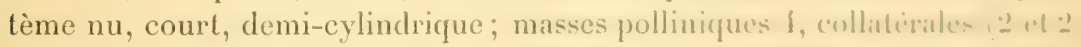
cohérentes; caudicule filiforme. - lil. durant la majeure partic de l'anmie. - Assez abondant sur les arbres de tous les grands bois de lit Cimateloupu proprement dite. Alt. $450-900$ mèt. [ No 33356 .

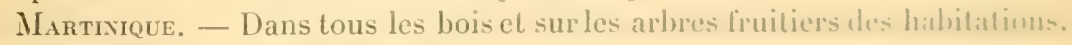
[No 2066.

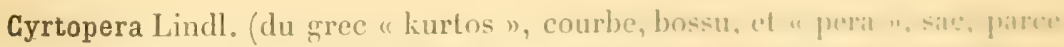
que le labelle, concave à la base el articulé avec le symustime. finme un petit creux.]

c. Woodfordii Lindl.; Cyrtopère de IVondford. - Terrestre, hatut de fll-

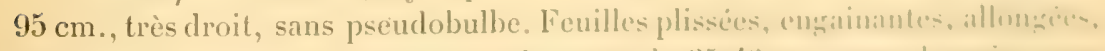

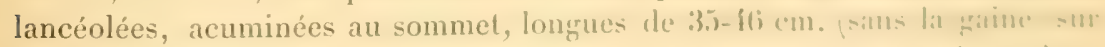
4-5 cm. de large, naissant au nombre de $\{-5)$, du sommet d'une racime tulueculeuse, fusiforme, grosse, très lisse, blanchitre el prolundement mblerrite.

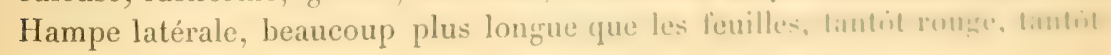


blanchitre, crlindrique. suceulente. Inflorescence en grappe allongée. terminale; fleur généralement pourpre foncé, avec des divisions légèrement jaunâtres à la base (je n'ai trouvé que dans deux spécimens des corolles pourpre violet au sommet el blanchitres it la base, lareze. pédicellée, at pédicelles d'abord filiformes, ensuite plus gros, garnis d'une bractée lancéolée, subulée, plus courte que le pédicelle. Divisions du périanthe, ascendantes, oblongues, brusquement pointues: les deux latérales, extérieures, et les deux intérieures, adhépentes au grnosteme; labelle articulé arec la base prolongée du gynostème, ventru-concave, trilobé, garni de deux callosités : lobes latéraux, très courts; celui du milieu, plat, arrondi, ové-oblong, plus large. Pollinies 4 : 2 postérieures et 2 antérieures. - Fl. en juin, juillet, août. Cia et lit dans les terres argilo-ferrugineuses de l'infra-morenne région : Gourherre Grande-Savane. Dole et habitation Saint-Charles, Gommier, les Palmistes, Trois-Rivières. Alt. 250-600 mèt. [Nº 3338.]

Marmixique. - Fontaine Alsalon, bois de la Grand'Anse (dans les clairières). [No 378.$]$

Oncidium Sw. (du grec " oncos ", enflure, exhaussement, à cause clu renflement qui caractérise la base du gynostème.)

0. tetrapetalum Willd, Oncidium à quatre pétales. Jacq., Sel. Am. stirp. hist., t. 142. - Haut de $25-60 \mathrm{~cm}$., à tige horizontale ou penchée, rarement dressée. Fenilles peu nombreuses, confinées a la base de la tige, recourbées. équitantes. camnelées, oblongues-linéaires, acuminées, longues de $5-13 \mathrm{~cm}$., beaucoup plus courtes que la tige grede, rigide. noueuse. et garnie de petites bractées. Inflorescence en graple ou en panicule; llems jame d'or vif. Divisions du périanthe, étalées: les pièces du calice spatulées les deux latérales Etant soudies presque jusqua sommet ; celles de la corolle, oborées, léxierement ondulées; labelle contigu à la base du gynostème et garni de crêtes lamelleuses, à trois lobes : les deux latéraux petits et arrondis; celui du milieu, bien plus larpe et plus longr, réniforme, bilobé, ondulé, uni sur les bords ou crénelé. Gynostème court, garni, au sommet, de deux petites ailes demi-ovées-obtuses et entières. - Fl. en arril, mai, juin. - Assez abondant sur les petits arbres, plus rare sur les rochers, dans les endroits secs, chauds, pierreux des mornes inférieurs: Vieux-Fort, Houëlmont (bois de l'habitation Bisdary, riviere des Pires. Désirade, les saintes mornes du Chameau . Marie-(valante bois de Folle-Anse et Capesterre . Alt. J-380 mit. No 3337.]

Martixigue. - Trois-Ilets, hauteurs du Diamant, Marin (Gommier). $\left[\mathrm{N}^{\circ} 377 \mathrm{~b}.\right]$

0. variegatum Sw.; Oncidium ì fleurs panachées. Sl., t. 148, f. 2. - Ressemble.au précédent quant au port. à la taille et ì la lorme des feuilles; il en diffère : par les gaines de la tige cylindriques, plus courtes que les entrenoxuds, blanches, ce qui tranche bien arec la tige verte; parses grappes plus 
courtes, enfin par ses flcurs blanches, panachece ol strifes de man. - Suz

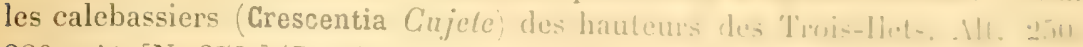

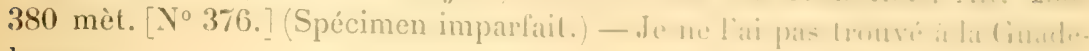
loupe.

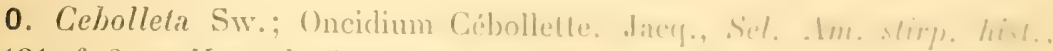

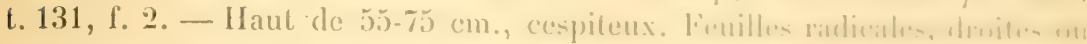

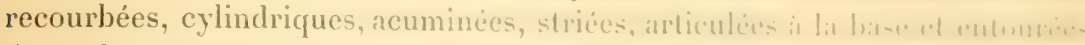

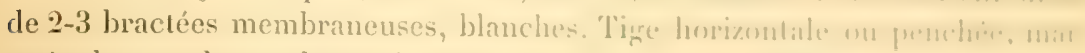

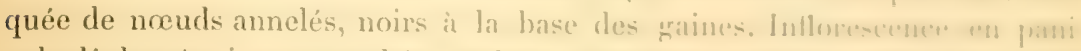
cule lâche, toujours penchée, élalée, it branches allormes-di-ligne- : lhom-

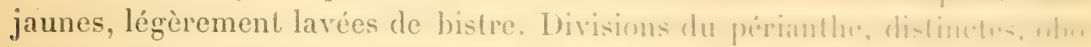
vées-oblongues; labelle pourvu d'une crête it la hase, it trois lolues : lu- lati: raux, très petits ou réduits ì deux petits moliments; colui du milien, trir distant, large, veiné, rénilorme, bilobé. Liles du zryostime plus mu moim an

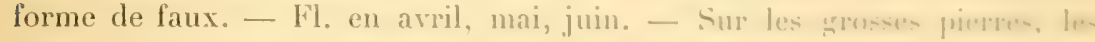

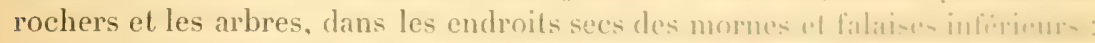

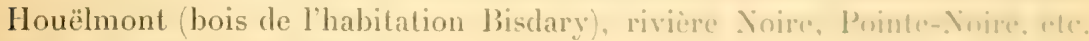
Alt. 40-300 mèt. [No 3847 .]

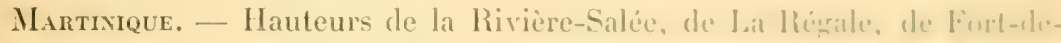
France, etc. $\left[\mathrm{N}^{\circ} 278.\right]$

0. altissimum Sw.; Oncidium ì hampe très Iongur. lulgo : Paprillum

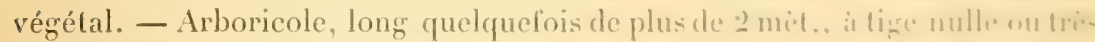
courte, portant 1-8 leuilles, au-dessous d'un pseudobulte comprime, rilli, ws ou elliptique-oblong et surmonté de 1-2 leuilles terminales. Finulles imbri-

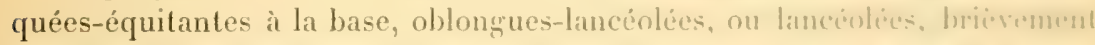
acuminées, habituellement ondulées, jo-8 fois plus courtes quic la hampu. Hampe latérale, ligneuse, toujours penchée, panaché de vert at de hrun.

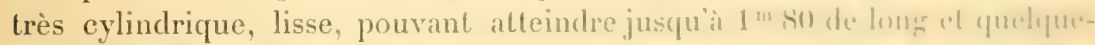
fois au delà, garnie dans le bas de bractées très appriméc, blanchés. femuluejusqu'à la base, plus courtes que les entre-ncruds marqués d'un ammenu mir. Panicule 4-5, plus longue que la partic nue de la hampe, il brameles altermes. courtes; bractées florales courtes, blanchatres, concaves, pointure, plus courtes que les pédicelles. Fleurs jaunes, panachées de hrm. Drivi-imu- du périanthe, distinctes, égales, oblongues-lancéolées, muduliun: livre anm-i longue que les divisions; base de la livre garnic d'une crete et de phusinu:

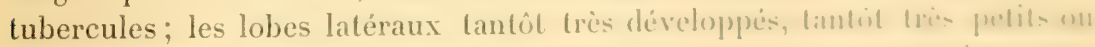
rudimentaires : celui du milieu, distant, larese, reniforme, souvent humcont'

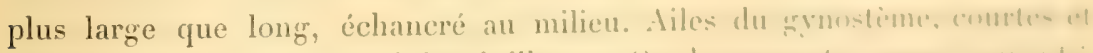

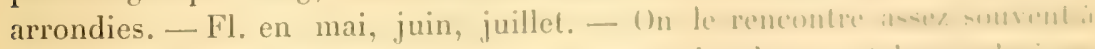

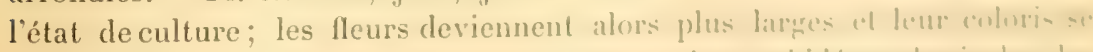

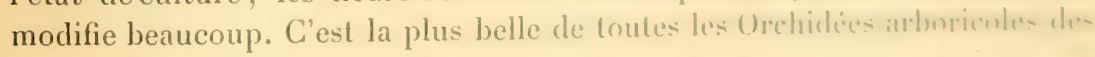


deux colonies. - Chà et là dans presque tous les bois inférieurs, mais plus alondant an IJoü̈mont, dans les hauteurs de Baillif, des Vieux-IJabitants, de Deshaies. Alt. 150-550 mèt. [No 3346 .

Martinique. V́ulgo : Papillon végétal. - Assez abondant : Fonds-SaintDenis. Champllore. Ajoupa-Bouillon, fontaine Didier, Trois-Ilets. Diamant, etc. $\left[\mathrm{N}^{\circ} 2072\right.$.

0. Iuridum Lindl.; Oncidium it fleurs sombres. - Arboricole, haut de $70-95$ cm. sans pseudobulbe. Fenilles longues de $25-30 \mathrm{~cm}$. épaisses. rigides. plates. lancéolies-oblongues, avee une pointe terminale obtuse : deux a cinq. parmi les inférieuress sont beaucoup plus courtes. Hampe latérale, penchée. noueuse, à nœuds marqués d'un anneau noir; bractées de la hampe blanchâtres, engainantes, cinq à six plus courtes que les entre-nœuds. Inflorescence en panicule allongée, lâche, ì branches courtes. Fleurs dlun jaune très sombre. panaché de brun sombre. Divisions du périanthe, distinctes obovées, assez lorusquement onguiculées, à onglet de longueur variable; labelle garni d'une crete is cing tubercules; lobes latéraux légèrement recourbés, pointus, à pointes tournées vers le gynostème : celui du milieu très distant, de même forme que dans le précédent. Ailes du gynostème charnues et arrondies. Fl. en mai, juin, juillet. - Assez rare : çà et là dans la partie supérieure de la vallée du Carbet. Alt. 50-90 mèt. [N०2073.] - Je ne l'ai pas vu à la Guadeloupe.

On cultive asice sourent a la Martinique lOncidium papilio Lindl., originaire de la Trinidad. $\left[\mathrm{X}^{\circ} 2071\right.$.

Leochilus kinowles el Westo. du gree "leins ", lisse, whabre, et "cheilos", lèvre, parce que le labelle est entier et lisse.)

L. cochlearis Lindl.; Leochile à lèvre en forme de cuiller. - Épidendre, minuscule, haut de $8-1.2$ cm., a pseudobulbe court, comprimé, ové. Feuilles oblongues, fermes, au nombre de 3-5: une d'entre elles surmonte le bulbe; les deux ou quatre autres, radicales, sont situeses an-dessous du bulbe. Hampe radicale, enveloppée à la hase par le pétiole ençainant, sarnie de bractées ovees-lanceleces, tris acumines, distantes, enzainantes vers la base. Inflorescence en wrappe simple ou composée de $2-3$ branches tres courtes. portant 3-ti fleurs jaune pàle. 1)ivisions du périanthe, droites, rigides, ovées, obtuses: les deux intérieures situées lateralement et cohérentes; labelle libre, coneave en dessous, sessile, entier, obové, garni à la base d'une crête en forme de fer à cheval; gynostème court, garni de deux petites cornes tournées vers la lèvre. - Fl. en avril, mai, juin. - Peu répandu. Endroits sees ou humides: Gourbeyre (les Palmistes, sur des arbrisseaux), Port-Louis (sur de petits arbres du bord de mer), Petit-Canal (mornes calcaires), les Saintes (morne du Chameau) (rare). Alt. 0-400 mèt. [Nos 3391, 3731.] - Je ne l'ai pas trouvé à la Guadeloupe. 
Ionopsis H. B. el Kth (du gree " ion ", violetle, el "opsis ", a-prect, patre" que les espèces-types n'ont pas de tige et ressemblent it des piealis d. violette.)

I. utricularioides Lindl.; Inopside ressemblant it un L'tricularir. - Irfori-

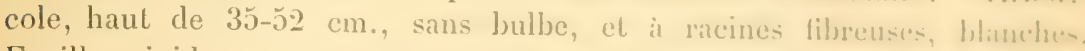
Feuilles rigides, courtes, peu nombreuses, lancénlées, envirm quatre for

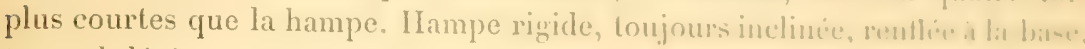

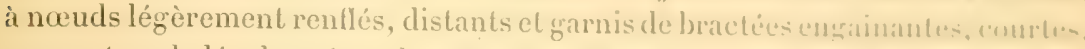
souvent mal développées; bractées des fleurs très pelites. Inthrescence and grappe ou plus souvent en panicule. Fleurs blanches, veincin du rouge.

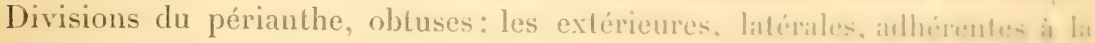
base et se prolongeant en un petit sac court atu-dessous du laluellu : livirr attachée à la base du gynostème par un onglet cunéiforme el grarni de dent callosités; limbe de la lèvre, grand, plat, bien plus loner que les divisime du périanthe, bilobé, il lobes carrés-armondis ou mods; ryostime tricourt, nu; rostellum pointu; pollinies 2, sillonnées sur ledos. - l'eu alumbant:

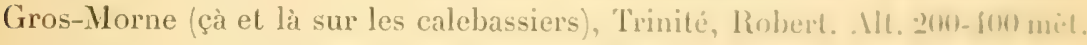
[No 377.$]$ - Je ne l'ai pas vu à la Guadeloupe.

\section{TRIBU IV. ARETHUSLES.}

Vanilla Plum. (du mot espagnol "vainilla ", diminutil" de vaina ", frousice. à cause de la forme des fruits.)

V. anaromatica Sw.; Vanillier a lruits sans arome. Vuleo : Vanillicr sauvage, vanille sauvage. Plum., édit. Burm., L. 188. - Crimpint, radicant, à tige cylindrique ou subcylindrique. Feuilles subcharmes-membaneuses, nettement et largement ovales, pointues, à $28-3-1$ nervures, avere des arivlecarrées et régulières; pétiole court, cannelé, demi-amplexicaule is la bare. Inflorescence en grappes axiliaires, situées dans les parties supirienter der tiges; bractées de la grappe, larges, loliacées, elliptiques, sesciles. Filemr: inconnues (spécimens imparfaits). Gousses légèrement aplatios, pendantes, longues de $12-19 \mathrm{~cm}$., sans parfum, le plus souvent lintement courbes, mais ayant une assez grande ressemblance avec la vanille du Mexique. - Peu abondant: Ajoupa-Bouillon (habilation liden: fontarise Absalon (plus rare), Case-Pilote (plateau militaire). All. fult-fifl) miel. [No 2081.] - Je ne l'ai pas trouvé ì la Guadeloupe.

On cultive dans les deux colonies, surtout it la Ciundeloupu, le Vanilla planifolia Andr., vulgo: Vanillier du Mexique, origrinare du Mexique vi du Brésil, à gousses subcylindriques, vert clair, qui alteignent ordinatrement de.

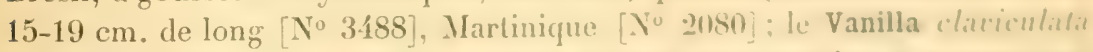
Sw., vulgo: Vanillon, à feuilles, lleurs el liges plus grandes, à grumsects verl 
foncé brun, longues de 9-11 cm., oblongues. Desc., vol. V, t. 362, p. 221 [No 3487], Martinique $\left[\mathrm{N}^{\circ} 2080 \mathrm{~b}\right.$.]

A la Guadeloupe, on rencontre assez souvent le Vanillier du Mexique ì l'état sauvage, autour des vieilles habitations abandonnées et en ruine, comme on en voit dans plusieurs quartiers du Gommier; ces pieds, qui grimpent à une hauteur considérable. ne doivent pas ètre confondus aver le vanillier sauvage proprement dit.

\section{TRIBU Y. NÉOTTIÉES.}

Ponthieva R. Mr. dédié à de Ponthieu, qui fournissait au botaniste anglais Banks des plantes d'Amérique.)

P. petiolatit Lindl. : Ponthiève à feuilles Innguement pétiolées. - Terrestre. hant de 55-75 cm., très droit, à racines fasciculées, blanchatres, longues. velues, demi-cylindriques. Feuilles larges, radicales, rosulées, flasques, au nombre de 5-7, lancéolées-oblongues et amplexicaules ì la base, de un lier: ou de un quart plus courtes que la hampe, qui est cylindrique, velue, grèle, ì nouds distants et garnis de poils couleur de rouille. Inflorescence en grappe longue de 15-20 cm.; rachis, pédicelles, ovaires, bractées florales revêtus de poils de mème couleur que ceux de la hampe. I)ivisions du périanthe, rosées, délicatement veinées, étalées : les deux extérieures, latérales, très léyèrement courbes, oblonğues-lancéolées; la troisième, centrale. lancéolée-acuminée et plus étroite; les deux intérieures, arquées, plus courtes, demi-cordées, adhérentes i leur sommet et en mème temps avec le sommet de la division centrale extérieure, de manière à former un limbe ovale rondâtre, garni ì l'extrénité de trois petites dents: labelle situé en arrière, plus court que les autres divisions périanthiques, très concave, pointu, adhérent par sa base au gynostème et aux divisions intérieures, garni, en dehors, d'une pubescence courte et brune; gynostème très court, nu; pollinies 2. - Fl. de janvier à avril el d'aout à octobre. - Endroits sees ou humides el ombragés des grands bois: bois inférieurs du Nez-Cassé, des mornes élevés de Deshaies; où il abonde; plus rare dans les mornes de Houëlmont. Alt. 400-800 mèt. $\left[\mathrm{N}^{\circ} 3337\right.$.

Martixique. - Calebasse, bois de la Grand Anse, du Lorrain, du Champflore. $\left[\mathrm{N}^{\circ} 373.\right]$

P. glandulosa R. Br. ; Ponthiève â poils glanduleux. - Terrestre, très droit, à tige ferme, haute de $15-28 \mathrm{~cm}$., à racines fasciculées et courtes. Fenilles 3-t, lancéolées-clliptiques, pointues, beaucoup plus courtes que la hampe, et brièvement pétiolées, à pétiole engainant ì la base: hampe, rachis, pédicelles et ovaires revêtus de poils glanduleux courts, couleur de rouille; bractées de la hampe concaves, ovées, pointues: les inférieures, 


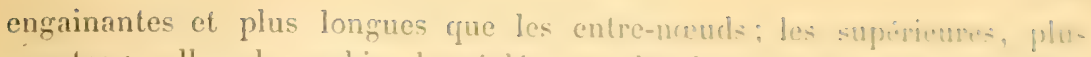

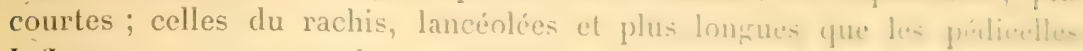

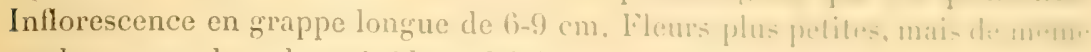
couleur que dans le précédent. Divisions extéricures du pirianthe, wex-

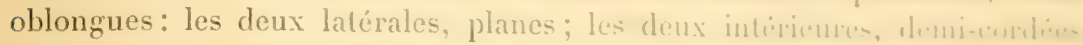

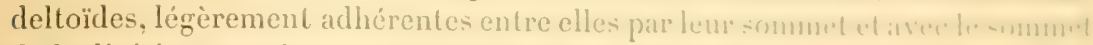

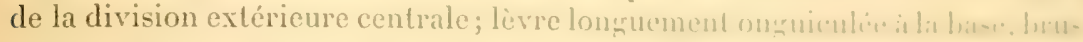
quement élargie, concave, el armée sur le dos, prís du sommul, d inm pritu.

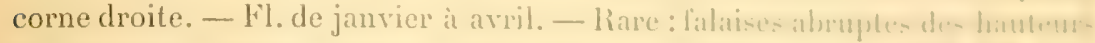

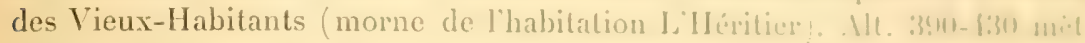
[No3614.] - Je ne l’ai pas trouvé à la Martinique.

Granichis Sw. (du gree "Kranos ), casque, allusion it lit limm du labellı.

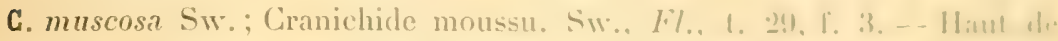

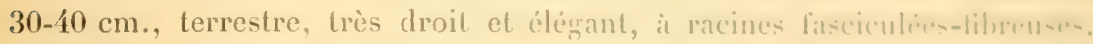

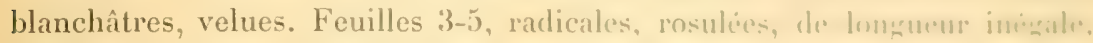

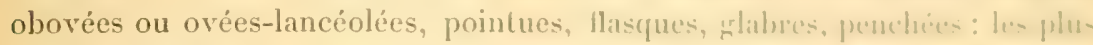
longues, une fois plus courles que la hampe; pétioles de lompurur varialife.

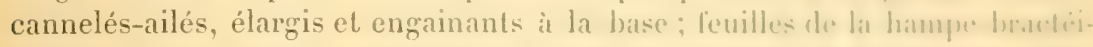
formes, longuement engainantes, ovées-ronditres: les inliorienres, plularges, et en forme de cuiller; les supérieures, sradurllement fulus fonter:

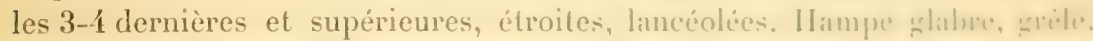

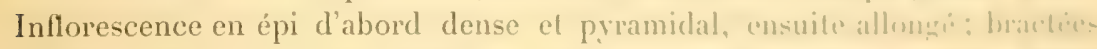
de l'épi oblongues-lancéolées, un peu plus courtes que l'uvalure; Hemr: blanches, petites, subsessiles, plus longues que l'ovinu. ldivisinns du

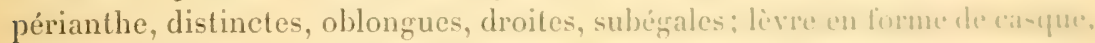
non adhérente au gynostème, sessile, aussi lnngue que les divi-inns du périanthe, obovée-oblongue, tubereuléc en dedans. - Iscoz almumant dam

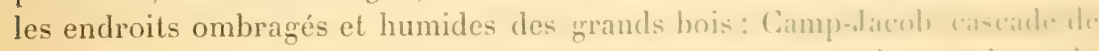
Vauchelet), hauteurs de la rivière Yoire, Bains-tannes. partic supririm du Gommier, bois intérieurs de la Pointe-Xoire, ele. Alt. \{011-sint\} mat. [No 3355.$]$

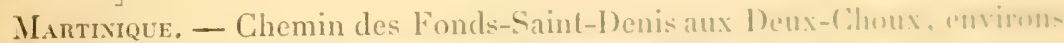
des Deux-Choux, bois des Pitons-du-Carl)el, ele. [X" :34.5.

Prescottia Lindl. (dédié à l'Anglais John Presenll, qui, itahli it SirintPétersbourg, voyagea en Sibérie dans un intérit hotanique.

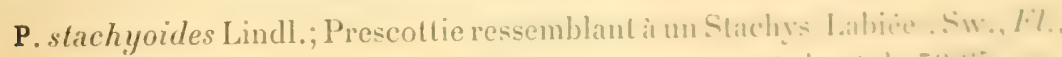
t. 29, f. 4, analyt. - Terrestre, très élégant par son port, hant de ill-kit ent..

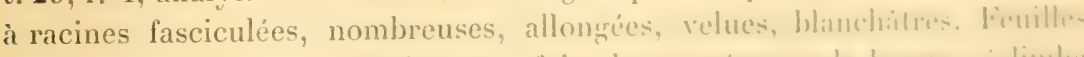
2-3, radicales, rosulées, environ une fois plus contes que la hampe, it limbe

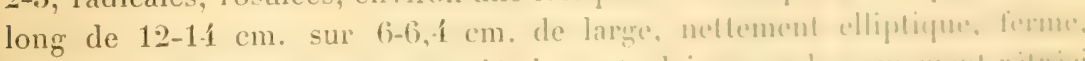

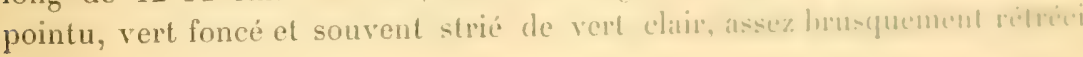


en un pétiole plus long que le limbe, étroit, plié en deux longitudinalement, élaryi it la base el embrassant. Hampe grèle, glabre; feuilles de la hampe, bractéiformes, non apprimécs, obovées-lancéolées, pointues, engainantes : celles du bas, presque aussi longues que les entre-nœuds; celles du haut, graduellement plus courtes et plus distantes. Inflorescence en épi effilé, grêle, long de 18-24 cm.; fleurs très petites, vertes : les inférieures, distantes; bractées de l'épi lancéolées, acuminées, aussi longues que l'ovaire. Divisions du périanthe, obtuses; les extérieures, oblongues-linéaires; lère postérieure aux divisions du périant he, charnue, en forme de cuiller profondément creusée, conique-obtuse, surmontant le sac obliquement adné aux divisions; gynostème extrèmement court, garni, à la base, de deux appendices auriculaires, linéaires. - Fl. de mars à mai. - Assez abondant dans les mornes secs et pierreux de IIouëlmont, des V'ieux-IIabitants, de Pigeon et de la Pointe-Noire. Alt. 300-600 mèt. [No 3391.]

Martinque. - Hauteurs boisées des Trois-Ilets et du Diamant. [ [No 372.$]$

P. myurus Griseb., P. Myosurus Reichb fils; Prescottie à inflorescence en queue de souris. Sw., Fl., t. 29, 1. 2, analyt. - Terrestre, très droit, haut de $18 \mathrm{~cm}$., à racines fasciculées, blanchàtres, très velues. Feuilles 2-1, ovées ou elliptiques, longues de $3-3,5 \mathrm{~cm}$., brièvement pétiolées, rosulées, très rapprochées du sol, environ quatre lois plus courtes que la hampe garnie de bractées lancénlées-acuminées, subulées. Fipi longr de 4 cm., efflé; bractées de l'épi, linéaires-acuminées, un peu plus courtes que l'ovaire. Fleurs rougeâtre blanc, très petites. Divisions extérieures latérales du périanthe, deltoüdes, dressées et renfermant la livre, qui est de forme hémisphérique-conique el obtuse : la division extérieure et antérieure et les deux divisions intérieures sont linéaires, obtuses et recourbécs; appendices auriculaires de la base de la lèvre, extrêmement courts. - Très rare : dans les bois inférieurs des Bains-Jaunes, le long du canal de Montéran. Alt. 600680 mèt. [No3849.] - Je ne l'ai pas trouvé à la Martinique.

Spiranthes Rich. (du gree "speira ", spirale, et "anthos ", Heur, parce que les fleurs de l'épi sont disposées en spirale.)

S. tortilis Rich.; Spiranthe tordu. Sw., Fl., t. 28, f. e, analyt. - Terrestre, haut de $40-55 \mathrm{~cm}$., droit, à racine tubériforme, profondément enterrée. Feuilles radicales, linéaires, disparaissant complètement ì l'époque de la floraison. Iampe gréle, garnie de bractées lancéolées-acuninées, faiblement apprimées, engainantes, graduellement plus petites. Inflorescence en épi effilé, long de $8-11 \mathrm{~cm}$.; fleurs légèrement pubescentes, blanc mat, courbes, unilatérales, disposées autour du rachis en 22-4 spirales; bractées de l'épi, concaves, plus longues que l'ovaire, largement ovées et terminées en une pointe rigide et subulée. Divisions du périanthe, oblongues-lancéolées: les deux extérieures, obliques à la base, anssi longues que la lèvre; la supé- 


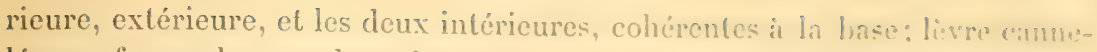
lée, en forme de capuchon, bossue à la base, carénée sur le dos, (mulumas-int la base du gynostème, orale et onduléc-crispée it l'extrémité. — Hl. wn mil:

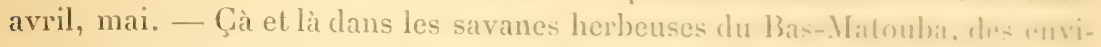
rons de la Ravine-Ghaude, et clans les savanes de Sainfe-linse. Mlı. Iun. 400 mèt. [N³393.]

Martinique. - Fonds-Sainl-1)enis, fontaine Didier, envimens du find Desaix (Fort-de-France). [No 379.]

Stenorhynchus Rich. (du gree "stemos ", courl, el "runchus ", her, parre que les divisions du périanthe, sondées inlérieurement, lonment un pulil sac en bec arrondi.)

S. orchioides Rich., S. aphyllus I.indl.; Sténorhynche en lome d'urchis. Sw., Fl., t. 28, f. a, b. - Terrestre, très droit, haut de f0-fi.) crm. it ratim. fasciculées, nombreuses, allongées, spongrieuses, velues. Fenilles longrues. largement lancéolées, pointues, insérées a la base de la hampe, di-parati--ant complètement à l'époque de la floraison, disposition qui imprime ì lat planter tout d'abord l'apparence d'une grande Orobanche. Iampe "ylindrique, cunverte, surtout dans le haut, d'une pubeseence courle, coulenr de rouille.

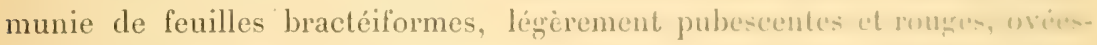
lancéolées, pointues, non apprimées el engainantes it la base. Infhrrescencer en épi long de 9-13 cm.; bractées de l’épi, brunes, lancéoléé-linciares, actuminées, aussi longues que l'ovaire; tleurs rouge brun, frarmics de trie pretiter écailles. Divisions du périanthe, lancéolées-linéaires, trís atcuminéc. sululées : les deux extérieures et latérales, soudées inlérieurement en un sa allongé ou éperon adné à la moitié de l'ovaire el libre ensuite sur unc pretite étendue; division extérieure médiane el les deux interiemes libres. lífirement obliques; lèvre sans callosités, oblongue, pointue; gynostimc muni d'un rostellum long et acuminé. - Fl. en mars, avril, mai. - Isic alun-

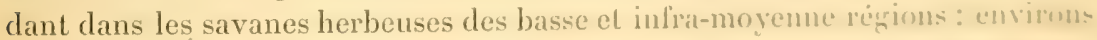
de la Basse-Terre, Montéran, Ducharmois, Gourbeyre (hahitation saintCharles), Trois-Rivières, Bas-_latouba, etc. Alt. 10-100 mìt. 1 Yo 33., (1).

Martinique. - Fonds-Saint-Denis, vallée du Carlect, hanteurs de l'hathitation-Pécoul, Trois-llets, etc. [No371.

Physurus Rich. (du gree "phusa ", ressie", el "nula ", quenc, parce" que" la lève est garnie inférieurement d'une petite quence anrondic an forme de vessie.)

P. plantagineus Lindl, Physure à feuilles de plantinin. S1., 1. I \{7. 1. :-:

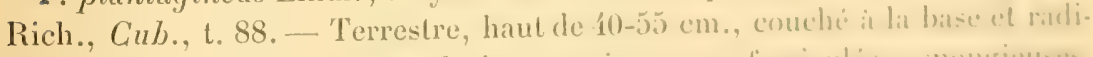

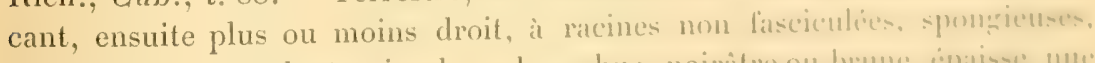

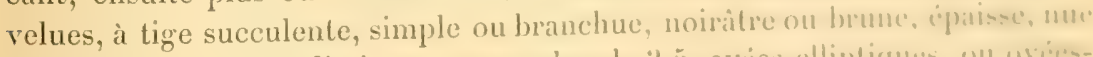
dans le bas. Feuilles distiques, au nombre de 3-5, oves-elliptiques, on we és- 
lancéolées, pointues, rétrécies à la base en un pétiole étroit qui ensuite s'élargit fortement pour devenir engainant; nervures 15-17, délicates. IIampe srêle, légèrement pubercente, warnie de bractées peu nombreuses, distantes, lancéolées, pointues : les inférieures, engainantes. Inflorescence en

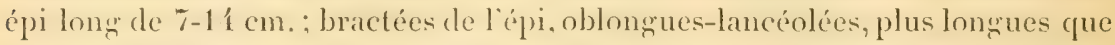
lovaire. Dirisions extérieures du périanthe, vertes et pubeseentes en dehors: les intérieures et la lèrre, blanches; les deux extérieures et latérales, oblongues-lancéolées et obtuses; les deux intérieures, adhérentes à la supérieure extérieure; lèvre située en avant, terminée au sommet par une feuille ovée-oblongue et à trois petits lobes, dont celui du milieu est exsert, acuminé et légèrement roulé en dedans; sac libre, en forme de massue, transparent à l'état frais, jaunâtre, descendant le long de l'ovaire et dépassant un peu en longueur la moitié de celui-ci, qui est brun foncé, poilu. - Fl. de décembre à mai. - Très abondant dans les endroits ombragés et très humides des bois des Bains-Jaunes, du Haut-Matouba, des bois devés des Vieux-Habitants et de la Pointe-Noire, de Pigeon, de Bouillante, etc. [No 3352.]

Martinque. - Abondant dans tous les bois humides supérieurs. Alt. 600900 mèt. [No673.]

P. hirtellus Lindl.; Physure hérissé de poils. - T'errestre, haut de 35$43 \mathrm{~cm}$, à tige couchée à la base et succulente, à racines fibreuses, sponwieuses, plus petites et moins allongées que daus le précédent. Feuilles disliques: les deux ou trois inférieures, ovées-elliptiques; les supérieures, lancéolées, toutes pointues, subcharnues, vert noir et comme veloutées à la face supérieure, quelquefois striées au milieu de vert clair; pétiole étroit, élargi a la batse et engainant. Iampe habituellement hérissée de poils courts et droits, ainsi que le rachis et l'ovaire, le plus souvent rouge, tantôt longue el alors très grêle, lantît courte: bractées de la hampe peu nombreuses, distantes ou rapprochées, lancénlées-acuminées, légèrement engainantes. Épi long de $5-9 \mathrm{~cm}$.; bractées de l'épi, blanchâtres, plus courtes que l'ovaire allongé et courbe. Fleurs vertes en dehors et d'un blanc très pur en dedans, un peu plus courtes et environ deux fois plus sveltes que dans le précédent. Divisions extérieures el latérales, lancéolées-linéaires, obtuses; lève exserte, dilatée à l'extrémité en une petite feuille ayant assez exactement la forme d'un fer à cheval, caractère qui distingue facilement cette espèce de la précédente. - Fl. de mars à juillet. - Abondant dans les endroits ombragés, très humides des grands bois des Bains-daunes le longe du canal de Montéram), du Gommier, du Nez-Cassé, de Bouillante, de Pigneon de de lintérieur de la Pointe-Noire. Alt.400-800 mèt. [Nos 3353, 3392.

Martinique, - Bois de la Grand'Anse, du Lorrain, du Camp de l'Alma el des Deux-Choux. [Nº 384.] 


\section{TIRIBU VI. OPIIRTIIES.}

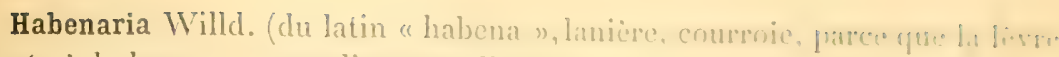
porte à la base um appendice très allongé,

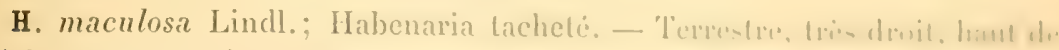

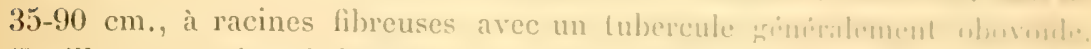

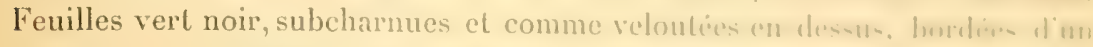

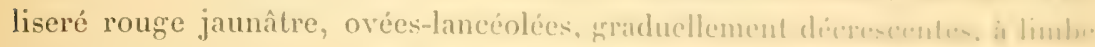
semi-amplexicaule à la base, passant à un pútinle engatinant rel fortument

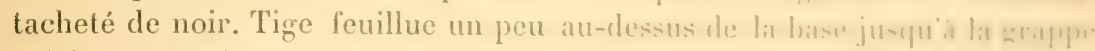

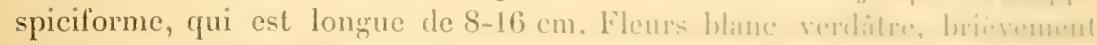

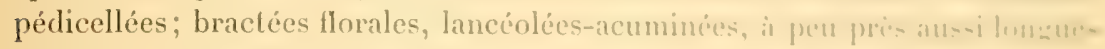

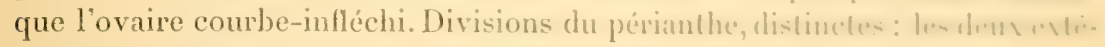

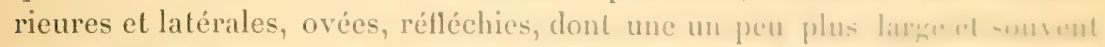

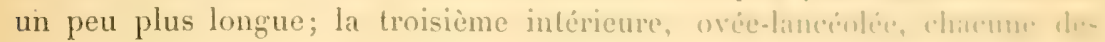
deux intérieures très profondément divisées en deux sezrments. dont l'umlarer. 'droit, obtus; l'autre sétiforme el subulé, tous les quatre de mime funzrurur.

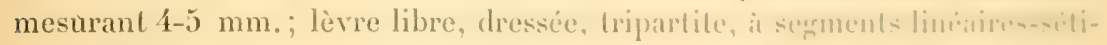
formes, égaux; stigmate garni de deux appendices en forme de lian ; apprn-

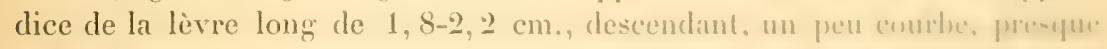
toujours fortement redressé, élargi vers l'extrémiti puintur, haluilmellement

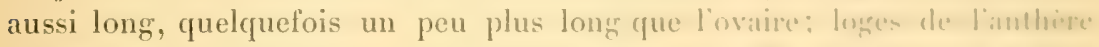
divergentes; glandes des masses polliniques nues. - Fl. de movember a mar ou avril. - Cà et là dans les savanes herdecuses, arrilo-ferrurimeu-ce du Lamentin, de Baie-Mahault, des hautenrs des Vieux-Mahitants. .11. :H. 500 mèt. [No 3586 .

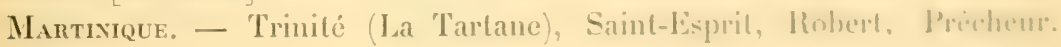
$[\mathrm{N} \circ 2067$.

H. alata Hook.; Habenaria à ovaire ailé. - Terrestre, hatul de fll-4:3 con.. à port, racines et tubercule comme dans le précédent. Fenillés mustifires. lancéolées, engainantes : les supérieures, graduellement plus putites at pluacuminées. Tige rougeâtre, sans taches. Inllorescence en ipi sialle, lung de 12-15 cm.; bractées florales oblongues, lancéolées, roupreitres. diplataint l'ovaire; fleurs vert brun foncé. Divisions extérienres, orits : lesthens late-

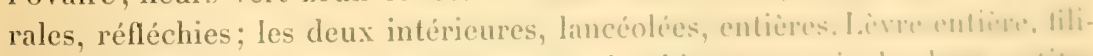
forme, aussi longue que les divisions périanthiques, frarnic de deus furtite-

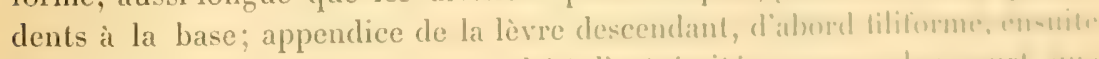
en forme de massue, obtus, recourbé à l'extrémite, un peu phlus comrt que lovaire 6-ailé; appendices du stigmate obluners, ololus. - lil. d'imil at

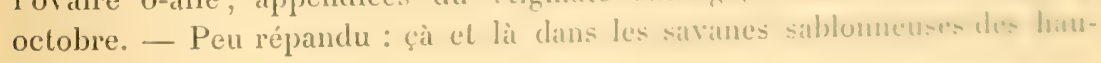


Lemrs du Tieux-Fort, de Deshaies. Alt. 200-380 mèt. X's 2537, 35.51.? - Je ne l'ai pas trouré à la Martinique.

\section{GIMNOSPERMES.}

\section{CENT QUARANTE-CINQUIÈme FAMILLE. - CONIFËRES.}

Podocarpus Lillér. du gree "pous", pied, et "karpos", fruit, allusion au support charnu qui porte le fruit.)

P. salicifolius Kl. et Karst.; Podocarpe a feuilles de saule. Vulgo : Laurier rose. - Arbre haut de 10-14 mèt, rarement plus haut, peu élégant, souvent tortueux, à écorce noirâtre, fendillée, à tronc et branches nus, à branches divariquées. Feuilles coriaces, luisantes, très vertes, oblongues-linéaires ou lancéolées, loneruement acuminées. Fleurs dioüques : les mâles en chatons blanc pâle, d'abord droits, ensuite plus ou moins penchés, longrs de 3-4 cm., cylindriques, solitaires ou géminés; les femelles, solitaires, confinées aux extrémités des branches. Fruit drupacé; drupe de la grosseur d'une petite cerise, rouge écarlate, insérée sur un disque bilobé au sommet et latéralement comprimé, plus court que le pédoncule. - L'ensemble du fruit rappelle bien la forme d'un pied dhomme dont le talon est représenté par la drupe el le reste par le disque allongé. - Le bois, à nuances de jaune rouge veiné, est très apprécié pour la construction, mais surtout pour l'ébénisterie, la menuiserie. - Fl. de décembre à février ; fruits mûrs en avril, mai, juin. Assez abondant dans tous les grands bois supérieurs du massil de la Soufriere. Alt. 600-950 mèt. [No 2397.]

Martinique. Vulgo : Laurier-rose-montagne. - Assez abondant sur les crêtes très aérées des Pitons-du-Carbet. [No 2097.]

Le P. Purdieanus Hook., grand arbre, droit, ressemblant à un peuplier d'Italie, originaire de la Jamaïque, est cultivé au Jardin botanique de SaintPierre. [No 2096.]

De la famille des Conifères, on rencontre dans les deux colonies : l'Araucaria excelsa R. Br., le Cupressus (Cryptomeria) japonica I.., le Cupressus sempervirens L., le Thuya sinensis Tournef., le Gryptomeria eleyans Veitch, le Taxodium distichum Rich., etc. 


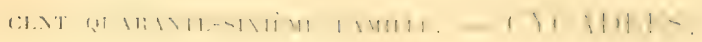

1.es Cycas revoluta Thunb, vulgo: Petite pahnue, al Cycas virrinalis 1...

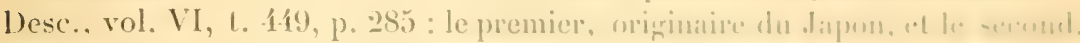

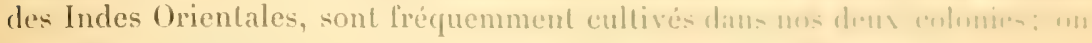
se sert des leuilles pour les cérémonies du dimanche de- Rameanu.

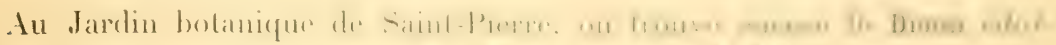

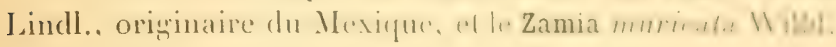





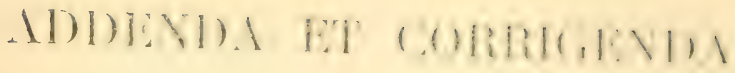

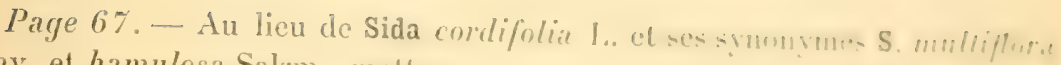
Cav. et hamulosa Salzm, melle\%:

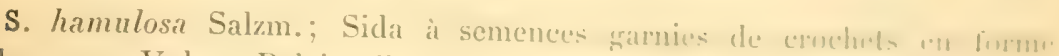

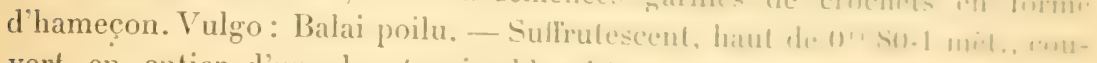
vert en entier d'un duvel gris blanchâtre, étrile, soserux .

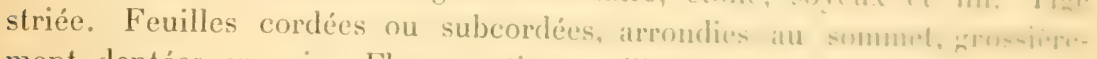
ment dentées en scie. Fleurs petites, axillaires el leminalı, mama-..... en glomérules; corolle jaune, plus longue que le calice; lube du (ailice it In

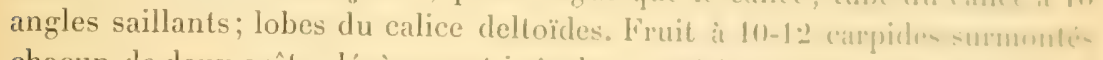
chacun de deux arêtes légèrement inégales, aussi longues que le carpide- - l garnies du sommet à la base de nombreux crochels tourucis de haut on hia-. caractère qui le distingue facilement de tous ses contrinceres. - Vit mlitarm. ou le plus souvent en société sur les coteaux secs, arides ct mravelens : rnvirons de la Basse-Terre, Baillif, Vicux-Habitants, Bouillante, l'igenn. Ihi-irade, Marie-Galante, les Saintes, etc. [X".2335]. - Marlinique. X \$7। it et $b$.

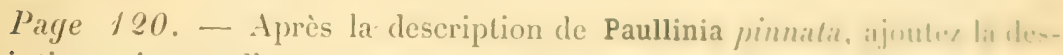
cription suivante d'une espèce omise :

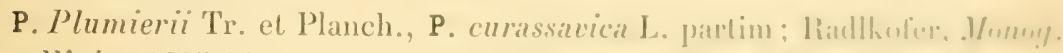
Paullinix, 1895-96, p.309; 'Triana et Planchon, P'roul. Flur. . lorm-limanal. Ann. des Sc. nal., 1862. Vulgo : Liane-persil. - Arbriscenu grimprant, mammus jeunes, presque ronds, recouverts d'une poussière jaume sale, di-critr, phu-

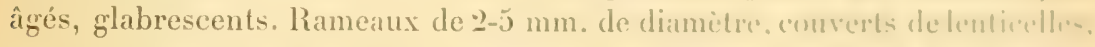

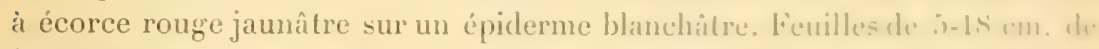

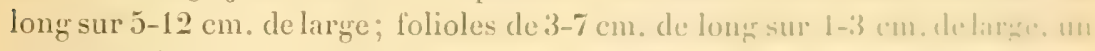
peu recourbées sur les bords, brillantes ou presque obscomes ; pilinlectmmmm rond, pubérule, $1-1 \mathrm{~cm}$. de long; rachis le plus souvent un pen plu- conth.

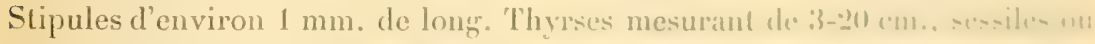

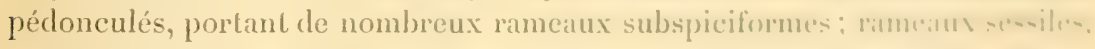

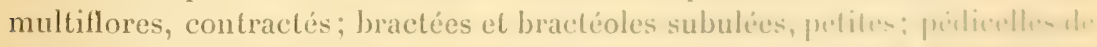

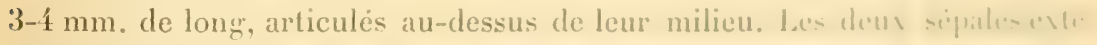

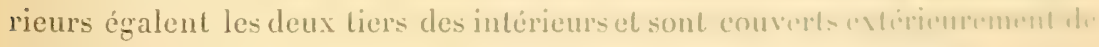
poils jaune sale; les intérieurs sont lanpenent ovales : its mesment inum 
3 mm. de longr el sont submembraneux. Pélales oblongs, fres lendres; écaille éralant les deux liers des pétales, un peu villeux sur les bords: les supérieures. pourvues d'une courte crête suborbiculaire el d'un appendice déjelé el barbu. Glandes du torus suborbiculaires, pubérules, comme le torus luimême. Filets staminaux aplatis, pileux; anthères glabres; ovaire recouvert d'un duvet court. Capsule triailée, de $1,8 \mathrm{~cm}$. de longr sur 1,7 cm. de larges sèche, jaune rougeâtre. Graine elliptique de presque $1 \mathrm{~cm}$. de long sur environ $6 \mathrm{~mm}$. de large, noirâtre.- Fl. en novembre, décembre et janvier.

Guabloup. - Rare. - Grands fonds du Morne-äl'Eau, Capesterre (Guadeloupe), route de Saint-Sauveur à l'habitation Montlong. Alt. 100-10, mèt. No $^{2} 90(0)$. $]$

Mantrique. Vulgo : Liane-persil. - Quartier du Prêcheur, vallée du Carbet, Case-Navire, etc. [No $1-181$.

Parge $16 \%$ - Ajoutez à la famille des Polygonées :

J:Antigonon leplopus. ILok. Vulgo : Belle Mexicaine. - Superbe liane i racines filipendulées, à fleurs tantôt rose tendre, lantôt rose foncé, tantôt blanches, en wrappes pendantes, nombreuses, qui se succedent toute lanné - Originaire du Mexique, naturalisé et cultivé dans tous les jardins. [No 2182.] - Martinique. Vulgo: Liane du Mexique. [No 2093.]

\section{Page 248. - Après Acacia tamarindifolia Willd., mettez:}

A. mudifrora IVilld., Mimosa nudifloral.., M. muricala Willd.: Acacia a lleurs nues. Vulgo : 'Tendre à caillou. Pl. édil. Burm., t. 11. - Grand arbre ¿ tronc d'un diamètre de $50-65 \mathrm{~cm}$, à écorce brun clair ou grisâtre dans les vieux pieds, crevassée peu adhérente. Branches longues, divariquées. Pétioles et jeunes rameaux glabres ou souvent légèrement pubescents; pameaux plus àges tantit grlabres, fantit finement muriqués, tantot garnis de lenticelles ef d'aspérites blanches. Feuilles deux lois composées, a t-fi pares de pemnes, portant 10-16 paires de folinles oblongues, noirâtres el luisantes en dessus, rougeâtres en dessous, inégrales à la base, arrondies au sommet; pétiole principal zarni, entre chaque penne ou seulement entre la premiere el la dernière, d'une glande large, scutelliforme, elliptique ou arrondie. Fleurs petites, blanches, en épis terminaux et axillaires, effilés, longs de y$15 \mathrm{~cm}$. Gousses brièvement stipitées, souvent courbes, oblongues-linéaires, fissurées, coriaces et noiratres, de longueur tris variable : les plus longues ne dépassant pas 11 cm., sur près de $22 \mathrm{~cm}$. de large. Semences jusqu’à 12 , roudâtres, amincies sur les bords et teintées d'un liseré vert jaunâtre.

Le T'endre à caillon fournit un bois des plus précieux. L'aubier est jaunâtre et dure peu de temps; le cour, au contraire, d'une teinte rougeâtre à l'élat frais, tournant ensuite au gris noirutre, est dur, lourd, incorruptible dans l'eau et dans la terre; ses fibres, très longues et très pressées, ne laissent 
pas, malgré leur compacilé, d'ètre élástigues. I causc de sir dureli. un linnploie rarement pour les constructions, mais on le priblite it lout antre frum

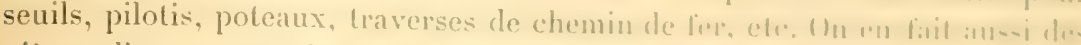

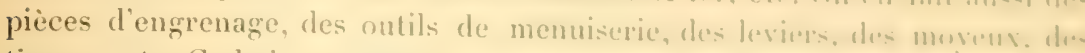
timons, ete. Ce bois se vend couramment dans les matsasin de lmin de la

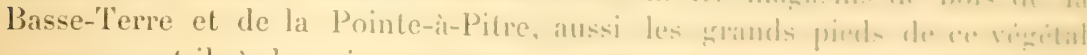

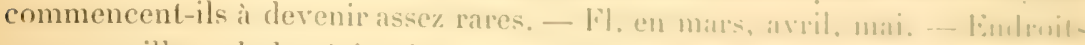

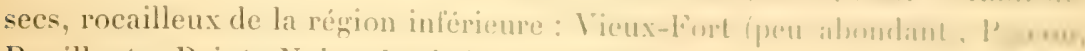
Bouillante, Pointe-Inire, I)eshaies. [X" :301:3.

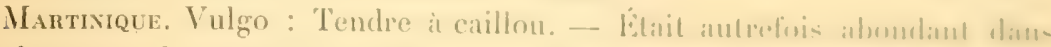
les hauteurs du Lamentin, du I)neos, dn L)iananl, du Marin, d. Ia Thinili.

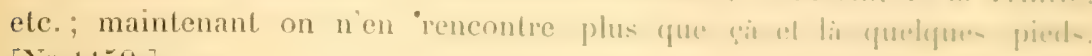
$\left[\Upsilon^{*} 11.5 \%.\right]$

Page 290. - Au lieu de Ammannia humilis Mich., mellus:

Rotala L. (du latin "rota ", roue, paree que les lenilles verficillin- finment comme une roue autour de la tige.

R. ramosior lioehne.

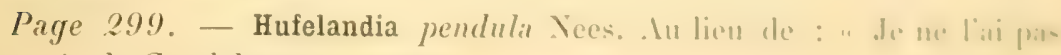
trouvé à la Guadeloupe ", meltez:

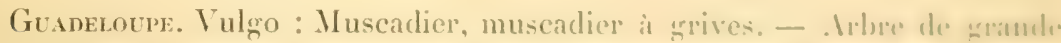
taille (à la Guadeloupe), à trone nu sur une Instrueur de 1:3-17 mil. — - sum bois, rouge en dedans, craint l'eau ef l'humidile, mais il col rechrodni fum

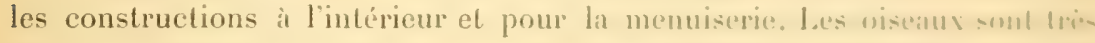
friands de ses graines noires et pulpeuses. - 1il. habitudlement an metulne et novembre; graines mûres en avril el mai - Lsse\% alumdant dam- tre

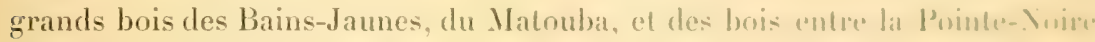
et la Ravine-Chaude. [X"1:3\%.

Page 327. - A l'article Loranthus americanus dacer.. iljulter:

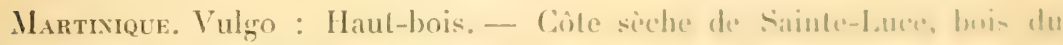
Champllore el de la fontaine Ibsalon. [X" 1:376.

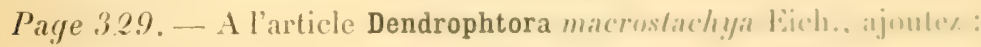

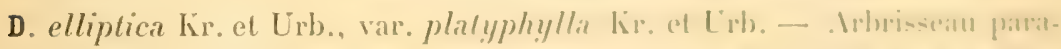

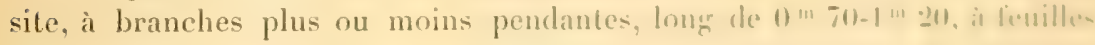
subcharnues, petites, elliptiques-obovales, sonvent échancries an smmmel.

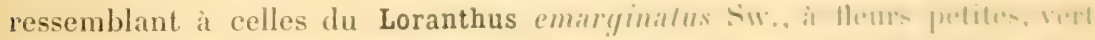

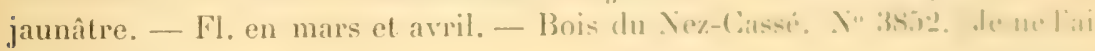
- pas vu à la Martinique.

Page 388. - A la suite de Bumelia Sw... ajoute\%:

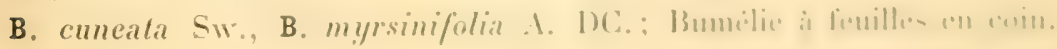


Vulgo : Bois de bouis, petit bouis. - Arbrisseau ou grand arbuste extrêmement toutfu et feuillu, haut de 1 m 50-3 mèt., ressemblant beaucoup, quant au port el au feuillage, au Myrsine fioribunda R. Br. Jeunes rameaux garnis d'un duvet très léger. Feuilles petites, obovées, arrondies ou réluses au sommet, rétrécies à la base en un pétiole très court. Inflorescence axillaire, en fascicules de 5-8 rayons courts. Fleurs blanches, petites. Fruit très petit, long de 4-6 mm., cylindrique-obovoïde, pulpeux, rempli d'un sue laiteux, visqueux, surmonté du style persistant. - Fl. en août, septembre et octobre. - Peu abondant : cote et plateau calcaires de la Désirade; çà et là sur les mornes calcaires du Petit-Canal, et des mornes entre Port-Louis et l'Anse-Bertrand. [No 2910.]

Martinique. Vulgo: Bois buis, bois de fer. - Endroits pierreux de la Caravelle fenvirons du Phare), mornes calcaires de Sininte- Inne (abondant). $[\mathrm{N} \cdot 260$.

Page 391. - A la suite du Diospyros Ehenaster Retz., meltez:

D. Philippensis Gürke, D. discolor Willd. Vulgo: Mabolo. - Arbre superbe, très droit, à fruits ronds, fortement veloutés, du volume d'une urrosse sapotille. - Origrinaire des îles Philippines, cultivé fà el là dans les pares et autour des maisons : Sainte-Rose, Petit-Bourg (habitation Bel), etc. - Fl, en avril et mai. [No 2574.]

Martinque. Vulgo: Mabolo. - Au Jardin bolanique el sur plusieurs habitations. [No 1922.

Le D. Kaki Roxb, originaire de la Chine, est cultivé sur l'habitation d'Id. Cabre, au Matouba, où il rapporte régulierement Ious les ans. (Ápécimen manque.) 


\section{TABLE IOES MUTHAES}

A

Ahica................... itik

Abelmoschus esculentus Willd... Tis - moschatus Mich.... 7. Abilgaardia monostachya Vahl... ith Abricot bâtard................. Ill:;

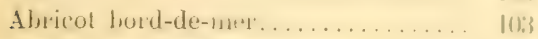
Aluicotio bitard............ |1, I10 Aluricotier-montagne............ $110 ;$ Abricotier du pays................ 1(t)2 Abroma rengustu L. fils........... \&

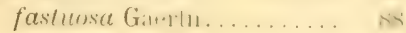

Abrus piecutorius I............. 2iri

Absinthe anglaise...............

Absinthe bord-de-mer. . . . . . . . . . . . i... Absinthe de la Dominique.......... . . .

Abutilon auritum TVall ............ (?) - crispmm fi. Don........ in

- hirtum li. Hon.......... it

- indicume fr. Jon......... ti

- mollissimum li. Itun..... tix

- striulmm Dicks......... the

Aciria amete-lupif". . . . . . . . . . .

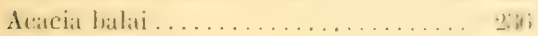

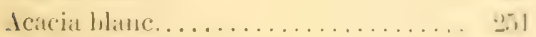

Acacia lroml-de-1nter. . . . . . . . . . .

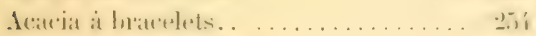

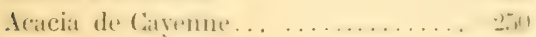

Acacia i cornes ...................

Acacia comes-de-bocuf .............

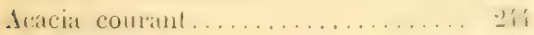

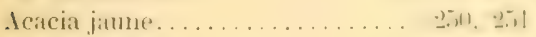

Araciat odorant. . . . . . . . . . . . . . . .

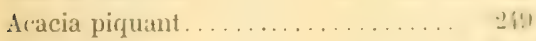

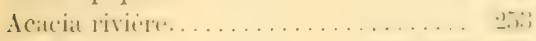

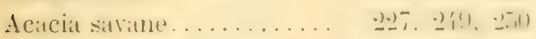

Acacia arabica Willd............ . . . . . .

- comigera Willd............

- Farnesiana Willd......... Itid
Acacia shenere Willst.

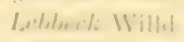

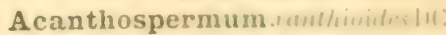

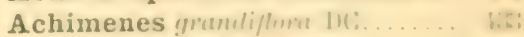
- longriflura $11: \ldots \ldots \ldots$ b.

Achras Siepolu 1.............. in

Achyranthes mponten Litu..... it

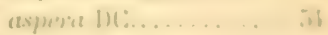

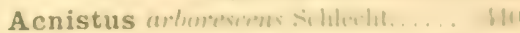

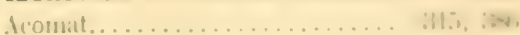

Aromat batam . . . . . . . . . . . . . a

Ientnat hostcall. ............

Aromat coletelte... . . . . . . . . . ise

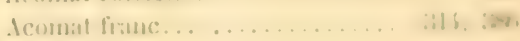


Acomit du pilys.................. 391

Acontias helleborifolius Schott.... 180

Acrocomia selerocarpe Nart...... 489

Acrodiclidium salicifolium Grisel,. 299 sericeum Griseb.... 299

Actinostemon concolor Müll. Arg . 40

Adansonia digitata L.......... 89

Adenanthera pavonina L....... 242

Adenocalymna alliace $\alpha$ Miers.... 422

Aechmea dichlamydea Baker... . . 570

$$
\begin{aligned}
& \text { fulgens brongu. } \\
& \text { serrata Mez... }
\end{aligned}
$$

Aegiphila glabra Lam

$$
\text { Hanabea Sw. }
$$

martinicensis 1

Aeschynomene americana $\mathrm{L}$

$$
\text { - sensitiva Sw }
$$

Agati grandiflora Ad

Agave americana L

- feotida L....

Ageratum coerulaeum Sieb. conyzoides $\mathrm{L}$. . .

Agoman ou Agouman....

Arinostmili:

Agrostis virginica L

Aile ì mouches. .

dile it rarets.

Aile ravet bord-de-mer.

........ 114

Aiphanes corallina Wendl....... 490

Akitia blance

Akeesia africana Tuss...........

Aletra brasiliensis Benth.

Aletris fragraus 1 .

Aleurites triloba Forst.

Alibertia edulis Rich.

ALISILACEES .

Allamanda cathaslice L.

$$
\text { - Silmitii l'ohl. }
$$

Allium ascalonicum $\mathrm{L}$...

$$
\text { - cepu I........ }
$$

Alocasia marem/isa sichott.

Aloe vulgaris Lam..............

- barbadensis Mill.

Alpinia muluks L

Alstonia scholaris R. Br..

Alternanthera achyrantha $\mathrm{R} . \mathrm{Br}^{2}$. par onychioides St.

Hil............

Alysicarpus vaginalis I)C.

122

i)'t

56 '

330

行

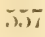

7.37

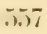

.727

$\overline{i 17}$
Amande glaciale................ 374

Amandier...................... 294

Amanoa caribæa Kr. et Urb...... 21

AMARANTACEES ............ 52

Amarante bord-de-mer........... 56

Amarantine ................... 53

Amarantus caudatus L........ 58 spinosuts L.......... 58 tristis L............. 58

AMARYLLIDEES... .......... 557

Amaryllis Atamasco L.......... 562

- cavinata Spreng....... 563

- tubispatha Herb... . . 561

- vittata L'Hérit......... 562

Amblogyne polygonoides Raf..... 58

Ambrosia artentisifolia L........ 365

A IIENTACEES. . . . . . . . . . . . . 190

Ammannia humilis Mlich......... $2(x)$

- latifolia L........... 290

- ovientalis DC........ 290

- ramosior L.......... 90

Amomis cavyophyllata lir. et Urb.. 262

- fragrans Willd.......... 274

Amourette... 245, 246, 249, 254, 427, 169

Imourette grand-bois............ 24

Amourette-rivière............... 2ui

AMPELIDEES. . . . . . . . . . . . . . . . פ

Amphilophium paniculatum H. B.

Kith................. 422

Amyris elemifera Willd.......... 183

30

393

393

隹是

$5 \mathrm{jti}$

$551 \mathrm{i}$

5xi":

30.5

57

57

199 marilima Jacq .......... 18 1

Anacardium occidentale $\mathrm{I} \ldots \ldots \ldots . \quad 189$

Ananas............................ 50 50

Ananas anglais.................. 569

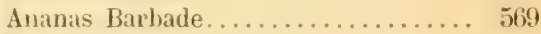

Ananats Barot.................. 509

Ananas-bois................... 576

Ananas-bouteille.................. 569

Ananas Cayenne... . . . . . . . . . . . . 569

Ananas grand-bois .......... $5 \pi 1$, 575

Ananas jaune ordinaire........... 569

Ananas pain-de-sucre... . . . . . . . . . . 569

Ananas-porcelaine ....... ......... 569

Inanas pot-ai-eau............... 569

Ananas rouge bitard............. 572

Ananas rouge montagne.......... 5. 5\%

Ananas saurage... 570, 571, 572, 573, 574

Ananas sauvage inontagne...... 576,577

Ananas vert. . . . . . . . . . . . . . . . . . 569

Ananassa sativa Lindl. . . . . . . . . . 56!)

Anatherum bicome P. Beaur..... 530

- domingense Roem. et Schult. 5:30 
Anatherum muricatum P. Beauv. . 52!

Andira inermis H. B. Kith ......... 2.

Andropogon bicornis L. .........

\begin{tabular}{|c|}
\hline citralus DC.. \\
\hline condensatus lith..... \\
\hline imberbis lith... \\
\hline leucophaeus $\mathrm{I} . . . . .$. \\
\hline lencostachyus H.B.Kth. \\
\hline muricatus Retz. .. \\
\hline Nardus L........ . \\
\hline saccharoides Sw... \\
\hline secundus Willd. \\
\hline Sorghum Brot. . \\
\hline squarrosus L. fil \\
\hline
\end{tabular}

Angelin. squariosus L. fils.

Angelin battard.

Augelin palmiste.

Angelonia angustifolia II. B. Kith .. Anguria Plumieriana Schlect..... Aniba bracteata Mez........... 30

- Ramageana Mez........... 30't

Anis étoilé......................

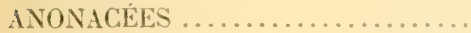

Anona muscos $\alpha$ Jacq.............

- muricata L...............

- palustris $\mathrm{L}$.

- reticulata $\mathrm{L}$

- squamosa $\mathrm{L}$

Anthacanthus spinosus Vees .

Anthephora elegans Schreb...... 527

Anthistiria ciliaris L.............. 531

Antirrhaea cristata Benth.... ....

Anthraxon ciliaris L............ 531

Anthurium dominicense Scholt....

- gracile Schott........ 470

- Guildingii Scholl..... . 46

- Huegelii Schott....... 47 t

- lanceolatum kth..... 47t

- grandifolium lith .... 47is

- palmatum Kith....... tifi

- scandens Engl........ $57 \%$

- violaceum Scholt...... 473

Antigonum leplopus Hook. - add. 1il?

Aphelandra pectinaita Willd..... 130

Apium Ammi Urb ..............

APOCYNÉES.................. 393

Apteria hymenanthera Miq....... 527

- lilacina Miers...........

- setacea Nutt............ 587

Arachis hypogxa L............ 203

Aralia capitata Jacq............. 321

- filicifolia Hort.............. 39?
ARALTACERE, . . . . . . . . . .

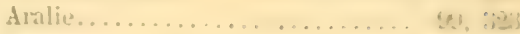

Aralie cerise............. . . 1:

Aralie montagre ................

Iratie pretite cerise.............. lis

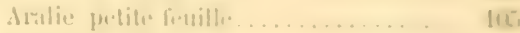

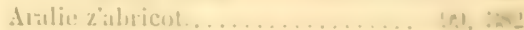

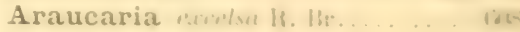

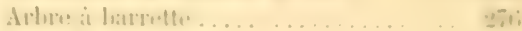

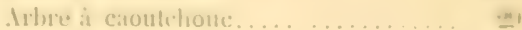

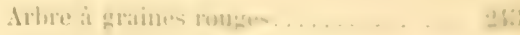

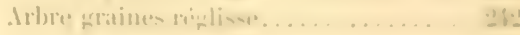

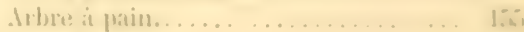

Arlue a rolisse...............

Arbre at rubans.................

Arbre it raisiss. ................

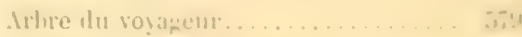

Ardisia cremulatu lient.......... si:

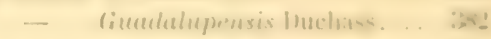

- lemerifulin . I. 116.........

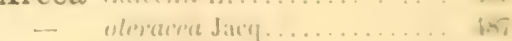

- regin hith .............. hist

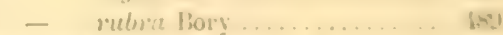

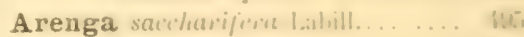

- Wightii (iredr........... Wh

ARETHUSEES ............ (A)

Argemone mexicunat $1 . \ldots \ldots \ldots \ldots$.

Argyreia bracteata citoi-.........

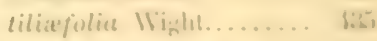

Argyrothamnia lanceifoliu Mull. Ar........... is

Aristida americuna 1 .......... int:

- stricte Mich............. in

Aristolochia anguicida Jitiy....... 314:

- ionstriclut liriseh..... 3lti

- galeata Mart. en \%oce. 311

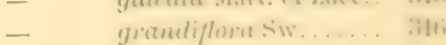

- obusabs siw..........

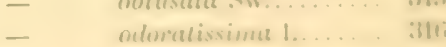

- briluluata l............

IRISTOLOCHILE. . . . . . . . . .

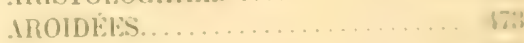

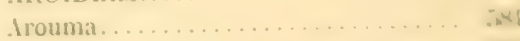

Arrachichat................ . . .

Arrachacha esoulemu $\|$........

Irtidit..................... it

Artabotrys menculiswmu li. lir...

Artanthe incurmu .

- martinimes Mị .... 17

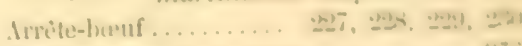

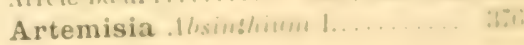


Artemisia vulgaris L........... 376

Artocarpus incisa L........... 155 integrifolia L ....... 157

Lacucha Roxb....... 15x

Arthrostemma glomeratum Nand. 288

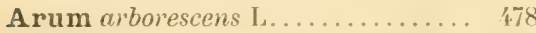

Arundinella martinicensis Trin... $\quad 527$

Arundo Donax $[$. ............... 500

- occidentalis Sieb.......... כ

ASCLÉPIADEEES................ 398

Asclepias curassavica L ......... 398

Aspidistra elatior $\mathrm{Bl}$............ 557

ASPHODÉLEES . . . . . . . . . . 5ૅ0

Aster simensis L................. 360

Astrapæa Wallichii Lindl........ 88

B

Baccharis dioica Vahl.......... 361

Baconia.

nervosa DC.

speciosa DC.

Bactris socialis Mart.

Bailleria aspera Aubl.

Balai. .

Balai cinq-heures.

Balai denx-heures:

Balai dix-heures.

Balai doux.

Balai wrand

Ballia inidi.

Balai onze-heures.......... 63, 64, 65

Balai savane 63,6 ' $, 65,233,236,401,403$

Balai savane bâtard .............. 401

BALANOPHORÉES ............... 325

Balsaminum hortense Desp....... 133

BALSAMINEES................. 133

Balata rouge................. 387

Balisier a chapelets .............. 586

Balisier jaune........... 579, 580, 587

Balisier rouge............. 579, 586

Bambon........................ 499

Bambou indien ................ 500

Bambusa arundinacea Ait....... 499

- Thouarsii Kth ......... 499

- vulgaris Schrad......... 499

BAMBLSFE. . . . . . . . . . . . 1999

Banane .................... 578

Banane d'Aris ................. 578

Banane blanche................ 578

Binane de Chine ............... 58

Banane colossale................ 57
Atropa arborescens L........... ill

Attalea Maripa Mart ........... 59

Atlrape-sot....................

Anberwine...................

AURANTIACEEES ............... 1.31

Averrhoa Bilimbi $1 . . . \ldots \ldots \ldots \ldots$. 13,5

Avicennia nitida Jacq.......... 彷

Avocat......................

Avocatier................ 298, $2 ! ! !$

Avoine batard . .......... 505, 506, 52.

Avoine is (hikn . . . . . . . . . . . . . . 50,

Aroine savane .................

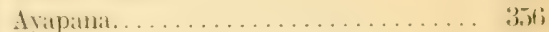

Aydendron bracteatum Nees...... 301

Bamane-ronte.................. is

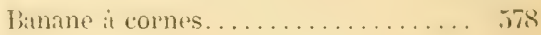

Banane franche................. ז

Banane jaune....................

Banane naine................

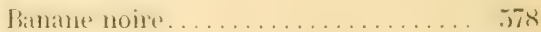

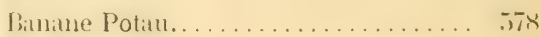

Bimatne-puce................. Iis

Banane à quatorze pattes ..........

Banane sans nombril........... 5is

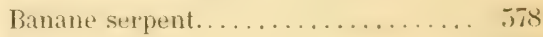

Banane sucrée.............. sis

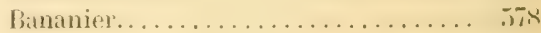

Bananier rose................

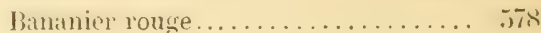

Baoba ....................... s.2.

Baraguette................. 2:30

Barbacocar....................

Barbadine.................. $31: 3$

Parbe a larbre .................

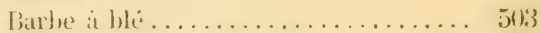

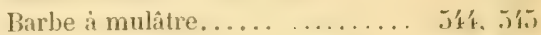

Barbe à nègre .............. 淮. Jí

Barbe zarbre.................. 万í

Barleria conulaea Roxb.......... 4.

cristata $\mathrm{I} . . . \ldots \ldots \ldots \ldots$.......

Barringtonia speciosa L. fils..... 276

Basanacantha armata Hook. fils. 331

Basilic ........................ 仿任

Bastardia viscosa Kth........... (i)

Bitard de fongive............... 2.2

Batatas edulis Chois........... 19.3

Batis maritima L.............. 52

Bauhinia Krugii hir. et Urb....... ? ? ? 
Bauhinia Outimoutou Aub\}....... 2 - tomentosa L.......... 2io

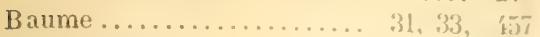

Baume batard................. :31

Baume blanc........... 32, fik sti.

Baune safran ................ iti.

Baume savane................ i

Baume z'anglais camphré......... 位

Beaumontia grandiflora WVall.... : $3 ! 17$

Begonia dominicalis $1, D \mathrm{C}$....... 32

- humilis Dryand.........

- marlinicensis A. 1)C..... \$2l

BÉGONIACEEES

$\because: 20$

Belameanda chinensis Red ...... il is

Bilingere bilant............... iti

Bélangère petite ............... 隹

Bélangère piquante ............. 11'

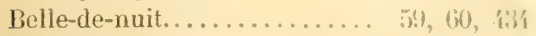

Bellucia grossularioides l'riana.... 20.

Beloperone violacea Planch.......

Bénéfice..................... f7

Bernardia corensis $\mathrm{Kl} \ldots . . . \ldots \ldots$. 35

Besleria lutea I. ............. \{i

- puchella Plum.......... $\$ 31$

Bétel...................... 179, 181

Beurreria succulenta Jacr......... 住!

Bidens bipinnatus L............ 3it!

- coreopsidis DG............ 3tis

- leuconthes WVilld.......... 31 i8

Bignonia xquinoctialis L ........

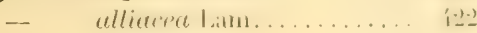

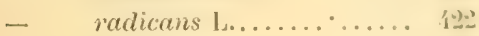

- stans L.............. 促)

- spectabilis L........... \{1

— unguis-cati I.......... \$2!

BIGNONIACEES ................ \{.

Bilimbi ..................... 314

Bixa Orellana L ............... 14

BIXINELA.................. Ii

Blakea pulverulenta Vihl........ ㄴ.. 87

Blechum Brownei Juss ........... th

Bletia verecunda $\mathrm{R} . \mathrm{Br} \ldots \ldots \ldots \ldots .5 .15$

Blighia sapida Roem ............ I t.

Bocconia frutescens L........... !)

Boehmeria raniflore Jacr......... $1(i ;\}$

Boerhaavia erecta $\mathrm{I}$............. (i)

- hirsuta Milld...... (io

- paniculata Rich.....

Bois à agouti .................. iti

Bois de l'ail ................... 2lis

Bois z'amande................ 15il

Bois ame' bois de l'Anglais.

livis : misutle:

Bois anoli .

djuis ancounuis.

luois dlitrine'ul

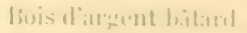

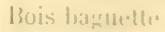

Bois Joalatia.

livis lablate.

liois trambli:

livis lilim.

Muis liour:

bois de lounis.

Buis latacenel

livis laramdia.

Boc: call: .

Buis catcil. .

Bois cateit-ral

Buis anchimant.

Bois $1: a 160$.

Bois eafi

Bois ealii lobis. ................. I1"

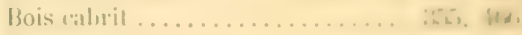

Bois cabrit hitallal . . . . . . . . . . . . . \$ \$:!

Bois cilnit noir . . . . . . . . . . . . .

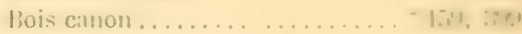

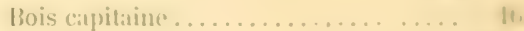

liois camal. . . . . . . . . . . . . . in

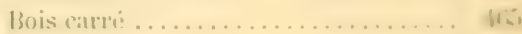

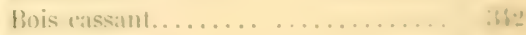

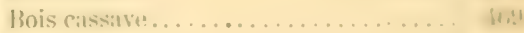

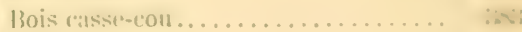

Bois cassir-rose . . . . . . . . . . . M

Bois cemline. . . . . . . . . . . . . . .

Bois champignon ............... . . .

Bois chandelle.............. |in., |s|

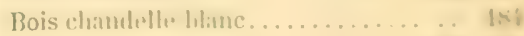

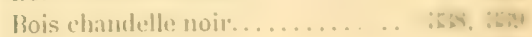

Bois chittignitr . . . . . . . . . . . $1: 01$

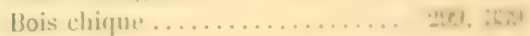

Bois ritron ............... 16, If!

Bois citronnier............... 1i, 18!

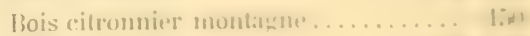

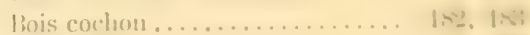

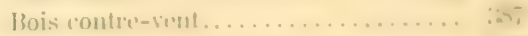

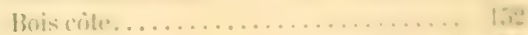

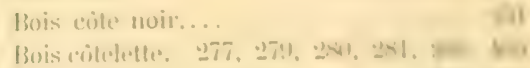

Bnis criblette muntarme the

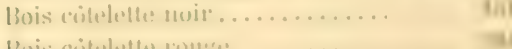

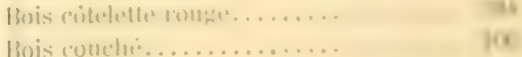


Bois couilles .................. 106

Bois couis.. ................ 385

Bois conleuvre..... . . . . . . . . 476

Bois crécré rouge .............. 234

Bois Chypre ............... 298, 44'

Bois de basse blanc.............. 260

Bois de basse rouge .............. 267

Bois diable. . . . . . . . . . . . . . . . .

Bois doux...............

Bois doux blanc .............. . 303

Bois doux couronne. . . . . . . . . . . . 302

Bois doux d'encens ......... . ..... 182

Bois doux Deshonnes ... . . ...... 303

Bois doux grand-feuille....... 166, 304

Bois doux Isahelle .............. 302

Bois doux jaune ................. 302

Bois doux pimenté. . ............ 302

Bois droit.................. 39

Bois de l'eau.................. 181

Bois d'éhène ... . . . . . . . . . . . . . 420

Bois d'encens.... . . . . . . . . . . . 182

Bois enivrant.......... 290, 262, 263

Bois a enivrer ................ 22

Bois d'épice............. . 96, 288

Bois etti .................... 20

Bois de fer. . ............ 23, 50, 466

Bois de fer bâtard................ 229

Bois de fer blanc.... $365,337,338,465$

Bois de fer franc............ 92,93

Bois de fer rouge ............... 340

Bois tlambeau .............. 138, 139

Bois flambeau montagne .......... 339

Bois flambeau noir .............. 139

Bois tlèche.................. 341

Bois flot........... 3, 78, 81, 82, 446

Bois flots des hats. . . . . . . . . . . . 336;

Bois flot montagne.............. 333

Bois foufou............. 332, 345

Bois fourmi . . . . . . . . . . . . . . . . . 299

Bois fragile.................. 180

Bois de frédoche ................ 161

Bois fricassé.................... 40

Bois fustet .................... 263

Bois gamelle. . . . . . . . . . . . . . . . 223

Bois genou .............. 425, 464

Bois gli-gli. . . . . . . . . . . . . . 296

Bois glu .................. 385

Bois gommier ................. 182

Bois goyavier................... 337

Bois graine rouge............... 432

Bois à graines rouges.............. 110

Bois grigri ..................... 296
Bois grillé................. 281

Bois gris ............... 149, 259

Bois guépois .................. 264

Bois Guillaume.......... 146, 360, 361

Bois de hètre .............. 84, 314

Bois de hêtre vert............. 84.

Bois immortel................ 218

Bois immortel grand............. 218

Bois immortel jaune .............. 219

Bois immortel vrai.............. 217

Bois d'Inde............... 2962, 263

Bois d'Inde bâtard .............. 274

Bois d'Inde marron............ 138

Bois indien................. 425

Bois jaune ................... 30.

Bois José .................... 10,

Bois Kabi..................... 385

Bois Kaklin ................... 295

Bois la glu ................... 37

Bois lait...............

Bois lait bord-de-mer............. 代

Bois lait petit................ 393

Bois de lan................. 5

Bois de lance . . . . . . . . . . . . . . . . 23:1

Bois de lance noir .............. 450

Bois lélé................. 396, $\$ 13$

Bois de laurier ................. 800

Bois lépineux blanc............. 139

Bois lépineux rouge ............. 110

Bois l'épreuve .................... Mi

Bois de liège .................. 361

Bois lézard. . . . . . . . . . . . . . . 490

Bois mabi.....................

Bois mabouge ............... 13

Bois mahouia.................. 14

Bois madame............. 143, 337

Bois mamzelle................ 4

Bois mandé................. 19

Bois mapou ................ 83

Bois mapou baril ............. 83

Bois mapou lélé ............... 82

Bois marbre................... 39

Bois marbré ................ 19, 39

Bois marbré bàtard . . . . . . . . . . . 109

Bois marguerite............ $3 \mathbf{3 5}, 3 \mathbf{3 0}$

Bois de mèche............. 14, 470

Bois mille branches............ 21

Bois mille fleurs jaune ........... 46 '

Bois montagne.............. 142, 30'

Bois mouri debout . . . . . . . . . . . . 469

Bois moussara................. $\quad 20$

Bois mousseux.................. 121 
Bois muscade ................. of

Bois négresse ...... 3. 87, 123, :3(0)1, :381) Bois noir.............. 1:3, 51, iks

Bois noyer . . . . . . . . . . . . . . . 1 . 1 3

Bois noyau..................

Bois olive . . . . . . . . . . . . . . 123

Bois l'onguent................ (1).

Bois de l'orme............. 8, .

Bois ortolan . . . . . . . . . . . . . .

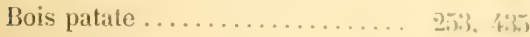

Bois patate marron ............. f.3:3

Bois pays. . . . . . . . . . . . . . . . . .

Bois pelé.................... פ

Bois perdrix. . . . . . . . . . . . . . 321

Bois pétard............ T(4;, 39) 1, 34h

Bois petit chique............... $3 x_{2}$

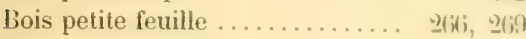

Bois petit houx................. 11 亿

Bois petit Jean............ 1, (1), :H(1)

Bois pilori..................... 121

Bois pini. . . . . . . . . . . . . . . 18

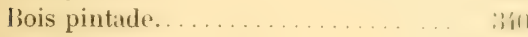

Bois piquette. . . . . . . . . . . . . 110

Bois pissenlit................. 12

Bois pistolet................... 128

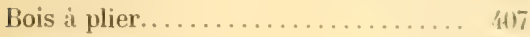

Bois poison. . . . . . . . . . . . . . . 377;

Bois poisson................... 112

Bois puant......... 13, 323, 337, \{ki

Bois quenouille................ . ; 30

Jois a rames . . . . . . . . . . . . . . . . . . .

Bois rape .................. 住

Bois rasoir. ................ $\times 2$

Bois résolu . . . . . . . . . . . . . 2,

Bois résolu montagne . . . . . . . . . . . 3:3i

Bois royal. . . . . . . . . . . . . . . . . 11:;

Bois de rose .............. 128, 倠

bois de Rhodes.................... ii

Bois rouge............. $1: 31,11(i j, 11 i 7$

Bois rouge à grives... . . . . . . . . . . 110

Bois de Sainte-Iucie ............. ; $3 t_{i 3}$

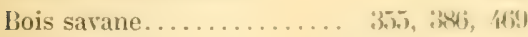

Bois de savane................

Bois saroll ................... illi

Bois savonnelte . . . . . . . . . . . . . ?

Bois de sept ans ............... 126;

Bois siffleur . . . . . . . . . . . . . . . . ; 320 ()

Bois de soie ................... 337

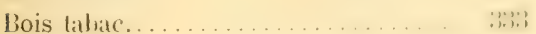

Bois tall. . . . . . . . . . . . . . . . 111

Bois titn montaturn.............. 111

Bois lan rouge................ 320
Jiois thinant ............... In

liois tromputle .............. 1: .

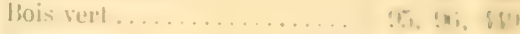

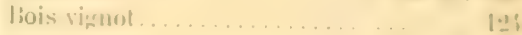

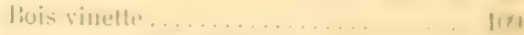

liois vincthe pretile fentlle... (1p)

bois violet . . . . . . . . .

lisois zizi ........... Hi

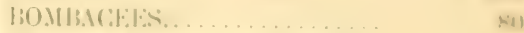

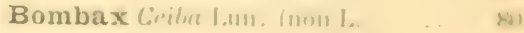

linslion noir.... . [ial

lionhon ronel. ............ in

lionuel carria.......... Iln

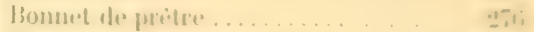

Bontia derphumides I........... sil

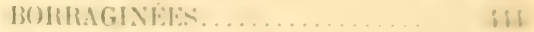

Borrera laris diriwh ............. in

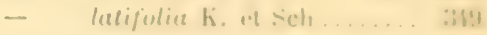

- previflume

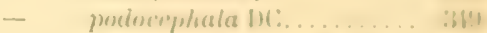

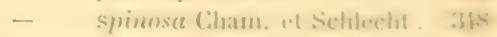

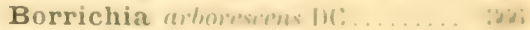

Bonis. . . . . . . . . . . . . . . . . W

Bouis poilu. . . . . . . . . . . . . . . . . . . .

Boulet it catton .............. .

Boussingaultia leptostachyu Min . il

Bouteloua liligiusa lair . . . . . . . . in

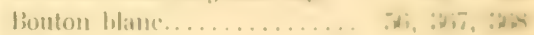

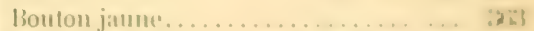

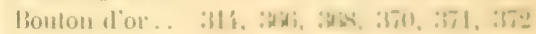

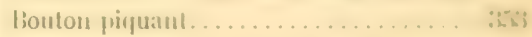

lionton violet. ..................

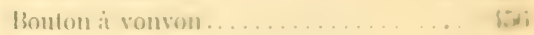

Bovilu-chit..................... .tis;

Brachypteris borrulix ful..... II

Brachyrhamphus inlylutem f) (: : :

Buandat frumd lois . . . . . . . . . . . . if:-

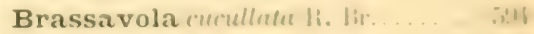

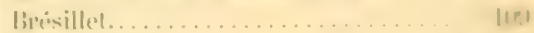

Bresine .................... 沙,

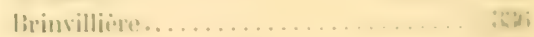

Brinvilliurs litimel ............. Is

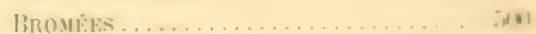

Bromelia liumtus l............ wit

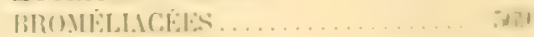

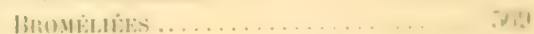

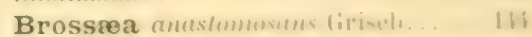

Broussonetia pupmifira lint (1a)

Brownea gramlicrus Jacy ....... .

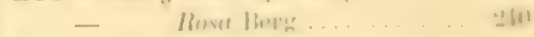

Browallia temissu 1 . . . . . . in in

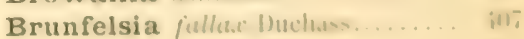


Bryophyllum calycimum Salish ... 31!

Bucida Buceras L .............. 296 capitata Vent .......... 296

BUETTNÉRIACÉES .............. 8 '́

Bugainvillea fastuosa Hening .... 62 spectabilis Willd.... $\quad 02$

Buis de Chine ................. 132

Bumelia cuneata Sw. - add...... 612

- pallida Sw............. 386

- myrisinifolia A.DC.-add. 612

- tena Willd............. 386
Bunchosia glandulifera Desc..... 112

Bunchosia glandulosa Rich....... 112

BURMANNIACEEES............. 587

Bursera gummifera L........... 181

Buxus subcolumnaris Müll. Arg.... 19

Byrsonima levigata Rich ....... 110

- lucida Rich.......... 111

- martinicensis $\mathrm{Kr}$. et Urb. 111

- $\quad$ spicata Rich.......... 111

- $\quad$ trinitensis Juss....... 111
Cabouva........................ 503

Caca poule................... 395

Caca rat......................... 390

Caca ratret... 151, 153, 191, 277, 381, 382

Cacio .......................

Cacio montagne ...............

Cacao du Pérou................. 86

Cacao siuvage................ 80

Cacaoyer....................... 85

Cachibou .

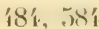

Cachiman.

Cachiman cochon.

Cachiman cœur de bœuf............

Cachiman crène.

Cachiman montagne ............ 4

Caconnier blanc.............. 221, 225

Caconnier rouge ............. 120, 225

Cresalpinia pulcherrima Sw ...... 230 cepiaria Roxb ........ 229

\section{C.IESALPINIEES}

226

Café bàtard ............ 235, 341, 34k

Café bâtard montagne............ 342

Café blanc ................... 342

Café bois........... 98, 112, 327, 313

Café bois marron ............... 343

Café jaune ................... 122

Café Liberia .................... 341

Café marron.............. 343, 34.

Café marron grand bois............ 343

Cafẻ moka................. 112, 31

Café montagne................. 342

Caféier ......................... 34.

Cafier........................ 34:

Cajanus flavus DC............ 205

indicus Spreng .......... 205

Gakile xqualis L'Hérit........... 10

- cubensis Kth............ 10

- maritima Rich............. 10
Galadium Belleymii Hort......... 483

- bicolor Vent........... 482

- Chantini Cham. etSchl.. 483

Calalou ..................... 481

Calalou diable . . . . . . . . . . . . . . 481

Calalou sauvage ................. 483

Calathea Allouya Lind ............ 584

Calebasse .................... 418

Calebasse douce................. 308

Calebasse herbe... . . . . . . . . . . . . 308

Calebasse musquie................ 308

Calebassier .................... $\quad \mathbf{4 1 8}$

Calebassier bàtard .............. 418

Calebassier poison ................ 419

Calliandra lalifolia Griseb........ 253

- Portoricensis Benth.... 254

- purpurea Benth...... 252

- lengemina Benth...... 253

Gallisia repens L............... 498

- umbellulata Lam......... 497

Galonyction grandiflor um Chois... 431

- megalocarpum Rich.. 434

Calophyllum Calaba L......... 103

Galosanthes indica Blum........ 423

Calotropis procera Ait............ 399

Catalpa...................... 80

Calumet............. 512, 521, 523

Galyptranthes elegans Kir. et Urb. . 266

- pallens Griseb..... 260

Forsteri Berg...... 267 sericea Griseb..... 267

Catnanioc ................... 29

Ciumomille ..................... 369

Camomille rouge................ 369

Campêche............... 226, 227

Cananga odorata J. Hook........ 5

Ganavalia gladiata DC.......... 215 oblusifolia DC........ 215 


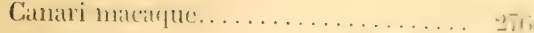

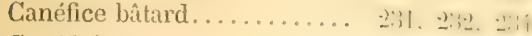

Canéficier .....................

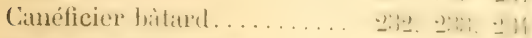

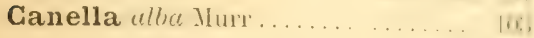
laurifolia Lodd.......... (11.;

Canelle bois .................. III

Canellier..................

Canellier sauvage ................

Canicroc ...................

Canique jaune.....................

Canna coccinea Mill............. तivi

- edulis liet................ is

- glauca L................. is

- indica L................ ivi

-. pallida Rosc............. is:

Canne brûlante ................... (i)

Canne Congo................... ix

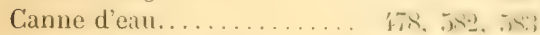

Canne marronne . . . . . . . . . . . . . . क tir

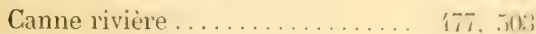

Canne siguine ..................

Canne à sucre .........................

Cannées .......................... ini

Caperonia castaneifolia St. Hil.... : :

C.APPARIDEES............... II

Capparis amygdalina Lam....... I:;

- Breynia L............... I:

- cynophallophora L

- frondosa Jacr

- intermedia H. B. Kth

Capraria biflorce $\mathrm{L}$. jamaicensis Jacq

CAPRIFOLIACÉES

Gaprifolium pubescens Goldie..... . :

Gapsicum annum L......... i1:

- baccalum L.......... ill

- ceratocarpum fingerhut. il.

- conoides Roem. et Schult. i!:?

- dulce Horl

i1:

- frutescens $\mathrm{L}$

Caractère des dames. ill. il:

Caractère des hommes

Citrambolier .

Carapa Guianersis Aubl.......... 1:;1

Carapate................. 1 , ;1,

Curapate bitlitid.

.... in

Cardiospermum Halicacalum L. IIT microcarpum Bi. IIs

Carex Dussiana Boekeler...............

CarucinéEs........................

Carica Papaya L
Carissa Cimemulu: I

Carludovica mustipulue $\leq$ - m

youndes simb.

maimas Inth-tas.

pulmates tuis of las

l'lumierith

1:11. 1.

Carolinea !rumliptente Tus.

- matrems L. li!

cinsele

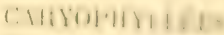

Caryophyllus ctmmulicus Wilhel

Caryota uens I.

Casse ailin

l.ase habilar.:

C.... hatlin, s

Casse puante.

Ciasse savamu. .

Casser coutelas

Gassia alatu I.

biectpsuluris 1 .

émaryinata 1 .

fistule I.

glandulesere 1.

glauceu l.aun

leirsulti I.

lignestrina $1 .$.

mullijung llich.

mivivens l...

othusifulia L.

nerielentalix 1 .

plunisilupu Iinn

spectubilis IIC

Cassipourea elliplice l'oir.

Casuarina e'puiselifuliut for queulrimelvis !abill temuissimu liert.

Cassyta emericume News....

Catalpa

$$
\text { filifinmis L..... }
$$

Gatopsis vilide (irisol, mutans diriats.

(in+11,111.

Cava bord de riviere

Calva jaum.

(ailat it eipines.

Ciavili.

Cayaponia tmerictmu cu;n.

(ailyul'i

Ceanothus usiulious I.

ferreus bese.

Cecropia ublusulu Tine.... 
Cedrela odorata L . . . . . . . . . . . 129

GÉLASTRINÉES................ 145

Celosia argentea L............. 52

- nitida Vihl............. 53

- maniculata Willd.......... is

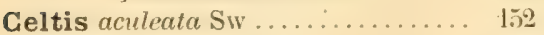

Cenchrus echinatus L........... 526

- spinifex Cav ........... 506

- tribuloides L........... 526

Gentella asiatica Un............

Centratherum muticum Less

Centropogon Berteroanus DC. Surinamensis Presl.

Gentrosema Plumieri Benth. pubescens Benth virginicum Benth.

Gephælis axillaris Sw. muscosa Siv.

$$
\text { - Swartzii DC. }
$$

Cerbera Thevetia $L$.

Ceratosanthes comiculata Cosn. .

Cereus compressus Mill.

$$
\text { - Gurtisii Otto...... }
$$

Cerise bord-de-mer

Cerise de Cayenne.

Cerise it còtes.

Cerise montagne. .

Cerise montagne petite feuille...... $207,27,278$

Cerise noire

Cerisier capitaine ................ 113

Cerisier grosses côtes. . . . . . . . . . . . 113

Cerisier du pars.............. 112, 113

Cestram.

Cestrum latifolium Lam.

- laurifolium L'Hérit

- nocherum L - vespertinum L.

Chaddek .. . .

Ghaetogastra chamrcistus Griseb. chironioides Griseb..

Chaetocalyx Vincentinus DC. CHAILLETTIACEES

Chalotte.

Chalotte bois. .

Chalotte savane.

Chamerops excelsa Thunb

Chamissoa altissima Kth .

Champignon.

Chance...

Chandelier
Chapeau d'eau. 8

Chapeau chinois................ 470

Ghaptalia mutans Hens].......... 375

Charderon.................... 318

Charderon brini . . . . . . . . . . . . . 32.

Chardon..................... 8, 318

Chardon béni ............. 324, 325

Charianthus coriaceus DC....... 285

- cormmbosus Cogn .... 286

- nodosus Triana...... 285

Chataigne..................... 150

Châtaignier............... 80, 156

Chataignier coco.............. 92

Châtaignier grand-feuille .......... 91

Chat taignier petit coco ........... 92

Chàtaignier petite-feuille ........... 91

Ghavica Betle Miq. . . . . . . . . . . . . 179

Chène d'Amérique ............... 420

CHÉNOPODÉES................ 51

Chenopodium ambrosioides L..... 51 murale L......... 51

Chevalliera lingulata Gaudich.... 570

Cheveu de Vénus ................. 4 亿

Chevrefeuille de Chine ............ 329

Chien-coq...................... 538

Chiendent..................... 509

Chimarrhis cymose Jacq......... 332

China-grass................. 116 ,

Chiococca racemosa Jacq ......... 339

Chionanthus compacta Sw ....... 391

CHLORANTHACEES.............. 180

GHLORIDÉES ............. 506

Chloris baibata Sw ............ 508

- ciliata Sw............. 508

291 - radiata Sw............ 507

417 Chou amer.................. 188

416 Chou bitard................. 482

\$17 Chon carailue.................

417 Chou caraïbe sauvage............ 480

132) Chou cochon................. 18:2

288 Chou colonne................... 487

288 Chou diable ................... 481

203 Chou franc..................... 188

151 Chou franc montagne .............. 489

557 Chou palmiste................. 487

$56 \times$ Chon palmiste franc .............. 488

568 Chou palmiste montagne.......... 188

485 Christophine................... 306

53 Chrysanthème................... 371

326 Ghrysanthemum indicum L.... 37

CRYSOBALANÉES ............... 257

Chrysobalanus cuspidalus Griseb $\quad 258$ 
Chrysobalanus Icaco $\mathrm{L} \ldots . . . . .$.

Chrysophyllum argenetenm Jacf... ' the

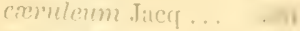
tir.

Cicca antillana Juss glabmm Jacr

-.. distiche $\mathrm{I}$.

Cierest.

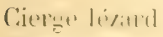

Cierser diatle

Cicrine roming.

\section{CINCHONACEES}

Cinnamomum eorticosum Mlict. zexlanienem IB]

Cipura mavinicensis lith

- plicata Griseb.

Cissampelos Pareira I.

Gissus discolor BI

- ovata Lam

- sicenoirtes L

- smilacina lith

Githarexylon mrinerem |,$\ldots \mid$

- iucidum Cham. ol

Schlechht ........ is

Citronnier ............. 131, 149, 化

Citronnier batle.............. 14!

Citromier inontanne............ 1,is

Citrosma glabrescens l'resl......... Ii

Citrullus vulgaris Schrad ........ : :

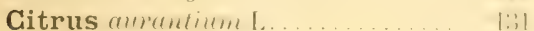

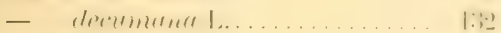

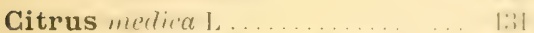

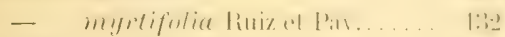

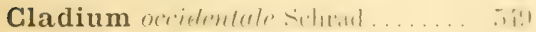

Clematis amerieana Mill. ......... |

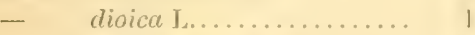

domingr'msis T.ant1.

Gleome aculeatu L

- jantar)hylli I..

- Imm!res II illil

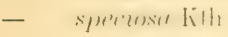

- visirasa 1 .

Clerodendron auleatum Grisel...

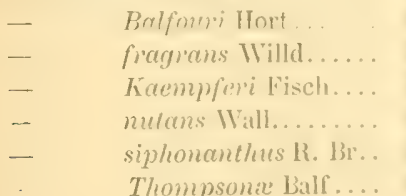

Diss - Pluntes Guadeloupe et Martinique.
Clerodendron rivim....m: $\|$....

Cileyera rimm Tisl

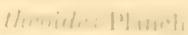

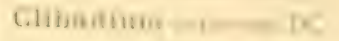

$$
\text { - Inulingilisint. }
$$

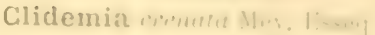

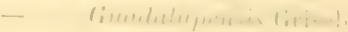

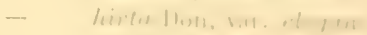

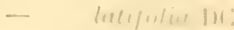

$$
\begin{aligned}
& \text { - mollomel lin-14. }
\end{aligned}
$$

Clitoria m.tumen. Ii !lyeiminle. \$11: Tirnulem I.

Coccoloba movelems lum

- Introulemin Jus

Inusii lir. ol ['il.

meromiatnel.

niven Jay?

resmeli

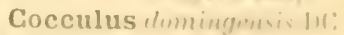

forlylinariat

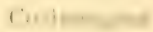

Co(n)-ciamento

i.m w.rthes

Coco-maciupe:

Coceos amami Mart. nuciferes.

1.......t. . .

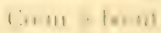

Coffea arabiral.

$$
\text { lilmerive Ilimat }
$$

COFFEAC:WES

Coix Latevymul L.

Cola truminutu K. Hr, in l:.nm

Coleus amburinims l.um armmulieus limbth. lomonin Iles

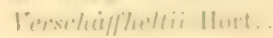

Colibri vignital.

isollane

Colliery du dialle.

Colocasia untipmutum selioult.

$$
\text { isculentu sichull }
$$

Colubrina ievliment lironen

Columnea setudin: I.

Commelyna ilegurs lill.

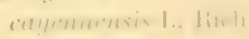

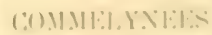

Commersonia whimutn lins:

Comocladia ilicipolius . 
Concombre bâtard.

307,309

408, 109

Concombre à chien

101

Concombre a chien grand........... 40

Concombre Coolis............... 307

Concombre cornichon............ 310

Concombre diable.............. 309

Concombre hallier............. 307

Concombre marron.............. 307

Condalia ferrec Griseb........... 92

CONIFÈRES ................

CONNARACELS............... $\mathbf{2 5 6}$

Connarus grandifolize Planch ..... 250

Conocarpus erectus L . . . . . . . . . 295

Consonde srind hois.

Conostegia calyptrata Don

$$
\text { subhirsuta Don }
$$

(O)NVOITLLICEE

Convolvulus pentanthus Jacq.

Gonyza arborescens L

\section{carolinensis Jacq .}

odorata I

Gookia punctala Retz............ 133

Copahu................... 31, 240

Copahu båtard.................. 31

Copaifera officinalis Jacq. ........ 249

Corquelicot.

Corail.

$7 \cdot$

Corail végétal.

Corchorus hirtus Planch.

$$
\text { - } \quad \text { siliquosus L... }
$$

279

279

(i3i)

412

351

361

361

Corde it violon.... 199, 203, 210, 305, 1 亿3

Cordia alba Roem. et schult....... 任

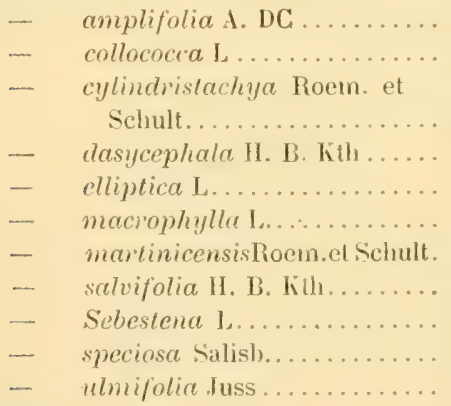

Cordon de violon.

419

彷

418

418

416

146

48

447

415

任

44

$20 \%$

Coriandre

Coriandrum sativim L

305

325

135

Cornichon. .

Cornutia myanidala $\mathrm{I}$.

Corosol ì chien.

Curosol diable
Corosol montagne. ............ \&

Corosolier..................... 23

GORYMBIFERES............ 350

Corypha umbraculifera L........ 495 rolundifolia Lam........ 495

Cosmos caudatues II. B. Kth....... 369

Costus speciosus Smith.......... 582

- spicalus Sw............. 581

Côtelette grand bois............. 279

Côtelette grand feuille............ . 281

Côtelette petite feuille............. $\mathbf{2 8 0}$

Côte lézard.................... $\quad \mathbf{2 1 8}$

Coton de france. . . . . . . . . . . . . . . . 399

Cou de canard. . . . . . . . . . . . . . . . 316

Coumarounit.................... 9

Coubaril....................... 238

Coudtel ....................... 137

Conis . . . . . . . . . . . . . . . . . . 32:3

Couronne de lit Vierge............. 562

Couroupita guianensis Aubl...... 276

Cousin blanc............ 81, 197, 202

Cousin falaise.................. 200

Cousin grand savane ............ 200

Cousin petit............... 71, 89

Cousin rouge................. 71

(Gousin trifle...................

Cousse-conche .................. 566

Coutarea speciosa Aubl .......... 332

Coutoubea densiflora Mart....... 401

Gracca caribæa Benth............ 195

Cranichis muscosa Sw.......... 603

CRASSULACEES . . . . . . . . . . . 319

Cratæva Tapia L................ 12

Crécré ...................... 250

Grécré blanc............... 281, 283

Crécré falaise.................... 979

Crécré grand bois........... 277, 283

Crécré grand'feuille.......... 279, 288

Crécré montagne............ 278, 283

Crécré noir................... 286

Criosote.................. 370,371

Créosote du pars............... 370

Crescentia Cujete L........... 418

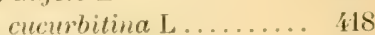

Cresson bittard ................. 405

Cresson courant ................ 136

Ciresson de Pitlit ................. 370

Cresson sauvage ............... 9

Cresson de savane ..............

409 Grête à coq.................... 452

400 Crète codinde................ $\$ 52$

\{00 Crin regetal ................ 
Crinum amabile Don............. 55

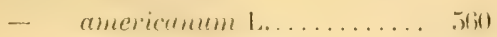

- giganteum Andr......... 560

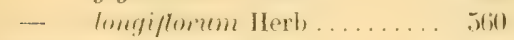

Critonia macropoda DG.......... 357 parviflora l)C......... 357

Croc chien ......... 61, 222, 216, 247

Croc it chien............... 152, 221

Crossandra infunlibuliformis Nees 127

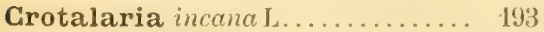

- juncea L............. 191

- lotifolia L............ 193

- pendula Benth....... 193

- quinquefolia L........ 19 '

- retusa L............ 193

- stipularis Desr........ 192

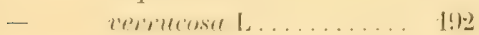

Groton astroites Ait............. 33

- balsanifer L............ 31

- betulimes Vahl............ 32

- resylifolius Lam........... \$1

- floceulosus fieiss. . . . . . . . . \$1

- Guildingii Grisel.......... 31

- hivtus L................. 33

- lobatus I.

Groton montanus Geiss............

- niveus Jacq................

- origanifolius Lam..........

- ovalifolius Lam..

- populifolius Lim.

- Tiglium L.

CRUCIFÈRS

Cryptomeria elegans Veitch ...... 608 juponicet $\mathrm{L}, \ldots . . \ldots \ldots$ tits

Cryptostegia grandiflor $a$ R. Br.... 101

Cucumis Anguria L ............. 309

Cucurbita maxima Duch ........ : 310

CUCURBITACEES... . . . . . . . . . . . 309

Cupania americand L .......... 120

- fulva Mart............ 120

_... triquetra Rich........... 120

Guphæa Balsaniona Cham. et

Schlecht............ 289

- Myssopifolia Griseb....... 28.

- macropetala Kith ....... 900

- platycentra Benth ....... 290

Cupressus japonica L . . . . . . . . . 608

- sempervirens L........

Curage........................

Curage des bois. ................

Curage rivière.
Curcuma.................... 583

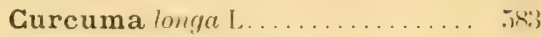

Guscuta americana L........... 193

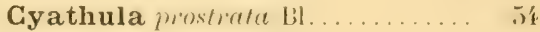

GYCADEES.................... 609

Cycas incinalis I. . . . . . . . . . . (it)

- revoluta Thunb............ 60

Cycnopodium latifolium Naud..... 287

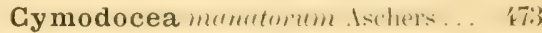

Cynodon Dactylon Pers .......... 509

CYCLANTHEES............... 48.5

Gyclanthus Plumieri Poit......... 485

CYPERACEES.................

CYPEREES. . . . . . . . . . . . . . . 535

Cyperus acicularis With .......... 5.39

- alopecuroides Rottb....... 535

- allemifolius I.......... $\$ .37$

- articulatus I............ 538

- Balbisii Kth........... 538

- bivnnetes L . . . . . . . . . . 539

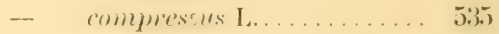

imfertus 1. .......... 5i3li

distans L............. 510

Dussianus Boekeler....... 5’

elatus Rotth.............. 5, 50

elegans Walt........ 536, 537

esculentus L........... 510

ferax Rich ............. 511

flavicomus Schlecht....... 536

flavomariscus Griseb...... 512

Hartii Boekeler.......... 53

hexastachyos Rottb........ 538

IIydra Mich.............. 538

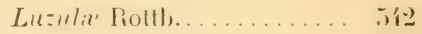

martinicensis Bockeler.... 512

monostachyus L......... כ任

nitidus Boekeler......... 51

achraceus Vahl.......... 537

odoratues L............. 510

olivaris $\operatorname{Tarr}_{0} . . . . . . . . . . .5 .338$

Ottonis Boekeler.......... 539 !

Papynus L.............. 512

planifolius Rich.......... 539

polystachyus Rottb....... 535

purpurascens Vahl........ 539

jurpureo-z'ciegalus

Boekeler. . . . . . . . . . 539

rolundus L.............. .

sphacelatus Rottb......... 5,58

surinamensis Rottl....... . 537

Trinitalis Steud..........

trispicalus Boekeler....... 5ł 
Cyperus umbellatus Benth....... 536

- viscosus Siw ............ 537

Cypre-orintrer.................. 389

Gyrilla antillana Mich............ 145

\section{$\mathrm{D}$}

Dacryodes hexandra Griseb...... 1 15 을

Dactyloctenium aegyptiacum

$$
\text { Willd. }
$$

meronatum

IVilld...

Dalechampia scandens I

I)andis.

Daltier.

Datura justuose L.

— $\quad$ Ited L...............

Daucus Ciruta I.

Deguelia scandens Aubl

Dendrobium ruscifolizm Sw......

Dendrophtora macrostachya Eich. - elliptica Kir. et Urb. var. platyphylla. - add.

Desmanthus depressus Willd..... virgatus Willd.......

Desmodium ascendens DC.......

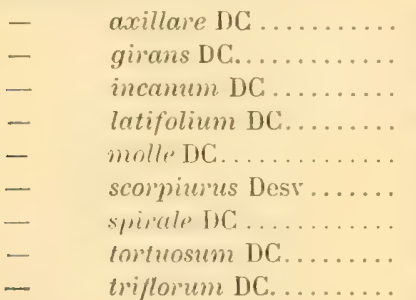

Devant-nègre................. 50

Diaballe..................... 25

Dianthera androsemifolia Griseb... 425

- pectoralis J. F. Gmel.. sessilis J. F. Gimel.......

Didymopanax attenuatum Narch. .

Urbanianum lir. el [il].

Dichæa echinocarpa Lindl..........

Dichorisandra Aubletiana Roem.

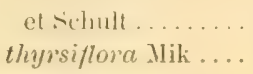

Dichromena setacer lith........... micranthe Kth...... 552
CYRILLEES.................. 145

Cyrtopera Woodfordii Lindl...... 597

Gytisus Cajan L............... 205

Dichromena leucocephala \$lich.... Dicliptera martinicensis Juss..... . i2 DICOTYLÉDONES .......... 1 l)iclime.................... .

Dieffenbachia Seguine Schott .... iT Barraquinina Cham. et Schlecht ...... i

Dillenia speciosa Thunb.......... ?

Dindi........................ i is

Dipladenia Harrisii Hook......... $3, \mathbb{K}$

Diodia samentosa Sw .......... 331

Dioon edule Lindl . . . . . . . . . . . . . 309

Dioscorea alatı J............... thti

- altisima siet......... 5it.

- Beiterorma lith ....... ifis

- Cayennensis Lam....... 5i,

- multiflora Presl....... 5is

- pilosiuscula Bert....... Jit

- trifide L..............

- luberosa Till ........... iviti

DIOSCORÉACEES.............. it:

Diospyros Ebenaster Reiz......... 3.

- Philippensis Gürke.-add. til't

- discolor Willd. - add... lil's

- Kati Roxb. - add...... til't

|liotine....................

Du-t,on-matin................. 20.

Duranta Plumieri Jacq.......... iti.) Fillisice Jactr........... the ti.

Lussia martinicensis $\mathrm{Kr}$. el $\mathrm{L} r \mathrm{~b} . .$. . 2y't

Dipholis salicifolia A. DC........

Dipterix odorata Schreb.......... ‥21i

Distreptus nudicaulis Less ........ 352

Ditaxis glabella Griseb........... 3'

Dividivi. . . . . . . . . . . . . . . . . 231

Dodonæa riscosa $\mathrm{L} \ldots \ldots \ldots \ldots \ldots$ 1:2,3

Dolichos albiflomes DC.......... 213

Lablab L............. 느는

Dombeya mollis Par........... k s

los blanc................... 33.3. 37.

Dorstenia contrayerva L......... 1,5?

Honci-annere. . . . . . . . . . . . . . 11:3

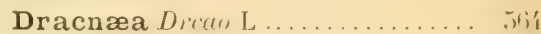

- Guilfoylei Veitch ....... Tit

- inrlivisa forst......... grit 
Dracaena marginata Lam....... 56 't - Sieberi Planch......... 5tis

- striete sims.......... 56rt

- umbraculifera Jacq..... 5fik

Drepanocarpus lunatus $\mathrm{Ney}$

221
Drymaria coidata Willd........ 45

Drypetes Dussii Lir. el Urb....... 20

- glauca Vahl........... 20

glomerata Griseb....... 20

serrata lir. et Urb........ 20
ÉBENACEES $\ldots \ldots \ldots \ldots \ldots \ldots \ldots \ldots$

Échalotte....................... 557

Echinodorus cordifolizs Griseb.... 472

- rostratus Engel ..... 172

Echinops fruticosus L . . . . . . . . . 333

Echites biflor a Jacq. . . . . . . . . . . . . 396

Ehretia Berureria L . . . . . . . . . . . 4'?

Eclipte alba L ................. 366

Eichhornia crassipes Solms....... 568

Elaphrium elemiferum Royle.... 183

Elais guyanensis L..............

Elephantopus angustifolius 1..... 352 scaber L. . . . . . . . . 352

spicatus L........ $\quad 352$

Eleusine indica Gaert.

Eleutheranthera ovata Poil ..... 363

Elleanthus capitatus Rchb), fils.... 595

Emilia flammea Cass

- sagittata DC.

- sonchifolia DC

En bas feuilles.

En bas feuilles grand bois ...........

En bas feuilles rouge ........... 23, 24

Ln bas feuilles vert

Enckea articulata Miq Sieberi Mliq .

Enicostema littorale Blum.

Enivrage

Enterolobium cyclocarpum Macf...

\section{EPIDENDRÉES.}

Epidendron ciliaie L

difforme Jacq

globosum Jacq. elongatum Jacq.

fuscatum $\mathrm{Sw}$. . .

nocturnum L.

ophioglossoides L. .

paniculatum Cogn.....

ramosum. L.

rigidum Jacq.

strobiliferum Griseb...

teretifolium Sw

umbellatum Sw
Epidendron vincentinum Lindl.... 593

Epicar...................... 97

Epinard bord-de-mer.............. of

Epinard de Cayenne................ 49

Epinard doux..................... 49

Epinard rouge................. 58

Episcia melittifolia Mart......... 431

pulchella I: $\mathrm{rt} . . . \ldots \ldots \ldots .431$

Eragrostis ciliaris Lk.......... 502

- gigantea Trin....... 501

- pilosa P. Beauv....... 502

- plumosa Lk......... 502

- prolifera Steud....... 501

reptans Nees........ 502

Eranthemum bicolor Spreng...... 429

- nervosum $\mathrm{R} . \mathrm{Br} \ldots . .429$

Erectites hieracifolia Raft ....... 374

præalta Ratl.......... 374

Erigeron bonariensis L........... 360

Canadensis L............ 360

cuneifolius DC.......... 359

- Jamaicencis L.......... 359

- spathulatus Vahl ....... 359

Eriobothria japonica Lindl ....... 261

Eriochloa punctata Hamilt....... 513

Eriodendron anfractuosum DC... 80

Erithalis angustifolia DC ........ 339 finticose L............ 338

Ernodea littoralis Sw ........... 397

Eryngium fotidum I........... 32'

\begin{tabular}{c|ccc}
590 & Erythrina Amasica Spruce........ & 299 \\
592 & $-\quad$ corallodendion L . . . . . & 217
\end{tabular}

59\% - indice Lam.......... 218

591 ERYTHROXYLEES.............. 109

591 Erythroxylon areolatum Poep..... 110

$593 \quad-\quad \operatorname{coc} \alpha$ L . . . . . . . . 110

$589 \quad-\quad$ havanense Jacq..... 110

$592 \quad$ - obusum Desc...... 109

592 - squamatum Vahl... 110

591 Ethulia sparganophora L ........ 350

592 Eucharis amazonica Linden...... $5(62$

591 - grandiflora Planch..... 569

592 Euterpe edulis Mart............. 195 
Eugenia albicans Rich ........... 268

- aromatica Baill.......... 275

- axillaris Willd........... 270

- baruensis Balb....... 267, 270

- brachystachya Berg...... 272

- chrysobolanoides IIC...... 269

- coffeifolia DC........... 273

- distycha Bello........... 273

- Duchassaingiana Berg.... 271

- Dussii Kr. et Urb......... 270

- emarginata Macf........ 274

- fermeginea Griseb........ 273

- floribunda West......... 273

- fragrans Willd.......... 274

- Gregii Poir.............. 272

- gryposperma kir. et Urb... 271

- Guadalupensis IIC....... 270

- Jambos 1.............. 271

- javenica Lam............ 275

- Lambertiana I)C ........ 270

- ligustrina Willd......... 269

- Malaccensis L........... 974

- Michelii Lam............ 268

- monticola DC........... 269

- nigro-punctata I......... 270

- octopleura lir. et Urb..... 273

- pseudopsidium Jacq...... 270

- sinemariensis Berg....... 273

- smaragdina Berg......... 270

- Tapacumensis Berg...... 27

- Trinitatis I)C .......... 269

- uniflora L.............. 268

Eucalyptus amygdalina Labill.... . 276

- grandiflora L'Hérit.... 270

- robuste smith....... פ27

Eupatorium Ayapana Vent...... 35,

- brachialum Wickst... 3.34

- canescens Vahl ....... 35.

- celtidifolium Jam.... 356
Eupatorium Guadalupense Spreng. . 336

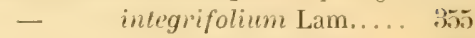

- ivesinoides H. B. Kth .. 3\%

- ivafolium Mart ..... 3... 3.

- macrophyllum L.... . 35

- odoratrm I......... 351

- paniculatum Schrad... 35iti

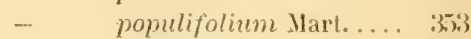

- punclatum L........ 351

- Sieberianum DC......

- sinuatum Lam .......

- triplinerve Vahl ....... 350

- urlicrfolium Hb. Banks. 356

- Vahlianum Urb...... 35ot

Euphorbia Berteroana Balb....... 43

- buxifolia Lam ........

- Dussii Kŕr. et Urb..... \$ \$4

- geniculata Ort....... 任

- heterophylla L....... í

- hirta L............ 仁

- leypericifolia L....... 仿

- linearis lietz......... \&1

- petiolaris Sims....... 特

- pilulifera L......... 42

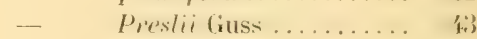

- mostrala lit........... 任

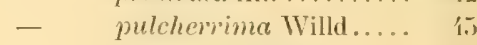

- thymifolia Burm......

- verticillata Poir....... (i)

Euphoria Litchi Commers ........ I't

Evelyna capitata Poepp........... Th

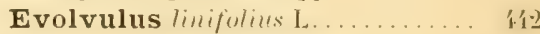

- nummellarines $\mathrm{I} . . . .$. it.

- sericres Sw.......... i i-

Excæcaria bicolo Hass ......... (1)

- caribare Gristh....... (1)

- lucider sw..........

Exostemma ceribæum R. S ......

- floribundum R.S.... : : $; 1 ;$

\section{$\mathbf{F}$}

Fagara microphylla Desf......... 139

$\begin{array}{rr}\text { - pterota L................ } & 139 \\ \text { Fagræa zeylanica Thunb........ } & 377\end{array}$

Faramea odoratissima DC....... 34

Farine chaude................ 25

Farine it zomli ................ 25

Faux ipéca ................... 376

Fenouil ...................... 32.

FESTUCEES.............. 500

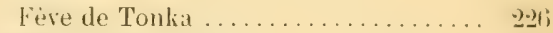

Ficus carica L ................. 15.

- crassinervia Desf..........

- elastiea I................. 15.

- lanerifolia Lam............. 15:3

- Imatigiuesa Vihlo........... 15,

- martinicensis Willd ......... 154

- metallica Ilort........... 15.

- virens dit.............. 15i3 
Figue banane............... 578

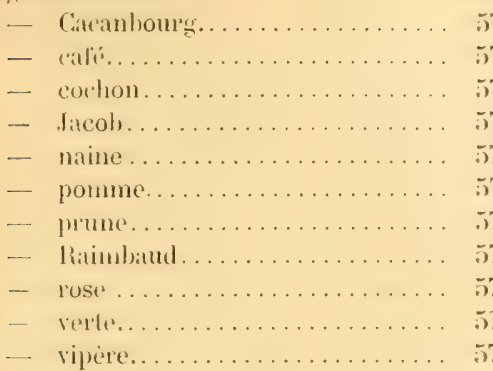

Finguier it anouti . . . . . . . . . . . . 15:

Figuier dratie.......... . . . . . . 3:21

Fisuier blanc. . . . . . . . . . . . . 15

Fignier de France. . . . . . . . . . . . . 155

Figuier grand feuille ............ 154

Figuier maudit........... 54, 99, 154

Figuier maudit marron........... 99

Figuier maudit montagne.........

Filao .................... 190, 191

Fimbristylis autumnalis R. et Sch. Juti capillairis Ás. Gr...... in fermeginea Vahl..... sit obtusifolia Kth...... 5i polymorpha Boekeler. 5i! spadicea Vahl....... in its spalhacea Vahl...... 5 it

Flacourtia cataphrata Roxb..... I. Ramoutchi L'Hérit.... I.

Flinmbean carailbe.

$1: 38$

Flambeau noir................ lis

Flamboyant.............. 230, 231

Flemingia strobilifera $\mathrm{R}, \mathrm{Br} \ldots \ldots$, 2 h;
Fignier hetre. . . . . . . . . . . . 321

Figuier petile feuille............. 15\%

Fleur d'amour.................. 317

Fleur corail ................... 331

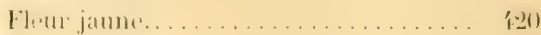

Fleur jaume montagne. . . . . . . . . . . 370

Fleur jaune savane.............. 128

Fleur de mai ................... $5 \times 3$

Fleur montagne................... 377

Fleur de paon.................... 230

Fleur rouge montagne............. 408

Fleur du Sacri-Contr.............. 240

Flenr trois coulents. . . . . . . . . . . . 296

Fleur trompelte............ 108, 561

Fleur vanille................... 45

Fleurit-Noël ................... 354

Fleurya wchens Gaud........... 160

Follet femelle................. 409

Forestiera rhamnifolia Griseb..... 391

Fougère.................. 22, 254

Fourcroya gigantea Vent....... 558

Framboise..................... 960

Framboisier........... $260,275,287$

Framboisin.............. 256, 257

Frangipan blanc............ 395, 396

Frangipanier blanc................ 395

Frangipanier jaune............... 396;

Frangipanier rouge . . . . . . . . . . . . 395

Freziera coidata Tul ............ 96

- undulata Sw........... 90

Fromatyer.................... sif

Fromager inatron ............. si

Fruit à pain.................. 155

Fuirena umbellata Rott.......... 518

Fuchsia........................ 285

Fuchsia des bois............... 432

Fuchsia montagne ............... 432

Fuchsia sauvage .............. 432

G

Gitgne-pelit.................

Gaïac ..................... 137

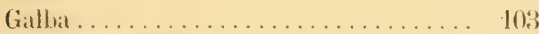

Galactia angustifolia Kth........ 210

filiformis Benth........ 210

longiflora Arn.......... 210

Galium hypocarpium Endl....... 3.50

Garcia mutans Rohr............. 29

Gaultheria buxifolia Willd....... 141

Gendarussa vulgaris Nees........ 1.30

Grinipit, . . . . . . . . . . . . . . . 399

Genipa americuna I.

3330
Génipayer................... 329

Godapail ................... 183

Gentiana uniflora Griseb........ 102 verticillata $\mathrm{L}$.......... (1)!

Geonoma vaga Wendl........... 491

Geophila reniformis Don......... $\mathbf{3} 60$

Geranium odoratissimum 1....... 133

(ivirolle mate . . . . . . . . . . . . . . .

Gigiri...................... 499

Gingembre.................. 583

Girollier ..................... 975

(rirofma..................... 110 
Giromon! ................... 3!

Gironflé........... 169, 173, 174, 272

Gironflé grand'feuille............. 173

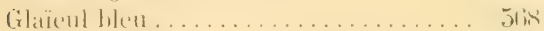

Glouglou,.................... 490

Glouglou rouge................ 490

Globa untuns I...................

Gloxinia maculata L'Hérit........ $\$ 33$

Gothea strictiflora Nees et Nart... $\quad 80$

Gombo......................... 73

Gombo bitard .................. 70

Gombo chanrre................. 77

liombo de mit.................. it

Gombo grand bois ............... 74

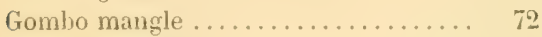

Gombo musqué................. 73

Gomb riviere.................... is

Gombo sarane................ 69

(iommite barriere............... 181

Gommier blane ............. 182, 183

Gommier 1014 ................. 181

Gomphia longifolia Dese......... 98 nitida Sw ................... 97

Gomphrena globosa L........... 5í

Gonolobus martinicensis Dene.... 400

Gonzalea spicala DC........... 332

GOODENIACEES............... 378

Gossypium arborescens L........ 78

Gouania domingensis L.......... 93

Goutte de sang............. 374, 406

Goyavier ................ 261, 262

Goyavier bâtard... 206, 266, 270, 272, 339

Goyavier bois............. 198, 261

Goyavier fraise............... 262

Goyavier grand bois.............. 273

Goyavier inontagne..... 96, 266, 274, 276

Goyavier petite feuille........... $26 \mathbf{1}^{\prime}$

Goyarier prune................ 962

Goyavier queue de rat............ 266

Govavier rose................ 287

Graine bleue.............. 287, 390

Graine bleue montagne........... 390

Graine dorée........... 14', 316,317

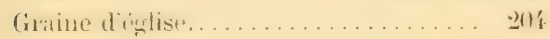

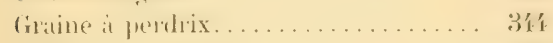

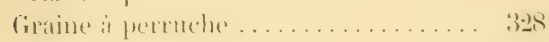

Graine rouge............. 343, 31 1

Graine rouge montagne........... 314

Graines vertes.............. 143, 149

Graines riolettes................ 126

Grammadenia parasitica Gíriseb.. 382

Grand baume.............. 45i, 457 (iramel loranda ..................

(irand collint.................... it

Gimul cosmatal ............... 12

Gimd consin...................

Grand consin bois...............

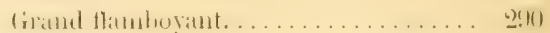

Grand follet...................

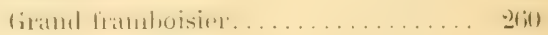

firand fianboisin............... 你

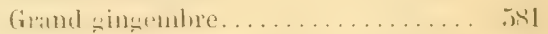

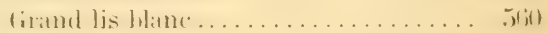

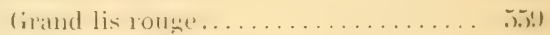

Grand mahot cousin ..............

Grand'oreille mouton.............

Grand'oseille...................

Grand pourpier................ iti

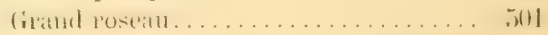

Cirtule

Grande marguerite........... 352, 但;

Grande ortie................. ltil

Grande ortie des bois............ 11i;

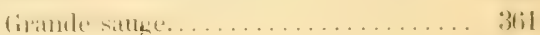

Grande saronnette ................25

Grande violette ........... 206, 351, 3..,

Graptophyllum hortense Nees.... .

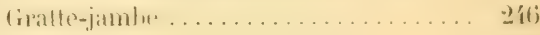

Gros halai..........................

Gros baume .................

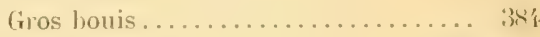

Gros bonton ................ ; 308 , itou

Gros chiendent.............. 513, 5l't

(iros coutin. . . . . . . . . . . . . . . 36rí

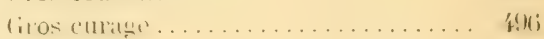

Gros-fort................... 35s

Gros lins rouge................ tin

(irus millet....................

Gros pompon................. the

fims thim.................... 15.

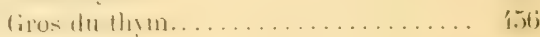

Grosille....................

Groseille de la Barbade........... : $31 !$

Groseille de liminte............ is

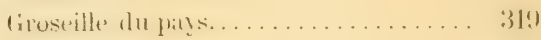

Grosse cerise................. $11 ; 3$

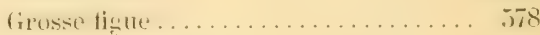

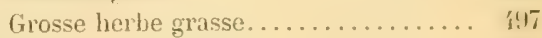

Grosse mal-nommée............... it

Grosse mithre ................. ii

Grosse merise............. 268, 271

Grosse oreille.................. 11

Grosse prune-calé .............. I.

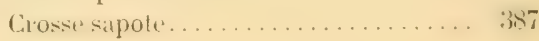


Grosie verreine................ 152

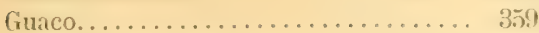

Guajacum officinale $1 . \ldots . . . \ldots .136$

Guarea humilis Bertero.......... 128

- Kunthicmum A.Juss...... 128

- Perottellii A.Juss......... 128

- ramiflora Vent......... I. I

- trichilioides Griseb........ I. I

Guatteria Ouregou Dun .......... i

Guazuma tomentos $\alpha$ Lam......... sí — ulmifoliu Litn.

Guepois bitard.

Guérit-tout 51,354, 362, 457, 461

Guchit-trop-rite.

licririt-rite....

ว1, 35k, 362, 457, 16

Guettarda crispifloid lahl ....... :3.;t

H

Habenaria alata Hook.......... 607 maculosa Jindl ....... 607

Hamatoxylon Campechianum L..

Hamelia patens Jiteq

Haricot hitard.

Haricot lilane.

Haricot marron.

Harieot ordinatire.

Hatricol rames. .

Hitricot sabre.

Haricot terre

Hastingia coccinea Smith........

Haut hois.

Hebeclinium macrophyllum I)C...

Hecastophyllum Brownei Pers.

$$
\text { - monetaria DC. }
$$

monetaria DC. .

Hedychium

flavum Wall..............

- Glavumerianum Wall..

Hedyosmum arborescens Sw......

Heisteria coccinea Jacq. . . . . . . . . 32

Helenium quadridentatum Labill... :37:

Heleocharis Dussiana Boekeler.... . ji.

capitata R. Br....... 们

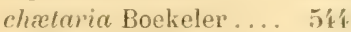

maculosa R. Br...... i. 份

plantaginea $\mathrm{R} . \mathrm{Br} . . .5 \mathrm{~s}$

punctulata Boekeler... 5’1́

siriralis R. Br....... 545

Helianthus tuberosus L......... 3titi

Heliconia Biluri L. Siw... . . . . . . . 379

cannoidea A. Rich...... - jیl
Guettarda paviflora Siv ......... :1:; scabia Lam ........... :3:;

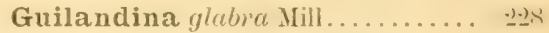

- Gisebacliana hir. el

Urh............ 2,3 !

Guimanre...................

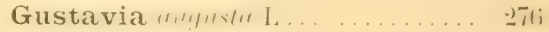

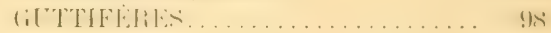

Guzmania Jussii \ez... . . . . . . . п.

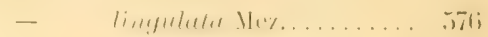

- merjastachya Me\%......

- Plumeri...........

Gymnanthes hucidus Sw......... :3!)

Gynerium saccharoides Humb. el Bonp ............. . . ill

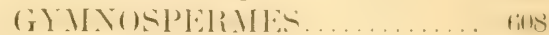

Heliconia caribace Lam. . . . . . . . 5 579

- luteofusca Jacq. . . . . . . . 379

- psiltccorum I.......... 580

Helicarpus americanus L......... 90

Helosciadium leptophyllum DC... 325

Heliotropium curassavicum L ..... 晿3

- fruticosum L...... 150

- indicum L........ 452

- parviflorum L....

peruvianum L..... 453

Helmskioldia coccinea Retz . . . . . 4 470

Helosis guyanensis Hook.......... . 326

Hemerocallis /

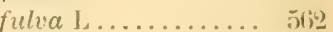

Henrietella Duswii Coyn......... 277

lateriflora Triana..... 277

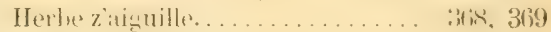

Herbe $z$ aiguille liane. . . . . . . . . . . . \$368

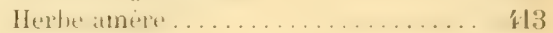

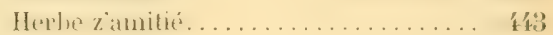

Herbe a l'angine................ 16 I

Herbe argentrip . . . . . . . . . . . . . 353

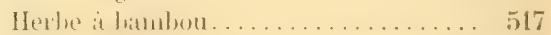

Hewle i hli..............

Herbe blanche ............... 49, 35\%

Herle a homhomine . . . . . . . . . . . . . 528

Horles it hordures. . . . . . . . . . . . . 162

Herbe à bouc ............... 38', 48

Herbe à bouquets ............... . 502

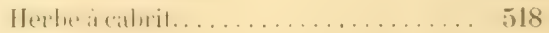

Herbre cabrit............. 510, 518

Herlw cali. .................. 5ll 
Herbe ì calalon ............... 413

Herle it lat chance...............

Herhe chamblelle.................

Herbe charpentier.............. 196

Herhe aux charpentiers........... 426

Herbe chape:al............ 159, 501

Herbe à chat................... 351

Herbe a cheval ............... 512

Jerbe aux (hesathx............. 509

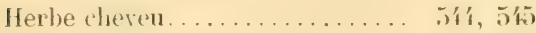

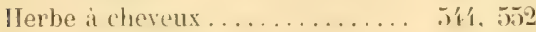

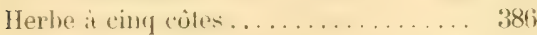

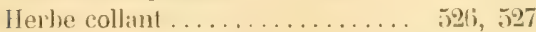

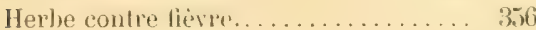

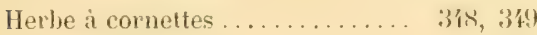

Herbe cotelette................. 278

Herbe coton .................... 37\%

Herbe couche ................. 14

Herbe à couleuvre . . . . . . . . . . . 458

Herhe coulatule................. 551

Herbe is courresie........... 171, 360

Herlse coure.................. 171

Herbe it comrome... . . . . . . . . . . 俰任

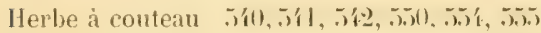

Herbe couleatu . . . . . . . . . . . . . 50

Herhe à crahes.................. 52

Herbe it dirtres. . . . . . . . . . . . . . . 234

Herbe d'au . . . . . . . . . . . . . . 179

Herle it dind . . . . . . . . . . . . . . 357

Herbe droite............... 507

Herle à l'encre ................ $366^{\circ}$

Herhe enivratute . . . . . . . . . . . . 202

Herbe a tritrex............. 195

Herhe etam............... 472

Herbe a ilernuer................. 140

Herbe it frmme................ 360

Herhe à fen .................

Herbe fine. $507,508,509,510,519,523,54$

Herbe fine lemelle. . . . . . . . . . . . .

Herbe fine mate............... .

Herbe tragile .................. firí

Herbe gazon. . . . . . . . . . . . . . . ,

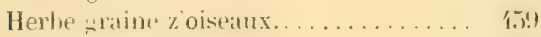

Herlue grand hois. . . . . . . . . . . 3it

Herbe grand Jean.............. in

Herbe sraste ................. 细

Herbe wrasse des hois . . . . . . . . . t thi

Herbe grist.................. 作

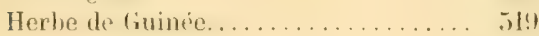

Herbe de fiuinée bitard... . . . . . . . il!?

Herbe Lhalliers. . . . . . . . . . . 任, 位)

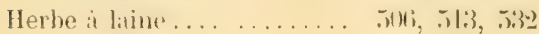

Herbe it lipin............. 37\%, 375

Herbe an long case............ 49

Herbe à long cou.............. 468

Herbe à macornet........ 247, 218, 219

Herlue madame Bihoret........... 380

Herhe undame Boivin............. 3918

Herbe madame Lalie............. . 459

Herbe madame Villaret........... $4 \mathrm{4i7}$

Herbe Madeleine .............. 907

Herbe mal aux dents............. 371

Herbe it malingres............. (i.)

Herbe mal lète ................. 332!

Herhe mare............ 290, 324, 472

Herhe it méchant ............... 479

Herhe mélisse .................. 4. 4.

Herbe à miel .............. 131 , 450

Herbe it miel bitard ............. 131

Herbe i mouches............ 289, 伍

Herbe it mouton................ fin

Herbe à mouton femelle. ......... 5og

Herbe mouton. .................. 510

Herhe muraille ................. 458

Herlue it mulet................. 512

Herbe aux ortolans........... 96,33

Herbe it onate. .................

Herbe panache............. 529, 530

Herbe it pantache............... 331

Herbe panachée ............... 455

Herle de Pirla ..................

Herbe au pauvre homme.......... 530

Herbe it pians ................ 452

Herbe pilori................. 352

Herbe piment ................ 16.

Herhe piment vache............. 16.5

Herbe piquante................ 5.21

Herbe it pirque............ 279, $27 \%$

Herbe a pique bâtard......... 375, 131

Herloe à pisser................... 353

Herbe à plomb................. 413

Herhe à poc................... 411

Herle poison .............. 336, 378

Herbe pou hois................. 32'

Herbe à pou bois.............. 323

Herle aux poules de Guinée........ 31

Herbe proule mile. . . . . . . . . . . 521;

Herbe puante........ 235, 321, 467, 408

Herbe puante bitard.............. 235

Herbe queue blanche.............. 533

Herbe queue de renard........ 506, 516

Herbe quene de souris ........... 528

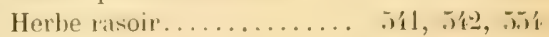

Herbe rasoir mile.............. n.t) 
Herbe ravine ................... 4x

Herbe à riz......... 514, 515, 516, 517

Herbe rivière................. 472

Herbe rude................ 512, 526

Herbe de Saint-Domingue.......... 50

Herbe de Saint-Jlartin .............. 108

Herhe salade..................

Herlue salon .................. 521

Ilerbe savane ... 289, 263, 361, 377, 121, \{27, 506, 519, 531

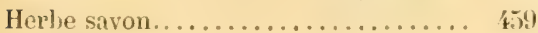

Herbe scorpion................ 152

Herbe seche. . . . . . . . . . . . . . .

Herle is soies. . . . . . . . . . . 372, 5.25

Herbe soleil......... 136, 366, 368, 373

Herbe aux sorciers . . . . . . . . . 3. 35, 390

Herbe soyeuse.................. 372

Herlye sire. . . . . . . . . . . . . . . . . 50

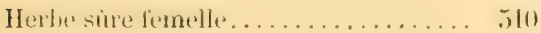

Herlye sùre mille. . . . . . . . . . . . . . . . 509

Herbe tchacha .............. 19:2, 193

Herbe a terre................. 3 . 3

Herbe a thé ................... $35, i$

Herbe à Trément ................ 17

Herbe à vache................. $360^{\circ}$

Herbe à rache mâle .......... 988, 352

Herbe a vache noire.............. 352

Herbe de Vauchelet ............. 133

Herbe à verrues. . . . . . . . . . . . . 152

Herle a vers................. il

Herhe de la Vierge... . . . . . . . . . . 353

Herbe vulnéraire .............. 357

Hẻrisson blanc.................. 89

Heritiera littoratis dit.......... 81

Hernandia sonon L.... . . . . . . . 305

Herpestis Monieria H. B. Ktl..... 105

Herrania albiflor $a$ Goudot........ 86

Herse. .................... 1:3ti

Heteropteris platyptera DC...... 116 purpurea Kth ...... I16;

Hevea guianensis Aubl.......... 29

Hibiscus arborescens Desc ........ 79 bifurcalus Cav .......... Th Boryanus Desc......... 76 cannabinus L.......... 77 Cooperi Hort............ Th
Hibiscus esculenlus L........... 7?

Lampas Gav ........... 78

lavateroides Mench...... 76

mosthulus $\mathrm{L}, \ldots \ldots \ldots \ldots \ldots$ 7;

mulahilis I...........

phoenceus Jaci.......... 7 (j)

inst-simmsis L......... 7f;

Sialudurifu L........... 77

schizopretalus Hort....... Ts

s(r)

Sirrmlersis 1.......... 76

ritifulims $1 \ldots \ldots \ldots \ldots \ldots$ is

Hillia longiflora siw............. . . :3:3i

Hippeastrum equestre Hort ...... jo jil occidentale Hoem ... 561

Hippocratea ovala Iam......... 150 HIPPOCRATEACEES........... 150

Hippomane Mancinella L........ 37

Hirtella pendula Sol. ............ 258

linumlice.iw........... .

Hoffmannia pedoncula Sw........ $3 ; 32$

ubiflora Griseb...... 33\%2

Hulocanste................. 218

H(MILIAEL ... ........... 314

Homalium racemosum Jacq....... 31 1

Honteuse femelle.........197, 198, 214

Honteuse mile ................ 197

Houx du pays. . . . . . . . . . . . . . . 184

Hoya e(t)hosu li. Br............. 101

Hufelandia pendula Nees... . . . . . . 999

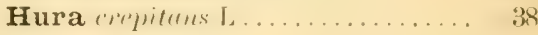

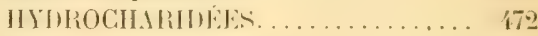

Hydrocotyle asiatica L ........ 324

umbellata $1 . \ldots \ldots \ldots ., 3: 3$

verticillata Thunh.... 323

Hymenza Courbaril L . . . . . . . . . 238

Hymenocallis caribea Hort ..... 5. 5!

HYPERICINEES . . . . . . . . . . . . 10 .

Hypoxis decumbens $1 . \ldots . \ldots \ldots . .562$

Hyptis atrorubens Poit ..........

- iepritrta P'oit............ 55.

- glandulosa Sieber.........

- dertinala Poil........... 经

- sprirala Poit............. 仿6

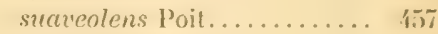

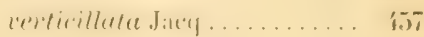


Ibatea muicata (iriseb.........., 100 leaque .................. 257,258 Icagne ..tand bois.............. 258 Iearpe montagne .............. 258 Icique poileux................ 958 Icargue poilu................. 298

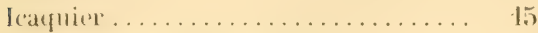

Icica heplaphylla Aubl.......... 182 Igname bamboche bâtard........... 5060 Igname hilard............... .16í, 565

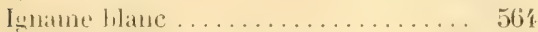
Iqnatune hondat................. 566 [onature catrène............... 566 Igname Gityeume .............. 566 Isname deill ................... 56 Igname grand hois............... 56 Igname grand monsieur.......... 566 Igname jaune grosse tète......... 560 Igriane marron ................. 565

Igname monsieur................. 566 ;

Ignane ollionat ............. 560,567

Igname pas possible............. 566

Igname portugaise $\ldots \ldots \ldots \ldots \ldots \ldots .56 \%$

Igname Saint-Martin ............ 56'

Ilex dioica (irisebeh............. 150

- montana Griseb............. 149

- nitida (iriseb.............. 149

- sideroxyloides Griseb....... 149

ILLICINEES ................. 1/48

Illicium anisalmm $\mathrm{L} \ldots \ldots \ldots \ldots \ldots$.

Immortelle..................

Immortelle blanche..............

Immortelle grande.............. 28

Immortelle jamne. . . . . . . . . . . . 2 209

Immortelle rouge .................. .;

Imperata caudata Trin........... 53.3 contracta II. B. Kith..... 533

Indigo................. 19\%, 195, Indigo hitard................. I!'s

Indigo vrit................... 19.

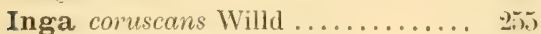

- Guadalupensis Desv........... ...

- ingoides Willd .............. 2...

- laurina IVilld...............

- Martinicensis Presl......... 25

- Saman Willd............. 29.6

- tergemina Willd........... 2.53

Ionidium linearifolium Vent...... 17 - strictum IVilld......... 17
Ionopsis utricularioides Lindl..... Ipicat bitard.............. 似, 424 Ipicat noir................. 366

Ipomea acetosifolia R. S......... 438

- bona-nox L............. 433́

- coccinea L.............. 440

- dissecta Putsch .......... 435

- fastigiata $\mathrm{Sw} . . . . . . . . .4830$

- filiformis Jucq........... 139

- hederacea Jacq........... 4t1

- Martinicensis G. F. W. Mey. 139

- mollicoma Viq.... ...... 438

- Nil Roth............... 住

- palmata Forsk.......... 140

- pendula R. Br........... 440

- pentaphylla Jacq.......... 438

- pes-celpio L............. 438

- quamoclit L............ 440

- Pepurele daey ........... 439

- $\quad$ setifera Poir............. 437

- sinuata Ortega.......... 435

- triloba L.............. 437

- tuba G. Don ............ 434

- tuberosa $\mathrm{I} . \ldots . . . . . . . . .435$

- umbellata G. F. W. Mey.... 438

- ventricosa Chois.......... 131

Iresine celosoides $\mathrm{Moq} . . . . . . . . . .5$ 5i

- elatior Rich.............

- Herbstii Hook........... 万ू.

- vermiculata Moq......... 5i

IRIDEL .................. of

Iris de Florente................ $5 * 3$

Iris Martinicensis L............. . jti

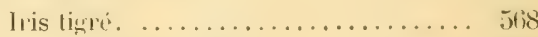

Iachne arundinacea Griseb........ rigen Trin............. 52'

Ischæmopogon latifolius Griseb... 5id

Ischæmum latifolium Kth........ . 5.3.

Ischnosiphon nemorosus Sw ..... 520

Isochilus linearis R. Br......... 518

Isotoma longifloid Presl .......... $37 \%$

Ixora Bandhuca Roxb............ 311

- blanda ker-Gawl........... 310

- coccinea L................ 330

- jerrea Benth............. 330

- odorata Hook............. 330

- Pavetta Roxb.............. 33

- salicifolia DC............. 390

- termifolia Catr............. 330 

violacen Chois ...... th?

Jacquinia aristata Jacq ........ : is

- amillaris Jacq..........

- ruscifolia Jacq..........

Jambosa Malaccensis DC......... 20.' melyaris DC..............

Janipha manihot Kith........... 래

Jasmin battard.................. 117

Jasmin bane..................

Jasmin hois . . . . . . . .

Jissnin des hois. . . . . . . . . . . . . . \$ \$

Jasmin it louquet . . . . . . . . . .

Jasnin grand hois . . . . . . . . . . $\$ 17$

Jasmin olorant . . . . . . . . . . . . . . .

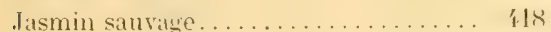

Jasmin trompette............... 但

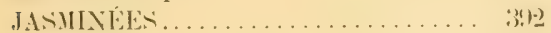

Jasnimum azoricum L..........

- grandiflorum L ...... 39.9

- humile L........... 3.2

- multiflorum Andr..... 392

- pubescens Willd ....... 392

- Sambac Ait......... 392

- undulatum Ker-Gawl... 392
Jacaranda filicifolic G. Don...... 侻:

Jacquemontia tammifolia Girisel.. iti

Jatropha Curcas I............ 27

- dulcis Banks........ 28, 29

- gossymifolia L........... 26

- hastata Jaeq ............ 26

- integerima Jacr........ 26

- manihot 1............. 28

- meltifida L............ 96

- pandurifolia Andr....... 96

- podagrice llook........ 97

Jaune d'œuf . . . . . . . . . . . . . 17

Jone ......................... 万人

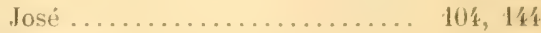

Josi vrai . . . . . . . . . . . . . . . . .

Jonezia dzoca Roxh.............. פg

Jububier . . . . . . . . . . . . . . .

Jussieua ereeta L.............. 29.2

- linifolia Vahl........... 292

- palustris Xliq .......... 292

- suffruticosa L........... 991

Justicia Adhateda I............. 42]

- Caracassana Sieh......... 427

- Canthaginensis Jacq...... 496

- enstachiana Jacq ........ 490

- martinicensis Sieb....... 129

- $\operatorname{picta}$ L............... 495

$\mathbf{K}$

Kaempferia longa Jaeq ......... 58,3

Kaimitier ...... . . . . . . . . . . . . 385

Kiämitier J latue . . . . . . . . . . . . 384

Kialmitier bois............... . 385

Kaïmitier noir .................. 385

kitinitier................... 385

Karatas........... 558, 559, 569, 570

limipier.................. 123

$\mathbf{L}$

LABTEFS . . . . . . . . .

Lactuca sativa L.............. :

Lil donce-innere . . . . . . . . . . . . . . 1:3

Lagenaria vulgaris Ser ......... th th

Lagerstromia indica L .........

regina $\mathrm{L} \ldots \ldots \ldots$. .

Laguncularia racemosa Griseb ... 2.
Kénettier................... 123

Koumarré................. 273

Kleinhovia fruticosa A. DC...... 397

Kyllinga brevifolia Rottb........ 543

- cespilosa Ness.......... 593

- velumla Vithl........... iti;

- squamala Vahl......... 543 
Langue it vache................ 35.

Langue i vache femelle ........... $36 i_{2}$

1.arme de Jol, ... . . . . . . . . . . . . . 133

Lantana (immara $\mathrm{I}, \ldots \ldots \ldots \ldots$, crocea Jacq ............. stí

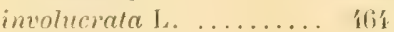

Latania borbonica Lam .........

Latanice.....................

Laugeria resinosa Vahl.......... \$38

Laurier avocat .................. 29.

Laurier bord-de-mer............ 30:

Laturier calle... . . . . . . .

Laturier cantelk .................. 298

Lauriej caraible................

Iatrier Chrpre.................. 301

Laurier a cerise . . . . . . . . . . . . . . 300

Laturier doux. .

Laurier falaise

laurier fine

Laurier gland

Laurier gombo

Lamier Isalulle

Laurier Isabelle rouse ........... 301

Lanrier madame .................... 302

Laurier noir . . . . . . . . . . . . . . . 30,3

Laurier rose.............. 39. 608

Laurier rose montagne............ 608

LAURINEES. . . . . . . . . . . . . . 99

Lallande.................... 583

lavande blanche ................. 580

Lavande grand bois............. 580

lalvande rouge ................ 581

Lawsonia inermis $1 . \ldots \ldots \ldots \ldots . .291$

Lebidibia coriaced Schlecht....... 231

Lecy this grandiflora Aubl ...... . 276

Leersia monandra Sw........... 50t

LÉGUMINEUSES............... 199

Lemna pancicostala Hegelm ...... 484 iraleliriana Phil ............ 48'

LENTIBULARIEES. . . . . . . . . . . . 380

I.entille sauvage .............. 207

L'envers femelle................ 568

L'envers mâle................. Б6

Leochilus cochlearis Lindl........ $\quad(000$

Leonurus sibiricus I........... $\$ 99$

Leonotis nepetxfolia R. Br....... 100

Lépiné blanc................... I'1

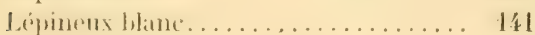

Lepinetx jaune................. 14.1

Lipineux ronge............. lis, lín

Leptactinia Mannii Hook........ 331

Lepidagathis alopecuroidea Willd. 仼'
Lepidium Heris Desc........... !

virginicum I.......... 9

Leptochloa filiformis R. et Sch.... 5 517 virgata $\mathrm{P}$. Beauv..... . .

Lerya melans liC..............

Lekhi..................... 12'

Liane a agoutis............... 住1

Liane aile a ravets ............. 115

Liane amande amère ............ 仿

Liane amère ................. 316

Liane d'argent................ 仿任

Liane d'argent bâturd............ 431

Lianc batmboche............... stis

Liane bamboche bitard ........... 7

Liane barrique...... 222, 223, 256, 2.5

Lianes à barriques........... 222, 25; ;

Liane à barriques bord-de-mer...... 2292

Liane bercean................. the

Liane bord-de-mer........ 114, 410, 435

Liane blanche .... $49,141,150,151$, 434

Liane blanche montagne ........... :33:

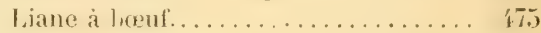

Liane boudin tordu.............. 2往

Liane brulante .......... 36, 95, 得

liane brùlée .................. It

Liane caco................... 117

Liane canot ou liane à canot........ 12.2

Liane caraile.............. 116, 仿!

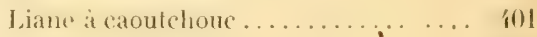

lian it chisseur............... מn

Liane cercle ou liane a cercle....... $\$ 160$

Liane à chique............ 451, 4.52

Liane à chique poilue........... 何

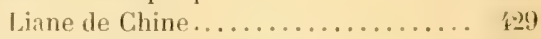

Liane colibri montagne...........

Liane corde......... 7, 201, 398, 621

Liane i corde.............. 115, 37

Liane à cornette................. 3hí

Liante it rouleuvre .............. 312

liane it coutine................ 仿

Liane crabe ou liane a crabes.... 151, 任

Liane donce.......... 95, 316, 136, 137

Liane donce bord-de-mer........... 保

Liane douce jaune ............. 仿

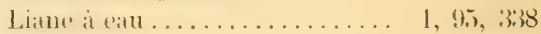

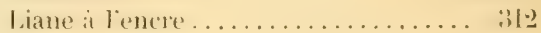

liane it fanx . . . . . . .

liane fer it cheral .................

Liane ficelle.................. 305

Liane flenrs violettes............. 仿

litute framboisin ............. it

liane fanche............... 1.6 
Liane gaufre 358

Liane gros boudin 133

Liane hallier. . :狧

liane à hébichel. 479

liane jaune ................. 430

liane à lait. . . . . . . . . . . . . . . . 3983

Linne lilas.................... \& 13

liane mangle.............. \49, 396

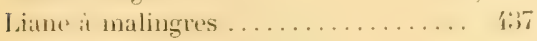

Liane molle....................

Liane noire........... 115, 400, 451

liane i novau............... 435

liane ortie ................ \&

liane onaon ................. 241

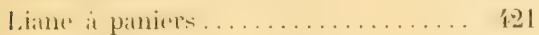

Liane papave.................. 39

liane paques .................. 19

Liane patate.................. 439

Liane P'entecôte................. 466

Liane perruche.

Liane ì perruche.............. 328

Liane persil.. 118, 119, 120, 138, 477, 610

Liane poilue............. 4, 36, 41

liane pomme. ............... (i)

Liane porcelaine.............. 401

Liane quinze jours .............. T

Liane à ravets................... 110

Liane razier bord-de-mer.......... 4 40

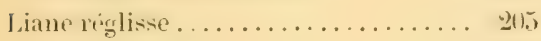

Lime à réglisse ............... 20)

Liane it remide.................. 7

Liane rouge . . . . . . . . . . 150, 376

lime rude.................. ititi

Liane Saint-Jean............... 406

Liane sans fin .................. 306

Liane savon............... 93, 118

Liane à scie ................... 119

liane sèche ................. 317

Liane serpent .......... 359, 400, 435

liane terre.................... 彷

Liane à tonnelle . . . . . . . . . . . . . 43.

Liane tordue............... 168,358

Liane trompette .............. 107

Liane it vache.................. $\$ 00$

Liane violette................. 460

Liane zannande................ 1.,

Licania pykifolia Griseb) .......... 259

Ternatensis Hook......... 25

Licuala spinosa Thumb ......... 49.5

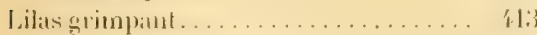

Lilas du pays .............. 120,127

Lilium longiflorum Thumb ........ $56 \%$

\section{Limnanthemum Humboldtianem}

(iriset. ...... iti.)

Limnobium stoloniferum Girisel,... it:

Limnochloa plantaginea P. Beanw. 份 spiralis Nees....... in

Limodorum pendulum Aubl..... . . .

Limonia trifoliate L . . . . . . . . . . lit)

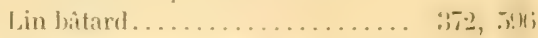

Linociera cribua .

Lippia citriodora Kth ........... iti:;

- geminuta Kth ........... \{tii;

- mediflura lich .......... iti:

- veptans II. B. Kth......... itie

Lis blinc......................

Lis à bordures.....................

Lis de France......................

Lis a l'huile ........................

Lis jaune sarane................. . thi

Lis panaché.................. itil

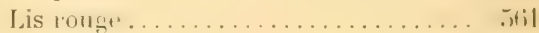

Lis de Saint-Joseph............. . .ti-

Lis sillane... .................. of

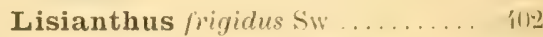

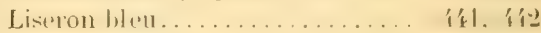

Liseron hatlier................... 保

liserom ranpanl...............

Liseron rouge. ............... 倠

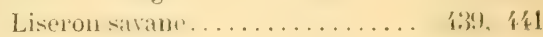

Litchi....................... 121

Lithophila muscoides siw........ 56

Lobelia cirsiifolia A, I)C........ 377

— riffirtianer L........... :377

- conglobata A. DG......... :378

- plavescens A. DG.......... :378

- persicxfolia A. IIC....... :58

stricta A. DC .......... : :777

Lonchocarpus latifolius lith..... 21!?

- serisers lith...... 20.21)

violaceus kith...... 20.1!

Loranthus americanus Jacf...... 327

- emarginatus Sw ...... 3. 3.

- parviflomes Jam...... 320

uniflorus Jact .........

Lourea vespertilionis Dest ......... II I

Lucuma Dussiana Pierre......... ;

- mammose Gart.......... 沁

Luffa acutangula Roxb.......... : $3(\mathrm{~s}$

- ary!yptiuce Mili............ 308

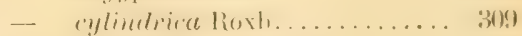

Lycopersicum cerasiforme l)un... 件2

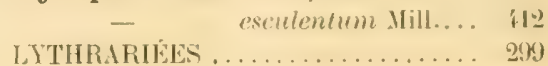


Mabonia .................... 14

Mabouia falaise................. 14

Mahouge................. 13,503

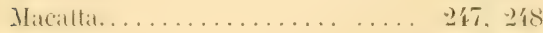

Nacatta bourse.............. 247, 218

Nacatta jaune.................. 230

Machærina restioides Vahl ....... 519

Maclura xanthoxyloides Endl..... 159

Madère ... . . . . . . . . . . . . . . . . 482

Nadère bâtard................ . 482

Magloire................... 57

Magloire blanc................ 57

Magnolia grandiflora Sw.........

- Plumieri Sw............

MAGNOLIACÉES. . . . . . . . . . . .

Mahogani du Sénégal .............

Mithot anylais.

Mahot baba.

Vahot blane.

Nahot bord-de-mer ...............

Mahot bré..........................

Mahot cousin....................

Mlahot cousin rouge $\ldots . . . \ldots \ldots \ldots$.

Yahol fin ..................... 住

Mahot franc.................. 79

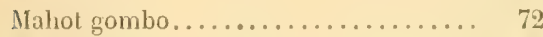

Mahot jaune................... 79

Milsot mangle................ 72

Nahot noir........... 87, 447, 448

Mithot piment..................

Mahot pimenté.................. 297

Nais........................ 131

Malachra alcifolia Jacr......... 70

capitata L........... 69

- fasciala Jacq.......... 70

Maladrière ................... 33t

Malanga...................... 480

Matinnit hatird .............

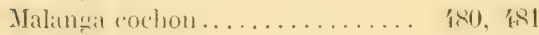

Malanga d'eau.................. 478

Malatrat

Malanga noison................. 480

Malanga rivière.................. 478

Malanga sauvage................ 181

MALAXIDEES ..............

Mâle codinde.................. $3 t$

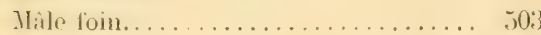

Malinbé................ 177, 17
Mal nommée................ 48

Nal nommée fine............. 43

Mal nommée verte.............. 42

Jalokio................... 1:2

Malpighia angustifolic L........ 113

- coccigera L........... 114

- glabra Cas........... 113

- meneifolia L......... 113

- urens L............. 113

NALPIGHIACEES ............. 110

Malva americana L............ 63

- coromandeliana Sw....... 63

- polystaclıya Cav.......... $\quad 62$

MALVACEEES .................. 62

Malvastrum spicatum Griseb..... 62

. - tricuspidatum As. Gr. ti3

Manain. . . . . . . . . . . . . . . . 3

Mammea americana L . . . . . . . . 102

humilis Vahl.......... 102

Mancenillier............... 37, 38

Mandarine ................... 132

Manetta calycosa Griseb......... 334

Mangifera indica L........... 187

Nangle. . . . . . . . . . . . . . . . .2.2

NIangle blanc . . . . . . . . . . . . . . 275

Mangle bois . . . . . . . . . . . . . . . 20 295

Mangle chandelle........... 292, 293

Nangle gris ................. 295

Hangle médaille ............ 221, 222

Jangle montagne. . . . . . . . . . . . . !9

Mangle noire ................. 292

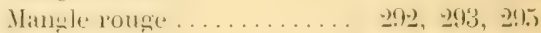

Mangle oseille ................. 123

Manihot Aipi Pohl ............ 28

- palmata Müll.......... 28

- utilissima Pohl......... 28

Manioc amer................. 28

Vanioc: batard ................. 28

Yinioc brilant .................

Manioc doux.................. 29

Mitnioc la chituelle ................ 星

Maniolia ....................... 2

Manguier ................... 187

Manisuris granularis Sw ........ 527

Iapon batril.................... 仵

Mapou blanc.............. 322, 445

Japon gramd bois............... 仵

Mapou grand feuille............. 仿 
Mipon liki

像

Mapon noir.

337,338

Matpou fllatut

俋保

Mitpou rivierte

们

Mapou rouge.

传

Mapouria herbacea Miill. Arg...... 346

Maranta Allovia Aubl ... . . . . . . . 584

Arouma Jacq........... 58

arundinacea $\mathrm{L} \ldots \ldots \ldots \ldots .585$

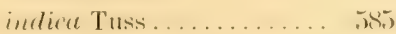

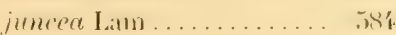

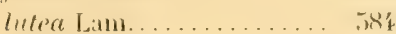

- petiolata Rudge......... 584

zebrina sims........... 580

MARANTÉES

Marcgraavia spiciflora Rich . umbellata L.

MARCGRAAVIACÉES

Mitrjolaine

Malyuerit

Marguerite blanche

Marguerite bord-de-mer.

Marie-Gougeat.

Marie-honte.

Mariel'hupital.

Marie-périne

Marica plicula Gurt

Marila racemos $\alpha$ Siv.

Mariscus flavus Vaht. rufus H. B. Kth.

583

105

106

104

461

51

55

372

312

24

33

49

568

107

$5+2$

542

Marlieria Dussii Kr. et Urb

267 glomerata Berg........ 207

Marlieriopsis Eggersii Kiersk. . . . 263

Marsdenia elliptica Dcne... . . . . . 400

Marsypianthes hyptoides llart. . . 455

Martinezia corallina Mart. . . . . . 490 camjotxfolia Lam.... 495 truncata Brongn..... . 495

Martynia diandra Glox. ........ 433

Matricaire. . . . . . . . . . . . . . . 365

Matricaire bord-de-mer . . . . . . . . . 373

Matricaire savane................ 373

Manressif on Mauricil.............. 111

Mauve...............67, 86, 87

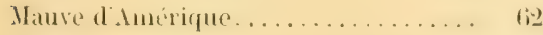

Mauve savane. . . . . . . . . . . . . . . . 63

Mavison.... . . . . . . . . . . . . . 463

Maximiliana regia Mart.......... 495

Mayepea Dussii Kr. et Urb ... . . . . 391

Maytenus elliptica Kr, et Uw, .... 145 guyanensis Griseh .... . $146^{\circ}$

Médecinier barrière. ............... 27
Médecinier bitard ............

Médecinier béni .......... . . .

Médecinier hlane. ............ .

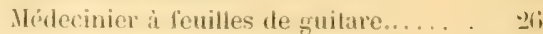

Médecinier à feuilles de violon. ... .

Ilédecinier purgatif.... . . . . . . 291

Mélecinim ronge . . . . . . . . . .

Melampodium perfoliatum. H. B. et lith....... $\left.3 f_{i}\right\}$

Melanthera delloidea Mich....... :367

Mèle............. ...... 284i

Melia Azedarach I.............. 196;

- sempervirens Sw. . . . . . . . . 19;

MÉLIACEES ....... . . . . . . . . 12 i

Melicocca bijurgu l.... . ....... 123

Meliosma Herbertii Rolic... . . . . 126 Pardoni Kr. et Uri..... 125

Melocactus communis Link et Otto. 316

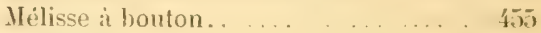

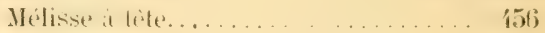

Melochia nodiflora sw......... 87

- pyramidata L........ 86 i

- tomentosa L......... 81

Mélongène................. . 4 . 45

Mélogène batard... . . . . ....... 14

Ilélogène diable ............... 作5

Mélogène diable bord-de-sutr. . . . . . 40 \&

Mélongène de Guince. . . . . . . . . . 415

Mélongène liane bâtard............ \$13

Mélongẻne liane razier ........... \$14

Mélongène piquant.............. . 4 .

Mélongène raziè ................ 414

Melothria guadalupensis Cogrn.... :309

MTENISPRPIEFS. . . . . . . . . . . . . . .

MENISPERMEES. . . . . . . . . . .

Mentha jiperilı l. . . . . . . . . . . $\mathbf{\text { itil }}$

Menthe glaciale............... 376

Menth poirré . . . . . . . . . . . . . 161

Merisier. 148, 263, 261, 266, 269, 270, 271, 272

Merisior hois . . . . . . . . . . . . . . . 273

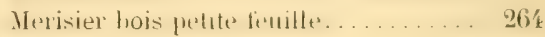

Merisier montagne.............. 264

Icrisier noir. . . . . . . . . . . . . . . . .

Merisier petite feuille . . . . . . . . . 20.

Metroxylon viniferum liollb...... sin

Meyenia alba Hort ... . . . . . . . . 130

- erecte Benth ......... 亿:31

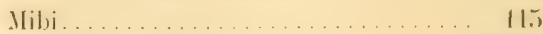

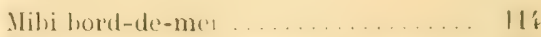

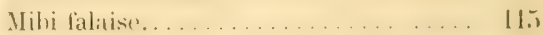

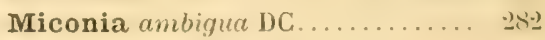
collina $[1, \ldots \ldots \ldots \ldots \ldots \ldots .2 .2$ 
Miconia minceu

- discolor DC............. 28

- Vurfuracea Girisel......... 283

- globulifera Cham......... 282

- Guyanensis Cogn......... 281

- impetiolaris Don.......... 284

- livirgula D)C............ 281

- presina DC............ g8.

- striata $\operatorname{Cog} n \ldots \ldots \ldots \ldots .284$

- tetrandra Naud ......... 282

- trichotoma Cogn ........ 281

Microstylis spicata Lindl......... 590

Microtea debilis iw. . . . . . . . . 49

Milium digitavium Sw......... 522

Mille-Hlenrs

Mille-graines.

Mille-pattes.

33.5. 334

596

$37 !$

Mimosa asperalu

紧斻

约

辌

是行

当任

251

(i1.2

(it) 2

ㄴít

25í

251

MIMOSEES

ixt

$3 \times 7$

Mirabilis dichotoma L..........

Yirobolan ........................

Mlirobolan bâtard.

84,310

Misanteca triandra Mez......... $33_{1}^{\prime}$

Mithranthes Eggersii Niedenzu... .

Mitreola petiolata Torr. et Gras.... 33.5

Mitrospora polycephala Nees..... . 51

Mogiphanes Jacquini Schrad ...... if

Momordica Charantia L ........ :30

Monl,in

Monbin rouge.

MONOCOTYLEDONE

Monstera pertusa Griseb.

Montrichardia aculeata Crueg....

- arborescens Schott.

Jionvitl.

Moraea plicata Sw.

Moringa pterigosperma Gaert.....

Morinda ritrifolice L. macrophylla Desf.
Morisonia americana L......... 14

Moronobea coccined dubl........ 101

Mort aux cabrits ................. 378

Mort aux poissons................. 195

Hort aux vaches................ 378

Morus nigira L.................. 180

Mouriria Domingensis Walp...... 286

Mouron........ 45, 75, 141, 173, 192

Mouron blanc............... 45, 46

Mlouron grand bois............. 172

Mouron grand'feuille............. 172

Mouron sauvage ................ 174

Mouron vivace................ 170

Moutarde.................... 10

Moutarde du pays.............. 380

Moutarde sauvage.............. 10

Mouzambé blanc................ 33

Mouzambé à fleurs blanches ......... 11

Mouzambé à fleurs roses........... 11

Mouzambé jaune................ 12

Mouzambé à six feuilles ........... 11

Mouzambé zépineux.............. 11

Mucuna altissima DC........... 217

- muriens DC ........... 211

- urens JC ............... 211

Muhlenbeckia platyclada Lindl... 169

Mluguet...................... $\mathbf{4}$.

Iluguet bleu. . . . . . . . . . . . . . . . 400

Muguet jaune.................. 409

Iuguet montagne................ 402

Muguet savane.................. 401

Multipliant .................. 155

Mûrier noir .................. 160

Mủrier du pays............... 159

Murraya exolica L.............. 132

Musa Cavendishii Lam........... 578

- coccinea Andr............ 578

- paradisiaca L............. 578

- rosea Jacr................ 578

- sapientum L............. 578

- superba Roxb............. 579

- textilis Nees............... 578

MUSACEES . . . . . . . . . . . . . . 578

Niuscade .................... 300

Muscadier.................... 6

Muscadier bois................. 267

Muscadier bois doux .............. 310

Muscadier fou ................... 6

Huscadier porte-suif . . . . . . . . . . . . 6

Musæenda frondosa L......... 331

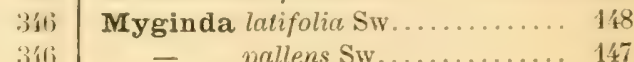


Myginda Rhacoma Sw.......... lí

MYOPORINEES . . . . . . . . . . I7

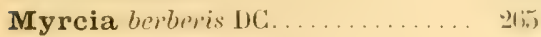

- deflexa DC............... zhti

- divaricata Griseb......... g(i.

- dumosa Kr. et Urb......... glif

- edulis Kir. et Urb......... פtí

- ferruginea Berg.......... פtitj

- leptoclada DC............ grit

- martinicensis Kr. et Urb.... 24.5

- paniculata Kr. et Urb ..... 29.;

- splendens DC............. 当

Myristica fatua Sw ............. (i

- fragrans Houtt........
Myristica moschata Thunb....... if

Myrobolanus lulea IIact ........ 18;

My rodia tubinatu I. . . . . . . . 82

Myroxylon buxifolium lir. et Urb.. If martinicense Kir. et Urb. If;

Myrsine coriacea R. Br.......... 381

- floribunda R. Br........ 382

- $\operatorname{letata.DC..........381~}$

MYRSINÉES ...............

IIYRTACÉES. . . . . . .

Iyrte de France..............

Virtille..................... I's

Myrtille du pays .............. 1伯

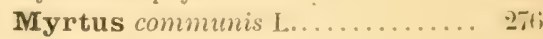

NAIADEES.

Nama jamaicensis L.............

Nasturtium of ficinale $\mathrm{R}$. Br..... 10

Navet de Jérusalem............ 39.5, 3tif

Nectandra Antillana Meiss....... ; 30$\}$

- coriacea Griseb........ 301

- Dominicana Mez...... 3140

- nembranacea Griseb... 301

- patens Griseb........ 301

Néflier des bois ............... 1:28

Néflier des Indes . . . . . . . . . . . . . . 3 't0

Néflier du Mexique............... . 287

Ne m'oublie pas ................. 106

NEOTTIEES . . . . . . . . . . . .

Nephelium Litchi L........... 12'

Nepsera aquatica Naud........... 987

Neptunia plena Benth........... 2'

Nerium Oleander L............ 397
$\mathbf{N}$

Neurolæna lobala R. Br........ 375

Nicotiana Tabacum L.......... qu the

Nissolia pinnata Aubl .......... 226

Noisette des Grands-Fonds ........ . 30

Noiselte purative................

Noix d'acajou.............. 189,190

Noix de Bancoul. ................ 30

Noix des Moluques............... 311

Noix de Situt-Pomingue ......... 30

Nopal....................... 3in

Nopalea coccinellifera Solms. Dyck. 318

Norantea guyanensis Aubl........ 106

Noyaut ...................... 1'1

Noyau de France ................

NYCTAGINEE . . . . . . . . . . .

Nyctago arbur-tristis L......... 392

Nymphaea ampla I............. \&

NYMPH.EGEE $\ldots \ldots \ldots \ldots \ldots \ldots 8$
OCHNACÉES . . . . . . . . . . 10,

Ochroma Lagopus Sw ......... 81

Ocimum Basilicum L........... 位

- gratissimum [.......... 55 t

micranthum Willd....... 451

Ocotea cernua Mez............. :302

- Egersii Мez ............. 30 ?

- falcata Mez.............. 303

- Jacyuiniana Мez.

303

302

589

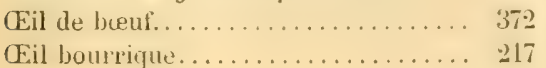

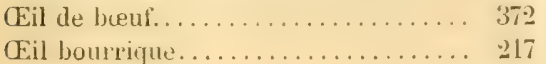

O

(Eil de hourique............... 216

Eil de chat............... 228, 20.2!

Eil du Christ ................. 200

Eil de cralue....................

Ogiera ruderalis Griseb .......... 343

Oignon ...................... 5.5

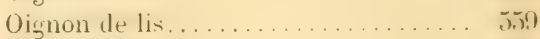

OLACINEES . . . . . . . . . . . . . . 3: 32 ;

Oldenlandia corymbosa L....... 3335

_- Halei Chap.......... 33.5

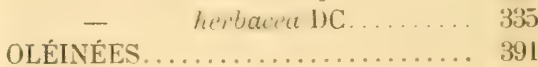

Olivier...................... 111 
Olivier bâtari.............. 383, 471

Olivier bord-de-mer....... 124, 295, 471

Olivier de montagne ............. 145

Olivier du pays................. 471

Olyra latifolia L.............. 50,

- pauciflora SW ........... 505

OMBELLIFERES. . . . . . . . . . . . 32

Omphalea diandia L. .......... 39

ONAGRARIEES................ 291

Oncidium altissimum Sw ........ 599

Cebolleta Sw . . . . . . . . 599

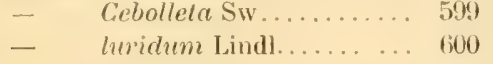

- Papilio Linal ..........600

- tetrapetalum Willd..... 598

- variegatum Sw........ 598

Onkoba spinose Forst............ 17

OPHRIDEES .............. 607

Oplismenus africanus P. Beauv.... 514

- $\quad$ composilus P. Beaur... 514

- loliaceus Spreng...... 514

- setarius Roem. et

Schult.......... 514

Opuntia coccinellifera Mill........ 318

spinosissima Mill ....... 318

Tuna Mill............ 318

Orange des bois . . . . . . . . . . . . 131

Orange douce ................. 131

Orange macaque................. 132

ORCHIDEEES . . . . . . . . . . . . . . . 588

Orégine...................... 376

Ureille mouton ................. 350

Oreille mouton long ............ 393

Orelia grandiflora Vahl ..... . . . . 393

Oreodaphne cernua Mez......... 302 Martinicensis Mez.... 302
Oreodoxa oleracea Mart.......... isi

Oréopanax capitatum Dcne. et

Planch .......... 3:1

Inssii kir. of Unl. . . . . 329

Origanum Majorana L........ 4 .

Orme du pays ............. 152, 153

Ormosia dasycanpa Jacks........ 225

Ornithidium coccinerm Salish.... . 596

Orthoclada rariflor a Nees........ 501

Orthopogon loliaceus R. Br....... 514 setwrius R. Br....... 514

()rtie bitard.................. lit

Ortie des bois.............. 16.3, thiti

(1)tie brilimte . . . . . . ... . 160, 161

Ortie grande................ 162

Ortie montagne..... . . . . . . . . . 162

Ortie ronge . . . . . . . . . . . . . 16. 10.

Ortie savane.................. 16,

Oryza satica I................. 50 t.

ORYZEES . . . . . . . . . . . . . 5$\left.)^{\prime}\right)^{\prime}$

Oseille bâtard ................... 13\%4

Oseille bois............... 3?0, 321

Oseille bois jaune........... . 1335

Oseille marronne .............. 131

Oseille marronne des bois ........ 134

Useille sauragr ............... 13'

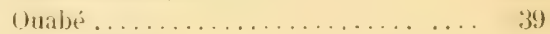

OXALIHELA . . . . . . . $1: 3 \ldots \ldots \ldots$

Oxalis Barrelieri Jacq . . ........ $131 \mathrm{x}$

- comiculata L........... 1:3í

- frutescens L. ......... 134

- Martiana Zue........... 13:3

Oxandra laurifolia Rich......... 5

Oxyanthus longiflorus Lam ...... 331

Oxythece Hahnianum Pierre..... 387
Pachira aquatica Aubl.......... 86 grandiflora Tuss......... 80

Pachyrhizus angulatus Rich..... 211

Pachystachys coccinea Nees..... 425

Paille-mare .................... 550

Paléturier.................... 221

Palétuvier grand bois............. 100

Paléturier gris . . . . . . . . . . . . . . 295

Palétuvier jaune ................. 101

Palétuvier montagne ............. 99

Palétuvier rouge......... 292, 293, 295

Palicourea crocea DC........... 345 Panetta DC.......... 345
Palissade à Jacques ............... 280

Palna-Christi................. 31

PALMIERS ................. 你

Palmier i batai............ $\{86,48 \pi$

Palmier dinde. . . . . . . . . . . . .

Palmier grigri................. 190

Palmier de Guinée. . . . . . . . . . . . . $49 \mathbf{y}^{\prime}$

Palmier at linuile................ 4916

Palmier sagou.................. . 490

Palmiste franc................ 487

Panax cochleatum DC........... 323

- fruticosum L........... 323

- Morototoni Aubl .......... 322 
Pancratium amcenum Salisłs..... 559 caribrum L . ........ 559 declinatum Jacr..... 559

PANDANEES.

Pandanus odoratissimus L........ 485 utilis Bory........... 485

Pain de singe..

Panicum anplexicaule Rudge. arborescens Sieb..... arundinaceum S.w. bambusoides Hannilt. barbinode Trin. brevifolium $\mathrm{L}$... cayennense Lan. . colonum I compactum siv. . . crus-galli $\mathrm{L}$...... Dalloni Parlat. diffusum Sw. . dispermum Lam distichum Lam. divaricatum $\mathrm{L}$ Duchassaingii Steud. flavescens Sw. foumentaceum Roxb fuscum Sw.. Guadalupense Steud. grossarium L. . insularum Steud jumentorum Pars lanatum Rottb... leucophæum Kth: maximum .Тacq molle Sw nenrorosum Siw. pallens Sw........ palmifolium Poir paspaloides Pers. pilosum Sw. plicatum (hailiense) hit. plicaturm (hailiense) Kih. prostratum Lam. pseudocolonum Roth..... pulchellum Radd......... rivulave Trin ............ sanguinale Trin samentosum Roxb...... Shonei (iriseb. truncalum Trin. umbrosum Griseb

PAPAVERACEES ................... PAPAYACELS.

523
Papayer..................... 310

PAPILIONACEES ............. 192

Papillon végétal............ 599, 600

PAPPOPHOFEES.......... 506

Pappophorum alopecurviderm

Vaht......... 506

laguroideum schrad. 506

Pardanthus sinensis Van-Houtte... 568

Paritium tiliaceum Ad. Juss ...... 79

Parkinsonia aculeata L......... 227

Parthenium hysterophorum L.... 365

Paspalum ciliatum Lam......... 509

- compressum Nees...... 509

- conjugatum Berg....... 509

- distichum L......... 510

- fimbriatum Kth....... 511

- glabrum Poir......... 511

- Guadalupense Steud.... 509

- notatum Flügg........ 510

- $\quad$ paniculatrem L......... 512

- platycaule Poir......... 509

- plicatulum Mich........ 511

- pusillum Vent......... 510

- saccharoides Nees..... 512

- setaceum Mich........ 511

- undulatum Poir........ 511

Passiflora capsutar is Lk ......... 312

- fotida L............ 313

$\begin{array}{lll}\text { - } & \text { hederacea Cav ......... } 311 \\ \text { - } \quad \text { laurifolia L........... } 312\end{array}$

- maliformis L........ 312

- minima L .......... 311

- Murucuja L.......... 314

- peltata Cav .......... 312

- rolundifolia L......... 312

- mbra L............. 312

- quadrangularis L..... 313

- servata L............ 313

- suberosa L............ 311

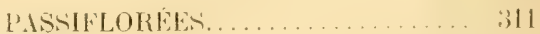

Patagon..................... 60

Patagon rouge .............. 60,61

Patate hâtard................ 436

Patate cochon ................ 211

Patate donce.................. 434

Patate grand truis . . . . . . . . . . . . . 1.39?

Patate macarue............... 42 t

Patate marronne............... 436

Patate sauvage............ $\mathbf{1 3 6 , 4 3 7}$

Pite dianamde ................. tisti 
Patte à cheval .................... 566

Pavonia nemoralis St. Hil ....... 73

- racemrosa Sw............ 72

- rosea Schlect........... 73

- spicata Cav ............. 72

- spinifex Cav ............ 72

Pectis carthusianonum Less...... 372

- humifusa Siw.

- linifolia $\mathbf{L}$

- punctata Jacq. .

Pedilanthus tilhymaloides Poir

Pentaclethra filamentosa Benth.

Peirescia aculeata Mill. . grandiflora Haw

Pelargonium zonale L. .

Peltau.

Pennisetum setosum Rich

Pensée créole

Pentarhaphia longiflora Lindl. .

Pentas camea Benth. .

Peperomia acuminata $\mathrm{L}$.

- Balbisii Dahlstad

- bracticiflora DC.

- emarginella Sw.

- exilis Griseb.

- glabella Dietr.

- hernandifolia Dietr.

- magnolifolia Dietr.

- nummulasifolia Kth.

- pellucida Kth .

- rotundifolia Kth.

Peperomia tenella Dietr.

Persea gratissima I.....

Persil..

Persil bâtard.

Persil noir.

Peste à pou

Petit acacia

Petit œil.

Petit ananas sauvage.

Petit balai.

Petit balai poileux.

Petit balai savane.

Petit balisier

Petit bambou ...

Petit basilic

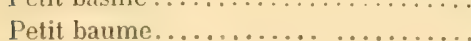

petit bois de fer ..................

Petit bouis

Petit cachiman des bois

Petit café

372

371

371

41

213

319

319

133

484

525

420

430

334

171

174

173

170

170

172

172

173

169

171

170

170

174

298

395

117,368

119

302

244

557

574

89,90

236

580

523

$15 \mathrm{t}$

464

93

383

4
Petit café bois. 327

P'etit café marron................ 313

Petit calumet .............. 505, 525

Petit chiendent................ 509

Petit citronnier................ 149

Petit coco.......... 92, 330, 49t, 558

Petit concombre............... 309

90

122

Petit concombre hallier ........... 309

Petit cornichon................. 309

Petit crécri................. 282

Petit curage................. 497

Petit épinard................. 58

Petit fiquier blanc.............. 287

Petit flamborant . . . . . . . . . . . . . 239

Petit follet ................... 102

Petit goyavier batard montagne...... 265

Petit haricot................. 214.

Petit lis blanc.............. 561, 562

Petit lis rose................. 562

Petit liseron.................. 439

Petit madere........ . . . . . . . 182

Petit merisier.......... 1'7 1 , 1'8, 265

Petit mibi.............. 115, 116

Petit millet .......... 380, 527, 528

Petit mouron................ 170

Petil orme ................. 152

Petit pain doux ................ 35

Petit pied de poule......... 507, 508

Petit pois.................. 209

Petit résolu .................. 334

Petit romarin. . . . . . . . . . . . . 323

Petit roseau................. . 527

Petit safran.............. 562, 563

Petit teigne................... 162

Petit teigne blanc... ........... 161

Petit thrm a lipin .............. . 456

Petit trèle........... 199, 201, 202

Pelite amourette............... 245

Petite avoine ................. 522

Petite diotine.................. 236

Petite gironflée............... 170

Petite feuille des hauts............ 265

Petite herbe grasse.............. 497

Petite liane blanche.............. 439

Pelite marguerite............... 359

Petite marguerite jaune .......... 372

Petite ortie.................. 163

Petite oseille ................. 134

Petite oseille savane............. 134

Petite palne .................. 609

Petite patate savane............. $43 \bar{\imath}$

Petite queue de renard........... 524 
Petite siguine............. 172, 仵

Petite teirne.................. Iti-

Petite teigne blanche.... ........ lfil

Petite véronique.... . . . . . 40\%, 405, 11:;

Petite verveine......... 452,453. iti;;

Petite verveine queue de rat ....... 4 t $i 2$

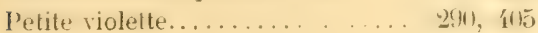

Petiveria alliacea L........... . It)

Petræa volubilis $\mathrm{L}$.............. ftili

Petroselinum sativum Hollm..... . :3:-,

PHALARIDEES .............. . \%

Pharus glaber H. B. Kth ........ . it,

- latifolius L............ . . 5.,

- ovalifolius Hamilt........ $51 \%$

- scuber H. B. Kth... ....... ji.

Phaseolus adenanthus Mey ....... 21 i

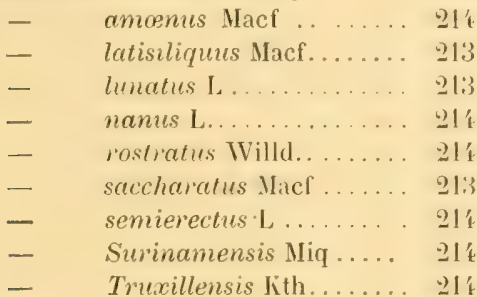

Phenax vulgaris Wedd............ Li\}

Philodendron dispai Schott...... if!!

- giganteum Schott....

- hederaceum Schott..

- Kastenianum Schott

Philoxerus vermicularis $\mathrm{R}, \mathrm{Br} \ldots$. , if

Phlomis caribæa Jacq. . . . . . . . . . 4. 4.

- martinicensis Sw. . . . . . . 45!

Phzebe elongala Nees...... . . . . . . 298

Phoenix dactylifera L . . . . . . . . . . (9),

- reclinata Jacq .......... \$!.

silvestris Roxb............ H

Phoradendron hexastichum Griseb. ․․고 Martinicense Griseb. 228 trinervium Griseb. . 2 에

Phragmites Martinicensis Trin... J) (1)

Phyllanthus Brasiliensis Miill. Arg. Carolinensis Walt... Conami Sw.......... epiphyllanthus L.... . falcatus Siw......... lathyroides H. B. Kth. mimosoides L....... Niruri. L............ nivosus Hort ......... ovatus Poir........... piscatorum lith......
Phyllanthus roseo-pictus Hort . . .

- $u$ rinaria $\mathrm{L} \ldots \ldots \ldots \ldots$

PHYLIOCORYNElES............. 织

Physalis murulutu 1. . ....... \$11

fotens Poir............ ill

Physurus hirtellus Lind!........ till; plantagineus Lindl...... (it),

Phytolacca icosandra L........ \$!

PIIYTOLACGEE................ is

Picanier femelle...... ........ ili

Picanier jaune...............

Picanier male................ ili

Picrana excelsa I.indl............ I

Picramnia micrantha Tul....... l往

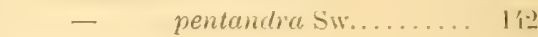

Pied de poule ................. , in .

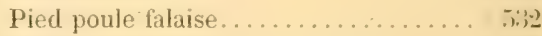

P'ied poule rible. . . . . . . . . . . . . . .

Pied de poule de Saint-Domingue.... 5. 51\%

Pilea chamxdrys Willd .......... (ii,)

- cilicris Winded ........... 1ti-2

- microplyylla Liebm .......... |lil

Pilocarpus racemosus Vahl....... li's

Pinnent bonda Madame Jacques...... ily

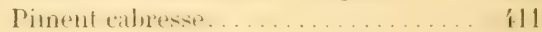

Piment caraibe................ ill

Pinent cerise ................ 住

Pinent doux ................ il:

Pinent enrigi................. \$11

Piment à grives ............... il:

P'inent mokit................ 41.

Piment oisedul. ..............

Piment poivre.... ........... 11:

Pinent rond ................. \$11

l'iment rouge . . . . . . . . . . . . . . 112

Piment vachte .............. Ifí

Piment $z$ indien. . . . . . . . . . .

Pinenl zoisean ............... 亿l

Pimenté ....................

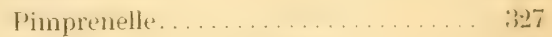

Pinzona calineoides lichl......... 1

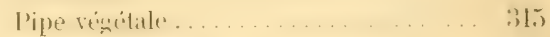

Piper æquale Vahl............. IT

- B?tle I. . . . . . . . . . . . . .

- Deremanam Milli. . . . . . 17.

- dilatatum Richti............ 17ti

- ceanothifolium 11. B Kilh.... 17\%

- ritrifolimm l.atm.......... IR

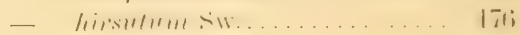

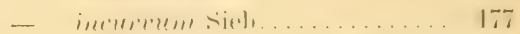

- macrophyllem H. B. Kilı.... 17ti

- medium Jacq............. 177 
Piper nignum L............. 17?

- pellatum $\mathrm{L}$

17.

- reticulatum $\mathrm{L}$.

175

- smilacifolium H. B. Kth ..... 17i

- tuberculatum H. B. Kth...... 178

PIPLRACLLS.

Piriqueta cistoides G. F. WV. Mer...

Piscidia Erythrina L.

Pisonia aculeata $\mathrm{L}$.

- oblusata Sw.

- suborbiculata Hemsi .

Pistache.....

Pistache bâtard ...

Pistache vrate

Pistia occidenlalis Blum stratiotes: L.

Pitcairnia bracteata Dry latifolia Red penduliflora A. Rich...

$$
\text { - penduliflora }
$$
sulfurea Andr.

Pithecolobium micradenium

Benth:. unguis-cati Benth. .

\section{PL.NTAGINÉLS}

Plantago lanceolata $\mathrm{L}$

$$
\text { major } \mathrm{L}
$$

I'lastain diean. virginica 1

Pleurothallis aristata Hook. - v'uscifolia $\mathrm{R} . \mathrm{Br}$

PIuchea odorata Cass.

$$
\text { pu'purascens DC' }
$$

Plumbago capensis Thunb coccinea Salisb. scandens $\mathrm{L}$

Plumet d'olficier. .

Plumiera alba $\mathrm{L}$

$$
\text { pudica Jacq. }
$$

\section{POACEES} mubra $\mathrm{I}$

Poc..

Podocarpus Purdicanus Hook.... salicifolius Kil..

Pogostemon Patchouly Pellet..... Poinciana regia Boj............. Poinsettia pulchervima Graham... Poireilu...

Poirier.

Poirier du pays.

Pois bâtard.
178

314

220

61

62

61

62

203

193

203

483

$48: 3$

51

571

51

52

.11

254

254

379

380

379

379

472

588

.58

361

315

350

380

$3 \times 0$

125

393

396

396

499

411

$6(18$

608

4il

230

行

5.7

420

419

207, 218
Pois bàtard razier.............. 210

Pois bâtard savanc.............. 209

Pois bois ou pois de bois .......... 206

Pois bort-de-mer................ 215

Pois bourcoussou . . . . . . . . . . . . . 213

Pois cabrit .................. 215

Pois carré..................... 212

Pois casse-canari ................ 212

Pois chicane................. 212

Pois chique .................. 212

Pois chouche.................. 213

Pois colibri... . . . . . . . . . . . . . . . 209

Pois contour .................. 213

Pois Coolis...................... 213

Pois doux batard. . . . . . . . . . . . . . . 253

Pois doux blanc.................. 255

Pois doux gris.................. 256

Pois doux marron ............... 214

Pois doux montagne........... 255, 256

Pois doux poilu................ 256

Pois énivrant. . . . . . . . . . . . . . . 209

Pois ficelle ................... 212

Pois goganne.................. 215

Pois it gratler................. 216

Pois halliers........... 205, 297, 208

Pois haricol ................... 21 't

Pois haricot sabre .............. 216

Pois indien.............. 212, 266

Pois lisière................... 206

Pois long ...................... 213

Pois Makendal.................. 216

Pois mare. . . . . . . . . . . . . . . 197

Pois marron................... 207

Pois marron savane............ 209

Pois patate.................. 211

Pois pigeon.................. 212

Pois poison................... 214

Pois puant .................. 235

Pois rigoise ................ 212

Pois rouge batard.............. 210

Pois de Sainte-Catherine.......... 213

Pois de Saint-Martin.............. 213

Pois savane............... 193, 210

Pois sauvage.............. 208, 209

Pois savon ................... 213

Pois d'un soll................... 213

Pois sucré................... 205

Pois en tout temps.............. 213

I'ois ontonta................. $\$ 15$

Pois zoiseau........... 195, 205, 209

Pois zombi............ 192, 193, 211

Pois á zombi ................ 193 
Pois à zombi jaune .............. 193

Poivrier..................... 179

Poivrier aromatique............ 179

Poivrier bâtard ............. 170, 177

Poivrier des Indiens . . . . . . . . . . . 179

Poivrier vrai ................ 179

Polyanthes tuberosa L .......... 562

Polanisia viscosa DC ............ 12

Poly bæa corensis K1........... 35

Polygala angustifolia Kth ........ 18

POLYGALELE. .

POLYGONEES .................. 161

Polygonum acre lith .. ....... . 165

- acuminatum lith..... 165

Polyscias pinnata Lam.......... 323

Polystachya luteola Hook........ 597

Pomme ditcajou ............. 18!, 190

Pomme i agouti. . ............ 313

Pomme Cooli.................. $\$ 307$

Pomme Gythère................ 186

Pomme d'Hä̈ti ................. 274

Pomme hallier bâtard............. 309

Pomme de Java.................. 275

Pomme jardin................ 317

Pomme z'Indien. . ............ 307

Pomme liane.................. 312

Pomme liane batard... . . . . . 311, 312

Pomme liane collant.... .. ........ 314

Pomme lane de la Guadeloupc...... 313

Pomme liane hallier.......... 311, 314

Pomme liane manicolı ... ... . .... 313

Pomme liane rouge hallier ......... 312

Pomme liane zoisean............. $: 311$

Pomme de Malacca .............. 275

Pomme de vermeille............. 308

Pomme pain .................. 388

Pomme poison .................. 415

Pomme it rats .............. 311, 312

Pomme rose.............. 274, 275

Pomme de singe.............. 316

Pomme de Tiriti ................ 27 .

Pomme zombi .................. 416

Pompon blanc.................. 2 隹

Pompon jaune............. 243, 251

Pompon rouge................. 253

Ponthieva glandulosa R. Br...... 602 petiolata Lindl ........ 602

Pontederia crassipes L .......... . 568

PONTÉDÉRIACEES ............. 568

Porana paniculata Roxb......... 413

Porophyllum ruderale Cass ...... 372
Porreall ...................... 5.5

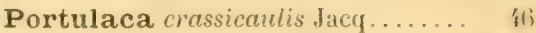

- halimoides L......... it

deraera L............ 伍

- paniculata Jacq........ 410

- pilosa $\mathrm{L} \ldots \ldots \ldots \ldots \ldots$....... i7

Posoqueria latifolia Roem. et

schult ........... 310

palustris Mart........ 3(10)

Potamogeton fluitans Roth...... 472

Pothos remidati L . . . . . . . . . . . 475

Potiron ..... . . . . . . . . . . . . 310

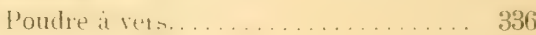

Pourpier...................... 131

Pourpier bitard .......... 136, 171, 172

P'ompin hoi ....... . . . . . . . . 172

Pourpier bord-de-rner . ........ 136, 166

Pourpier jaune .... .... ... ....... 136

Prescottia myosums Reichb. tils... 604

- myurus G. Reichb..... 60\%

- stachyoides Lindl...... 603

Pripri........................ 81

Priva exhmete Juss. . . . . . . . . 隹

Prookia wris L................ 16

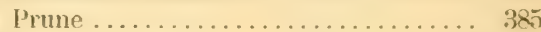

Prune des bois ................ 271

Prune bord-de-mer .... 146, 147, 326, 378

Prume cafe..................... 112

Prume de Chili................... 187

Prume de Chine................... $\quad 15$

Prune épine..................... 396

Prune d'Espagne............ 186, 18!

Prune Monbin.................... 185

Prune Mrrobolau . . . . . . . . . . . . . . . 185

Prune Pacỏme .................. 187

Prune rouge............... 184i, 187

Prune it tite................. 186

Pruneau .................... 19 .

Pruneau noir.................. 199

Prunus Dussii Kr. et Urb ......... 20.?

Psidium Araca Radd.............. 21:

- Callleyanum sabine..... 20

- Guava L................ 26

- pomiferum L.......... 26

- pyriferm L...........

Psophocarpus tetragonolobus DC. . ㄴ12

Psychotria chimarroides Nutt.... 313

- crassa Benth......... 31 í

- flovibunda H. B. lith ... 3 I3

- horizontalis Siv...... 3 it

- lanceolata Nutt....... 3it

- parasitica Sw........ 314 
Psychotria pubescens Sw ........ 343 subcrocea Müll. Arg... 345
Psychotria tenuifolia Sw uliginosa Sw.
343

312

Q

Quadrille....................... 399

Quassia amara L.............. 141

Quidec zerbe poison.............. 378

(ueve de cheral.

575

Queue de lézard

173,176

Queue de rat...... 53,51, 175, 176, 178

Queue de rat blanc.............. 175

Queue de renard ......... 424, 425, 506
Quinine.................... 27

Quinine de Cayenne............. 141

Quinquina bord-de-mer........... 453

Quinquina cararbe ............... 333

Quinquina montagne............ 333

Quinquina piton ................ 333

Quisqualis indica L........... 296

\section{$\mathbf{R}$}

Raisin d'Amérique.............. 49

Raisin coudre.............. 168, 169

Raisin marron.................. 167

Raisinier bord-de-mer ........... 169

Raisinier coudres............... 169

Raisinier des coudres ............ 169

Raisinier grand bois............. $16 \times$

Raisinier grand'feuille............ 166

Raisinier marron............... 167

Rajania cordata L............ 566

Ramie....................... 164

Randia aculeala L ............ 330

- armata DC .............. 330

- dumetorum Lk........... 331

- grandiflora Lam .......... 331

- Mussendæ DC .......... 330

Raphia vinifera P. Beauv......... 490

Raphiolepis indica Lindl......... 261

Raquette bord-de-mer............ 318

Raquette à piquants.............. 318

Raquette sans piquants............ 318

Raquette volante................. 318

Rauwolfia biauriculata J. Muell... 39't

- Lamarkii A. DC...... 393

Ravenala madagascarensis Poir... 579

Renealmia caribæa Griseb....... 580

- $\quad$ exaltata L.......... 581

- racemosa Roem. et Schult.

RENONCULACEES

Réséda de France.................. 291

Réséda du pays. . . . . . . . . . . . . . 29:

RHAMNEES ................. 92

Rhamnus ellipticus Siv.......... 93
Rhamnus iguaneus L............ 152

Rhapis flabelliformis L'Hérit..... 487

Rheedia lateriflora L. . . . . . . . . 102

Rhizophora Mangle L.......... 292

RHIZOPHOREES............... 292

Rhoeo discolor Hance............ 496

Rhubarlue caraihe............. 340

Rhynchospora aurea Vahl, R. Br . 550

- $\quad$ corymbifera Nees. 550

- $\quad$ cyperoides Mart ... 550

- $\quad$ Dussii Boekeler ... 553

- $\quad$ emaciata Boekeler. 551

- fermuginea Sieb... 551

- Jelskeana Boekeler. 552

- micrantha Vihl... 552

- polycephala Wydl. 550

- polyphylla Vahl... 551

- pubera Boekeler... 552

- $\quad$ setacea Boekeler... 551

- $\quad$ sparsa Sieb...... 552

Rhynchospora stellata Grisel).... 552

- surinamensis Nees. 550

Richeria grandis Vahl. .......... 19

Ricin...................... 31

Ricin båtard................. 28

Ricin brùlant................. 28

Ricinus communis L.......... 30

Ris de veau ................. 122

Rivinia humilis L............. 49

- laevis L............... 49

- octandra L............. 50

Riz...................... 50 f

Riz lhâtard................... 50 t

Robe à l'érêque................... 453 
Rochefortia cuneata Sw......... 隹

Roconyer ................... I't

Rolandra argentea Rottb . . . . . . . . $33 ;, 3$

Rollinia Sieberi Dun ...........

Romarin blanc................ 仿

Romain blanc bord-de-mer . . . . . . 40

Rornarin bord-de-mer............. (3),

Romarin de France . . . . . . . . . . . . fril

Romarin noir................ 48,

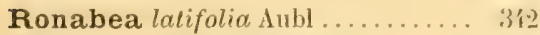

Rondeletia speciosa Paxt......... 3, 3;

ROSACEES stereocarpa Griseb.

Rose de Cilventue.

Rose de Venézuela.

Roseau d'Inde.

Roseau mare

Sabal umbraculifera Mart........ inf

SABIACEES.

S.ICCHARÉES

Saccharum caudatum $\mathrm{Hiq}$

Sagouier

Sagus vinifera Pers

Salade à lapins.

SALICINEES

Salix babylonica siv. . . . . . . . . . . . 108

- Humboldtianum WVilld....... 107

Salvia farinacea Benth .... ...... 158

- lamiifolia Jacq. ............. 459

- micrantha Vahl.

1.58

- occidentalis Sw.

158

$s p$ splendens Ker-Gawl

458

251

329

Sambucus canadensis I

Samyda serrulata Lam.

Sanseviera zeylanica Willd...... 56 i

Sapium aucuparium Jacq......... 37

SAPINDACEES.

Sapindus saponaria L........... 121

Sapota Achras Mill ............. 3. 3.5

SAPOTACEES ................ 33it

Sapote à crème............... 3, 387

Sapotillier .................. 38.

Sapotillier rnaron............ 387

Siturge... . . . . . . . . . . . . . . 4ti;

Sauge de la Barbade... . . . . . . . . . $\$(6.3$

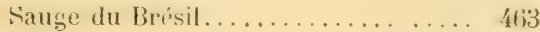

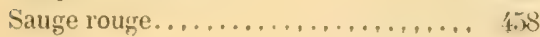

Roseau des mares ............... 50 00

Roseau de rivière................ 501

Rosmarinus officinalis L........ 440

Rotala ramosior Koelme. - edd... 613

Roucou ....................... 14

Roucouyer .................... 14

Roupellia grata Wall, et Hook ..... 397

Rubus Jamaicensis Sw. . . . . . . . . 360

- rosifolius Smith........... 360

Ruellia clandestina I. ......... 42'

- geminiflora H. B. Kth..... 121

- varians Vent............. 429

Ruppiamavitima L . . . . . . . . . 473

Russelia junced Zuc . . . . . . . . . . . . 406

RUTACEES...................... 138

Ruyschia clusiafolia Jacq........ 10 '

Saule peuplier.............. 107, 108

Saule pleureur.................. 108

Sauvagesia erecta L............ 108

SAUVAGESIEES................. 108

Sivometle................. 121

Savonnette grand bois........ 219, 220

Savonnette rivière ... . . . . . . . . . 220

Savonnier.................... 121

Savonnettier ............... 122

SAXIFRAGEES .............. 320

Scavola Koenigii Vahl ......... 379 Plumieri Vahl ........ 378

Schøfferia frulescens Jacq. ..... 148

Schlegelia Urbaniana Kr. et Urb... 419

Schmidelia occidentalis Sw....... 122

Schnella splendens Benth......... 240

Schœnus aureus L............. 550

- Cladium Sw.......... 549

- rypermat L ......... 50

- polycephalus Pers....... 550

- polyphyllus L......... 551

- setaceus Rottb.......... 550

- triceps Vahl........... 550

Schreffia arborescens Roem.et Schult. 327

Schradera capitata Vahl......... 331

Schrankia leptocaipa DC........ 2 IT

Sciadophyllum capitatum Griseb. 321

SCIRPEES. . . . . . . . . . . . . 5

Scirpus autumnalis L............ 516

— Dussianus Boekeler....... 518

- capillaris L............. 518

- capilatus L .............. 5 55 
Scirpus monostachyus Boekeler... It

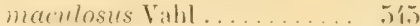

- micranthus Vahl......... jis

-- sperticeus $L \ldots \ldots \ldots \ldots \ldots$. sift

- spiralis Rottl........... 51

- tenuifolius Rudge ........ 5it

SCITAMINÉES.

Scleria communis Kth.

- fitiformis Sw.

- flagellum Berg.

- latifoliasis. .

- lithosperma Willd.........

- microcarpa Nees.

- pratensis Lindl.

- purpurea Poir

- reflera lith

- scindens Nees.

Scoparia duli is $\mathrm{L}$.

SCROPHILARINEEL

Scutellaria purpuracens $\mathrm{Sw} \ldots \ldots$. 400 ?

Seaforthia elegans R. Br....... 495

Sibestiey

Sechium edule sw

Securidaca $L$ (m) urlii (iriseh.

- scandens Lam. .

Semen-contra

Senebiera pinnatifida DC..

Senecio lucichs I)C

sint ...

Siné zomb.

Sinsitive

Serissa foetiela L.

Sesamun orientale I.

Sesbania sericen DC

Sesuvium portulacastrum L.....

Setaria glauca P. Beauv ...........

- italin (irisel) .............

- setosa P. Beanr.......... . .

- verticillata P. Beauv ......

Sicydium tamnifolium . Cogn..... 347

Sida acuta Burm............. . . 3017

- aiguta sir................ rib

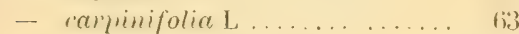

... riliaris $\mathrm{l}$................. $60^{\prime}$

- cordifolia 1 ................ (it

- demosa sw............... 66

- hamulosa Salzm 67 et add.... 611

- jamairensis L . . ........... 61

- mulliflora Ciar............ 67

- pyramidata Car ............ 66

- rhombifolia L............. 05

- spinosa l................ 05
Sida stipulate Cav.............. fi.3

- tmenrata LiHérit............. biti

- ulmifolic Cav............... bifj

- mens L................... (iis)

- repticillutu Cilr............. nis

Sideroxylon Mastichodendron Jacq. 384; Siguine..................... in

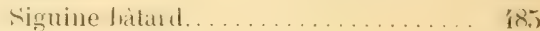

sicruine blanche .............. fin

Siguine d'ean ................. tin

siguine couleurre ............. $\$ 77$

siguine srand bois . . . . . . . . . . iz?

Siguine liane................ \$77

siguine noire. . . . . . . . . . . . 179

Signine ronge . . . . . . . . . . . .

siguine violeth . . . . . . . . . . . tit

Simaruba anaia duh.......... 119

- exelsa DC............. 113

- officimalis IC...........

Sinapis junce L............... . 10

nigma llesc . . . . . . . . II

Sinapisıne.................... 380

Siphocampylus Berteroanus G. Don 376

Siphonia elastica Pers........... 29

Sisyrinchium latifolium Sw.... $510 \%$

Slevogtia occidentalis Griseb ...... 401

SMILACINEES .............. 5 $5(i)$

Smilax macrophylla Wiild........ $5 f_{i}, 3$

Sloanea caribra $\mathrm{Kr}$. et Urb....... (11)

- Massonisw........... 91

Surinamensis Aubl ....... 91

Solandra grandiflora Sw........ $\{(17$

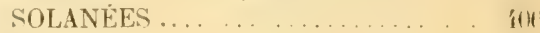

Solanum asperum Vahl ........ \$13

- caribæun Dun ........ \$12

- ferrugineum Jacq........ 415

- lancexfolium Jacq ... . . . \$1

- macrocarpum L ... ... . 415

- mammosum L.......... 415

- Melongena L........... 415

- neglectum Dun........... $\$ 13$

- nodiflorum Jacq . . ....... \$1

- racemosum Jacq ......... it'

- Seaforthianum Andr..... 4l.3

- triste Jacq ............ 413

- tomum Sw ............ 41.5

Sonchus asper Vill............. 375

- oleraceus $\mathrm{L} \ldots \ldots \ldots \ldots \ldots$

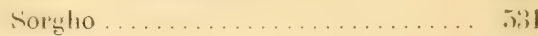

Sorgho it mil................... 5331

Soumarqué ............231, 235. 2:3ti

Soumarque bitard ............. 935 
Soumarqué poilu

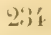

Sophora tomentosa L........... .

Sorghum vulgare Pers........... inl

Sparganaphorus Vaillantii Griseb. 20.1)

Spermacoce hirta L............ 3it?

- latifolia Aubl....... 33!

- Portoricensis Ball.... :3

- $\quad$ tenuior L......... 317

Spermodon setaceus P. Beaur..... the

Spigelia anthelmia L........... 336

Spilanthes Acmella Murr.... : 370,371

- exasperata Jacr....... 37̈

- oleracea L.......... 371

- uliginosa Sw......... 371

- urens Jacq .......... 370

Spiranthes lortilis Rich ........ tith

Spondias Cytherea Tuss.......... 185

- Monbin Jacr........... 18́

Sponia Lamartiana Dees........ 153

micrantha Decs........... 152

Sporobolus indicus R. Br.........

- Jacquemontii Kith...... 503

- littoralis Kth ......... 50.8

- viryinicus lill, . . . . . 503

Stachys patens Sw............

arvensis L.............

Stachytarpha Cayennensis Vithl... it

- Jamaicensis Vahl... $\quad$ itil

Stadmannia australis G. Don .... 88

Staphylea occidentalis Sw....... 1.2'

STAPHTLEACELS............... 12.

Stelis ophioglossuides Sw......... 589

Stellaria media L.............. 行

Stemodia arenaria H. B. Kth..... 10 ti

- parviflora dit .........

Stenorhynchus aphyllus Lindl... tits

- orchioides Rich.... li, 05

Stenostomum aculatum DC...... resinosum Griseb... 337
- pleiogyne L........... 187

- prepurea L............ 187

- tenacissimus P. Beauv. 503

Stenotaphrum americanm Schrk. il:3 Stephanophysumventricosum Nees. is Stephanotis floribunda dd. Brongn. (1) Sterculia caribed R. Br......... roccines lioxh .........

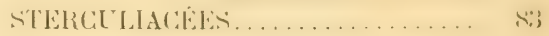
Steriphoma aurantiaca Spreng.... lí Stigmatophyllum convolvulifolium Juss. ........ 11 i emarginatum Juss ......... 11 ' periplerifulium Juss . . . . . . 115 puberum Juss. 11'

Stillingia sebifera Mich........... ;it STIPACEES ................ J13 Strumpfia maritinza Jacq....... :3:38 Stylosanthes procumbens L...... : 30: STYRACIEL . . . . . . . . . . . . . . . Styrax glabrum Sw.......... . 35!

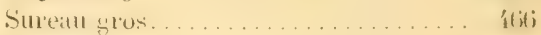
Surelle..................... Suretle.........................

Suriana meritimu I........... is suriatu. . . . . . . . . . . . . . . .

Suriau maladil................. ITs

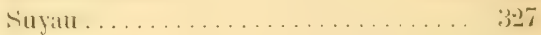

Suyau bitirt................ 117

Swartzia tomentosa Aubl........ 2⿺廴

Swietenia Mahogani L......... I:30 Senegalensis Desr......

Syagrus amarce Mart........... i?!

Symphonia globulifera L........ (1) Symphysia Guadalupensis lil.... lit Hartinicensis Deless... lí

Symphytum officinale $\mathrm{L}$......... 位 Symplocos Guadalupensis Kr et Urb. : : : i) (3)! SINANTHEREES . . . . . . . . . . 350 Synedrella nodiflora Gaert...... Syngonium podophyllum Schott .. is.; Syzygium Jambolanum DC....... 276

$\mathbf{T}$

Tabac................. 409, 410

Tabac diable............. 363, 373

Tabac diable bâturd.......... 351, 357

Tabac diable grand bois.......... 357

Tabac à Jacot..... . . . . . . . . . . . 361

Tibac a Jacot petit........... 3.1, 356
Tabac montagne............... 3333

Talauma Plumieri DC.......... 2

Talinum patens Willd.......... is

- triangulare Willd...... it

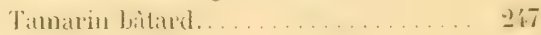

Tamarin des bois............... 1요 
Tamarin des Indes.

310

Tamarindus Indica L.......... 237

Tamarinier.................. 237

Tanæcium crucigerum Seem.... 422

Tanacetum vulgare L........... 376

Tanghinia venenifera Poir....... 397

Tapura Guyanensis Aubl........ 151

Taxodium distichum Rich........ 608

Taraxacum officinale Wigg...... 376

Tchacha....................... 192

Tecoma capensis Lindl.......... 421

- leucoxylon Mart......... 420

- pentaphylla DC........ 419

- $\quad$ stans Juss.............. 420

Tectona grandis L. fils.......... 470

Teigne.................. 161, 328

Teigne bord-de-mer.............. 327

Télégraphe................... 202

Teliostachya alopecuroides Nees.. 424

Tendre it caillou................. 25k

Tendre à caillou rivière.......... 251

Tendre en gomme.............. 333

Tephrosia cinerea Pers......... 195

Teramnus labialis Spren........ 209

- volubilis Macf........ 209

TÉRÉBINTHACÉES.............. 181

Ternstromia elliptica Rich...... 96 ovalis Rich.................. 95

Tète d'Anglais................. 317

Tête à l'Anglais................. 317

Tète de mort................... 433

Tête à nègre............... 88, 89

Tété négresse................. 276

Tetranthera laurifolia Jacq ...... 306

Tetrapteris inæqualis Cav....... 117

Tetrazygia angustifolia DC..... 280 discolor DC.

280

Thalassia testudinum Koenig..... 473

Thé bord-de-mer................ 467

Thé du Mexique............... 51

Thé montagne.................. 108

Thé muraille.............. 403, 40t

Thé $d u$ pays................. 403

Thé savane............. 108, 109, 403

Themeda ciliata Hack.......... 531

Theobroma Cacao L........... 85

Grazuma L
Thespesia populnea Corr........ 79

Thevetia neriifolia Juss.......... 39:

Thrinax argentea Lodd.......... 487

- barbadensis Lodd........ 486

- parviflora Sw......... 487

- radiata Lodd............ 487

Thunbergia alata Boy.......... 128

- flagrans Roxb...... 428

- grandiflora Roxb.... 128

Thuya sinensis Tournef......... 608

THYMÉLEES . . . . . . . . . . . . . . . 997

Thyrsacanthus nitidus Nees.... 425

Tibouchina chamæcistus Cogn.... 288

TILIACEES ................... 88

Tillandsia bulbosa Hook......... 573

- fasciculata Sw........ 572

- polystachya L......... 573

- recurvata L.......... 574

- splendens Brongn..... 575

- usneoides L.......... 57k

- utriculata L.......... 563

Tricholæna insularis Griseb..... 52.

- saccharoides Griseb.... 512

Trichosanthes Anguina L...... 310 colubrina Jacq.... 310

Trilix crucis Griseb............. 16

Tripsacum hermaphroditum L... 527

Trixis $e r o s a$ sw............... 363

- scabra Sw.............. 362

Trompette à canon.............. 322

Trompette du jugement....... 403, 409

Triphasia trifoliata DC........ 139

Triumfetta grandiflora Vahl.....

- havanensis Kth...... 8!

- heterophylla Lam.... 89

- Lappula L . . ...... 88

- semitriloba L....... 89

Tubéreuse..................... 562

Tupa cirsiifolia A. DC......... 377

- conglobata A. DC........... 378

- pavescens A. DC........... 377

- stricta A. DG............ 377

TURNĖRACÉES . . . . . . . . . . . 314

Turpinia occidentalis Don........ 12 '

Tussacia puichella Reichb........ 431

Thym de l'Inde............... 461

Thym de montagne.............. 288

Thym violet.................. 288 
Unona odorata Dun

Urania speciosa Willd.......... 579

Urena lobata L.

simeala siw.

- Swarlzii Mace.

Urera caracassana Gaud.......... 162

Urtica æstuans Jacq............. 160 niued I. URTICEES . . . . . . . . . . . . . 152

Urvillea umacer lith........... 118

Vacour....................... 185

Vandées ..................... 596

Vandelia crustace Benth........ 405

Vanilla anaromatica Sw.......... 601

- claviculata Sw.......... 681

- planifolia Andr.......... 601

Vanille batard.................. 398

Vanille du Mexique............... 601

Vanille sauvage................. 601

Vanillier du Mexique............. 601

Vanillier sauvage............... 601

Vanillon..................... 601

Varronia dasycephala P. Br...... 448 martinicensis $\mathrm{P} . \mathrm{Br}$.... $\mathbf{k} 8$

Verbena Jamaicensis L......... 461

VERBÉNACEES ............... 461

Verbesina alata L............. 369

- $\quad$ gigantea Jicq.......... 369 helianthoides $\mathbf{H}$. B. Kth. 370

Vermicelle................... 443

Vernonia aiborescens sw........ 351

- cinerea Less............ 351

- $\quad$ icosantha DC.......... 351

- punctata Sw............ 351

Véronique................ 324, 442

Véronique bord-de-mer.......... 4 4 亿3

Verveine blanche............... 453

Verveine blanche savane........... 453

Verveine bord-de-mer. . . . . . . . . . . 453

Verveine courante.............. $40^{\circ} 2$

Verveine à crête de coq........... 452

Verveine à pian................ 452

Verveine queue de rat............ 461

Verveine terre................. 450

Tétiver..................... 529
Vetiveria amundinacea Griseb.... 529 odorata Virey......... 529

Vieille fille.................... 251

Vilfa virginica $\mathrm{P}$. Beauv.......... 563

Vigna luteola Benth............... 211

- sesquipedalis L........... 212

- sinensis Endl.............. 212

Vinca roseu L. . . . . . . . . . . . . . . . 395

Viola stipularis L.............. 18

VIOLACEES................. 17

Violette des bois................ 426

Violette bord-de-mer.............. 355

Violette montagne............... 18

Violette savane.......... 355, 425, 460

Vitex agnus-castus L............ $\quad 470$

- divaricatus L............. 469

- multiflora Mig............

Volkameria aculeatea L........ 467

Vonvon....................... 213

Voyria uniflura Pers........... 402

Vriesia Guadalupensis Mez....... 575

Waltheria americana L........ 87 glabra Poir.......... 87

Wappe................ 358, 359

Wappe montagne............... 359

Wedelia buphthalmoides Giriseb... 367

- camosa Rich............ 366

- fintesceis Jacq.......... 367

- pulchella H. B. Kth...... 367

Weinmannia hivta Sw........ 320

pinnata L....... 320

Winterana Canella L.......... 103

Wittmackia lingulata Mez...... 570

Wulfia Havanensis DC........... 368 stenoglossa $\mathrm{DC}$........... $36 \mathrm{~s}$ 
Xanthium orientale

Xanthosoma atrovirens C. Lioch it Bouchí........ hastatum Egg.......

- filamentosa $\mathrm{L}$
361

481 481
Xanthosoma hastifolium C. Koch.. 481 sagittifolium Schott.. 481

Ximenia americana L......... 856

Xylophylla falcata Siw........ 25

\section{$\mathbf{Y}$}

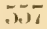
557

Yucca flacrida Haw........... 55 - gloniosa L.............. 557
Yucca aluifulia L.

\section{$\mathbf{Z}$}

Zitipuille matite............... 196

Zamia muricata Willd... . . . . . . 609

Lamourette.

295, 246

Zimoureste violet.

246

Zanthoxylon aromaticum Willd... 140

- flavum Vahl.........
- martinicense L.......
- microcarpum Griseb.

Zea Mays I. microcaipum Griseb.

Zephyrantes carinata Herl).......

7épinard cochon.

tubispatha Herb.... itil

Zépinard de France

140

141

140

534

562

58

59

Zispinated du pays

Lipinard piquant.

Lerlue Jouton.

Zerbe brilante

Zerbe cabrit.

Zerhe à calalou

Zerbe it chique.

Zerbe coton

Zerbe Jean.
Zerbe mamzelle................ 211

Zerbe mal nommée............... 42

Zerbe mouton.................... 198

Zerbe à mouton................ 511

Zerbe papillon................. 399

Zerbe s'amuser................. 245

Zerbe savane...............99, 199

Zicaque ................. 957, 258

Ziccaque montagne.............. 258

Zieux à boeuf................... 216

Zieux bourriqut................ 916 ;

Zieux chat................. 228, 229

Zingiber officinale Rose........ . 583

ZINGIBÉRÉES . . . . . . . . . . . . 580

Zingting ..................

Zinnia elegars Jacq. . . . . . . . . . 36 multiflora L............ 365

Zizyphus emarginatus Sw....... 92 Jububa Lam........... 91

Zornia diphylla Pers............. 198

ZYGOPHYLLEES............. 135

Omission dans la table

Endlicheria sericed Nees......................... 303 



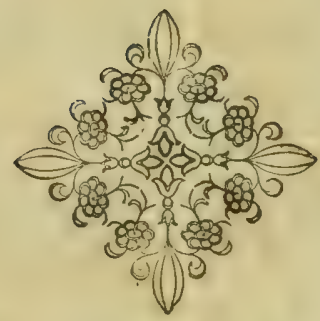




New York Botanical Garden Library 


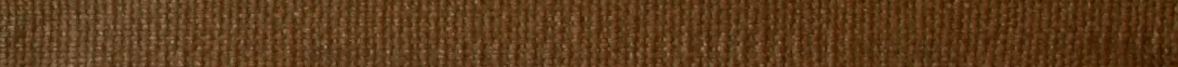

H.

H.

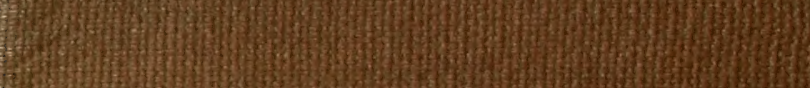

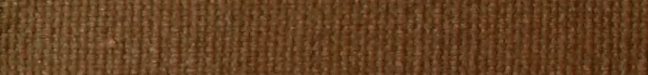

(115)

3)

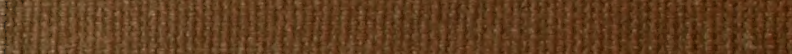

3.t.

Sin

How

3.

3.

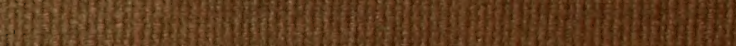

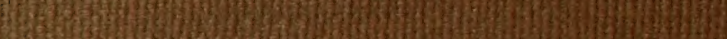

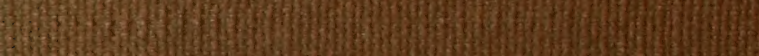

H.

(5)

20

3)

Gan

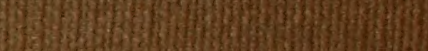

gas

3.

2ivang

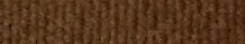

tos

arisy?

19.

igi? 